\title{
GOLD AND SILVER NANOPARTICLES AS HIGH-VALUE COLOURANTS AND MULTI-FUNCTIONAL ENTITIES FOR NATURAL FIBRES AND MINERALS
}

\author{
By \\ Kerstin Ann Burridge
}

\begin{abstract}
A thesis
submitted to Victoria University of Wellington

in fulfillment of the requirements for the degree of

Doctor of Philosophy

in Chemistry
\end{abstract}

2010 


\section{Acknowledgments}

Firstly I would like to acknowledge and thank my supervisors, Prof. Jim Johnston and Dr. Thomas Borrmann for their tireless support and inspiration. You have both been fantastic mentors; it has been a real pleasure working with you. A big thank you to the members of LB 107, in particular Dr. Fern Kelly and Dr. Aaron Small.

David Flynn and Dr. Colin Doyle, thanks for your help in all aspects of electron microscopy and x-ray photoelectron microscopy respectively. Thank you to Prof. Ken MacKenzie for collecting solid state NMR spectra, this is very much appreciated. Dr Errol Wood and Steve McNeil of AgResearch, thank you for your help and expertise relating to wool science, and thank you also for the colourfastness, lightfastness and insect resistance testing carried out on our materials. I would like to acknowledge Capital and Coast Wellington Hospital for carrying out anti-microbial testing and thank Jo Reeves, of Titahi Bay, Porirua and Jane Clark of Wellington for spinning and weaving our various gold nanoparticle-merino wool or silk materials. Your help doing this has been invaluable.

Very importantly, Mum and Dad, thanks for financial support during the earlier years of my study and the use of your home computer (and fridge!) whilst I was writing this thesis. Thank you to all of my family members for enduring numerous recitals of presentations relating to this research, especially my dashing husband Tim, although Tim, you have made me practice in the stairwell a few times!

Funding from The Curtis Gordon Research Scholarship, New Zealand Wool Industry, Enterprise Scholarship, the World Gold Council and the Victoria University Submission Scholarship is gratefully acknowledged.

And thank you for reading this thesis! 


\section{ABSTRACT}

Significant opportunities exist in both the scientific and industrial sectors for the development of novel multi-functional materials that combine the inherent properties of all precursor components in a synergistic manner, thereby providing new products and opportunities. Processes that add value to natural materials in a facile and refined manner are particularly sought after. Thus this research combines useable substrates, notably natural protein fibres and minerals with gold or silver nanoparticles, producing high value, multifunctional materials that display the strength, softness and shine (of the protein fibres), or high surface area and dispersibility (of the minerals) with the high value and wealth associated with the noble metal nanoparticles, their broad spectrum of intense colours, antimicrobial, insecticide and anti-static properties. This adds significant worth to the substrates, transforming them from commodities to valuable materials.

Silk, merino wool and crossbred wool were the natural fibres employed kaolinite and halloysite clays the minerals. They were combined with gold and silver nanoparticles of various sizes and shapes (and hence colours) producing the following composite materials:

- Gold nanoparticle-merino wool composites

- Gold nanoparticle-crossbred wool composites

- Gold nanoparticle-silk composites

- Silver nanoparticle-kaolinite composites

- Silver nanoparticle-halloysite composites

The most successful method for producing silver nanoparticle-clay composites involved the external preparation of silver nanoparticles and their subsequent attachment to the clay substrates by means of a layer-by-layer deposition approach, which capitalised on electrostatic interactions between oppositely charged polyelectrolytes capping the nanoparticles and bound to the clay surfaces. 
Three general approaches were employed in the production of the gold nanoparticle-natural fibre composite materials. The nanoparticles were either synthesised ex-situ and subsequently attached to the fibres, or the natural fibres were utilised as redox active biotemplates in which the wool or silk absorbed and subsequently reduced $\mathrm{Au}^{3+}$ to nanoparticulate $\mathrm{Au}^{0}$ on and within the fibres. Thirdly, a seed mediated growth approach was employed in which additional $\mathrm{Au}^{3+}$ was reduced to nanoparticulate $\mathrm{Au}^{0}$ on the surface of gold nanoparticles already bound to the fibres. This was facilitated by an external reductant. 


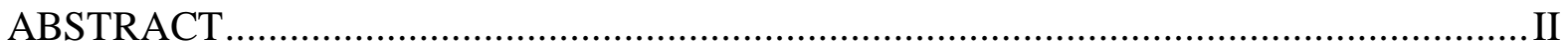

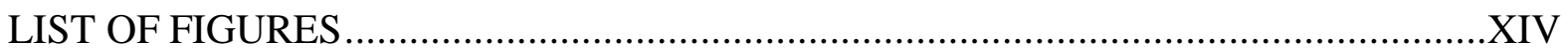

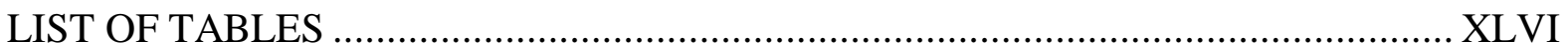

LIST OF ABBREVIATIONS ...........................................................................

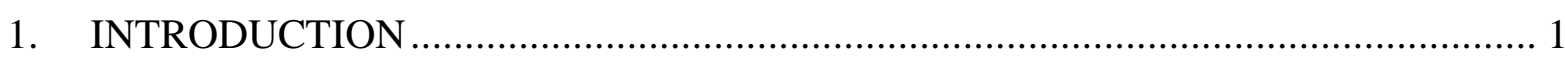

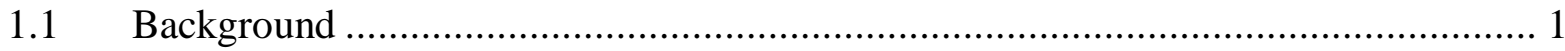

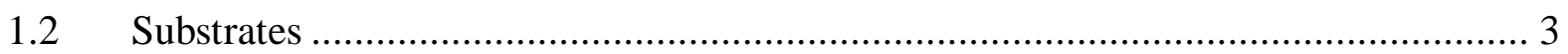

1.2.1 Mineral Substrates........................................................................ 3

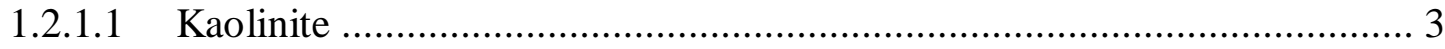

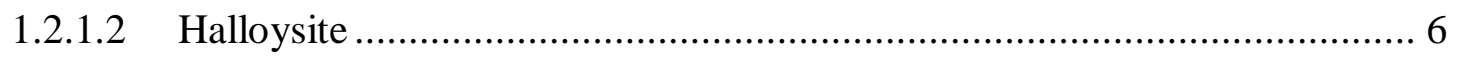

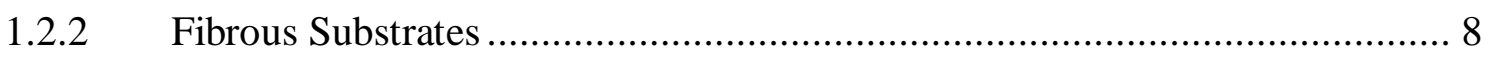

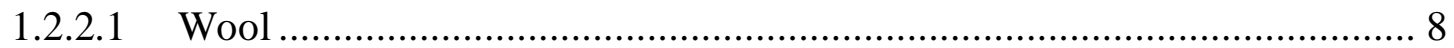

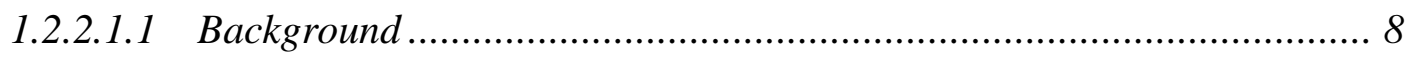

1.2.2.1.2 Chemical Composition ............................................................... 9

1.2.2.1.3 Physical Properties...................................................................11

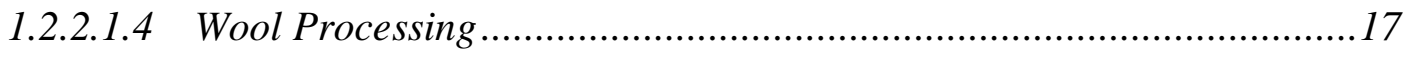

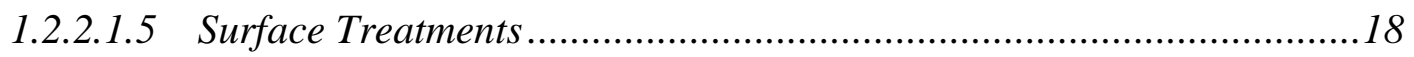

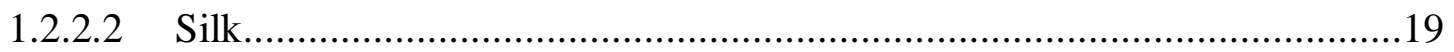

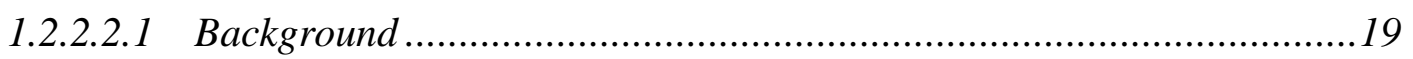

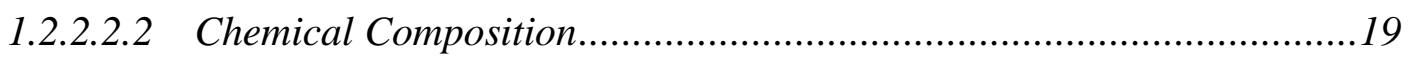

1.2.2.2.3 Physical Properties....................................................................21 
1.3 Metal Nanoparticles

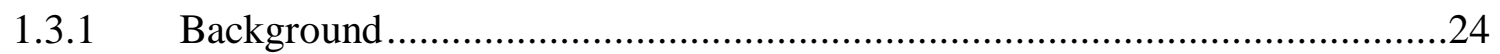

1.3.2 Preparation of Metal Nanoparticles ....................................................267

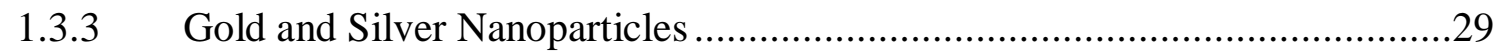

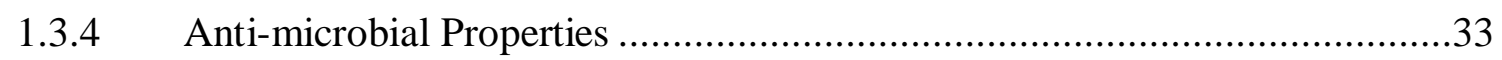

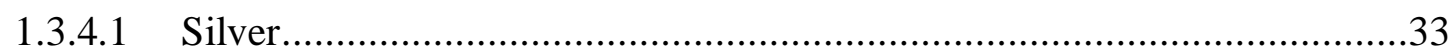

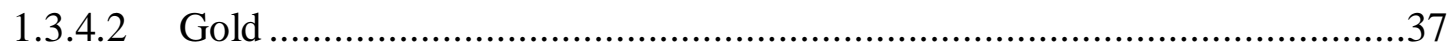

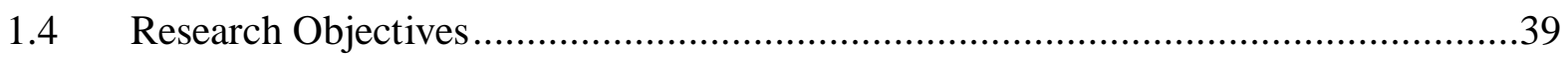

2. EXPERIMENTAL METHODS ...................................................................... 41

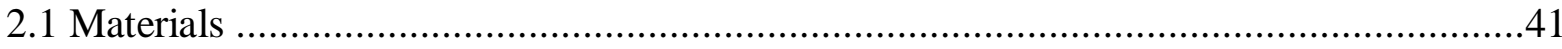

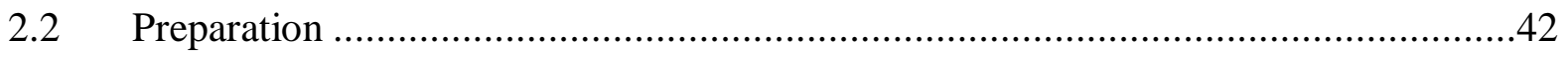

2.2.1 Preparation of Silver Nanoparticle-Clay Composites .................................42

2.2.1.1 ex-situ Preparation of Silver Nanoparticles and Subsequent Attachment to

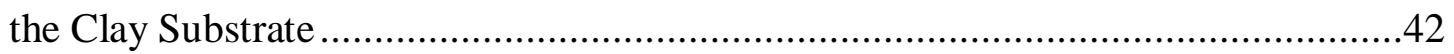

2.2.1.1.2 Attachment of Silver Nanoparticles to Clay Substrate Through a Linker Molecule of Opposite Net Charge to the Nanoparticles .......................................44

2.2.1.2 Silver Nanoparticles Formed in the Presence of the Clay Substrate Using an External Reducing Agent With In-Situ Binding of Nanoparticles to Substrate .45

2.2.1.3 Preparation of Silver Nanoparticle-Clay Composites by a Reductant Bound to the Clay Substrates. .46

2.2.2 Preparation of Gold Nanoparticle-Natural Fibre Composites .47

2.2.2.1 ex-situ Preparation of Gold Nanoparticles and Subsequent Attachment to Merino Wool Fibres. .48

2.2.2.2 Gold Nanoparticles Formed in the Presence of Wool by an External Reducing Agent with in-situ Binding of Nanoparticles to Fibres .50 
2.2.2.2.1 in-situ Preparation of Gold Nanoparticles by Sodium Metabisulfite in the Presence of Merino Fibres

2.2.2.2.2 in-situ Preparation of Gold Nanorods.

2.2.2.3. in-situ Preparation of Gold Nanoparticles Utilising Wool and Silk as Redox Active Biotemplates

2.2.2.3.1 Fibre Pre-Treatment ..................................................................... 54

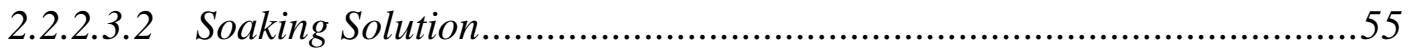

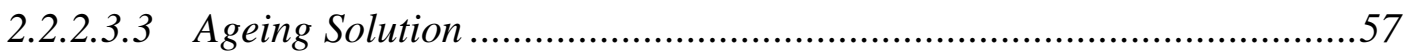

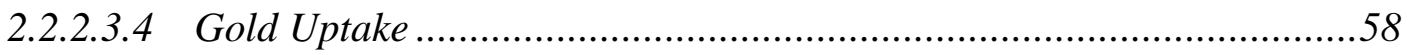

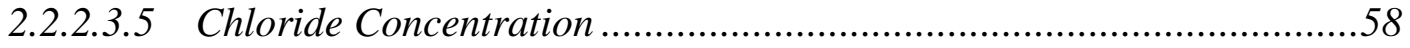

2.2.2.4 Seeded Growth of Gold Nanoparticles by an External Reductant Employing Gold Nanoparticle-Fibre Composite Materials as Seed Source .59

2.2.2.5 Leaching 61

2.3 Characterisation .62

2.3.1 Scanning Electron Microscopy …...........................................................62

2.3.2 Transmission Electron Microscopy.......................................................62

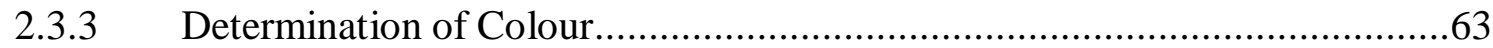

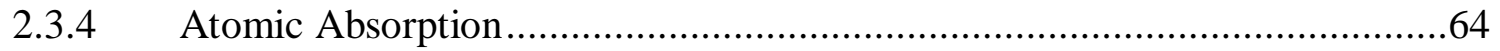

2.3.5 Determination of Chloride Concentration ..............................................64

2.3.6 X-ray Photoelectron Spectroscopy...........................................................65

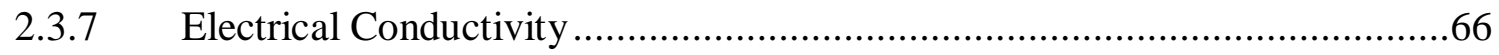

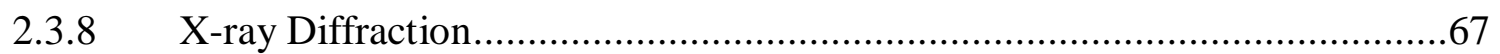

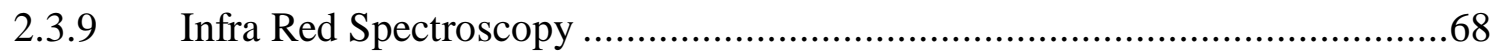

2.3.10 Ultra Violet Visible Spectroscopy .....................................................6 
2.3.12 Solid State NMR .........................................................................6

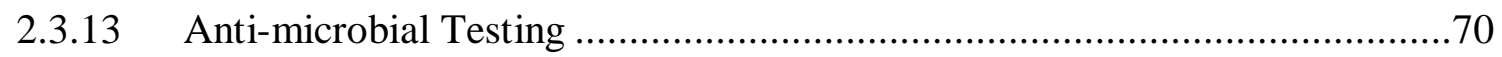

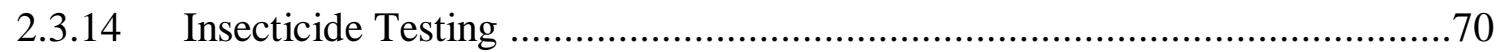

2.3.15 Light Fastness, Washability and Wearability ............................................ 70

3. SILVER NANOPARTICLE-CLAY COMPOSITES ….........................................73

3.1 ex-situ Preparation of Nanoparticles and Subsequent Attachment to Clay Substrates 73

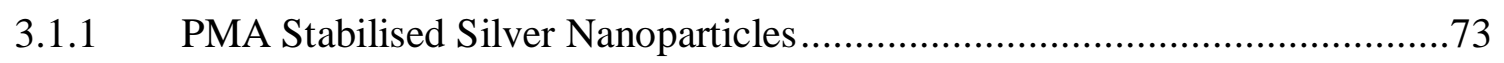

3.1.1.1 PMA Stabilised Silver Nanoparticles Prepared via a Photo Induced

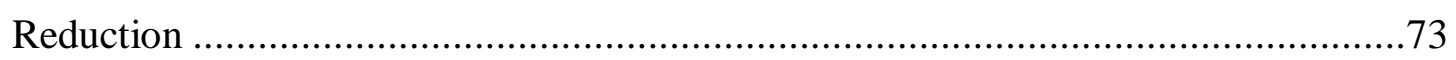

3.1.1.2 PMA Stabilised Silver Nanoparticles Prepared via $\mathrm{NaBH}_{4}$ Reduction.......80

3.1.2 PMA Stabilised Silver Nanoparticle-Clay Composites..............................83

3.1.2.1 Physical Characterisation and Morphology .........................................83

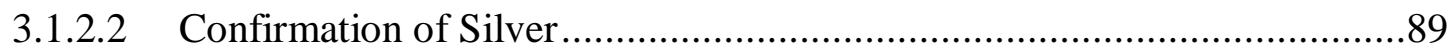

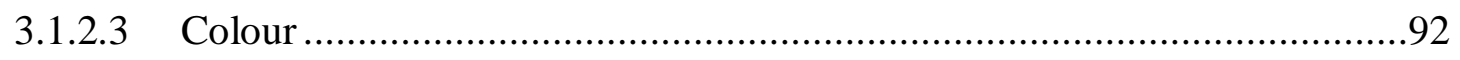

3.1.2.4 Bonding of Nanoparticles to Clay Substrates ....................................... 97

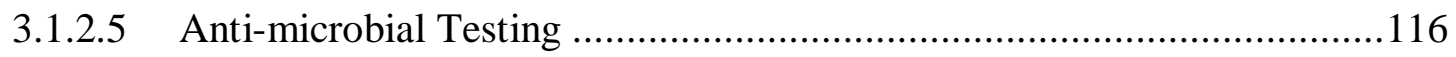

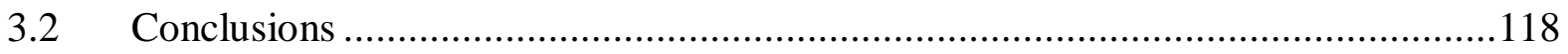

4 GOLD NANOPARTICLE-MERINO WOOL COMPOSITES: EX-SITU PREPARATION OF GOLD NANOPARTICLES WITH SUBSEQUENT ATTACHMENT

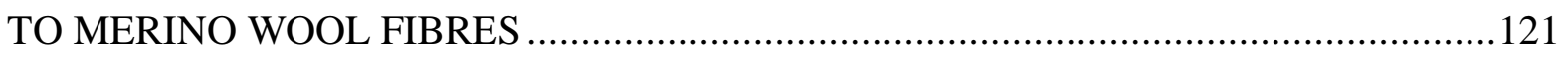

4.1 Gold Nanoparticles Prepared with Trisodium Citrate or Tannic Acid ....................121

4.1.1 ex-situ Preparation of Gold Nanoparticles..................................................122

4.1.1.1 TSC Reduced and Stabilised Gold Nanoparticles.................................122 
4.1.1.2 TA Reduced and Stabilised Gold Nanoparticles.

4.1.2 TSC or TA Reduced and Stabilised Gold Nanoparticle-Merino Wool Composites

4.1.2.1 Physical Characterisation and Morphology

4.1.2.2 Colour 136

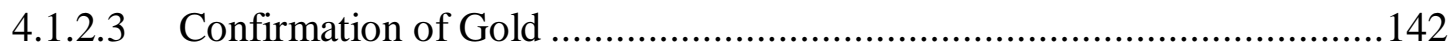

4.1.2.4 Bonding of Nanoparticles to Merino Wool Fibres ................................... 148

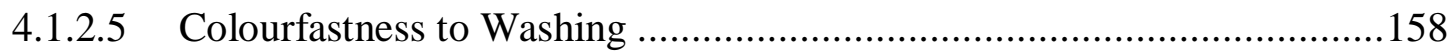

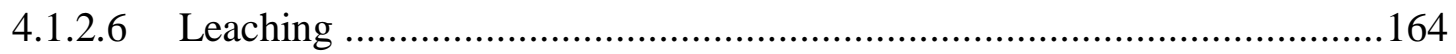

4.1.2.7 Chlorine Hercosett Shrink Resistance Treatment .................................166

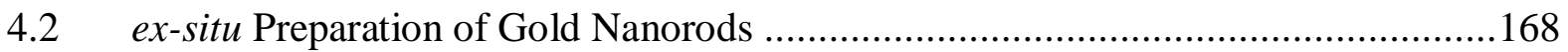

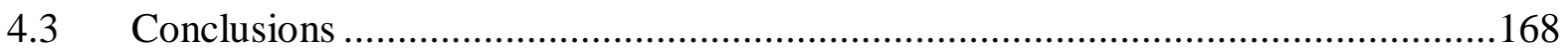

5. GOLD NANOPARTICLE-MERINO WOOL COMPOSITES: IN-SITU PREPARATION OF GOLD NANOPARTICLES UTILISING THE REDOX PROPERTIES

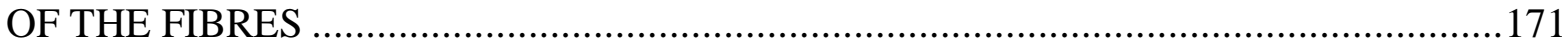

5.1 Physical Characterisation and Morphology .................................................. 171

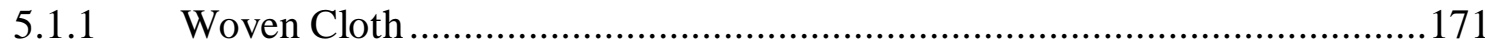

5.1.2 Untreated Semi-Worsted Gilled Sliver................................................ 173

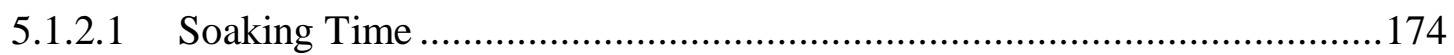

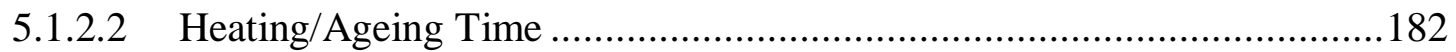

5.1.2.3 Soaking and Heating/Ageing Solution Compositions .............................186

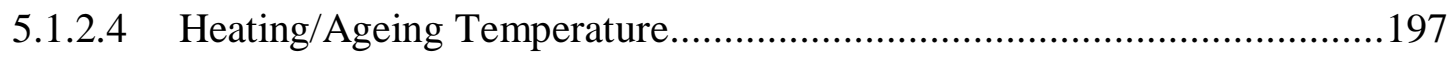

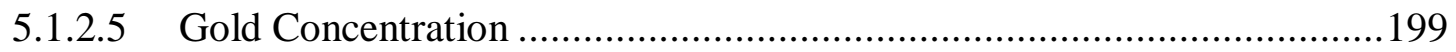

5.1.2.6 Production of Light Pink Coloured Composites .....................................205 
5.1.3 Acid Treated Semi-Worsted Gilled Sliver..............................................2215

5.1.4 KOH/EtOH Treated Semi-Worsted Gilled Sliver....................................216

5.1.5 Chlorine Hercosett Treated Semi-Worsted Gilled Sliver ..........................217

5.1.5.1 KOH Treated Chlorine Hercosett Semi-Worsted Gilled Sliver................221

5.1.6 Untreated Worsted Combed Top ........................................................225

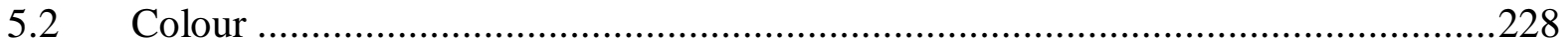

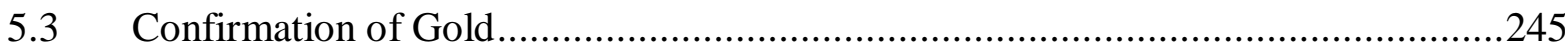

5.4 Extent of Gold Uptake by Merino Wool Fibres .................................................256

5.5 Bonding of Gold Nanoparticles to Merino Wool Fibres ....................................262

5.5.1 Untreated Semi-Worsted Gilled Sliver.................................................262

5.5.2 KOH/MeOH Treated Semi-Worsted Gilled Sliver .....................................275

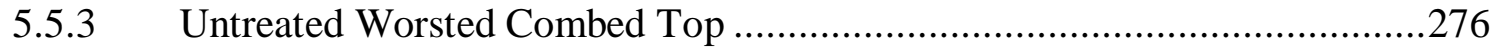

5.5.4 Chlorine Hercosett Treated Semi-Worsted Gilled Sliver .............................280

5.5.4.1 KOH Treated Chlorine Hercosett Treated Semi-Worsted Gilled Sliver ...284

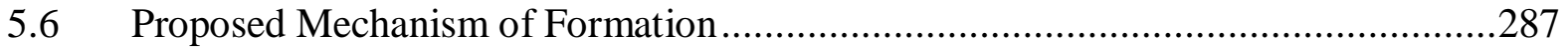

5.7 Colour Fastness, Light Fastness, Washability and Wearability ..............................312

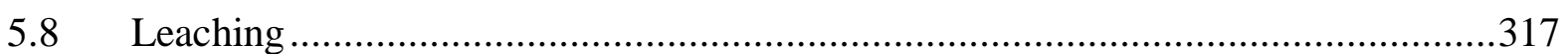

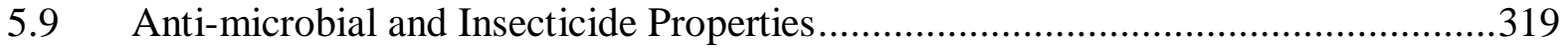

5.10 Chlorine Hercosett Shrink Resistance Treatment................................................322

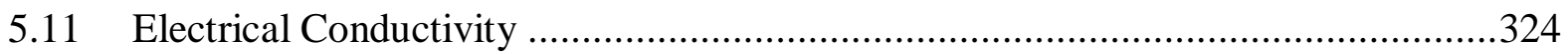

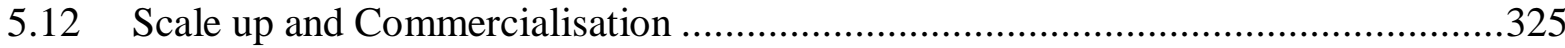

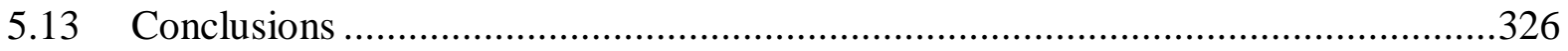




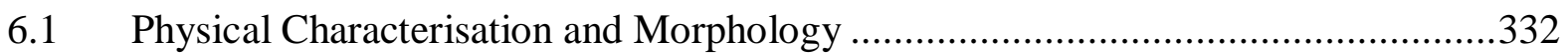

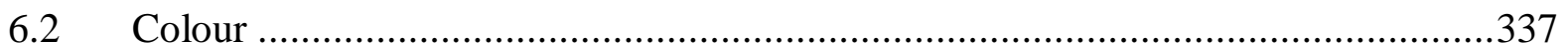

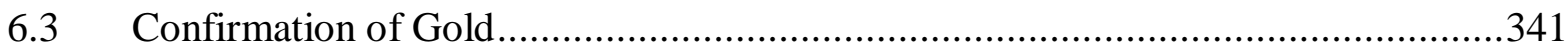

6.4 Extent of Gold Uptake by Crossbred Wool Fibres ..............................................345

6.5 Bonding of Gold Nanoparticles to Crossbred Wool Fibres ...................................347

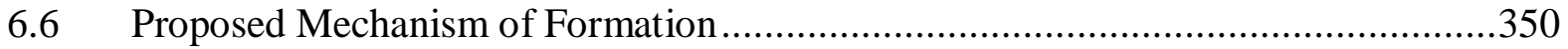

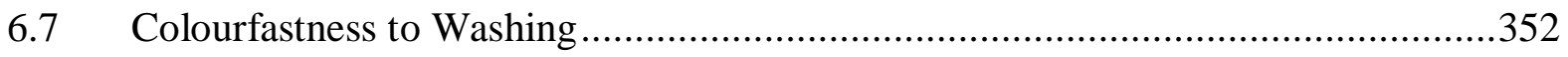

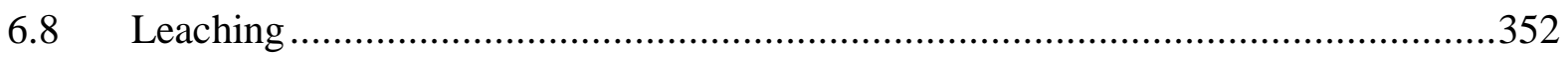

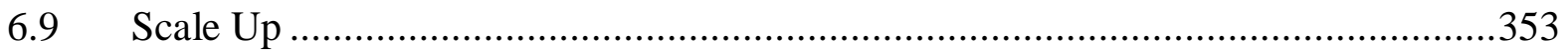

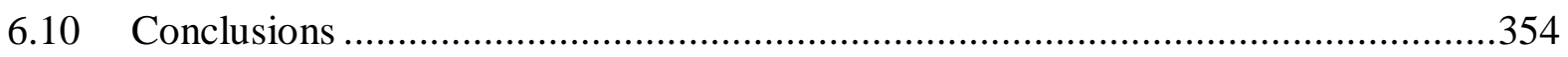

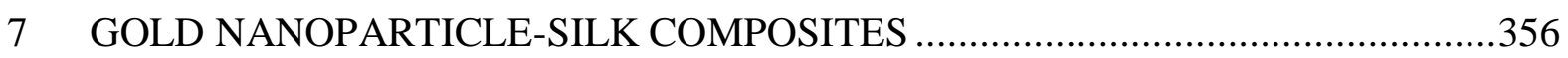

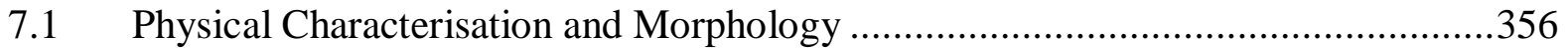

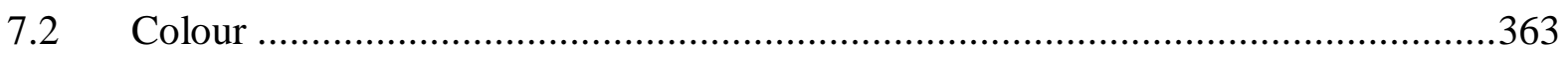

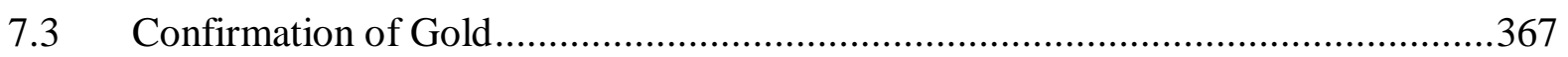

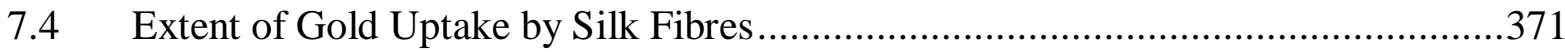

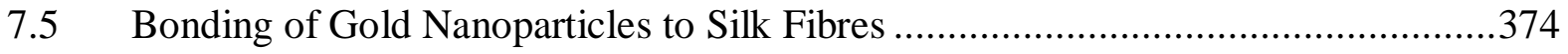

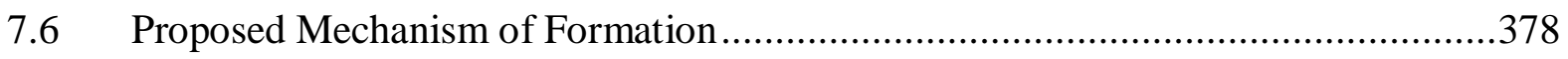

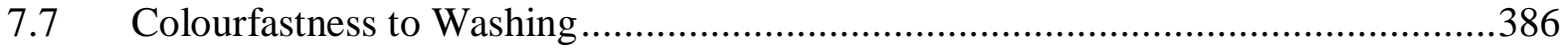

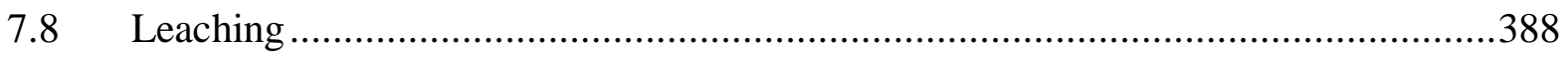

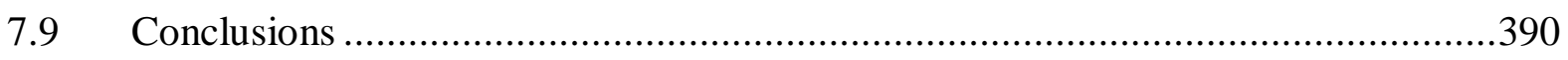


8. SEED MEDIATED GROWTH OF GOLD NANOPARTICLES BY AN EXTERNAL REDUCTANT EMPLOYING GOLD NANOPARTICLE-FIBRE COMPOSITE MATERIALS AS SEED SOURCES

8.1 Gold Nanoparticle-Merino Wool Composites ...................................................392

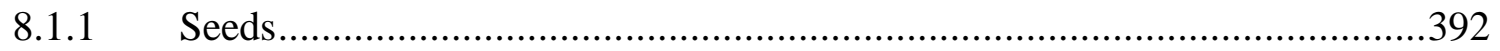

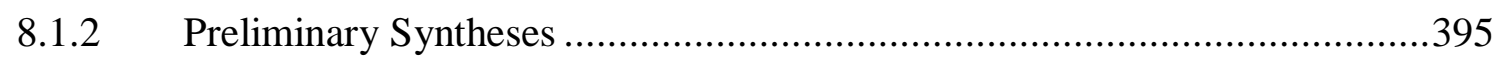

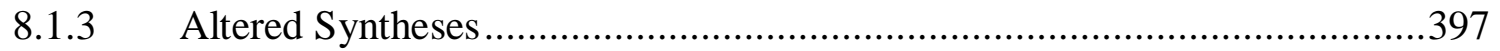

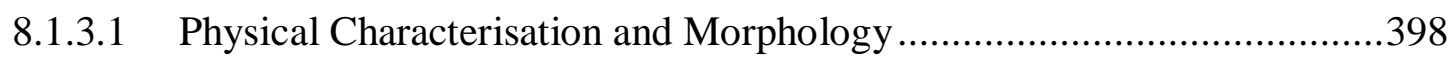

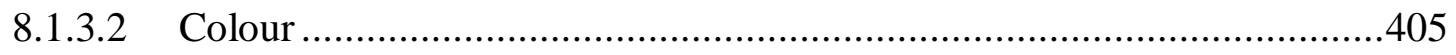

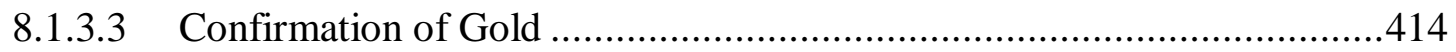

8.1.3.4 Proposed Mechanism for Seeded Growth and Bonding of Gold to Merino

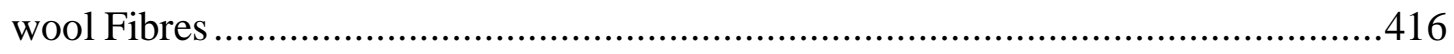

8.1.3.5 Colourfastness to Washing ............................................................425

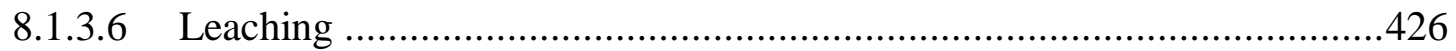

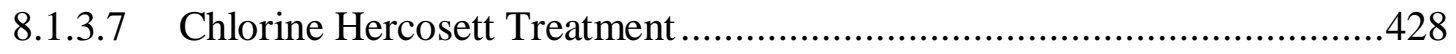

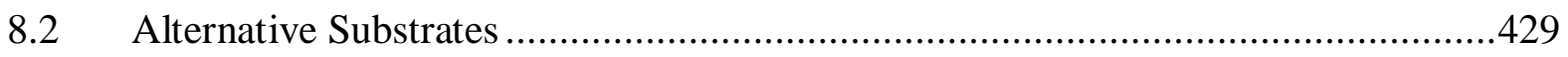

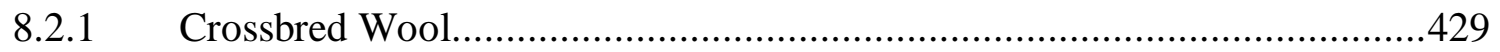

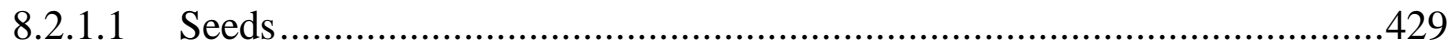

8.2.1.2 Physical Characterisation and Morphology …...................................432

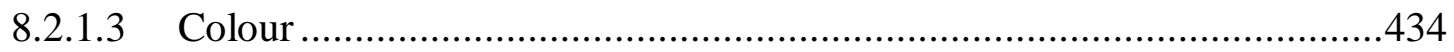

8.2.1.4 Bonding of Gold Nanoparticles to Crossbred Wool Fibres ......................436

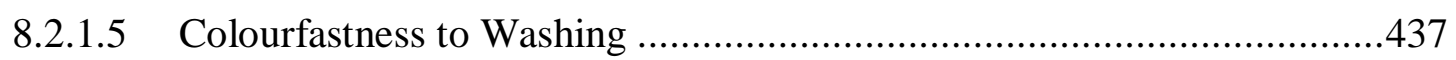

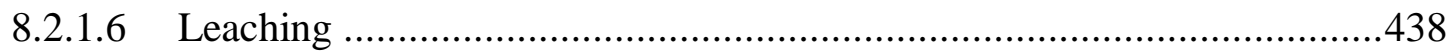

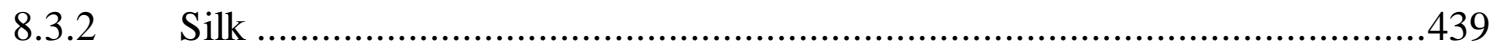


8.3.2.2 Physical Characterisation and Morphology ...........................................442

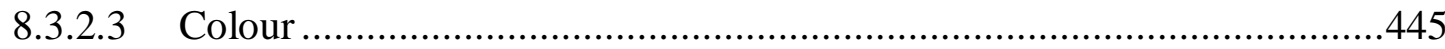

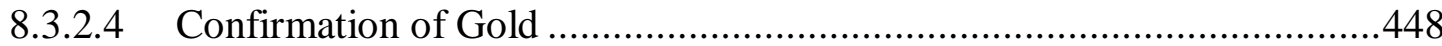

8.3.2.5 Bonding of Gold Nanoparticles to Silk Fibres .......................................449

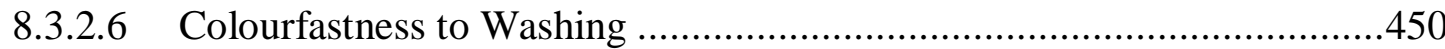

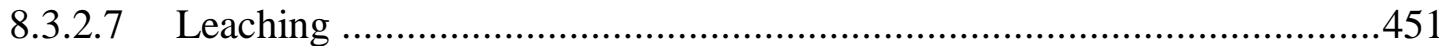

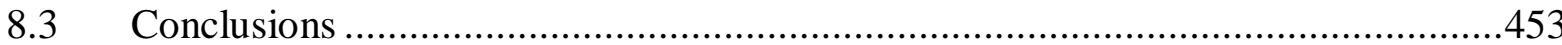

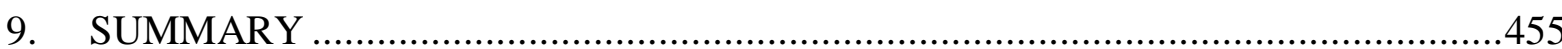

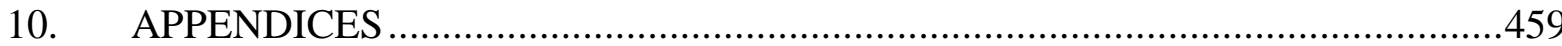

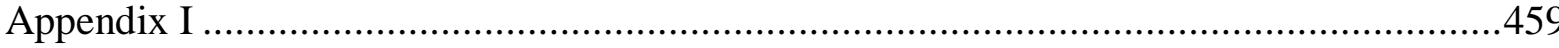

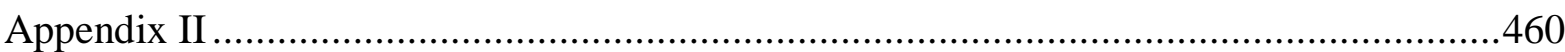

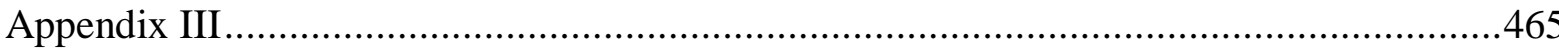

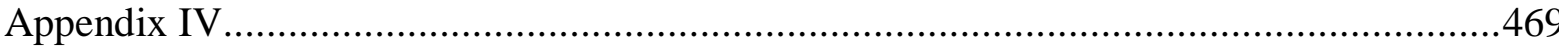

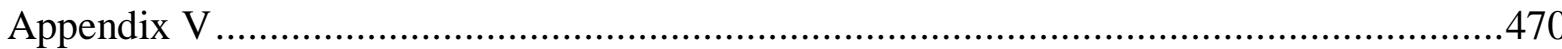

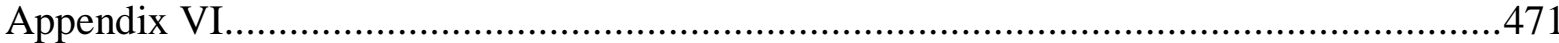

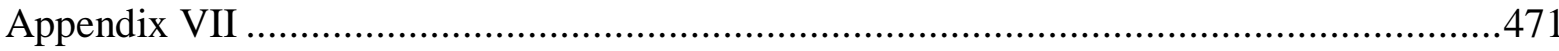

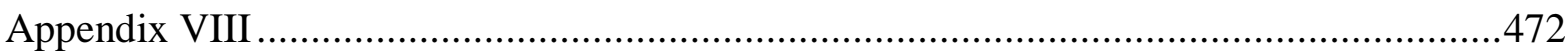

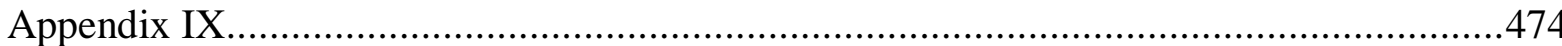

Appendix X

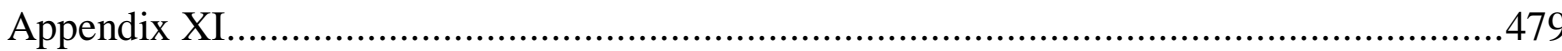

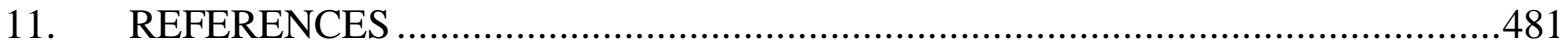




\section{LIST OF FIGURES}

Figure 1.1: (I) $\mathrm{SiO}_{4}{ }^{4}$ tetrahedra. (II) Sheet of silicon tetrahedron.[23].............................. 4

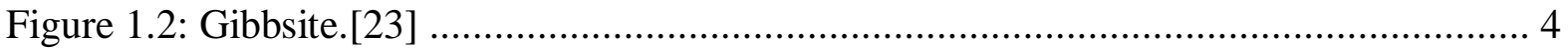

Figure 1.3: Combination of gibbsite and silicon tetrahedral layers.[23] ............................. 5

Figure 1.4: Scanning electron microscopy (SEM) micrograph of kaolinite. Characteristic hexagonal platelets are evident. ............................................................... 5

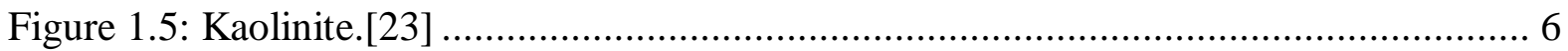

Figure 1.6: Crystalline structure of halloysite-(10 $\AA$ ).[22] ................................................ 7

Figure 1.7: Transition electron microscopy (TEM) micrographs of various morphologies of halloysite; a) spherical and b) tubular.[22]. 7

Figure 1.8: Diagram showing the numerous bonds liking adjacent polypeptide chains in wool keratin, notably intermolecular disulfide crosslinks, isopeptide crosslinks and hydrophobic and ionic interactions.[42] .................................................11

Figure 1.9: Image showing types of medulla that can occur in wool fibres. a) Fragmental, b) interrupted and c) continuous.[36] .12

Figure 1.10: Structure of fine wool. Note, coarse wool may also contain a medulla, not shown here.[39].

Figure 1.11: Light micrograph of cross sections of merino wool fibres stained to show the bilateral differentiation of the orthocortex $(\mathrm{O}$; darkly stained) and paracortex $(\mathrm{P}$; lightly stained).[46] .13

Figure 1.12: Schematic representation of the cortical structure and crimp of merino wool fibres; (I) side view and (II) cross sectional end view.[49] ..............................14

Figure 1.13: Scanning electron micrograph of a merino wool fibre. Overlapping cuticle cells are evident on the fibre surface. .14

Figure 1.14: Model for the epicuticle of keratin fibres. Diagram represents a slice of the outer $100 \AA$ of a cuticle cell. The protein matrix is heavily acylated with 18-MEA, which forms a hydrophobic surface.[55] (Note: diagram is not drawn to scale)..16

Figure 1.15: Hercosett 125, a polyamide epichlorhydrin type polymer employed in shrink resistant treatment of wool. .18

Figure 1.16: The structure of B. mori silk thread.[76] .22

Figure 1.17: Schematic showing the interactions of the two different $\beta$-sheet regions in silk fibroin.[76]

Figure 1.18: Implementation of metal nanoparticles as colourants for stained glass windows, which was common practice throughout the Middle Ages.[99] .25 
Figure 1.19: Schematic drawing of the interaction of the electromagnetic field of incoming light with a) spherical nanoparticles, and b) nanorods. A dipole is induced in the spherical nanoparticles that oscillates in plane with the electric field of incoming light, whilst both transverse and longitudinal oscillations are evident in the metal nanorods.[107]

Figure 1.20: Left TEM images of a) gold nanorods, and c) silver nanoprisms and truncated triangles. Right pictures of colloidal dispersions of b) gold nanorods of increasing aspect ratio and d) silver nanoprisms with increasing lateral size.[107].... .29

Figure 1.21: SEM micrograph taken from Lofton et. al.[130] Illustrates the diversity of colloid shapes synthesised in a homogeneous reaction environment, including tapes, rods, platelets, tetrahedra and isotropic particles. .30

Figure 1.22: Schematic showing a single twin plane. Alternating A- and B-type faces with reentrant grooves of A-type faces causing rapid growth that stops when the face grows itself out, resulting in a triangular prism.[130] .31

Figure 1.23: TEM micrographs of gold produced via a polyol method (left) and altered

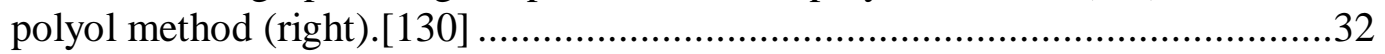

Figure 1.24: a) SEM micrographs of native E. coli cells and b) cells treated with $50 \mu \mathrm{g} \mathrm{ml}$ of silver nanoparticles.[156]

Figure 1.25: TEM micrograph of an E. coli cell treated with $50 \mu \mathrm{g} \mathrm{ml}$ of silver nanoparticles.[156]. .35

Figure 1.26: Schematic illustration of the preparation of silver nanoparticles in the interlayer spacings of kaolinite.[8]

Figure 1.27: Layer-by-layer deposition of silver nanoparticles capped with anionic PMA onto fibres coated with the cationic polymer PDADMAC. ....................................36

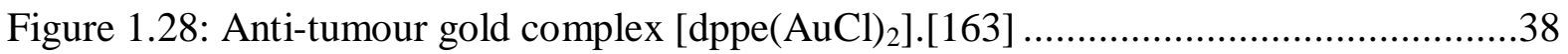

Figure 2.1: Murphy et al. Seed-mediated method for the production of gold nanorods of controlled aspect ratio.[127, 171] .............................................................50

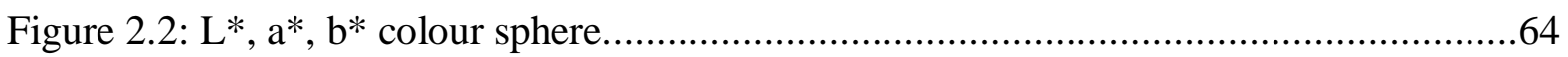

Figure 2.3: Samples loaded into sample holder in preparation for XPS analysis..................65

Figure 2.4: Linear four point probe for measuring the conductivity of fibres......................67

Figure 3.1: PMA reduced and stabilised silver nanoparticles. Increasing $\left[\mathrm{AgNO}_{3}\right]$ :[PMA] (left to right) and increasing irradiation time (top to bottom). ...........................74

Figure 3.2: UV/Vis absorption spectra showing an increase in peak intensity and a shift to lower wavelengths with increasing irradiation time. .75

Figure 3.3: UV/Vis absorption spectra showing an increase in peak intensity and shift to higher wavelengths with an increasing [AgNO3]:[PMA] ratio. .76

Figure 3.4: TEM micrographs showing the range of morphologies present in PMA stabilised silver nanoparticles prepared via a photo induced reduction. Predominantly 
nanospheres (a), and to a lesser extent hexagonal platelets (b), five-fold twinned

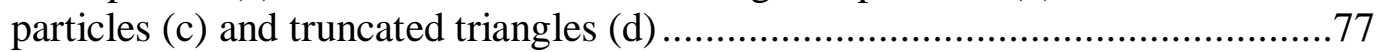

Figure 3.5: Deconvoluted high resolution Ag 3d spectrum of a) PMA capped silver nanoparticles, b) O1s spectrum of PMA and c) O1s spectrum of PMA capped silver nanoparticles. Peak positions are summarised in Table 17. .79

Figure 3.6: Left: $\mathrm{NaBH}_{4}$ reduced and PMA stabilised silver nanoparticles. Right: $\mathrm{NaBH}_{4}$ reduced and PMA stabilised silver nanoparticles following irradiation. .80

Figure 3.7: a) UV/Vis absorption spectrum of yellow silver nanoparticles colloids and b) green silver nanoparticles colloids.

Figure 3.8: TEM micrographs of $\mathrm{NaBH}_{4}$ reduced and PMA stabilised silver nanoparticles. a) Yellow colloids (before irradiation) and b) green colloids (following irradiation).

Figure 3.9: TEM micrograph of $\mathrm{NaBH}_{4}$ reduced and PMA stabilised silver nanoparticles, arrows show the position of twin plane defects. .82

Figure 3.10: Range of silver nanoparticle-kaolinite (top) and halloysite (bottom) composite materials produced, incorporating Ag-PMA nanoparticles prepared via a photo induced reduction (left) and $\mathrm{NaBH}_{4}$ reduction (right). .83

Figure 3.11: SEM micrographs of kaolinite (a) and increasing magnifications of a Ag-PMAkaolinite composite (photo induced reduction) (b-f). The position of some nanoparticles are indicated by arrows. .84

Figure 3.12: Increasing magnification SEM micrographs of a Ag-PMA-kaolinite composite $\left(\mathrm{NaBH}_{4}\right.$ reduced). Nanoparticle positions indicated by arrows. .85

Figure 3.13: Increasing magnification SEM micrographs of a Ag-PMA-halloysite composite, prepared via photo induced (a-c) or $\mathrm{NaBH}_{4}$ reduction (d-f). Nanoparticles circled. .86

Figure 3.14: Increasing magnification TEM micrographs of Ag-PMA-kaolinite composites, prepared via photo induced (a-c) and $\mathrm{NaBH}_{4}$ reduction (d-f). .87

Figure 3.15: Increasing magnification TEM micrographs of Ag-PMA-halloysite composites prepared via photo induced (a-c) or $\mathrm{NaBH}_{4}$ reduction (d-f). .88

Figure 3.16: Increasing magnification TEM micrographs of of Ag-PMA-halloysite composites prepared via photo induced reduction. Arrows indicate the location of nanoparticles inside the cylindrical pores of halloysite. .88

Figure 3.17 Increasing magnification TEM micrographs of of Ag-PMA-halloysite composites prepared via or $\mathrm{NaBH}_{4}$ reduction. Arrows indicate the location of nanoparticles inside the cylindrical pores of halloysite. .89

Figure 3.18: SEM micrographs and corresponding silver EDS maps of Ag-PMA-kaolinite composites produced via a photo induced (a) kaolinite, c) halloysite) or $\mathrm{NaBH}_{4}$ reduction (b) kaolinite and d) halloysite). 90 
Figure 3.19: Wide XPS scans. a) and b) Ag-PMA-kaolinite and Ag-PMA-halloysite composites incorporating nanoparticles produced via a photo induced reduction. c) and d) Ag-PMA-kaolinite and -halloysite composites incorporating nanoparticles produced via a $\mathrm{NaBH}_{4}$ reduction. 91

Figure 3.20: Kubelka Munk transformed UV/Vis reflection spectrum of a) a Ag-PMAkaolinite PMA composite (photo induced reduction) and b) a Ag-PMA colloid (photo induced reduction).

Figure 3.21: Kubelka Munk transformed UV/Vis reflection spectrum of a) a Ag-PMAkaolinite composite $\left(\mathrm{NaBH}_{4}\right.$ reduction) and b) a Ag-PMA colloid $\left(\mathrm{NaBH}_{4}\right.$ reduction).

Figure 3.22: Kubelka Munk transformed UV/Vis reflection spectrum of a) a Ag-PMAhalloysite composite (photo induced reduction) and b) a Ag-PMA colloid (photo induced reduction). .95

Figure 3.23: Kubelka Munk transformed UV/Vis reflection spectrum of a) a Ag-PMAhalloysite composite $\left(\mathrm{NaBH}_{4}\right.$ reduction) and b) a Ag-PMA colloid $\left(\mathrm{NaBH}_{4}\right.$ reduction). . .96

Figure 3.24: Kubelka Munk transformed UV/Vis reflection spectra of a) a Ag-PMA-kaolinite composite (photo induced reduction) and b) a Ag-PMA-halloysite composite. Both prepared via a photo induced reduction. .96

Figure 3.25: XRD patterns of a) kaolinite, b) Ag-PMA-kaolinite (photo induced reduction) and c) Ag-PMA-kaolinite $\left(\mathrm{NaBH}_{4}\right.$ reduction).

Figure 3.26: High resolution O 1s XPS spectra of a) kaolinite-PDADMAC, b) an overlay of kaolinite (red)

Figure 3.27: High resolution N 1s XPS spectra of a) kaolinite-PDADMAC O 1s, b) an overlay of PDADMAC (red). .99

Figure 3.28: High resolution Al 2p (a) and Si 2p (c) XPS spectra of kaolinite-PDADMAC. b) and d) show an overlay of the corresponding Al 2p and Si 2p spectra of kaolinite (in red) respectively. 100

Figure 3.29: High resolution XPS spectra of a Ag-PMA-kaolinite composite (produced via a photo induced reduction) and an overlay of the corresponding kaolinitePDADMAC materials (red lines) (a-b) $\mathrm{O} 1 \mathrm{~s}$ and (c-d) $\mathrm{N} 1 \mathrm{~s}$. 102

Figure 3.30: High resolution XPS spectra of a Ag-PMA-kaolinite composite (produced via a photo induced reduction) and an overlay of the corresponding kaolinitePDADMAC materials (red lines) (a-b) Al 2p and (c-d) Si 2p. 102

Figure 3.31: High resolution Ag 3d XPS spectra of a Ag-PMA-kaolinite composite a) photo induced production and c) $\mathrm{NaBH}_{4}$ production. b) and d) overlay of Ag-PMAkaolinite composites (in black) and their corresponding Ag-PMA nanoparticles (in red). 104

Figure 3.32: High resolution XPS spectrum of a Ag-PMA-halloysite (photo induced reduction) a) $\mathrm{O} \mathrm{1s,} \mathrm{c)} \mathrm{Al} 2 \mathrm{p}$, e) $\mathrm{Si} 2 \mathrm{p}$, and g) $\mathrm{N}$ 1s. b), d) and f) are the $\mathrm{O} 1 \mathrm{~s}, \mathrm{Al}$ $2 p$ and $\mathrm{Si} 2 \mathrm{p}$ spectra of halloysite (red) and the corresponding overlays of 
deconvoulted Ag-PMA-halloysite (black). h) overlay of $\mathrm{N}$ 1s spectrum of PDADMAC (red) and Ag-PMA-halloysite (black).

Figure 3.33: High resolution Ag 3d XPS spectra of a) Ag-PMA-halloysite (photo induced reduction) and b) overlay of Ag-PMA-halloysite (in black) and Ag-PMA (in red).

107

Figure 3.34: High resolution XPS spectrum of a Ag-PMA-kaolinite composites (incorporating nanoparticles prepared by $\mathrm{NaBH}_{4}$ ) a) O 1s, c) Al 2p, e) $\mathrm{Si} 2 \mathrm{p}$, and g) $\mathrm{N} \mathrm{1s.} \mathrm{b),} \mathrm{d)} \mathrm{and} \mathrm{f)} \mathrm{are} \mathrm{the} \mathrm{corresponding} \mathrm{overlays} \mathrm{of} \mathrm{O} 1 \mathrm{~s}, \mathrm{Al} \mathrm{2p}$ and $\mathrm{Si} 2 \mathrm{p}$ spectra of kaolinite-PDADMAC (red) and deconvoluted Ag-PMA-kaolinite (black), h) overlay of $\mathrm{N} 1 \mathrm{~s}$ spectrum of PDADMAC (red) and deconvoluted AgPMA-halloysite (black).

108

Figure 3.35: High resolution XPS spectrum of a Ag-PMA-halloysite $\left(\mathrm{NaBH}_{4}\right.$ reduction) a) $\mathrm{O}$ 1s, c) Al 2p, e) Si 2p, and g) N 1s. b), d) and f) are the corresponding overlays of $\mathrm{O} 1 \mathrm{~s}, \mathrm{Al} 2 \mathrm{p}$ and $\mathrm{Si} 2 \mathrm{p}$ spectra of halloysite (red) and deconvoluted Ag-PMAhalloysite (black), h) overlay $\mathrm{N}$ 1s spectrum of PDADMAC (red) and deconvoluted Ag-PMA-halloysite (black). 109

Figure 3.36: High resolution Ag 3d XPS spectra of a) Ag-PMA-kaolinite and c) Ag-PMAhalloysite. Both prepared with $\mathrm{NaBH}_{4}$. b) and d) offer an overlay of a silver colloid prepared with $\mathrm{NaBH}_{4}$ (in red). 112

Figure 3.37: FT-IR spectra of kaolinite (black line) and a Ag-PMA-kaolinite composite (red line). .113

Figure 3.38: Solid state ${ }^{27}$ Al NMR spectra of kaolinite and Ag-PMA-kaolinite composites (photo induced and $\mathrm{NaBH}_{4}$ production). .113

Figure 3.39: Solid state ${ }^{27}$ Al NMR spectra of halloysite and Ag-PMA-halloysite composites (photo induced and $\mathrm{NaBH}_{4}$ production). 115

Figure 3.40: Solid state ${ }^{29} \mathrm{Si}$ NMR spectra of kaolinite and Ag-PMA-kaolinite composites (photo induced and $\mathrm{NaBH}_{4}$ production). 115

Figure 3.41: Solid state ${ }^{29} \mathrm{Si}$ NMR spectra of halloysite and Ag-PMA-halloysite composites (photo induced and $\mathrm{NaBH}_{4}$ production). 115

Figure 3.42: Agar plates containing Staphylococcus aureus. Left a) kaolinite, b) kaolinitePDADMAC, c) halloysite and d) halloysite-PDADMAC. Right, increased magnification image of halloysite on agar. 117

Figure 3.43: Inhibition zones of Staphylococcus aureus microbial growth. a) Ag-PMAkaolinite and b) Ag-PMA-halloysite, both incorporating nanoparticles prepared via a photo induced production. c) Ag-PMA-kaolinite and d) Ag-PMA-halloysite composites incorporating nanoparticles prepared with $\mathrm{NaBH}_{4}$ .117

Figure 4.1: Gold nanoparticle-merino wool composites prepared by the ex-situ reduction of $\mathrm{Au}^{3+}$ to $\mathrm{Au}^{0}$ by TSC (top) or TA (bottom).

Figure 4.2: Gold nanoparticle solutions prepared with increasing amounts of TSC (left to right) 
Figure 4.3: UV/Vis absorption spectra of TSC reduced and stabilised gold nanoparticles. .124

Figure 4.4: TEM micrographs of gold nanoparticles prepared with $20 \mu \mathrm{L}$ of $10 \mathrm{wt} \%$ TSC.

Figure 4.5: Increasing magnification TEM micrographs of a gold nanoparticle colloid prepared with $50 \mu \mathrm{L}$ of $10 \mathrm{wt} \% \mathrm{TSC}$. .126

Figure 4.6: Gold nanoparticle solutions prepared with increasing amounts of TA (left to right). 126

Figure 4.7: UV/Vis absorption spectra of TA reduced and stabilised gold nanoparticles ....127

Figure 4.8: Increasing magnificantion TEM micrographs of a gold nanoparticle colloid prepared with $10 \mu \mathrm{L}$ of $1 \mathrm{wt} \% \mathrm{TA}$. 128

Figure 4.9: TEM micrographs of a gold nanoparticle colloid prepared with $20 \mu \mathrm{L}$ of $10 \mathrm{wt} \%$ TA. .128

Figure 4.10: Increasing magnification TEM micrographs of a gold nanoparticle colloid prepared with $50 \mu \mathrm{L}$ of $10 \mathrm{wt} \% \mathrm{TA}$. .129

Figure 4.11: Increasing magnification SEM micrographs of a gold nanoparticle-merino wool composite incorporating gold nanoparticles prepared with $10 \mu \mathrm{L}$ of $1 \mathrm{wt} \% \mathrm{TSC}$ (top), $20 \mu \mathrm{L}$ of $10 \mathrm{wt} \% \mathrm{TSC}$ (middle) and $50 \mu \mathrm{L}$ of $10 \mathrm{wt} \% \mathrm{TSC}$ (bottom)....130

Figure 4.12: Increasing magnification SEM micrographs of a gold nanoparticle-merino wool composite incorporating gold nanoparticles prepared with $10 \mu \mathrm{L}$ of 1 wt \% TA (top) and $50 \mu \mathrm{L} 10 \mathrm{wt} \% \mathrm{TA}$ (bottom).

Figure 4.13: Increasing magnification TEM micrographs of a gold nanoparticle-merino wool composite incorporating gold nanoparticles prepared with $10 \mu \mathrm{L}$ of 1 wt \% TA (top) or $50 \mu \mathrm{L}$ of $1 \mathrm{wt} \% \mathrm{TA}$ (bottom). 132

Figure 4.14: Left: A Cross sectional SEM micrograph of a gold nanoparticle-merino wool composite (incorporating nanoparticles prepared with $10 \mu \mathrm{L}$ of 1 wt $\%$ TSC). Right: the corresponding gold EDS map. 133

Figure 4.15: Left: Gold EDS map of a gold nanoparticle-merino wool composite (incorporating nanoparticles prepared with $10 \mu \mathrm{L}$ of $1 \mathrm{wt} \% \mathrm{TSC}$ ), and right: the corresponding line profile showing higher concentrations of gold on the surface of the fibre than in the centre. .133

Figure 4.16: Left: A Cross sectional SEM micrograph of a gold nanoparticle-merino wool composite (incorporating nanoparticles prepared with $50 \mu \mathrm{L}$ of $10 \mathrm{wt} \% \mathrm{TSC}$ ). Right: the corresponding gold EDS map...... 134

Figure 4.17: Left: Gold EDS map of a gold nanoparticle-merino wool composite (incorporating nanoparticles prepared with $50 \mu \mathrm{L}$ of $10 \mathrm{wt} \% \mathrm{TSC}$ ), and right: the corresponding line profile showing higher concentrations of gold on the surface of the fibre than in the centre. .134 
Figure 4.18: Left: A Cross sectional SEM micrograph of a gold nanoparticle-merino wool composite (incorporating nanoparticles prepared with $10 \mu \mathrm{L}$ of 1 wt $\% \mathrm{TA}$ ). Right: the corresponding gold EDS map.

Figure 4.19: Left: Gold EDS map of a gold nanoparticle-merino wool composite (incorporating nanoparticles prepared with $10 \mu \mathrm{L}$ of $1 \mathrm{wt} \% \mathrm{TA}$ ), and right: the corresponding line profile showing higher concentrations of gold on the surface of the fibre than in the centre. 135

Figure 4.20: Left: Left: A Cross sectional SEM micrograph of a gold nanoparticle-merino wool composite (incorporating nanoparticles prepared with $50 \mu \mathrm{L}$ of $10 \mathrm{wt} \%$ TA). Right: the corresponding gold EDS map. 135

Figure 4.21: Left: Gold EDS map of a gold nanoparticle-merino wool composite (incorporating nanoparticles prepared with $50 \mu \mathrm{L}$ of $10 \mathrm{wt} \% \mathrm{TA}$ ), and right: the corresponding line profile showing higher concentrations of gold on the surface of the fibre than in the centre. 135

Figure 4.22: SEM micrographs of gold nanoparticle-merino wool composites prepared with, left: $10 \mu \mathrm{L}$ of 1 wt $\%$ TSC and right: $50 \mu \mathrm{L}$ of $10 \mathrm{wt} \%$ TSC. Shows the relationship between the colour of the composites and the size and shape of the gold particles bound to the wool.

Figure 4.23: Kubelka Munk transformed UV/Vis reflection spectra of gold nanoparticlemerino wool composites incorporating nanoparticles prepared with TSC.

Figure 4.24: Kubelka Munk transformed UV/Vis reflection spectra of a) a gold nanoparticle colloid prepared with $20 \mu \mathrm{L}$ of $10 \mathrm{wt} \% \mathrm{TSC}, \mathrm{b})$ a gold nanoparticle-merino wool composite incorporating nanoparticles prepared with $50 \mu \mathrm{L}$ of $10 \mathrm{wt} \% \mathrm{TSC}$ and c) $20 \mu \mathrm{L}$ of $10 \mathrm{wt} \% \mathrm{TSC}$. 139

Figure 4.25: SEM micrographs relating the colour of the composites to the size and shape of the nanoparticles on the fibre surface. Left) a gold nanoparticle-merino wool composite incorporating nanoparticles prepared with $10 \mu \mathrm{L}$ of $1 \mathrm{wt} \% \mathrm{TA}$ and right) $50 \mu \mathrm{L}$ of $10 \mathrm{wt} \% \mathrm{TA}$. 140

Figure 4.26: Kubelka Munk transformed UV/Vis reflection spectra of gold nanoparticlemerino wool composites incorporating nanoparticles prepared with TA. 141

Figure 4.27: Comparison of the TSC and TA reduced and stabilised gold colloids and the gold nanoparticle-merino wool composites made from such materials. 142

Figure 4.28: Left: an SEM micrograph of a gold nanoparticle-merino wool composite (incorporating nanoparticles prepared with $10 \mu \mathrm{L}$ of $1 \mathrm{wt} \% \mathrm{TSC}$ ), and right: the corresponding gold EDS map.

Figure 4.29: EDS spectrum of the gold nanoparticle-merino wool composite shown in Figure 104. 143

Figure 4.30: Left: an SEM micrograph of a gold nanoparticle-merino wool composite (incorporating nanoparticles prepared with $50 \mu \mathrm{L}$ of $10 \mathrm{wt} \% \mathrm{TSC}$ ), and right: the corresponding gold EDS map. 144 
Figure 4.31: EDS spectrum of the gold nanoparticle-merino wool composite shown in Figure 106. .144

Figure 4.32: Left: an SEM micrograph of a gold nanoparticle-merino wool composite (incorporating nanoparticles prepared with $10 \mu \mathrm{L}$ of $1 \mathrm{wt} \% \mathrm{TA}$ ), and right: the corresponding gold EDS map. 145

Figure 4.33: EDS spectrum of the gold nanoparticle-merino wool composite shown in Figure 108. 145

Figure 4.34: Left: an SEM micrograph of a gold nanoparticle-merino wool composite (incorporating nanoparticles prepared with $50 \mu \mathrm{L}$ of $10 \mathrm{wt} \% \mathrm{TA}$ ), and right: the corresponding gold EDS map. 146

Figure 4.35: EDS spectrum of the gold nanoparticle-merino wool composite shown in Figure 110. 146

Figure 4.36: Wide XPS scans of gold nanoparticle-merino wool composites incorporating gold nanoparticles prepared with a) $10 \mu \mathrm{L}$ of $1 \mathrm{wt} \% \mathrm{TSC}$, b) $50 \mu \mathrm{L}$ of $10 \mathrm{wt} \%$ TSC, c) $10 \mu \mathrm{L}$ of $1 \mathrm{wt} \% \mathrm{TA}$ and d) $50 \mu \mathrm{L}$ of $10 \mathrm{wt} \% \mathrm{TA}$. 149

Figure 4.37: High resolution C 1s XPS spectra of gold nanoparticle-merino wool composites incorporating colloids prepared with a) $10 \mu \mathrm{L}$ of $1 \mathrm{wt} \% \mathrm{TSC}$ and c) $50 \mu \mathrm{L}$ of 10 wt \% TSC. b) and d) show the overlay of the C 1 s spectra of merino (in red)...150

Figure 4.38: High resolution N 1s XPS spectra of gold nanoparticle-merino wool composites incorporating colloids prepared with $10 \mu \mathrm{L}$ of 1 wt $\%$ TSC (a-b) or $50 \mu \mathrm{L}$ of 10 wt \% TSC (c-d). Figures (b) and (c) show an overlay of the corresponding N 1s spectra of merino wool (in red). 150

Figure 4.39: High resolution S 2p XPS spectra of gold nanoparticle-merino wool composites incorporating colloids prepared with $10 \mu \mathrm{L}$ of 1 wt $\%$ TSC (a-b) or $50 \mu \mathrm{L}$ of 10 wt \% TSC (c-d). Figures (b) and (c) show an overlay of the corresponding S 2p spectra of merino wool (in red).

Figure 4.40: High resolution O 1s (c, d) XPS spectra of gold nanoparticle-merino wool composites incorporating colloids prepared with $(\mathrm{a}, \mathrm{c}) 10 \mu \mathrm{L}$ of $1 \mathrm{wt} \% \mathrm{TSC}$ and (b d) $50 \mu \mathrm{L}$ of $10 \mathrm{wt} \% \mathrm{TSC}$. 152

Figure 4.41: High resolution $\mathrm{Au}$ 4f XPS spectra of gold nanoparticle-merino wool composites incorporating colloids prepared with a) $10 \mu \mathrm{L}$ of 1 wt $\%$ TSC and b) $50 \mu \mathrm{L}$ of $10 \mathrm{wt} \% \mathrm{TSC}$.

Figure 4.42: High resolution C 1s XPS spectra of gold nanoparticle-merino wool composites incorporating colloids prepared with (a) $10 \mu \mathrm{L}$ of $1 \mathrm{wt} \% \mathrm{TA}$ and (c) $50 \mu \mathrm{L}$ of 10 wt \% TA. Figures (b) and (d) show an overlay of the corresponding $\mathrm{C} 1 \mathrm{~s}$ spectra of merino wool (in red). 155

Figure 4.43: High resolution N 1s (a-d) and S 2p (e-h) XPS spectra of gold nanoparticlemerino wool composites incorporating colloids prepared with (a) and (e) $10 \mu \mathrm{L}$ of 1 wt $\%$ TA and (c) and (g) $50 \mu \mathrm{L}$ of $10 \mathrm{wt} \%$ TA. Figures (b, d) and (f, g) show an overlay of the corresponding $\mathrm{N} 1 \mathrm{~s}$ and $\mathrm{S} 2 \mathrm{p}$ spectra of merino wool (in red). 
Figure 4.44: High resolution $\mathrm{Au}$ 4f XPS spectra of gold nanoparticle-merino wool composites incorporating colloids prepared with (a) $10 \mu \mathrm{L}$ of 1 wt $\%$ TA and (b) $50 \mu \mathrm{L}$ of $10 \mathrm{wt} \% \mathrm{TA}$

Figure 4.45: Gold nanoparticle-merino wool composites (incorporating colloids prepared with $50 \mu \mathrm{L}$ of $10 \mathrm{wt} \% \mathrm{TSC}$ ) following simulated washability tests. 159

Figure 4.46: Gold nanoparticle-merino wool composites (incorporating colloids prepared with $50 \mu \mathrm{L}$ of $10 \mathrm{wt} \% \mathrm{TA}$ ) following simulated washability tests. 160

Figure 4.47: Changes in $\mathrm{L}^{*}, \mathrm{a}^{*}, \mathrm{~b}^{*}, 457 \mathrm{~nm}$ brightness and $580 \mathrm{~nm}$ brightness values for a gold nanoparticle-merino composite (incorporating TA prepared nanoparticles) following simulated washability tests show the colour change due to washing. Washing at RT (black lines) or $50^{\circ} \mathrm{C}$ (red lines). 161

Figure 4.48: Changes in $\mathrm{L}^{*}, \mathrm{a}^{*}, \mathrm{~b}^{*}, 457 \mathrm{~nm}$ brightness and $580 \mathrm{~nm}$ brightness values for a gold nanoparticle-merino composite (incorporating TSC prepared nanoparticles) following simulated washability tests show the colour change due to washing. Washing at RT (black lines) or $50^{\circ} \mathrm{C}$ (red lines).... .161

Figure 4.49: Kubelka Munk transformed UV/Vis reflection spectra of gold nanoparticlemerino wool composites (incorporating nanoparticles prepared with $50 \mu \mathrm{L}$ of 10 wt \% TA) following washing at RT. 162

Figure 4.50: Kubelka Munk transformed UV/Vis reflection spectra of gold nanoparticlemerino wool composites (incorporating nanoparticles prepared with $50 \mu \mathrm{L}$ of 10 wt $\%$ TA) following washing at $50{ }^{\circ} \mathrm{C}$.

Figure 4.51: Kubelka Munk transformed UV/Vis reflection spectra of gold nanoparticlemerino wool composites (incorporating nanoparticles prepared with $50 \mu \mathrm{L}$ of 10 wt \% TSC) following washing at RT. 163

Figure 4.52: Kubelka Munk transformed UV/Vis reflection spectra of gold nanoparticlemerino wool composites (incorporating nanoparticles prepared with $50 \mu \mathrm{L}$ of 10 wt $\%$ TSC) following washing at $50{ }^{\circ} \mathrm{C}$. 164

Figure 4.53: SEM micrographs of a gold nanoparticle-merino wool composite incorporating nanoparticles prepared with $50 \mu \mathrm{L}$ of $10 \mathrm{wt} \%$ TSC both before $(\mathrm{a}, \mathrm{b})$ and after (c, d) washing at $50{ }^{\circ} \mathrm{C}$ for $24 \mathrm{~h}$. 166

Figure 4.54: Left: a gold nanoparticle-merino wool composite (incorporating nanoparticles prepared with $50 \mu \mathrm{L}$ of $10 \mathrm{wt} \% \mathrm{TSC}$ ). Right: the same composite material following Chlorine Hercosett treatment. 167

Figure 5.1: Gold nanoparticle-merino wool composites employing a woven cloth form of merino wool. Merino wool was soaked in the $\mathrm{Au}^{3+}$ solutions at RT, overnight, followed by ageing at $50{ }^{\circ} \mathrm{C}$ for 3 or 6 hours. 172

Figure 5.2: Gold nanoparticle-merino wool composites using a woven cloth form of merino wool. Merino wool was soaked in water at $50{ }^{\circ} \mathrm{C}$ overnight, followed by soaking in a gold solution overnight at RT and then ageing at $50{ }^{\circ} \mathrm{C}$ for 3 hours. 173

Figure 5.3: An example of the obtainable colours of gold nanoparticle-merino wool composite materials prepared via the in-situ method. 174 
Figure 5.4: Gold nanoparticle-merino wool composites prepared via the in-situ method. Merino wool soaked in a $160 \mathrm{ppm}\left(8.13 \times 10^{-4} \mathrm{M}\right)$ gold solution for 0 or 24 hours at RT, followed by ageing at $50{ }^{\circ} \mathrm{C}$ for $168 \mathrm{~h}$. Shows the effect of soaking time on colour development. 175

Figure 5.5: Gold nanoparticle-merino wool composites prepared via the in-situ method. Merino wool soaked in a $160 \mathrm{ppm}\left(8.13 \times 10^{-4} \mathrm{M}\right)$ gold solution for $72-96$ hours at RT, followed by ageing at $50{ }^{\circ} \mathrm{C}$ for $48-168 \mathrm{~h}$. Shows the effect of soaking time on colour development. 175

Figure 5.6: Gold nanoparticle-merino wool composite materials prepared by soaking untreated semi-worsted merino wool in a $160 \mathrm{ppm}\left(8.13 \times 10^{-4} \mathrm{M}\right) \mathrm{Au}^{3+}$ solution for 24 hours at RT without (left) and with (right) gentle agitation, followed by ageing at $50{ }^{\circ} \mathrm{C}$ for 168 hours. 176

Figure 5.7: Increasing magnification SEM micrographs of gold nanoparticle-merino wool composites prepared by soaking in a $160 \mathrm{ppm}\left(8.13 \times 10^{-4} \mathrm{M}\right) \mathrm{Au}^{3+}$ solution for 0 (top) or 24 hours (bottom) at RT, followed by ageing at $50{ }^{\circ} \mathrm{C}$ for 168 hours...177

Figure 5.8: Increasing magnification TEM micrographs of a gold nanoparticle-merino wool composite prepared by soaking in a $160\left(8.13 \times 10^{-4} \mathrm{M}\right) \mathrm{Au}^{3+}$ solution for 24 hours at RT, followed by ageing at $50{ }^{\circ} \mathrm{C}$ for 168 hours. Shows the nanoparticles on the surface of the fibre to be five fold twinned particles, approximately $20-$ $30 \mathrm{~nm}$ in diameter. 177

Figure 5.9: Cross sectional SEM micrographs (left), and corresponding Au EDS maps (right) of composite materials prepared from a $160 \mathrm{ppm}\left(8.13 \times 10^{-4} \mathrm{M}\right)$ gold solution, with $0 \mathrm{~h}$ (top) or $24 \mathrm{~h}$ (bottom) soaking and $168 \mathrm{~h}$ ageing at $50^{\circ} \mathrm{C}$. A line profile of each is offered. 178

Figure 5.10: Gold nanoparticle-merino wool composites prepared by soaking untreated merino in an $840-1200 \mathrm{ppm} \mathrm{Au}^{3+}\left(4.26 \times 10^{-3}-6.09 \times 10^{-3} \mathrm{M}\right)$ solution for 24 hours at $50{ }^{\circ} \mathrm{C}$. 179

Figure 5.11: Increasing magnification SEM micrographs of a gold nanoparticle-merino wool composite prepared by ageing in a $960 \mathrm{ppm} \mathrm{Au}^{3+}\left(4.87 \times 10^{-3} \mathrm{M}\right)$ solution for 24 hours at $50^{\circ} \mathrm{C}$ 180

Figure 5.12: Increasing magnification SEM micrographs of a gold nanoparticle-merino wool composite prepared by ageing in a $1040 \mathrm{ppm} \mathrm{Au}^{3+}\left(5.28 \times 10^{-3} \mathrm{M}\right)$ solution for 24 hours at $50{ }^{\circ} \mathrm{C}$. 181

Figure 5.13: TEM micrographs of gold nanoparticles in composite materials prepared by soaking in a $160 \mathrm{ppm} \mathrm{Au}^{3+}\left(8.13 \times 10^{-4} \mathrm{M}\right)$ solution for 24 hours at RT, followed by ageing at $50{ }^{\circ} \mathrm{C}$ for 24 hours. Arrows indicate the position of the twin plane defects. 182

Figure 5.14: Gold nanoparticle-merino wool composites prepared via the in-situ method. Merino wool soaked in a gold solution for 24 hours at RT, followed by ageing at $50{ }^{\circ} \mathrm{C}$ for $24-168 \mathrm{~h}$. Shows the effect of ageing time on colour development. 182

Figure 5.15: Increasing magnification SEM micrographs of gold nanoparticle-merino wool composites prepared by soaking in a $160 \mathrm{ppm}\left(8.13 \times 10^{-4} \mathrm{M}\right) \mathrm{Au}^{3+}$ solution for 
Figure 5.16: Increasing magnification TEM micrographs of gold nanoparticle-merino wool composites prepared by soaking in a $160 \mathrm{ppm}\left(8.13 \times 10^{-4} \mathrm{M}\right) \mathrm{Au}^{3+}$ solution for 24 hours followed by ageing at $50{ }^{\circ} \mathrm{C}$ for 24,72 or 168 hours (top to bottom). 185

Figure 5.17: Increasing magnification TEM micrographs of nanoparticles located in the fibre centre of composites prepared by soaking in a $160 \mathrm{ppm}\left(8.13 \times 10^{-4} \mathrm{M}\right) \mathrm{Au}^{3+}$ solution for 24 hours followed by ageing at $50{ }^{\circ} \mathrm{C}$ for 168 hours. 185

Figure 5.18: Cross sectional SEM micrograph (left), and corresponding Au EDS map (right) of a composite material prepared from a $160 \mathrm{ppm}\left(8.13 \times 10^{-4} \mathrm{M}\right)$ gold solution, with $24 \mathrm{~h}$ soaking and $24 \mathrm{~h}$ ageing at $50^{\circ} \mathrm{C}$. A line profile is offered (bottom) showing higher gold concentrations at the fibre surface relative to the centre. .186

Figure 5.19: Gold nanoparticle-merino wool composites prepared by soaking untreated semiworsted merino in a $160 \mathrm{ppm}\left(8.13 \times 10^{-4} \mathrm{M}\right) \mathrm{Au}^{3+}$ solution for 1 hour at RT, after which the fibres were transferred to alternate solutions (top and middle) and soaking continued for a further 23 hours and then heated at $50{ }^{\circ} \mathrm{C}$ for $24-168$ hours. 187

Figure 5.20: Gold nanoparticle-merino wool composites prepared by soaking untreated semiworsted merino in a $160 \mathrm{ppm}\left(8.13 \times 10^{-4} \mathrm{M}\right) \mathrm{Au}^{3+}$ solution for 1 hour at RT, after which it was transferred to: middle: Millipore water or right: a $\mathrm{pH} 3$ buffer, and soaked for a further 23 hours, and heated at $50{ }^{\circ} \mathrm{C}$ for 48 hours. The soaking solution of the sample on the left was not altered. 188

Figure 5.21: Gold nanoparticle-merino wool composites prepared by soaking untreated semiworsted merino wool in a $160 \mathrm{ppm}\left(8.13 \times 10^{-4} \mathrm{M}\right) \mathrm{Au}^{3+}$ solution for 24 hours, transferring to an alternate ageing solution and ageing at $50{ }^{\circ} \mathrm{C}$ for $24-168$ hours. 189

Figure 5.22: Gold nanoparticle-merino wool composites prepared by soaking untreated semiworsted merino wool in a $160 \mathrm{ppm}\left(8.13 \times 10^{-4} \mathrm{M}\right) \mathrm{Au}^{3+}$ solution for 24 hours at $\mathrm{RT}$, followed by ageing at $50{ }^{\circ} \mathrm{C}$ in a $0.1 \mathrm{M} \mathrm{NaCl}$ solution (top) or the original soaking solution (bottom) for 24-168 hours. .190

Figure 5.23: Increasing magnification SEM micrographs of gold nanoparticle-merino wool composites prepared by soaking untreated semi-worsted merino wool in a 160 $\operatorname{ppm}\left(8.13 \times 10^{-4} \mathrm{M}\right) \mathrm{Au}^{3+}$ solution for 24 hours at RT, followed by ageing at 50 ${ }^{\circ} \mathrm{C}$ in a $0.1 \mathrm{M} \mathrm{NaCl}$ solution for 24 or 168 hours (row a and c respectively) or the original soaking solution for 24 or 168 hours (row b and d respectively.

Figure 5.24: Increased magnification SEM micrographs of gold nanoparticle-merino wool composites prepared by soaking untreated semi-worsted merino wool in a 160 $\operatorname{ppm}\left(8.13 \times 10^{-4} \mathrm{M}\right) \mathrm{Au}^{3+}$ solution for 24 hours at RT, followed by ageing at 50 ${ }^{\circ} \mathrm{C}$ in a $0.1 \mathrm{M} \mathrm{NaCl}$ solution for 24 (top) or 168 (bottom) hours.

Figure 5.25: Cross sectional SEM micrograph of a gold nanoparticle-merino wool composite prepared with a $0.1 \mathrm{M} \mathrm{NaCl}$ ageing solution. 193 
Figure 5.26: Cross sectional SEM and corresponding Au EDS map of a gold nanoparticlemerino wool composite prepared by soaking untreated semi-worsted merino wool in a $160 \mathrm{ppm}\left(8.13 \times 10^{-4} \mathrm{M}\right) \mathrm{Au}^{3+}$ solution for 24 hours at RT, followed by ageing at $50{ }^{\circ} \mathrm{C}$ for 168 hours in a $0.1 \mathrm{M} \mathrm{NaCl}$ solution. 193

Figure 5.27: Concentration of chloride in the reaction mixture against time. 194

Figure 5.28: Cross sectional SEM and corresponding Cl EDS maps of gold nanoparticlemerino wool composites prepared by soaking untreated semi-worsted merino wool in a $160 \mathrm{ppm}\left(8.13 \times 10^{-4} \mathrm{M}\right) \mathrm{Au}^{3+}$ solution for 24 hours at RT, followed by ageing at $50{ }^{\circ} \mathrm{C}$ for 168 hours in a $0.1 \mathrm{M} \mathrm{NaCl}$ solution (top) or the original soaking solution (bottom).

Figure 5.29: Top: gold nanoparticle-merino wool composites prepared by soaking untreated semi-worsted merino wool in a $160 \mathrm{ppm}\left(8.13 \times 10^{-4} \mathrm{M}\right) \mathrm{Au}^{3+}$ for 1 hours $\backslash$ at RT followed by soaking at $\mathrm{RT}$ in a $0.1 \mathrm{M} \mathrm{NaCl}$ solution for a further 23 hours, and ageing in the original gold solution for $24-168$ hours at $50{ }^{\circ} \mathrm{C}$. Bottom: The corresponding composite materials prepared by soaking and ageing in the same gold solution.

196

Figure 5.30: Top: gold nanoparticle-merino wool composites prepared by soaking untreated semi-worsted merino wool in a $160 \mathrm{ppm}\left(8.13 \times 10^{-4} \mathrm{M}\right) \mathrm{Au}^{3+}$ solution for 1 hours at RT, followed by soaking in a $0.1 \mathrm{M} \mathrm{MgCl}_{2}$ solution for 23 hours at RT, and ageing at $50{ }^{\circ} \mathrm{C}$ for 24 or 168 hours. Bottom: gold nanoparticle-merino wool composites prepared by soaking untreated semi-worsted merino wool in a 160 $\operatorname{ppm}\left(8.13 \times 10^{-4} \mathrm{M}\right) \mathrm{Au}^{3+}$ solution for 24 hours at RT, followed by ageing at 50 ${ }^{\circ} \mathrm{C}$ in a $0.1 \mathrm{M} \mathrm{MgCl}_{2}$ solution for 24 or 168 hours.

Figure 5.31: Gold nanoparticle-merino wool composites prepared by soaking in a $160 \mathrm{ppm}$ $\left(8.13 \times 10^{-4} \mathrm{M}\right)$ gold solution for 24 hours, followed by ageing at 80 (top) or 50 ${ }^{\circ} \mathrm{C}$ (bottom) for $24,48,72$ or 168 hours (left to right). 198

Figure 5.32: Gold nanoparticle-merino wool composites prepared by soaking mrino wool in a gold solution for 0 or 24 hours at RT, followed by ageing at $80{ }^{\circ} \mathrm{C}$ for $24-168 \mathrm{~h}$. Shows the effect of soaking time and ageing (ageing) temperature on colour development..... 198

Figure 5.33: Increasing magnification SEM micrographs of a gold nanoparticle-merino wool composite prepared by soaking in a $160 \mathrm{ppm}\left(8.13 \times 10^{-4} \mathrm{M}\right)$ gold solution for 24 hours, followed by ageing at $80{ }^{\circ} \mathrm{C}$ for 24 hours (top) or 168 hours (bottom)...199

Figure 5.34: Cross sectional SEM micrographs of a gold nanoparticle-merino wool material prepared by soaking in a $160 \mathrm{ppm}\left(8.13 \times 10^{-4} \mathrm{M}\right)$ gold solution for 24 hours, followed by ageing at $80{ }^{\circ} \mathrm{C}$ for 168 hours. 199

Figure 5.35: Gold nanoparticle-merino wool composites prepared by soaking in gold solutions of various concentrations for 24 hours at RT, followed by ageing at 50 ${ }^{\circ} \mathrm{C}$ for 24 or 168 hours. .200

Figure 5.36: Gold nanoparticle-merino wool composites prepared by soaking in 80, 120 or $160 \mathrm{ppm} \mathrm{Au}^{3+}\left(4.06 \times 10^{-4}, 6.09 \times 10^{-4}\right.$ or $8.13 \times 10^{-4} \mathrm{M}$ respectively) (top to bottom) for $24 \mathrm{~h}$ at RT, followed by ageing at $50{ }^{\circ} \mathrm{C}$ for $24-168$ hours. .201 
Figure 5.37: Increasing magnification SEM micrographs of gold nanoparticle-merino wool composites prepared by soaking in a 80 or $160 \mathrm{ppm} \mathrm{Au}^{3+}\left(4.06 \times 10^{-4}\right.$ or $8.13 \mathrm{x}$ $10^{-4} \mathrm{M}$ respectively) (top and bottom) for $24 \mathrm{~h}$ at $\mathrm{RT}$, followed by ageing at $50{ }^{\circ} \mathrm{C}$ for 168 hours. .202

Figure 5.38: Gold nanoparticle-merino wool composite materials prepared by soaking untreated semi-worsted merino wool in a left: $107 \mathrm{ppm}\left(5.41 \times 10^{-4} \mathrm{M}\right) \mathrm{Au}^{3+}$ solution $\left(40 \mu \mathrm{L} 4 \mathrm{wt} \% \mathrm{Au}^{3+}: 0.1 \mathrm{~g}\right.$ wool: $\left.15 \mathrm{ml} \mathrm{H}_{2} \mathrm{O}\right)$ or right: a $160 \mathrm{ppm}(8.13 \mathrm{x}$ $\left.10^{-4} \mathrm{M}\right) \mathrm{Au}^{3+}$ solution $\left(40 \mu \mathrm{L} 4 \mathrm{wt} \% \mathrm{Au}^{3+}: 0.1 \mathrm{~g}\right.$ wool: $\left.10 \mathrm{ml} \mathrm{H}_{2} \mathrm{O}\right)$ for 24 hours at $\mathrm{RT}$, followed by ageing at $50{ }^{\circ} \mathrm{C}$ for 168 hours. 202

Figure 5.39: Gold nanoparticle-merino wool composites prepared by soaking untreated semiworsted merino wool in various $\mathrm{Au}^{3+}$ solutions for 24 hours at RT, followed by ageing at $50{ }^{\circ} \mathrm{C}$ for $24-168$ hours. Illustrates the effect of the ratio between the $\mathrm{Au}^{3+}$ concentration and amount of wool has on colour development. .204

Figure 5.40: Gold nanoparticle-merino wool composites prepared by soaking untreated semiworsted merino wool in a $320 \mathrm{pp},\left(1.6 \times 10^{-3} \mathrm{M}\right) \mathrm{Au}^{3+}$ solution for 1,3 or 6 hours at RT, followed by ageing at $50{ }^{\circ} \mathrm{C}$ for 24 hours in Millipore water (top) or a dilute $\mathrm{HCl}$ solution $\left(40 \mu \mathrm{L} 0.1 \mathrm{M} \mathrm{HCl} \rightarrow 10 \mathrm{ml} \mathrm{H} \mathrm{H}_{2} \mathrm{O}\right.$ ) (bottom).....................206

Figure 5.41: Gold nanoparticle-merino wool composites prepared by soaking untreated semiworsted merino wool in a $320 \mathrm{ppm}\left(1.6 \times 10^{-3} \mathrm{M}\right) \mathrm{Au}^{3+}$ solution for 5-50 minutes at RT, followed by ageing in Millipore water for 72 hours at $50{ }^{\circ} \mathrm{C}$. .206

Figure 5.42: Absorption of $\mathrm{Au}^{3+}$ by untreated semi-worsted merino wool from a $320 \mathrm{ppm}$ $\left(1.6 \times 10^{-3} \mathrm{M}\right) \mathrm{Au}^{3+}$ solution at RT.

Figure 5.43: Gold nanoparticle-merino wool composites prepared by soaking untreated semiworsted merino wool various gold solutions at RT, followed by soaking in Millipore water or an aqueous $\mathrm{HCl}$ solution $\left(40 \mu \mathrm{L}\right.$ of $0.1 \mathrm{M} \mathrm{HCl} \rightarrow 10 \mathrm{ml} \mathrm{H}_{2} \mathrm{O}$ ) for a further 23 hours at RT, and ageing at $50{ }^{\circ} \mathrm{C}$ for $24-168$ hours. The samples on the bottom are prepared in the normal way (employing a $\mathrm{Au}^{3+}$ solution of 160 ppm $\left(8.13 \times 10^{-4} \mathrm{M}\right)$, a soaking time of 24 hours, and the original soaking solution as the ageing solution). .208

Figure 5.44: Gold nanoparticle-merino wool composites prepared by adjusting the $\mathrm{pH}$ of the $160 \mathrm{ppm}\left(8.13 \times 10^{-4} \mathrm{M}\right) \mathrm{Au}^{3+}$ soaking solution to $\mathrm{pH} 7$ (left) or 10 (right), soaking at RT for 24 hours and ageing at $50{ }^{\circ} \mathrm{C}$ for 168 hours. .209

Figure 5.45: Gold nanoparticle-merino wool composites prepared by soaking in a $160 \mathrm{ppm}$ $\left(8.13 \times 10^{-4} \mathrm{M}\right) \mathrm{Au}^{3+}$ for 24 hours, followed by ageing at $50{ }^{\circ} \mathrm{C}$ for $24-168$ hours. The samples on top were prepared by altering the $\mathrm{pH}$ of the soaking solution to pH 7 once the majority of $\mathrm{Au}^{3+}$ had been absorbed. 211

Figure 5.46: Gold nanoparticle-merino wool composites prepared by soaking in a $160 \mathrm{ppm}$ $\mathrm{Au}^{3+}\left(8.13 \times 10^{-4} \mathrm{M}\right)$ solution for 24 hours at $\mathrm{RT}$, following which the $\mathrm{pH}$ of the reaction mixture was adjusted to $4,7,9$ or 12 , and the samples heated for $24-$ 168 hours at $50^{\circ} \mathrm{C}$

Figure 5.47: SEM micrographs of a gold nanoparticle-merino wool composite prepared by soaking in a $160 \mathrm{ppm} \mathrm{Au}^{3+}\left(8.13 \times 10^{-4} \mathrm{M}\right)$ solution for 24 hours at RT, following which the $\mathrm{pH}$ of the reaction mixture was adjusted to 12 , and the samples heated 
for 168 hours at $50{ }^{\circ} \mathrm{C}$. Note: the micrograph on the right is the centre image viewed under backscatter conditions.....

Figure 5.48: SEM (left) and corresponding Au EDS map (right) of a gold nanoparticlemerino wool composite prepared by soaking in a $160 \mathrm{ppm} \mathrm{Au}^{3+}\left(8.13 \times 10^{-4} \mathrm{M}\right)$ solution for 24 hours at $\mathrm{RT}$, following which the $\mathrm{pH}$ of the reaction mixture was adjusted to 12, and the samples heated for 168 hours at $50^{\circ} \mathrm{C}$. High concentrations of gold are depicted in white. .213

Figure 5.49: Increasing magnification TEM micrographs of a gold nanoparticle-merino wool composite prepared by soaking in a $160 \mathrm{ppm} \mathrm{Au}^{3+}\left(8.13 \times 10^{-4} \mathrm{M}\right)$ solution for 24 hours at RT, following which the $\mathrm{pH}$ of the reaction mixture was adjusted to 12 , and the samples heated for 168 hours at $50{ }^{\circ} \mathrm{C}$ 214

Figure 5.50: Increasing magnification SEM (top) and TEM (bottom) micrographs of a gold nanoparticle-merino wool composite prepared by soaking in a $160 \mathrm{ppm} \mathrm{Au}^{3+}$ $\left(8.13 \times 10^{-4} \mathrm{M}\right)$ solution for 24 hours at RT.

Figure 5.51: Gold nanoparticle-merino wool composites prepared from acid treated merino wool (left) and un-treated merino wool (right). Prepared by dispersing the respective merino wool in a $160 \mathrm{ppm} \mathrm{Au}^{3+}\left(8.13 \times 10^{-4} \mathrm{M}\right)$ solution for 24 hours at RT, followed by ageing at $50{ }^{\circ} \mathrm{C}$ for 168 hours. 215

Figure 5.52: Gold nanoparticle-merino wool composites prepared with merino wool which had been soaked in a $0.1 \mathrm{M} \mathrm{KOH} / \mathrm{MeOH}$ solution for 5,10 or 30 minutes, followed by a $160 \mathrm{ppm} \mathrm{Au}^{3+}\left(8.13 \times 10^{-4} \mathrm{M}\right)$ solution for 24 hours at RT and heated at $50{ }^{\circ} \mathrm{C}$ for 168 hours. .216

Figure 5.53: Gold nanoparticle-merino wool composites prepared by soaking $\mathrm{Cl} / \mathrm{H}$ treated merino wool in an 80,120 or $160 \mathrm{ppm} \mathrm{Au}^{3+}\left(4.06 \times 10^{-4}, 6.09 \times 10^{-4}\right.$ or $8.13 \times 10^{-}$ ${ }^{4} \mathrm{M}$ respectively) solution for 24 hours at $\mathrm{RT}$, followed by ageing at $50{ }^{\circ} \mathrm{C}$ for 24 -168 hours. 218

Figure 5.54: Increasing magnification SEM micrographs of gold nanoparticle-merino wool composites prepared by soaking $\mathrm{Cl} / \mathrm{H}$ treated merino wool in an 80 (a) and b)) or $160 \mathrm{ppm}(\mathrm{c})$ and d) $\left(4.06 \times 10^{-4}\right.$ or $8.13 \times 10^{-4} \mathrm{M}$ respectively) $\mathrm{Au}^{3+}$ solution for 24 hours at RT, followed by ageing at $50{ }^{\circ} \mathrm{C}$ for 24 (a) and c)) or 168 hours (b) and d)).

Figure 5.55: Cross sectional SEM micrograph of a gold nanoparticle-merino wool composite prepared by soaking $\mathrm{Cl} / \mathrm{H}$ treated merino wool in a $160 \mathrm{ppm}\left(8.13 \times 10^{-4} \mathrm{M}\right)$ $\mathrm{Au}^{3+}$ solution for 24 hours at RT, followed by ageing at $50{ }^{\circ} \mathrm{C}$ for 168 hours...220

Figure 5.56: Cross sectional SEM and corresponding Au, N and S EDS maps of a gold nanoparticle merino wool composite prepared by soaking $\mathrm{Cl} / \mathrm{H}$ treated merino wool in a $160 \mathrm{ppm}\left(8.13 \times 10^{-4} \mathrm{M}\right) \mathrm{Au}^{3+}$ solution for 24 hours at RT, followed by ageing at $50^{\circ} \mathrm{C}$ for 168 hours. .221

Figure 5.57: Gold nanoparticle-merino wool composites prepared by soaking base treated$\mathrm{Cl} / \mathrm{H}$ treated semi-worsted merino wool in a 40,80 or $160 \mathrm{ppm}\left(2.03 \times 10^{-4}, 4.06\right.$ x $10^{-4}$ or $8.13 \times 10^{-4} \mathrm{M}$ respectively) $\mathrm{Au}^{3+}$ solution for 0 or 24 hours at RT, followed by ageing at $50{ }^{\circ} \mathrm{C}$ for $24-168$ hours. 
Figure 5.58: Increasing magnification SEM micrographs of gold nanoparticle-merino wool composites prepared by soaking $\mathrm{KOH}$ pre-treated $\mathrm{Cl} / \mathrm{H}$ treated merino wool in a top: $80 \mathrm{ppm}\left(4.06 \times 10^{-4} \mathrm{M}\right)$ or bottom: $160 \mathrm{ppm}\left(8.13 \times 10^{-4} \mathrm{M}\right) \mathrm{Au}^{3+}$ solution for 24 hours at RT, followed by ageing at $50{ }^{\circ} \mathrm{C}$ for 168 hours .223

Figure 5.59: Cross sectional SEM micrograph of a gold nanoparticle-merino wool composite prepared by soaking $\mathrm{KOH}$ pre-treated $\mathrm{Cl} / \mathrm{H}$ treated merino wool in a $160 \mathrm{ppm}$ $\left(8.13 \times 10^{-4} \mathrm{M}\right) \mathrm{Au}^{3+}$ solution for 24 hours at RT, followed by ageing at $50^{\circ} \mathrm{C}$ for 168 hours.

Figure 5.60: TEM micrographs of the gold nanoparticles formed in solution when ageing $\mathrm{KOH}$ treated $\mathrm{Cl} / \mathrm{H}$ treated merino wool. .224

Figure 5.61: Gold nanoparticle-merino wool composites prepared with untreated semiworsted merino wool (top) or worsted merino wool (bottom). Samples were soaked in a $160 \mathrm{ppm} \mathrm{Au}^{3+}\left(8.13 \times 10^{-4} \mathrm{M}\right)$ solution for 24 hours at RT, followed by ageing at $50{ }^{\circ} \mathrm{C}$ for $24-168$ hours .225

Figure 5.62: Top and bottom: Increasing magnification SEM micrographs of a gold nanoparticle-merino wool composite employing worsted merino wool. Composite prepared by soaking merino wool in a $160 \mathrm{ppm} \mathrm{Au}^{3+}\left(8.13 \times 10^{-4} \mathrm{M}\right)$ solution for 24 hours at RT, followed by ageing at $50{ }^{\circ} \mathrm{C}$ for 168 hours. .226

Figure 5.63: SEM micrograph (left) and the corresponding Au EDS map (right), of a gold nanoparticle-merino wool composite employing worsted merino wool. Composite prepared by soaking merino wool in a $160 \mathrm{ppm} \mathrm{Au}^{3+}\left(8.13 \times 10^{-4} \mathrm{M}\right)$ solution for 24 hours at RT, followed by ageing at $50{ }^{\circ} \mathrm{C}$ for 168 hours. .226

Figure 5.64: Gold nanoparticle-merino wool composites prepared from Soxhlet treated worsted merino wool (top) and untreated worsted merino wool (bottom). Prepared by soaking in a $160 \mathrm{ppm} \mathrm{Au}^{3+}\left(8.13 \times 10^{-4} \mathrm{M}\right)$ solution for 24 hours at $\mathrm{RT}$, followed by ageing at $50{ }^{\circ} \mathrm{C}$ for 24 of 168 hours. 228

Figure 5.65: Changes in the $\mathrm{a}^{*}$ and $\mathrm{b}^{*}$ CIE values of gold nanoparticle-merino wool composites induced with increasing ageing time at $50{ }^{\circ} \mathrm{C}$.

Figure 5.66: CIE $a^{*}$ and $b^{*}$ values of gold nanoparticle-merino wool composites utilising the original $\mathrm{Au}^{3+}$ soaking solution or $0.1 \mathrm{M} \mathrm{NaCl}$ as the ageing solution. 230

Figure 5.67: Changes in the $\mathrm{a}^{*}$ and $\mathrm{b}^{*}$ CIE values of gold nanoparticle-merino wool composites induced with different ageing temperatures. .232

Figure 5.68: Changes in the a* CIE values of gold nanoparticle-merino wool composites prepared with increasing $\mathrm{Au}^{3+}$ concentrations.

Figure 5.69: Changes in the a* CIE values of gold nanoparticle-merino wool composites prepared with ageing solutions of elevated $\mathrm{pH}$. .234

Figure 5.70: Changes in the $b^{*}$ CIE values of gold nanoparticle-merino wool composites prepared with ageing solutions of elevated $\mathrm{pH}$. .235

Figure 5.71: Changes in CIE $\mathrm{a}^{*}$ and $\mathrm{b}^{*}$ values of gold nanoparticle-merino wool composites incorporating worsted or semi-worsted merino wool. .238 
Figure 5.72: Changes in CIE 475 and $580 \mathrm{~nm}$ brightness values of gold nanoparticle-merino wool composites incorporating worsted or semi-worsted merino wool. .239

Figure 5.73: Gold nanoparticle-merino wool composites, showing the relationship between the pink and purple colour of these materials and the size, shape and distribution of the gold nanoparticles. In the pink coloured materials the nanoparticles are located predominantly at the cuticle edges, whilst in the purple materials the nanoparticles spread slightly across the fibre surface. The purple materials also possess smaller nanoparticles (approximately 5-10 $\mathrm{nm}$ in diameter) in the fibre centre. .240

Figure 5.74: Kubelka Munk transformed UV/Vis reflection spectra of light pink to purple coloured gold nanoparticle-merino wool composites. .241

Figure 5.75: Gold nanoparticle-merino wool composites, showing the relationship between the light (top) and dark (bottom) grey colour of these materials and the size, shape and distribution of the gold nanoparticles. These materials possess gold nanoparticles in a range of sizes and shapes, with agglomerations seen. .242

Figure 5.76: Kubelka Munk transformed UV/Vis reflection spectra of light pink to purple and grey coloured gold nanoparticle-merino wool composites.

Figure 5.77: Gold nanoparticle-merino wool composites, showing the relationship between the spectrally impure and vibrant colour of these materials and the size, shape and distribution of the gold nanoparticles. 244

Figure 5.78: Gold nanoparticle-merino wool composites, showing the relationship between the yellow colour of these materials and the size, shape and distribution of the gold, here present as amorphous $\mathrm{Au}(\mathrm{OH})_{3}$ 245

Figure 5.79: SEM micrographs of a gold nanoparticle-merino wool composite viewed under secondary electron (left) and back scatter conditions (right). Prepared by soaking untreated semi-worsted merino wool (top) or base treated $\mathrm{Cl} / \mathrm{H}$ treated merino wool in a $160 \mathrm{ppm}\left(8.13 \times 10^{-4} \mathrm{M}\right) \mathrm{Au}^{3+}$ solution for 24 hours at RT, followed by ageing at $50{ }^{\circ} \mathrm{C}$ for 24 or 168 hours respectively. 246

Figure 5.80: SEM and corresponding gold EDS map of a gold nanoparticle-merino wool composite prepared by soaking untreated semi-worsted merino wool in a 160 $\operatorname{ppm}\left(8.13 \times 10^{-4} \mathrm{M}\right) \mathrm{Au}^{3+}$ solution for 24 hours at RT, followed by ageing at 50 ${ }^{\circ} \mathrm{C}$ for 24 hours.

Figure 5.81: EDS spectrum of the gold nanoparticle-merino wool composite shown in Figure 210. 247

Figure 5.82: SEM and corresponding gold EDS map of a gold nanoparticle-merino wool composite prepared by soaking untreated semi-worsted merino wool in a 160 $\operatorname{ppm}\left(8.13 \times 10^{-4} \mathrm{M}\right) \mathrm{Au}^{3+}$ solution for 24 hours at RT, followed by ageing at 50 ${ }^{\circ} \mathrm{C}$ for 168 hours. .248

Figure 5.83: EDS spectrum of the gold nanoparticle-merino wool composite shown in Figure 212. 
Figure 5.84: SEM and corresponding gold EDS map of a gold nanoparticle-merino wool composite prepared by soaking untreated semi-worsted merino wool in a 960 $\operatorname{ppm}\left(4.87 \times 10^{-3} \mathrm{M}\right) \mathrm{Au}^{3+}$ solution for 24 hours at RT, followed by ageing at 50 ${ }^{\circ} \mathrm{C}$ for 24 hours. .249

Figure 5.85: EDS spectrum of the gold nanoparticle-merino wool composite shown in Figure 214. .249

Figure 5.86: SEM and corresponding gold EDS map of a gold nanoparticle-merino wool composite prepared by soaking untreated semi-worsted merino wool in a 1040 $\operatorname{ppm}\left(5.28 \times 10^{-3} \mathrm{M}\right) \mathrm{Au}^{3+}$ solution for 24 hours at RT, followed by ageing at 50 ${ }^{\circ} \mathrm{C}$ for 24 hours. .250

Figure 5.87: EDS spectrum of the gold nanoparticle-merino wool composite shown in Figure 216. .250

Figure 5.88: SEM and corresponding Au EDS micrograph of a gold nanoparticle-merino wool composite prepared by soaking $\mathrm{KOH} \mathrm{Cl/H}$ treated semi-worsted merino wool in a $160 \mathrm{ppm}\left(8.13 \times 10^{-4} \mathrm{M}\right) \mathrm{Au}^{3+}$ solution for 24 hours at RT, followed by ageing at $50{ }^{\circ} \mathrm{C}$ for 24 hours.

Figure 5.88: EDS spectrum of the gold nanoparticle-merino wool composite shown inFigure 218. .251

Figure 5.90: TEM and corresponding Au STEM micrograph of a gold nanoparticle-merino wool composite prepared by soaking untreated semi-worsted merino wool in a $160 \mathrm{ppm}\left(8.13 \times 10^{-4} \mathrm{M}\right) \mathrm{Au}^{3+}$ solution for 24 hours at RT, followed by ageing at $50{ }^{\circ} \mathrm{C}$ for 168 hours. .252

Figure 5.91: Wide XPS scans of gold nanoparticle-merino wool composites prepared by soaking untreated semi-worsted merino wool in a $160 \mathrm{ppm}\left(8.13 \times 10^{-4} \mathrm{M}\right) \mathrm{Au}^{3+}$ solution for 24 hours at RT, followed by ageing at $50{ }^{\circ} \mathrm{C}$ for (a) 24 hours or (b) 168 hours. (c and d) Are analogues of (a) and (b) however untreated worsted merino wool was used as the fibre substrate. (e and f) Composite prepared by $\mathrm{Cl} / \mathrm{H}$ treated semi-worsted merino wool (e) or base treated $\mathrm{Cl} / \mathrm{H}$ treated merino wool (f) in a $160 \mathrm{ppm}\left(8.13 \times 10^{-4} \mathrm{M}\right) \mathrm{Au}^{3+}$ solution for 24 hours at RT, followed by ageing at $50{ }^{\circ} \mathrm{C}$ for 168 hours. .253

Figure 5.92: Gold uptake by untreated semi-worsted merino wool at RT or $50{ }^{\circ} \mathrm{C}$. A $\mathrm{Au}^{3+}$ concentration of $160 \mathrm{ppm}\left(8.13 \times 10^{-4} \mathrm{M}\right)$ with a $\mathrm{pH}$ of 2.7 was employed. .....257

Figure 5.93: Gold absorption by untreated semi-worsted merino wool at RT, employing a $\mathrm{Au}^{3+}$ concentration of $160,200,240,280$ or $320 \mathrm{ppm}\left(8.13 \times 10^{-4} \mathrm{M}, 1.01 \times 10^{-3}\right.$, $1.22 \times 10^{-3}, 1.42 \times 10^{-3}$ and $1.62 \times 10^{-3} \mathrm{M}$ respectively) all with a $\mathrm{pH}$ of approximately 2.7. Shows the effect the $\mathrm{Au}^{3+}$ concentration has on absorption. .258

Figure 5.94: Gold absorption by untreated semi-worsted merino wool at RT, employing $\mathrm{Au}^{3+}$ concentrations in the range of 160-400 ppm, achieved with lower solvent volumes Shows the effect the $\mathrm{Au}^{3+}$ concentration has on absorption. .258

Figure 5.95: Gold absorption by untreated semi-worsted merino wool at RT. Shows the effect increasing the $\mathrm{pH}$ of the soaking solution has on absorption. .259 
Figure 5.96: Gold absorption, at RT, of acid pre-treated, $\mathrm{KOH} / \mathrm{EtOH}$ pre-treated and untreated semi-worsted merino wool.

Figure 5.97: Gold absorption by untreated, $\mathrm{Cl} / \mathrm{H}$ treated and $\mathrm{KOH}$ treated $\mathrm{Cl} / \mathrm{H}$ treated semiworsted merino wool at RT. 261

Figure 5.98: Gold absorption by untreated worsted and semi-worsted merino wool at RT..262

Figure 5.99: EDS spectrum of a gold nanoparticle-merino wool composite material prepared by soaking untreated semi-worsted merino wool in a $160 \mathrm{ppm}\left(8.13 \times 10^{-4} \mathrm{M}\right)$ $\mathrm{Au}^{3+}$ solution for 24 hours at RT, followed by ageing at $50{ }^{\circ} \mathrm{C}$ for 168 hours...263

Figure 5.100: Cross sectional SEM micrograph and corresponding EDS micrographs of a gold nanoparticle-merino wool composite material, prepared by soaking untreated semi-worsted merino wool in a $160 \mathrm{ppm}\left(8.13 \times 10^{-4} \mathrm{M}\right) \mathrm{Au}^{3+}$ solution for 24 hours at RT, followed by ageing at $50{ }^{\circ} \mathrm{C}$ for 168 hours. .264

Figure 5.101: TEM and corresponding Au and S STEM micrographs of a gold nanoparticlemerino wool composite prepared by soaking untreated semi-worsted merino wool in a $160 \mathrm{ppm}\left(8.13 \times 10^{-4} \mathrm{M}\right) \mathrm{Au}^{3+}$ solution for 24 hours at RT, followed by ageing at $50{ }^{\circ} \mathrm{C}$ for 168 hours. .264

Figure 5.102: a and c) high resolution S 2p XPS spectra of gold nanoparticle-merino wool composites prepared by soaking untreated semi-worsted merino wool in a 160 $\operatorname{ppm}\left(8.13 \times 10^{-4} \mathrm{M}\right) \mathrm{Au}^{3+}$ solution for 24 hours at RT, followed by ageing at 50 ${ }^{\circ} \mathrm{C}$ for 24 or 168 hours respectively. b and d) an overlay (in red) of untreated semi-worsted merino wool. .265

Figure 5.103: High resolution $\mathrm{Au} 4 \mathrm{f}$ XPS spectra of gold nanoparticle-merino wool composites prepared by soaking untreated semi-worsted merino wool in a 160 $\operatorname{ppm}\left(8.13 \times 10^{-4} \mathrm{M}\right) \mathrm{Au}^{3+}$ solution for 24 hours at RT, followed by ageing at 50 ${ }^{\circ} \mathrm{C}$ for 24 or 168 hours (a) and b) respectively). .266

Figure 5.104: Schematic illustrating the proposed bonding of gold nanoparticles to merino wool fibres. .267

Figure 5.105: High resolution XPS spectra of C 1s (a), N 1s (c) and O 1s (e) of a gold nanoparticle merino wool composite prepared by soaking untreated semi-worsted merino wool in a $160 \mathrm{ppm}\left(8.13 \times 10^{-4} \mathrm{M}\right) \mathrm{Au}^{3+}$ solution for 24 hours at RT, followed by ageing at $50{ }^{\circ} \mathrm{C}$ for 24 hours. b), d) and f) show an overlay or the corresponding $\mathrm{C} 1 \mathrm{~s}, \mathrm{~N}$ 1s and $\mathrm{O}$ 1s spectra of untreated semi-worsted merino wool (in red) .268

Figure 5.106: High resolution XPS spectra of C 1s (a), N 1s (c) and O 1s (e) of a gold nanoparticle merino wool composite prepared by soaking untreated semi-worsted merino wool in a $160 \mathrm{ppm}\left(8.13 \times 10^{-4} \mathrm{M}\right) \mathrm{Au}^{3+}$ solution for 24 hours at RT, followed by ageing at $50{ }^{\circ} \mathrm{C}$ for 168 hours. b), d) and f) show an overlay or the corresponding $\mathrm{C} 1 \mathrm{~s}, \mathrm{~N}$ 1s and $\mathrm{O}$ 1s spectra of untreated semi-worsted merino wool (in red) .269

Figure 5.107: High resolution S 2p (a), Au 4f (b), C 1s (c), N 1s (d) and O 1s (e) XPS spectra of a gold nanoparticle-merino wool composite prepared by soaking untreated semi-worsted merino wool in a $160 \mathrm{ppm}\left(8.13 \times 10^{-4} \mathrm{M}\right) \mathrm{Au}^{3+}$ solution for 24 
hours at RT, followed by adjusting the $\mathrm{pH}$ of the ageing solution to 12 and ageing at $50{ }^{\circ} \mathrm{C}$ for 168 hours

Figure 5.108: High resolution S 2p (a), Au 4f (b), C 1s (c), N 1s (d) and O 1s (e) XPS spectra of a gold nanoparticle-merino wool composite prepared by ageing untreated semi-worsted merino wool in a $160 \mathrm{ppm}\left(8.13 \times 10^{-4} \mathrm{M}\right) \mathrm{Au}^{3+}$ solution for 168 hours at $50{ }^{\circ} \mathrm{C}$. (Note, no soaking at RT prior to ageing).

.273

Figure 5.109: High resolution $\mathrm{S} 2 \mathrm{p}$ (left) and $\mathrm{Au} 4 \mathrm{f}$ (right) XPS spectra of a gold nanoparticle-merino wool composite prepared by soaking $\mathrm{KOH} / \mathrm{MeOH}$ treated semi-worsted merino wool in a $160 \mathrm{ppm}\left(8.13 \times 10^{-4} \mathrm{M}\right) \mathrm{Au}^{3+}$ solution for 24 hours at RT, followed by ageing at $50{ }^{\circ} \mathrm{C}$ for 168 hours. .275

Figure 5.110: a) high resolution S 2p XPS spectra of gold nanoparticle-merino wool composites prepared by soaking untreated worsted merino wool in a $160 \mathrm{ppm}$ $\left(8.13 \times 10^{-4} \mathrm{M}\right) \mathrm{Au}^{3+}$ solution for 24 hours at RT, followed by ageing at $50{ }^{\circ} \mathrm{C}$ for 168 hours. b) an overlay (in red) of untreated worsted merino wool. .277

Figure 5.111: a) high resolution Au 4f XPS spectra of a gold nanoparticle-merino wool composite prepared by soaking untreated worsted merino wool in a $160 \mathrm{ppm}$ $\left(8.13 \times 10^{-4} \mathrm{M}\right) \mathrm{Au}^{3+}$ solution for 24 hours at RT, followed by ageing at $50{ }^{\circ} \mathrm{C}$ for 168 hours. 277

Figure 5.112: High resolution C 1s (a) and N 1s (c) XPS spectra of a gold nanoparticle merino wool composite prepared by soaking untreated worsted merino wool in a $160 \mathrm{ppm}\left(8.13 \times 10^{-4} \mathrm{M}\right) \mathrm{Au}^{3+}$ solution for 24 hours at RT, followed by ageing at $50{ }^{\circ} \mathrm{C}$ for 168 hours. b) and d) and f) show an overlay or the corresponding spectra of untreated worsted merino wool (in red). .278

Figure 5.113: High resolution O 1s (a) XPS spectra of a gold nanoparticle merino wool composite prepared by soaking untreated worsted merino wool in a $160 \mathrm{ppm}$ $\left(8.13 \times 10^{-4} \mathrm{M}\right) \mathrm{Au}^{3+}$ solution for 24 hours at RT, followed by ageing at $50{ }^{\circ} \mathrm{C}$ for 168 hours. b) shows an overlay or the corresponding spectra of untreated worsted merino wool (in red). .279

Figure 5.114: EDS spectrum of a gold nanoparticle-merino wool composite material prepared by soaking $\mathrm{Cl} / \mathrm{H}$ treated semi-worsted merino wool in a $160 \mathrm{ppm}\left(8.13 \times 10^{-4} \mathrm{M}\right)$ $\mathrm{Au}^{3+}$ solution for 24 hours at RT, followed by ageing at $50{ }^{\circ} \mathrm{C}$ for 168 hours...280

Figure 5.115: Cross sectional SEM micrograph and corresponding EDS micrographs of a gold nanoparticle-merino wool composite material, prepared by soaking $\mathrm{Cl} / \mathrm{H}$ treated semi-worsted merino wool in a $160 \mathrm{ppm}\left(8.13 \times 10^{-4} \mathrm{M}\right) \mathrm{Au}^{3+}$ solution for 24 hours at RT, followed by ageing at $50{ }^{\circ} \mathrm{C}$ for 168 hours. 281

Figure 5.116: High resolution S 2p (a) and Au 4f (c) XPS spectra of gold nanoparticlemerino wool composites prepared by soaking $\mathrm{Cl} / \mathrm{H}$ treated merino wool in a 160 ppm $\left(8.13 \times 10^{-4} \mathrm{M}\right) \mathrm{Au}^{3+}$ solution for 24 hours at RT, followed by ageing at 50 ${ }^{\circ} \mathrm{C}$ for 168 hours. b) An overlay (in red) of the S 2p XPS spectrum of $\mathrm{Cl} / \mathrm{H}$ treated merino wool. .282

Figure 5.117: a) High resolution $\mathrm{N}$ 1s spectra of a gold nanoparticle-merino wool composite prepared by soaking $\mathrm{Cl} / \mathrm{H}$ treated merino wool in a $160 \mathrm{ppm}\left(8.13 \times 10^{-4} \mathrm{M}\right) \mathrm{Au}^{3+}$ 
solution for 24 hours at RT, followed by ageing at $50{ }^{\circ} \mathrm{C}$ for 168 hours. b) An overlay (in red) of the $\mathrm{N}$ 1s XPS spectrum of $\mathrm{Cl} / \mathrm{H}$ treated merino wool. 283

Figure 5.118: High resolution C 1s (a) and O 1s (c) XPS spectra of gold nanoparticle-merino wool composites prepared by soaking $\mathrm{Cl} / \mathrm{H}$ treated merino wool in a $160 \mathrm{ppm}$ $\left(8.13 \times 10^{-4} \mathrm{M}\right) \mathrm{Au}^{3+}$ solution for 24 hours at RT, followed by ageing at $50{ }^{\circ} \mathrm{C}$ for 168 hours. $b$ and d) offer an overlay (in red) of the C 1s and O 1s XPS spectrum of $\mathrm{Cl} / \mathrm{H}$ treated merino wool respectively. .283

Figure 5.119: High resolution S 2p (a) and Au 4f (c) XPS spectra of gold nanoparticlemerino wool composites prepared by soaking $\mathrm{KOH}$ pre-treated $\mathrm{Cl} / \mathrm{H}$ treated merino wool in a $160 \mathrm{ppm}\left(8.13 \times 10^{-4} \mathrm{M}\right) \mathrm{Au}^{3+}$ solution for 24 hours at RT, followed by ageing at $50{ }^{\circ} \mathrm{C}$ for 168 hours. b) An overlay (in red) of the $\mathrm{S} 2 \mathrm{p}$ XPS spectrum of $\mathrm{KOH}$ pre-treated $\mathrm{Cl} / \mathrm{H}$ treated merino wool. .285

Figure 5.120: a) High resolution N 1s XPS spectra of gold nanoparticle-merino wool composites prepared by soaking $\mathrm{KOH}$ pre-treated $\mathrm{Cl} / \mathrm{H}$ treated merino wool in a $160 \mathrm{ppm}\left(8.13 \times 10^{-4} \mathrm{M}\right) \mathrm{Au}^{3+}$ solution for 24 hours at RT, followed by ageing at $50{ }^{\circ} \mathrm{C}$ for 168 hours. b) An overlay (in red) of the N 1s XPS spectrum of KOH pre-treated $\mathrm{Cl} / \mathrm{H}$ treated merino wool. 285

Figure 5.121: Cross sectional SEM micrograph (a and c) and corresponding Au (b and d) or $\mathrm{S}$ (e) EDS maps of merino wool fibres soaked in a $160 \mathrm{ppm}\left(8.13 \times 10^{-4} \mathrm{M}\right) \mathrm{Au}^{3+}$ solution for 1 ( $a$ and b) or 24 hours (c-d) at RT. .288

Figure 5.122: High resolution Au 4f XPS spectra of merino wool fibres that had been soaked in a $160 \mathrm{ppm}\left(8.13 \times 10^{-4} \mathrm{M}\right) \mathrm{Au}^{3+}$ solution, at RT, for a) 1 hour or b) 24 hours. .289

Figure 5.123: High resolution S 2p XPS spectra of a) untreated semi-worsted merino wool, b) untreated semi-worsted merino wool soaked in a $160 \mathrm{ppm}\left(8.13 \times 10^{-4} \mathrm{M}\right)$ $\mathrm{Au}^{3+}$ solution for 1 hour at RT and c) soaked for 24 hours at RT. .292

Figure 5.124: Comparisons of the deconvoluted high resolution $S$ 2p XPS spectra of untreated semi-worsted merino wool (black lines) and gold nanoparticle merino wool composites, prepared by soaking untreated merino-wool in a $160 \mathrm{ppm} \mathrm{Au}^{3+}$ $\left(8.13 \times 10^{-4} \mathrm{M}\right)$ solution for 24 hours at RT followed by ageing at $50{ }^{\circ} \mathrm{C}$ for 24 (green lines) or 168 hours (red lines).

Figure 5.125: High resolution S 2p XPS spectrum of merino wool that had been soaked in a pH 3 solution for 24 hours at RT, followed by heating at $50{ }^{\circ} \mathrm{C}$ for 168 hours. 294

Figure 5.126: Schematic illustrating the electrostatic attraction between the $\mathrm{Cl}^{-}$ions of $\mathrm{AuCl}_{4}{ }^{-}$ and positively charged amine groups (1), destabilising the $\mathrm{AuCl}_{4}{ }^{-}$complex and facilitating the $\mathrm{Au}^{3+}$ to $\mathrm{Au}^{+}$reduction (2). The resultant $\mathrm{Au}^{+}$ions are thought to bond to the wool fibre via a Au-S bond (3). .296

Figure 5.127: Concentration of chloride in the reaction mixture against time. .297

Figure 5.128: Schematic illustration showing the formation of gold nanoclusters and their subsequent reduction to nanoparticulate $\mathrm{Au}^{0}$. .298

Figure 5.129: SERS spectrum of a gold nanoparticle-merino wool composite. .299 
Figure 5.130: FT-IR Raman spectra of untreated semi-worsted merino wool.

.301

Figure 5.131: Gold nanoparticle-merino wool composites prepared by soaking TCEP pretreated merino wool, merino wool that had been soaked in a $\mathrm{pH} 4.5$ buffer and untreated merino wool in a $160 \mathrm{ppm}\left(8.13 \times 10^{-4} \mathrm{M}\right) \mathrm{Au}^{3+}$ solution for 24 hours at $\mathrm{RT}$, followed by ageing at $50{ }^{\circ} \mathrm{C}$ for 24 or 168 hours. .302

Figure 5.132: Gold nanoparticle-merino wool composites prepared by soaking TCEP + maleic acid pre-treated merino wool, merino wool that had been soaked in a $\mathrm{pH}$ 4.5 and $\mathrm{pH} 8$ buffer and untreated merino wool in a $160 \mathrm{ppm}\left(8.13 \times 10^{-4} \mathrm{M}\right)$ $\mathrm{Au}^{3+}$ solution for 24 hours at RT, followed by ageing at $50{ }^{\circ} \mathrm{C}$ for 24 or 168 hours. .303

Figure 5.133: High resolution S 2p XPS spectra of a) TCEP treated merino wool and b) an overlay (in red) of untreated semi-worsted merino wool. 303

Figure 5.134: High resolution Au 4f XPS spectra of a gold nanoparticle-merino wool composites prepared by soaking TCEP treated and alkylated merino wool in a $160 \mathrm{ppm}\left(8.13 \times 10^{-4} \mathrm{M}\right) \mathrm{Au}^{3+}$ solution for 24 hours at RT, followed by ageing at $50{ }^{\circ} \mathrm{C}$ for 168 hours 304

Figure 5.135: High resolution C 1s (a), N 1s (b) and S 2p (c) XPS spectra of a gold nanoparticle-merino wool composites prepared by soaking TCEP treated and alkylated merino wool in a $160 \mathrm{ppm}\left(8.13 \times 10^{-4} \mathrm{M}\right) \mathrm{Au}^{3+}$ solution for 24 hours at RT, followed by ageing at $50{ }^{\circ} \mathrm{C}$ for 168 hours. 305

Figure 5.136: An overlay of the high resolution S 2p XPS spectra of a gold nanoparticlemerino wool composites prepared by soaking TCEP treated and alkylated merino wool in a $160 \mathrm{ppm}\left(8.13 \times 10^{-4} \mathrm{M}\right) \mathrm{Au}^{3+}$ solution for 24 hours at RT, followed by ageing at $50{ }^{\circ} \mathrm{C}$ for 168 hours (black lines) and TCEP treated and alkylated merino wool (red lines). .305

Figure 5.137: a) High resolution $\mathrm{N}$ 1s spectra of a gold nanoparticle-merino wool composite prepared by soaking $\mathrm{Cl} / \mathrm{H}$ treated merino wool in a $160 \mathrm{ppm}\left(8.13 \times 10^{-4} \mathrm{M}\right) \mathrm{Au}^{3+}$ solution for 24 hours at RT, followed by ageing at $50^{\circ} \mathrm{C}$ for 168 hours. b) An overlay (in red) of the $\mathrm{N} 1 \mathrm{~s}$ XPS spectrum of $\mathrm{Cl} / \mathrm{H}$ treated merino wool. 307

Figure 5.138: a) High resolution $\mathrm{O}$ 1s spectra of a gold nanoparticle-merino wool composite prepared by soaking $\mathrm{Cl} / \mathrm{H}$ treated merino wool in a $160 \mathrm{ppm}\left(8.13 \times 10^{-4} \mathrm{M}\right) \mathrm{Au}^{3+}$ solution for 24 hours at RT, followed by ageing at $50{ }^{\circ} \mathrm{C}$ for 168 hours. b) An overlay (in red) of the $\mathrm{O} 1 \mathrm{~s}$ XPS spectrum of $\mathrm{Cl} / \mathrm{H}$ treated merino wool. ..........308

Figure 5.139: High resolution $\mathrm{C}$ 1s (a) and $\mathrm{N} 1 \mathrm{~s}$ (c) XPS spectra of base treated $\mathrm{Cl} / \mathrm{H}$ treated merino wool. b) and d) show an overlay or the corresponding $\mathrm{C} 1 \mathrm{~s}$ and $\mathrm{N} 1 \mathrm{~s}$ spectra of untreated $\mathrm{Cl} / \mathrm{H}$ treated merino wool (in red). 310

Figure 5.140: High resolution O 1s(a) and S 2p (c) XPS spectra of base treated $\mathrm{Cl} / \mathrm{H}$ treated merino wool. b) and d) show an overlay or the corresponding $\mathrm{O} 1 \mathrm{~s}$ and $\mathrm{S} 2 \mathrm{p}$ spectra of untreated $\mathrm{Cl} / \mathrm{H}$ treated merino wool (in red). 311

Figure 5.141: a) High resolution N 1s XPS spectra of gold nanoparticle-merino wool composites prepared by soaking $\mathrm{KOH}$ pre-treated $\mathrm{Cl} / \mathrm{H}$ treated merino wool in a $160 \mathrm{ppm}\left(8.13 \times 10^{-4} \mathrm{M}\right) \mathrm{Au}^{3+}$ solution for 24 hours at RT, followed by ageing at 
$50{ }^{\circ} \mathrm{C}$ for 168 hours. b) An overlay (in red) of the N 1s XPS spectrum of $\mathrm{KOH}$ pre-treated $\mathrm{Cl} / \mathrm{H}$ treated merino wool.

Figure 5.142: Gold nanoparticle-merino wool composites (prepared by soaking untreated semi-worsted merino wool in a $160 \mathrm{ppm}\left(8.13 \times 10^{-4} \mathrm{M}\right) \mathrm{Au}^{3+}$ solution for 24 hours at RT followed by heating at $50{ }^{\circ} \mathrm{C}$ for 24 hours) following simulated washability tests.

Figure 5.143: Gold nanoparticle-merino wool composites (prepared by soaking untreated semi-worsted merino wool in a $160 \mathrm{ppm}\left(8.13 \times 10^{-4} \mathrm{M}\right) \mathrm{Au}^{3+}$ solution for 24 hours at RT followed by heating at $50{ }^{\circ} \mathrm{C}$ for 168 hours) following simulated washability tests. .314

Figure 5.144: Changes in $\mathrm{L}^{*}, \mathrm{a}^{*}, \mathrm{~b}^{*}, 457 \mathrm{~nm}$ brightness and $580 \mathrm{~nm}$ brightness values for a gold nanoparticle-merino composite (prepared by soaking untreated semiworsted merino wool in a $160 \mathrm{ppm}\left(8.13 \times 10^{-4} \mathrm{M}\right) \mathrm{Au}^{3+}$ solution for 24 hours followed by heating at $50{ }^{\circ} \mathrm{C}$ for 24 hours) following simulated washability tests show the colour change due to washing. Washing at RT (black lines) or $50{ }^{\circ} \mathrm{C}$ (red lines). .315

Figure 5.145: Changes in $\mathrm{L}^{*}, \mathrm{a}^{*}, \mathrm{~b}^{*}, 457 \mathrm{~nm}$ brightness and $580 \mathrm{~nm}$ brightness values for a gold nanoparticle-merino composite (prepared by soaking untreated semiworsted merino wool in a $160 \mathrm{ppm}\left(8.13 \times 10^{-4} \mathrm{M}\right) \mathrm{Au}^{3+}$ solution for 24 hours followed by heating at $50{ }^{\circ} \mathrm{C}$ for 168 hours) following simulated washability tests show the colour change due to washing. Washing at RT (black lines) or $50{ }^{\circ} \mathrm{C}$ (red lines).

Figure 5.146: Gold nanoparticle-merino wool composites embedded on agar plates incubated with Staphylococcus aureus. Left: prepared by soaking untreated semi-worsted merino wool in a $160 \mathrm{ppm}\left(8.13 \times 10^{-4} \mathrm{M}\right) \mathrm{Au}^{3+}$ solution for 24 hours at RT, followed by ageing at $50{ }^{\circ} \mathrm{C}$ for 24 hours. Middle and right: prepared by ageing untreated semi-worsted merino wool in a $960 \mathrm{ppm}\left(4.87 \times 10^{-3} \mathrm{M}\right)$ or $1040(5.28$ $\left.\mathrm{x} 10^{-3} \mathrm{M}\right) \mathrm{Au}^{3+}$ solution respectively for 24 hours at $50{ }^{\circ} \mathrm{C}$. .319

Figure 5.147: Left top and bottom: gold nanoparticle-merino wool composites (prepared by soaking untreated semi-worsted merino wool in a $160 \mathrm{ppm}\left(8.13 \times 10^{-4} \mathrm{M}\right) \mathrm{Au}^{3+}$ solution for 24 hours at RT, followed by heating at $50{ }^{\circ} \mathrm{C}$ for 24 (top) or 168 (bottom) hours). Right: the same composite materials following Chlorine Hercosett treatment. 323

Figure 5.148: Examples of gold nanoparticle-merino wool sample that has been hand spun into a yarn (left) and subsequently hand woven into a scarf (right). .326

Figure 6.1: Cross sectional light micrographs of merino wool (left) and crossbred wool fibres (right) dyed with methylene blue to differentiate between the paracortex (Plightly stained) and orthocortex (O- darkly stained).[46]. .332

Figure 6.2: Gold nanoparticle-crossbred wool composite materials, prepared by soaking crossbred wool fibres in an 80,120 or $160 \mathrm{ppm}\left(4.06 \times 10^{-4}, 6.09 \times 10^{-4}\right.$ and 8.13 $\left.\mathrm{x} 10^{-4} \mathrm{M}\right) \mathrm{Au}^{3+}$ solutions for 24 hours at RT, followed by ageing at $50{ }^{\circ} \mathrm{C}$ for 24 168 hours. 333 
Figure 6.3: Gold nanoparticle-crossbred wool composite materials, prepared by soaking crossbred wool fibres in an $80 \mathrm{ppm}\left(4.06 \times 10^{-4} \mathrm{M}\right)(\mathrm{a}$ and b) or $160 \mathrm{ppm}(8.13 \mathrm{x}$ $\left.10^{-4} \mathrm{M}\right)(\mathrm{c}$ and $\mathrm{d}) \mathrm{Au}^{3+}$ solution for solutions for 24 hours at RT, followed by ageing at $50{ }^{\circ} \mathrm{C}$ for 24 (a and c) or 168 hours (b and d).

Figure 6.4: Left: cross sectional SEM micrograph and right: corresponding Au EDS map of a gold nanoparticle-crossbred composite prepared by soaking crossbred wool in a $160 \mathrm{ppm}\left(8.13 \times 10^{-4} \mathrm{M}\right) \mathrm{Au}^{3+}$ solution for 24 hours at RT, followed by ageing at $50{ }^{\circ} \mathrm{C}$ for 168 hours. .336

Figure 6.5: CIE $\mathrm{L}^{*}, \mathrm{a}^{*}, \mathrm{~b}^{*}, 457 \mathrm{~nm}$ brightness and $580 \mathrm{~nm}$ brightness values for gold nanoparticle-crossbred wool composites prepared by soaking the fibres in an 80 $\operatorname{ppm}\left(4.06 \times 10^{-4} \mathrm{M}\right) \mathrm{Au}^{3+}$ solution for 24 hours at RT, followed by ageing, at 50 ${ }^{\circ} \mathrm{C}$ for $24-168$ hours. .338

Figure 6.6: CIE L*, a*, $\mathrm{b}^{*}, 457 \mathrm{~nm}$ brightness and $580 \mathrm{~nm}$ brightness values for gold nanoparticle-crossbred wool composites prepared by soaking the fibres in a 160 $\operatorname{ppm}\left(8.13 \times 10^{-4} \mathrm{M}\right) \mathrm{Au}^{3+}$ solution for 24 hours at RT, followed by ageing, at 50 ${ }^{\circ} \mathrm{C}$ for $24-168$ hours.

Figure 6.7: CIE L*, a*, $\mathrm{b}^{*}, 457 \mathrm{~nm}$ brightness and $580 \mathrm{~nm}$ brightness values for gold nanoparticle-crossbred wool composites prepared by soaking the fibres in an 80, 120 or $160 \mathrm{ppm}\left(4.06 \times 10^{-4}, 6.09 \times 10^{-4}\right.$ or $\left.8.13 \times 10^{-4} \mathrm{M}\right) \mathrm{Au}^{3+}$ solution for 24 hours at RT, followed by ageing, at $50{ }^{\circ} \mathrm{C}$ for 168 hours.

Figure 6.8: Kubelka Munk transformed UV/Vis reflection spectra of gold nanoparticlecrossbred wool composites prepared by soaking crossbred wool in a $160 \mathrm{ppm}$ $\left(8.13 \times 10^{-4} \mathrm{M}\right) \mathrm{Au}^{3+}$ solution for 24 hours at RT, followed by ageing at $50{ }^{\circ} \mathrm{C}$ for 24-168 hours. .340

Figure 6.9: Kubelka Munk transformed UV/Vis reflection spectra of gold nanoparticlecrossbred wool composites prepared by soaking crossbred wool in an 80, 120 or $160 \mathrm{ppm}\left(4.09 \times 10^{-4}, 6.09 \times 10^{-4}\right.$ or $\left.8.13 \times 10^{-4} \mathrm{M}\right) \mathrm{Au}^{3+}$ solution for 24 hours at RT, followed by ageing at $50{ }^{\circ} \mathrm{C}$ for $24-168$ hours 341

Figure 6.10: SEM micrographs of gold nanoparticle-crossbred wool composite materials (prepared by soaking the fibres in a $160 \mathrm{ppm}\left(8.13 \times 10^{-4} \mathrm{M}\right) \mathrm{Au}^{3+}$ solution for 24 hours at RT, followed by ageing at $50{ }^{\circ} \mathrm{C}$ for 24 hours (top) or 168 hours (bottom)). The micrographs on the left are collected with a secondary electron detector whilst those on the right are detected with a back scatter detector........342

Figure 6.11; SEM micrographs and corresponding EDS Au maps of gold nanoparticlecrossbred wool composite materials. 343

Figure 6.12: EDS spectrum of the gold nanoparticle-crossbred wool composite shown in Figure 6.11 top. .343

Figure 6.13: EDS spectrum of the gold nanoparticle-crossbred wool composite shown in Figure 6.11 bottom. .344

Figure 6.14: Wide XPS scans of gold nanoparticle-crossbred wool composites prepared by soaking the fibres in a $160 \mathrm{ppm}\left(8.13 \times 10^{-4} \mathrm{M}\right) \mathrm{Au}^{3+}$ solution for 24 hours at RT, followed by ageing at $50{ }^{\circ} \mathrm{C}$ for a) 24 hours or b) 168 hours. .345 
Figure 6.15: Gold uptake by crossbred or merino wool at RT. A Au ${ }^{3+}$ concentration of 160 $\operatorname{ppm}\left(8.13 \times 10^{-4} \mathrm{M}\right)$ was employed.

Figure 6.16: Gold uptake by crossbred or merino wool at RT. A Au ${ }^{3+}$ concentration of 160

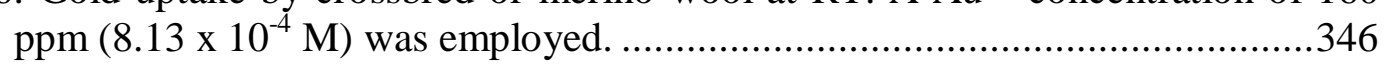

Figure 6.17: Cross sectional $\mathrm{Au}$ (left) and $\mathrm{S}$ (right) EDS maps of a gold nanoparticlecrossbred wool composite prepared by soaking crossbred wool in a $160 \mathrm{ppm}$ $\left(8.13 \times 10^{-4} \mathrm{M}\right) \mathrm{Au}^{3+}$ solution for 24 hours at RT, followed by ageing at $50{ }^{\circ} \mathrm{C}$ for 168 hours. 348

Figure 6.18: a) high resolution S 2p XPS spectra of gold nanoparticle-crossbred wool composites prepared by soaking crossbred wool in a $160 \mathrm{ppm}\left(8.13 \times 10^{-4} \mathrm{M}\right)$ $\mathrm{Au}^{3+}$ solution for 24 hours at RT, followed by ageing at $50{ }^{\circ} \mathrm{C}$ for 168 hours. b) an overlay (in red) of crossbred wool. .348

Figure 6.19: a) high resolution Au 4f XPS spectra of gold nanoparticle-crossbred wool composites prepared by soaking crossbred wool in a $160 \mathrm{ppm}\left(8.13 \times 10^{-4} \mathrm{M}\right)$ $\mathrm{Au}^{3+}$ solution for 24 hours at RT, followed by ageing at $50{ }^{\circ} \mathrm{C}$ for 168 hours...349

Figure 6.20: High resolution Au 4f (a) and S 2p (b) XPS spectra of crossbred wool fibres that had been soaked in a $160 \mathrm{ppm}\left(8.13 \times 10^{-4} \mathrm{M}\right) \mathrm{Au}^{3+}$ solution, at RT for 24 hours. 351

Figure 6.21: Comparisons of the deconvoluted high resolution S 2p XPS spectra of crossbred wool (black lines) and gold nanoparticle-crossbred wool composites, prepared by soaking fibres in a $160 \mathrm{ppm} \mathrm{Au}^{3+}\left(8.13 \times 10^{-4} \mathrm{M}\right)$ solution for 24 hours at RT followed by ageing at $50{ }^{\circ} \mathrm{C}$ for 24 (green lines) or 168 hours (red lines).........351

Figure 6.22: Gold nanoparticle-crossbred wool composites prepared by soaking crossbred wool in a $160 \mathrm{ppm}\left(8.13 \times 10^{-4} \mathrm{M}\right) \mathrm{Au}^{3+}$ solution for 24 hours at RT and ageing, at $50{ }^{\circ} \mathrm{C}$ for 168 hours, following simulated washability testing......................352

Figure 7.1: A selection of gold nanoparticle-silk composites. .356

Figure 7.2: Gold nanoparticle-silk composite materials, prepared by soaking silk in a 160 $\operatorname{ppm}\left(8.13 \times 10^{-4} \mathrm{M}\right) \mathrm{Au}^{3+}$ solution for 10 minutes to 24 hours at RT. .356

Figure 7.3: Gold nanoparticle-silk composite materials, prepared by soaking silk in a 160 $\mathrm{ppm}\left(8.13 \times 10^{-4} \mathrm{M}\right) \mathrm{Au}^{3+}$ solution for 24 hours at RT, followed by ageing at 50 ${ }^{\circ} \mathrm{C}$ for $24-168$ hours. .357

Figure 7.4: Gold nanoparticle-silk composite materials, prepared by soaking silk fibres in a $160 \mathrm{ppm}\left(8.13 \times 10^{-4} \mathrm{M}\right) \mathrm{Au}^{3+}$ solution for 10 minutes (top) or 24 hours at RT (middle), followed by ageing at $50{ }^{\circ} \mathrm{C}$ for 168 hours (bottom). .357

Figure 7.5: Cross sectional SEM micrographs of a gold nanoparticle-silk composite prepared by soaking silk fibres in a $160 \mathrm{ppm}\left(8.13 \times 10^{-4} \mathrm{M}\right) \mathrm{Au}^{3+}$ solution for 24 hours at $\mathrm{RT}$, followed by ageing at $50{ }^{\circ} \mathrm{C}$ for 168 hours .358

Figure 7.6: Cross sectional SEM micrograph (left) and corresponding Au EDS map of a gold nanoparticle-silk composite prepared by soaking silk fibres in a $160 \mathrm{ppm}(8.13 \mathrm{x}$ $\left.10^{-4} \mathrm{M}\right) \mathrm{Au}^{3+}$ solution for 24 hours at RT, followed by ageing at $50{ }^{\circ} \mathrm{C}$ for 168 hours. .359 
Figure 7.7: A selection of gold nanoparticle-silk composite materials prepared by soaking silk in a $160 \mathrm{ppm}\left(8.13 \times 10^{-4} \mathrm{M}\right) \mathrm{Au}^{3+}$, with a pH of 7, 9-10 or 12, for 10 minutes -24 hours at RT, followed by ageing at $50{ }^{\circ} \mathrm{C}$ for 24 hours. .360

Figure 7.8: Increasing magnification TEM micrographs of an evaporated sample of the $\mathrm{pH} 9$ 10 ageing solution. 361

Figure 7.9: Increasing magnification SEM micrographs of gold nanoparticle-silk composites prepared by soaking silk fibres in a pH 7 (top), 9-10 (middle) or 12 (bottom) 160 $\operatorname{ppm}\left(8.13 \times 10^{4} \mathrm{M}\right) \mathrm{Au}^{3+}$ solution for 6 hours at $\mathrm{RT}$, followed by ageing at $50{ }^{\circ} \mathrm{C}$ for 24 hours. .362

Figure 7.10: Cross sectional SEM micrographs of a gold nanoparticle-silk composite prepared by soaking silk fibres in a $160 \mathrm{ppm}\left(8.13 \times 10^{-4} \mathrm{M}\right) \mathrm{Au}^{3+}$ solution at $\mathrm{pH}$ 9-10 for 6 hours at RT, followed by ageing at $50{ }^{\circ} \mathrm{C}$ for 168 hours. 362

Figure 7.11: TEM micrographs of a silk seed prepared with a 6 hour soaking time in a pH 910 gold solution and 24 hours heating at $50{ }^{\circ} \mathrm{C}$. Left: Micrograph showing fibre surface and centre. Middle: Micrograph showing nanoparticles on the fibre surface and right: micrograph showing nanoparticles in the fibre centre. .363

Figure 7.12: Relationship between size, shape and concentration of nanoparticles on the silk fibre and the colour of the resultant composite materials. .363

Figure 7.13: CIE L*, $\mathrm{a}^{*}, \mathrm{~b}^{*}, 457 \mathrm{~nm}$ brightness and $580 \mathrm{~nm}$ brightness values for silk fibres soaked in a $160 \mathrm{ppm}\left(8.13 \times 10^{-4} \mathrm{M}\right) \mathrm{Au}^{3+}$ solution, with a $\mathrm{pH}$ of 2.7 for 10 minutes to 24 hours at RT. 364

Figure 7.14: CIE L*, $\mathrm{a}^{*}, \mathrm{~b}^{*}, 457 \mathrm{~nm}$ brightness and $580 \mathrm{~nm}$ brightness values for gold nanoparticle-silk composites, prepared by soaking silk in a $160 \mathrm{ppm}\left(8.13 \times 10^{-4}\right.$ M) $\mathrm{Au}^{3+}$ solution, with a pH of 2.7 for 24 hours at RT followed by ageing at 50 ${ }^{\circ} \mathrm{C}$ for 0-168 hours. .365

Figure 7.15: Kubelka Munk transformed UV/Vis reflection spectra of gold nanoparticle-silk composites prepared by soaking silk in a $160 \mathrm{ppm}\left(8.13 \times 10^{-4} \mathrm{M}\right) \mathrm{Au}^{3+}$ solution, with a $\mathrm{pH}$ of 2.7 for 24 hours at RT, followed by ageing at $50{ }^{\circ} \mathrm{C}$ for $24-168$ hours. 366

Figure 7.16: Kubelka Munk transformed UV/Vis reflection spectra of silk and gold nanoparticle-silk composites prepared by soaking silk in a $160 \mathrm{ppm}\left(8.13 \times 10^{-4}\right.$ M) $\mathrm{Au}^{3+}$ solution, with a $\mathrm{pH}$ of 2.7, 7, 9-10 or 12 for 6 hours at RT, followed by ageing at $50{ }^{\circ} \mathrm{C}$ for 24 hours. .367

Figure 7.17: SEM micrographs of a gold nanoparticle-silk composite prepared by soaking silk fibres in a $160 \mathrm{ppm}\left(8.13 \times 10^{-4} \mathrm{M}\right) \mathrm{Au}^{3+}$ solution, at $\mathrm{pH} 7$ for 6 hours at RT, followed by ageing at $50{ }^{\circ} \mathrm{C}$ for 24 hours. .368

Figure 7.18: SEM micrograph and corresponding Au EDS map of a gold nanoparticle-silk composite prepared by soaking silk in a $160 \mathrm{ppm}\left(8.13 \times 10^{-4} \mathrm{M}\right) \mathrm{Au}^{3+}$ solution, at $\mathrm{pH} 7$, for 6 hours at RT, followed by ageing at $50{ }^{\circ} \mathrm{C}$ for 24 hours...............368

Figure 7.19: EDS spectra of the gold nanoparticle-silk composite shown in Figure 316.....369 
Figure 7.20: SEM micrograph and corresponding Au EDS map of a gold nanoparticle-silk composite prepared by soaking silk in a $160 \mathrm{ppm}\left(8.13 \times 10^{-4} \mathrm{M}\right) \mathrm{Au}^{3+}$ solution, at $\mathrm{pH} 9-10$, for 6 hours at RT, followed by ageing at $50{ }^{\circ} \mathrm{C}$ for 24 hours .369

Figure 7.21: EDS spectra of the gold nanoparticle-silk composite shown in Figure 318.....370

Figure 7.22: Wide XPS scans of gold nanoparticle-silk composites prepared by soaking the fibres in a $160 \mathrm{ppm}\left(8.13 \times 10^{-4} \mathrm{M}\right) \mathrm{Au}^{3+}$ solution for 6 hours at RT, with a $\mathrm{pH}$ of a) $9-10$ or b) 12 , followed by ageing at $50{ }^{\circ} \mathrm{C}$ for 24 hours. 371

Figure 7.23: Gold uptake by silk at RT and $50{ }^{\circ} \mathrm{C}$. A Au ${ }^{3+}$ concentration of $160 \mathrm{ppm}(8.13 \mathrm{x}$ $10^{-4} \mathrm{M}$ ), with a $\mathrm{pH}$ of 2.7 was employed. .372

Figure 7.24: Gold uptake by silk at RT and $50{ }^{\circ} \mathrm{C}$. A Au ${ }^{3+}$ concentration of $160 \mathrm{ppm}(8.13 \mathrm{x}$ $\left.10^{-4} \mathrm{M}\right)$, with a $\mathrm{pH}$ of 2.7 was employed. .372

Figure 7.25: Gold uptake by silk at RT. A Au ${ }^{3+}$ concentration of $160 \mathrm{ppm}\left(8.13 \times 10^{-4} \mathrm{M}\right)$, with a $\mathrm{pH}$ of 2.7 or $9-10$ was employed. 373

Figure 7.26: Cross sectional SEM micrograph and corresponding EDS micrographs of a gold nanoparticle-silk composite material, prepared by soaking silk fibres in a 160 $\operatorname{ppm}\left(8.13 \times 10^{-4} \mathrm{M}\right) \mathrm{Au}^{3+}$ solution, with a $\mathrm{pH}$ of 9-10 for 6 hours at RT, followed by ageing at $50{ }^{\circ} \mathrm{C}$ for 24 hours. 375

Figure 7.27: a) high resolution N 1s XPS spectrum of a gold nanoparticle-silk composite prepared by soaking silk in a $160 \mathrm{ppm}\left(8.13 \times 10^{-4} \mathrm{M}\right) \mathrm{Au}^{3+}$ solution, with a $\mathrm{pH}$ of 9-10 for 6 hours at RT, followed by ageing at $50{ }^{\circ} \mathrm{C}$ for 24 hours. b) an overlay (in red) of silk. .375

Figure 7.28: High resolution Au 4f XPS spectra of a gold nanoparticle-silk composite prepared by soaking silk in a $160 \mathrm{ppm}\left(8.13 \times 10^{-4} \mathrm{M}\right) \mathrm{Au}^{3+}$ solution, with a $\mathrm{pH}$ of $9-10$ for 6 hours at RT, followed by ageing at $50{ }^{\circ} \mathrm{C}$ for 24 hours.... 376

Figure 7.29: a) high resolution S 2p XPS spectra of a gold nanoparticle-silk composite prepared by soaking silk in a $160 \mathrm{ppm}\left(8.13 \times 10^{-4} \mathrm{M}\right) \mathrm{Au}^{3+}$ solution, with a $\mathrm{pH}$ of 9-10 for 6 hours at RT, followed by ageing at $50{ }^{\circ} \mathrm{C}$ for 24 hours. b) an overlay (in red) of silk. .377

Figure 7.30: a) high resolution N 1s XPS spectra of a gold nanoparticle-silk composite prepared by soaking silk in a $160 \mathrm{ppm}\left(8.13 \times 10^{-4} \mathrm{M}\right) \mathrm{Au}^{3+}$ solution, with a $\mathrm{pH}$ of $9-10$ for 6 hours at RT, followed by ageing at $50{ }^{\circ} \mathrm{C}$ for 24 hours. b) an overlay (in red) of silk. .379

Figure 7.31: High resolution XPS spectra of C 1s (a) and O 1s (c) of a gold nanoparticle silk composite prepared by soaking silk in a $160 \mathrm{ppm}\left(8.13 \times 10^{-4} \mathrm{M}\right) \mathrm{Au}^{3+}$ solution, with a pH of 9-10 for 6 hours at RT, followed by ageing at $50{ }^{\circ} \mathrm{C}$ for 24 hours. b) and d) show an overlay or the corresponding $\mathrm{C} 1 \mathrm{~s}$ and $\mathrm{O} 1 \mathrm{~s}$ spectra of silk (in red). 381

Figure 7.32: Wide XPS scan of the evaporated $\mathrm{pH} 2.7 \mathrm{Au}^{3+}$ soaking solution in which silk fibres had been soaked. .382

Figure 7.33: High resolution C 1s (a), N 1s (b), O 1s (c), 2 Sp (d) and Au 4f (e) XPS spectra of a $\mathrm{pH} 2.7 \mathrm{Au}^{3+}$ soaking solution following the soaking of silk fibres at RT...383 
Figure 7.34: Gold nanoparticle-silk composites prepared by soaking untreated (top) or degummed silk (bottom) in a $160 \mathrm{ppm} \mathrm{Au}^{3+}$ solution, with a $\mathrm{pH}$ of 9-10, for 10 minutes or 24 hours, followed by ageing at $50{ }^{\circ} \mathrm{C}$ for 24 hours. .385

Figure 7.35: UV/Vis spectra of the gold colloids produced in the ageing solutions of untreated or degummed silk. .385

Figure 7.36: Gold nanoparticle-silk composites prepared by soaking crossbred wool in a 160 ppm $\left(8.13 \times 10^{-4} \mathrm{M}\right) \mathrm{Au}^{3+}$ solution with a $\mathrm{pH}$ of 2.7 for 24 hours at RT and ageing, at $50{ }^{\circ} \mathrm{C}$ for 168 hours, following simulated washability testing at RT and $50{ }^{\circ} \mathrm{C}$. 387

Figure 7.37: Gold nanoparticle-silk composites prepared by soaking crossbred wool in a 160 ppm $\left(8.13 \times 10^{-4} \mathrm{M}\right) \mathrm{Au}^{3+}$ solution with a $\mathrm{pH}$ of 9-10 for 6 hours at RT and ageing, at $50{ }^{\circ} \mathrm{C}$ for 24 hours, following simulated washability testing at RT and $50{ }^{\circ} \mathrm{C}$.

Figure 7.38: Changes in $\mathrm{L}^{*}, \mathrm{a}^{*}, \mathrm{~b}^{*}, 457 \mathrm{~nm}$ brightness and $580 \mathrm{~nm}$ brightness values for a gold nanoparticle-silk composite (prepared by soaking silk in a $160 \mathrm{ppm}(8.13 \mathrm{x}$ $10^{-4} \mathrm{M}$ ) $\mathrm{Au}^{3+}$ solution, with a $\mathrm{pH}$ of 2.7 for 24 hours at RT followed by heating at $50{ }^{\circ} \mathrm{C}$ for 24 hours) following simulated washability tests show the colour change due to washing. Washing at RT (black lines) or $50^{\circ} \mathrm{C}$ (red lines). .388

Figure 8.1: TEM micrographs of a) seed 1, b) seed 5 and c) seed 7. Showing initially the increase in amount of nanoparticles on the fibre surface and then in the centre with prolonged heating. .394

Figure 8.2: SEM micrographs of seeds 5, 6 and 7 (left to right). These appear similar in morphology. .394

Figure 8.3: Seeds. Top, left to right, seed 1-5. Bottom, left to right, seed 6-10. .394

Figure 8.4: TEM micrographs of a) seed 1 and b-c) seed 7. Showing high magnification images of the nanoparticles on the fibre surface ( $a$ and $b$ ) and in the fibre centre (c). 395

Figure 8.5: Composites prepared via the seed mediated approach. Top: produced from seed 1 and bottom: from seed 7 . .396

Figure 8.6: Kubelka Munk transformed UV/Vis reflection spectrum of gold nanoparticlemerino wool composites prepared via the seed mediated approach, utilising seed 1. 396

Figure 8.7: Kubelka Munk transformed UV/Vis reflection spectrum of gold nanoparticlemerino wool composites prepared via the seed mediated approach, utilising seed 7. 397

Figure 8.8: Gold nanoparticle-merino wool composites prepared with a $2.5 \times 10^{-4} \mathrm{M}$ gold solution $\left(12.3 \mu \mathrm{L} 4 \mathrm{wt} \% \mathrm{Au}^{3+}\right.$ to $\left.10 \mathrm{ml}\right)$ and corresponding seeds. .398

Figure 8.9: Gold nanoparticle-merino wool composites prepared with a $4.2 \times 10^{-4}$ or $6.8 \times 10^{-}$ ${ }^{4} \mathrm{M}$ gold solution (12.3 or $20 \mu \mathrm{L} 4 \mathrm{wt} \% \mathrm{Au}^{3+}$ to $6 \mathrm{ml}$ ) and corresponding seeds. 
Figure 8.10: Gold nanoparticle-merino wool composites prepared with a $1.02 \times 10^{-3}$ or $1.35 \mathrm{x}$ $10^{-3} \mathrm{M}$ gold solution ( 30 or $40 \mu \mathrm{L} 4 \mathrm{wt} \% \mathrm{Au}^{3+}$ to $6 \mathrm{ml}$ ) and corresponding seeds.

Figure 8.11: Gold nanoparticle-merino wool composites prepared with a $4.2 \times 10^{-4}$ or $6.8 \mathrm{x}$ $10^{-4} \mathrm{M}$ gold solution (12.3 or $20 \mu \mathrm{L} 4 \mathrm{wt} \% \mathrm{Au}^{3+}$ to $6 \mathrm{ml}$ ) and corresponding seeds. 400

Figure 8.12:Top: increasing magnification SEM micrographs of a gold nanoparticle-merino wool composite prepared via the seed mediated approach, utilising seed 5, a gold concentration of $2.5 \times 10^{-4} \mathrm{M}$ and a $1: 1$ ratio of $\left[\mathrm{Au}^{3+}\right]:\left[\mathrm{NH}_{2} \mathrm{OH}\right]$. Bottom: Increasing magnification SEM micrographs of seed 5. 401

Figure 8.13; TEM micrograph of a gold nanoparticle-merino wool composite prepared via the seed mediated approach. Shows gold nanoparticles agglomerated at a cuticle edge. .401

Figure 8.14: Increasing magnification SEM micrographs of a gold nanoparticle-merino wool composite prepared via the seed mediated approach, utilising seed 5, a gold concentration of $2.5 \times 10^{-4} \mathrm{M}$ and a $1: 8$ ratio of $\left[\mathrm{Au}^{3+}\right]:\left[\mathrm{NH}_{2} \mathrm{OH}\right]$. 402

Figure 8.15: Increasing magnification SEM micrographs of gold nanoparticle-merino wool composites prepared via the seed mediated approach, utilising seed 5, a $\left[\mathrm{Au}^{3+}\right]:\left[\mathrm{NH}_{2} \mathrm{OH}\right]$ concentration ratio of $1: 16$ and a gold concentration of, top: 2.5 x $10^{-4} \mathrm{M}$, middle: $4.2 \times 10^{-4} \mathrm{M}$ and bottom: $6.8 \times 10^{-4} \mathrm{M}$.

Figure 8.16: TEM micrographs of gold nanoparticle-merino wool composites prepared via the seed mediated approach, utilising seed 5 , a $\left[\mathrm{Au}^{3+}\right]:\left[\mathrm{NH}_{2} \mathrm{OH}\right]$ concentration ratio of 1:16 and a gold concentration of top: $4.2 \times 10^{-4} \mathrm{M}$ and middle and bottom: $1.35 \times 10^{-3} \mathrm{M}$. .403

Figure 8.17: Increasing magnification SEM micrographs of gold nanoparticle-merino wool composites prepared via the seed mediated approach, utilising seed 5, a $\left[\mathrm{Au}^{3+}\right]:\left[\mathrm{NH}_{2} \mathrm{OH}\right]$ concentration ratio of $1: 16$ and a gold concentration of, top: $1.02 \times 10^{-3} \mathrm{M}$ and bottom: $1.35 \times 10^{-3} \mathrm{M}$. .403

Figure 8.18: Increasing magnification SEM micrographs of gold nanoparticle-merino wool composites prepared from seed 5 (top) and seed 7 (bottom), employing a gold concentration of $2.50 \times 10^{-4} \mathrm{M}$, and $\mathrm{a}\left[\mathrm{Au}^{3+}\right]:\left[\mathrm{NH}_{2} \mathrm{OH}\right]$ concentration ratio of $1: 16$. 404

Figure 8.19: Gold nanoparticle-merino wool composites produced from seeds 8-10. A colour change upon increasing gold concentration is apparent. 408

Figure 8.20: Gold nanoparticle-merino wool composites produced from seeds 2, 5 and 7. A colour change upon increasing gold concentration is apparent.

Figure 8.21: SEM micrographs of gold nanoparticle-merino wool composites prepared via the seed mediated approach. Shows the relationship between the colour of the composites and the size of the nanoparticles bound to the fibre surface. 411 
Figure 8.22: Kubelka Munk transformed UV/Vis reflection spectra of composites prepared from various seeds, with a gold concentration of $4.2 \times 10^{-4} \mathrm{M}$ and a $\left[\mathrm{Au}^{3+}\right]:\left[\mathrm{NH}_{2} \mathrm{OH}\right]$ ratio of $1: 128$.

Figure 8.23: Kubelka Munk transformed UV/Vis reflection spectra of composites prepared seed 5 with various gold concentrations and $\left[\mathrm{Au}^{3+}\right]:\left[\mathrm{NH}_{2} \mathrm{OH}\right]$ ratio of 1:128.413

Figure 8.24: Kubelka Munk transformed UV/Vis reflection spectra of composites prepared seed 5 with a gold concentration of $4.2 \times 10^{-4} \mathrm{M}$ and various $\left[\mathrm{Au}^{3+}\right]:\left[\mathrm{NH}_{2} \mathrm{OH}\right]$ ratios.

Figure 8.25: Left: Cross sectional SEM micrograph of a gold nanoparticle-merino wool composite prepared via the seed mediated approach, utilising seed 5, a gold concentration of $4.2 \times 10^{-4} \mathrm{M}$ and $\mathrm{a}\left[\mathrm{Au}^{3+}\right]:\left[\mathrm{NH}_{2} \mathrm{OH}\right]$ concentration ratio of $1: 16$, and right: the corresponding EDS map.

Figure 8.26: EDS spectrum of the gold nanoparticle-merino wool composite shown in Figure 8.25 . 414

Figure 8.27: Left: Cross sectional SEM micrograph of a gold nanoparticle-merino wool composite prepared via the seed mediated approach, utilising seed 5, a gold concentration of $4.2 \times 10^{-4} \mathrm{M}$ and $\mathrm{a}\left[\mathrm{Au}^{3+}\right]:\left[\mathrm{NH}_{2} \mathrm{OH}\right]$ concentration ratio of 1:128, and right: the corresponding EDS map.

Figure 8.28 EDS spectrum of the gold nanoparticle-merino wool composite shown in Figure 8.27 . 415

Figure 8.29: Left: a solution containing $\mathrm{Au}^{3+}$ and $\mathrm{NH}_{2} \mathrm{OH}$ that had been left to react over night. Middle: the same solution also containing untreated merino wool, and right: the same merino wool following 24 hours in the $\mathrm{Au}^{3+} / \mathrm{NH}_{2} \mathrm{OH}$. 416

Figure 8.30: High resolution Au 4f XPS spectrum of merino wool soaked in a $\mathrm{Au}^{3+} / \mathrm{NH}_{2} \mathrm{OH}$ solution for 24 hours at RT.

Figure 8.31: High resolution C 1s (a-b) and N 1s (c-d) XPS spectra of a gold nanoparticlemerino wool composite prepared via the seed mediated approach. Figures (b and d) show an overlay of the corresponding $\mathrm{C} 1 \mathrm{~s}$ and $\mathrm{N} 1 \mathrm{~s}$ spectra of the seed material (in red) 418

Figure 8.32: High resolution O 1s (a-b) and S 2p (c-d) XPS spectra of a gold nanoparticlemerino wool composite prepared via the seed mediated approach. Figures $(b$ and d) show an overlay of the corresponding $\mathrm{O} 1 \mathrm{~s}$ and $\mathrm{S} 2 \mathrm{p}$ spectra of the seed material (in red). .419

Figure 8.33: a) High resolution Au 4f XPS spectra of a gold nanoparticle-merino wool composite prepared via the seed mediated approach. b) overlay of the corresponding spectra of the seed material (in red). 420

Figure 8.34: Left: Cross sectional SEM micrograph of a gold nanoparticle-merino wool composite prepared via the seed mediated approach, utilising seed 5, a gold concentration of $4.2 \times 10^{-4} \mathrm{M}$ and a 1:128 ratio of $\left[\mathrm{Au}^{3+}\right]:\left[\mathrm{NH}_{2} \mathrm{OH}\right]$ and right: the corresponding EDS map. 
Figure 8.35: Left: Gold EDS map of a gold nanoparticle-merino wool composite prepared via the seed mediated approach, and right: the corresponding line profile showing higher concentrations of gold on the surface of the fibre than in the centre. .....422

Figure 8.36: Gold nanoparticle-merino wool composites prepared from seed 5, and a $\left[\mathrm{Au}^{3+}\right]:\left[\mathrm{NH}_{2} \mathrm{OH}\right]$ ratio of 1:1 (top), 1:8 (middle) or 1:16 (bottom), showing colour development with increased reaction time. .423

Figure 8.37: Kubelka Munk transformed UV/Vis reflection spectra of composites prepared from seed 5, with a gold concentration of $2.5010^{-4} \mathrm{M}$ and a $\left[\mathrm{Au}^{3+}\right]:\left[\mathrm{NH}_{2} \mathrm{OH}\right]$ ratio of $1: 1$.

Figure 8.38: Kubelka Munk transformed UV/Vis reflection spectra of composites prepared from seed 5, with a gold concentration of $2.5010^{-4} \mathrm{M}$ and a $\left[\mathrm{Au}^{3+}\right]:\left[\mathrm{NH}_{2} \mathrm{OH}\right]$ ratio of $1: 8$. .424

Figure 8.39: Kubelka Munk transformed UV/Vis reflection spectra of composites prepared from seed 5, with a gold concentration of $2.50 \times 10^{-4} \mathrm{M}$ and a $\left[\mathrm{Au}^{3+}\right]:\left[\mathrm{NH}_{2} \mathrm{OH}\right]$ ratio of $1: 16$. .424

Figure 8.40: Gold nanoparticle-merino wool composites prepared from seed 5, a gold concentration of $4.2 \times 10^{-4} \mathrm{M}$ and $\mathrm{a}\left[\mathrm{Au}^{3+}\right]:\left[\mathrm{NH}_{2} \mathrm{OH}\right]$ ratio of $1: 64$ following simulated washability testing. .425

Figure 8.41: Kubelka Munk transformed UV/Vis reflection spectra of a gold nanoparticlemerino wool composite following simulated washability testing .426

Figure 8.42: Right: a gold nanoparticle-merino wool composite prepared via the seed mediated approach. Left: the same composite material following chlorine Hercosett treatment .428

Figure 8.43: Seeds used in the production of gold nanoparticle-crossbred wool composites. 430

Figure 8.44: Increasing magnification SEM micrographs of seeds employed in the production of gold nanoparticle-crossbred wool composites. Top to bottom, seed 1, seed 3, seed 4 and seed 6 . 431

Figure 8.45: Cross sectional SEM micrographs of seed 4 (left) and seed 6 (right) .431

Figure 8.46: Gold nanoparticle-crossbred wool composites prepared via the seed mediated approach. 433

Figure 8.47: Increasing micrographs of a gold nanoparticle-crossbred wool composite prepared from seed 2, a gold concentration of $4.2 \times 10^{-4} \mathrm{M}$ and a $\left[\mathrm{Au}^{3+}\right]:\left[\mathrm{NH}_{2} \mathrm{OH}\right]$ concentration ratio of $1: 128$. 433

Figure 8.48: Kubelka Munk transformed UV/Vis reflection spectra of composites prepared from seed 1 and seed 3, with a gold concentration of $6.77 \times 10^{-4} \mathrm{M}$ and a $\left[\mathrm{Au}^{3+}\right]:\left[\mathrm{NH}_{2} \mathrm{OH}\right]$ concentration ratio of $1: 128$. .435

Figure 8.49: Kubelka Munk transformed UV/Vis reflection spectra of composites prepared from seed 1 , various gold concentrations and ratios of $\left[\mathrm{Au}^{3+}\right]:\left[\mathrm{NH}_{2} \mathrm{OH}\right]$. 435 
Figure 8.50: Kubelka Munk transformed UV/Vis reflection spectra of composites prepared from seed 4, various gold concentrations and ratios of $\left[\mathrm{Au}^{3+}\right]:\left[\mathrm{NH}_{2} \mathrm{OH}\right]$. 436

Figure 8.51: Gold nanoparticle-crossbred wool composites prepared from seed 1, a gold concentration of $4.2 \times 10^{-4} \mathrm{M}$ and $\mathrm{a}\left[\mathrm{Au}^{3+}\right]:\left[\mathrm{NH}_{2} \mathrm{OH}\right]$ ratio of $1: 16$ following simulated washability testing. .437

Figure 8.52: Kubelka Munk transformed UV/Vis reflection spectra of a gold nanoparticlecrossbred composite following washing at RT or $50^{\circ} \mathrm{C}$ .438

Figure 8.53: Increasing magnification (left to right) cross sectional SEM micrographs of silk seeds prepared with one hour soaking at RT followed by 24 hours at $50{ }^{\circ} \mathrm{C}$. Top: the gold solution had a $\mathrm{pH}$ of $\sim 3$, whilst the bottom had a $\mathrm{pH}$ of 9-10.

Figure 8.54: a) SEM micrographs of silk seeds prepared at RT, with a pH 3 gold solution, 10 minutes (left) and 1 hour reaction time (right ). Shows effect of increasing soaking time. .441

Figure 8.55: SEM micrographs of gold nanoparticle-silk composites prepared with a 6 hour soaking time and 24 hour heating time. a) Soaking in a gold solution of $\mathrm{pH} \mathrm{3,b)}$ and c) $\mathrm{pH}$ 9-10. Shows effect of increased $\mathrm{pH}$. 442

Figure 8.56: TEM micrographs of a silk seed prepared with a 6 hour soaking time in a pH 910 gold solution and 24 hours heating at $50{ }^{\circ} \mathrm{C}$. Left: Micrograph showing fibre surface and centre. Middle: Micrograph showing nanoparticles on the fibre surface and right: micrograph showing nanoparticles in the fibre centre. .442

Figure 8.57: Gold nanoparticle-silk composites prepared from seed 3 (top) and seed 8 (bottom), employing a gold concentration of $4.2 \times 10^{-4} \mathrm{M}$ or $6.77 \times 10^{-4} \mathrm{M}$, and a $\left[\mathrm{Au}^{3+}\right]:\left[\mathrm{NH}_{2} \mathrm{OH}\right]$ ratio of between $1: 16-1: 128$. 443

Figure 8.58: Gold nanoparticle-silk composites prepared from seeds 1, 2, 4, 5, 6, 7 and 9 (top to bottom), employing a gold concentration of $4.2 \times 10^{-4} \mathrm{M}$ or $6.77 \times 10^{-4} \mathrm{M}$, and $\mathrm{a}\left[\mathrm{Au}^{3+}\right]:\left[\mathrm{NH}_{2} \mathrm{OH}\right]$ ratio of between $1: 16-1: 128$. 443

Figure 8.59: Increasing magnification SEM micrographs of gold nanoparticle-silk composites prepared via the seed mediated approach. Top: incorporating seed 1 , a gold concentration of $4.2 \times 10^{-4} \mathrm{M}$ and a $\left[\mathrm{Au}^{3+}\right]:\left[\mathrm{NH}_{2} \mathrm{OH}\right]$ ratio of $1: 16$. Bottom: incorporating seed 1, a gold concentration of $6.8 \times 10^{-4} \mathrm{M}$ and a $\left[\mathrm{Au}^{3+}\right]:\left[\mathrm{NH}_{2} \mathrm{OH}\right]$ ratio of $1: 128$. .444

Figure 8.60: Cross sectional SEM micrograph of a gold nanoparticle-silk composite prepared via the seed mediated approach. .445

Figure 8.61: Kubelka Munk transformed UV/Vis reflection spectra of composites prepared from various seeds, with a gold concentration of $4.2 \times 10^{-4} \mathrm{M}$ and a a $\left[\mathrm{Au}^{3+}\right]:\left[\mathrm{NH}_{2} \mathrm{OH}\right]$ ratio of $1: 128$. .446

Figure 8.62: Kubelka Munk transformed UV/Vis reflection spectra of composites prepared from seed 9, with various gold concentrations and ratios of $\left[\mathrm{Au}^{3+}\right]:\left[\mathrm{NH}_{2} \mathrm{OH}\right] . .447$

Figure 8.63: Kubelka Munk transformed UV/Vis reflection spectra of composites prepared from seed 5, with various gold concentrations and ratios of $\left[\mathrm{Au}^{3+}\right]:\left[\mathrm{NH}_{2} \mathrm{OH}\right] . .448$ 
Figure 8.64: Left: Cross sectional SEM micrograph of a gold nanoparticle-silk composite prepared via the seed mediated approach and right: the corresponding EDS map.

Figure 8.65: EDS spectrum of the gold nanoparticle-silk composite shown in Figure 400..449

Figure 8.66: Gold nanoparticle-silk composites prepared from seed 1, a gold concentration of $4.2 \times 10^{-4} \mathrm{M}$ and $\mathrm{a}\left[\mathrm{Au}^{3+}\right]:\left[\mathrm{NH}_{2} \mathrm{OH}\right]$ ratio of $1: 16$ following simulated washability testing. 450

Figure 8.67: Kubelka Munk transformed UV/Vis reflection spectra of a gold nanoparticlesilk composite following simulated washability testing...... .451 


\section{LIST OF TABLES}

Table 1.1: New Zealand Wool Exports to the year ending September 2009 (\$NZ Million

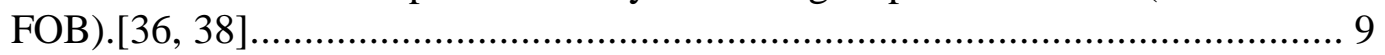

Table 1.2: Amino acid composition of merino wool.[41] ............................................ 10

Table 1.3: Functionality and concentration of side groups in the amino acids of silk fibroin

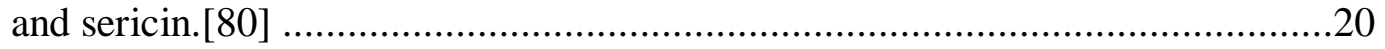

Table 2.1: Preparation of silver nanoparticles and subsequent attachment to clay substrate by a linker molecule.

Table 2.2: Preparation of silver nanoparticles by external reductants in the presence of clay substrate with in-situ binding of nanoparticles to clay.....

Table 2.3: ex-situ preparation of gold nanoparticles and subsequent attachment to wool fibres.

Table 2.4: Preparation of gold nanoparticles in the presence of merino by an external reductant with in-situ binding of nanoparticles to fibre.

Table 2.5: Preparation of gold nanoparticle-merino wool materials used as a seed source fo the preparation of gold nanorods.

Table 2.6: Single soaking solution. Soaking time and soaking solution composition...........56

Table 2.7: Multiple soaking solutions. Soaking times and soaking solution compositions. ...56

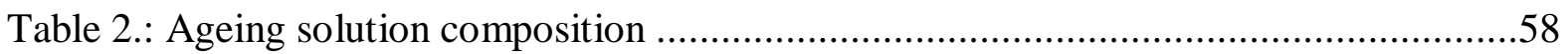

Table 2.9: Sample preparation for the determination of the chloride concentration. ............59

Table 2.10: Hydroxylamine seeded growth. Seed preparation. ${ }^{*}$........................................60

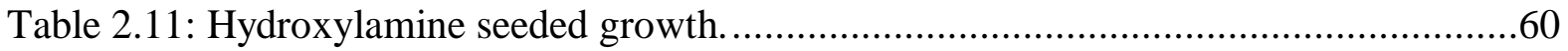

Table 3.1: UV/Vis $\lambda_{\max }$ values for the absorption spectra of silver nanoparticles prepared with

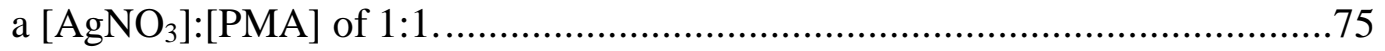

Table 3.2: UV/Vis $\lambda_{\max }$ values with an irradiation time of 120 minutes and increasing

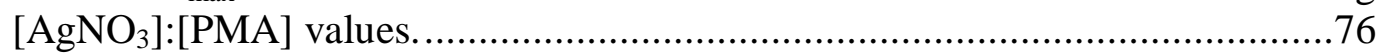

Table 3.3: XPS assignments of PMA and PMA capped silver nanoparticles produced via a photo induced reduction method......................................................................79

Table 3.4: XPS peak assignments for the high resolution Ag 3d XPS spectra of Ag-PMA-

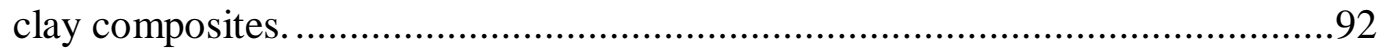

Table 3.5: XPS assignments for kaolinite, kaolinite-PDADMAC and PDADMAC...........100

Table 3.6: XPS assignments of Ag-PMA-kaolinite composites incorporating nanoparticles produced via a photo induced or $\mathrm{NaBH}_{4}$ reduction. 
Table 3.7: XPS assignments of Ag 3d in Ag-PMA-kaolinite composites incorporating nanoparticles prepared via photo induced or $\mathrm{NaBH}_{4}$ reduction. 104

Table 3.8: Vibrational assignments of Ag-PMA-clay composite materials. 111

Table 3.9: Inhibition zones of Staphylococcus aureus by Ag-PMA-clay composites 118

Table 4.1: L*, $\mathrm{a}^{*}, \mathrm{~b}^{*}, 457 \mathrm{~nm}$ brightness and $580 \mathrm{~nm}$ brightness values for gold nanoparticlemerino wool composites prepared by the ex-situ reduction of $\mathrm{Au}^{3+}$ to $\mathrm{Au}^{0}$ by TSC or TA. 137

Table 4.2: Au 4f XPS assignments for gold nanoparticle-merino wool composites prepared with 10 or $50 \mu \mathrm{L}$ of 1 or 10 wt $\%$ TSC or TA. 148

Table 4.3: XPS assignments for merino wool and gold nanoparticle-merino wool composites incorporating nanoparticles prepared with TSC. .154

Table 4.4: XPS assignments for gold nanoparticle-merino wool composites prepared with 1 $\mu \mathrm{L}$ of 1 wt $\%$ TA or $50 \mu \mathrm{L}$ of 10 wt \% TA. Showing peak N-Au and S-Au peak areas.

Table 4.5: XPS assignments for merino wool and gold nanoparticle-merino wool composites incorporating nanoparticles prepared with TA.

Table 4.6: Gold leached from gold nanoparticle-merino wool composites (incorporating colloids prepared with TSC or TA) following simulated washability testing....165

Table 5.1: $\mathrm{Au}^{3+}$ solutions employed when increasing the concentration of $\mathrm{Au}^{3+}$. All systems were used with $0.1 \mathrm{~g}$ untreated semi-worsted merino wool.

Table 5.2: $\mathrm{Au}^{3+}$ solutions employed in the attempted production of vibrant pink coloured composites. .205

Table 5.3: Absorption of $\mathrm{Au}^{3+}$ by untreated semi-worsted merino wool from a $320 \mathrm{ppm}$ (1.6 $\left.\mathrm{x} 10^{-3} \mathrm{M}\right) \mathrm{Au}^{3+}$ solution at RT.

Table 5.4: CIE $\mathrm{a}^{*}$ and $\mathrm{b}^{*}$ values for gold nanoparticle-merino wool composites prepared from alternate ageing solutions. Employing a $160 \mathrm{ppm}\left(8.13 \times 10^{-4} \mathrm{M}\right) \mathrm{Au}^{3+}$ solution, a soaking time, at RT of 24 hours and ageing times at $50{ }^{\circ} \mathrm{C}$ of $24-168$ hours.

Table 5.5: CIE $\mathrm{a}^{*}$ and $\mathrm{b}^{*}$ values of gold nanoparticle-merino wool composites, prepared with a gold concentration of $160 \mathrm{ppm}\left(8.13 \times 10^{-4} \mathrm{M}\right)$, soaking time of 24 hours and ageing time, at $50{ }^{\circ} \mathrm{C}$ of $168 \mathrm{~h}$. Shows the effect of the soaking solution $\mathrm{pH}$...233

Table 5.6: CIE L*, a* and $\mathrm{b}^{*}$ values of gold nanoparticle-merino wool composites prepared from $\mathrm{HCl}$ or $\mathrm{KOH} / \mathrm{EtOH}$ pre-treated merino wool (top three data rows) and untreated merino wool (bottom data row). .236

Table 5.7: CIE $a^{*}$ and $b^{*}$ values of gold nanoparticle-merino wool composites prepared from $\mathrm{Cl} / \mathrm{H}$ treated and untreated merino wool 236

Table 5.8: CIE L*, a* and $b^{*}$ values of gold nanoparticle-merino wool composites prepared from untreated or base treated $\mathrm{Cl} / \mathrm{H}$ treated merino wool. Employing a $\mathrm{Au}^{3+}$ 
concentration of $160 \mathrm{ppm}\left(8.13 \times 10^{-4} \mathrm{M}\right)$ and a soaking time, at RT of 24 hours.

Table 5.9: CIE $\mathrm{a}^{*}$ and $\mathrm{b}^{*}$ values for gold nanoparticle-merino wool composites prepared from Soxhlet treated worsted merino wool and untreated worsted merino wool.

Table 5.10: Amount of gold present on or near the the surface of gold nanoparticle-merino wool composites prepared with a $\mathrm{Au}^{3+}$ concentration of $160 \mathrm{ppm}\left(8.13 \times 10^{-4} \mathrm{M}\right)$ $\mathrm{Au}^{3+}$ solution, a soaking time at RT of 24 hours and various ageing times. Determined by XPS. .254

Table 5.11: Au 4f XPS assignments for gold nanoparticle-merino wool composites prepared with $160 \mathrm{ppm}\left(8.13 \times 10^{-4} \mathrm{M}\right) \mathrm{Au}^{3+}$ solutions. .255

Table 5.12: XPS assignments for untreated semi-worsted merino wool and gold nanoparticlemerino wool composites (prepared by soaking untreated semi-worsted merino wool in a $160 \mathrm{ppm}\left(8.13 \times 10^{-4} \mathrm{M}\right) \mathrm{Au}^{3+}$ solution for 24 hours at RT, followed by ageing at $50{ }^{\circ} \mathrm{C}$ for 24 or 168 hours). 270

Table 5.13: XPS assignments of untreated semi-worsted merino wool and gold nanoparticlemerino wool composite materials, prepared with altered soaking and ageing solutions, soaking times and ageing temperatures. .276

Table 5.14: XPS assignments for $\mathrm{KOH} / \mathrm{MeOH}$ treated semi-worsted merino wool and gold nanoparticle-merino wool composites (prepared by soaking $\mathrm{KOH} / \mathrm{MeOH}$ treated semi-worsted merino wool in a $160 \mathrm{ppm}\left(8.13 \times 10^{-4} \mathrm{M}\right) \mathrm{Au}^{3+}$ solution for 24 hours at RT, followed by ageing at $50{ }^{\circ} \mathrm{C}$ for 24 or 168 hours). .276

Table 5.15: XPS assignments for a gold nanoparticle-merino wool composite material employing worsted merino wool as the fibre substrate, $\mathrm{a} \mathrm{Au}^{3+}$ concentration of $160 \mathrm{ppm}\left(8.13 \times 10^{-4} \mathrm{M}\right)$, a soaking time, at RT, of 24 hours and an ageing time, at $50^{\circ} \mathrm{C}$ or 168 hours. .279

Table 5.16: XPS assignments for $\mathrm{Cl} / \mathrm{H}$ treated semi-worsted merino wool and gold nanoparticle-merino wool composites (prepared by soaking $\mathrm{Cl} / \mathrm{H}$ treated merino wool in a $160 \mathrm{ppm}\left(8.13 \times 10^{-4} \mathrm{M}\right) \mathrm{Au}^{3+}$ solution for 24 hours at RT, followed by ageing at $50{ }^{\circ} \mathrm{C}$ for 168 hours). .284

Table 5.17: XPS assignments for $\mathrm{KOH}$ pre-treated $\mathrm{Cl} / \mathrm{H}$ treated semi-worsted merino wool and gold nanoparticle-merino wool composites (prepared by soaking $\mathrm{KOH}$ pretreated $\mathrm{Cl} / \mathrm{H}$ treated merino wool in a $160 \mathrm{ppm}\left(8.13 \times 10^{-4} \mathrm{M}\right) \mathrm{Au}^{3+}$ solution for 24 hours at RT, followed by ageing at $50{ }^{\circ} \mathrm{C}$ for 168 hours). 286

Table 5.18: $\mathrm{Au}$ 4f XPS assignments for merino wool soaked in a $160 \mathrm{ppm}\left(8.13 \times 10^{-4} \mathrm{M}\right)$ $\mathrm{Au}^{3+}$ solution, at RT, for 1 or 24 hours. .290

Table 5.19: Au 4f XPS assignments for merino wool soaked in a $160 \mathrm{ppm}\left(8.13 \times 10^{-4} \mathrm{M}\right)$ $\mathrm{Au}^{3+}$ solution, at RT, for 1 or 24 hours, and gold nanoparticle-merino wool composites (prepared by soaking untreated semi-worsted merino wool in a 160 $\operatorname{ppm}\left(8.13 \times 10^{-4} \mathrm{M}\right) \mathrm{Au}^{3+}$ solution for 24 hours at RT, followed by ageing at 50 ${ }^{\circ} \mathrm{C}$ for 24 or 168 hours). 290 
Table 5.20: Relative percentage of sulfur species in untreated semi-worsted merino wool and merino wool soaked in a $160 \mathrm{pppm}\left(8.13 \times 10^{-4} \mathrm{M}\right) \mathrm{Au}^{3+}$ solution at RT for 1 or 24 hours.

Table 5.21: Relative percentage of sulfur species in untreated semi-worsted merino wool, wool soaked in $\mathrm{Au}^{3+}$ at RT, and gold nanoparticle-merino wool composites (prepared by soaking untreated semi-worsted merino wool in a $160 \mathrm{ppm}(8.13 \mathrm{x}$ $\left.10^{-4} \mathrm{M}\right) \mathrm{Au}^{3+}$ solution for 24 hours at RT, followed by ageing at $50{ }^{\circ} \mathrm{C}$ for 24 or 168 hours). .294

Table 5.22: Vibrational assignments of untreated semi-worsted merino wool and a gold nanoparticle-merino wool composite. 301

Table 5.23: S 2p XPS assignments of untreated TCEP treated and alkylated merino wool, and a gold nanoparticle-merino wool composite prepared from these fibres. .306

Table 5.24: Results of industry standard colour fastness and light fastness tests. Note: the values in brackets are the obtainable grades, with the lowest being poor and highest excellent.

Table 5.25: Gold leached from gold nanoparticle-merino wool composites (prepared by soaking untreated semi-worsted merino wool in a $160 \mathrm{ppm}\left(8.13 \times 10^{-4} \mathrm{M}\right) \mathrm{Au}^{3+}$ solution for 24 hours at RT, followed by ageing at $50{ }^{\circ} \mathrm{C}$ for 24 or 168 hours) following simulated washability testing. 318

Table 5.26: Results of Tineola bisselliella (moth larvae) bioassays. Note, \% pupation refers to the $\%$ of moth larvae reaching the pupa stage, the stage of metamorphosis that immediately precedes the adult stage. 320

Table 5.27: Results of Anthrenocerus flavipes (beetle larvae) bioassays. Note, \% pupation refers to the $\%$ of moth larvae reaching the pupa stage, the stage of metamorphosis that immediately precedes the adult stage. .321

Table 6.1: Amount of gold present in gold nanoparticle-crossbred wool composites prepared by soaking the fibres in a $160 \mathrm{ppm}\left(8.13 \times 10^{-4} \mathrm{M}\right) \mathrm{Au}^{3+}$ solution for 24 hours at $\mathrm{RT}$, followed by ageing at $50{ }^{\circ} \mathrm{C}$ for 24 or 168 hours. .345

Table 6.2: Absorption of gold by crossbred and merino wool at RT. A $\mathrm{Au}^{3+}$ concentration of $160 \mathrm{ppm}\left(8.13 \times 10^{-4} \mathrm{M}\right)$ was employed. 347

Table 6.3: XPS assignments of crossbred wool and gold nanoparticle-crossbred wool composite materials, prepared by soaking crossbred wool in a $160 \mathrm{ppm}(8.13 \mathrm{x}$ $\left.10^{-4} \mathrm{M}\right) \mathrm{Au}^{3+}$ solution for 24 hours at RT, followed by ageing at $50{ }^{\circ} \mathrm{C}$ for 168 hours.

Table 6.4: Amount of gold present in crossbred wool soaked in $\mathrm{Au}^{3+}$ and gold nanoparticlecrossbred wool composite materials. .351

Table 6.5: Gold leached from gold nanoparticle-crossbred wool composites (prepared by soaking crossbred wool in a $160 \mathrm{ppm}\left(8.13 \times 10^{-4} \mathrm{M}\right) \mathrm{Au}^{3+}$ solution for 24 hours at RT, followed by ageing at $50{ }^{\circ} \mathrm{C}$ for 24 or 168 hours) following simulated washability testing. .353 
Table 7.1: CIE a* values for gold nanoparticle-silk composites prepared by soaking silk in a $160 \mathrm{ppm}\left(8.13 \times 10^{-4} \mathrm{M}\right) \mathrm{Au}^{3+}$ solution, with a pH of $2.7,7$ or 9-10 for 24 or 6 hours at RT, followed by ageing at $50{ }^{\circ} \mathrm{C}$ for 24 hours. .365

Table 7.2: XPS assignments for silk and a gold nanoparticle-silk composite (prepared by soaking silk in a $160 \mathrm{ppm}\left(8.13 \times 10^{-4} \mathrm{M}\right) \mathrm{Au}^{3+}$ solution, with a $\mathrm{pH}$ of 9-10 for 6 hours at RT, followed by ageing at $50{ }^{\circ} \mathrm{C}$ for 24 hours).[212]. 378

Table 7.3: XPS assignments of a $\mathrm{pH} 2.7 \mathrm{Au}^{3+}$ soaking solution following the soaking of silk fibres at RT. .384

Table 7.4: Gold leached from gold nanoparticle-silk composites (prepared by soaking silk in a $160 \mathrm{ppm}\left(8.13 \times 10^{-4} \mathrm{M}\right) \mathrm{Au}^{3+}$ solution, with a $\mathrm{pH}$ of 2.7 or $9-10$ for 6 or 24 hours at RT, followed by ageing at $50{ }^{\circ} \mathrm{C}$ for 168 or 24 hours respectively) following simulated washability testing. 389

Table 8.1: Seed source preparation. Note, $0.1 \mathrm{~g}$ of merino wool was used in each system. .393

Table 8.2: Relative percentage of $\mathrm{Au}^{0}$ and $\mathrm{Au}^{3+}$ present in the seeds 1 and 7. Illustrating the effect of prolonged heating. .394

Table 8.3: CIE L*, $\mathrm{a}^{*}, \mathrm{~b}^{*}, 457 \mathrm{~nm}$ brightness and $580 \mathrm{~nm}$ brightness values for composites prepared using a gold solution concentration of $2.50 \times 10^{-4}$ moldm $^{-3}$. Shows the effect of increasing the ratio of $\left[\mathrm{Au}^{3+}\right]:\left[\mathrm{NH}_{2} \mathrm{OH}\right]$ (refer toFigure 344-Figure 347 for pictures of these materials). 407

Table 8.4: CIE L*, a*, b* $457 \mathrm{~nm}$ brightness and $580 \mathrm{~nm}$ brightness values of composites prepared from seeds $2,5,7,8-10$, with a $\left[\mathrm{Au}^{3+}\right]:\left[\mathrm{NH}_{2} \mathrm{OH}\right]$ ratio of $1: 128$. Illustrates the effect of increasing gold concentrations. (Refer to Figure 355 and Figure 356 for pictures of these materials). 410

Table 8.5: XPS assignments for merino wool, seed 5, and a gold nanoparticle-merino wool composite (prepared from seed 5, a gold concentration of $4.2 \times 10^{-4} \mathrm{M}$ and a $\left[\mathrm{Au}^{3+}\right]:\left[\mathrm{NH}_{2} \mathrm{OH}\right]$ concentration ratio of $\left.1: 16\right)$. 420

Table 8.6: CIE L*, a*, $\mathrm{b}^{*}, 457 \mathrm{~nm}$ brightness and $580 \mathrm{~nm}$ brightness values of a gold nanoparticle-merino wool composite following simulated washability testing. 426

Table 8.7: Gold leached from a gold nanoparticle-merino wool composite (prepared via the seed mediated approach) and the corresponding seed source following simulated washability testing. .427

Table 8.8: Gold nanoparticle-crossbred wool seed source preparation. .430

Table 8.9: Gold leached from a gold nanoparticle-crossbred composite (prepared via the seed mediated approach) and the corresponding seed source following simulated washability testing.

Table 8.10: Gold nanoparticle-silk seed source preparation. (Note a gold concentration of 160 $\operatorname{ppm}\left(8.125 \times 10^{-4} \mathrm{M}\right)$ was employed in the synthesis). 440

Table 8.11: Gold leached from a gold nanoparticle-silk composite (prepared via the seed mediated approach) and the corresponding seed source following simulated washability testing. 452 
Table 9.1: Estimated cost of silver nanoparticle-clay composite materials and gold nanoparticle-fibre composite materials. Based on the amount of silver and gold used in their production.*. .458

Table 10.1: CIE L*, a*, b*, 457 brightness and 580 brightness values following simulated washability tests for gold nanoparticle-merino wool composites incorporating TSC prepared nanoparticles.

Table 10.2: CIE L*, a*, b*, 457 brightness and 580 brightness values following simulated washability tests for gold nanoparticle-merino wool composites incorporating TA prepared nanoparticles.

Table 10.3: CIE L*, a*, $\mathrm{b}^{*}, 457 \mathrm{~nm}$ brightness and $580 \mathrm{~nm}$ brightness values of gold nanoparticle-merino wool composites prepared by soaking untreated merino wool in an 80, 120 or $160 \mathrm{ppm} \mathrm{Au}^{3+}\left(4.06,6.09\right.$ or $\left.8.13 \times 10^{-4} \mathrm{M}\right)$ solution for 24 hours at RT followed by ageing at $50{ }^{\circ} \mathrm{C}$ for $24-168$ hours. Shows the effect of increased gold concentrations and ageing times on colour development. .460

Table 10.4: CIE L* a*, b*, $457 \mathrm{~nm}$ brightness and $580 \mathrm{~nm}$ brightness values for gold nanoparticle-merino wool composites prepared from alternate ageing solutions. Employing a $160 \mathrm{ppm}\left(8.13 \times 10^{-4} \mathrm{M}\right) \mathrm{Au}^{3+}$ solution, a soaking time, at RT of 24 hours and ageing times at $50{ }^{\circ} \mathrm{C}$ of $24-168$ hours. 461

Table 10.5: CIE L*, a*, $\mathrm{b}^{*}, 457 \mathrm{~nm}$ brightness and $580 \mathrm{~nm}$ brightness values of gold nanoparticle-merino wool composites prepared by soaking untreated merino wool in an 80, 120 or $160 \mathrm{ppm} \mathrm{Au}^{3+}\left(4.06,6.09\right.$ or $\left.8.13 \times 10^{-4} \mathrm{M}\right)$ solution for 24 hours at RT followed by ageing at $80{ }^{\circ} \mathrm{C}$ for $24-168$ hours. Shows the effect of ageing temperature on colour development 461

Table 10.6: CIE L*, a*, $\mathrm{b}^{*}, 457 \mathrm{~nm}$ brightness and $580 \mathrm{~nm}$ brightness values of gold nanoparticle-merino wool composites prepared by soaking untreated merino wool in a $160 \mathrm{ppm} \mathrm{Au}^{3+}\left(8.13 \times 10^{-4} \mathrm{M}\right)$ solution with a $\mathrm{pH}$ of 7 or 10 for 24 hours at RT followed by ageing at $50{ }^{\circ} \mathrm{C}$ for 168 hours. Shows the effect of $\mathrm{pH}$ of the soaking solution on colour development. 462

Table 10.7: CIE L*, a*, $\mathrm{b}^{*}, 457 \mathrm{~nm}$ brightness and $580 \mathrm{~nm}$ brightness values of gold nanoparticle-merino wool composites prepared by soaking untreated merino wool in a $160 \mathrm{ppm} \mathrm{Au}^{3+}\left(8.13 \times 10^{-4} \mathrm{M}\right)$ solution with a $\mathrm{pH}$ of 3 for 24 hours at RT followed by adjusting the $\mathrm{pH}$ to $4,7,9$ or 12 and ageing at $50{ }^{\circ} \mathrm{C}$ for $24-168$ hours. Shows the effect of $\mathrm{pH}$ of the ageing solution on colour development...462

Table 10.8: CIE L*, a*, $\mathrm{b}^{*}, 457 \mathrm{~nm}$ brightness and $580 \mathrm{~nm}$ brightness values of gold nanoparticle-merino wool composites prepared by soaking untreated merino wool processed via the worsted route in a $160 \mathrm{ppm} \mathrm{Au}^{3+}\left(8.13 \times 10^{-4} \mathrm{M}\right)$ solution for 24 hours at RT followed by ageing at $50{ }^{\circ} \mathrm{C}$ for $24-168$ hours. .463

Table 10.9: CIE L*, a*, $\mathrm{b}^{*}, 457 \mathrm{~nm}$ brightness and $580 \mathrm{~nm}$ brightness values of gold nanoparticle-merino wool composites prepared by soaking Soxhlet pre-treated merino wool processed via the worsted route in a $160 \mathrm{ppm} \mathrm{Au}^{3+}\left(8.13 \times 10^{-4} \mathrm{M}\right)$ solution for 24 hours at RT followed by ageing at $50{ }^{\circ} \mathrm{C}$ for 24 or 168 hours...463

Table 10.10: CIE L*, a*, b*, $457 \mathrm{~nm}$ brightness and $580 \mathrm{~nm}$ brightness values of gold nanoparticle-merino wool composites prepared by soaking merino wool in a 0.1 
$\mathrm{M} \mathrm{HCl}$ solution for 5,10 or 15 mins, followed by soaking in a $160 \mathrm{ppm} \mathrm{Au}^{3+}$ $\left(8.13 \times 10^{-4} \mathrm{M}\right)$ solution for 24 hours at RT and ageing at $50{ }^{\circ} \mathrm{C}$ for 168 hours. 463

Table 10.11: CIE L*, a*, b*, $457 \mathrm{~nm}$ brightness and $580 \mathrm{~nm}$ brightness values of gold nanoparticle-merino wool composites prepared by soaking merino wool in a 0.1 $\mathrm{M} \mathrm{KOH} / \mathrm{EtOH}$ solution for 5, 10 or $15 \mathrm{mins}$, followed by soaking in a $160 \mathrm{ppm}$ $\mathrm{Au}^{3+}\left(8.13 \times 10^{-4} \mathrm{M}\right)$ solution for 24 hours at RT and ageing at $50{ }^{\circ} \mathrm{C}$ for 168 hours. .464

Table 10.12: CIE L*, a*, $\mathrm{b}^{*}, 457 \mathrm{~nm}$ brightness and $580 \mathrm{~nm}$ brightness values of gold nanoparticle-merino wool composites prepared by soaking $\mathrm{Cl} / \mathrm{H}$ treated merino wool in an 80, 120 or $160 \mathrm{ppm} \mathrm{Au}^{3+}\left(4.06,6.09\right.$ or $\left.8.13 \times 10^{-4} \mathrm{M}\right)$ solution for 24 hours at RT followed by ageing at $50{ }^{\circ} \mathrm{C}$ for $24-168$ hours. .464

Table 10.13: CIE L*, a*, $\mathrm{b}^{*}, 457 \mathrm{~nm}$ brightness and $580 \mathrm{~nm}$ brightness values of gold nanoparticle-merino wool composites prepared by soaking base treated $\mathrm{Cl} / \mathrm{H}$ treated merino wool in a $160 \mathrm{ppm} \mathrm{Au}^{3+}\left(8.13 \times 10^{-4} \mathrm{M}\right)$ solution for 24 hours at $\mathrm{RT}$ followed by ageing at $50{ }^{\circ} \mathrm{C}$ for $24-168$ hours. .465

Table 10.14: Absorption of gold by untreated semi-worsted merino wool at RT or $50^{\circ} \mathrm{C}$. A $\mathrm{Au}^{3+}$ concentration of $160 \mathrm{ppm}\left(8.13 \times 10^{-4} \mathrm{M}\right)$ was eemployed. 465

Table 10.15: Absorption of gold by untreated semi-worsted merino wool at RT. $\mathrm{Au}^{3+}$ increased through the addition of more $\mathrm{Au}^{3+}$, constant wool:solution volume. 466

Table 10.16: Absorption of gold by untreated semi-worsted merino wool at RT. $\mathrm{Au}^{3+}$ increased by lowering the solvent volume. .466

Table 10.17: Gold absorption by untreated semi-worsted merino wool at RT. A $\mathrm{Au}^{3+}$ concentration of $160 \mathrm{ppm}\left(8.13 \times 10^{-4} \mathrm{M}\right)$ was employed. 467

Table 10.18: Gold absorption by untreated or treated semi-worsted merino wool. 468

Table 10.19: Gold absorption by untreated worsted and semi-worsted merino wool at RT. 468

Table 10.20: CIE Co-ordinates of a gold nanoparticle-merino wool composite (prepared by soaking untreated semi-worsted merino wool in a $160 \mathrm{ppm}\left(8.13 \times 10^{-4} \mathrm{M}\right) \mathrm{Au}^{3+}$ solution for 24 hours at RT, followed by heating at $50{ }^{\circ} \mathrm{C}$ for 24 hours) following washing. 469

Table 10.21: CIE Co-ordinates of a gold nanoparticle-merino wool composite (prepared by soaking untreated semi-worsted merino wool in a $160 \mathrm{ppm}\left(8.13 \times 10^{-4} \mathrm{M}\right) \mathrm{Au}^{3+}$ solution for 24 hours at RT, followed by heating at $50{ }^{\circ} \mathrm{C}$ for 168 hours) following washing. 469

Table 10.22: CIE L*, a*, b*, $457 \mathrm{~nm}$ brightness and $580 \mathrm{~nm}$ brightness values for gold nanoparticle-crossbred wool composite materials. 470

Table 10.23: CIE Co-ordinates of a gold nanoparticle-crossbred wool composite (prepared by soaking crossbred wool in a $160 \mathrm{ppm}\left(8.13 \times 10^{-4} \mathrm{M}\right) \mathrm{Au}^{3+}$ solution for 24 hours at RT, followed by heating at $50{ }^{\circ} \mathrm{C}$ for 168 hours) following washing. 471 
Table 10.24: CIE Co-ordinates of a gold nanoparticle-silk composite prepared by soaking silk in a $160 \mathrm{ppm}\left(8.13 \times 10^{-4} \mathrm{M}\right) \mathrm{Au}^{3+}$ solution with a pH of 2.7 for 24 hours at RT, followed by heating at $50{ }^{\circ} \mathrm{C}$ for $24-168$ hours.

Table 10.25: CIE Co-ordinates of a gold nanoparticle-silk composite prepared by soaking silk in a $160 \mathrm{ppm}\left(8.13 \times 10^{-4} \mathrm{M}\right) \mathrm{Au}^{3+}$ solution with a $\mathrm{pH}$ of $7,9-10$ or 12 for 10 minutes or 6 hours at RT, followed by heating at $50{ }^{\circ} \mathrm{C}$ for 24 hours. 472

Table 10.26: CIE Co-ordinates of a gold nanoparticle-silk composite (prepared by soaking silk in a $160 \mathrm{ppm}\left(8.13 \times 10^{-4} \mathrm{M}\right) \mathrm{Au}^{3+}$ solution with a pH of 2.7 for 24 hours at $\mathrm{RT}$, followed by heating at $50{ }^{\circ} \mathrm{C}$ for 168 hours) following washing. 472

Table 10.27: CIE Co-ordinates of a gold nanoparticle-silk composite (prepared by soaking silk in a $160 \mathrm{ppm}\left(8.13 \times 10^{-4} \mathrm{M}\right) \mathrm{Au}^{3+}$ solution with a $\mathrm{pH}$ of 9-10 for 6 hours at $\mathrm{RT}$, followed by heating at $50{ }^{\circ} \mathrm{C}$ for 24 hours) following washing. 473

Table 10.28: CIE L*, a*, $b^{*}, 457 \mathrm{~nm}$ brightness and $580 \mathrm{~nm}$ brightness values for composites prepared via the preliminary synthesis route, using a $\mathrm{NH}_{2} \mathrm{OH}$ concentration of $2.50 \times 10^{-4}$ moldm $^{-3}$ .474

Table 10.29: CIE L*, $\mathrm{a}^{*}, \mathrm{~b}^{*}, 457 \mathrm{~nm}$ brightness and $580 \mathrm{~nm}$ brightness values for composites prepared using a gold solution concentration of $2.50 \times 10^{-4}$ moldm $^{-3}$. 474

Table 10.30: CIE L*, $\mathrm{a}^{*}, \mathrm{~b}^{*}, 457 \mathrm{~nm}$ brightness and $580 \mathrm{~nm}$ brightness values for composites prepared using a gold solution concentration of $4.2 \times 10^{-4}$ moldm $^{-3}$. .475

Table 10.31: CIE L*, $\mathrm{a}^{*}, \mathrm{~b}^{*}, 457 \mathrm{~nm}$ brightness and $580 \mathrm{~nm}$ brightness values for composites prepared using a gold solution concentration of $6.8 \times 10^{-4}$ moldm $^{-3}$. 476

Table 10.32: CIE L*, $\mathrm{a}^{*}, \mathrm{~b}^{*}, 457 \mathrm{~nm}$ brightness and $580 \mathrm{~nm}$ brightness values for composites prepared using a gold solution concentration of $1.02 \times 10^{-3}$ moldm $^{-3}$. .478

Table 10.33: CIE L*, $\mathrm{a}^{*}, \mathrm{~b}^{*}, 457 \mathrm{~nm}$ brightness and $580 \mathrm{~nm}$ brightness values for composites prepared using a gold solution concentration of $1.35 \times 10^{-3}$ moldm $^{-3}$. .478

Table 10.34: CIE L*, a*, b*, $457 \mathrm{~nm}$ brightness and $580 \mathrm{~nm}$ brightness values for gold nanoparticle-silk composites. .479 


\section{LIST OF ABBREVIATIONS}

18-MEA: 18-methyleicosanoic acid

AA: Atomic absorption

Ag/PMA: PMA capped silver nanoparticles

Cl/H: Chlorine Hercosett

CTAB: Cetyl trimethylammonium bromide

DMSO: Dimethyl sulfoxide

EDS: Energy dispersive spectroscopy

PDADMAC: Polydiallyldimethylammonium chloride

PEI: Polyethyleneimine

PMA: Polymethacrylic acid

PVP: Polyvinylpyrrolidone

SEM: Scanning electron microscopy

SERS: Surface enhanced Raman spectroscopy

SPR: Surface plasmon reasonance

STEM: Scanning transmission electron microscopy

TA: Tannic acid

TCEP: Tris(2-carboxyethly)phosphine

TEM: Transmission electron microscopy

TSC: Trisodium citrate

Vit C: Ascorbic acid

XPS: X-ray photoelectron spectroscopy 


\section{INTRODUCTION}

\subsection{Background}

The development of new multi-functional materials based on the immobilization of nanostructures on the surface of numerous substrates has recently received growing interest from industry and academia.[1-3] Today a wide range of nanoparticles and nano-structures (materials with at least one dimension $<100 \mathrm{~nm}$ ) can be produced, and immobilized on substrates, introducing new properties to the end product.[4-8] Particular emphasis has been placed on the production of self-cleaning materials by means of surface modification with self-cleaning, anti-stain or anti-microbial coatings. Self-cleaning surfaces have been designed through the use of titanium dioxide nanoparticles which have the ability to act as photocatalysts under ultra violet light.[1] Anti-stain coatings have been prepared by the deposition of a fluorinated surface layer,[9] or a coating whose roughness mimics the wellknown lotus flower effect.[10, 11] Anti-microbial composites that utilize silver nanoparticles have also been prepared, and are abundant in the consumer market place in the form of antimicrobial clothing, wound dressings and water filtration systems.[2, 8, 12, 13]

Numerous methods have been employed for the inclusion of nanoparticles onto useable substrates including blending of nanoparticles in a polymeric matrix before spinning into synthetic fibres, $[14,15]$ or attaching nanoparticles to substrates by means of a linker molecule, such as polyethylene imine.[16, 17] Alternatively, layer-by-layer deposition methods, known as polyelectrolyte multi-layers, have been employed in which successive layers of oppositely charged polyelectrolytes (one of which acts to stabilise the desired nanoparticles) are absorbed onto the substrate surface.[2, 18] The immobilization of the polyelectrolyte layers generally occurs via electrostatic and/or hydrophobic interactions.

A significant challenge in the production of hybrid materials containing nanoparticles is combining the various components in such a way as to either retain the desirable properties of all precursor components, or express them in a synergistic manner. Often one or more of 
the properties inherent to these materials are lost; for example the broad spectrum of colours inherent to gold and silver nanoparticles.[8] Additionally, the majority of composite materials containing nanoparticles comprise synthetic fibres such as nylon, rayon or spandex, or minerals such as montmorillonite. There has been very little research into the production of composite materials containing nanoparticles and natural fibres, or the more common 1:1 alumino silicate minerals. Thus in this research it is proposed to produce composite materials of natural fibres (merino wool, crossbred wool and silk) and alumino silicate minerals (kaolinite and halloysite) with gold and silver nanoparticles.

Gold and silver are both valued precious metals, gold in particular has a rich and varied history and represents quality and worth within society, occupying a premier position in the world economy. Silver has a similar standard, however at a lesser value than gold. Traditionally both metals have been utilized in monetary, ornamental and jewellery applications in their respective yellow and white lustrous bulk metallic forms. However as the particle size of gold or silver is reduced to nano-dimensions (at least one dimension $<100$ $\mathrm{nm}$ ), visible absorptions take place and their traditional metallic colours are no longer observed. Instead gold and silver nanoparticles exhibit a variety of brilliant hues. The emitted colours are due to the well documented, classical effect, surface plasmon resonance (section 1.3.1) and are largely dependent upon the size and shape of the nanoparticles. Thus by controlling the formation of the nanoparticles, the resultant colour maybe specifically tuned.

Additionally, silver, and to a lesser extent gold, are known to actively inhibit the growth of microbes (sections 1.3.4.1 and 1.3.4.2). Nanoparticles of these materials exhibit increased chemical and anti-microbial activities due to their large effective surface areas and crystallographic surface structures.[12,19] This research intends to exploit these properties in the production of composite materials of gold and silver nanoparticles with natural fibres and minerals, with the metallic nanoparticles acting as simultaneous high-value colourfast colourants and anti-microbial agents. In doing so, the high-value and prestige associated with gold and to a lesser extent silver, will be transferred to the substrates, thereby linking the wealth associated with these metals to the natural fibres and minerals. 
The following introductory chapter provides a background to the various components that have been incorporated into composite materials throughout the course of this research.

\subsection{Substrates}

\subsubsection{Mineral Substrates}

The majority of research and development of composite materials containing clay minerals utilize montorillonite (MMT) as the substrate. MMT is a 2:1 alumino silicate, consisting of two-dimensional layers (or lamellae), which can easily be swollen (disaggregated), allowing for intercalation of numerous functional entities (conducting polymers, nanoparticles etc) between the lamellae, making these materials popular in the production of composite materials containing clays. Very little scientific literature exists on the use of common 1:1 alumino silicate minerals in composites containing nanoparticles. Hence kaolinite (section 1.2.1.1) and halloysite (section 1 .2.1.2) which are inexpensive, readily available and posses reasonably high surface areas, have been chosen as the substrates with which to prepare silver nanoparticle composites.

\subsubsection{Kaolinite}

Kaolinite $\left(\mathrm{Al}_{2} \mathrm{Si}_{2} \mathrm{O}_{5}(\mathrm{OH})_{4}\right)$ is a common alumino silicate formed through the weathering of aluminium rich silicate minerals such as feldspars. Kaolinite is classified as belonging to the silicate class, phyllosilicate subclass and more generally belonging to the clay group.[20] It is characterized by high reflectivity, inertness, fine particle size and low fluid viscosity. Because of these properties it has many industrial applications, notably in paper filling, the production of plastics, porcelain, ceramics and paint.[21]

Kaolinite is composed of silicate sheets $\left(\mathrm{SiO}_{2}\right)$ tightly bound to aluminium oxide/hydroxide layers $\left(\mathrm{Al}(\mathrm{OH})_{6}\right)$ otherwise known as gibbsite, with a basal $\left(d_{001}\right)$ spacing of $\sim 7 \AA$. [22] The silicate layer comprises $\mathrm{SiO}_{4}{ }^{4-}$ tetrahedra (Figure 1.1 [I][23]), arranged so that in a plane, one 
oxygen atom is bound to two silicon atoms, forming a sheet of silicon tetrahedron (Figure 1.1 [II][23]).

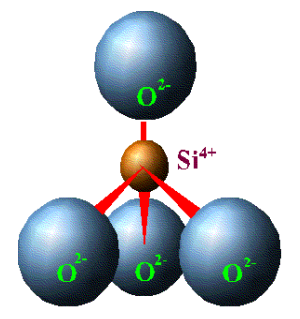

I

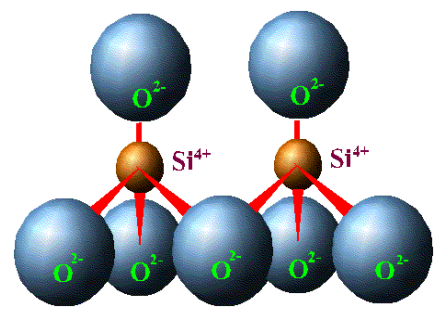

II

Figure 1.1: (I) $\mathrm{SiO}_{4}{ }^{4}$ tetrahedra. (II) Sheet of silicon tetrahedron.[23]

The gibbsite layer is based on the aluminium octahedral unit (Figure 1.2),[23] with the aluminium atom sharing +0.5 of its charge with each surrounding oxygen atom, resulting in a net charge of -1.5 . This charge is balanced as each corner oxygen is shared between two aluminium atoms, and the remaining oxygen atoms bond with hydrogen to form surface hydroxyl groups. Expansion of this arrangement in three dimensions forms the mineral gibbsite.

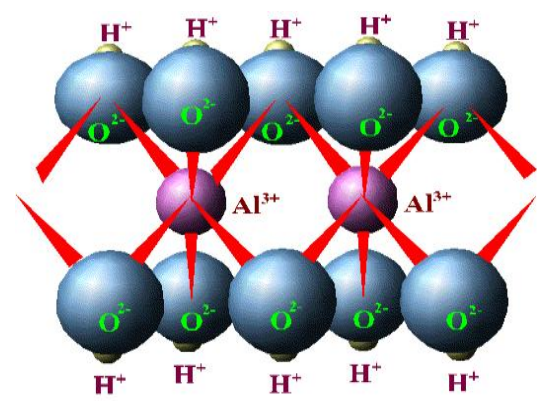

Figure 1.2: Gibbsite.[23]

Rather than balancing the charge in gibbsite with hydrogen atoms on each side, one hydroxyl layer can be replaced by a silicon tetrahedral layer, as is the case in kaolinite. This results in 
the apical oxygens of the tetrahedral layer also residing in the octahedral layer, forming a 1:1 kaolinite unit (Figure 1.3).[23]

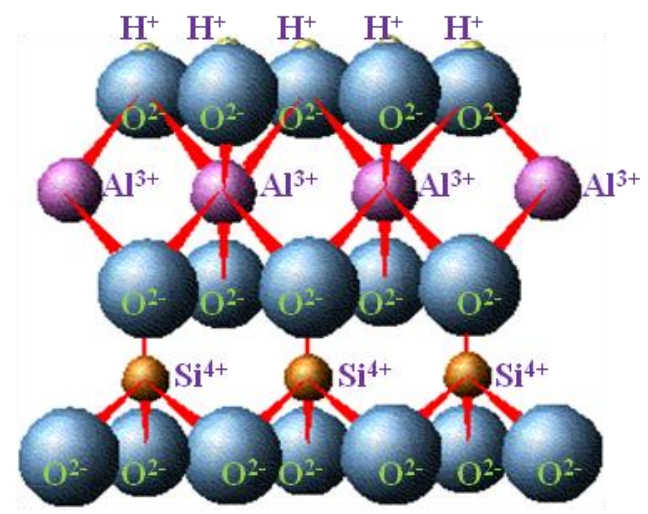

Figure 1.3: Combination of gibbsite and silicon tetrahedral layers.[23]

These 1:1 units come together through hydrogen bonding between the apical hydrogens of the gibbsite layer and the basal oxygens of the silicate later, resulting in the basic structure of kaolinite as shown in Figure 1.5.[23] Kaolinite is classed as a nanomaterial as it has one dimension less than $100 \mathrm{~nm}$ in diameter. Electron microscopy images illustrate the hexagonal plate-like structure typical of kaolinite (Figure 1.4).

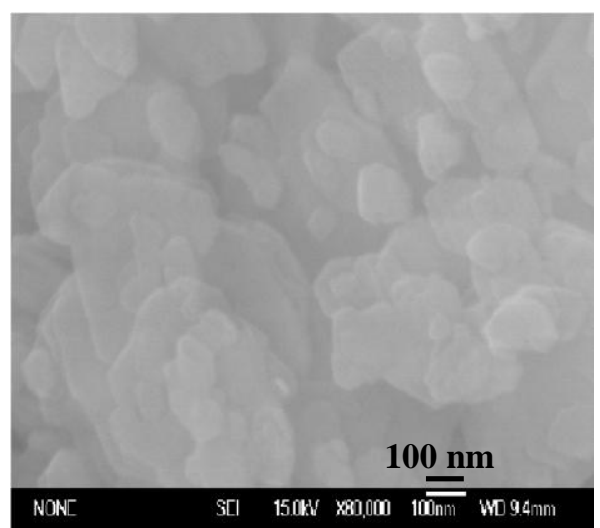

Figure 1.4: Scanning electron microscopy (SEM) micrograph of kaolinite. Characteristic hexagonal platelets are evident. 


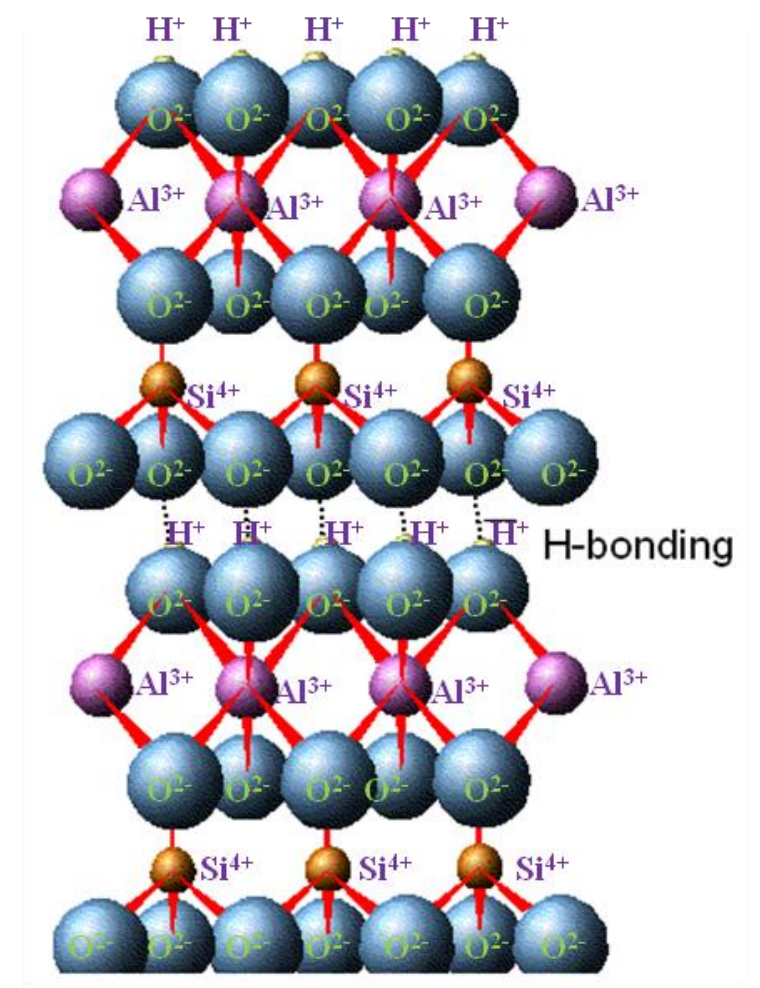

Figure 1.5: Kaolinite.[23]

\subsubsection{Halloysite}

The structure and chemical composition of halloysite is similar to that of kaolinite, however the unit layers are separated by a monolayer of water molecules (Figure 1.6).[22] As a result, hydrated halloysite (known as halloysite-(10 $\AA)$ ) has a basal $\left(d_{001}\right)$ spacing of $10 \AA$, approximately $3 \AA$ larger than that of kaolinite.[22] The water molecules in the interlayer spacings are only weakly held and can readily and irreversibly dehydrate to give the corresponding halloysite-(7 $\AA$ ).[24] Halloysite has the same theoretical chemical composition as kaolinite except for a higher water content, with the ideal formula for halloysite-(10 $\AA$ ) and halloysite- $(7 \AA)$ being $\mathrm{Al}_{2} \mathrm{Si}_{2} \mathrm{O}_{5}(\mathrm{OH})_{4} n \mathrm{H}_{2} \mathrm{O}$ where $n=2$ and 0 respectively.[22] 


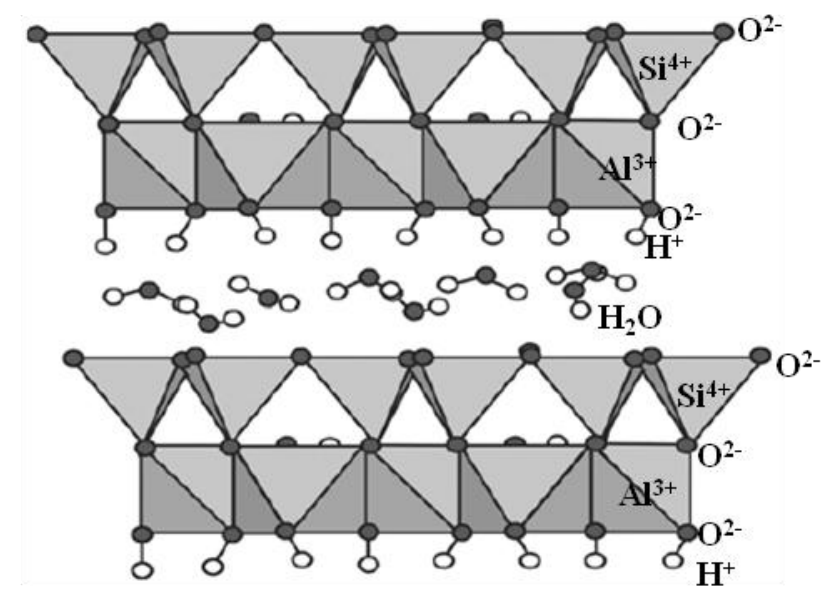

Figure 1.6: Crystalline structure of halloysite-(10 ̊̊).[22]

Particles of halloysite can adopt various morphologies, notably spherical (Figure 1.7 a),[25] tubular (Figure 1.7 b)[26] or plate-like (comparable to kaolinite (Figure 1.4)),[27] the most common of which is tubular. These tubules may be long and thin, short and stubby or emerge from other tubes, with lengths ranging from 0.02 to $>30 \mu \mathrm{m}$, and widths from $<0.05$ $\mu \mathrm{m}$ to $0.2 \mu \mathrm{m}$. Small tubules $(<0.08 \mu \mathrm{m}$ wide) commonly posses central cylindrical pores of between 5 to $20 \mathrm{~nm}$, whilst bigger tubules ( $>1 \mu \mathrm{m}$ wide) are largely filled so that there are virtually no cylindrical pores.[28]

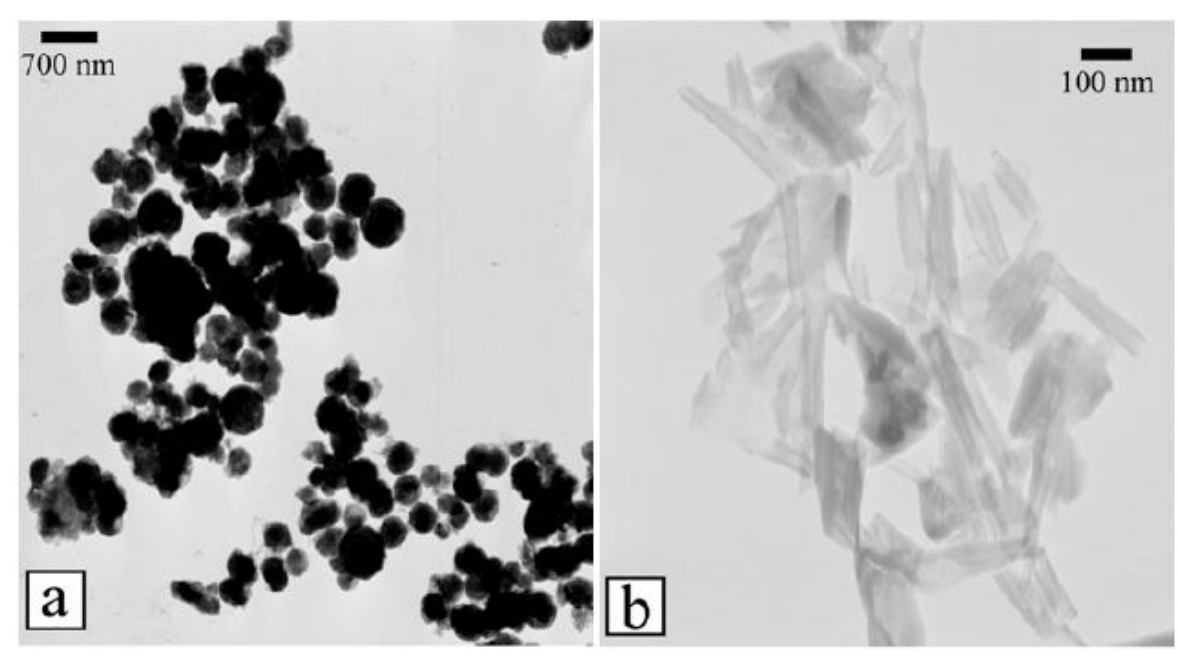

Figure 1.7: Transition electron microscopy (TEM) micrographs of various morphologies of halloysite; a) spherical and b) tubular.[22] 
Bates et al.[26] and Bailey[29] postulated that the tubular form of halloysite arises due to a misfit between the octahedral and tetrahedral sheets making up the 1:1 aluminosilicate layers. They suggested that in kaolinite there is tetrahedral rotation of the basal oxygens of the silicate sheets compensating for this mismatch, whereas in halloysite this rotation is blocked by water molecules absorbed in the interlayer. This tubular form of halloysite remains even after dehydration and removal of the interlayer waters, suggesting that tetrahedral rotation is also blocked by physical constraints.[30] Therefore in a very approximate way, the chemical properties of the outermost surface of halloysite can be associated with the properties of $\mathrm{SiO}_{2}$, and the properties of the inner surface of the cylindrical core with $\mathrm{Al}(\mathrm{OH})_{3}$.[31-34]

\subsubsection{Fibrous Substrates}

\subsubsection{Wool}

\subsection{Background}

The history of the New Zealand wool industry has been heavily influenced by New Zealand's climate, terrain, and world demand for sheep products. Consequently a wide range of wools are produced, suitable for a variety of end products.

Merino were the first permanent flock of sheep to be introduced to New Zealand, established on Mana Island, Wellington, by James Bell Wright in 1834.[35] It remained New Zealand's dominant breed until the late $19^{\text {th }}$ century, when it was replaced by the hardier Romney. In 2008 the number of sheep, of all breeds in New Zealand totalled approximately 38 million; with merino comprising an estimated $5 \%$,[36] and strong crossbred approximately $50 \%$.[37]

Merino is a specialty fine wool breed, providing a source of natural protein fibres that are utilized in numerous applications including clothing and interior furnishings within the textile industry. Strong crossbred wool comprises a group of thicker diameter wools (> 35.4 $\mu \mathrm{m})$, and finds application in carpet manufacture and coarse textiles. New Zealand is the 
largest exporter of crossbred wool, and second only to Australia in the export of all wools. The New Zealand wool sector accounts for approximately $1.3 \%$ of New Zealands total merchandise exports, however this figure has seen a significant decrease over the past years (Table 1.1),[36] with this trend continuing today. This is likely attributable to a reduction in sheep numbers due to an increase in the profitability of alternative types of farming, notably dairy and beef.[36, 38]

Table 1.1: New Zealand Wool Exports to the year ending September 2009 (\$NZ Million FOB).[36, 38]

\begin{tabular}{cccc}
\hline $\begin{array}{c}\text { Year } \\
\text { Ending } \\
\text { September }\end{array}$ & $\begin{array}{c}\text { Total Wool } \\
\text { Exports }\end{array}$ & $\begin{array}{c}\text { Total Merchandise } \\
\text { Exports }\end{array}$ & $\begin{array}{c}\text { Wool Sector as \% of Total } \\
\text { Merchandise Exports }\end{array}$ \\
\hline $\mathbf{1 9 9 5}$ & $1,478.7$ & $20,065.3$ & $\mathbf{7 . 4} \%$ \\
$\mathbf{2 0 0 1}$ & $1,170.8$ & $30,985.7$ & $\mathbf{3 . 8} \%$ \\
$\mathbf{2 0 0 2}$ & $1,115.0$ & $31,111.7$ & $\mathbf{3 . 6} \%$ \\
$\mathbf{2 0 0 3}$ & $1,121.4$ & $28,241.6$ & $\mathbf{4 . 0} \%$ \\
$\mathbf{2 0 0 4}$ & 726 & 30,048 & $\mathbf{2 . 4} \%$ \\
$\mathbf{2 0 0 5}$ & 663 & 30,770 & $\mathbf{2 . 2} \%$ \\
$\mathbf{2 0 0 6}$ & 685 & 33,868 & $\mathbf{2 . 0} \%$ \\
$\mathbf{2 0 0 7}$ & 625 & 34,591 & $\mathbf{1 . 8} \%$ \\
$\mathbf{2 0 0 8}$ & 613 & 41,973 & $\mathbf{1 . 5} \%$ \\
$\mathbf{2 0 0 9}$ & 528 & 39,667 & $\mathbf{1 . 3} \%$ \\
\hline
\end{tabular}

The current situation in the New Zealand wool industry presents an opportunity to add value to New Zealand wool, in particular premium merino, through the use of innovative science based on nanotechnology.

\subsection{Chemical Composition}

Wool belongs to a family of fibrous proteins known as $\alpha$-keratins. Keratins are common to higher vertebrates (reptiles, birds and mammals) and exercise a protective function. Wool fibres are over $90 \%$ keratin, with the remainder comprising lipids, waxes and saccharides. 
Keratin fibres have a characteristically high sulfur content, mainly present as the disulfidecontaining amino acid cystine. Twenty other amino acids, in various combinations depending on the breed and diet of the sheep, are found in wool (Table 1.2).[39] Depending on their side chains, these amino acids are either hydrophilic or hydrophobic, acidic or basic. In its ionized state, a deprotonated carboxylic acid group may be regarded as being basic, and a protonated amino group acidic, with the proportion of acidic and basic groups being approximately equal (800-850 $\mu \mathrm{mol} / \mathrm{g}$ of fibre of each).[39, 40]

Table 1.2: Amino acid composition of merino wool.[41]

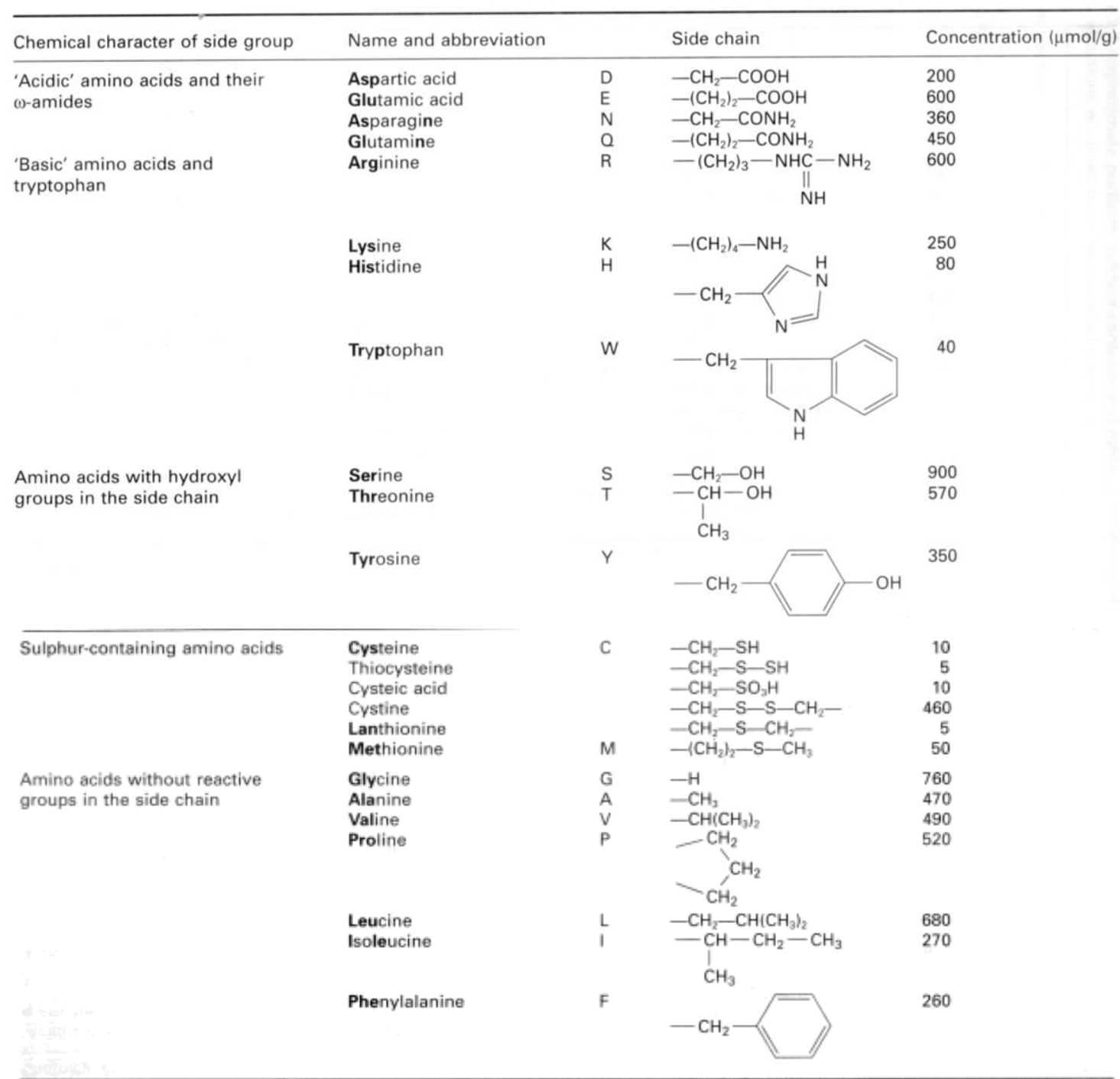

Individual polypeptide chains are joined together to form proteins by a variety of covalent bonds, called crosslinks, and non-covalent physical interactions (Figure 1.8).[42] The most important crosslinks in terms of strength are disulfide bonds formed between adjacent cystine 
groups (Figure 1.8). A second type of crosslinks are isopeptide bonds formed between glutamic or aspartic acid residues and lysine residues. In addition to covalent crosslinks, polypeptide chains are joined by hydrophobic and ionic bonds, due to interactions between amino acids with hydrocarbon side chains and acidic and basic side chains respectively (Figure 1.8).

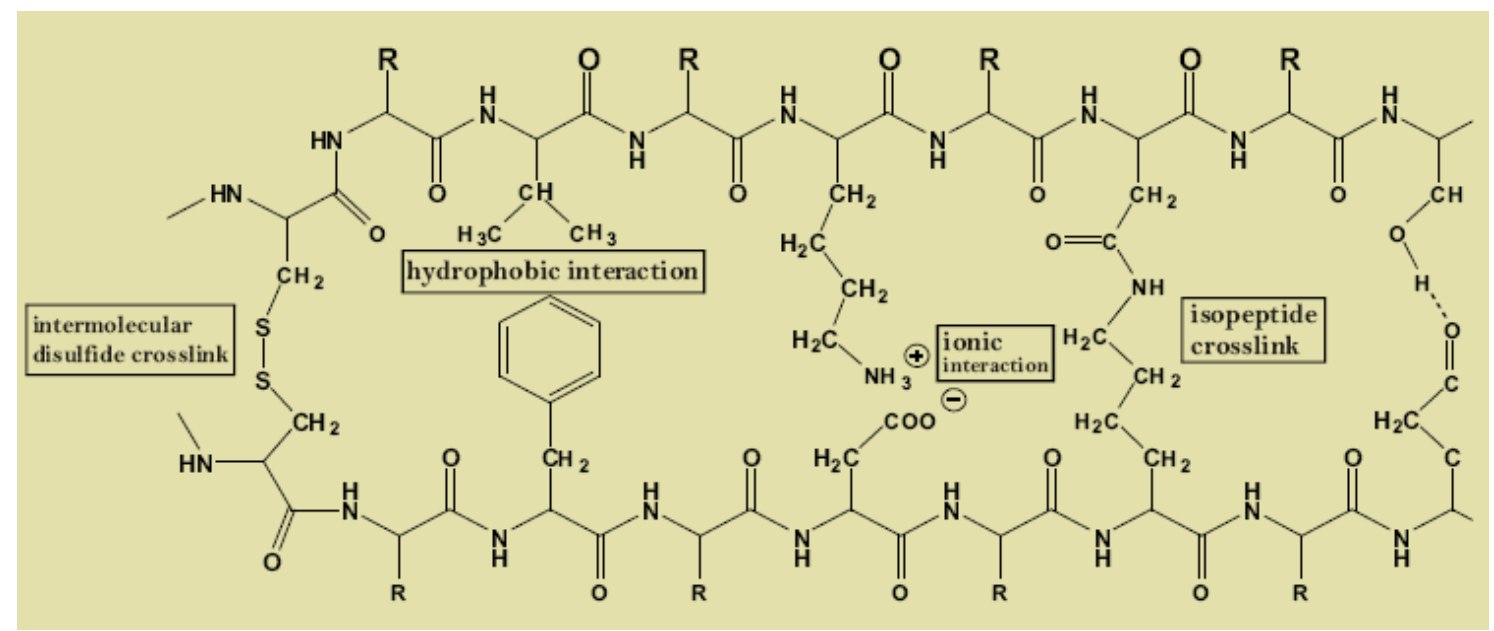

Figure 1.8: Diagram showing the numerous bonds liking adjacent polypeptide chains in wool keratin, notably intermolecular disulfide crosslinks, isopeptide crosslinks and hydrophobic and ionic interactions.[42]

In addition to proteins, wool contains about two percent internal and external lipids. The latter are commonly termed woolgrease and are almost completely removed by scouring and refined to produce lanolin. Internal lipids consist mainly of cholesterol, fatty acids and polar lipids.[39]

\subsection{Physical Properties}

Merino and other fine wool fibres contain two types of cells, notably flattened external cuticle cells and long, polyhedral cortical cells. In coarse wool fibres, such as seen in the New Zealand Drysdale, there is a third cellular component called the medulla. In medullated fibres, the cortex has a hollow core of cell remnants which runs through the centre of the 
fibre. These may either be fragmented (sporadic), interrupted, or continuous (Figure 1.9).[43] Medullated fibres are lower in density than non-medullated fibres, and as such take up dye in an irregular fashion, deeming them unsuitable for end use in apparel and high quality textiles. However they have found applications in carpet manufacture, where uniform dyeing is not always imperative.[35]

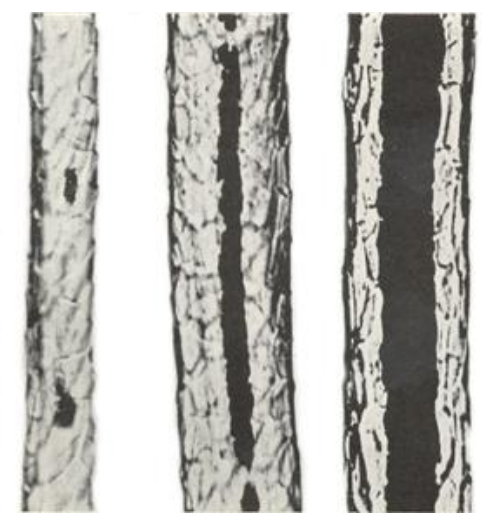

Figure 1.9: Image showing types of medulla that can occur in wool fibres. a) Fragmental, b) interrupted and c) continuous. [35]

The physical structure of the wool fibre is very complex, as shown in Figure 1.10.[39] The centre of the fibre comprises the cortex, which is divided into two sections called the paraand orthocortex. The paracortex possesses more sulfur than the orthocortex, and as such it is more highly crosslinked and tougher. The proportion of paracortical cells in crossbred wools is approximately 40-10\%, and orthocortical cells 60-90\%. Conversely, in merino wool fibres the paracortex is approximately 50-30\% of the total amount of the cortex, increasing with increasing fibre diameter.[44, 45] The structure within each cortical cell is intricate. Throughout each are remains of the cellular apparatus of once living cells, termed nuclear remnants.[46] In addition, there are successively smaller structural units, notably macrofibrils, microfibrils, protofibrils and twisted molecular chains ( $\alpha$-helices) of protein. 


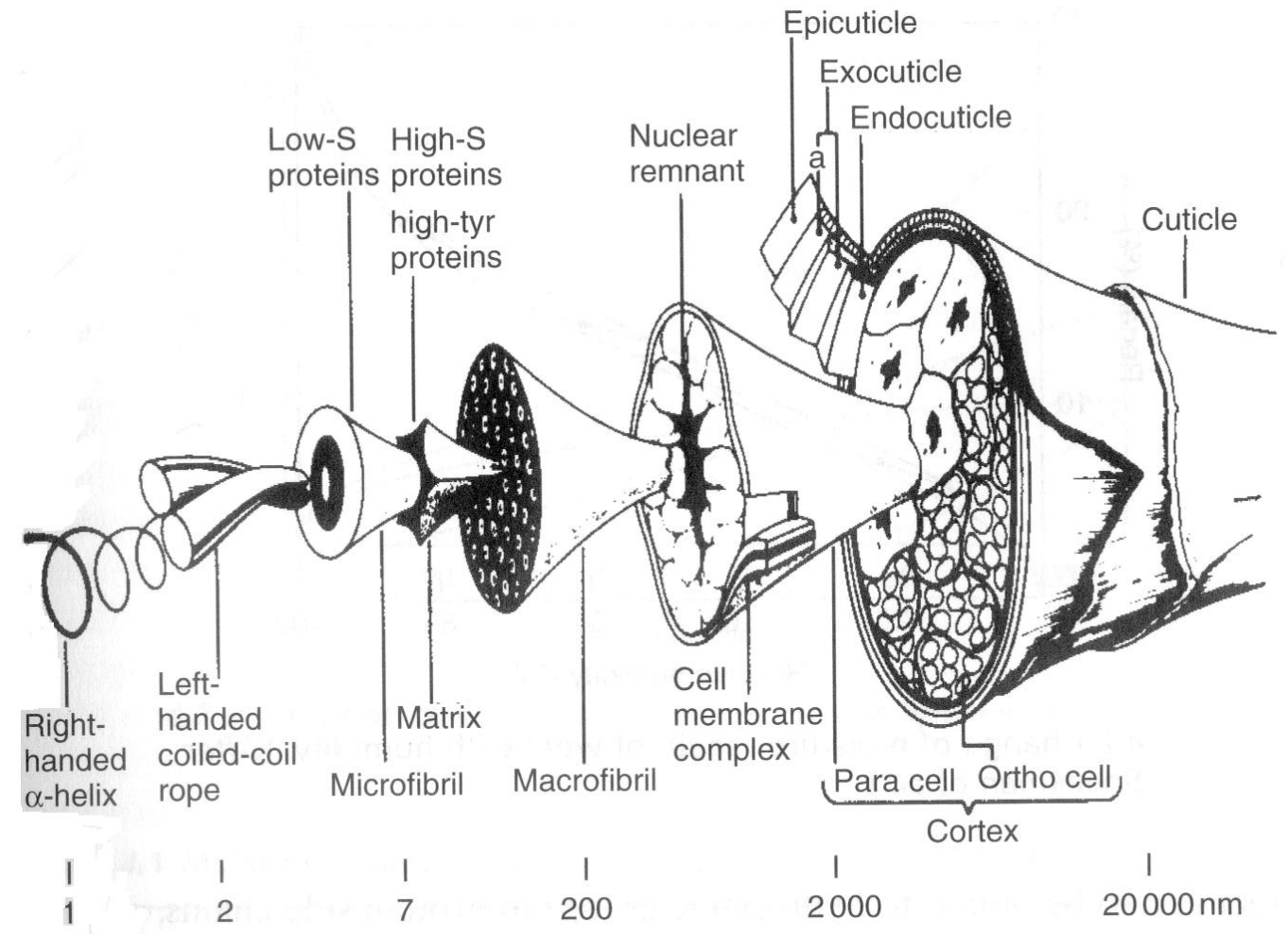

Figure 1.10: Structure of fine wool. Note, coarse wool may also contain a medulla, not shown here.[39]

The ortho- and paracortex can be approximated as hemicylinders (Figure 1.11),[47] wound around each other helically in phase with the crimp of the fibre.[48] This arrangement, which occurs during the growth of the fibres, produces a regular wave or crimp. The orthocortex is more absorbent than the paracortex, and as such, when moisture is absorbed the orthocortex is always found on the outside edge of the crimp curvature (Figure 1.12).[49]

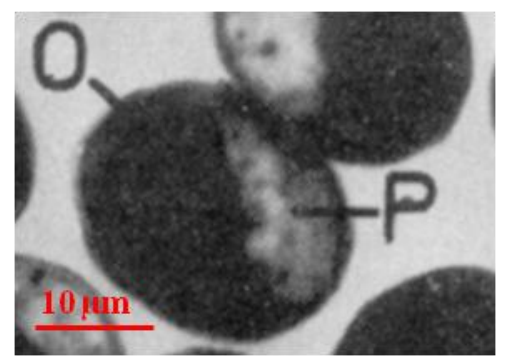

Figure 1.11: Light micrograph of cross sections of merino wool fibres stained to show the bilateral differentiation of the orthocortex $(O$; darkly stained) and paracortex (P; lightly stained).[46] 


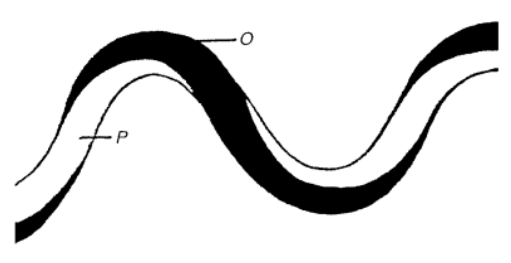

I

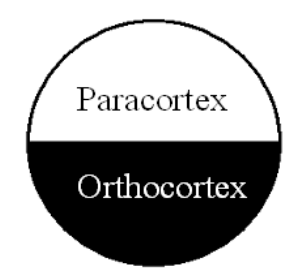

II

Figure 1.12: Schematic representation of the cortical structure and crimp of merino wool fibres; (I) side view and (II) cross sectional end view.[49]

The cuticle is the outermost layer of wool fibres, and consists of at least four layers, the epicuticle, the A- and B-layer of the exocuticle and the endocuticle. Both cuticle and cortical cells are separated from each other and the cortex by a cell membrane complex consisting of non-keratinous proteins and lipids.[49] Compared to the cortical cells, cuticle cells have a higher proportion of cystine, proline, serine and valine residues.[50] In merino wool, the cuticle cells are approximately $20 \mu \mathrm{m} \times 30 \mu \mathrm{m} \times 0.7 \mu \mathrm{m}$.[51] Cuticle cells overlap in the longitudinal direction of the fibre in a manner similar to that of roof tiles (Figure 1.13). A key function of cuticle cells is to both secure the fibres to the skin of the animal and keep it free of foreign objects. The scale edges always point outward from the root towards the tip (distal end) of the fibre, resulting in the coefficient of friction being less in the root to tip direction that than in the tip to root direction.[52] This directional friction effect acts as a self-cleaning mechanism, expelling dirt and vegetable matter lodged in the fibres of an animal.[46, 53] It is also the source of felting and shrinkage seen in wool.[35, 54]

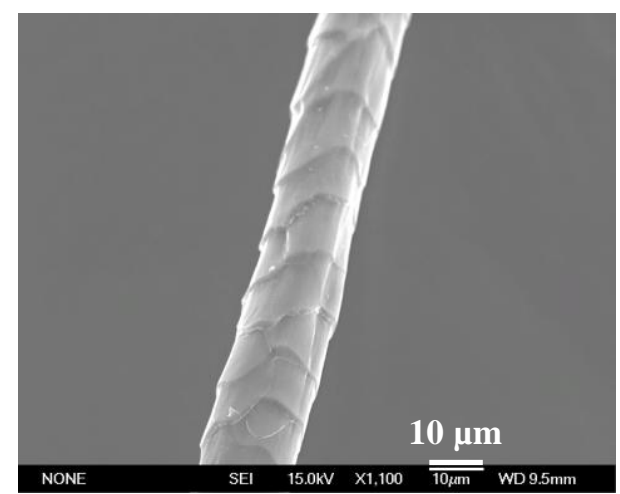

Figure 1.13: Scanning electron micrograph of a merino wool fibre. Overlapping cuticle cells are evident on the fibre surface. 
The A-layer (the outer layer of the exocuticle) is sulfur rich, consisting of $35 \% \mathrm{~S}$, and is characterised by a high degree of crosslinking via disulfide and isopeptide bonds. There is a high portion of the protein loricrin $(65-70 \%)$ which is rich in glycine, serine and cystine. The B-layer contains $20 \% \mathrm{~S}$ and is correspondingly less cross-linked than the A-layer. Conversely, the endocuticle is very low in $\mathrm{S}$, is more permeable and is the usual diffusion pathway for water and other reagents.[39]

The epicuticle is the outermost membrane of the cuticle, and is resistant to acids, alkalis, oxidizing agents and enzymatic attack.[55] It contains little or no phospholipids,[48] limiting the number of molecules that can diffuse through into the fibres. Because of its location on the exterior of the fibre, the epicuticle exerts a major influence on the surface properties of merino wool.

The epicuticle consists of approximately $75 \%$ protein and $25 \%$ lipid.[55-57] The protein component contains around $12 \%$ cystine,[57] and the lipid component a mixture of fatty acids, predominantly 18-methyleicosanoic acid (18-MEA) covalently bound to the protein most likely by means of a thio-ester bond through cysteine residues. [58] The presence of the fatty acid imparts a hydrophobic nature to the fibre surface, which can be very problematic in many important textile procedures such as dye uptake and polymer adhesion.[59, 60]

Alcoholic alkali treatment has been shown to reduce the hydrophobic nature of the epicuticle (wool surface) by means of removal of the bound fatty acid.[49, 55, 58, 60, 61] Comparisons of the treatment of merino wool with potassium $t$-butoxide in $t$-butanol (a surface-selective reagent),[55] and potassium hydroxide in methanol (a non-surface-selective reagent),[61] resulted in the former treatment removing only $65 \%$ fatty acid compared to the latter. This suggests that the fatty acid surrounds each individual cuticle cell, and that the overlap of cells and hindrance by the cell membrane complex makes it difficult for the bulky alkali to reach the bound fatty acid on the underlying cuticle surface. Alcoholic alkali treatment also results in partial oxidation of the fibre surface.[62] 
The epicuticle membrane is $5-7 \mathrm{~nm}$ thick, and 18 -MEA is approximately $2.8-3 \mathrm{~nm}$ long.[57, $63,64]$ Negri [55] proposed a model for the epicuticle in which the protein matrix is studded with fatty acid chains orientated in the lowest energy configuration, directed away from the fibre (Figure 1.14).[55] This model was supported by x-ray photoelectron spectroscopy, which detected a very high proportion of carbon in the outer $30 \AA$ of the cuticle cells, [56] and secondary ion mass spectroscopy, which yielded almost exclusively hydrocarbon fragments on the fibre surface. The protein component was proposed to be an ordered structure in which a repeating amino acid sequence is folded as a $\beta$-pleated sheet, arranged in such a way as to present an abundance of cysteine residues at the protein surface, which would be available for acylation.[55]

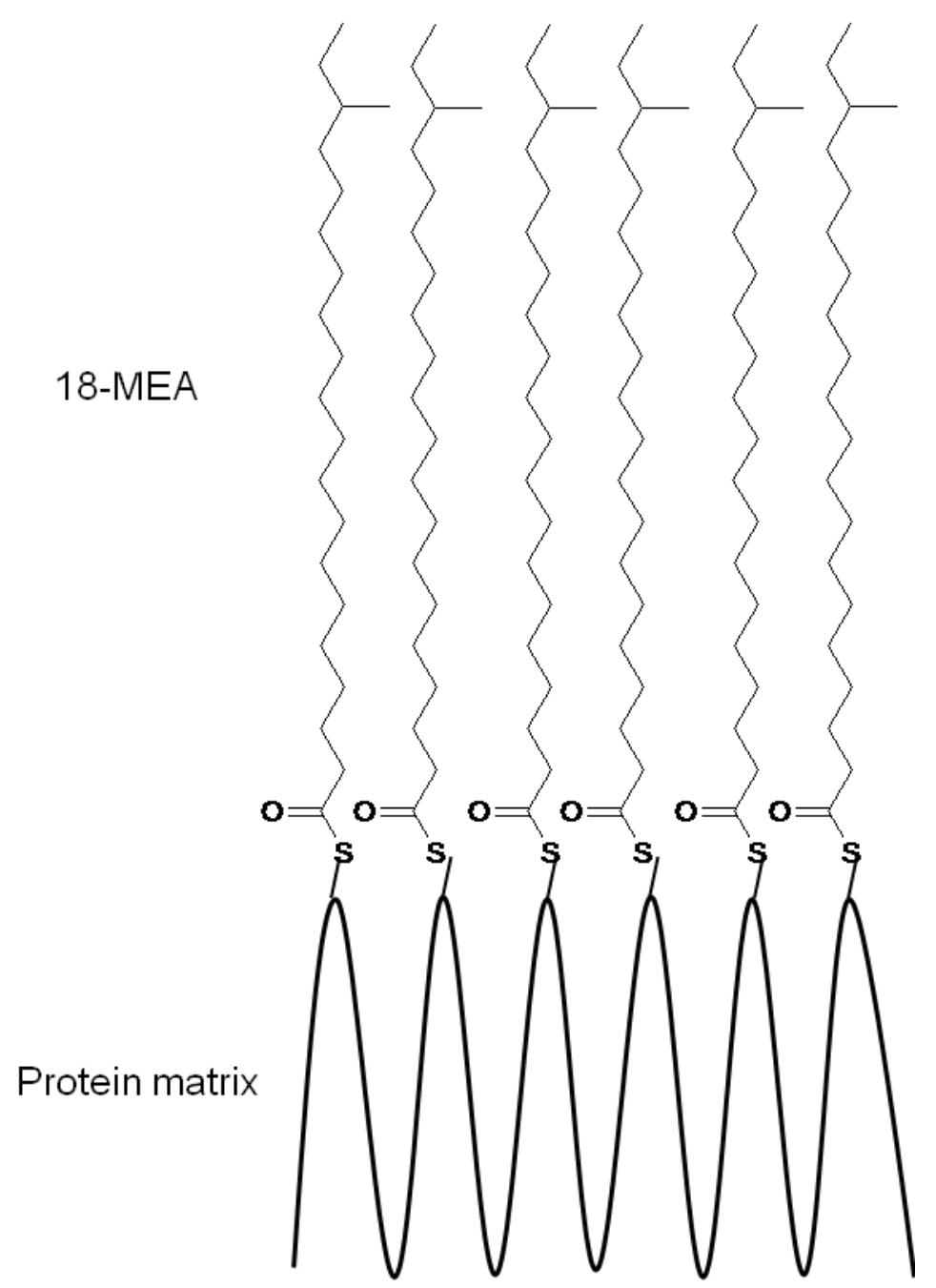

Figure 1.14: Model for the epicuticle of keratin fibres. Diagram represents a slice of the outer $100 \AA$ of a cuticle cell. The protein matrix is heavily acylated with 18-MEA, which forms a hydrophobic surface.[55] (Note: diagram is not drawn to scale). 


\subsection{Wool Processing}

There are three main systems for processing wool from fibre into yarn; notably the worsted, semi-worsted and woollen systems. There are a number of processes common to all three systems including blending of the wool types to be processed, scouring to remove impurities such as dirt, grease and vegetable matter, carding to disentangle the fibres and further remove impurities, and spinning of the fibres into a yarn. The type of processing route employed, and hence the attributes of the produced yarn depend largely on the properties of the wool.

Fine wools, such as merino, which are destined for high quality apparel, are commonly processed via the worsted system. This route involves the most steps and is the most complex of the three systems, producing a fine, smooth and strong yarn. To achieve the requisite yarn quality there are generally stringent requirements on the raw material, notably wool with good length and strength. Alternatively, the woollen system, which is the most common route for coarser wools, such as crossbred wools, is tolerant of wide variations in wool quality, especially length. The resultant woollen yarn has markedly different properties to a typical worsted yarn. It is a relatively coarse, less regular yarn with a bulky, soft handle. Woollen yarns are well suited for carpets and heavy apparel. Between these two routes is the semi-worsted system. This is essentially a shortened version of the worsted route, and produces a yarn that is intermediate in properties between worsted and woollen yarns.[65]

Throughout these processing steps lubricants are required to improve processing efficiency and reduce fibre damage and breakage. The three different processing routes have different requirements in terms of lubrication. The worsted processing route utilises the largest amount of lubricants (of different types) as it is the most complex route, involving the most steps. The lubricants are commonly poly alkylene glycols, ethoxylated fatty acids and fatty acid esters combined with oxidation stabilisers. In contrast, the woollen and semi-worsted routes often use only one lubricant, typically ethylene oxide polymers or ethylene oxide/propylene oxide block co-polymers.[66] These lubricants are applied in $0.8-3$ wt \%, and unless the wool is re-scoured following processing, they remain on the wool surface. This affects the surface properties of the processed wool, and hence wools which have been 
processed via the woollen, semi-worsted or worsted systems may differ in their surface chemistry.

\subsection{Surface Treatments}

The most widely used surface specific treatment for wool is the chlorine Hercosett process $(\mathrm{Cl} / \mathrm{H})$, invented by CSIRO in the 1950's.[67] This procedure reduces felting by lowering the directional frictional difference between the fibres, rendering them shrink resistant.[51] It is an oxidative process in which fibres are exposed to chlorine gas, generated in-situ from sodium hypochlorite and sulfuric acid, or chlorine gas dissolved in water; resulting in the oxidation of cystine moieties and hydrolysis of peptide bonds within the exocuticle. $[68,69]$ The treatment is surface specific as the reaction with the exocuticle takes place in less than 10 seconds.[70] Following surface oxidation, the fibres are treated with an aqueous base to neutralise the positive surface charge, and a cationic polymer is applied. This polymer is Hercosett 125 , a polyamide epichlorhydrin type polymer (Figure 1.15) which is capable of crosslinking via condensation reactions through primary and secondary amino groups in the polyamide backbone.

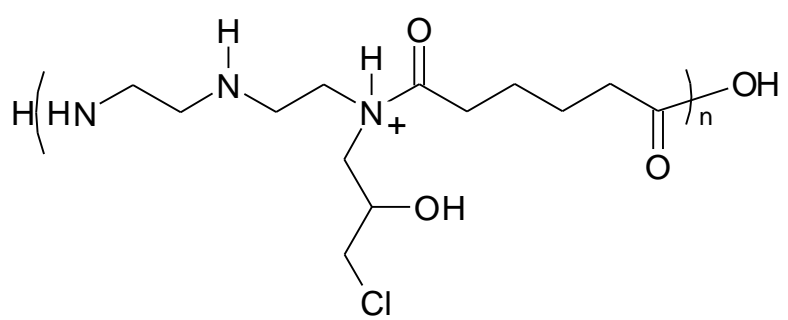

Figure 1.15: Hercosett 125, a polyamide epichlorhydrin type polymer employed in shrink resistant treatment of wool.

Hercosett films undergo considerable increases in volume when immersed in water. The volume when wet is approximately ten times that of the air-dry volume.[71, 72] This characteristic is a result of the highly cationic character of the polymer and its low degree of crosslinking. The significant swelling prevents the scales edges of adjacent fibres from interacting and causing felting (shrinkage) during washing. 


\subsubsection{Silk}

\subsection{Background}

Silk and the production of silk, (sericulture), originated in China more than 4,000 years ago with the Chinese utilising silk in luxury clothing, decorations and musical instruments. For more than 2,000 years China kept the secret of sericulture to itself; it wasn't until the opening of the Silk Road that the West was introduced to this luxurious natural fibre. In spite of competition from the development of man-made fibres, which have taken over many of silk's former established uses (hosiery, parachutes etc) silk has retained its supremacy in the production of luxury apparel and specialised goods of the highest quality, with world silk production approximately doubling over the last thirty years.[73] Silk is harvested from cocoons produced by the larvae of a variety of insects and spiders of the phylum Arthropoda. Worldwide, the larvae of the domesticated mulberry silkworm Bombyx mori (B. mori), are the most widely exploited and most important source of silk.[74] Today the major countries involved in sericulture are China and India, producing 54 and $14 \%$ of the total worldwide raw silk production respectively. Japan, Brazil and Thailand are also key contributors. New Zealand does not produce silk.[75]

\subsection{Chemical Composition}

The raw silk thread, obtained from the cocoon of silk producing larvae such as $B$. mori, has a "sheath around two cores" composite structure. It is comprised of two fibroin filaments (brins) embedded in a protein gum called sericin, forming a singular thread (bave) which has a diameter of $15-25 \mu \mathrm{m}$. Both fibroin and sericin are proteins, with the former accounting for approximately $70-80 \mathrm{wt} \%$ of the raw silk thread. Other minor components are waxes and fats $(\sim 1.5 \mathrm{wt} \%)$, carotenoid pigments and mineral components $(\sim 1 \mathrm{wt} \%)$ which occur exclusively in the sericin layer. 
Fibroin constitutes the core of the silk fibre, however it is not a single protein, rather it is divided into two major polypeptide components, a heavy component (H-chain) and a light component (L-chain). Additionally there is a third component, $\mathrm{P}_{25}$, which has been suggested to act as a chaperone assisting in the transport and secretion of $\mathrm{H}$-fibroin from $B$. mori.[76] $\mathrm{P}_{25}$ associates with the $\mathrm{H}$ - and L-fibroin via non-covalent (largely hydrophobic) interactions.[77] $\mathrm{H}$-fibroin, L-fibroin and $\mathrm{P}_{25}$ are thought to be assembled in the ratio of 6:6:1.[78] All of the fibroins possess a high content of the amino acids glycine ( $44.6 \mathrm{~mol} \%)$, alanine $(29.4 \mathrm{~mol} \%)$, serine $(12.1 \mathrm{~mol} \%)$ and tyrosine $(5.17 \mathrm{~mol} \%)$, which together comprise more than $90 \mathrm{~mol} \%$ of the total residues in B. mori.[79] On average, the total acidic groups in fibroin is two to three times that of basic groups.

Table 1.3: Functionality and concentration of side groups in the amino acids of silk fibroin and sericin.[80]

\begin{tabular}{lcc}
\hline \multicolumn{1}{c}{ Amino Acid } & g amino acid per 100 g protein \\
\cline { 2 - 3 } & Fibroin & Sericin \\
\hline INERT & & \\
Glycine & 44.6 & 8.8 \\
Alanine & 29.4 & 4.0 \\
Valine & 3.2 & 3.1 \\
Leucine & 0.8 & 0.9 \\
Isoleucine & 1.4 & 0.6 \\
Phenylalanine & 1.5 & 0.6 \\
ACIDIC & & \\
Aspartic acid & 3.0 & 16.8 \\
Glutamic acid & 2.0 & 10.1 \\
BASIC & & \\
Lysine & 1.5 & 5.5 \\
Arginine & 0.9 & 4.2 \\
Histidine & 1.1 & 30.1 \\
HYDROXY CONTAINING & 0.5 & \\
Serine & & \\
Threonine & & \\
& &
\end{tabular}




\begin{tabular}{lcc}
\hline \multicolumn{1}{c}{ Amino Acid } & \multicolumn{2}{c}{ g amino acid per $\mathbf{1 0 0}$ g protein } \\
\cline { 2 - 3 } & Fibroin & Sericin \\
\hline Tyrosine & 5.1 & 4.9 \\
SULFUR CONTAINING & & \\
Cystine & 0.3 & 1.4 \\
Cysteine & 0.1 & 0.2 \\
Methionine & 0.2 & 0.1 \\
MISCELLANEOUS & & \\
Proline & 1.5 & 0.5 \\
Tryptophan & 0.5 & 0.5 \\
\hline
\end{tabular}

Sericin is the protein constituent that glues the two fibroin filaments together when they are spun by the silkworm to form the cocoon. It not only plays an important role in the structure of the cocoon but also assists in binding filaments together during the reeling of silk through the filature (silk producing gland of the silkworm). It constitutes about 20-30 wt $\%$ of the cocoon proteins, is soluble in hot water and gels upon cooling. In composition, sericin is distinctly different from fibroin. It is rich in serine, glycine and aspartic acid, which together comprise about two-thirds of the total residues. It is also a lot richer in cystine.[81, 82] About $60 \%$ of the amino acids in sericin possess hydroxyl groups, $30 \%$ acidic groups, and $10 \%$ basic groups. The hydrogen bonding ability of these hydroxyl groups is considered responsible for the glue like properties of sericin (Table 1.3).[77]

\subsection{Physical Properties}

As mentioned, silk from the mulberry tree silkworms, B. mori, is composed of two protein fibroins (brins) embedded in a gluelike sericin coating, forming a bave.[76, 83, 84] A similar structure has been observed for silk from other silkworm silks. [85] The fibroin filaments comprise bundles of filaments, approximately $5 \mathrm{~nm}$ in diameter, with a bundle diameter of around $100 \mathrm{~nm}$.[84] The nanofibrils are orientated parallel to the axis of the fibre, and are thought to interact strongly with each other.[82] A schematic representation of the structure of B. mori thread is offered in Figure 1.16.[76] 
The two major polypeptide components, the H- and L-chain can be separated by reductive cleavage, and have been shown to be linked via disulfide bonds.[81, 86, 87] Until the work of Schroeder and Kay,[88] which was later confirmed by Zuber et al.[89] it was assumed that cystine and methionine ( $\mathrm{S}$ containing amino acids) were absent from the fibroins. This was likely due to their extremely small quantities ( $\sim 0.3$ and $0.5 \mathrm{M} \%$ respectively) and to their partial destruction during degumming (the removal of sericin).[90] Cystine is considered to play a small but vital role in the secondary structure of fibroin by forming interchain disulfide links between the $\mathrm{H}$ - and L-chains.[81, 86, 87, 91] L-fibroin polypeptides contain three cystine residues. Two of which form an intra-molecular disulfide bridge, whilst the third, in position 172 binds with cystine- $\mathrm{C}_{20}$ (20 residues from the $\mathrm{C}$ terminus) of $\mathrm{H}$-fibroin to form the intermolecular disulfide bridge which connects the two main fibroin polypeptides.[82]

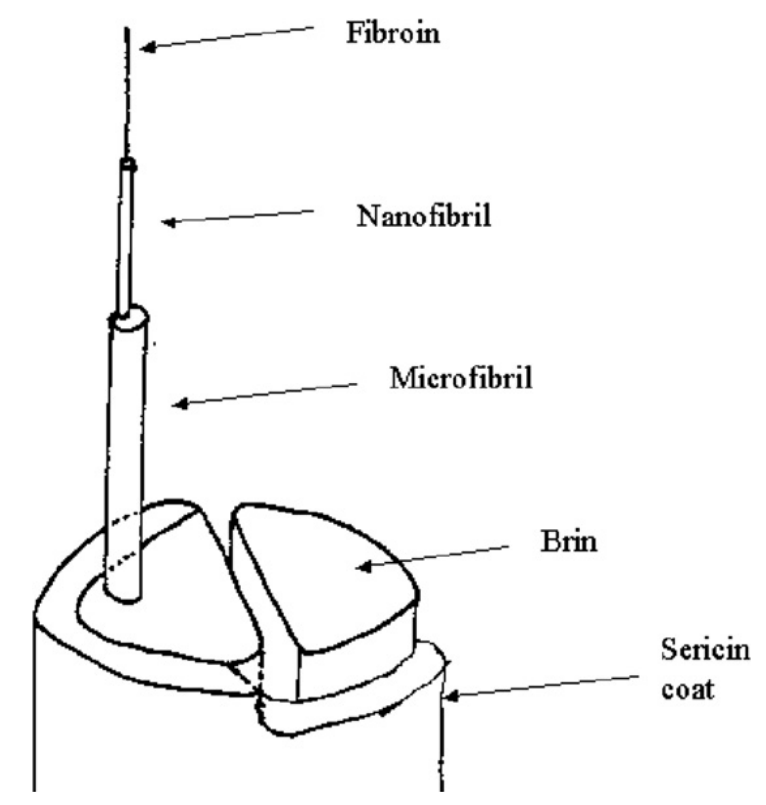

Figure 1.16: The structure of $B$. mori silk thread.[76]

Silk fibroin are repetitive $\mathrm{AB}$ block copolymers, with alternating hydrophobic (crystalline) and less hydrophobic (non-crystalline) regions.[92] The H-chain makes up the crystalline region and has been identified as rigid, tightly packed anti-parallel $\beta$-pleated sheets.[93] The $\beta$-pleated sheets are either poly-alanine (poly-Ala), or poly-glycine-alanine (poly-Gly-Ala) repeat units, each interlocking with adjacent chains via hydrogen bonding (Figure 1.17).[76, 
94] The sheets are assembled through hydrophobic interactions and are orientated in such a way that in any one sheet, all of the glycine side chains $(-\mathrm{H})$ project from the same side, and the alanine $\left(-\mathrm{CH}_{3}\right)$ side chains from the other. The sheets then stack together so that the methyl and hydrogen groups interact to form inter-sheet stacking in the crystals.[77] The non-crystalline domains of fibroin are poorly orientated, randomly coiled sections of the peptide, and are considered amorphous.[95]
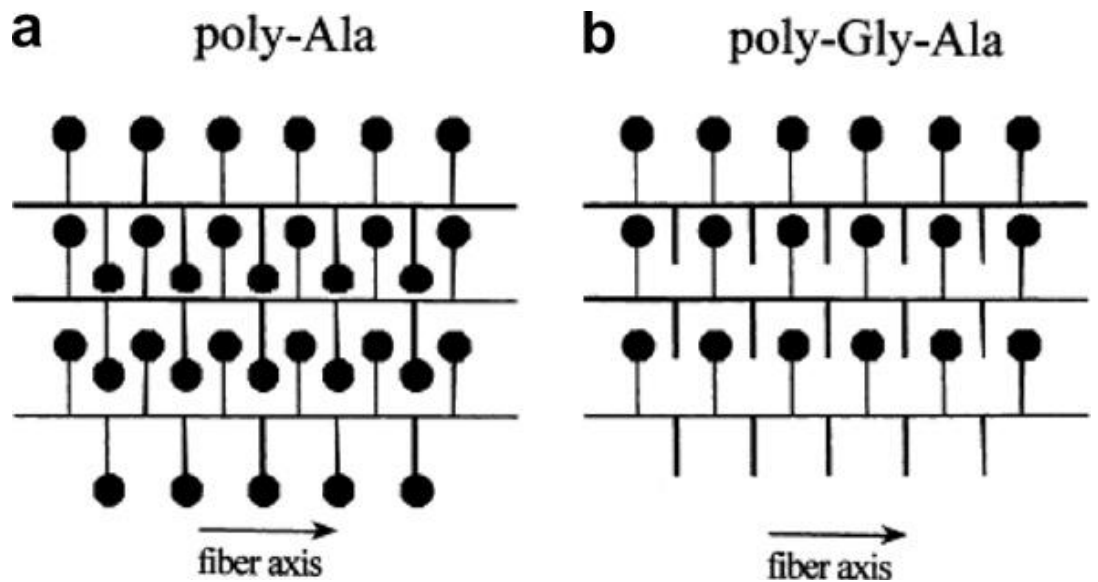

Figure 1.17: Schematic showing the interactions of the two different $\beta$-sheet regions in silk fibroin.[76]

As mentioned in section 1.3.2.2.2, the sericin coating consists $20-30 \mathrm{wt} \%$ of the $B$. mori silk fibre. Sericins are known to have several extraordinary properties: they are anti-bacterial, UV resistant, and can easily absorb and release water.[76, 96] These properties are valuable in the protection of silk from microbial degradation, animal digestion and other detrimental processes. Although sericin is advantageous to the silk fibre whilst part of the cocoon, from an aesthetic point of view it is not. Silk with sericin intact does not possess the shine and softness for which silk is renowned. The gummy sericin imparts a harsh handle and must be removed in order to bring out the typical shine, lustre, soft handle and drape highly appreciated by consumers.

The removal of sericin from silk is termed degumming. It is a simple but important process usually employing hot dilute soap or alkaline solutions and occasionally dilute acids, [97] and usually occurs before dyeing and finishing processes. Degumming has a great influence on 
dyeing silk. Often, defects found in the final dyed product (for example non-uniform colour) can arise due to incomplete removal of sericin, or fibre damage produced by over harsh degumming conditions.[77] However in some cases, partial degumming may be desired; souple and crude (ecru) silks are obtained in this way. Although degummed silk has a degree of whiteness, it is often necessary to bleach in order to obtain a pure white material, and this is generally achieved through oxidation by hydrogen peroxide.

Due to the combination of extensive hydrogen bonding, high levels of crystallinity, and the general hydrophobic nature of silk fibroin, silk proteins are insoluble in most solvents, including water and dilute acid and alkali. The alkali resistance of silk is much more pronounced compared to that of wool, due to its small number of cystine linkages.

\subsection{Metal Nanoparticles}

\subsubsection{Background}

A nanoparticle, by definition, is a particle with at least one dimension less than $100 \mathrm{~nm}$. Metal nanoparticles, in particular gold and silver in the form of colloids or sols, have a rich history as colourants, dating back to the Middle Ages, where they were unknowingly implemented throughout Europe and China as colourants of stained glass windows and ceramics (Figure 1.18).[98] 


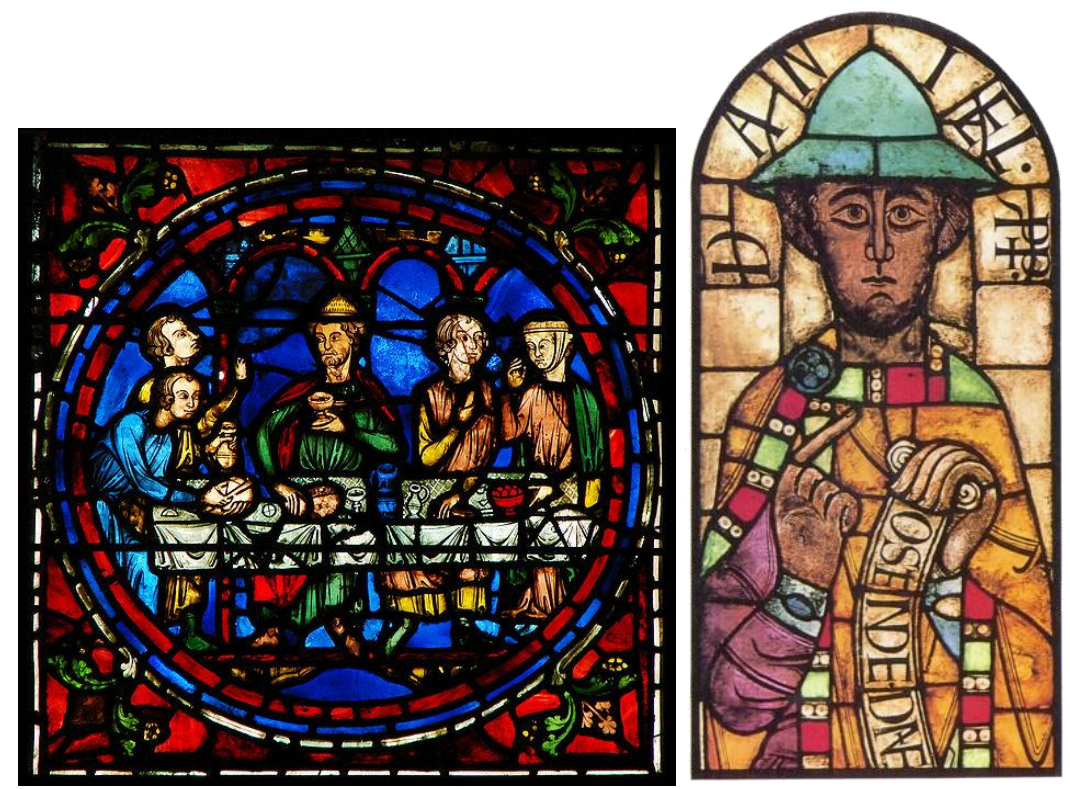

Figure 1.18: Implementation of metal nanoparticles as colourants for stained glass windows, which was common practice throughout the Middle Ages.[98]

In the seventeenth century, "Purple of Cassis", a colloid of heterocoagulated tin dioxide and gold nanoparticles, became a popular colourant of glass.[99] Additionally, gold nanoparticles, combined with smaller amounts of both silver and copper nanoparticles were famously used as colourants of the Lycurgus cup from the fourth century AD.[100] However it was not until 1857, that the notion that these gold sols contained small metallic particles was expressed. Michael Faraday reported a systematic study of the optical properties of thin films prepared from dried colloidal gold solutions.[101] He postulated that the colour of gold containing glass, such as ruby red glass, arose due to the presence of finely divided gold particles, and presented a mechanism for the formation of colloidal metals.[101]

It was not until the work of Mie in 1908, that the colour reflected by very small metal particles was first explained theoretically to be due to strong visible absorptions known as surface plasmon resonances (SPR's).[102] SPR is correlated to the interaction between the collective oscillation frequency of conduction band electrons in small particles with the electromagnetic field of incoming light. Metal nanoparticles, of sizes intermediate between the size of a small molecule and that of the bulk metal display electronic structures governed by quantum mechanical rules.[103] When the de Broglie wavelength of the valence 
electrons is of the same order as the size of the particle itself, a quantum size effect is invoked. The particles behave electronically as zero-dimensional quantum dots relevant to quantum-mechanical rules. Freely mobile electrons are trapped in such boxes and show a characteristic collective oscillation frequency, termed surface plasmons.[104]

The intense colour of noble metal nanoparticles is due to the SPR band, a broad absorption in the visible region, occurring at approximately $520 \mathrm{~nm}$ in red-coloured spherical gold colloids. SPR bands occur when incoming light (with a wave vector comparable to the wavelength of surface plasmons), transfers energy to the nanoparticle, inducing a dipole. A restoring force in the nanoparticle tries to compensate for this, resulting in the formation of a unique resonance wavelength (a surface plasmon). The coupling of the incident light to the surface plasmons results in a loss of energy, and therefore a reduction in the intensity of reflected light.[104]

The oscillation wavelength, and hence emitted colour, depends on a number of factors, among which particle size and shape, as well as the nature of the surrounding medium, are the most important.[104, 105] For non-spherical, elongated nanoparticles, such as nanorods and ellipsoids, the resonance wavelength also depends on the orientation of the electric field with respect to the nanoparticles. Therefore two electron oscillations, longitudinal and transverse are possible.[106] The longitudinal oscillation is very sensitive to the aspect ratio of the nanoparticles, so that slight deviations from spherical geometry can lead to impressive colour changes.[107] Figure 1.19 illustrates the effect of the interaction of the electromagnetic field of light with both spherical and anisometric metal nanoparticles.

The unique optical and electrical properties of metal nanoparticles has led to a huge amount of interest and research activity within the scientific community, as they have the potential to be utilised in many applications, ranging from controlled drug delivery devices to biological sensors, amongst others.[108] 


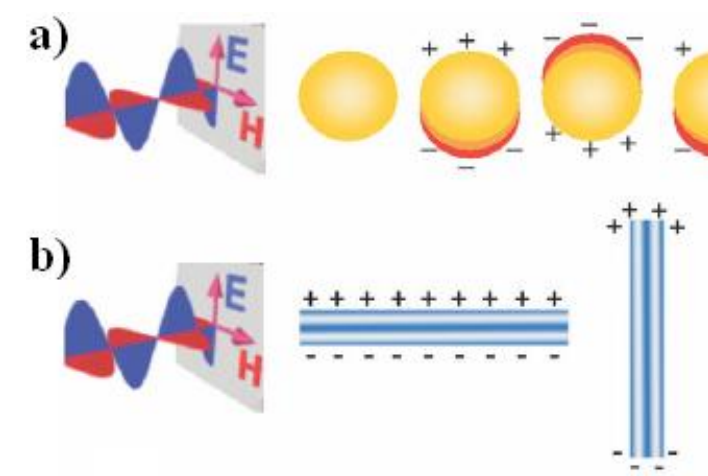

Figure 1.19: Schematic drawing of the interaction of the electromagnetic field of incoming light with a) spherical nanoparticles, and b) nanorods. A dipole is induced in the spherical nanoparticles that oscillates in plane with the electric field of incoming light, whilst both transverse and longitudinal oscillations are evident in the metal nanorods.[106]

\subsubsection{Preparation of Metal Nanoparticles}

The preparation of metal nanoparticles generally involves the chemical reduction of a metal salt in an aqueous, organic or two-phase system. The high surface energy of metal nanoparticles make them extremely reactive, and most systems undergo aggregation without protection or passivation of their surfaces due to attractive van der Waals forces. Typically, metal nanoparticles are prepared by chemical reduction of the corresponding metal salt in the presence of a stabiliser which binds to the surface of the formed nanoparticles, imparting high stability and the desired charge and solubility properties.[109] Some of the commonly used methods for surface passivation include encapsulation in the aqueous pools of reverse microemulsions,[110] dispersion in polymeric matrixes [111] and protection by selfassembled monolayers, the most popular being citrate [112] and thiol-functionalised organic molecules.[113]

The synthesis of gold nanoparticles by reduction of gold(III) derivatives was first introduced by Turkevitch and co-workers in 1951.[114] They reported on the production of uniform gold nanospheres, approximately $20 \mathrm{~nm}$ in diameter, through the reduction of gold tetrachloride in a boiling sodium citrate solution. The average particle diameter can be tuned over quite a large range (approximately $10-100 \mathrm{~nm}$ ) by varying the concentration ratio 
between the gold salt and sodium citrate.[112] The same procedure can be utilised to reduce silver, but particle size control is very limited.[106] This method is often used when a loose shell of ligands is required around the gold core, in order to produce gold nanoparticles with varying surface functionalities. Addition of an alternative stabiliser, (for example polyvinylpyrrolidone, sodium 3-mercaptopropionate) simultaneously with tri-sodium citrate can result in replacement of the citrate stabilisers.[115]

An alternative procedure for the synthesis of metal nanoparticles (in particular gold) is the two-phase reduction method developed by Brust and co-workers.[116, 117] This involves dissolving a metal salt, for example gold tetrachloride in water, and subsequently transporting it into an organic phase such as toluene by means of a phase transfer agent such as tetraoctylammonium bromide. The toluene solution containing the gold salt is then thoroughly mixed with an aqueous solution of sodium borohydride, in the presence of thioalkanes or aminoalkanes, which readily stabilise the resultant gold nanoparticles. By varying the ratio of gold salt, reductant and stabiliser $\left(\mathrm{Au}^{3+}:\right.$ thiol : amine) the size of produced nanoparticle can be tuned to between approximately 1-10 $\mathrm{nm}$.

Microemulsions,[117] co-polymer micelles,[118] reversed micelles [117] and surfactants have also been employed in the synthesis of gold nanoparticles. The syntheses generally involve a two-phase system with surfactants that cause the formation of the microemulsions or micelles, maintaining favourable microenvironments into which the metal ions from the aqueous phase are extracted. Uniform colloids of spherical gold nanoparticles of the order of $4 \mathrm{~nm}$ have been prepared in this way.[119]

The use of UV irradiation, generally in collaboration with surfactants, is a further procedure by which to produce metal nanoparticles, with UV light inducing a photochemical reduction of the metal salt. The irradiation of aqueous solutions containing equi molar concentrations of silver nitrate and polymethacrylic acid with UV light causes the formation of silver nanospheres, of the order of $20 \mathrm{~nm}$ in diameter. Varying both the UV exposure time and ratio of silver ions to stabiliser results in the formation of nanoparticles with sizes varying between $10-60 \mathrm{~nm} .[2]$ 
UV radiation has also been reported to convert spherical nanoparticles into truncated triangular nanoparticles.[120-122] Exposure of citrate stabilised spherical silver nanoparticles, with an average diameter of $15 \mathrm{~nm}$, to UV light results in the formation of truncated triangular nanoparticles, with diameters varying between 40-100 nm. This shape change induces a colour change from yellow to green.[120]

\subsubsection{Gold and Silver Nanoparticles}

As previously mentioned the colour reflected by noble metal nanoparticles is largely dependent upon particle size and shape, as varying these factors shifts the surface plasmon band of the nanoparticles. Increasing the diameter of spherical gold nanoparticles from approximately 10 to $100 \mathrm{~nm}$ progressively changes the colour of the resultant colloid from wine red to blue. Silver nanospheres show a similar trend. Varying the aspect ratio of anisotropic nanoparticles of both gold and silver results in intense colour changes, as these particles exhibit both transverse and longitudinal Plasmon bands (Figure 1.20).[106]
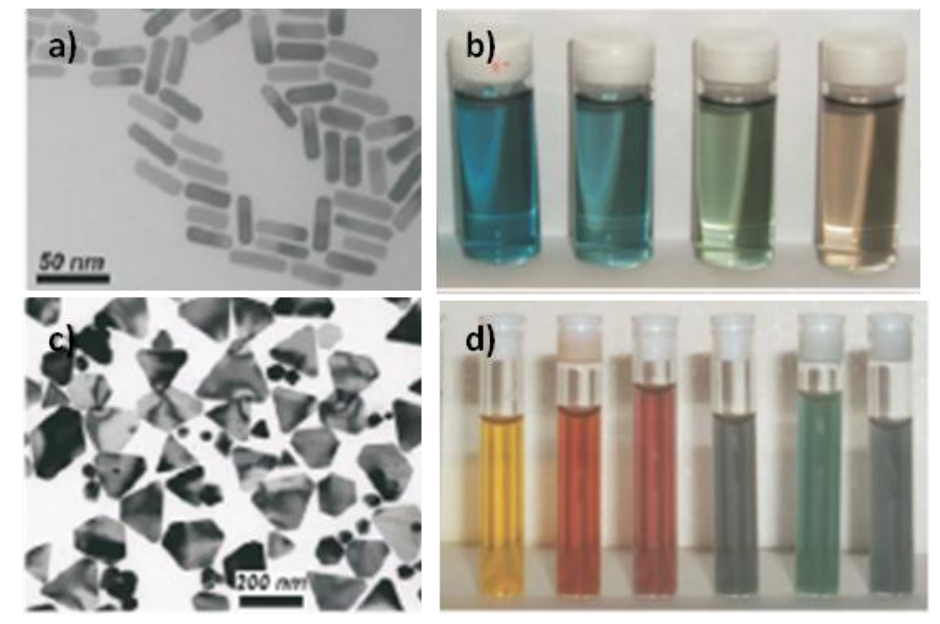

Figure 1.20: Left TEM images of a) gold nanorods, and c) silver nanoprisms and truncated triangles.

Right pictures of colloidal dispersions of b) gold nanorods of increasing aspect ratio and d) silver nanoprisms with increasing lateral size.[106]

Examples of gold and silver anisotropic particles, such as nanorods and triangular nanoprisms have appeared in the scientific literature for many decades. There have been numerous mechanistic explanations for the formation of such particles, with the proposed 
mechanisms falling into two general categories. One uses the presence of organic molecules to poison or accelerate the addition of adatoms to specific crystal faces (the surface modification model),[123-125] whilst the second group of explanations propose that soft templates such as micelles formed by high concentrations of surfactants, physically direct crystal growth through shape confinement (the physical constraint model).[126, 127]

A review of the literature on the production of anisotropic colloidal particles reveals both the surface-modification model and the physical constraint model have difficulty explaining several observations.[128] Foremost is the apparent difficulty in producing a high yield of anisotropic particles of a specific shape. Even when reaction conditions are highly homogeneous, a diverse range of shapes are produced, with the reaction products generally consisting of a mixture of isotropic particles (spheres etc), with a small portion of anisotropic particles (Figure 1.21). Additionally, the two models cannot explain why nearly identical crystal shapes are produced with thoroughly different synthesis environments and techniques.

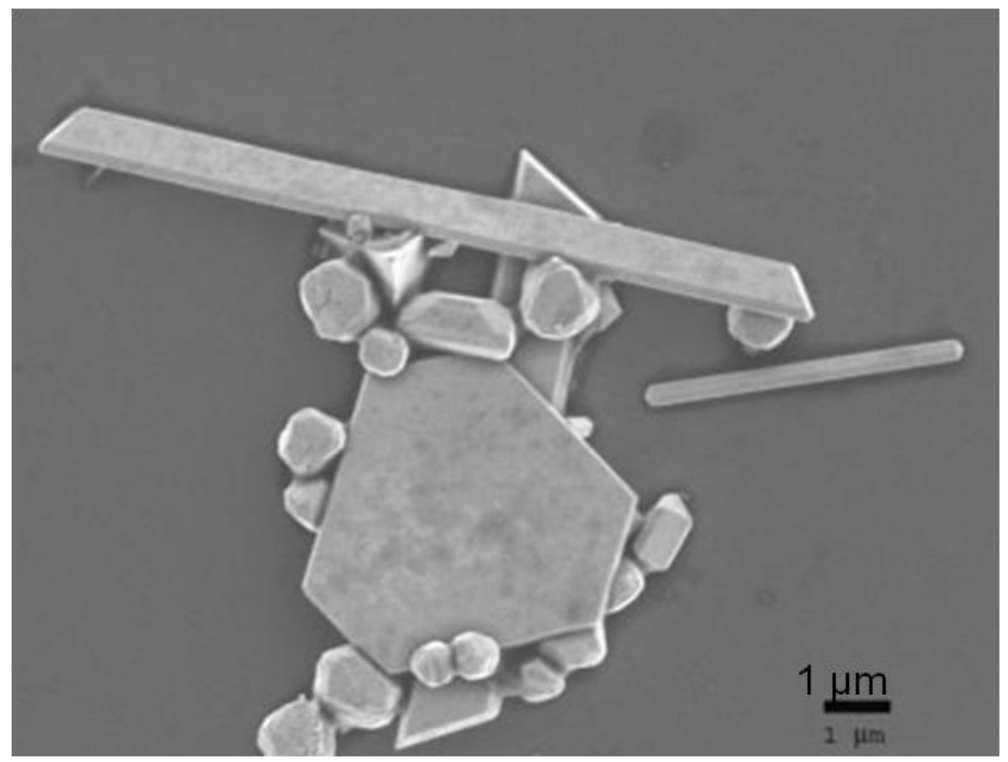

Figure 1.21: SEM micrograph taken from Lofton et. al.[128] Illustrates the diversity of colloid shapes synthesised in a homogeneous reaction environment, including tapes, rods, platelets, tetrahedra and isotropic particles. 
In light of these observations, Lofton and co-workers proposed an alternative mechanism for the growth of anisotropic gold and silver colloids, in which [111] twin planes in silver and gold nanoparticles direct the shape of the particles to become anisotropic. This occurs through the formation of re-entrant grooves that are favourable sites for adatom (additional metal ion) attachment, reducing the nucleation energy required to form a new atomic layer in these areas. Twin planes readily form in silver halides, as well as in silver and gold, where the stacking fault energy is lower than most metals, decreasing the energy required to form a twin plane.[129, 130] Due to the sixfold symmetry of the face centred cubic (fcc) system, these twinned crystals form hexagonal-shaped nuclei. The stacking fault of the twin plane causes $\{111\}$ faces to form in alternating concave and convex orientations, A- and B-type sides respectively (Figure 1.22). On a B-type side, an adatom has limited stabilisation energy due to the presence of only three nearest atomic neighbours. This makes the probability of dissolution of the adatom back into the solution likely, and therefore growth of these surfaces is very slow. Conversely, the concave nature of the A-type sides creates a re-entrant groove, a self-perpetuating ledge that increases the number of nearest neighbours for an adatom, increasing the stabilisation energy of these adatoms and greatly accelerating the growth of Atype sides. As the A sides are bounded on each side by slow growing B sides, the A sides quickly grow themselves out of existence, producing a triangular prism of a size defined by the size of the original twinned particle.[128]

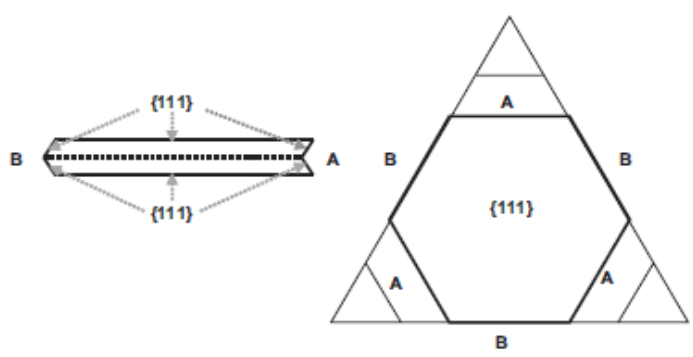

Figure 1.22: Schematic showing a single twin plane. Alternating A- and B-type faces with re-entrant grooves of A-type faces causing rapid growth that stops when the face grows itself out, resulting in a triangular prism.[128]

The formation of particles with multiple twin planes results in the production of alternate anisotropic nanoparticles such as rods or wires.[128, 131] It is unclear why certain 
nucleation events promote single or multiple twinning events, however methods can be altered so that such twinned seed particles are produced in a high yield. Following the initial nucleation event in which a distribution of seed particles with different twinning structures occurs a competitive growth stage can be set up in which seeds are allowed to ripen without additional metal salts so that the twinned seeds consume the un-twinned seeds. Once the desired seeds are obtained, metal salt addition below the concentration required for nucleation promotes growth of the seeds over new nucleation events, generating the desired particle shape in high yield.[128]

For example, Lofton and co-workers altered a polyol synthesis for gold particles (which originally produced gold nanoparticles in a range of morphologies), to yield a high percentage of gold platelets (Figure 1.23). This was achieved by initially adding a percentage of the total reductant employed in the synthesis, and allowing the reaction mixture to sit for approximately 20 minutes before adding a surfactant followed by the slow addition of the resultant seed particles to the remaining reductant. Lofton postulated that the gold seeds initially formed contained parallel twin planes that would later define their shape. Slow addition of these colloidal seeds to the remaining reductant was thought to keep the concentration of adatoms in solution (unreduced $\mathrm{Au}^{3+}$ ) low, favouring growth of seeds over new nucleation events. Once the supply of gold chloride was exhausted, the growth of particles would occur only at the expense of other particles dissolving. In other words, by changing the degree of supersaturation of gold in solution, Lofton and co-workers were able to discourage the growth of un-twinned particles, instead encouraging the growth of twinned particles resulting in nearly the entire quantity of gold to form as platelets.[128]
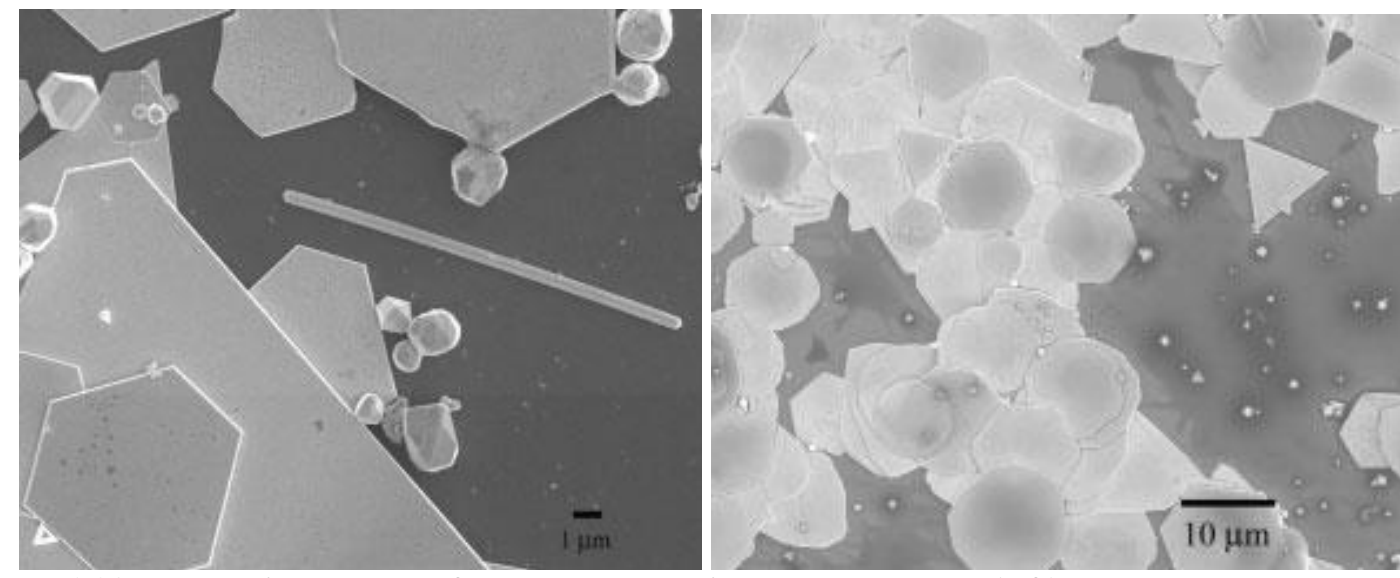

Figure 1.23: TEM micrographs of gold produced via a polyol method (left) and altered polyol method (right).[128] 


\subsubsection{Anti-microbial Properties}

The medicinal properties of metals have been recognised throughout the ages, and have represented some of the most fundamental breakthroughs in medicine.[132] Two of the most exploited metals in health care throughout history have been silver and gold.

\subsubsection{Silver}

The anti-microbial properties of silver have been known for centuries. Silver and its salts, typically silver nitrate, were commonly used during the nineteenth century in the treatment of skin ulcers, compound fractures and suppurating (draining pus) infected wounds.[133] Perhaps the most memorable use of silver in medicine came about in 1884, with the instillation of dilute solutions of silver nitrate into the eyes of new born children to offset infantile blindness (opthalmia neonatorum).[133] Silver ions, and silver based compounds have been shown to be highly toxic to microorganisms, [134] showing strong biocidal effects on as many as sixteen species of bacteria including Escherichia coli (E. coli), Staphylococcus aureus[135] and the human immuno-deficiency virus (HIV).[136] However silver has been shown to be non toxic to human cells, and appears to be biocompatible.[137] Thus silver ions, as an anti-bacterial component, have been used in the formulation of dental resin composites,[138] ion exchange fibres,[139] municipal water systems,[140] wound dressings [141] and in coatings for medical devices.[142-144]

Several proposals have been developed to explain the bacterial inhibitory effect of silver materials. It is suggested that silver ions interact with nucleophilic amino acid residues in proteins, and attach to sulphydryl, amino, imidazole, phosphate and carboxyl groups of membrane or enzyme proteins, thus leading to protein denaturation and cell death.[145-147] Silver is also known to inhibit a number of oxidative enzymes such as yeast alcohol dehydrogenase [148] and the respiratory chain of E. coli, as well as causing metabolic efflux [149] and interfering with DNA replication.[142, 150] Silver has been shown to associate with the cell wall,[151] cytoplasm and cell envelope,[152] and there is a general consensus that surface binding and damage to membrane function are the most important mechanisms 
for the killing of bacteria by silver, with only low levels of silver, approximately 5-10 ppm, required to induce cell death.[12, 132, 150] The anti-microbial action of silver metal is thought to arise due to the formation of a surface oxide layer and/or the release of silver ions.[136]

Recent advances in facile syntheses of silver nanoparticles with a narrow size distribution have seen increased research into the use of nanoparticles in various biomedical applications. It is expected that due to their high specific surface area and high fraction of surface atoms, nanoparticles should display a greater effective anti-microbial activity relative to the bulk metal. Several studies comparing the anti-microbial activity of silver nanoparticles to that of silver ions and silver metal have shown this to be the case, with nanoparticles effecting a much greater anti-microbial activity than their bulk counterpart, with nano-molar and micromolar concentrations required respectively.[136, 153]

Electron microscopy studies on the anti-microbial activity of silver nanoparticles against $E$. coli revealed the mode of action to be very similar to that of silver metal and silver ions, with nanoparticles targeting cell walls and membranes, resulting in the seepage of intracellular substances, and cell death.[154] Figure 1.24 shows the surface morphology of both native (un-treated) E. coli, and E. coli treated with silver nanoparticles. The treated cells are significantly changed, and show major damage, evident as 'pits' in the cell walls.

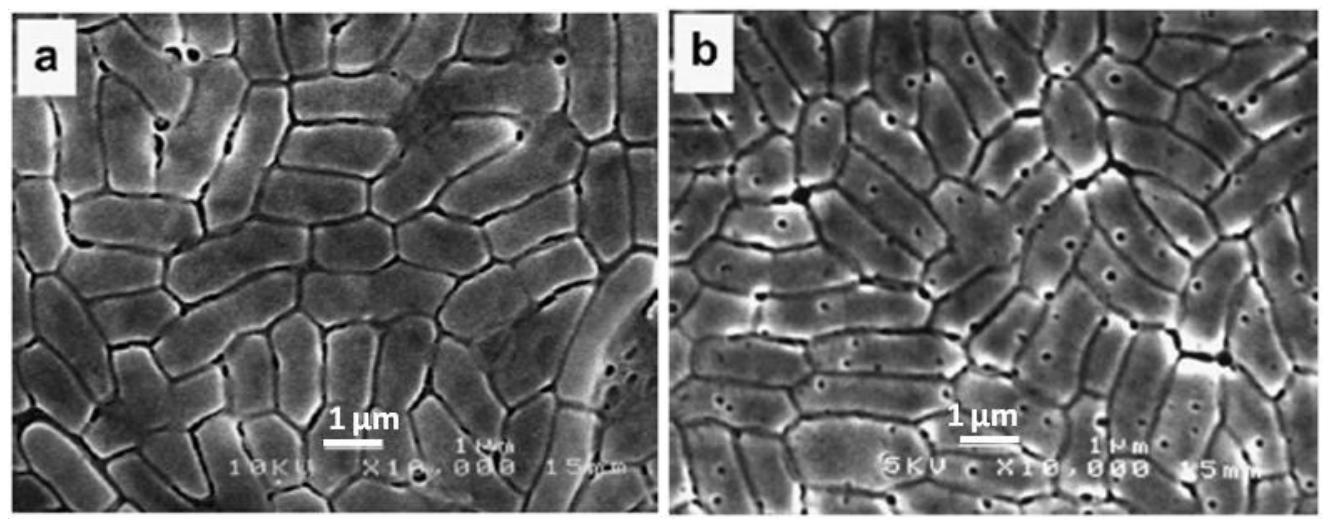

Figure 1.24: a) SEM micrographs of native $E$. coli cells and b) cells treated with $50 \mu \mathrm{g} \mathrm{ml}$ of silver nanoparticles.[154] 
TEM analysis confirmed the presence of silver nanoparticles in the membrane, with some seen to penetrate into the cells, causing leakage of intracellular substances (Figure 1.26).[154]

Silver nanoparticles have been immobilised onto various substrates through numerous procedures in order to impart their anti-microbial properties.[2, 8, 13, 155-158] Synthetic textile fibres with silver nanoparticles have been prepared by blending nanoparticles into the polymer matrix before spinning,[3] or by immersing the substrate in a solution of silver ions, which are then reduced inside the substrate. $[8,13]$ Such examples include dispersing fine cellulose fibres in a silver nitrate solution, followed by a sodium borohydride solution, resulting in a dispersion of silver nanoparticles throughout the three-dimensional network of cellulose.[13] Additionally, silver ions have reportedly been reduced in the interlayer spacings of kaolinite, by firstly disaggregating the kaolinite lamellae with dimethyl sulfoxide (DMSO), and introducing the expanded clay to a solution of silver nitrate, followed by sodium borohydride (Figure 1.26).[8] This resulted in a grey black coloured powder.

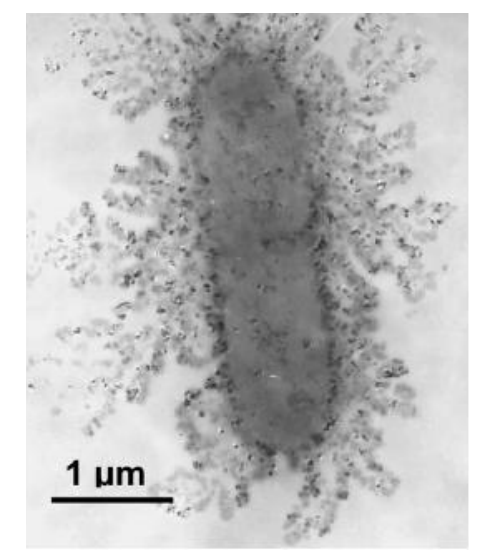

Figure 1.25: TEM micrograph of an $E$. coli cell treated with $50 \mu \mathrm{g} \mathrm{ml}$ of silver nanoparticles.[154] 


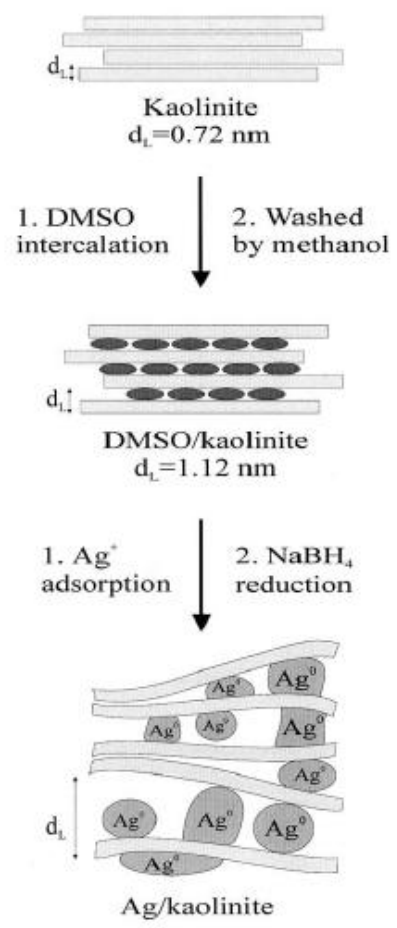

Figure 1.26: Schematic illustration of the preparation of silver nanoparticles in the interlayer spacings of kaolinite.[8]

Alternatively nanoparticles can be prepared separately and attached to the substrate by means of a chemical linker. Dubas and co-workers reported on the immobilisation of silver nanoparticles on nylon and silk fibres through utilisation of a layer-by-layer deposition process.[2] This involved the sequential dipping of nylon or silk fibres in dilute solutions of poly(diallyldimethylammonium chloride) (PDADMAC) and silver nanoparticles capped with polymethacrylic acid (PMA), resulting in a layered polymeric multi-composite textile (Figure 1.27). 


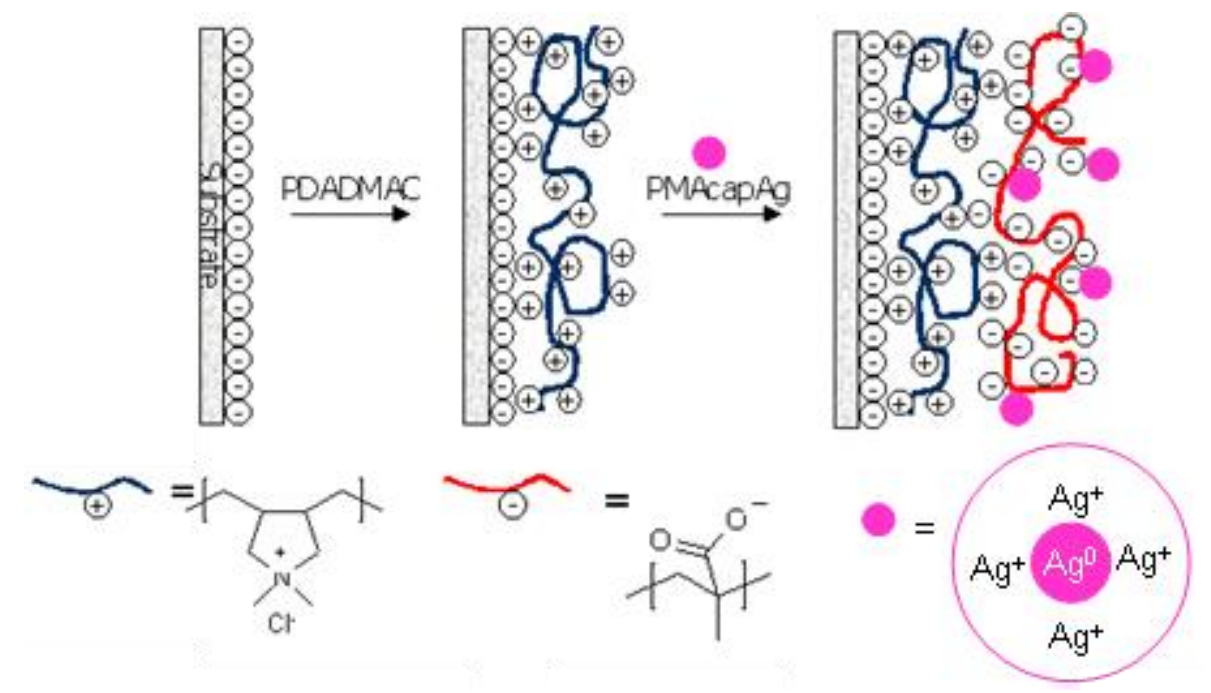

Figure 1.27: Layer-by-layer deposition of silver nanoparticles capped with anionic PMA onto fibres coated with the cationic polymer PDADMAC.

To the best of our understanding the use of silver nanoparticles as both anti-microbial agents and colourants for fine powders has not been reported, thus presenting an opportunity gap that we would like to fill with the production of silver nanoparticle-clay hybrids.

\subsubsection{Gold}

Gold, in a variety of forms, has been used in medicine throughout the history of civilisation.[159, 160] Its earliest medical use can be traced back to the Chinese in $2500 \mathrm{BC}$. In medieval Europe alchemists produced the reputably therapeutic elixir aurum potabile. During the $17^{\text {th }}$ century gold colloids were employed in the treatment of aliments such as fainting, fevers and melancholy, and later in the $19^{\text {th }}$ century a mixture of gold tetrachloride and sodium chloride was used to treat syphilis. The predominant use of gold in modern, $20^{\text {th }}$ century medicine was the use of gold complexes in the treatment of rheumatoid arthritis, culminating in the introduction of the oral drug Auranofin in 1985.[161] Additionally, gold complexes demonstrated anti-tumour properties, with the development of a series of di-gold phosphine complexes, the lead complex being [dppe $(\mathrm{AuCl})_{2}$ ] (Figure 1.28).[161, 162] 


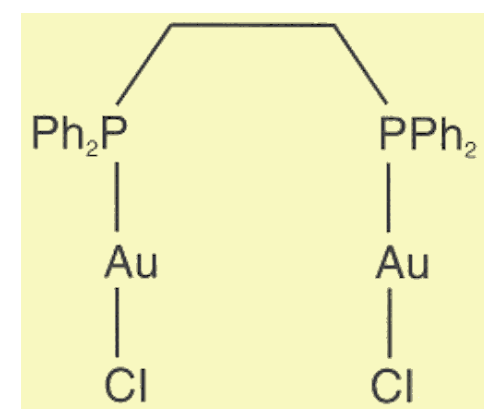

Figure 1.28: Anti-tumour gold complex [dppe $\left.(\mathrm{AuCl})_{2}\right] .[161]$

Gold complexes have also demonstrated anti-microbial activities,[163] the more common complexes containing either $\mathrm{Au}(\mathrm{III})$ or (I). The anti-microbial activity of $\mathrm{Au}(\mathrm{III})$ complexes is thought to arise due to the instability of $\mathrm{Au}(\mathrm{III})$ in a biological environment. Many $\mathrm{Au}(\mathrm{III})$ complexes are strong oxidants, able to be reduced to $\mathrm{Au}(\mathrm{I})$ (or indeed $\mathrm{Au}(0)$ ) by biologically occurring reductants such as thiols (-SH) or disulfides (-S-S-), which are themselves oxidised, inhibiting processes essential to cellular survival.[161] However it is not only gold complexes that display anti-microbial activities. Gold nanoparticles have also been shown to be highly toxic to numerous Gram-positive and Gram-negative bacteria ((Escherichia coli (E. coli, ATCC 8739), Staphylococcus aureus (S. aureus, ATCC 6538), Bacillus subtilis (B. subtilis, ATCC 21332), and Klebsiella mobilis (K. mobilis, ATCC 13048)) and fungi (Aspergillus niger (A. niger, ATCC 16404) and Penicillium citrinum (P. citrinum, ATCC 10499)), inhibiting up to approximately $98 \%$ of growth at $2.8 \mu \mathrm{g} / \mathrm{mL}(2.8 \mathrm{ppm})$. Similarly to silver, the anti-microbial action of these nanoparticles is suggested to arise due to their strong binding to electron donating groups in the bacterial cells.[163] With smaller diameter nanoparticles exhibiting increased anti-microbial activities due to their increased surface area to volume ratio, with more metal atoms available on the surface to interact with bacteria and fungi. It is not clear whether the anti-microbial action of the gold nanoparticles arises due to $\operatorname{Au}(0)$ or $\mathrm{Au}(\mathrm{I})$ on the surface of the nanoparticles, however due to the reported antimicrobial nature of $\mathrm{Au}(\mathrm{I})$, the latter is more likely. 


\section{$1.4 \quad$ Research Objectives}

It was proposed that gold and silver nanoparticles be combined in a synergistic manner with inexpensive particulate (kaolinite and halloysite clays) and fibre substrates (merino wool, crossbred wool and silk fibres), thus producing novel hybrid materials that could be incorporated into commercial products or act alone as high-value multi-functional entities.

Incorporation of silver nanoparticles into hybrids with clays has the potential to yield a novel suite of attractively coloured materials processing anti-microbial activities, thus giving rise to applications requiring the inhibition of microbial growth. It was envisaged that silver nanoparticles could be incorporated into hybrid materials containing clays through two main processes. Firstly silver nanoparticles would be prepared separately and attached to the clay through means of a linker molecule. Alternatively a dual reductant/stabiliser would be deposited onto the surface of the clay substrates, acting both to reduce ionic silver and subsequently bind the resultant nanoparticles through bonding to the clay surface. The rationale for attaching silver nanoparticles to clays was to produce attractively coloured, antimicrobial powders. As such, we were interested in retaining both the optical and antimicrobial properties of the nanoparticles.

It was proposed that gold nanoparticles be incorporated into silk, merino and crossbred wool fibres in much the same way. The nanoparticles will be produced ex-situ and subsequently attached to the fibre substrates by means of a linker molecule, or simply through their capping agents. Alternatively the natural fibres were to be utilised as redox active biotemplates in which the wool or silk absorbs and subsequently reduces $\mathrm{Au}^{3+}$ ions to $\mathrm{Au}^{0}$ nanoparticles. Gold nanoparticles were to act as colourfast colourants of the natural fibres, linking the wealth associated with this precious metal to silk, merino and crossbred wools, producing a novel suite of multi-functional, high quality textiles based on nanotechnology. It is envisaged that these materials will primarily be utilised in high-value, niche markets such as high-quality textiles for use in high-end fabrics and fashions. They also have the potential to be used as multi-functional textiles capitalising on the anti-microbial or insecticide and anti-static nature of gold nanoparticles. 
It was proposed that characterisation of the hybrid materials be undertaken through various methods. The morphology of the materials were studied with scanning electron microscopy, energy dispersive spectroscopy, transmission electron microscopy and scanning transmission electron microscopy. The optical properties were measured by ultra violet visible spectroscopy. X-ray dispersive, X-ray photoelectron, infra-red and Raman spectroscopy were utilised in determining the nature of the interaction between the nanoparticles and substrate. The anti-microbial properties of the composites were also measured. The colour stability to light, washing and rubbing of the gold nanoparticle-wool and silk materials were evaluated. Leaching tests were undertaken in which atomic absorption would be utilised to study the amount of gold leached from the gold nanoparticle-wool and silk materials following washing. Association with AgResearch Ltd, Lincoln, will assist in the industry certified testing of the physical properties of gold nanoparticle-wool and silk composite materials.

The new knowledge developed in this research will provide essential information for the scale-up of gold nanoparticle-fibre composites. The optimum synthesis procedures and conditions determined by this research will be employed in the large scale production of said materials, enabling market evaluation and the potential commercialisation of the high quality multi-functional textiles in high end apparel or luxury carpets. 


\section{EXPERIMENTAL METHODS}

\subsection{Materials}

$100 \%$ merino wool, untreated semi-worsted, and worsted gilled sliver and combed top respectively were supplied by Ashford Handicrafts Ltd Ashburton. Chlorine Hercosett treated semi-worsted sliver and untreated crossbred wools were supplied by AgResearch New Zealand Ltd, whilst silk fibres were provided by Commercio Laniero Italiano, Italy. Kaolinite and halloysite were obtained from Pure Science Ltd. All substrates (fibres and minerals) were used as received unless otherwise stated.

All chemicals employed were of analytical grade unless otherwise stated. Gold tetrachloride trihydrate $\left(\mathrm{HAuCl}_{4} .3 \mathrm{H}_{2} \mathrm{O}(99 \%)\right)$ was sourced from Sigma Aldrich, and silver nitrate from Scientific and Chemical Supplies. Sodium borohydride, trisodium citrate, tannic acid, sodium metabisulfite, polyethyleneimine, polymethacrylic acid, cetyl trimethylammonium bromide, polydiallyldimethylammonium chloride and poly(vinylpyrrolidone) were all sourced from Sigma Aldrich.

Hydroxylamine and ascorbic acid were sourced from Merck, whilst sodium chloride and sodium bromide were supplied by Unilab. Potassium phosphate dibasic, potassium phosphate monobasic, acetic acid, potassium hydroxide, sodium hydroxide, hydrochloric acid, tris(2-carboxyethly)phosphine and maleic acid were sourced from BDH Chemicals Ltd and ethanol, methanol, and n-heptane were provided by Pure Science Ltd. Distilled water was employed unless otherwise stated. 


\subsection{Preparation}

\subsubsection{Preparation of Silver Nanoparticle-Clay Composites}

The preparation of silver nanoparticle-clay composites included three general methods as outlined below. Preparation of silver nanoparticles, and subsequent attachment to the clay substrate using a linker molecule (section 2.2.1.1); preparation of silver nanoparticles in the presence of the clay substrate with in-situ binding of nanoparticles to the substrate (section 2.2.1.2); and the reduction of silver ions to metallic silver nanoparticles by a reductant bound to the clay substrate (section 2.2.1.3).

\subsubsection{1 ex-situ Preparation of Silver Nanoparticles and Subsequent Attachment to the Clay Substrate}

Numerous methods were employed to produce silver nanoparticles so that a range of colours were produced through the production of nanoparticles of different sizes and shapes. These methods involved the reduction of ionic silver (silver nitrate) by various reductants, surfactants and reaction conditions, as outlined in Table 2.1. (Note: occasionally there was no need for the inclusion of a surfactant, as the reductant also acted to stabilise the produced nanoparticles. Such materials included polyethyleneimine (PEI) and polymethacrylic acid (PMA)). Once produced, the clays were dispersed in the nanoparticle colloids in the aim of attaching the nanoparticles to the clay substrate either directly through the surrounding capping agents, or through the use of an ionic linker of opposite net charge to the stabiliser used in the production of the nanoparticles. For example, when using PMA as a stabiliser, the produced nanoparticles were surrounded by an anionic polymer, and as such a cationic linker such as polydiallyldimethylammonium chloride (PDADMAC) would be utilised. 
Table 2.1: Preparation of silver nanoparticles and subsequent attachment to clay substrate by a linker molecule.

\begin{tabular}{|c|c|c|c|c|c|c|}
\hline Reference & $\begin{array}{c}\text { Reducing } \\
\text { Agent }\end{array}$ & $\begin{array}{c}\text { Stabilising } \\
\text { Agent }\end{array}$ & $\begin{array}{l}\text { Reaction } \\
\text { Conditions }\end{array}$ & Linker & $\begin{array}{l}\text { Colloid } \\
\text { Colour }\end{array}$ & $\begin{array}{l}\text { Successful } \\
\text { Attachment }^{\star}\end{array}$ \\
\hline $\begin{array}{l}\text { Frens et } \\
\text { al.[112] }\end{array}$ & TSC & - & Heat at $90^{\circ} \mathrm{C}$ & - & $\begin{array}{l}\text { Orange } \\
\text { to blue }\end{array}$ & $\mathrm{X}$ \\
\hline $\begin{array}{l}\text { Sun et } \\
\text { al.[115] }\end{array}$ & $\mathrm{NaBH}_{4}$ & PVP & React at RT & PDADMAC & Yellow & $\mathrm{X}$ \\
\hline $\begin{array}{l}\text { Sun et } \\
\text { al.[115] }\end{array}$ & $\mathrm{NaBH}_{4}$ & PVP & $\begin{array}{l}\text { React at RT } \\
\text { followed by } \\
\text { irradiation } \\
\text { with broad } \\
\text { spectrum light }\end{array}$ & PDADMAC & Green & $\mathrm{X}$ \\
\hline $\begin{array}{l}\text { Sun et } \\
\text { al.[115] }\end{array}$ & $\mathrm{NaNH}_{4}$ & PMA & React at RT & PDADMAC & Yellow & $\sqrt{ }$ \\
\hline $\begin{array}{l}\text { Sun et } \\
\text { al.[115] }\end{array}$ & $\mathrm{NaBH}_{4}$ & PMA & $\begin{array}{l}\text { React at RT } \\
\text { followed by } \\
\text { irradiation } \\
\text { with broad } \\
\text { spectrum light }\end{array}$ & PDADMAC & Green & $\mathrm{X}$ \\
\hline $\begin{array}{c}\text { Dubas et } \\
\text { al.[2] }\end{array}$ & PMA & PMA & $\begin{array}{l}\text { Irradiate with } \\
\text { broad } \\
\text { spectrum light }\end{array}$ & PDADMAC & $\begin{array}{l}\text { Yellow, } \\
\text { orange } \\
\text { and red }\end{array}$ & $\sqrt{ }$ \\
\hline
\end{tabular}

* Successful attachment was determined optically by a colour development on the clays and a loss of colour in the colloid.

As can be seen from Table 2.1, the reduction of ionic silver and subsequent stabilisation of the produced nanoparticles by trisodium citrate (TSC) was unsuccessful in producing clay-silver nanoparticle hybrid materials. This is likely due to electrostatic repulsions between the TSC capped silver nanoparticles and clay surfaces. The TSC capped silver nanoparticle colloidal solutions have a $\mathrm{pH}$ of approximately 7.5 , which is higher than the pKa values of TSC,[164] kaolinite and halloysite,[165] and as such both the nanoparticles and clays would exhibit a net negative surface charge and thus electrostatically repel each other. However the use of a linker molecule, of opposite 
net charge to that of the stabilising agent resulted in the production of attractively coloured silver nanoparticle-clay composite materials, and this method is discussed in greater detail in section 2.2.1.1.2 below.

\subsection{Attachment of Silver Nanoparticles to Clay Substrate through a Linker Molecule of Opposite Net Charge to the Nanoparticles}

This method was the most successful in producing silver nanoparticle-clay composite materials. It involved absorbing the anionic polymeric linker molecule, PDADMAC, to the clay surfaces, followed by subsequent attachment of silver nanoparticles capped with the cationic polymer PMA via an electrostatic interaction (Figure 1.27).

Silver nanoparticle colloids capped with the cationic polymer PMA were prepared via two methods. Firstly, aqueous solutions of silver nitrate $(10 \mathrm{ml}, 10 \mathrm{mM})$ and PMA $(10 \mathrm{ml}, 10$ $\mathrm{mM}$ ) were combined and irradiated (at room temperature) with a broad spectrum light, upon which the UV component of the light reduced $\mathrm{Ag}^{+}$to $\mathrm{Ag}^{0}$ nanoparticles via a photo induced reduction.[2] PMA acted as a capping agent (stabiliser) to the produced nanoparticles. By varying the molar ratio between silver nitrate and PMA, and also irradiation time, silver nanoparticle colloids ranging in colour from yellow to orange, and pink to red were produced. Alternatively, silver nanoparticles capped with PMA were produced through the reduction of silver nitrate by sodium borohydride in the presence or TSC and PMA. This synthesis involved the addition of aqueous solutions of TSC $(0.5 \mathrm{ml}, 30 \mathrm{mM})$, silver nitrate $(1 \mathrm{ml}, 5 \mathrm{mM})$ and freshly prepared sodium borohydride $(0.5 \mathrm{ml}, 50 \mathrm{mM})$ to $47.5 \mathrm{ml} \mathrm{de}-$ oxygenated Millipore water under vigorous stirring at room temperature.[115] The solution was stirred for a further 30 seconds, then either poly(vinylpyrrolidone) (PVP) or PMA (0.5 $\mathrm{ml}, 5 \mathrm{mg} / \mathrm{ml}$ ) was added and the reaction left to proceed under constant stirring at room temperature for 30 minutes. This produced a yellow colloidal solution of spherical silver nanoparticles. Prolonged exposure $(\sim 1$ week) of this colloid to sunlight resulted in a photo induced conversion of nanospheres to triangular nanoplates, producing a green coloured colloidal solution.[115] Attachment of nanoparticles capped with PVP to the clays through a 
linker molecule was unsuccessful, which is likely attributable to the fact that PVP does not exhibit a net charge, and therefore is not electrostatically attracted to the ionic linker molecules.

Once produced, the PMA capped silver nanoparticles were attached to the clay substrates via an electrostatic interaction with PDADMAC adsorbed onto the clay surfaces. PDADMAC was attached to kaolinite or halloysite by dispersing the clays in an aqueous solution of PDADMAC (0.2 g clay per $20 \mathrm{ml}, 1 \mathrm{mM}$ PDADMAC solution). The $\mathrm{pH}$ of the solution was adjusted to 6.5 so that the surface Al-OH and edge Si-OH groups were deprotonated, increasing the electrostatic attraction between the cationic polymer and clay substrate. (Note, the basal silicate layers in both kaolinite and halloysite possess a net negative charge regardless of $\mathrm{pH}$ due to the replacement of a selection of $\mathrm{Si}^{4+}$ atoms with $\mathrm{Al}^{3+}$ atoms). The solution was stirred for 24 hours, upon which it was filtered and the resultant clayPDADMAC materials were collected and added to PMA capped silver nanoparticle solutions ( 0.1 g clay per $2 \mathrm{ml}$ nanoparticle colloid) and stirred vigorously for 5 minutes after which time the solutions were centrifuged (1200 rpm, 5 minutes) and the supernate decanted. The solid was re-dispersed in an aqueous PDADMAC solution $(2 \mathrm{ml}, 1 \mathrm{mM})$, stirred for 5 minutes, re-centrifuged, then re-dispersed in the silver nanoparticle suspensions. This layerby-layer deposition process (PMA-Ag nanoparticle deposition followed by a layer of cationic PDADMAC) was repeated at least four times to ensure an adequate deposition of nanoparticles onto the clays and hence colour development.

\subsubsection{Silver Nanoparticles Formed in the Presence of the Clay Substrate Using an External Reducing Agent With In-Situ Binding of Nanoparticles to Substrate}

Clays were dispersed in silver nitrate solutions and the $\mathrm{Ag}^{+}$to $\mathrm{Ag}^{0}$ reduction was attempted through the addition of various reductants (Table 2.2). It was hoped that by varying reaction time, temperature and reactant concentrations, a range of colloidal solutions of different colours would be obtained. 
Table 2.2: Preparation of silver nanoparticles by external reductants in the presence of clay substrate with in-situ binding of nanoparticles to clay.

\begin{tabular}{|c|c|c|c|c|}
\hline $\begin{array}{l}\text { Reducing } \\
\text { Agent }\end{array}$ & $\begin{array}{l}\text { Stabilising } \\
\text { Agent }\end{array}$ & Reaction Conditions & $\begin{array}{l}\text { Composite } \\
\text { Colour }\end{array}$ & $\begin{array}{l}\text { Successful } \\
\text { Production }\end{array}$ \\
\hline TSC & - & $\begin{array}{l}\text { Soak clay in a } \mathrm{AgNO}_{3} \\
\text { solution at } 90^{\circ} \mathrm{C} \text {, add } \mathrm{TSC}\end{array}$ & Grey & $\mathrm{X}$ \\
\hline TA & - & $\begin{array}{l}\text { Soak clay in a } \mathrm{AgNO}_{3} \\
\text { solution at } 90^{\circ} \mathrm{C} \text {, add } \mathrm{TA}\end{array}$ & Grey & $\mathrm{X}$ \\
\hline $\mathrm{NaBH}_{4}$ & - & $\begin{array}{l}\text { Soak clay in a } \mathrm{AgNO}_{3} \\
\text { solution at } 90{ }^{\circ} \mathrm{C} \text {, reduce } \\
\text { temperature, add } \mathrm{NaBH}_{4}\end{array}$ & Grey & $\mathrm{X}$ \\
\hline $\mathrm{NaBH}_{4}$ & PVP & $\begin{array}{l}\text { Soak clay in a } \mathrm{AgNO}_{3} \\
\text { solution at } 60^{\circ} \mathrm{C} \text {, filter, add } \\
\text { to solution containing } \\
\mathrm{NaBH}_{4}, \mathrm{TSC} \text { and PVP }\end{array}$ & $\begin{array}{c}\text { Pale } \\
\text { cream/yellow }\end{array}$ & $\mathrm{X}$ \\
\hline
\end{tabular}

None of the methods outlined in Table 2.2 above were successful. The resultant materials were grey in colour, suggesting agglomerations of nanoparticles and the formation of silver oxide. This suggests that combined with the clays, TSC, TA and PVP did not impart sufficient stabilisation to the resultant nanoparticles. This may be due to TSC, TA and PVP interacting preferentially with the clay substrates rather than the nanoparticles. As such, these methods were not pursued.

\subsubsection{Preparation of Silver Nanoparticle-Clay Composites by a Reductant Bound to the Clay Substrate}

The clay surfaces were modified by incorporation of polyethyleneimine (PEI), a polymer capable of reduction and stabilisation of silver in its ionic and metallic states respectively. The amino groups present in this polymer have previously been reported to be capable of reducing ionic silver to metallic silver nanoparticles.[16] It is cationic in character and as such will have a strong affinity towards both the anionic silicate layers in kaolinite and halloysite, and the surface hydroxyl groups following de-protonation. 
This production involved dispersing the clay $(10 \mathrm{~g})$ in an aqueous PEI solution $(30 \mathrm{mM}, 1$ $\mathrm{dm}^{3}$ water) with rapid stirring. The $\mathrm{pH}$ of the solution was adjusted to 6.5 with $0.1 \mathrm{M} \mathrm{HCl}$. (At this pH PEI will be partially protonated, and the surface $\mathrm{Si}-\mathrm{OH}$ and $\mathrm{Al}-\mathrm{OH}$ groups of the clays de-protonated (pKa of PEI and clays approximately 9 and 6 respectively)).[166, 167] As such absorption of PEI onto the clay surface will be facilitated by the electrostatic interaction between the cationic PEI and anionic clays. The resultant clay-PEI materials were filtered and washed well with water, after which they were added $(0.5 \mathrm{~g})$ to an aqueous silver nitrate solution $\left(50 \mathrm{ml}, 3.8 \times 10^{-5}-2.28 \times 10^{-4} \mathrm{M}\right)$ and stirred at $30^{\circ} \mathrm{C}$ for 1 hour, upon which a colour change from cream to a very faint pink was noted. As the colour change denoting the formation of silver nanoparticles was very minimal, this method was not pursued.

\subsubsection{Preparation of Gold Nanoparticle-Natural Fibre Composites}

The preparation of gold nanoparticle-natural fibre composites was attempted via the following four main methods:

- $\mathrm{Au}^{3+}$ was reduced to nanoparticulate $\mathrm{Au}^{0}$ ex-situ by an external reducing agent and subsequently attached to the fibrous substrates through their capping agents (section 2.2.2.1).

- The reduction of $\mathrm{Au}^{3+}$ to nanoparticulate $\mathrm{Au}^{0}$ was carried out in the presence of the fibre substrates (section 2.2.2.2).

- The natural fibres were utilised as redox active templates, in which the wool or silk absorbs and subsequently reduces $\mathrm{Au}^{3+}$ to $\mathrm{Au}^{0}$ nanoparticles (section 2.2.2.3).

- A seed mediated growth approach was employed in which gold nanoparticle-fibre composites catalysed the reduction of $\mathrm{Au}^{3+}$ by $\mathrm{NH}_{2} \mathrm{OH}$ to nanoparticulate $\mathrm{Au}^{0}$ (section 2.2.2.4). 


\subsubsection{1 ex-situ Preparation of Gold Nanoparticles and Subsequent Attachment to Merino Wool Fibres}

Similar to the ex-situ production of silver nanoparticles (section 2.2.1.1), various methods were employed to produce gold nanoparticles so that a range of colours were produced through the production of nanoparticles of different sizes and shapes. This was achieved through the reduction of gold(III) (typically as a $4 \mathrm{wt} \% \mathrm{Au}^{3+}$ solution made from $\mathrm{HAuCl}_{4} .3 \mathrm{H}_{2} \mathrm{O}$ dissolved in $0.1 \mathrm{M} \mathrm{HCl}$ ) by various reductants, stabilising agents and reaction conditions, as outlined in Table 2.3 below.

Table 2.3: ex-situ preparation of gold nanoparticles and subsequent attachment to wool fibres.

\begin{tabular}{|c|c|c|c|c|c|c|}
\hline Reference & $\begin{array}{c}\text { Reducing } \\
\text { Agent }\end{array}$ & $\begin{array}{l}\text { Stabilising } \\
\text { Agent }\end{array}$ & $\begin{array}{l}\text { Reaction } \\
\text { Conditions }\end{array}$ & $\begin{array}{l}\text { Colloid } \\
\text { Colour }\end{array}$ & $\begin{array}{l}\text { Composite } \\
\text { Colour }\end{array}$ & $\begin{array}{l}\text { Successful } \\
\text { Attachment }^{\star}\end{array}$ \\
\hline \multirow[t]{2}{*}{$\begin{array}{l}\text { Turkevitch } \\
\text { et al.[114] }\end{array}$} & TSC & - & $\begin{array}{l}\text { Heat at } 90 \\
{ }^{\circ} \mathrm{C}\end{array}$ & $\begin{array}{c}\text { Pale } \\
\text { yellow to } \\
\text { wine red }\end{array}$ & $\begin{array}{c}\text { Pale yellow } \\
\text { to grey }\end{array}$ & $\sqrt{ }$ \\
\hline & TA & - & $\begin{array}{l}\text { Heat at } 90 \\
{ }^{\circ} \mathrm{C}\end{array}$ & $\begin{array}{l}\text { Light pink } \\
\text { to wine red } \\
\text { and } \\
\text { orange }\end{array}$ & $\begin{array}{l}\text { Murky pale } \\
\text { pink to } \\
\text { purple }\end{array}$ & $\sqrt{ }$ \\
\hline $\begin{array}{l}\text { Murphy et } \\
\text { al.[125, } \\
168]\end{array}$ & $\begin{array}{l}\mathrm{NaBH}_{4}, \\
\text { ascobic } \\
\text { acid }\end{array}$ & CTAB & $\begin{array}{c}3 \text { step } \\
\text { seeded } \\
\text { growth, RT }\end{array}$ & $\begin{array}{l}\text { Not re- } \\
\text { producible }\end{array}$ & - & $X$ \\
\hline $\begin{array}{l}\text { Huang et } \\
\text { al.[169] }\end{array}$ & $\begin{array}{c}\mathrm{NaBH}_{4}, \\
\text { Ascorbic } \\
\text { acid }\end{array}$ & CTAB & $\begin{array}{l}\text { Seeded } \\
\text { growth, RT }\end{array}$ & Yellow & - & $X$ \\
\hline
\end{tabular}

* Successful attachment was determined optically by a colour development on the fibres and a loss of colour in the colloid.

The synthesis of gold nanoparticles by the reduction of $\mathrm{Au}^{3+}$ (in the form of $\mathrm{AuCl}_{4}{ }^{-}$) follows the method outlined by Turkevitch and co-workers. $\mathrm{Au}^{3+}$ solutions $(160 \mathrm{ppm}, 40 \mu \mathrm{L} 4 \mathrm{wt} \%$ $\mathrm{Au}^{3+}$ added to $10 \mathrm{ml}$ distilled water) were heated to $90{ }^{\circ} \mathrm{C}$ under rapid stirring. Once at 90 ${ }^{\circ} \mathrm{C}$, TSC or TA was added, and heating continued for a further 10 minutes. Colloids in a range of colours were produced by varying the ratio of $\mathrm{Au}^{3+}$ :TSC or TA. This was achieved through the addition of different amounts of reductant $(10,20$ or $50 \mu \mathrm{L}$ of 1 or 10 wt $\%$ TSC or TA). Once produced, the colloids were cooled to room temperature, and merino wool was added $(0.1 \mathrm{~g}$ wool per $10 \mathrm{ml}$ colloid). The reaction mixtures were gently agitated at room 
temperature from 10 minutes to 24 hours to facilitate in the adsorption of TSC or TA capped Au nanoparticles. The resultant merino wool-TSC or TA capped gold nanoparticle materials were washed thoroughly with water and air dried under ambient conditions.

In an attempt to increase the colour range of gold nanoparticle-merino wool materials, the synthesis of gold nanorods was undertaken. Various procedures were employed however the methods that were the most amenable to the production of gold nanoparticle-merino wool materials are the two based on those reported by Murphy et al.[125] and Huang et al.[169] summarised in Table 2.3. Both of these methods are seed-mediated approaches and involve the reduction of $\mathrm{Au}^{3+}$ with a strong reducing agent to produce $\mathrm{Au}^{0}$ seed particles (average diameter $4 \mathrm{~nm}$ ) followed by the subsequent reduction of additional $\mathrm{Au}^{3+}$ ions with a weak reducing agent (ascorbic acid (Vit $\mathrm{C}$ )), in the presence of the seed particles and a structure directing agent cetyl trimethylammonium bromide (CTAB).

When employing the Murphy method, gold seeds were produced by adding, $\mathrm{HAuCl}_{4} .3 \mathrm{H}_{2} \mathrm{O}$ $(0.5 \mathrm{ml}, 10 \mathrm{mM})$ and $\mathrm{TSC}(0.5 \mathrm{ml}, 10 \mathrm{mM})$ were to Millipore water $(18 \mathrm{ml})$ and stirring (Figure 2.1 (1)). Freshly prepared $\mathrm{NaBH}_{4}$ was added $(0.5 \mathrm{ml}, 0.1 \mathrm{M})$ and stirring was stopped. The solution was left undisturbed for two hours. For gold nanorod growth from the produced seeds, three growth solutions, A, B and C were prepared (Figure 2.1 (2)). Growth solutions A and B consisted of CTAB $(9 \mathrm{ml}, 0.1 \mathrm{M}), \mathrm{HAuCl}_{4} \cdot 3 \mathrm{H}_{2} \mathrm{O}(0.25 \mathrm{ml}, 10 \mathrm{mM})$ ascorbic acid $(50 \mu \mathrm{L}, 0.1 \mathrm{M})$ and $\mathrm{NaOH}(50 \mu \mathrm{L}, 0.1 \mathrm{M})$. (For nanorods with an aspect ratio of $\sim 20$, heptane was added to make a final heptane concentration of $0.1 \mathrm{M}$, and $\sim 25$, the volume of $\mathrm{NaOH}$ was doubled to $100 \mu \mathrm{L})$. Growth solution C consisted of CTAB $(90 \mathrm{ml}$, $0.1 \mathrm{M}) \mathrm{HAuCl}_{4} .3 \mathrm{H}_{2} \mathrm{O}(2.5 \mathrm{ml}, 10 \mathrm{mM})$, ascorbic acid $(0.5 \mathrm{ml}, 0.1 \mathrm{M})$ and $\mathrm{NaOH}(0.5 \mathrm{ml}, 0.1$ M). The growth protocol consisted of adding $1 \mathrm{ml}$ of the seed solution to growth solution A, shaking growth solution A for 3-5 seconds and then adding $1 \mathrm{ml}$ of A to B. B was then shaken for 3-5 seconds upon which all of B was added to growth solution C (Figure 2.1 (3)). $\mathrm{C}$ was left to react at room temperature overnight.[125, 168] 

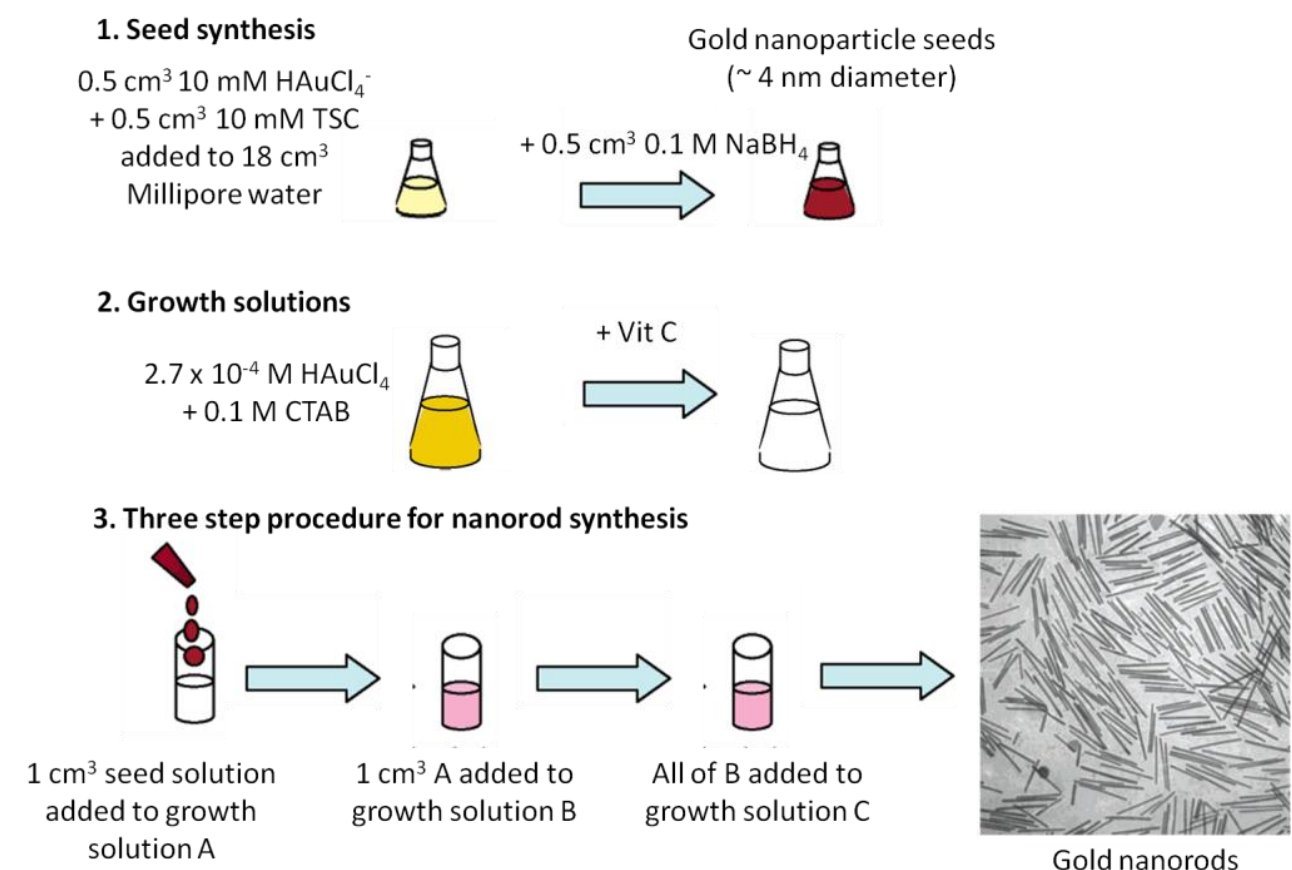

Gold nanorods

Figure 2.1: Murphy et al. Seed-mediated method for the production of gold nanorods of controlled aspect ratio.[125, 168]

In a typical proceduce reported by Huang and co-workers,[169] gold seeds were produced through the addition of aqueous $\mathrm{HAuCl}_{4} \cdot 3 \mathrm{H}_{2} \mathrm{O}(0.25 \mathrm{ml}, 10 \mathrm{mM})$ to a CTAB solution (7.5 $\mathrm{ml}, 0.1 \mathrm{M})$, followed by the addition of freshly prepared, ice cold $\mathrm{NaBH}_{4}(0.6 \mathrm{ml}, 0.01 \mathrm{M})$ with rapid stirring for 2 minutes. The reaction vessel was immersed in water and maintained at a constant temperature of $25{ }^{\circ} \mathrm{C}$ for 2 hours. To produce gold nanorods, CTAB (4.75 ml, $0.1 \mathrm{M}), \mathrm{HAuCl}_{4} .3 \mathrm{H}_{2} \mathrm{O}(0.2 \mathrm{ml}, 10 \mathrm{mM})$ and $\mathrm{AgNO}_{3}(30 \mu \mathrm{L}, 10 \mathrm{mM})$ were combined. Ascorbic acid was added to this reaction mixture $(10-40 \mu \mathrm{L}, 0.1 \mathrm{M})$, and finally $10 \mu \mathrm{L}$ of the seed solution was added and the reaction mixture was stirred gently for 10 seconds before it was left to react at room temperature for at least 3 hours.[169]

2.2.2.2 Gold Nanoparticles Formed in the Presence of Wool by an External Reducing Agent with in-situ Binding of Nanoparticles to Fibres

Merino wool $(0.1 \mathrm{~g})$ was dispersed in aqueous gold tetrachloride solutions $(10 \mathrm{ml})$ and the reduction of $\mathrm{Au}^{3+}$ to $\mathrm{Au}^{0}$ nanoparticles was facilitated by the addition of various reductants 
(Table 2.4). Alternatively, merino wool was dispersed in aqueous solutions of various reductants, followed by the addition of gold tetrachloride. It was hoped that through variation of the ratio between the reductants and $\mathrm{Au}^{3+}$, gold nanoparticles of different sizes and hence different colours would be produced. Additionally, gold nanoparticle-merino wool composites (prepared through utilisation of the redox active nature of merino) were added to a solution containing additional $\mathrm{Au}^{3+}$ ions, a mild reducing agent and a structural directing agent in the hope of synthesising gold nanorods.

Table 2.4: Preparation of gold nanoparticles in the presence of merino by an external reductant with insitu binding of nanoparticles to fibre.

\begin{tabular}{|c|c|c|c|c|c|}
\hline Reference & $\begin{array}{l}\text { Reducing } \\
\text { Agent }\end{array}$ & $\begin{array}{l}\text { Stabilising } \\
\text { Agent }\end{array}$ & Reaction Conditions & $\begin{array}{l}\text { Composite } \\
\text { Colour }\end{array}$ & $\begin{array}{l}\text { Successful } \\
\text { Production* }\end{array}$ \\
\hline & TSC & - & $\begin{array}{l}\text { Soak merino in a } \mathrm{HAuCl}_{4} \\
\text { solution, add TSC }\end{array}$ & - & $\mathrm{X}$ \\
\hline & TSC & - & $\begin{array}{l}\text { Soak merino in a TSC } \\
\text { solution, add } \mathrm{HAuCl}_{4}\end{array}$ & $\mathrm{X}$ & $\mathrm{X}$ \\
\hline & $\mathrm{Na}_{2} \mathrm{~S}_{2} \mathrm{O}_{5}$ & - & $\begin{array}{l}\text { Soak merino in a } \mathrm{HAuCl}_{4} \\
\text { solution, add } \mathrm{Na}_{2} \mathrm{~S}_{2} \mathrm{O}_{5}\end{array}$ & $\mathrm{X}$ & $\mathrm{X}$ \\
\hline & $\mathrm{Na}_{2} \mathrm{~S}_{2} \mathrm{O}_{5}$ & - & $\begin{array}{l}\text { Soak merino in a } \mathrm{Na}_{2} \mathrm{~S}_{2} \mathrm{O}_{5} \\
\text { solution, add } \mathrm{HAuCl}_{4}\end{array}$ & $\begin{array}{l}\text { Pale to } \\
\text { steely grey }\end{array}$ & Partial \\
\hline $\begin{array}{l}\text { Huang et } \\
\text { al.[169] }\end{array}$ & $\begin{array}{l}\text { Ascorbic } \\
\text { acid }\end{array}$ & CTAB & $\begin{array}{l}\text { Soak a merino-gold } \\
\text { material in a gold solution } \\
\text { containing CTAB and } \\
\mathrm{AgNO}_{3} \text {, add ascorbic acid }\end{array}$ & $\begin{array}{l}\text { Light pink } \\
\text { to deep } \\
\text { purple }\end{array}$ & Partial \\
\hline $\begin{array}{l}\text { Liu et } \\
\text { al.[170] }\end{array}$ & $\begin{array}{l}\text { Ascorbic } \\
\text { acid }\end{array}$ & CTAB & $\begin{array}{l}\text { Soak a merino-gold } \\
\text { material in a gold solution } \\
\text { containing CTAB, add } \\
\text { ascorbic acid }\end{array}$ & Purple/Grey & Partial \\
\hline
\end{tabular}

* Successful attachment was determined optically by a colour development on the fibres.

Dispersing merino wool in a gold solution for various times (1, 5 or 360 minutes) at a range of temperatures (room temperature, 50 or $90{ }^{\circ} \mathrm{C}$ ) followed by addition of a reductant (TSC or $\mathrm{Na}_{2} \mathrm{~S}_{2} \mathrm{O}_{5}$ ) was unsuccessful in the production of merino wool-gold nanoparticle composites. However when the opposite approach was taken, and merino was dispersed in an aqueous solution containing the reductant $\mathrm{Na}_{2} \mathrm{~S}_{2} \mathrm{O}_{5}$, followed by the addition of $\mathrm{HAuCl}_{4}$ gold nanoparticle-merino wool composites of attractive colours, ranging from light grey to bluey grey and finally steely grey were produced, however this method was unreliable and not reproducible. This synthesis method is outlined in section 2.2.2.2.1 below. Utilising TSC in 
place of $\mathrm{Na}_{2} \mathrm{~S}_{2} \mathrm{O}_{5}$ was unsuccessful in the production of gold nanoparticle-merino wool composites, with little to no $\mathrm{Au}^{3+}$ being reduced to $\mathrm{Au}^{0}$. This suggests that TSC may be a stronger reductant than $\mathrm{Na}_{2} \mathrm{~S}_{2} \mathrm{O}_{5}$, reducing the wool and becoming oxidised, and therefore being unable to execute the reduction of $\mathrm{Au}^{3+}$ to nanoparticulate $\mathrm{Au}^{0}$.

\subsubsection{1 in-situ Preparation of Gold Nanoparticles by Sodium Metabisulfite in the} Presence of Merino Fibres

Merino wool $(0.1 \mathrm{~g})$ was added to an aqueous solution of $\mathrm{Na}_{2} \mathrm{~S}_{2} \mathrm{O}_{5}(50 \mu \mathrm{L} 10$ wt $\%$ in $10 \mathrm{ml}$ distilled water) and heated at $90{ }^{\circ} \mathrm{C}$ for 10 minutes. Following this, $\mathrm{HAuCl}_{4}$ was added with gentle agitation $\left(10 \mu \mathrm{L} 4 \mathrm{wt} \% \mathrm{Au}^{3+}\right)$. The reaction mixture was removed from the heat and agitated at room temperature for 30 minutes, upon which the produced $\mathrm{S}_{2} \mathrm{O}_{5}{ }^{2-}$ capped gold nanoparticles were absorbed onto the wool surface. The resultant materials were washed well with distilled water and dried under ambient conditions. The volume of $4 \mathrm{wt} \% \mathrm{Au}^{3+}$ was varied between $10-40 \mu \mathrm{L}$ in the aim of producing composite materials of different colours. As mentioned above this method was not reproducible as the colour of the resultant materials varied, even when great precion was used in their preparation. As such this method was not pursued.

\subsubsection{2 in-situ Preparation of Gold Nanorods}

In an attempt to extend the colour range of the gold nanoparticle-merino wool composites, particularly to green, the in-situ preparation of gold nanorods was undertaken. These syntheses were based on reports from Huang [169] and Liu.[170] The first involved the addition of aqueous ascorbic acid $(0,10,20,30$ or $40 \mu \mathrm{L}$ of $0.1 \mathrm{M})$ to an aqueous solution containing CTAB $(4.75 \mathrm{ml}, 0.2 \mathrm{M}), \mathrm{AuCl}_{4}{ }^{-}\left(19.66 \mu \mathrm{L}\right.$ of 4 wt \%) and $\mathrm{AgNO}_{3}(30 \mu \mathrm{L}$ of 0.01 M). Following this, a gold nanoparticle-wool composite (prepared via the in-situ method outlined in section 2.2.2.3 and Table 2.6 below) was added to the reaction mixture and left to react for at least 3 hours at RT. 
Alternatively, a 'growth solution' was prepared through the addition of CTAB (6 g) to an aqueous gold solution $(200 \mathrm{ml}, 250 \mu \mathrm{M})$ at $60^{\circ} \mathrm{C}$. This was then left to cool and reaction solutions were prepared through the addition of ascorbic acid $(5,50$ and $500 \mu \mathrm{L}, 10 \mathrm{mM})$ to three volumes of 'growth solution' $(0.2,20$ and $200 \mu \mathrm{L}$ ). A gold seed (seed 1 or 2 from Table 2.5) was added to the reaction solution containing $5 \mu \mathrm{L}$ ascorbic acid and $0.2 \mu \mathrm{L}$ growth solution, and the two remaining solutions (the 20 and $200 \mu \mathrm{L}$ growth solutions containing 50 and $500 \mu \mathrm{L}$ of Ascorbic acid respectively) were added, (in order of increasing volume) at 1 minute intervals. The reaction mixtures were left to react, with gentle agitation, for 72 hours at room temperature.

Table 2.5: Preparation of gold nanoparticle-merino wool materials used as a seed source for the preparation of gold nanorods.

\begin{tabular}{cccc}
\hline Seed & $\begin{array}{c}\text { Gold Concentration } \\
\text { (ppm) }\end{array}$ & $\begin{array}{c}\text { Soak Time } \\
\text { (RT, hours) }\end{array}$ & $\begin{array}{c}\text { Age Time } \\
\left(\mathbf{5 0} \mathbf{\circ}^{\circ} \mathbf{C}, \text { hours }\right)\end{array}$ \\
\hline $\mathbf{1}$ & 80 & 24 & 24 \\
$\mathbf{2}$ & 160 & 24 & 24 \\
$\mathbf{3}$ & 160 & 24 & 168 \\
\hline
\end{tabular}

\subsubsection{3. in-situ Preparation of Gold Nanoparticles Utilising Wool and Silk as Redox Active Biotemplates}

It has been established by ourselves [171] that the proteins found in merino wool are capable of facilitating the reduction of $\mathrm{Au}^{3+}$ to nanoparticulate $\mathrm{Au}^{0}$, with in-situ binding of the produced nanoparticles to the fibre, resulting in the deposition of gold nanoparticles on the surface, and throughout the fibre centre. This technology has also been successfully extended to crossbred wools and silk (see sections 6 \& 7).

The typical procedure involved dispersing the fibre $(0.1 \mathrm{~g})$ in an aqueous gold tetrachloride solution (160 ppm, $40 \mu \mathrm{L} 4 \mathrm{wt} \% \mathrm{Au}^{3+}$ to $10 \mathrm{ml}$ distilled water) with gentle agitation at room temperature (0-48 hours) to facilitate the absorption and subsequent diffusion of $\mathrm{Au}^{3+}$ or 
$\mathrm{AuCl}_{4}$. Following this, the reaction mixture was 'aged' through heating $\left(50,80\right.$ or $\left.100{ }^{\circ} \mathrm{C}\right)$ for 1-168 hours, during which time the $\mathrm{Au}^{3+}$ to $\mathrm{Au}^{0}$ nanoparticles reduction occurred.

Numerous factors were altered to both optimise this process and produce a broad range of attractively coloured composite materials, with a primary aim of minimising the amount of gold used. These variations included: fibre pre-treatment, soaking solution composition, gold uptake (soaking time), ageing (heating) solution composition and ageing time and are summarised in the following sections (2.2.2.3.1 - 2.2.2.3.3).

\subsection{Fibre Pre-Treatment}

Merino wool (semi-worsted gilled sliver, worsted combed top or woven fabric), crossbred wool (slubbing) and silk (top) were either used as received or pre-treated as follows. Fibres (1 g) were dispersed in the requisite treatment solution $(10 \mathrm{ml}, 0.1 \mathrm{M} \mathrm{HCl}, 0.1 \mathrm{M}$ $\mathrm{CH}_{3} \mathrm{CHOOH}, 0.01-1 \mathrm{M} \mathrm{KOH}, 0.001 \mathrm{mM}-1 \mathrm{M} \mathrm{NaCl}$ at room temperature) for times ranging from 5-30 minutes. These pre-treatments were employed in an attempt to change the surface chemistry of the fibres, and to investigate the effect of such changes on the production of the gold nanoparticle-merino wool composite materials.

Alcoholic alkali pre-treatments were also undertaken in the aim of removing the fatty acid layer bound to the wool surface. This involved dispersing wool $(1 \mathrm{~g})$ in $\mathrm{KOH}$ dissolved in methanol (100 ml, 0.1 M) for 5-30 minutes at room temperature. Alternatively the wool was cleaned by Soxhlet extraction in a 2:1 chloroform : methanol solution for 5 hours to remove surface contaminants such as processing lubricants.[172]

Chlorine Hercosett treated merino wool supplied by AgResearch Ltd Lincoln was also used. As mentioned in section 1.2.2.1.5, the chlorine Hercosett treatment renders fibres shrink resistant through oxidation and chlorination of the fibre surface (by chlorine gas generated in-situ from sodium hypochlorite and sulfuric acid) and subsequent application of the cationic Hercosett polymer. 
Additionally the disulfide bonds of cystine in merino wool were reduced to thiol groups ($\mathrm{SH})$ through exposure of wool $(1 \mathrm{~g})$ to tris(2-carboxyethly)phosphine (TCEP) $(1 \mathrm{mM})$ in a pH 4.5 acetate buffer $(40 \mathrm{ml}, 0.4 \mathrm{M})$ for 3 hours at room temperature. Following this, the reduced wool was alkylated to prevent re-oxidation of the thiol groups. This involved soaking the reduced wool $(1 \mathrm{~g})$ in a pH 8 phosphate buffer solution $(50 \mathrm{ml}, 0.4 \mathrm{M})$ containing the alkylating agent maleic acid $(10 \mathrm{mM})$ and $\mathrm{n}$-propanol $(50 \mathrm{ml})$ for 1 hour at room temperature.

Silk fibres ( $1 \mathrm{~g}$ in top form) were heated, under reflux, in an aqueous $\mathrm{Na}_{2} \mathrm{CO}_{3}$ solution (10 $\mathrm{ml}, 0.1 \mathrm{M}$ ) for 1 hour, with the aim of removing any residual sericin not previously removed during degumming. Following treatment, all pre-treated fibres were washed thoroughly with distilled water and dried under ambient conditions prior to use.

\subsection{Soaking Solution}

The effect that the soaking solution had on the uptake of $\mathrm{Au}^{3+}$ ions by the fibres, and subsequent reduction to $\mathrm{Au}^{0}$ nanoparticles was studied by varying the soaking time and soaking solution composition (Table 2.6) (or compositions, as on particular occasions the fibres were soaked in one solution and then transferred to another (Table 2.7)). All soaking took place at room temperature, with gentle agitation. The fibrous substrate (silk, merino or crossbred wool, $0.1 \mathrm{~g}$ ) was added to the soaking solution and stirred to ensure an even 'wetness' of fibres. Glass or plastic rods were used in place of metal spatulas when stirring the gold soaking solutions to prevent the reduction of $\mathrm{Au}^{3+}$ to $\mathrm{Au}^{0}$ by the stainless steel spatulas, and subsequent deposition of $\mathrm{Au}^{0}$. 
Table 2.6: Single soaking solution. Soaking time and soaking solution composition. Single Soaking Solution

\begin{tabular}{|c|c|c|c|}
\hline $\begin{array}{l}\text { Vol. } 4 \text { wt \% Au }{ }^{3+} \\
\qquad(\mu \mathrm{L})\end{array}$ & Solvent & $\mathrm{pH}$ & $\begin{array}{c}\text { Soaking Time } \\
\text { (RT) }\end{array}$ \\
\hline $10-50$ & $\begin{array}{l}\text { 4-10 ml distilled } \\
\text { water }\end{array}$ & $2.7-12$ & 10 min-48 hours \\
\hline 40 & $10 \mathrm{ml} 0.1 \mathrm{M} \mathrm{NaCl}$ & $2.7-9$ & 24 hours \\
\hline 40 & $\begin{array}{l}10 \mathrm{ml} 0.1 \mathrm{M} \mathrm{NaCl} \text {, } \\
\mathrm{NaBr}, \mathrm{MgCl}_{2} \\
\mathrm{~K}_{2} \mathrm{HPO}_{4} \text { or } \\
\mathrm{KH}_{2} \mathrm{PO}_{4}\end{array}$ & $2.7-8$ & 24 hours \\
\hline 40 & $\begin{array}{l}10 \mathrm{ml} \text { distilled } \\
\text { water }\end{array}$ & $\begin{array}{l}2.7 \text { for first hour, } \\
6.5-8 \text { for remaining } \\
23 \text { hours }\end{array}$ & 24 hours \\
\hline
\end{tabular}

Table 2.7: Multiple soaking solutions. Soaking times and soaking solution compositions.

\begin{tabular}{|c|c|c|c|c|c|c|c|}
\hline \multicolumn{8}{|c|}{ Multiple Soaking Solutions } \\
\hline \multicolumn{4}{|c|}{ Soaking Solution I } & \multicolumn{4}{|c|}{ Soaking Solution II } \\
\hline $\begin{array}{l}\text { Vol. } 4 \text { wt \% } \\
\mathrm{Au}^{3+}(\mu \mathrm{L})\end{array}$ & Solvent & $\mathrm{pH}$ & $\begin{array}{l}\text { Soaking } \\
\text { Time (RT) }\end{array}$ & $\begin{array}{l}\text { Vol. } 4 \text { wt \% } \\
\mathrm{Au}^{3+}(\mu \mathrm{L})\end{array}$ & Solvent & $\mathrm{pH}$ & $\begin{array}{l}\text { Total Soaking } \\
\text { Time (RT) }\end{array}$ \\
\hline 40 & $\begin{array}{l}10 \mathrm{ml} \text { distilled } \\
\text { water }\end{array}$ & 2.7 & $\begin{array}{l}6 \text { or } 18 \\
\text { hours }\end{array}$ & - & Distilled water & 7 & 24 or 48 hours \\
\hline 40 & $\begin{array}{l}10 \mathrm{ml} \text { distilled } \\
\text { water }\end{array}$ & 2.7 & $\begin{array}{l}6 \text { or } 18 \\
\text { hours }\end{array}$ & - & $\begin{array}{l}0.1 \mathrm{M} \text { acetate } \\
\text { buffer }\end{array}$ & 2.7 & 24 or 48 hours \\
\hline 40 & $\begin{array}{l}10 \mathrm{ml} \text { distilled } \\
\text { water }\end{array}$ & 2.7 & 6 hours & - & $0.1 \mathrm{M} \mathrm{NaCl}$ & 7 & 48 hours \\
\hline $50-80$ & $\begin{array}{l}10 \mathrm{ml} \text { distilled } \\
\text { water }\end{array}$ & 2.7 & $5-15$ mins & - & Distilled water & 7 & 24 hours \\
\hline $50-80$ & $\begin{array}{l}10 \mathrm{ml} \text { distilled } \\
\text { water }\end{array}$ & 2.7 & $5-15$ mins & - & $1 \mathrm{mM} \mathrm{NaCl}$ & 7 & 24 hours \\
\hline 60 & $\begin{array}{l}10 \mathrm{ml} \text { distilled } \\
\text { water }\end{array}$ & 2.7 & 10 mins & - & $0.1-1 \mathrm{M} \mathrm{NaCl}$ & 7 & 24 hours \\
\hline 60 & $\begin{array}{l}10 \mathrm{ml} \text { distilled } \\
\text { water }\end{array}$ & 2.7 & 10 mins & - & $\begin{array}{l}0.1 \mathrm{M} \mathrm{NaCl} \text { in } \\
10 \mathrm{ml} 0.1 \mathrm{M} \\
\mathrm{HCl}\end{array}$ & 1 & 24 hours \\
\hline 60 & $\begin{array}{l}10 \mathrm{ml} \text { distilled } \\
\text { water }\end{array}$ & 2.7 & 10 mins & - & $0.4 \mathrm{mM} \mathrm{NaCl}$ & 7 & 24 hours \\
\hline 60 & $\begin{array}{l}10 \mathrm{ml} \text { distilled } \\
\text { water }\end{array}$ & 2.7 & 10 mins & - & $0.4 \mathrm{mM} \mathrm{HCl}$ & 7 & 24 hours \\
\hline $20-40$ & $\begin{array}{l}4-7.5 \mathrm{ml} \\
\text { distilled water }\end{array}$ & 2.7 & $\begin{array}{l}1 \text { min- } 6 \\
\text { hours }\end{array}$ & - & $0.1 \mathrm{M} \mathrm{NaCl}$ & 7 & 24 hours \\
\hline
\end{tabular}


The standard soaking solution contained $\mathrm{Au}^{3+}\left(40 \mu \mathrm{L}, 4\right.$ wt $\% \mathrm{Au}^{3+}$ (typically $0.8 \mathrm{~g}$ $\mathrm{HAuCl}_{4} \cdot 3 \mathrm{H}_{2} \mathrm{O}$ was weighed into a glass jar and made up to $10 \mathrm{~g}$ with $0.1 \mathrm{M} \mathrm{HCl}$ to obtain the desired concentration)) in distilled water $(10 \mathrm{ml})$ to produce a $160 \mathrm{ppm}$, or $8.13 \times 10^{-4} \mathrm{M}$, gold solution. The gold concentration was altered through both the addition of more or less gold (10-50 $\mu \mathrm{L} 4 \mathrm{wt} \%)$, or through changing the solvent volume (4-10 ml). The $\mathrm{pH}$ of these solutions was approximately 2.7 .

The composition of the soaking solution was varied through the addition of $\mathrm{Au}^{3+}$ to aqueous solutions of $\mathrm{NaCl}, \mathrm{NaBr}, \mathrm{MgCl}_{2}, \mathrm{~K}_{2} \mathrm{HPO}_{4}$ or $\mathrm{KH}_{2} \mathrm{PO}_{4}(10 \mathrm{ml}, 0.1 \mathrm{M})$ in place of distilled water. In addition the $\mathrm{pH}$ of the soaking solution was adjusted ( $\mathrm{pH} 4-12)$ through the addition of $0.1 \mathrm{M} \mathrm{KOH}$. Wool was either added directly to these altered solutions, or firstly soaked in a normal $\mathrm{Au}^{3+}$ solution $\left(40 \mu \mathrm{L} 4 \mathrm{wt} \% \mathrm{Au}^{3+}\right.$ added to distilled water) for 5 minutes to 18 hours (in order to absorb the gold) before being transferred to the altered soaking solutions (thus investigating the effect the soaking solution had on the diffusion of gold through the fibres and the reduction of $\mathrm{Au}^{3+}$ to $\mathrm{Au}^{0}$ ).

\subsection{Ageing Solution}

Similarly to the soaking solution, the effect of the ageing solution on the reduction of $\mathrm{Au}^{3+}$ to nanoparticulate $\mathrm{Au}^{0}$ was studied through variation of the ageing time, temperature and ageing solution composition. The reduction of $\mathrm{Au}^{3+}$ to $\mathrm{Au}^{0}$ nanoparticles was facilitated by heat.

Ageing was carried out in the original soaking solution at 50,80 or $100{ }^{\circ} \mathrm{C}$ for $1-168$ hours.

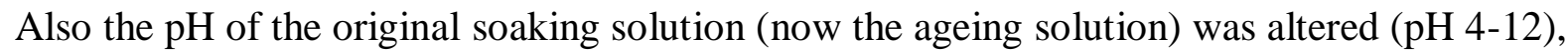
or the wool soaked in gold was transferred to an alternate ageing solution containing extra electrolytes $\left(\mathrm{NaCl}, \mathrm{NaBr}, \mathrm{MgCl}_{2}, \mathrm{~K}_{2} \mathrm{HPO}_{4}\right.$ or $\left.\mathrm{KH}_{2} \mathrm{PO}_{4}\right)$ or simply aged in distilled water (Table 2.8). 


\begin{tabular}{lcll}
\hline Ageing Solution & & & \\
\hline \multicolumn{1}{c}{ Composition } & $\mathbf{p H}$ & Age Temperature $\left({ }^{\circ} \mathbf{C}\right)$ & Age Time (hours) \\
\hline Original soaking solution & Unchanged & 50,80 or 100 & $1-168$ \\
Original soaking solution & $4-12$ & 50 & $24-168$ \\
Distilled water & 7 & 50 & $24-168$ \\
$0.1 \mathrm{M} \mathrm{pH} 3$ acetate buffer & 3 & 50 & $24-168$ \\
$0.1 \mathrm{M} \mathrm{NaCl}$ & 7 & 50 & $24-168$ \\
$0.4 \mathrm{mM} \mathrm{HCl}$ & 3.4 & 50 & $24-168$ \\
$0.4 \mathrm{mM} \mathrm{NaCl}$ & 7 & 50 & $24-168$ \\
\hline
\end{tabular}

\subsection{Gold Uptake}

During the production of the gold nanoparticle-fibre composites, the uptake of $\mathrm{Au}^{3+}$ by the fibres was quantitatively determined by atomic absorption spectroscopy (see section 2.3.4). Sample preparation was achieved as follows. $0.1 \mathrm{~g}$ of fibre (merino wool, silk or crossbred wool) was dispersed in the $\mathrm{Au}^{3+}$ solution under analysis, for various amounts of time $(5,10$ or 30 mins, 1, 2, 5 or 24 hours) and agitated at RT, 50 or $80{ }^{\circ} \mathrm{C}$. Following this time the samples were removed and squeezed to displace any residual solution, which was then filtered on sintered glass crucibles (previously rinsed with aqua regia) to remove any residual fibres that could potentially block the aspirator tube of the spectrometer, and analysed by atomic absorption spectroscopy (section 2.3.4).

\subsection{Chloride Concentration}

During the production of the gold nanoparticle-merino wool composites, prepared through utilisation of the redox active nature of merino, the concentration of chloride in the reaction solutions (during the uptake and subsequent reduction of $\mathrm{Au}^{3+}$ ) was quantitatively followed. $0.1 \mathrm{~g}$ of merino was dispersed in a $160 \mathrm{ppm}\left(8.13 \times 10^{-4} \mathrm{M}\right) \mathrm{Au}^{3+}$ solution for 5 minutes to 24 hours, and then heated at $50{ }^{\circ} \mathrm{C}$ for 5 minutes to 168 hours (Table 2.9), after which the fibres were removed and the concentration of chloride in the residual solutions determined (section 2.3.5). 
Table 2.9: Sample preparation for the determination of the chloride concentration.

\begin{tabular}{|c|c|c|c|}
\hline Soak Time (RT) & Heat Time $\left(50^{\circ} \mathrm{C}\right)$ & Soak Time (RT) & Heat Time $\left(50^{\circ} \mathrm{C}\right)$ \\
\hline 5 mins & - & 24 hours & 30 mins \\
\hline 10 mins & - & & 1 hour \\
\hline 30 mins & - & & 3 hours \\
\hline 1 hour & - & & 6 hours \\
\hline 2 hours & - & & 24 hours \\
\hline 3 hours & - & & 48 hours \\
\hline \multirow[t]{2}{*}{24 hours } & - & & 72 hours \\
\hline & & & 168 hours \\
\hline
\end{tabular}

\subsubsection{Seeded Growth of Gold Nanoparticles by an External Reductant Employing} Gold Nanoparticle-Fibre Composite Materials as a Seed Source

In an attempt to produce grey coloured gold nanoparticle-fibre materials, a seeded growth approach was employed.[173] This involved dispersing gold nanoparticle-fibre composites in a solution containing additional $\mathrm{Au}^{3+}$, followed by the addition of a weak reductant (hydroxylamine, $\mathrm{NH}_{2} \mathrm{OH}$ ). $\mathrm{NH}_{2} \mathrm{OH}$ is thermodynamically capable of reducing $\mathrm{Au}^{3+}$ to $\mathrm{Au}^{0}$, although the reaction is slow. Introducing a gold surface dramatically increases the rate of reduction. As such, under the reaction conditions employed, no new gold particle nucleation should occur in solution, and all additional $\mathrm{Au}^{3+}$ will go into the growth of the existing gold nanoparticles in the gold nanoparticle-fibre composites.

In this approach, various gold nanoparticle-fibre composites $(0.1 \mathrm{~g})$, termed seed sources (Table 2.10), were added to aqueous $\mathrm{Au}^{3+}$ solutions $(8$ or $5 \mathrm{ml}$ ) followed by the drop-wise addition of $\mathrm{NH}_{2} \mathrm{OH}$ ( 2 or $1 \mathrm{ml}$ to 8 or $5 \mathrm{ml} \mathrm{Au}^{3+}$ solutions respectively) under rapid stirring. The mixture was then left to react at room temperature for at least three hours. Varying the seed source, $\mathrm{Au}^{3+}$ concentration and $\left[\mathrm{Au}^{3+}\right]:\left[\mathrm{NH}_{2} \mathrm{OH}\right]$ molar ratio altered the colour of the resultant composite materials (Table 2.11). 
Table 2.10: Hydroxylamine seeded growth. Seed preparation."

\begin{tabular}{|c|c|c|c|}
\hline $\begin{array}{l}\text { Fibrous } \\
\text { Substrate }\end{array}$ & $\begin{array}{c}\text { Gold Solution } \\
\text { (Vol } 4 \text { wt } \% \mathrm{Au}^{3+} \text { added) }\end{array}$ & $\begin{array}{l}\text { Soak Time } \\
\text { (RT, hours) }\end{array}$ & $\begin{array}{c}\text { Heat Time } \\
\left(50^{\circ} \mathrm{C}, \text { hours }\right)\end{array}$ \\
\hline \multirow[t]{8}{*}{ Merino } & $40 \mu \mathrm{L} \rightarrow 10 \mathrm{ml} \mathrm{pH} 3$ & 6 & - \\
\hline & $20 \mu \mathrm{L} \rightarrow 10 \mathrm{mlpH} 3$ & 24 & 24 \\
\hline & $20 \mu \mathrm{L} \rightarrow 10 \mathrm{ml}$ pH 3 & 24 & 72 \\
\hline & $20 \mu \mathrm{L} \rightarrow 10 \mathrm{mlpH} 3$ & 24 & 168 \\
\hline & $40 \mu \mathrm{L} \rightarrow 10 \mathrm{mlpH} 3$ & 24 & 24 \\
\hline & $40 \mu \mathrm{L} \rightarrow 10 \mathrm{mlpH} 3$ & 24 & 72 \\
\hline & $40 \mu \mathrm{L} \rightarrow 10 \mathrm{mlpH} 3$ & 24 & 168 \\
\hline & $40 \mu \mathrm{L} \rightarrow 6 \mathrm{mlpH} 3$ & 24 & 24 \\
\hline \multirow[t]{2}{*}{ Merino } & $50 \mu \mathrm{L} \rightarrow 6 \mathrm{mlpH} 3$ & 24 & 24 \\
\hline & $60 \mu \mathrm{L} \rightarrow 6 \mathrm{mlpH} 3$ & 24 & 24 \\
\hline \multirow[t]{3}{*}{ Silk } & $40 \mu \mathrm{L} \rightarrow 10 \mathrm{ml} \mathrm{pH} 3$ or 9.5 & - & $1-5 \mathrm{~h}$ \\
\hline & $40 \mu \mathrm{L} \rightarrow 10 \mathrm{ml} \mathrm{pH} 3$ or 9.5 & 1 & $24 \mathrm{~h}$ \\
\hline & $40 \mu \mathrm{L} \rightarrow 10 \mathrm{ml} \mathrm{pH} 3$ or 9.5 & $1-6$ & - \\
\hline
\end{tabular}

Table 2.11: Hydroxylamine seeded growth.

\begin{tabular}{cccc}
\hline $\begin{array}{c}\text { Gold Solution (volume of } \\
\mathbf{4} \text { wt } \% \mathrm{Au}^{3+} \text { added to } \\
\text { distilled water) }\end{array}$ & $\mathbf{N H}_{2} \mathrm{OH}$ added & $\begin{array}{c}\text { Final Gold } \\
\text { Concentration } \\
\text { (M) }\end{array}$ & {$\left[\mathrm{Au}^{3+}\right]:\left[\mathrm{NH}_{2} \mathrm{OH}\right]$} \\
\hline $7.7 \mu \mathrm{L} \rightarrow 8 \mathrm{ml}$ & $2 \mathrm{ml}$ of $1.25 \mathrm{mM}$ & $2.50 \times 10^{-4}$ & $1: 1$ \\
$15.4 \mu \mathrm{L} \rightarrow 8 \mathrm{ml}$ & $4.80 \times 10^{-4}$ & $2: 1$ \\
$30.8 \mu \mathrm{L} \rightarrow 8 \mathrm{ml}$ & $9.60 \times 10^{-4}$ & $4: 1$ \\
$61.5 \mu \mathrm{L} \rightarrow 8 \mathrm{ml}$ & $2 \mathrm{ml}$ of $1.25 \mathrm{mM}$ & $2.50 \times 10^{-4} \mathrm{M}$ & $8: 1$ \\
$12.3 \mu \mathrm{L} \rightarrow 8 \mathrm{ml}$ & $2 \mathrm{ml}$ of $2.5 \mathrm{mM}$ & & $1: 1$ \\
& $2 \mathrm{ml}$ of $5.0 \mathrm{mM}$ & & $1: 2$ \\
& $2 \mathrm{ml}$ of $10 \mathrm{mM}$ & $1: 4$ \\
& $2 \mathrm{ml}$ of $20 \mathrm{mM}$ & $1: 8$ \\
& $2 \mathrm{ml}$ of $40 \mathrm{mM}$ & $1: 16$ \\
& $2 \mathrm{ml}$ of $80 \mathrm{mM}$ & $1: 32$ \\
& & & $1: 64$ \\
\hline
\end{tabular}




\begin{tabular}{|c|c|c|c|}
\hline $\begin{array}{c}\text { Gold Solution (volume of } \\
4 \mathrm{wt} \% \mathrm{Au}^{3+} \text { added to } \\
\text { distilled water) }\end{array}$ & $\mathrm{NH}_{2} \mathrm{OH}$ added & $\begin{array}{c}\text { Final Gold } \\
\text { Concentration } \\
\text { (M) }\end{array}$ & {$\left[\mathrm{Au}^{3+}\right]:\left[\mathrm{NH}_{2} \mathrm{OH}\right]$} \\
\hline & $2 \mathrm{ml}$ of $160 \mathrm{mM}$ & & $1: 128$ \\
\hline \multirow[t]{4}{*}{$12.3 \mu \mathrm{L} \rightarrow 5 \mathrm{ml}$} & $1 \mathrm{ml}$ of $40 \mathrm{mM}$ & $4.20 \times 10^{-4} \mathrm{M}$ & $1: 16$ \\
\hline & $1 \mathrm{ml}$ of $80 \mathrm{mM}$ & & $1: 32$ \\
\hline & $1 \mathrm{ml}$ of $160 \mathrm{mM}$ & & $1: 64$ \\
\hline & $1 \mathrm{ml}$ of $320 \mathrm{mM}$ & & $1: 128$ \\
\hline \multirow[t]{4}{*}{$20 \mu \mathrm{L} \rightarrow 5 \mathrm{ml}$} & $1 \mathrm{ml}$ of $65 \mathrm{mM}$ & $6.77 \times 10^{-4} \mathrm{M}$ & $1: 16$ \\
\hline & $1 \mathrm{ml}$ of $130 \mathrm{mM}$ & & $1: 32$ \\
\hline & $1 \mathrm{ml}$ of $260 \mathrm{mM}$ & & $1: 64$ \\
\hline & $1 \mathrm{ml}$ of $520 \mathrm{mM}$ & & $1: 128$ \\
\hline \multirow[t]{4}{*}{$30 \mu \mathrm{L} \rightarrow 5 \mathrm{ml}$} & $1 \mathrm{ml}$ of $98 \mathrm{mM}$ & $1.02 \times 10^{-3} \mathrm{M}$ & $1: 16$ \\
\hline & $1 \mathrm{ml}$ of $196 \mathrm{mM}$ & & $1: 32$ \\
\hline & $1 \mathrm{ml}$ of $392 \mathrm{mM}$ & & $1: 64$ \\
\hline & $1 \mathrm{ml}$ of $783 \mathrm{mM}$ & & $1: 128$ \\
\hline \multirow[t]{4}{*}{$40 \mu \mathrm{L} \rightarrow 5 \mathrm{ml}$} & $1 \mathrm{ml}$ of $127 \mathrm{mM}$ & $1.35 \times 10^{-3} \mathrm{M}$ & $1: 16$ \\
\hline & $1 \mathrm{ml}$ of $259 \mathrm{mM}$ & & $1: 32$ \\
\hline & $1 \mathrm{ml}$ of $518 \mathrm{mM}$ & & $1: 64$ \\
\hline & $1 \mathrm{ml}$ of $1.037 \mathrm{M}$ & & $1: 128$ \\
\hline
\end{tabular}

\subsubsection{Leaching}

The amount of gold leached from all gold nanoparticle-fibre composites, prepared by an external reductant or through the redox active nature of the fibres during stimulated washability tests was determined. Samples $(0.1 \mathrm{~g})$ were agitated in $0.1 \mathrm{wt} \%$ dishwashing detergent solutions $(10 \mathrm{ml})$ for various amounts of time $(0.5,1,2,5$ or 24 hours $)$ at RT or 80 ${ }^{\circ} \mathrm{C}$, following which they were removed and squeezed to displace any excess solution. The washing solutions were then filtered and the amount of gold leached was determined through atomic absorption analysis of the solutions (see section 2.3.4). 


\subsection{Characterisation}

\subsubsection{Scanning Electron Microscopy}

Scanning electron microscopy (SEM) is an important characterisation technique for studying the morphology of the base fibres and minerals, and for drawing comparisons between the base substrates and the produced composite materials. Individual fibres or small amounts of the clay minerals were mounted on stepped aluminium stubs using double sided carbon tape, and coated twice with $7 \mathrm{~nm}$ of carbon by a Jeol JEC-560 carbon coater. Images were taken at various positions throughout the samples in order to obtain an accurate representation of the materials surface morphology. Backscatter conditions were employed in which the gold and silver nanoparticles were more apparent due to their high molecular weight. Imaging was carried out on a JEOL $6500 \mathrm{~F}$ field emission gun scanning electron microscope.

Energy dispersive spectroscopy (EDS) showed the elemental distribution across the fibre and mineral surfaces. Additionally, the correlation between gold or silver and other elements was noted. The penetration of gold into the centre of fibres, was studied by cross sectional SEM and EDS analysis. Fibres were aligned between two sections of double sided carbon tape and frozen with liquid nitrogen. The frozen carbon tape encased fibres were then cut (orthogonal to the direction of the fibres) with a clean, sharp scalpel, and mounted on the vertical face of a stepped aluminium stub, exposing a surface of cross sectional fibres.

\subsubsection{Transmission Electron Microscopy}

High resolution transmission electron microscopy (HR TEM) and scanning transmission electron microscopy (STEM) are complementary techniques to SEM and EDS, however they offer increased spatial resolution, allowing for more accurate elucidation of nanoparticle size, shape and composition. Micrographs were recorded on a JEOL 2010 instrument with a $\mathrm{LaB}_{6}$ filament operated at a $200 \mathrm{keV}$ accelerating voltage. Silver nanoparticle-clay composites were slurried in ethanol and a drop of the slurry was placed on a carbon coated copper grid 
(200 mesh) and the ethanol was left to evaporate under a heat lamp. Due to the organic nature of the fibres, the fibre composites required dehydration and embedding in a resin (54:32:12:1 Procure 812:NMA:DDSA:BDMA composition) to enable TEM analysis, and were prepared as follows. Samples were dehydrated in ascending ethanol solutions, 20 minutes in each $(70 \%, 80 \%, 90 \%, 95 \%$ and $100 \%$ ethanol). This was then followed by two soak periods (1 hour) in propylene oxide. The composite materials were then infused with a 1:1 propylene oxide:resin mixture for 24 hours followed by infusion by resin (soaked overnight). The materials were then transferred to a mould containing resin and cured in an oven at $80{ }^{\circ} \mathrm{C}$ for 48 hours. Semi-thin $(1-2 \mu \mathrm{m})$ sections of the composites embedded in resin were prepared using a glass knife on the Reichert-Jung Ultracut E microtome, and then ultra-thin $(70-90 \mathrm{~nm})$ sections were cut using a Diatome diamond knife. These sections were mounted on copper grids (200 mesh) and coated with $7 \mathrm{~nm}$ of carbon by a Jeol JEC-560 carbon coater to minimise charging.

\subsubsection{Determination of Colour}

The colour of the gold nanoparticle-fibre composites was determined by measuring their spatial reflectance. Measurements were carried out in the visible region using a HunterLab ColourQuest spectrophotometer, and values for $\mathrm{L}^{*}, \mathrm{a}^{*}, \mathrm{~b}^{*}$ and 457 and $580 \mathrm{~nm}$ brightness were recorded. Values for $\mathrm{L}^{*}, \mathrm{a}^{*}$ and $\mathrm{b}^{*}$ are coordinates depicting colour (Figure 2.2). $\mathrm{L}^{*}$ is the measure of lightness, with $\mathrm{L}^{*}=0$ being black and $\mathrm{L}^{*}=100$ white. Positive values of $\mathrm{a}^{*}$ and $b^{*}$ denote a red and yellow colour respectively, whilst negative $a^{*}$ values denote green and negative $b^{*}$ blue. The 457 and $580 \mathrm{~nm}$ brightness values represent the TAPPI and ISO brightness respectively. For each sample analysed, a set of values for each coordinate are given, so that when comparing samples very slight changes in colour can be detected. 


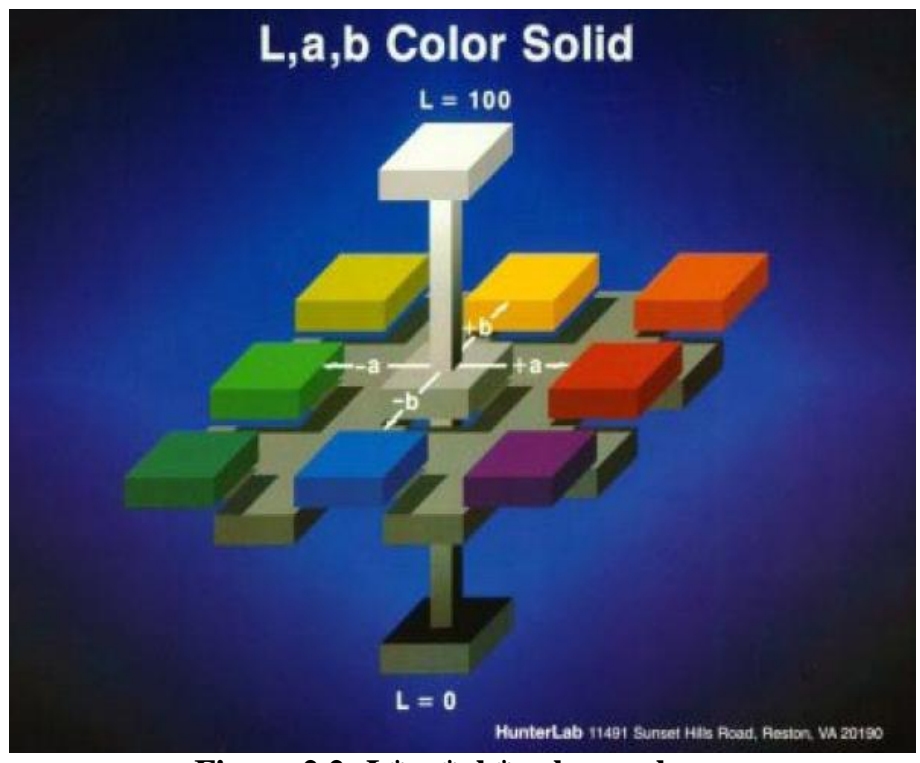

Figure 2.2: $\mathrm{L}^{*}, \mathrm{a}^{*}, \mathrm{~b}^{*}$ colour sphere.

\subsubsection{Atomic Absorption}

Flame Atomic Absorption spectroscopy (AA) was employed to quantitatively determine both the uptake of gold by the fibrous substrates during the in-situ preparation methods, and also the leaching of gold from all produced gold nanoparticle-fibre composites (see sections 2.2.2.3.4, and 2.2.2.3.5 respectively). The gold uptake and leaching solutions were analysed on a GBC 906AA spectrometer, according to manufacturer recommended methods, employing light with a wavelength of $242.8 \mathrm{~nm}$, and referenced to 3.5, 7.5, 10, 12 and 14 ppm $\mathrm{Au}^{3+}$ standards. The detection limit of the spectrometer used was $0.2 \mathrm{ppm}$, and combined with the percentage uncertainties of the glassware used in the synthesis of the samples and standards, all AA results were accurate to $\pm 0.5 \mathrm{ppm}$.

\subsubsection{Determination of Chloride Concentration}

During the production of the gold nanoparticle-merino wool composites, prepared through utilisation of the redox active nature of merino, the concentration of chloride in the reaction solutions was quantitatively analysed with a consort solid state chloride ion selective electrode (ISE24B, with a combination epoxy body) attached to a EUTECH EcoScan pH $5 / 6 /$ Ion meter. The ionic strength of all analysed samples was adjusted with $5 \mathrm{M} \mathrm{NaNO}_{3}$. 


\subsubsection{X-ray Photoelectron Spectroscopy}

X-ray photoelectron spectroscopy (XPS) is a non-destructive surface sensitive technique that provides information about the composition and electronic state of the surface region (top 10 nm) of a sample. As such it was utilised in elucidating the nature of the chemical bonding between the substrates and nanoparticles in all of the produced composite materials. Comparing any changes between the original base fibres and the composites also provided insight into the role of the natural fibres in the reduction of $\mathrm{Au}^{3+}$. XPS spectra were obtained by loading samples into a specially designed holder (Figure 2.3) and irradiating the sample, under vacuum, with a beam of aluminium or magnesium x-rays whilst simultaneously measuring the kinetic energy and number of core electrons that were consequently emitted from the top $10 \mathrm{~nm}$ of sample. As there is a characteristic binding energy associated with each atomic orbital for every element, shifts in binding energy peaks in an XPS spectrum provide information about the chemical environment of all materials on the sample surface.

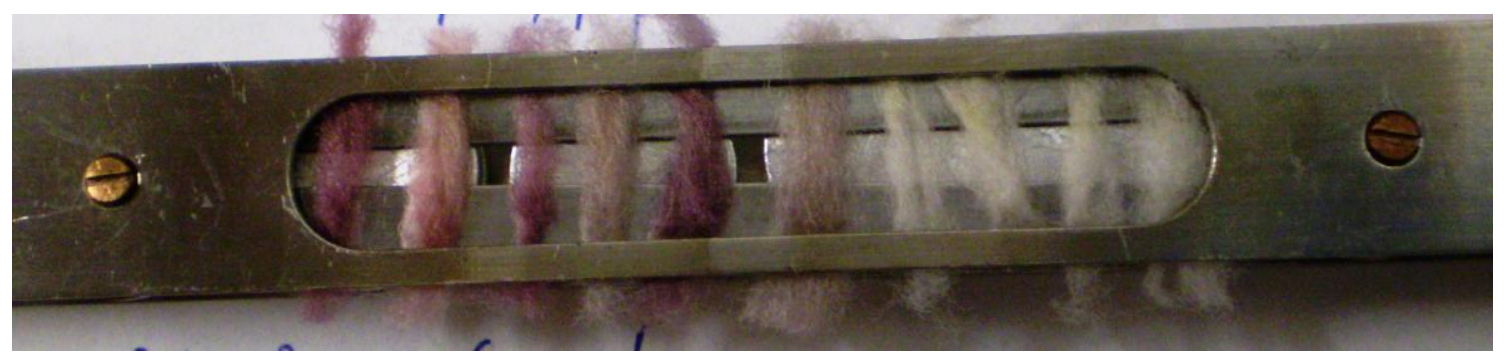

Figure 2.3: Samples loaded into sample holder in preparation for XPS analysis.

XPS analysis was undertaken at the Surface Science Department located at the University of Auckland with the assistance of Dr Colin Doyle. Measurements were performed on a Kratos Axis Ultra system with an aluminium anode operating at $10 \mathrm{~mA}$ and $15 \mathrm{kV}$, using the $\mathrm{K} \alpha$ line. Charging from samples was minimized by the charge neutraliser, a thoria coated filament with tunable current, filament voltage and bias settings of 1.95-2.1 A, 2.9-3.3 V and 1.1-1.3 V respectively. The pass energy for the wide survey scans was $160 \mathrm{eV}$ and $20 \mathrm{eV}$ for the narrow scans. The sample area was $300 \times 700 \mu \mathrm{m}$. 
Gaussian lorentzian (70:30) peaks were fitted to the recorded spectra using the CasaXPS Version 2.3.13 program. The binding energies were calibrated using the $\mathrm{C}-\mathrm{C} 1 \mathrm{~s}$ photoelectron peak centred at $285.0 \mathrm{eV}$. This involved primarily defining peak regions and removing the background spectrum using a Shirley line functionality. Literature was consulted to provide information on the regular peak positions of functional groups that were expected to be present. Peaks of comparable full widths at half maximum were then fitted at these specified positions. Quantitative estimations of elemental compositions were made using a built in function of the CasaXPS program. This employed sensitivity factors of 0.278 (C 1s), 0.477 (N 1s), 0.780 (O 1s), 0.979 (S 2p), Ag 3d (18.04) and 8.56 (Au 4f), and the equation: [174]

$$
C_{x}=\frac{n_{x}}{\sum n_{i}}=\frac{I_{x} / S_{x}}{\sum I_{i} / S_{i}},
$$

where $C_{x}$ is the atomic fraction of component $x$ in sample $C, n$ is the number of atoms present, $I_{x}$ is the peak area of $x$, and $S$ is the relative sensitivity factor for the particular instrument under defined operating conditions. These quantified values possess error values of $\pm 10 \%,[175]$ whilst the binding energy values were accurate to $\pm 0.2 \%$.[176-179]

\subsubsection{Electrical Conductivity}

The DC-conductivities of individual fibres, or groups of fibres of the gold nanoparticle-fibre composites were analysed through implementation of the linear four point probe method (Figure 2.4). Fibres were aligned so that they were in even contact with every electrode. Source potentials were set at 2, 5 and $10 \mathrm{~V}$, and the potential (P) current (I) was measured at each. The thickness $(t)$ of the fibres or group of fibres was similarly measured. 


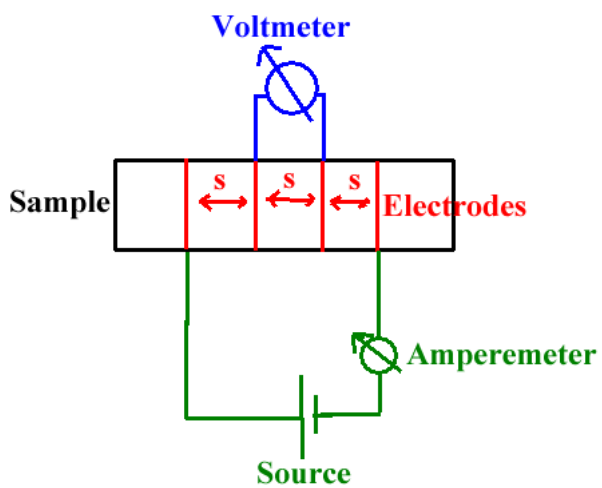

Figure 2.4: Linear four point probe for measuring the conductivity of fibres.

The resistivity $(\mathrm{R})$ of the samples was calculated using the following formula:

$$
R=2 \times \pi \times t \times P / I
$$

After calculating the resistivity of the samples via either of the two methods described above, the conductivity ( $\mathrm{C}$ in $\mathrm{S} \mathrm{cm}^{-1}$ ) was calculated by taking the inverse of the resistivity.

$$
C=1 / R
$$

\subsubsection{X-ray Diffraction}

X-ray diffraction (XRD) provides information about a material's crystal structure and helps to identify crystalline compounds. As such it was utilised in determining the structural relationship between the silver nanoparticles and clays. XRD powder diffraction patterns were measured on a Philips PW 3170 mpd controlled spectrometer; anode material $\mathrm{Cu}, \lambda=$ $1.54060 \AA$. Comparisons of the XRD patterns of both kaolinite and halloysite before and after inclusion of silver nanoparticles provided information as to whether the nanoparticles were been incorporated into the interlayer spacings of the clays, or simply dispersed on the surface of individual platelets or tubules respectively. 


\subsubsection{Infra Red Spectroscopy}

Infra red (IR) spectroscopy is a subset of spectroscopy that deals with the infra red region of the electromagnetic spectrum $\left(\sim 400-4000 \mathrm{~cm}^{-1}\right)$. By comparing slight changes in the IR spectra of the base substrates to those of the composites, insight into the nature of the interaction between the nanoparticles and substrates were obtained. Samples (both minerals and fibres) were homogeneously mixed with $\mathrm{KBr}$, in a ratio of approximately 1:1000 parts sample to $\mathrm{KBr}$ and pressed into disks. Spectra were recorded on a PerkinsElmer Spectrum One FT-IR Spectrometer

\subsubsection{Ultra Violet Visible Spectroscopy}

Ultra violet visible (UV/Vis) spectroscopy was used to characterise all of the produced hybrid materials. By comparing the UV/Vis spectra of colloidal nanoparticle solutions to the corresponding composite materials (excluding the in-situ method that utilised the redox active nature of the natural fibres) it was possible to approximately compare the size of the nanoparticles in solution to those in the composite materials, and also between various composites, evidenced by either a shift of the absorption maxima, or a broadening of the absorption peaks. Absorption and reflectance UV/vis (the latter incorporating KubelkaMunk transformations) were performed on a Varian Cary 100 scan spectrometer. The Kubelka-Munk theory is generally used for analysis of diffuse reflectance obtained from weakly absorbing samples. It provides a correlation between reflectance and absorbance, and is expressed as follows:

$$
f(R)=\frac{(1-R)^{2}}{2 R}=\frac{k}{S}
$$

Where $R$ is the absolute reflectance of the sampled layer, $k$ is the molar absorption coefficient and $s$ is the scattering coefficient.[180] This transformation was carried out by software included in the spectrometer's analysis program. 


\subsubsection{Raman Spectroscopy}

Raman spectroscopy is a form of molecular spectroscopy that is based on the inelastic scattering of light, and provides information about the internal structure of a material such as the functional groups present. The Raman spectroscopic signal is often enhanced by noble metal nanoparticle such as silver or gold. This occurs through a surface sensitive process termed surface enhanced Raman spectroscopy (SERS), with the Raman signal of molecules in close proximity to the nanoparticles having the potential to be enhanced by a factor of up to $10^{14}-10^{15}$. The Raman spectra of the base samples were compared to those of the composite materials, and any differences, including signal enhancements, (suggesting the proximity of certain functional groups to the nanoparticles and hence providing potential bonding information) or the appearance or loss of certain signals (providing information on the reducing nature of the natural fibres) were noted. Single fibres of the fibrous samples were mounted on microscope slides, and irradiated with 514 or $633 \mathrm{~nm}$ laser light.

\subsubsection{Solid State NMR}

${ }^{27} \mathrm{Al}$ and ${ }^{29} \mathrm{Si}$ solid state NMR was utilised to provide information about the nature of the interaction between the silver nanoparticles and clay substrates in the composite materials. Comparing the spectra of the clay substrates to that of the composite materials highlights any changes in the coordination environment of both aluminium and silicon, and hence may provide information on the bonding between the clays and nanoparticles. The spectra were acquired at a magnetic field of $11.7 \mathrm{~T}$ on a Varian Unity 500 spectrometer under the following conditions. The ${ }^{27} \mathrm{Al}$ spectrometer frequency was set at $130.224 \mathrm{MHz}$ using a $1 \mathrm{~s}$ $(\pi / 10)$ pulse with a $1 \mathrm{~s}$ delay. A $4 \mathrm{~mm}$ Doty MAS probe was spun at $10-12 \mathrm{kHz}$ and the spectra referenced to $\mathrm{Al}\left(\mathrm{H}_{2} \mathrm{O}\right)_{6}{ }^{3+}$. The ${ }^{29} \mathrm{Si}$ spectrometer frequency was $99.926 \mathrm{MHz}$, using a $6 \mu \mathrm{s}(\pi / 10)$ pulse with a 30 s delay. A $5 \mathrm{~mm}$ Doty MAS probe wsa spun at 5-6 kHz. All spectra were referenced to tetramethylsilane. 


\subsubsection{Anti-microbial Testing}

The anti-microbial properties of all composite materials were testing at the PTA Microbiology Laboratory of Capital and Coast Health, Wellington Hospital. Samples were pressed into pellets and incubated for 24 hours on agar plates containing Staphylococcus aureus (ATCC 25923). All samples were tested against reference samples. Following incubation, the samples were photographed and analysed visually and under an optical microscope and the zones of inhibition (microbial free areas surrounding the samples) were measured.

\subsubsection{Insecticide Testing}

The gold nanoparticle-wool composite materials were tested for insect resistance against moth and beetle larvae (Tineola bisselliella (T. bisselliella) and Anthrenocerus flavipes respectively) (Wools of New Zealand Test Method 25. Tineola bisselliella and Anthrenocerus flavipes). This testing was undertaken at the Textile Chemistry Section of AgResearch Ltd, Lincoln. A pass rate for these tests was based on the ratio of sample mass loss to larval mortality rate. To exert resistance to the growth of moth or beetle larvae a sample must exhibit a mass loss of $15 \mathrm{mg}$ or less, or a mortality rate of greater than $90 \%$. If this mortality rate is achieved the mass loss is irrelevant, and losses of over $15 \mathrm{mg}$ are acceptable.

\subsubsection{Light Fastness, Washability and Wearability}

The feasibility of the application of the gold nanoparticle-fibre composites in consumer products was determined through the testing of the materials light fastness, colourfastness to rubbing and washing and colourfastness to chlorinated swimming pool water. These tests were undertaken at AgResearch Ltd Lincoln, under industry certified standards. 
Colour fastness to rubbing tests (Australian/New Zealand Standard 2111.19.1), involved the use of a testing device consisting of a rectangular rubbing finger measuring $19 \mathrm{~mm}$ x $25 \mathrm{~mm}$, which is able to be moved in a line along a $103 \mathrm{~mm}$ track, with a downward force of $9 \mathrm{~N}$. The finger is mounted with the longer dimension $90^{\circ}$ to the rubbing direction. The sample (dry or wet) is placed on the base of the device. Ten complete turns of the crank are used to rub the sample and it is then evaluated for colour change by visual comparison with a set of greyscale fabrics at $20^{\circ} \mathrm{C}$ and $65 \%$ relative humidity. Values of 1 to 5 are obtainable, with 1 being poor and 5 excellent.

In colourfastness to washing testing (Australian/NZ Standard 2111.19.2), samples are placed in a flat-bottomed dish and covered with two pieces of undyed cloth, then covered with shampoo solution (consisting of sodium dodecyl benzene sulphonate (1 g/l) and lauric monoisopropanolamide $(0.2 \mathrm{~g} / \mathrm{l})$ at $\mathrm{pH} 7.5)$ preheated to $40^{\circ} \mathrm{C}$. A smooth glass plate is placed on top of the cloths and sample, and weighed down with a $5 \mathrm{~kg}$ weight. After 15 minutes, the weight-piece is removed and the dish placed in an oven at $40^{\circ} \mathrm{C}$ for 1.5 hours, following which the sample is removed from the dish, hydroextracted, dried, conditioned, and the evaluated for colour change by visual comparison with a set of greyscale fabrics, with a value of 1 denoating poor colourfastness to washing and 5 excellent.

Colourfastness to chlorinated swimming pool water (Australian Standard 2001.4.5) tests involved placing the test sample $(50 \mathrm{~mm} \times 50 \mathrm{~mm})$ into a $500 \mathrm{ml}$ cylinder containing $300 \mathrm{ml}$ solution of sodium hypochlorite (with $25 \mathrm{mg} / \mathrm{L}$ available chlorine) and rotating the cylinder end over end at $40 \mathrm{rpm}$ for one hour in a water bath maintained at $25^{\circ} \mathrm{C}$. The sample is then removed, squeezed, rinsed in cold water, dried and colour changes are assessed by comparison to greyscale fabrics. Grades of grades 1 (poor) to 5 (excellent) are obtainable. Washability tests were undertaken by agitating samples $(0.1 \mathrm{~g})$ in a $0.1 \mathrm{wt} \%$ detergent solution $(10 \mathrm{ml})$ for 10 minutes to 168 hours at room temperature or $50{ }^{\circ} \mathrm{C}$.

During the lightfastness tests (ISO test Method 105 BO2:1994), samples are exposed to a Xenon arc lamp operating at $300-400 \mathrm{~nm}$, with a correlated colour temperature of 5500 $6000 \mathrm{~K}$. The sample temperature is maintained close to $50^{\circ} \mathrm{C}$. The colour changes of the 
samples are compared to the colour changes of a set of eight reference samples of varying degrees of lightfastness, with possible lightfastness grades of 1 to 8 , with 1 being poor and 8 excellent. 


\section{SILVER NANOPARTICLE-CLAY COMPOSITES}

\section{1 ex-situ Preparation of Nanoparticles and Subsequent Attachment to Clay Substrates}

A successful production method of silver nanoparticle-clay composites resulted in the production of vibrantly coloured powders, in which the colour arose due to the surface plasmon reasonances of the silver nanoparticles. As outlined in section 2.2.1.1.2 the most successful production method involved the synthesis of polymethacrylic acid (PMA) capped silver nanoparticles with their subsequent attachment to the clay substrate through the cationic polymeric linker polydiallyldimethylammonium chloride (PDADMAC). The PMA capped nanoparticles were characterised prior to attachment to the clay substrates, and the results are outlined in sections 3.1.1.1 and 3.1.1.2 below.

\subsubsection{PMA Stabilised Silver Nanoparticles}

\subsubsection{PMA Stabilised Silver Nanoparticles Prepared via a Photo Induced Reduction}

PMA capped silver nanoparticles (Ag-PMA) were produced through the photo induced reduction of $\mathrm{Ag}^{+}$to nanoparticulate $\mathrm{Ag}^{0}$ in an aqueous solution of PMA. The reaction has been proposed to occur through the photolysis of water and the formation of solvated radicals $\left(\mathrm{OH}^{\cdot}{ }_{(\mathrm{aq})}, \mathrm{H}^{\cdot}(\mathrm{aq})\right.$ and electrons, [181-183] with the electrons acting as the potential reductants.

Depending on the concentration ratio of silver nitrate to PMA, exposure of the reaction mixture to broad spectrum UV light induced a colour change from colourless to yellow, faint pink and finally red after several hours of irradiation (Figure 3.1 (top to bottom)). With silver nitrate to PMA ratios of 3:1 or larger, unstable colloids were produced and these precipitated from solution almost immediately (Figure 3.1 (left to right)). This was likely 
attributable to agglomeration of the particles arising as a result of Ostwald Ripening, occurring as there was insufficient PMA to passivate the surfaces of produced nanoparticles.

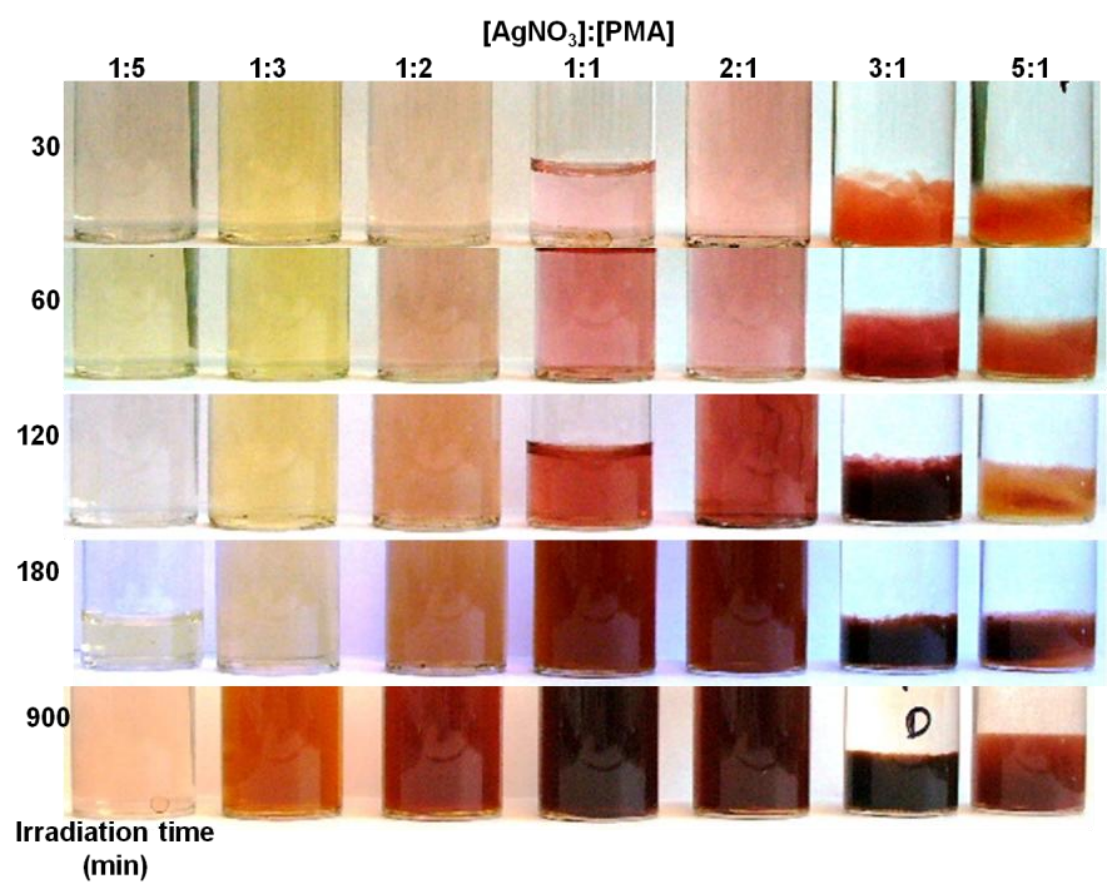

Figure 3.1: PMA reduced and stabilised silver nanoparticles. Increasing $\left[\mathrm{AgNO}_{3}\right]:[\mathrm{PMA}]$ (left to right) and increasing irradiation time (top to bottom).

The development of silver nanoparticles in these systems was monitored by ultra violet visible (UV/Vis) spectroscopy. When the particles form, an intense visible absorption a surface plasmon band appears. The position of this plasmon band is dependent upon the size and shape of the nanoparticles, and also the dielectric constant of the surrounding medium, and is generally centered between $320-500 \mathrm{~nm}$ (see section 1.3.1). Figure 3.2 shows the absorption spectra of silver nanoparticles prepared from a silver nitrate/PMA mixture with a 1:1 concentration ratio, whilst Table 3.1 offers the corresponding $\lambda_{\max }$ values. Increasing the irradiation time from 10 minutes to 3 hours resulted in both an increase in intensity and broadening of the plasmon band centered at $510 \mathrm{~nm}$, and a slight blue shift. The peak broadening suggests inhomogeneity in particle size and shape (confirmed by transmission electron microscopy (TEM) analysis, see below), whilst the slight blue shift and increase in intensity suggests the formation of additional smaller nanoparticles. 


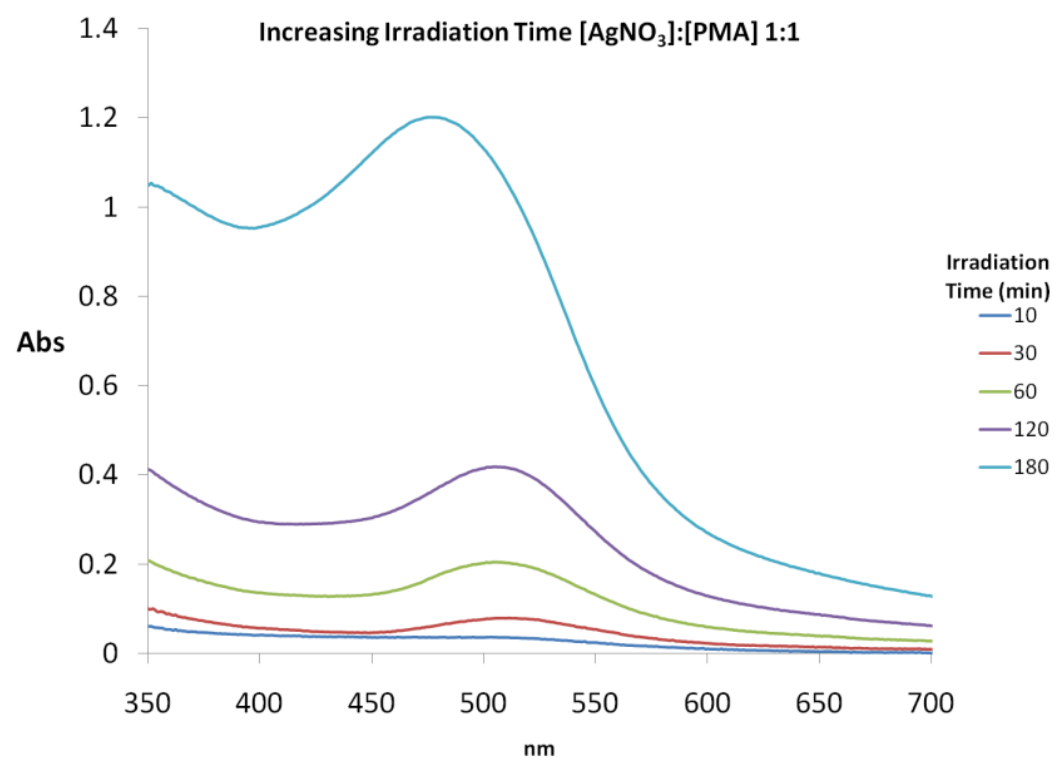

Figure 3.2: UV/Vis absorption spectra showing an increase in peak intensity and a shift to lower wavelengths with increasing irradiation time.

Table 3.1: $\mathrm{UV} / \mathrm{V}$ is $\lambda_{\max }$ values for the absorption spectra of silver nanoparticles prepared with a $\left[\mathrm{AgNO}_{3}\right]$ :[PMA] of 1:1.

\begin{tabular}{cc}
\hline Irradiation Time (min) & $\lambda_{\max }$ \\
\hline 10 & 520 \\
30 & 516 \\
60 & 511 \\
120 & 509 \\
180 & 480 \\
\hline
\end{tabular}

The change in colloid colour associated with increasing the silver nitrate to PMA ratio from 1:5 to 2:1 was also reflected in UV/Vis spectroscopy (Figure 3.3), and is associated firstly with an increase in intensity of the surface plasmon band, followed by a subsequent shift to higher wavelengths. This suggests an increase in the proportion of similarly sized nanoparticles and the subsequent production of larger nanoparticles. When the ratio of silver nitrate to PMA was 1:5 (120 minutes irradiation), the produced colloid possessed a slight 
yellow tinge, and this was reflected by a weak absorption band centered at approximately $425 \mathrm{~nm}$. Increasing the silver nitrate to PMA ratio to 1:3 produced a deeper yellow coloured colloid which was accompanied by an increase in intensity of the $425 \mathrm{~nm}$ plasmon band. When the silver nitrate to PMA ratio was 1:2 the surface plasmon band began to shift to approximately $510 \mathrm{~nm}$, suggesting a change in particle size. This shift was complete when the ratio of silver nitrate to PMA was $1: 1$, decreasing in intensity with a ratio of $2: 1$. As mentioned above, higher ratios of silver nitrate to PMA resulted in unstable colloids for which particles precipitated from solution almost immediately.

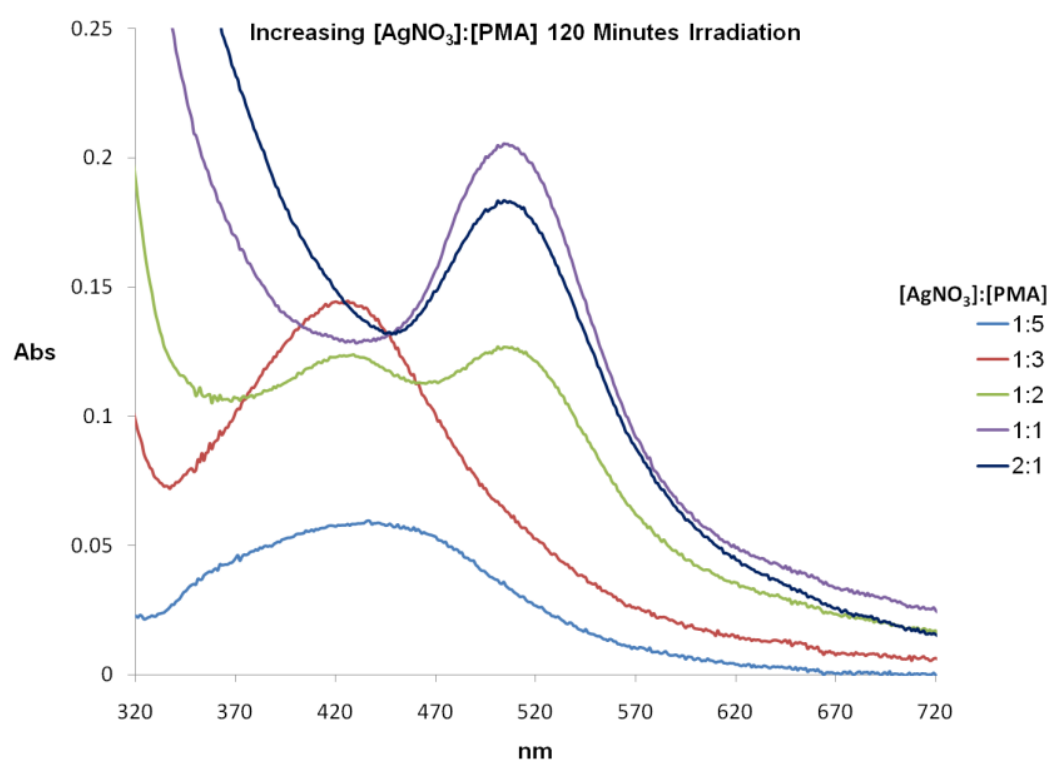

Figure 3.3: UV/Vis absorption spectra showing an increase in peak intensity and shift to higher wavelengths with an increasing [AgNO3]:[PMA] ratio.

Table 3.2: $\mathrm{UV} / \mathrm{Vis} \lambda_{\max }$ values with an irradiation time of 120 minutes and increasing [ $\left.\mathrm{AgNO}_{3}\right]:[\mathrm{PMA}]$ values.

\begin{tabular}{|c|c|}
\hline$\left[\mathrm{AgNO}_{3}\right]:[\mathrm{PMA}]$ & $\lambda_{\max }$ \\
\hline $1: 5$ & 425 \\
\hline $1: 3$ & 425 \\
\hline $1: 2$ & 425,510 \\
\hline $1: 1$ & 510 \\
\hline 180 & 510 \\
\hline
\end{tabular}


Considering the intensity of colour, and stability of the colloids, a silver nitrate to PMA concentration ratio of $1: 1$, with an irradiation time of 2 hours was chosen to produce PMA capped silver nanoparticles for inclusion in silver nanoparticle-clay composite materials (section 3.1.2). TEM analysis of the colloids produced via this method revealed the silver nanoparticles to be predominantly spherical in morphology $(\sim 10-25 \mathrm{~nm}$ in diameter) (Figure 3.4 a). Alternate forms, notably hexagonal platelets ( $25 \mathrm{~nm}$ in diameter) (Figure $3.4 \mathrm{~b}$ ), particles with five fold twinning $(\sim 30 \mathrm{~nm}$ in diameter) (Figure $3.4 \mathrm{c})$ and truncated triangles $(\sim 25 \mathrm{~nm}$ in diameter) (Figure $3.4 \mathrm{~d})$, were also present, however in much lower concentrations.
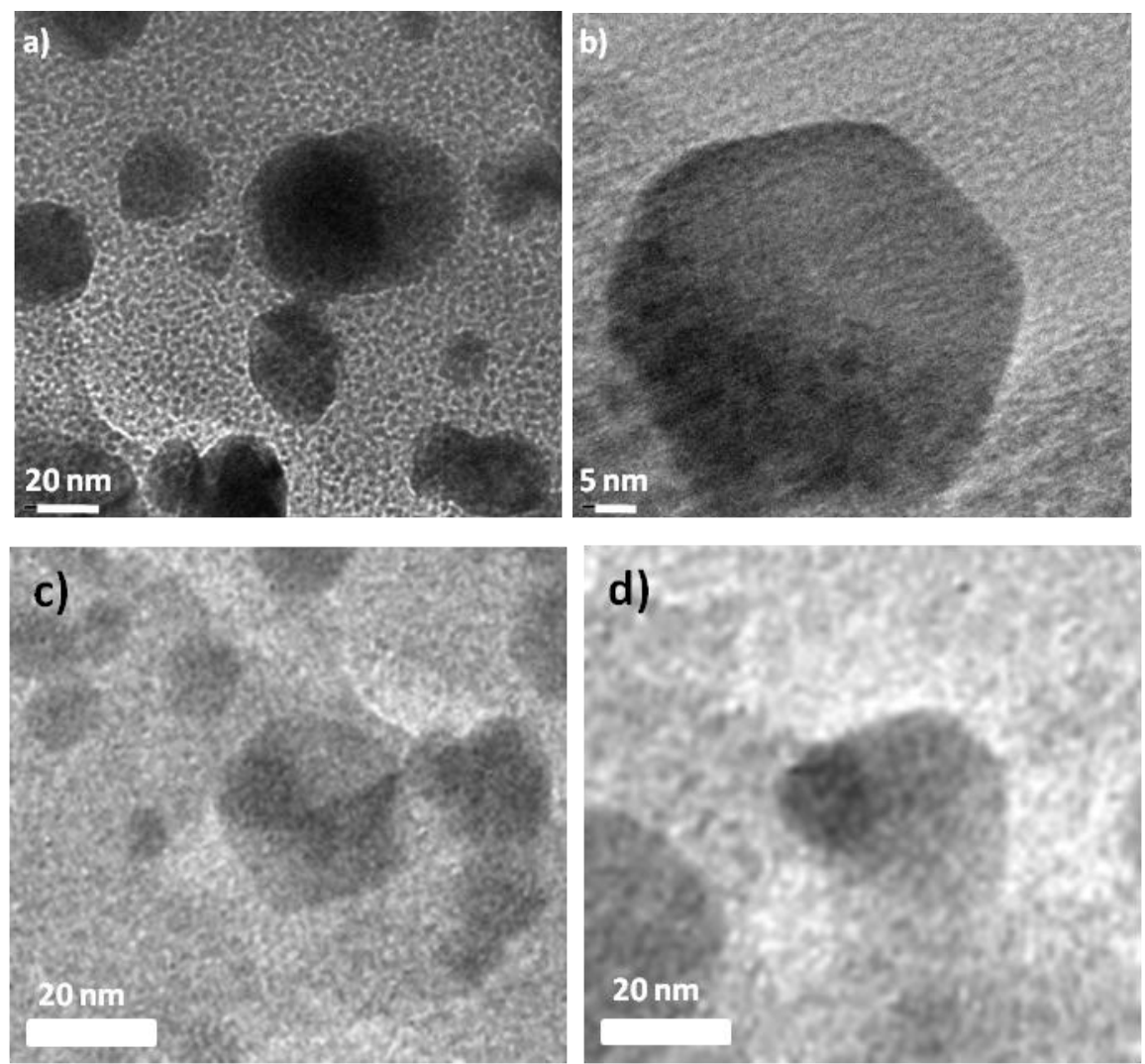

Figure 3.4: TEM micrographs showing the range of morphologies present in PMA stabilised silver nanoparticles prepared via a photo induced reduction. Predominantly nanospheres (a), and to a lesser extent hexagonal platelets (b), five-fold twinned particles (c) and truncated triangles (d)

X-ray photoelectron spectroscopy (XPS) confirmed the produced silver nanoparticles to be capped with PMA, and the results are summarised in Table 3.3. Examination of the deconvoluted high resolution $\mathrm{Ag} 3 \mathrm{~d}$ peaks of an evaporated colloidal solution showed the 
asymmetrical $5 / 2$ and $3 / 2$ peaks of zero valent, nanoparticulate silver at 368.80 and 374.85 respectively (Figure 3.5 a).[184, 185] A second pair of smaller peaks, attributed to $\mathrm{Ag}^{+}$, were seen at 369.7 and $375.7 \mathrm{eV}$. The $\mathrm{O} 1 \mathrm{~s}$ spectrum of these silver nanoparticles shows that these peaks are not due to $\mathrm{Ag}_{2} \mathrm{O}$, as the peak indicative of this oxide, centred at $529.0 \mathrm{eV}$ is absent (Figure 3.5 c).[186] Both the $\mathrm{Ag}^{0}$ and $\mathrm{Ag}^{+}$sets of peaks have shifted to slightly higher binding energies relative to bulk silver and $\mathrm{Ag}^{+}$in silver nitrate,[184] indicating an interaction of $\mathrm{Ag}^{+}$with PMA and confirming the role of the cationic polymer in the stabilisation of the produced silver nanoparticles. Comparing the $\mathrm{O} 1 \mathrm{~s}$ high resolution spectra of PMA (Figure $3.5 \mathrm{~b}$ ) to that of the nanoparticles (Figure $3.5 \mathrm{c}$ ) confirms this interaction, as it shows a shift in the position of both $\mathrm{C}=\mathrm{O}$ and $-\mathrm{COO}^{-}$in the nanoparticles relative to PMA from 531.50 and $533.20 \mathrm{eV}$ to 531.30 and $532.80 \mathrm{eV}$ respectively. This suggests a bonding interaction between the $\mathrm{C}=\mathrm{O}$ and $-\mathrm{COO}^{-}$groups of PMA with the silver nanoparticles. Considering this, these particles are likely to be present as nanoparticles with a $\mathrm{Ag}^{0}$ core surrounded with a layer of $\mathrm{Ag}^{+}$ions which interact with PMA. Additionally, a peak centred at $536.11 \mathrm{eV}$ is evident in the $\mathrm{O} 1 \mathrm{~s}$ spectra of both PMA and Ag-PMA colloids. There is very little data available on this peak, however it may be due to a pi-pi* type interaction between $\mathrm{C}=\mathrm{O}$ groups of PMA.[187] 

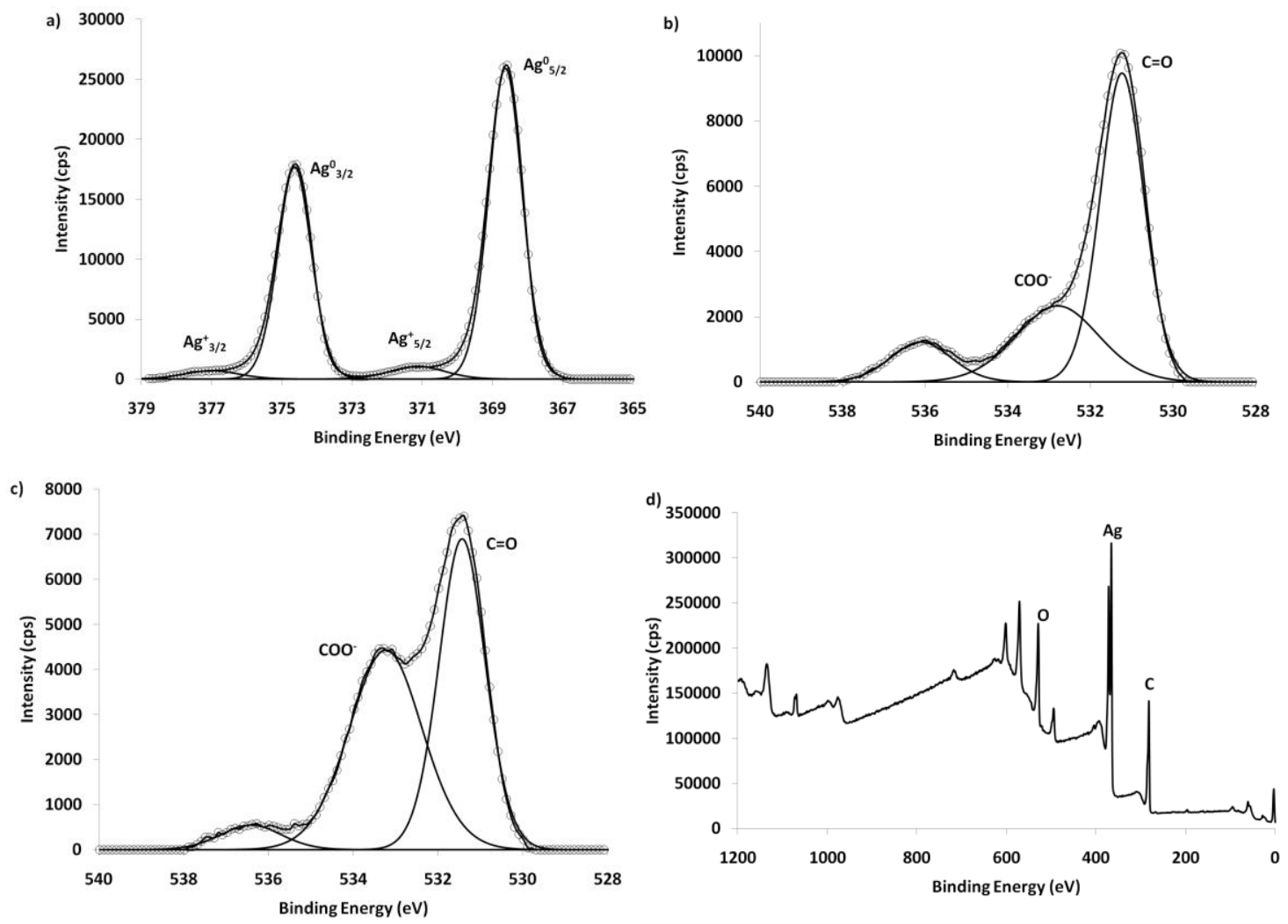

Figure 3.5: Deconvoluted high resolution Ag 3d spectrum of a) PMA capped silver nanoparticles, b) O1s spectrum of PMA and c) O1s spectrum of PMA capped silver nanoparticles. Peak positions are summarised in Table 3.3. d) Wide scan.

Table 3.3: XPS assignments of PMA and PMA capped silver nanoparticles produced via a photo induced reduction method.

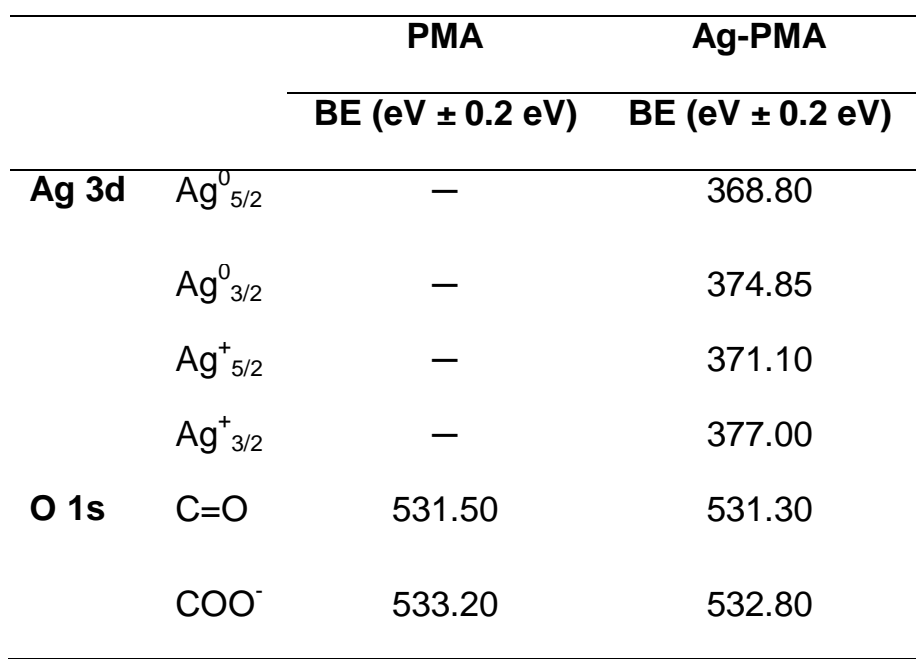




\subsubsection{PMA Stabilised Silver Nanoparticles Prepared via $\mathrm{NaBH}_{4}$ Reduction}

An alternate production method of Ag-PMA nanoparticles involved the reduction of silver nitrate with sodium borohydride (scheme 3.3), in the presence of trisodium citrate (TSC) and later PMA (section 2.2.1.1.2).

$$
\begin{gathered}
\mathrm{Ag}_{(\mathrm{aq})}^{+}+\mathrm{e}^{-} \rightarrow \mathrm{Ag}_{(\mathrm{s})} \\
\frac{\mathrm{BH}_{4}^{-}(\mathrm{aq})}{8 \mathrm{OH}_{(\mathrm{aq})}^{-} \rightarrow \mathrm{BO}_{2}^{-}(\mathrm{aq})}+6 \mathrm{H}_{2} \mathrm{O}_{(\mathrm{l})}+8 \mathrm{e}^{-} \\
8 \mathrm{Ag}_{(\mathrm{aq})}^{+}+\mathrm{BH}_{4(\mathrm{aq})}^{-}+8 \mathrm{OH}_{(\mathrm{aq})}^{-} \rightarrow 8 \mathrm{Ag}_{(\mathrm{s})}+ \\
\mathrm{BO}_{2}^{-}(\mathrm{aq})+6 \mathrm{H}_{2} \mathrm{O}_{(\mathrm{l})}
\end{gathered}
$$

In this solution phase synthesis, silver nanoparticles with a loose shell of TSC ligands were initially produced, which were subsequently displaced by polymeric PMA.[104] Colloidal solutions of the resultant Ag-PMA nanoparticles were yellow in colour (Figure 3.6 left), and showed a moderately sharp absorption peak in the visible region, centred at $400 \mathrm{~nm}$ (Figure 3.7, line a).

Figure 3.6: Left: $\mathrm{NaBH}_{4}$ reduced and PMA stabilised silver nanoparticles. Right: $\mathrm{NaBH}_{4}$ reduced and PMA stabilised silver nanoparticles following irradiation. 


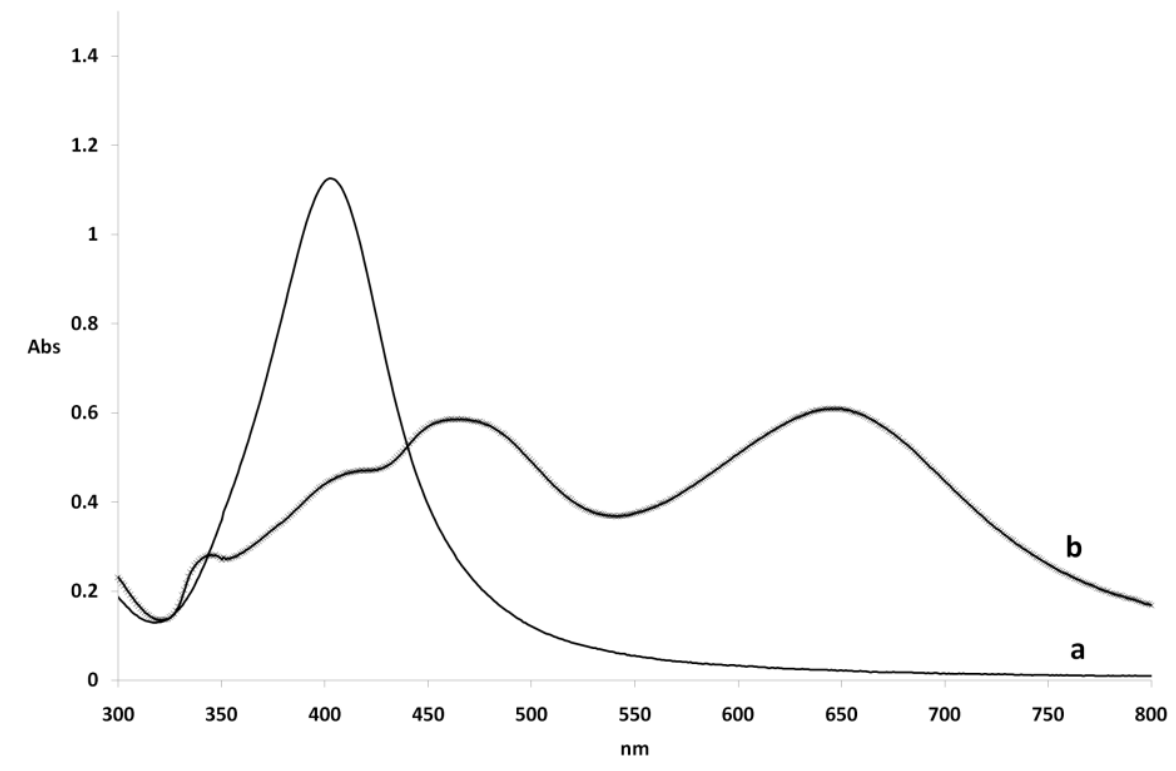

Figure 3.7: a) UV/Vis absorption spectrum of yellow silver nanoparticles colloids and b) green silver nanoparticles colloids.

TEM analysis revealed these nanoparticles to be spheres, approximately $2-5 \mathrm{~nm}$ in diameter (Figure 3.8 a). These nanoparticles were considerably more monodisperse than those produced via the photo induced reduction of $\mathrm{Ag}^{+}$to $\mathrm{Ag}^{0}$. Exposing these colloidal solutions to sunlight induced a transformation from nanospheres to triangular nanoplates $(\sim 30 \mathrm{~nm}$ in diameter), and resulted in a colour change from yellow to green (Figure 3.6). This colour change was accompanied with a change in the surface plasmon band of the particles, indicated by the disappearance of the peak at $400 \mathrm{~nm}$ and the appearance of two new peaks at 460 and $640 \mathrm{~nm}$ in the UV/Vis absorption spectrum, corresponding to the transverse and longitudinal plasmon bands of the triangular nanoplates respectively (Figure 3.7, line b).[115]

The mechanism for the transformation of spherical silver nanoparticles to triangular nanoplates is discussed in section 1.3.3. The UV portion of visible light is thought to induce the slow dissolution of silver atoms from the initially formed spherical nanoparticles, with subsequent re-attachment of these ions onto seed particles containing twin plane defects. Particles with such defects were observed in colloidal solutions of Ag-PMA prior to irradiat- 

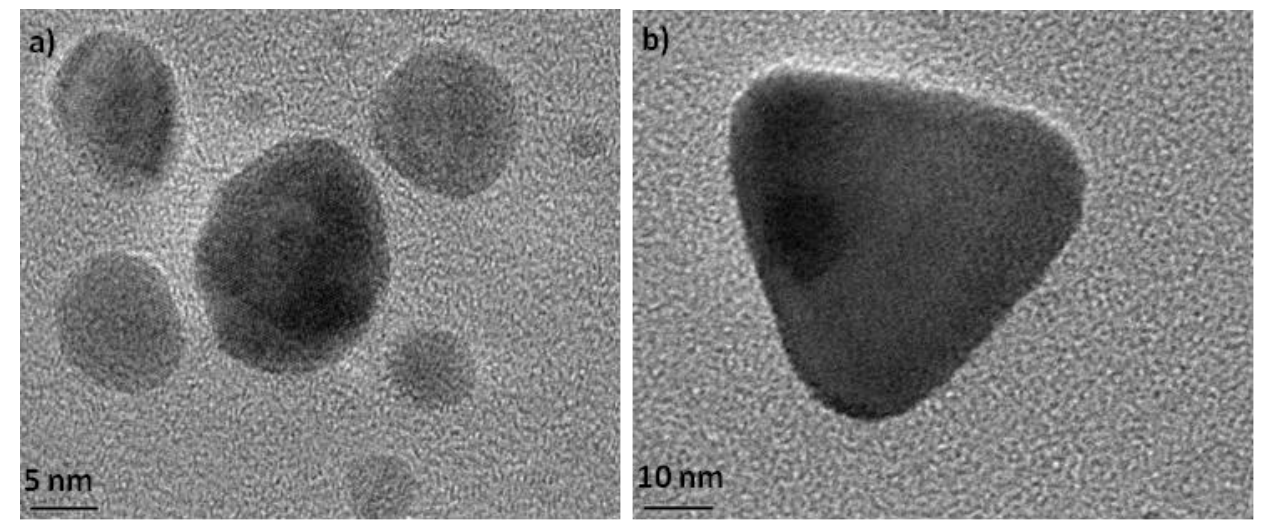

Figure 3.8: TEM micrographs of $\mathrm{NaBH}_{4}$ reduced and PMA stabilised silver nanoparticles. a) Yellow colloids (before irradiation) and b) green colloids (following irradiation).

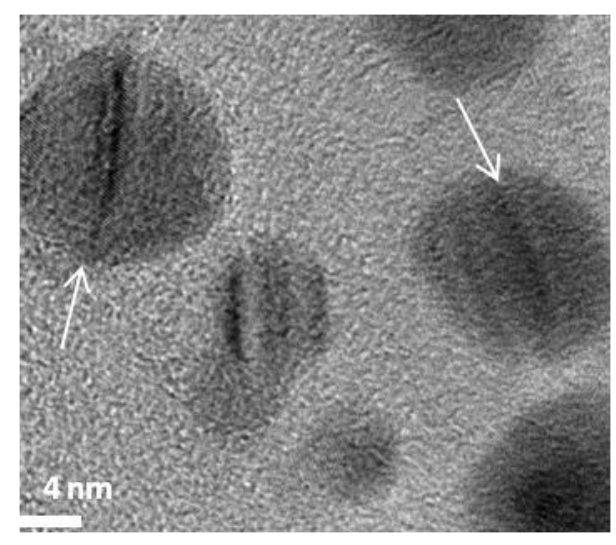

Figure 3.9: TEM micrograph of $\mathrm{NaBH}_{4}$ reduced and PMA stabilised silver nanoparticles, arrows show the position of twin plane defects.

ion (Figure 3.9). As discussed in section 1.3.3 these twin plane defects act as re-entrant grooves that are favourable sites for ion attachment, reducing the nucleation energy required to form new atomic layers in these areas. As such, faces containing these re-entrant grooves grow at a faster rate than those that do not, resulting in the formation of anisotropic particles such as triangular platelets. The concentration of the dissolved silver never reaches that necessary for nucleation, and therefore no new particles are formed, rather all of the silver atoms go into the growth of the triangular nanoplates. Evidence for the dissolution and reprecipitation of silver from such particles, in similar reaction conditions have been reported in the literature (also see section 1.3.3).[121, 189-191] Unfortunately these triangular silver nanoplates could not be produced in a large yield, and as such they were unable to be incorporated into composite materials. 


\subsubsection{PMA Stabilised Silver Nanoparticle-Clay Composites}

When utilising broad spectrum UV light to facilitate the reduction of $\mathrm{Ag}^{+}$to metallic silver nanoparticles, the resultant silver nanoparticle-clay (Ag-PMA-clay) composites were purple in colour, whilst composites incorporating $\mathrm{NaBH}_{4}$ produced nanoparticles were yellow (Figure 3.10).

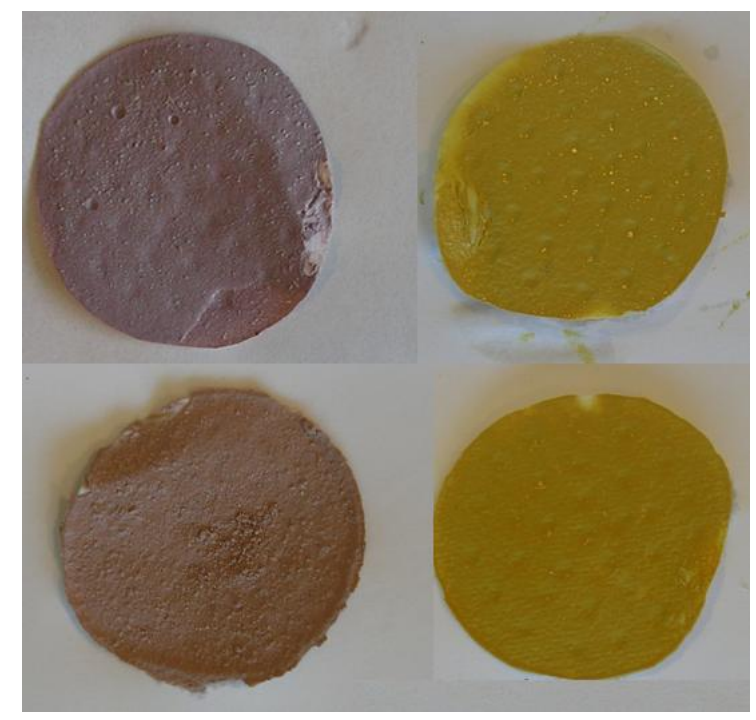

Figure 3.10: Range of silver nanoparticle-kaolinite (top) and halloysite (bottom) composite materials produced, incorporating Ag-PMA nanoparticles prepared via a photo induced reduction (left) and $\mathrm{NaBH}_{4}$ reduction (right).

\subsubsection{Physical Characterisation and Morphology}

The morphologies of the resultant Ag-PMA-clay composites were analysed by electron microscopy. Comparing low magnification SEM micrographs of the kaolinite substrate and its silver nanoparticle analogue (prepared via a photo induced reduction of $\mathrm{Ag}^{+}$to $\mathrm{Ag}^{0}$ ) revealed the presence of a substantial amount of organic matter in the composite (Figure 3.11 $\mathrm{a}$ and $\mathrm{b}$ respectively). This organic matter appeared to act as an adhesive, causing individual platelets of kaolinite to clump together. As this is absent in kaolinite alone, it is likely to be a combination of PMA and PDADMAC. This is confirmed in IR spectroscopy, with the peak centred at approximately $1565 \mathrm{~cm}^{-1}$ indicative of $\mathrm{COO}^{-}$stretching (see section 3.1.2.4). 
Increasing magnification micrographs further confirmed the presence of silver nanoparticles on the kaolinite substrate (Figure $3.11 \mathrm{c}$ ), and due to the relatively high molecular mass of silver, these were increasingly evident under back scatter conditions (Figure $3.11 \mathrm{~d}$ and f). It is difficult to accurately ascertain the size of the silver nanoparticles on the surface of the kaolinite platelets due to the resolution of the SEM and slight charging of the materials. However it does show the nanoparticles to be present predominantly as isolated particles, with small populations of clumping. The nanoparticles also appear to be encapsulated in the organic matter coating the kaolinite platelets (Figure $3.11 \mathrm{f}$ ), verifying the role of PMA and PDADMAC as capping and linking agents respectively. This organic matter encapsulating the nanoparticles follows the surface morphology of the kaolinite, suggesting that the nanoparticles are bound to the clay through PMA and PDADMAC, rather than simply dispersed throughout the platelets.
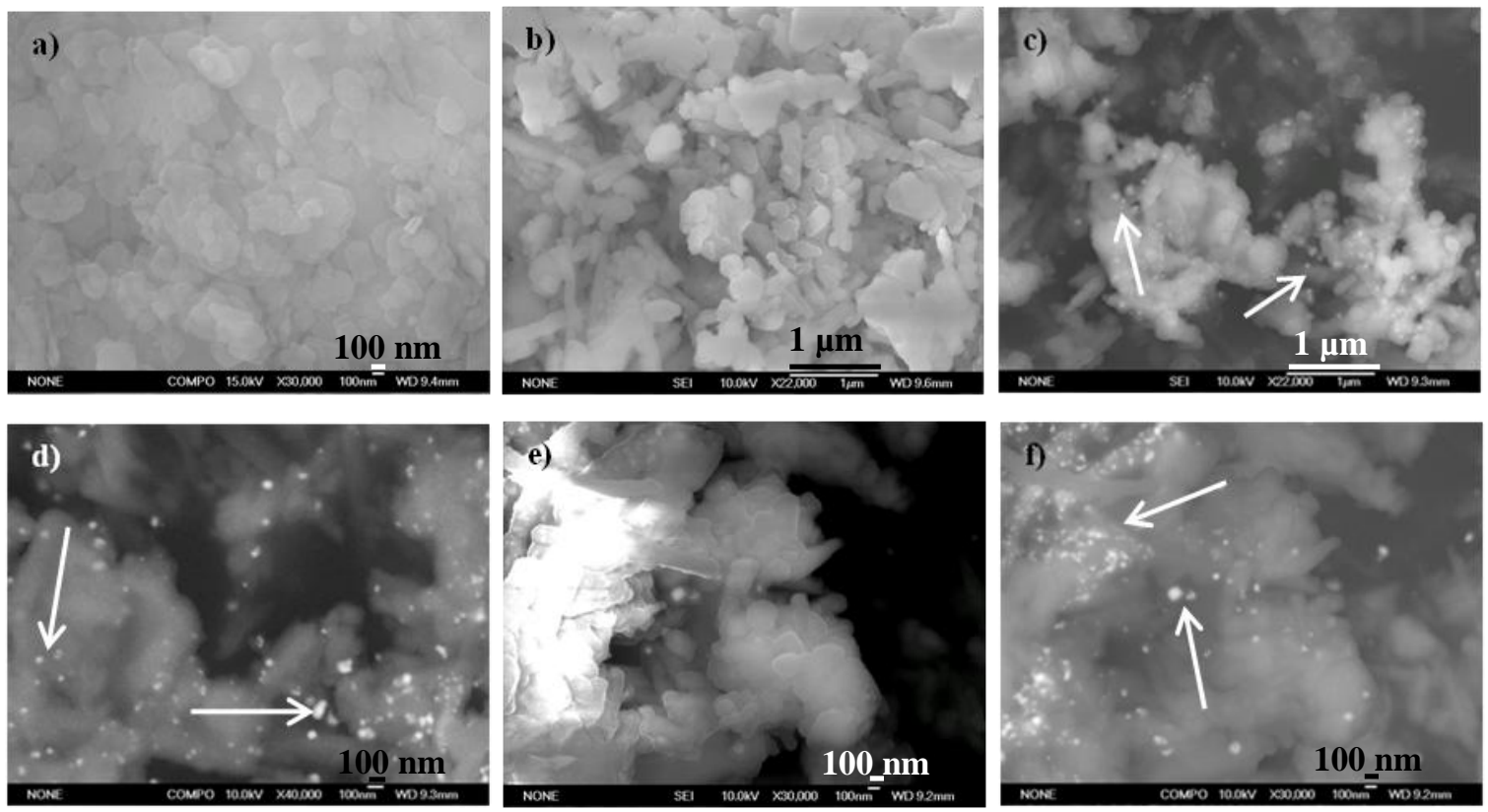

Figure 3.11: SEM micrographs of kaolinite (a) and increasing magnifications of a Ag-PMA-kaolinite composite (photo induced reduction) (b-f). The position of some nanoparticles are indicated by arrows.

Additionally, Ag-PMA-kaolinite composites incorporating nanoparticles prepared with $\mathrm{NaBH}_{4}$ do not appear to have as great a coating of organic matter (Figure $3.12 \mathrm{a}$ ). This is to be expected as their production method employed approximately five times less PMA. Additionally, there is a much lower concentration of nanoparticles on the kaolinite surface 
(Figure 3.12 b-c), which can also be attributed to the synthesis of the nanoparticles, as this process employed approximately twenty times less silver nitrate than the alternate photo induced production.
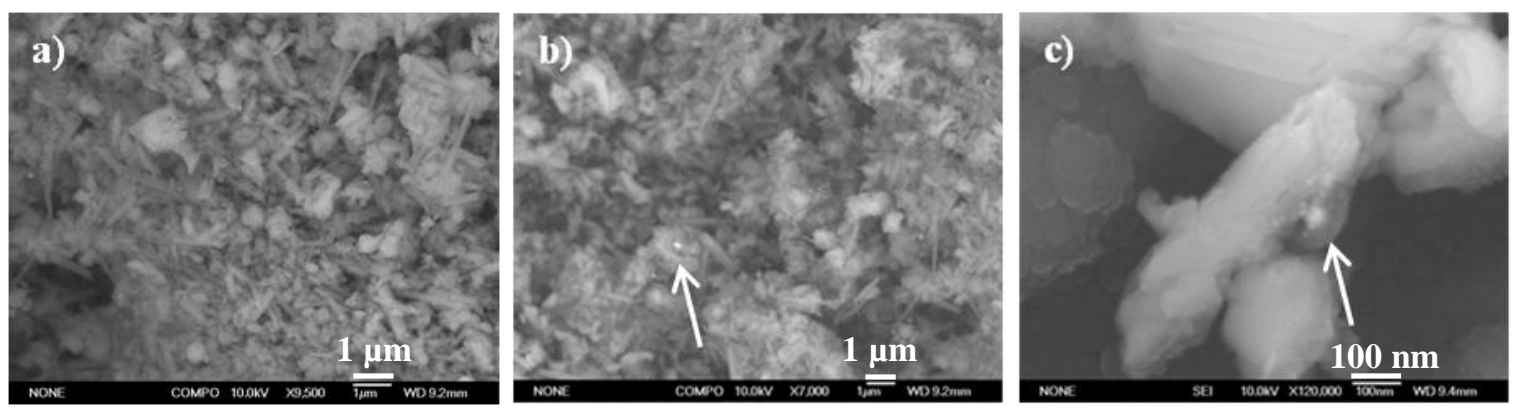

Figure 3.12: Increasing magnification SEM micrographs of a Ag-PMA-kaolinite composite $\left(\mathrm{NaBH}_{4}\right.$ reduced). Nanoparticle positions indicated by arrows.

Similar morphological trends were observed in the Ag-PMA-halloysite composites. There is a substantial amount of organic matter present in the composite materials incorporating nanoparticles produced via the photo induced reduction method (Figure $3.13 \mathrm{a}-\mathrm{c}$ ), and there appear to be less nanoparticles on the composites incorporating colloids produced via the $\mathrm{NaBH}_{4}$ reduction method (Figure 3.13 d-f). However in both cases there are markedly less nanoparticles in the halloysite composites relative to the corresponding kaolinite materials. This is likely due to the morphological differences of the two clays. The tubular morphology of halloysite presents the potential for PDADMAC to be absorbed into the centre of the tube where it could electrostatically interact with the deprotonated Al-OH groups of this inner surface. This would decrease the amount of PDADMAC available to interact with the negatively charged outer $\mathrm{SiO}_{2}$ halloysite surface, in turn limiting the amount of PMA-Ag nanoparticles attracted to, and subsequently deposited onto the tubule surface. The inner cylindrical pores of halloysite are approximately $15-20 \mathrm{~nm}$ in diameter, so therefore it is feasible that a portion of small PMA-Ag nanoparticles (diameters less than approximately 15 $\mathrm{nm}$ ) may have been deposited inside the tubes rather than on the surface, which would also account for the lower amount of nanoparticles evident on the halloysite composite surface relative to the corresponding kaolinite materials. The smaller quantity of nanoparticles on the surface of halloysite relative to kaolinite would account for the less intense colour of the silver nanoparticle-clay composites incorporating halloysite or kaolinite respectively. 

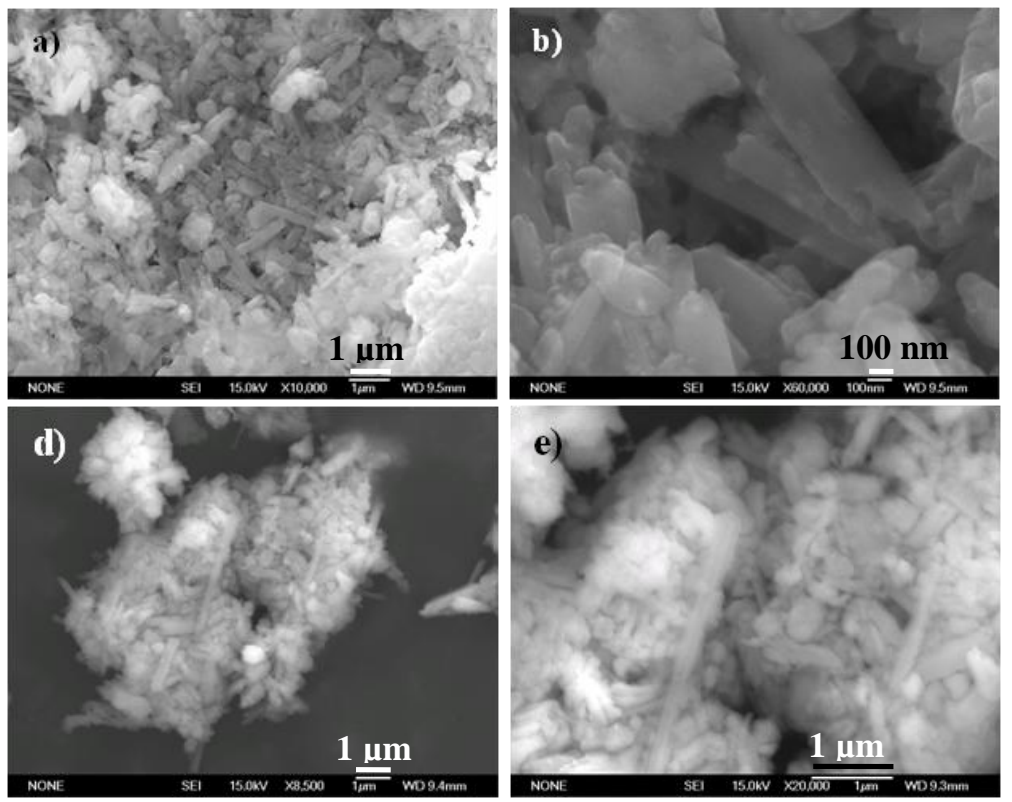
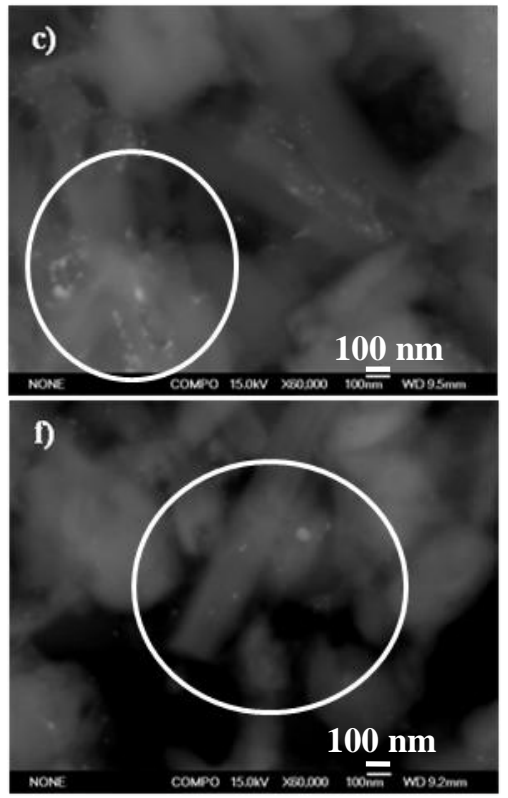

Figure 3.13: Increasing magnification SEM micrographs of a Ag-PMA-halloysite composite, prepared via photo induced (a-c) or $\mathrm{NaBH}_{4}$ reduction (d-f). Nanoparticles circled.

TEM offers increased spatial resolution thus allowing for a more precise determination of the size and shape of the Ag-PMA nanoparticles incorporated into the produced composites. Analysis of the Ag-PMA-kaolinite materials (employing nanoparticles produced via a photo induced reduction) showed a relatively high concentration of nanoparticles, ranging in size from approximately 10-40 $\mathrm{nm}$ in diameter (Figure $3.14 \mathrm{a}-\mathrm{c}$ ). These were predominantly spherical in morphology. The hexagonal platelets, truncated triangles and five fold twinned nanoparticles that were present in the colloidal solution were not immediately apparent in the composites. This may be due to an increase in organic matter upon incorporation of PDADMAC and also the thickness of kaolinite, which makes viewing these materials difficult. The composites incorporating nanoparticles produced by $\mathrm{NaBH}_{4}$ reduction were also spherical in morphology, however as with their analogous colloidal solutions, they were a lot smaller (approximately $5 \mathrm{~nm}$ in diameter) and monodisperse.

Similar trends are observed in the Ag-PMA-halloysite composites. TEM analysis confirmed the tubular morphology of halloysite and the incorporation of nanoparticles on its surface and also in its cylindrical pores. The silver in the composites employing nanoparticles produced via a photo induced reduction are predominantly spheres, approximately 10-40 nm in 
diameter, and are thus similar to their corresponding kaolinite composites (Figure 3.15 a-c). Similarly, the composites incorporating nanoparticles produced by $\mathrm{NaBH}_{4}$ reduction were comparable to the kaolinite materials in that the nanoparticles in these composites appeared spherical in morphology. Additionally they were and a lot smaller (approximately 5-10 nm in diameter) and monodisperse than those produced via a photo induced reduction (Figure $3.15 \mathrm{~d}-\mathrm{f})$.

TEM also suggested that as proposed above, silver nanoparticles may be incorporated inside the cylindrical pores of halloysite. Figure 3.16 and Figure 3.17 offer large TEM micrographs of Ag-PMA-halloysite composites prepared via both synthesis methods. These micrographs clearly show small nanoparticles, (approximately $5 \mathrm{~nm}$ in diameter) incorporated inside the halloysite tubes, particularly near the ends/openings of these tubes. It is difficult to say whether these nanoparticles are incorporated right through the length of the tubes.
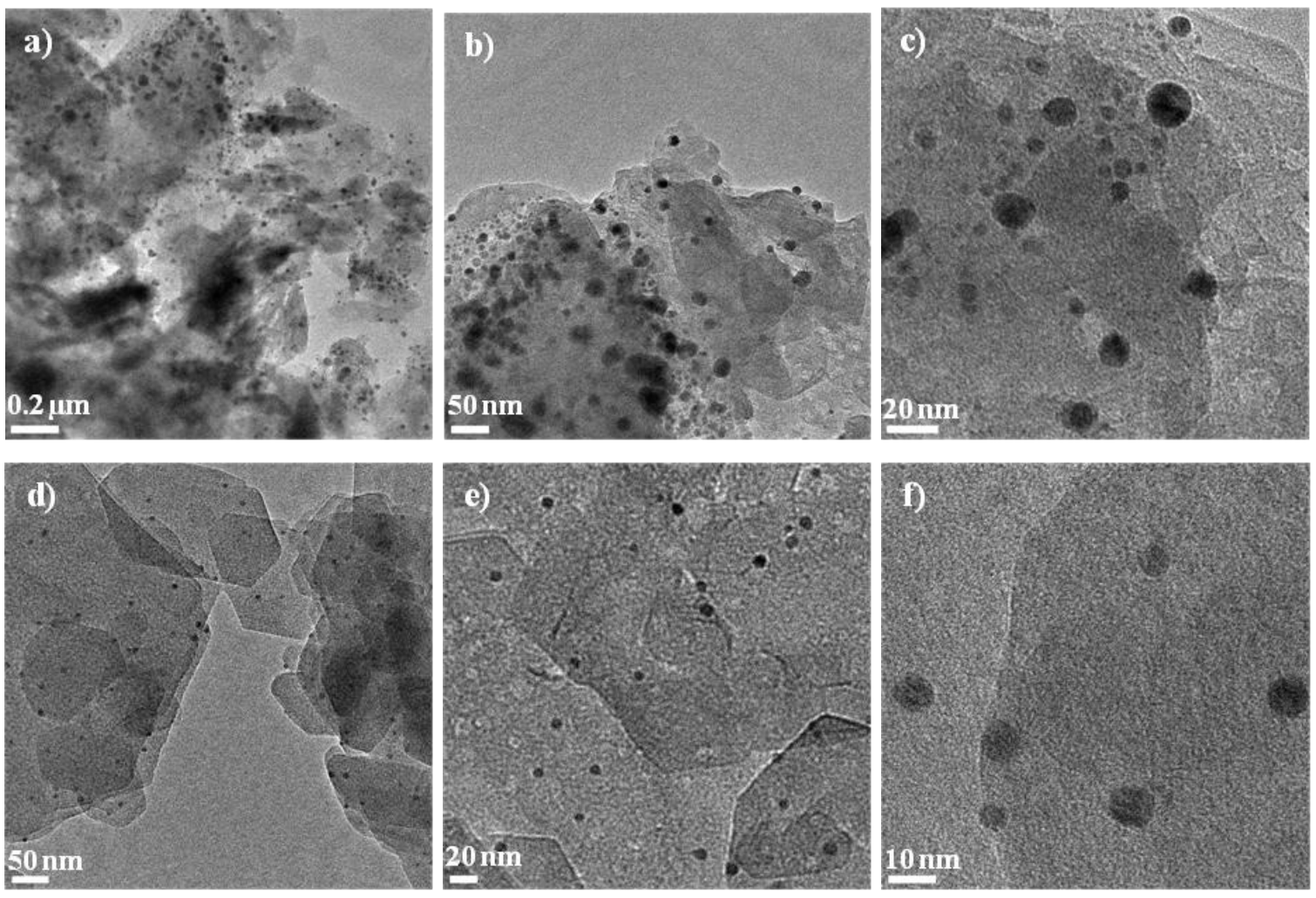

Figure 3.14: Increasing magnification TEM micrographs of Ag-PMA-kaolinite composites, prepared via photo induced (a-c) and $\mathrm{NaBH}_{4}$ reduction (d-f). 

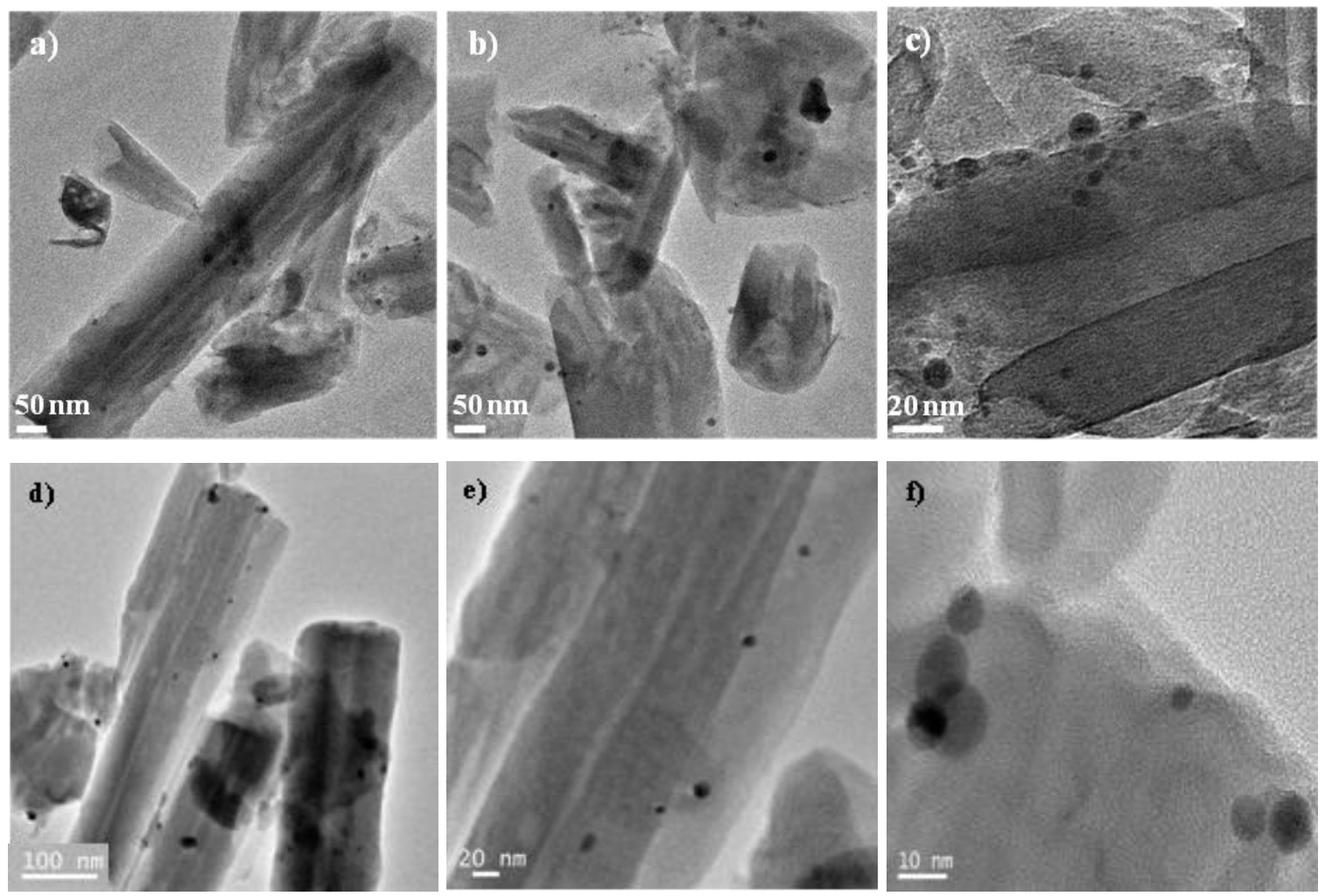

Figure 3.15: Increasing magnification TEM micrographs of Ag-PMA-halloysite composites prepared via photo induced (a-c) or $\mathrm{NaBH}_{4}$ reduction (d-f).
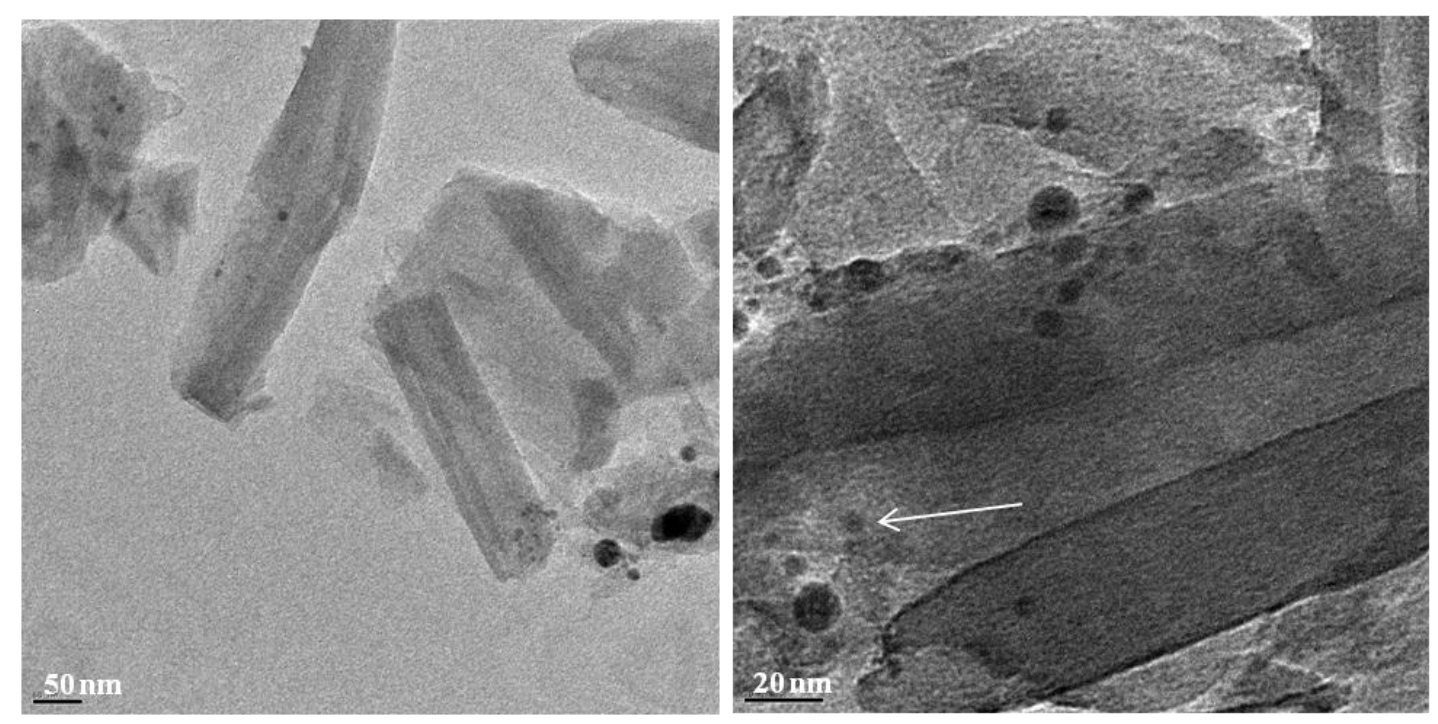

Figure 3.16: Increasing magnification TEM micrographs of of Ag-PMA-halloysite composites prepared via photo induced reduction. Arrows indicate the location of nanoparticles inside the cylindrical pores of halloysite. 

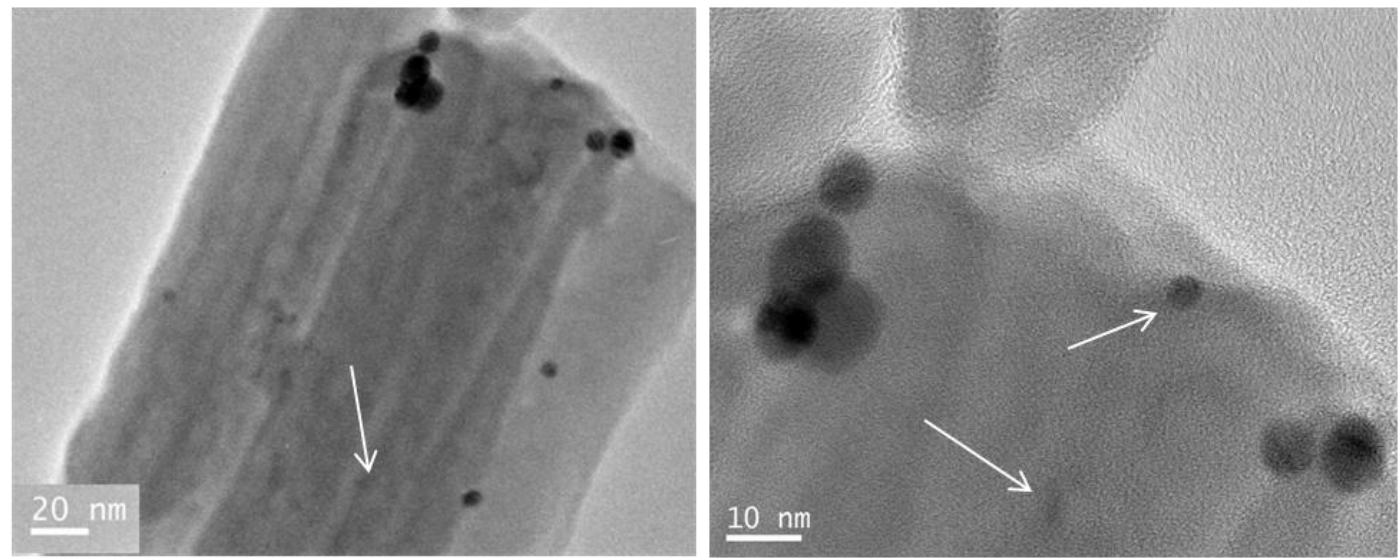

Figure 3.17: Increasing magnification TEM micrographs of of Ag-PMA-halloysite composites prepared via or $\mathrm{NaBH}_{4}$ reduction. Arrows indicate the location of nanoparticles inside the cylindrical pores of halloysite.

As seen in these TEM and the corresponding SEM micrographs of all composites produced, the nanoparticles follow the morphology of the clay substrates, suggesting that the silver nanoparticles are attached to the clays rather than simply dispersed throughout. Relative to the amount of the clay, these nanoparticles are present in very low concentrations, however they still manage to impart colourant properties owing to the strong plasmon resonances of the nanoparticles.

\subsubsection{Confirmation of Silver}

The presence of silver in the Ag-PMA-clay composites was confirmed by both energy dispersive spectroscopy (EDS) and x-ray photo electron spectroscopy (XPS), and verified the trend noted above, in which composite materials incorporating nanoparticles prepared via a photo induced reduction contained a larger proportion of silver than those incorporating $\mathrm{NaBH}_{4}$ produced nanoparticles.

EDS provides information about the elemental composition on the surface of a material, and as such confirmed that when viewed under back scatter conditions, the bright white dots evident in SEM micrographs were silver. Figure 3.18 offers typical high resolution SEM micrographs of the produced Ag-PMA-clay composites and their corresponding silver maps, where high concentrations of silver are shown in bright white (Figure $3.18 \mathrm{a}, \mathrm{b}$ ) or pink 
(Figure $3.18 \mathrm{c}, \mathrm{d}$ ). EDS is able to define areas of high silver concentrations in composites incorporating silver nanoparticles prepared via a photo induced reduction, however it is unable to do so in those incorporating $\mathrm{NaBH}_{4}$ produced nanoparticles. This is likely due to the fact that the nanoparticles in the latter are too small to be distinguishable, whilst the in former group of composites they are much larger and in closer proximity to each other.
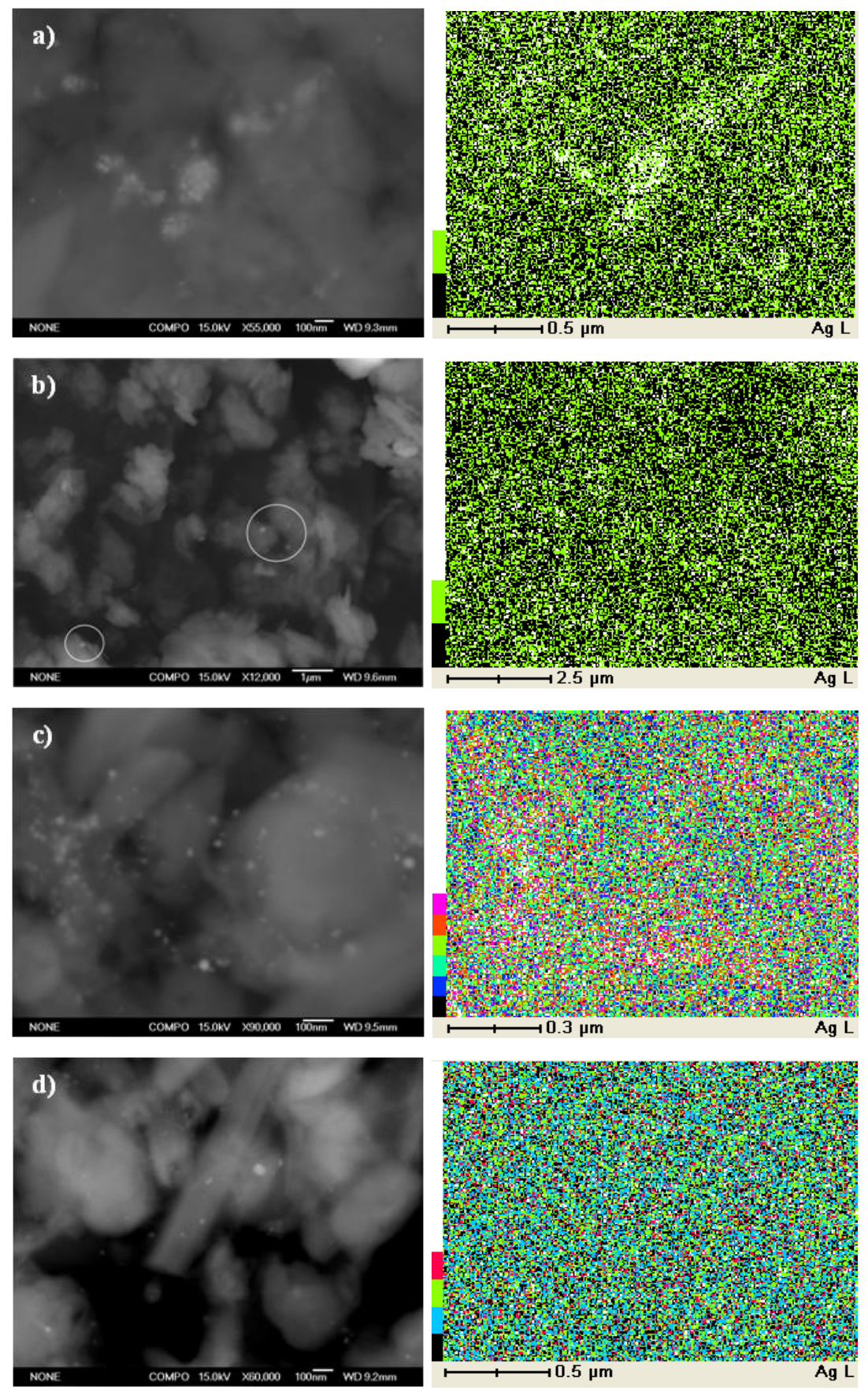

Figure 3.18: SEM micrographs and corresponding silver EDS maps of Ag-PMA-kaolinite composites produced via a photo induced (a) kaolinite, c) halloysite) or $\mathrm{NaBH}_{4}$ reduction (b) kaolinite and d) halloysite). 
XPS was utilised to provide quantitative estimations of the composites surface silver content. Kaolinite and halloysite composites incorporating nanoparticles prepared via a photo induced reduction contained 1.07 and $0.63 \%$ silver respectively (Figure 3.19 a and c), whilst the alternate kaolinite and halloysite materials prepared with $\mathrm{NaBH}_{4}$ produced nanoparticles possessed markedly lower silver contents, 0.11 and $0.04 \%$ respectively (Figure $3.19 \mathrm{~b}$ and d). Complementary to SEM and TEM analysis, XPS shows there to be less silver on the surface of the halloysite composites relative to the kaolinite composites.
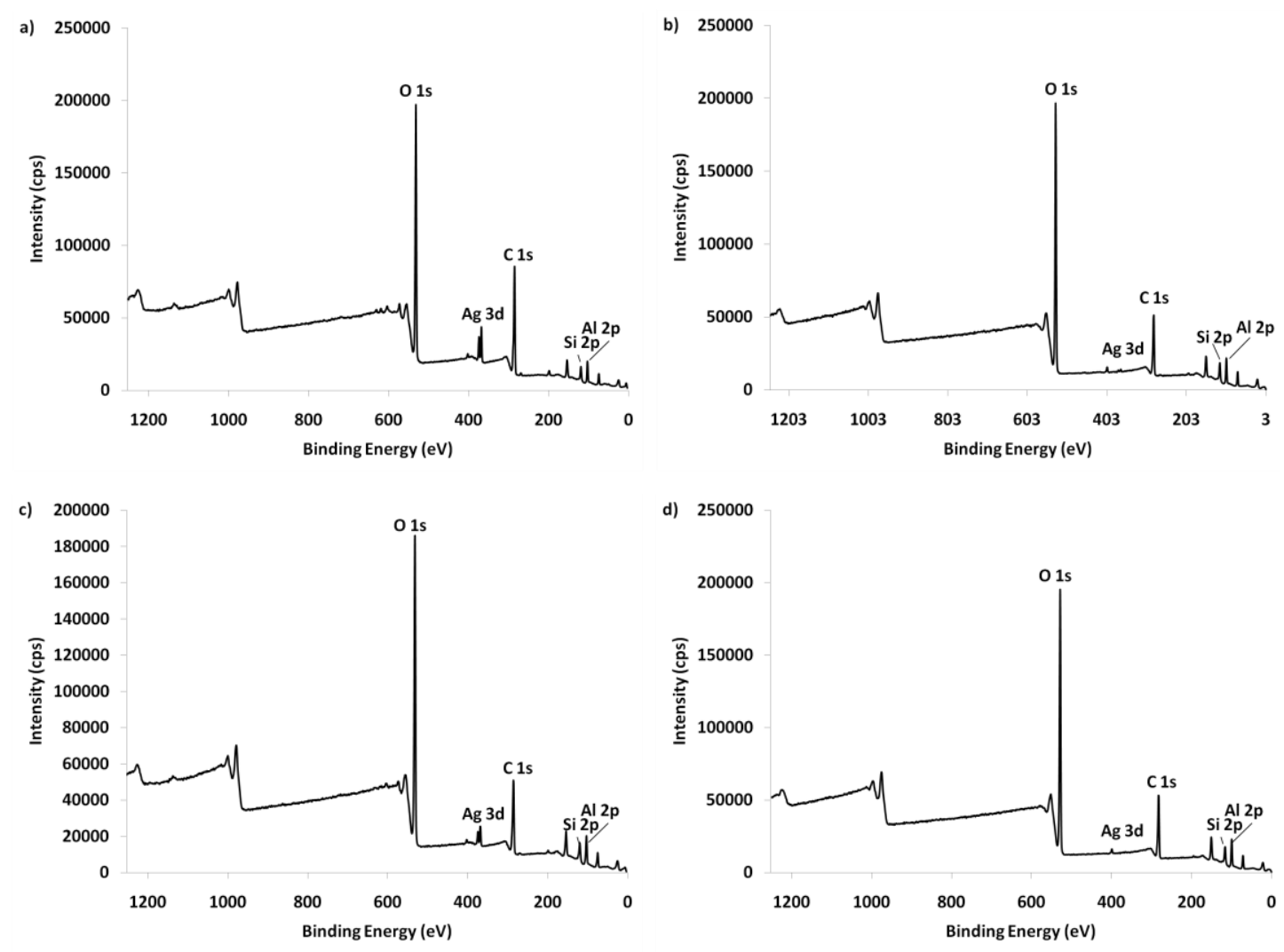

Figure 3.19: Wide XPS scans. a) and b) Ag-PMA-kaolinite and Ag-PMA-halloysite composites incorporating nanoparticles produced via a photo induced reduction. c) and d) Ag-PMA-kaolinite and halloysite composites incorporating nanoparticles produced via a $\mathrm{NaBH}_{4}$ reduction.

Examination of the high resolution Ag 3d spectra of the produced Ag-PMA-clay composites revealed the asymmetric $5 / 2$ and $3 / 2$ peaks of zero valent silver centred at approximately 368 and $374 \mathrm{eV}$ respectively. Additionally, two smaller peaks centred at approximately 369 and $375 \mathrm{eV}$, representative of $\mathrm{Ag}^{+}$were also present. Actual values are provided in Table 3.4 
below. These peaks confirm the presence of silver nanoparticles in the produced composites. Their composition is discussed in further detail in section 3.1.2.4 below.

Table 3.4: XPS peak assignments for the high resolution Ag 3d XPS spectra of Ag-PMA-clay composites. $[184,192]$

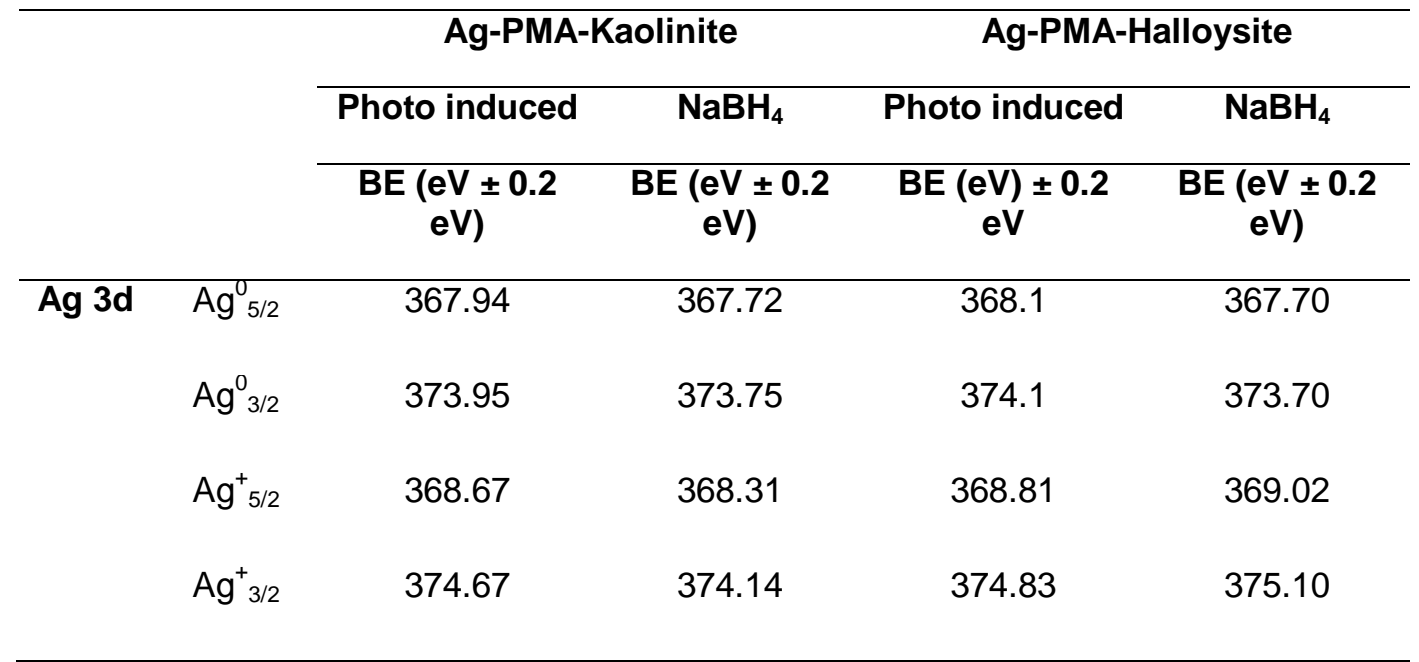

\subsubsection{Colour}

The colour of the composite materials incorporating Ag-PMA nanoparticles, prepared via photo induced or $\mathrm{NaBH}_{4}$ reduction, were studied with UV/Vis spectroscopy. As outlined in section 1.3.1 silver nanoparticles exhibit an intense visible absorption due to surface plasmon resonances, generally centred between 320-500 nm.[193] As previously mentioned, this absorption spans a broad range as it is greatly influenced by the size and shape of the nanoparticles and also the dielectric function of the surrounding medium, with increasing particle sizes inducing a shift in the absorption band to longer wavelengths. However when nanoparticles are sufficiently close together, interactions between neighbouring particles arise, so that models for isolated particles do not hold,[194] and the optical absorption of the aggregate is observed.

Figure 3.20 shows the Kubelka Munk transformed (see section 2.3.10 for an explanation) UV/Vis reflection spectrum of Ag-PMA nanoparticles, prepared via a photo induced 
reduction (line b). Kubulka Munk transformed UV/Vis reflection spectra can be treated as absorption spectra. This absorption is centred at $510 \mathrm{~nm}$, and is slightly blue shifted with respect to the absorption spectrum of similarly sized silver nanospheres, (25 $\mathrm{nm}$ diameter) protected by a stabilising agent.[195] The slight blue shift is likely due to the small proportion of different shaped nanoparticles. Comparing this spectrum to that of a corresponding Ag-PMA-kaolinite composite sees a broadening of the peak centred at $510 \mathrm{~nm}$ (Figure 3.20 line a). As mentioned, the full width at half maximum of the plasmon peak is dependent upon the extent of particle aggregation,[196] with broader peaks corresponding to more aggregated colloids. TEM analysis of the produced Ag-PMA-kaolinite composites shows that upon inclusion into the composites, there is an increase in the average size of the nanoparticles, from approximately $10-25 \mathrm{~nm}$ in diameter in the colloid to $10-40 \mathrm{~nm}$ in the composite. The broadness of the absorption peak of these composites suggests that the larger sized particles are formed as a result of agglomeration. The broadening may also be an indication of a bonding interaction between the Ag-PMA nanoparticles and the PDADMAC on the kaolinite.

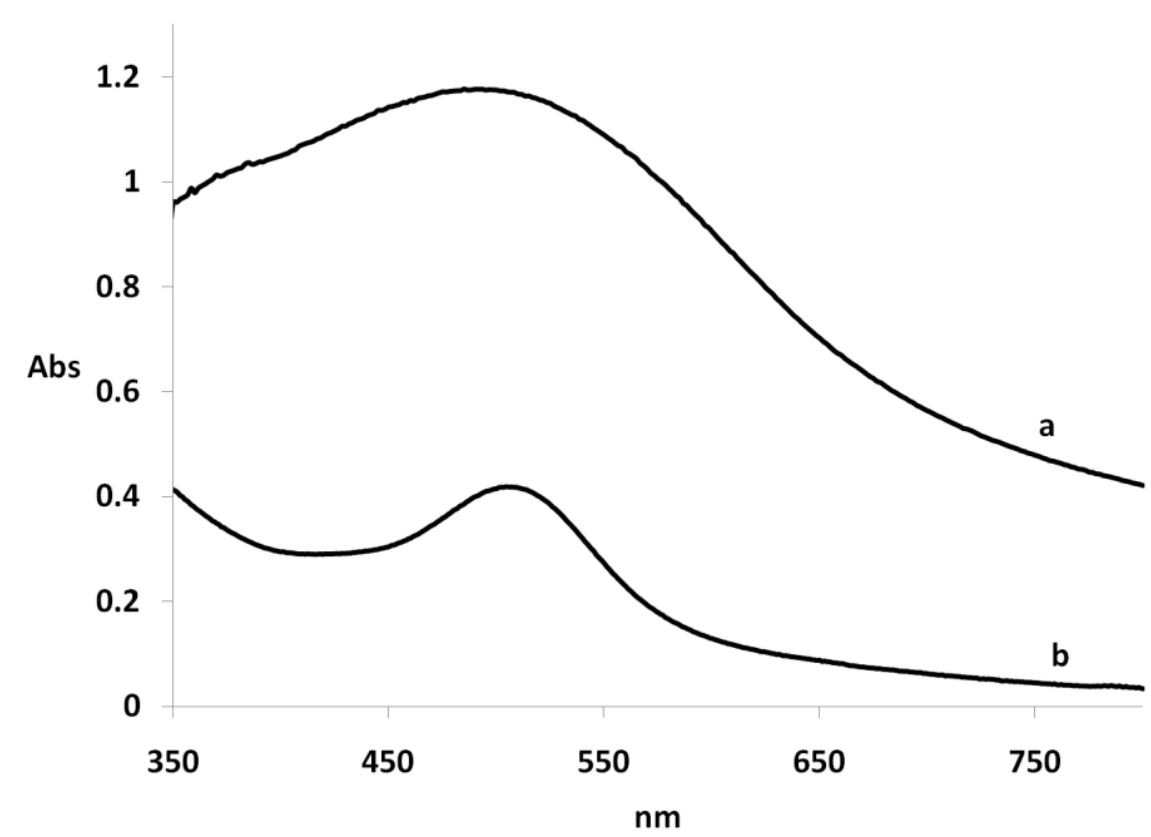

Figure 3.20: Kubelka Munk transformed UV/Vis reflection spectrum of a) a Ag-PMA-kaolinite PMA composite (photo induced reduction) and b) a Ag-PMA colloid (photo induced reduction). 
Similar results were obtained in the production of Ag-PMA-kaolinite composites incorporating nanoparticles produced via $\mathrm{NaBH}_{4}$ reduction (Figure 3.21). However the plasmon peak of these nanoparticles and the corresponding composite materials have blue shifted relative to the colloids prepared via a photo induced reduction, and are now centred at 401 and $406 \mathrm{~nm}$ respectively. This shift in the plasmon peak is reflective of the difference in nanoparticle size between the two colloids. The nanoparticles prepared via reduction with $\mathrm{NaBH}_{4}$ are much smaller, $\sim 2-5 \mathrm{~nm}$ in diameter. There is a slight red shift of this plasmon band $(\sim 5 \mathrm{~nm})$ upon incorporation of the nanoparticles into the composite materials, and as with the materials incorporating nanoparticle prepared via a photo induced reduction, there is also a broadening of this peak, however it is not as extensive. As there is no discernable change in particle size upon incorporation into the composite materials, this slight shift and broadening is likely to arise due to a change in the dielectric function of the surrounding medium (now a clay rather than water), and may also be indicative of a bonding interaction between the nanoparticles and clay.

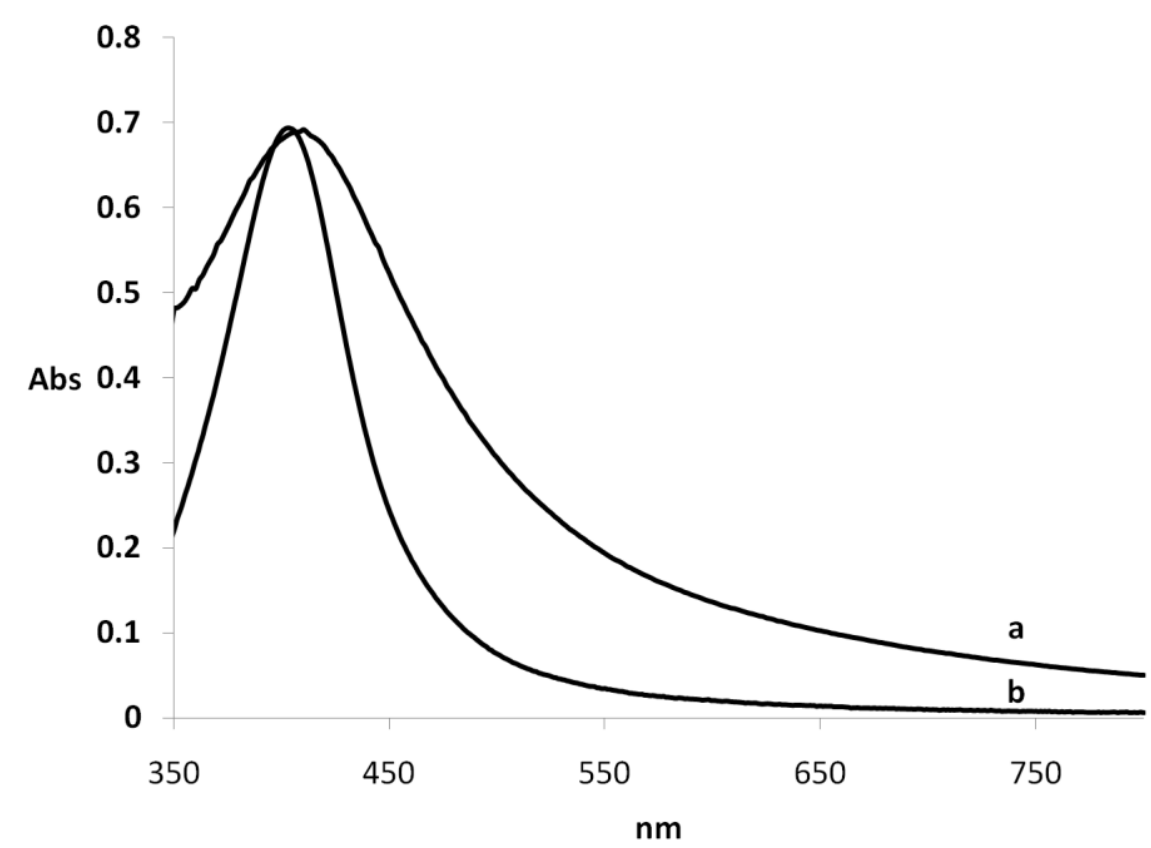

Figure 3.21: Kubelka Munk transformed UV/Vis reflection spectrum of a) a Ag-PMA-kaolinite composite $\left(\mathrm{NaBH}_{4}\right.$ reduction) and b) a Ag-PMA colloid ( $\mathrm{NaBH}_{4}$ reduction).

Comparable results were obtained for the corresponding halloysite composites, with a broadening, and slight red shift in the plasmon band of the composite materials relative to the 
colloids used in their production (Figure 3.22 and Figure 3.23). However, relative to the kaolinite composites the colour of the corresponding halloysite materials was slightly less intense, which was shown when comparing the materials Kubelka Munk transformed UV/Vis reflection spectra; with the plasmon band of the halloysite materials being less intense than the kaolinite (Figure 3.24). This is likely due to the decreased amount of nanoparticles on the surface of the halloysite composites.

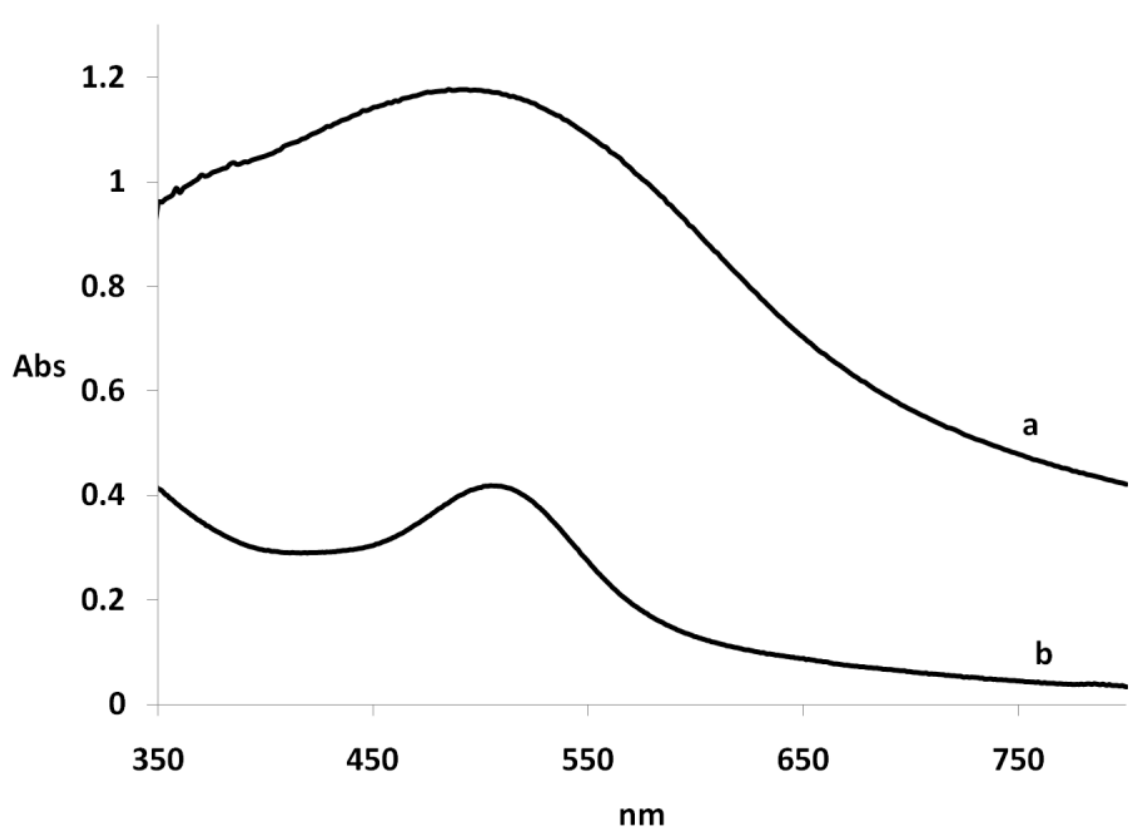

Figure 3.22: Kubelka Munk transformed UV/Vis reflection spectrum of a) a Ag-PMA-halloysite composite (photo induced reduction) and b) a Ag-PMA colloid (photo induced reduction). 


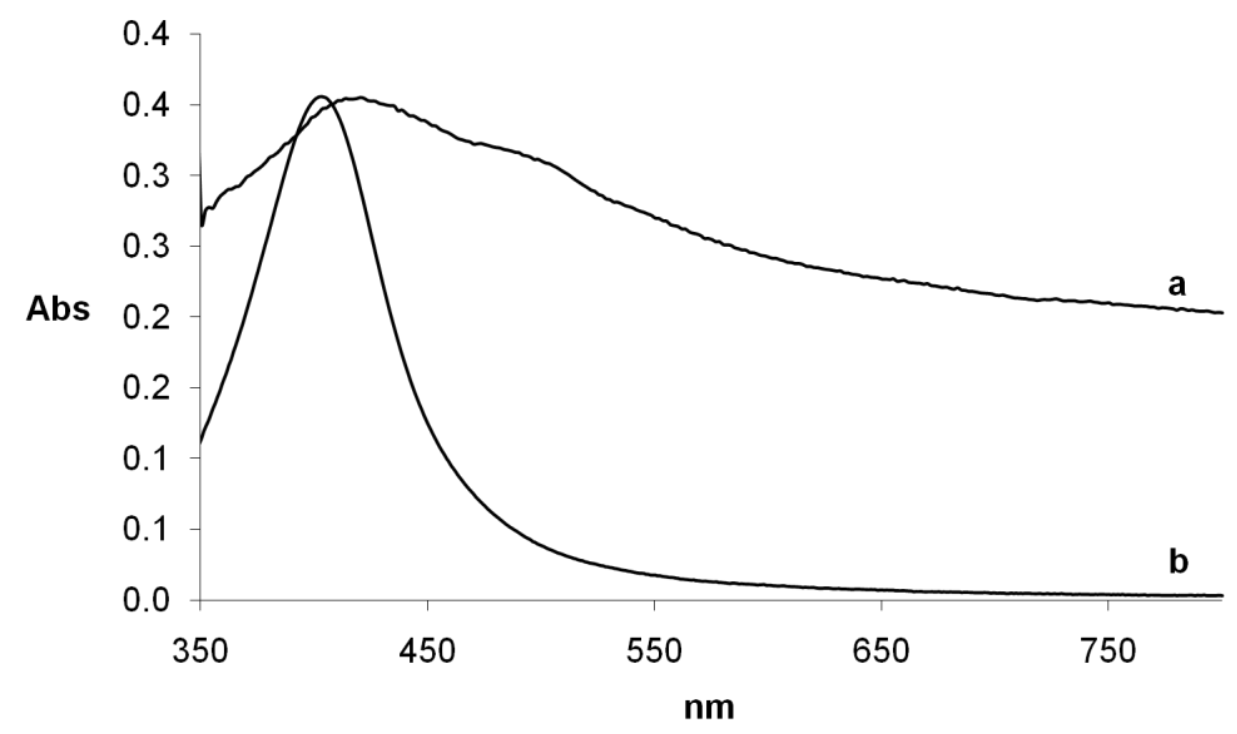

Figure 3.23: Kubelka Munk transformed UV/Vis reflection spectrum of a) a Ag-PMA-halloysite composite $\left(\mathrm{NaBH}_{4}\right.$ reduction) and b) a Ag-PMA colloid $\left(\mathrm{NaBH}_{4}\right.$ reduction).

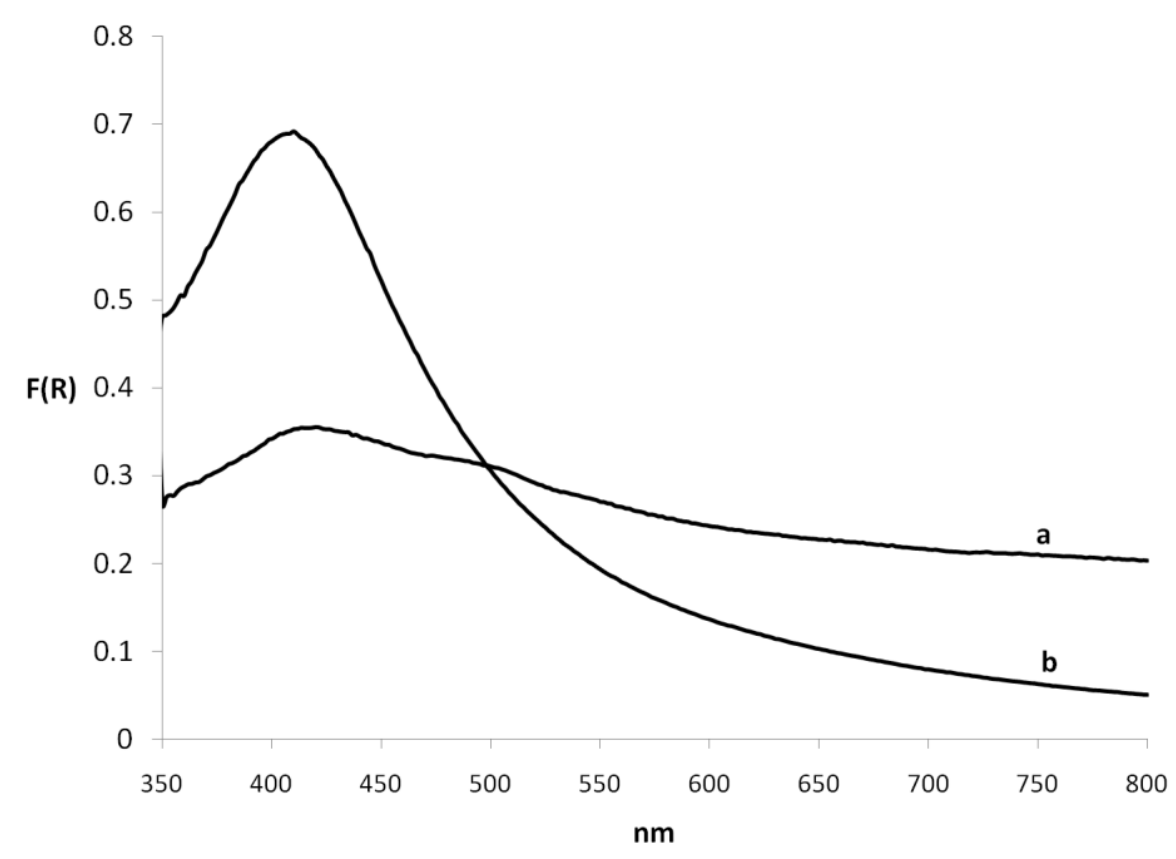

Figure 3.24: Kubelka Munk transformed UV/Vis reflection spectra of a) a Ag-PMA-kaolinite composite (photo induced reduction) and b) a Ag-PMA-halloysite composite. Both prepared via a photo induced reduction. 


\subsubsection{Bonding of Nanoparticles to Clay Substrates}

Under the reaction conditions employed, (reaction $\mathrm{pH}$ of approximately 6.5) both kaolinite and halloysite possess a net negative charge. The surface $\mathrm{Al}-\mathrm{OH}$ and edge $\mathrm{Si}-\mathrm{OH}$ groups (formed through the protonation of edge Si-O-Si species) of kaolinite have pKa values of 5.0 and 6.0 respectively, and are thus deprotonated. Additionally, the silicate planes of both kaolinite and halloysite carry a constant $\mathrm{pH}$-independent negative charge, attributed to the very slight isomorphous replacement of $\mathrm{Si}^{4+}$ by $\mathrm{Al}^{3+}$.[165] As the chemical composition of halloysite is similar to that of kaolinite, it exhibits comparable $\mathrm{pKa}$ values, however it is important to note that the chemistry of the outermost surface of halloysite can be associated with that of $\mathrm{SiO}_{2}$ and the inner cylindrical surface $\mathrm{Al}(\mathrm{OH})_{3}$ (see section 1.2.1.2).

The proposed binding mechanism of Ag-PMA nanoparticles to the clay substrates is through a layer-by-layer deposition process. This method capitalises on electrostatic interactions between oppositely charged polyelectrolytes, and as such a layer of the cationic polymer PDADMAC is initially absorbed onto the clay surface, followed by successive layers of negatively charged Ag-PMA nanoparticles and PDADMAC (as outlined in section 2.2.1.1.2). There are potentially two main ways by which PDADMAC, and consequently Ag-PMA nanoparticles could bond to the clay substrates; via electrostatic interactions between the negatively charged oxygen atoms of deprotonated surface and edge $\mathrm{Al}^{-} \mathrm{O}^{-}$and $\mathrm{Si}^{-} \mathrm{O}^{-}$groups, or with the anionic basal silicate planes in the interlayer spacing. To determine the mode of bonding, x-ray diffraction (XRD), X-ray photoelectron spectroscopy (XPS), infra-red spectroscopy (IR) and solid state NMR were employed.

Analysis of the XRD diffraction patterns of kaolinite and the resultant Ag-PMA-kaolinite composites, incorporating Ag-PMA nanoparticles produced via photo induced or $\mathrm{NaBH}_{4}$ reduction, revealed very slight changes in the basal spacing of the clay, from 7.06 to 7.09 and $7.10 \AA$ A respectively (Figure 3.25). These changes are very minimal, and may arise solely as a result of experimental uncertainties. Comparable results were obtained with halloysite as the clay substrate. The basal spacing of halloysite was recorded as $7.13 \AA$, and the corresponding Ag-PMA-halloysite composites, incorporating nanoparticles prepared via 
photo induced or $\mathrm{NaBH}_{4}$ reduction as 7.16 and $7.15 \AA$ respectively. (The recorded basal spacing of halloysite, of $7.13 \AA$, (rather than the expected $10 \AA$ ) suggested that the clay had been dehydrated, an irreversible process that occurs at temperatures slightly higher than room temperature).[22] This suggests that the PDADMAC, and later the Ag-PMA nanoparticles were deposited solely on the surface of both kaolinite and halloysite rather than incorporated into the interlayer spacings.

XPS confirmed the bonding between PDADMAC and kaolinite or halloysite to be an electrostatic interaction between positively charged PDADMAC and the negatively charged surface of the clay's. XPS peak positions are summarised in Table 3.5. Examination of the high resolution $\mathrm{O} 1 \mathrm{~s}$ spectrum of kaolinite both before and after inclusion of PDADMAC reveals large changes (Figure $3.26 \mathrm{~b}$ ). The peak representative of surface Al-OH groups of the clay is absent in the kaolinite-PDADMAC materials, and a new peak, centred at 531.72 $\mathrm{eV}$ appears (Figure 3.26 a). This peak is likely attributable to an electrostatic interaction

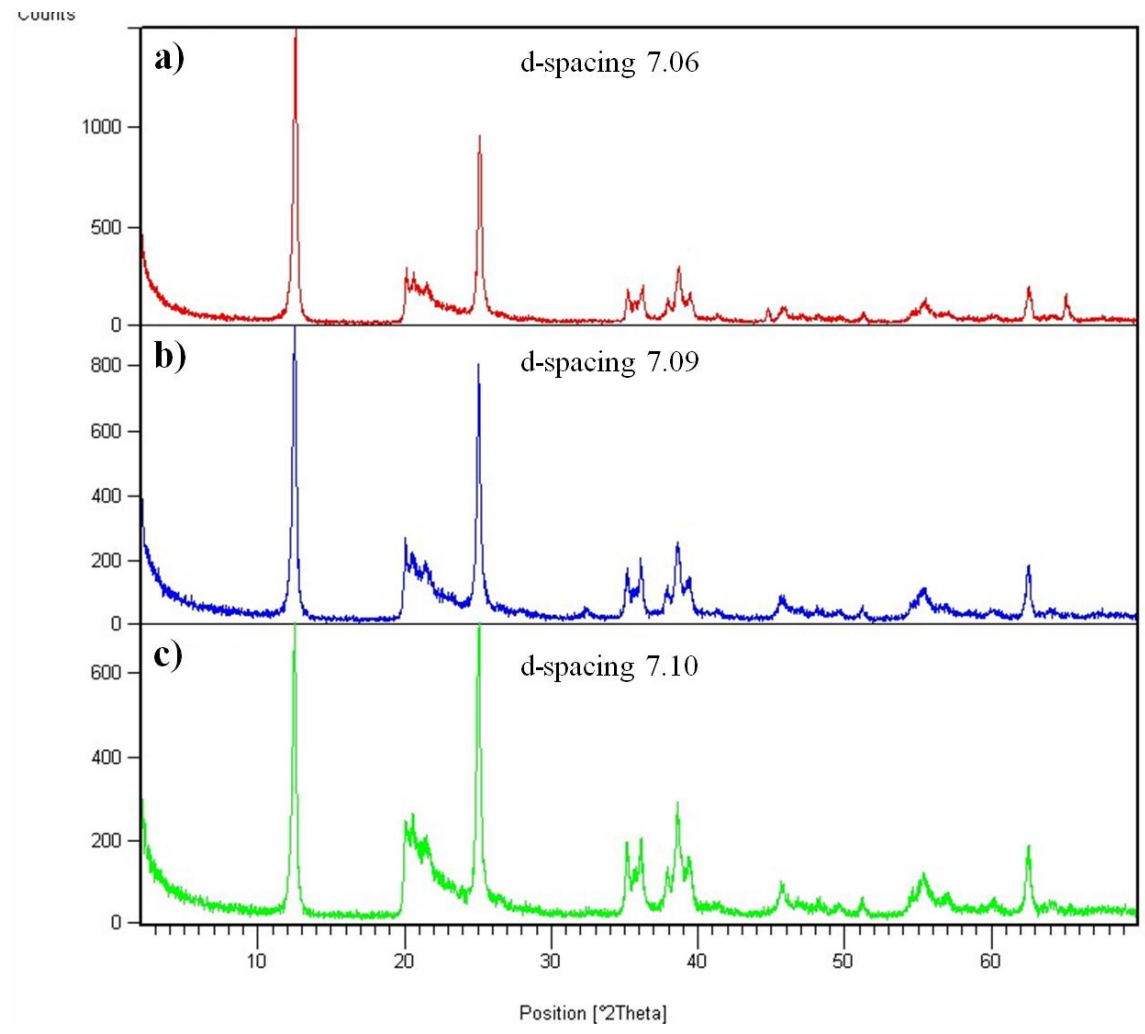

Figure 3.25: XRD patterns of a) kaolinite, b) Ag-PMA-kaolinite (photo induced reduction) and c) AgPMA-kaolinite $\left(\mathrm{NaBH}_{4}\right.$ reduction). 
between the positively charged quaternary nitrogens of PDADMAC and the negatively charged oxygens of deprotonated surface $\mathrm{Al}^{-} \mathrm{O}^{-}$and edge $\mathrm{Si}^{-} \mathrm{O}^{-}$groups of kaolinite. A similar peak has been reported for PDADMAC embedded on silica.[197] This is also evident in the high resolution $\mathrm{N}$ 1s spectrum of kaolinite-PDADMAC by a slight shift in the peak representative of the positively charged quaternary nitrogens of PDADMAC, and the appearance of the peak centred at $399.52 \mathrm{eV}$ (Figure $3.27 \mathrm{c}$ ), which is absent in PDADMAC (Figure $3.27 \mathrm{~d}$ ).
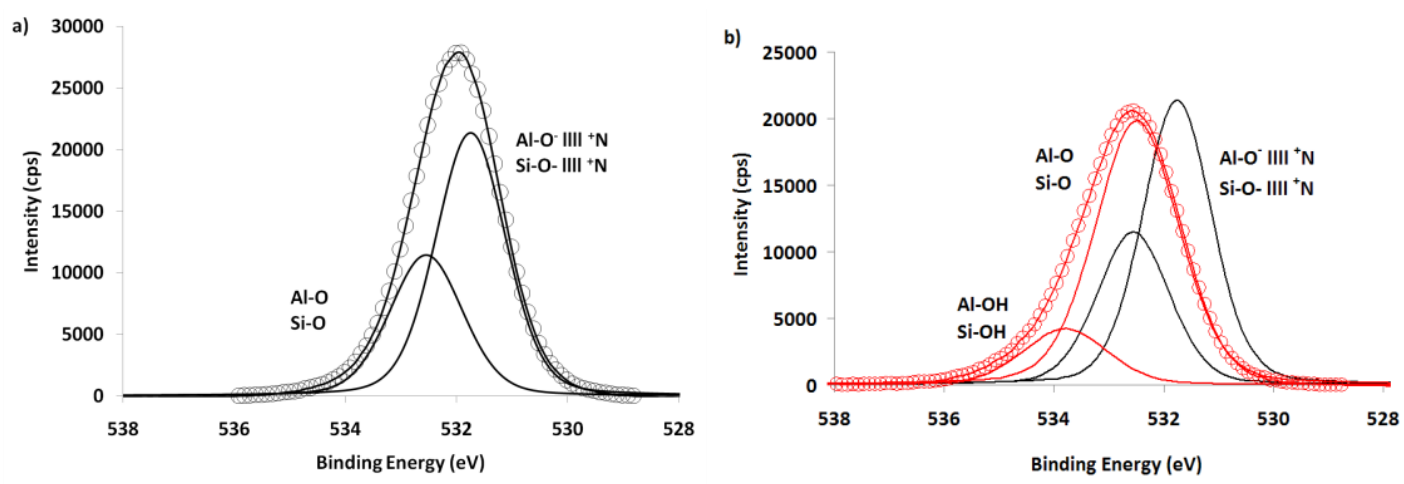

Figure 3.26: High resolution O 1s XPS spectra of a) kaolinite-PDADMAC b) an overlay of kaolinite (red).
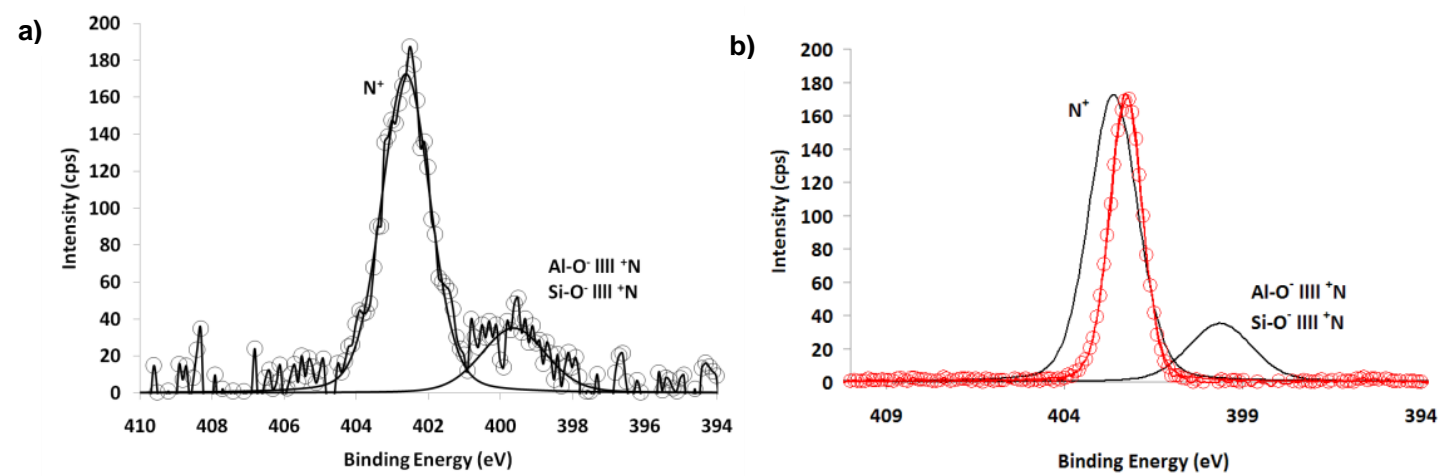

Figure 3.27: High resolution N 1s XPS spectra of a) kaolinite-PDADMAC O 1s, b) an overlay of PDADMAC (red).

This electrostatic interaction is confirmed when comparing the high resolution $\mathrm{Al} 2 \mathrm{p}$ and $\mathrm{Si}$ $2 \mathrm{p}$ spectra of kaolinite and kaolinite-PDADMAC (Figure $3.28 \mathrm{c}$ and $\mathrm{d}$, e and $\mathrm{f}$ ). In the spectra of both of these elements, the peak representative of $\mathrm{Al}-\mathrm{OH}$ and $\mathrm{Si}-\mathrm{OH}$ is lost upon inclusion of PDADMAC, and new, lower energy peaks are formed, centred at 74.52 and $102.62 \mathrm{eV}$ (in the $\mathrm{Al} 2 \mathrm{p}$ and $\mathrm{Si} 2 \mathrm{p}$ spectrum respectively). 

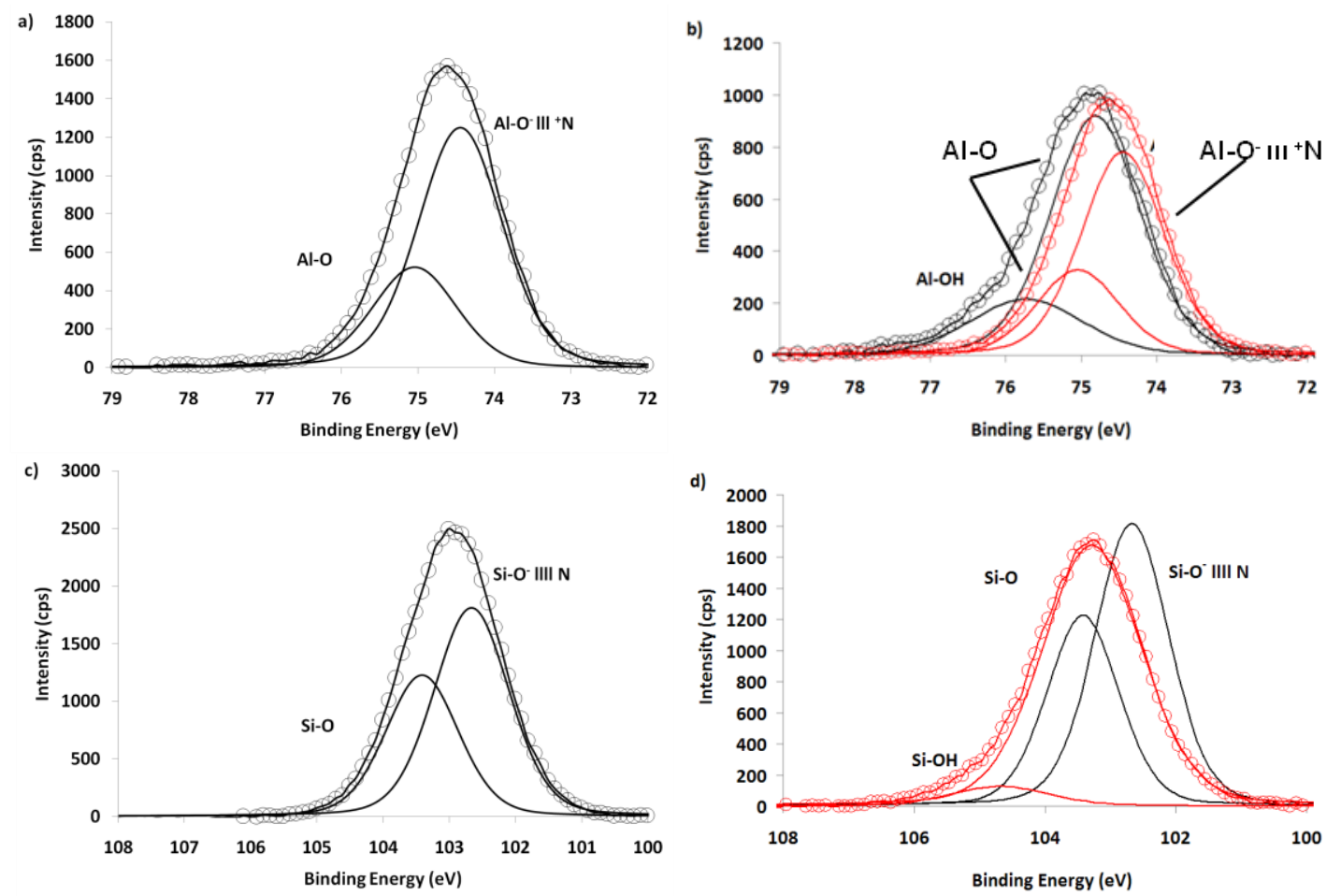

Figure 3.28: High resolution Al 2p (a) and Si 2p (c) XPS spectra of kaolinite-PDADMAC. b) and d) show an overlay of the corresponding $\mathrm{Al} 2 \mathrm{p}$ and $\mathrm{Si} 2 \mathrm{p}$ spectra of kaolinite (in red) respectively.

Table 3.5: XPS assignments for kaolinite, kaolinite-PDADMAC and PDADMAC.

\begin{tabular}{|c|c|c|c|c|c|}
\hline & & & $\begin{array}{c}\text { Kaolinite[198, } \\
199]\end{array}$ & PDADMAC & $\begin{array}{l}\text { Kaolinite- } \\
\text { PDADMAC }\end{array}$ \\
\hline & & & $\mathrm{BE}(\mathrm{eV} \pm 0.2 \mathrm{eV})$ & $\mathrm{BE}(\mathrm{eV} \pm 0.2 \mathrm{eV})$ & $\mathrm{BE}(\mathrm{eV} \pm 0.2 \mathrm{eV})$ \\
\hline $01 \mathrm{~s}$ & $\begin{array}{l}\mathrm{Al}-\mathrm{O} \\
\mathrm{Si}-\mathrm{O}\end{array}$ & & 532.49 & - & 532.52 \\
\hline & $\begin{array}{l}\mathrm{Al}-\mathrm{OH} \\
\mathrm{Si}-\mathrm{OH}\end{array}$ & & 533.80 & - & - \\
\hline & $\begin{array}{l}\mathrm{Al}-\mathrm{O}^{-} \\
\mathrm{Si}-\mathrm{O}^{-}\end{array}$ & $\begin{array}{l}+\mathrm{N} \\
{ }_{+}^{+} \mathrm{N}\end{array}$ & - & - & 531.72 \\
\hline Al 2p & $\mathrm{Al}-\mathrm{O}$ & & 74.81 & - & 75.02 \\
\hline & $\mathrm{Al}-\mathrm{OH}$ & & 75.73 & - & - \\
\hline & $\mathrm{Al}-\mathrm{O}^{-}$ & ${ }^{+} \mathrm{N}$ & - & - & 74.52 \\
\hline Si $2 p$ & Si-O & & 103.30 & - & 103.42 \\
\hline & $\mathrm{Si}-\mathrm{OH}$ & & 104.68 & - & - \\
\hline & $\mathrm{Si}^{-} \mathrm{O}^{-}$ & ${ }^{+} \mathrm{N}$ & - & - & 102.62 \\
\hline $\mathrm{N}$ 1s & $\mathrm{N}^{+}$ & & - & 402.19 & 402.23 \\
\hline & $\mathrm{N}^{+}$ & $\mathrm{O}$ & - & - & 399.52 \\
\hline
\end{tabular}


As described in section 3.1.2.2, XPS confirmed the produced silver nanoparticles to be capped with PMA. Deposition of these nanoparticles (produced via a photo induced or $\mathrm{NaBH}_{4}$ reduction) onto the kaolinite-PDADMAC surfaces induced very little change in the XPS spectra of kaolinite-PDADMAC (summarised in Table 3.6 below). As the nature of bonding between the PMA capped nanoparticles and PDADMAC is likely to be similar to the bonding between PDADMAC and kaolinite, (notably electrostatic interactions through negative oxygen atoms and positive nitrogen atoms), this similarity is to be expected. Examination of the high resolution XPS spectra of the composites incorporating silver nanoparticles prepared via a photo induced reduction showed the only notable changes to be a shift to higher binding energy of the peak corresponding to Al-O and Si-O groups in the O 1s spectra. This was attributed to a combination of $\mathrm{COO}^{-}$groups of PMA with Al-O and SiO groups of kaolinite (Figure $3.29 \mathrm{a}-\mathrm{b}$ ). Additionally, in the composite materials there was a slight downward shift in the peaks indicative of an $\mathrm{O}^{-}-\mathrm{N}^{+}$interaction, seen in the $\mathrm{Al} 2 \mathrm{p}$ and Si 2 p high resolution spectra (Figure $3.30 \mathrm{a}-\mathrm{d}$ ). This downward shift is likely attributable to a combination of the $\mathrm{O}^{-}-\mathrm{N}^{+}$bonding interaction between PDADMAC and kaolinite and also PDADMAC and Ag-PMA. The negatively charged PMA would impart more electrons to this interaction, resulting in an increased effective screening of the positive hole, which is the final state of the photoemission process, and hence the shift to lower binding energies.[200, 201] Additionally in the Ag-PMA-kaolinite composites, there is a decrease in relative peak area corresponding to $\mathrm{Si}-\mathrm{O}$ in the clay (Figure $3.30 \mathrm{c}-\mathrm{d}$ ). The silicate groups are not on the surface of the clay, and would thus be obscured by the successive layers of PDADMAC and PMA employed in the synthesis of these composites. Hence their signal intensity is decreased. 

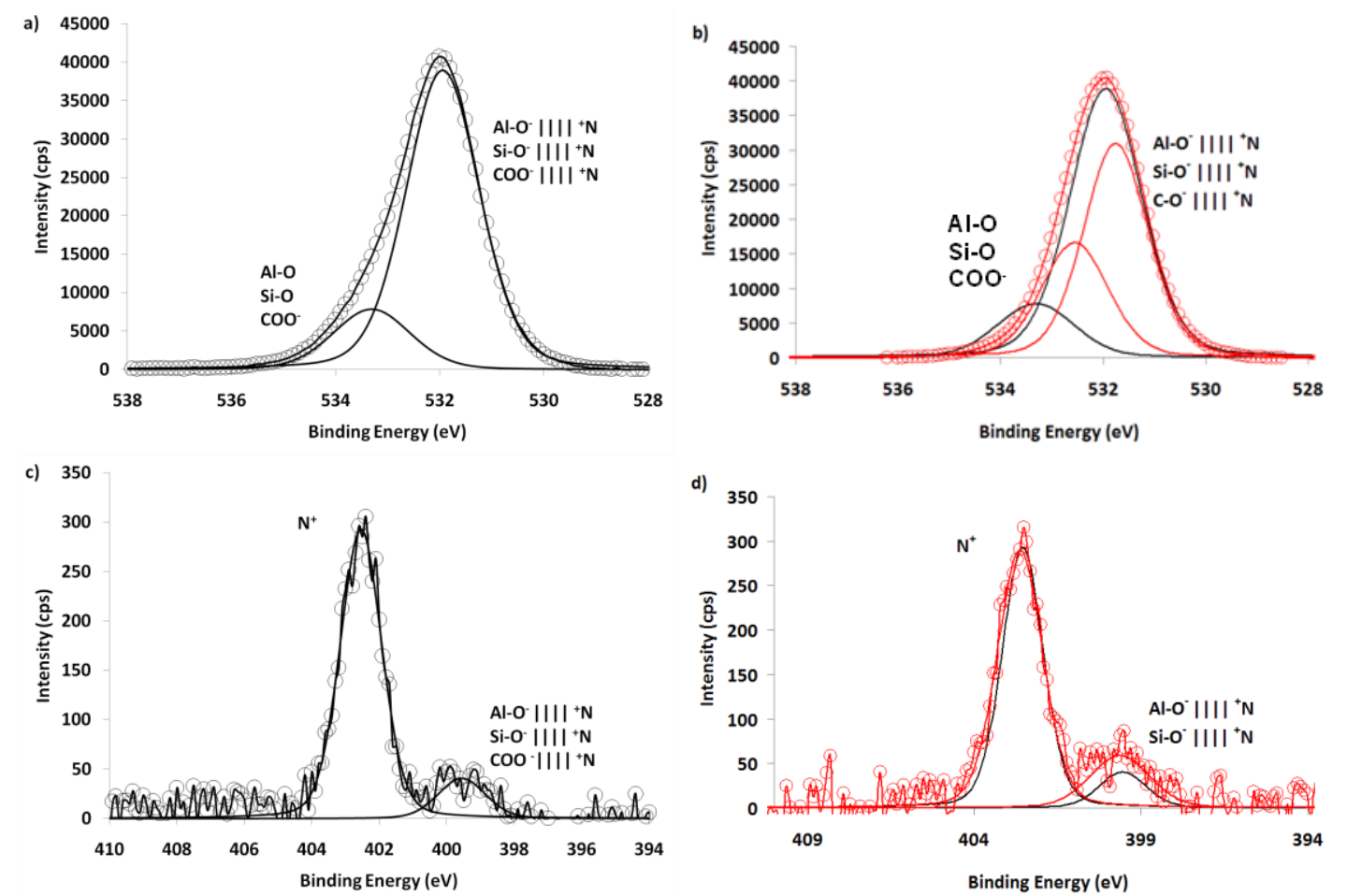

Figure 3.29: High resolution XPS spectra of a Ag-PMA-kaolinite composite (produced via a photo induced reduction) and an overlay of the corresponding kaolinite-PDADMAC materials (red lines) (a-b) $\mathrm{O} 1 \mathrm{~s}$ and (c-d) $\mathrm{N} 1 \mathrm{~s}$.
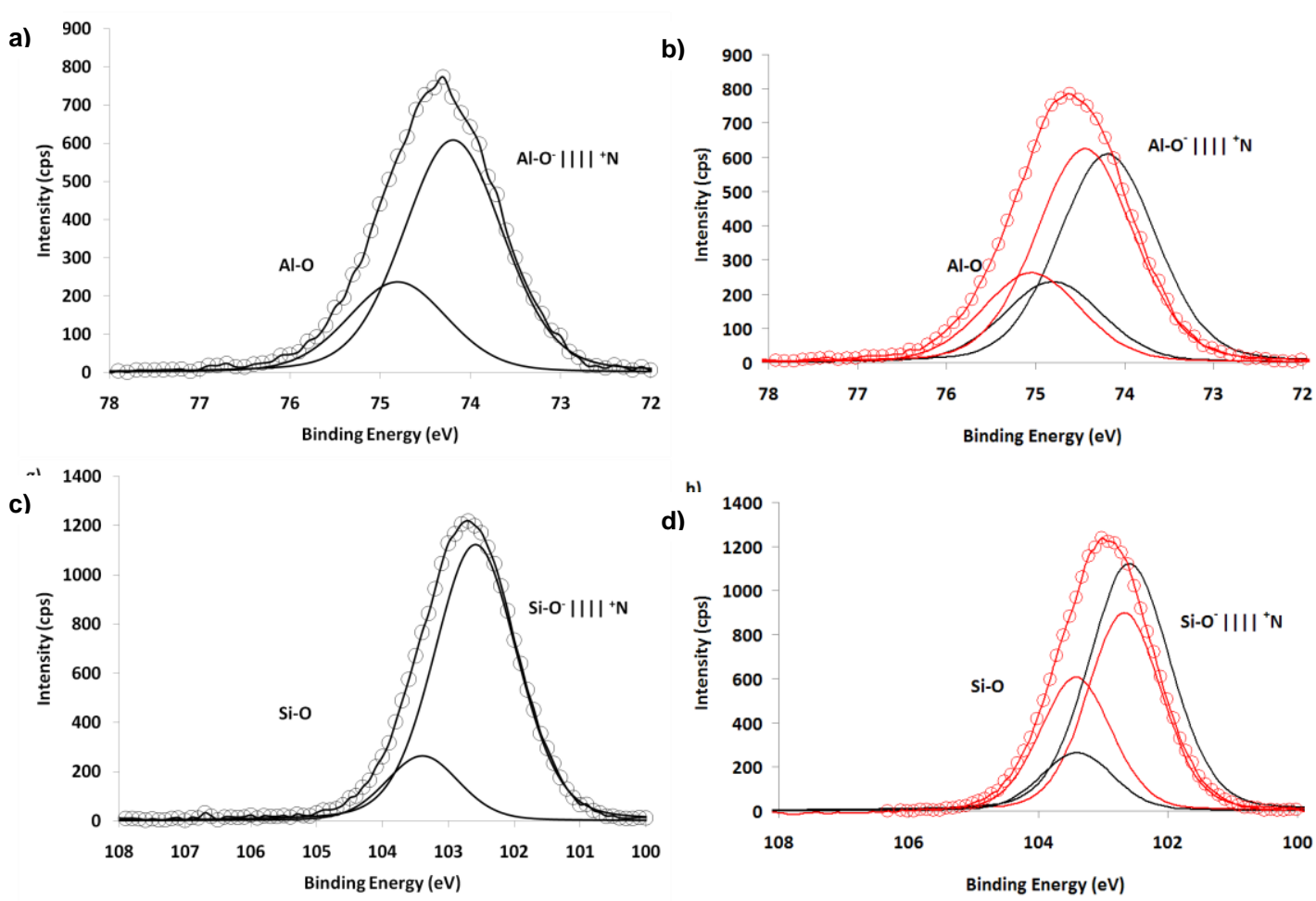

Figure 3.30: High resolution XPS spectra of a Ag-PMA-kaolinite composite (produced via a photo induced reduction) and an overlay of the corresponding kaolinite-PDADMAC materials (red lines) (a-b) Al 2p and (c-d) Si 2p. 
Table 3.6: XPS assignments of Ag-PMA-kaolinite composites incorporating nanoparticles produced via a photo induced or $\mathrm{NaBH}_{4}$ reduction.

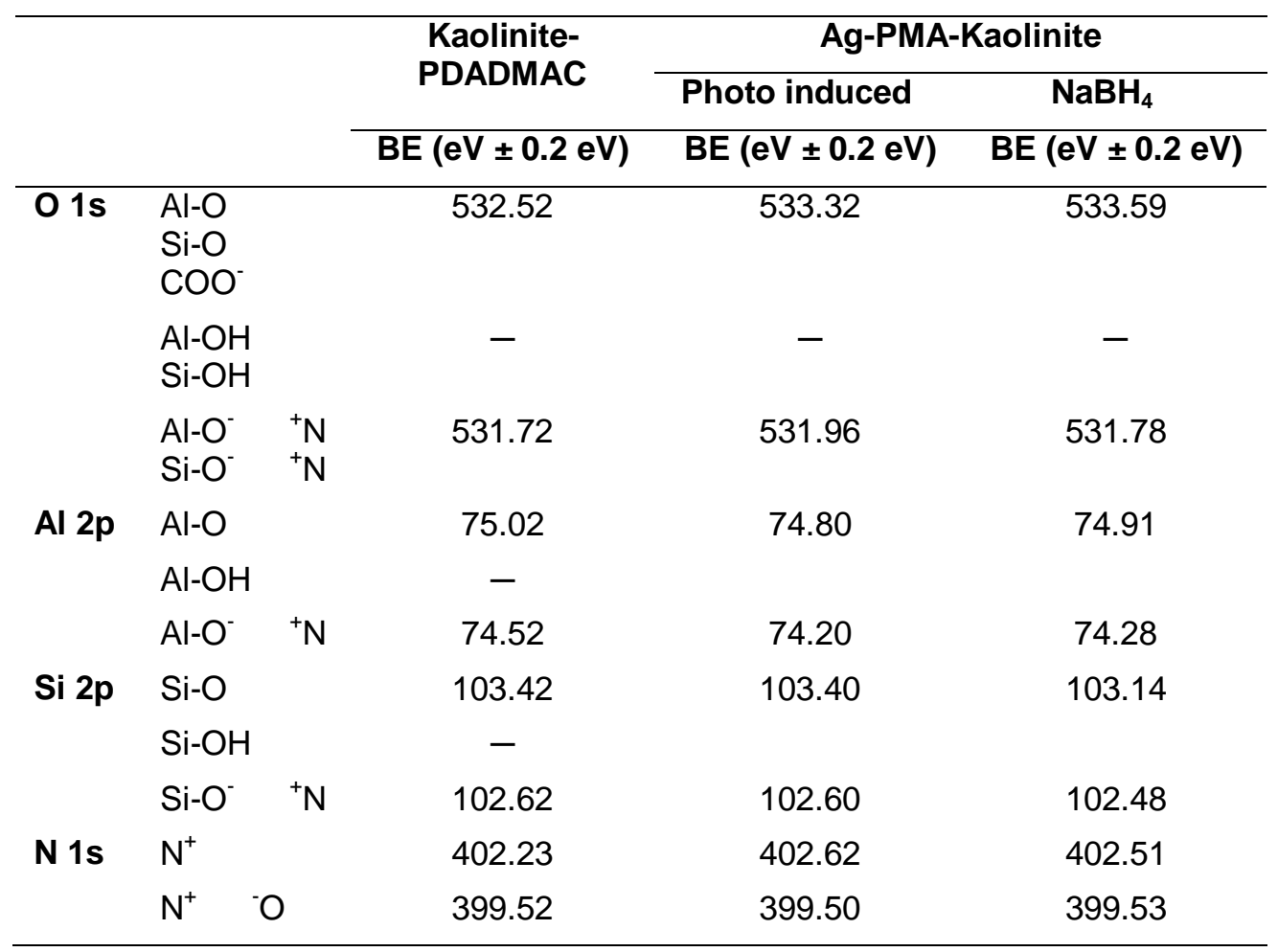

As mentioned in section 3.1.2.2, examination of the high resolution $\mathrm{Ag} 3 \mathrm{~d}$ spectrum of a AgPMA-kaolinite composite (incorporating silver nanoparticles produced via a photo induced reduction) showed the asymmetric $5 / 2$ and $3 / 2$ peaks of zero valent silver at 367.94 and $373.95 \mathrm{eV}$ respectively (Figure $3.31 \mathrm{a}$ ), and two smaller peaks centred at 368.67 and 374.67 $\mathrm{eV}$, representative of the 5/2 and 3/2 peaks of $\mathrm{Ag}^{+}$. Both sets of peaks have shifted to lower binding energies by $0.6 \mathrm{eV}$ relative to the analogous Ag-PMA colloidal solutions (Figure $3.31 \mathrm{~b}$, Table 3.7). This shift may be attributable to the increase in the nanoparticle size upon incorporation into the composite materials, as it is well known that smaller nanoparticles exhibit higher binding energies whilst larger behave more like the bulk material, thus their binding energies are closer to that of the bulk.[200] However examination of the Ag 3d spectrum of a composite incorporating silver nanoparticles prepared via reduction with $\mathrm{NaBH}_{4}$ shows additional factors influenced the position of these peaks (Figure $3.31 \mathrm{c} \& \mathrm{~d}$ ). The nanoparticles in these materials are on average a lot smaller, and as such the 5/2 and 3/2 peaks of $\mathrm{Ag}^{0}$ should be centred at higher binding energies. However they are not, they are centred at 367.72 and $373.35 \mathrm{eV}$ respectively. Therefore the shifts to lower binding energies relative to the analogous Ag-PMA colloids is likely attributable to a bonding interaction 
between the Ag-PMA and PDADMAC and may also be due to the increase in organic matter surrounding the nanoparticles in the colloids, due to the successive layers of PMA and PDADMAC, which significantly changes the chemical environment of the silver nanoparticles.[200]

Table 3.7: XPS assignments of Ag 3d in Ag-PMA-kaolinite composites incorporating nanoparticles prepared via photo induced or $\mathrm{NaBH}_{4}$ reduction.

\begin{tabular}{cccc}
\hline & & \multicolumn{2}{c}{ Ag-PMA-Kaolinite } \\
\cline { 3 - 4 } & & Photo induced & $\mathrm{NaBH}_{4}$ \\
\cline { 3 - 4 } & & $\mathrm{BE}(\mathbf{e V} \pm \mathbf{0 . 2} \mathrm{eV})$ & $\mathrm{BE} \mathrm{(eV} \mathrm{\pm 0.2} \mathrm{eV)}$ \\
\hline $\mathbf{A g} 3 \mathbf{d}$ & $\mathrm{Ag}_{5 / 2}^{0}$ & 367.94 & 367.72 \\
& $\mathrm{Ag}_{3 / 2}^{0}$ & 368.67 & 373.75 \\
& $\mathrm{AgCl}_{5 / 2}$ & 374.67 & 368.31 \\
& $\mathrm{AgCl}_{3 / 2}$ & & 374.14 \\
\hline
\end{tabular}
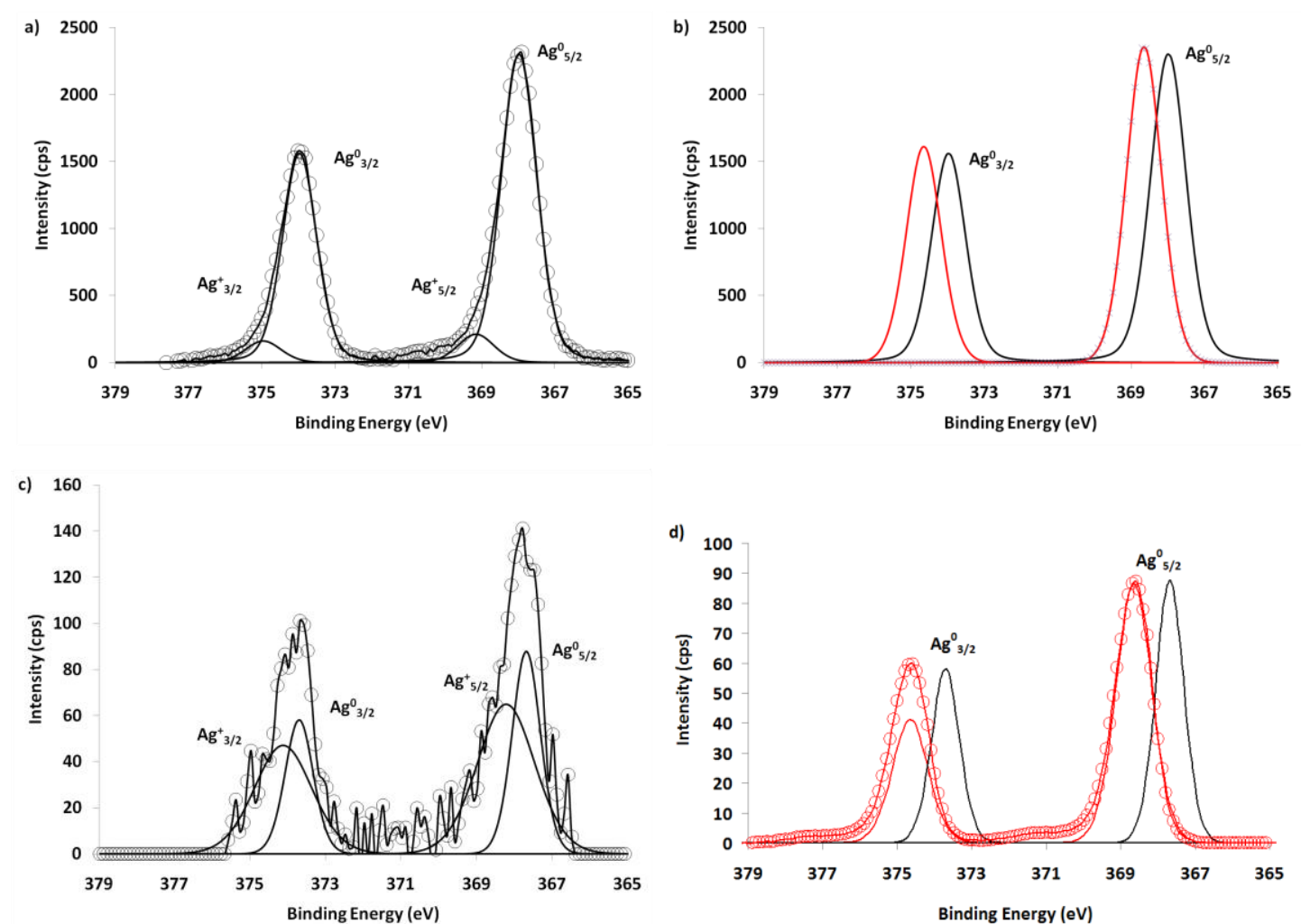

Figure 3.31: High resolution Ag 3d XPS spectra of a Ag-PMA-kaolinite composite a) photo induced production and c) $\mathrm{NaBH}_{4}$ production. b) and d) overlay of Ag-PMA-kaolinite composites (in black) and their corresponding Ag-PMA nanoparticles (in red). 

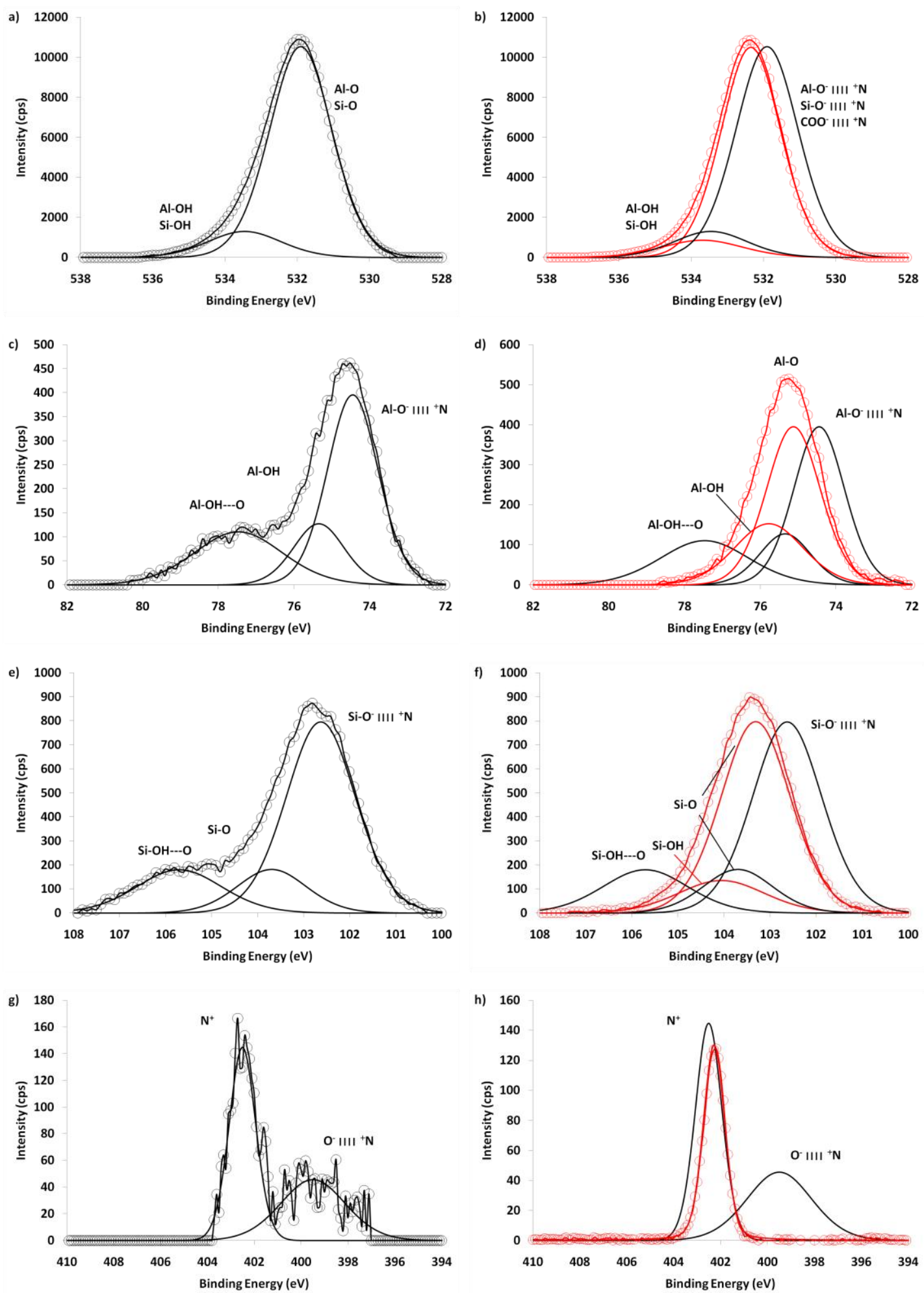

Figure 3.32: High resolution XPS spectrum of a Ag-PMA-halloysite (photo induced reduction) a) $O$ 1s, c) Al 2p, e) Si 2p, and g) N 1s. b), d) and f) are the $\mathrm{O}$ 1s, Al 2p and Si 2p spectra of halloysite (red) and the corresponding overlays of deconvoulted Ag-PMA-halloysite (black). h) overlay of N 1s spectrum of PDADMAC (red) and Ag-PMA-halloysite (black). 
The binding of PDADMAC and subsequently Ag-PMA nanoparticles (produced via a photo induced or $\mathrm{NaBH}_{4}$ reduction) to halloysite was comparable to the bonding exhibited in the corresponding Ag-PMA-kaolinite composite materials, which was not surprising as the chemical composition of halloysite and kaolinite are similar. Comparisons of the high resolution XPS spectra of a Ag-PMA-halloysite composite (incorporating silver nanoparticles produced via a photo induced reduction) to halloysite showed that the peaks indicative of $\mathrm{Al}-\mathrm{O}$ and $\mathrm{Si}-\mathrm{O}$ had shifted to lower binding energies, suggesting $\mathrm{Al}-\mathrm{O}^{-}-\mathrm{N}^{+}$(at the tubes inner surface), $\mathrm{Si}_{-} \mathrm{O}^{-}-\mathrm{N}^{+}$(edges), and $\mathrm{COO}^{-}-\mathrm{N}^{+}$interactions ( $\mathrm{COO}^{-}$from PMA) (Figure 3.32 a-f). Additionally, a new peak centred at $399.5 \mathrm{eV}$ in the $\mathrm{N} \mathrm{1s} \mathrm{spectrum,}$ representative of an $\mathrm{O}^{-}-\mathrm{N}^{+}$interaction also appeared (Figure $3.32 \mathrm{~g}$ and $\mathrm{h}$ ).

In comparison to the analogous Ag-PMA-kaolinite materials, higher binding energy peaks, (that are not observed in halloysite alone) arose in the $\mathrm{Al} 2 \mathrm{p}$ and $\mathrm{Si} 2 \mathrm{p}$ spectra of the halloysite composites (Figure $3.32 \mathrm{c}-\mathrm{f}$ ). These peaks are centred at 77.4 and $105.7 \mathrm{eV}$ respectively, and may be indicative of hydrogen bonding, between either the hydrogens of edge Si-OH or Al-OH groups of halloysite with oxygen in the carboxylate group of PMA, between the nitrogen of PDADMAC with the Al-OH groups on the inner surface of the halloysite tubes, or simply the edge $\mathrm{Si}-\mathrm{OH}$ or $\mathrm{Al}-\mathrm{OH}$ groups of halloysite with water.[202] This interaction may have been increasingly apparent in the halloysite materials, compared to the corresponding kaolinite composites due to the structural difference between the two clay substrates. As mentioned above, the tubular morphology of halloysite presents the potential for PDADMAC to be absorbed into the centre of the tube, decreasing the amount deposited on the surface, and thus the number of surface $\mathrm{SiO}_{2}$ and edge $\mathrm{Si}-\mathrm{OH}$ and $\mathrm{Al}-\mathrm{OH}$ groups involved in bonding with the polymer, leaving them free to hydrogen bond with the carboxylate groups of PMA. However examination of the Al 2p and Si 2p spectra of a AgPMA-halloysite material incorporating nanoparticles prepared with $\mathrm{NaBH}_{4}$ do not show these higher binding energy peaks (Figure 3.35). This suggests that this sample contained a lot of absorbed water, with the peaks corresponding to hydrogen bonding interactions between the clay and water.

The high resolution $\mathrm{Ag} 3 \mathrm{~d}$ spectrum of Ag-PMA-halloysite (incorporating nanoparticles prepared via a photo induced reduction) showed the asymmetrical $3 / 2$ and $5 / 2$ peaks of zero 
valent silver nanoparticles at 368.1 and $374.1 \mathrm{eV}$ respectively, and smaller peaks at 369.9 and $375.8 \mathrm{eV}$, representative of $\mathrm{Ag}^{+}$(Figure 3.33). As with the corresponding Ag-PMA-kaolinite materials, these peaks have shifted to lower binding energies relative to the analogous colloidal solutions, reflecting the increase in size of the nanoparticles upon incorporation into the composites. It should be noted that the full width at half maximum differ significantly for the $\mathrm{Ag}^{0}$ and $\mathrm{Ag}^{+}$species. This is due to the increased variability of the chemical environment at the surface of the nanoparticles, therefore of $\mathrm{Ag}^{+}$.
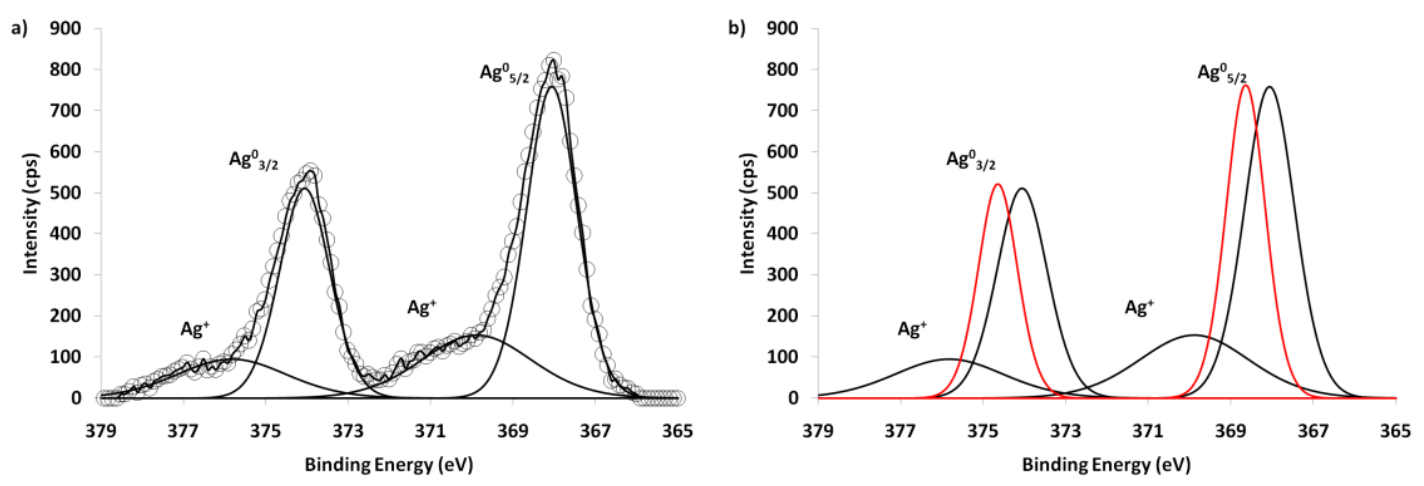

Figure 3.33: High resolution Ag 3d XPS spectra of a) Ag-PMA-halloysite (photo induced reduction) and b) overlay of Ag-PMA-halloysite (in black) and Ag-PMA (in red).

The synthesis method did not appear to alter the bonding between the resultant Ag-PMA nanoparticles and clay substrates. XPS revealed the bonding between the clay substrates and the nanoparticles prepared via reduction with $\mathrm{NaBH}_{4}$ to be very similar to that between the clays and nanoparticles prepared via a photo induced reduction, suggesting a comparable bonding mechanism between the nanoparticles and clay substrate. Upon incorporation of nanoparticles prepared with $\mathrm{NaBH}_{4}$ to the clays, the peaks representative of $\mathrm{Al}-\mathrm{OH}$ and $\mathrm{Si}$ $\mathrm{OH}$ were lost in the high resolution $\mathrm{O} 1 \mathrm{~s}, \mathrm{Al} 2 \mathrm{p}$ and $\mathrm{Si} 2 \mathrm{p}$ spectra of the composites, and new, lower binding energies peaks, indicative of electrostatic interactions between the positively charged PDADMAC, and negatively charged clay and PMA capped nanoparticles also appeared (Figure 3.34 and Figure 3.35, kaolinite and halloysite composites respectively). 

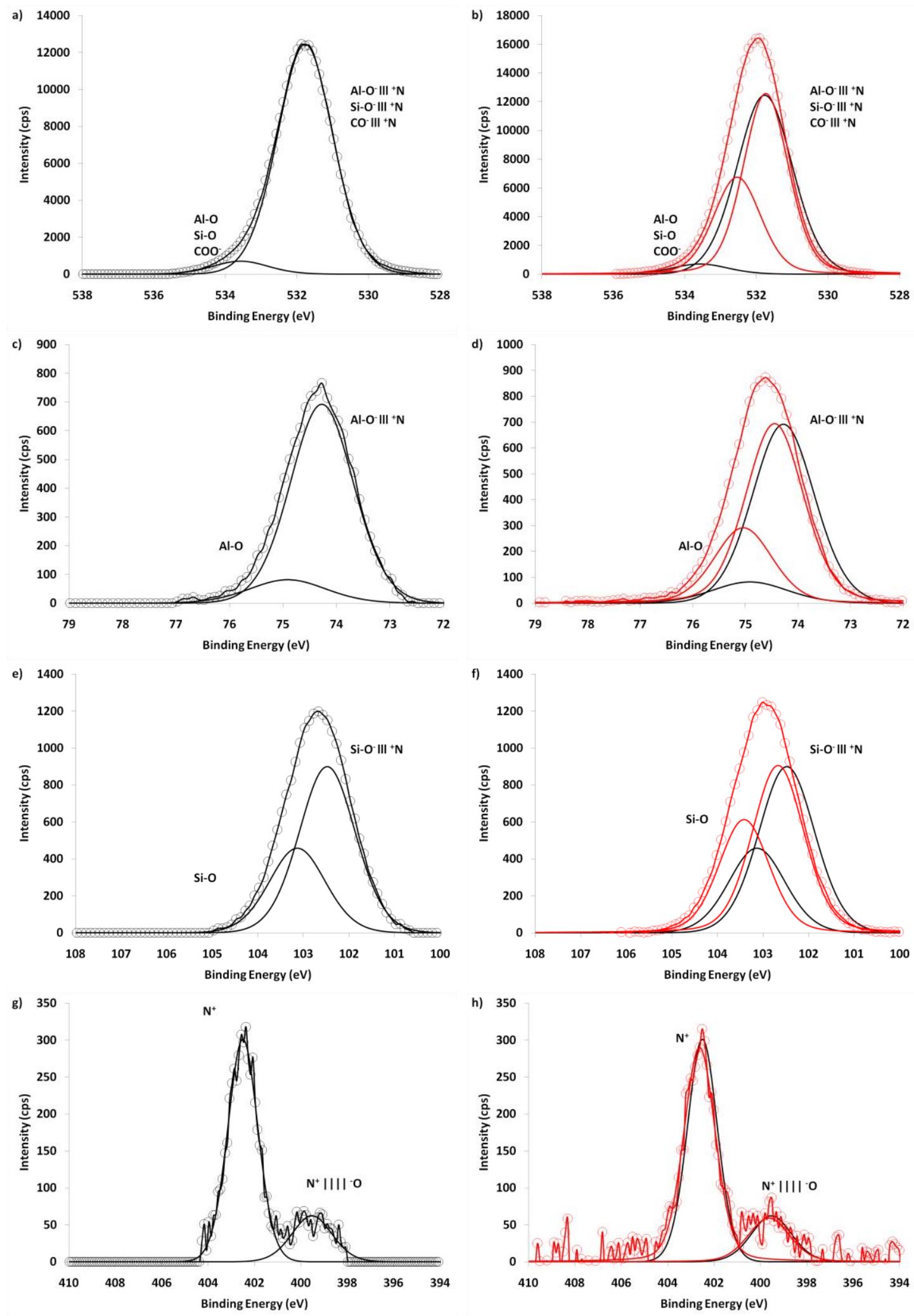

Figure 3.34: High resolution XPS spectrum of a Ag-PMA-kaolinite composites (incorporating nanoparticles prepared by $\mathrm{NaBH}_{4}$ ) a) $\mathrm{O}$ 1s, c) Al 2p, e) Si 2p, and g) N 1s. b), d) and f) are the corresponding overlays of $\mathrm{O}$ 1s, $\mathrm{Al} 2 \mathrm{p}$ and $\mathrm{Si} 2 \mathrm{p}$ spectra of kaolinite-PDADMAC (red) and deconvoluted Ag-PMA-kaolinite (black), h) overlay of N 1s spectrum of PDADMAC (red) and deconvoluted Ag-PMAhalloysite (black). 

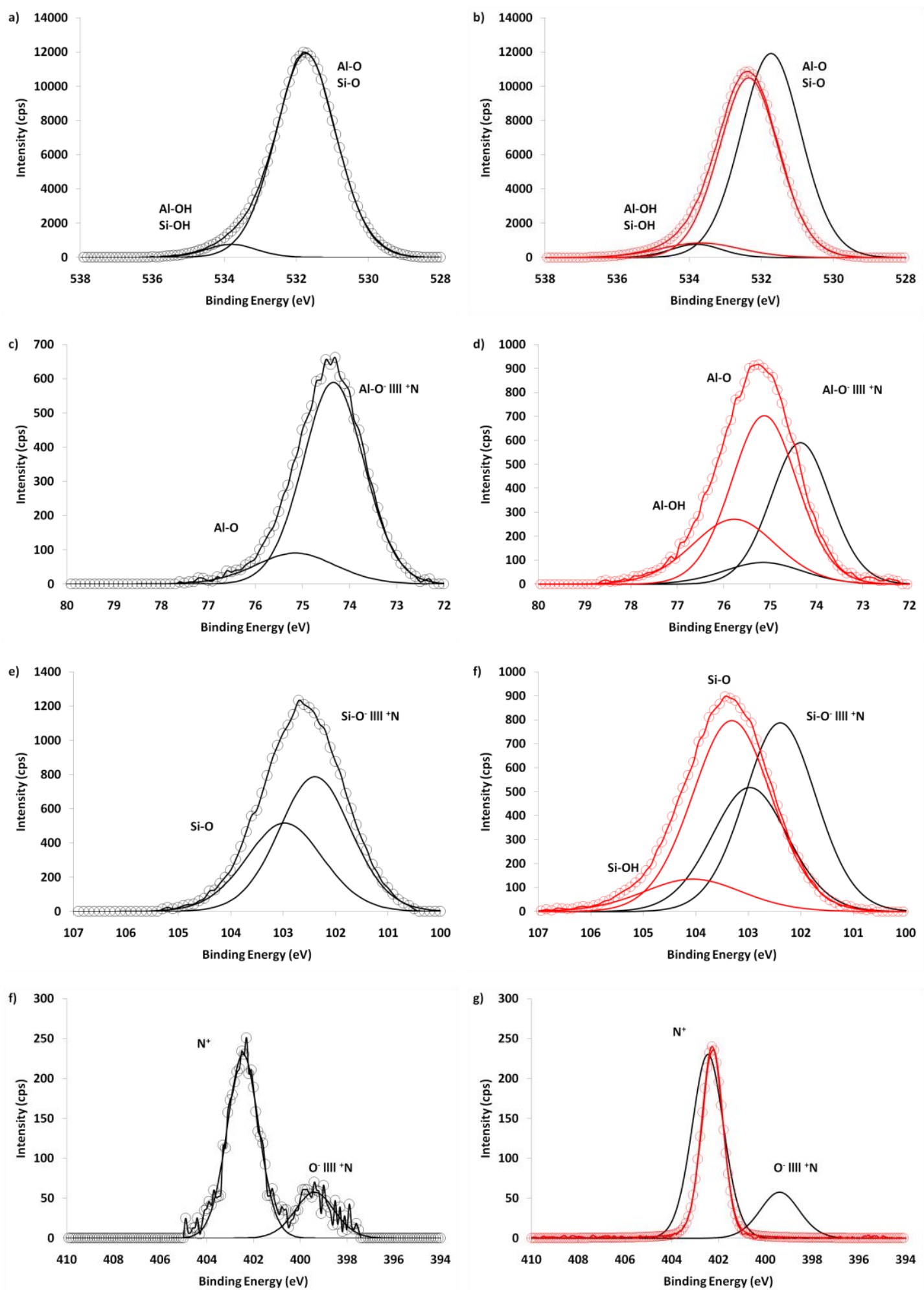

Figure 3.35: High resolution XPS spectrum of a Ag-PMA-halloysite $\left(\mathrm{NaBH}_{4}\right.$ reduction) a) $\mathrm{O}$ 1s, c) Al 2p, e) Si 2p, and g) N 1s. b), d) and f) are the corresponding overlays of $\mathrm{O} 1 \mathrm{~s}, \mathrm{Al} 2 \mathrm{p}$ and $\mathrm{Si}$ 2p spectra of halloysite (red) and deconvoluted Ag-PMA-halloysite (black), h) overlay N 1s spectrum of PDADMAC (red) and deconvoluted Ag-PMA-halloysite (black). 
As with the Ag-PMA-clay composites produced through the incorporation of nanoparticles prepared via a photo induced reduction, incorporating nanoparticles prepared with $\mathrm{NaBH}_{4}$ resulted in a shift in the $3 / 2$ and 5/2 peaks representative of metallic silver nanoparticles and $\mathrm{Ag}^{+}$to lower binding energies relative to the analogous Ag-PMA nanoparticles (Figure 3.36). This indicates a bonding interaction between the PMA surrounding the nanoparticles and PDADMAC on the clay surface.
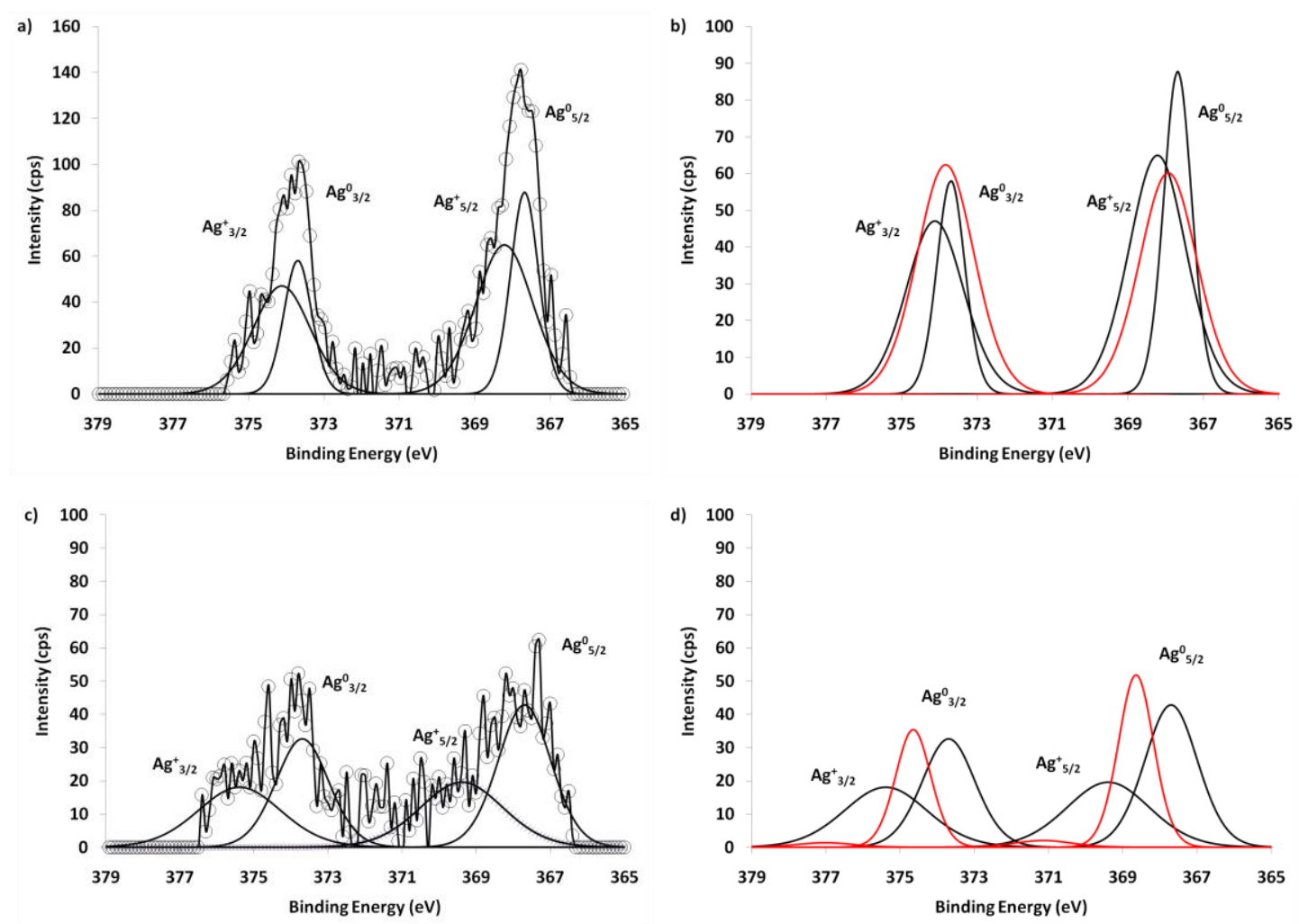

Figure 3.36: High resolution Ag 3d XPS spectra of a) Ag-PMA-kaolinite and c) Ag-PMA-halloysite. Both prepared with $\mathrm{NaBH}_{4}$. b) and d) offer an overlay of a silver colloid prepared with $\mathrm{NaBH}_{4}$ (in red).

Additionally IR was employed with the aim of further clarifying the mode of bonding between the Ag-PMA nanoparticles and clay substrates. It was hoped that comparisons of the spectra of the composites and base clays would provide bonding information and confirm the role of $\mathrm{Al}-\mathrm{O}$ and $\mathrm{Si}-\mathrm{O}$ groups in this bonding. The characteristic vibrations associated with kaolinite are seen in the spectra of all Ag-PMA-kaolinite composites, notably the bands at $3696-3620 \mathrm{~cm}^{-1}$ (O-H stretching), $1120-1000 \mathrm{~cm}^{-1}$ ( $\mathrm{Si}-\mathrm{O}$ stretching), $930-910 \mathrm{~cm}^{-1}$ (O-H bending) and 550-400 $\mathrm{cm}^{-1}\left(\mathrm{SiO}_{2}\right.$ bending regions) (Table 3.8).[21] In addition, a strong 
band around $3430 \mathrm{~cm}^{-1}$ and weaker bands at 1630 and $1618 \mathrm{~cm}^{-1}$ are present due to absorption of water by the clay (Table 3.8). The Ag-PMA-halloysite composites exhibited similar vibrations due to their comparable chemical composition. There were very little changes in the IR spectrum of both kaolinite and halloysite upon incorporation of the silver nanoparticles (prepared via photo induced or $\mathrm{NaBH}_{4}$ reduction). Figure 3.37 offers a comparison between kaolinite and a Ag-PMA-kaolinite composite incorporating nanoparticles prepared via a photo induced reduction. The spectrum of this material is representative of all composites produced. The only notable difference between the two spectra was the appearance of the peak at approximately $1560 \mathrm{~cm}^{-1}$ in the composite. This peak is indicative of $\mathrm{COO}^{-}$asymmetrical stretching, and confirms the presence of PMA. Due to the similarity of the clays and the resultant composite materials, IR provides little information about the bonding between the nanoparticles and clays. This is likely due to the fact that IR is a bulk analysis technique, and as such is not particularly sensitive to the small amount of nanoparticles on the surface of the clays relative to the amount of clay present.

Table 3.8: Vibrational assignments of Ag-PMA-clay composite materials.

\begin{tabular}{ll}
\hline Transition $\left(\mathbf{c m}^{-1}\right)$ & Proposed Assignment \\
\hline $3696-3920$ & O-H stretching [21, 30] \\
$1567-1560$ & $\mathrm{COO}^{-}$stretching [203] \\
$1120-1000$ & Si-O stretching [21] \\
$930-910$ & $\mathrm{O}-\mathrm{H}$ bending [21] \\
$550-400$ & $\mathrm{SiO}_{2}$ bending [21] \\
\hline
\end{tabular}




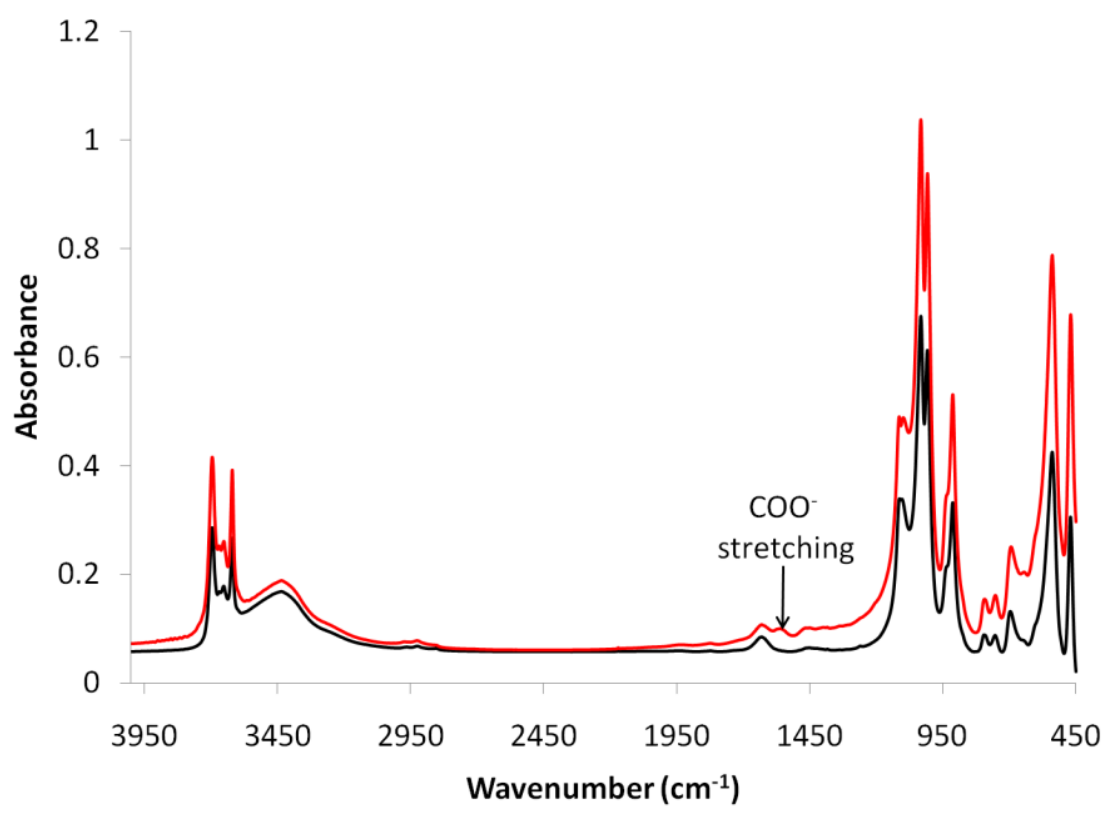

Figure 3.37: FT-IR spectra of kaolinite (black line) and a Ag-PMA-kaolinite composite (red line).

Solid state NMR, however does provide information about the bonding between the nanoparticles and clays. Analysis of the solid state ${ }^{27} \mathrm{Al}$ NMR spectrum of kaolinite shows a single resonance centred at $3.15 \mathrm{ppm}$, which is representative of six-coordinate octahedral aluminum of kaolinite.[204] Incorporation of Ag-PMA nanoparticles, prepared via a photo induced or $\mathrm{NaBH}_{4}$ reduction saw a shift to -0.37 and $0.51 \mathrm{ppm}$ respectively (Figure 3.38). Similar results were obtained with halloysite, however upon incorporation of Ag-PMA the shift in position of this resonance was not as large, from $3.15 \mathrm{ppm}$ in halloysite to 2.23 and $2.27 \mathrm{ppm}$ in those incorporating nanoparticles prepared via photo induced or $\mathrm{NaBH}_{4}$ reduction respectively (Figure 3.39).

The downfield shift of the signals in both kaolinite and halloysite upon incorporation of the Ag-PMA nanoparticles is likely to arise as a result of increased shielding imparted by the greater electron density arising due to successive layers of the polyelectrolytes PDADMAC and PMA. These shifts substantiate the proposed theory in which Al-O groups are involved in bonding to PDADMAC and Ag-PMA, and support the XPS data discussed above. 


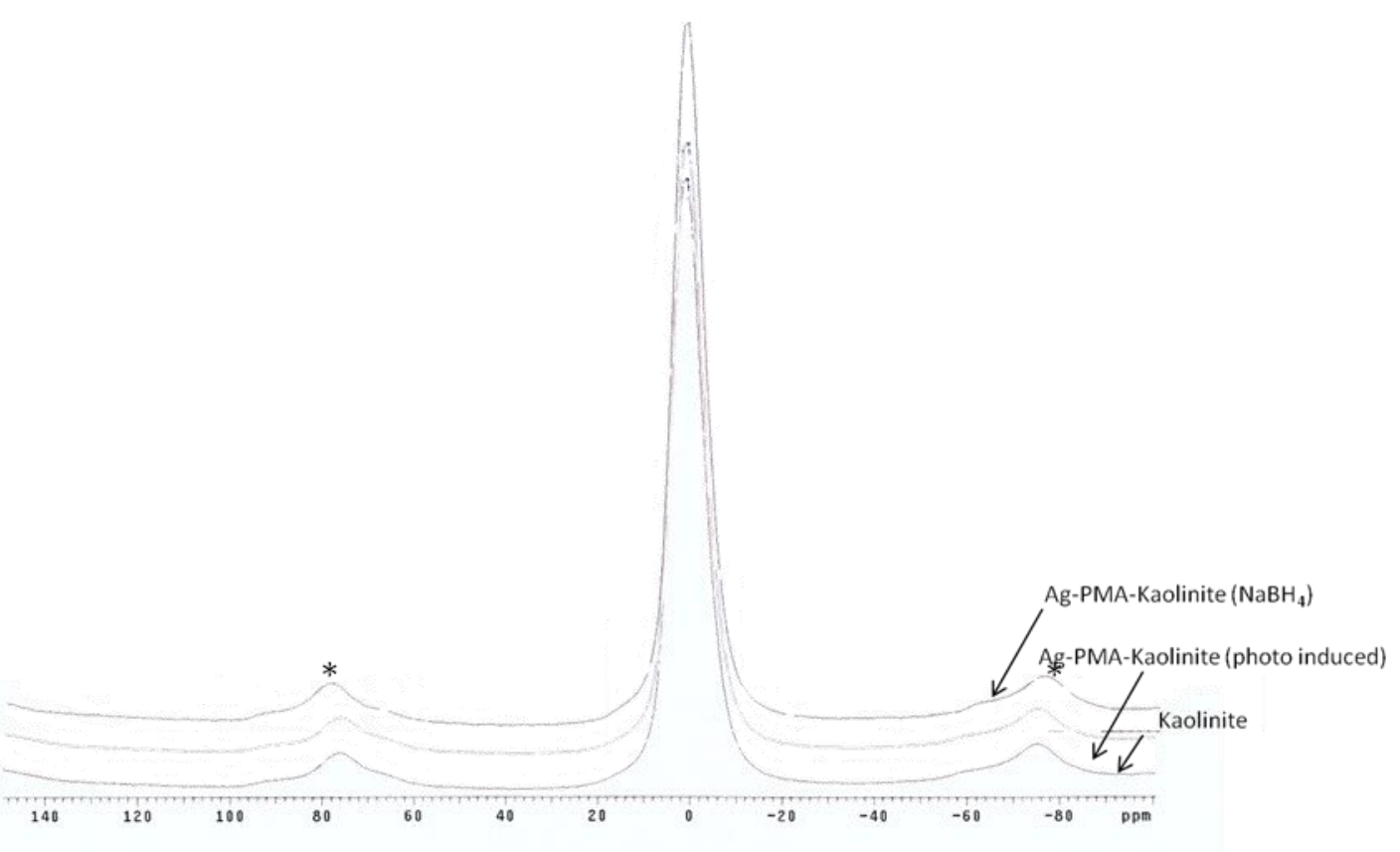

Figure 3.38: Solid state ${ }^{27} \mathrm{Al}$ NMR spectra of kaolinite and Ag-PMA-kaolinite composites (photo induced and $\mathrm{NaBH}_{4}$ production). Spinning side bands indicated by *.

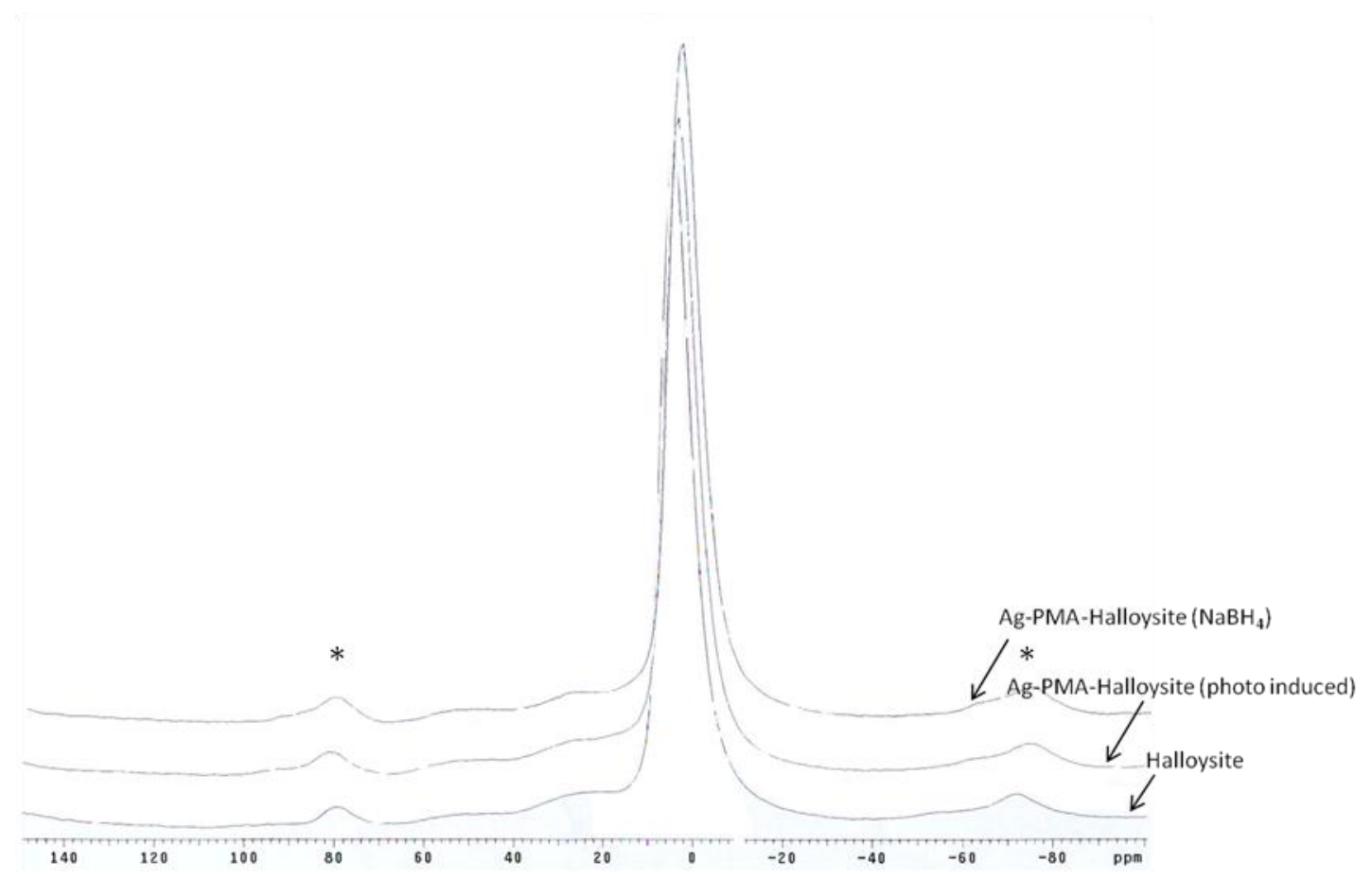

Figure 3.39: Solid state ${ }^{27} \mathrm{Al}$ NMR spectra of halloysite and Ag-PMA-halloysite composites (photo induced and $\mathrm{NaBH}_{4}$ production). Spinning side bands indicated by *. 
Similar results were obtained from solid state ${ }^{29} \mathrm{Si}$ NMR. The ${ }^{29} \mathrm{Si}$ spectrum of the base kaolinite displays a single resonance at $-91.1 \mathrm{ppm}$, which is consistent with previously published work.[204, 205] Upon incorporation of Ag-PMA nanoparticles (both photo induced and $\mathrm{NaBH}_{4}$ produced) there was a broadening in this resonance peak and a very slight shift to $-90.8 \mathrm{ppm}$. Similar results were observed in the corresponding Ag-PMAhalloyiste composites. The ${ }^{29} \mathrm{Si}$ spectrum of halloysite alone is not dissimilar to that of kaolinite. There is a sharp resonance centred at $-91.4 \mathrm{ppm}$, which is again consistent with previously published work on the ${ }^{29} \mathrm{Si}$ NMR spectra of halloysite.[204, 206] Additionally, minor signals representative of dehydroxylated halloysite and cristobalite impurities are seen at -102 and -107.6 ppm respectively.[206, 207] As with kaolinite, incorporation of Ag-PMA nanoparticles (both photo induced and $\mathrm{NaBH}_{4}$ produced) induced a broadening of halloyistes signal width, and a very slight shift of $0.7 \mathrm{ppm}$ to $-91.1 \mathrm{ppm}$.

In both the Ag-PMA-kaolinite and halloysite composites, the increased signal width is likely to correspond to a greater variation in the chemical environment of the silicon nuclei upon incorporation of PDADMAC and Ag-PMA, however as there are only extremely minimal shifts in the position of these signals, it is likely that the Si-O groups of kaolinite and halloysite do not play as great a role in bonding to PDADMAC and thus Ag-PMA as the Al$\mathrm{O}$ groups. This is in agreement with the obtained XRD results which show minimal increases in d-spacing upon incorporation of PDADMAC and Ag-PMA, suggesting that in the kaolinite materials, bonding is primarily through the surface and edge Al-O and Si-O groups respectively rather than interlayer $\mathrm{Si}-\mathrm{O}$ moieties. The bonding in halloysite is likely to be similar, notably through Al-O groups inside halloysites cylindrical pores, and surface Si-O groups. 


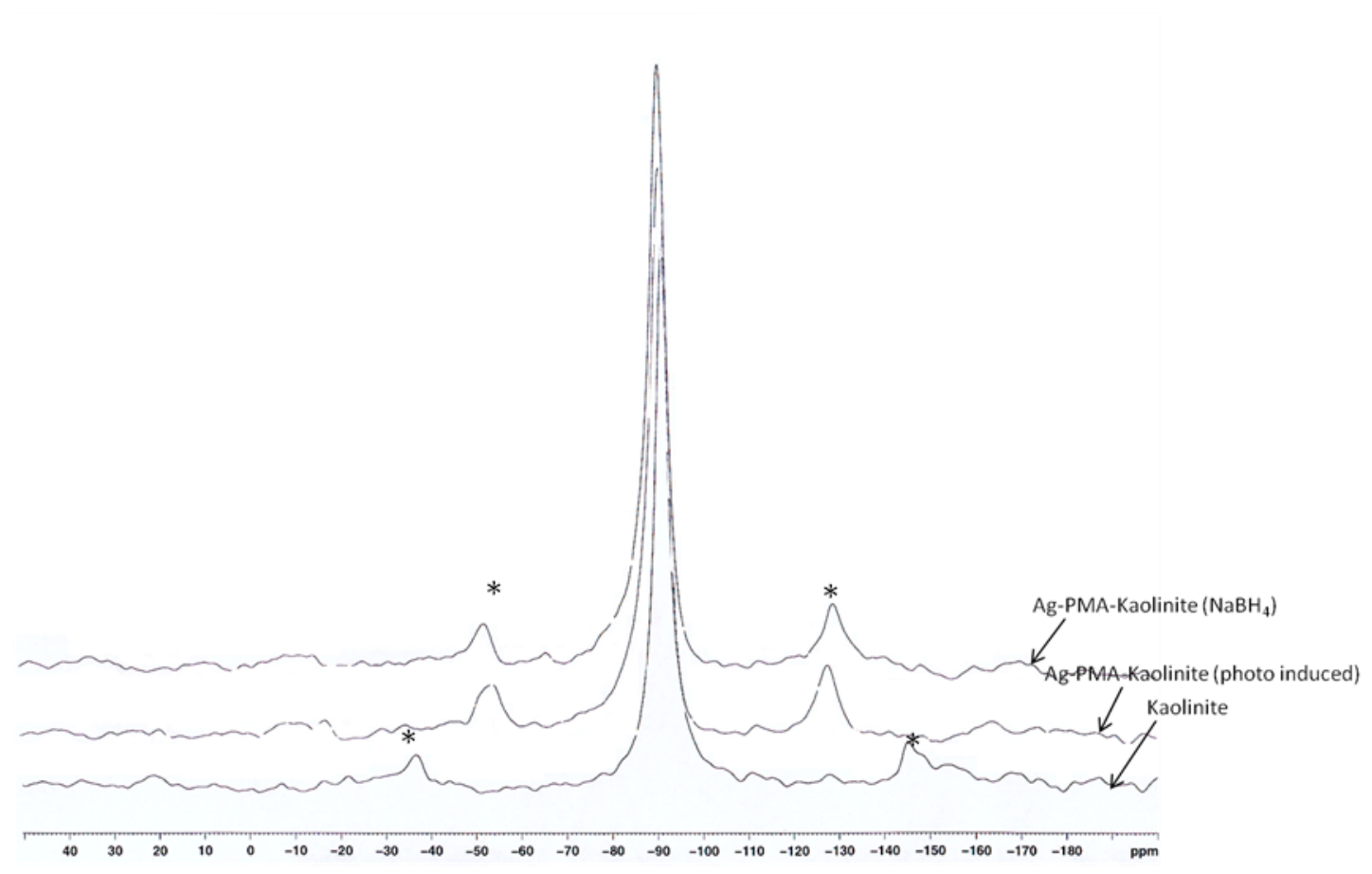

Figure 3.40: Solid state ${ }^{29} \mathrm{Si}$ NMR spectra of kaolinite and Ag-PMA-kaolinite composites (photo induced and $\mathrm{NaBH}_{4}$ production). Spinning side bands indicated by *.

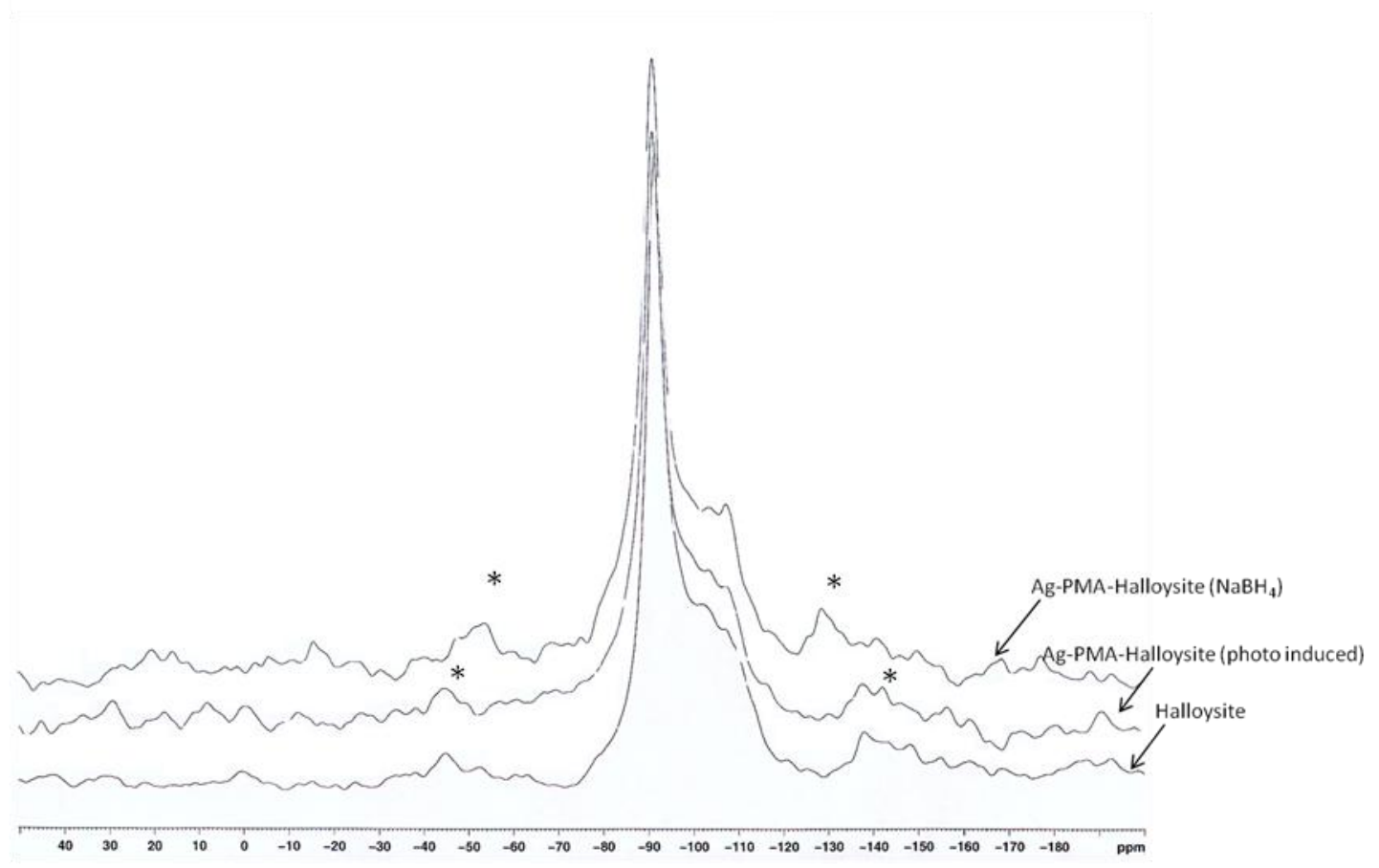

Figure 3.41: Solid state ${ }^{29} \mathrm{Si}$ NMR spectra of halloysite and Ag-PMA-halloysite composites (photo induced and $\mathrm{NaBH}_{4}$ production). Spinning side bands indicated by *. 


\subsubsection{Anti-microbial Testing}

The Ag-PMA-clay composites were tested for anti-microbial activity against the bacteria Staphylococcus aureus according to the procedure outlined in section 2.3.13 the results of these tests are summarized in Table 3.9 below. To be classed as anti-microbial, these materials must actively hinder the growth of bacteria and exhibit a clear zone of inhibition. Alternatively, samples may resist microbial attack, whereby bacteria grow up to but not on the sample. A negative test for anti-microbial activity is observed when bacteria grow over a sample. Figure 3.42 and Figure 3.43 depict samples on agar plates that have been incubated with Staphylococcus aureus for 24 hours and sterilized. The white hazy areas indicate bacterial growth, whilst the more transparent areas surrounding samples indicate bacteria free regions.

The base clays and corresponding kaolinite and halloysite-PDADMAC materials exhibited no anti-microbial resistance (Figure 3.42, left), indeed bacteria appeared to grow over these samples (Figure 3.42, right). Inclusion of Ag-PMA nanoparticles imparted increased antimicrobial properties to the clays, with Ag-PMA-kaolinite and Ag-PMA-halloysite composites (incorporating nanoparticles produced via a photo induced reduction) exhibiting 5 and $4 \mathrm{~nm}$ zones of inhibition respectively (Figure $3.43 \mathrm{a}$ and b). The anti-microbial activity of materials incorporating nanoparticles produced through reduction with $\mathrm{NaBH}_{4}$ was slightly less, with these kaolinite and halloysite composites presenting 3 and $2 \mathrm{~nm}$ zones of inhibition respectively (Figure $3.43 \mathrm{c}$ and d). 

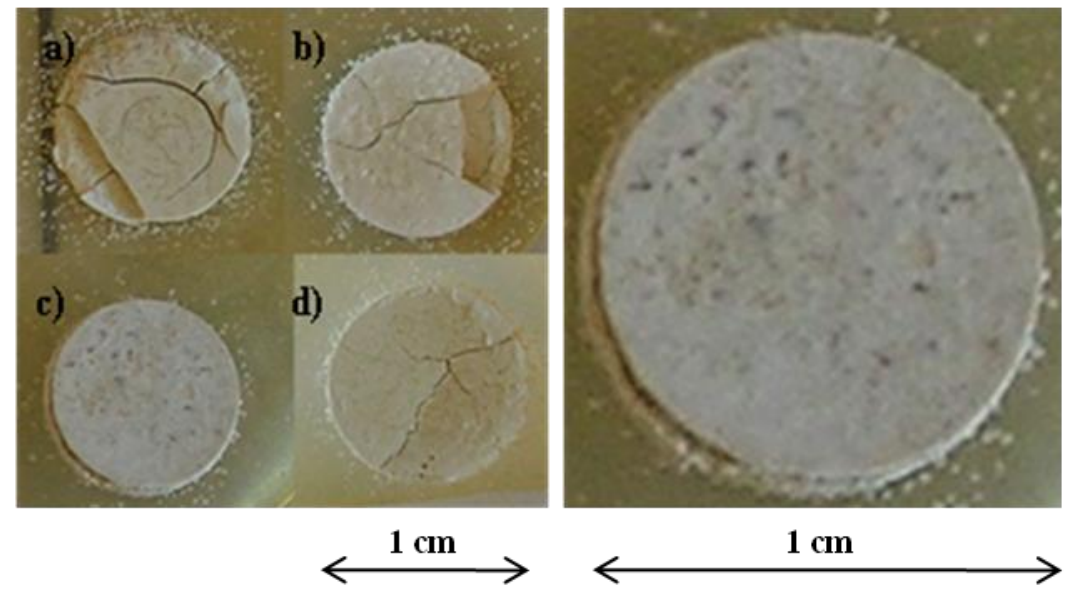

Figure 3.42: Agar plates containing Staphylococcus aureus. Left a) kaolinite, b) kaolinite-PDADMAC, c) halloysite and d) halloysite-PDADMAC. Right, increased magnification image of halloysite on agar.

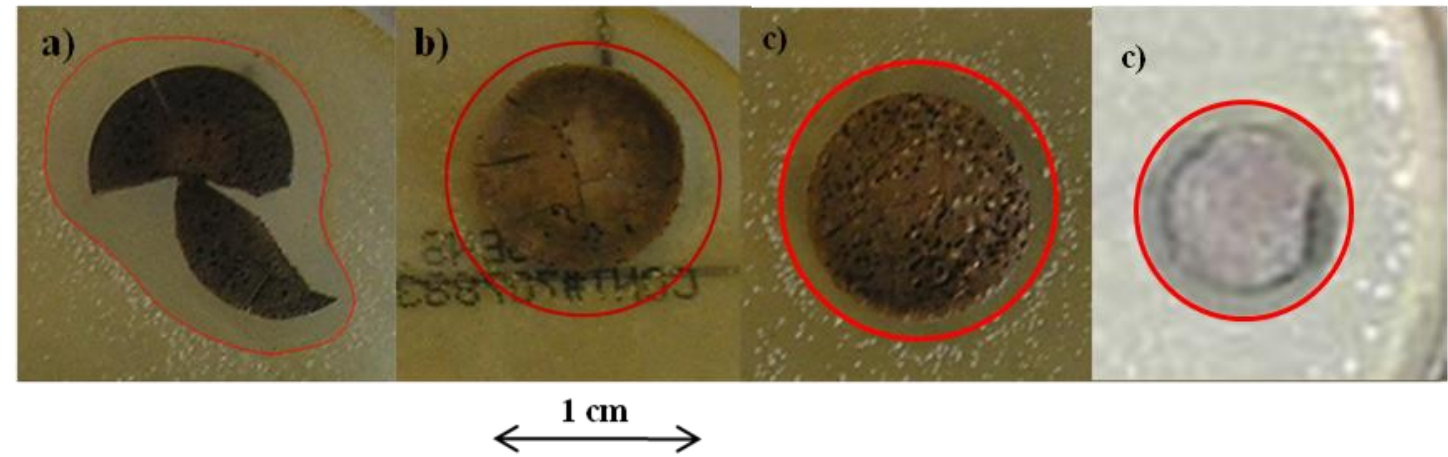

Figure 3.43: Inhibition zones of Staphylococcus aureus microbial growth. a) Ag-PMA-kaolinite and b) Ag-PMA-halloysite, both incorporating nanoparticles prepared via a photo induced production. c) AgPMA-kaolinite and d) Ag-PMA-halloysite composites incorporating nanoparticles prepared with $\mathrm{NaBH}_{4}$.

It is evident that the anti-microbial properties of these samples arise from the presence of the silver nanoparticles. Silver is thought to migrate from the surface of the Ag-PMA-clay composites, inhibiting the growth of microbes in its path, and therefore the samples with a higher silver loading would exhibit increased anti-microbial activities. This is indeed the case with the Ag-PMA-clay composites, as the materials with the higher silver content (shown in TEM, EDS and XPS analysis), those incorporating nanoparticles prepared via a photo induced reduction, exhibited larger areas of inhibition compared to the analogous composites that incorporated nanoparticles prepared by reduction with $\mathrm{NaBH}_{4}$. 
Table 3.9: Inhibition zones of Staphylococcus aureus by Ag-PMA-clay composites.

\begin{tabular}{c|c|c}
\hline Figure & Sample & $\begin{array}{c}\text { Zone of Inhibition } \\
(\mathbf{m m})\end{array}$ \\
\hline Figure 3.42 a & Kaolinite & $0^{*}$ \\
Figure 3.42 c & Halloysite & $0^{*}$ \\
Figure 3.42 b & Kaolinite-PDADMAC & $0^{*}$ \\
Figure 3.42 d & Halloysite-PDADMAC & $0^{*}$ \\
Figure 3.43 a & Ag-PMA-kaolinite (photo induced & 4 \\
production) & 3 \\
Figure 3.43 c & Ag-PMA-kaolinite (NaBH 4 reduction) & 5 \\
Figure 3.43 b & Ag-PMA-halloysite (photo induced \\
production) & 2 \\
Figure 3.43 d & Ag-PMA-halloysite $\left(\mathrm{NaBH}_{4}\right.$ & 2 \\
& reduction) & 2 \\
\hline
\end{tabular}

*Bacteria grew onto, and over the samples

\subsection{Conclusions}

The layer-by-layer deposition process in which kaolinite and halloysite were dispersed in successive solutions of the cationic polymeric linker PDADMAC and anionic PMA capped silver nanoparticles was successful in the production of silver nanoparticle-clay composite materials. Depending on the preparation method of the Ag-PMA nanoparticles (prepared via a photo induced or $\mathrm{NaBH}_{4}$ reduction), the resultant silver nanoparticle-clay composites were purple or yellow in colour respectively.

Electron microscopy showed that when employing Ag-PMA nanoparticles prepared via a photo induced reduction the silver nanoparticles in the resultant composites were predominantly spherical in morphology, ranging in size from approximately 10-40 $\mathrm{nm}$ in diameter. Incorporating nanoparticles prepared via $\mathrm{NaBH}_{4}$ reduction produced composites with a much lower concentration of silver nanoparticles, and these were smaller, approximately $5 \mathrm{~nm}$ in diameter and monodisperse. In all cases the nanoparticles appeared to 
follow the morphology of the clays, suggesting they were attached to the clays rather than simply dispersed throughout.

Relative to silver nanoparticle-halloysite composites, the analogous kaolinite composites appeared to possess a greater concentration of silver nanoparticles. This was proposed to be due to the structural difference of the clays, with the tubular morphology of halloysite presenting the opportunity for PDADMAC and the Ag-PMA nanoparticles to absorb into the centre of these tubules, thus lowering the concentration of nanoparticles on the halloysite surface.

XRD, XPS and solid state NMR suggested the bonding between the silver nanoparticles and clay substrates occurred through a layer-by-layer deposition process, which capitalised on electrostatic interactions between oppositely charged electrolytes, notably cationic PDADMAC, anionic Ag-PMA and the clay surfaces. PDADMAC was initially bound to the clay substrates via electrostatic interactions occurring through the positively charged quaternary nitrogens of PDADMAC and the negatively charged $\mathrm{Al}-\mathrm{O} \delta^{-}$and $\mathrm{Si}-\mathrm{O} \delta^{-}$groups of the clays (located on the surface $\left(\mathrm{Al}-\mathrm{O} \delta^{-}\right)$and edges $\left(\mathrm{Si}-\mathrm{O} \delta^{-}\right)$in kaolinite and on the inner surface $\left(\mathrm{Al}-\mathrm{O} \delta^{-}\right)$and edges $\left(\mathrm{Si}^{-} \mathrm{O} \delta^{-}\right)$of halloysite). Once bound to the clays, PDADMAC electrostatically attracted the negatively charged Ag-PMA nanoparticles, with electrostatic interactions occurring through the positively charged nitrogens of PDADMAC and deprotonated carboxyl groups of PMA capping the silver nanoparticles. The mechanism by which the nanoparticles were synthesised did not affect the way by which they bound to the clays.

The silver nanoparticles bound to the clays imparted anti-microbial properties to the resultant composites, with those incorporating a higher silver loading, notably the kaolinite and halloysite composites incorporating nanoparticles produced via a photo induced reduction, exhibiting increased anti-microbial properties compared to the analogous composites incorporating nanoparticles prepared by reduction with $\mathrm{NaBH}_{4}$. 
With the intent of expanding the suite of composite materials, it was hoped that gold nanoparticle-clay composites could be produced, however at the time of research, such gold nanoparticle-clay composites, exhibiting both anti-microbial and optical (colourant) properties had already been produced by Chen and co-workers.[16] As we did not want to re-produce materials with markedly similar properties to those already synthesized and reported on, the production of gold nanoparticle-clay composites was not pursued, and as our research group had had success in the production of silver nanoparticle-wool composites,[201] the direction of this research project was altered slightly, and the production of gold nanoparticle-natural fibre composites was pursued. It was hoped that the gold nanoparticles in these materials would impart similar properties to the base fibre as the silver nanoparticles did to the clays, particularly optical (colourant) effects. Discussions of the production and characterisation of such composite materials is provided in the following chapters. 
4 GOLD NANOPARTICLE-MERINO WOOL COMPOSITES: EX-SITU PREPARATION OF GOLD NANOPARTICLES WITH SUBSEQUENT ATTACHMENT TO MERINO WOOL FIBRES

\subsection{Gold Nanoparticles Prepared with Trisodium Citrate or Tannic Acid}

As outlined in section 2.2.2.1, the ex-situ production and subsequent attachment of gold nanoparticles to merino wool fibres involving the reduction of $\mathrm{Au}^{3+}$ to nanoparticulate $\mathrm{Au}^{0}$ was most successful when trisodium citrate (TSC) or tannic acid (TA) were employed as the reductants. When using TSC, the resultant composites ranged in colour from pale yellow to grey, whilst TA produced murky light pink to purple coloured materials (Figure 4.1).

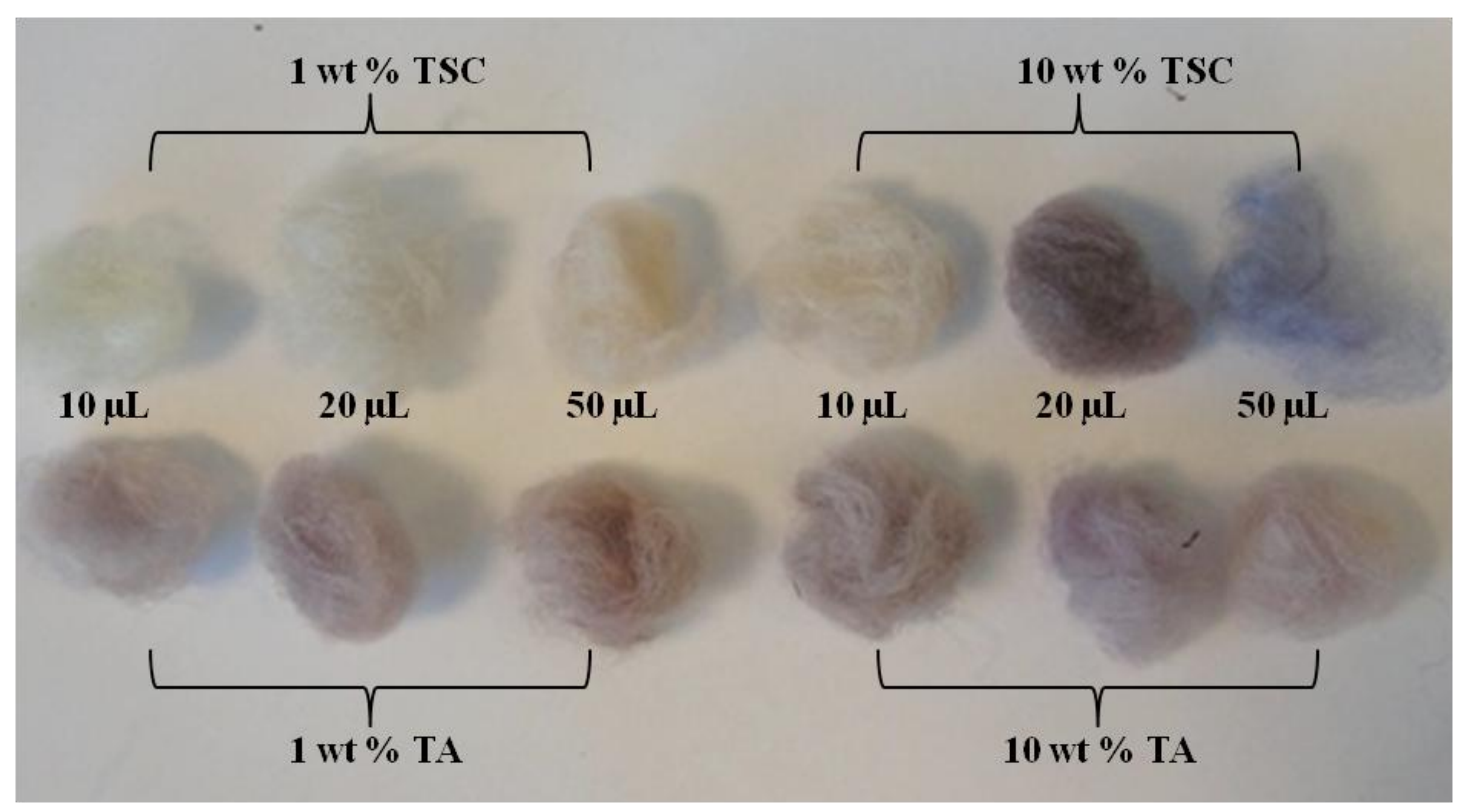

Figure 4.1: Gold nanoparticle-merino wool composites prepared by the $e x$-situ reduction of $\mathrm{Au}^{3+}$ to $\mathrm{Au}^{0}$ by TSC (top) or TA (bottom). 


\subsection{1 ex-situ Preparation of Gold Nanoparticles}

\subsubsection{TSC Reduced and Stabilised Gold Nanoparticles}

One preparation of gold nanoparticles as colloids involved the reduction of $\mathrm{Au}^{3+}$ to $\mathrm{Au}^{0}$ in aqueous solutions containing 10,20 or $50 \mu \mathrm{L}$ of 1 or $10 \mathrm{wt} \% \mathrm{TSC}$ (see section 2.2.2.1). The reaction proceeded as outlined in scheme (4.1) below.

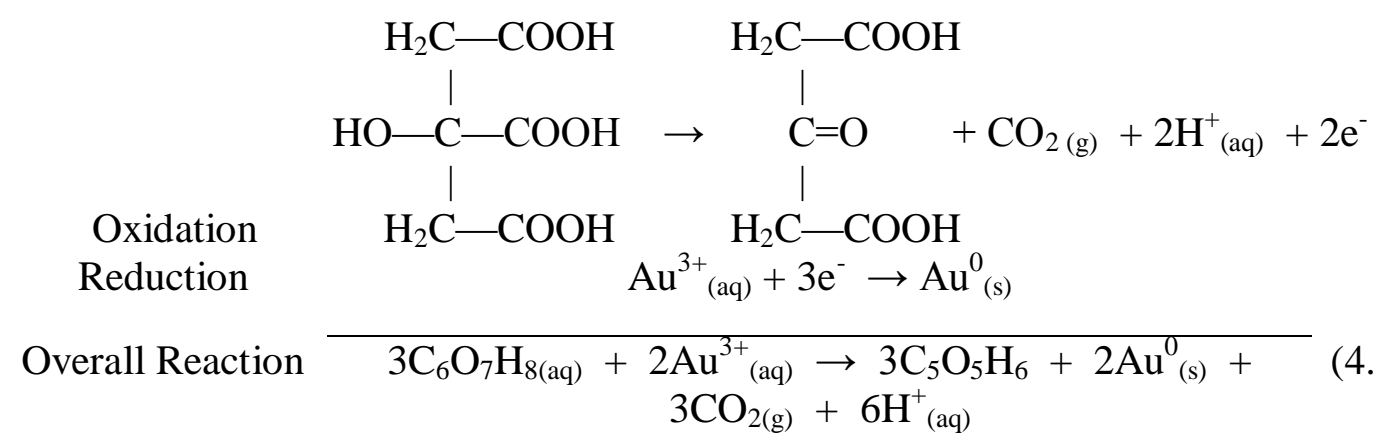

Increasing the amount of TSC employed in the reduction of $\mathrm{Au}^{3+}$ resulted in the production of pale yellow to deep red wine coloured colloids (Figure 4.2). This colour change occured due to the formation of nanoparticles and was reflected in the UV/Vis absorption spectrum of the colloids. Similarly to silver nanoparticles, gold nanoparticles exhibit an intense visible absorption due to surface plasmon resonances. Depending on the size and shape of the nanoparticles and also the dielectric function of the surrounding medium, this is generally centred between approximately 500-700 nm.[208]

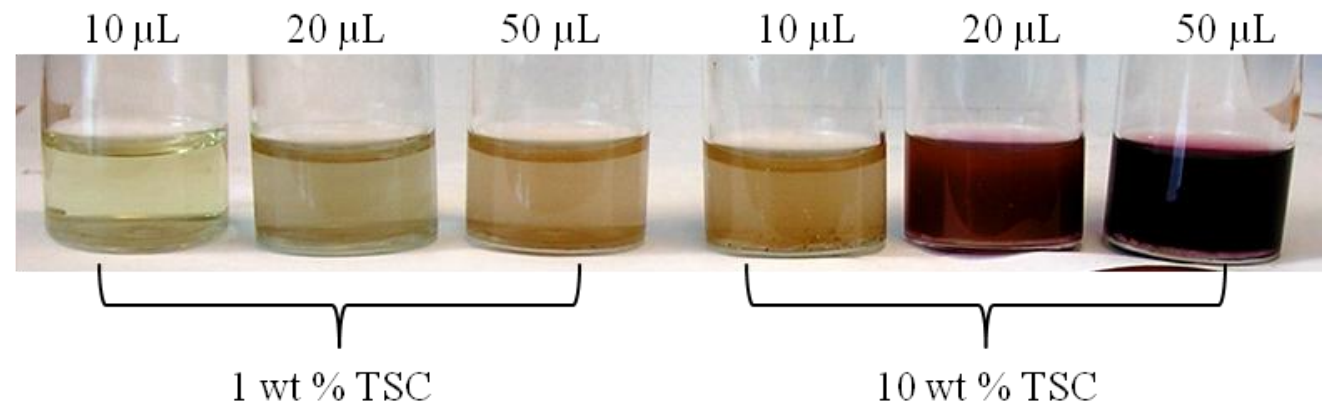

Figure 4.2: Gold nanoparticle solutions prepared with increasing amounts of TSC (left to right). 
It has been well documented that the concentration ratio between a reductant or stabiliser, and the species to be reduced (eg. an ionic metal) greatly influence the size and shape of the resultant nanoparticles.[104, 114] The citrate ion acts as a dual reductant/stabiliser and as such strongly influences the size of the resultant nanoparticles. Tannic acid behaves in a similar manner. The primary mode of action of citrate (or tannic acid) is to both reduce the metal, forming nanoclusters, and then stabilise the resultant nanoclusters through surface adsorption of citrate ions or the corresponding oxidation product. Depending on the concentration of citrate present, the resultant nanoclusters will grow into nanoparticles via coalescence or through surface reduction of gold ions adsorbed onto the surface of the clusters.

With low concentrations of citrate, a small number of nanoclusters are formed. These then coalesce to form large, irregularly shaped nanoparticles. However when the concentration of citrate is too low, an effective bi-layer of citrate surrounding the particles does not form, resulting in the continual aggregation of the nanoparticles producing large, microscale particles as a result of Ostwald Ripening. Alternatively, if higher citrate concentrations are employed, greater numbers of nanoclusters form, due to the increased amount of reductant. Generally these are sufficiently stabilised with adsorbed citrate ions, and as such nanoparticle growth occurs through the reduction of metal ions adsorbed onto the nanocluster surface, resulting in the formation of smaller, and more monodisperse particles. However, if the citrate concentration is too high, the particles may aggregate together due to the increased ionic strength of the solution, as at high ionic strengths, the repulsive electrostatic forces imparted by the adsorbed citrate ions can become screened, becoming overrun by attractive van der Waal forces between the particles,[209] resulting in the production of larger particles.

Figure 4.3 shows the UV/Vis absorption spectra of colloidal gold solutions prepared with increasing amounts of TSC. When $10 \mu \mathrm{L}$ of $1 \mathrm{wt} \%$ TSC was used, there was an absorption maximum centred at $305 \mathrm{~nm}$. This has been reported to be due to charge transfer between the gold centre and chloro ligands,[210, 211] implying little to no $\mathrm{Au}^{3+}$ had been reduced. This was confirmed by TEM analysis of the solution, as there were no gold nanoparticles evident. 


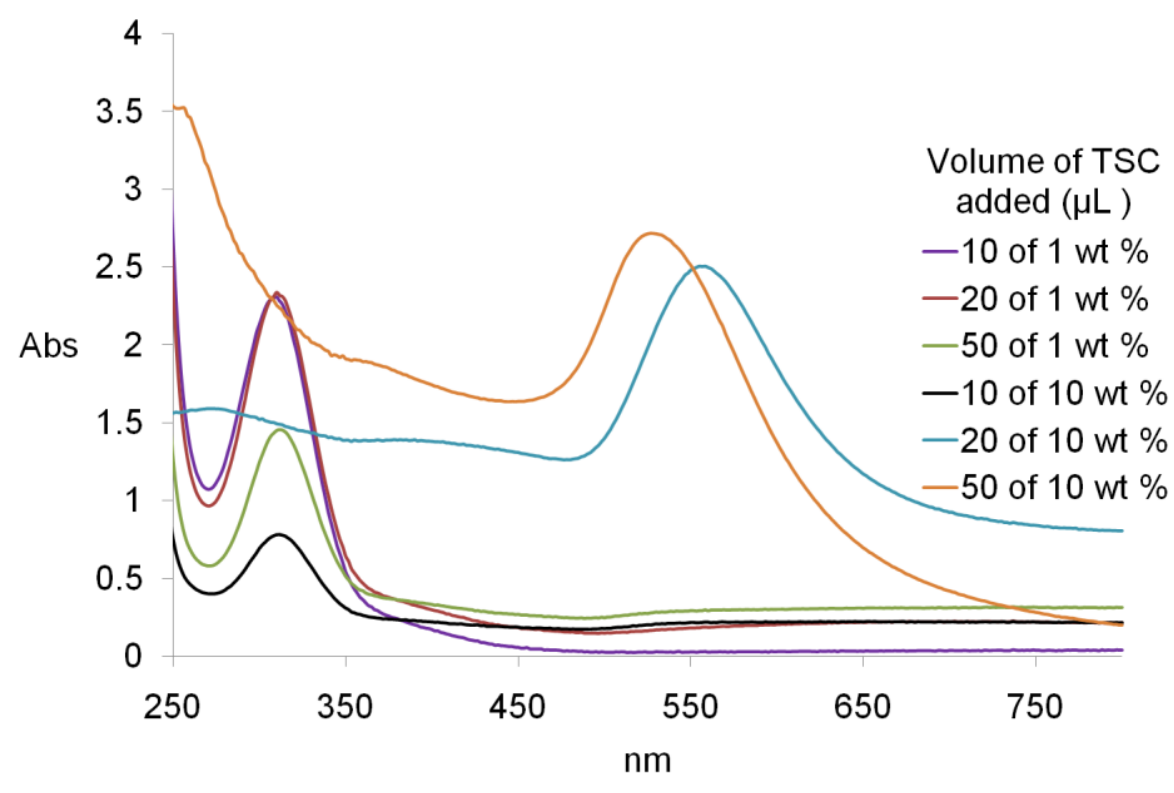

Figure 4.3: UV/Vis absorption spectra of TSC reduced and stabilised gold nanoparticles.

Employing increasing amounts of TSC (50 and $10 \mu \mathrm{L}$ of 1 and $10 \mathrm{wt} \%$ respectively) saw a decrease in the intensity of the $\mathrm{AuCl}_{4}{ }^{-}$peak $\left(\lambda_{\max }=305 \mathrm{~nm}\right)$, and the gradual formation of an extremely weak new peak centred at approximately $552 \mathrm{~nm}$. This peak is typical of nanoparticulate gold, suggesting that increasing amounts of TSC led to the reduction of more $\mathrm{Au}^{3+}$ to $\mathrm{Au}^{0}$ nanoparticles. However the very low intensity and extreme broadness of the peak suggests that there was insufficient screening of the attractive van der Waals forces between any small clusters formed, resulting in coalescence/aggregation forming large, irregularly shaped particles. However when $20 \mu \mathrm{L}$ of $10 \mathrm{wt} \% \mathrm{TSC}$ was used, this peak increased in intensity and the corresponding nanoparticle solution changed to a light red wine colour, indicating the formation of nanoparticles. TEM showed these nanoparticles to be of a variety of morphologies including hexagonal ( $50 \mathrm{~nm}$ diameter), triangular (including truncated triangles $\sim 60 \mathrm{~nm}$ diameter) and planar, the most common form being five fold twinned particles ( 20-25 $\mathrm{nm}$ in diameter) (Figure 4.4). 


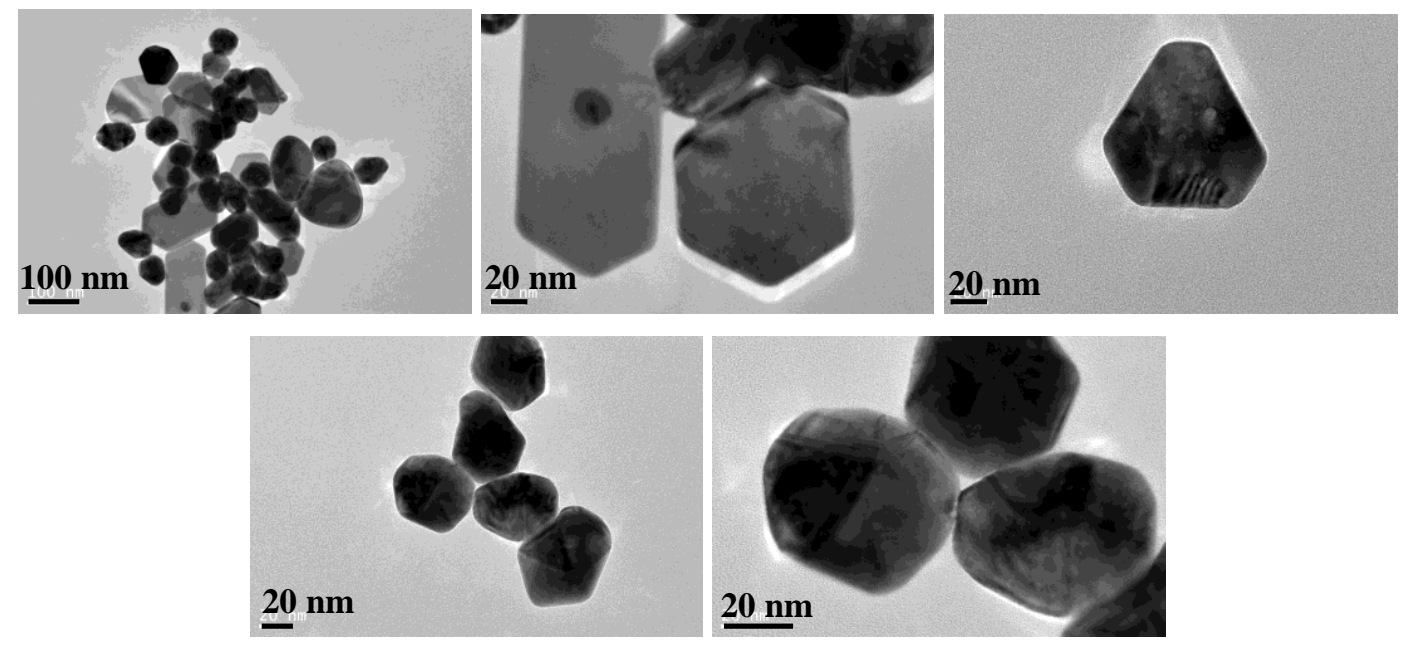

Figure 4.4: TEM micrographs of gold nanoparticles prepared with $20 \mu \mathrm{L}$ of $10 \mathrm{wt} \% \mathrm{TSC}$.

Employing $50 \mu \mathrm{L}$ of $10 \mathrm{wt} \%$ TSC saw a blue shift of the absorption peak centred at $552 \mathrm{~nm}$, indicating either the formation of smaller nanoparticles, or a more monodisperse system. This was confirmed in TEM, as the gold in these colloids was much more monodisperse, present largely as five-fold twinned particles, approximately $20-25 \mathrm{~nm}$ in diameter (Figure 4.5). This was likely to occur via the initial formation of an increased amount of nanoclusters, which were stabilised with a surrounding bi-layer of TSC resulting in growth of these clusters occurring predominantly via the reduction of gold ions adsorbed on the nanocluster surface rather than through aggregation. Additionally, the faster initial reduction rate (due to the increased amount of TSC) forming a larger proportion of nanoclusters would decrease the concentration of $\mathrm{Au}^{3+}$ in solution, making the formation of anisotropic nanoparticles via specific adsorption of gold ions onto areas with twin plane defects less likely (see section 1.3.3). 

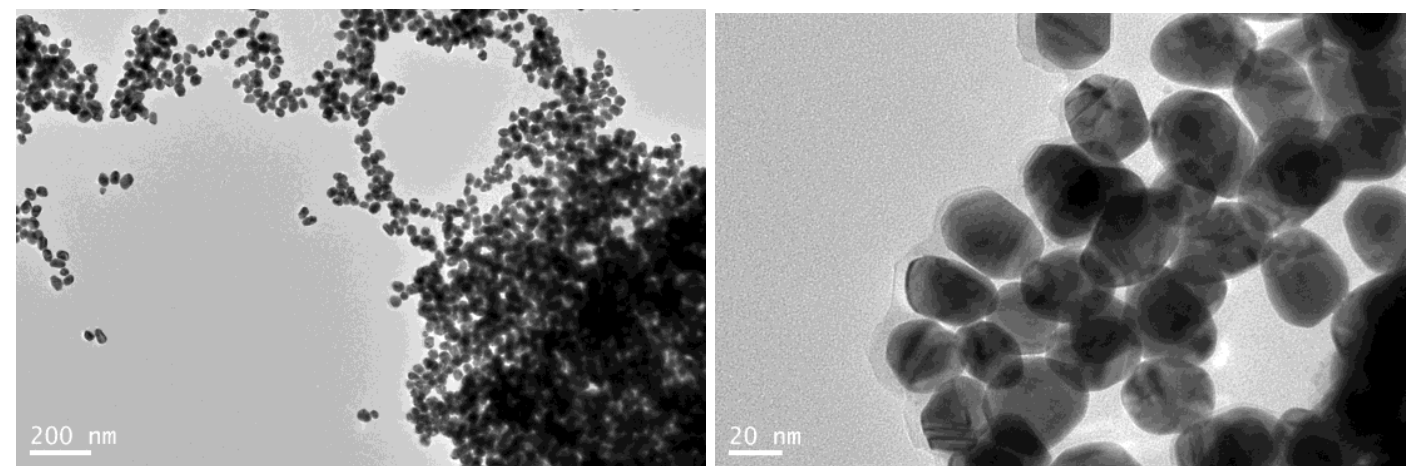

Figure 4.5: Increasing magnification TEM micrographs of a gold nanoparticle colloid prepared with 50 $\mu \mathrm{L}$ of $10 \mathrm{wt} \% \mathrm{TSC}$.

\subsubsection{TA Reduced and Stabilised Gold Nanoparticles}

Alternatively, gold nanoparticles were prepared through the reduction of $\mathrm{Au}^{3+}$ to $\mathrm{Au}^{0}$ nanoparticles in aqueous solutions containing 10,20 or $50 \mu \mathrm{L}$ of 1 or 10 wt $\%$ TA (section 2.2.2.1). The reaction mechanism for this reduction is offered in scheme (4.2) below.

Oxidation

$$
\mathrm{C}_{76} \mathrm{H}_{52} \mathrm{O}_{46(\mathrm{aq})}+20 \mathrm{OH}^{-} \rightarrow \mathrm{C}_{76} \mathrm{H}_{32} \mathrm{O}_{46}+20 \mathrm{H}_{2} \mathrm{O}+20 \mathrm{e}^{-}
$$

Reduction

$$
\mathrm{Au}^{3+}{ }_{(\mathrm{aq})}+3 \mathrm{e}^{-} \rightarrow \mathrm{Au}^{0}(\mathrm{~s})
$$

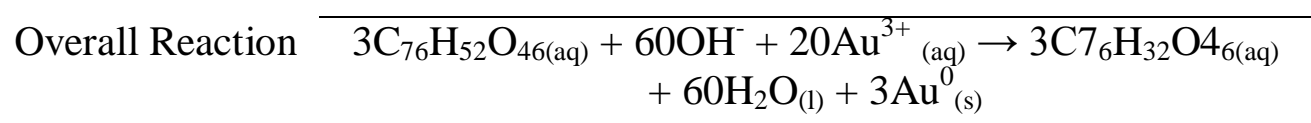

Increasing the amount of TA employed in the gold nanoparticle synthesis (from $10 \mu \mathrm{L}$ of 1 wt $\%$ to $50 \mu \mathrm{L}$ of $10 \mathrm{wt} \%$ ) saw a colour change in the resultant colloids from light pink to orange and finally wine red (Figure 4.6).

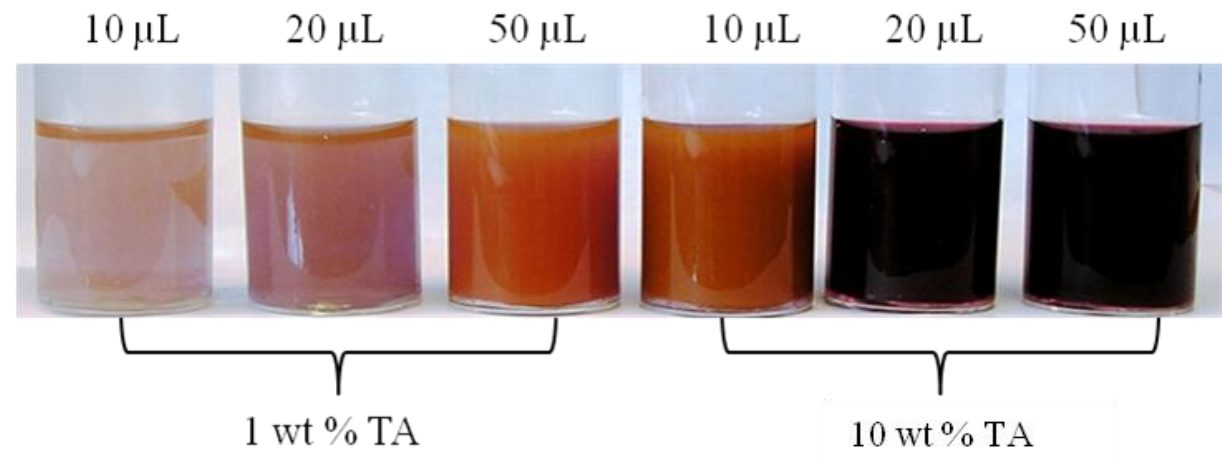

Figure 4.6: Gold nanoparticle solutions prepared with increasing amounts of TA (left to right). 
Similarly to the UV/Vis absorption spectra of nanoparticles prepared with TSC, peaks indicative of un-reduced $\mathrm{AuCl}_{4}^{-},\left(\lambda_{\max }=305 \mathrm{~nm}\right)$, and the plasmon band of nanoparticulate gold, $\left(\lambda_{\max }=\right.$ approximately 596 to $528 \mathrm{~nm}$ ), are evident in the UV/Vis absorption spectra of the TA reduced and stabilised gold nanoparticles (Figure 4.7). Increasing amounts of TA employed from 1 to $50 \mu \mathrm{L}$ of $1 \mathrm{wt} \%$ TA, saw a gradual decrease in intensity of the $\mathrm{AuCl}_{4}{ }^{-}$ peak, which disappeared completely with $10 \mu \mathrm{L}$ of 10 wt \% TA. The decrease (and subsequent loss) of this peak is accompanied by the formation and growth of a very broad peak, centred at approximately $596 \mathrm{~nm}$, which has a shoulder towards higher wavelengths. The broadness of this peak suggests insufficient TA was present to stabilise any resultant nanoparticles formed, resulting in their coalescence to form either large particles or large 'clumps' of smaller nanoparticles. TEM analysis of colloids prepared with $10 \mu \mathrm{L}$ of $1 \mathrm{wt} \%$ TA reveal the presence of very small gold nanoparticles, approximately $2 \mathrm{~nm}$ in diameter, and also very large clusters of these nanoparticles (Figure 4.8).

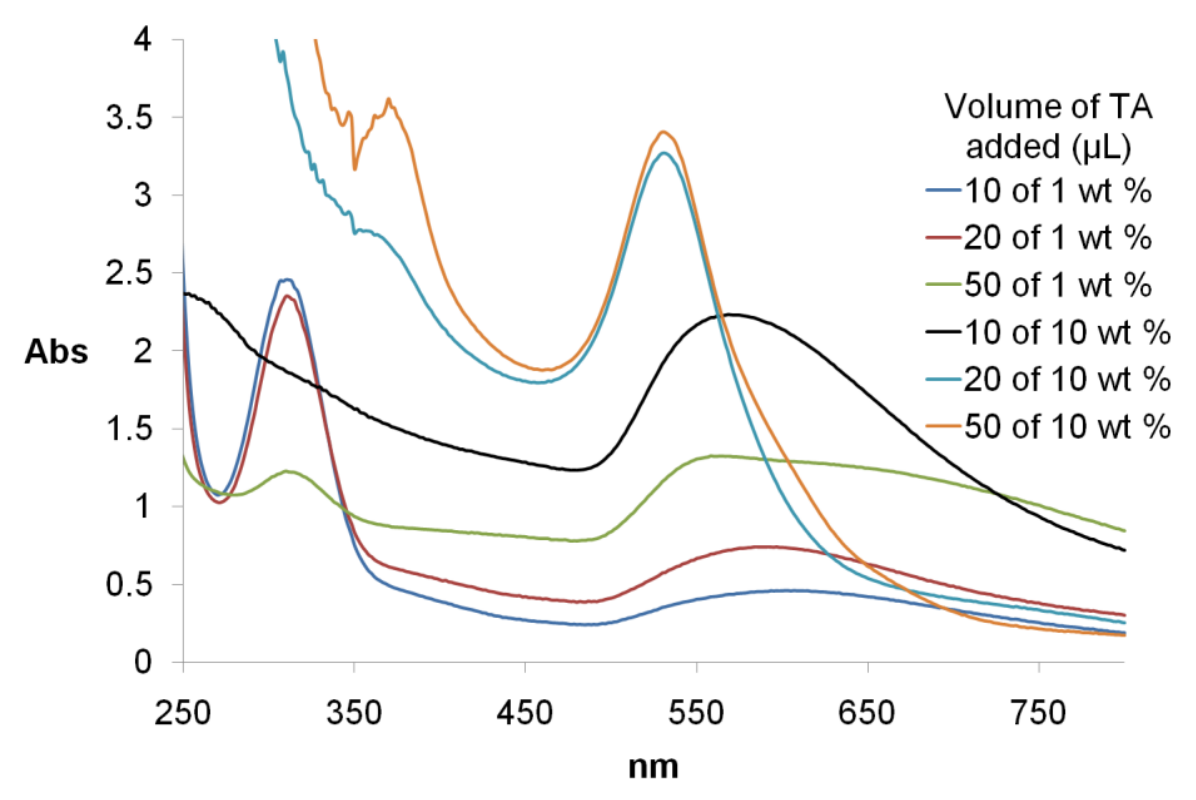

Figure 4.7: UV/Vis absorption spectra of TA reduced and stabilised gold nanoparticles 

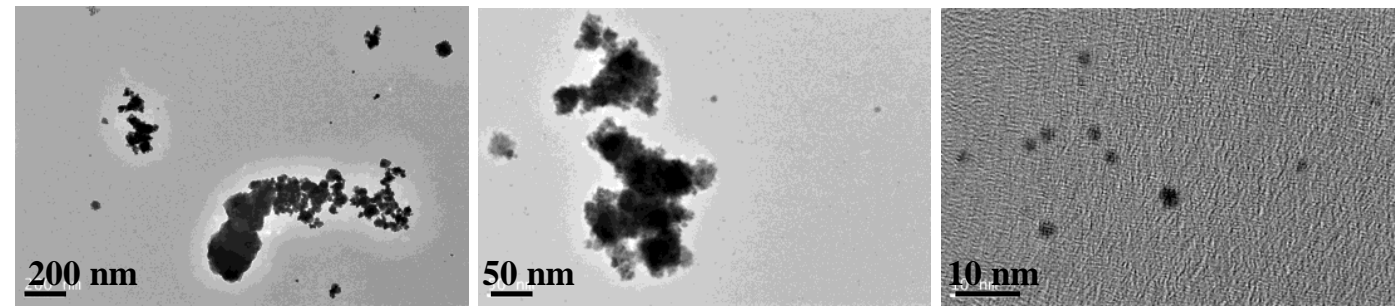

Figure 4.8: Increasing magnificantion TEM micrographs of a gold nanoparticle colloid prepared with 10 $\mu \mathrm{L}$ of 1 wt \% TA.

Increasing the amount of TA to $20 \mu \mathrm{L}$ of $10 \mathrm{wt} \%$ TA saw a blue shift in the peak at $596 \mathrm{~nm}$ to $528 \mathrm{~nm}$, and a corresponding decrease in the full width half maximum. As with the TSC system, the increase in TA concentration is likely to lead to a more comprehensive TA bilayer encapsulating the initially formed nanoclusters, with nanoparticle growth occurring through the reduction of gold ions adsorbed onto the nanocluster surface, rather than through coalescence/aggregation. (A peak centred at approximately $368 \mathrm{~nm}$ also appears in the $\mathrm{UV} / \mathrm{V}$ is spectra of this colloid and that prepared with $50 \mu \mathrm{L}$ of $10 \mathrm{wt} \% \mathrm{TA}$, this peak is likely an experimental uncertainty, arising when changing the light source from ultra violet to visible.) The gold in these composites is present as a variety of nanoparticulate morphological forms including triangular (between approximately $20-50 \mathrm{~nm}$ in diameter) and hexagonal (approximately $60 \mathrm{~nm}$ in diameter) (Figure 4.9 left and centre respectively). However the majority of particles are five-fold twinned particles, approximately $25 \mathrm{~nm}$ in diameter (Figure 4.9 right).
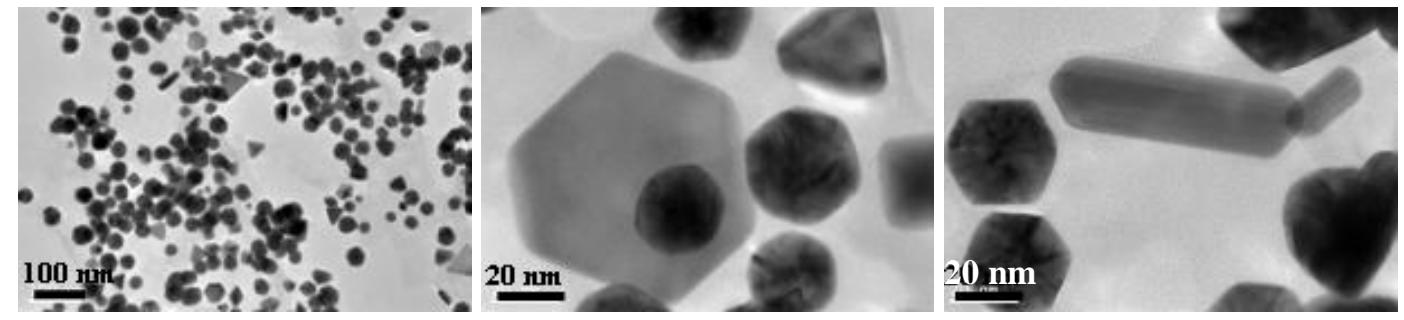

Figure 4.9: TEM micrographs of a gold nanoparticle colloid prepared with $20 \mu \mathrm{L}$ of 10 wt \% TA.

It is interesting to note that when $50 \mu \mathrm{L}$ of $10 \mathrm{wt} \%$ TA was used, the plasmon band of the gold nanoparticles increased in width. As the width of the plasmon peak is directly related to 
the extent of agglomeration, this suggests that there was increased agglomeration of the particles, most likely due to the increase in ionic strength of the solution, destabilising the repulsive forces between the TA capped nanoparticles. TEM analysis confirms this, as on average the main morphological form of the nanoparticles, in this colloid, the five-fold twinned particles are slightly larger (approximately 20-35 nm in diameter (Figure 4.10 right).
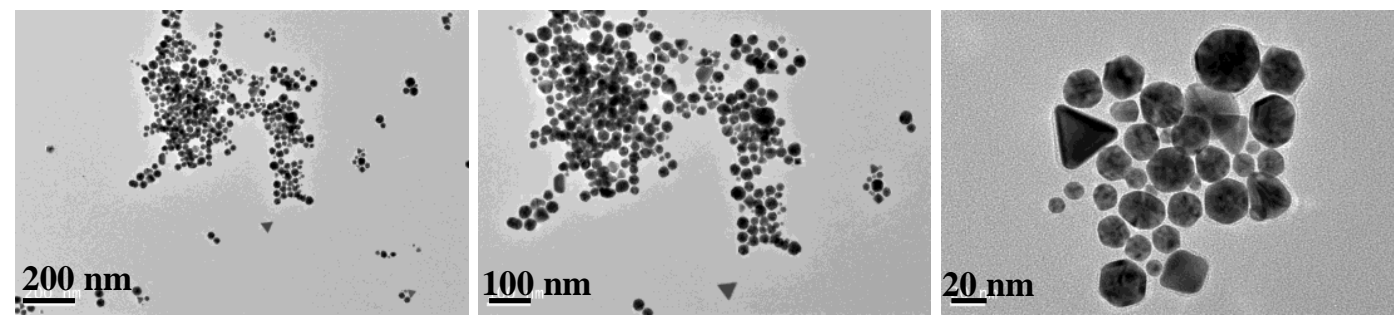

Figure 4.10: Increasing magnification TEM micrographs of a gold nanoparticle colloid prepared with 50 $\mu \mathrm{L}$ of $10 \mathrm{wt} \%$ TA.

\subsubsection{TSC or TA Reduced and Stabilised Gold Nanoparticle-Merino Wool Composites}

\subsubsection{Physical Characterisation and Morphology}

The morphology of the gold nanoparticle-merino wool composites, prepared by adsorbing TSC or TA prepared and stabilised gold nanoparticles onto the surface of the wool fibres were analysed by SEM. The gold in these composites incorporating colloids produced with $10 \mu \mathrm{L}$ of $1 \mathrm{wt} \%$ TSC was present as very large particles, ranging in size from approximately 100-500 nm (Figure $4.11 \mathrm{~b}$ and c). These particles appear to be hexagonal and triangular in shape, residing preferentially at cuticle edges, and do not form a very uniform coating on the wool fibres (Figure 4.11 a). As shown in section 4.1.1.1 $10 \mu \mathrm{L}$ of 1 wt \% TSC was unsuccessful in reducing a large proportion of $\mathrm{Au}^{3+}$ to $\mathrm{Au}^{0}$ (to either nanoparticulate or bulk form). Therefore the large gold particles observed in these composites may form due to a combination of TSC with the additional reductive nature of the wool fibres (section 5.6). It is likely that the $\mathrm{Au}^{3+}$ ions in solution would bind to the sulfur groups of wool, due to the strong affinity of gold for sulfur, and then be reduced to $\mathrm{Au}^{0}$ by a combination of the redox nature of the wool fibres and the TSC in solution. With large particles, rather than discrete 
nanoparticles forming as a result of Ostwald Ripening, due to insufficient TSC present to stabilise the resultant particles.

Increasing the amount of TSC employed in the production of the gold nanoparticles and thus the resultant composites saw both a decrease in the size and change in shape of the nanoparticles attached to the wool fibres, to approximately $30 \mathrm{~nm}$ diameter five-fold twinned particles, and an increase in amount of nanoparticles (Figure 4.11). The size of the nanoparticles in these composites is not dissimilar to those in the colloids used in their production. Again these particles appear to reside preferentially along the cuticle edges, suggesting that they are adsorbed primarily at these positions where surface tension is highest.
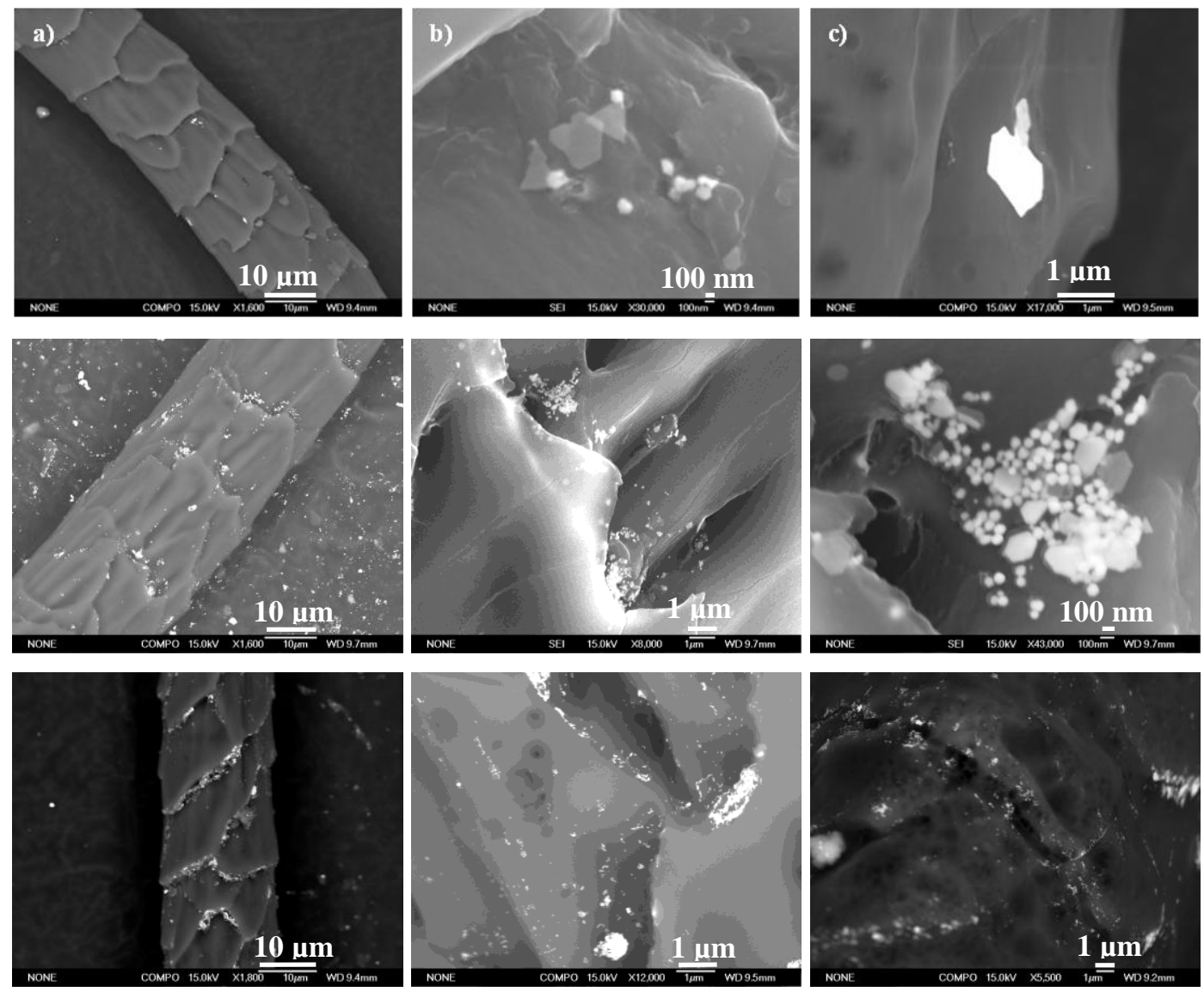

Figure 4.11: Increasing magnification SEM micrographs of a gold nanoparticle-merino wool composite incorporating gold nanoparticles prepared with $10 \mu \mathrm{L}$ of $1 \mathrm{wt} \%$ TSC (top), $20 \mu \mathrm{L}$ of 10 wt \% TSC (middle) and $50 \mu \mathrm{L}$ of $10 \mathrm{wt} \%$ TSC (bottom). 
Employing TA as the reductant imparted similar morphological characteristics to the resultant composites; however in these materials the gold nanoparticles were not as large (most likely due to the stronger reducing power of TA relative to TSC). The gold in the composites incorporating colloids prepared with $10 \mu \mathrm{L}$ of $1 \mathrm{wt} \%$ TA was present as small spherical nanoparticles (approximately $10-20 \mathrm{~nm}$ in diameter) larger trianglular (approximately 50-100 $\mathrm{nm}$ ) and five-fold nanoparticles (approximately 20-25 $\mathrm{nm}$ in diameter) some of which agglomerated together (Figure 4.12 top and Figure 4.13 top). Increasing the amount of TA to $50 \mu \mathrm{L}$ of $10 \mathrm{wt} \%$ saw an increase in the amount of nanoparticles on the surface of the fibres, however unlike the corresponding composites prepared with a similar amount of TSC, the size of the nanoparticles in these materials did not change (Figure 4.12 and Figure 4.13).
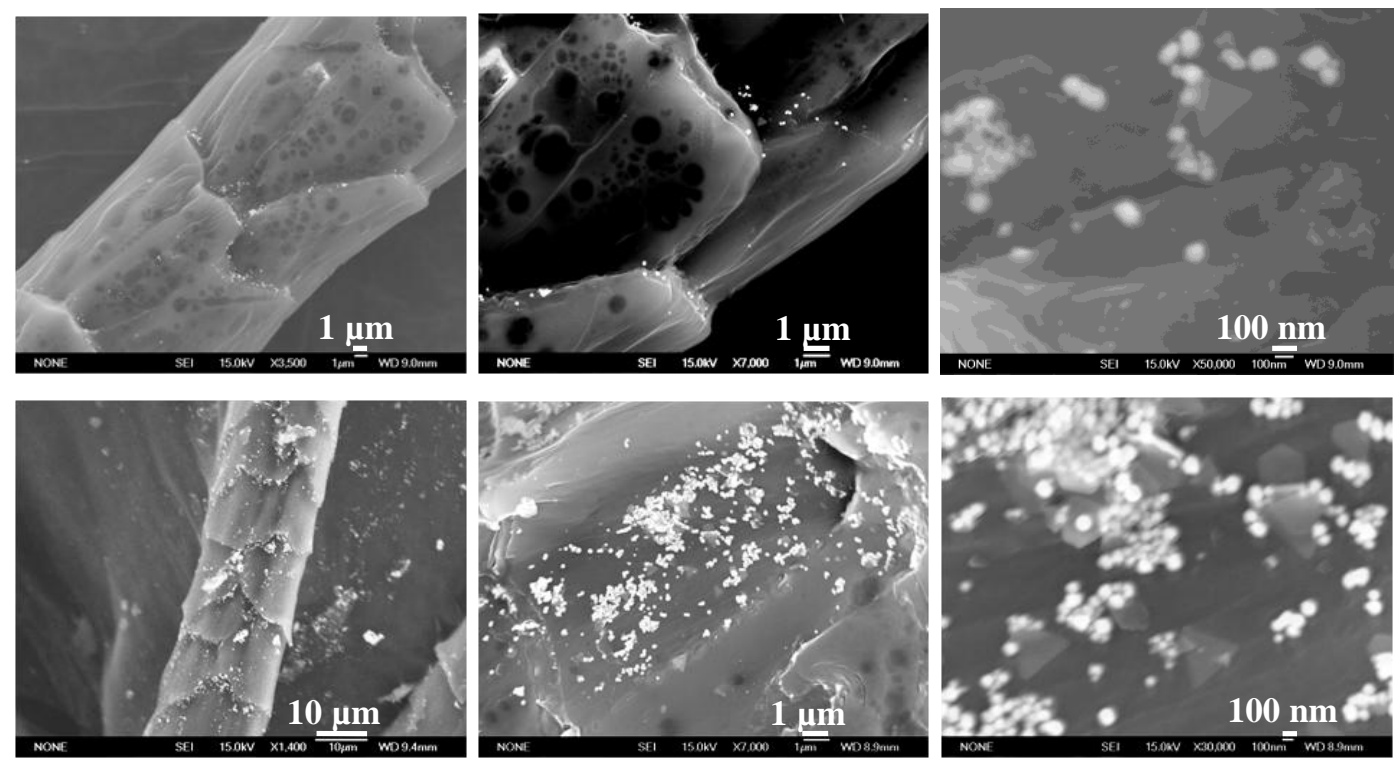

Figure 4.12: Increasing magnification SEM micrographs of a gold nanoparticle-merino wool composite incorporating gold nanoparticles prepared with $10 \mu \mathrm{L}$ of 1 wt \% TA (top) and $50 \mu \mathrm{L} 10$ wt \% TA (bottom).

It is interesting to note that there were notably less gold nanoparticles present on the fibres when viewed under TEM compared to SEM. It is likely that a large proportion of nanoparticles were dislodged from the fibres during TEM sample preparation, which as outlined in section 2.3.2 is quite harsh, employing numerous organic solvents and resins. 
This is likely due to the relative instability of the bond between the nanoparticles and fibres, and also their location at the fibre surface.

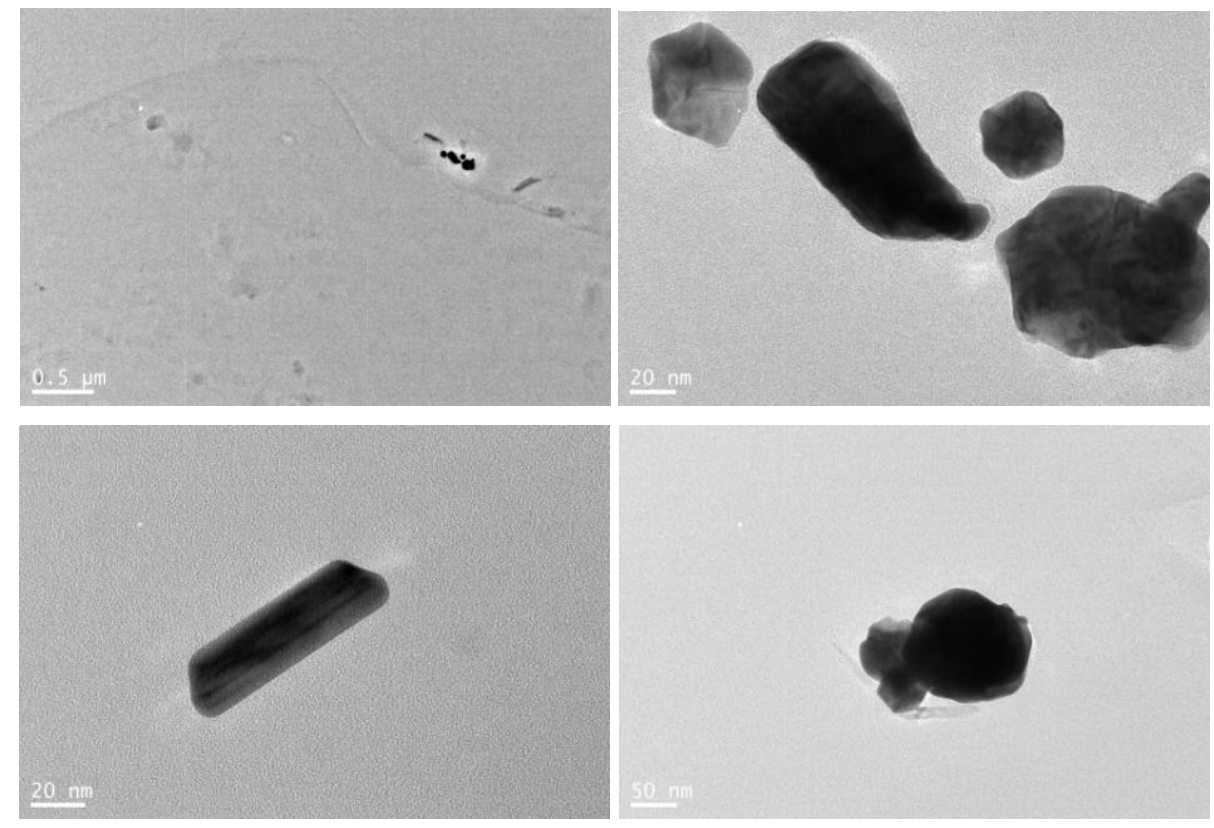

Figure 4.13: Increasing magnification TEM micrographs of a gold nanoparticle-merino wool composite incorporating gold nanoparticles prepared with $10 \mu \mathrm{L}$ of 1 wt \% TA (top) or $50 \mu \mathrm{L}$ of 1 wt \% TA (bottom).

SEM and EDS revealed the gold in all of the composites to be present solely on the surface of the fibres, and not dispersed throughout the centres. Figure 4.14 (left) offers a cross sectional SEM micrograph of a merino wool fibre that has been coloured with gold nanoparticles prepared with $10 \mu \mathrm{L}$ of 1 wt $\%$ TSC. Particles of gold are evident on the surface of the fibre (the bright white areas) but not in the centre. The right hand image in Figure 4.14 is the corresponding EDS gold map, where high concentrations of gold are depicted in red and white areas. A line profile of this micrograph, which provides information about elemental distribution across a defined area is shown in Figure 4.15. Again this showed gold to be present on the surface of the fibre and not in the centre. As mentioned above, incorporating gold nanoparticles prepared with a greater amount of TSC saw the resultant composites to have an increased amount of nanoparticles on the fibre surface. Cross sectional SEM and EDS analysis show these nanoparticles to remain predominantly on the fibre surface rather than in the centre (Figure 4.16 and Figure 4.17). Similar trends are observed in merino wool fibres coloured with TA reduced and stabilised gold nanoparticles (Figure 4.18 to Figure 4.21). 

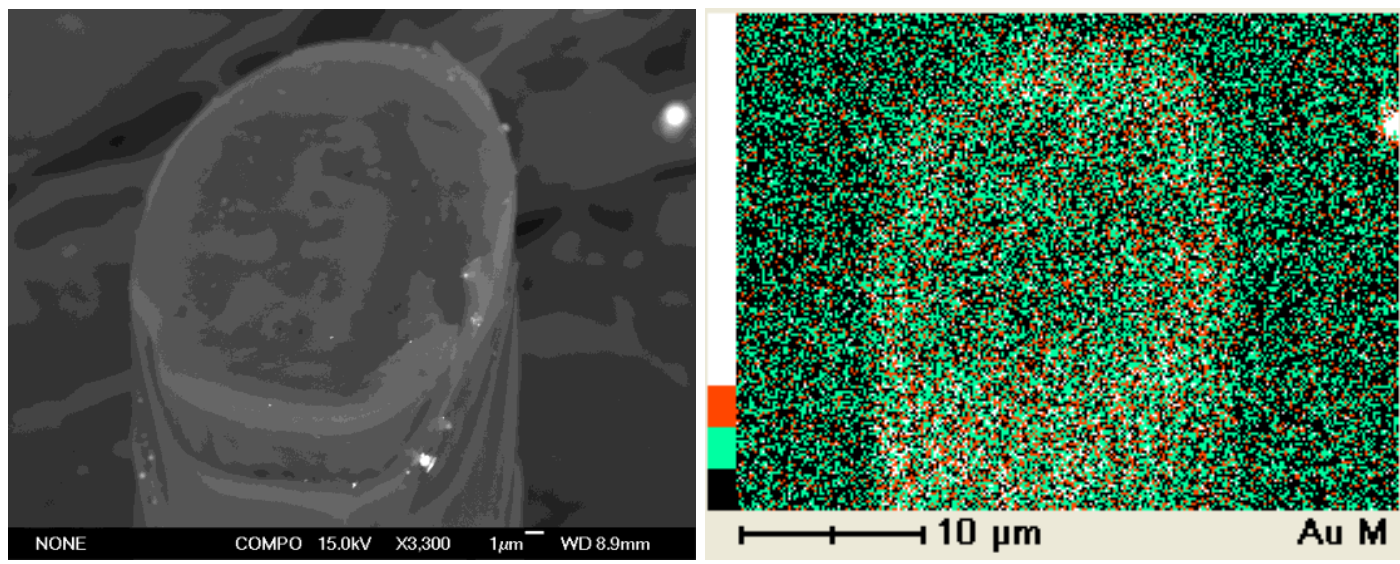

Figure 4.14: Left: A Cross sectional SEM micrograph of a gold nanoparticle-merino wool composite (incorporating nanoparticles prepared with $10 \mu \mathrm{L}$ of $1 \mathrm{wt} \%$ TSC). Right: the corresponding gold EDS map.

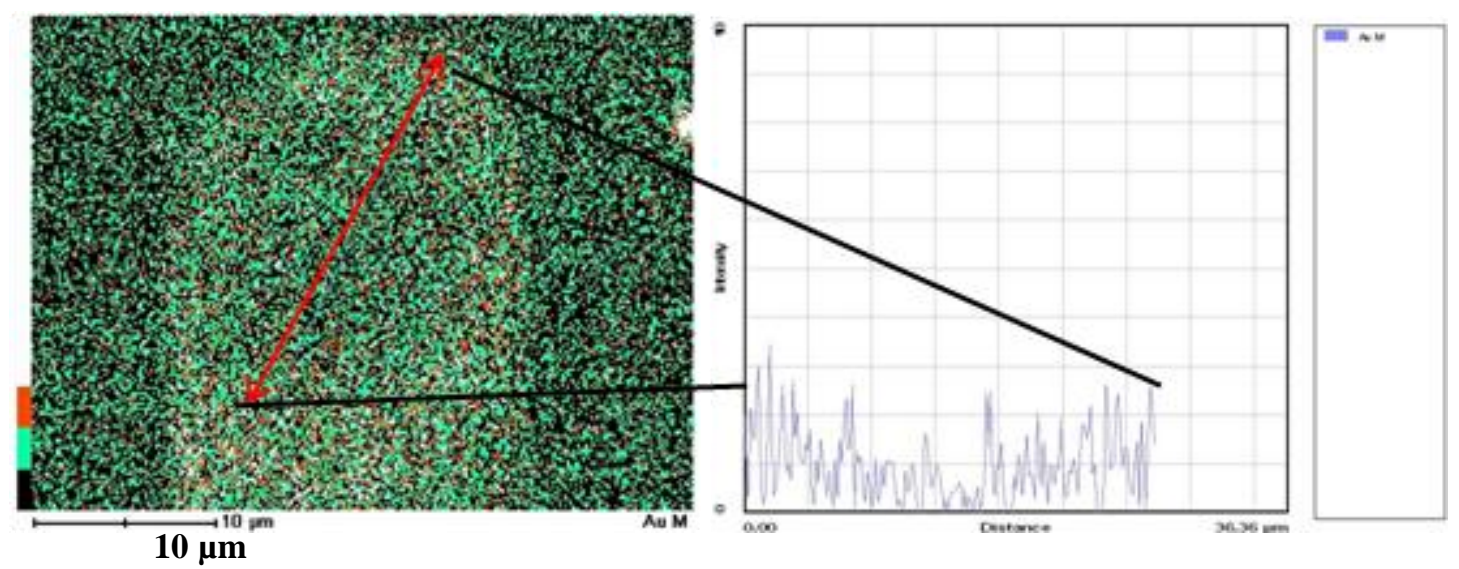

Figure 4.15: Left: Gold EDS map of a gold nanoparticle-merino wool composite (incorporating nanoparticles prepared with $10 \mu \mathrm{L}$ of $1 \mathrm{wt} \% \mathrm{TSC}$ ), and right: the corresponding line profile showing higher concentrations of gold on the surface of the fibre than in the centre. 

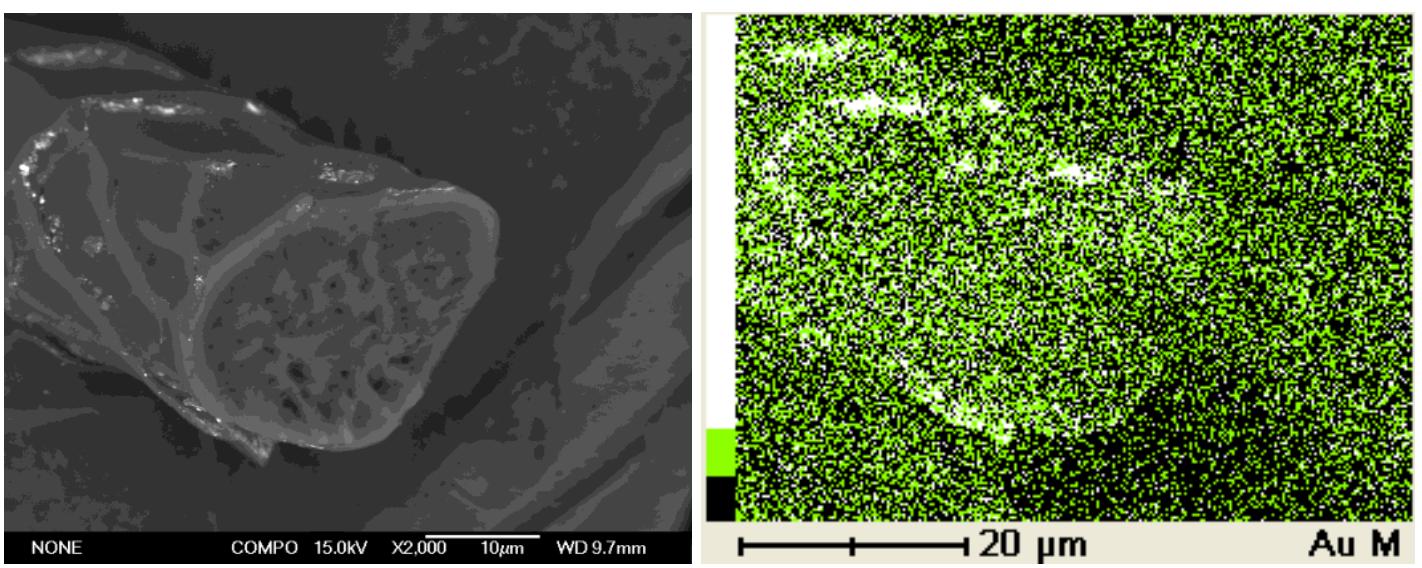

Figure 4.16: Left: A Cross sectional SEM micrograph of a gold nanoparticle-merino wool composite (incorporating nanoparticles prepared with $50 \mu \mathrm{L}$ of $10 \mathrm{wt} \%$ TSC). Right: the corresponding gold EDS map.
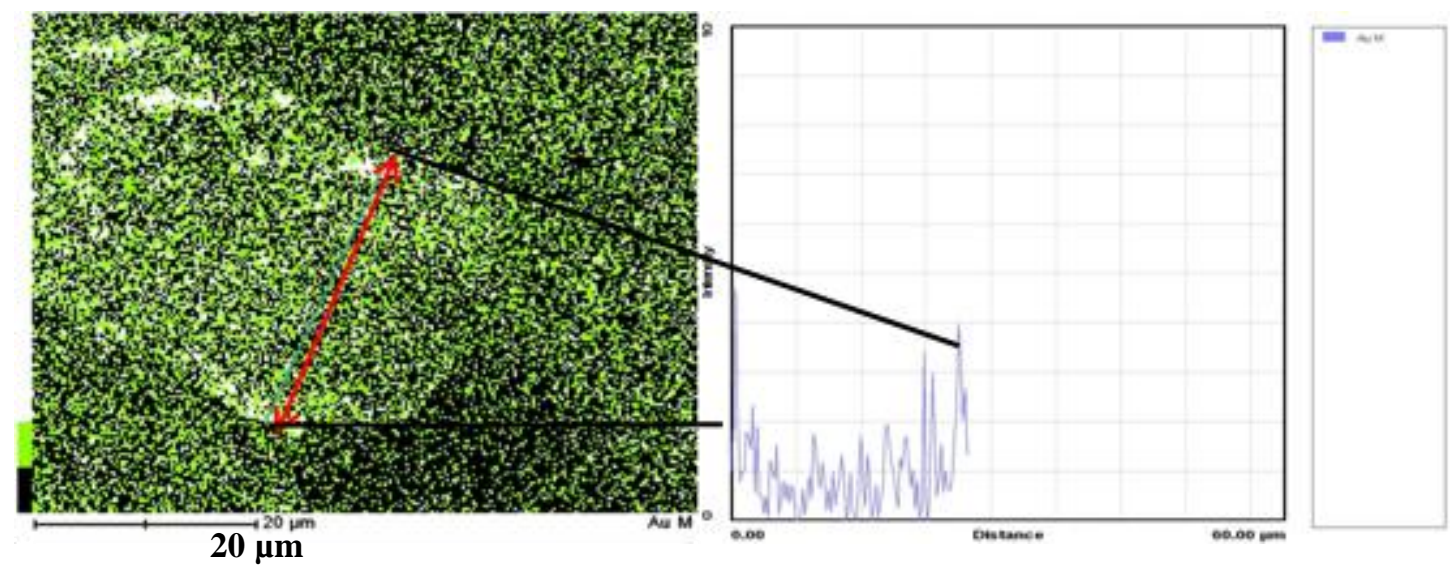

Figure 4.17: Left: Gold EDS map of a gold nanoparticle-merino wool composite (incorporating nanoparticles prepared with $50 \mu \mathrm{L}$ of $10 \mathrm{wt} \%$ TSC), and right: the corresponding line profile showing higher concentrations of gold on the surface of the fibre than in the centre.
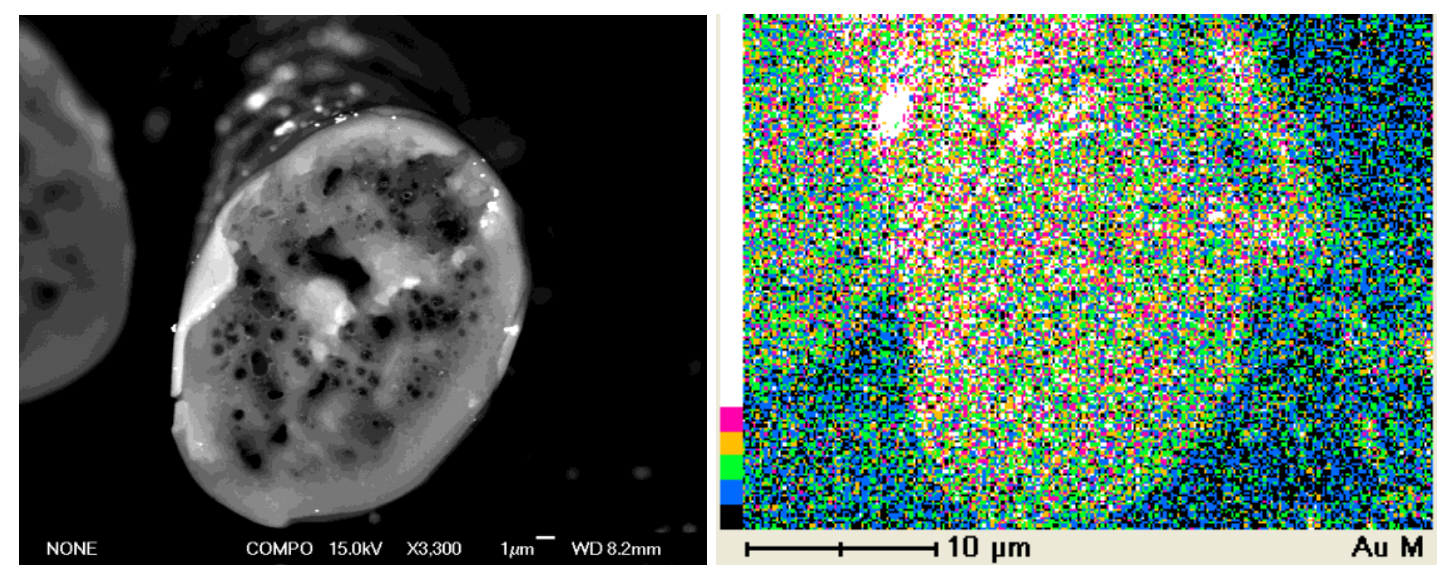

Figure 4.18: Left: A Cross sectional SEM micrograph of a gold nanoparticle-merino wool composite (incorporating nanoparticles prepared with $10 \mu \mathrm{L}$ of $1 \mathrm{wt} \%$ TA). Right: the corresponding gold EDS map. 


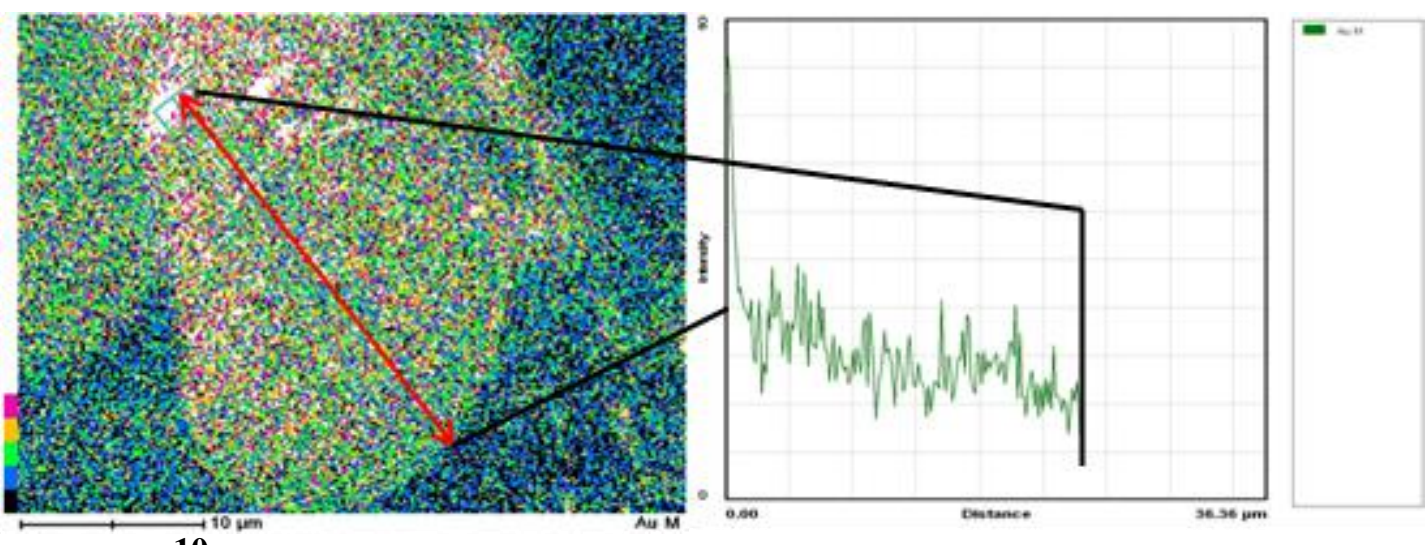

$10 \mu \mathrm{m}$

Figure 4.19: Left: Gold EDS map of a gold nanoparticle-merino wool composite (incorporating nanoparticles prepared with $10 \mu \mathrm{L}$ of $1 \mathrm{wt} \%$ TA), and right: the corresponding line profile showing higher concentrations of gold on the surface of the fibre than in the centre.
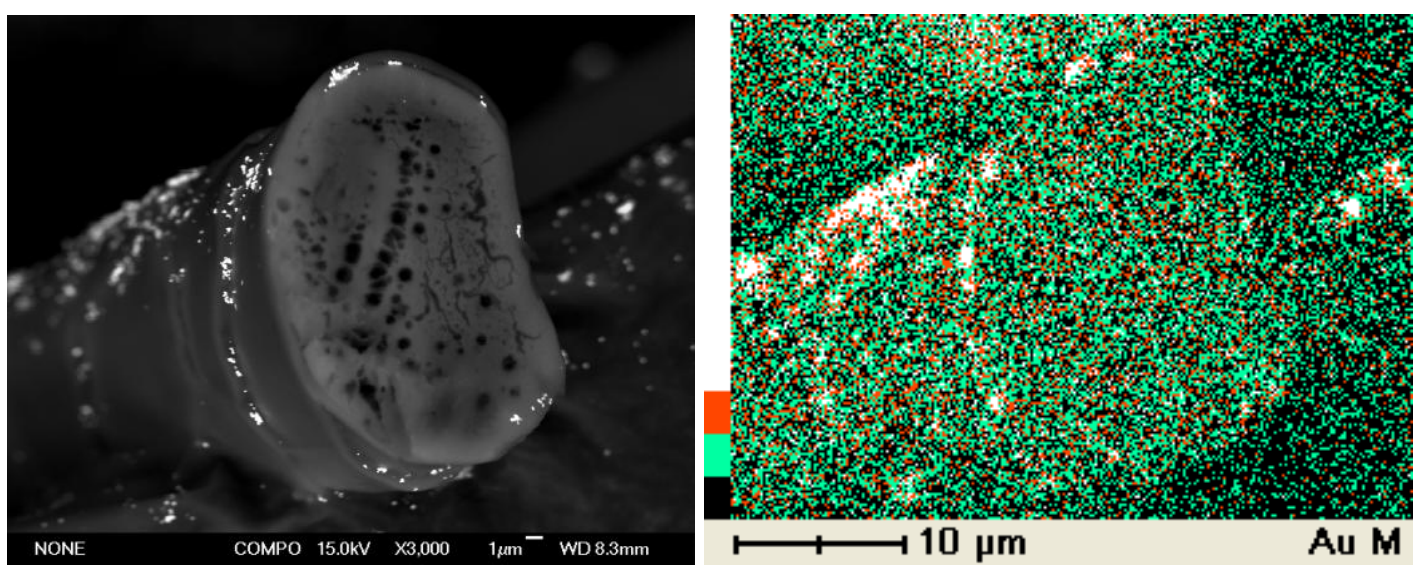

Figure 4.20: Left: Left: A Cross sectional SEM micrograph of a gold nanoparticle-merino wool composite (incorporating nanoparticles prepared with $50 \mu \mathrm{L}$ of 10 wt \% TA). Right: the corresponding gold EDS map.

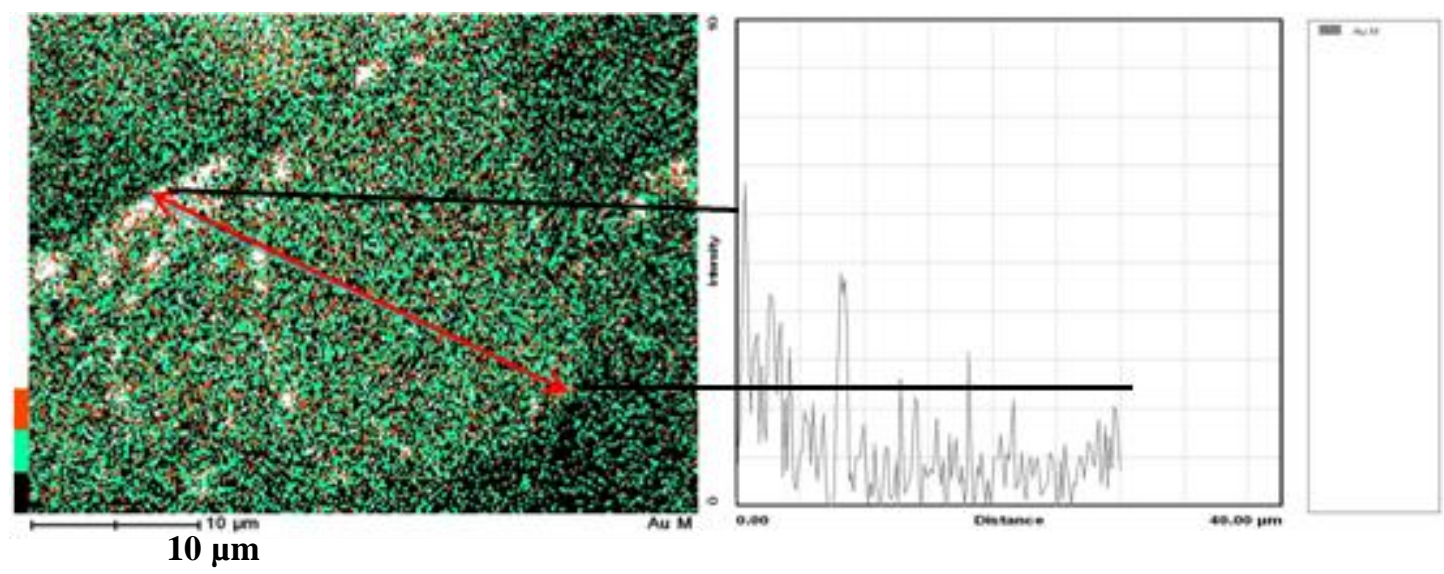

Figure 4.21: Left: Gold EDS map of a gold nanoparticle-merino wool composite (incorporating nanoparticles prepared with $50 \mu \mathrm{L}$ of $10 \mathrm{wt} \% \mathrm{TA}$ ), and right: the corresponding line profile showing higher concentrations of gold on the surface of the fibre than in the centre. 


\subsubsection{Colour}

As mentioned in section 4.1 above, when colouring merino wool with gold nanoparticles prepared with increasing amounts of TSC, the resultant composites changed colour from pale yellow to grey, whilst increasing amounts of TA produced light pink to purple/grey coloured materials (Figure 4.1). The colour of the gold nanoparticle-merino wool composites were studied with UV/Vis spectroscopy and through analysis of their CIE L*, a* and $b^{*}$ values.

The CIE L*, $\mathrm{a}^{*}$ and $\mathrm{b}^{*}$ values of the gold nanoparticle-merino wool materials (which are coordinates depicting colour), are offered in Table 4.1 below. As outlined in section 2.3.3 L* values represent a materials degree of lightness, with $L^{*}=0$ being black and $L^{*}=100$ white. Increasing the amount of TSC or TA employed in the production of the nanoparticles saw a darkening of the resultant composites. This was reflected by a general decrease in the $\mathrm{L}^{*}$, $457 \mathrm{~nm}$ brightness and $580 \mathrm{~nm}$ brightness values of these materials. The $\mathrm{a}^{*}$ value indicates a sample's colour between red and green (positive and negative values respectively). Incorporating nanoparticles with an increased amount of TSC, from $10 \mu \mathrm{L}$ of $1 \mathrm{wt} \%$ to 20 $\mu \mathrm{L}$ of $50 \mathrm{wt} \%$, saw a general increase in the values of $\mathrm{a}^{*}$ of the resultant composites, mirroring the visual darkening of the materials. However when $50 \mu \mathrm{L}$ of 10 wt $\%$ TSC was employed, the composites showed a marked decrease in $\mathrm{a}^{*}$, from 4.5 to 0.5 , corresponding to the materials' observed colour change (they were much less red in colour). The $\mathrm{a}^{*}$ values for the materials employing nanoparticles prepared with TA remain relatively constant, which is logical as these materials all exhibited a similar red tinge. Additionally, the $b^{*}$ value specifies how yellow or blue a material is (positive $b^{*}=$ yellow, negative $b^{*}=b l u e$ ). As such, the observed colour change of the composites, from pale to deeper yellow, red/brown to purple/blue upon incorporating of colloids prepared with increasing amounts of TSC is reflected by an increase, followed by a sharp decrease, in the composites values of $b^{*}$. Using nanoparticles with an altered amount of TA did not visually change the resultant composites degree of yellowness or blueness, and as such the value of $b^{*}$ for these materials remained relatively constant. 
This colour change, and the relationship between the colour of the composites and the size and shape of the gold nanoparticles bound to the fibre surfaces was also shown in SEM analysis and the UV/Vis absorption spectra of the composites, and appeared to be a function of nanoparticle size, shape and concentration (Figure 4.22).

Table 4.1: $\mathrm{L}^{*}, \mathrm{a}^{*}, \mathrm{~b}^{*}, 457 \mathrm{~nm}$ brightness and $580 \mathrm{~nm}$ brightness values for gold nanoparticle-merino wool composites prepared by the ex-situ reduction of $\mathrm{Au}^{3+}$ to $\mathrm{Au}^{0}$ by TSC or TA.

\begin{tabular}{|c|c|c|c|c|c|}
\hline Sample & $\mathbf{L}^{*}$ & $a^{*}$ & $\mathbf{b}^{\star}$ & $\begin{array}{c}457 \mathrm{~nm} \\
\text { Brightness }\end{array}$ & $\begin{array}{c}580 \mathrm{~nm} \\
\text { Brightness }\end{array}$ \\
\hline $10 \mu \mathrm{L} 1 \mathrm{wt} \% \mathrm{TSC}$ & 60.4 & 1.3 & 6.9 & 25 & 30 \\
\hline $20 \mu \mathrm{L} 1 \mathrm{wt} \% \mathrm{TSC}$ & 60.9 & 2.3 & 6.9 & 25 & 31 \\
\hline $50 \mu \mathrm{L} 1$ wt $\%$ TSC & 68.2 & 4.2 & 9.0 & 32 & 41 \\
\hline $10 \mu \mathrm{L} 10$ wt $\%$ TSC & 57.0 & 4.0 & 8.6 & 21 & 27 \\
\hline $20 \mu \mathrm{L} 10 \mathrm{wt} \% \mathrm{TSC}$ & 46.0 & 4.5 & 4.2 & 14 & 16 \\
\hline $50 \mu \mathrm{L} 10$ wt $\%$ TSC & 48.5 & 0.5 & -2.9 & 19 & 17 \\
\hline $10 \mu \mathrm{L} 1$ wt $\%$ TA & 50.4 & 4.0 & 4.0 & 17 & 20 \\
\hline $20 \mu \mathrm{L} 1$ wt $\%$ TA & 51.2 & 5.0 & 4.1 & 17 & 20 \\
\hline $50 \mu \mathrm{L} 1$ wt $\%$ TA & 50.5 & 5.6 & 5.8 & 16 & 20 \\
\hline $10 \mu \mathrm{L} 10$ wt $\%$ TA & 53.4 & 1.1 & 0.3 & 21 & 21 \\
\hline $20 \mu \mathrm{L} 10 \mathrm{wt} \% \mathrm{TA}$ & 55.3 & 2.1 & 4.1 & 21 & 24 \\
\hline $50 \mu \mathrm{L} 10$ wt \% TA & 50.8 & 3.9 & 3.8 & 17 & 20 \\
\hline
\end{tabular}
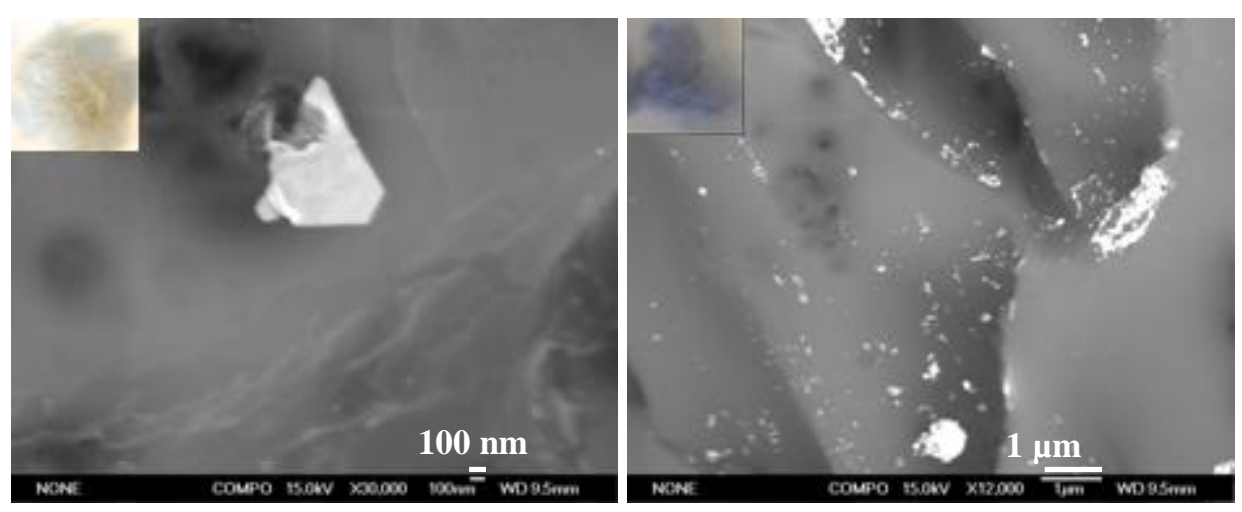

Figure 4.22: SEM micrographs of gold nanoparticle-merino wool composites prepared with, left: $10 \mu \mathrm{L}$ of $1 \mathrm{wt} \%$ TSC and right: $50 \mu \mathrm{L}$ of $10 \mathrm{wt} \%$ TSC. Shows the relationship between the colour of the composites and the size and shape of the gold particles bound to the wool. 
As described in section 4.1.2.1, the gold in the composites prepared with $10 \mu \mathrm{L}$ of $1 \mathrm{wt} \%$ TSC was present as large triangular or hexagonal particles, ranging in size from 100-500 nm in diameter. These particles are too large to exhibit significant surface plasmon resonances, instead they would display optical properties closer to that of bulk gold, accounting for the very pale yellow tinge of the composites. This was illustrated in their UV/Vis absorption spectrum with the absence of the surface plasmon band of gold, and a weak peak centred at approximately $500 \mathrm{~nm}$ (Figure 4.23). This peak has been reported to be that of the transverse plasmon band of large gold nanoplates (see section 1.3.1 for discussions about transverse and longitudinal plasmon bands),[210] and as such it is likely to be representative of the large triangular and hexagonal gold particles observed in the SEM micrographs of these composites. The colour of the composites did not change to a great extent until $20 \mu \mathrm{L}$ of 10 wt \% TSC was used in the production of the colloids, with the composites appearing browny red in colour. This colour change is reflected in the UV/Vis spectrum by the formation of a peak centred at approximately $560 \mathrm{~nm}$, and another smaller peak at approximately $690 \mathrm{~nm}$. There has been substantial literature confirming the first peak to be the plasmon resonance band of spherical or five-fold twinned gold nanoparticles, [17, 104, 107, 211, 212] and the later anisotropic gold particles such as triangular or hexagonal platelets. SEM confirms the presence of these morphological forms, revealing the gold in the composites incorporating nanoparticles prepared with $20 \mu \mathrm{L}$ of $10 \mathrm{wt} \%$ TSC to be predominately five-fold twinned particles, approximately $30 \mathrm{~nm}$ in diameter, with some large hexagonal (approximately 250 $\mathrm{nm}$ in diameter) and truncated triangular (approximately $200 \mathrm{~nm}$ in diameter) particles (Figure 4.11 middle). Incorporating nanoparticles prepared with $50 \mu \mathrm{L}$ of $10 \mathrm{wt} \% \mathrm{TSC}$ saw an increase in size or an agglomeration of these particles and hence a slight red shift in this peak, reflective of the colour change of the composite to a blue grey.

The UV/Vis absorption peaks for the materials incorporating colloids prepared with 20 or 50 $\mu \mathrm{L}$ of $10 \mathrm{wt} \%$ TSC are very broad in comparison to the corresponding nanoparticles, Figure 4.24, suggesting either agglomeration of the nanoparticles on the wool fibre surface, or a bonding interaction between the nanoparticles and wool fibres. 


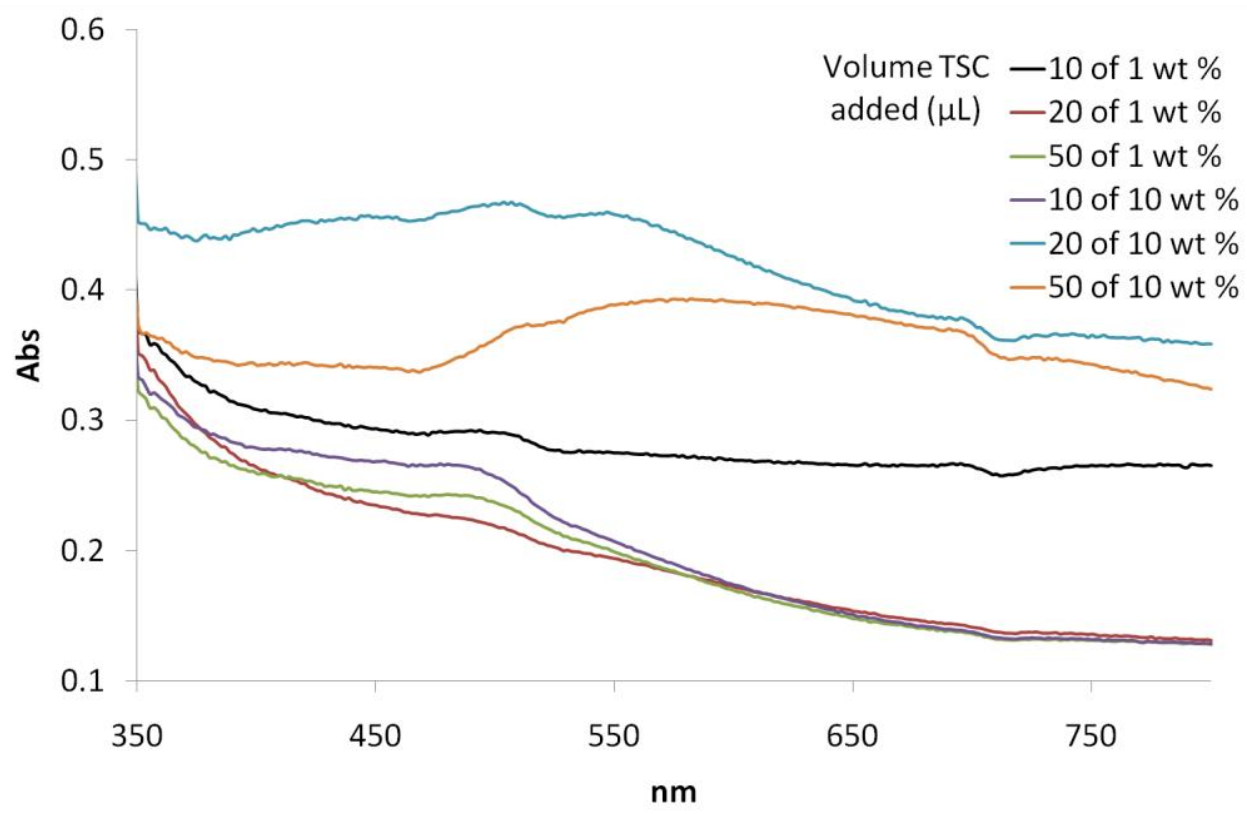

Figure 4.23: Kubelka Munk transformed UV/Vis reflection spectra of gold nanoparticle-merino wool composites incorporating nanoparticles prepared with TSC.

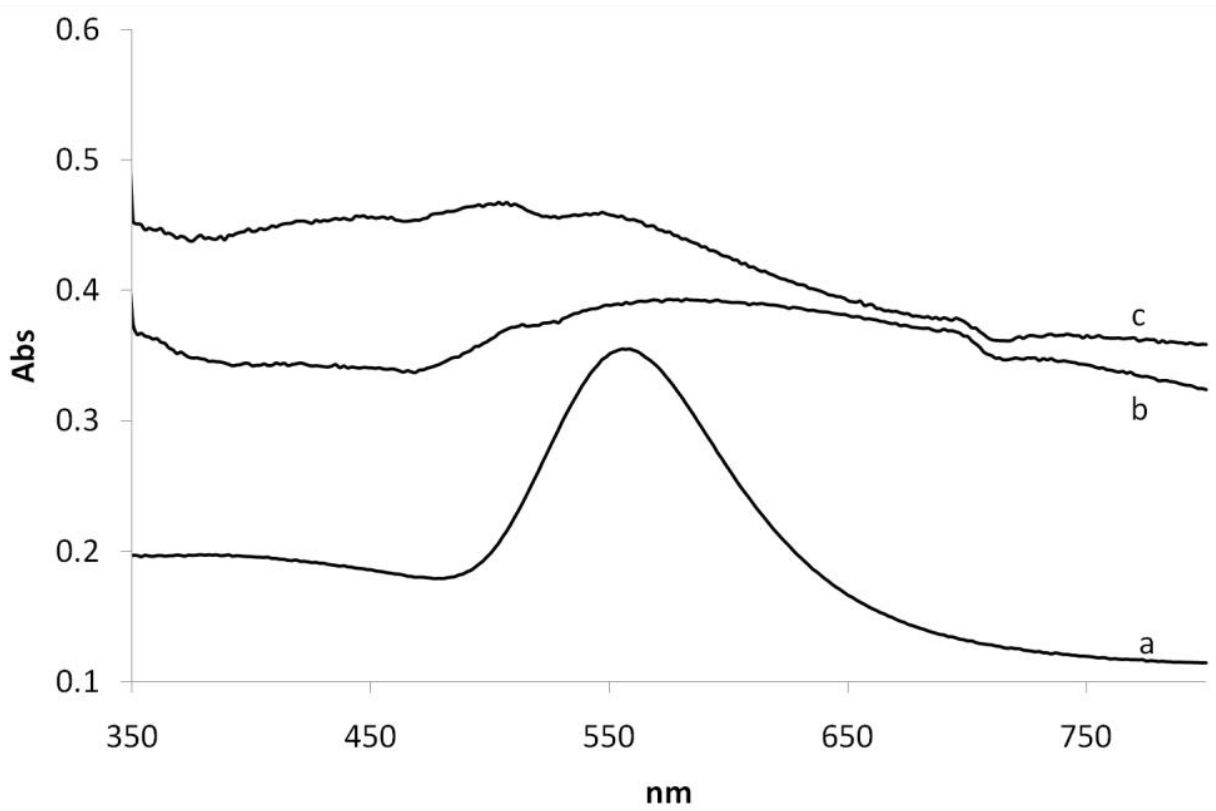

Figure 4.24: Kubelka Munk transformed UV/Vis reflection spectra of a) a gold nanoparticle colloid prepared with $20 \mu \mathrm{L}$ of $10 \mathrm{wt} \% \mathrm{TSC}$, b) a gold nanoparticle-merino wool composite incorporating nanoparticles prepared with $50 \mu \mathrm{L}$ of $10 \mathrm{wt} \%$ TSC and c) $20 \mu \mathrm{L}$ of $10 \mathrm{wt} \% \mathrm{TSC}$. 
The colour of the composites incorporating colloids produced with increasing amounts of TA appeared to be a function of nanoparticle concentration, and did not vary to a great extent. Increasing the amount of TA used in the production of the colloids (from $10 \mu \mathrm{L}$ of $1 \mathrm{wt} \%$ to $50 \mu \mathrm{L}$ of $10 \mathrm{wt} \% \mathrm{TA}$ ) resulted in a higher concentration of nanoparticles of a similar size and shape on the surface of the fibres (Figure 4.25) and corresponded to a slight colour change of the composites from a mirky light pink to purple.
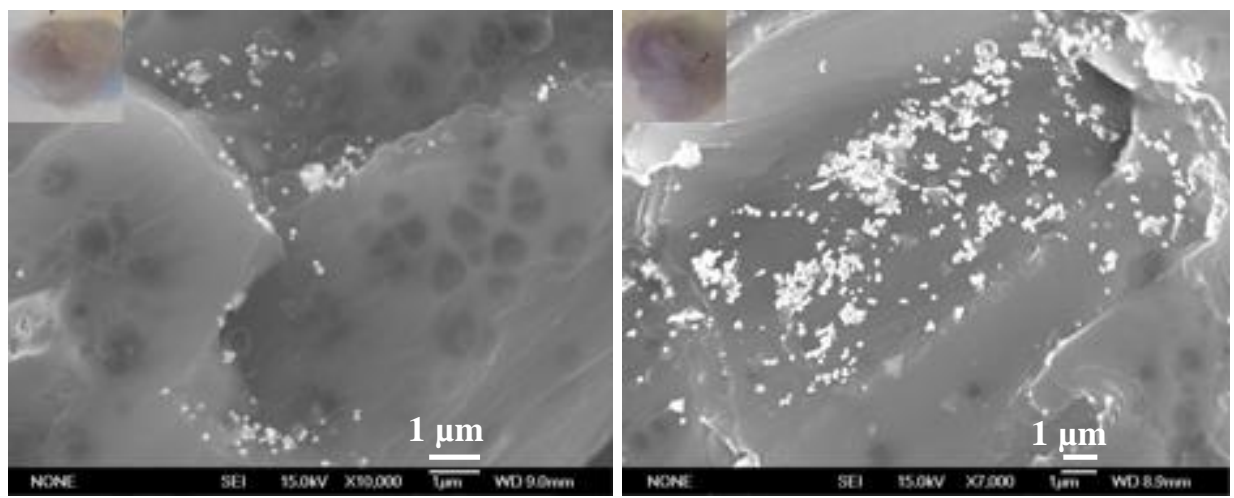

Figure 4.25: SEM micrographs relating the colour of the composites to the size and shape of the nanoparticles on the fibre surface. Left) a gold nanoparticle-merino wool composite incorporating nanoparticles prepared with $10 \mu \mathrm{L}$ of $1 \mathrm{wt} \% \mathrm{TA}$ and right) $50 \mu \mathrm{L}$ of $10 \mathrm{wt} \%$ TA.

This minor colour change was mirrored in the UV/Vis absorption spectra of the composites with a small blue shift of the peaks centred at 500 and $540 \mathrm{~nm}$ (Figure 4.26). The gold in these composites was present as a combination of spherical and triangular nanoparticles, approximately 10-20 and 50-100 $\mathrm{nm}$ in diameter respectively. The broad peaks evident in the UV/Vis absorption spectrum are reflective of the transverse plasmon bands of anisotropic particles and nanospheres, and correspond to the gold triangles and spheres observed in the SEM micrographs of these materials. This range of particle size and shape and hence plasmon resonances would account for the mirky pink to purple/grey colour of the materials. 


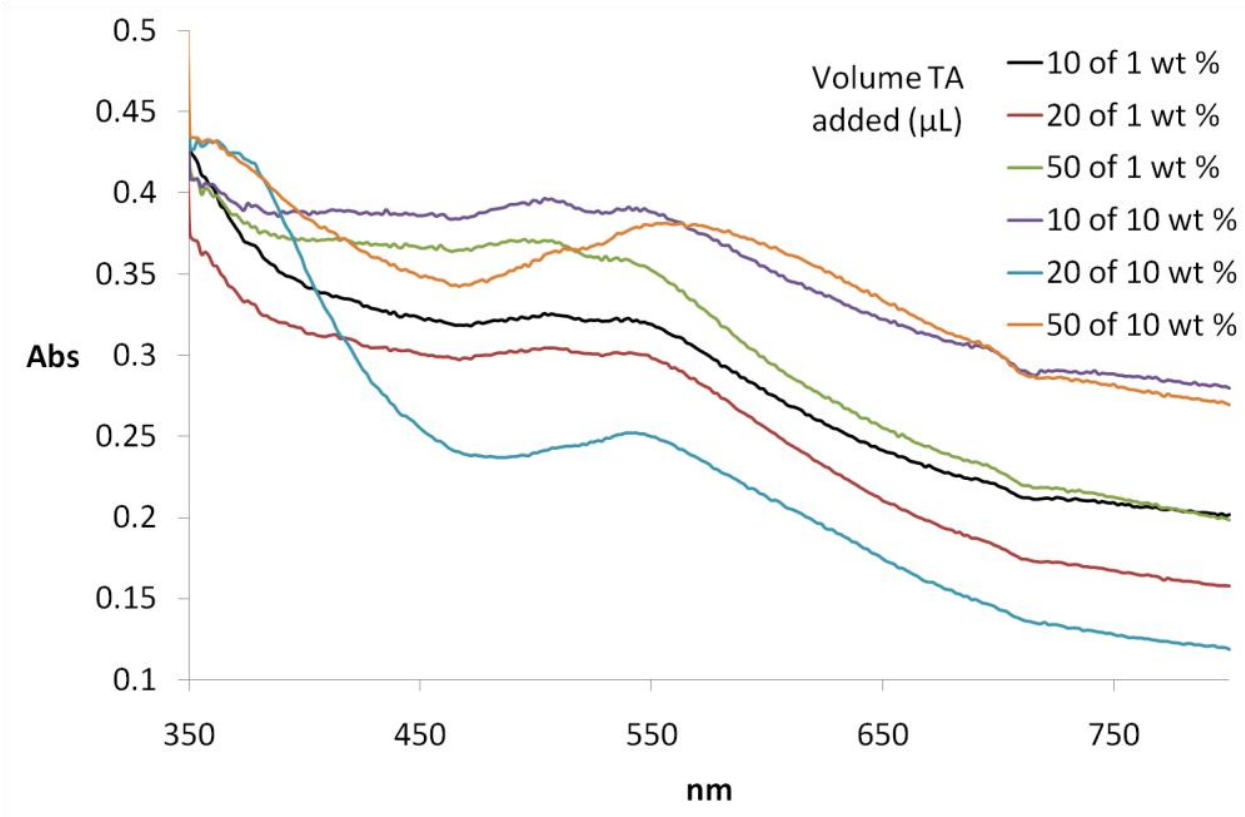

Figure 4.26: Kubelka Munk transformed UV/Vis reflection spectra of gold nanoparticle-merino wool composites incorporating nanoparticles prepared with TA.

The colour of the gold nanoparticle-merino wool composites incorporating TSC or TA reduced and stabilised gold nanoparticles varied from the gold colloids employed in their production (Figure 4.27). The composite materials were generally greyer and darker in colour relative to the colloids. This colour variation is likely due to a number of factors, with the primary reason being the agglomeration of the nanoparticles on the wool fibre surface. Additionally, the volume density of nanoparticles in solution and on the wool fibres (in the colloid and composite respectively) differs, as the nanoparticles are spread over a much larger area in the composites compared to the colloids, and hence have a lower density. The dielectric constant of merino wool and water is also different, and as surface plasmon reasonances and hence colours are influenced by the dielectric function of the nanoparticles surrounding medium, this change in dielectric function may also contribute to the difference in colour between the colloids and composites. 


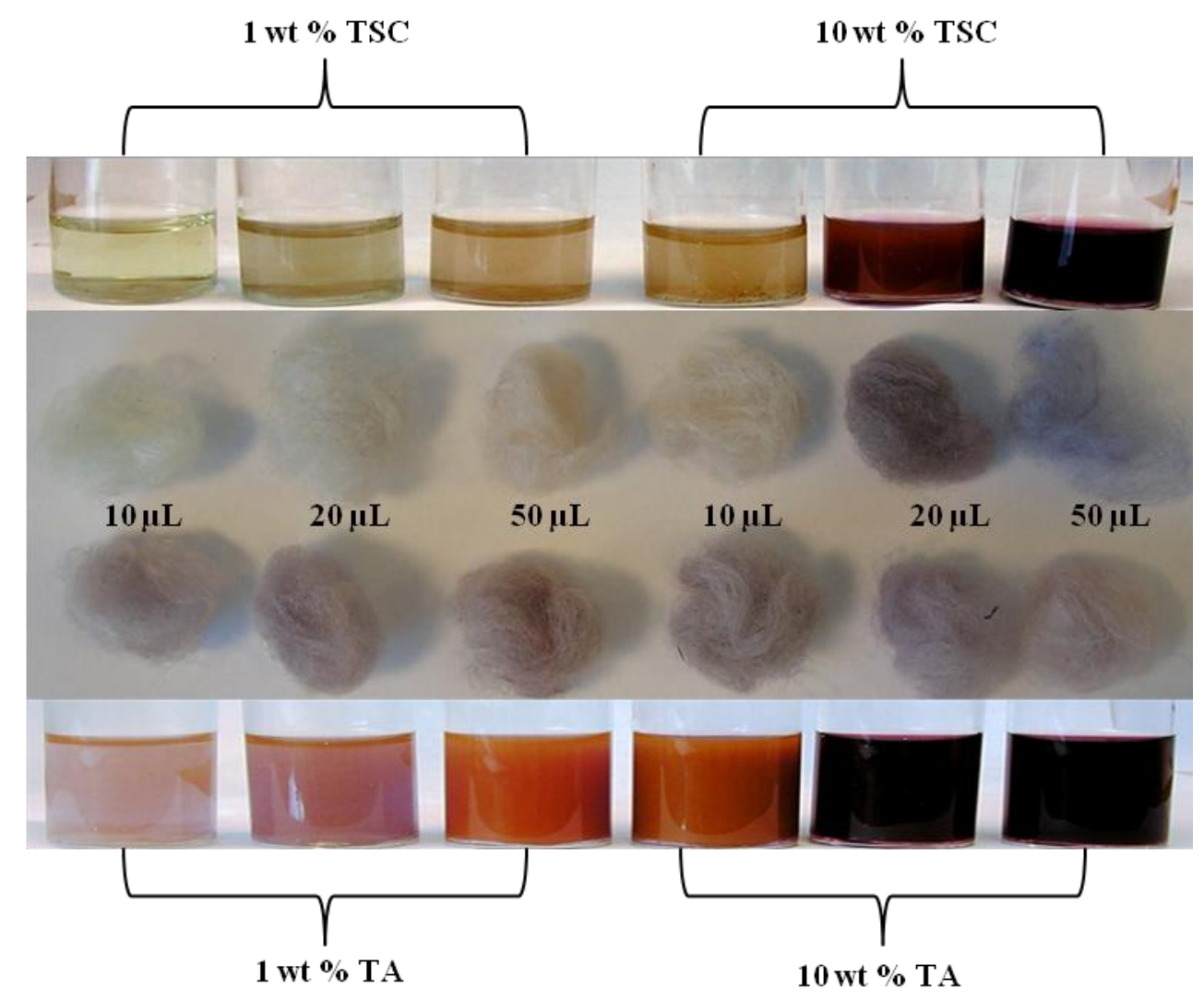

Figure 4.27: Comparison of the TSC and TA reduced and stabilised gold colloids and the gold nanoparticle-merino wool composites made from such materials.

\subsubsection{Confirmation of Gold}

The presence of gold in the gold nanoparticle-merino wool composites was confirmed by both energy dispersive spectroscopy (EDS) and x-ray photoelectron spectroscopy (XPS). EDS confirmed the bright white particles evident on the surface of the gold nanoparticlemerino wool composites incorporating nanoparticles prepared with various amounts of TSC or TA to be gold. The images on the right in Figure 4.28, Figure 4.30, Figure 4.32 and Figure 4.34 show SEM micrographs and corresponding gold EDS maps of the various composites, where high concentrations of gold are depicted as bright white or red areas. Additionally, Figure 4.29, Figure 4.31, Figure 4.33 and Figure 4.35 offer spectral snap shots of the areas under analysis, and substantiate the presence of gold due to the presence of the gold peaks. 

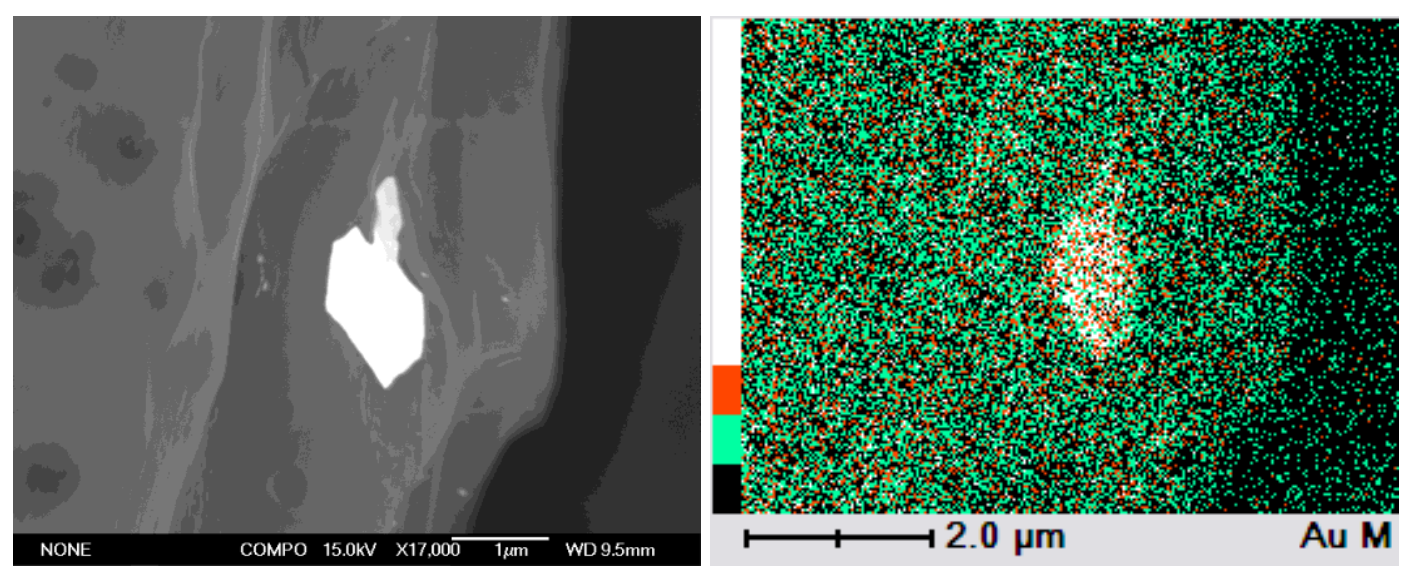

Figure 4.28: Left: an SEM micrograph of a gold nanoparticle-merino wool composite (incorporating nanoparticles prepared with $10 \mu \mathrm{L}$ of $1 \mathrm{wt} \%$ TSC), and right: the corresponding gold EDS map.

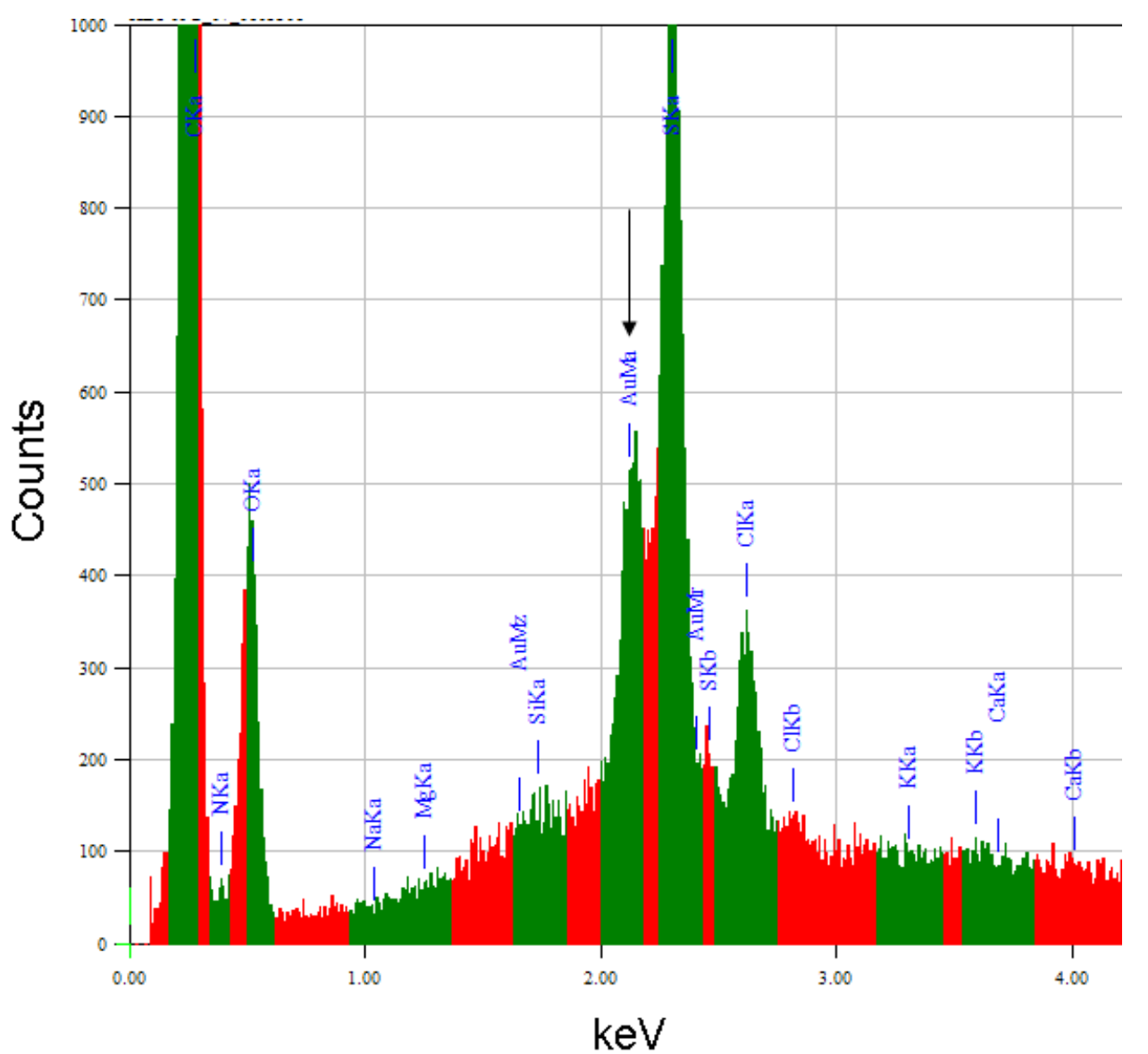

Figure 4.29: EDS spectrum of the gold nanoparticle-merino wool composite shown in Figure 4.28. 

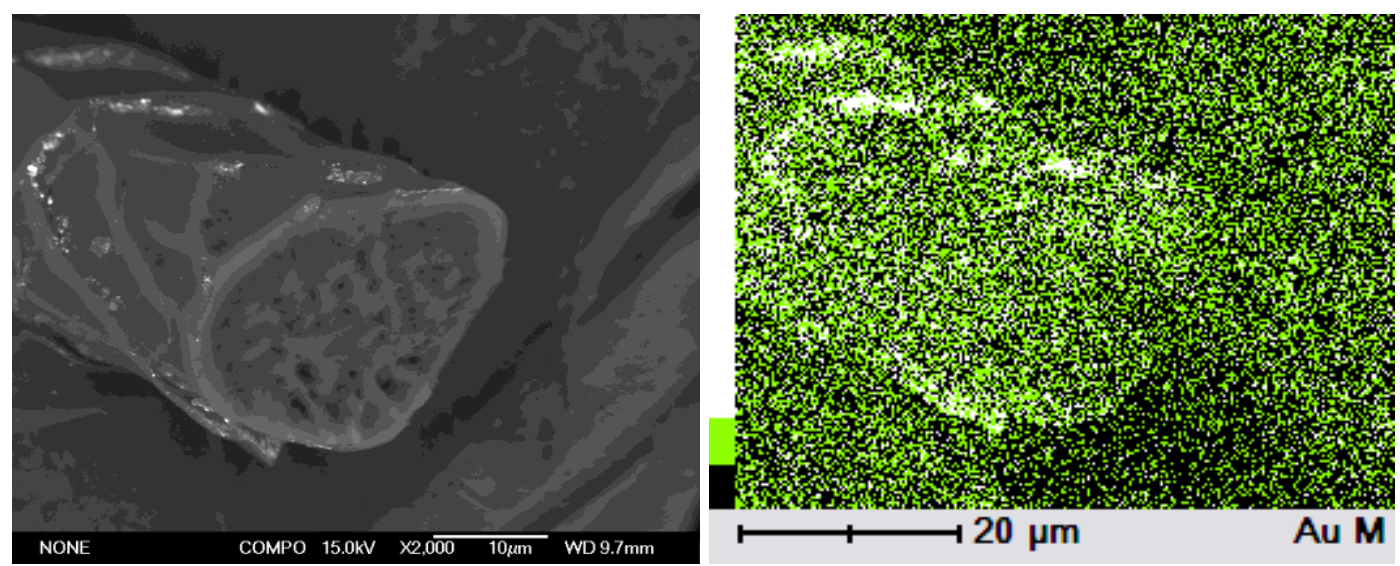

Figure 4.30: Left: an SEM micrograph of a gold nanoparticle-merino wool composite (incorporating nanoparticles prepared with $50 \mu \mathrm{L}$ of $10 \mathrm{wt} \%$ TSC), and right: the corresponding gold EDS map.

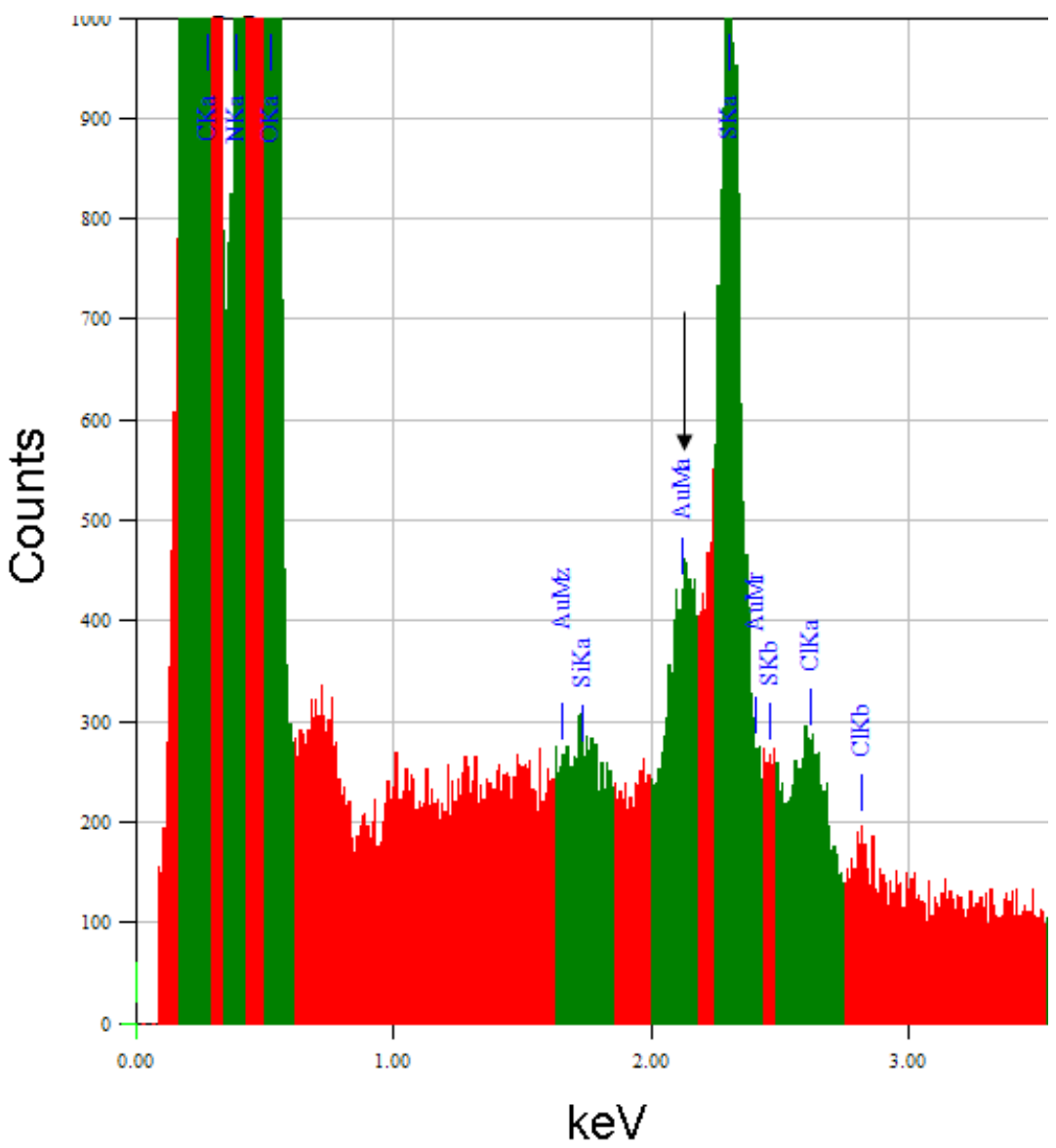

Figure 4.31: EDS spectrum of the gold nanoparticle-merino wool composite shown in Figure 4.30. 

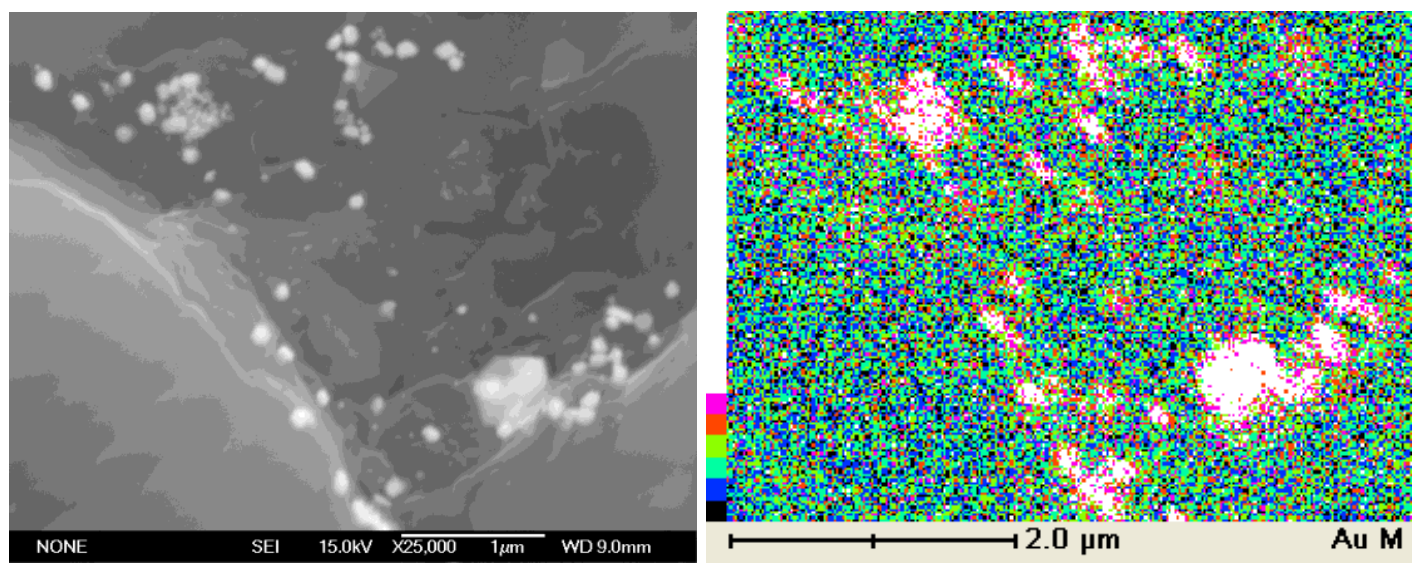

Figure 4.32: Left: an SEM micrograph of a gold nanoparticle-merino wool composite (incorporating nanoparticles prepared with $10 \mu \mathrm{L}$ of $1 \mathrm{wt} \% \mathrm{TA}$ ), and right: the corresponding gold EDS map.

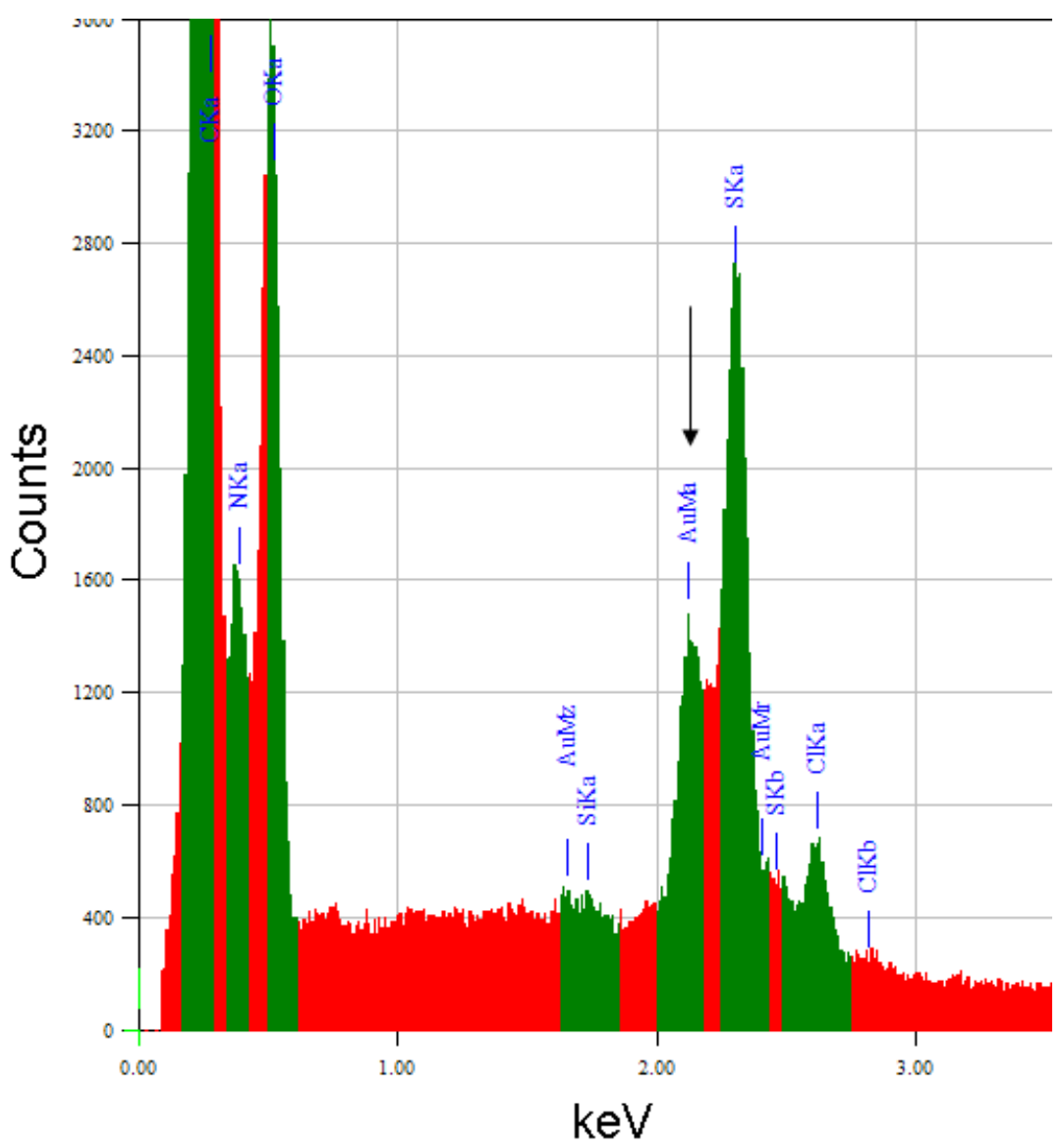

Figure 4.33: EDS spectrum of the gold nanoparticle-merino wool composite shown in Figure 4.32. 

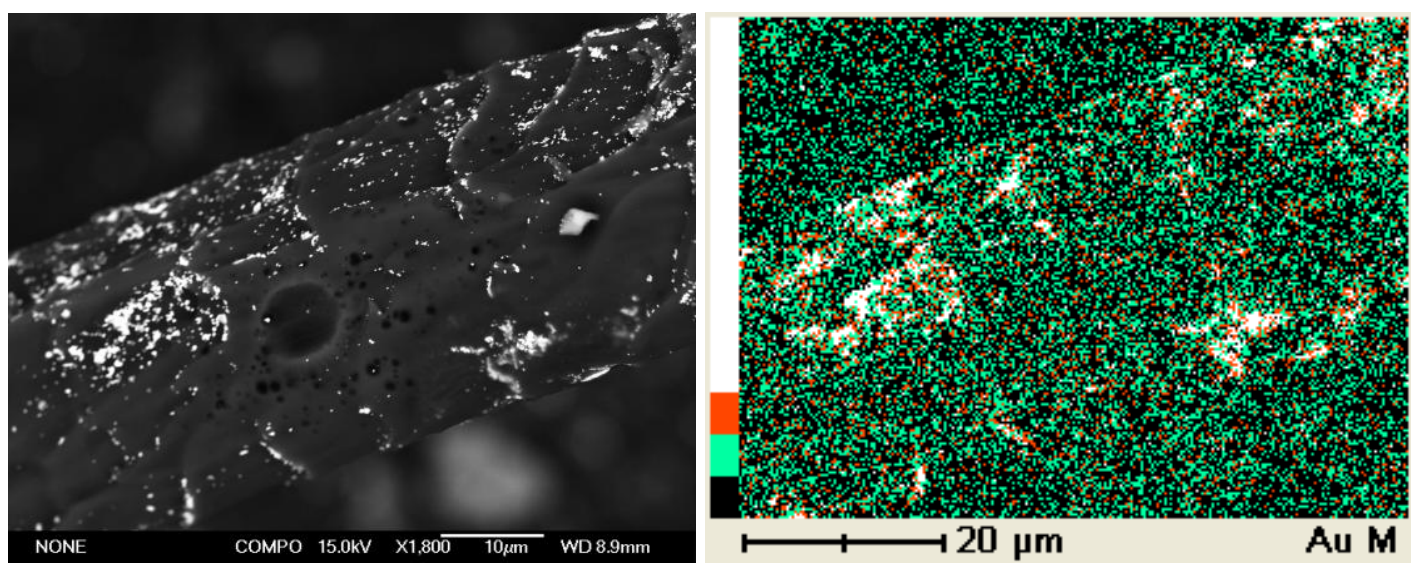

Figure 4.34: Left: an SEM micrograph of a gold nanoparticle-merino wool composite (incorporating nanoparticles prepared with $50 \mu \mathrm{L}$ of $10 \mathrm{wt} \% \mathrm{TA})$, and right: the corresponding gold EDS map.

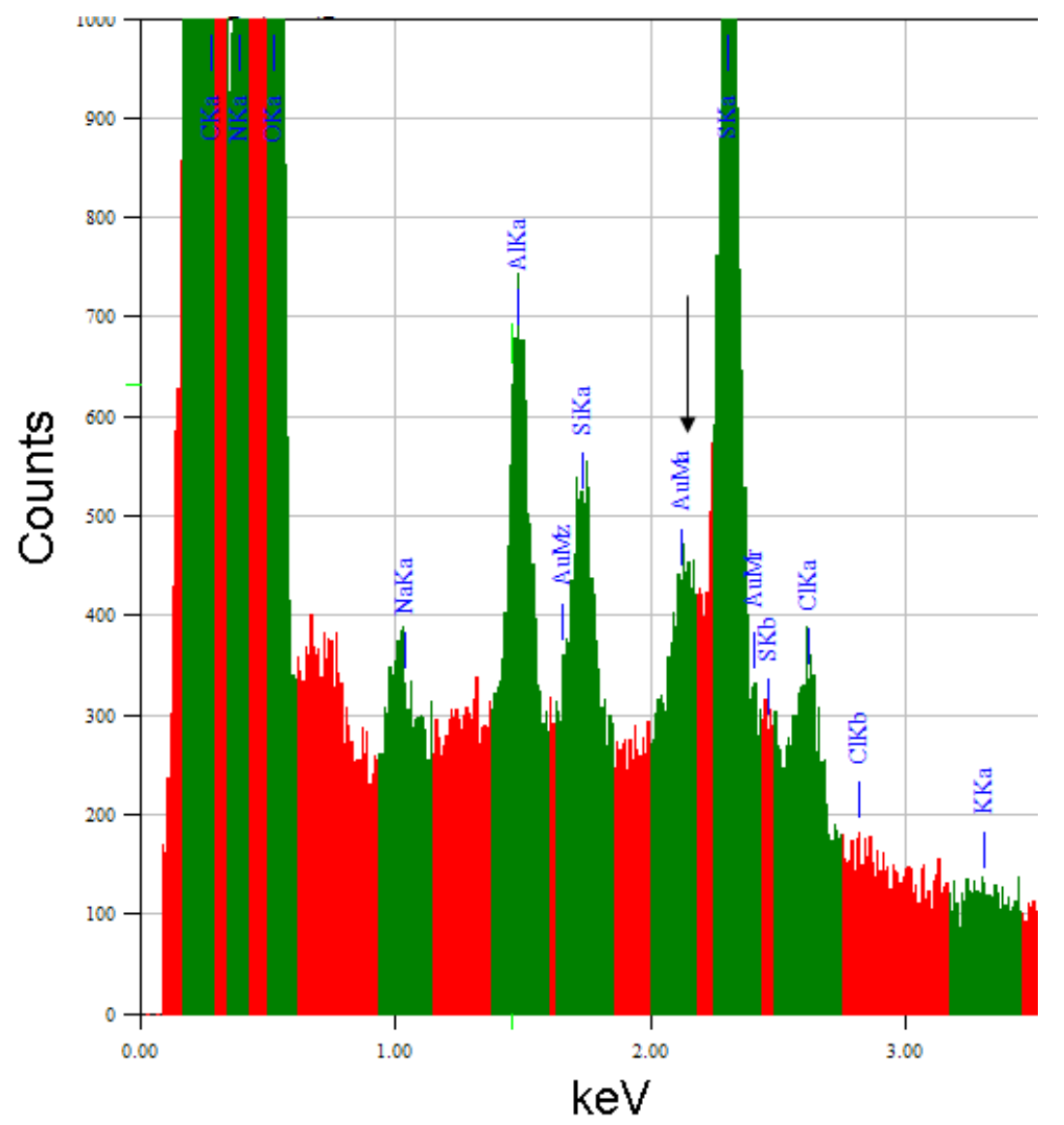

Figure 4.35: EDS spectrum of the gold nanoparticle-merino wool composite shown in Figure 4.34.

XPS, which combines elemental peak areas with relative sensitivity factors (Au 17.12, section 2.3.6) provided quantitative analysis of the elemental composition of the top $10 \mathrm{~nm}$ of the gold nanoparticle-merino wool composites. All composites contained similar amounts of 
gold. Those incorporating nanoparticles prepared with $10 \mu \mathrm{L}$ of 1 wt $\%$ or $50 \mu \mathrm{L}$ of 10 wt $\%$ TSC contained 0.29 or $0.27 \%$ gold respectively, whilst the corresponding materials incorporating TA reduced and stabilised nanoparticles contained 0.29 and $0.36 \%$ gold (Figure 4.36).
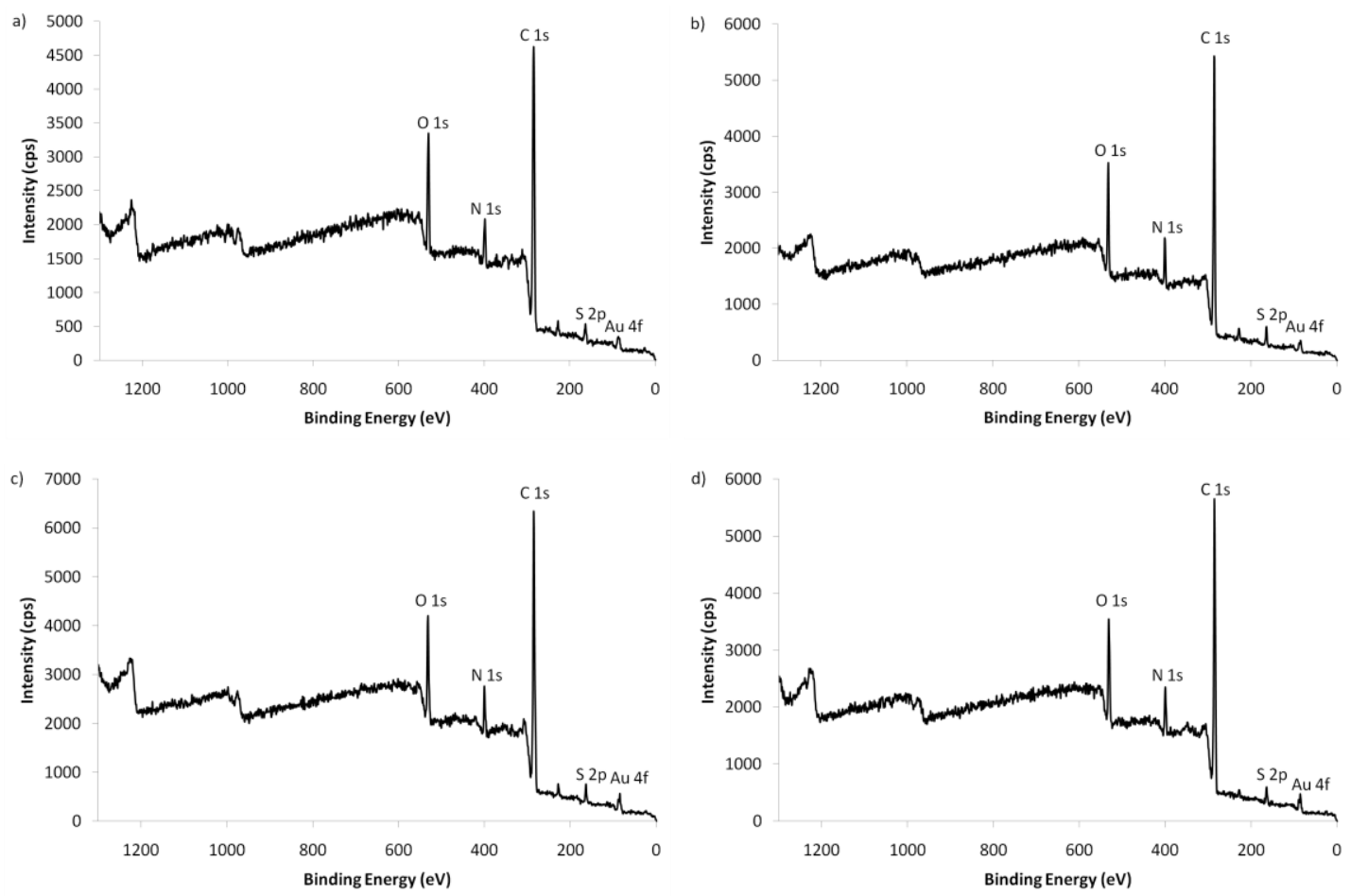

Figure 4.36: Wide XPS scans of gold nanoparticle-merino wool composites incorporating gold nanoparticles prepared with a) $10 \mu \mathrm{L}$ of 1 wt \% TSC, b) $50 \mu \mathrm{L}$ of 10 wt \% TSC, c) $10 \mu \mathrm{L}$ of 1 wt \% TA and d) $50 \mu \mathrm{L}$ of $10 \mathrm{wt} \% \mathrm{TA}$.

Examination of the deconvoluted, high resolution $\mathrm{Au} 4 \mathrm{f}$ spectra of the composites showed the materials incorporating nanoparticles prepared with a higher concentration of reductant to possess a higher percentage of $\mathrm{Au}^{0}$. For example, $13.3 \%$ of the gold in composites incorporating colloids prepared with $10 \mu \mathrm{L}$ of $1 \mathrm{wt} \% \mathrm{TSC}$ was $\mathrm{Au}^{0}$, with the unreduced $\mathrm{Au}^{3+}$ accounting for $29.3 \%$. Increasing the amount of TSC to $50 \mu \mathrm{L}$ of $10 \mathrm{wt} \%$ saw an increase in the amount of $\mathrm{Au}^{0}$, to $27.9 \%$. Similar trends were observed in composites incorporating TA prepared nanoparticles (Table 4.2), however there was a greater amount of $\mathrm{Au}^{0}$ in these materials relative to the analogous TSC composites. This is likely due to the increased reduction strength of TA.[213] The form of the gold in these materials is discussed in greater detail in section 4.1.2.4 below. 
Table 4.2: Au 4f XPS assignments for gold nanoparticle-merino wool composites prepared with 10 or 50 $\mu \mathrm{L}$ of 1 or 10 wt $\%$ TSC or TA.

\begin{tabular}{ccc}
\hline Sample & $\begin{array}{c}\% \mathrm{Au}^{0} \\
\mathbf{1 1 0} \%\end{array}$ & $\begin{array}{c}\% \mathrm{Au}^{3+} \mathbf{\pm} \\
\mathbf{1 0} \%\end{array}$ \\
\hline $\mathbf{1 0} \boldsymbol{\mu L} \mathbf{1}$ wt \% TSC & 13.3 & 29.3 \\
$\mathbf{5 0} \boldsymbol{\mu L ~ 1 0 ~ w t ~ \% ~ T S C ~}$ & 27.9 & 16.2 \\
$\mathbf{1 0} \boldsymbol{\mu L} \mathbf{1}$ wt \% TA & 19.9 & 17.7 \\
$\mathbf{5 0} \boldsymbol{\mu L ~ 1 0 ~ w t ~ \% ~ T A ~}$ & 21.1 & 8.2 \\
\hline
\end{tabular}

\subsubsection{Bonding of Nanoparticles to Merino Wool Fibres}

As described in section 1.2.2.1.2, keratin is the main constituent of merino wool fibres. As such merino wool possess a multitude of functional groups to which the TSC and TA reduced and stabilised gold nanoparticles could potentially bind, the most likely being sulfur (thiol, disulfide), nitrogen (amine) or carboxylate containing groups. To investigate the bonding between the gold nanoparticles and merino wool fibres, $\mathrm{x}$-ray photoelectron spectroscopy (XPS) studies were undertaken.

Comparing the high resolution XPS spectra of merino wool and gold nanoparticle-merino wool composites incorporating colloids prepared with various amount of TSC suggested the sulfur and nitrogen containing groups in wool displaced a large proportion of TSC encapsulating the gold nanoparticles, with bonding of the nanoparticles to the fibres occurring largely between the nitrogen and sulfur atoms of wool, and gold, and to a lesser extent through the TSC bi-layer surrounding the nanoparticles. There have been several reports in the scientific literature of numerous groups, including sulfur containing groups displacing citrate surrounding gold nanoparticles.[104, 214-216] Indeed, TSC is often used as a dual reductant/stabiliser when a loose shell of ligands is required around a gold core in order to prepare valuable gold nanoparticle based materials.[104]

The direct $\mathrm{C}-\mathrm{N}-\mathrm{Au}$ bond was evident in the high resolution $\mathrm{C} 1 \mathrm{~s}$ spectrum of a composite incorporating nanoparticles prepared with $10 \mu \mathrm{L}$ of 1 wt $\%$ TSC. This spectrum showed a 
new peak centred at $283.29 \mathrm{eV}$, which was absent in merino alone (Figure $4.37 \mathrm{a}$ and $\mathrm{b}$ respectively). This peak has been reported to be representative of a $\mathrm{C}-\mathrm{N}-\mathrm{Au}$ bond.[201] SEM showed the gold in composites incorporating nanoparticles prepared with an increased amount of TSC to be a lot smaller. As a result, these particles would have much larger surface areas, and as such they would be expected to form more Au-N bonds with the wool. However examination of the $\mathrm{C} 1 \mathrm{~s}$ spectra of such a composite saw a slight decrease in the $\mathrm{C}$ $\mathrm{N}-\mathrm{Au}$ peak area, from $22.3 \%$ to $17.2 \%$ (Figure $4.37 \mathrm{c}, \mathrm{d}$ ). This decrease is likely attributable to the increased amount of TSC surrounding the nanoparticles in these materials, resulting in the incomplete displacement of TSC, suggesting that the wool may bond to the gold directly and also through the TSC bi-layer surrounding the particles.
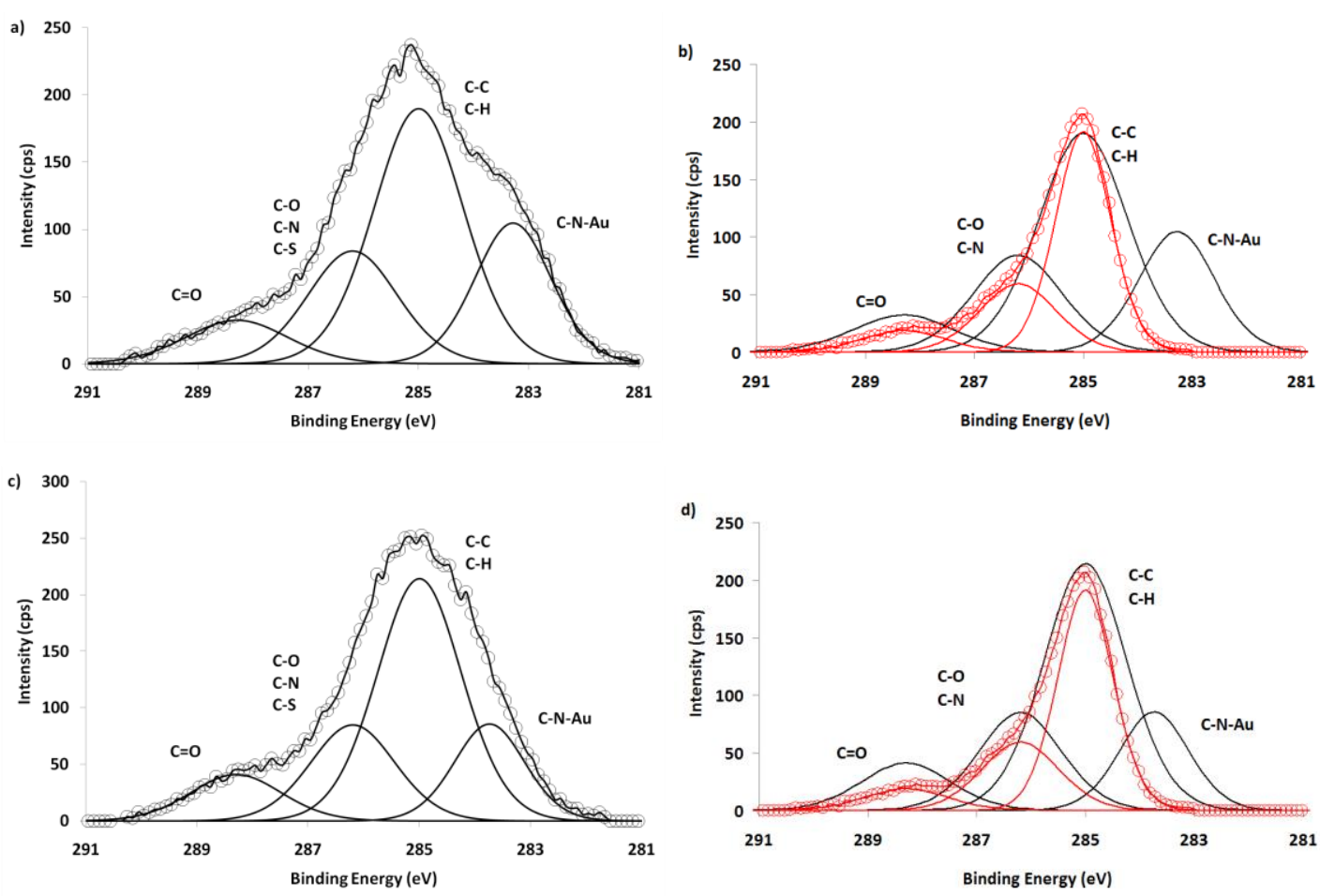

Figure 4.37: High resolution C 1s XPS spectra of gold nanoparticle-merino wool composites incorporating colloids prepared with a) $10 \mu \mathrm{L}$ of 1 wt \% TSC and c) $50 \mu \mathrm{L}$ of $10 \mathrm{wt} \%$ TSC. b) and d) show the overlay of the $\mathrm{C} 1 \mathrm{~s}$ spectra of merino (in red).

The direct $\mathrm{N}-\mathrm{Au}$ bond was also illustrated in the $\mathrm{N}$ 1s spectra of the composite materials, with the appearance of a peak centred at approximately $398.5 \mathrm{eV}$ (Figure 4.38). As in the C 1s spectra, the N-Au peak area was larger in composites incorporating colloids prepared with 
lower amounts of TSC (12.1 and $10.4 \%$ in composites incorporating nanoparticles prepared with $10 \mu \mathrm{L}$ of 1 wt $\%$ or $50 \mu \mathrm{L}$ of $10 \mathrm{wt} \%$ TSC respectively). Additionally, analysis of the high resolution $S 2 p$ sprectrum of the composites incorporating nanoparticles prepared with TSC showed that incorporation of the nanoparticles saw a decrease in area of the $3 / 2$ and $1 / 2$ peaks representing the main sulphur containing groups of wool (cystine and cysteine) and a corresponding increase in peak area of cysteic acid $\left(-\mathrm{SO}_{3}{ }^{-}\right)$(the oxidised form of cystine). This suggests that once displaced from the gold nanoparticles, any oxidised TSC may oxidise the merino fibres. The S $2 p$ spectra of the composites also revealed the bonding between the gold nanoparticles and merino wool fibres not to be solely via a Au-N bond, as these spectra exhibited clear Au-S interactions, evidenced by the $S_{3 / 2}$ peak centred at $162.00 \mathrm{eV}$ (Figure 4.39).[217]
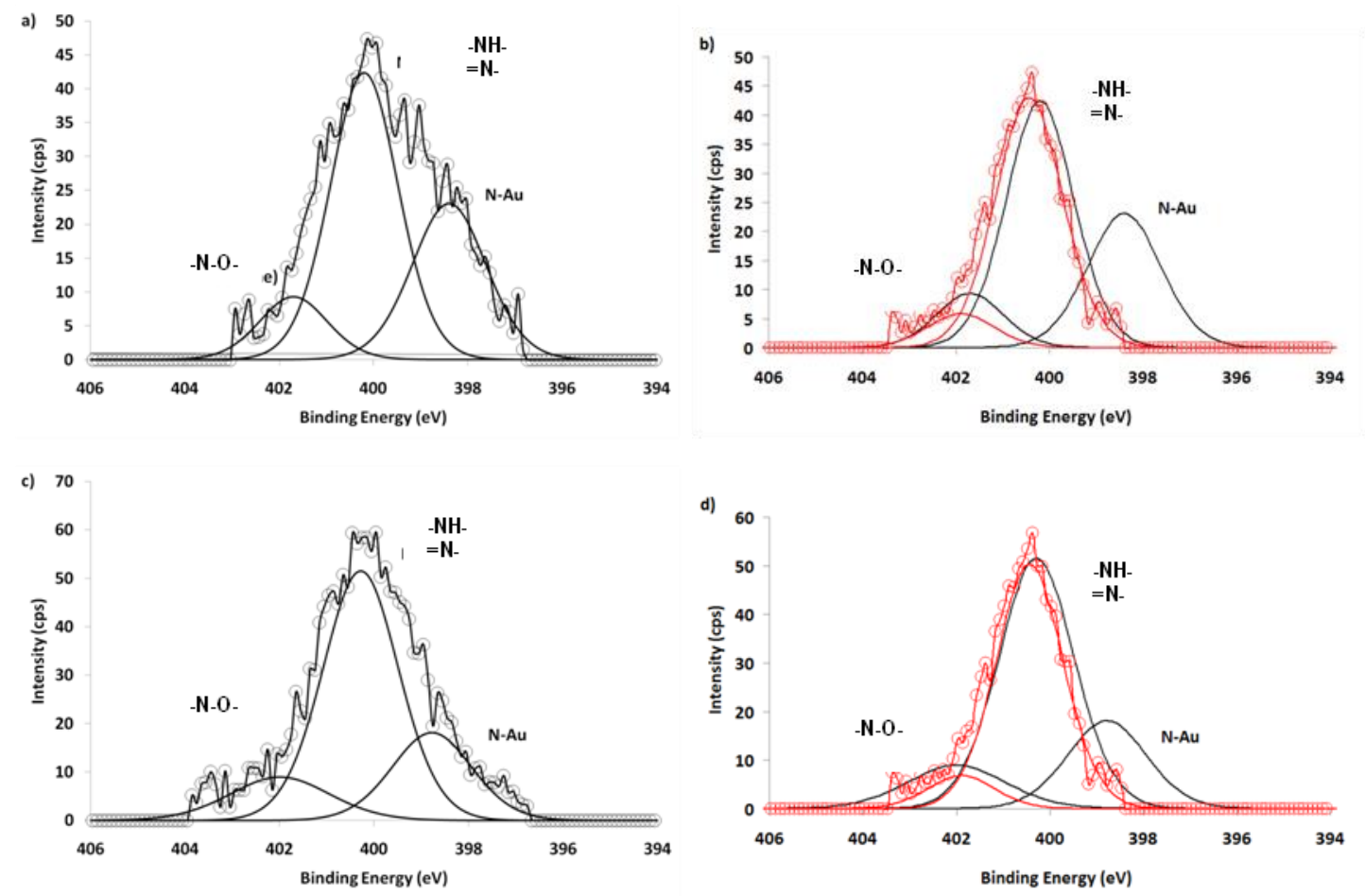

Figure 4.38: High resolution N 1s XPS spectra of gold nanoparticle-merino wool composites incorporating colloids prepared with $10 \mu \mathrm{L}$ of 1 wt \% TSC (a-b) or $50 \mu \mathrm{L}$ of 10 wt \% TSC (c-d). Figures (b) and (c) show an overlay of the corresponding $\mathrm{N} 1 \mathrm{~s}$ spectra of merino wool (in red). 

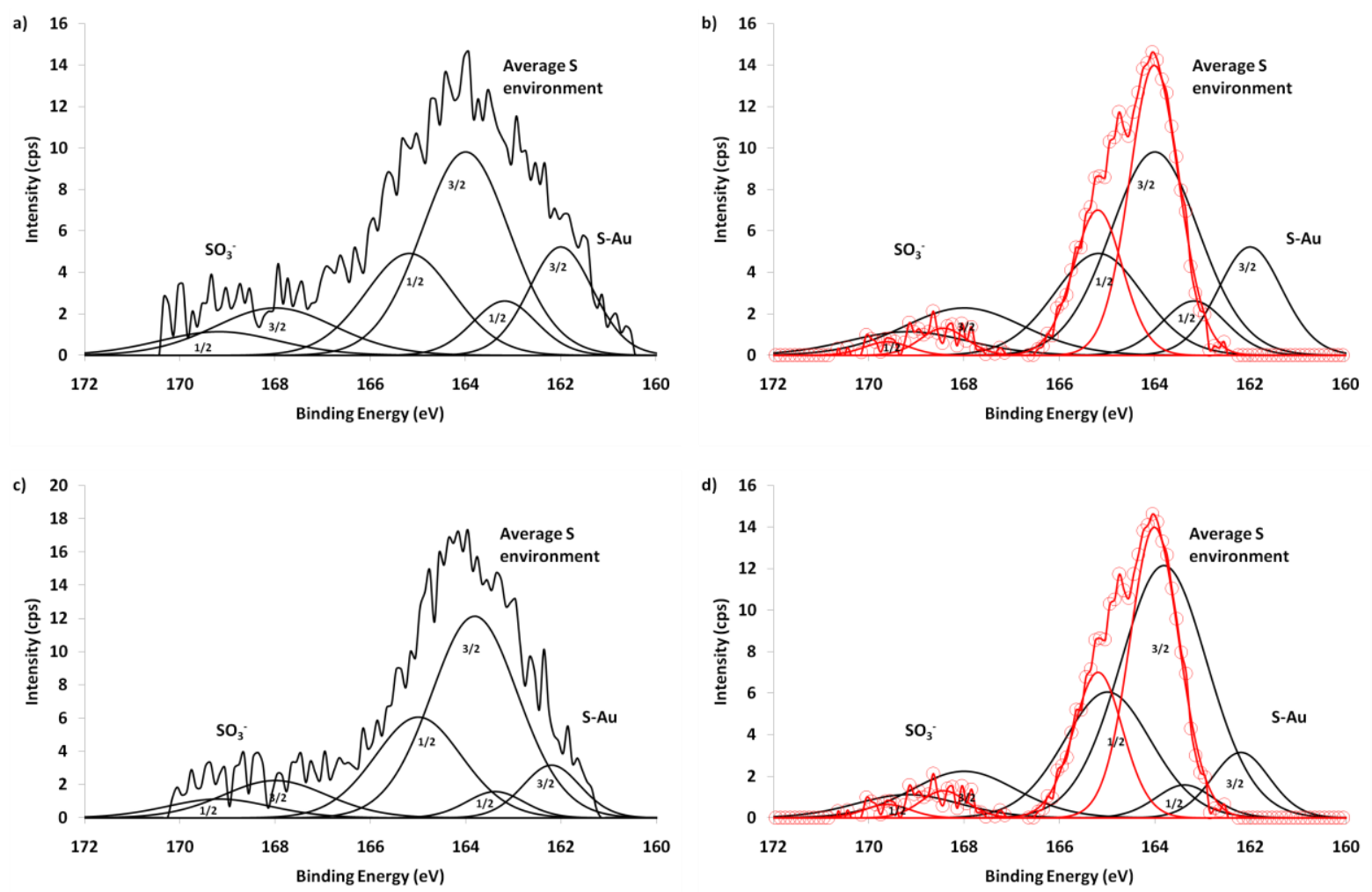

Figure 4.39: High resolution S 2p XPS spectra of gold nanoparticle-merino wool composites incorporating colloids prepared with $10 \mu \mathrm{L}$ of 1 wt \% TSC (a) or $50 \mu \mathrm{L}$ of 10 wt \% TSC (c). Figures (b) and (c) show an overlay of the corresponding $S 2$ p spectra of merino wool (in red).

The high resolution $\mathrm{O} 1 \mathrm{~s}$ spectrum of the composites also shows a new peak that was absent in merino and merino-TSC. This peak is centred at approximately $530 \mathrm{eV}$, with literature attributing it to various gold oxide, gold hydroxide or carboxylic species (Figure $4.40 \mathrm{c}$ and d).[218, 219] In this case however, it is likely to be representative of a Au-O bond resulting from TSC interacting with unreduced $\mathrm{Au}^{3+}$ ions present on the surface of the gold nanoparticles. To verify this proposed assignment, it would be interesting to study the XPS spectra of gold nanoparticles prepared and stabilised by TSC, which is work that will be undertaken in the future. 

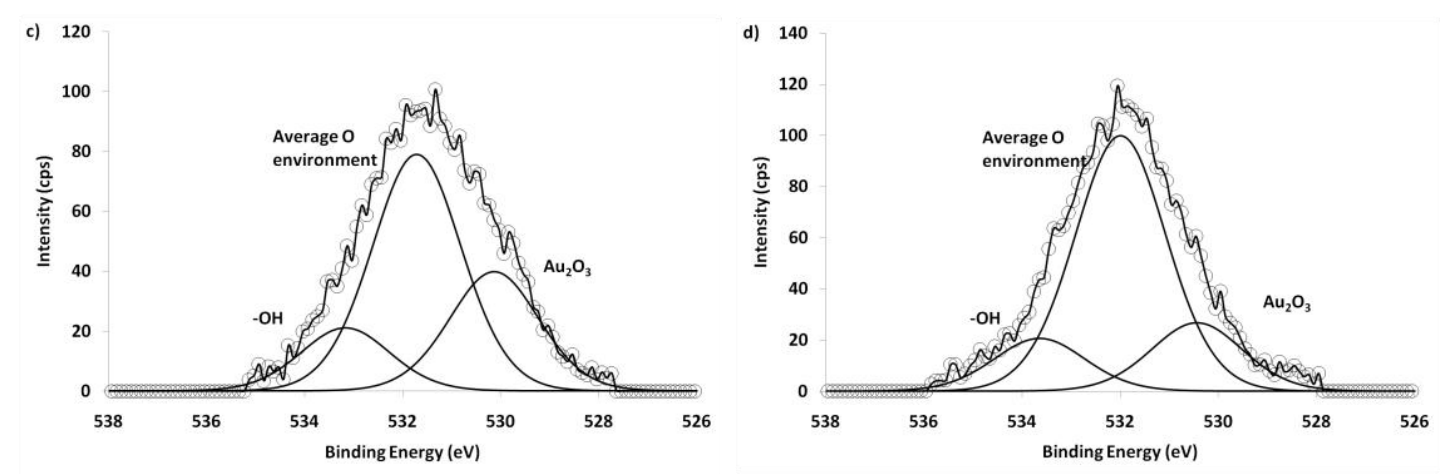

Figure 4.40: High resolution $O$ 1s (c, d) XPS spectra of gold nanoparticle-merino wool composites incorporating colloids prepared with (a, c) $10 \mu \mathrm{L}$ of $1 \mathrm{wt} \%$ TSC and (b d) $50 \mu \mathrm{L}$ of $10 \mathrm{wt} \%$ TSC.

Examination of the deconvoluted, high resolution $\mathrm{Au} 4 \mathrm{f}$ spectra of a gold nanoparticlemerino wool composite incorporating nanoparticles prepared with TSC confirms the bonding between the gold nanoparticles and merino wool to be through the nitrogen and sulfur atoms of wool. The Au $4 \mathrm{f}$ spectra of a composite incorporating a colloid prepared with $10 \mu \mathrm{L}$ of 1 wt $\%$ TSC showed the asymmetric $7 / 2$ and $5 / 2$ peaks of zero valent gold at 82.80 and 86.40 $\mathrm{eV}$ respectively (Figure 4.41 a). These peaks are shifted to lower binding energies by approximately $0.6 \mathrm{eV}$ relative to bulk gold.[220] This downfield shift is believed to be due to nitrogen of the amino groups in wool binding to the gold, imparting a larger negative charge at the gold surface, in turn leading to a greater screening of the gold and hence a lower binding energy. Similar effects have been reported in the bonding of polyethylene imine capped gold nanoparticles to wool [201] and in calcium screening of silicon in calcium silicates.[221] In addition to the Au-N peaks, peaks indicative of a Au-S bond were apparent at 84.21 and $87.81 \mathrm{eV}$. A final set of peaks were observed at 85.80 and $89.40 \mathrm{eV}$. These have been reported to be representative of the $7 / 2$ and $5 / 2$ peaks of $\mathrm{Au}^{3+}$.[201, 218] Incorporating colloids prepared with a greater amount of TSC (50 $\mu \mathrm{L}$ of $10 \mathrm{wt} \%)$ saw a decrease in the relative area of the $\mathrm{Au}^{3+}$ peaks (Figure $4.41 \mathrm{~b}$ ). Relative to bulk gold, whose peaks have full widths at half maximum of approximately $0.8 \mathrm{eV}$, the full width at half maximum of these peaks is quite large, approximately $1.6 \mathrm{eV}$. This is reflective of the variability in the bonding environment of the gold atoms in the nanoparticles. 

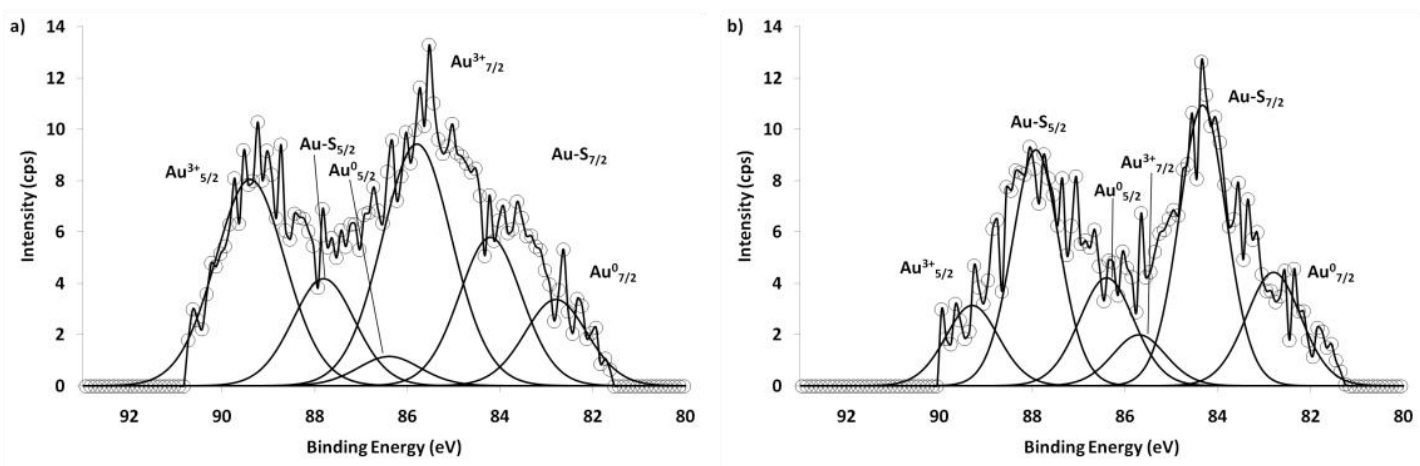

Figure 4.41: High resolution Au 4f XPS spectra of gold nanoparticle-merino wool composites incorporating colloids prepared with a) $10 \mu \mathrm{L}$ of $1 \mathrm{wt} \%$ TSC and b) $50 \mu \mathrm{L}$ of $10 \mathrm{wt} \%$ TSC.

It is likely that the nanoparticles prepared with various amount of TSC bind to the wool via both sulfur and nitrogen atoms, rather than simply through sulfur atoms, which is the case in the gold nanoparticle-merino wool composites prepared through utilisation of the redox active nature of merino (section 5.5), as a result of the surface charge of the gold nanoparticles. The pKa values of the carboxylate groups of TSC are 2.90, 4.35 and $5.65,[164]$ therefore under the reaction conditions employed ( $\mathrm{pH}$ of 3), the TSC capped nanoparticles would possess a net negative charge. Due to the presence of both amine and carboxylic acid groups, wool behaves in an amphoteric manner, with an isoelectric point of approximately 5 (scheme (4.3)).[222] Thus at pH 3 it would have a net positive charge, due to protonated amine and carboxylic groups.

$$
(\mathrm{pH}<5) \mathrm{H}_{3} \mathrm{~N}^{+}-\mathrm{COOH} \leftrightarrow(\mathrm{pH} \approx 5) \mathrm{H}_{2} \mathrm{~N}-\mathrm{COOH} \leftrightarrow \mathrm{H}_{2} \mathrm{~N}-\mathrm{COO}^{-}(\mathrm{pH}>5)
$$

Therefore it is likely that the negatively charged gold nanoparticles would initially be attracted to the positively charged amine groups, with bonding occurring either through this electrostatic interaction between the wool and surrounding TSC, or directly via N-Au and SAu bonds, following displacement of TSC by N and nearby $\mathrm{S}$ atoms. 
Table 4.3: XPS assignments for merino wool and gold nanoparticle-merino wool composites incorporating nanoparticles prepared with TSC.

\begin{tabular}{|c|c|c|c|c|}
\hline \multirow{4}{*}{ C 1s } & \multirow[b]{4}{*}{$\mathrm{C}-\mathrm{C}, \mathrm{C}-\mathrm{H}$} & \multirow[b]{2}{*}{ Merino Wool } & \multicolumn{2}{|c|}{ Composite Materials } \\
\hline & & & $10 \mu \mathrm{L} 1 \mathrm{w} \%$ & $50 \mu \mathrm{L} 10 \mathrm{w} \%$ \\
\hline & & \multicolumn{3}{|c|}{ Binding Energy (eV $\pm 0.2 \mathrm{eV}$ ) } \\
\hline & & $285.00(63 \%)$ & $285.00(48 \%)$ & $285.00(52 \%)$ \\
\hline & C-O, C-N, C-S & $286.20(27 \%)$ & $286.20(21 \%)$ & $286.20(21 \%)$ \\
\hline & $\mathrm{C}=\mathrm{O}$ & 288.30 (10 \%) & 288.30 (9 \%) & $288.30(11 \%)$ \\
\hline & $\mathrm{C}-\mathrm{N}-\mathrm{Au}$ & - & 283.29 (22 \%) & $283.74(16 \%)$ \\
\hline \multirow[t]{3}{*}{ N 1s } & $\mathrm{N}-\mathrm{H},=\mathrm{N}-$ & 400.43 (88 \%) & $400.20(51 \%)$ & $400.27(63 \%)$ \\
\hline & $-\mathrm{N}-\mathrm{O}-$ & 401.90 (12 \%) & 401.70 (12 \%) & 402.90 (14\%) \\
\hline & $\mathrm{N}-\mathrm{Au}$ & - & $398.40(37 \%)$ & $398.55(23 \%)$ \\
\hline \multirow[t]{3}{*}{$01 \mathrm{~s}$} & $\begin{array}{l}\text { Average } 0 \\
\text { environment }\end{array}$ & $532.14(86 \%)$ & $531.72(56 \%)$ & $532.02(68 \%)$ \\
\hline & $-\mathrm{OH}$ & 533.5 (14 \%) & $533.18(16 \%)$ & $534.06(14 \%)$ \\
\hline & O-Au & - & $530.14(28 \%)$ & $530.42(18 \%)$ \\
\hline \multirow[t]{6}{*}{ S 2p } & $\begin{array}{l}\text { Average } S \\
\text { environment } S_{3 / 2}\end{array}$ & $164.02(62 \%)$ & $164.00(36 \%)$ & $163.81(45 \%)$ \\
\hline & $\begin{array}{l}\text { Average } S \\
\text { environment } S_{1 / 2}\end{array}$ & $165.20(31 \%)$ & $165.20(18 \%)$ & $165.00(22 \%)$ \\
\hline & $\mathrm{SO}_{33 / 2}^{-}$ & $168.44(5 \%)$ & $168.00(11 \%)$ & $168.00(11 \%)$ \\
\hline & $\mathrm{SO}_{31 / 2}^{-}$ & 169.62 (2 \%) & $169.18(9 \%)$ & 169.18 (8 \%) \\
\hline & $\mathrm{S}-\mathrm{Au} \mathrm{u}_{3 / 2}$ & - & $162.00(14 \%)$ & $162.20(8 \%)$ \\
\hline & $\mathrm{S}-\mathrm{Au}_{3 / 2}$ & - & $163.18(12 \%)$ & $163.38(6 \%)$ \\
\hline \multirow[t]{6}{*}{ Au $4 f$} & $A u^{0} 7 / 2$ & - & $82.8(11 \%)$ & 82.80 (14 \%) \\
\hline & $A u-S_{7 / 2}$ & - & 84.2 (17\%) & 84.32 (30 \%) \\
\hline & $\mathrm{Au}^{3+} 7 / 2$ & - & 85.80 (31\%) & 85.70 (10 \%) \\
\hline & $A u_{5 / 2}^{0}$ & - & 86.4 (3 \%) & 86.40 (14\%) \\
\hline & $A u-S_{5 / 2}$ & - & 87.81 (12 \%) & $87.93(26 \%)$ \\
\hline & $\mathrm{Au}^{3+}{ }_{5 / 2}$ & - & $89.40(26 \%)$ & 89.30 (6 \%) \\
\hline
\end{tabular}

The bonding between nanoparticles prepared with TA and merino wool fibres was similar to that of the TSC colloids. The XPS spectra showing these bonding interactions are provided in Figure 4.42, Figure 4.43, Figure 4.44 and Table 4.5 below. The sulfur and nitrogen atoms of wool appeared to displace the bi-layer of TA encapsulating the nanoparticles, bonding 
directly to the gold itself via N-Au and S-Au bonds. Comparing the area of the peaks representing direct $\mathrm{N}-\mathrm{Au}$ and $\mathrm{S}-\mathrm{Au}$ bonds (seen in the $\mathrm{C} 1 \mathrm{~s}, \mathrm{~N} 1 \mathrm{~s}$ and $\mathrm{S} 2 \mathrm{p}$ spectra) saw a slight increase in area of all of these peaks upon incorporation of nanoparticles prepared with greater amounts of TA (Figure 4.42, Figure 4.43, Figure 4.44, Table 4.4). The opposite was seen in the TSC systems. In both systems increasing the amount of reductant (TSC or TA) used in the production of the nanoparticles resulted in an increased amount of gold nanoparticles present on the wool, which theoretically should result in an increased number of bonds between the wool and gold nanoparticles. However as discussed above, with the TSC systems this was not the case, this was attributed to an electrostatic affinity of the wool for the TSC surrounding the gold nanoparticles. The pKa of TA is approximately 10,[223] therefore under the reaction conditions employed $(\mathrm{pH} 3)$ the TA would be neutral and as such an electrostatic interaction between the wool and TA surrounding the gold nanoparticles would not exist.
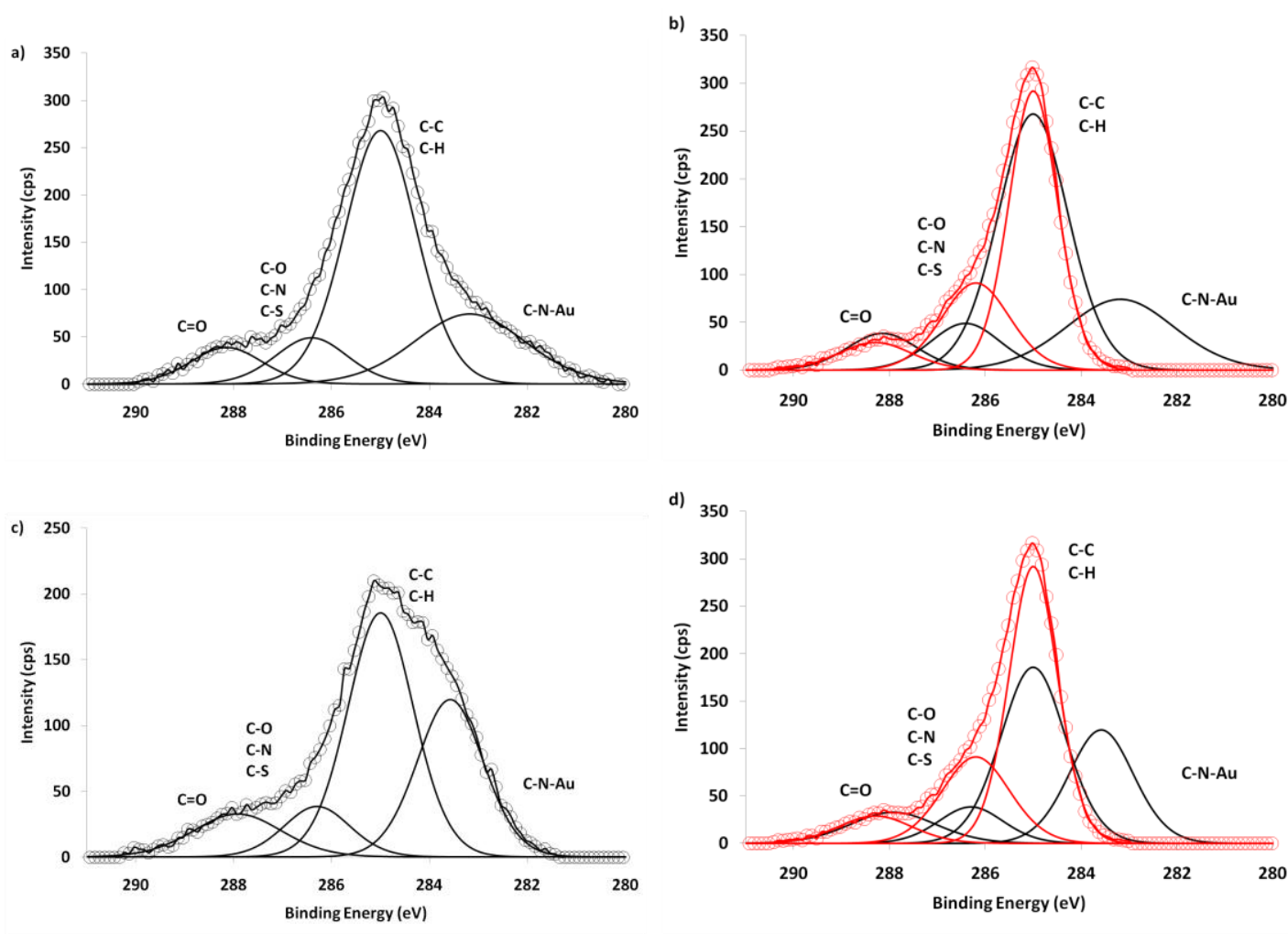

Figure 4.42: High resolution $C$ 1s XPS spectra of gold nanoparticle-merino wool composites incorporating colloids prepared with (a) $10 \mu \mathrm{L}$ of $1 \mathrm{wt} \% \mathrm{TA}$ and (c) $50 \mu \mathrm{L}$ of $10 \mathrm{wt} \% \mathrm{TA}$. Figures (b) and (d) show an overlay of the corresponding $\mathrm{C}$ 1s spectra of merino wool (in red). 
a)

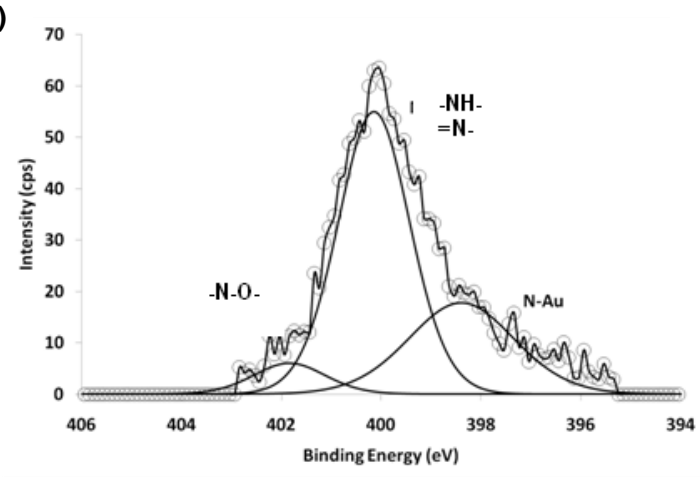

$\circ$
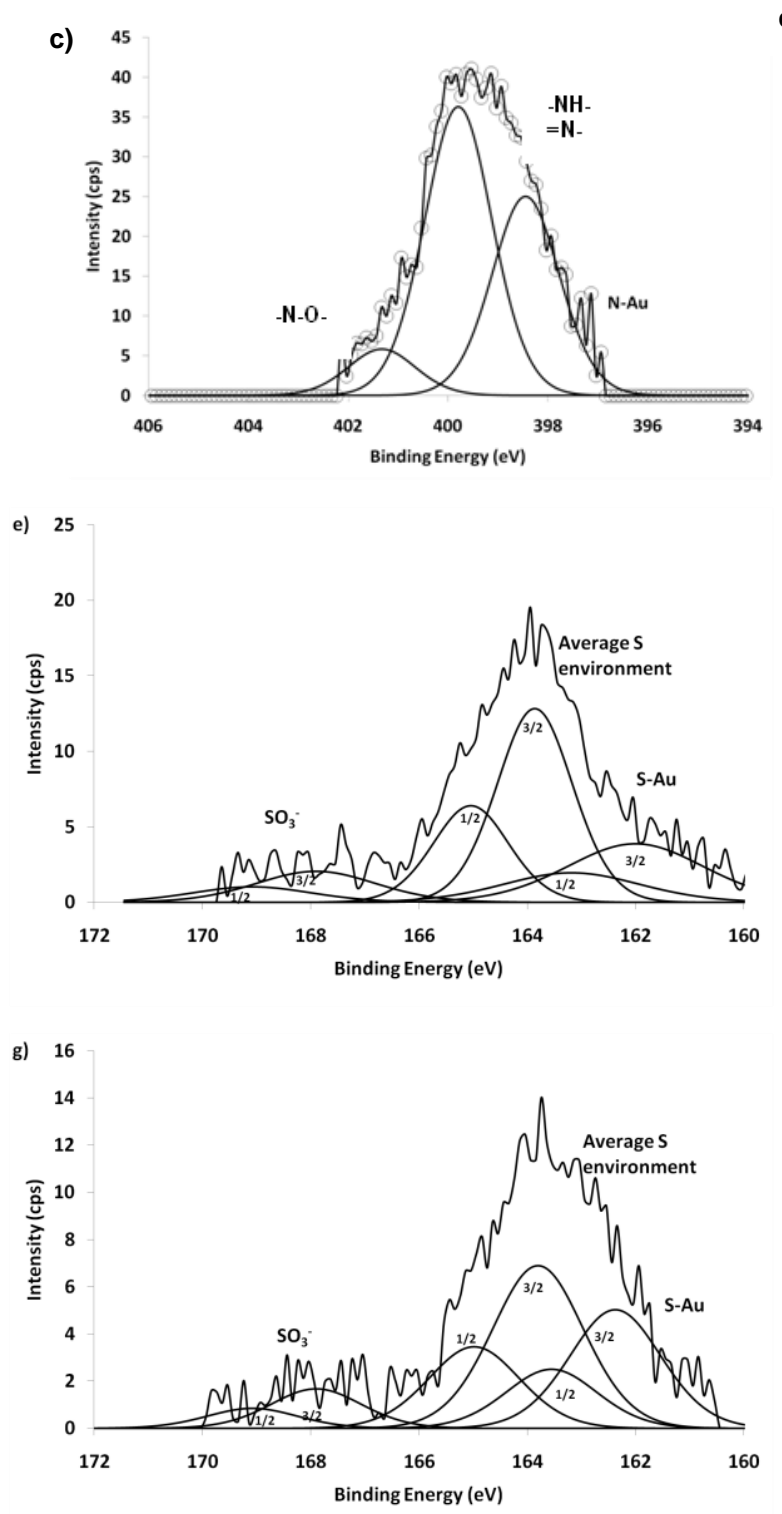

b) 70

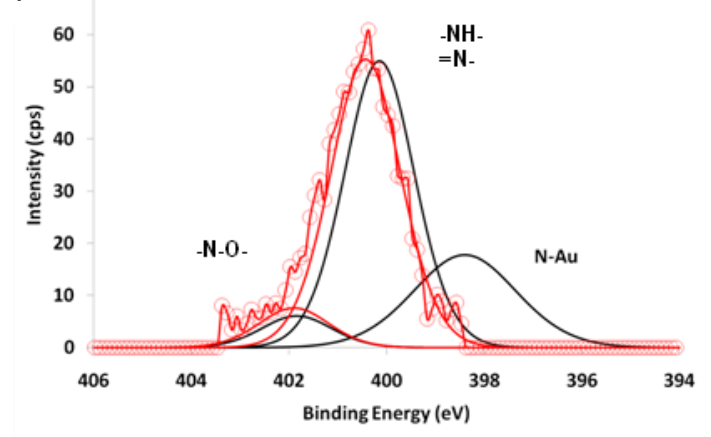

d) 70
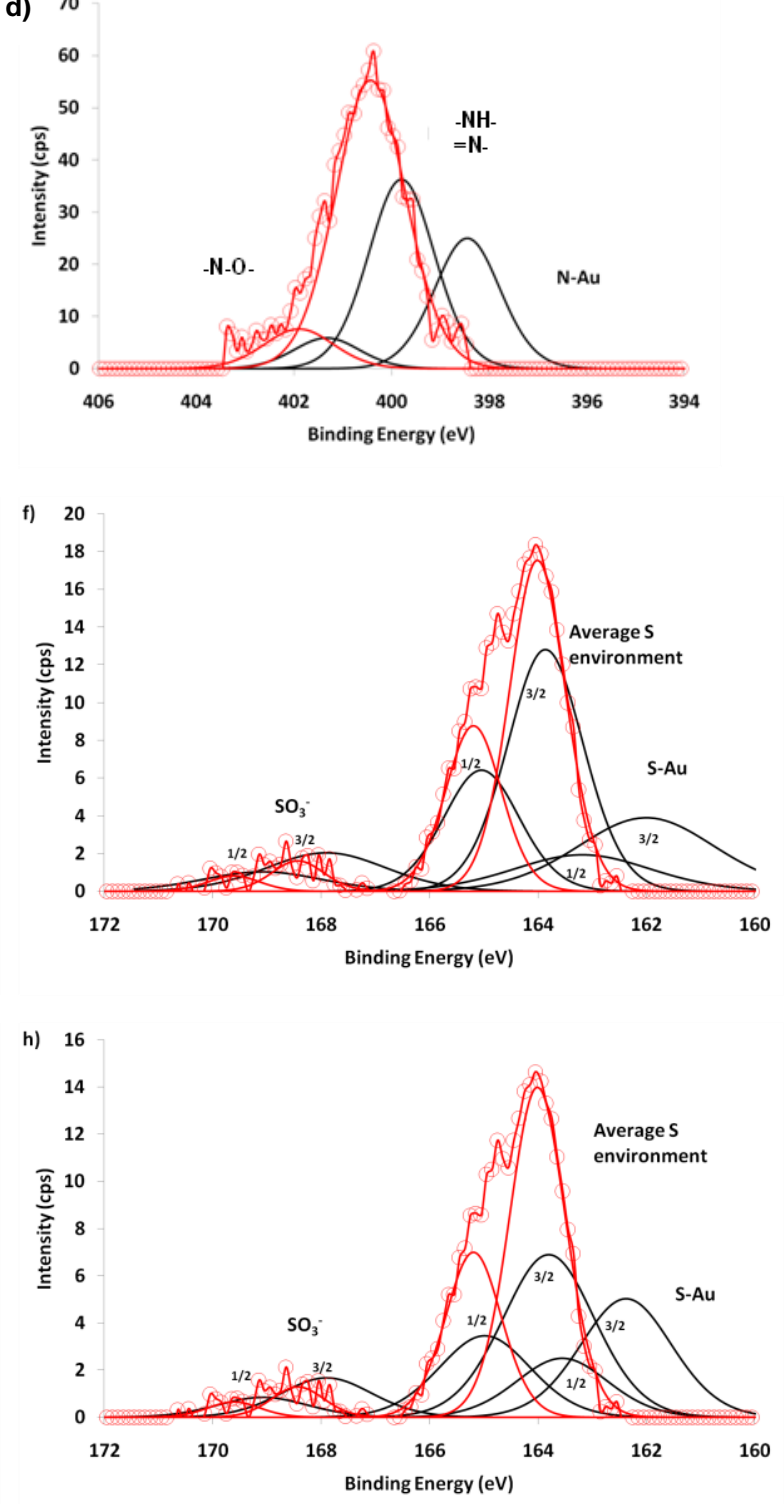

Figure 4.43: High resolution $N$ 1s (a-d) and $S$ 2p (e-h) XPS spectra of gold nanoparticle-merino wool composites incorporating colloids prepared with (a) and (e) $10 \mu \mathrm{L}$ of $1 \mathrm{wt} \% \mathrm{TA}$ and (c) and (g) $50 \mu \mathrm{L}$ of $10 \mathrm{wt} \%$ TA. Figures $(\mathrm{b}, \mathrm{d})$ and (f, g) show an overlay of the corresponding $N$ 1s and $S$ 2p spectra of merino wool (in red). 

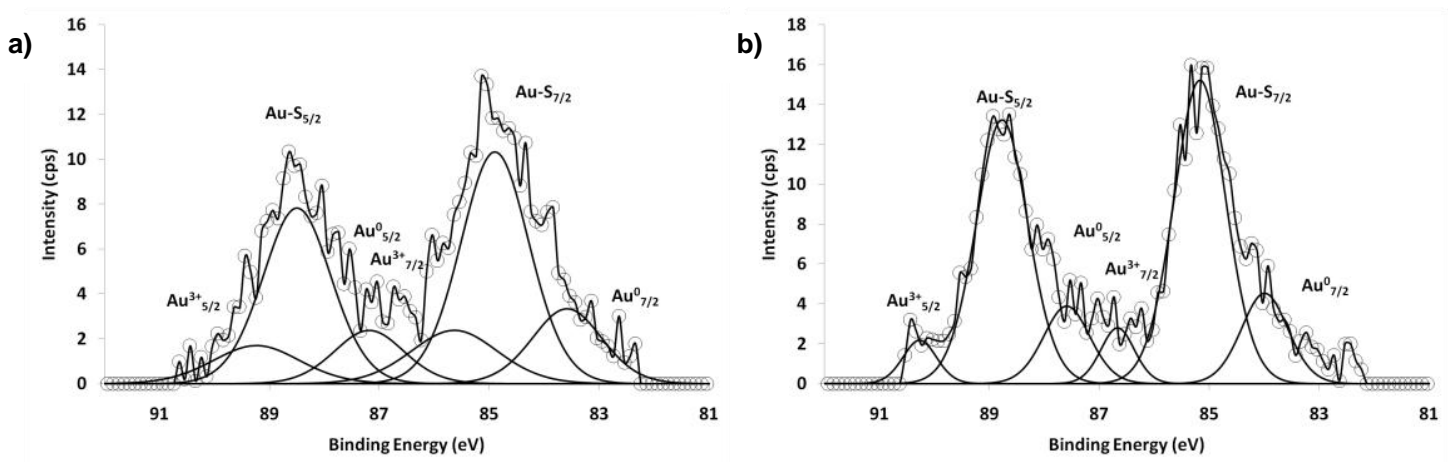

Figure 4.44: High resolution Au 4f XPS spectra of gold nanoparticle-merino wool composites incorporating colloids prepared with (a) $10 \mu \mathrm{L}$ of $1 \mathrm{wt} \% \mathrm{TA}$ and (b) $50 \mu \mathrm{L}$ of $10 \mathrm{wt} \% \mathrm{TA}$

Table 4.4: XPS assignments for gold nanoparticle-merino wool composites prepared with $1 \boldsymbol{\mu L}$ of 1 wt $\%$ TA or $50 \mu \mathrm{L}$ of $10 \mathrm{wt} \%$ TA. Showing peak N-Au and S-Au peak areas.

\begin{tabular}{llcc}
\hline & & \multicolumn{2}{c}{ Peak Area ( $\mathbf{1 0} \%)$} \\
& & $\mathbf{1} \boldsymbol{\mu L} \mathbf{1}$ wt \% & $\mathbf{5 0 ~} \boldsymbol{\mu L} \mathbf{1 0}$ wt \% \\
\hline C 1s & $\mathrm{N}-\mathrm{C}-\mathrm{Au}(\sim 283.2 \mathrm{eV})$ & 24 & 31 \\
$\mathbf{N} \mathbf{1 s}$ & $\mathrm{N}-\mathrm{Au}(\sim 389.5 \mathrm{eV})$ & 30 & 37 \\
$\mathbf{S ~ 2 p}$ & $\mathrm{S}-\mathrm{Au}_{3 / 2}(\sim 162.0 \mathrm{eV})$ & 34 & 40 \\
\hline
\end{tabular}

Table 4.5: XPS assignments for merino wool and gold nanoparticle-merino wool composites incorporating nanoparticles prepared with TA.

\begin{tabular}{|c|c|c|c|c|}
\hline & & \multirow[b]{2}{*}{ Merino Wool } & \multicolumn{2}{|c|}{ Composite Materials } \\
\hline & & & $10 \mu \mathrm{L} 1 \mathrm{wt} \%$ & $50 \mu \mathrm{L} 10$ wt \% \\
\hline & & \multicolumn{3}{|c|}{ Binding Energy $(\mathrm{eV} \pm 0.2 \mathrm{eV})$} \\
\hline \multirow[t]{4}{*}{ C 1s } & $\mathrm{C}-\mathrm{C}, \mathrm{C}-\mathrm{H}$ & $285.00(63 \%)$ & $285.00(57 \%)$ & $285.00(48 \%)$ \\
\hline & $\mathrm{C}-\mathrm{O}, \mathrm{C}-\mathrm{N}, \mathrm{C}-\mathrm{S}$ & 286.20 (27 \%) & 286.42 (10\%) & $286.30(10 \%)$ \\
\hline & $\mathrm{C}=\mathrm{O}$ & 288.30 (10 \%) & 288.15 (9 \%) & $287.93(11 \%)$ \\
\hline & $\mathrm{C}-\mathrm{N}-\mathrm{Au}$ & - & 283.18 (24 \%) & $283.58(31 \%)$ \\
\hline \multirow[t]{3}{*}{ N 1s } & $\mathrm{N}-\mathrm{H},=\mathrm{N}-$ & $400.43(88 \%)$ & $400.15(63 \%)$ & $399.80(54 \%)$ \\
\hline & $-\mathrm{N}-\mathrm{O}-$ & 401.90 (12\%) & 401.84 (7\%) & 401.33 (9 \%) \\
\hline & $\mathrm{N}-\mathrm{Au}$ & - & 398.40 (30\%) & 398.45 (37\%) \\
\hline
\end{tabular}




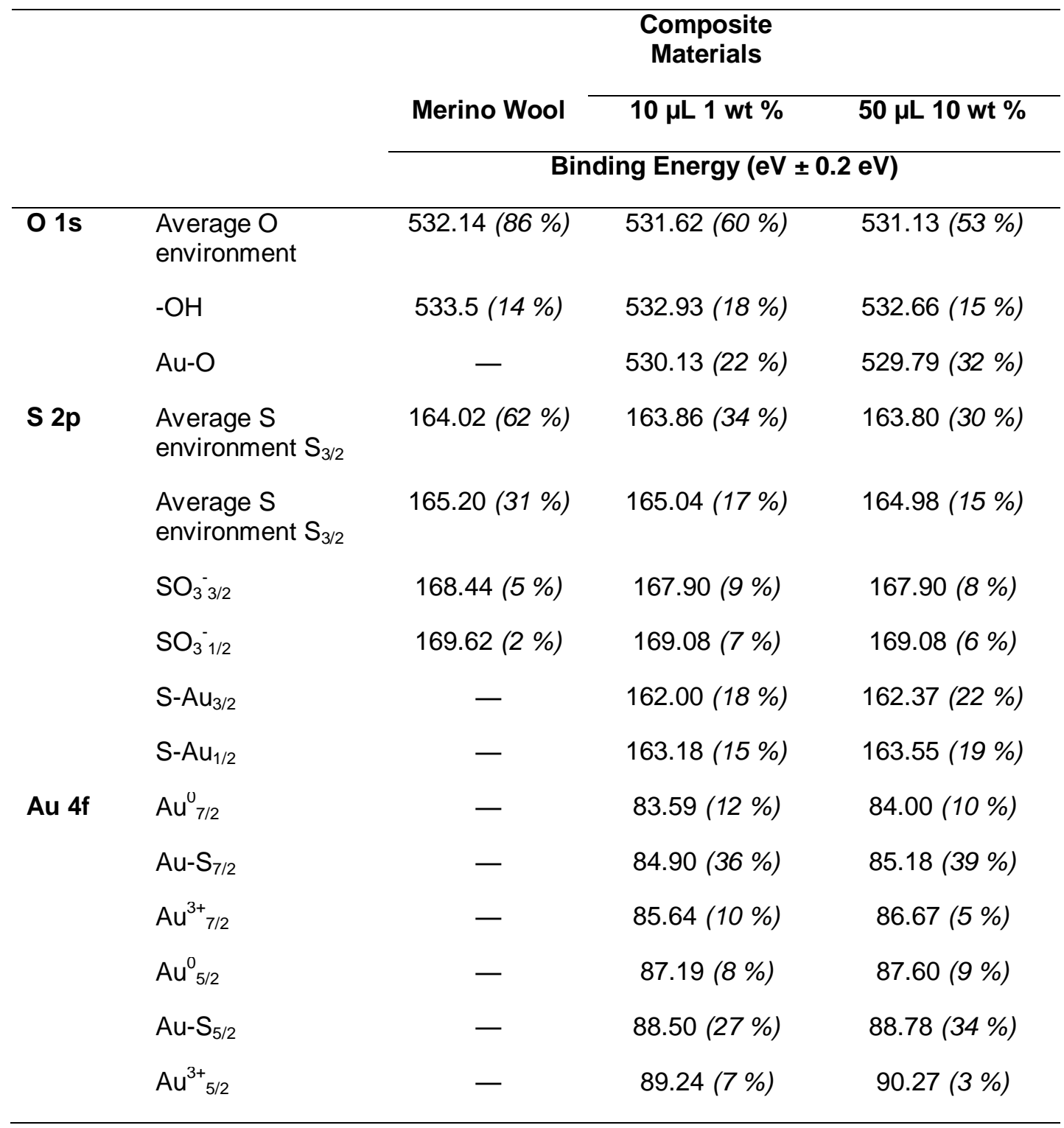

To summarise, the TSC and TA reduced and stabilised gold nanoparticles appear to bond to the merino wool fibres directly and also through the TSC or TA bi-layer encapsulating the nanoparticles, with bonding through the surrounding bi-layer more prevalent with the former nanoparticles. The bonding to the wool fibres occurred through both nitrogen and sulfur atoms.

\subsubsection{Colourfastness to Washing}

The colour stability of the gold nanoparticle-merino composites is dependent upon the stability of the nanoparticle size. In a solution environment metal nanoparticles are 
extremely reactive, and without surface passivation most systems undergo aggregation due to Ostwald Ripening. Immobilising the nanoparticles onto wool fibers removes them from a solution environment, decreasing their tendency to agglomerate. In theory this should stabilise the nanoparticles and hence the colour of the resultant gold nanoparticle-merino wool composites.

The stability of the bond between the gold nanoparticles and wool fibers, and hence the colour stability of the composites was investigated via a stimulated washability test (as outlined in section 2.3.15). This involved agitating the samples in a $0.1 \mathrm{wt} \%$ detergent solution for 0.5-24 hours at room temperature or $50{ }^{\circ} \mathrm{C}$. Composites incorporating gold nanoparticles prepared with $50 \mu \mathrm{L}$ of 10 wt \% TSC or TA were chosen as representatives of the two systems. Figure 4.45 and Figure 4.46 offer photographs of samples that have been in the washing solutions from 0.5-24 hours. It is apparent from these images that after only 0.5 $\mathrm{h}$ washing both at room temperature or $50{ }^{\circ} \mathrm{C}$, there was a marked decrease in the colour intensity of the composites incorporating nanoparticles prepared with TA. There was a slight colour change in those incorporating TSC prepared nanoparticles.

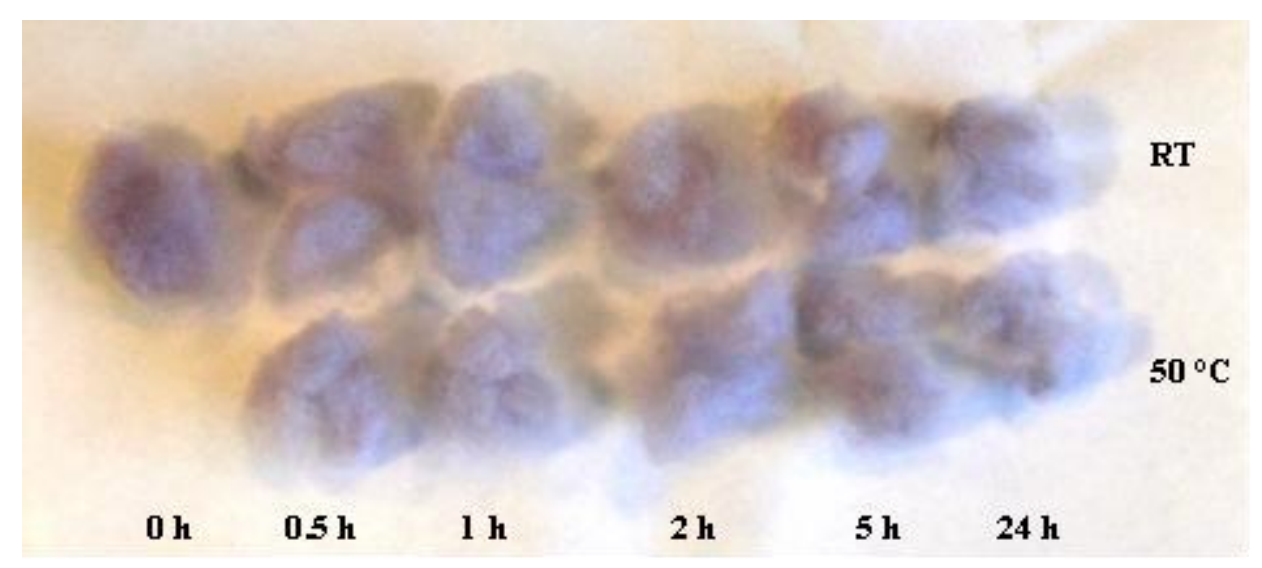

Figure 4.45: Gold nanoparticle-merino wool composites (incorporating colloids prepared with $50 \mu \mathrm{L}$ of $10 \mathrm{wt} \%$ TSC) following simulated washability tests. 


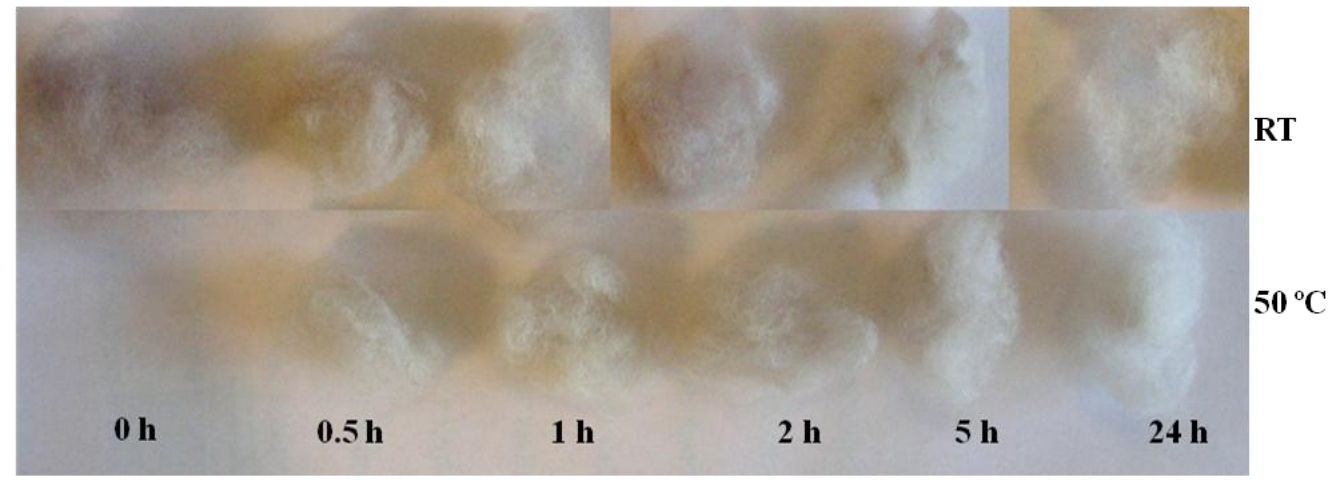

Figure 4.46: Gold nanoparticle-merino wool composites (incorporating colloids prepared with $50 \mu \mathrm{L}$ of $10 \mathrm{wt} \%$ TA) following simulated washability tests.

The CIE L*, a*, b*, $457 \mathrm{~nm}$ brightness and $580 \mathrm{~nm}$ brightness values of the composites following washing are provided in Appendix I. These values confirm the visual lightening or colour fading of the composites incorporating TA prepared nanoparticles following washing, with both a general increase in the $\mathrm{L}^{*}$ and brightness values observed (Figure 4.47). These increases occurred after only 30 minutes of washing at room temperature, with prolonged washing or increased washing temperatures not accentuating these changes. The $\mathrm{L}^{*}$ and brightness values of those incorporating TSC prepared nanoparticles do not change to such a great extent, reflective of their decreased colour change following washing (Figure 4.48). The mild conditions under which colour changes in the composites incorporating TA prepared nanoparticles were induced, suggested that the nanoparticles were easily dislodged from the merino wool fibres, which is likely due to the fact that they are present solely on the surface of the fibres, rather than dispersed throughout the centres. Additionally, compared to their TSC analogoues, they may be less colourfast with respect to washing as TA is much larger than TSC, which may sterically hinder its displacement by the wool fibres during bonding of the nanoparticles to the fibres, thus resulting in a weaker bond between the TA stabilised nanoparticles and wool. This ease in which gold appears to be dislodged from these composite materials presents significant potential hazards, as described in section 4.1.2.6. Future work is required to indentify the from of this leached gold. 


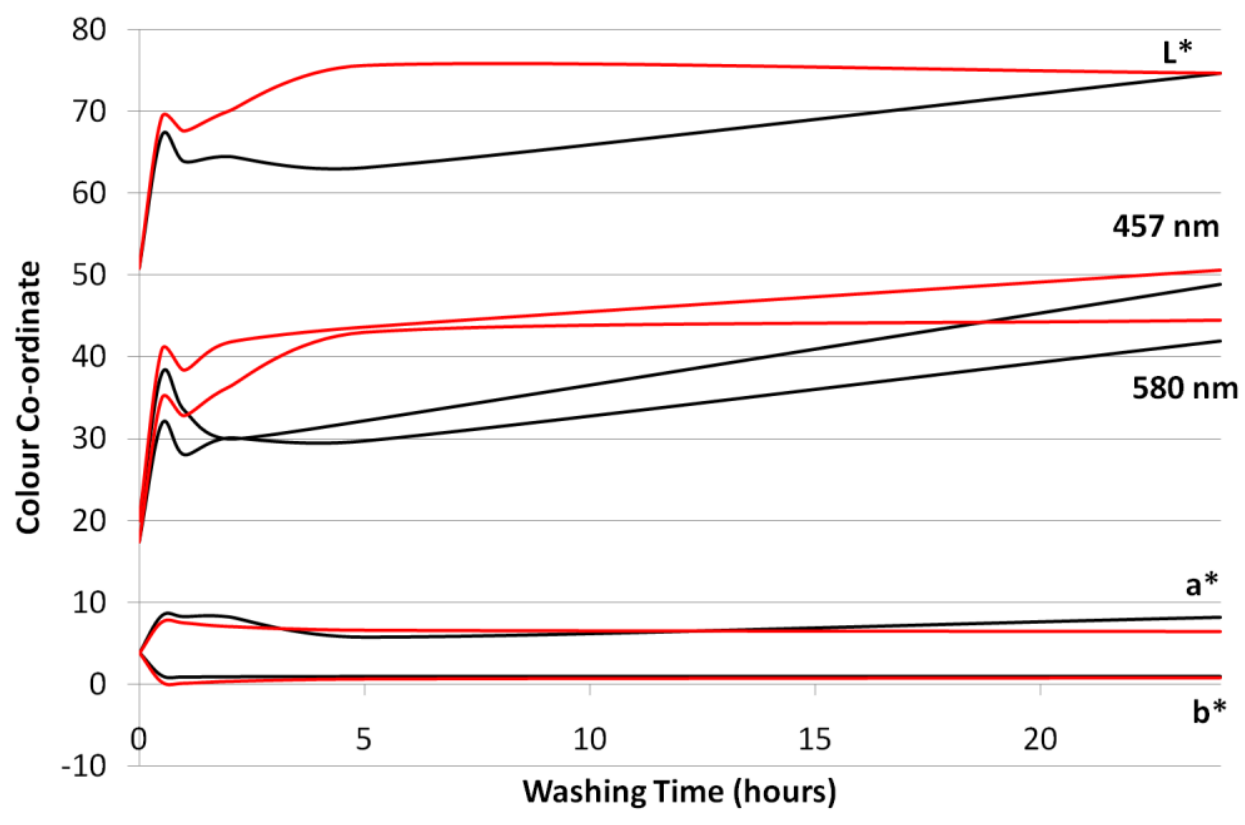

Figure 4.47: Changes in $\mathrm{L}^{*}, \mathrm{a}^{*}, \mathrm{~b}^{*}, 457 \mathrm{~nm}$ brightness and $580 \mathrm{~nm}$ brightness values for a gold nanoparticle-merino composite (incorporating TA prepared nanoparticles) following simulated washability tests show the colour change due to washing. Washing at RT (black lines) or $50{ }^{\circ} \mathrm{C}$ (red lines).

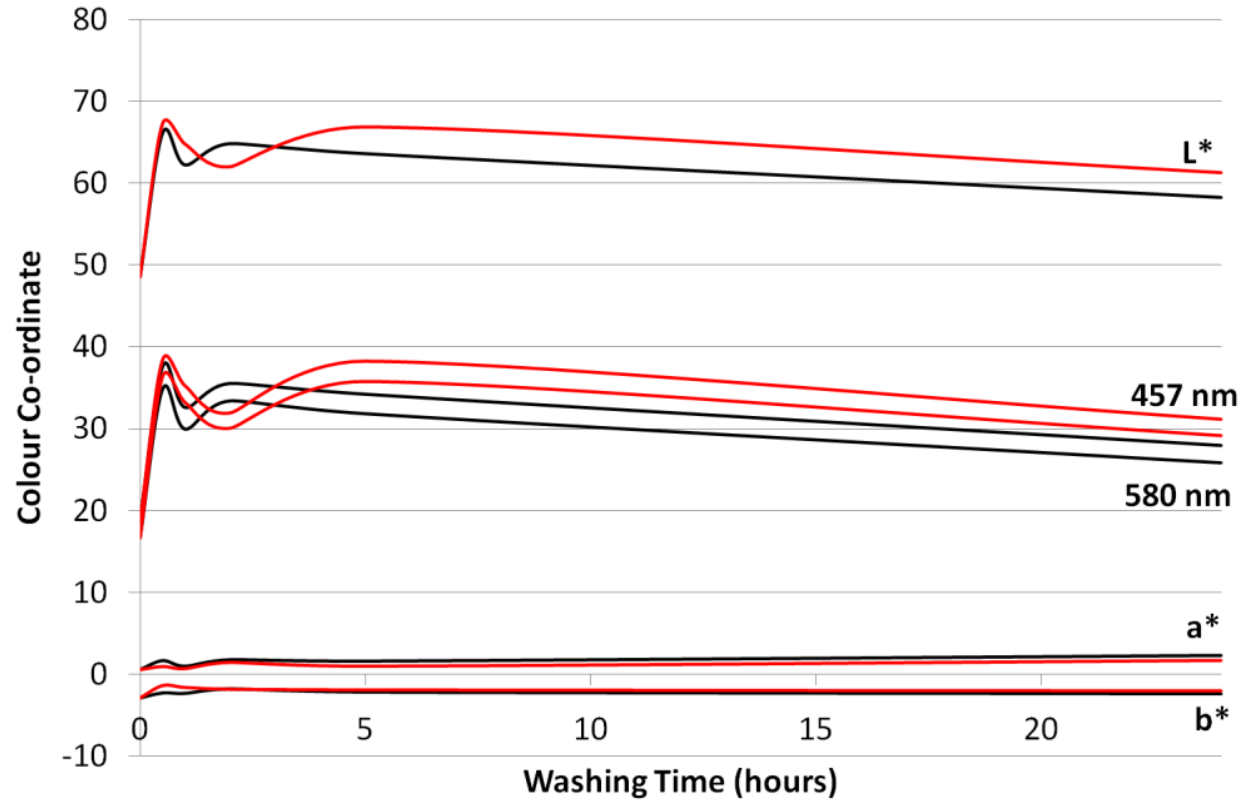

Figure 4.48: Changes in $L^{*}, a^{*}, b^{*}, 457 \mathrm{~nm}$ brightness and $580 \mathrm{~nm}$ brightness values for a gold nanoparticle-merino composite (incorporating TSC prepared nanoparticles) following simulated washability tests show the colour change due to washing. Washing at RT (black lines) or $50{ }^{\circ} \mathrm{C}$ (red lines). 
The colour change of the composites following washing was also illustrated in their UV/Vis spectra with a decrease in the intensity of the plasmon resonance band at approximately 540 $\mathrm{nm}$ (TA prepared) and $560 \mathrm{~nm}$ (TSC prepared). Again this decrease was more pronounced in the composites incorporating TA prepared nanoparticles (Figure 4.49 and Figure 4.50) compared to those prepared with TSC (Figure 4.51 and Figure 4.52). As such, these composites may not be viable materials for consumer applications, those incorporating TA prepared and stabilised nanoparticles more so.

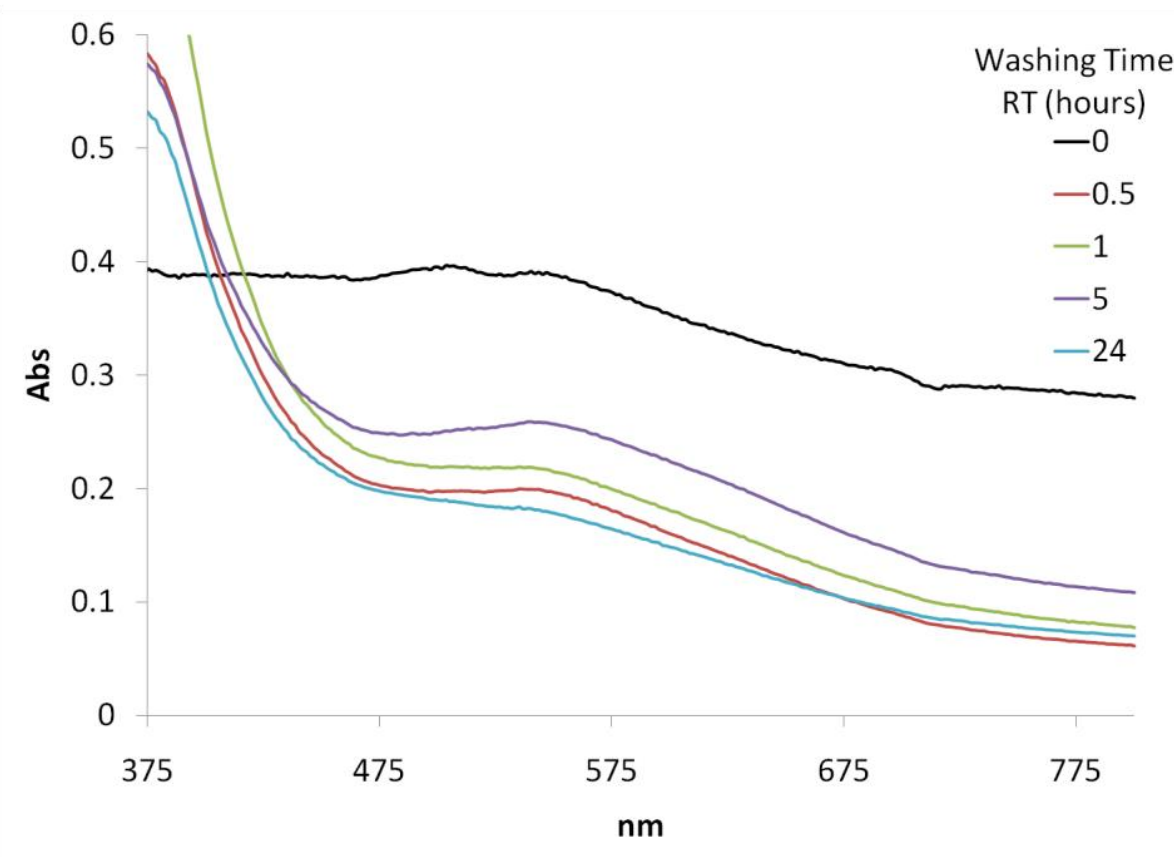

Figure 4.49: Kubelka Munk transformed UV/Vis reflection spectra of gold nanoparticle-merino wool composites (incorporating nanoparticles prepared with $50 \mu \mathrm{L}$ of $10 \mathrm{wt} \% \mathrm{TA}$ ) following washing at RT. 


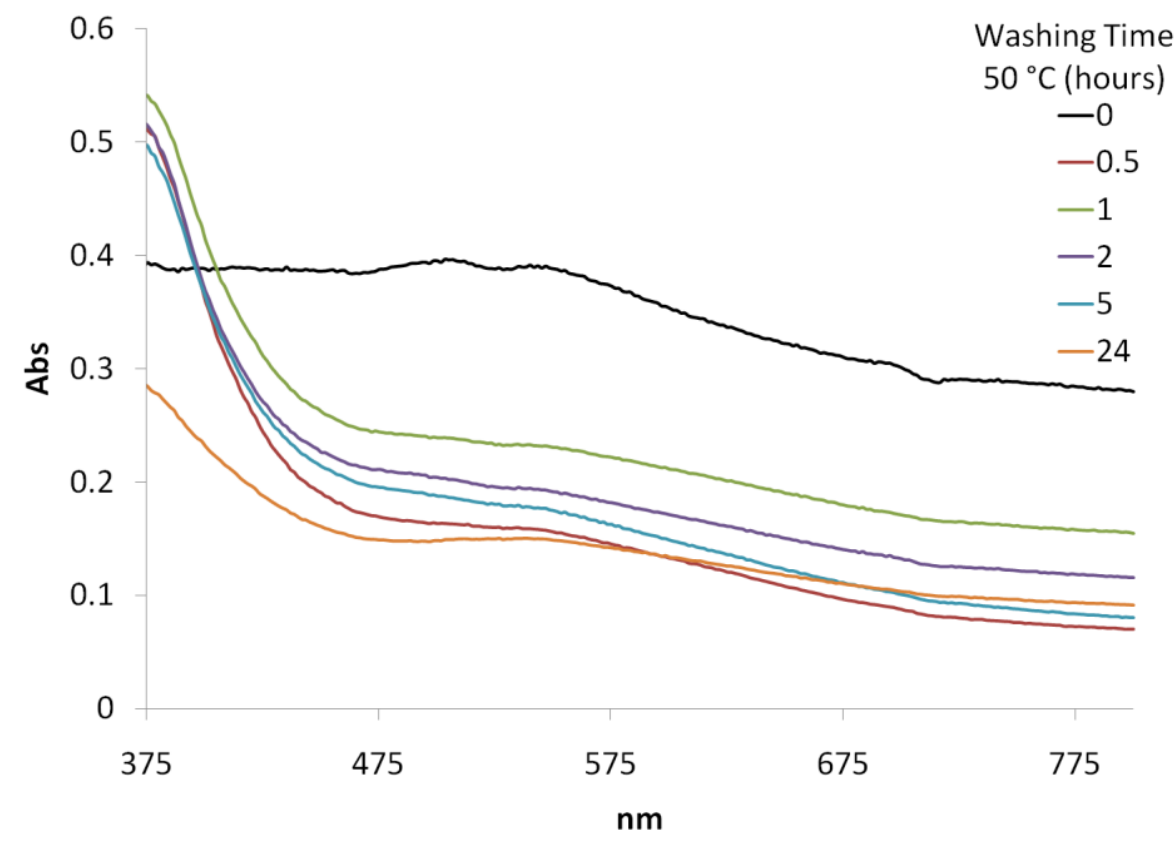

Figure 4.50: Kubelka Munk transformed UV/Vis reflection spectra of gold nanoparticle-merino wool composites (incorporating nanoparticles prepared with $50 \mu \mathrm{L}$ of $10 \mathrm{wt} \% \mathrm{TA}$ ) following washing at 50 ${ }^{\circ} \mathbf{C}$.

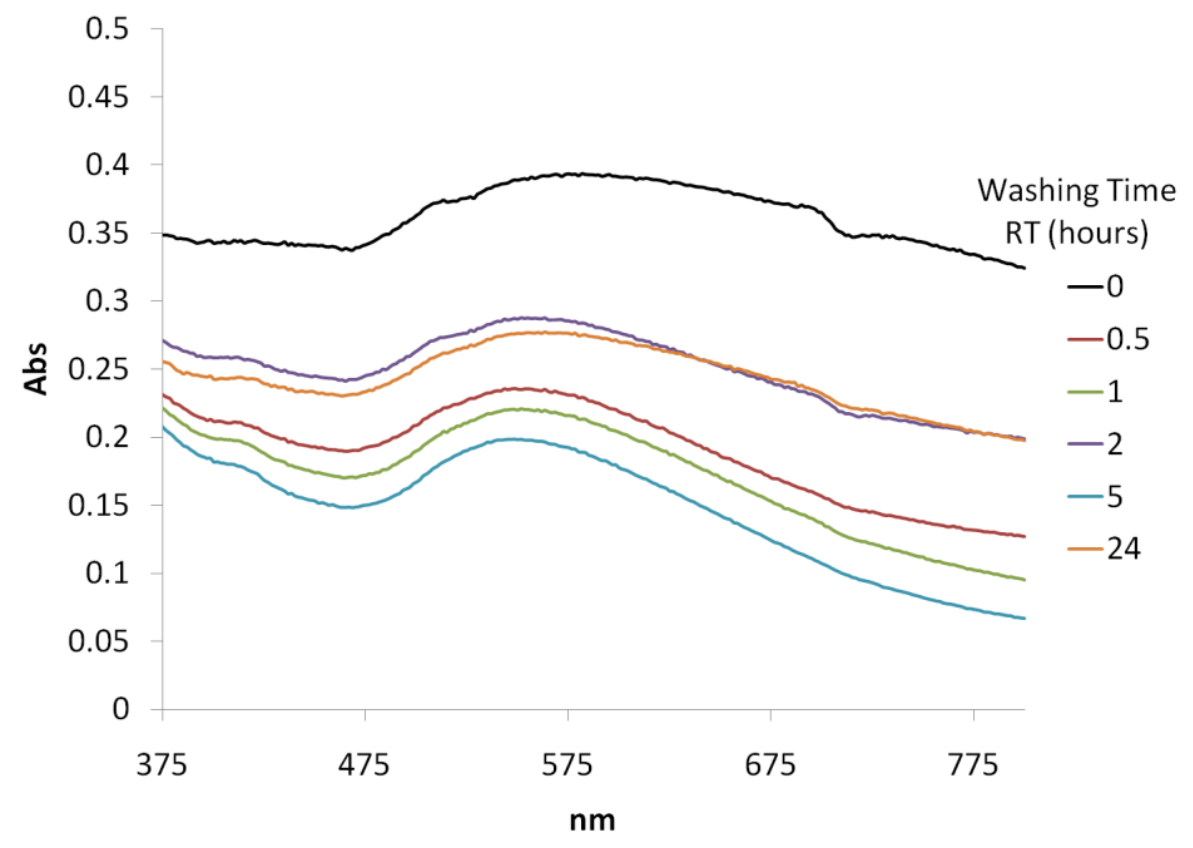

Figure 4.51: Kubelka Munk transformed UV/Vis reflection spectra of gold nanoparticle-merino wool composites (incorporating nanoparticles prepared with $50 \mu \mathrm{L}$ of $10 \mathrm{wt} \%$ TSC) following washing at RT. 


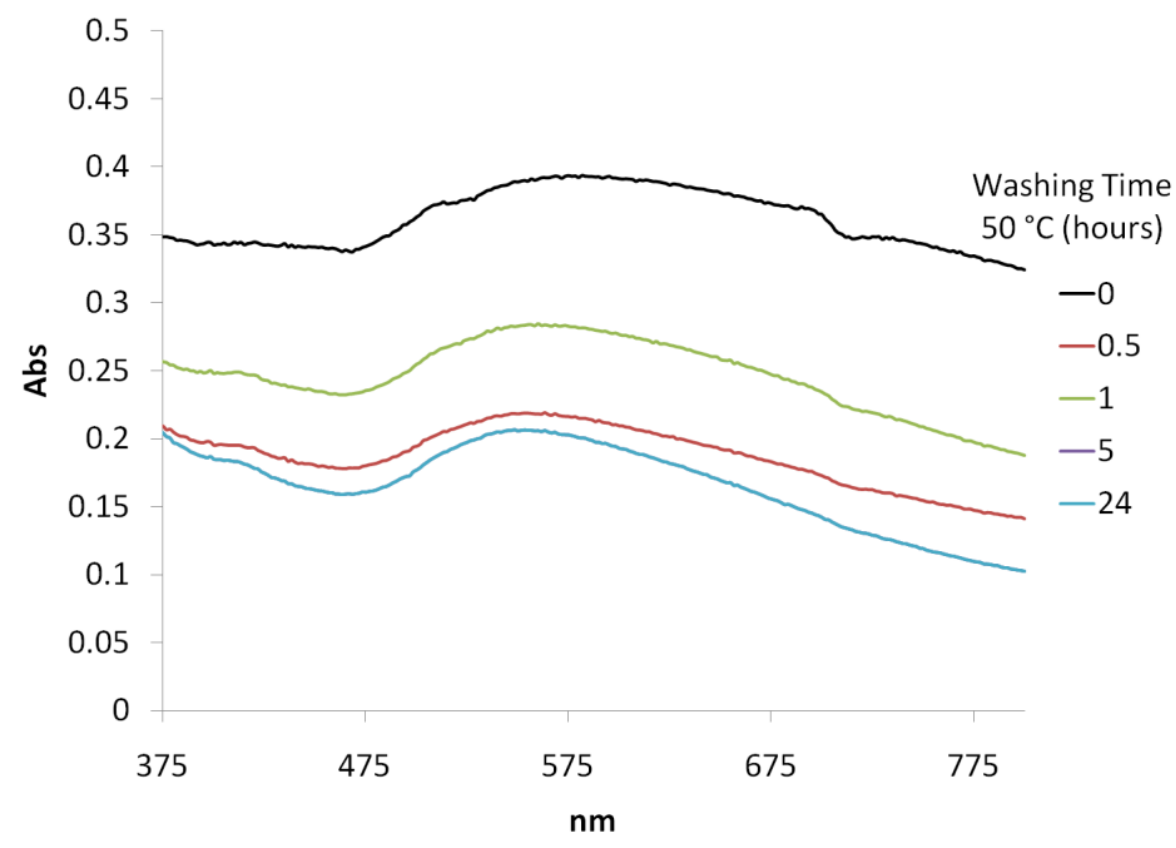

Figure 4.52: Kubelka Munk transformed UV/Vis reflection spectra of gold nanoparticle-merino wool composites (incorporating nanoparticles prepared with $50 \mu \mathrm{L}$ of $10 \mathrm{wt} \% \mathrm{TSC}$ ) following washing at 50 ${ }^{\circ}$ C.

\subsubsection{Leaching}

Currently there is increasing public interest in the long-term health and environmental impacts resulting from the inclusion of nanoparticles in consumer products.[224] Due to the increased surface area to volume ratio exhibited by nanoparticles', the majority display increased chemical reactivity compared to materials with the same chemical composition synthesised at the macroscale. As little is known of the long-term health and environmental effects of these nanoparticles, it is important to limit their leaching from consumer products.

Quantitative analysis of the washing solutions (see sections 2.2.2.5, 2.3.4 and 4.1.2.5) was undertaken to determine the leaching of gold from the gold nanoparticle-merino wool composites during washing, and revealed the leaching of on average $0.9 \mathrm{ppm} \pm 0.5 \mathrm{ppm}$ or 1.5 wt $\%$ of the total gold loading (Table 4.6). These amounts are very low, and do not reflect the observed colour change following washing. Initially it was proposed that during washing, the nanoparticles may have undergone agglomeration, as a result behaving more like bulk gold and not exhibiting surface plasmons, therefore accounting for the diminished 
colour of the washed composites. However SEM analysis of a material that had been washed for 24 hours at $50{ }^{\circ} \mathrm{C}$ revealed this to be not the case (Figure 4.53). There was no evidence of agglomerated particles following washing, and the washed material appeared to have a lower amount of gold deposited on the surface. This suggests that the low colourfastness to washing of these materials was simply due to the dislodgement of weakly bound surface particles. The form of this leached gold is unknown and will be clarified by future work. This gold may not have been detected by AA as the concentrations leached may have been at the limit of detection (approximately $0.2 \mathrm{ppm}$ ).

Table 4.6: Gold leached from gold nanoparticle-merino wool composites (incorporating colloids prepared with TSC or TA) following simulated washability testing.

\begin{tabular}{|c|c|c|c|c|}
\hline Sample & $\begin{array}{c}\text { Washing } \\
\text { Temperature }\end{array}$ & $\begin{array}{c}\text { Washing } \\
\text { Time (hours) }\end{array}$ & $\begin{array}{c}\text { Gold Leached } \\
\text { (ppm) } \pm 0.5 \\
\text { ppm }\end{array}$ & $\begin{array}{l}\text { Gold Leached } \\
\text { (\% total gold } \\
\text { loading) }\end{array}$ \\
\hline \multirow{10}{*}{$\begin{array}{l}\text { TSC } \\
\text { prepared }\end{array}$} & RT & 0.5 & 0.4 & 0.2 \\
\hline & & 1 & 0.7 & 0.4 \\
\hline & & 2 & 0.4 & 0.3 \\
\hline & & 5 & 0.5 & 0.3 \\
\hline & & 24 & 0.7 & 0.5 \\
\hline & $50 \stackrel{\circ}{C}$ & 0.5 & 0.7 & 0.4 \\
\hline & & 1 & 0.8 & 0.5 \\
\hline & & 2 & 0.7 & 0.5 \\
\hline & & 5 & 1.0 & 0.6 \\
\hline & & 24 & 1.4 & 0.9 \\
\hline \multirow{10}{*}{$\begin{array}{l}\text { TA } \\
\text { prepared }\end{array}$} & RT & 0.5 & 1.2 & 0.7 \\
\hline & & 1 & 1.8 & 1 \\
\hline & & 2 & 1.2 & 0.8 \\
\hline & & 5 & 0.8 & 0.5 \\
\hline & & 24 & 1.6 & 1 \\
\hline & $50 \stackrel{\circ}{\circ}$ & 0.5 & 2.8 & 2 \\
\hline & & 1 & 2.9 & 2 \\
\hline & & 2 & 2.5 & 2 \\
\hline & & 5 & 3.5 & 2 \\
\hline & & 24 & 3.5 & 2 \\
\hline
\end{tabular}



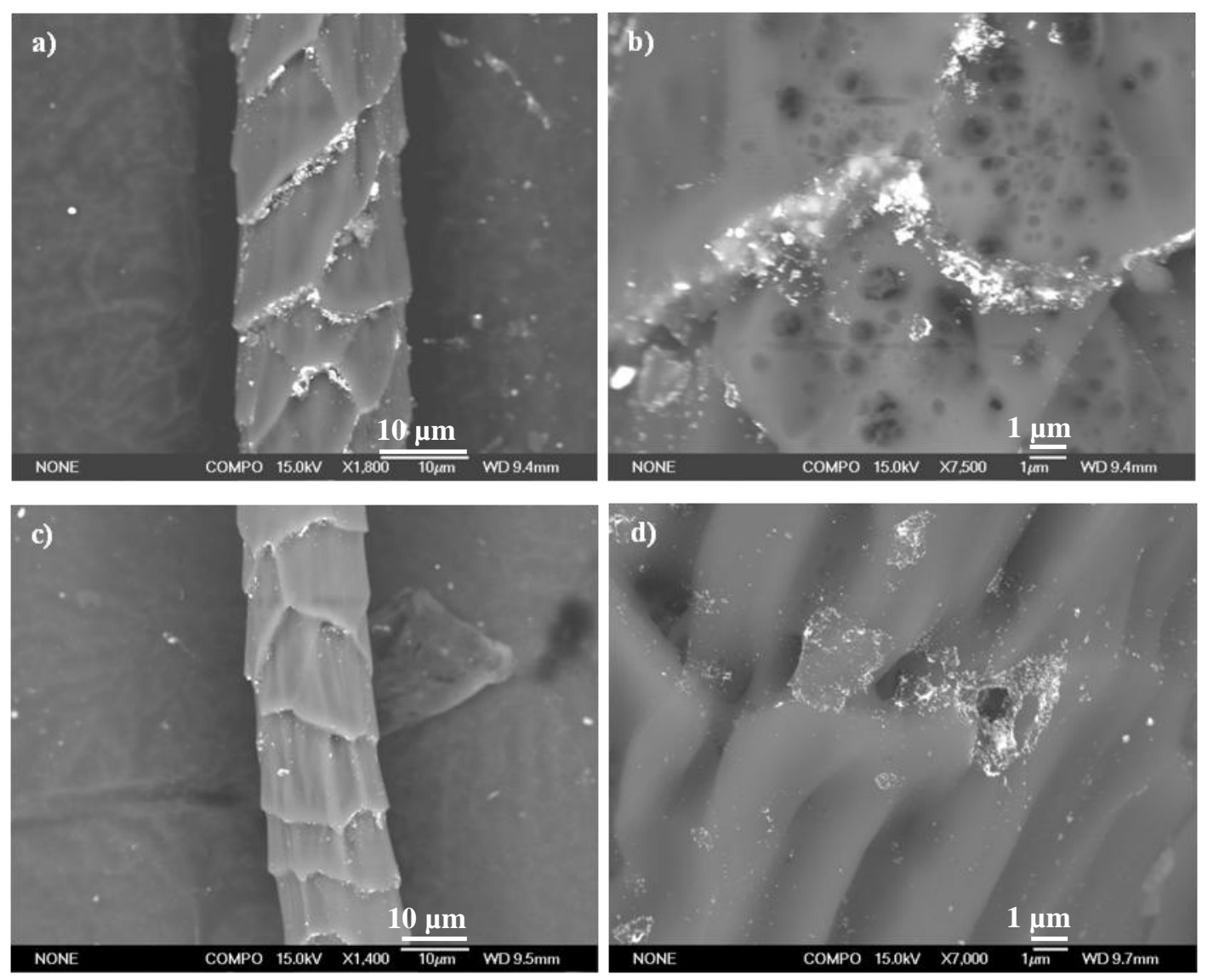

Figure 4.53: SEM micrographs of a gold nanoparticle-merino wool composite incorporating nanoparticles prepared with $50 \mu \mathrm{L}$ of $10 \mathrm{wt} \%$ TSC both before (a, b) and after (c, d) washing at $50{ }^{\circ} \mathrm{C}$ for $24 \mathrm{~h}$.

\subsubsection{Chlorine Hercosett Shrink Resistance Treatment}

To further ascertain the applicability of the gold nanoparticle-merino wool composites incorporating TSC or TA prepared nanoparticles in consumer applications, chlorine Hercosett $(\mathrm{Cl} / \mathrm{H})$ treatments were applied to the materials. As mentioned in section 1.2.2.1.5 the chlorine Hercosett treatment is one of the most common surface treatments applied to wool textiles. It involves oxidation of the fibre surface followed by the application of the Hercosett 125 polymer, resulting in the reduction of felting between fibres during washing, rendering the materials shrink resistant. 
Figure 4.54 shows a gold nanoparticle-merino wool composite (incorporating nanoparticles prepared with $50 \mu \mathrm{L} 10 \mathrm{wt} \% \mathrm{TSC}$ ) both before and after chlorine Hercosett treatment. The treatment clearly had a detrimental effect on the colour of the composite, causing areas to turn a yellowy/gold colour. As mentioned in section 1.2.2.1.5 during this process oxidation of the fibres occurs through exposure to chlorine gas. As such, the observed discolouration is likely to be due to oxidation of the $\mathrm{Au}^{0}$ nanoparticles to $\mathrm{Au}^{3+}$ (scheme (4.4)), which subsequently combine with the generated $\mathrm{Cl}^{-}$ions to form yellow $\mathrm{AuCl}_{4}{ }^{-}$(scheme (4.5)). To confirm whether this was the case, XPS studies of the resultant chlorine Hercosett treated composite materials will be carried out in the future.

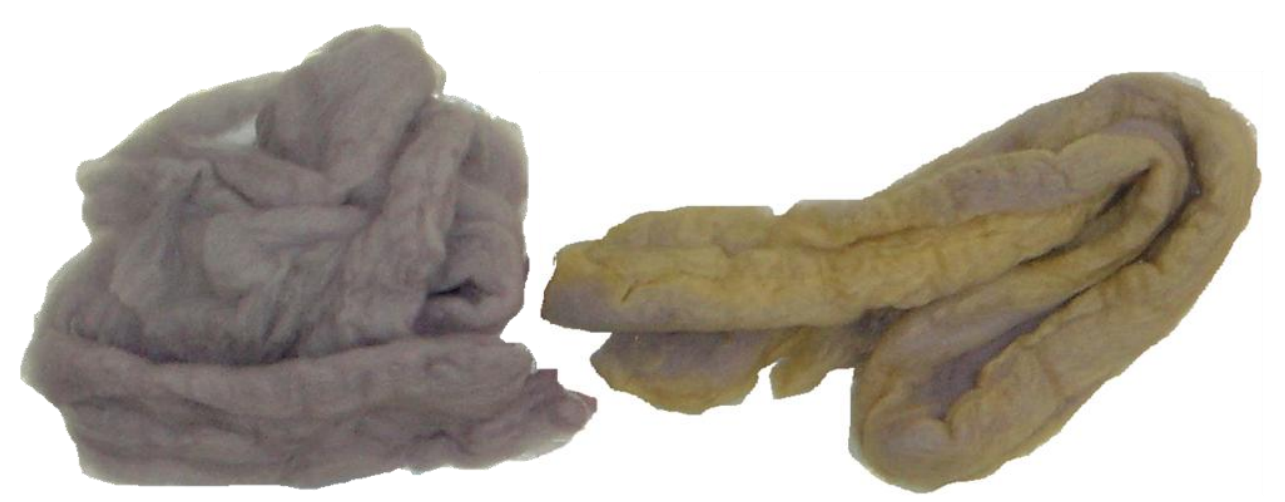

Figure 4.54: Left: a gold nanoparticle-merino wool composite (incorporating nanoparticles prepared with $50 \mu \mathrm{L}$ of $10 \mathrm{wt} \% \mathrm{TSC}$ ). Right: the same composite material following chlorine Hercosett treatment.

$$
\begin{gathered}
\mathrm{Cl}_{2(\mathrm{aq})}+2 \mathrm{e}^{-} \rightarrow 2 \mathrm{Cl}^{-}{ }_{(\mathrm{aq})} \\
\mathrm{Au}_{(\mathrm{s})} \rightarrow \mathrm{Au}^{3+}{ }_{(\mathrm{aq})}+3 \mathrm{e}^{-} \\
3 \mathrm{Cl}_{2(\mathrm{~g})}+2 \mathrm{Au}_{(\mathrm{s})} \rightarrow 6 \mathrm{Cl}_{(\mathrm{aq})}^{-}+2 \mathrm{Au}^{3+}{ }_{(\mathrm{aq})} \\
\mathrm{Au}^{+}+4 \mathrm{Cl}^{-} \rightarrow \mathrm{AuCl}_{4}^{-}
\end{gathered}
$$

SEM showed the gold nanoparticles in these composites to reside solely on the surface of the fibres, rather than throughout the centres. It is likely that the proximity of the nanoparticles to the fibre surface resulted in such an extensive discolouration of the composites, as this process is surface specific due to the short duration of exposure to chlorine gas. Additionally, following chlorine Hercosett treatment, composites in which the gold is spread 
more uniformly through the fibres, rather than being present solely on the surface did not exhibit as great a colour change (section 5.10).

\section{2 ex-situ Preparation of Gold Nanorods}

In an attempt to extend the colour range of the gold nanoparticle-merino wool composites, the synthesis of gold nanorods was undertaken (section 2.2.2.1), which would then be attached to the wool fibres directly, or via a linker molecule. The synthesis of gold nanorods involved the initial production of $\mathrm{Au}^{0}$ seed particles followed by the subsequent reduction of additional $\mathrm{Au}^{3+}$ by the weak reductant ascorbic acid, in the presence of the pre-formed seed particles and the structural directing agent cetyl trimethylammonium bromide.[125, 168, 169] The colour of the resultant colloids produced via both of these methods varied widely (the majority being wine red, pink or yellow in colour), and reactions were not reproducible, even when great care was taken to replicate the procedures exactly with fresh reagents and glassware cleaned with aqua regia. Similar irreproducibility was observed by Lofton and coworkers,[128] who undertook a review of the syntheses of gold nanorods. As such these approaches were not pursued.

\subsection{Conclusions}

The ex-situ preparation of gold nanoparticles by an external reductant, and the subsequent attachment of such nanoparticles to merino wool fibres was most successful when TSC or TA were employed as the reductants. When using TSC, the resultant composites ranged in colour from pale yellow to grey, whilst TA produced murky light pink to purple coloured materials. The preparation and subsequent attachment of gold nanorods to merino wool fibre was unsuccessful. 
When colouring merino wool with gold nanoparticles prepared with increasing amounts of TSC, the resultant composites changed colour from pale yellow to grey. This colour change arose due to a decrease in size and a change in shape of the nanoparticles bound to the surface of the wool fibres, from gold platelets, approximately 100-500 nm in diameter in the yellow coloured composites to spheres, approximately $30 \mathrm{~nm}$ in diameter in the grey materials. Similarly, colouring merino with gold nanoparticles prepared with increasing amounts of TA changed the colour of the resultant composite materials from a light pink to a purple/grey. However unlike the composites coloured with TSC, this colour change was due to a concentration effect, with the purple/grey coloured composite materials possessing a much greater surface coverage of gold nanoparticles of similar size and shape to the light pink coloured materials, notably small spherical nanoparticles (approximately 10-20 nm in diameter) larger trianglular (approximately 50-100 nm) and five-fold twinned nanoparticles (approximately $20-25 \mathrm{~nm}$ in diameter).

In all gold nanoparticle-merino wool composites incorporating TSC or TA reduced and stabilised gold nanoparticles, the nanoparticles appeared to reside preferentially on the surface of the wool fibres (particularly along cuticle edges) rather than throughout the fibre centres. XPS suggested bonding between these nanoparticles and the wool fibres occurred either through electrostatic interaction between the wool and surrounding TSC or TA bilayer, or directly via $\mathrm{N}-\mathrm{Au}$ and $\mathrm{S}-\mathrm{Au}$ bonds following displacement of the capping agent by $\mathrm{N}$ and $\mathrm{S}$ atoms. Bonding through the bi-layer surrounding the gold nanoparticles appeared to be more prevalent in the TSC capped nanoparticles, as under the reaction conditions employed, TSC would possess a net negative charge whilst TA would be neutral, and hence exhibit decreased electrostatic interactions with the wool fibre.

The composite materials incorporating TSC reduced and stabilised gold nanoparticles appeared to be relatively colourfast to washing, exhibiting only a slight colour change following washing. However those incorporating TA reduced and stabilised gold nanoparticles experienced a severe change in colour, even after half an hour washing at RT. This suggests that the bond between the merino wool fibres and TA reduced and stabilised nanoparticles was much weaker than that to the TSC reduced and stabilised nanoparticles. XPS suggested there were a greater percentage of direct bonds between the wool fibres and 
gold nanoparticles when employing TA rather than TSC as the dual reductant stabiliser in the production of the nanoparticles. These bonds should be stronger than electrostatic interactions between the wool fibre and capping agent, making the composites incorporating TA reduced and stabilised gold nanoparticles more colourfast. However as they are not, it is likely that even though less electrostatic interactions occur between the wool fibres and TA, more direct bonds do not occur, due to the much larger size of TA. TA may sterically hinder is displacement by the wool fibres resulting in the formation of a smaller amount of direct bonds, and hence an easier displacement of the nanoparticles during washing.

In addition to displaying average to poor colourfastness to washing properties, the gold nanoparticle-merino wool composites prepared through the incorporation of externally produced gold nanoparticles performed very badly with respect to chlorine Hercosett shrink resistant treatments. The treatment clearly had a detrimental effect on the colour of the composites, causing areas to turn a yellow/gold colour, which was proposed to be due to reoxidation of $\mathrm{Au}^{0}$ nanoparticles to $\mathrm{Au}^{3+}$, and the subsequent formation of yellow $\mathrm{AuCl}_{4}{ }^{-}$. In all, this method of producing gold nanoparticle-merino wool composite materials was not particularly successful. 


\section{GOLD NANOPARTICLE-MERINO WOOL COMPOSITES: IN-SITU PREPARATION OF GOLD NANOPARTICLES UTILISING THE REDOX PROPERTIES OF THE FIBRES}

Gold nanoparticle-merino wool composites were prepared without an external reducing agent according to the procedure outlined in section 2.2.2.3. The proteins present in merino wool acted as a redox active biotemplate, facilitating the reduction of $\mathrm{Au}^{3+}$ to nanoparticulate $\mathrm{Au}^{0}$, with simultaneous binding of the produced nanoparticles both on the surface and within the centre of the fibres. If not stated otherwise, the standard $\mathrm{Au}^{3+}$ solution was prepared through the addition of $40 \mu \mathrm{L}$ of $4 \mathrm{wt} \% \mathrm{Au}^{3+}$ to $10 \mathrm{ml}$ distilled water, and a wool : $\mathrm{Au}^{3+}:$ solvent volume of $0.1 \mathrm{~g}: 160 \mathrm{ppm}: 10 \mathrm{ml}$ was maintained.

\subsection{Physical Characterisation and Morphology}

\subsubsection{Woven Cloth}

In general, untreated merino wool in sliver (top) form, processed via the semi-worsted approach was employed as the merino wool substrate. However initially, merino wool that had been spun into a yarn and subsequently woven into a fabric was used. Utilising this form of merino wool proved to be unsuccessful as regardless of the reaction conditions employed, the resultant materials were very uneven in colour. Figure 5.1 offers a picture of such samples. These fabric samples $(0.1 \mathrm{~g})$ were soaked overnight at RT, in 80,200 or $300 \mathrm{ppm}$ (4.06 x $10^{-4}, 1.01 \times 10^{-3}$ and $1.52 \times 10^{-3} \mathrm{M}$ respectively, $\left.10 \mathrm{ml}\right) \mathrm{Au}^{3+}$ gold solutions, followed by heating/ageing at $50{ }^{\circ} \mathrm{C}$ for 3 or 6 hours. The colour of these materials is very nonuniform, suggesting an uneven diffusion of $\mathrm{Au}^{3+}$ through the merino wool cloth prior to its reduction to nanoparticulate $\mathrm{Au}^{0}$. 


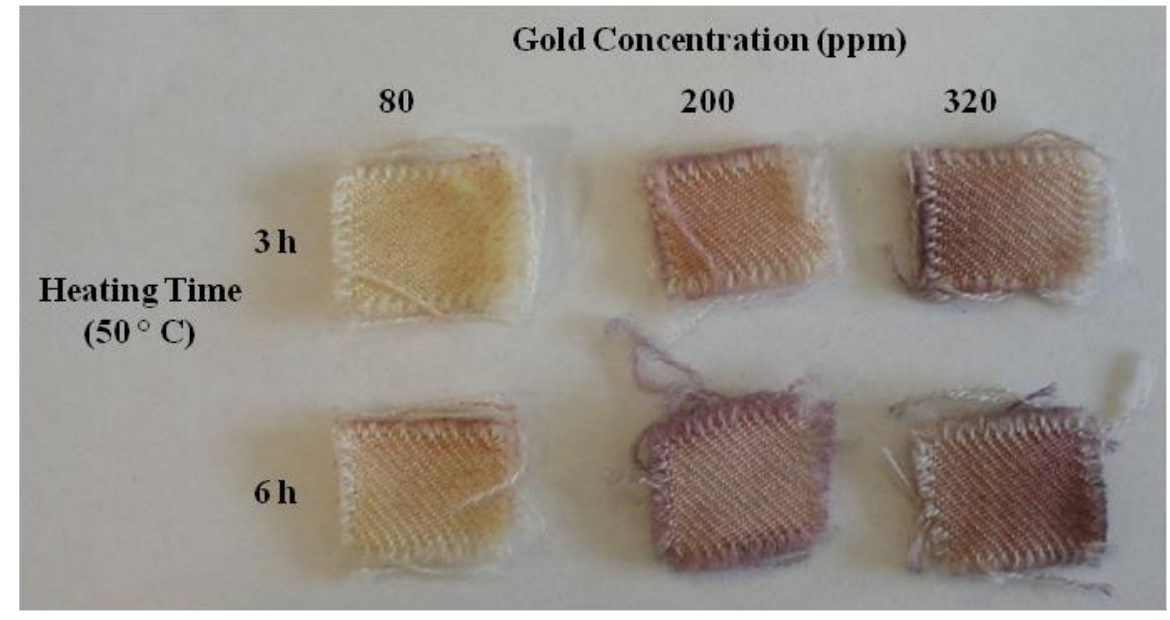

Figure 5.1: Gold nanoparticle-merino wool composites employing a woven cloth form of merino wool. Merino wool was soaked in the $\mathrm{Au}^{3+}$ solutions at RT, overnight, followed by ageing at $50{ }^{\circ} \mathrm{C}$ for 3 or 6 hours.

During the production of these composites difficulty in 'wetting' the merino wool cloth was observed. In an attempt to address the wetability of the cloth, with the aim of improving colour uniformity of the resultant composites, the merino wool cloth was soaked overnight in water at $50{ }^{\circ} \mathrm{C}$, prior to being soaked overnight in the respective $\mathrm{Au}^{3+}$ solutions at $\mathrm{RT}$, and heated at $50{ }^{\circ} \mathrm{C}$ for 3 hours. Figure 5.2 offers a picture of such samples, and compared to those shown in Figure 5.1, (prepared without soaking in water prior to $\mathrm{Au}^{3+}$ ) the colour of the cloth is much more uniform. However the loose fibres (formed from the fraying cloth) are much darker than the woven cloth itself, signifying a greater concentration of gold in these areas. This suggests that the colour development is directly related to the diffusion of $\mathrm{Au}^{3+}$ into and throughout the fibres. Diffusion into the loose fibres would be increasingly facile compared to that into the woven fibres, resulting in a greater gold concentration, and hence a more intense colour development in such loose fibres. Similar results were obtained when colouring the loose fibres themselves, with the ends of the fibres being much darker than the middle. 


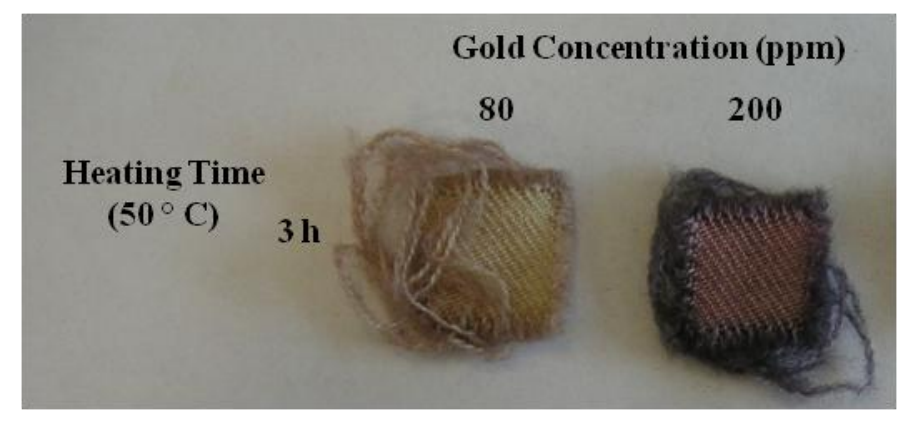

Figure 5.2: Gold nanoparticle-merino wool composites using a woven cloth form of merino wool. Merino wool was soaked in water at $50{ }^{\circ} \mathrm{C}$ overnight, followed by soaking in a gold solution overnight at RT and then ageing at $50{ }^{\circ} \mathrm{C}$ for 3 hours.

To improve the colour uniformity of the gold nanoparticle-merino wool composites incorporating merino wool in cloth form, the frayed edges of the cloth could have simply been removed post colouring, leaving a relatively evenly coloured cloth. However as one of the main requisites of this research was to use the lowest amount of $\mathrm{Au}^{3+}$ possible, discarding segments of the coloured cloth would be less than ideal. As such, colouring merino wool in the cloth form was not pursued, and instead, as mentioned above, the majority of work into the production of gold nanoparticle-merino wool composites was carried out on merino wool in the top/sliver form, prepared via the semi-worsted processing route.

\subsubsection{Untreated Semi-Worsted Gilled Sliver}

In a typical reaction, the production of gold nanoparticle-merino wool composites, with merino wool in the top/sliver form involved dispersing fibres $(0.1 \mathrm{~g})$ in a $\mathrm{Au}^{3+}$ solution, $(40-$ $\left.1200 \mathrm{ppm}\left(8.13 \times 10^{-4}-6.09 \times 10^{-3} \mathrm{M}, 10 \mathrm{ml}\right)\right)$ at room temperature for $0-24$ hours (termed soaking), followed by ageing at $50{ }^{\circ} \mathrm{C}$ for $24-168$ hours. As mentioned above, the colour, and colour intensity of the resultant composites can be changed by systematically altering the $\mathrm{Au}^{3+}$ concentration, soaking time, ageing time and ageing temperature. Figure 5.3 offers a picture of a selection of gold nanoparticle-merino wool composites, illustrating the obtainable colour range. 


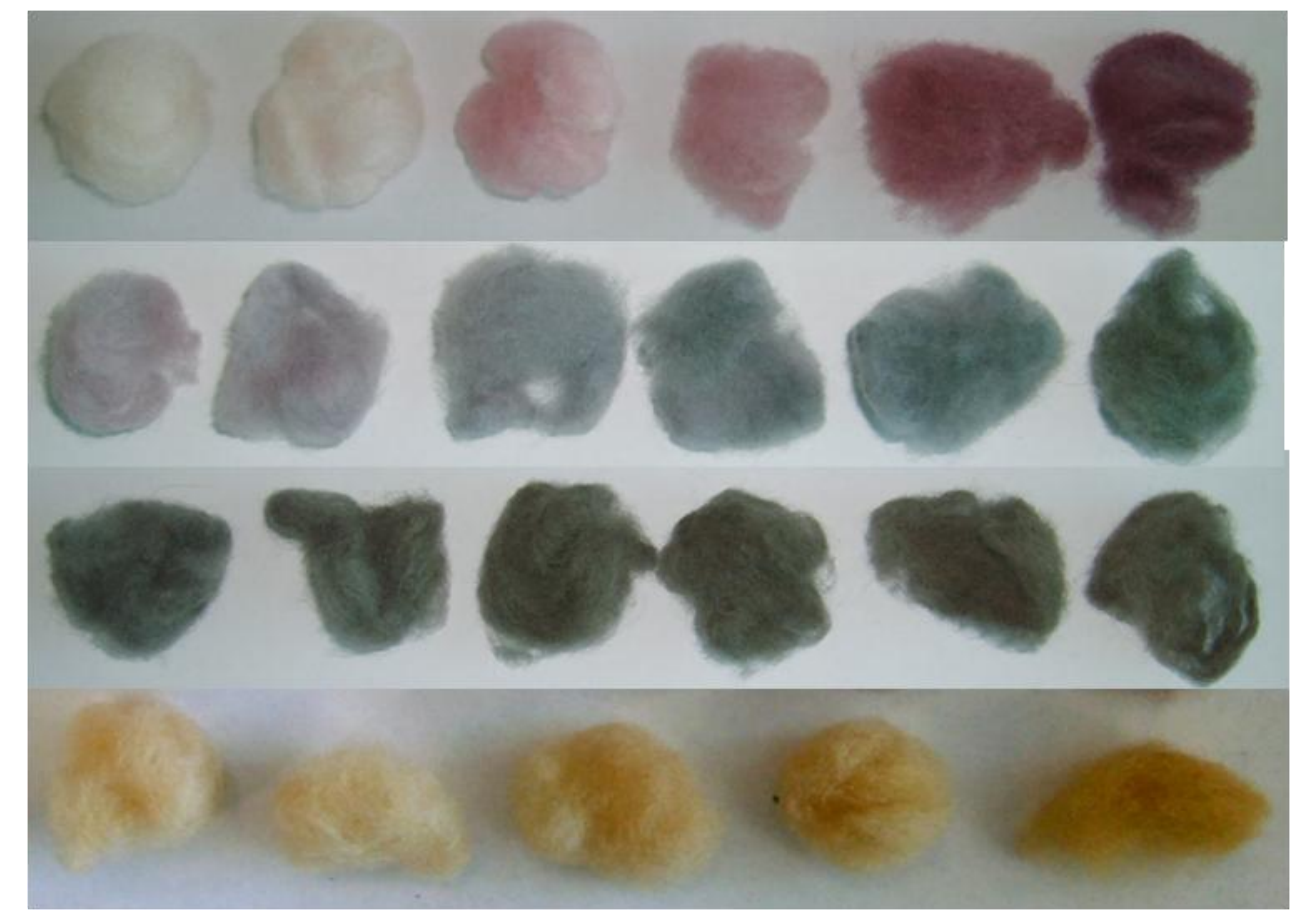

Figure 5.3: An example of the obtainable colours of gold nanoparticle-merino wool composite materials prepared via the in-situ method. Various parameters were altered to achieve the different colours and these are discussed in detail in the chapter 5 .

\subsubsection{Soaking Time}

In a typical production of gold nanoparticle-merino wool composites prepared through the redox active nature of merino, a soaking time of 24 hours was employed. It is apparent from Figure 5.4 below that a soaking time of 24 hours, was required to produce clean, vibrant coloured composites. Soaking times greater than 24 hours did not alter the colour of the materials (Figure 5.5). However when soaking times of less than 24 hours were employed, the colour of the resultant materials was quite dirty and spectrally impure, suggesting agglomeration of nanoparticles on the fibre surface. Additionally, whilst soaking, gentle agitation (not so much as to cause fibres to matt and felt together) was required to assure the uniform absorption and diffusion of $\mathrm{Au}^{3+}$ into and through the merino wool fibres, resulting in uniform colour development (Figure 5.5). (See section 5.4 for the uptake of gold by the wool fibres). 


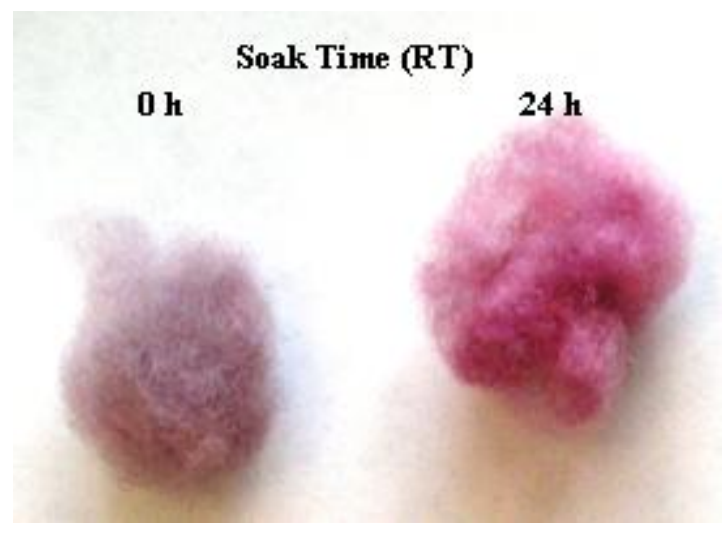

Figure 5.4: Gold nanoparticle-merino wool composites prepared via the in-situ method. Merino wool soaked in a $160 \mathrm{ppm}\left(8.13 \times 10^{-4} \mathrm{M}\right)$ gold solution for 0 or 24 hours at RT, followed by ageing at $50{ }^{\circ} \mathrm{C}$ for $168 \mathrm{~h}$. Shows the effect of soaking time on colour development.

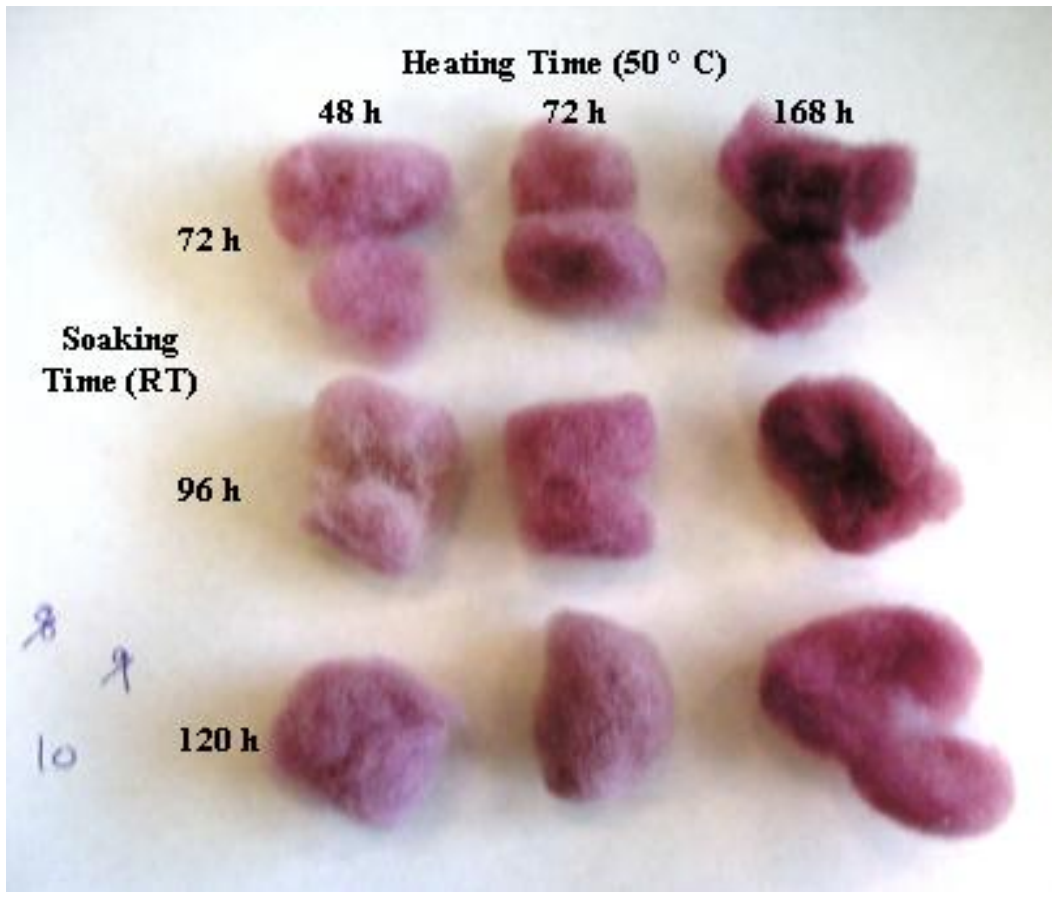

Figure 5.5: Gold nanoparticle-merino wool composites prepared via the in-situ method. Merino wool soaked in a $160 \mathrm{ppm}\left(8.13 \times 10^{-4} \mathrm{M}\right)$ gold solution for 72-96 hours at RT, followed by ageing at $50{ }^{\circ} \mathrm{C}$ for 48-168 $\mathrm{h}$. Shows the effect of soaking time on colour development. 


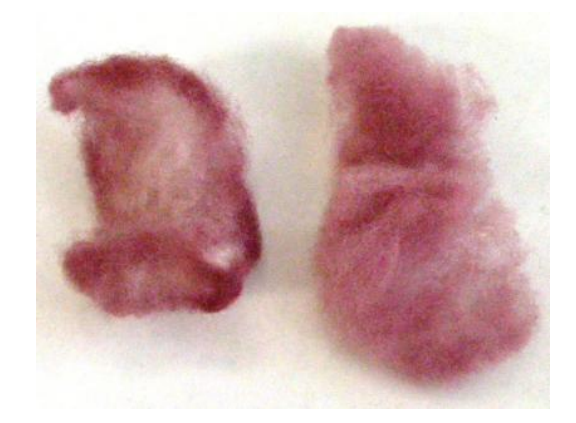

Figure 5.6: Gold nanoparticle-merino wool composite materials prepared by soaking untreated semiworsted merino wool in a $160 \mathrm{ppm}\left(8.13 \times 10^{-4} \mathrm{M}\right) \mathrm{Au}^{3+}$ solution for 24 hours at RT without (left) and with (right) gentle agitation, followed by ageing at $50{ }^{\circ} \mathrm{C}$ for 168 hours.

The presence of agglomerated nanoparticles on the fibre surface, forming when not soaking in $\mathrm{Au}^{3+}$ prior to ageing (denoted as a soaking time of 0 hours) was confirmed by SEM and TEM analysis. Figure 5.7 offers a comparison of the SEM micrographs of composite materials prepared by soaking at RT, in a $160 \mathrm{ppm}\left(8.13 \times 10^{-4} \mathrm{M}\right) \mathrm{Au}^{3+}$ solution for 0 and 24 hours, followed by ageing at $50{ }^{\circ} \mathrm{C}$ for 168 hours. In both materials the gold nanoparticles, (evident as bright white dots) are predominantly five-fold twinned particles, approximately 20-30 nm in diameter (Figure 5.8), located primarily along cuticle edges where the propensity for bonding and surface tension is highest (Figure 5.7). With 24 hours soaking time, these particles are largely isolated; however when the merino wool was not soaked in the $\mathrm{Au}^{3+}$ solution prior to ageing, the nanoparticles appeared to be agglomerated together (Figure 5.7 top (circled)). This agglomeration would account for the less spectrally pure colour displayed by such materials.

If the fibres are not soaked in $\mathrm{Au}^{3+}$ at $\mathrm{RT}$ prior to ageing, the diffusion of $\mathrm{Au}^{3+}$ into the fibres and the reduction of $\mathrm{Au}^{3+}$ to $\mathrm{Au}^{0}$ occur relatively simultaneously. As such, when ageing and hence reduction begins, there is a much greater concentration of $\mathrm{Au}^{3+}$ both in solution, and at the fibre surface. Therefore, more nanoparticles are formed at the surface of the fibres, rather than also in the centre, resulting in high concentrations of nanoparticles at the fibre surface. Due to the higher ratio of nanoparticles to wool, these nanoparticles may not be sufficiently stabilised by the proteins present in merino wool, resulting in their agglomeration as a consequence of Ostwald Ripening. Cross sectional SEM and EDS analysis (where high 
concentrations of gold are depicted by bright white or red areas) confirm that when merino wool was not soaked in $\mathrm{Au}^{3+}$ solutions prior to ageing, gold did not diffuse into the fibre
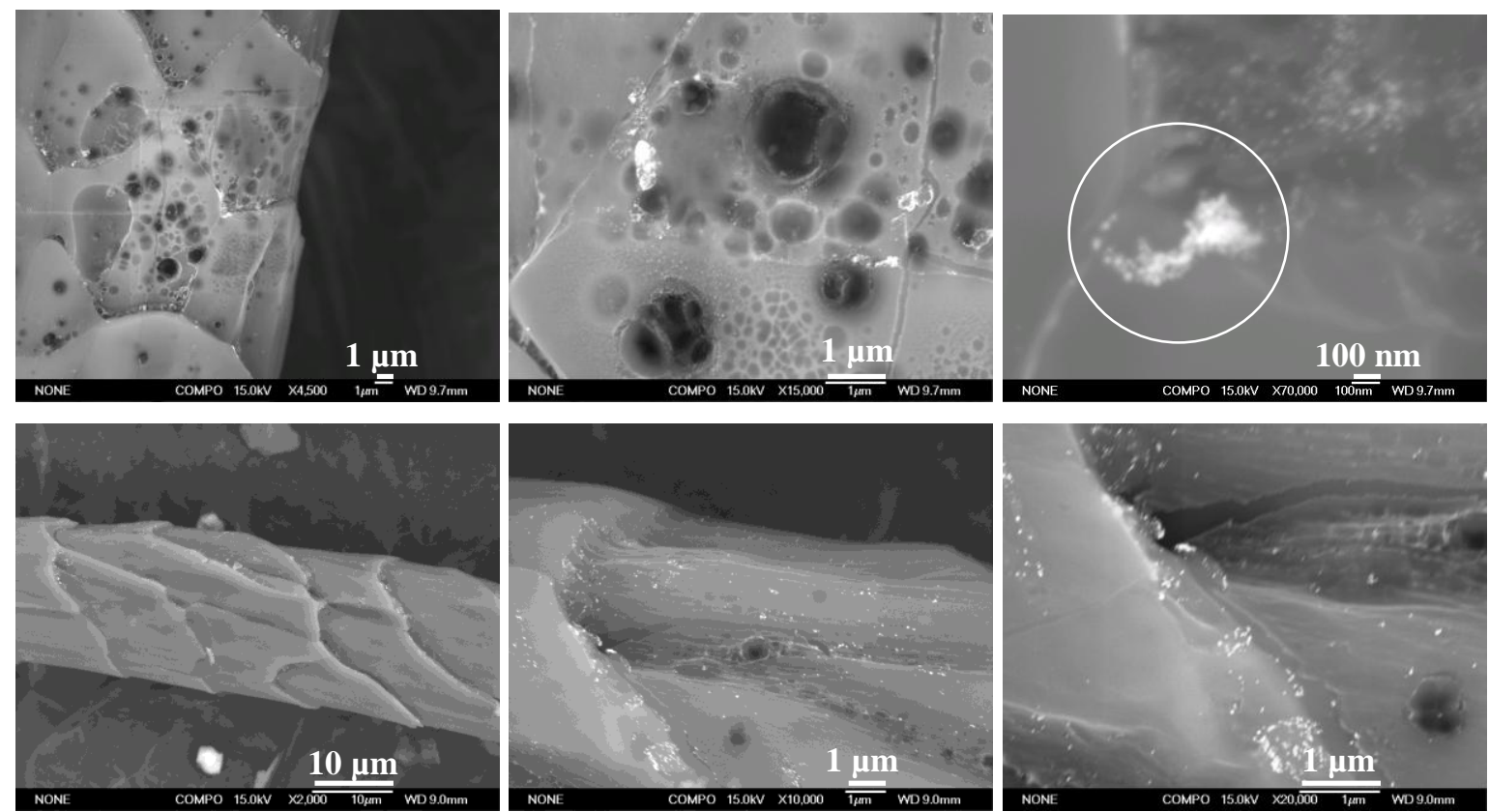

Figure 5.7: Increasing magnification SEM micrographs of gold nanoparticle-merino wool composites prepared by soaking in a $160 \mathrm{ppm}\left(8.13 \times 10^{-4} \mathrm{M}\right) \mathrm{Au}^{3+}$ solution for 0 (top) or 24 hours (bottom) at RT, followed by ageing at $50{ }^{\circ} \mathrm{C}$ for 168 hours.
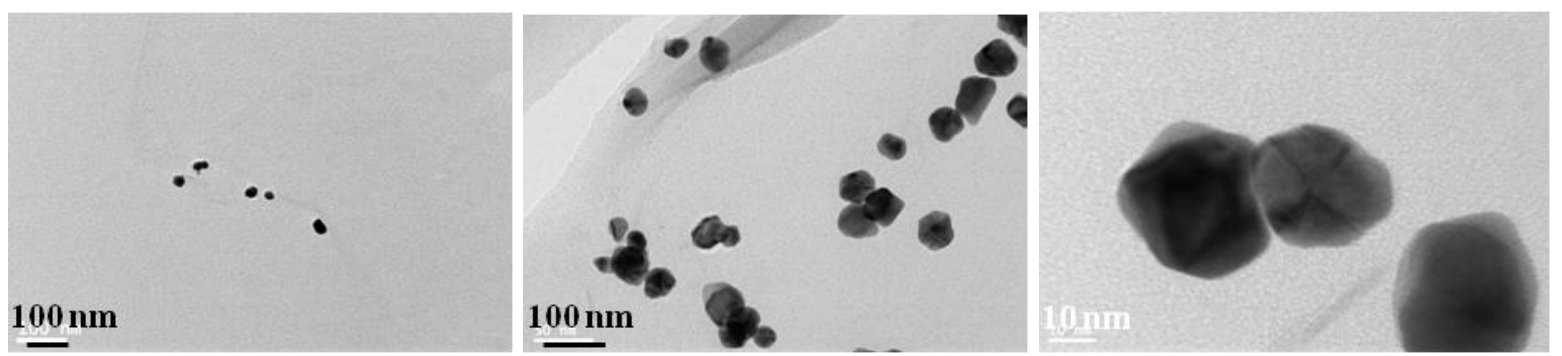

Figure 5.8: Increasing magnification TEM micrographs of a gold nanoparticle-merino wool composite prepared by soaking in a $160\left(8.13 \times 10^{-4} \mathrm{M}\right) \mathrm{Au}^{3+}$ solution for 24 hours at RT, followed by ageing at $50{ }^{\circ} \mathrm{C}$

for 168 hours. Shows the nanoparticles on the surface of the fibre to be five fold twinned particles, approximately $20-30 \mathrm{~nm}$ in diameter.

centres to a significant extent, rather high concentrations were evident at the surface (Figure 5.9 top). However the materials that had been soaked in $\mathrm{Au}^{3+}$ for 24 hours prior to ageing showed gold to have diffused through the fibres, and thus be present both on the surface and within the fibre centres (Figure 5.9 bottom). 

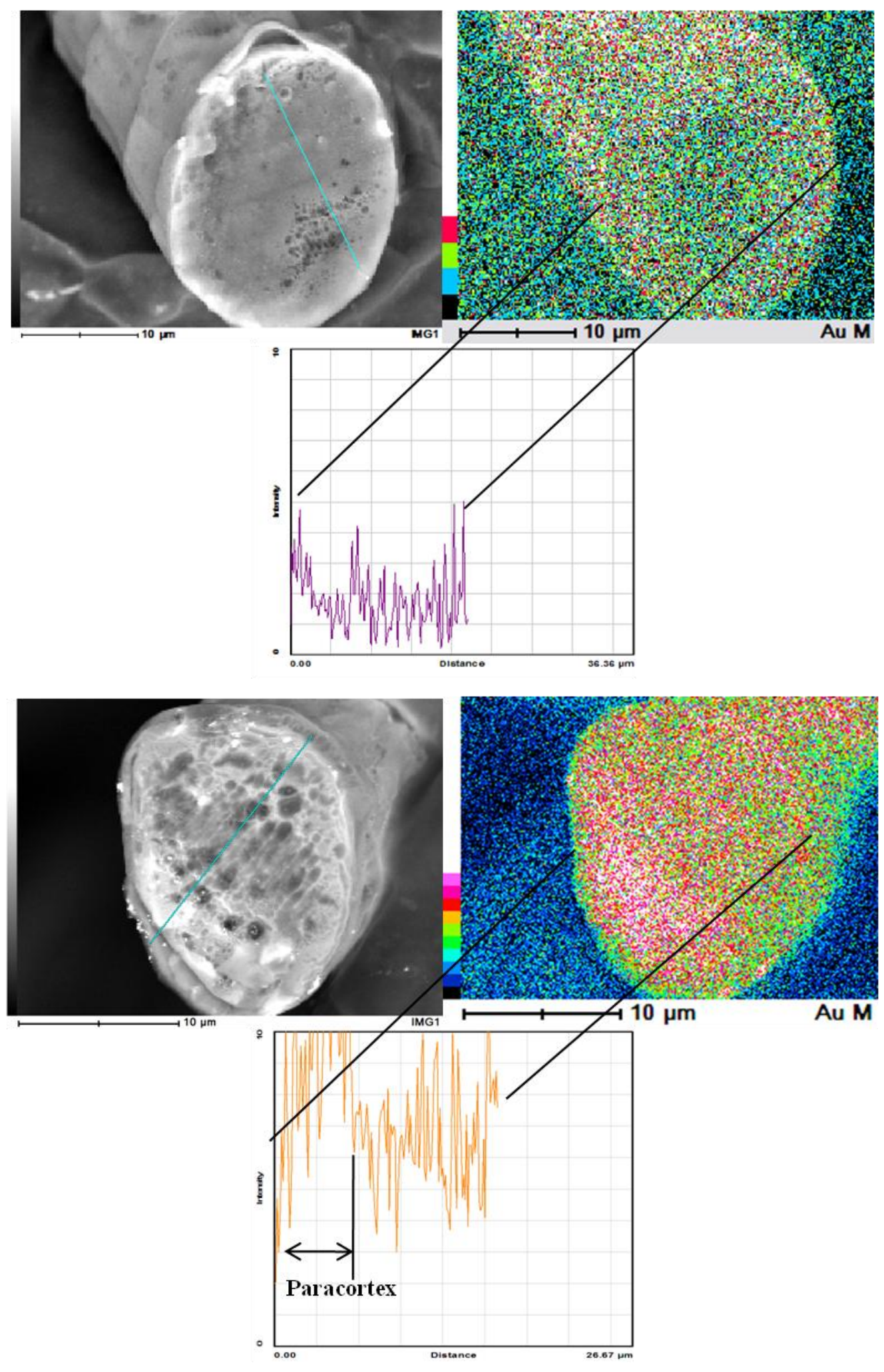

Figure 5.9: Cross sectional SEM micrographs (left), and corresponding Au EDS maps (right) of composite materials prepared from a $160 \mathrm{ppm}\left(8.13 \times 10^{-4} \mathrm{M}\right)$ gold solution, with $0 \mathrm{~h}$ (top) or $24 \mathrm{~h}$ (bottom) soaking and $168 \mathrm{~h}$ ageing at $50{ }^{\circ} \mathrm{C}$. A line profile of each is offered. 
Atomic absorption (AA) studies (section 5.4) showed that at RT, the absorption of gold by merino wool was largely complete after approximately 1 hour (depending upon the $\mathrm{Au}^{3+}$ concentration, soaking solution composition and temperature). However, as shown above if soaking times of less than 24 hours were employed, dirty, spectrally impure coloured composites were produced. As such, not only is the absorption of $\mathrm{Au}^{3+}$ influential in colour development, but also the diffusion of the absorbed $\mathrm{Au}^{3+}$ through the fibres prior to nanoparticle formation.

The formation of a large amount of nanoparticles at the fibre surface, and their subsequent agglomeration occurring when the merino wool was not soaked in $\mathrm{Au}^{3+}$ prior to ageing is not always undesirable, as it was possible to produce grey coloured gold nanoparticle-merino wool composites in this way. Figure 5.10 offers a picture of such materials. These were prepared by ageing untreated semi-worsted merino wool in high concentration $\mathrm{Au}^{3+}$ solutions (840-1200 ppm, or $4.26 \times 10^{-3}-5.89 \times 10^{-3} \mathrm{M}$ ) at $50{ }^{\circ} \mathrm{C}$ for 24 hours.

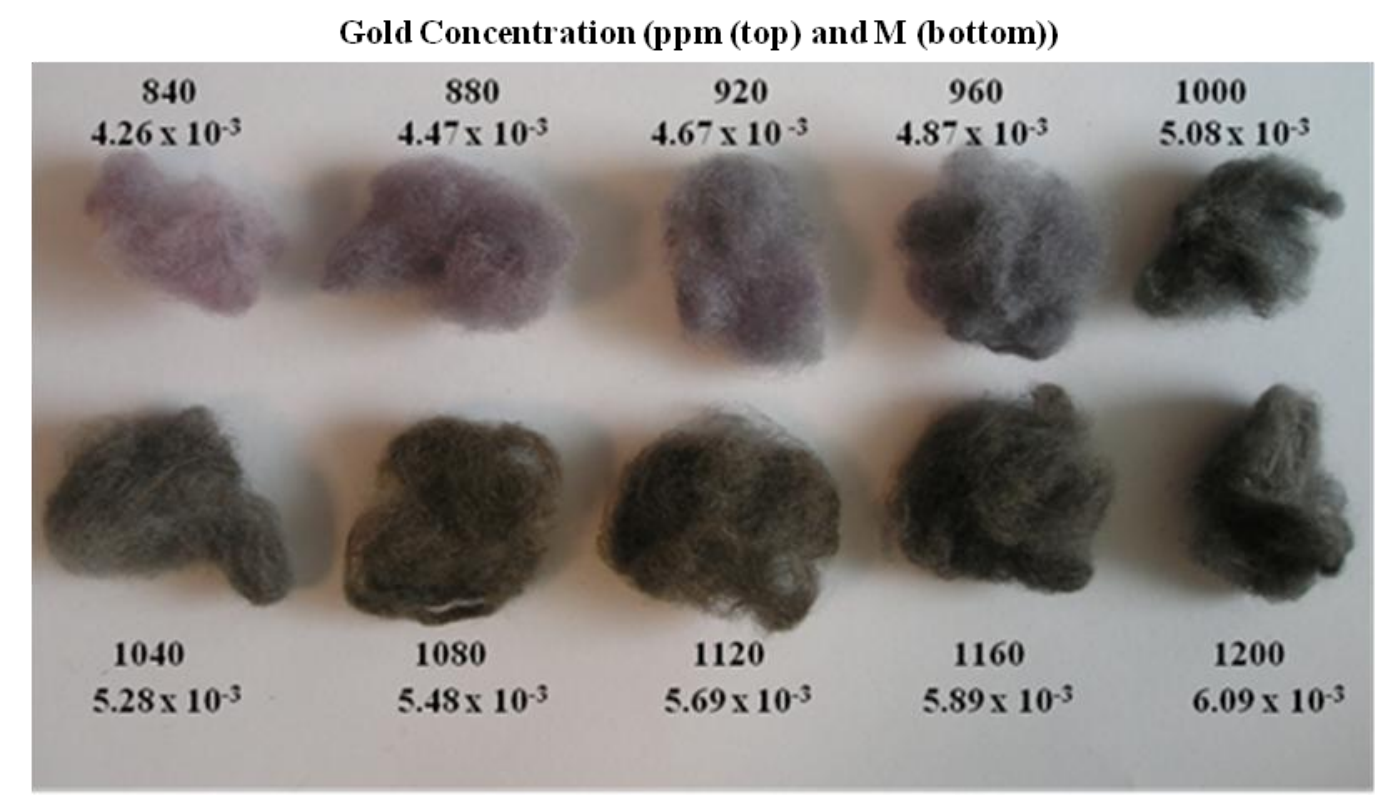

Figure 5.10: Gold nanoparticle-merino wool composites prepared by soaking untreated merino in an 840 $-1200 \mathrm{ppm} \mathrm{Au}^{3+}\left(4.26 \times 10^{-3}-6.09 \times 10^{-3} \mathrm{M}\right)$ solution for 24 hours at $50{ }^{\circ} \mathrm{C}$. 
SEM analysis (Figure 5.11) showed the nanoparticles in the composites prepared with a 960 $\operatorname{ppm}\left(4.87 \times 10^{-3} \mathrm{M}\right) \mathrm{Au}^{3+}$ solution to be predominantly spherical or five-fold twinned in morphology, approximately $30-40 \mathrm{~nm}$ in diameter, existing both as isolated and agglomerated particles. Triangular nanoplates and truncated triangular nanoplates, ranging in size from 50-100 $\mathrm{nm}$ in diameter were also apparent (circled). These nanoparticles were spread across the fibre surface, however the greatest nanoparticle population occurred along the cuticle edges.
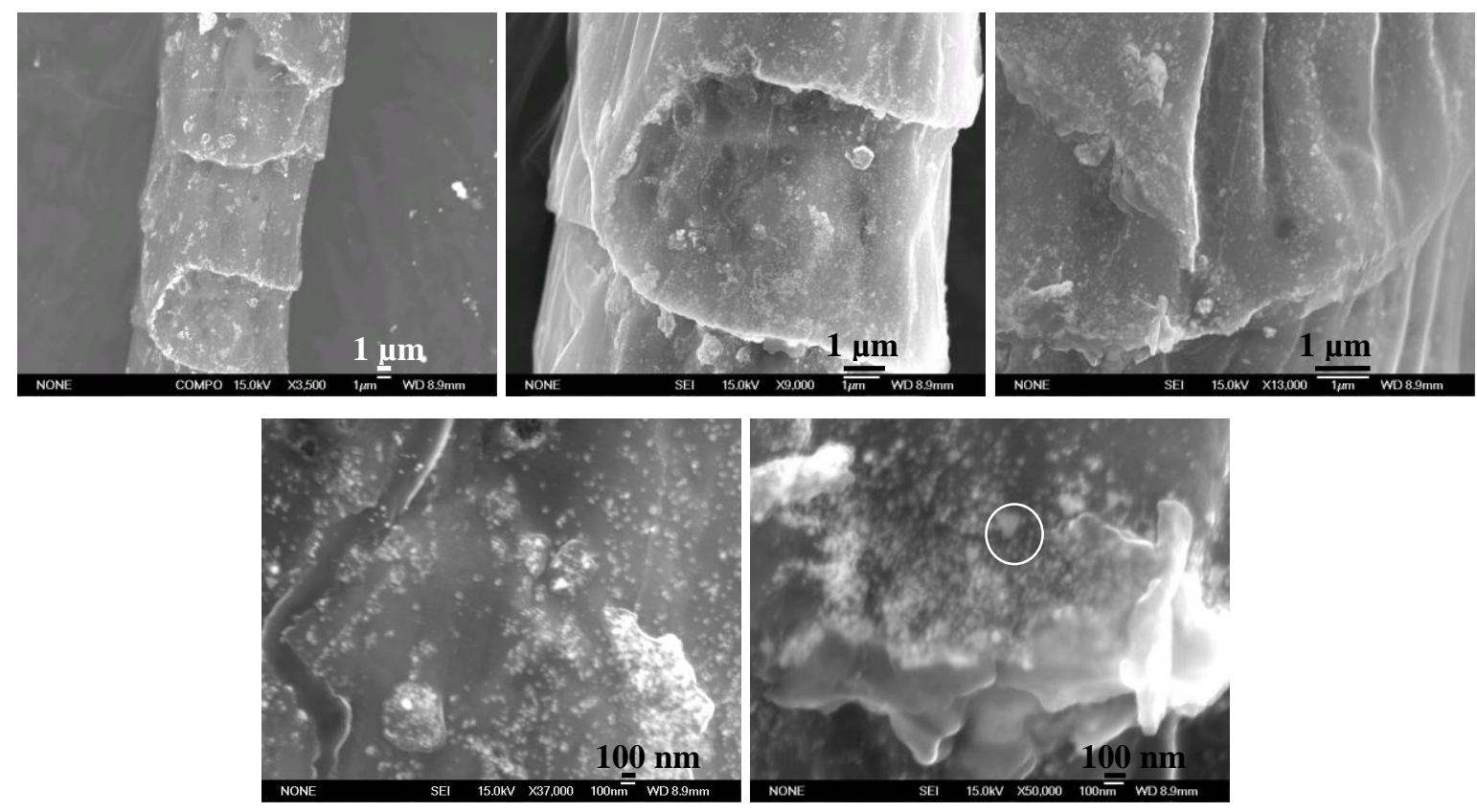

Figure 5.11: Increasing magnification SEM micrographs of a gold nanoparticle-merino wool composite prepared by ageing in a $960 \mathrm{ppm} \mathrm{Au}^{3+}\left(4.87 \times 10^{-3} \mathrm{M}\right)$ solution for 24 hours at $50{ }^{\circ} \mathrm{C}$.

Increasing the $\mathrm{Au}^{3+}$ concentration further to $1040 \mathrm{ppm}\left(5.28 \times 10^{-3} \mathrm{M}\right)$ saw a darkening of the resultant composite materials and the formation of slightly larger spherical nanoparticles (approximately 50-60 $\mathrm{nm}$ in diameter) and a greater proportion of triangular nanoplates and truncated triangular nanoplates (approximately $100 \mathrm{~nm}$ in diameter) (Figure 5.12, circled). These nanoparticles were not as isolated as those in the composite prepared with a $960 \mathrm{ppm}$ $\mathrm{Au}^{3+}$ solution, instead existing predominantly as large agglomerates. The range of particle sizes and shapes would give rise to broad absorptions in the visible region (see section 5.2), and hence the observed grey colour of these materials. 

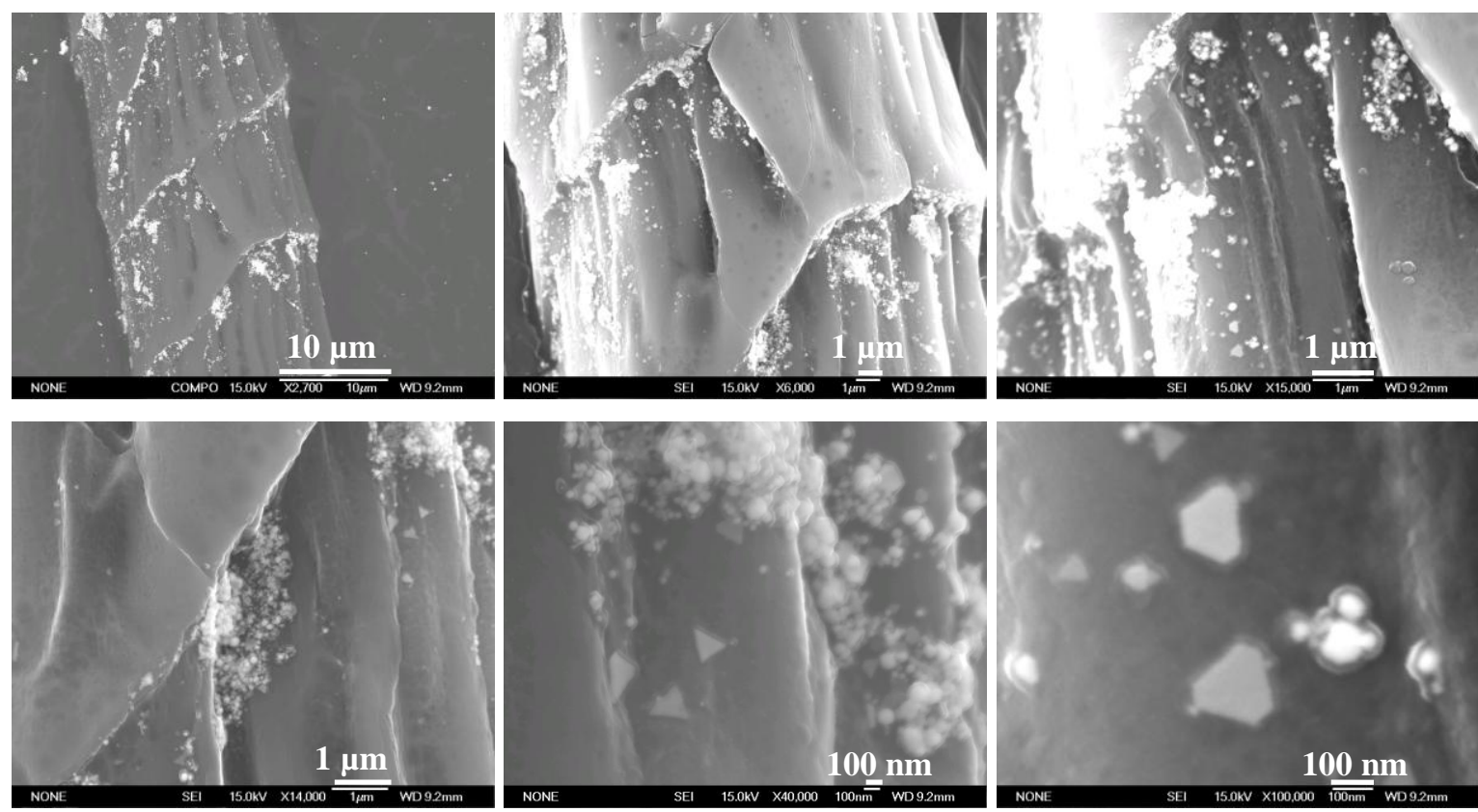

Figure 5.12: Increasing magnification SEM micrographs of a gold nanoparticle-merino wool composite prepared by ageing in a $1040 \mathrm{ppm} \mathrm{Au}^{3+}\left(5.28 \times 10^{-3} \mathrm{M}\right)$ solution for 24 hours at $50{ }^{\circ} \mathrm{C}$.

It is likely that there were a higher percentage of anisotropic, triangular gold nanoparticles present in composites prepared with high $\mathrm{Au}^{3+}$ concentrations, as in these systems the ratio of reductant (wool) to $\mathrm{Au}^{3+}$ is high, and as such when the initial nucleation events take place, only a small percentage of the $\mathrm{Au}^{3+}$ would initially be reduced, leaving a relatively high concentration of $\mathrm{Au}^{3+}$ in solution. It is probable that a percentage of these initially formed nanoparticles would contain twin plane defects, which as discussed in section 1.3.3 create favourable sites (grooves) for additional metal ions to adsorb and become reduced. This results in specific sides of the particles growing faster than others, thus promoting the formation of anisotropic nanoparticles such as triangular nanoplates. The unreduced $\mathrm{Au}^{3+}$ in solution may adsorb into these defects, thus forming triangular nanoplates or truncated triangular nanoplates, depending on the extent of growth. Alternatively, the $\mathrm{Au}^{3+}$ in solution may form new nucleation sites, growing into spheres or five-fold twinned particles. Such twinned particles could also be present in composite materials prepared with lower $\mathrm{Au}^{3+}$ concentrations, however they may not grow into anisotropic particles as following the initial nucleation events the concentration of $\mathrm{Au}^{3+}$ in solution would be lower, and as such there would be less $\mathrm{Au}^{3+}$ available to adsorb onto such twinned particles forming triangular nanoparticles etc. Due to the organic nature of the composite materials, it was difficult to obtain concise images of such twinned particles, however two TEM micrographs of a gold 
nanoparticle-merino wool composite, prepared by soaking untreated semi-worsted merino wool in a $160 \mathrm{ppm}\left(8.13 \times 10^{-4} \mathrm{M}\right) \mathrm{Au}^{3+}$ solution for 24 hours at RT, followed by ageing at $50{ }^{\circ} \mathrm{C}$ for 24 hours, are offered in Figure 5.13 in which such defects are faintly apparent.
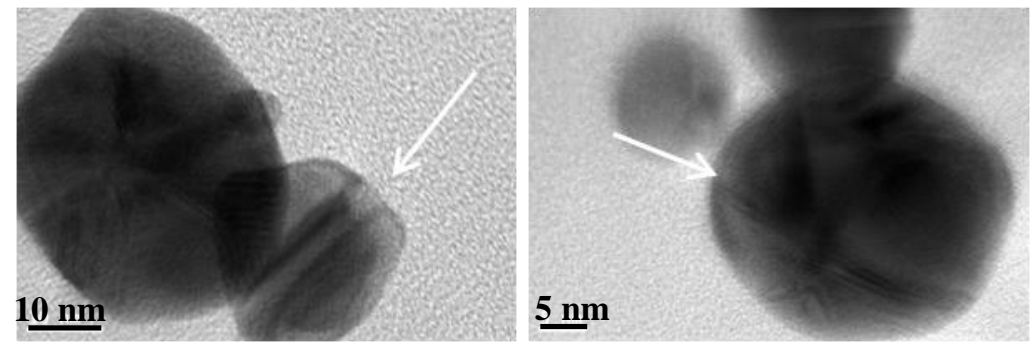

Figure 5.13: TEM micrographs of gold nanoparticles in composite materials prepared by soaking in a $160 \mathrm{ppm} \mathrm{Au}^{3+}\left(8.13 \times 10^{-4} \mathrm{M}\right)$ solution for 24 hours at RT, followed by ageing at $50{ }^{\circ} \mathrm{C}$ for 24 hours. Arrows indicate the position of the twin plane defects.

\subsubsection{Heating/Ageing Time}

In addition to the soaking time, the heating/ageing time also influenced the colour of the resultant gold nanoparticle-merino wool composites. Increasing the heating/ageing time (at $50{ }^{\circ} \mathrm{C}$ ) from 24 to 72 hours saw a very gradual change in colour of the resultant gold nanoparticle-merino wool composites. With a gold concentration of $160 \mathrm{ppm}\left(8.13 \times 10^{-4}\right.$ $\mathrm{M}$ ), and a soaking time, at RT, or 24 hours, this colour change was from pale pink to pink (neither of which were very vibrant). A major colour change was not observed until an ageing time of 168 hours was employed, with the development of a rich, regal purple coloured composite (Figure 5.14). Increasing the ageing time further did not alter the colour of the resultant composite materials.

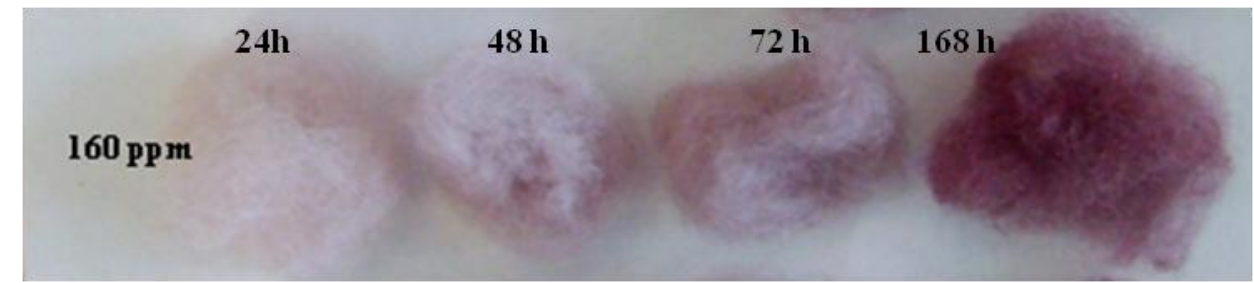

Figure 5.14: Gold nanoparticle-merino wool composites prepared via the in-situ method. Merino wool soaked in a gold solution for 24 hours at RT, followed by ageing at $50{ }^{\circ} \mathrm{C}$ for $24-168 \mathrm{~h}$. Shows the effect of ageing time on colour development. 
Figure 5.15 offers increasing magnification SEM micrographs of composites prepared with a $\mathrm{Au}^{3+}$ concentration of $160 \mathrm{ppm}\left(8.13 \times 10^{-4} \mathrm{M}\right)$, soaking time of 24 hours and ageing times at $50{ }^{\circ} \mathrm{C}$ varying from 24-168 hours. At low magnifications it is difficult to discern any morphological differences between the materials prepared with different ageing times. In all, the gold nanoparticles appear to reside preferentially at the cuticle edges where surface tension and free energy is highest. However in the material that had been aged for 168 hours, the nanoparticles no longer appear to be confined to these regions, rather they spread slightly across the fibre surface.

TEM, which offers increased spatial resolution was able to distinguish further morphological differences induced by increased ageing times. Figure 5.16 offers increasing magnification TEM micrographs of a selection of samples prepared with increased ageing times (soaking in a $160 \mathrm{ppm}\left(8.13 \times 10^{-4} \mathrm{M}\right) \mathrm{Au}^{3+}$ solution for 24 hours followed by ageing at $50{ }^{\circ} \mathrm{C}$ for 24,72 or 168 hours (top to bottom)). It is apparent from the low magnification micrographs that the nanoparticles located on the fibre surface reside preferentially along cuticle edges, confirming the SEM observations made above. The size of the nanoparticles on the fibre surface remains relatively constant following prolonged ageing, with these nanoparticles being predominantly five-fold twinned particles, approximately $20-25 \mathrm{~nm}$ in diameter. However closer examination of the centre of the fibres shows the formation of small spherical nanoparticles, appearing solely with ageing times greater than 72 hours (Figure 5.17). These spheres are approximately 5-10 $\mathrm{nm}$ in diameter and are relatively monodisperse. 

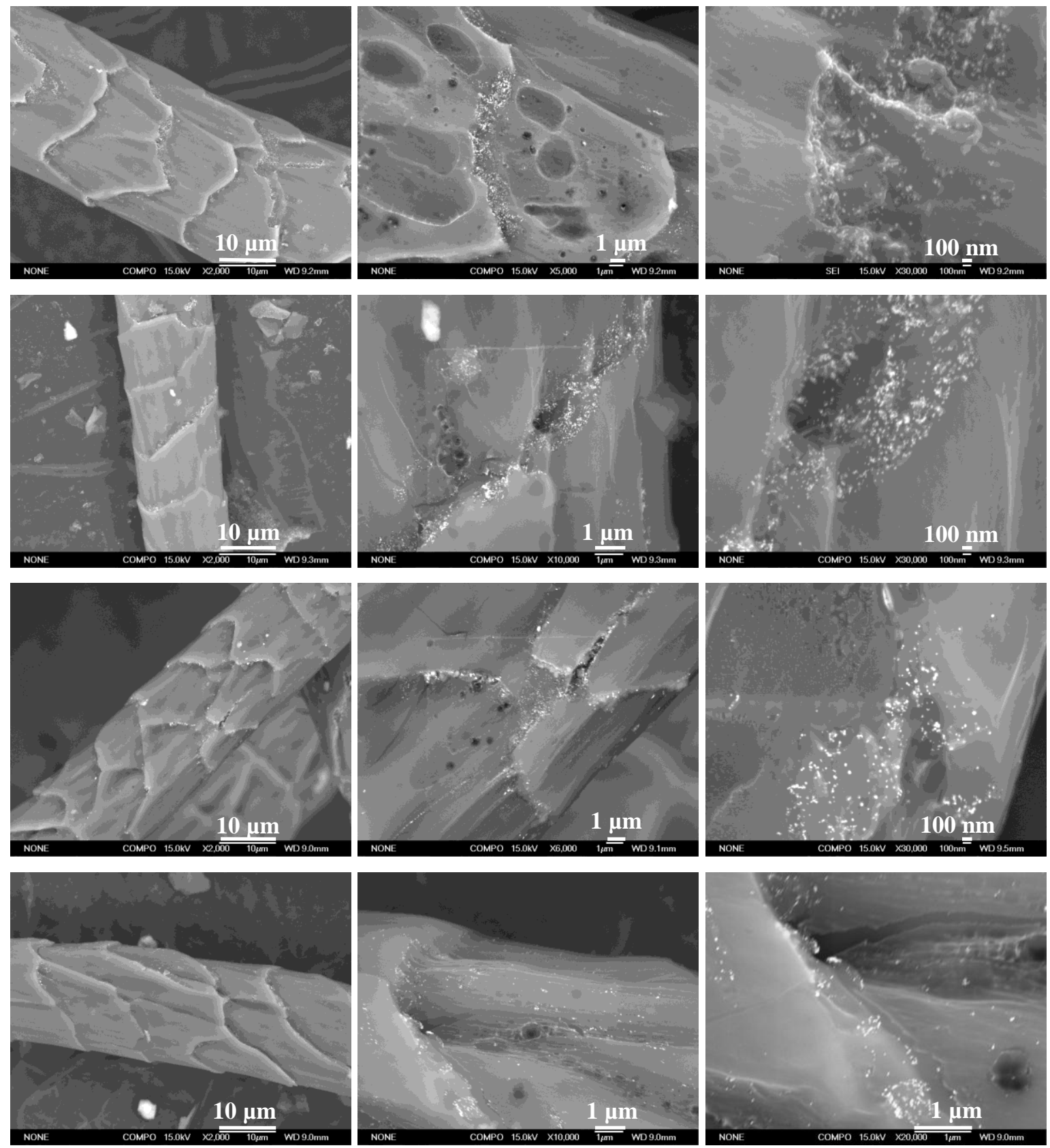

Figure 5.15: Increasing magnification SEM micrographs of gold nanoparticle-merino wool composites prepared by soaking in a $160 \mathrm{ppm}\left(8.13 \times 10^{-4} \mathrm{M}\right) \mathrm{Au}^{3+}$ solution for 24 hours followed by ageing at $50{ }^{\circ} \mathrm{C}$ for $24,48,72$ or 168 hours (top to bottom). 

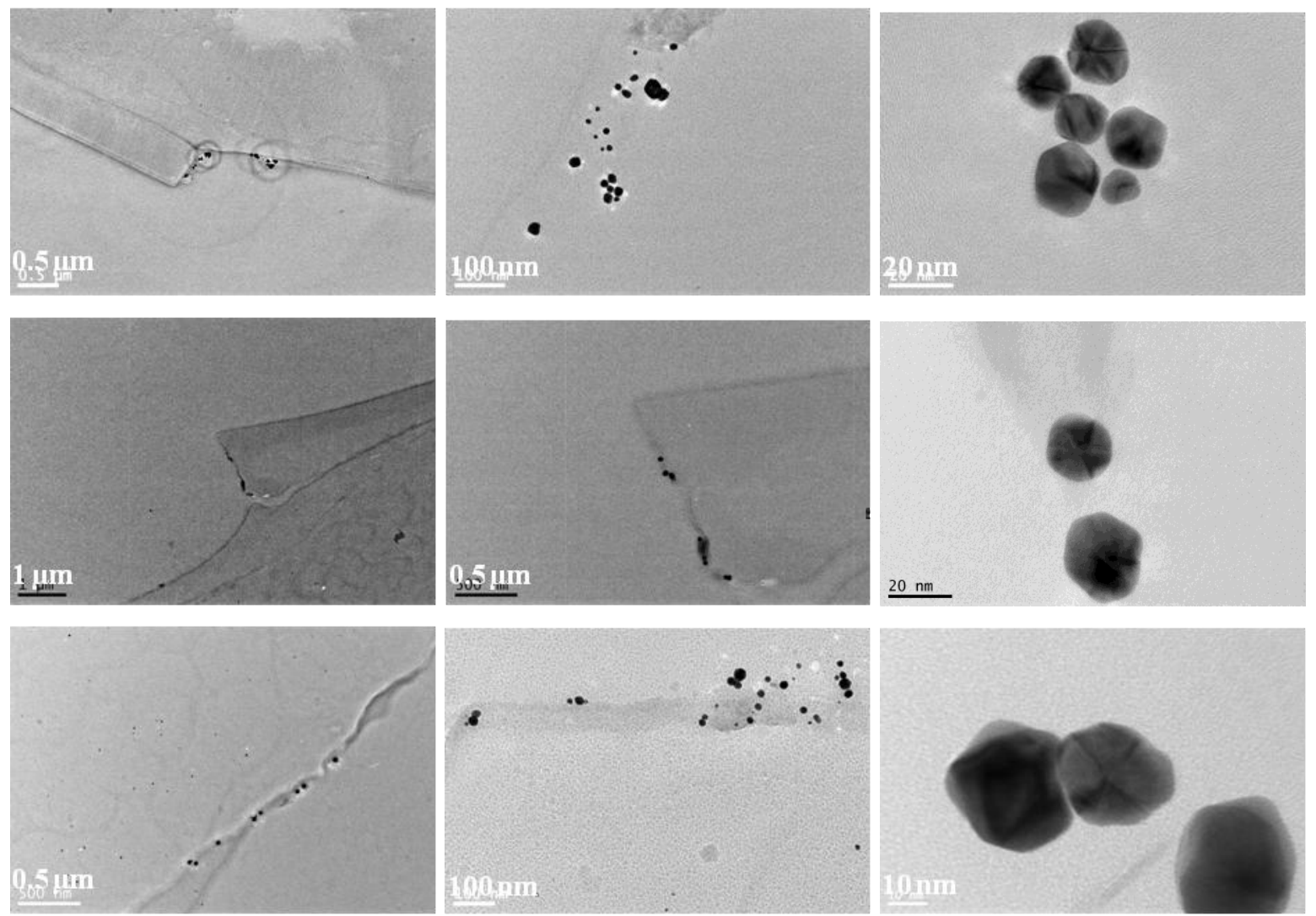

Figure 5.16: Increasing magnification TEM micrographs of gold nanoparticle-merino wool composites prepared by soaking in a $160 \mathrm{ppm}\left(8.13 \times 10^{-4} \mathrm{M}\right) \mathrm{Au}^{3+}$ solution for 24 hours followed by ageing at $50{ }^{\circ} \mathrm{C}$ for 24,72 or 168 hours (top to bottom).
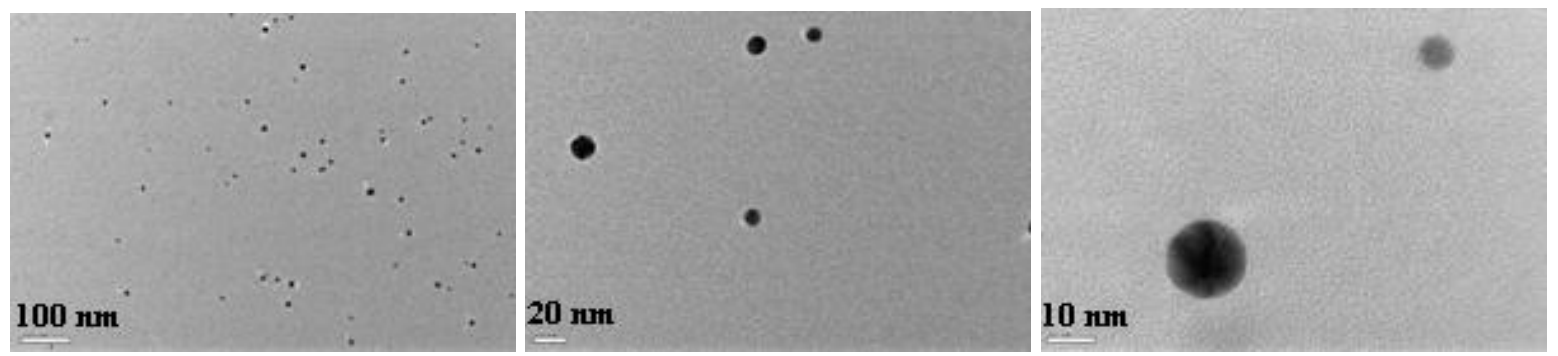

Figure 5.17: Increasing magnification TEM micrographs of nanoparticles located in the fibre centre of composites prepared by soaking in a $160 \mathrm{ppm}\left(8.13 \times 10^{-4} \mathrm{M}\right) \mathrm{Au}^{3+}$ solution for 24 hours followed by ageing at $50{ }^{\circ} \mathrm{C}$ for 168 hours.

Although gold nanoparticles were only evident in the centre of fibres that had been prepared with extended ageing periods, cross sectional EDS analysis showed that regardless of the ageing times, there were high concentrations of gold in the centre of all composites prepared by soaking in a $160 \mathrm{ppm}\left(8.13 \times 10^{-4} \mathrm{M}\right) \mathrm{Au}^{3+}$ solution for 24 hours followed by ageing at 50 ${ }^{\circ} \mathrm{C}$ for 24-168 hours (Figure 5.18 below and Figure 5.9 above). This suggested that in all 
samples, gold had diffused through to the centre of the fibres, however it was only reduced to nanoparticulate $\mathrm{Au}^{0}$ in those heated for longer than 72 hours.

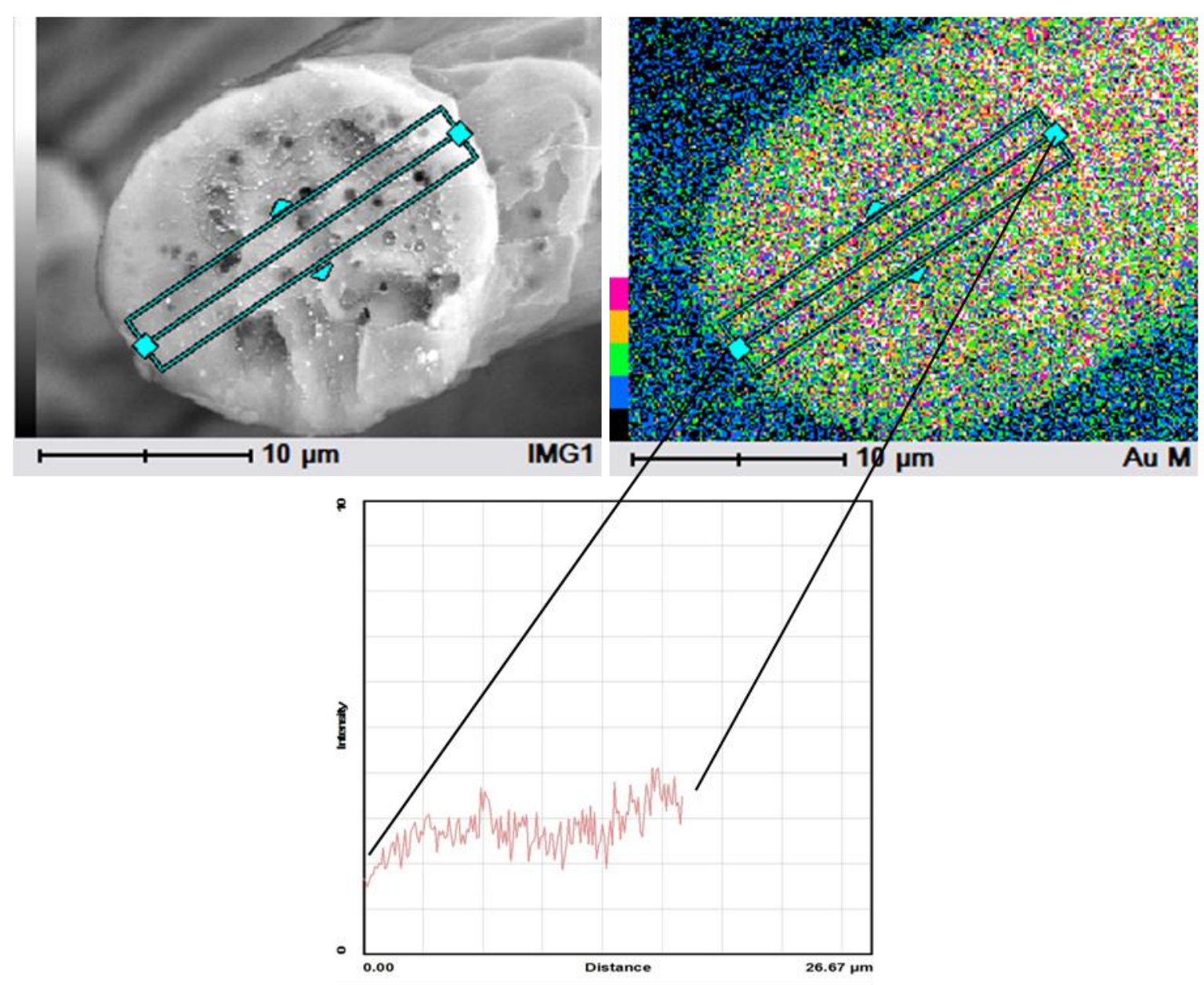

Figure 5.18: Cross sectional SEM micrograph (left), and corresponding Au EDS map (right) of a composite material prepared from a $160 \mathrm{ppm}\left(8.13 \times 10^{-4} \mathrm{M}\right)$ gold solution, with $24 \mathrm{~h}$ soaking and $24 \mathrm{~h}$ ageing at $50^{\circ} \mathrm{C}$. A line profile is offered (bottom) showing higher gold concentrations at the fibre surface relative to the centre.

\subsubsection{Soaking and Heating/Ageing Solution Compositions}

As mentioned in section 5.1.2.1 and elaborated in section 5.4, the absorption of gold by merino wool at RT was largely complete after 1 hour, however a soaking time of 24 hours was required for optimum colour development. The composition of this soaking solution was influential on colour development. Figure 5.19 offers a picture of gold nanoparticle- 
merino wool composites that had been soaked in a $160 \mathrm{ppm}\left(8.13 \times 10^{-4} \mathrm{M}\right) \mathrm{Au}^{3+}$ solution for 1 hour at RT to ensure the absorption of gold, after which they were transferred to $10 \mathrm{ml}$ aqueous solutions containing $40 \mu \mathrm{L}$ of $0.1 \mathrm{M} \mathrm{HCl}$ or $\mathrm{NaCl}$, soaked at $\mathrm{RT}$ for an additional 23 hours, and subsequently aged at $50{ }^{\circ} \mathrm{C}$ for $24-168$ hours. (These solutions were chosen as they are close representatives of the original $\mathrm{Au}^{3+}$ solutions, which comprise $40 \mu \mathrm{L}$ of $4 \mathrm{wt} \%$ $\mathrm{Au}^{3+}$ prepared by dissolving the requisite amount of $\mathrm{HAuCl}_{4} \cdot 3 \mathrm{H}_{2} \mathrm{O}$ in $0.1 \mathrm{M} \mathrm{HCl}$ ), and exhibit a $\mathrm{pH}$ of approximately 2.7. This does not change throughout the course of the reaction). Comparing these materials to those whose soaking (and therefore ageing) solution had not been altered shows that changing the soaking (and therefore ageing) solution influenced the colour of the resultant composites, producing materials that were much less intense in colour than those utilising the original $\mathrm{Au}^{3+}$ soaking solution as the ageing solution. Comparable results were obtained when transferring the merino wool fibres to Millipore water or a 0.1 M, pH 3 acetate buffer (Figure 5.20).

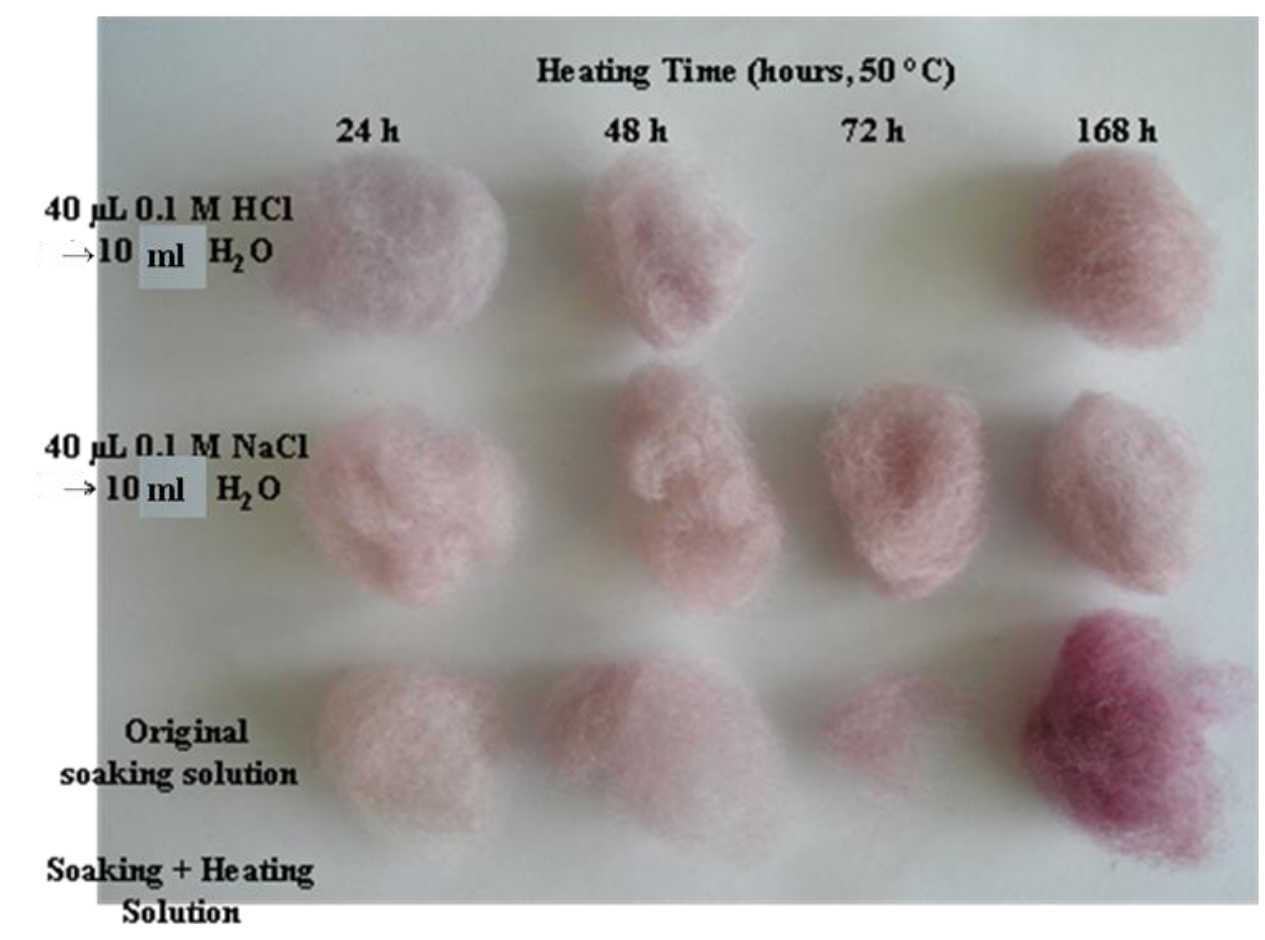

Figure 5.19: Gold nanoparticle-merino wool composites prepared by soaking untreated semi-worsted merino in a $160 \mathrm{ppm}\left(8.13 \times 10^{-4} \mathrm{M}\right) \mathrm{Au}^{3+}$ solution for 1 hour at RT, after which the fibres were transferred to alternate solutions (top and middle) and soaking continued for a further 23 hours and then heated at $50{ }^{\circ} \mathrm{C}$ for 24-168 hours. 


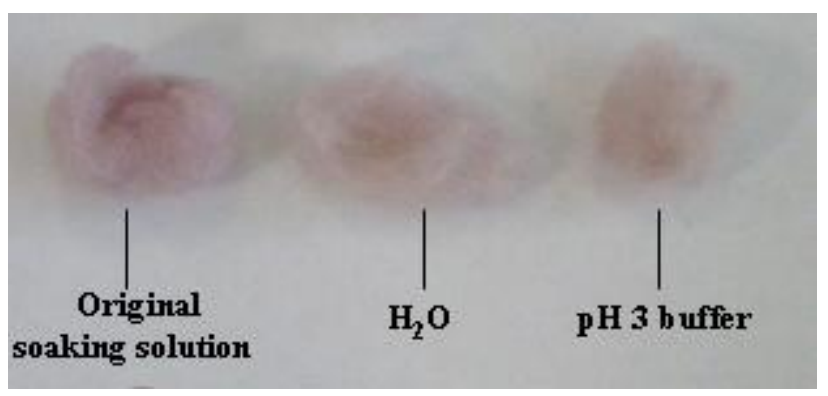

Figure 5.20: Gold nanoparticle-merino wool composites prepared by soaking untreated semi-worsted merino in a $160 \mathrm{ppm}\left(8.13 \times 10^{-4} \mathrm{M}\right) \mathrm{Au}^{3+}$ solution for 1 hour at RT, after which it was transferred to: middle: Millipore water or right: a pH 3 buffer, and soaked for a further 23 hours, and heated at $50{ }^{\circ} \mathrm{C}$ for 48 hours. The soaking solution of the sample on the left was not altered.

In addition to changing the composition of the soaking solution, changing the composition of the ageing solution alone also influenced the colour of the resultant composite materials. Figure 5.21 offers a picture of gold nanoparticle-merino wool composites that had been soaked in a $160 \mathrm{ppm}\left(8.13 \times 10^{-4} \mathrm{M}\right) \mathrm{Au}^{3+}$ solution for 24 hours at RT, followed by ageing in various solutions at $50{ }^{\circ} \mathrm{C}$ for $24-168$ hours. Ageing in Millipore water, or solutions of similar $\mathrm{pH}$ and $\mathrm{Cl}^{-}$concentrations $(10 \mathrm{ml}$ aqueous solutions containing $40 \mu \mathrm{L}$ of $0.1 \mathrm{M} \mathrm{HCl}$ or $\mathrm{NaCl}$ ) again produced materials that were much less intense in colour than the analogues aged in the original $\mathrm{Au}^{3+}$ soaking solutions. This decreased colour is likely reflective of the formation of less $\mathrm{Au}^{0}$ nanoparticles (as evidenced in SEM studies of similarly coloured composites).

The increased $\mathrm{pH}$ of the system is not likely to adversely affect the formation of nanoparticles and hence colour development, as discussed in section 5.1.2.7 below. Increasing the $\mathrm{pH}$ of the ageing solution acts to increase the $\mathrm{Au}^{3+}$ to $\mathrm{Au}^{0}$ reduction rate and hence colour development. Therefore it could be thought that less nanoparticles form due to the lower ionic strength of the ageing solution, resulting in a decrease in electrolytes present to facilitate the transfer of electrons from the reducing and oxidising species in the reaction mixture (the proteins in merino wool and $\mathrm{Au}^{3+}$ respectively). Aqueous solutions containing $40 \mu \mathrm{L}$ of $0.1 \mathrm{M} \mathrm{HCl}$ or $\mathrm{NaCl}$ should possess similar ionic strengths as the original $\mathrm{Au}^{3+}$ solution, and as such should produce similarly coloured gold nanoparticle-merino wool composites. The fact that they don't, suggests that during the absorption of gold, other ions 
(for example $\mathrm{Ca}^{2+}$ or $\mathrm{Na}^{+}$) may be displaced from the wool into the soaking solutioon, increasing the ionic strength of the original $\mathrm{Au}^{3+}$ solution, and hence the ease at which the $\mathrm{Au}^{3+}$ to $\mathrm{Au}^{0}$ reduction occurs.

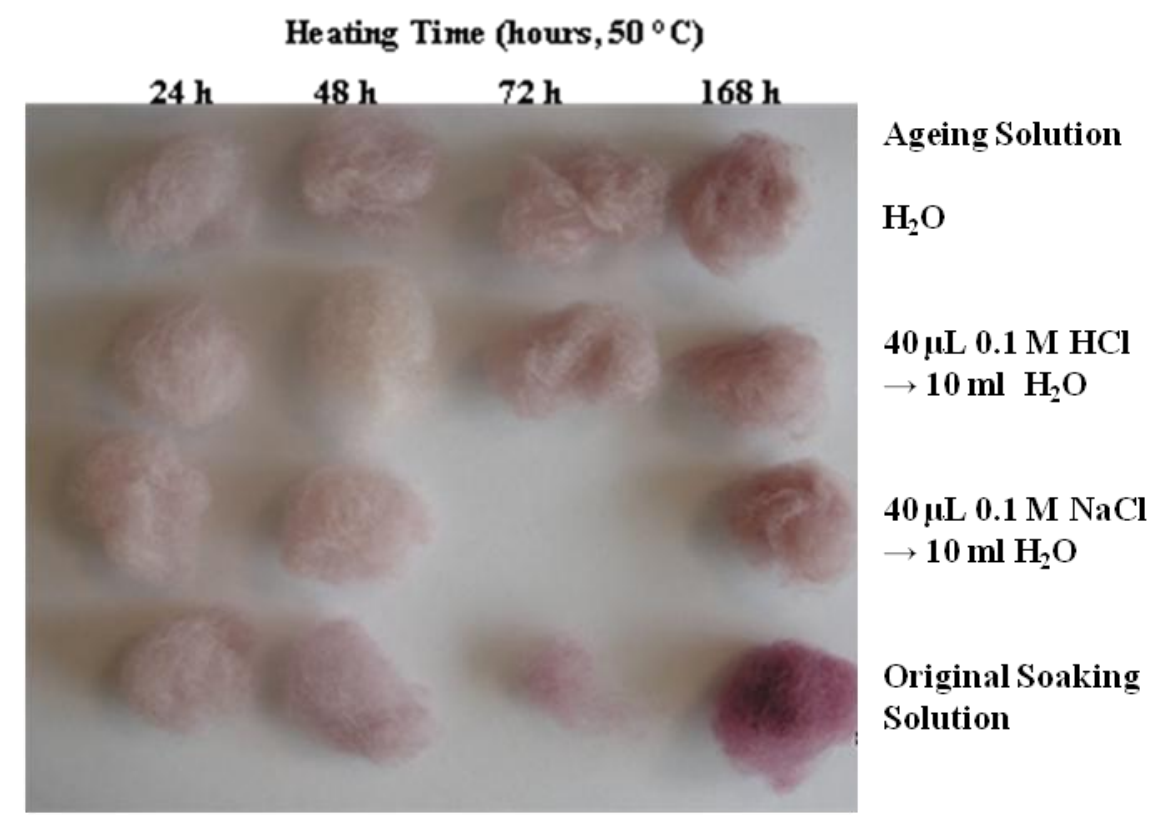

Figure 5.21: Gold nanoparticle-merino wool composites prepared by soaking untreated semi-worsted merino wool in a $160 \mathrm{ppm}\left(8.13 \times 10^{-4} \mathrm{M}\right) \mathrm{Au}^{3+}$ solution for 24 hours, transferring to an alternate ageing solution and ageing at $50{ }^{\circ} \mathrm{C}$ for $24-168$ hours.

To investigate whether the decreased colour intensity of the gold nanoparticle-merino wool composites prepared in alternate ageing solutions was a result of fewer electrolytes, the original $\mathrm{Au}^{3+}$ ageing solution was replaced with aqueous $\mathrm{NaCl}$ solutions $(0.1 \mathrm{M}, 10 \mathrm{ml})$. The resultant composite materials prepared with 24 hours soaking at RT and 24 hours ageing at $50{ }^{\circ} \mathrm{C}$ were more vibrant pink in colour, suggesting the formation of a greater amount of nanoparticles, occurring due to the increased ionic strength of the ageing solution. However prolonged ageing decreased the spectral purity of this pink colour (Figure 5.22), which even with 168 hours ageing at $50{ }^{\circ} \mathrm{C}$, did not develop into the deep, regal purple colour attained when ageing in the original $\mathrm{Au}^{3+}$ soaking solution. 


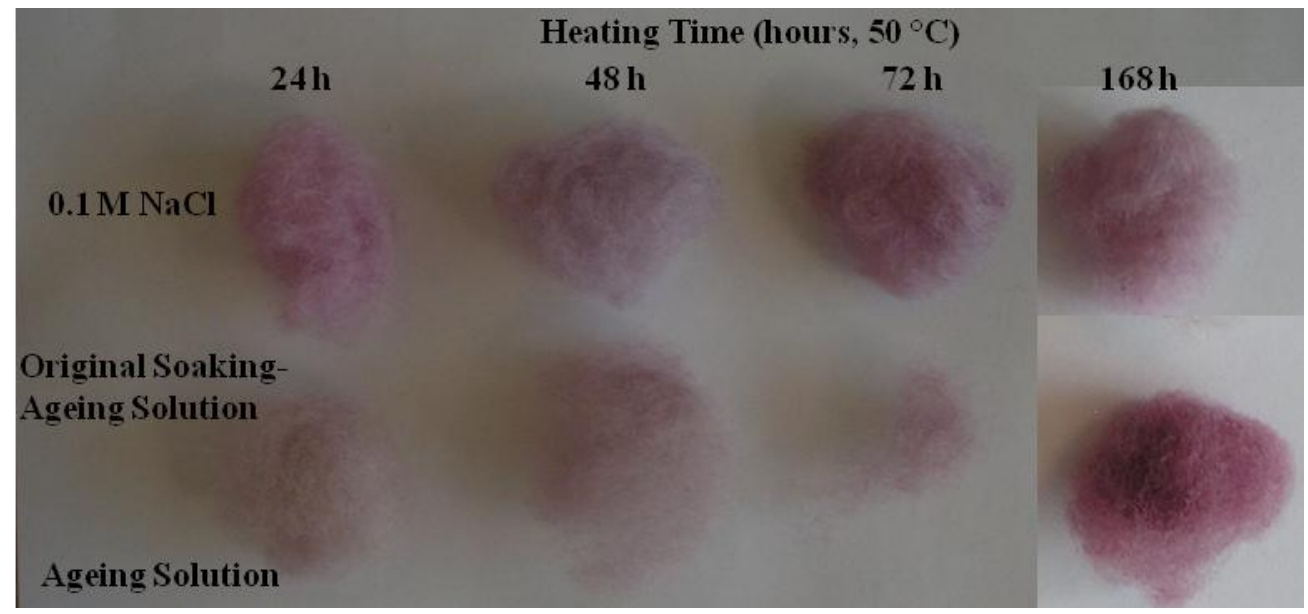

Figure 5.22: Gold nanoparticle-merino wool composites prepared by soaking untreated semi-worsted merino wool in a $160 \mathrm{ppm}\left(8.13 \times 10^{-4} \mathrm{M}\right) \mathrm{Au}^{3+}$ solution for 24 hours at $\mathrm{RT}$, followed by ageing at $50{ }^{\circ} \mathrm{C}$ in a $0.1 \mathrm{M} \mathrm{NaCl}$ solution (top) or the original soaking solution (bottom) for 24-168 hours.

Examination of the SEM micrographs of the gold nanoparticle-merino wool composites prepared with $0.1 \mathrm{M} \mathrm{NaCl}$ ageing solutions revealed slight differences in the morphologies of composites aged in the original soaking solutions (Figure 5.23), confirming that the more vibrant colours arose due to the formation of an increased number of nanoparticles. Ageing for 24 hours appeared to produce composites in which the nanoparticles were slightly more abundant and smaller (approximately 10-20 nm in diameter (Figure 5.24)), than those present on composites aged in the original soaking solution. Additionally, these nanoparticles were not confined to the cuticle edges to such a great extent, rather spreading slightly across the fibre surface. This is likely to account for the brighter, more vibrant colour of these materials. Increasing the ageing time to 168 hours saw the formation of more nanoparticles, some of which were slightly larger in size, approximately $20-30 \mathrm{~nm}$ in diameter (Figure 5.24). Agglomerations of a small percentage of particles also appeared, which would likely account for the less spectrally pure colour of these materials. 

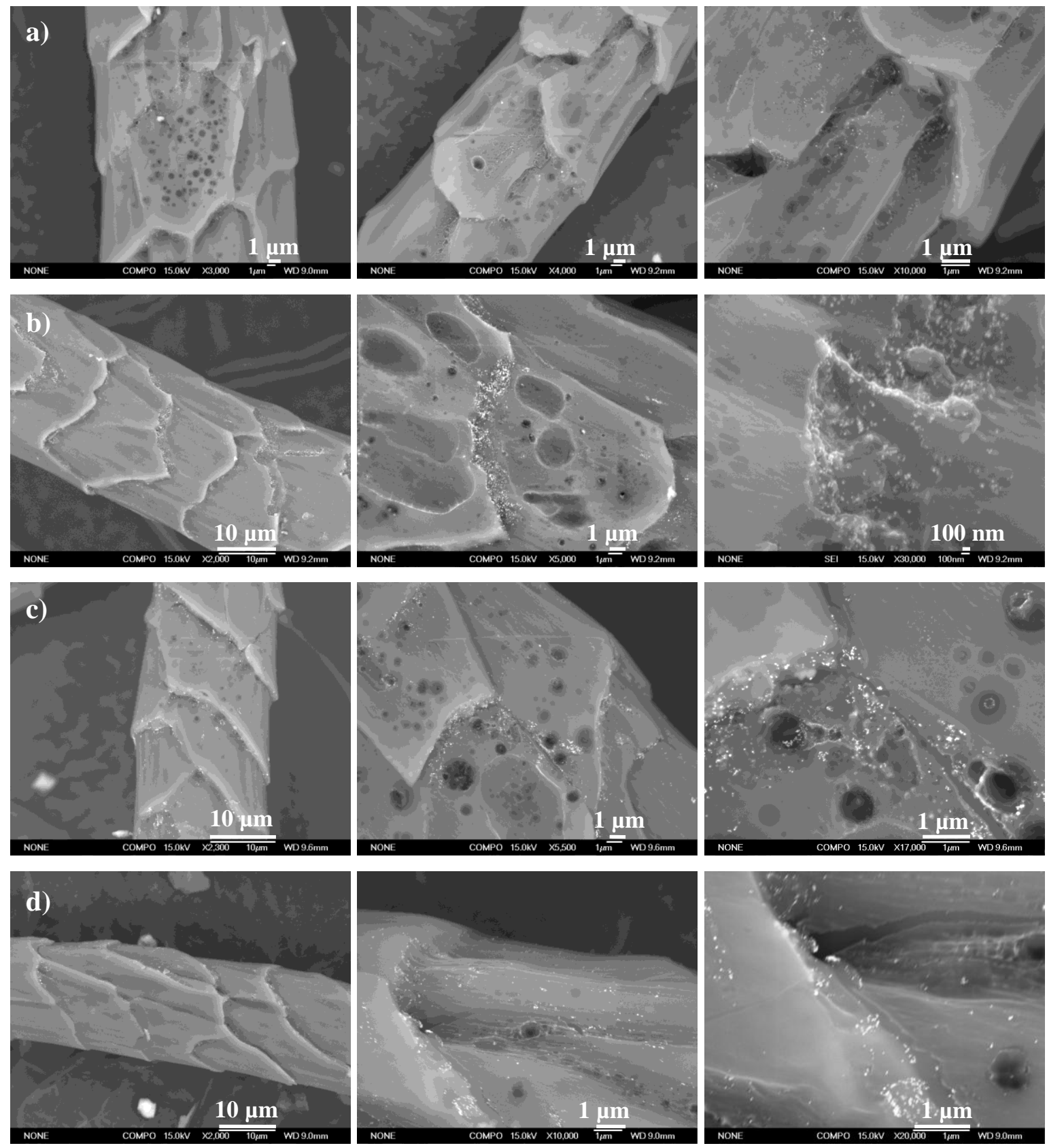

Figure 5.23: Increasing magnification SEM micrographs of gold nanoparticle-merino wool composites prepared by soaking untreated semi-worsted merino wool in a $160 \mathrm{ppm}\left(8.13 \times 10^{-4} \mathrm{M}\right) \mathrm{Au}^{3+}$ solution for 24 hours at RT, followed by ageing at $50{ }^{\circ} \mathrm{C}$ in a $0.1 \mathrm{M} \mathrm{NaCl}$ solution for 24 or 168 hours (row a and c respectively) or the original soaking solution for 24 or 168 hours (row b and d respectively. 

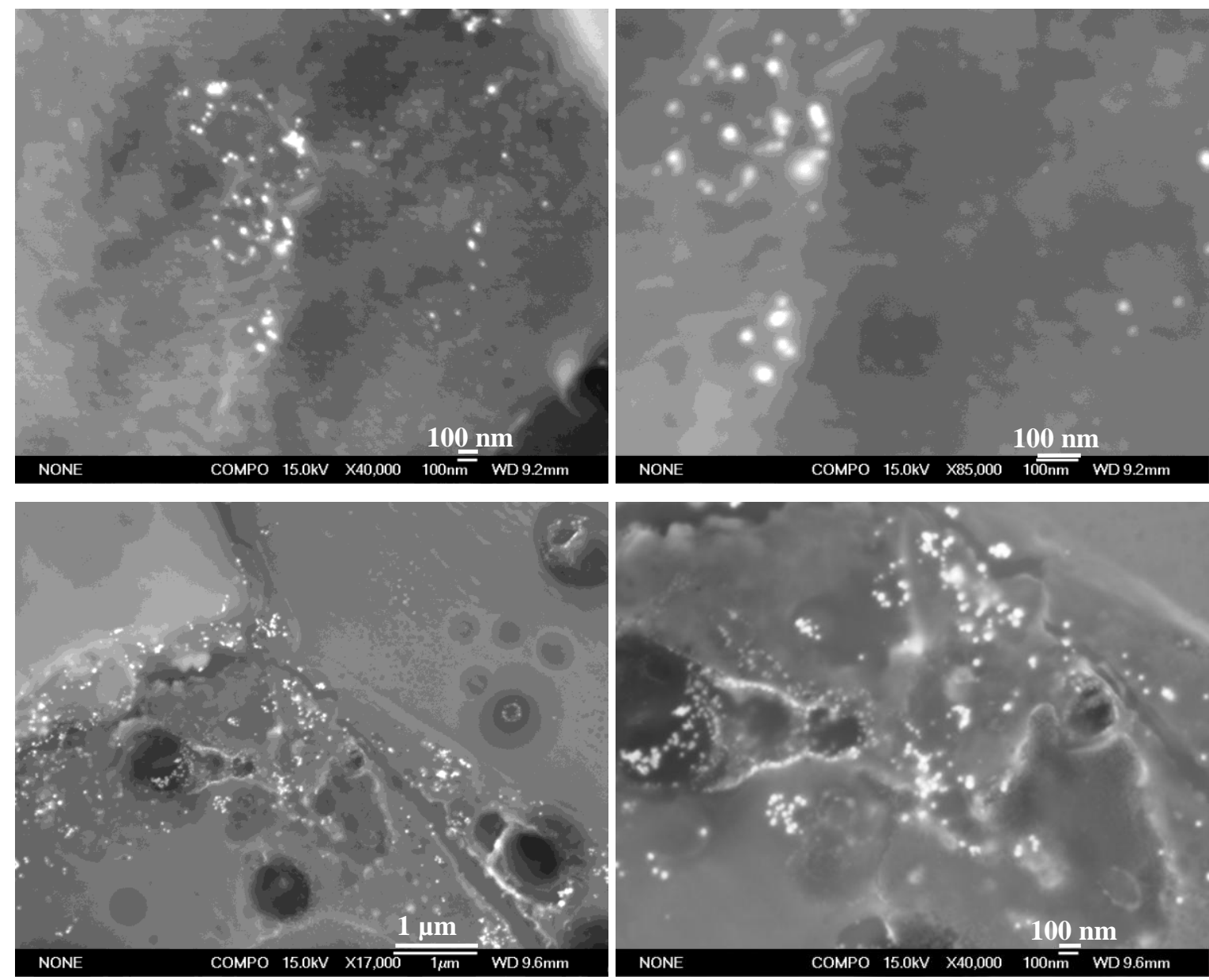

Figure 5.24: Increased magnification SEM micrographs of gold nanoparticle-merino wool composites prepared by soaking untreated semi-worsted merino wool in a $160 \mathrm{ppm}\left(8.13 \times 10^{-4} \mathrm{M}\right) \mathrm{Au}^{3+}$ solution for 24 hours at RT, followed by ageing at $50{ }^{\circ} \mathrm{C}$ in a $0.1 \mathrm{M} \mathrm{NaCl}$ solution for 24 (top) or 168 (bottom) hours.

Additionally, cross sectional SEM analysis of the gold nanoparticle-merino wool composites prepared with $0.1 \mathrm{M} \mathrm{NaCl}$ ageing solutions showed that compared to the composites utilising the original $\mathrm{Au}^{3+}$ soaking solutions as the ageing solutions in which nanoparticles were found right throughout the fibre centre, the nanoparticles were located predominantly on the fibre surface and within the cuticle cells (Figure 5.25). There were however high concentrations of gold right throughout the fibre (as shown by cross sectional EDS analysis), (Figure 5.26). As the regal purple colour of the gold nanoparticle-merino wool composites corresponds to materials in which nanoparticles are found both on the surface and within the centre of the fibres, this lack of nanoparticles located in the fibre centre may account for the spectrally impure pink rather than purple colour of the materials aged in $\mathrm{NaCl}$ for 168 hours. 

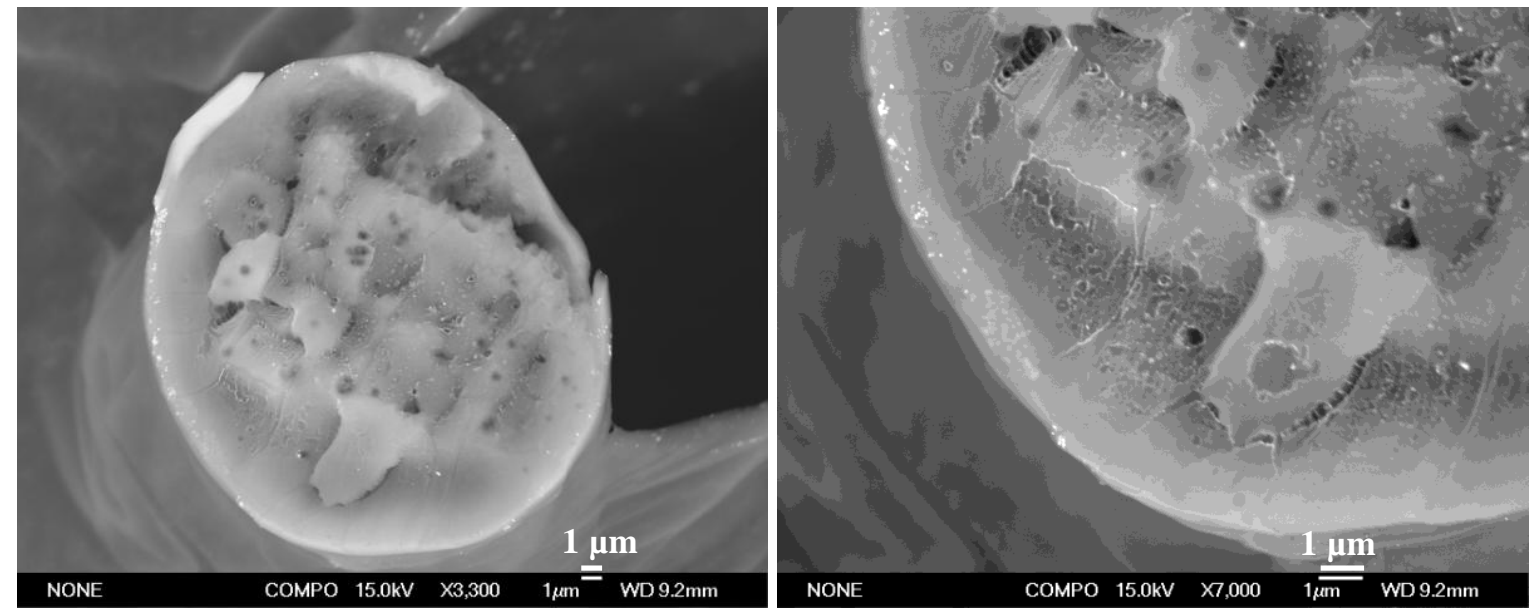

Figure 5.25: Cross sectional SEM micrograph of a gold nanoparticle-merino wool composite prepared with a $0.1 \mathrm{M} \mathrm{NaCl}$ ageing solution.
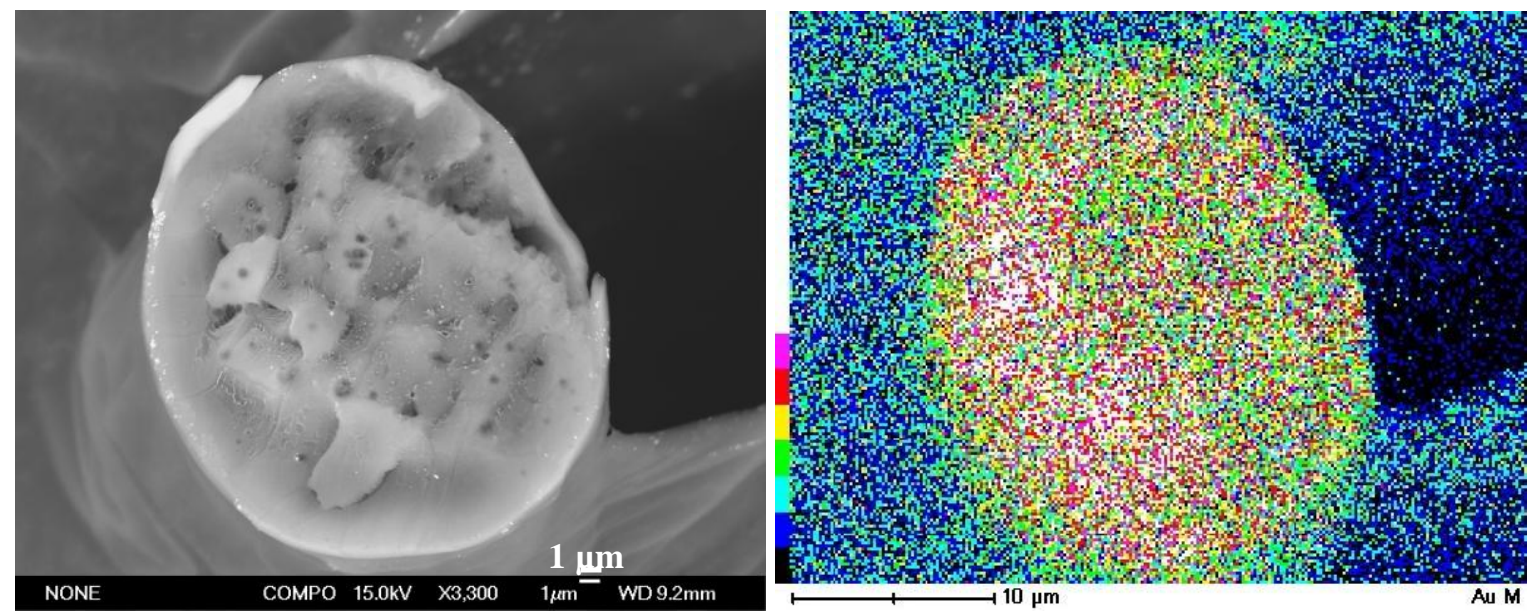

Figure 5.26: Cross sectional SEM and corresponding Au EDS map of a gold nanoparticle-merino wool composite prepared by soaking untreated semi-worsted merino wool in a $160 \mathrm{ppm}\left(8.13 \times 10^{-4} \mathrm{M}\right) \mathrm{Au}^{3+}$ solution for 24 hours at RT, followed by ageing at $50{ }^{\circ} \mathrm{C}$ for 168 hours in a $0.1 \mathrm{M}$ NaCl solution.

It is likely that more vibrantly coloured gold nanoparticle-merino wool composites are initially produced when soaking or ageing in a $0.1 \mathrm{M} \mathrm{NaCl}$ solution as the increased concentration of electrolytes facilitates the transfer of electrons from the reductant to the oxidant, forming a greater number of nanoparticles in a shorter period of time. The fact that the deep regal purple colour is not produced, even with prolonged ageing at $50{ }^{\circ} \mathrm{C}$, may also be related to the increased electrolyte $\left(\mathrm{Cl}^{-}\right)$concentration. Cross sectional EDS analysis of composites prepared with $0.1 \mathrm{M} \mathrm{NaCl}$ ageing solutions showed there to be relatively high concentrations of $\mathrm{Cl}^{-}$inside the wool fibre, markedly more so than in composites prepared by soaking and ageing in the original $\mathrm{Au}^{3+}$ solution (Figure 5.28). Analysis of the reaction 
mixtures employing the original $\mathrm{Au}^{3+}$ soaking solution as the ageing solution showed that the $\mathrm{Cl}^{-}$concentration fell dramatically during the first three hours of soaking, after which it slowly increased (Figure 5.27). This suggests that chloride is absorbed in the form of $\mathrm{AuCl}_{4}{ }^{-}$, and then as the reduction of $\mathrm{Au}^{3+}$ to $\mathrm{Au}^{+}$occurs (see section 5.6), $\mathrm{Cl}^{-}$ions diffuse out into the reaction mixture. Increasing the chloride concentration by soaking and or ageing in $\mathrm{NaCl}$ solutions is likely to impede the desorption of $\mathrm{Cl}^{-}$ions as with an increased $\mathrm{Cl}^{-}$concentration, the concentration gradient between the fibre and solution would be less, lowering the driving force for the diffusion of $\mathrm{Cl}^{-}$ions back out of the fibre.

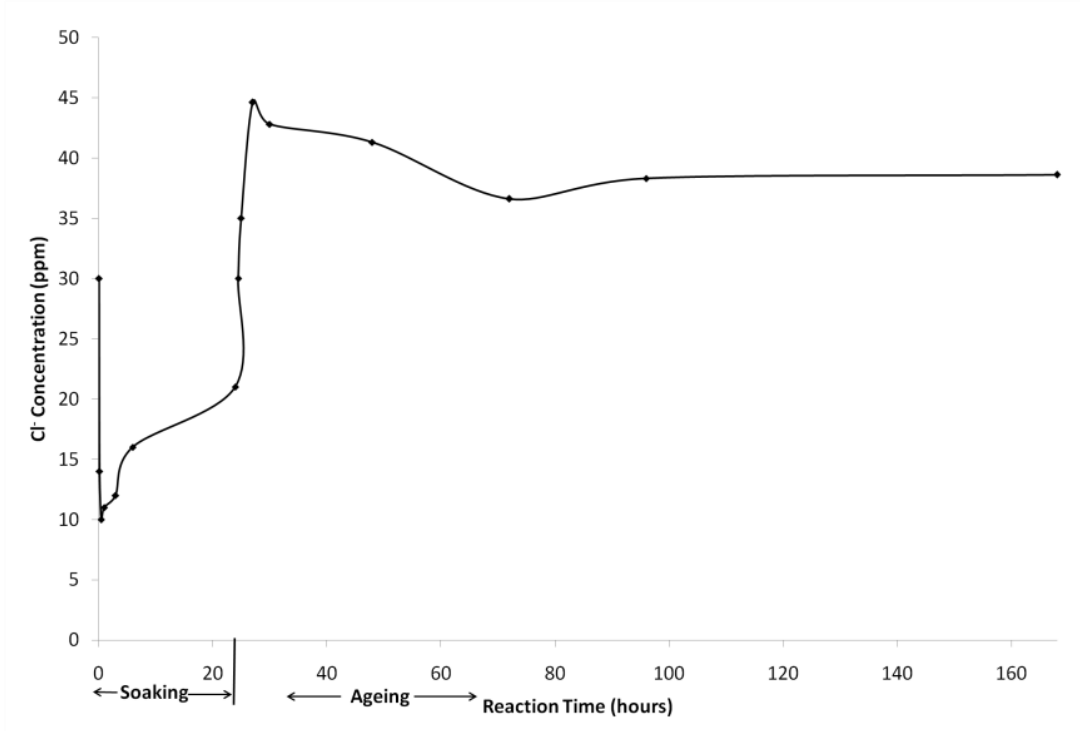

Figure 5.27: Concentration of chloride in the reaction mixture against time.

The chloride ions located inside the fibre centre may hinder the formation of $\mathrm{Au}^{0}$ nanoparticles in the centre of the fibres by obstructing $\mathrm{Au}^{3+}$ or $\mathrm{AuCl}_{4}{ }^{-}$ions converging and nucleating. This effect may be more apparent in the fibre centre rather than surface due to the increased steric hindrance imparted on the $\mathrm{Au}^{3+}$ or $\mathrm{AuCl}_{4}{ }^{-}$ions in the fibre centre. Additionally, as AA studies (see section 5.4) suggest that gold is absorbed in the form of $\mathrm{AuCl}_{4}^{-}$rather than $\mathrm{Au}^{3+}$, and as the reaction mixture has a $\mathrm{pH}$ of approximately 3 thus imparting a predominantly positive charge to the proteins in the wool fibre (due to protonation of the amine groups), the formation of $\mathrm{Au}^{0}$ nanoparticles may be assisted by the destabilisation of the $\mathrm{AuCl}_{4}{ }^{-}$complex. This could occur through the cationic quaternary 
amines of the wool fibre protein attracting the $\mathrm{Cl}^{-}$ions initially complexed to the gold. With high concentrations of $\mathrm{Cl}^{-}$a greater percentage of these cationic sites would already be passivated, preventing the attraction of $\mathrm{Cl}^{-}$ions complexed to the gold and thus increasing the energy required to break the $\mathrm{AuCl}_{4}{ }^{-}$complex and reduce $\mathrm{Au}^{3+}$ to $\mathrm{Au}^{0}$. However if this latter theory is correct, it is unclear as to why reduction still occurs at the fibre surface.
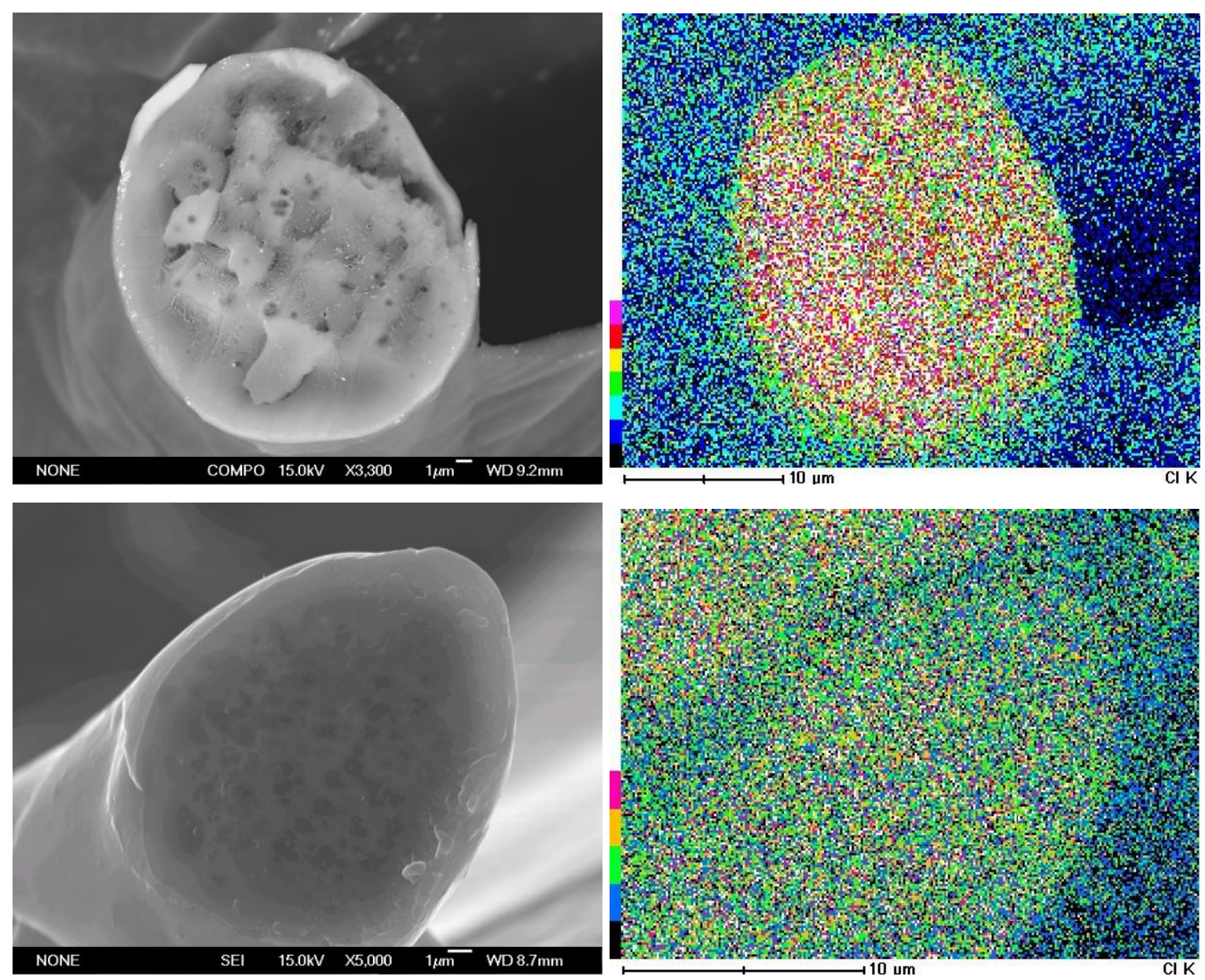

Figure 5.28: Cross sectional SEM and corresponding CI EDS maps of gold nanoparticle-merino wool composites prepared by soaking untreated semi-worsted merino wool in a $160 \mathrm{ppm}\left(8.13 \times 10^{-4} \mathrm{M}^{-\mathrm{Au}^{3+}}\right.$ solution for 24 hours at RT, followed by ageing at $50{ }^{\circ} \mathrm{C}$ for 168 hours in a $0.1 \mathrm{M} \mathrm{NaCl}$ solution (top) or the original soaking solution (bottom).

In addition to ageing in $0.1 \mathrm{M} \mathrm{NaCl}$, soaking in the same solution also influenced the colour of the resultant gold nanoparticle-merino wool composites. Figure 5.29 offers a picture of such materials. These were prepared by soaking in a $160 \mathrm{ppm}\left(8.13 \times 10^{-4} \mathrm{M}\right) \mathrm{Au}^{3+}$ solution 
for 1 hour at RT, after which they were removed and soaked at RT in a $0.1 \mathrm{M} \mathrm{NaCl}$ solution for a further 23 hours before being transferred back to the original soaking solution and aged at $50{ }^{\circ} \mathrm{C}$ for $24-168$ hours. As with ageing in a $0.1 \mathrm{M} \mathrm{NaCl}$ solution, ageing these materials for 24 hours produced a much more vibrant pink coloured composite, with increased ageing decreasing the spectral purity of the materials, rather than producing a deep regal purple coloured composite. This suggests that when soaking in a $0.1 \mathrm{M} \mathrm{NaCl}$ solution, the $\mathrm{Cl}^{-}$ions penetrate into the fibre and remain there during the ageing process, thus increasing the ionic strength of the ageing solution and facilitating the reduction of $\mathrm{Au}^{3+}$ to nanoparticulate $\mathrm{Au}^{0}$ on the fibre surface, however the $\mathrm{Cl}^{-}$ions hinder the formation of such nanoparticles in the fibre centre.

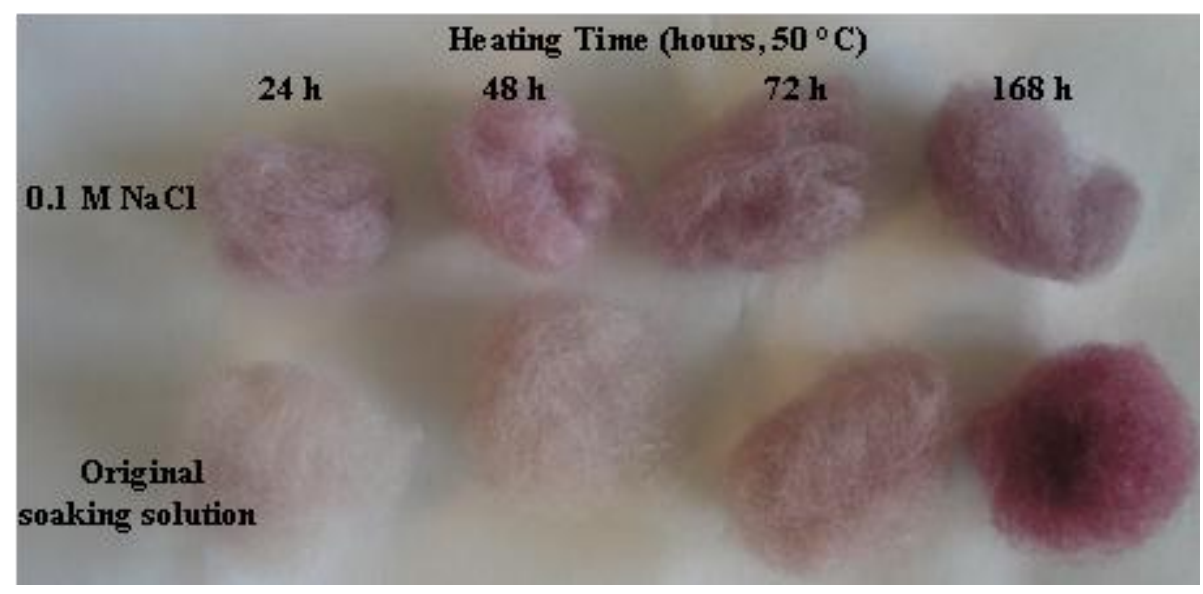

Figure 5.29: Top: gold nanoparticle-merino wool composites prepared by soaking untreated semiworsted merino wool in a $160 \mathrm{ppm}\left(8.13 \times 10^{-4} \mathrm{M}\right) \mathrm{Au}^{3+}$ for 1 hours $\backslash$ at $\mathrm{RT}$ followed by soaking at $\mathrm{RT}$ in a $0.1 \mathrm{M} \mathrm{NaCl}$ solution for a further 23 hours, and ageing in the original gold solution for 24-168 hours at 50 ${ }^{\circ} \mathrm{C}$. Bottom: The corresponding composite materials prepared by soaking and ageing in the same gold solution.

Similar results were obtained when soaking or ageing in alternate aqueous electrolyte solutions such as $0.1 \mathrm{M} \mathrm{MgCl}_{2}, \mathrm{KCl}, \mathrm{NaNO}_{3}, \mathrm{KNO}_{3}, \mathrm{Na}_{2} \mathrm{SO}_{4}$ and $\mathrm{K}_{2} \mathrm{SO}_{4}$ (with a pH of approximately 2.7 ). Figure 5.30 shows an example of such composites, prepared by altering both the soaking and ageing solution or solely the ageing solution. 


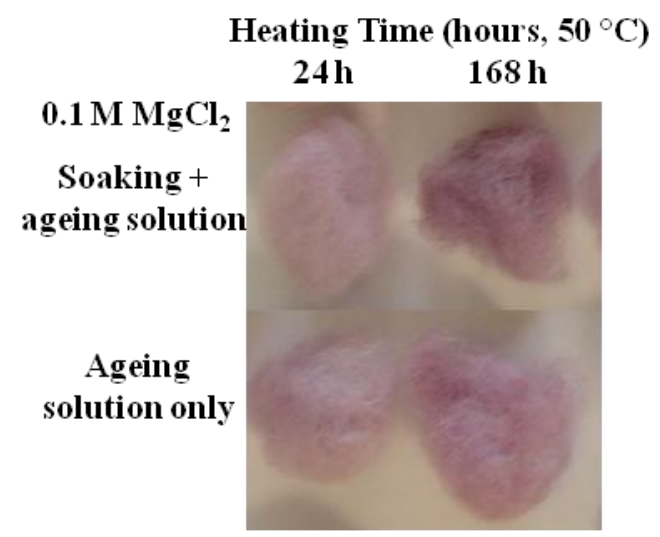

Figure 5.30: Top: gold nanoparticle-merino wool composites prepared by soaking untreated semiworsted merino wool in a $160 \mathrm{ppm}\left(8.13 \times 10^{-4} \mathrm{M}\right) \mathrm{Au}^{3+}$ solution for 1 hours at $\mathrm{RT}$, followed by soaking in

a $0.1 \mathrm{M} \mathrm{MgCl}$ solution for 23 hours at $\mathrm{RT}$, and ageing at $50{ }^{\circ} \mathrm{C}$ for 24 or 168 hours. Bottom: gold nanoparticle-merino wool composites prepared by soaking untreated semi-worsted merino wool in a 160 $\operatorname{ppm}\left(8.13 \times 10^{-4} \mathrm{M}\right) \mathrm{Au}^{3+}$ solution for 24 hours at $\mathrm{RT}$, followed by ageing at $50{ }^{\circ} \mathrm{C}$ in a $0.1 \mathrm{M} \mathrm{MgCl}_{2}$ solution for 24 or 168 hours.

\subsubsection{Heating/Ageing Temperature}

In addition to the soaking and ageing times, the heating/ageing temperature also influenced the colour of the resultant gold nanoparticle-merino wool composites. An ageing temperature of $50{ }^{\circ} \mathrm{C}$ was determined to be the optimum temperature, as higher temperatures, notably $80{ }^{\circ} \mathrm{C}$, produced slightly murky, spectrally impure coloured materials that were not as intense in colour relative to their analogues produced at $50{ }^{\circ} \mathrm{C}$ (Figure 5.31, Figure 5.32).

SEM analysis revealed the gold nanoparticles in these materials to be present both on the surface, and within the centre of the fibres (Figure 5.33 and Figure 5.34). These nanoparticles appear to be similar in size to those in the composites prepared at $50{ }^{\circ} \mathrm{C}$, approximately $20-25 \mathrm{~nm}$ in diameter on the surface, and $10 \mathrm{~nm}$ in the centre, however the nanoparticles on the surface are not as isolated, instead existing as agglomerates. These agglomerates would account for the less spectrally pure colour of the materials prepared at 80 ${ }^{\circ} \mathrm{C}$. It is likely that agglomerates rather than isolated particles form at $80{ }^{\circ} \mathrm{C}$, as the higher temperature would increase the $\mathrm{Au}^{3+}$ to $\mathrm{Au}^{0}$ reduction rate, forming more nanoparticles in a shorter time period. The larger density of nanoparticles may have resulted in agglomerations of nanoparticles due to insufficient stabilisation by the wool fibres. 


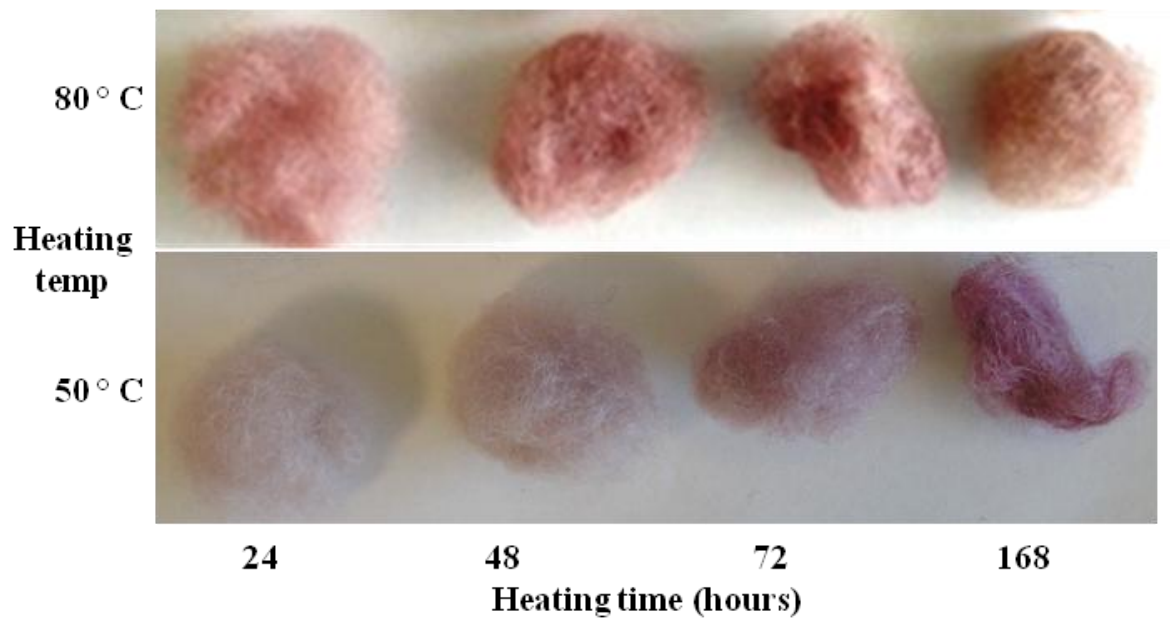

Figure 5.31: Gold nanoparticle-merino wool composites prepared by soaking in a $160 \mathrm{ppm}\left(8.13 \times 10^{-4} \mathrm{M}\right)$ gold solution for 24 hours, followed by ageing at 80 (top) or $50{ }^{\circ} \mathrm{C}$ (bottom) for $24,48,72$ or 168 hours (left to right).

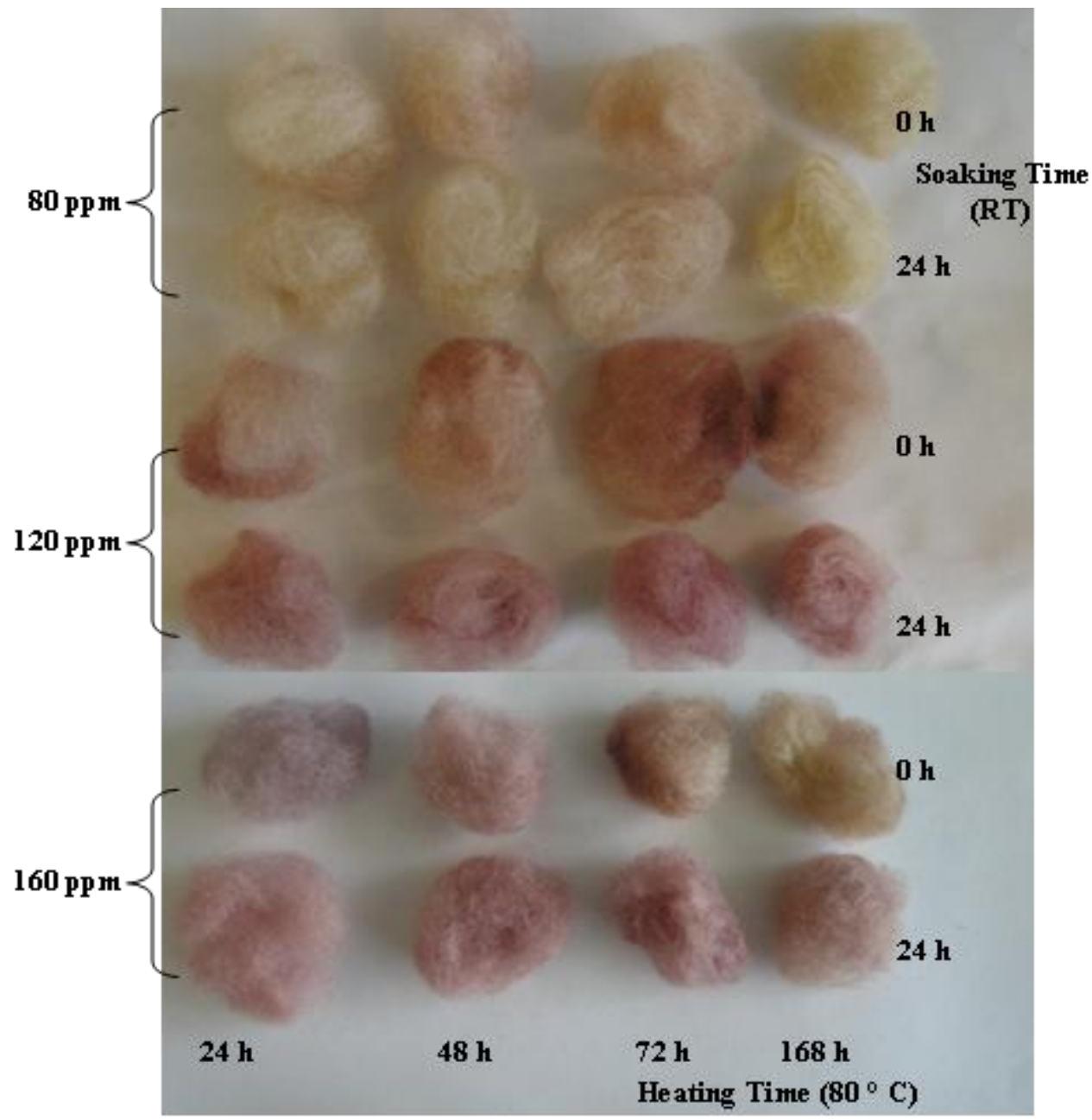

Figure 5.32: Gold nanoparticle-merino wool composites prepared by soaking merino wool in a gold solution for 0 or 24 hours at RT, followed by ageing at $80{ }^{\circ} \mathrm{C}$ for $24-168 \mathrm{~h}$. Shows the effect of soaking time and ageing (ageing) temperature on colour development. 

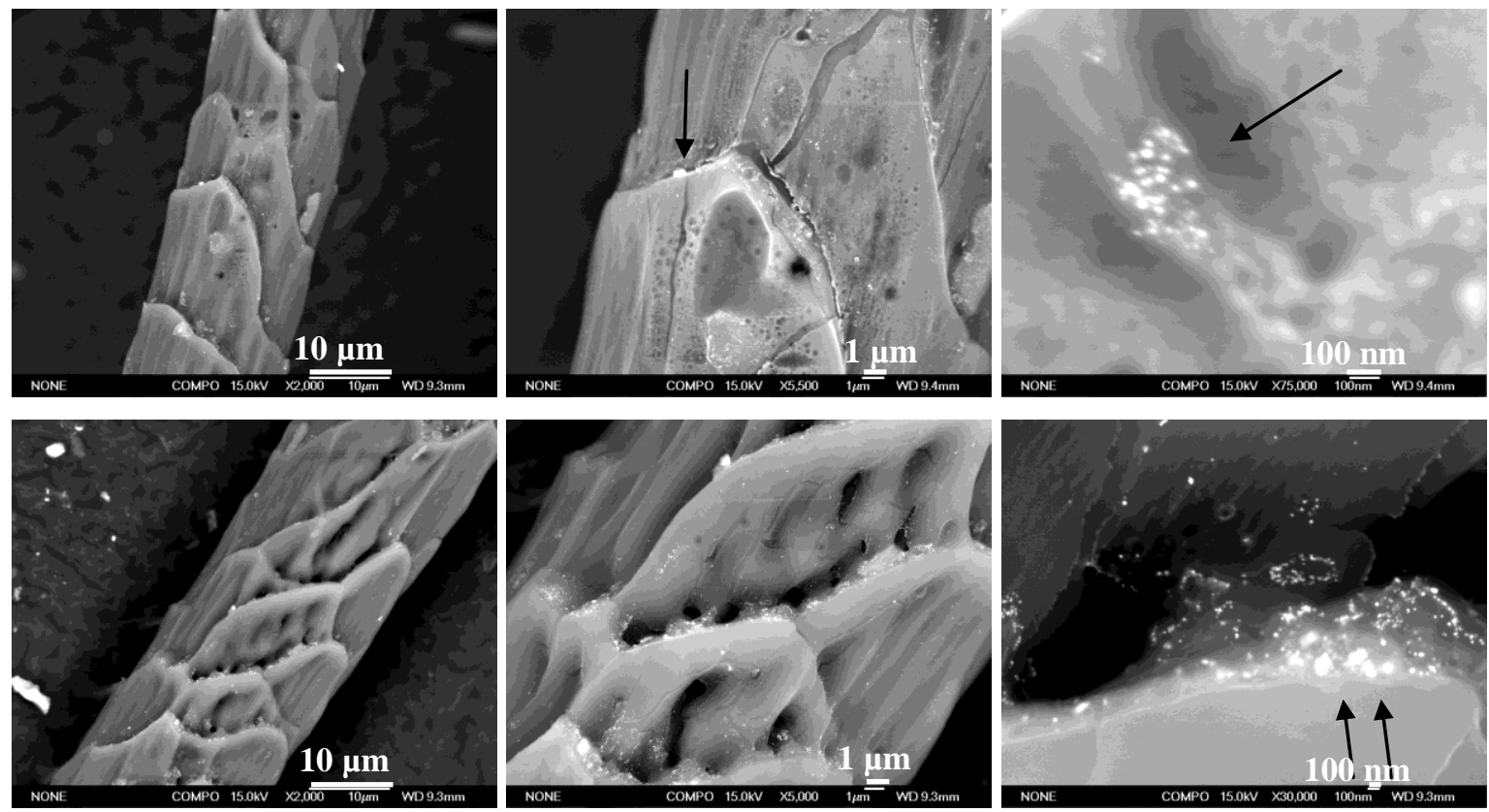

Figure 5.33: Increasing magnification SEM micrographs of a gold nanoparticle-merino wool composite prepared by soaking in a $160 \mathrm{ppm}\left(8.13 \times 10^{-4} \mathrm{M}\right)$ gold solution for 24 hours, followed by ageing at $80{ }^{\circ} \mathrm{C}$ for 24 hours (top) or 168 hours (bottom).
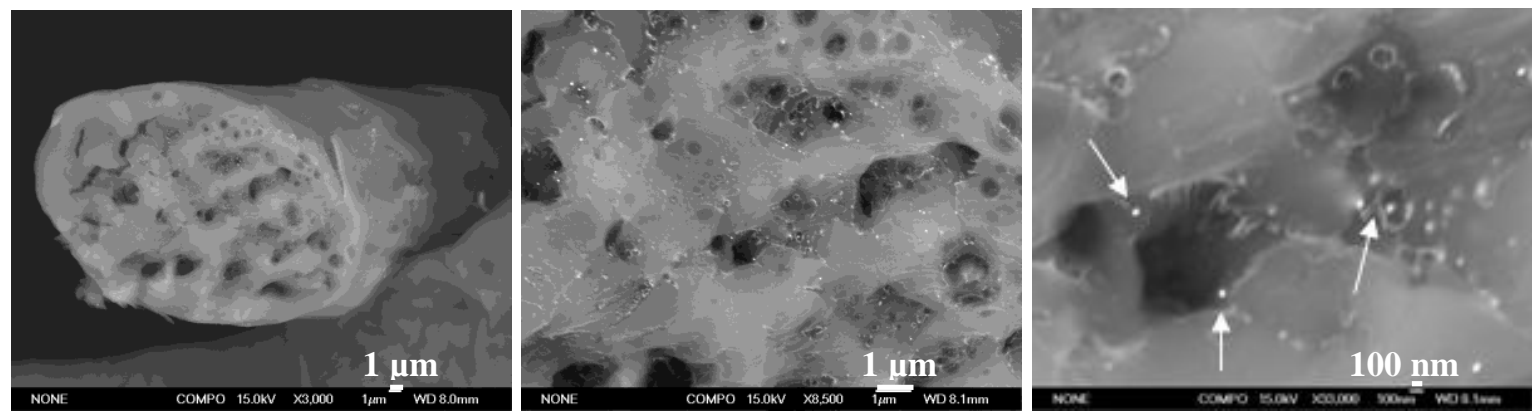

Figure 5.34: Cross sectional SEM micrographs of a gold nanoparticle-merino wool material prepared by soaking in a $160 \mathrm{ppm}\left(8.13 \times 10^{-4} \mathrm{M}\right)$ gold solution for 24 hours, followed by ageing at $80{ }^{\circ} \mathrm{C}$ for 168 hours.

\subsubsection{Gold Concentration}

The $\mathrm{Au}^{3+}$ concentration also influenced the colour of the resultant gold nanoparticle-merino wool composites. A concentration of at least $3.05 \times 10^{-4} \mathrm{M} \mathrm{Au}^{3+}$ was required to achieve colour development. Employing lower concentrations produced materials that were not dissimilar in colour to untreated merino wool (Figure 5.35). In general, $160 \mathrm{ppm}\left(8.13 \times 10^{-4}\right.$ M) was the highest $\mathrm{Au}^{3+}$ solution employed. Increasing the gold concentration to $160 \mathrm{ppm}$, 
through the addition of more gold did not appear to alter the hue of the resultant materials to a great extent; rather it intensified their colour (Figure 5.36).

$24 h$

$168 \mathrm{~h}$

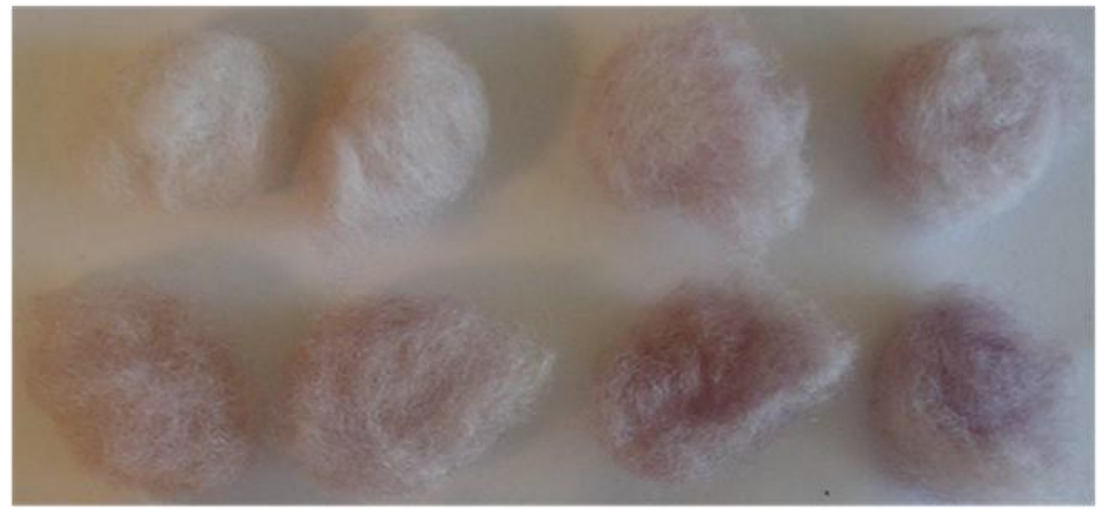

\begin{tabular}{lrrr}
$3.05 \times 10^{-4} \mathrm{M}$ & $5.08 \times 10^{-4} \mathrm{M}$ & $6.09 \times 10^{-4} \mathrm{M}$ & $7.61 \times 10^{-4} \mathrm{M}$ \\
\hline $15 \mu \mathrm{L} \rightarrow 10 \mathrm{ml}$ & $15 \mu \mathrm{L} \rightarrow 6 \mathrm{ml}$ & $15 \mu \mathrm{L} \rightarrow 5 \mathrm{ml}$ & $15 \mu \mathrm{L} \rightarrow 4 \mathrm{ml}$
\end{tabular}

$\mathrm{Au}^{3+}$ concentration

241

$168 \mathrm{~h}$

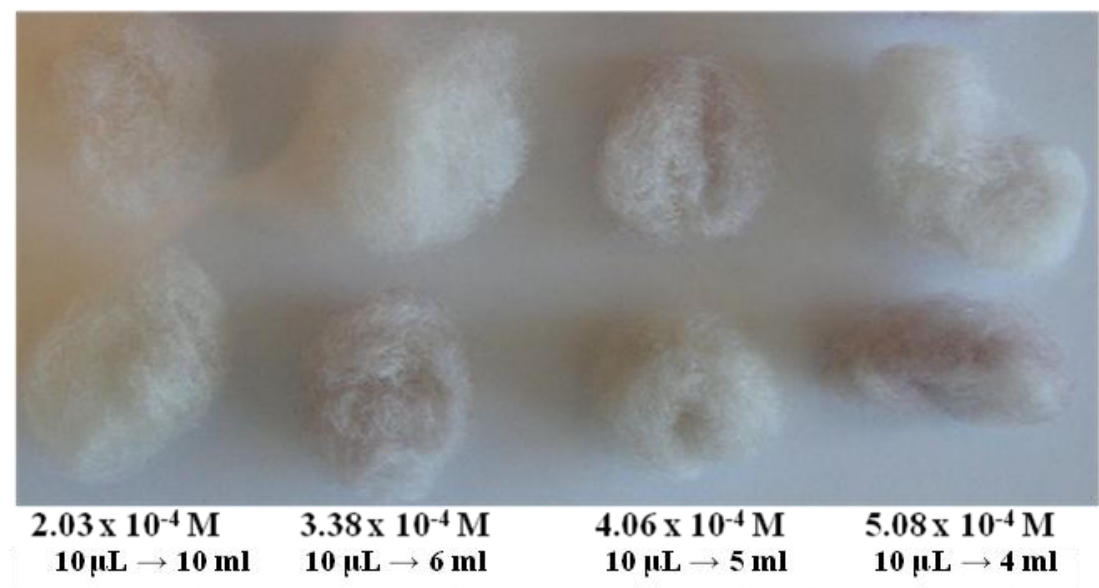

$\mathrm{Au}^{3+}$ concentration

Figure 5.35: Gold nanoparticle-merino wool composites prepared by soaking in gold solutions of various concentrations for 24 hours at RT, followed by ageing at $50{ }^{\circ} \mathrm{C}$ for 24 or 168 hours. 


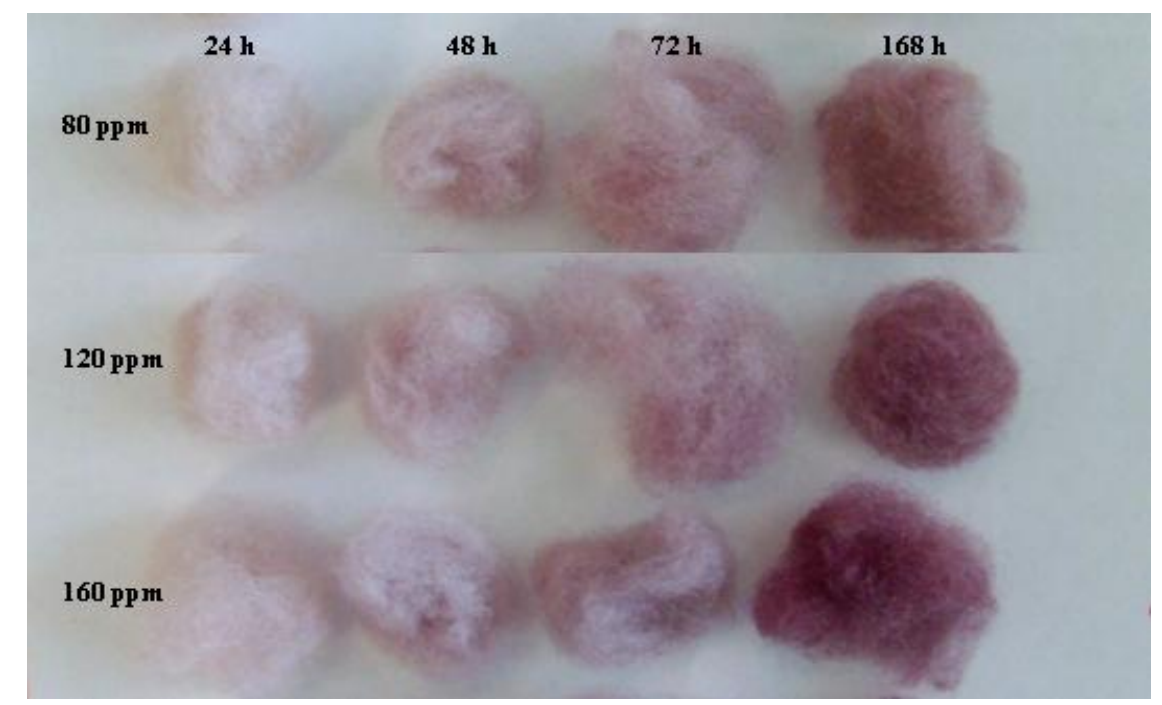

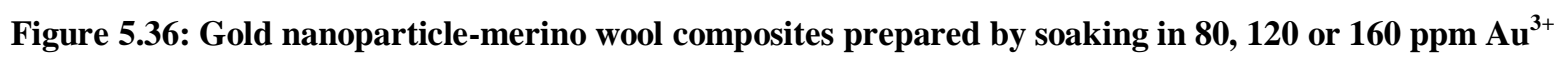
$\left(4.06 \times 10^{-4}, 6.09 \times 10^{-4}\right.$ or $8.13 \times 10^{-4} \mathrm{M}$ respectively) (top to bottom) for $24 \mathrm{~h}$ at $\mathrm{RT}$, followed by ageing at $50{ }^{\circ} \mathrm{C}$ for 24-168 hours.

SEM analysis of gold nanoparticle-merino wool composites prepared with various amounts of $\mathrm{Au}^{3+}$ showed that increasing concentrations resulted in the production of greater amounts of similarly sized nanoparticles (Figure 5.37), with both of these factors accountable for the production of deeper coloured composites.

The concentration of dissolved $\mathrm{Au}^{3+}$ in relation to the surface area of the wool fibre is important, and influences the colour of the resultant gold nanoparticle-merino wool materials. In much the same way as increasing the $\mathrm{Au}^{3+}$ concentration through the addition of more $\mathrm{Au}^{3+}$, increasing the concentration through the use of smaller solvent volumes (whilst keeping the ratio of the amount of $\mathrm{Au}^{3+}$ to wool fibre constant) intensified the colour of the resultant composites. This was discovered during a scale up production of the gold nanoparticle-merino wool materials. In a typical procedure, the ratio of $\mathrm{Au}^{3+}$ : wool : solution volume is maintained at $40 \mu \mathrm{L} 4 \mathrm{wt} \% \mathrm{Au}^{3+}: 0.1 \mathrm{~g}$ wool : $10 \mathrm{ml}$ water, however in the initial scale up, the ratio of $\mathrm{Au}^{3+}$ : wool was keep constant and the solution volume varied (due to the capacity of the reaction vessel), so that a ratio of $40 \mu \mathrm{L} 4 \mathrm{wt} \% \mathrm{Au}^{3+}: 0.1 \mathrm{~g}$ wool : $15 \mathrm{ml}$ water was employed, effectively decreasing the $\mathrm{Au}^{3+}$ concentration from $8.13 \times 10^{-4} \mathrm{M}$ to $5.41 \times 10^{-4} \mathrm{M}$. This resulted in the production of a lighter, more mauve coloured composite (Figure 5.38). 

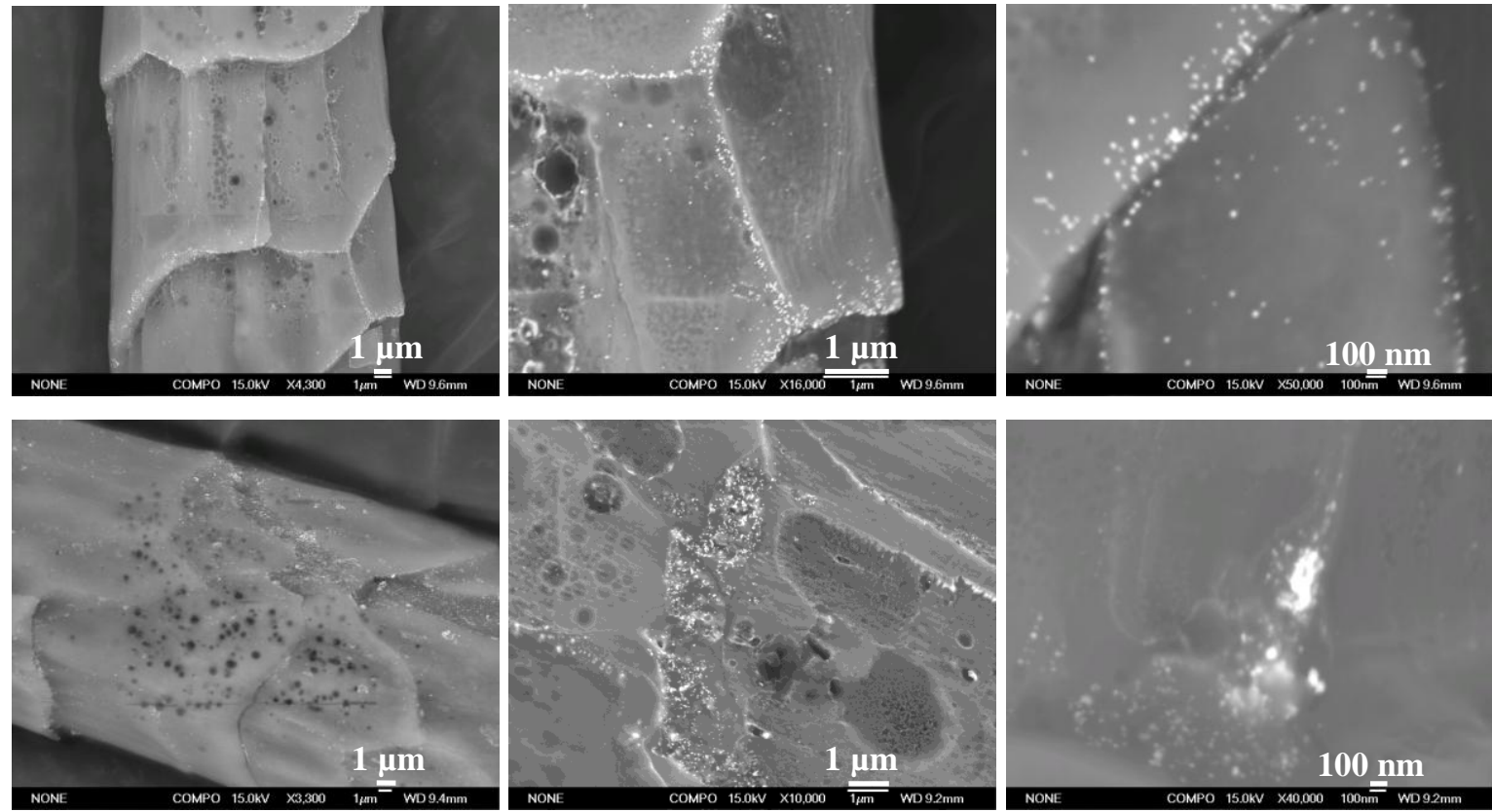

Figure 5.37: Increasing magnification SEM micrographs of gold nanoparticle-merino wool composites prepared by soaking in a 80 or $160 \mathrm{ppm} \mathrm{Au}^{3+}\left(4.06 \times 10^{-4}\right.$ or $8.13 \times 10^{-4} \mathrm{M}$ respectively) (top and bottom) for $24 \mathrm{~h}$ at RT, followed by ageing at $50{ }^{\circ} \mathrm{C}$ for 168 hours.

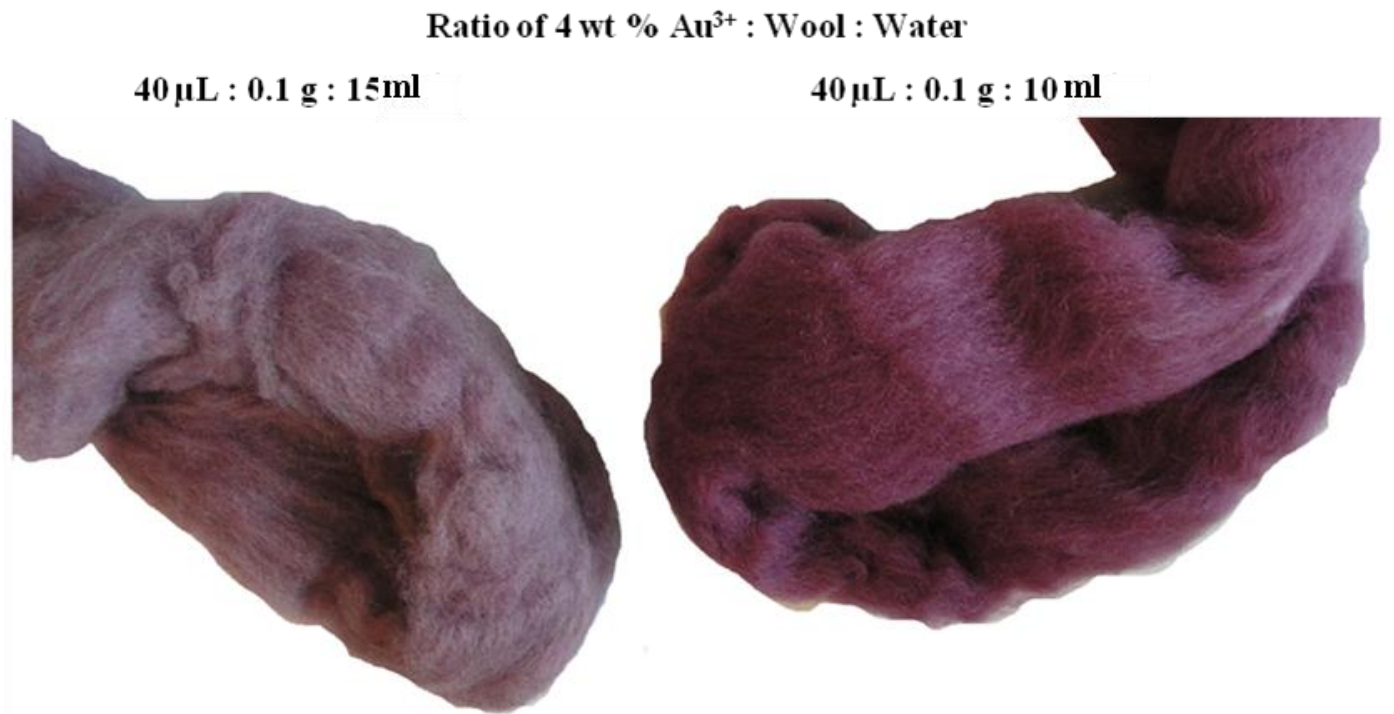

Figure 5.38: Gold nanoparticle-merino wool composite materials prepared by soaking untreated semiworsted merino wool in a left: $107 \mathrm{ppm}\left(5.41 \times 10^{-4} \mathrm{M}\right) \mathrm{Au}^{3+}$ solution $\left(40 \mu \mathrm{L} 4 \mathrm{wt} \% \mathrm{Au}^{3+}: 0.1 \mathrm{~g} \mathrm{wool:15} \mathrm{ml}\right.$ $\left.\mathrm{H}_{2} \mathrm{O}\right)$ or right: a $160 \mathrm{ppm}\left(8.13 \times 10^{-4} \mathrm{M}\right) \mathrm{Au}^{3+}$ solution $\left(40 \mu \mathrm{L} 4 \mathrm{wt} \% \mathrm{Au}^{3+}: 0.1 \mathrm{~g}\right.$ wool:10 ml $\left.\mathrm{H}_{2} \mathrm{O}\right)$ for 24 hours at RT, followed by ageing at $50{ }^{\circ} \mathrm{C}$ for 168 hours.

Through the production of gold nanoparticle-crossbred wool composite materials (chapter $\boldsymbol{6}$ ), the colour difference occurring with different $\mathrm{Au}^{3+}$ concentrations was found to be related to 
the ratio of the $\mathrm{Au}^{3+}$ concentration and specific surface area of the wool fibres. The average fibre diameter of crossbred wool is greater than merino wool; approximately $35 \mu \mathrm{m}$ compared to $20 \mu \mathrm{m}$, and as such the specific surface area of crossbred wool is much lower than merino. Therefore for the same ratio of $\mathrm{Au}^{3+}$ : wool : solution volume, there is a higher density of absorbed $\mathrm{Au}^{3+}$ at the surface of the crossbred wools, producing more intense and darker coloured composites relative to the finer fibres (discussed in further detail in section 5.6 below).

A desirable consequence of this is that the same colour can be achieved by using a higher concentration of $\mathrm{Au}^{3+}$ in solution but a reduced solution volume in relation to the amount of wool fibre and hence a reduced amount of $\mathrm{Au}^{3+}$ to overall weight of wool (keeping the ratio of the concentration of $\mathrm{Au}^{3+}$ : wool constant) (Table 5.1). For example, increasing the concentration of $\mathrm{Au}^{3+}$ by decreasing the solution volume produces more vibrant coloured composites, and decreasing both the amount of $\mathrm{Au}^{3+}$ and solution volume, (thus keeping the ratio between the $\mathrm{Au}^{3+}$ concentration and amount of wool constant), also produces the same coloured composites (Figure 5.39). This yields more favourable economic conditions, as less $\mathrm{Au}^{3+}$ is required to produce the desired colour.

Table 5.1: $\mathrm{Au}^{3+}$ solutions employed when increasing the concentration of $\mathrm{Au}^{3+}$. All systems were used with $0.1 \mathrm{~g}$ untreated semi-worsted merino wool.

\begin{tabular}{cccc}
\hline $\begin{array}{c}\mathrm{Au}^{3+} \text { conc. } \\
(\mathrm{M})\end{array}$ & $\begin{array}{c}\mathrm{Au}^{3+} \text { conc. } \\
(\mathrm{ppm})\end{array}$ & $\begin{array}{c}\text { Volume } 4 \mathrm{wt} \% \\
\mathrm{Au}^{3+}(\mu \mathrm{L})\end{array}$ & $\begin{array}{c}\text { Solution } \\
\text { Volume }(\mathrm{ml})\end{array}$ \\
\hline $1.08 \times 10^{-3}$ & 213 & 40 & 7.5 \\
$1.35 \times 10^{-3}$ & 267 & 40 & 6 \\
$1.62 \times 10^{-3}$ & 320 & 40 & 5 \\
$2.03 \times 10^{-3}$ & 400 & 40 & 4 \\
$1.22 \times 10^{-3}$ & 240 & 30 & 5 \\
$1.52 \times 10^{-3}$ & 300 & 30 & 4 \\
$8.13 \times 10^{-4}$ & 160 & 40 & 10 \\
\hline
\end{tabular}




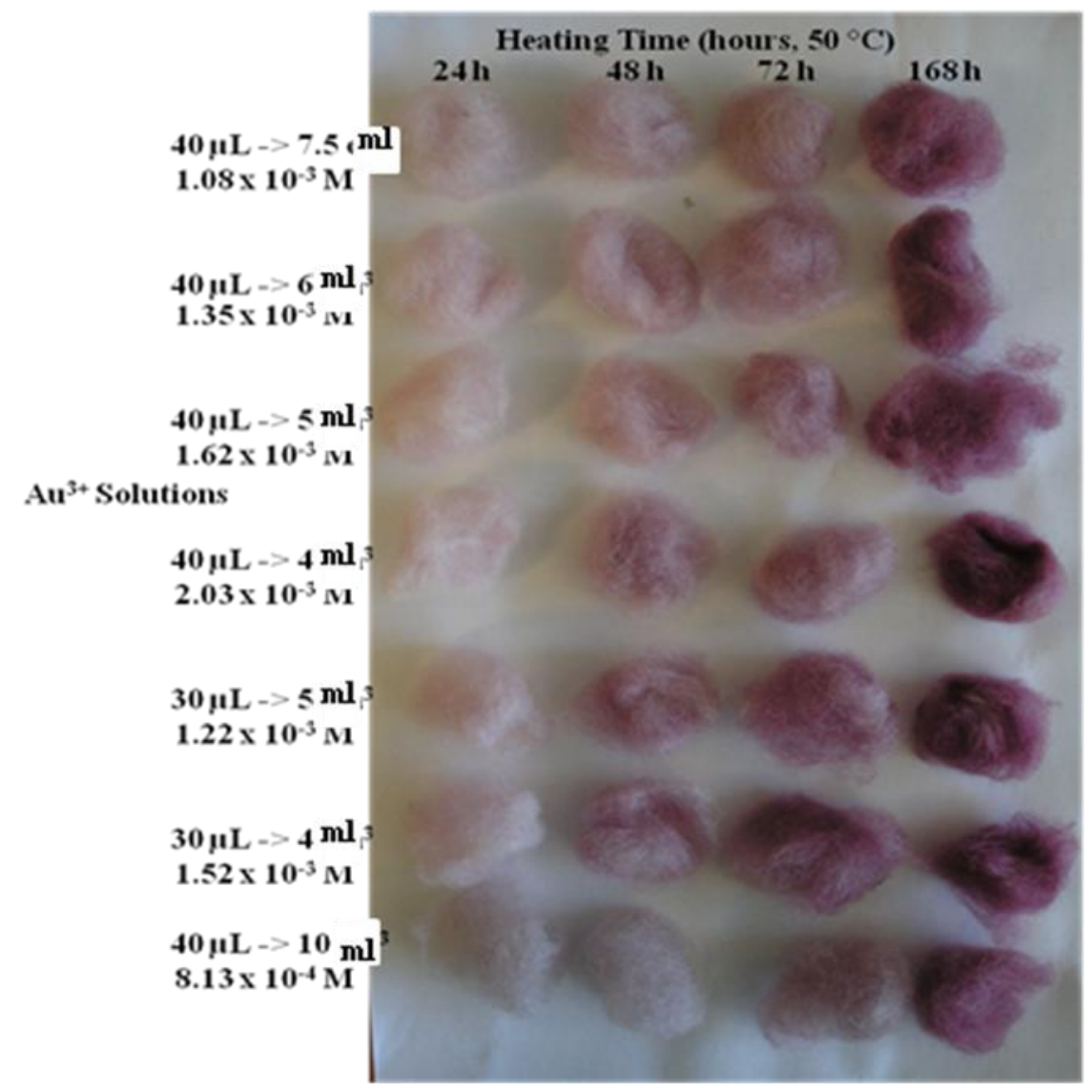

Figure 5.39: Gold nanoparticle-merino wool composites prepared by soaking untreated semi-worsted merino wool in various $\mathrm{Au}^{3+}$ solutions for 24 hours at $\mathrm{RT}$, followed by ageing at $50{ }^{\circ} \mathrm{C}$ for 24-168 hours. Illustrates the effect of the ratio between the $\mathrm{Au}^{3+}$ concentration and amount of wool has on colour development.

For the same soaking and ageing conditions and times, the colour of the resultant gold nanoparticle-merino wool composites is a function of the $\mathrm{Au}^{3+}$ solution concentration, the volume of solution and the surface area of wool. It is likely that similar coloured composite materials are produced when the ratio of the concentration of $\mathrm{Au}^{3+}$ to wool fibre is kept constant, even when less $\mathrm{Au}^{3+}$ is used, as with the same $\mathrm{Au}^{3+}$ concentrations, there is a similar density of $\mathrm{Au}^{3+}$ at the fibre surface, inducing the same amount of collisions between $\mathrm{Au}^{3+}$ ions, and hence nucleations; forming a similar amount of $\mathrm{Au}^{0}$ nanoparticles. XPS has shown that even after 168 hours ageing at $50{ }^{\circ} \mathrm{C}$, not all of the $\mathrm{Au}^{3+}$ is reduced (section 5.3), and therefore employing a lower amount of $\mathrm{Au}^{3+}$ would not be detrimental as generally it is not all converted to nanoparticulate $\mathrm{Au}^{0}$, and therefore should lead to the formation of a similar amount of nanoparticles. 


\subsubsection{Production of Light Pink Coloured Composites}

The pink colour observed in composites prepared with ageing times of less than 168 hours was relatively dull, and lowering the $\mathrm{Au}^{3+}$ did not produce pink coloured composites, rather it decreased the purple colour of the materials, making them appear less vibrant and spectrally pure. In an attempt to rectify this, and produce vibrant pink coloured gold nanoparticlemerino wool composites, procedures were altered in the aim of reducing $\mathrm{Au}^{3+}$ to nanoparticulate $\mathrm{Au}^{0}$ preferentially at the fibre surface. This involved soaking untreated semiworsted merino wool in $\mathrm{Au}^{3+}$ solutions of increased concentrations (200-320 ppm, achieved through the addition of more $\mathrm{Au}^{3+}$ (Table 5.2)) for shorter periods of time (5-15 minutes depending upon the $\mathrm{Au}^{3+}$ concentration employed), followed by ageing in alternate solutions (Millipore water, aqueous dilute $\mathrm{HCl}$ ) at $50{ }^{\circ} \mathrm{C}$ for $24-168$ hours. As the concentration of $\mathrm{Au}^{3+}$ was higher in these systems, the concentration gradient of $\mathrm{Au}^{3+}$ or $\mathrm{AuCl}_{4}{ }^{-}$across the solution/fibre interface, and hence the driving force for absorption of gold onto the wool fibre was higher. This allowed for faster absorption of $\mathrm{AuCl}_{4}{ }^{-}$, whilst the shorter soaking times limited diffusion through the fibres, resulting in higher gold concentrations at the fibre surface, which was hopefully to lead to the development of an increased amount of nanoparticles at the surface, and hence the production of brighter, more vibrantly coloured composite materials.

Table 5.2: $\mathrm{Au}^{3+}$ solutions employed in the attempted production of vibrant pink coloured composites.

\begin{tabular}{cccc}
\hline $\begin{array}{c}\mathrm{Au}^{3+} \text { conc. } \\
(\mathrm{M})\end{array}$ & $\begin{array}{c}\mathrm{Au}^{3+} \text { conc. } \\
(\mathrm{ppm})\end{array}$ & $\begin{array}{c}\text { Volume } 4 \mathrm{wt} \% \\
\mathrm{Au}^{3+}(\boldsymbol{\mu L})\end{array}$ & $\begin{array}{c}\text { Solvent } \\
\text { Volume }(\mathrm{ml})\end{array}$ \\
\hline $1.02 \times 10^{-3}$ & 200 & 50 & 10 \\
$1.21 \times 10^{-3}$ & 240 & 60 & 10 \\
$1.42 \times 10^{-3}$ & 280 & 70 & 10 \\
$1.63 \times 10^{-3}$ & 320 & 80 & 10 \\
\hline
\end{tabular}

Figure 5.40 and Figure 5.41 offer pictures of gold nanoparticle-merino wool composites prepared by soaking untreated semi-worsted merino wool a $320 \mathrm{ppm}\left(1.6 \times 10^{-3} \mathrm{M}\right) \mathrm{Au}^{3+}$ solution for 5 minutes to 6 hours, followed by ageing at $50{ }^{\circ} \mathrm{C}$ for 24 or 72 hours. It is 
apparent from these images that the desired vibrant pink coloured composites were not produced, rather the materials appeared dull and spectrally impure relative to their analogous materials prepared with a soaking time of 24 hours, which as described in section 5.1.2.1 above. This is likely due to the agglomeration of nanoparticles at the fibre surface, occurring as a result of insufficient stabilisation of the large amount of nanoparticles present at the fibre surface. Additionally, AA studies showed that high concentrations of gold had been absorbed, approximately 102-316 ppm, depending on the soaking time (Table 5.3, Figure 5.42)), which would increase the number of nanoparticles formed at the fibre surface, increasing the ratio of nanoparticles to wool and thus the probability of agglomeration.

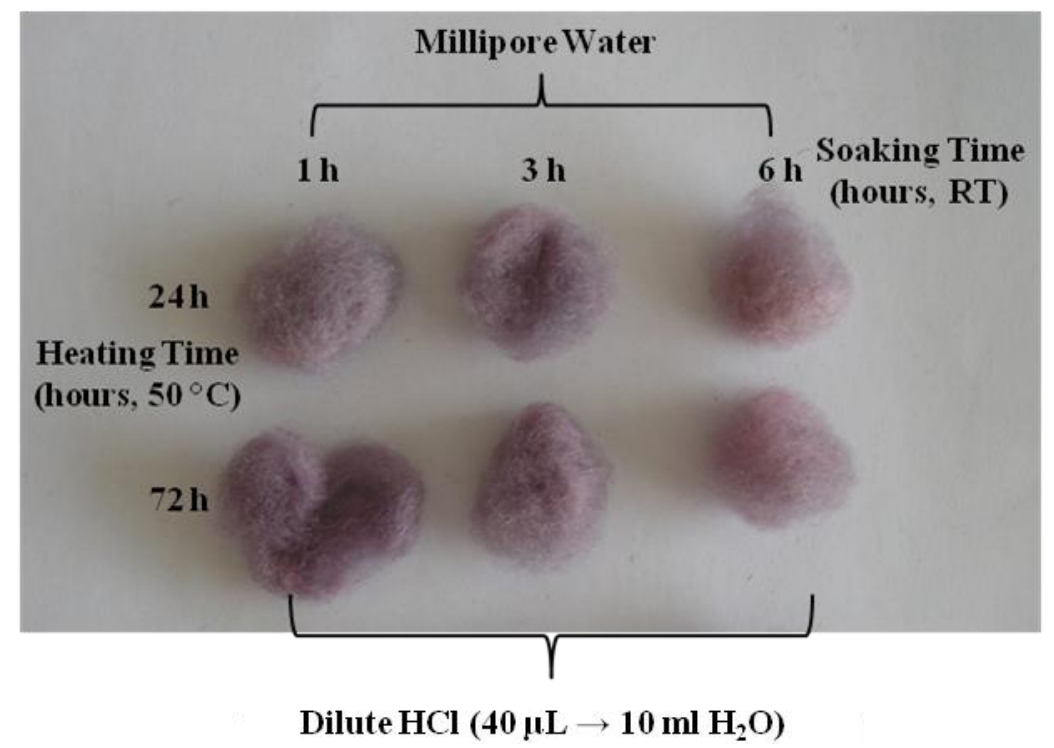

Figure 5.40: Gold nanoparticle-merino wool composites prepared by soaking untreated semi-worsted merino wool in a $320 \mathrm{pp},\left(1.6 \times 10^{-3} \mathrm{M}\right) \mathrm{Au}^{3+}$ solution for 1,3 or 6 hours at RT, followed by ageing at 50 ${ }^{\circ} \mathrm{C}$ for 24 hours in Millipore water (top) or a dilute $\mathrm{HCl}$ solution $\left(40 \mu \mathrm{L} 0.1 \mathrm{M} \mathrm{HCl} \rightarrow 10 \mathrm{ml} \mathrm{H}_{2} \mathrm{O}\right.$ ) (bottom).

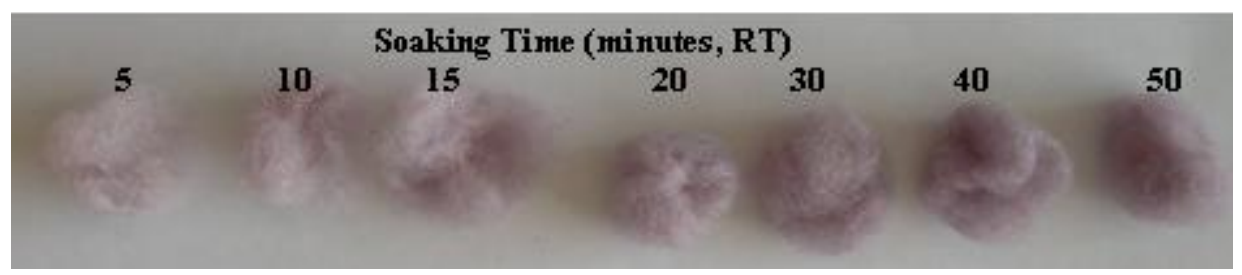

Figure 5.41: Gold nanoparticle-merino wool composites prepared by soaking untreated semi-worsted merino wool in a $320 \mathrm{ppm}\left(1.6 \times 10^{-3} \mathrm{M}\right) \mathrm{Au}^{3+}$ solution for 5-50 minutes at RT, followed by ageing in Millipore water for 72 hours at $50{ }^{\circ} \mathrm{C}$. 
Table 5.3: Absorption of $\mathrm{Au}^{3+}$ by untreated semi-worsted merino wool from a $320 \mathrm{ppm}\left(1.6 \times 10^{-3} \mathrm{M}\right) \mathrm{Au}^{3+}$ solution at RT.

\begin{tabular}{|c|c|c|}
\hline \multirow[b]{2}{*}{ Soaking Time (minutes) } & \multicolumn{2}{|c|}{$\mathrm{Au}^{3+}$ concentration (ppm) } \\
\hline & In solution & Absorbed $^{*}$ \\
\hline 2 & 218 & 102 \\
\hline 5 & 154 & 166 \\
\hline 10 & 115 & 205 \\
\hline 15 & 80 & 240 \\
\hline 20 & 60 & 260 \\
\hline 30 & 24 & 296 \\
\hline 40 & 8 & 312 \\
\hline 60 & 4 & 316 \\
\hline 180 & 1 & 319 \\
\hline 360 & 1 & 319 \\
\hline 1140 & 0 & 320 \\
\hline
\end{tabular}

*Note: the concentration of $\mathrm{Au}^{3+}$ absorbed was determined by the difference between the amount of $\mathrm{Au}^{3+}$ in solution following soaking and the initial concentration.

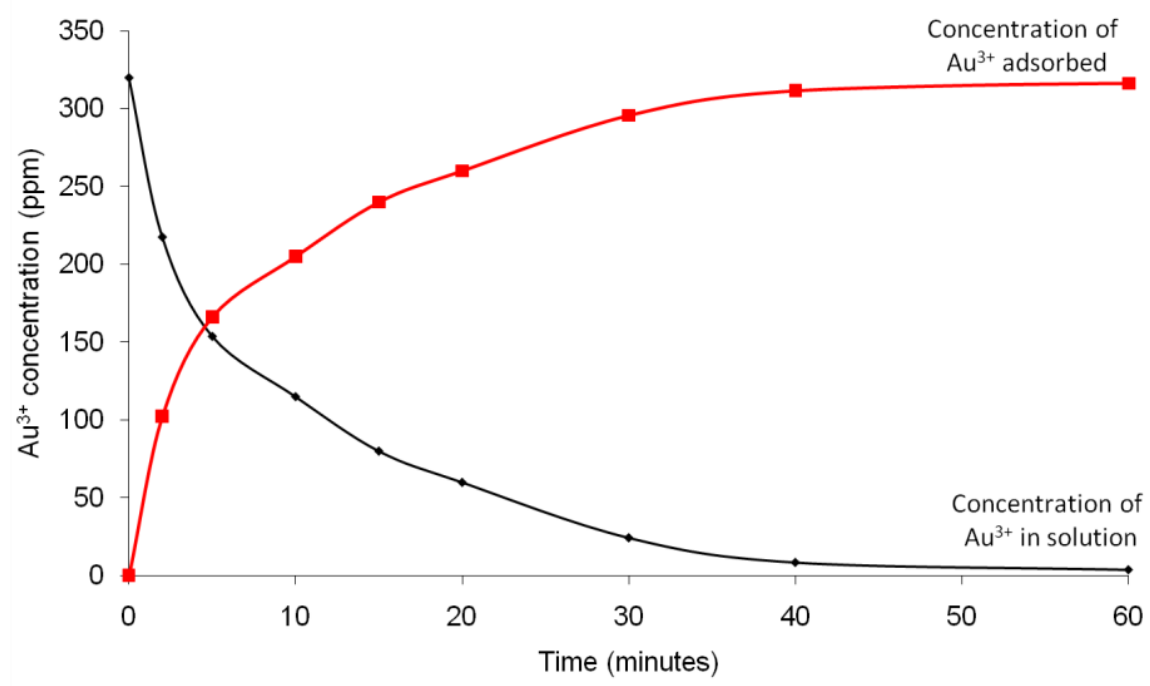

Figure 5.42: Absorption of $\mathrm{Au}^{3+}$ by untreated semi-worsted merino wool from a $320 \mathrm{ppm}\left(1.6 \times 10^{-3} \mathrm{M}\right)$ $\mathrm{Au}^{3+}$ solution at RT.

In an attempt to improve the spectral purity of the gold nanoparticle-merino wool materials, and to increase the vibrancy of their colour, the amount of gold absorbed was reduced by decreasing the soaking times so that approximately $8.12 \times 10^{-6}$ moles of gold were absorbed, 
(the same amount as absorbed in the normal system employing a $160 \mathrm{ppm}\left(8.13 \times 10^{-4} \mathrm{M}\right)$ $\mathrm{Au}^{3+}$ solution and a soaking time, at RT of 24 hours). Additionally, following soaking in the $\mathrm{Au}^{3+}$ solutions, the merino wool fibres were transferred to alternate solutions (Millipore water or dilute aqueous $\mathrm{HCl}\left(40 \mu \mathrm{L} 0.1 \mathrm{M} \mathrm{HCl} \rightarrow 10 \mathrm{ml} \mathrm{H}_{2} \mathrm{O}\right)$, soaked for a further 23 hours at RT and then aged at $50{ }^{\circ} \mathrm{C}$ for $24-168$ hours. A picture of such samples is shown in Figure 5.43 below. It is apparent that vibrant pink coloured materials were not produced in this approach. Employing extended soaking times (24 hours) at RT, allows for the diffusion of $\mathrm{Au}^{3+}$ through the fibres, decreasing the concentration of $\mathrm{Au}^{3+}$ at the fibre surface, which was a principal aim of this approach.

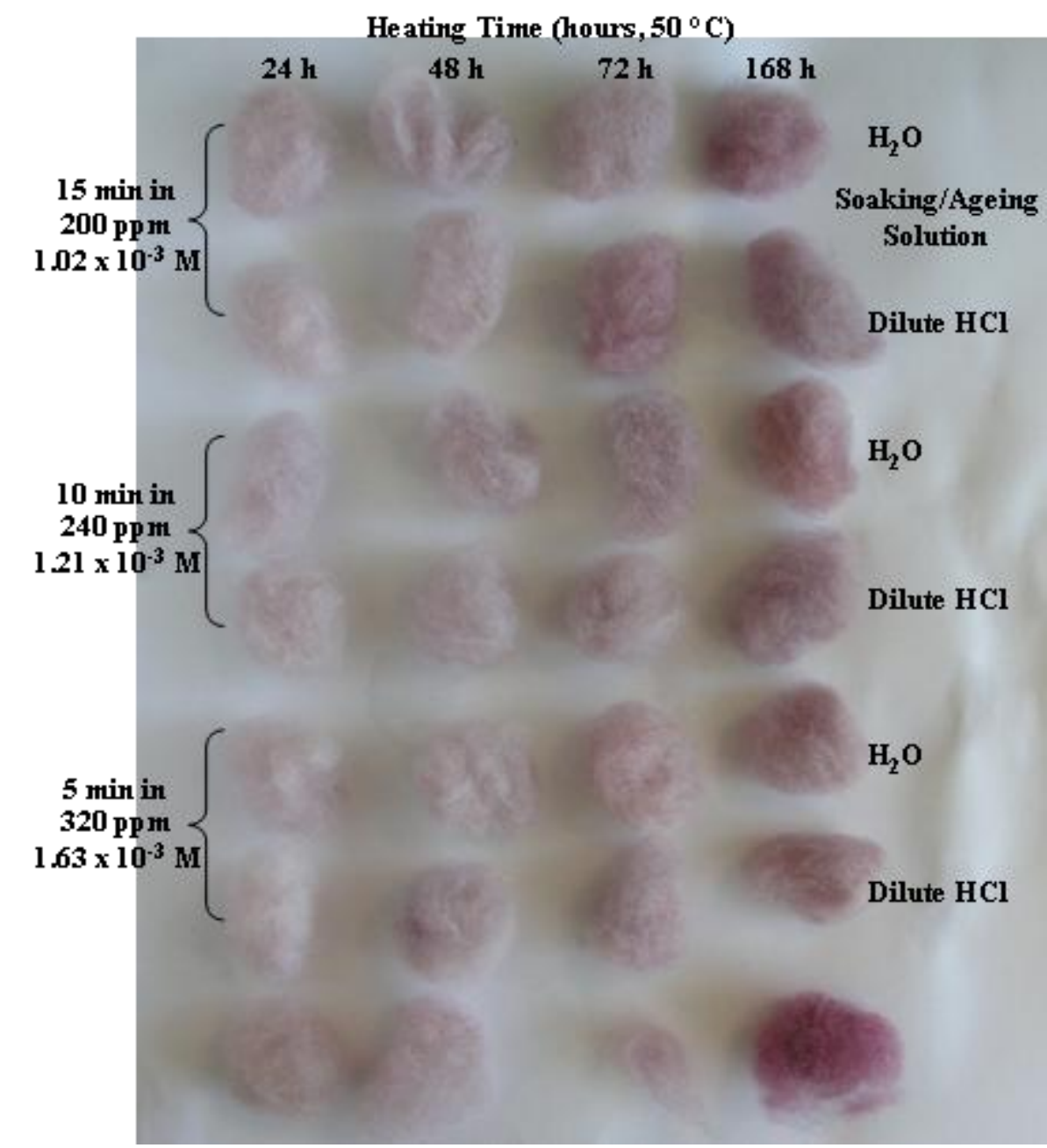

Figure 5.43: Gold nanoparticle-merino wool composites prepared by soaking untreated semi-worsted merino wool various gold solutions at RT, followed by soaking in Millipore water or an aqueous $\mathrm{HCl}$ solution (40 $\mu \mathrm{L}$ of $0.1 \mathrm{M} \mathrm{HCl} \rightarrow 10 \mathrm{ml} \mathrm{H}_{2} \mathrm{O}$ ) for a further 23 hours at $\mathrm{RT}$, and ageing at $50{ }^{\circ} \mathrm{C}$ for 24-168 hours. The samples on the bottom are prepared in the normal way (employing a $\mathrm{Au}^{3+}$ solution of $160 \mathrm{ppm}$ $\left(8.13 \times 10^{-4} \mathrm{M}\right)$, a soaking time of 24 hours, and the original soaking solution as the ageing solution). 
As such, the best method by which to produce vibrant pink coloured materials appears to be one in which the wool is soaked in a $160 \mathrm{ppm}\left(8.13 \times 10^{-4} \mathrm{M}\right) \mathrm{Au}^{3+}$ solution for 24 hours at $\mathrm{RT}$, following which it is transferred to a $0.1 \mathrm{M} \mathrm{NaCl}$ solution and aged at $50{ }^{\circ} \mathrm{C}$ for 24 hours (section 5.1.2.3).

\subsubsection{7 pH}

A further factor that influenced the colour of the resultant composite materials was the $\mathrm{pH}$ of the reaction solutions. Depending on the $\mathrm{Au}^{3+}$ concentration, the $\mathrm{pH}$ of the soaking solution was generally between 2.5-3. However adjusting the $\mathrm{pH}$ of the soaking solution to $\mathrm{pH} 7$ or 10 through the addition of aqueous base adversely affected the colour of the resultant composite materials. (It should be noted that these values are only representative of the original $\mathrm{pH}$ of the soaking solutions. Over the period of an hour, the $\mathrm{pH}$ of the solutions dropped to approximately 5.3 and 6.7 in the $\mathrm{pH} 7$ and 10 systems respectively. This occurred due to the amphoteric nature of merino wool, in which the carboxylic acid and amine groups titrated the added base, achieving equilibrium at the wool surface).[39] The colour of these materials was very under developed; even with $168 \mathrm{~h}$ ageing at $50{ }^{\circ} \mathrm{C}$ the produced materials were a pale, spectrally impure purple colour (Figure 5.44).

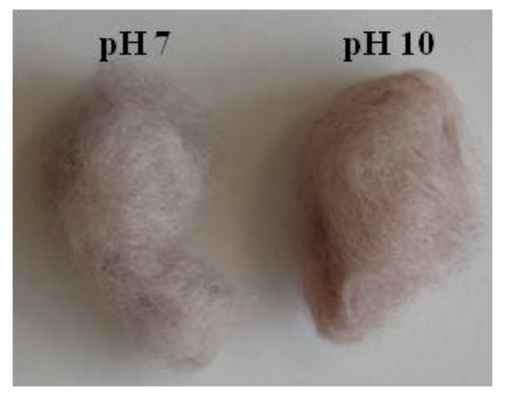

Figure 5.44: Gold nanoparticle-merino wool composites prepared by adjusting the $\mathrm{pH}$ of the $160 \mathrm{ppm}$ $\left(8.13 \times 10^{-4} \mathrm{M}\right) \mathrm{Au}^{3+}$ soaking solution to $\mathrm{pH} 7$ (left) or 10 (right), soaking at RT for 24 hours and ageing at $50{ }^{\circ} \mathrm{C}$ for 168 hours.

Uptake studies revealed that adjusting the $\mathrm{pH}$ of the soaking solution to 7 or 10 , decreased the $\mathrm{Au}^{3+}$ absorption rate (see section 5.4), and hence the amount of $\mathrm{Au}^{3+}$ absorbed and 
available for the formation of nanoparticulate $\mathrm{Au}^{0}$. This would account for the decreased colour intensity of the gold nanoparticle-merino wool composites prepared with soaking solutions of increased $\mathrm{pH}$. At a $\mathrm{pH}$ of 5.3 or 6.7 , (the equilibrium $\mathrm{pH}$ of the $\mathrm{pH} 7$ and 10 systems respectively), the wool fibre would exert a net negative charge, and thus electrostatically repel the $\mathrm{AuCl}_{4}^{-}$ion, (the gold species absorbed). As such, when ageing began, only a relatively small percentage of $\mathrm{Au}^{3+}$ had been absorbed $(66 \%, 105 \mathrm{ppm}$ in the pH 7 system, compared to $99 \%$ or $158 \mathrm{ppm}$ in the conventional system employing a $\mathrm{pH}$ of 2.7) and the concentration of $\mathrm{Au}^{3+}$ in solution was relatively high. Instead of continuing to absorb during ageing, the $\mathrm{Au}^{3+}$ in solution was reduced to nanoparticulate $\mathrm{Au}^{0}$, evidenced by a change in colour of the solution to wine red, a colour typical of colloidal gold. This reduction was likely to be facilitated by low molecular weight peptides displaced from wool when ageing in water at temperature of $50{ }^{\circ} \mathrm{C}$ or higher.[225]

Alternatively, adjusting the $\mathrm{pH}$ of the soaking system to $\mathrm{pH} 7$ once absorption of $\mathrm{AuCl}_{4}{ }^{-}$had occurred (after 1 hour) was not entirely detrimental to colour development; instead increasing the $\mathrm{Au}^{3+}$ to $\mathrm{Au}^{0}$ reduction rate, and hence colour development in the resultant composites. Figure 5.45 offers a picture of such samples, and compares them to corresponding composites prepared with a soaking solution of $\mathrm{pH}$ 2.7. It is apparent that the materials in which the $\mathrm{pH}$ of the soaking solution had been adjusted following $\mathrm{AuCl}_{4}{ }^{-}$absorption developed colour at a faster rate than the conventional systems, achieving a deep, regal purple colour after 48 hours ageing at $50{ }^{\circ} \mathrm{C}$ rather than 168 hours. However the colour of these composites is not as spectrally pure as those prepared in a soaking solution of constant $\mathrm{pH}$, suggesting slight agglomeration of some of the nanoparticles on the fibre surface, as seen in similarly coloured composites. 


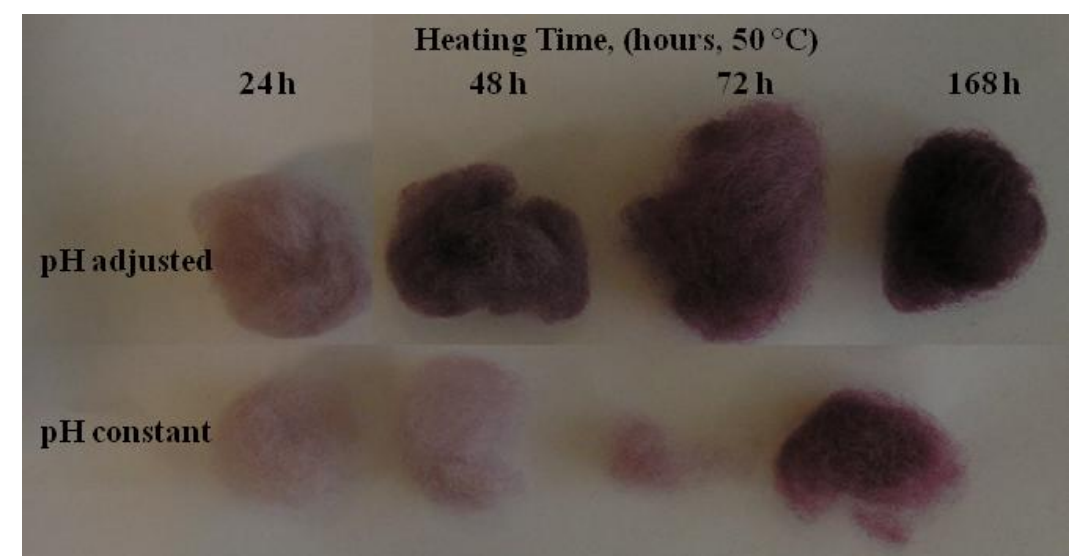

Figure 5.45: Gold nanoparticle-merino wool composites prepared by soaking in a $160 \mathrm{ppm}\left(8.13 \times 10^{-4} \mathrm{M}\right)$ $\mathrm{Au}^{3+}$ for 24 hours, followed by ageing at $50{ }^{\circ} \mathrm{C}$ for 24-168 hours. The samples on top were prepared by altering the $\mathrm{pH}$ of the soaking solution to $\mathrm{pH} 7$ once the majority of $\mathrm{Au}^{3+}$ had been absorbed.
\end{abstract}

Similar effects were observed when adjusting the $\mathrm{pH}$ of the heating/ageing solution. Adjusting the $\mathrm{pH}$ of the ageing solution to approximately 9 increased the speed at which the colour of the composite materials developed (Figure 5.46). (It should be noted that, as with the soaking solutions, these values are only representative of the original $\mathrm{pH}$ of the ageing solutions, with the $\mathrm{pH}$ of the 4, 7, 9 and 12 systems reaching an equilibrium $\mathrm{pH}$ of 3.5, 5.3, 5.5 and 8.5 respectively). This is likely to occur as increasing the $\mathrm{pH}$ acts to destabilise the $\mathrm{AuCl}_{4}^{-}$system so that $\mathrm{Au}^{0}$ becomes the favoured species, increasing the $\mathrm{Au}^{3+}$ to $\mathrm{Au}^{0}$ reduction rate.[17]

Increasing the $\mathrm{pH}$ further to 12 resulted in the formation of yellow coloured composites. The yellow colour of these materials is due to the presence of $\mathrm{Au}(\mathrm{OH})_{3}$ (discussed in further detail in section 5.5.1 below). Raising the $\mathrm{pH}$ of the gold solution to 12 through the addition of a base hydrolyses the $\mathrm{AuCl}_{4}{ }^{-}$ion to form six major species of the general form $\left[\mathrm{Au}(\mathrm{OH})_{\mathrm{x}} \mathrm{Cl}_{4-\mathrm{x}}\right]^{-}$depending on the $\mathrm{pH}$ and extent of hydrolysis, which in turn is dependent upon the pH.[226] Out of these six species, only $\left[\mathrm{Au}(\mathrm{OH})_{3} \mathrm{Cl}\right]^{-}$is insoluble, precipitating as $\mathrm{Au}(\mathrm{OH})_{3} . \quad\left[\mathrm{Au}(\mathrm{OH})_{3} \mathrm{Cl}\right]^{-}$is the prevalent form of gold in the $\mathrm{pH}$ range of $8-9,[227]$ thus by adjusting the $\mathrm{pH}$ to 12 , which following equilibrium with the wool results in a solution $\mathrm{pH}$ of approximately 8.5, it is likely that any absorbed $\mathrm{AuCl}_{4}{ }^{-}$would precipitate as $\mathrm{Au}(\mathrm{OH})_{3}$. 


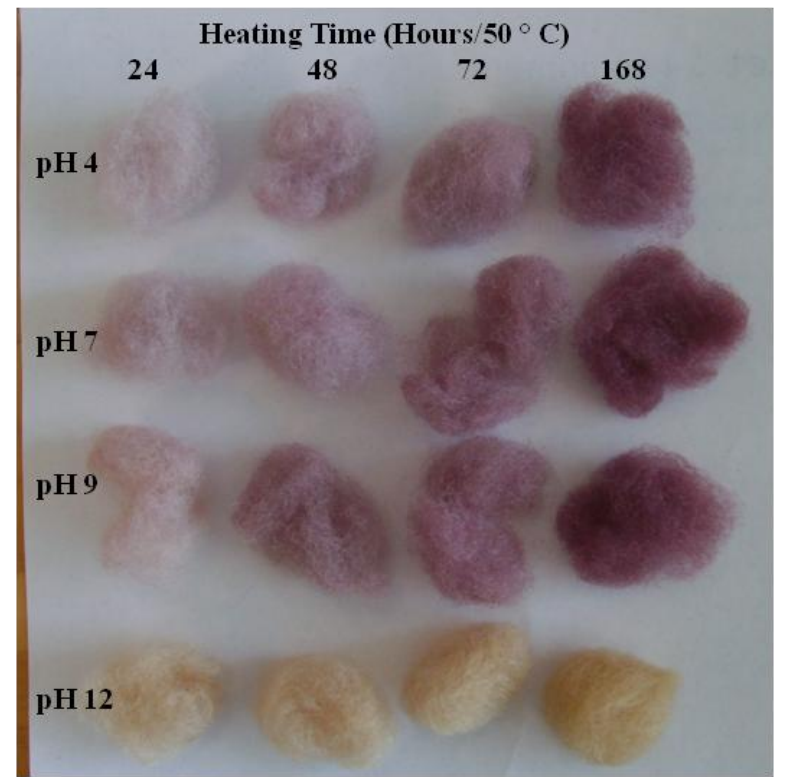

Figure 5.46: Gold nanoparticle-merino wool composites prepared by soaking in a $160 \mathrm{ppm} \mathrm{Au}^{3+}(8.13 \mathrm{x}$ $10^{-4} \mathrm{M}$ ) solution for 24 hours at RT, following which the $\mathrm{pH}$ of the reaction mixture was adjusted to $4,7,9$ or 12, and the samples heated for $24-168$ hours at $50{ }^{\circ} \mathrm{C}$.

Figure 5.47 offers SEM micrographs of a composite prepared with a $\mathrm{pH} 12$ ageing solution. The cuticle cells of the wool fibres in these materials do not look as defined as those of untreated merino wool, suggesting the fibre may have been damaged by the high $\mathrm{pH}$ of the ageing solution. Additionally, it is very difficult to discern any nanoparticulate gold on the fibre, however there are large amorphous deposits which EDS verifies as being gold (Figure 5.48). These large clumps of gold are consistent with the precipitation of $\mathrm{Au}(\mathrm{OH})_{3}$. They are also evident in TEM micrographs of such materials (Figure 5.49). Additionally, TEM suggests that there is also a very small percentage of nanoparticulate gold present in these samples (highlighted by the arrows in Figure 5.49). These are likely to form during the soaking period, as SEM and TEM analysis of samples that had been soaked in a $160 \mathrm{ppm}$ $\left(8.13 \times 10^{-4} \mathrm{M}\right) \mathrm{Au}^{3+}$ solution for 24 hours at $\mathrm{RT}$, showed the presence of a very small amount of five-fold twinned gold nanoparticles, approximately 10-20 nm in diameter (Figure 5.50). However these nanoparticles do not impart any colour to the composite materials as they are present in such a small amount. 

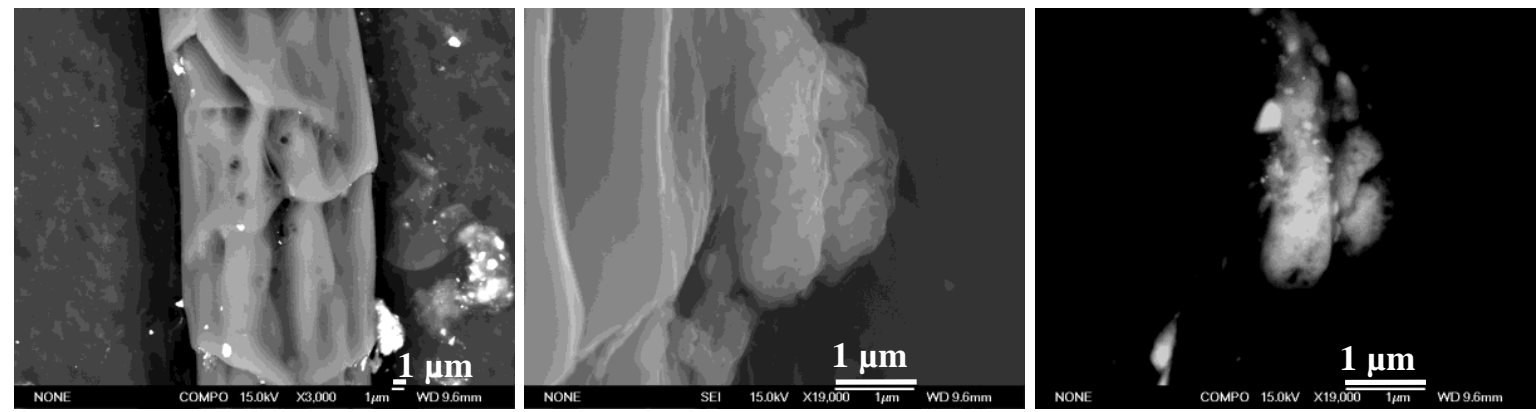

Figure 5.47: SEM micrographs of a gold nanoparticle-merino wool composite prepared by soaking in a $160 \mathrm{ppm} \mathrm{Au}^{3+}\left(8.13 \times 10^{-4} \mathrm{M}\right)$ solution for 24 hours at $\mathrm{RT}$, following which the $\mathrm{pH}$ of the reaction mixture was adjusted to 12 , and the samples heated for 168 hours at $50^{\circ} \mathrm{C}$. Note: the micrograph on the right is the centre image viewed under backscatter conditions.
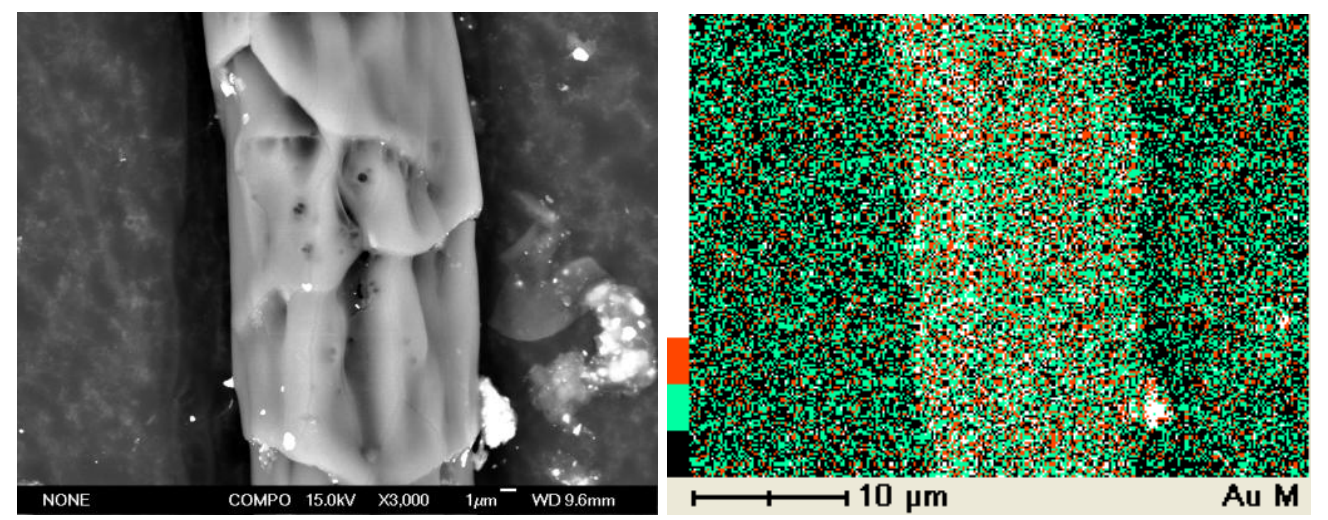

Figure 5.48: SEM (left) and corresponding Au EDS map (right) of a gold nanoparticle-merino wool composite prepared by soaking in a $160 \mathrm{ppm} \mathrm{Au}^{3+}\left(8.13 \times 10^{-4} \mathrm{M}\right)$ solution for 24 hours at $\mathrm{RT}$, following which the pH of the reaction mixture was adjusted to 12, and the samples heated for 168 hours at $50{ }^{\circ} \mathrm{C}$.

High concentrations of gold are depicted in white. 

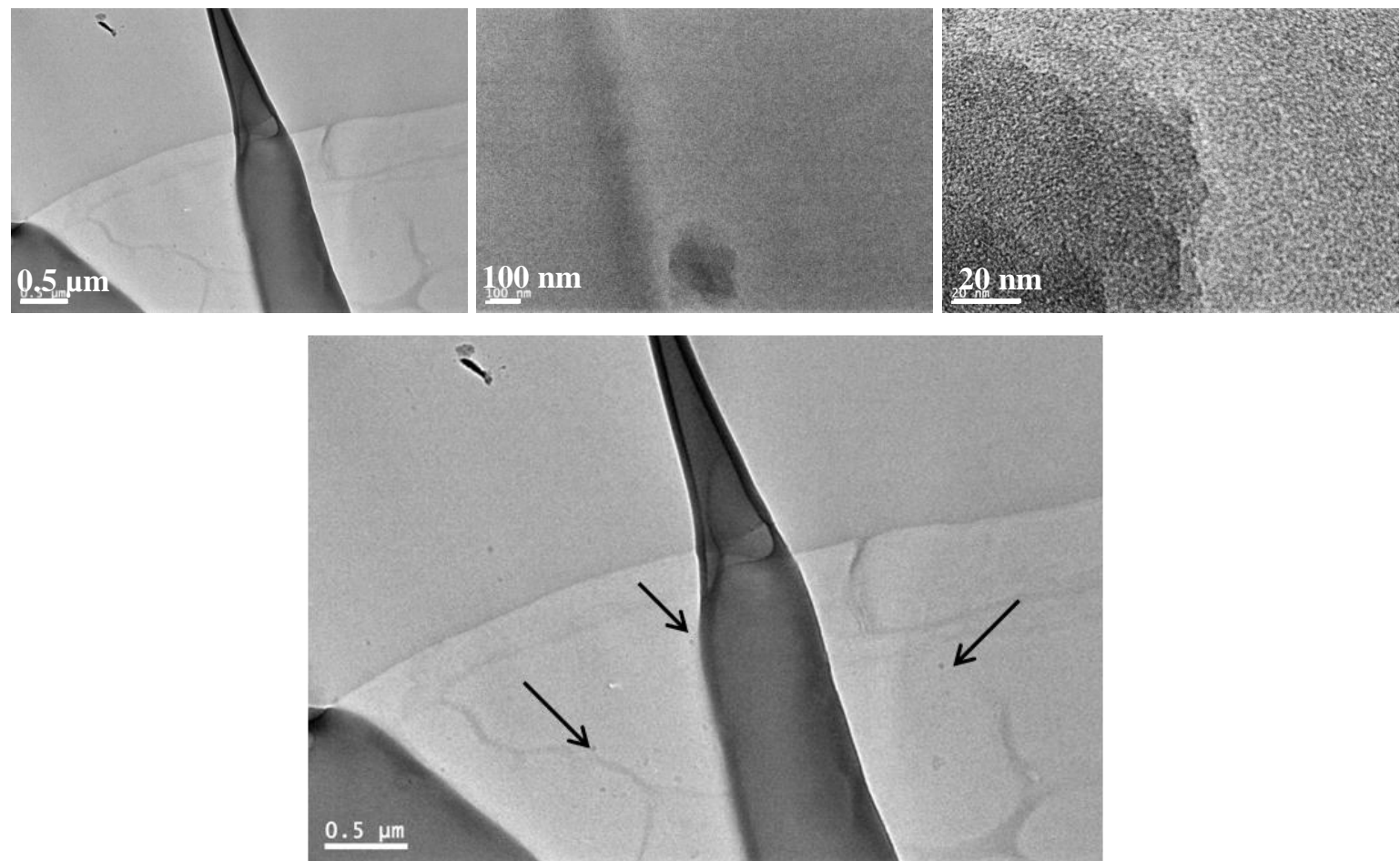

Figure 5.49: Increasing magnification TEM micrographs of a gold nanoparticle-merino wool composite prepared by soaking in a $160 \mathrm{ppm} \mathrm{Au}^{3+}\left(8.13 \times 10^{-4} \mathrm{M}\right)$ solution for 24 hours at RT, following which the $\mathrm{pH}$ of the reaction mixture was adjusted to 12 , and the samples heated for 168 hours at $50{ }^{\circ} \mathrm{C}$.
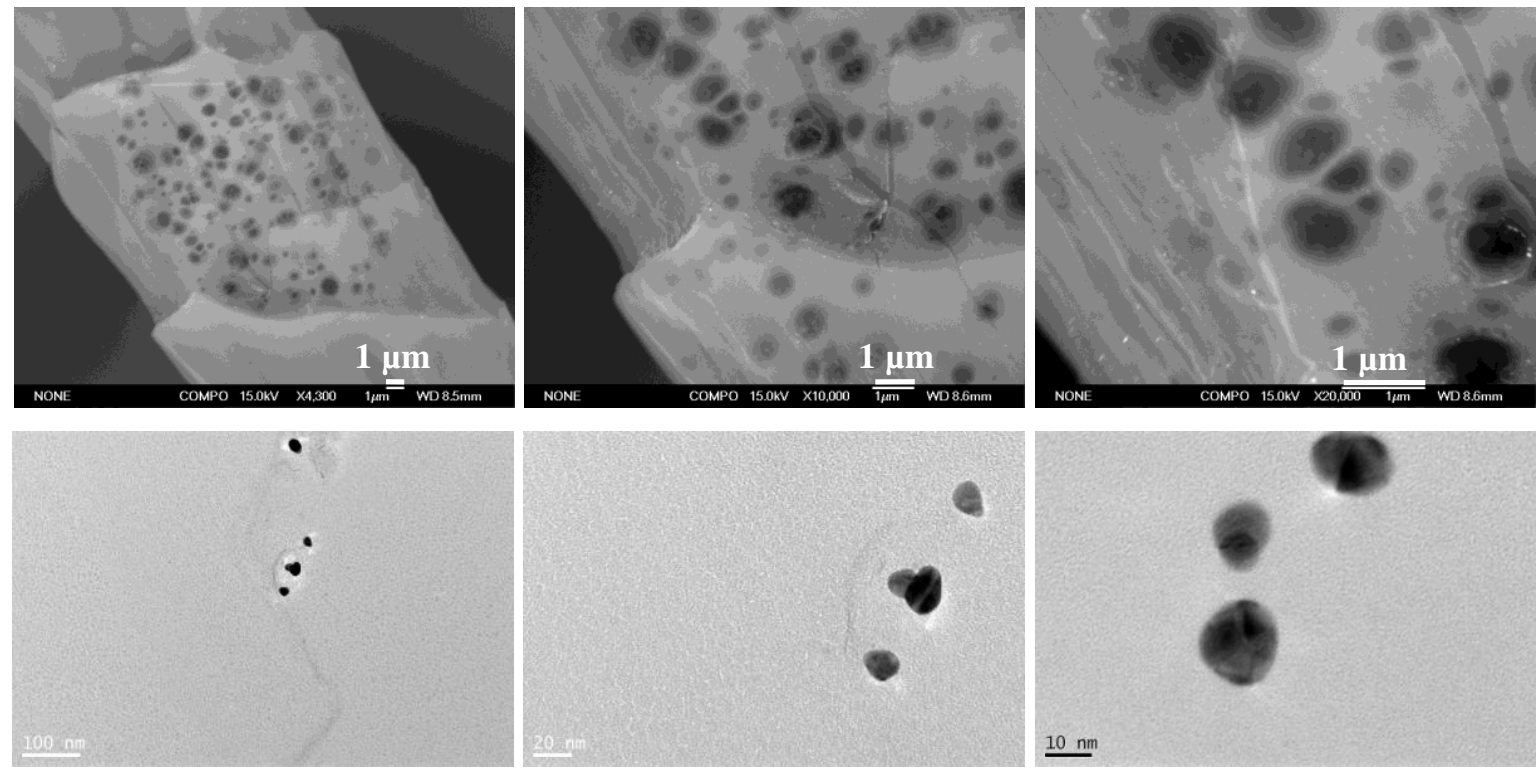

Figure 5.50: Increasing magnification SEM (top) and TEM (bottom) micrographs of a gold nanoparticlemerino wool composite prepared by soaking in a $160 \mathrm{ppm} \mathrm{Au}^{3+}\left(8.13 \times 10^{-4} \mathrm{M}\right)$ solution for 24 hours at RT. 


\subsubsection{Acid Treated Semi-Worsted Gilled Sliver}

In an attempt to broaden the colour spectrum of the gold nanoparticle-merino wool composite materials, merino wool was treated with $0.1 \mathrm{M} \mathrm{HCl}$ prior to being introduced into the $\mathrm{Au}^{3+}$ solutions (outlined in section 2.2.2.3.1). This was unsuccessful as the colour of the resulting composites was significantly lighter than the corresponding materials prepared from untreated merino wool (Figure 5.51.), suggesting less $\mathrm{Au}^{3+}$ had been reduced to nanoparticulate $\mathrm{Au}^{0}$.

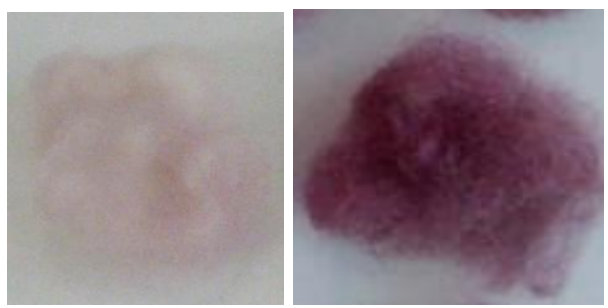

Figure 5.51: Gold nanoparticle-merino wool composites prepared from acid treated merino wool (left) and un-treated merino wool (right). Prepared by dispersing the respective merino wool in a $160 \mathrm{ppm}$ $\mathrm{Au}^{3+}\left(8.13 \times 10^{-4} \mathrm{M}\right)$ solution for 24 hours at RT, followed by ageing at $50{ }^{\circ} \mathrm{C}$ for 168 hours.

In general, the treatment of wool with acid hydrolyzes the peptide bonds of the keratin chains (the proteins found in merino wool).[82]

$$
\text { -NH-CHR-CO-NH-CHR'-CO- } \rightarrow \text {-NH-CHR-COOH + } \mathrm{H}_{2} \mathrm{~N}-\mathrm{CHR} \text {-CO- }
$$

However it has also been shown that acidic chloride solutions (of a $\mathrm{pH}$ less than 2) are capable of breaking the thioester bond between the wool and fatty acid layer (18-MEA) on the surface through oxidation of the sulfur.[55, 82] This results in a lipid reduced surface with a percentage of the cysteine and cystine sulfur components oxidised to cysteic acid residues. The oxidation of these sulfur containing groups to cysteic acid may account for the reduced colour intensity of the gold-nanoparticle merino wool composites, prepared from acid pre-treated merino wool, as cystine and to a lesser extent cysteine may be involved in the reduction of $\mathrm{Au}^{3+}$ to nanoparticulate $\mathrm{Au}^{0}$ (section 5.6), thus their oxidation would decrease the reducing capacity of the wool. 


\subsubsection{KOH/MeOH Treated Semi-Worsted Gilled Sliver}

As with acid pre-treatment, alcoholic base treatment removes the lipid layer from the surface of merino wool, (section 1.2.2.1.3), however this occurs to a greater extent. As such, $\mathrm{KOH} / \mathrm{MeOH}$ pre-treatments were undertaken to investigate whether removal of this lipid layer would facilitate the production of gold nanoparticle-merino wool composites by allowing for greater ease of penetration of gold ions into the fibre. The use of alcoholic alkali pre-treated merino wool (prepared according to the procedure outlined in section 2.2.2.3.1) as the fibre substrate in the production of gold nanoparticle-merino wool composites produced materials for which the colour was very under developed (Figure 5.52), (even following extended ageing times, $\left(168\right.$ hours at $\left.50{ }^{\circ} \mathrm{C}\right)$ ) and much lighter in colour than the corresponding materials prepared from untreated merino wool.

Time in $\mathrm{KOH} / \mathrm{MeOH}$

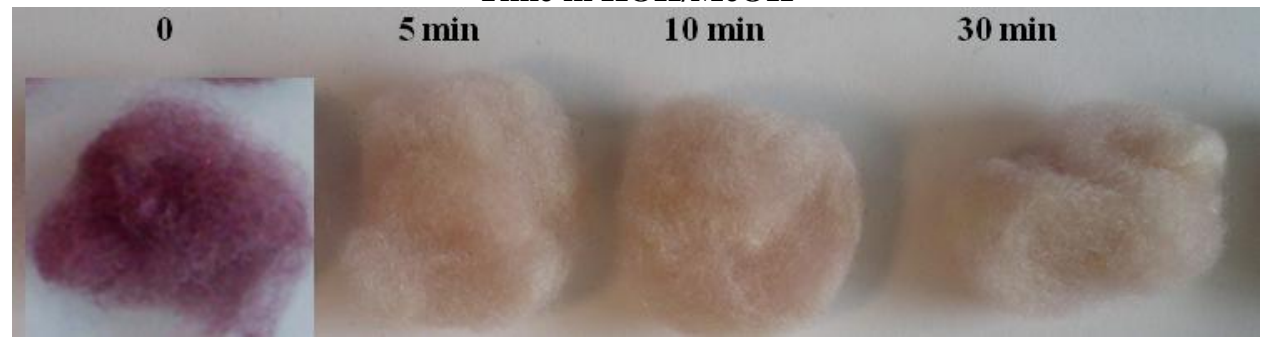

Figure 5.52: Gold nanoparticle-merino wool composites prepared with merino wool which had been soaked in a $0.1 \mathrm{M} \mathrm{KOH} / \mathrm{MeOH}$ solution for 5,10 or 30 minutes, followed by a $160 \mathrm{ppm} \mathrm{Au}^{3+}\left(8.13 \times 10^{-4}\right.$ M) solution for 24 hours at RT and heated at $50{ }^{\circ} \mathrm{C}$ for 168 hours.

As shown in section 5.4 below, removal of the lipid layer through $\mathrm{KOH} / \mathrm{MeOH}$ pre-treatment was successful in accelerating the absorption of $\mathrm{AuCl}_{4}^{-}$by merino wool, however once absorbed the wool was not able to facilitate the reduction of $\mathrm{Au}^{3+}$ to nanoparticulate $\mathrm{Au}^{0}$. This is likely due to the fact that in addition to removing the lipid layer, alkaline solutions also attack cystine residues in wool, forming lanthionine groups. [39, 82] This is thought to occur via attack at the $\beta$-carbon. The principal reaction steps are outlined in scheme (5.1): 


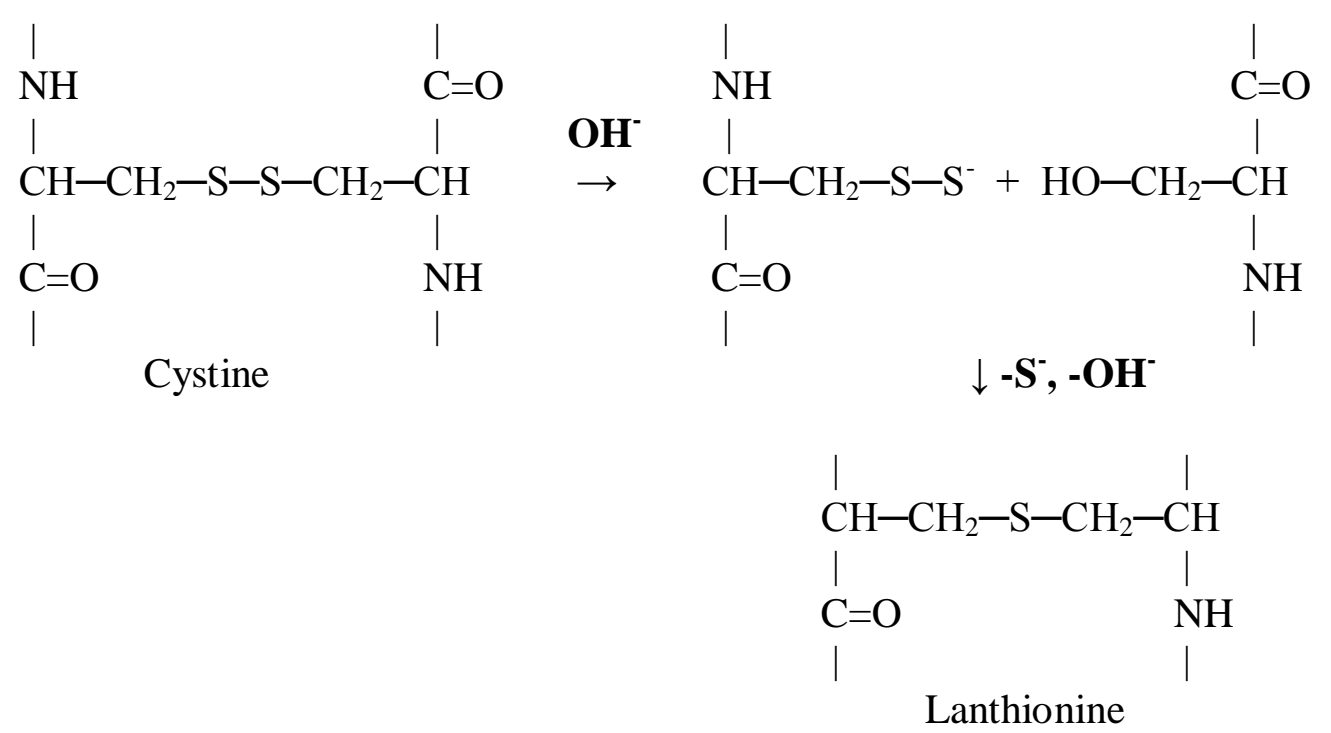

Lanthionine crosslinks are slightly more stable than the disulfide bonds of cystine,[82] and therefore the treatment of merino wool with base and the formation of such groups may decrease the reducing capacity of merino wool, accounting for the poor colour development in composites employing such pre-treated fibres. Due to time constraints, SEM analysis of such materials was not able to be undertaken, however from comparisons of similarly coloured composites, it is likely that these composites did not possess a large amount of gold nanoparticles.

\subsubsection{Chlorine Hercosett Treated Semi-Worsted Gilled Sliver}

The chlorine Hercosett shrink resist treatment is one of the most common surface treatments applied to woollen textiles destined for use in clothing applications (section 1.2.1.2.5), as such it was employed as an alternative substrate in the production of gold nanoparticlemerino wool composite materials. Employing such chlorine Hercosett shrink resist treated $(\mathrm{Cl} / \mathrm{H}$ treated) merino wool was unsuccessful. The colour of the resultant composite materials was very under developed, and did not vary to a great extent from that of untreated merino (Figure 5.53). Even after 168 hours ageing at $50{ }^{\circ} \mathrm{C}$, only a faint, spectrally impure pink tinge had developed, and this was very non-uniform. 


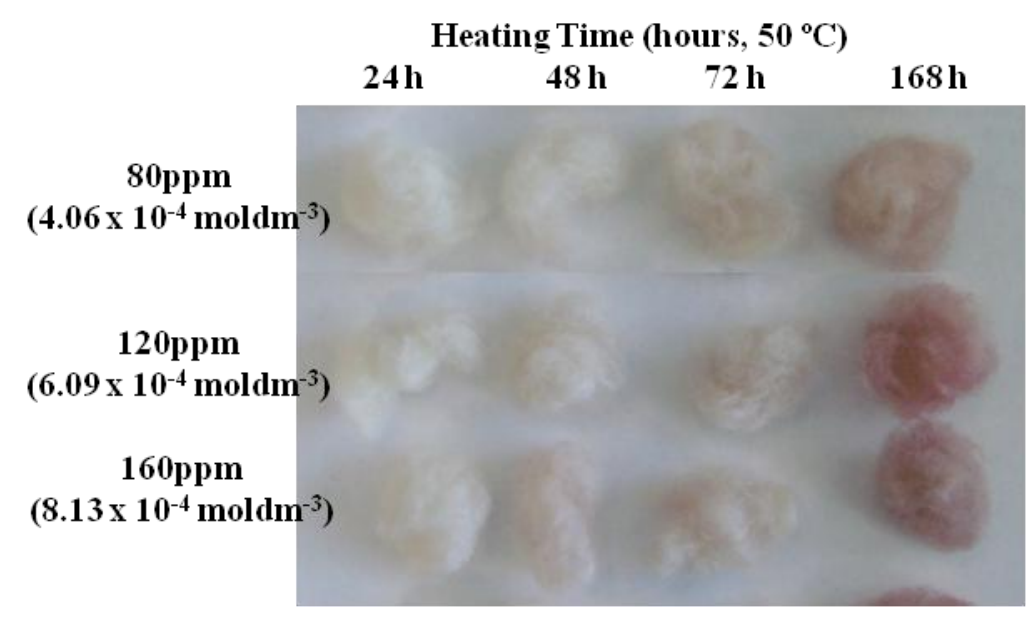

Figure 5.53: Gold nanoparticle-merino wool composites prepared by soaking $\mathrm{Cl} / \mathrm{H}$ treated merino wool in an 80, 120 or $160 \mathrm{ppm} \mathrm{Au}^{3+}\left(4.06 \times 10^{-4}, 6.09 \times 10^{-4}\right.$ or $8.13 \times 10^{-4} \mathrm{M}$ respectively) solution for 24 hours at RT, followed by ageing at $50{ }^{\circ} \mathrm{C}$ for $24-168$ hours.

Figure 5.54 offers increasing magnification SEM micrographs of gold nanoparticle-merino wool composites incorporating $\mathrm{Cl} / \mathrm{H}$ treated merino wool, prepared by soaking the fibres in an 80 or $160 \mathrm{ppm}\left(4.06 \times 10^{-4}\right.$ or $\left.8.13 \times 10^{-4} \mathrm{M}\right) \mathrm{Au}^{3+}$ solution for 24 hours at RT, followed by ageing at $50{ }^{\circ} \mathrm{C}$ for 24 or 168 hours. Comparing these micrographs to those of composites incorporating untreated semi-worsted merino wool show clear differences (Figure 5.15). At low magnifications a discernable difference between the wool fibres themselves is observed. In the $\mathrm{Cl} / \mathrm{H}$ treated fibres the cuticles are obscured by the Hercosett polymer, giving the fibres a much smoother appearance. Additionally, in the materials incorporating $\mathrm{Cl} / \mathrm{H}$ treated merino wool, there are many fewer nanoparticles on the fibre surface, and those present are not confined to the cuticle edges, rather they are spread across the fibre surface. When employing a $\mathrm{Au}^{3+}$ concentration of $80 \mathrm{ppm}\left(4.06 \times 10^{-4} \mathrm{M}\right)$ and an ageing time $\left(\right.$ at $\left.50{ }^{\circ} \mathrm{C}\right)$ of 24 hours, the nanoparticles in the resultant composites appear to be spherical or five-fold twinned in shape, approximately $20-25 \mathrm{~nm}$ in diameter, and as such are similar in morphology to those in composites incorporating untreated semi-worsted merino as the fibre substrate. Increasing the ageing time to 168 hours did not change the size or shape of the nanoparticles, rather slightly more were produced. Similar trends were observed when increasing the $\mathrm{Au}^{3+}$ concentration to $160 \mathrm{ppm}\left(8.13 \times 10^{-4} \mathrm{M}\right)$. The nanoparticles in composites prepared with 24 hours ageing at $50{ }^{\circ} \mathrm{C}$ were of comparable size as seen with 80 ppm $\left(4.06 \times 10^{-4} \mathrm{M}\right) \mathrm{Au}^{3+}$ solutions, notably 20-25 nm in diameter. Employing an ageing time of 168 hours produced similarly sized nanoparticles, however they were dramatically 
increased in number, spreading across the fibre surface and completely encapsulating it. In all composites incorporating $\mathrm{Cl} / \mathrm{H}$ treated merino wool, there were populations of agglomerated nanoparticles, with the occurrence of these agglomerates increasing with increased ageing times and higher $\mathrm{Au}^{3+}$ concentrations. The presence of these agglomerated particles would give rise to the murky, spectrally impure colour of the composites.
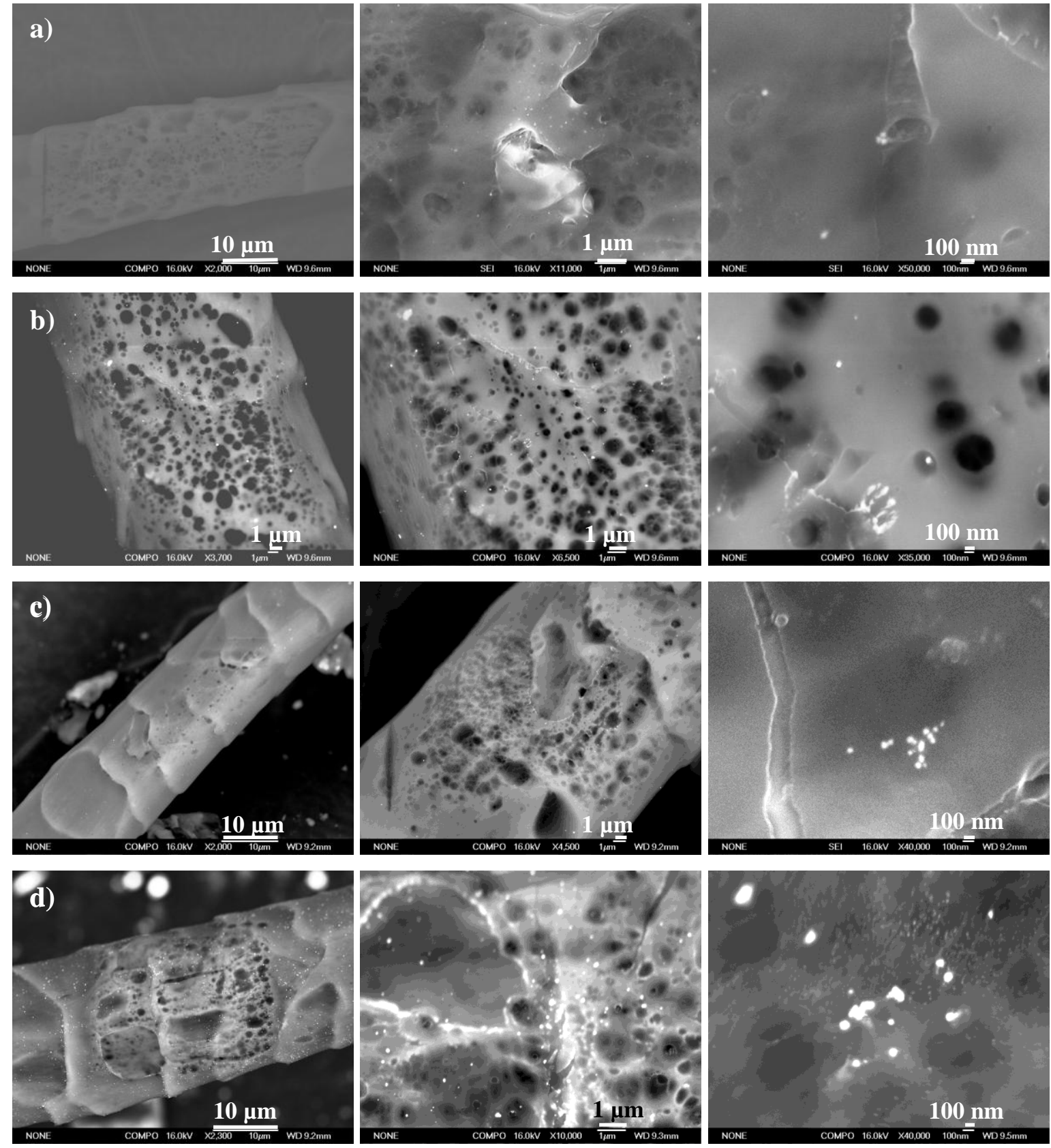

Figure 5.54: Increasing magnification SEM micrographs of gold nanoparticle-merino wool composites prepared by soaking $\mathrm{Cl} / \mathrm{H}$ treated merino wool in an 80 (a) and b)) or $160 \mathrm{ppm}(\mathrm{c})$ and d)) $\left(4.06 \times 10^{-4}\right.$ or $8.13 \times 10^{-4} \mathrm{M}$ respectively) $\mathrm{Au}^{3+}$ solution for 24 hours at $\mathrm{RT}$, followed by ageing at $50{ }^{\circ} \mathrm{C}$ for 24 (a) and c)) or 168 hours (b) and d)). 
Cross sectional SEM analysis showed the gold nanoparticles in the composites prepared from $\mathrm{Cl} / \mathrm{H}$ treated merino wool to reside preferentially at the fibre surface, with little to no nanoparticles evident in the centre (Figure 5.55). However EDS analysis of the same cross section revealed high concentrations of gold within the fibre centre (particularly in the paracortex where the concentration of sulfur is high) (Figure 5.56). This suggests that gold diffused into the centre of the fibres, however was not reduced to nanoparticulate $\mathrm{Au}^{0}$, or if it was the nanoparticles formed were too small to be viewed under SEM analysis.

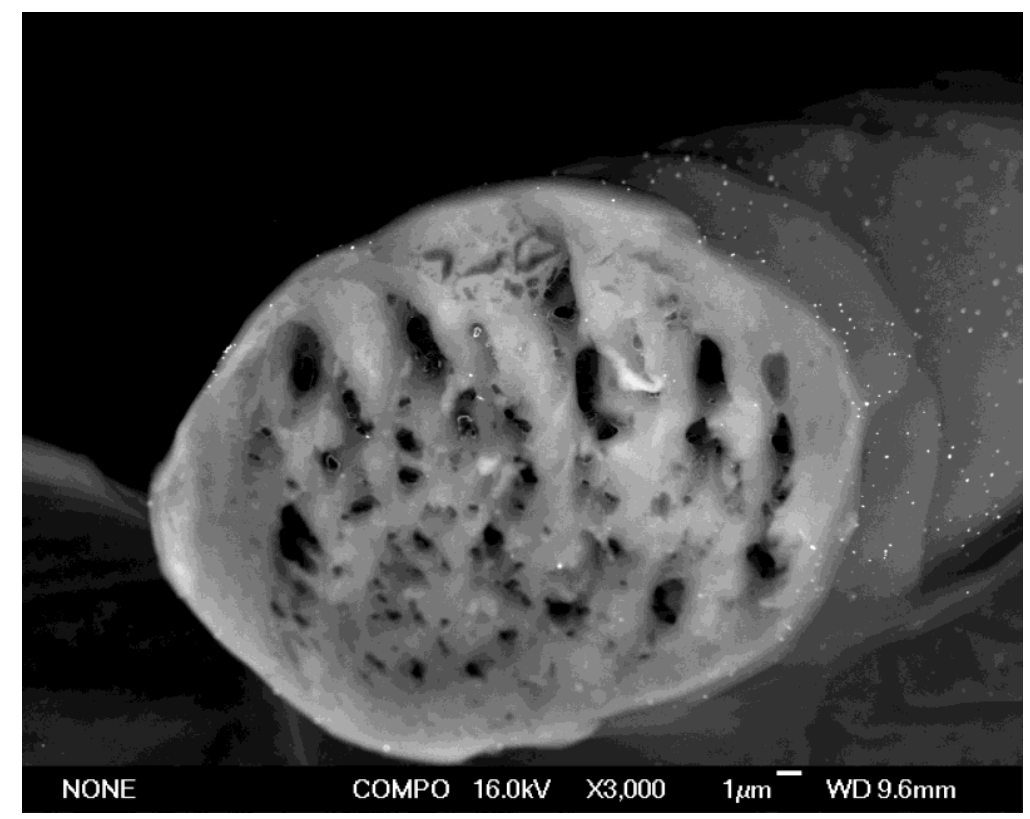

Figure 5.55: Cross sectional SEM micrograph of a gold nanoparticle-merino wool composite prepared by soaking $\mathrm{Cl} / \mathrm{H}$ treated merino wool in a $160 \mathrm{ppm}\left(8.13 \times 10^{-4} \mathrm{M}\right) \mathrm{Au}^{3+}$ solution for 24 hours at RT, followed by ageing at $50{ }^{\circ} \mathrm{C}$ for 168 hours. 

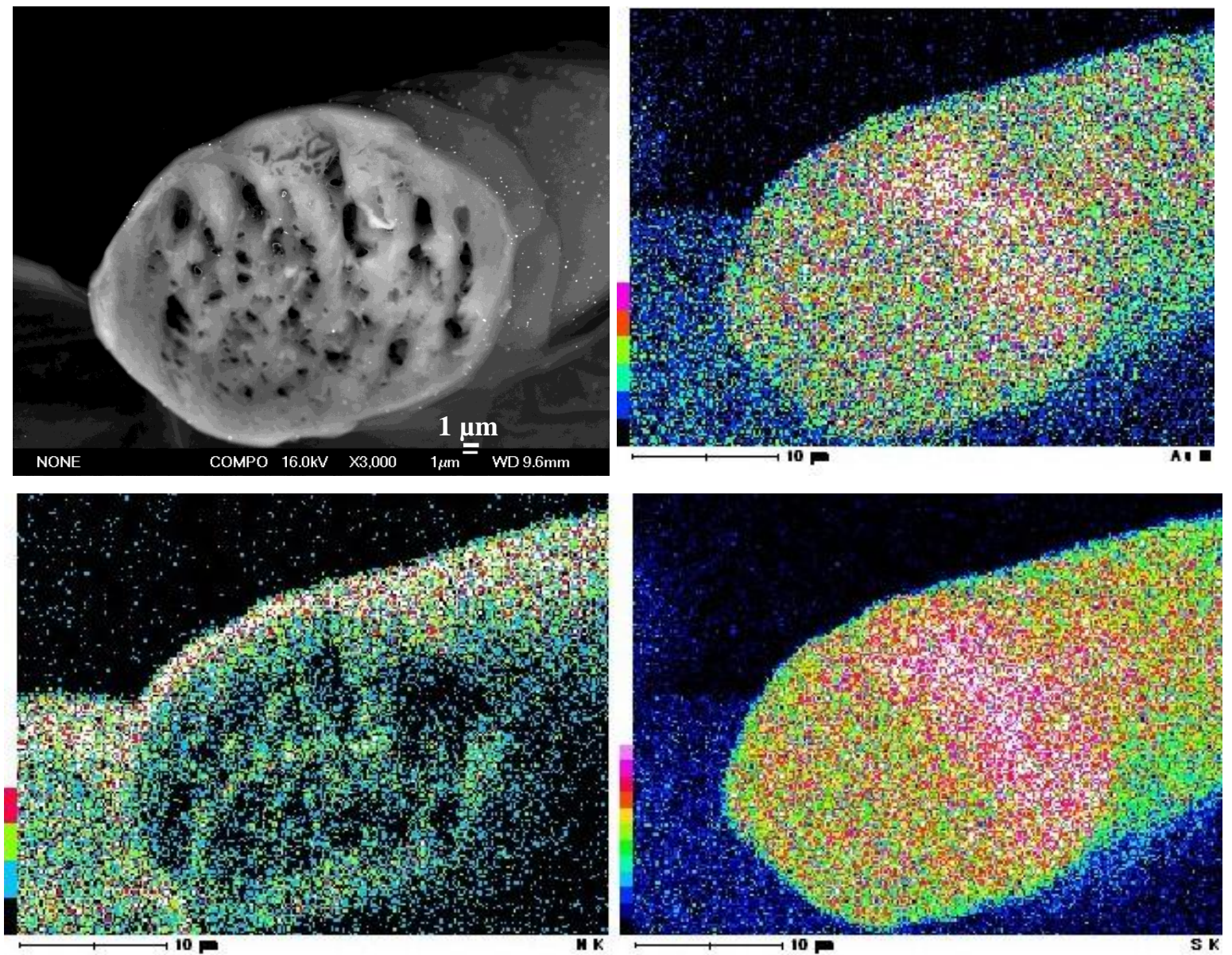

Figure 5.56: Cross sectional SEM and corresponding Au, $\mathrm{N}$ and S EDS maps of a gold nanoparticle merino wool composite prepared by soaking $\mathrm{Cl} / \mathrm{H}$ treated merino wool in a $160 \mathrm{ppm}\left(8.13 \times 10^{-4} \mathrm{M}^{-\mathrm{Au}^{3+}}\right.$ solution for 24 hours at RT, followed by ageing at $50{ }^{\circ} \mathrm{C}$ for 168 hours.

\subsubsection{KOH Treated Chlorine Hercosett Semi-Worsted Gilled Sliver}

Pre-treating the $\mathrm{Cl} / \mathrm{H}$ treated merino wool fibres with $0.1 \mathrm{M} \mathrm{KOH}$ solutions (as outlined in section 2.2.2.3.1) significantly increased the colour of the resultant composites incorporating $\mathrm{Cl} / \mathrm{H}$ treated merino wool, producing vibrant pink or purple coloured materials, depending on the $\mathrm{Au}^{3+}$ concentration and ageing time (Figure 5.57). Although improved by comparison with the composites incorporating untreated $\mathrm{Cl} / \mathrm{H}$ treated merino wool, the colour of these composites was still non-uniform. 


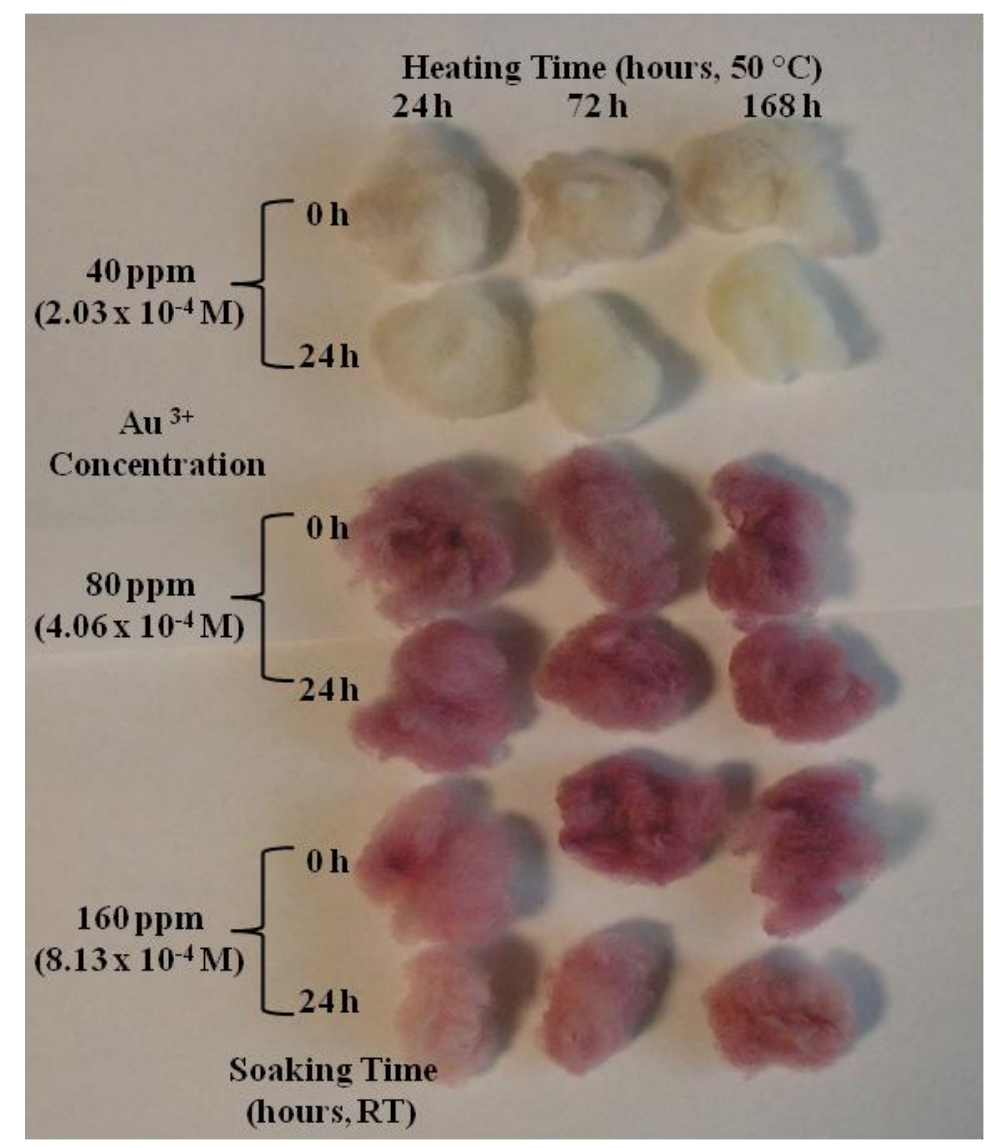

Figure 5.57: Gold nanoparticle-merino wool composites prepared by soaking base treated-Cl/H treated semi-worsted merino wool in a 40,80 or $160 \mathrm{ppm}\left(2.03 \times 10^{-4}, 4.06 \times 10^{-4}\right.$ or $8.13 \times 10^{-4} \mathrm{M}$ respectively $)$ $\mathrm{Au}^{3+}$ solution for 0 or 24 hours at RT, followed by ageing at $50{ }^{\circ} \mathrm{C}$ for $24-168$ hours.

Figure 5.58 offers increasing magnification SEM micrographs of gold nanoparticle-merino wool composites incorporating $\mathrm{KOH}$ pre-treated $\mathrm{Cl} / \mathrm{H}$ treated merino wool, prepared by soaking the pre-treated fibres in an 80 or $160 \mathrm{ppm}\left(4.06 \times 10^{-4}\right.$ or $\left.8.13 \times 10^{-4} \mathrm{M}\right) \mathrm{Au}^{3+}$ solution for 24 hours at RT, followed by ageing at $50{ }^{\circ} \mathrm{C}$ for 168 hours. Comparing these micrographs to those of composites incorporating $\mathrm{Cl} / \mathrm{H}$ treated merino wool shows clear differences. Base treating $\mathrm{Cl} / \mathrm{H}$ treated merino wool prior to addition to the $\mathrm{Au}^{3+}$ solutions dramatically increased the amount of nanoparticles on the fibre surface. These nanoparticles spread evenly across the fibre surface, completely encapsulating it. When employing a $\mathrm{Au}^{3+}$ concentration of $80 \mathrm{ppm}\left(4.06 \times 10^{-4} \mathrm{M}\right)$, and an ageing time of 168 hours, the nanoparticles in the resultant composite materials are on average much smaller than those seen in the corresponding composites incorporating either untreated semi-worsted merino wool or $\mathrm{Cl} / \mathrm{H}$ treated merino wool, existing as spherical nanoparticles, approximately $10-15 \mathrm{~nm}$ in 
diameter; however there are some larger, approximately 20-25 $\mathrm{nm}$ particles present. Increasing the $\mathrm{Au}^{3+}$ concentration to $160 \mathrm{ppm}\left(8.13 \times 10^{-4} \mathrm{M}\right)$ also produced composites with a mixture of both small, approximately $10-15 \mathrm{~nm}$ in diameter, and large, approximately 25 $30 \mathrm{~nm}$ diameter spherical nanoparticles. Compared to the composite materials produced with untreated $\mathrm{Cl} / \mathrm{H}$ treated merino wool, the nanoparticles in these materials are more dispersed and isolated, and combined with the slightly smaller average size of the nanoparticles, these factors would account for the much more spectrally pure, intense colour of the composites induced by base pre-treatment.
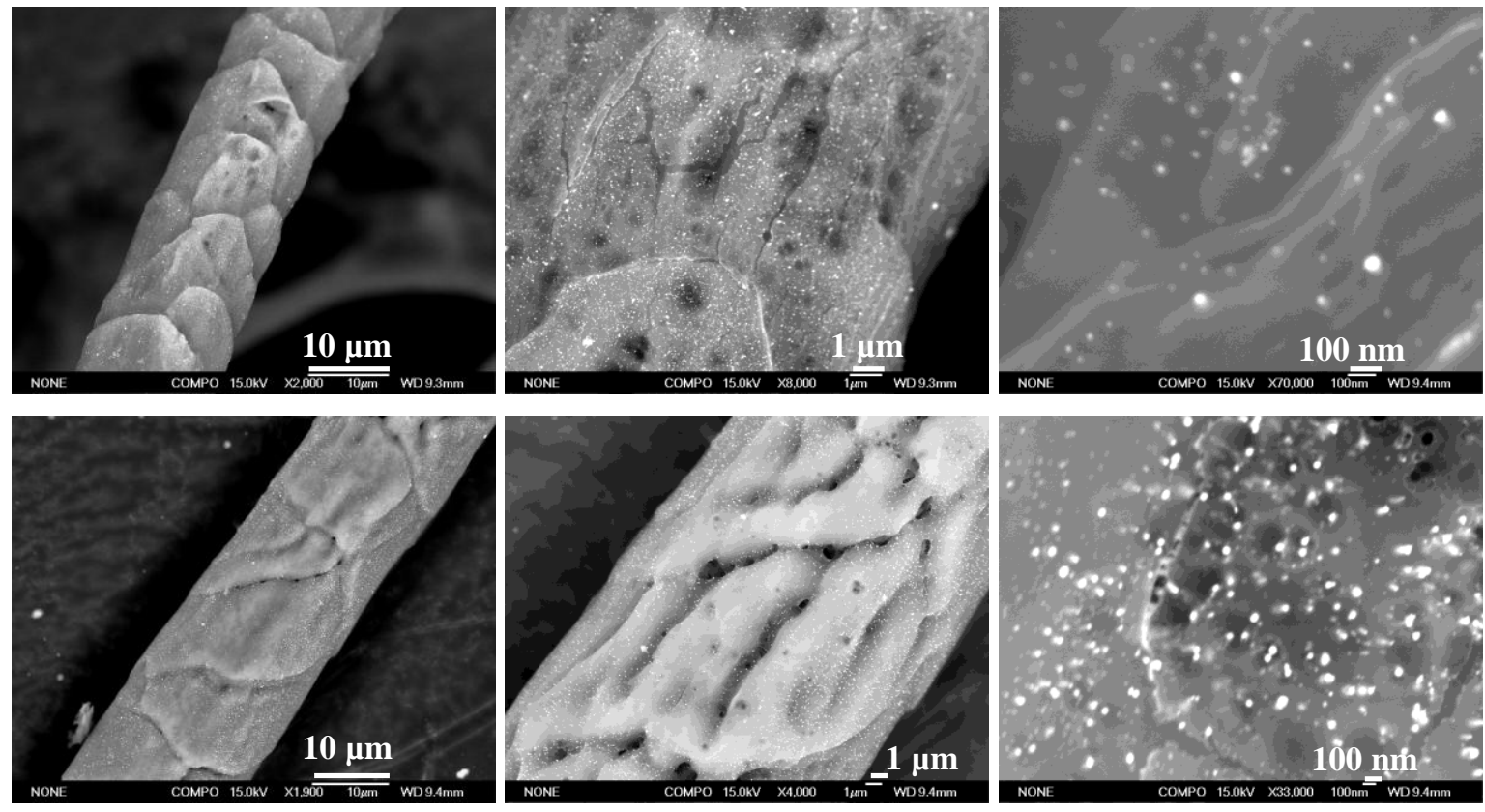

Figure 5.58: Increasing magnification SEM micrographs of gold nanoparticle-merino wool composites prepared by soaking $\mathrm{KOH}$ pre-treated $\mathrm{Cl} / \mathrm{H}$ treated merino wool in a top: $80 \mathrm{ppm}\left(4.06 \times 10^{-4} \mathrm{M}\right)$ or bottom: $160 \mathrm{ppm}\left(8.13 \times 10^{-4} \mathrm{M}\right) \mathrm{Au}^{3+}$ solution for 24 hours at RT, followed by ageing at $50{ }^{\circ} \mathrm{C}$ for 168 hours.

As with the composites incorporating untreated $\mathrm{Cl} / \mathrm{H}$ treated merino wool as the base fibre, cross sectional SEM micrographs show the nanoparticles in these materials to reside preferentially at the fibre surface rather than being dispersed throughout the centre, appearing to be lodged in the Hercosett polymer encapsulating the fibres (Figure 5.59). 


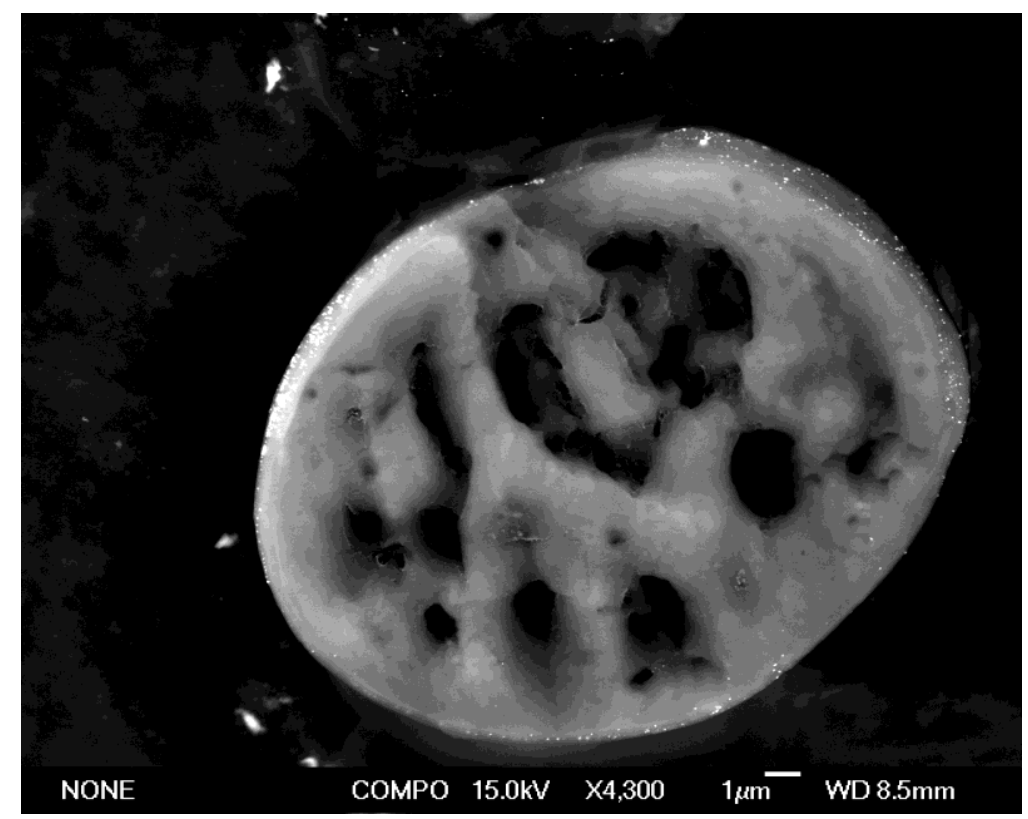

Figure 5.59: Cross sectional SEM micrograph of a gold nanoparticle-merino wool composite prepared by soaking KOH pre-treated $\mathrm{Cl} / \mathrm{H}$ treated merino wool in a $160 \mathrm{ppm}\left(8.13 \times 10^{-4} \mathrm{M}\right) \mathrm{Au}^{3+}$ solution for 24 hours at RT, followed by ageing at $50^{\circ} \mathrm{C}$ for 168 hours.

During the production of these composite materials, gold nanoparticles were formed in the reaction solution during ageing. This was evidenced by the development of a deep pink colour in the reaction solution. Figure 5.60 offers TEM micrographs of such ageing solutions that had been evaporated on a copper TEM grid. It is clear from these micrographs that nanoparticles had formed in solution. These nanoparticles were spherical or five-fold twinned in morphology, ranging in size from approximately 5-20nm in diameter.
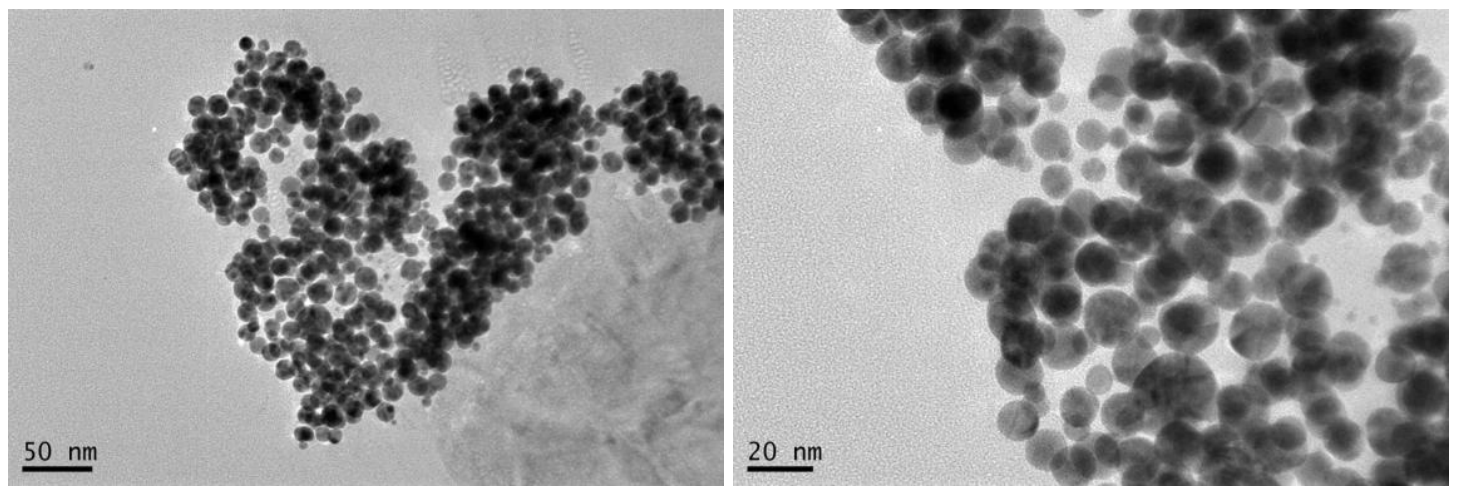

Figure 5.60: TEM micrographs of the gold nanoparticles formed in solution when ageing KOH treated $\mathrm{Cl} / \mathrm{H}$ treated merino wool. 


\subsubsection{Untreated Worsted Combed Top}

Employing merino wool prepared via the worsted processing route as the base substrate in the production of gold nanoparticle-merino wool composites produced materials that were less intense and more spectrally impure in colour relative to their analogous materials prepared with merino processed via the semi-worsted route (Figure 5.61).

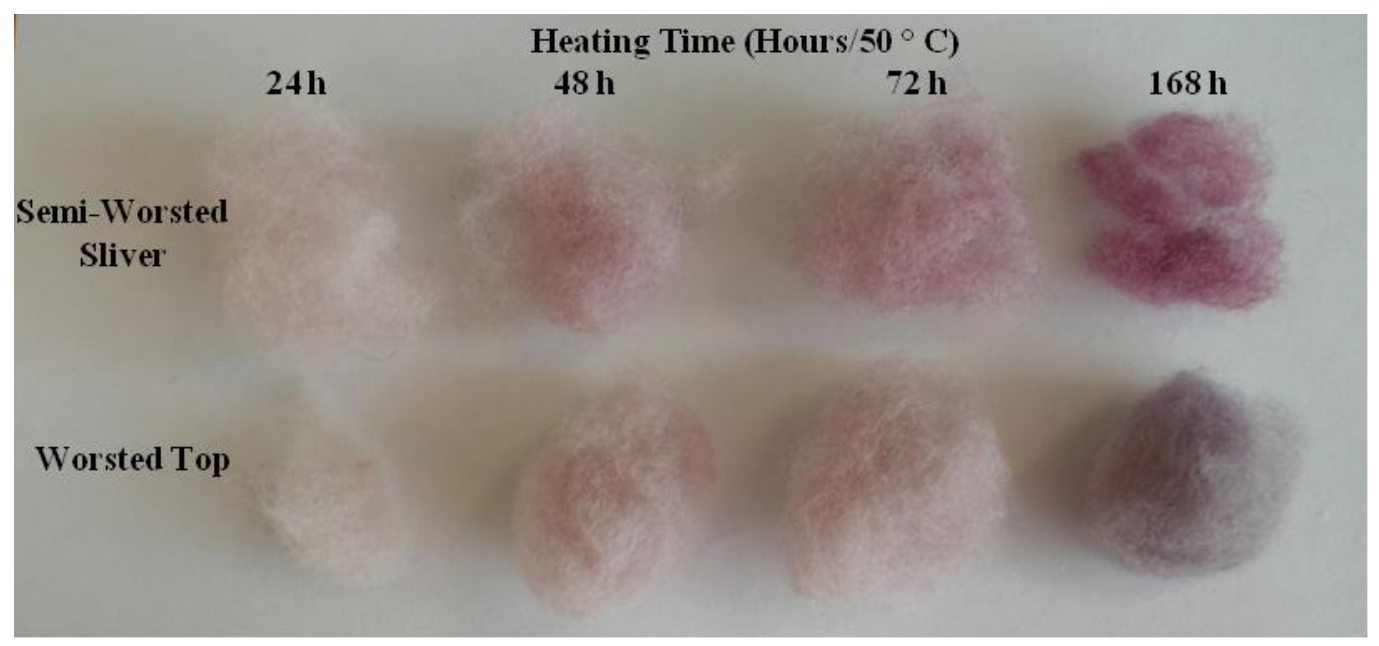

Figure 5.61: Gold nanoparticle-merino wool composites prepared with untreated semi-worsted merino wool (top) or worsted merino wool (bottom). Samples were soaked in a $160 \mathrm{ppm} \mathrm{Au}^{3+}\left(8.13 \times 10^{-4} \mathrm{M}\right)$ solution for 24 hours at $\mathrm{RT}$, followed by ageing at $50{ }^{\circ} \mathrm{C}$ for $24-168$ hours.

Comparing SEM micrographs of gold nanoparticle-merino wool composites prepared with worsted merino wool to those employing semi-worsted merino wool reveals the former to possess less gold nanoparticles than the latter. The nanoparticles are of comparable size, approximately $20-30 \mathrm{~nm}$ in diameter, and appear to be spherical in morphology (although five-fold twinned particles are not discernable at the resolutions offered in SEM, they cannot be ruled out as they are the common morphological form of gold seen in the gold nanoparticle-merino wool composites) (Figure 5.62). Additionally, compared to composites incorporating semi-worsted merino wool, there are also areas of agglomerated nanoparticles (confirmed by EDS analysis (Figure 5.63)). The decreased amount of nanoparticles, and the presence of agglomerated particles would account for the less intense and spectrally impure colour of these composite materials. 

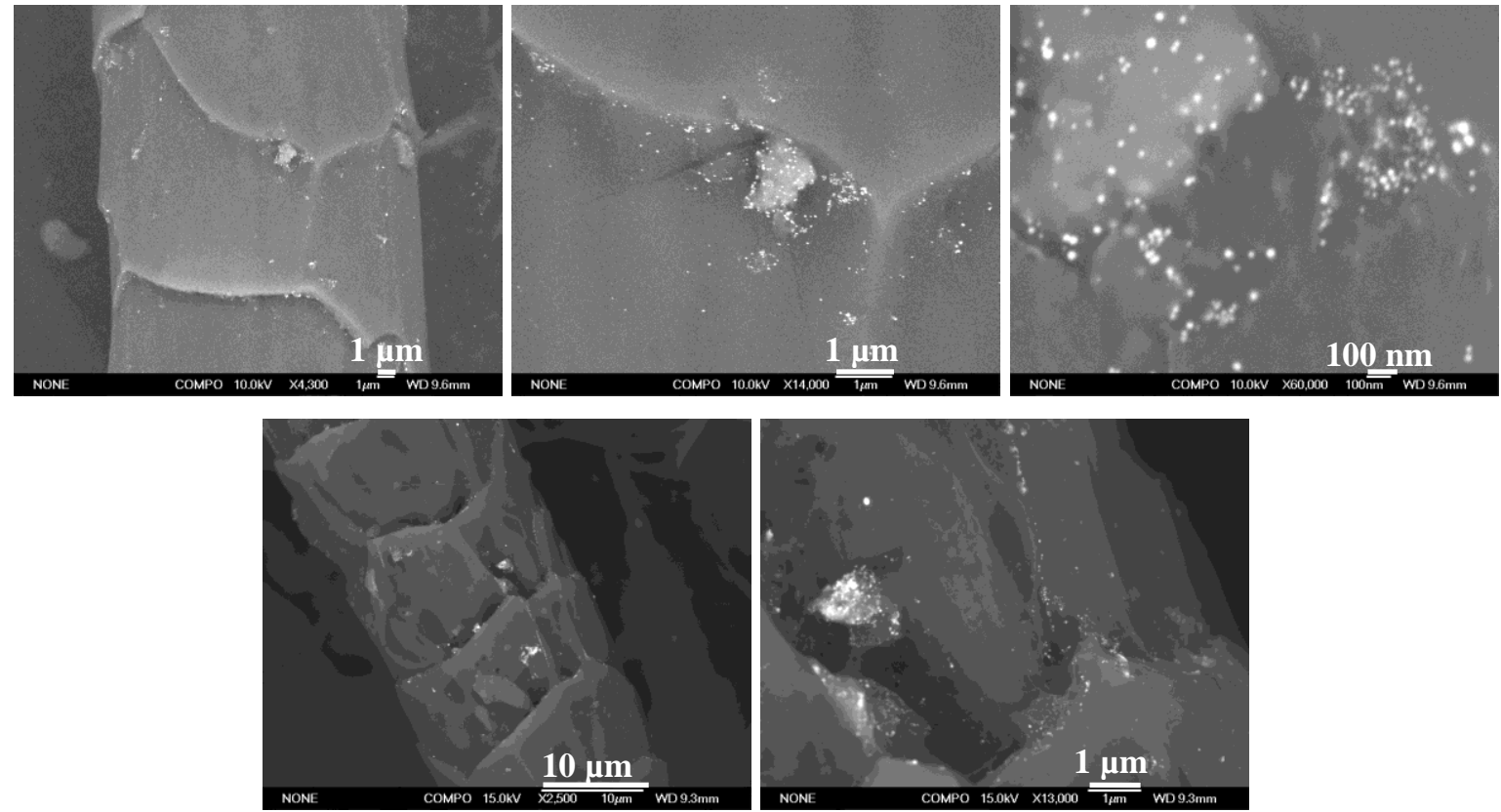

Figure 5.62: Top and bottom: Increasing magnification SEM micrographs of a gold nanoparticle-merino wool composite employing worsted merino wool. Composite prepared by soaking merino wool in a 160 ppm $\mathrm{Au}^{3+}\left(8.13 \times 10^{-4} \mathrm{M}\right)$ solution for 24 hours at RT, followed by ageing at $50{ }^{\circ} \mathrm{C}$ for 168 hours.
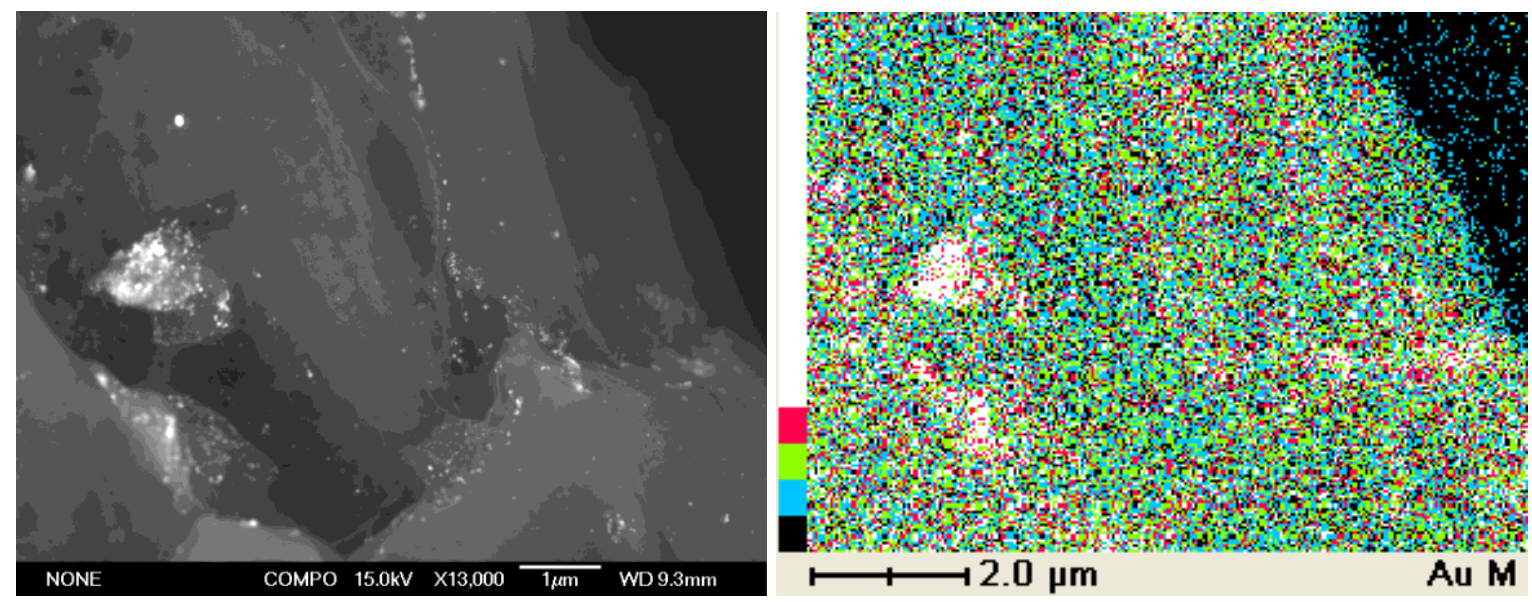

Figure 5.63: SEM micrograph (left) and the corresponding Au EDS map (right), of a gold nanoparticlemerino wool composite employing worsted merino wool. Composite prepared by soaking merino wool in a $160 \mathrm{ppm} \mathrm{Au}^{3+}\left(8.13 \times 10^{-4} \mathrm{M}\right)$ solution for 24 hours at RT, followed by ageing at $50{ }^{\circ} \mathrm{C}$ for 168 hours.

The chemical composition of worsted and semi-worsted merino wool is the same, so it is unlikely that the decreased amount of nanoparticles formed in the gold nanoparticle-merino wool composites incorporating worsted merino wool arose due to irregularities in its chemical composition. Uptake studies (see section 5.4) show that the absorption of $\mathrm{Au}^{3+}$ by worsted and semi-worsted merino wool is similar, thus the limited colour development of the 
composites prepared from worsted merino wool was likely related to the reduction of $\mathrm{Au}^{3+}$ to nanoparticulate $\mathrm{Au}^{0}$. The worsted and semi-worsted merino wools are of comparable diameters, notably 22.4 and $22.2 \mu \mathrm{m}$ respectively so the difference in their ability to reduce $\mathrm{Au}^{3+}$ is not due to a concentration effect (discussed in section 5.1.2.5 and section 5.6).

As discussed in section 1.2.2.1.4, the principal differences between the semi-worsted and worsted processing routes are the number of steps involved and hence the requirements of the systems in terms of lubrication. The worsted processing route is more complex than the semi-worsted route, involving additional steps and as such it utilises a greater amount of lubricants (of different types, see section 1.2.2.1.4). In both systems, lubricants are applied in $0.8-3 \mathrm{wt} \%$, and unless the wool is re-scoured following processing, these lubricants remain on the wool surface. This affects the surface properties of the processed wool, and hence wools which have been processed via the worsted or semi-worsted systems may differ in their surface chemistry.

As such, it is likely that the decreased ability of merino wool processed via the worsted route to facilitate the reduction of $\mathrm{Au}^{3+}$ to nanoparticulate $\mathrm{Au}^{0}$ may be due to the presence of lubricants on the fibre surface. To investigate whether this was the case, worsted merino wool fibres were pre-treated prior to addition to the $\mathrm{Au}^{3+}$ solution in an attempt to remove such lubricants. This involved cleaning the fibres by Soxhlet extraction in a 2:1 mixture of chloroform/methanol for 5 hours (as described in section 2.2.2.3.1). Figure 5.64 offers a picture of the composite materials prepared from such Soxhlet extracted cleaned fibres, and compares them to the corresponding materials prepared from untreated worsted merino wool. It is apparent that the colour of the composites incorporating the Soxhlet extracted fibres are much more developed, intense and spectrally pure relative to the composites prepared with untreated fibres, and are comparable in colour to the corresponding materials prepared from semi-worsted merino wool (Figure 5.36). This suggests that the presence of the lubricants on the surface of the worsted fibres adversely affected the ability of the wool to reduce $\mathrm{Au}^{3+}$ to nanoparticulate $\mathrm{Au}^{0}$. Additionally it is likely that agglomerations of nanoparticles formed as the lubricants may have obstructed the contact between the nanoparticles and wool fibres, thus hindering the stabilisation effect imparted to the nanoparticles by the proteins in the wool, resulting in increased agglomeration of these nanoparticles. 


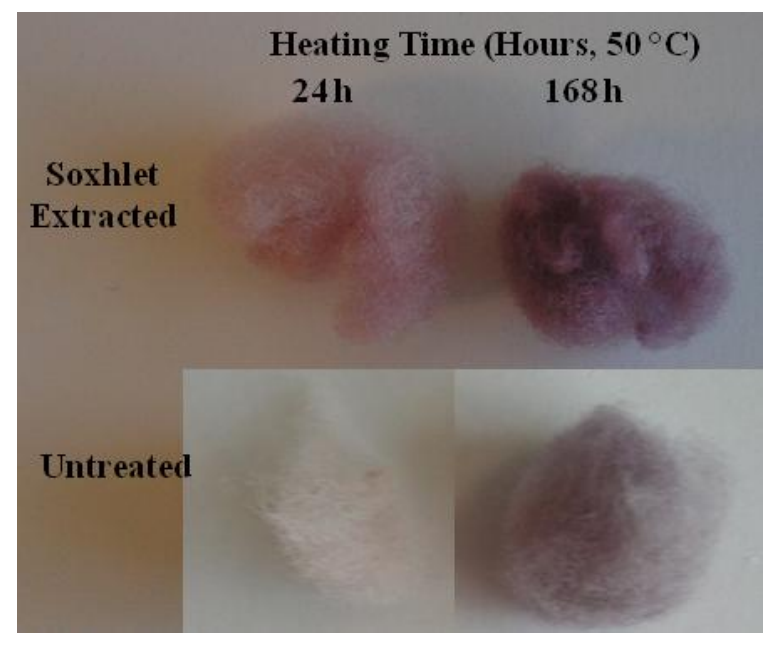

Figure 5.64: Gold nanoparticle-merino wool composites prepared from Soxhlet treated worsted merino wool (top) and untreated worsted merino wool (bottom). Prepared by soaking in a $160 \mathrm{ppm} \mathrm{Au}^{3+}(8.13 \mathrm{x}$ $10^{-4} \mathrm{M}$ ) solution for 24 hours at RT, followed by ageing at $50{ }^{\circ} \mathrm{C}$ for 24 of 168 hours.

\subsection{Colour}

The colour of the gold nanoparticle-merino wool composites prepared through utilisation of the redox active nature of the proteins present in merino wool was characterised through UV/Vis spectroscopy and via analysis of their CIE L*, a*, $\mathrm{b}^{*}, 457 \mathrm{~nm}$ brightness and $580 \mathrm{~nm}$ brightness values. A comprehensive set of CIE values are offered in Appendix II. In general, an increase in the amount of similarly sized nanoparticles (both on the surface and within the centre of fibres) corresponded to a change in composite colour from pale pink to pink, purple, light grey to steely grey. This suggests that as with the gold nanoparticlemerino wool composites prepared via the seed mediated approach (section 8.1.3.2), the change in reflected colour of these materials was initially due to an increase in the concentration of similarly sized nanoparticles followed by an increase in particle size, and extent of agglomeration.

Various factors influenced the colour of the resultant composites, including the ageing time, soaking and ageing solution composition (including $\mathrm{pH}$ ), ageing temperature, the $\mathrm{Au}^{3+}$ concentration, fibre pre-treatments and processing routes. As mentioned, the CIE L*, $\mathrm{a}^{*}, \mathrm{~b}^{*}$, $457 \mathrm{~nm}$ brightness and $580 \mathrm{~nm}$ brightness values of the composites reflected these changes, 
in particular the $\mathrm{a}^{*}$ and $\mathrm{b}^{*}$ values. The CIE $\mathrm{a}^{*}$ value indicates the colour of a sample between red (positive $a^{*}$ values) and green (negative $a^{*}$ values), whilst $b^{*}$ values indicate yellow (positive $b^{*}$ ) or blue (negative $b^{*}$ ) hues. Therefore by monitoring the measured $a^{*}$ and $b^{*}$ values of prepared gold nanoparticle-merino wool composites, the colour development observed by the eye may be confirmed.

When employing a $\mathrm{Au}^{3+}$ concentration of $160 \mathrm{ppm}\left(8.13 \times 10^{-4} \mathrm{M}\right)$, increasing the ageing time from 24 to 168 hours resulted in a change in composite colour from light pink to pink and finally purple. This colour change was reflected in the CIE L*, $a^{*}$ and $b^{*}$ values of the composite materials. Increasing the ageing time from 24 to 168 hours saw a gradual increase in $\mathrm{a}^{*}$ values, and a corresponding decrease in $\mathrm{b}^{*}$ values of the produced materials, with the greatest changes occurring between 72 and 168 hours ageing (Figure 5.65). These changes correspond to the observed colour change from pink to increasingly deeper shades of pink to purple induced with prolonged ageing times.

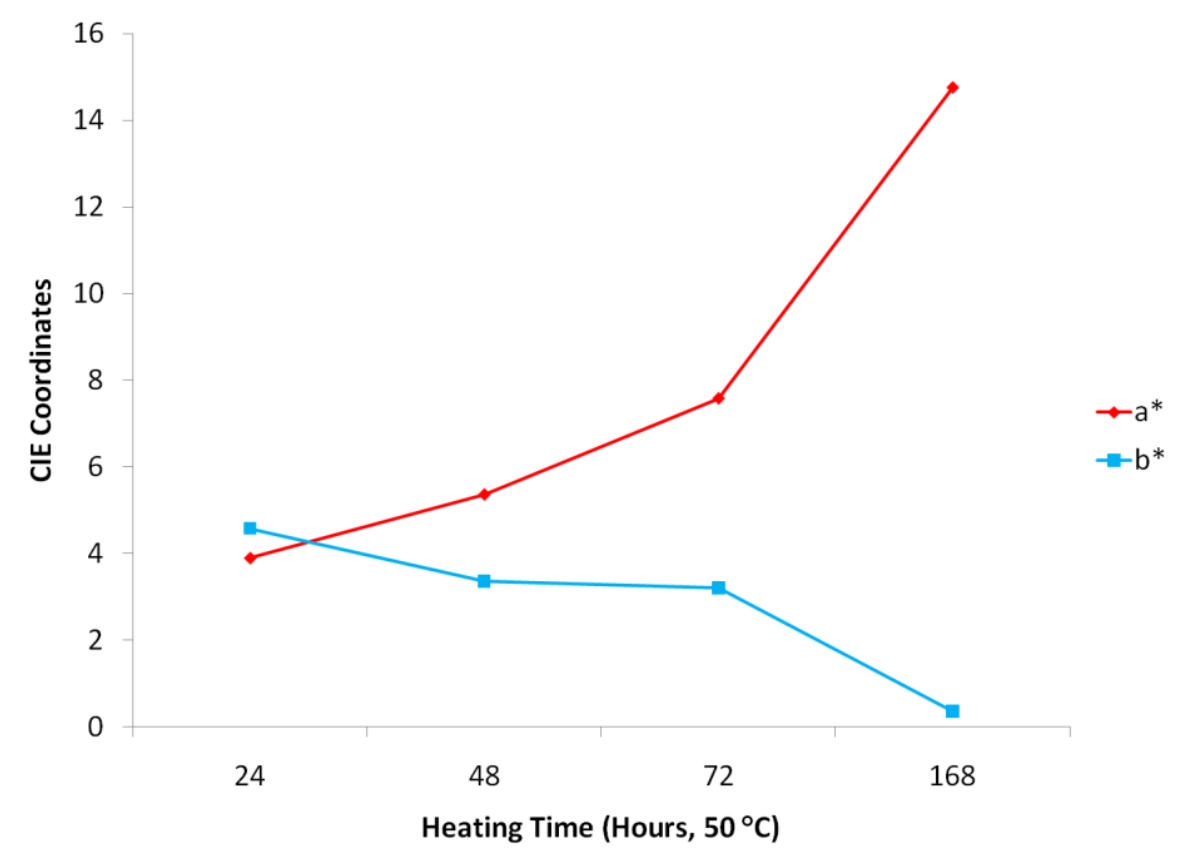

Figure 5.65: Changes in the $a^{*}$ and $b^{*}$ CIE values of gold nanoparticle-merino wool composites induced with increasing ageing time at $50{ }^{\circ} \mathrm{C}$. 
In addition to the ageing time, the composition of the soaking and ageing solutions influenced the colour of the resultant materials. Soaking and ageing in solutions of lower ionic strength than the original $\mathrm{Au}^{3+}$ soaking solution produced materials that were less intense and spectrally pure than their corresponding materials which employed the original $\mathrm{Au}^{3+}$ soaking and ageing solution. This observed decrease in colour intensity was reflected in the $a^{*}$ and $b^{*}$ values of the composites, which on average were lower and higher respectively (Table 5.4, and Appendix II). Alternatively, employing soaking and ageing solutions of increased ionic strength, for example $0.1 \mathrm{M} \mathrm{NaCl}$ or $\mathrm{MgCl}_{2}$ initially produced composite materials that were more vibrant in colour. However a deep, regal purple colour was not obtainable in these systems. These vibrant colours, and also the failure to produce the deep purple coloured composites was reflected in comparisons of the the $a^{*}$ and $b^{*}$ values of the materials, with those utilising $0.1 \mathrm{M} \mathrm{NaCl}$ soaking and ageing solutions initially exhibiting higher and lower $\mathrm{a}^{*}$ and $\mathrm{b}^{*}$ values respectively compared to materials prepared with the original $\mathrm{Au}^{3+}$ soaking and ageing solutions. However after 168 hours of ageing, these values did not increase and decrease to such an extent as those of the materials aged in the original $\mathrm{Au}^{3+}$ soaking solution (Figure 5.66, Table 5.4).

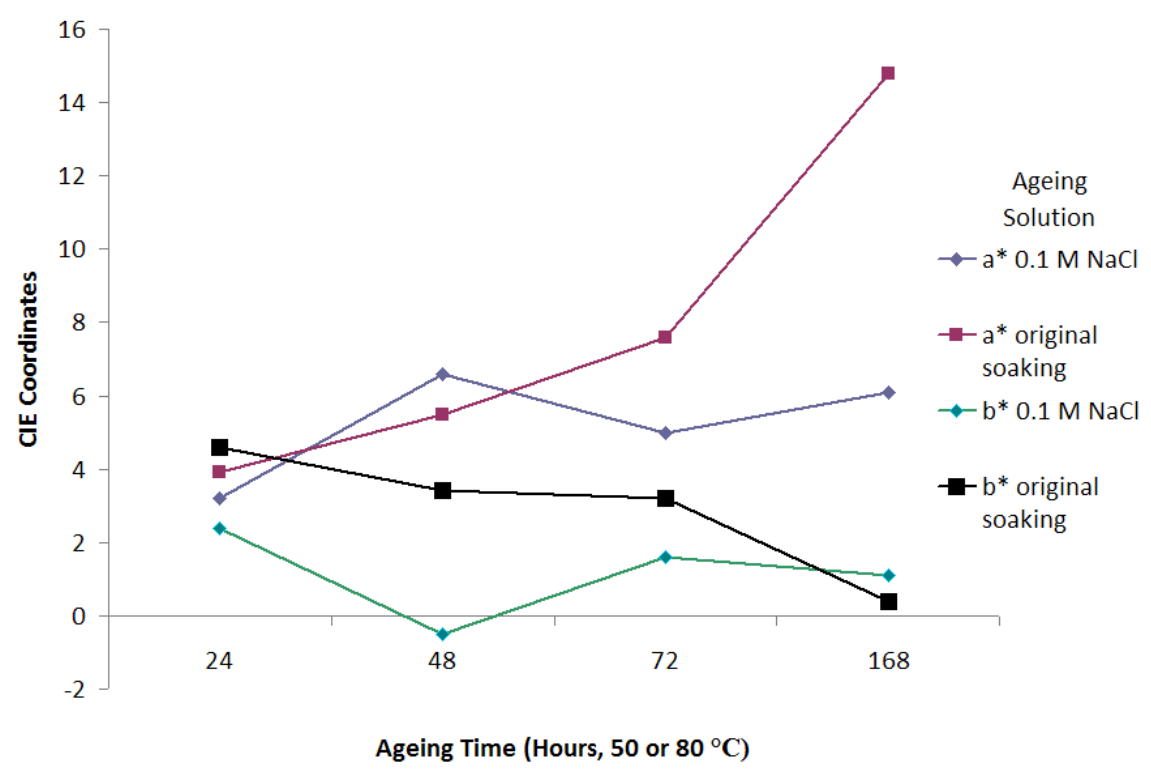

Figure 5.66: CIE $a^{*}$ and $b^{*}$ values of gold nanoparticle-merino wool composites utilising the original $\mathrm{Au}^{3+}$ soaking solution or $0.1 \mathrm{M} \mathrm{NaCl}$ as the ageing solution. 
Table 5.4: CIE $a^{*}$ and $b^{*}$ values for gold nanoparticle-merino wool composites prepared from alternate ageing solutions. Employing a $160 \mathrm{ppm}\left(8.13 \times 10^{-4} \mathrm{M}\right) \mathrm{Au}^{3+}$ solution, a soaking time, at RT of 24 hours and ageing times at $50{ }^{\circ} \mathrm{C}$ of $24-168$ hours.

\begin{tabular}{|c|c|c|c|}
\hline $\begin{array}{l}\text { Ageing } \\
\text { Solution }\end{array}$ & $\begin{array}{c}\text { Ageing Time } \\
\text { (hours, } 50^{\circ} \mathrm{C} \text { ) }\end{array}$ & $\mathbf{a}^{*}$ & $\mathbf{b}^{*}$ \\
\hline \multirow{4}{*}{$\begin{array}{l}\text { Original } \mathrm{Au}^{3+} \\
\text { soaking } \\
\text { solution }\end{array}$} & 24 & 3.9 & 4.6 \\
\hline & 48 & 5.5 & 3.4 \\
\hline & 72 & 7.6 & 3.2 \\
\hline & 168 & 14.8 & 0.4 \\
\hline \multirow[t]{2}{*}{$\mathrm{H}_{2} \mathrm{O}$} & 24 & 3.3 & 4.6 \\
\hline & 168 & 5.8 & 5.3 \\
\hline \multirow{2}{*}{$\begin{array}{c}40 \mu \mathrm{L} 0.1 \mathrm{M} \\
\mathrm{HCl} \rightarrow 10 \mathrm{ml} \\
\mathrm{H}_{2} \mathrm{O}\end{array}$} & 24 & 3.6 & 5.1 \\
\hline & 168 & 5.7 & 4.6 \\
\hline \multirow{2}{*}{$\begin{array}{c}40 \mu \mathrm{L} 0.1 \mathrm{M} \\
\mathrm{NaCl} \rightarrow 10 \mathrm{ml} \\
\mathrm{H}_{2} \mathrm{O}\end{array}$} & 24 & 3.3 & 4.9 \\
\hline & 168 & 5.8 & 4.9 \\
\hline \multirow[t]{4}{*}{$0.1 \mathrm{M} \mathrm{NaCl}$} & 24 & 3.2 & 2.4 \\
\hline & 48 & 6.6 & -0.5 \\
\hline & 72 & 5.0 & 1.6 \\
\hline & 168 & 6.1 & 1.1 \\
\hline
\end{tabular}

The ageing temperature also influenced the colour of the resultant gold nanoparticle-merino wool composites, with temperatures of greater than $50{ }^{\circ} \mathrm{C}$ producing spectrally impure materials whose colour was less intense than the corresponding materials prepared with an ageing temperature of $50{ }^{\circ} \mathrm{C}$. This variation in colour, induced by different ageing temperatures was confirmed in the CIE $a^{*}$ and $b^{*}$ values, which on average were lower and higher respectively than the corresponding composites prepared at $50{ }^{\circ} \mathrm{C}$ (Figure 5.67, and Appendix II). 


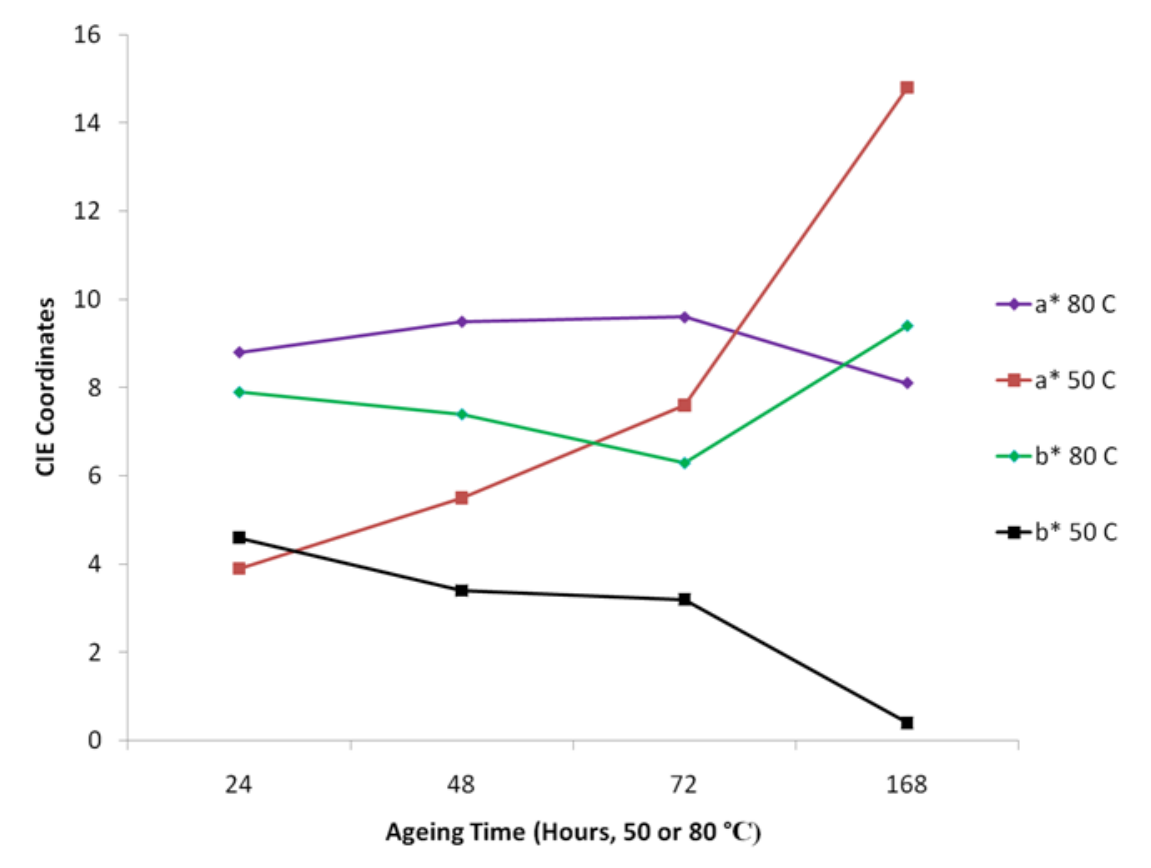

Figure 5.67: Changes in the $a^{*}$ and $b^{*}$ CIE values of gold nanoparticle-merino wool composites induced with different ageing temperatures.

As mentioned above, increasing the $\mathrm{Au}^{3+}$ concentration from approximately 80 to $160 \mathrm{ppm}$ (4.06 $\times 10^{-4}-8.13 \times 10^{-4} \mathrm{M}$ respectively) did not alter the hue of the resultant composites, rather it intensified their pink or purple colour. With a soaking time, at RT, of 24 hours, and an ageing time, at $50{ }^{\circ} \mathrm{C}$, of 168 hours, increasing the $\mathrm{Au}^{3+}$ concentration from 80 to $160 \mathrm{ppm}$ saw the production of more intense purple coloured materials, and this was reflected in the $\mathrm{a}^{*}$ and $b^{*}$ values of the composites, with those prepared with higher $\mathrm{Au}^{3+}$ concentrations possessing higher $\mathrm{a}^{*}$ and lower $\mathrm{b}^{*}$ values (Figure 5.68, and Appendix II). 


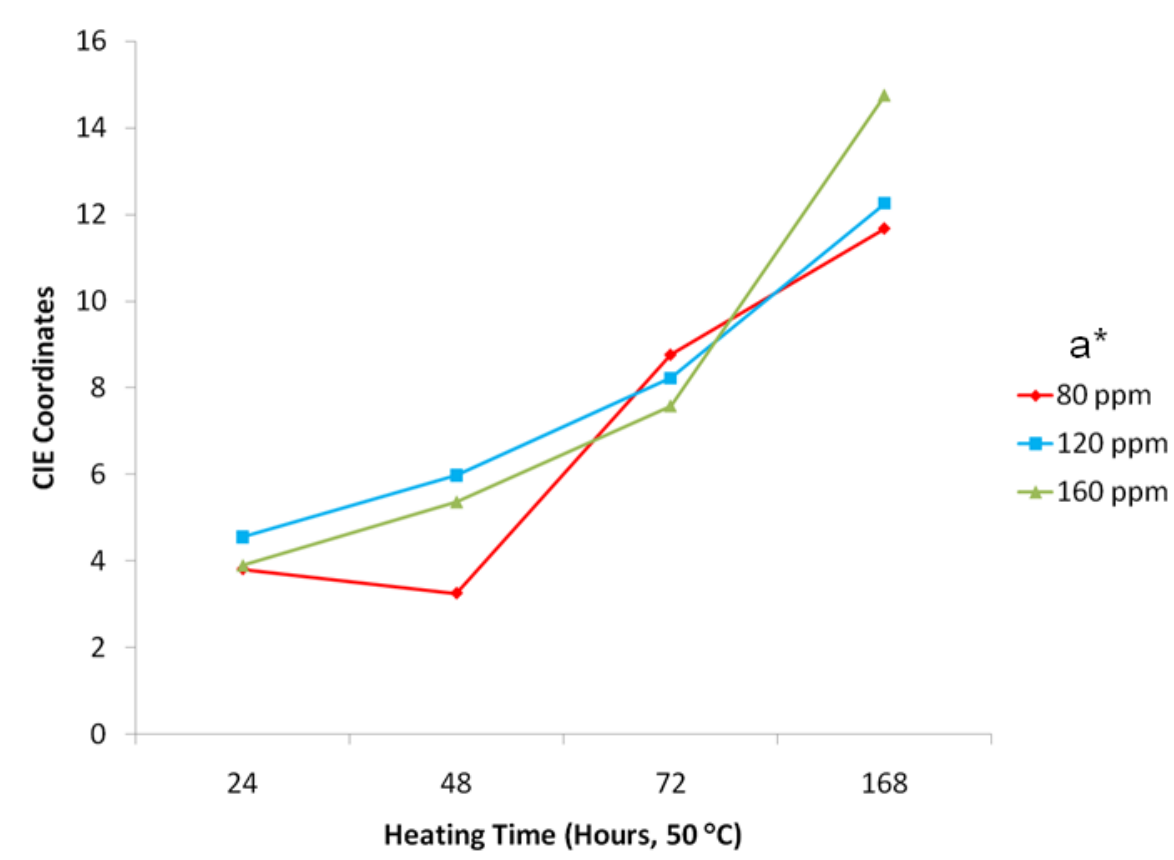

Figure 5.68: Changes in the $\mathrm{a}^{*}$ CIE values of gold nanoparticle-merino wool composites prepared with increasing $\mathrm{Au}^{3+}$ concentrations.

Altering the $\mathrm{pH}$ of both the soaking and ageing solutions influenced the colour of the resultant composite materials. Increasing the $\mathrm{pH}$ of the soaking solutions (whilst the absorption of $\mathrm{Au}^{3+}$ was occurring) was detrimental on colour development, producing murky, spectrally impure coloured materials, which even after 168 hours ageing at $50{ }^{\circ} \mathrm{C}$, were very under-developed with respect to colour. The CIE $a^{*}$ and $b^{*}$ values of these materials reflected their under developed colour, as compared to materials prepared with a soaking solution of $\mathrm{pH} 2.7$, the $\mathrm{a}^{*}$ and $\mathrm{b}^{*}$ values were lower and higher respectively (Table 5.5 below and Appendix II).

Table 5.5: CIE $a^{*}$ and $b^{*}$ values of gold nanoparticle-merino wool composites, prepared with a gold concentration of $160 \mathrm{ppm}\left(8.13 \times 10^{-4} \mathrm{M}\right)$, soaking time of 24 hours and ageing time, at $50{ }^{\circ} \mathrm{C}$ of $168 \mathrm{~h}$.

Shows the effect of the soaking solution pH

\begin{tabular}{ccc}
\hline $\begin{array}{c}\text { Soaking } \\
\text { Solution pH }\end{array}$ & $\mathbf{a}^{\star}$ & $\mathbf{b}^{\star}$ \\
\hline $\mathbf{2 . 7}$ & 14.8 & 0.4 \\
$\mathbf{7}$ & 3.7 & 7.6 \\
$\mathbf{9}$ & 4.8 & 5.9 \\
\hline
\end{tabular}


Alternatively, increasing the $\mathrm{pH}$ of the ageing solutions acted to increase the rate of reduction of $\mathrm{Au}^{3+}$ to nanoparticulate $\mathrm{Au}^{0}$, subsequently accelerating colour development in such materials. Comparing the CIE values of composites prepared in ageing solutions of $\mathrm{pH} 4,7$ or 9 to those prepared with ageing solutions of $\mathrm{pH} 2.7$, (the $\mathrm{pH}$ of the typical $160 \mathrm{ppm} \mathrm{Au}^{3+}$ $\left(8.13 \times 10^{-4} \mathrm{M}\right)$ solution) confirms the increased speed of the reduction of $\mathrm{Au}^{3+}$ to nanoparticulate $\mathrm{Au}^{0}$ and subsequent colour development (Appendix II). Figure 5.69 and Figure 5.70 offer graphs of $\mathrm{a}^{*}$ and $\mathrm{b}^{*}$ against time respectively for composites prepared from ageing solutions of various $\mathrm{pHs}$. It can be seen that increasing the $\mathrm{pH}$ of the ageing solution to a maximum of $\mathrm{pH} 9$ increases the rate of colour development, with higher a* values (reflective of redder materials) achieved in shorter time periods. Similar trends were observed in the $b^{*}$ values, however these fell rather than rose, reflecting the development of the purple colour observed in the composite materials. Employing an ageing solution with a $\mathrm{pH}$ of 12 produced yellow coloured materials, and this is reflected in $\mathrm{b}^{*}$ values of these materials, as they are much higher than the corresponding materials prepared with ageing solutions of $\mathrm{pH}<9$.

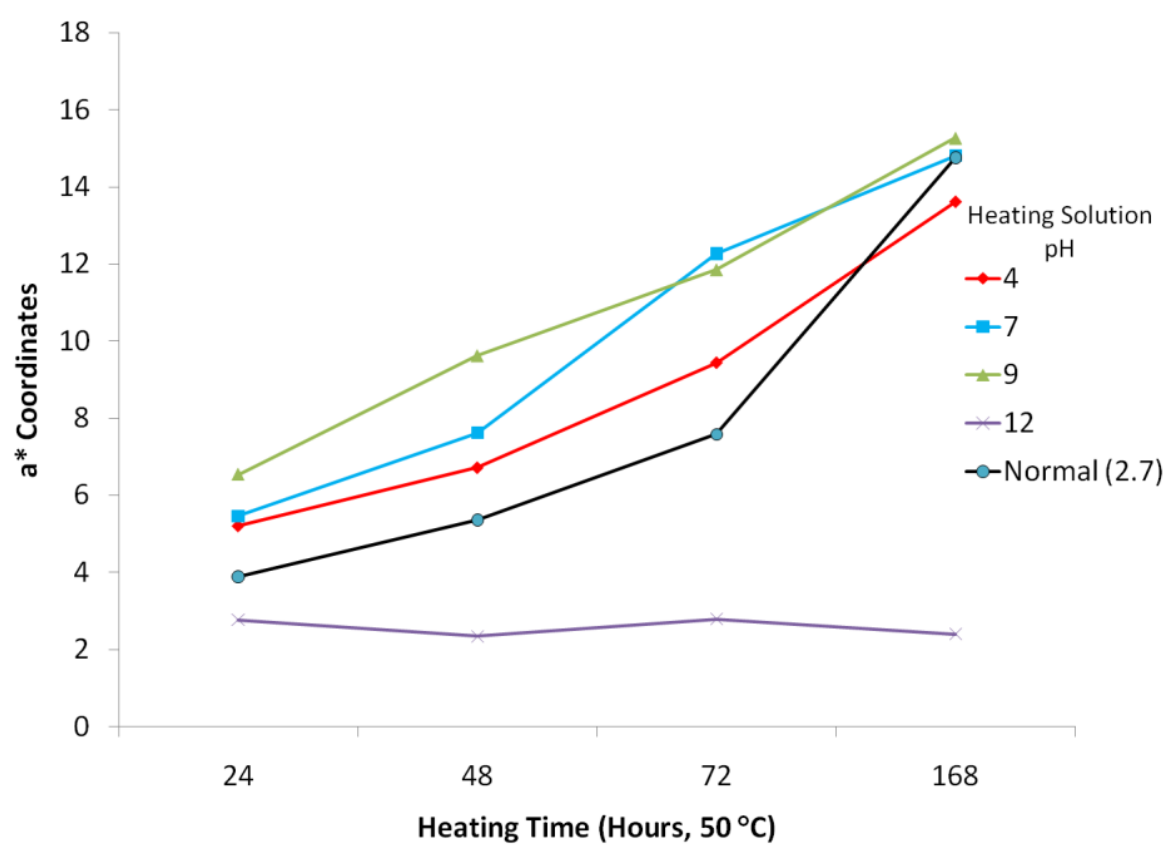

Figure 5.69: Changes in the $a^{*}$ CIE values of gold nanoparticle-merino wool composites prepared with ageing solutions of elevated $\mathrm{pH}$. 


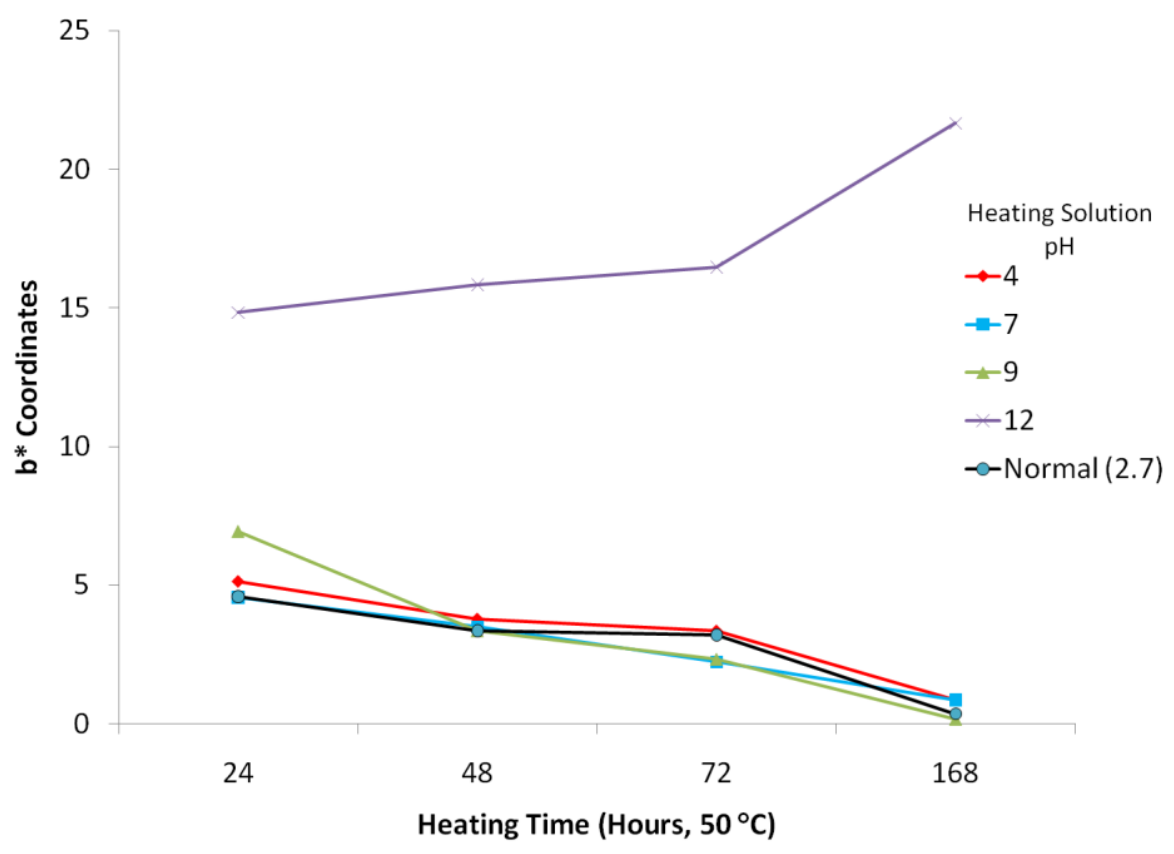

Figure 5.70: Changes in the $b^{*}$ CIE values of gold nanoparticle-merino wool composites prepared with ageing solutions of elevated $\mathrm{pH}$.

Pre-treating semi-worsted merino wool prior to addition to the $\mathrm{Au}^{3+}$ soaking solution also influenced the colour of the composites. Both acid and base pre-treatments markedly reduced the ability of the wool to facilitate the reduction of $\mathrm{Au}^{3+}$ to nanoparticulate $\mathrm{Au}^{0}$, producing materials that did not differ to a great extent in colour from the base merino wool fibres. Compared to composites prepared with untreated merino wool, the CIE L* values (which measure a materials degree of lightness) of materials incorporating either acid or base treated merino wool were higher. Additionally, the $a^{*}$ and $b^{*}$ values were lower and higher respectively, verifying the less pronounced purple colour of the composites prepared from acid or base treated merino wool (Table 5.6).

In addition to employing pre-treated merino wool as the base fibre, employing $\mathrm{Cl} / \mathrm{H}$ treated semi-worsted merino wool also influenced the colour of the resultant composite materials, resulting in the production of much less intensely coloured composites. Comparing the CIE $a^{*}$ and $b^{*}$ values of such materials to their analogues incorporating untreated semi-worsted merino illustrates this (Table 5.7, and Appendix II). The $\mathrm{a}^{*}$ values of the $\mathrm{Cl} / \mathrm{H}$ composites were lower than the corresponding materials prepared from untreated merino wool, 
Table 5.6: CIE $L^{*}, a^{*}$ and $b^{*}$ values of gold nanoparticle-merino wool composites prepared from $\mathrm{HCl}$ or KOH/EtOH pre-treated merino wool (top three data rows) and untreated merino wool (bottom data row).

\begin{tabular}{|c|c|c|c|c|c|c|}
\hline & \multicolumn{6}{|c|}{ Pre-treatment } \\
\hline & $\mathrm{HCl}$ & KOH/EtOH & $\mathrm{HCl}$ & KOH/EtOH & $\mathrm{HCl}$ & KOH/EtOH \\
\hline $\begin{array}{l}\text { Pre-treatment } \\
\text { Time (mins) }\end{array}$ & \multicolumn{2}{|c|}{$\mathbf{L}^{*}$} & \multicolumn{2}{|c|}{$\mathbf{a}^{*}$} & \multicolumn{2}{|r|}{$\mathbf{b}^{*}$} \\
\hline 5 & 62.1 & 63.4 & 3.1 & 3.3 & 8.1 & 7.2 \\
\hline 10 & 63.7 & 65.9 & 3.3 & 2.2 & 6.9 & 7.8 \\
\hline 30 & 65.8 & 71.7 & 2.9 & 3.8 & 7.1 & 7.2 \\
\hline $\begin{array}{l}0 \text { (no pre- } \\
\text { treatment) }\end{array}$ & \multicolumn{2}{|c|}{45.7} & \multicolumn{2}{|c|}{14.8} & \multicolumn{2}{|c|}{0.4} \\
\hline
\end{tabular}

Table 5.7: CIE $a^{*}$ and $b^{*}$ values of gold nanoparticle-merino wool composites prepared from $\mathrm{Cl} / \mathrm{H}$ treated and untreated merino wool

\begin{tabular}{|c|c|c|c|c|c|c|}
\hline \multirow[b]{2}{*}{$\begin{array}{l}\text { Gold Conc. } \\
\text { (M) }\end{array}$} & \multirow[b]{2}{*}{$\begin{array}{l}\text { Soak Time } \\
\text { (Hours, RT) }\end{array}$} & \multirow[b]{2}{*}{$\begin{array}{c}\text { Heat Time } \\
\text { (Hours, } 50^{\circ} \mathrm{C} \text { ) }\end{array}$} & \multicolumn{2}{|c|}{$\mathbf{a}^{\star}$} & \multicolumn{2}{|c|}{$\mathbf{b}^{\star}$} \\
\hline & & & $\begin{array}{c}\mathrm{Cl} / \mathrm{H} \\
\text { Treated }\end{array}$ & Untreated & $\begin{array}{c}\mathrm{Cl} / \mathrm{H} \\
\text { Treated }\end{array}$ & Untreated \\
\hline \multirow{4}{*}{$\begin{array}{l}4.06 \times 10^{-4} \\
(80 \mathrm{ppm})\end{array}$} & 24 & 24 & 0.3 & 3.8 & 7.7 & 5.7 \\
\hline & & 48 & 0.6 & 8.8 & 8.1 & 3.1 \\
\hline & & 72 & 1.9 & 3.3 & 9.3 & 4.6 \\
\hline & & 168 & 5.6 & 11.7 & 7.6 & 2.1 \\
\hline \multirow{4}{*}{$\begin{array}{l}6.09 \times 10^{-4} \\
(120 \mathrm{ppm})\end{array}$} & 24 & 24 & -0.2 & 4.6 & 8.1 & 5.9 \\
\hline & & 48 & 1.3 & 6.0 & 10.1 & 3.0 \\
\hline & & 72 & 1.7 & 8.2 & 8.9 & 3.2 \\
\hline & & 168 & 7.3 & 12.3 & 6.5 & 1.4 \\
\hline \multirow{4}{*}{$\begin{array}{l}8.13 \times 10^{-4} \\
(160 \mathrm{ppm})\end{array}$} & 24 & 24 & 0.4 & 3.9 & 8.5 & 4.6 \\
\hline & & 48 & 2.1 & 5.5 & 9.3 & 3.4 \\
\hline & & 72 & 2.4 & 7.6 & 8.7 & 3.2 \\
\hline & & 168 & 7.4 & & 7.6 & \\
\hline
\end{tabular}

confirming the markedly less intense pink and purple colour of the former materials. Additionally the $b^{*}$ values of the $\mathrm{Cl} / \mathrm{H}$ composites were higher than the corresponding 
materials prepared from untreated merino wool, again reflecting the decreased intensity of the pink and purple colour of the $\mathrm{Cl} / \mathrm{H}$ materials.

Base treating the $\mathrm{Cl} / \mathrm{H}$ treated semi-worsted merino wool dramatically increased the colour intensity of the resultant materials, producing vibrant pink or purple coloured composites depending on the $\mathrm{Au}^{3+}$ concentration and ageing time. This was illustrated by comparing the $a^{*}$ and $b^{*}$ values of the two sets of materials, which were higher and lower respectively. Additionally, the $\mathrm{L}^{*}, 457 \mathrm{~nm}$ and $580 \mathrm{~nm}$ brightness values of the materials prepared with base treated $\mathrm{Cl} / \mathrm{H}$ treated merino wool were higher than the values obtained when using untreated $\mathrm{Cl} / \mathrm{H}$ treated merino wool, confirming the observed increased brightness of the former materials (Table 5.8, and Appendix II).

Table 5.8: CIE $L^{*}$, $a^{*}$ and $b^{*}$ values of gold nanoparticle-merino wool composites prepared from untreated or base treated $\mathrm{Cl} / \mathrm{H}$ treated merino wool. Employing a $\mathrm{Au}^{3+}$ concentration of $160 \mathrm{ppm}(8.13 \mathrm{x}$ $\left.10^{-4} \mathrm{M}\right)$ and a soaking time, at RT of 24 hours.

\begin{tabular}{ccccccc}
\hline & \multicolumn{2}{c}{$\mathbf{a}^{*}$} & \multicolumn{2}{c}{$\mathbf{b}^{*}$} & \multicolumn{2}{c}{$\mathbf{L}^{*}$} \\
\cline { 2 - 7 } $\begin{array}{c}\text { Heat Time (Hours, } \\
\mathbf{5 0} \mathbf{~}^{\mathbf{C}} \text { ) }\end{array}$ & Untreated & $\begin{array}{c}\text { Base } \\
\text { Treated }\end{array}$ & Untreated & $\begin{array}{c}\text { Base } \\
\text { Treated }\end{array}$ & Untreated & $\begin{array}{c}\text { Base } \\
\text { Treated }\end{array}$ \\
\hline $\mathbf{2 4}$ & 0.4 & 6 & 8.5 & 7 & 76.6 & 72 \\
$\mathbf{4 8}$ & 2.1 & 7 & 9.3 & 7 & 69.4 & 74 \\
$\mathbf{7 2}$ & 2.4 & 7 & 8.7 & 6 & 70.0 & 74 \\
$\mathbf{1 6 8}$ & 7.4 & 8 & 7.6 & 4 & 57.6 & 76 \\
\hline
\end{tabular}

The processing route employed when preparing the merino wool fibres also influenced the colour of the composite materials. Utilising worsted merino wool in place of semi-worsted merino wool decreased the intensity and clarity of the resultant materials. The CIE $a^{*}, b^{*}$ and brightness values reflect this (Appendix II). After 168 hours ageing, the $a^{*}$ value of materials incorporating worsted merino wool had only increased from -1.3 (for untreated worsted merino wool) to 5.6, whilst those prepared with semi-worsted merino wool increased from -0.8 (for untreated semi-worsted merino wool) to 14.8 , reflecting the decreased redness of the former materials. Additionally, the $b^{*}$ values (with higher values denoting a more 
yellow hue and lower blue) of composites prepared from worsted merino wool were higher than the corresponding materials prepared from semi-worsted merino wool, verifying the observation that worsted merino wool produced materials that were less purple in colour than did semi-worsted merino wool (Figure 5.71). Comparing the 457 and $580 \mathrm{~nm}$ brightness values of composites prepared from worsted or semi-worsted merino wool also illustrated this, with the brightness values of the worsted materials being higher and closer to that of the untreated merino wool (Figure 5.72).

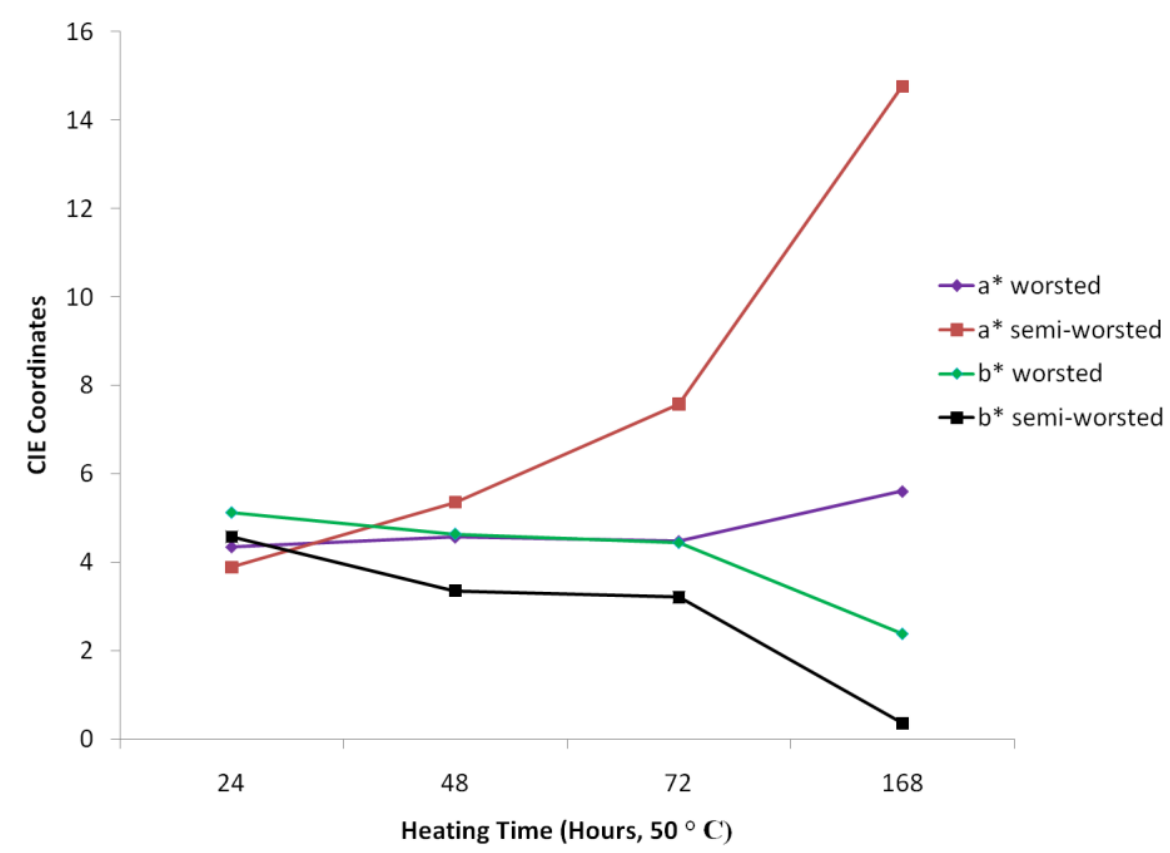

Figure 5.71: Changes in CIE $a^{*}$ and $b^{*}$ values of gold nanoparticle-merino wool composites incorporating worsted or semi-worsted merino wool. 


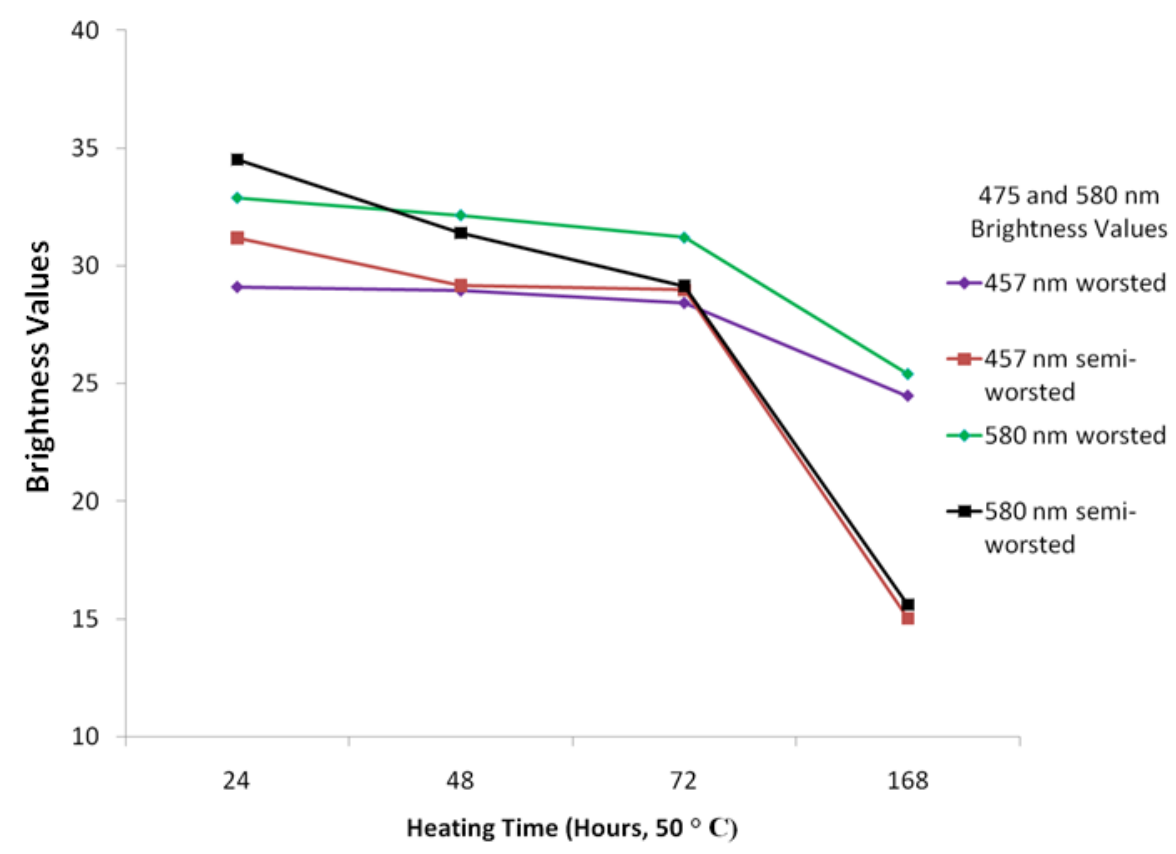

Figure 5.72: Changes in CIE 475 and $580 \mathrm{~nm}$ brightness values of gold nanoparticle-merino wool composites incorporating worsted or semi-worsted merino wool.

Cleaning the worsted merino wool fibres via Soxhlet extraction prior to addition to the $\mathrm{Au}^{3+}$ soaking solution resulted in the production of much more intense, spectrally pure coloured composites. Comparing the CIE $\mathrm{a}^{*}$ and $\mathrm{b}^{*}$ values of the composites prepared from Soxhlet treated worsted merino wool and untreated worsted merino wool confirmed this (Appendix II). The composites incorporating the Soxhlet treated fibres exhibited higher $\mathrm{a}^{*}$ values and lower $b^{*}$ values than the corresponding untreated composites (Table 5.9). As higher $a^{*}$ and $b^{*}$ values depict redder and bluer material respectively, these changes confirm the observed deeper purple colour of the composites prepared from Soxhlet treated materials.

Table 5.9: CIE $a^{*}$ and $b^{*}$ values for gold nanoparticle-merino wool composites prepared from Soxhlet treated worsted merino wool and untreated worsted merino wool.

\begin{tabular}{ccccc}
\hline $\begin{array}{c}\text { Ageing Time (hours, } \\
\left.\mathbf{5 0}{ }^{\circ} \mathbf{C}\right)\end{array}$ & \multicolumn{2}{c}{ 24 hours } & \multicolumn{2}{c}{$\mathbf{1 6 8}$ hours } \\
\hline Base Fibre & $\begin{array}{c}\text { Soxhlet } \\
\text { Treated }\end{array}$ & Untreated & $\begin{array}{c}\text { Soxhlet } \\
\text { Treated }\end{array}$ & Untreated \\
$\mathbf{a}^{*}$ & 5.3 & 4.6 & 9.8 & 5.6 \\
$\mathbf{b}^{*}$ & 6.8 & 5.1 & 0.4 & 2.4 \\
\hline
\end{tabular}


The colour change in the composites and the relationship between the size and shape of the nanoparticles bound to the merino wool fibres was also shown in SEM analysis, TEM analysis and UV/Vis spectroscopy. In general, progressing through the colour spectrum from light pink to pink and pink to a deep, regal purple initially saw an increase in the concentration of similarly sized spherical and five-fold twinned nanoparticles (approximately 20-25 nm) on the fibre surface, followed by the formation of smaller, (approximately 5-10 $\mathrm{nm}$ in diameter) spherical nanoparticles in the fibre centre (Figure 5.73).
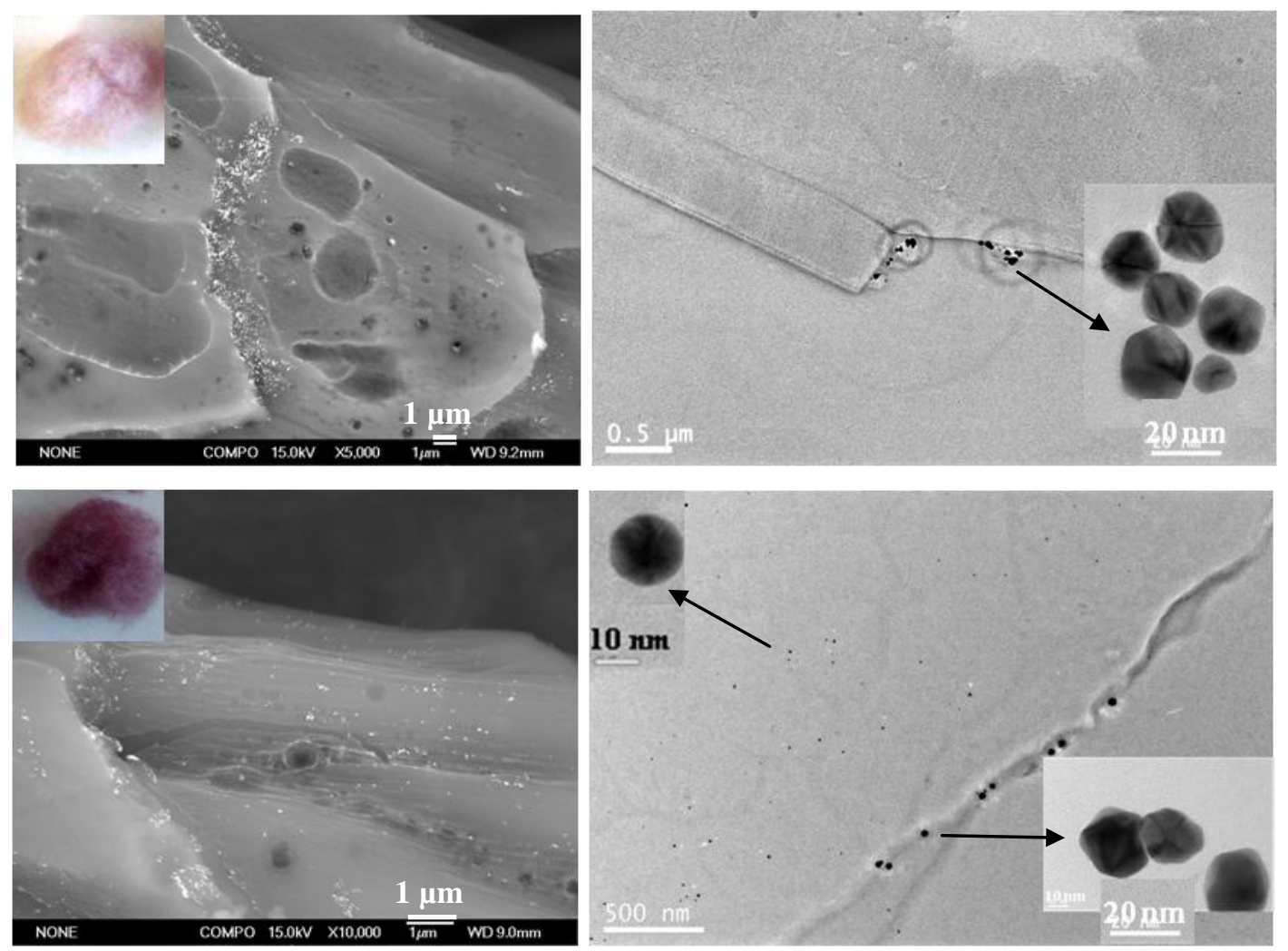

Figure 5.73: Gold nanoparticle-merino wool composites, showing the relationship between the pink and purple colour of these materials and the size, shape and distribution of the gold nanoparticles. In the pink coloured materials the nanoparticles are located predominantly at the cuticle edges, whilst in the purple materials the nanoparticles spread slightly across the fibre surface. The purple materials also possess smaller nanoparticles (approximately 5-10 $\mathrm{nm}$ in diameter) in the fibre centre.

This change in colour from light pink through increasingly deeper shades of pink to purple with increased ageing time was reflected in the Kubelka Munk transformed UV/Vis reflection spectra of the composites (Figure 5.74). Increasing the ageing time at $50{ }^{\circ} \mathrm{C}$ from 
24 to 72 hours saw the gradual increase in intensity of the peak centred at $541 \mathrm{~nm}$. This position of this peak is in the range expected for spherical or five-fold twinned gold nanoparticles approximately 20-25 $\mathrm{nm}$ in diameter, and as such agrees with the SEM and TEM observations made in section 5.1.1.2.2 above. Increasing the ageing time further to 168 hours saw a dramatic increase in intensity of this peak, and also a slight broadening. The increase in intensity of this peak corresponds to the formation of a greater number of similarly sized nanoparticles on the fibre surface, whilst the broadening is likely representative of the range of particle sizes present in the purple coloured composites, due to the formation of smaller, approximately $5-10 \mathrm{~nm}$ in diameter, nanoparticles in the fibre centres.

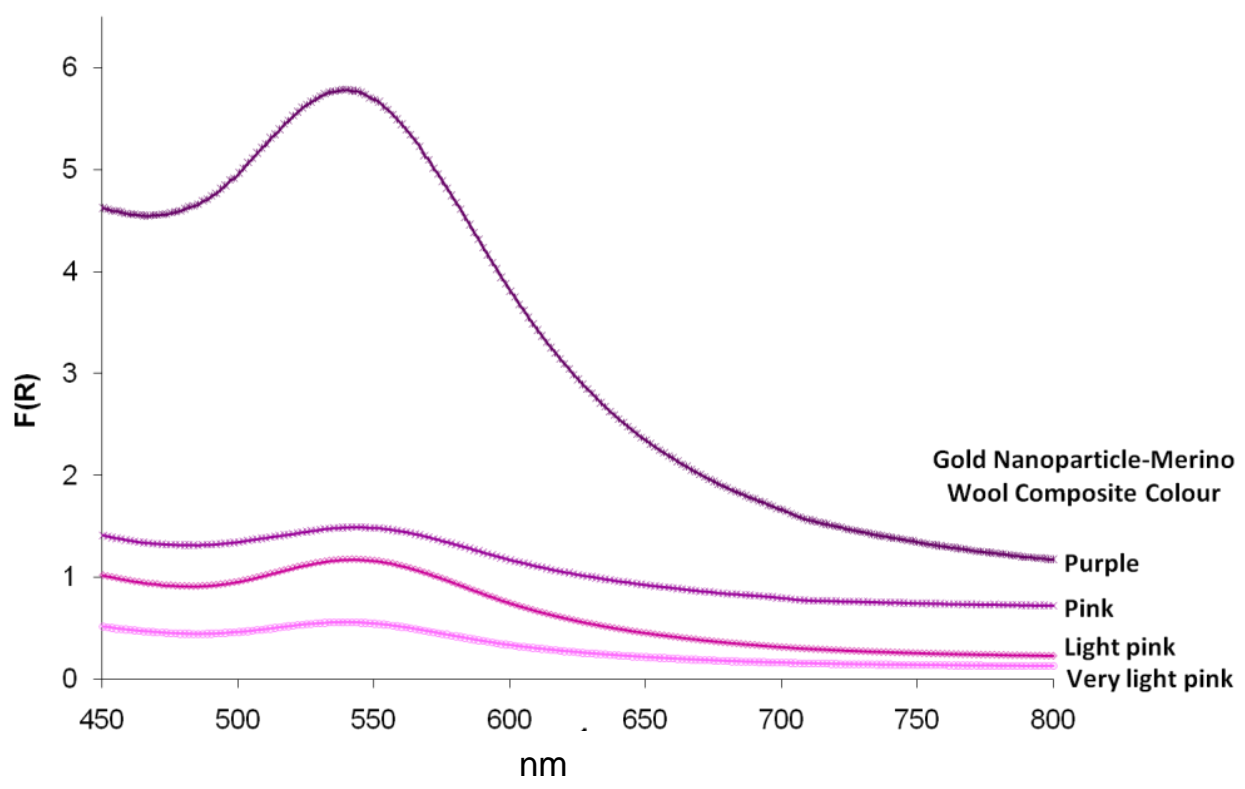

Figure 5.74: Kubelka Munk transformed UV/Vis reflection spectra of light pink to purple coloured gold nanoparticle-merino wool composites.

The grey colours observed in composites prepared with no soaking at RT, and very high $\mathrm{Au}^{3+}$ concentrations arose due to the formation of slightly larger gold nanoparticles, and also the presence of agglomerates, with nanoparticles forming on the fibre surface rather than in the centre. Typically, lighter grey coloured materials possessed both five-fold twinned nanoparticles (approximately $30-40 \mathrm{~nm}$ in diameter) and triangular and truncated triangular nanoplates (approximately 50-100 $\mathrm{nm}$ in diameter) (Figure 5.75 top), whilst in the darker 
grey materials, these particles were larger, approximately $50-60 \mathrm{~nm}$ and $100 \mathrm{~nm}$ in diameter respectively (Figure 5.75 bottom). Both exhibited agglomerated nanoparticles, however these were more pronounced in the darker grey composites. The presence of the agglomerated nanoparticles greatly increased the full width at half maximum of the plasmon peaks in the Kubelka Munk transformed UV/Vis spectra of the composites, and a new peak, reported to be due to the longitudinal plasmon band of anisotropic nanoparticles such as triangular nanoplates,[211] was seen at approximately $708 \mathrm{~nm}$ (Figure 5.76).
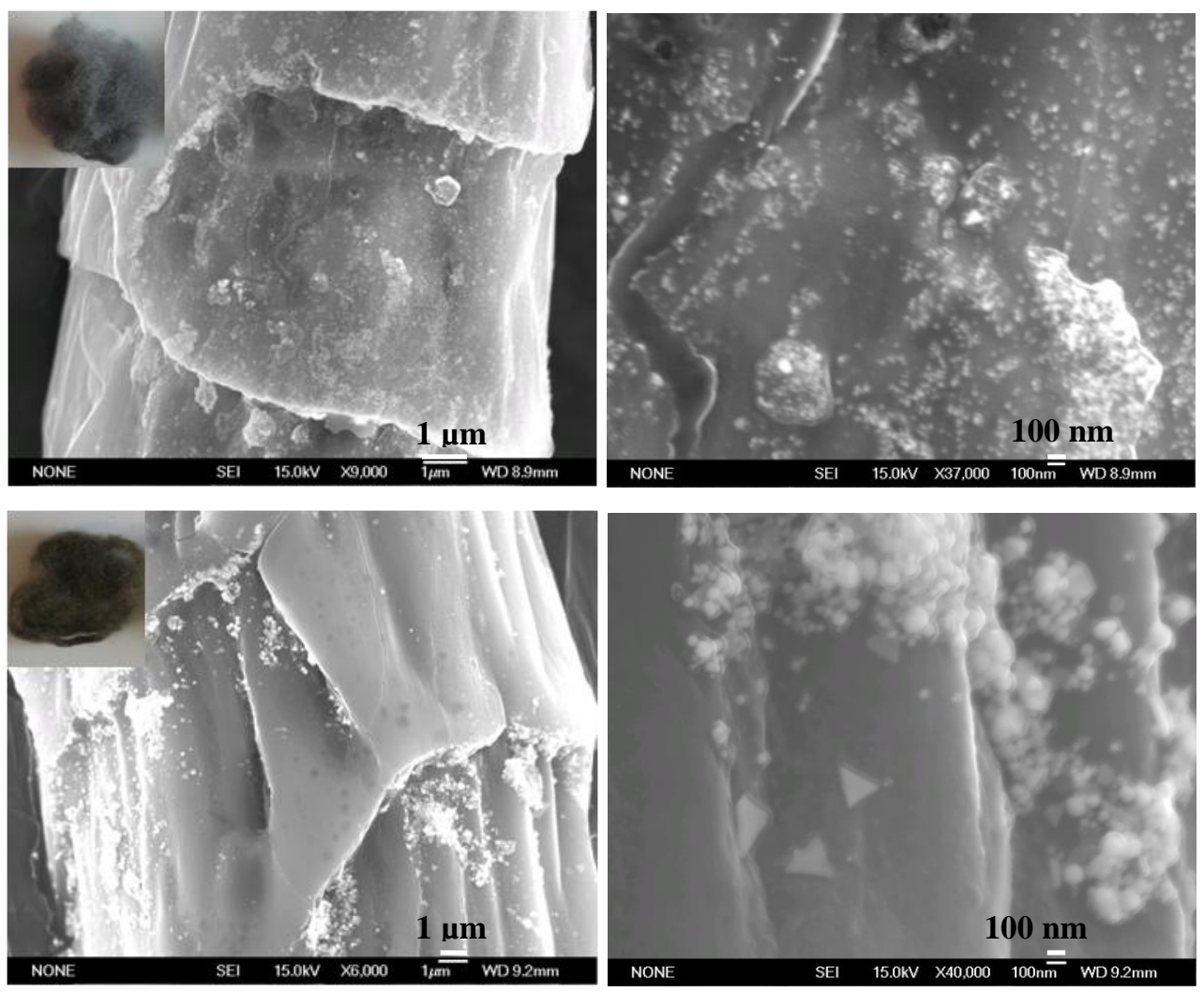

Figure 5.75: Gold nanoparticle-merino wool composites, showing the relationship between the light (top) and dark (bottom) grey colour of these materials and the size, shape and distribution of the gold nanoparticles. These materials possess gold nanoparticles in a range of sizes and shapes, with agglomerations seen. 


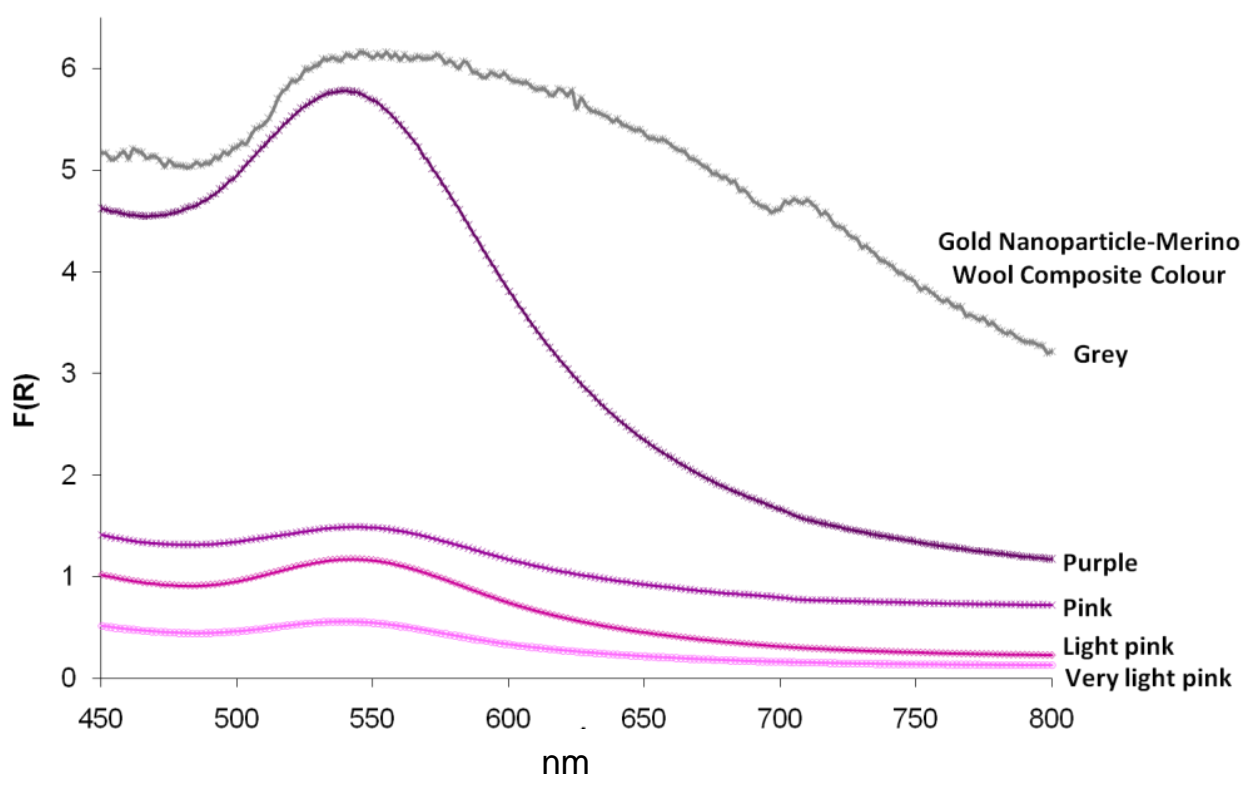

Figure 5.76: Kubelka Munk transformed UV/Vis reflection spectra of light pink to purple and grey coloured gold nanoparticle-merino wool composites.

Agglomerated nanoparticles were also evident in materials that had been prepared without soaking in $\mathrm{Au}^{3+}$ prior to ageing, and were a common morphological feature of murky, spectrally impure coloured composites (Figure 5.77 top). Alternatively, vibrant coloured materials possessed a high concentration of isolated nanoparticles, present preferentially at the surface of the fibre, rather than in the centre. This was the case for composites prepared with a soaking and ageing solution of increased ionic strength, and a short (24 hour) ageing time, with these nanoparticles being spheres approximately 20-30 $\mathrm{nm}$ in diameter (Figure 5.77 middle). Additionally, base treated $\mathrm{Cl} / \mathrm{H}$ treated materials also produced very vibrant coloured composites (although these colours were non-uniform) with the vibrant coloured fibres possessing an extremely high concentration of spherical nanoparticles, approximately 10-20 $\mathrm{nm}$ in diameter, located across the fibre surface (Figure 5.77 bottom). 

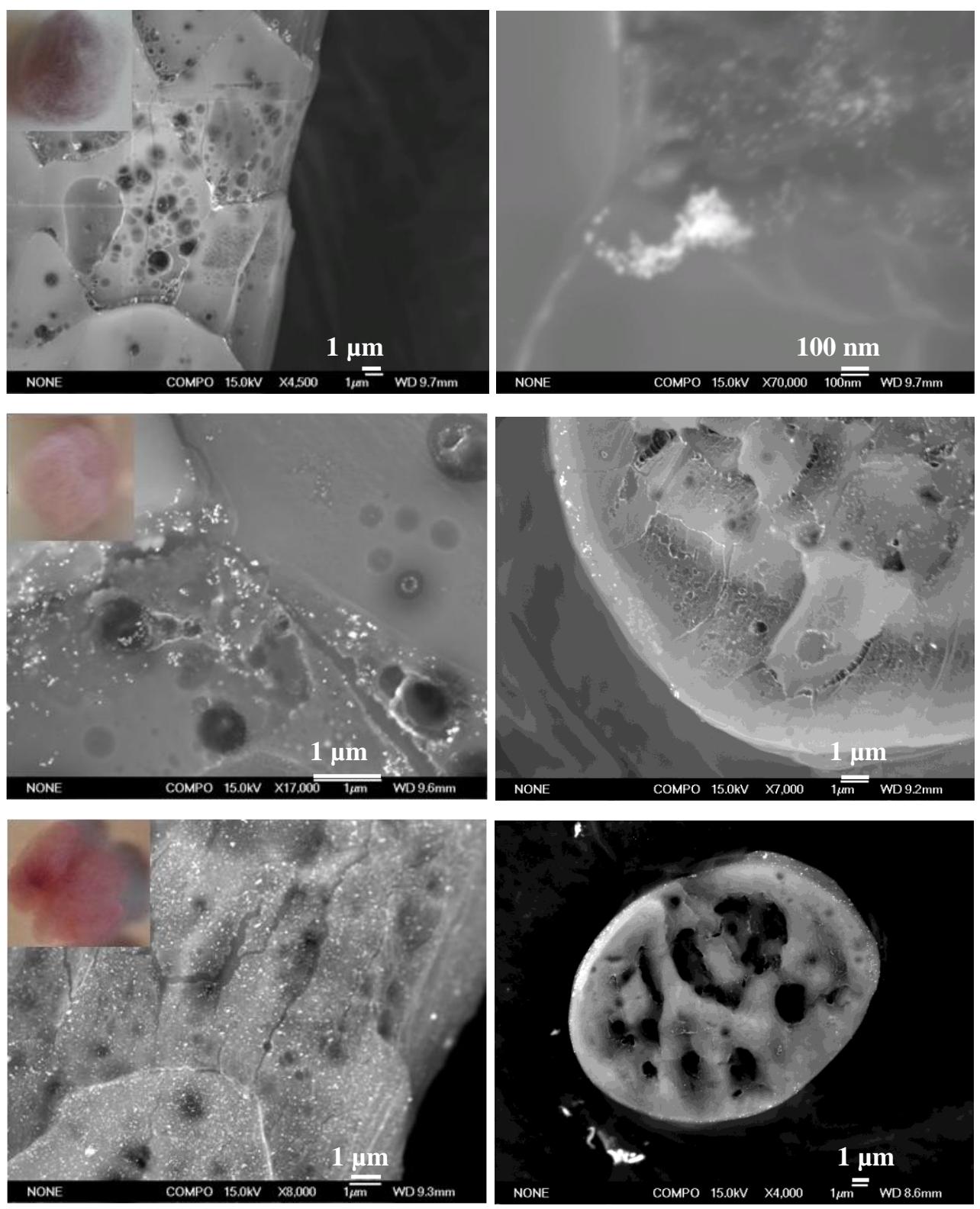

Figure 5.77: Gold nanoparticle-merino wool composites, showing the relationship between the spectrally impure and vibrant colour of these materials and the size, shape and distribution of the gold nanoparticles.

The yellow colour of composites prepared with ageing solutions of $\mathrm{pH} \mathrm{12,} \mathrm{arose} \mathrm{due} \mathrm{to}$ precipitated $\mathrm{Au}(\mathrm{OH})_{3}$, rather than nanoparticulate $\mathrm{Au}^{0}$. This was present as large, amorphous deposits on the surface of the merino wool fibres (Figure 5.78). 

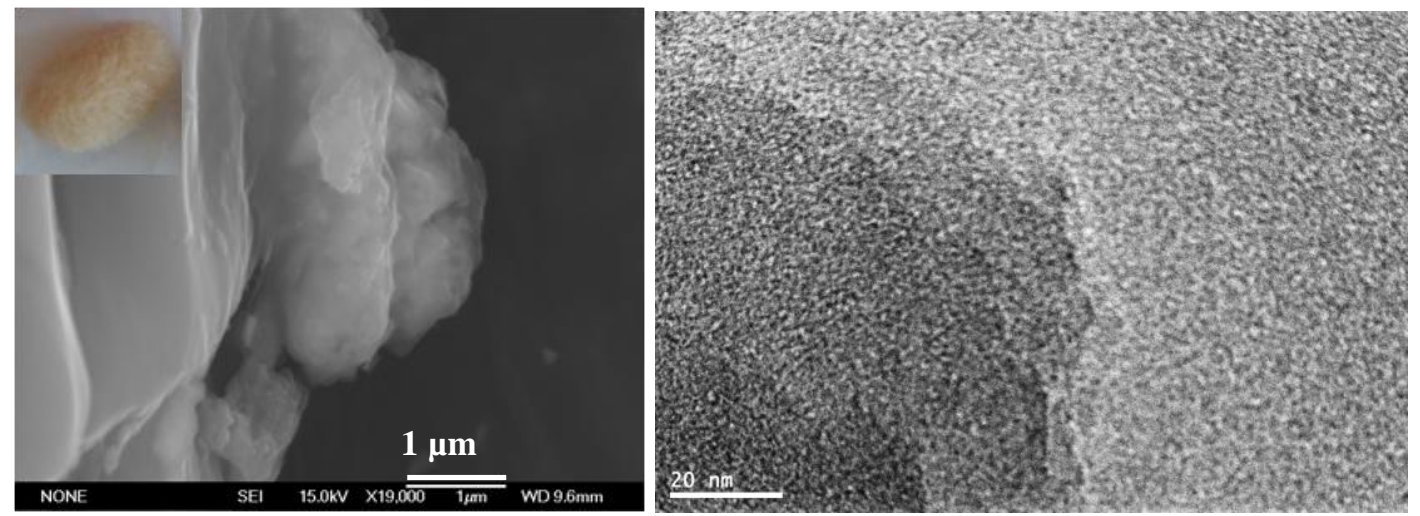

Figure 5.78: Gold nanoparticle-merino wool composites, showing the relationship between the yellow colour of these materials and the size, shape and distribution of the gold, here present as amorphous $\mathrm{Au}(\mathbf{O H})_{3}$.

\subsection{Confirmation of Gold}

The presence of gold in the gold nanoparticle-merino wool composites prepared using the reducing nature of the proteins within the fibre was first suggested with SEM backscatter, and subsequently confirmed with EDS and XPS analysis. As an example, Figure 5.79 shows SEM micrographs of two gold nanoparticle-merino wool composite prepared by soaking either untreated, semi-worsted merino wool (top) or base treated $\mathrm{Cl} / \mathrm{H}$ treated merino wool (bottom) in a $160 \mathrm{ppm}\left(8.13 \times 10^{-4} \mathrm{M}\right) \mathrm{Au}^{3+}$ solution for 24 hours at RT, followed by ageing at $50{ }^{\circ} \mathrm{C}$ for 24 hours or 168 hours respectively. The micrographs on the left are viewed under secondary electron conditions, whilst the ones on the right are viewed under back scatter conditions. The intensity of the backscatter signal is directly related to atomic number, with heavier elements reflecting more signal than lighter elements and thus appearing brighter, or whiter. As such, when viewed under backscatter conditions, the gold nanoparticles, which have higher atomic numbers than the main constituents of merino wool, notably C, S, N and O, should appear much brighter. Comparing the micrographs on the left and right in Figure 5.79 shows this to be the case as the nanoparticles that are weakly evident when viewed under secondary electron conditions become increasingly apparent in back scatter conditions, appearing as bright white dots.

The presence of gold, as suggested by back scatter SEM was confirmed by EDS mapping and elemental analysis. Figure 5.80, 5.82, 5.84 and 5.86 offer SEM and corresponding gold 

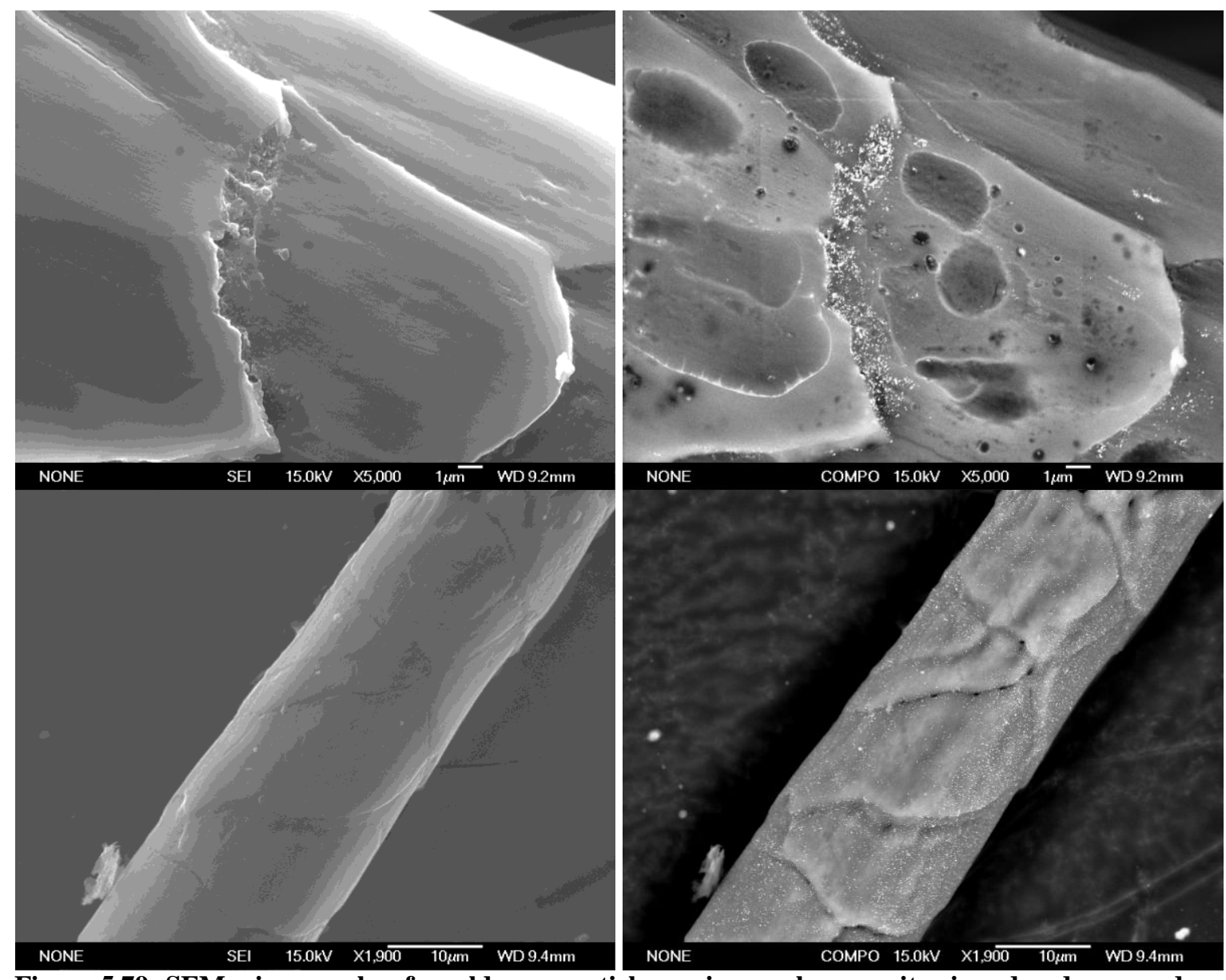

Figure 5.79: SEM micrographs of a gold nanoparticle-merino wool composite viewed under secondary electron (left) and back scatter conditions (right). Prepared by soaking untreated semi-worsted merino wool (top) or base treated $\mathrm{Cl} / \mathrm{H}$ treated merino wool in a $160 \mathrm{ppm}\left(8.13 \times 10^{-4} \mathrm{M}\right) \mathrm{Au}^{3+}$ solution for 24 hours at RT, followed by ageing at $50{ }^{\circ} \mathrm{C}$ for 24 or 168 hours respectively.

EDS maps of gold nanoparticle-merino wool composites prepared by soaking untreated semi-worsted merino wool in various $\mathrm{Au}^{3+}$ solutions for 0 or 24 hours at RT, followed by ageing at 50 or $80{ }^{\circ} \mathrm{C}$ for $24-168$ hours. High concentrations of gold are depicted in bright white or red areas, and correspond to the areas where gold nanoparticles are seen in the corresponding SEM micrographs, confirming the bright white dots (spherical or five-fold twinned particles) and triangular nanoplates evident on the various composite materials to be gold. These nanoparticles were generally found along the cuticle edges of the fibre, however when $\mathrm{Cl} / \mathrm{H}$ treated and base treated $\mathrm{Cl} / \mathrm{H}$ treated merino wool was employed as the substrate, there was a high concentration of gold uniformly spread across the surface of the fibre (Figure 5.88). Additionally, Figures 5.81, 5.83, 5.85, 5.87 and 5.89 offer spectral snap shots of the areas under analysis, and substantiate the presence of gold due to the existence of the gold peaks. 

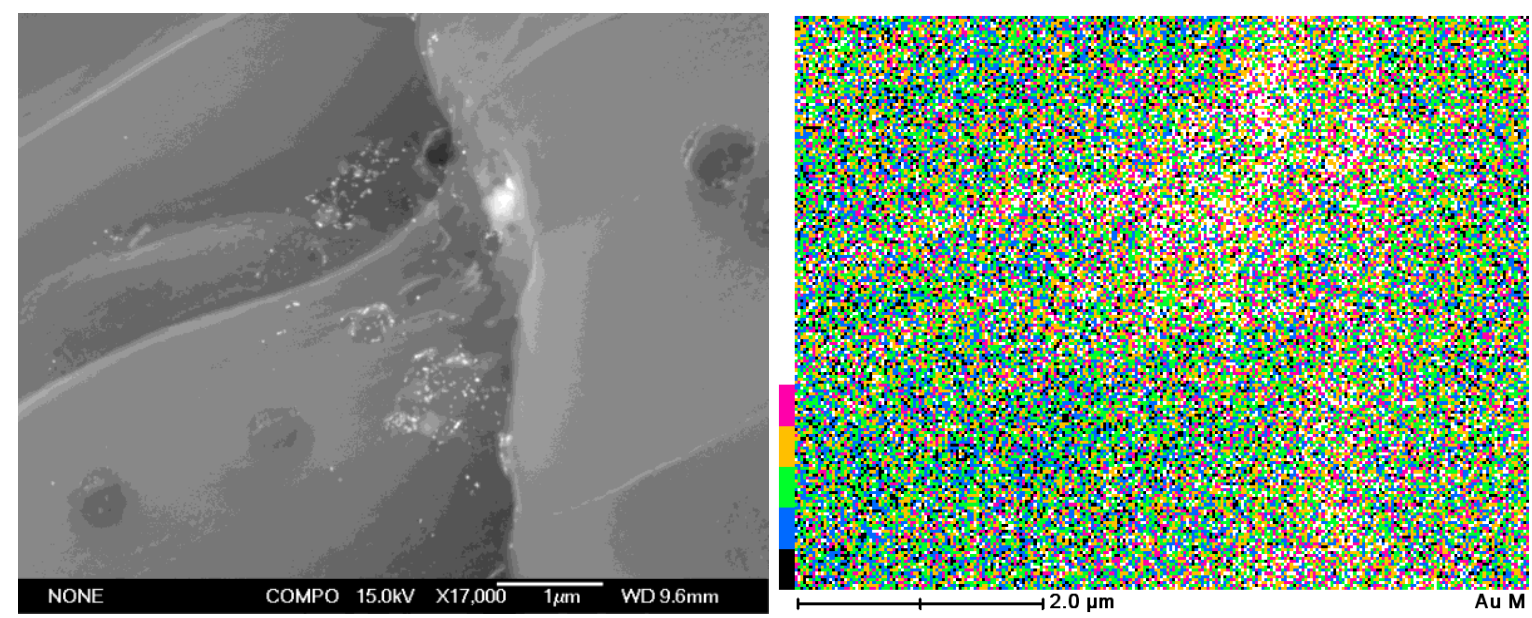

Figure 5.80: SEM and corresponding gold EDS map of a gold nanoparticle-merino wool composite prepared by soaking untreated semi-worsted merino wool in a $160 \mathrm{ppm}\left(8.13 \times 10^{-4} \mathrm{M}\right) \mathrm{Au}^{3+}$ solution for 24 hours at RT, followed by ageing at $50{ }^{\circ} \mathrm{C}$ for 24 hours.

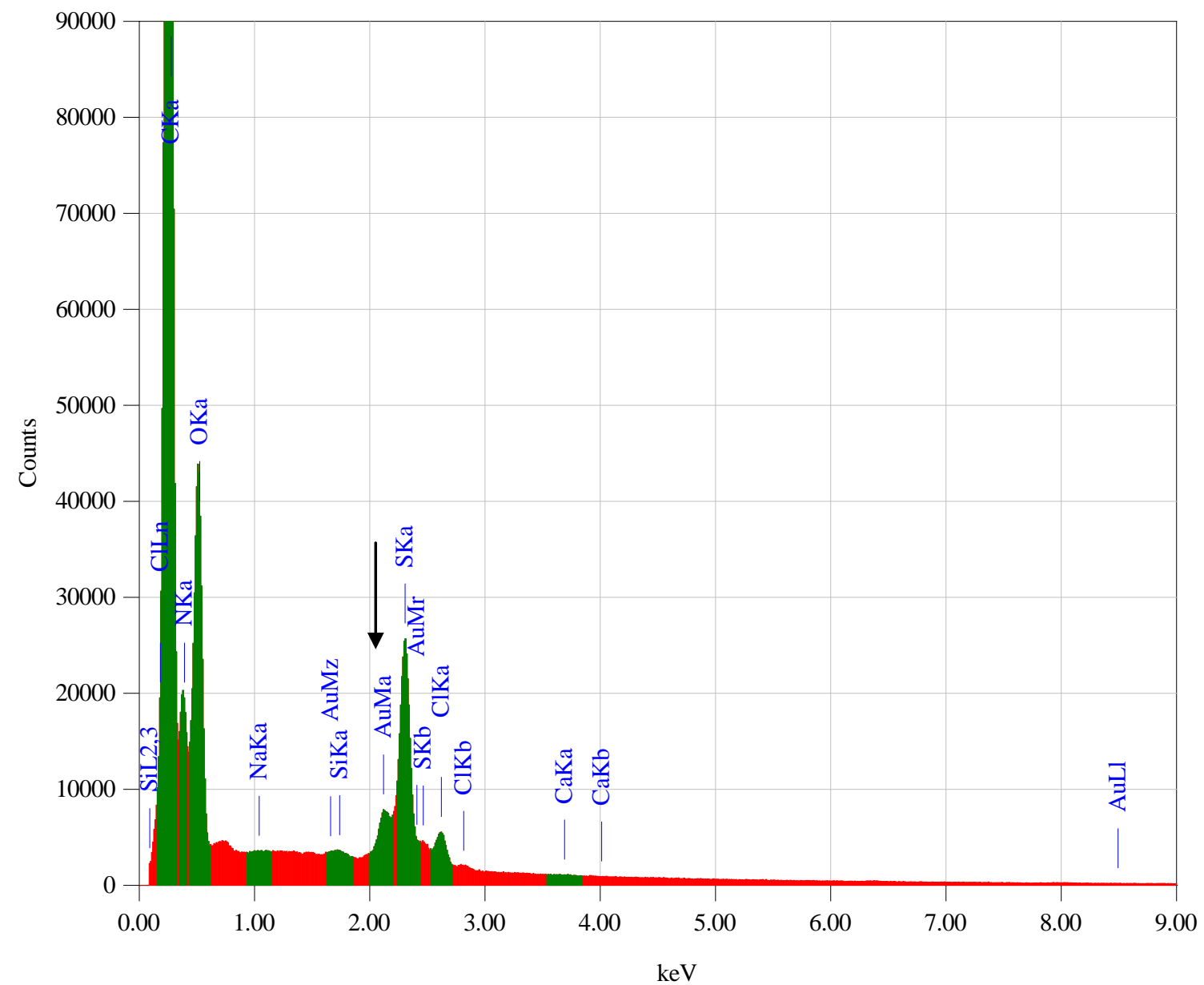

Figure 5.81: EDS spectrum of the gold nanoparticle-merino wool composite shown in Figure 5.80. 

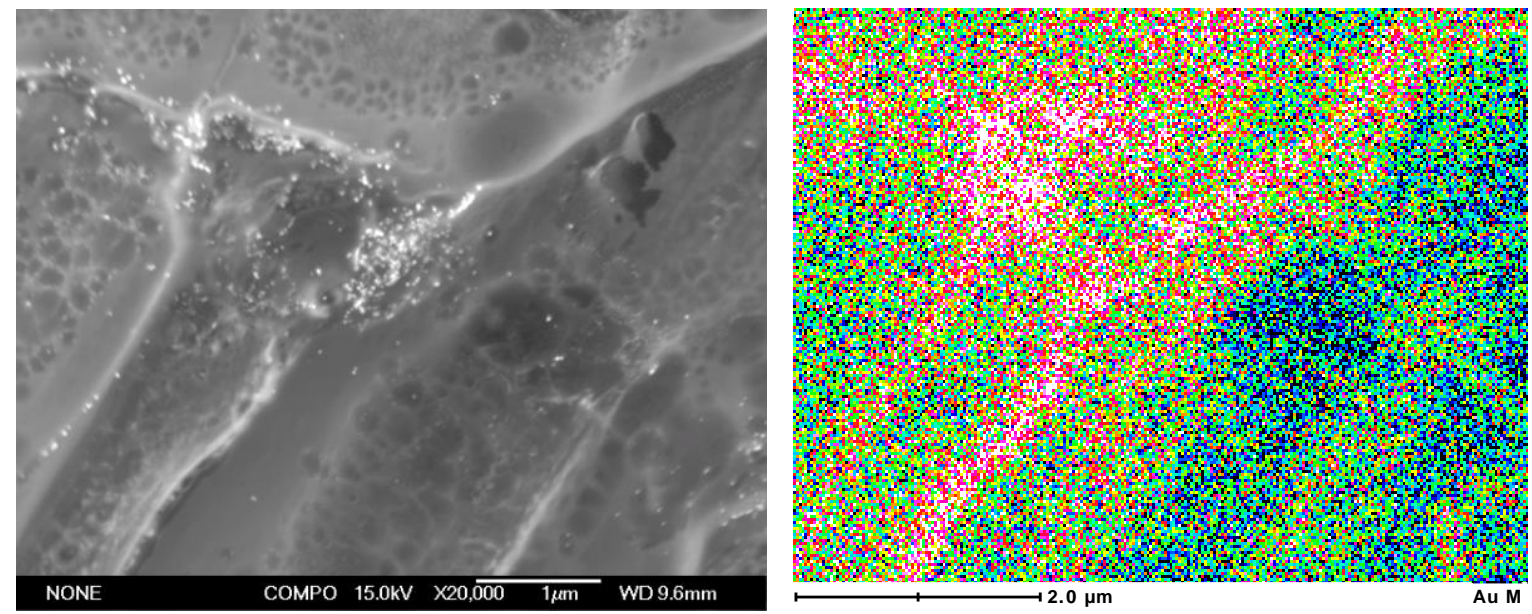

Figure 5.82: SEM and corresponding gold EDS map of a gold nanoparticle-merino wool composite prepared by soaking untreated semi-worsted merino wool in a $160 \mathrm{ppm}\left(8.13 \times 10^{-4} \mathrm{M}\right) \mathrm{Au}^{3+}$ solution for 24 hours at RT, followed by ageing at $50{ }^{\circ} \mathrm{C}$ for 168 hours.

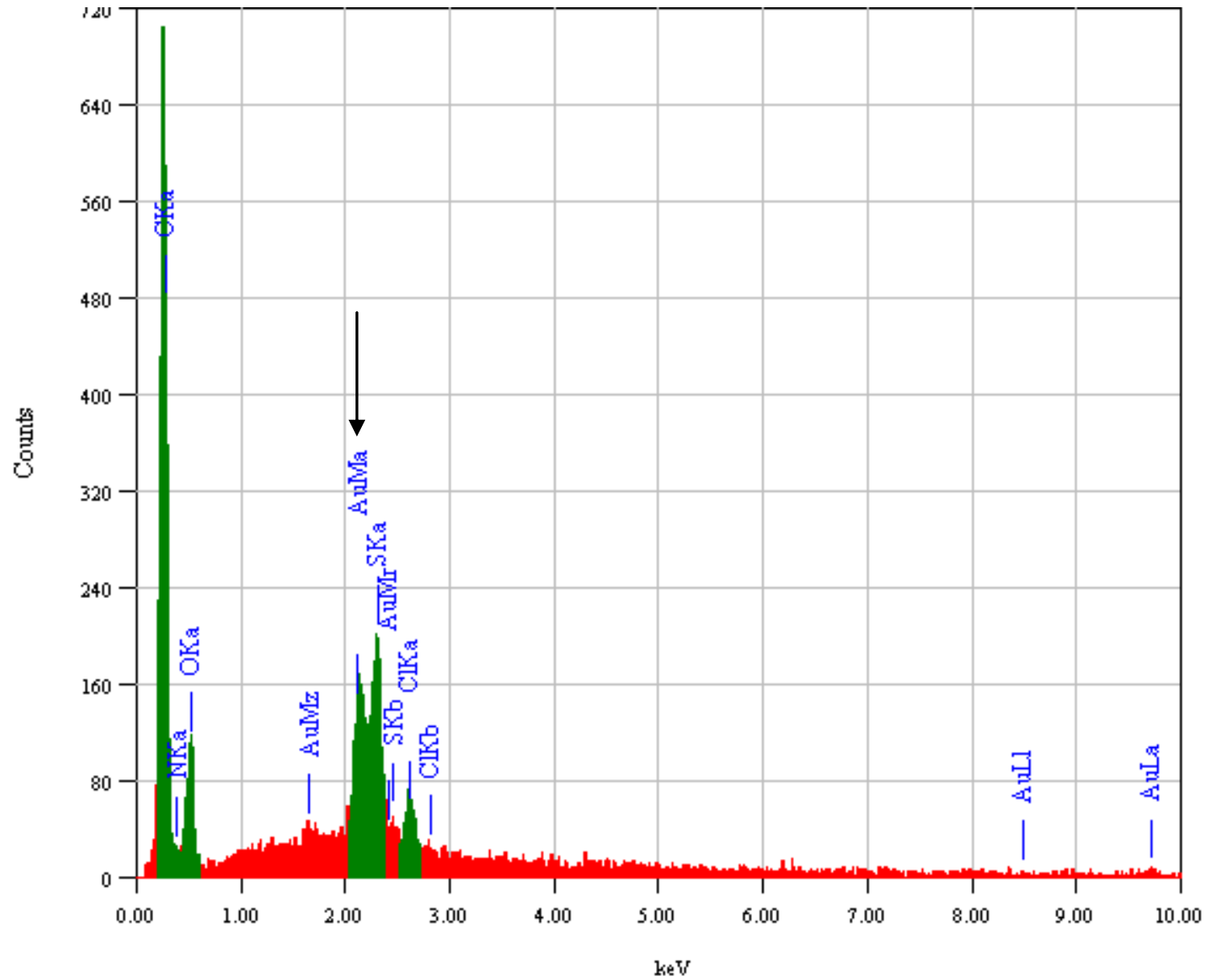

Figure 5.83: EDS spectrum of the gold nanoparticle-merino wool composite shown in Figure 5.82. 

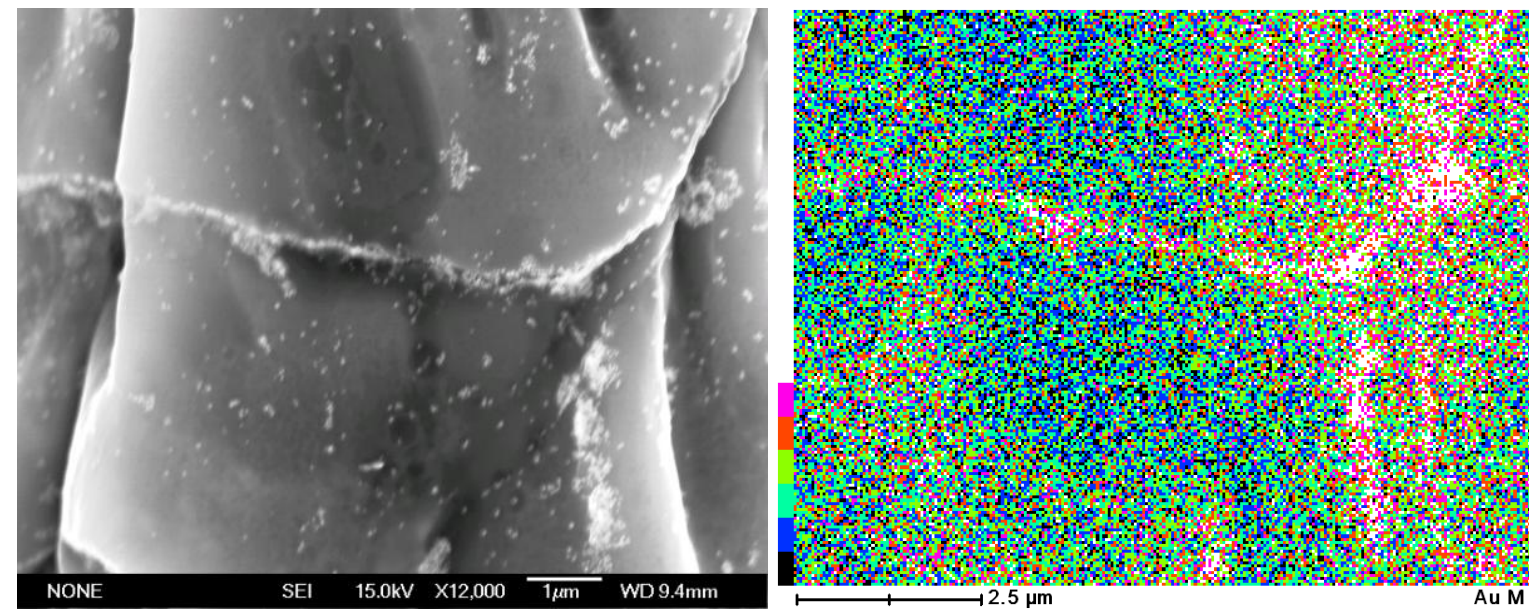

Figure 5.84: SEM and corresponding gold EDS map of a gold nanoparticle-merino wool composite prepared by soaking untreated semi-worsted merino wool in a $960 \mathrm{ppm}\left(4.87 \times \mathrm{10}^{-3} \mathrm{M}\right) \mathrm{Au}^{3+}$ solution for 24 hours at RT, followed by ageing at $50{ }^{\circ} \mathrm{C}$ for 24 hours.

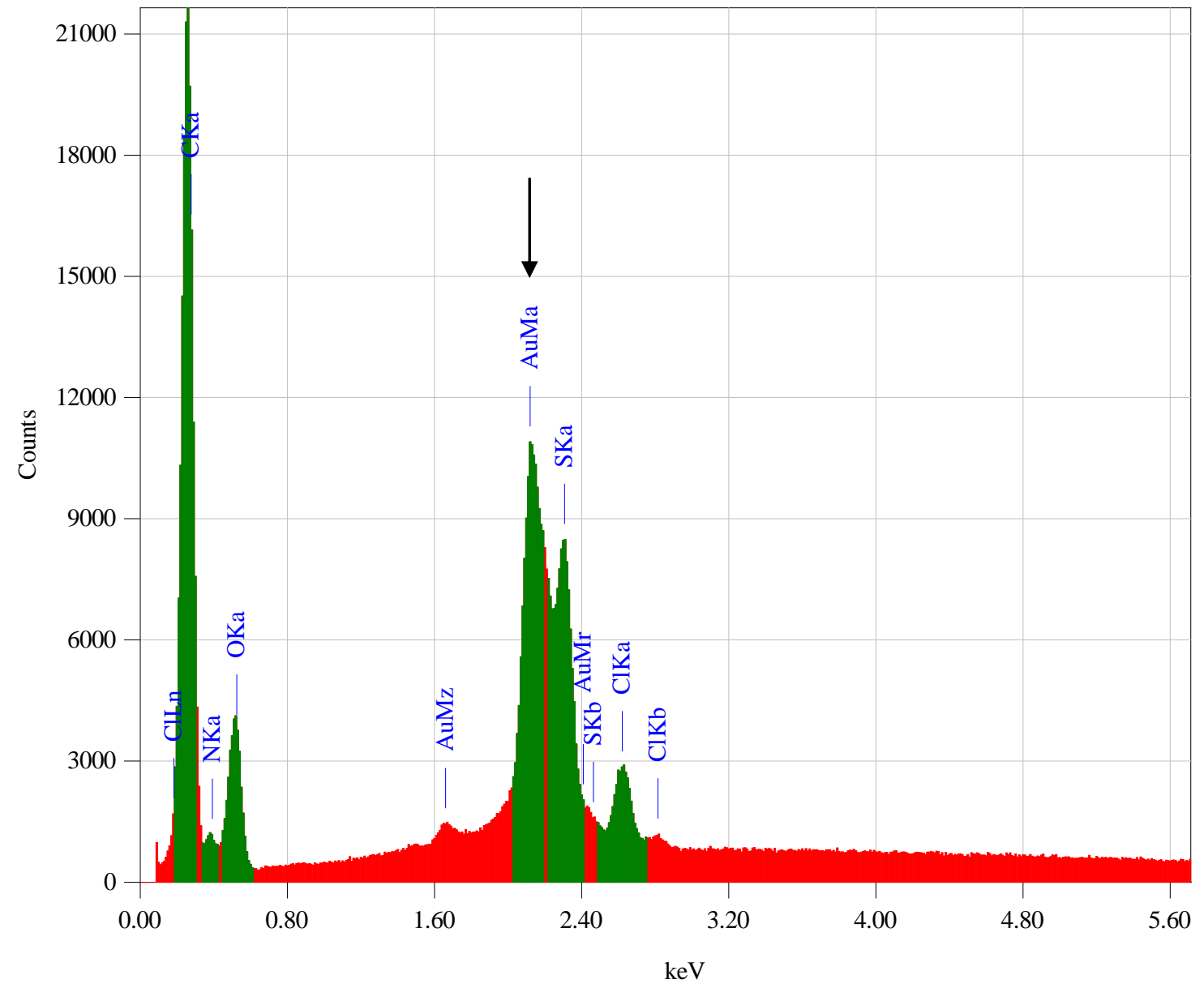

Figure 5.85: EDS spectrum of the gold nanoparticle-merino wool composite shown in Figure 5.84. 

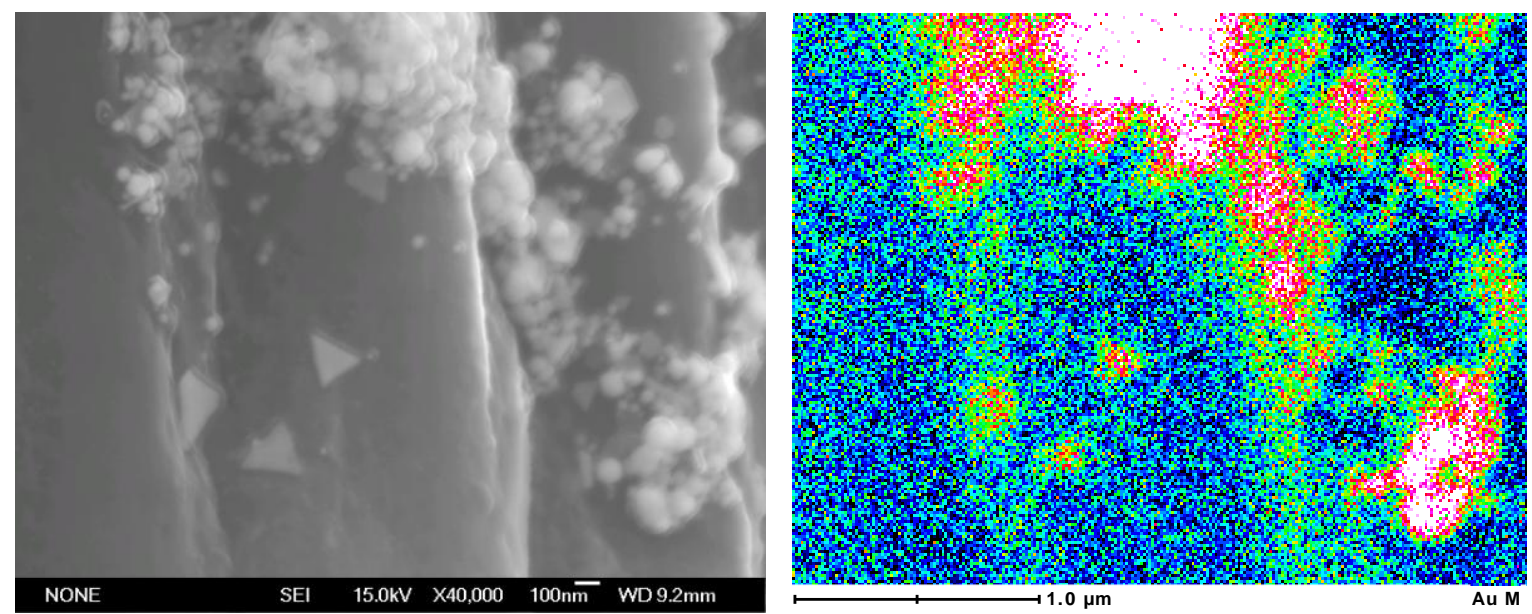

Figure 5.86: SEM and corresponding gold EDS map of a gold nanoparticle-merino wool composite prepared by soaking untreated semi-worsted merino wool in a $1040 \mathrm{ppm}\left(5.28 \times 10^{-3} \mathrm{M}\right) \mathrm{Au}^{3+}$ solution for 24 hours at RT, followed by ageing at $50{ }^{\circ} \mathrm{C}$ for 24 hours.

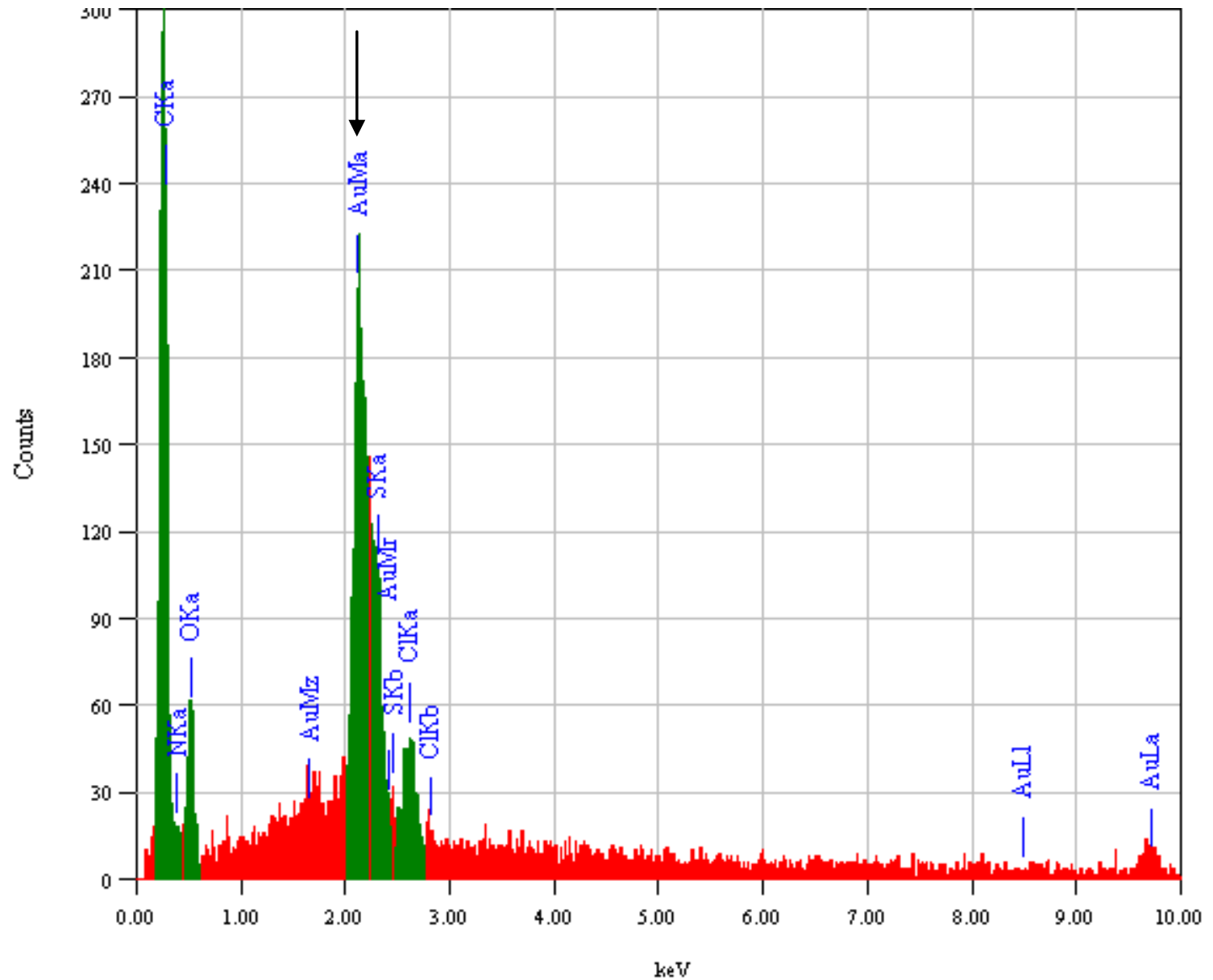

Figure 5.87: EDS spectrum of the gold nanoparticle-merino wool composite shown in Figure 5.86. 

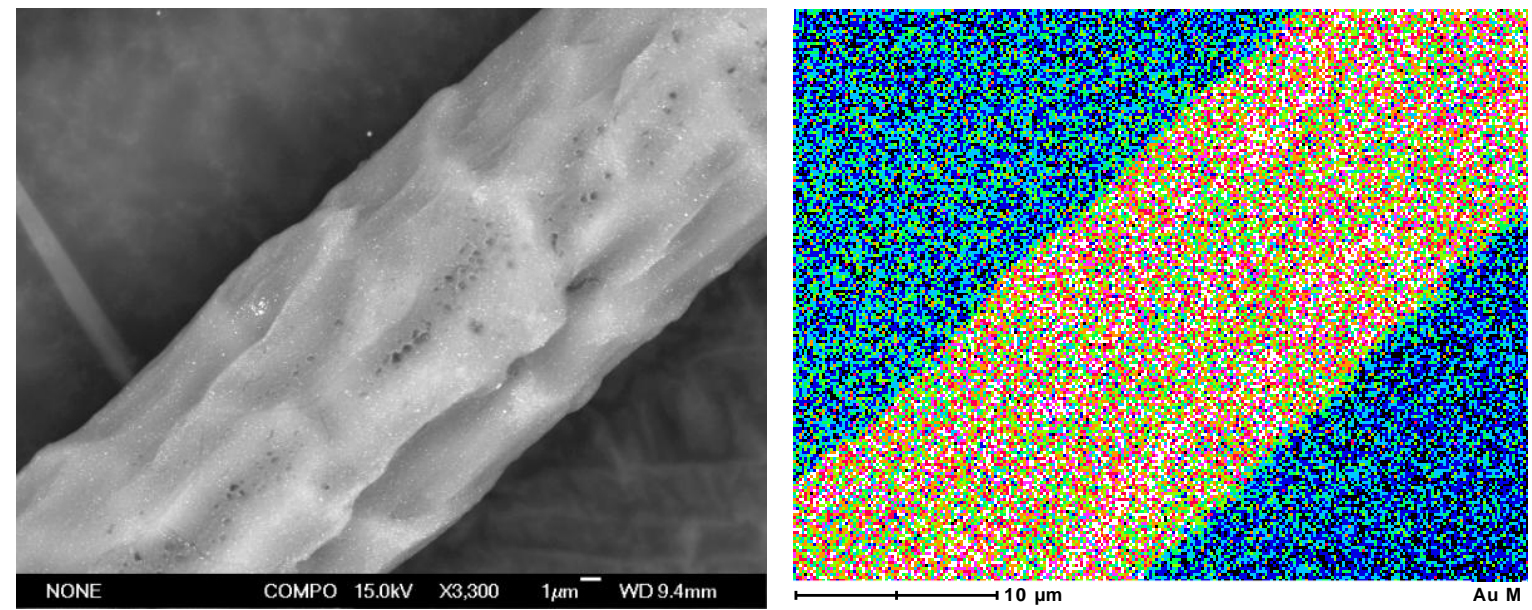

Figure 5.88: SEM and corresponding Au EDS micrograph of a gold nanoparticle-merino wool composite prepared by soaking $\mathrm{KOH} \mathrm{Cl/H}$ treated semi-worsted merino wool in a $160 \mathrm{ppm}\left(8.13 \times 10^{-4} \mathrm{M}\right) \mathrm{Au}^{3+}$ solution for 24 hours at RT, followed by ageing at $50{ }^{\circ} \mathrm{C}$ for 24 hours.

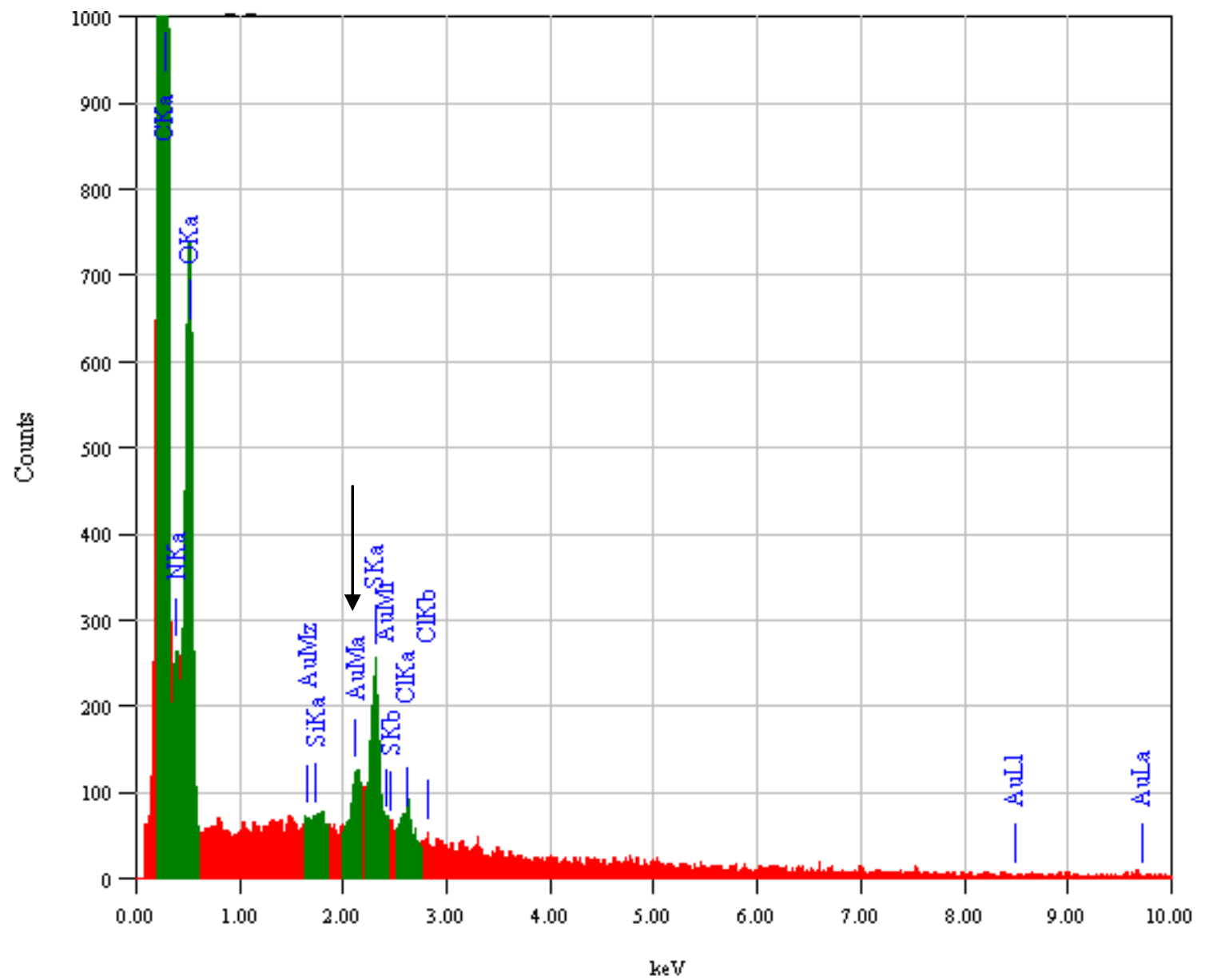

Figure 5.89: EDS spectrum of the gold nanoparticle-merino wool composite shown in Figure 5.88. 
Scanning transmission electron microscopy (STEM), which relative to SEM, offers increased resolution, additionally confirmed the nanoparticles on the gold nanoparticle-merino wool composites to be gold. Figure 5.90 offers a TEM micrograph of a composite material prepared by soaking untreated semi-worsted merino wool in a $160 \mathrm{ppm}\left(8.13 \times 10^{-4} \mathrm{M}\right) \mathrm{Au}^{3+}$ solution for 24 hours at RT, followed by ageing at $50{ }^{\circ} \mathrm{C}$ for 24 hours. The corresponding $\mathrm{Au}$ STEM map shows that where the nanoparticles are located, there are very high concentrations of gold (depicted in bright green/white). These STEM micrographs are typical of all gold nanoparticle-merino wool composites produced.
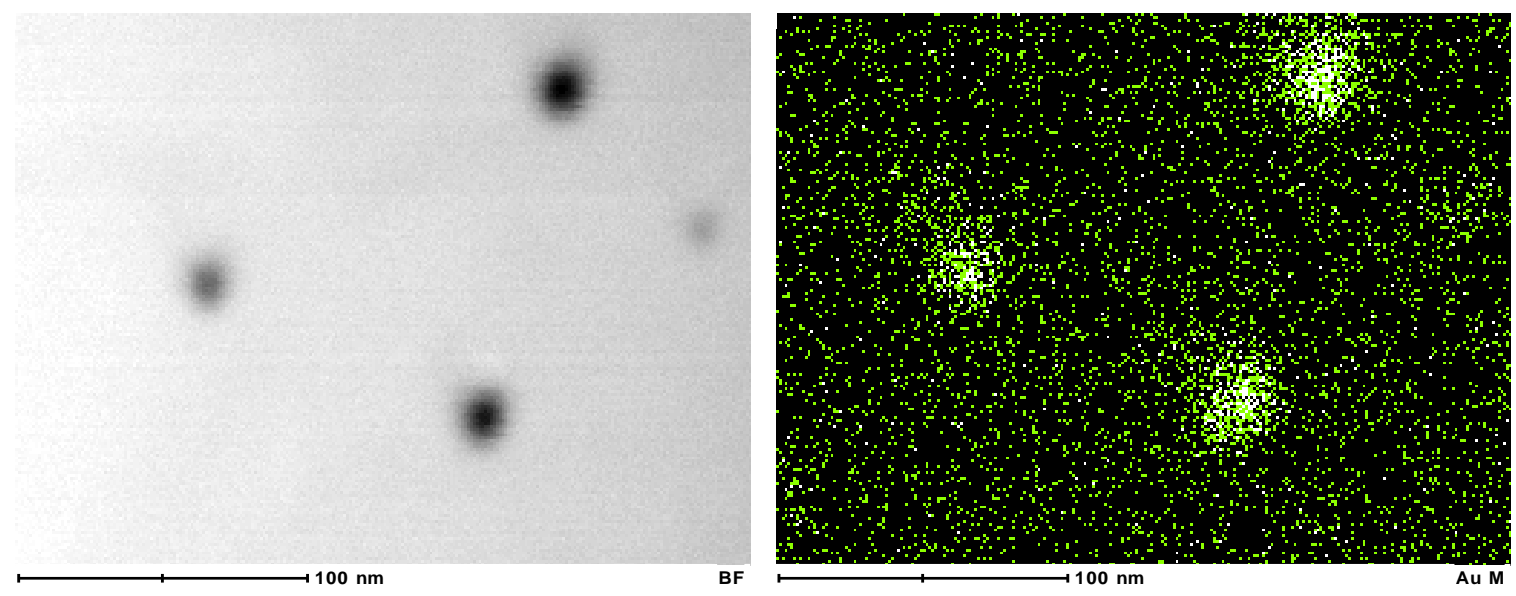

Figure 5.90: TEM and corresponding Au STEM micrograph of a gold nanoparticle-merino wool composite prepared by soaking untreated semi-worsted merino wool in a $160 \mathrm{ppm}\left(8.13 \times 10^{-4} \mathrm{M}^{-\mathrm{Au}^{3+}}\right.$ solution for 24 hours at RT, followed by ageing at $50{ }^{\circ} \mathrm{C}$ for 168 hours.

XPS, which combines elemental peak areas with relative sensitivity factors $(\mathrm{Au} \mathrm{17.12}$, section 2.3.6) provided quantitative analysis of the elemental composition of the top $10 \mathrm{~nm}$ of the gold nanoparticle-merino wool composites (the depth from which photo electrons generated during the XPS process are able to return), and additionally XPS confirmed the presence of gold (Figure 5.91, Table 5.10). The amount of gold present in the composites was dependent upon the fibre substrate and amount of $\mathrm{Au}^{3+}$ employed. When incorporating untreated semi-worsted merino wool, a $\mathrm{Au}^{3+}$ concentration of $160 \mathrm{ppm}\left(8.13 \times 10^{-4} \mathrm{M}\right)$ and an ageing time of 24 or 168 hours, the resultant composites contained 0.21 or $0.27 \%$ gold respectively. The amount of gold present in composites prepared from untreated worsted merino wool was similar, notably 0.28 or $0.33 \%$. However when employing $\mathrm{Cl} / \mathrm{H}$ treated merino wool as the fibre substrate, the amount of gold present in the resulting composites 
was considerably less, notably $0.05 \%$ (prepared with a $\mathrm{Au}^{3+}$ of $160 \mathrm{ppm}\left(8.13 \times 10^{-4} \mathrm{M}\right)$ and ageing time of 168 hours). Base treating these fibres increased the amount of gold in the resultant composites to $0.78 \%$.
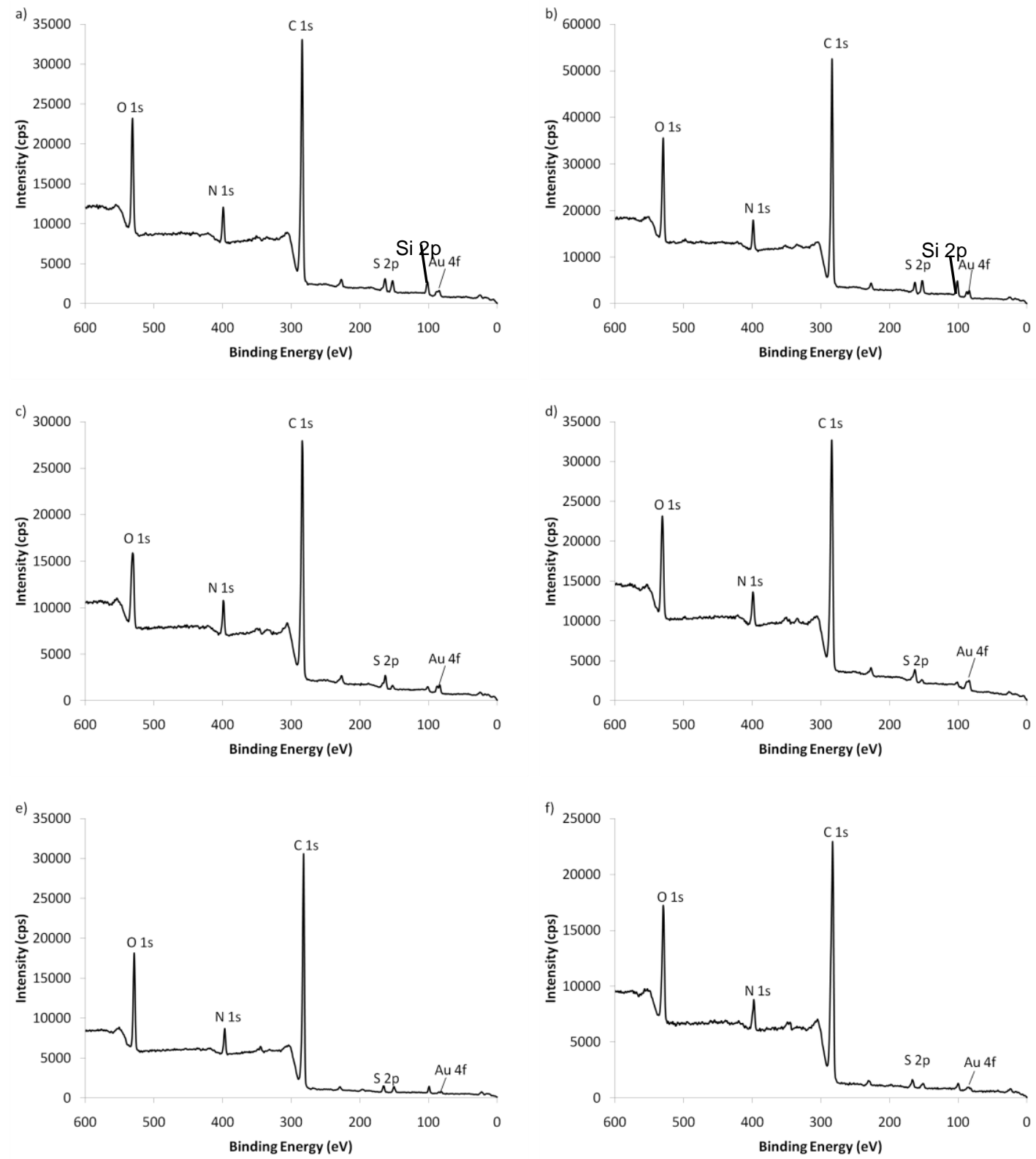

Figure 5.91: Wide XPS scans of gold nanoparticle-merino wool composites prepared by soaking untreated semi-worsted merino wool in a $160 \mathrm{ppm}\left(8.13 \times 10^{-4} \mathrm{M}\right) \mathrm{Au}^{3+}$ solution for 24 hours at RT, followed by ageing at $50{ }^{\circ} \mathrm{C}$ for (a) 24 hours or (b) 168 hours. (c and d) are analogues of (a) and (b) however untreated worsted merino wool was used as the fibre substrate. (e and f) Composite prepared by $\mathrm{Cl} / \mathrm{H}$ treated semi-worsted merino wool (e) or base treated $\mathrm{Cl} / \mathrm{H}$ treated merino wool (f) in a $160 \mathrm{ppm}$ $\left(8.13 \times 10^{-4} \mathrm{M}\right) \mathrm{Au}^{3+}$ solution for 24 hours at RT, followed by ageing at $50{ }^{\circ} \mathrm{C}$ for 168 hours. 
Table 5.10: Amount of gold present on or near the the surface of gold nanoparticle-merino wool composites prepared with a $\mathrm{Au}^{3+}$ concentration of $160 \mathrm{ppm}\left(8.13 \times 10^{-4} \mathrm{M}\right) \mathrm{Au}^{3+}$ solution, a soaking time at RT of 24 hours and various ageing times. Determined by XPS.

\begin{tabular}{lcc}
\hline \multicolumn{1}{c}{ Fibre Substrate } & Ageing Time (hours, $\left.\mathbf{5 0}^{\circ} \mathbf{C}\right)$ & $\begin{array}{c}\% \text { Gold } \\
(\mathbf{\pm 1 0} \%)\end{array}$ \\
\hline Untreated semi-worsted merino & 24 & 0.21 \\
& 168 & 0.27 \\
$\mathrm{Cl} / \mathrm{H}$ treated semi-worsted merino & 168 & 0.05 \\
Base treated Cl/H treated semi-worsted merino & 168 & 0.78 \\
Untreated worsted merino & 24 & 0.28 \\
& 168 & 0.33 \\
\hline
\end{tabular}

Examination of the deconvoluted, high resolution $\mathrm{Au} 4 \mathrm{f}$ spectra of the various composites showed the relative percentages of $\mathrm{Au}^{3+}, \mathrm{Au}^{+}$(in the form of $\mathrm{Au}-\mathrm{S}$ ) and $\mathrm{Au}^{0}$ (Table 5.11). When employing untreated semi-worsted merino wool as the fibre substrate, a $\mathrm{Au}^{3+}$ concentration of $160 \mathrm{ppm}\left(8.13 \times 10^{-4} \mathrm{M}\right)$ and a soaking time, at RT, of 24 hours, increasing the ageing time from 0 to 24 hours and 24 to 168 hours saw a decrease in $\mathrm{Au}^{3+}$ from $55 \%$ to $44 \%$ and 44 to $16 \%$ respectively. This decrease in $\mathrm{Au}^{3+}$ was accompanied by a corresponding increase in $\mathrm{Au}^{+}$and $\mathrm{Au}^{0}$ from 42 and $3 \%$ to 48 and $8 \%$ respectively after 24 hours ageing, and 74 and $10 \%$ after 168 hours. This decrease in $\mathrm{Au}^{3+}$ and subsequent increase in $\mathrm{Au}^{+}$and $\mathrm{Au}^{0}$ with prolonged ageing is reflective of the increase in nanoparticle population with increasing ageing. Alternatively, when the fibres were not soaked in $\mathrm{Au}^{3+}$ solutions prior to ageing, the resultant composite materials possessed less $\mathrm{Au}^{3+}$ and more $\mathrm{Au}^{0}$. As XPS is a surface technique, only analysing the top $10 \mathrm{~nm}$ of a sample, this suggests that not soaking in $\mathrm{Au}^{3+}$ prior to ageing resulted in the formation of more nanoparticles at the fibre surface, confirming the observations made by SEM analysis (section 5.1.2.1).

Employing untreated worsted merino wool as the substrate in place of untreated semiworsted merino wool saw an increase in the amount of $\mathrm{Au}^{3+}$ present in the composites prepared with an ageing time of 24 hours. This suggests less $\mathrm{Au}^{3+}$ had been reduced to nanoparticulate $\mathrm{Au}^{0}$. Increasing the ageing time to 168 hours saw a decrease in $\mathrm{Au}^{3+}$ and a subsequent increase in $\mathrm{Au}^{0}$. Comparing these values to those recorded in composites 
incorporating untreated semi-worsted merino wool reveals the amount of $\mathrm{Au}^{3+}$ and $\mathrm{Au}^{0}$ to be greater in the worsted materials, and the amount of $\mathrm{Au}^{+}$to be less. SEM analysis showed the composites prepared from worsted merino wool to possess less nanoparticles relative to those prepared from semi-worsted merino wool, so the higher values of $\mathrm{Au}^{3+}$ are expected, although the larger amounts of $\mathrm{Au}^{0}$ are not, as SEM showed these materials to possess fewer nanoparticles. However SEM also showed the materials prepared from worsted merino wool to possess a proportion of agglomerated nanoparticles. The effective surface area of the agglomerates would be lower than isolated nanoparticles, and as such they would exhibit less $\mathrm{Au}^{+}$(in the form of Au-S interactions occurring at the surface of the nanoparticles), behaving more as $\mathrm{Au}^{0}$, bulk gold. This is discussed in greater detail in section 5.5.3 below.

Similar trends were observed when incorporating $\mathrm{Cl} / \mathrm{H}$ treated merino wool as the fibre substrate. XPS showed there to be a greater percentage of $\mathrm{Au}^{3+}$ and $\mathrm{Au}^{0}$, and less $\mathrm{Au}-\mathrm{S}$ relative to the composites utilising untreated semi-worsted merino wool as the base fibre. Again this is reflective of the dull, spectrally impure colour of these materials, due to the increased amount of agglomerates present on their surface. Base treating the $\mathrm{Cl} / \mathrm{H}$ treated merino wool decreased the amount of $\mathrm{Au}^{3+}$ and $\mathrm{Au}^{0}$, and increased the amount of $\mathrm{Au}-\mathrm{S}$, bringing the values closer to those reported in composites employing untreated merino wool. This confirms the smaller average size, and increased dispersity of the nanoparticles present in composites incorporating base treated $\mathrm{Cl} / \mathrm{H}$ treated merino wool. The form of the nanoparticles in all gold nanoparticle-merino wool composite materials is discussed in greater detail in section $\mathbf{5 . 5}$ below.

Table5.11: Au 4f XPS assignments for gold nanoparticle-merino wool composites prepared with $160 \mathrm{ppm}$ $\left(8.13 \times 10^{-4} \mathrm{M}\right) \mathrm{Au}^{3+}$ solutions.

\begin{tabular}{|c|c|c|c|c|c|}
\hline Fibre Substrate & $\begin{array}{l}\text { Soaking Time } \\
\text { (Hours, RT) }\end{array}$ & $\begin{array}{l}\text { Ageing Time } \\
\text { (Hours, } 50^{\circ} \mathrm{C} \text { ) }\end{array}$ & $\begin{array}{c}\% \mathrm{Au}^{0} \\
( \pm 10 \%)\end{array}$ & $\begin{array}{c}\% \mathrm{Au}^{+} \\
( \pm 10 \%) \\
(\mathrm{Au}-\mathrm{S})\end{array}$ & $\begin{array}{l}\% \mathrm{Au}^{3+} \\
( \pm 10 \%)\end{array}$ \\
\hline \multirow{5}{*}{$\begin{array}{l}\text { Untreated semi-worsted } \\
\text { merino wool }\end{array}$} & 24 & 0 & 3 & 42 & 55 \\
\hline & 24 & 24 & 8 & 48 & 44 \\
\hline & & 168 & 10 & 74 & 16 \\
\hline & 0 & 24 & 11 & 53 & 36 \\
\hline & & 168 & 18 & 46 & 36 \\
\hline
\end{tabular}




\begin{tabular}{cccccc}
\hline Fibre Substrate & $\begin{array}{c}\text { Soaking Time } \\
\text { (Hours, RT) }\end{array}$ & $\begin{array}{c}\text { Ageing Time } \\
\left.\text { (Hours, 50 }{ }^{\circ} \mathbf{C}\right)\end{array}$ & $\begin{array}{c}\% \mathrm{Au}^{\mathrm{0}} \\
(\mathbf{\pm 1 0} \%)\end{array}$ & $\begin{array}{c}\% \mathrm{Au}^{+} \\
(\mathbf{\pm 1 0} \%) \\
(\mathbf{A u - S})\end{array}$ & $\begin{array}{c}\% \mathrm{Au}^{3+} \\
(\mathbf{\pm 1 0} \%)\end{array}$ \\
\hline Untreated worsted merino wool & 24 & 24 & 0 & 32 & 68 \\
& & 168 & 18 & 40 & 42 \\
$\mathrm{Cl} / \mathrm{H}$ treated merino wool & 24 & 168 & 38 & 39 & 23 \\
Base treated Cl/H merino wool & 24 & 168 & 31 & 51 & 18 \\
\hline
\end{tabular}

\subsection{Extent of Gold Uptake by Merino Wool Fibres}

The uptake of gold by merino wool during the production of gold nanoparticle-merino wool composites was quantitatively analysed by atomic absorption (AA). The procedure is provided in section 2.2.2.3.4 and 2.3.4. However briefly, this was completed by measuring the amount of residual gold in solution following the removal of the merino wool fibres at defined times. The uptake of gold by merino wool was influenced by the soaking (absorption) solution temperature, soaking solution $\mathrm{pH}$ and fibre pre-treatment. Comprehensive tables of uptake results are provided in Appendix III.

When employing untreated semi-worsted merino wool as the fibre substrate, a $\mathrm{Au}^{3+}$ concentration of $160 \mathrm{ppm}\left(8.13 \times 10^{-4} \mathrm{M}\right)$ with a $\mathrm{pH}$ of 2.7 , the absorption of gold was complete following one hour soaking at RT. Increasing the temperature of the soaking solution to $50{ }^{\circ} \mathrm{C}$ increased the rate of absorption, so that the majority of gold was absorbed after approximately 20 minutes (Figure 5.92). 


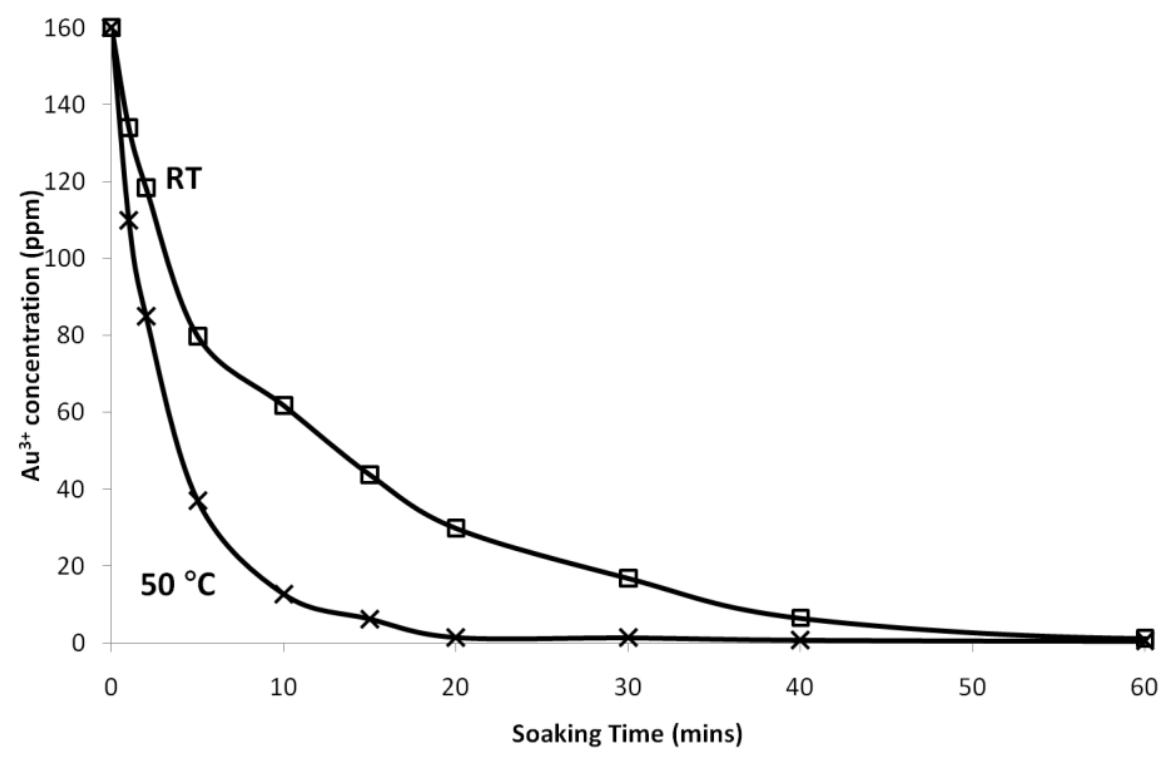

Figure 5.92: Gold uptake by untreated semi-worsted merino wool at $\mathrm{RT}$ or $50^{\circ} \mathrm{C}$. $\mathrm{A} \mathrm{Au}^{3+}$ concentration of $160 \mathrm{ppm}\left(8.13 \times 10^{-4} \mathrm{M}\right)$ with a $\mathrm{pH}$ of 2.7 was employed.

Increasing the $\mathrm{Au}^{3+}$ concentration to $320 \mathrm{ppm}\left(1.62 \times 10^{-3} \mathrm{M}\right)$ whilst keeping the wool:solution volume ratio constant (therefore adding greater amounts of $\mathrm{Au}^{3+}$ ) slightly increased the absorption rate, so that at room temperature the majority of gold was absorbed by the wool after approximately 40-50 minutes (Figure 5.93). Similar effects were seen when increasing the $\mathrm{Au}^{3+}$ concentration by reducing the solvent volume (thus keeping the ratio of wool:amount of $\mathrm{Au}^{3+}$ constant) (Figure 5.94). This is logical as increasing the $\mathrm{Au}^{3+}$ concentration, either through the addition of more $\mathrm{Au}^{3+}$, or a reduction of the solvent volume, creates a greater concentration gradient at the solution/wool fibre interface, thus providing a greater driving force for the absorption of gold by merino wool.

Increasing the $\mathrm{pH}$ of the $\mathrm{Au}^{3+}$ soaking solution to 5 or 7 dramatically decreased the rate of gold absorption by merino wool, to the extent that even following 24 hours soaking at RT only $66 \%, 105 \mathrm{ppm}$ and $94 \%, 150 \mathrm{ppm}$ of the gold had been absorbed in the pH 7 and 5 systems respectively (Figure 5.95). As mentioned previously, due to the presence of both amine and carboxylic acid groups, wool behaves in an amphoteric manner, displaying an isoelectric point of approximately 5.[222] Therefore at $\mathrm{pH}$ 5, the surface charge of the wool fibre would be largely neutral, however at $\mathrm{pH} 7$ it would possess a negative charge. If gold was being absorbed in the form of $\mathrm{Au}^{3+}$, due to electrostatic attractions the absorption would 


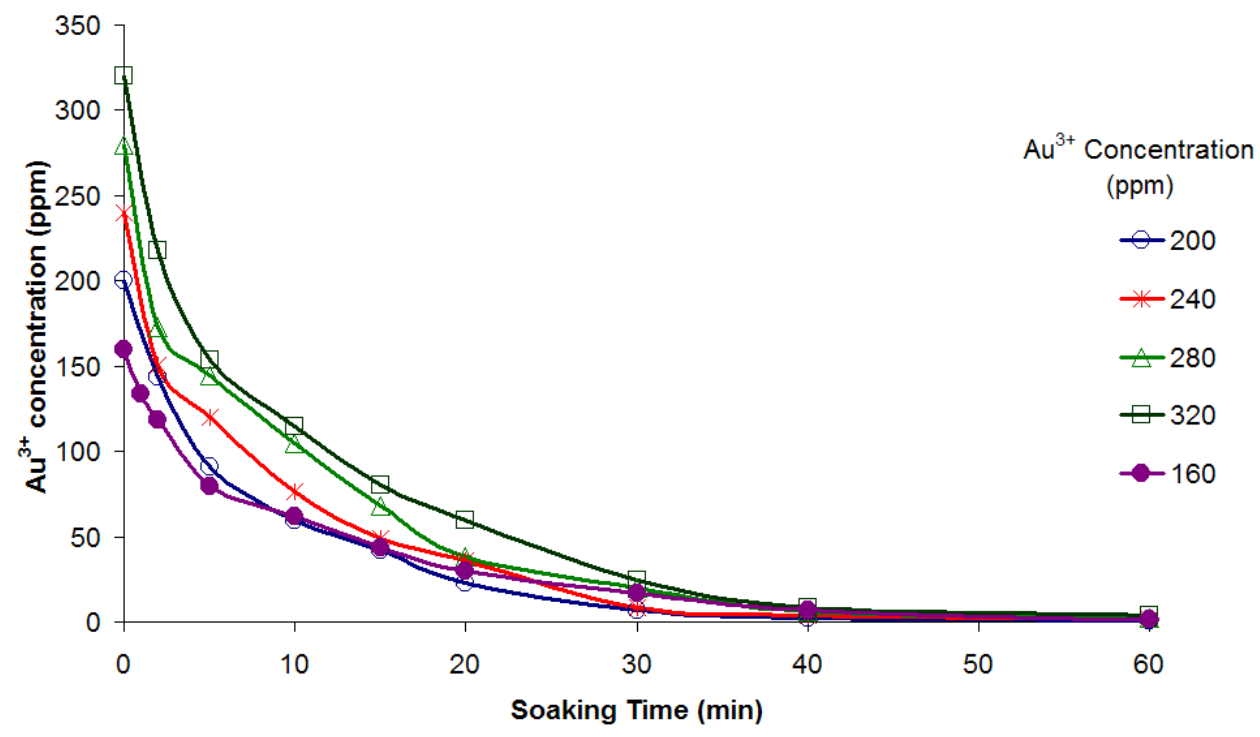

Figure 5.93: Gold absorption by untreated semi-worsted merino wool at RT, employing a $\mathrm{Au}^{3+}$ concentration of $160,200,240,280$ or $320 \mathrm{ppm}\left(8.13 \times 10^{-4} \mathrm{M}, 1.01 \times 10^{-3}, 1.22 \times 10^{-3}, 1.42 \times 10^{-3}\right.$ and $1.62 \times$ $10^{-3} \mathrm{M}$ respectively) all with a $\mathrm{pH}$ of approximately 2.7 . Shows the effect the $\mathrm{Au}^{3+}$ concentration has on absorption.

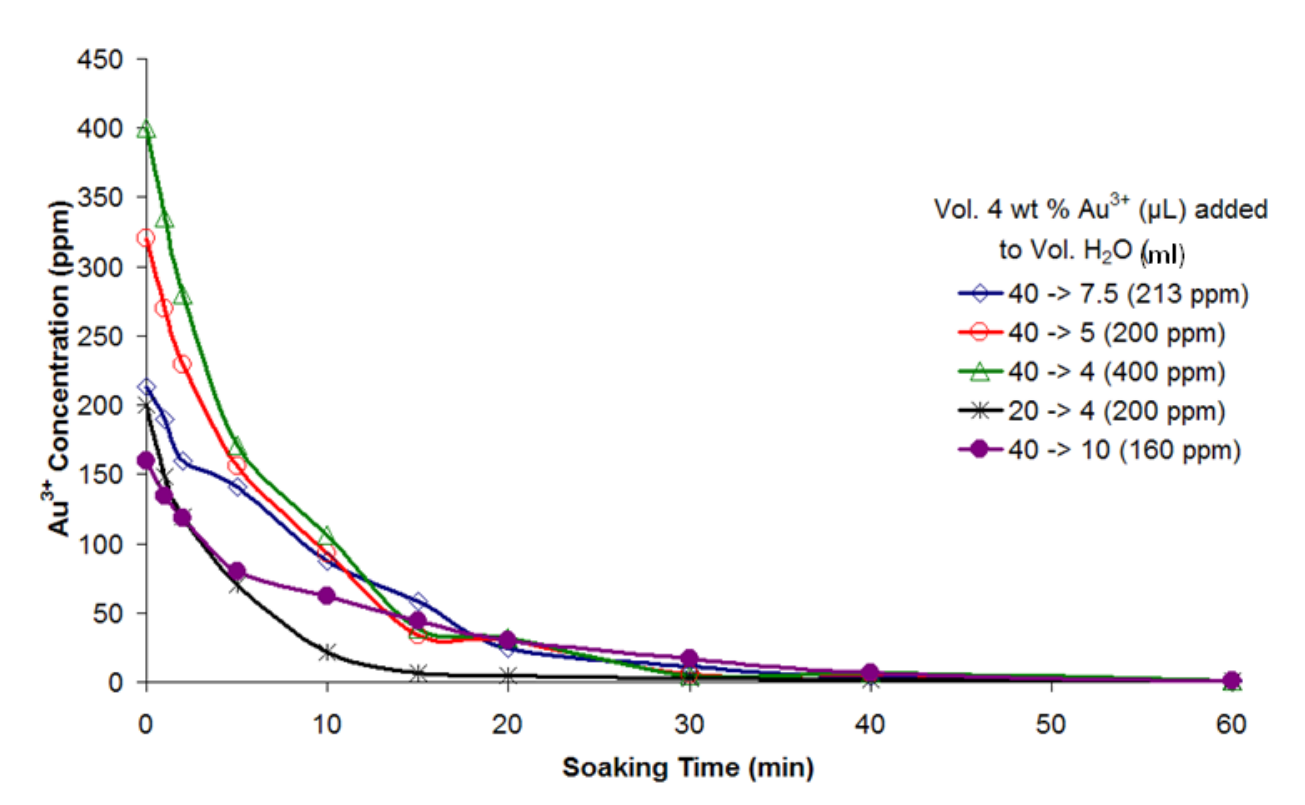

Figure 5.94: Gold absorption by untreated semi-worsted merino wool at RT, employing $\mathrm{Au}^{3+}$ concentrations in the range of 160-400 ppm, achieved with lower solvent volumes Shows the effect the $\mathrm{Au}^{3+}$ concentration has on absorption.

be expected to increase with increasing $\mathrm{pH}$. However as it decreases with increasing $\mathrm{pH}$, it is likely that it is $\mathrm{AuCl}_{4}{ }^{-}$that is absorbed, as higher $\mathrm{pHs}$ induce a net negative charge at the 
wool fibre surface, acting to electrostatically repel $\mathrm{AuCl}_{4}{ }^{-}$and thus decrease the gold absorption rate.

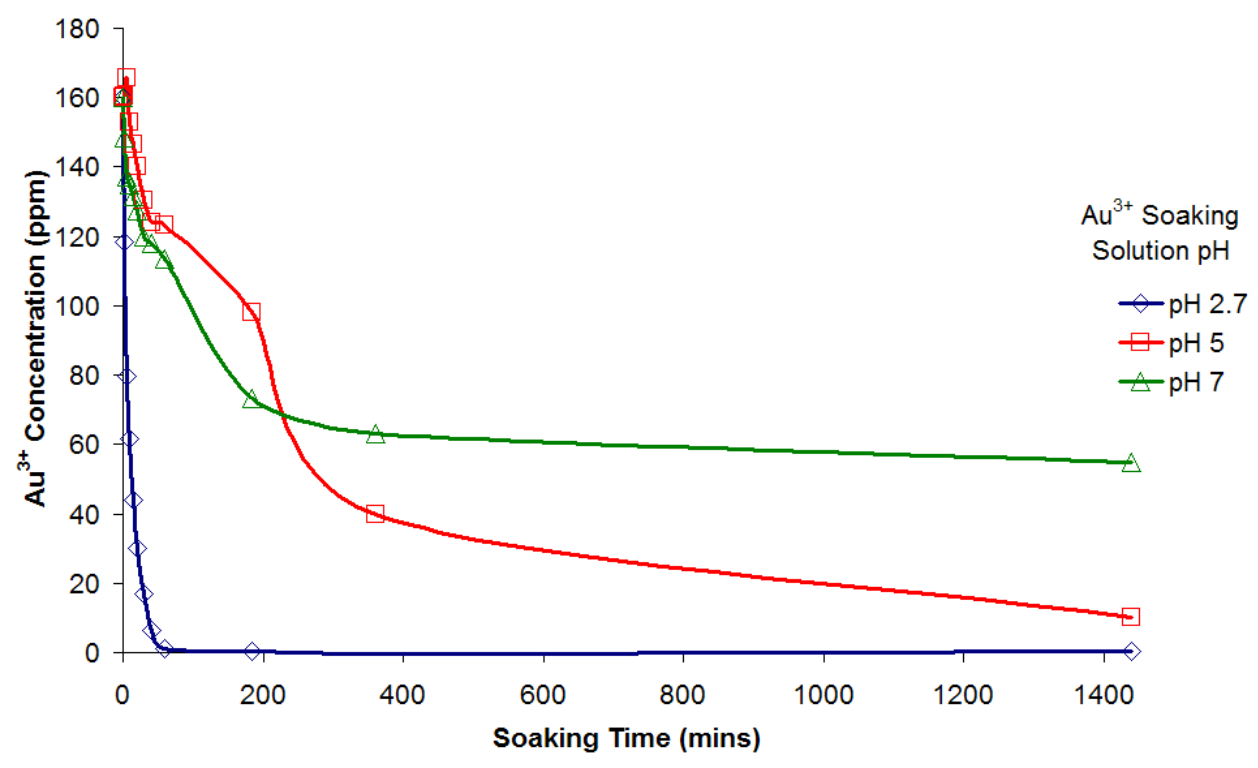

Figure 5.95: Gold absorption by untreated semi-worsted merino wool at RT. Shows the effect increasing the $\mathrm{pH}$ of the soaking solution has on absorption.

In addition to adjusting the $\mathrm{pH}$ of the soaking solution, pre-treating the merino wool fibres prior to addition to the $\mathrm{Au}^{3+}$ solution also influenced the rate of absorption. Pre-treating the fibres with dilute acid slightly increased the gold absorption rate (Figure 5.96). This is likely due to additional amine groups on the surface of the wool fibre becoming protonated, thus increasing the positive charge at the wool fibre surface and therefore the electrostatic attraction between the wool fibre and negatively charged $\mathrm{AuCl}_{4}{ }^{-}$. However pre-treating the merino wool fibres with a dilute alcoholic base solution $(0.1 \mathrm{M} \mathrm{KOH}$ in $\mathrm{EtOH})$, also acted to increase the rate of gold absorption (Figure 5.96), which is counterintuitive as base pretreating should act to de-protonate the wool fibre surface, inducing a more negative surface charge and thus lessening the electrostatic attraction between the wool fibre and $\mathrm{AuCl}_{4}{ }^{-}$, hence producing a slower absorption rate. However as mentioned in section 5.1.4, in addition to de-protonating the surface of the wool fibre, dilute alcoholic alkaline solutions also remove the lipid layer from the surface of the merino wool. Sterically this would allow for a greater ease of penetration of $\mathrm{AuCl}_{4}{ }^{-}$into the wool fibres, and hence a faster absorption. 


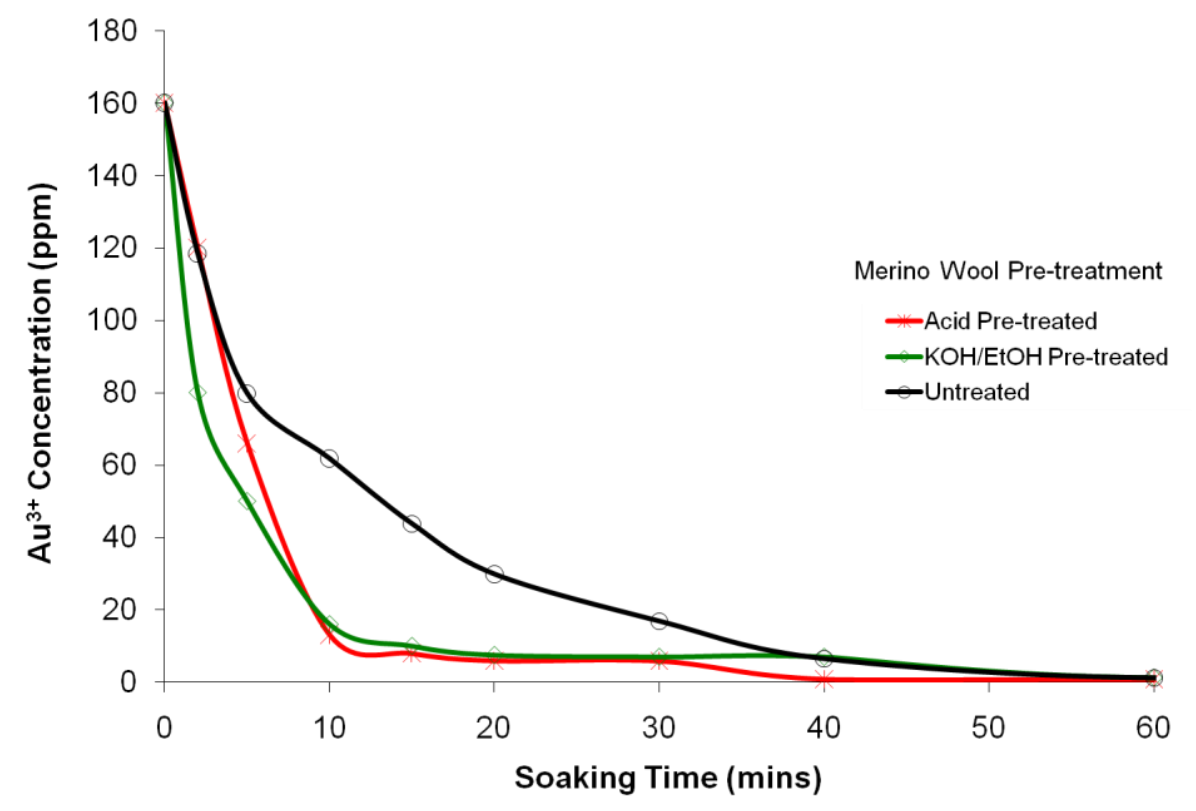

Figure 5.96: Gold absorption, at RT, of acid pre-treated, KOH/EtOH pre-treated and untreated semiworsted merino wool.

Employing $\mathrm{Cl} / \mathrm{H}$ treated semi-worsted merino wool in place of untreated merino wool as the fibre substrate, dramatically increased the absorption rate of gold by the wool fibres (Figure 5.97). This is likely due to both the highly cationic nature of the Hercosett polymer bound to the surface of the $\mathrm{Cl} / \mathrm{H}$ treated fibres, and also its propensity to swell, swelling up to ten times its original volume when dispersed in water, thus making the absorption of the negatively charged $\mathrm{AuCl}_{4}^{-}$group increasingly facile as a result of both electrostatic attractions and steric ease. Pre-treating $\mathrm{Cl} / \mathrm{H}$ treated merino wool fibres with dilute $\mathrm{KOH}$ did not alter the gold absorption rate (Figure 5.97). 


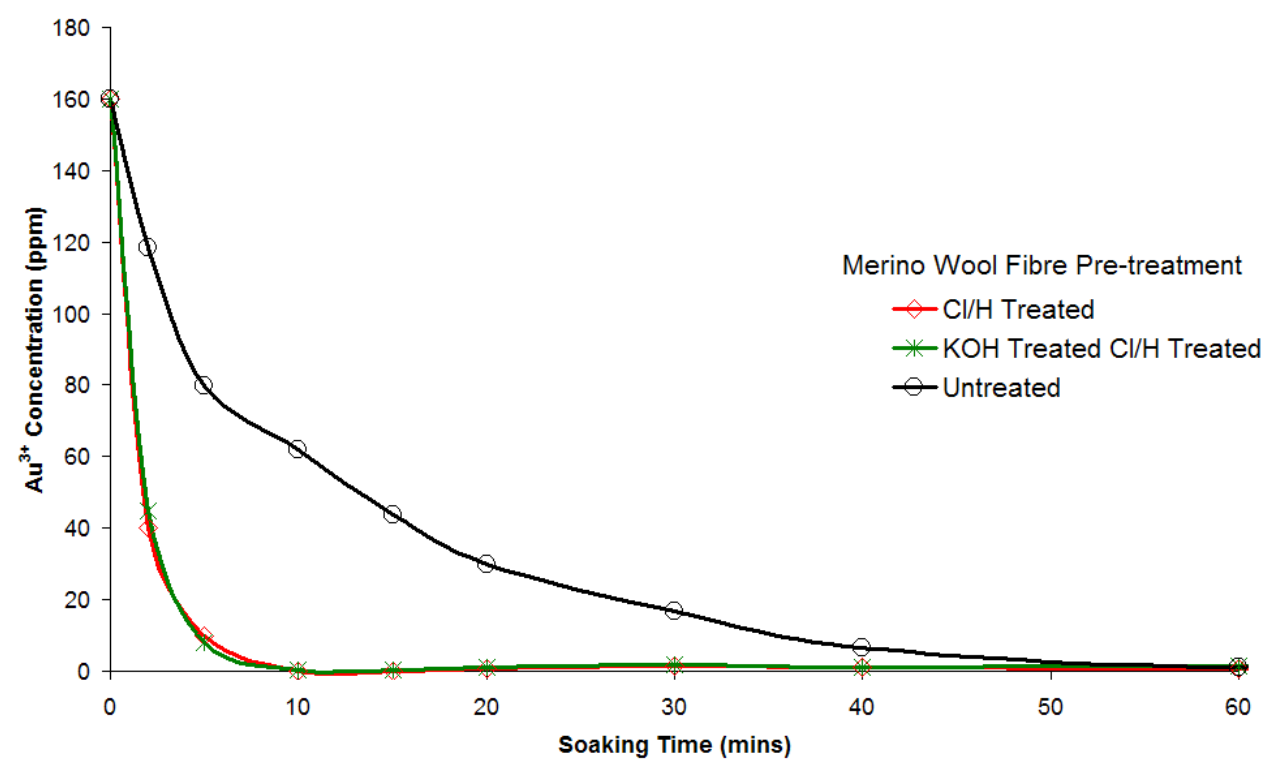

Figure 5.97: Gold absorption by untreated, $\mathrm{Cl} / \mathrm{H}$ treated and $\mathrm{KOH}$ treated $\mathrm{Cl} / \mathrm{H}$ treated semi-worsted merino wool at RT.

Employing untreated worsted merino wool in place of untreated semi-worsted merino wool as the fibre substrate did not alter the rate of absorption of gold by the fibres, with the majority of gold being absorbed following 1 hour soaking at RT (Figure 5.98). This suggests that the lubricants present on the surface of the worsted fibres did not influence or affect the absorption of gold, and the decreased colour intensity of the composites made from these fibres was due to the decreased ability of these materials to facilitate the reduction of $\mathrm{Au}^{3+}$ to $\mathrm{Au}^{0}$ nanoparticles.

Considering the effect of the soaking/absorption solution $\mathrm{pH}$ and also fibre pre-treatments on the rate of gold absorption by wool, with faster absorptions occurring when the merino wool fibres possess a negative surface charge (and also when there is less steric hindrance imparted by lipids etc bound to the fibre surface) $\mathrm{AuCl}_{4}{ }^{-}$rather than $\mathrm{Au}^{3+}$ is the likely gold species absorbed by merino wool. 


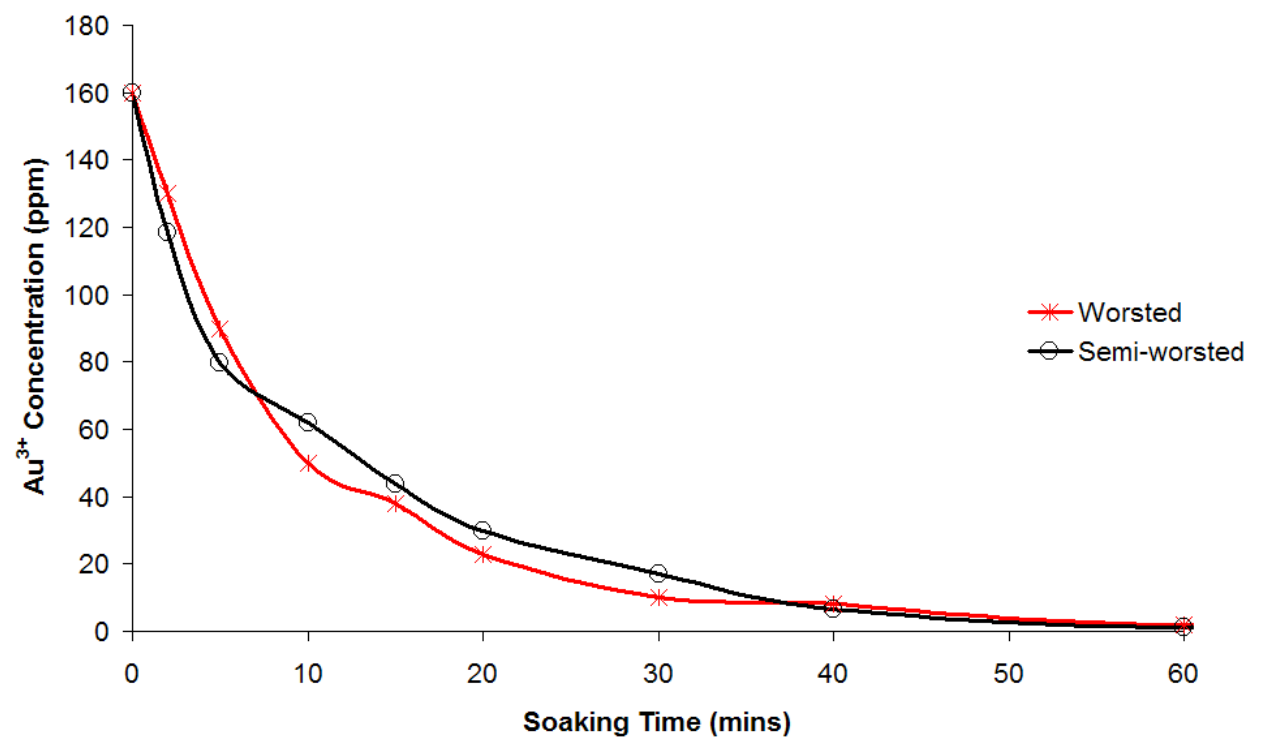

Figure 5.98: Gold absorption by untreated worsted and semi-worsted merino wool at RT.

\subsection{Bonding of Gold Nanoparticles to Merino Wool Fibres}

As mentioned, keratin is the main constituent of merino wool fibres, and as such offers numerous sites through which the gold nanoparticles could potentially bond, particularly in the form of sulfur (thiol, disulfide) and or nitrogen (amine, amide etc) containing amino acid groups. To investigate this bonding, EDS and XPS analysis of the produced composites was undertaken.

\subsubsection{Untreated Semi-Worsted Gilled Sliver}

Figure 5.99 offers the EDS spectrum of a gold nanoparticle-merino wool composite, and Figure 5.100 the cross sectional SEM and corresponding EDS micrographs. This material was prepared by soaking untreated semi-worsted merino wool in a $160 \mathrm{ppm}\left(8.13 \times 10^{-4} \mathrm{M}\right)$ $\mathrm{Au}^{3+}$ solution for 24 hours at RT, followed by ageing at $50{ }^{\circ} \mathrm{C}$ for 168 hours, and is typical of all composite materials prepared with a soaking time, at RT, of at least 24 hours. The main elemental constituents of merino wool are present, notably carbon, nitrogen, sulfur and oxygen (Figure 5.99). There are also low concentrations of chlorine, likely a residue of 
$\mathrm{AuCl}_{4}{ }^{-}$. As seen previously in section 5.3, gold is present both of the surface, and also throughout the centre of the merino wool fibres. Of note is that where there are high concentrations of gold, there are also high concentrations of sulfur (indicated by bright pink or white areas in the Au and S EDS maps). This is most apparent in the lower left hand quadrant of the wool fibre, which due to its relatively high sulfur content, can be identified as the paracortex. Additionally, high resolution STEM micrographs also show that where there are high concentrations of gold, there are also high concentrations of sulfur (Figure 5.101). This overlay of gold and sulfur suggests a chemical affinity of gold for suflur in the wool, most likely in the main sulfur containing amino acids cysteine and cystine, and may indicate the bonding between the gold nanoparticles and wool to be via Au-S bonds.

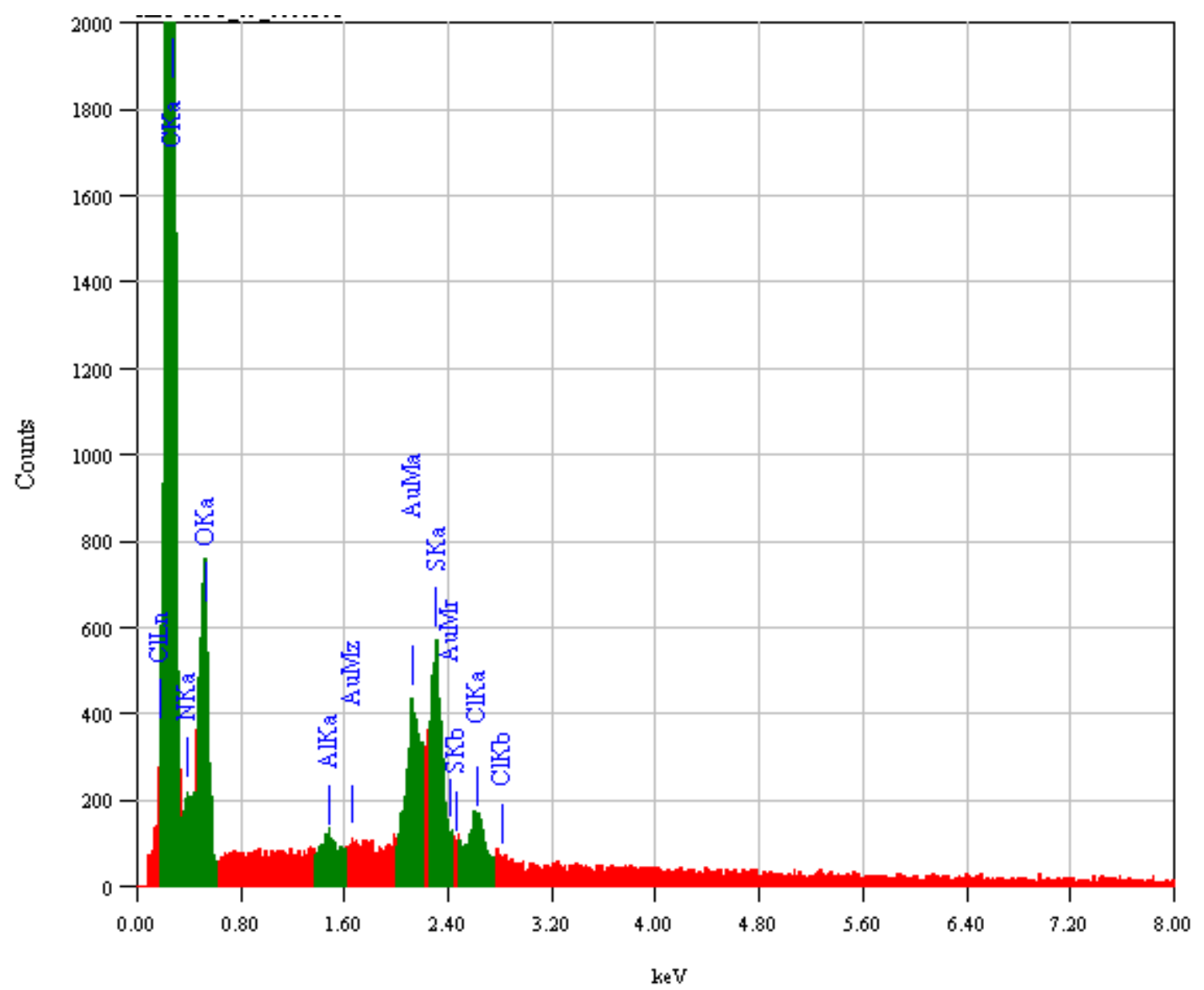

Figure 5.99: EDS spectrum of a gold nanoparticle-merino wool composite material prepared by soaking untreated semi-worsted merino wool in a $160 \mathrm{ppm}\left(8.13 \times 10^{-4} \mathrm{M}\right) \mathrm{Au}^{3+}$ solution for 24 hours at RT, followed by ageing at $50{ }^{\circ} \mathrm{C}$ for 168 hours. 

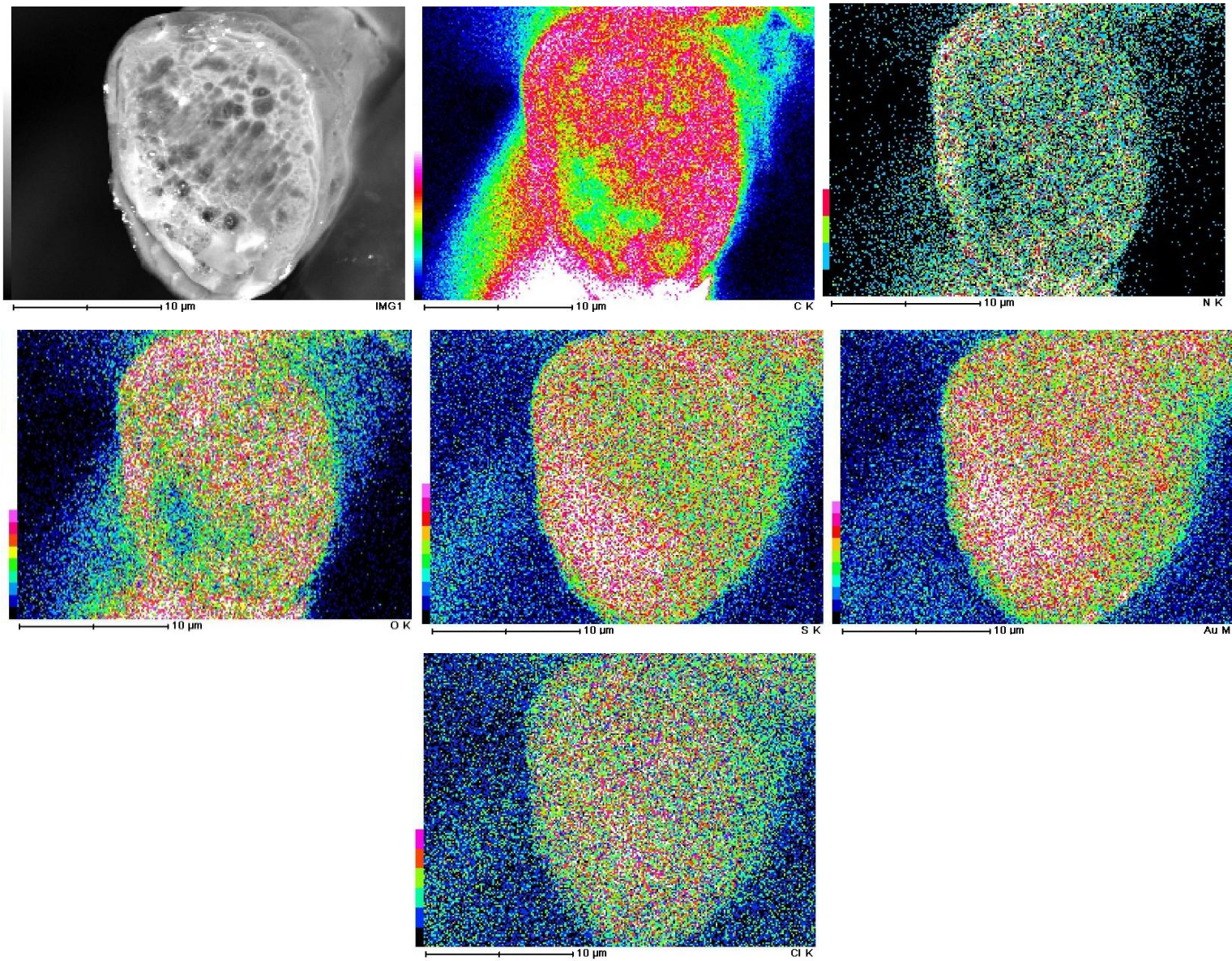

Figure 5.100: Cross sectional SEM micrograph and corresponding EDS micrographs of a gold nanoparticle-merino wool composite material, prepared by soaking untreated semi-worsted merino wool in a $160 \mathrm{ppm}\left(8.13 \times 10^{-4} \mathrm{M}\right) \mathrm{Au}^{3+}$ solution for 24 hours at RT, followed by ageing at $50{ }^{\circ} \mathrm{C}$ for 168 hours.
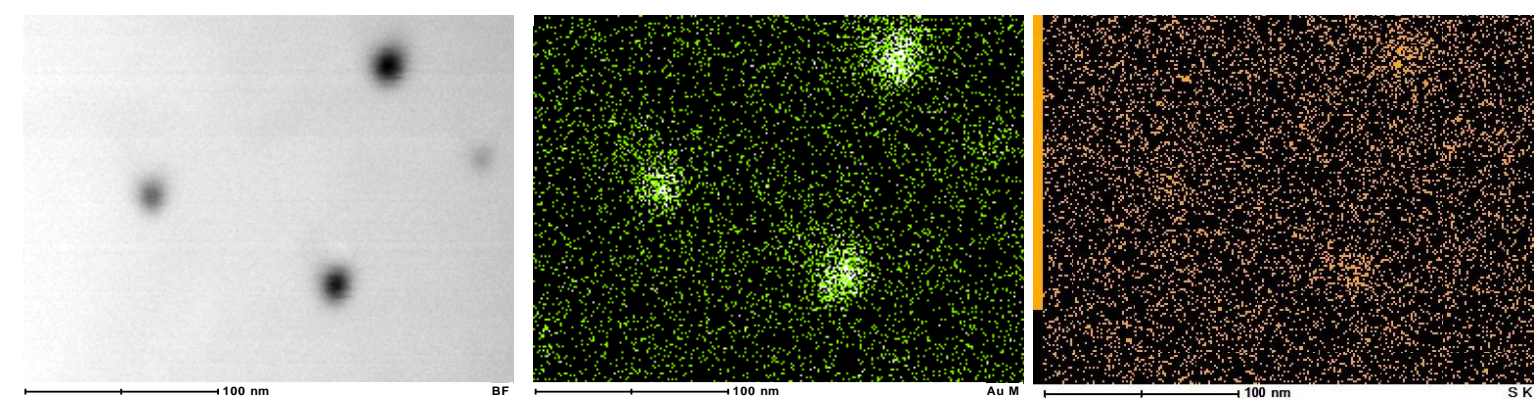

Figure 5.101: TEM and corresponding Au and S STEM micrographs of a gold nanoparticle-merino wool composite prepared by soaking untreated semi-worsted merino wool in a $160 \mathrm{ppm}\left(8.13 \times 10^{-4} \mathrm{M}\right) \mathrm{Au}^{3+}$ solution for 24 hours at RT, followed by ageing at $50{ }^{\circ} \mathrm{C}$ for 168 hours.

This gold-sulfur interaction was confirmed in XPS analysis of the gold nanoparticle-merino wool composites. A complete list of peak assignments is provided in Table 5.12 below. This interaction was particularly apparent when comparing the S 2 p spectra of the composites to 
that of the base fibre; untreated semi-worsted merino wool, and also through analysis of the $\mathrm{Au} 4 \mathrm{f}$ spectrum of the composite. The $\mathrm{S} 2 \mathrm{p}$ spectrum of both untreated semi-worsted merino wool, and a composite prepared by soaking such wool in a $160 \mathrm{ppm}\left(8.13 \times 10^{-4} \mathrm{M}\right) \mathrm{Au}^{3+}$ solution for 24 hours at RT, followed by ageing at $50{ }^{\circ} \mathrm{C}$ for 24 or 168 hours shows peaks representative of the main sulfur containing groups (thiol groups of cysteine (-SH), and disulfide groups of cystine (S-S)) and cysteic acid (- $\mathrm{SO}_{3}{ }^{-}$an oxidised form of sulfur) (Figure 5.102).[172, 228] Additionally, a new set of peaks centred at approximately 161.5 and 161.7 $\mathrm{eV}$, which were absent in the base merino wool appeared in the composite material. This set of peaks is representative of a S-Au interaction,[217] and substantiate the chemical affinity of gold for sulfur suggested in EDS analysis. Employing an ageing time of 168 hours saw an increase in the area of this peak, from $6 \%$ to $9 \%$, reflective of the increased amount of nanoparticles which formed with increased ageing times (Table 5.12).
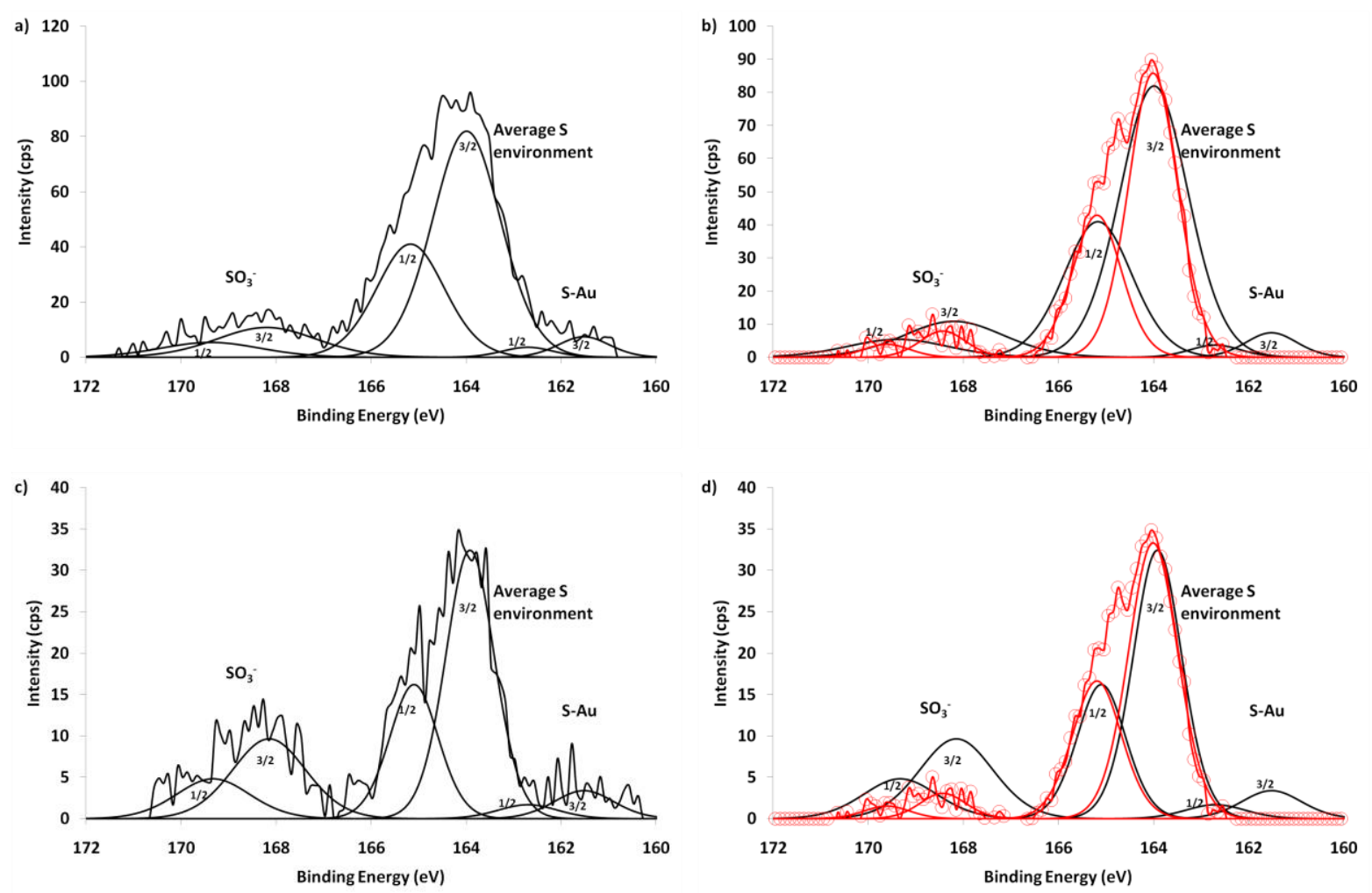

Figure 5.102: a and c) high resolution S 2p XPS spectra of gold nanoparticle-merino wool composites prepared by soaking untreated semi-worsted merino wool in a $160 \mathrm{ppm}\left(8.13 \times 10^{-4} \mathrm{M}\right) \mathrm{Au}^{3+}$ solution for 24 hours at RT, followed by ageing at $50{ }^{\circ} \mathrm{C}$ for 24 or 168 hours respectively. b) and d) an overlay (in red) of untreated semi-worsted merino wool. 
This Au-S interaction was also illustrated in the Au $4 \mathrm{f}$ spectra of the composite materials. Figure 5.103 offers the high resolution Au 4f XPS spectra of these materials. The expected asymmetrical 7/2 and 5/2 peaks of $\mathrm{Au}^{0}$ are evident at $\sim 84.0$ and $87.6 \mathrm{eV}$ respectively. While the spacing between the two peaks matches that of the bulk metal, both have shifted to higher binding energies by approximately $1 \mathrm{eV}$. This shift is believed to be due to the nanoparticulate nature of the gold particles, as when the size of the particle decreases, the delectron count also decreases resulting in reduced repulsive forces between the d-electrons and core electrons.[229-231] Additionally, it has been reported that the hole produced from the XPS photoemission process is not effectively screened in nanoparticles, resulting in the positive shift in binding energy of nanoparticles relative to the bulk metal.[231] This shift may also be due to the presence of $S$ bound to the surface of the nanoparticles, as similar shifts to higher binding energies were observed for $\mathrm{Au}$ nanoparticles capped with cysteine.[217] Opposite effects have been observed for nanoparticles capped with nitrogen containing groups.[201]
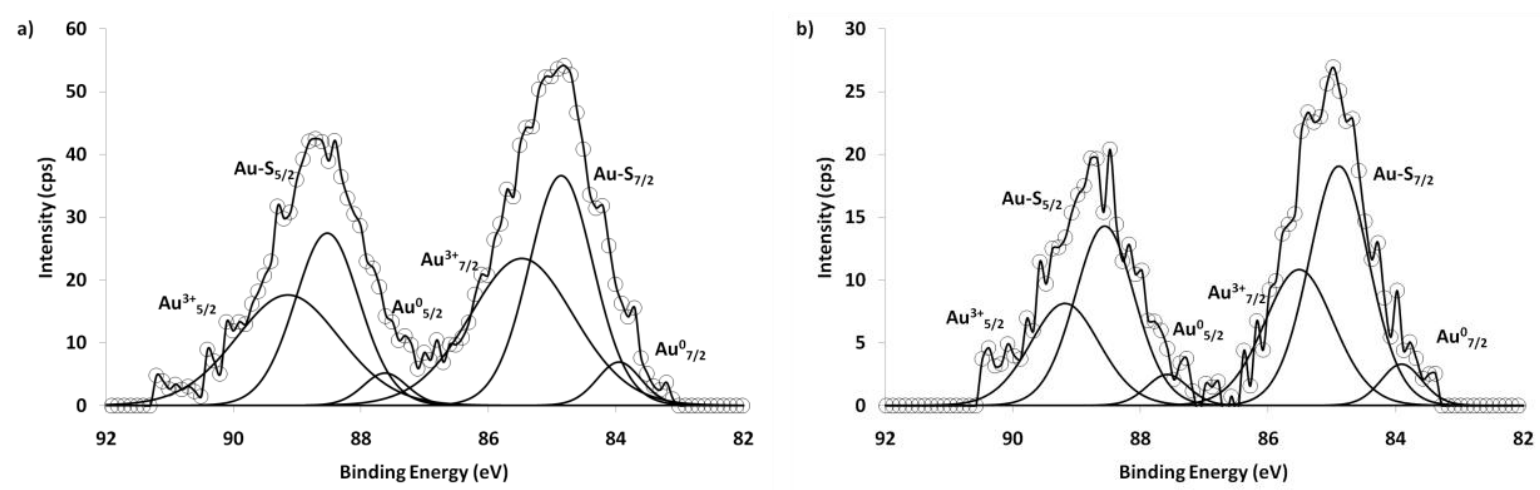

Figure 5.103: High resolution Au 4f XPS spectra of gold nanoparticle-merino wool composites prepared by soaking untreated semi-worsted merino wool in a $160 \mathrm{ppm}\left(8.13 \times 10^{-4} \mathrm{M}\right) \mathrm{Au}^{3+}$ solution for 24 hours at RT, followed by ageing at $50{ }^{\circ} \mathrm{C}$ for 24 or 168 hours (a) and b) respectively).

Additionally, broad peaks indicative of $\mathrm{Au}^{3+}$ were present at approximately 85.5 and 89.1 $\mathrm{eV}$, suggesting a percentage of unreduced $\mathrm{Au}^{3+}$. However the predominant peaks are those indicating a Au-S bond, centred at approximately 85.0 and $88.6 \mathrm{eV}$. Considering the relative percentages of $\mathrm{Au}^{0}$ and $\mathrm{Au}^{+}$(in the form of $\mathrm{Au}-\mathrm{S}$ ), it is likely that the gold nanoparticles bound to the surface of the merino wool fibres possess $\mathrm{Au}^{0}$ cores, surrounded by $\mathrm{Au}^{+}$ions 
that bind to the wool fibre via $\mathrm{Au}-\mathrm{S}$ bonds, most likely through the main sulfur containing amino acids cystine and cysteine (Figure 5.104). Due to the limitations of XPS, in which the irradiating x-rays only penetrate the top $10 \mathrm{~nm}$ of a sample, the bonding between the nanoparticles residing in the centre of the fibre and the fibre cannot be proposed with as much certainty. However as cross sectional EDS analysis showed areas of high concentrations of gold to correlate with areas of high concentrations of sulfur, it is likely that the bonding between the nanoparticles and merino wool fibre is the same regardless of the location of the nanoparticles (either on the surface or in the centre of the fibres).

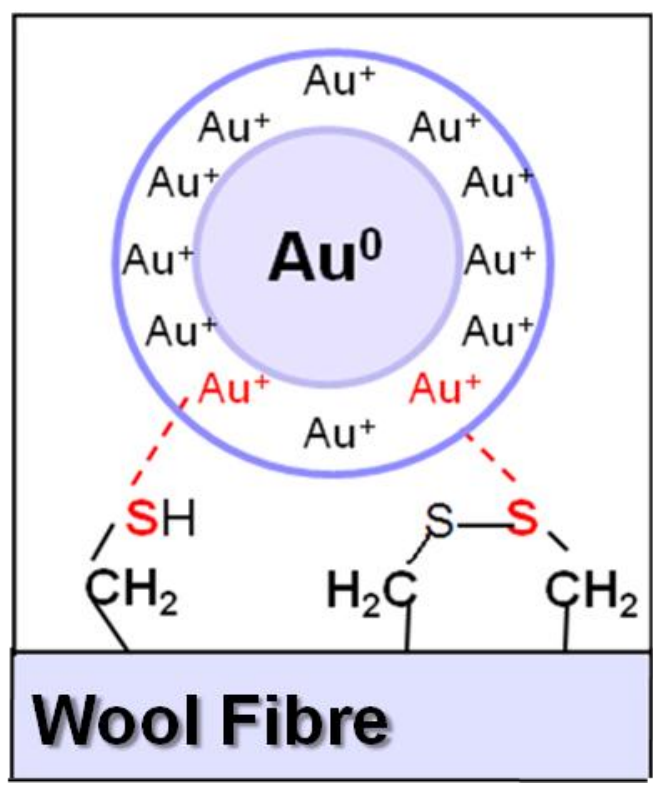

Figure 5.104: Schematic illustrating the proposed bonding of gold nanoparticles to merino wool fibres.

Additionally there was no conclusive evidence of alternate forms of bonding, such as Au-N (through amine groups) or Au-O (through carboxylate groups) bonding. This was seen through comparisons between the high resolution $\mathrm{C} 1 \mathrm{~s}, \mathrm{~N} 1 \mathrm{~s}$ and $\mathrm{O} 1 \mathrm{~s}$ spectra of the composite materials and untreated semi-worsted merino, in which only slight differences in the $\mathrm{N}$ 1s spectra were discernable, with the $\mathrm{C} 1 \mathrm{~s}$ and $\mathrm{O}$ 1s spectra remaining unchanged upon incorporation of the gold nanoparticles (Figure 5.105 and Figure 5.106). There was a slight downward shift, and broadening in the peaks of both amine, imine and oxidised nitrogen (centred at approximately 400 and $401.9 \mathrm{eV}$ respectively) in the $\mathrm{N} 1 \mathrm{~s}$ spectra of the composites, suggesting the nitrogen groups may be slightly involved in bonding to the gold nanoparticles. However, as was the case in the bonding between the merino wool fibres and 
TSC or TA capped gold nanoparticles, a direct N-Au bond, illustrated by a peak centred at $398.5 \mathrm{eV}$ in the $\mathrm{N}$ 1s spectrum was not evident, nor was a C-N-Au bond, which would be expected to appear in the $\mathrm{C} 1 \mathrm{~s}$ spectrum at $283.3 \mathrm{eV}$. Additionally, if there were direct $\mathrm{Au}-\mathrm{N}$ bonds, the $\mathrm{Au}^{0}$ peaks in the $\mathrm{Au} 4 \mathrm{f}$ spectra of the composites would be expected to shift to lower binding energies relative to bulk $\mathrm{Au}^{0}$ rather than higher.[201] Therefore instead of reflecting a direct $\mathrm{Au}-\mathrm{N}$ bond, the shifts in the nitrogen peaks are likely a result of the $\mathrm{S}$ atoms in the main $\mathrm{S}$ containing amino acids binding to the $\mathrm{Au}^{0}$ nanoparticles.
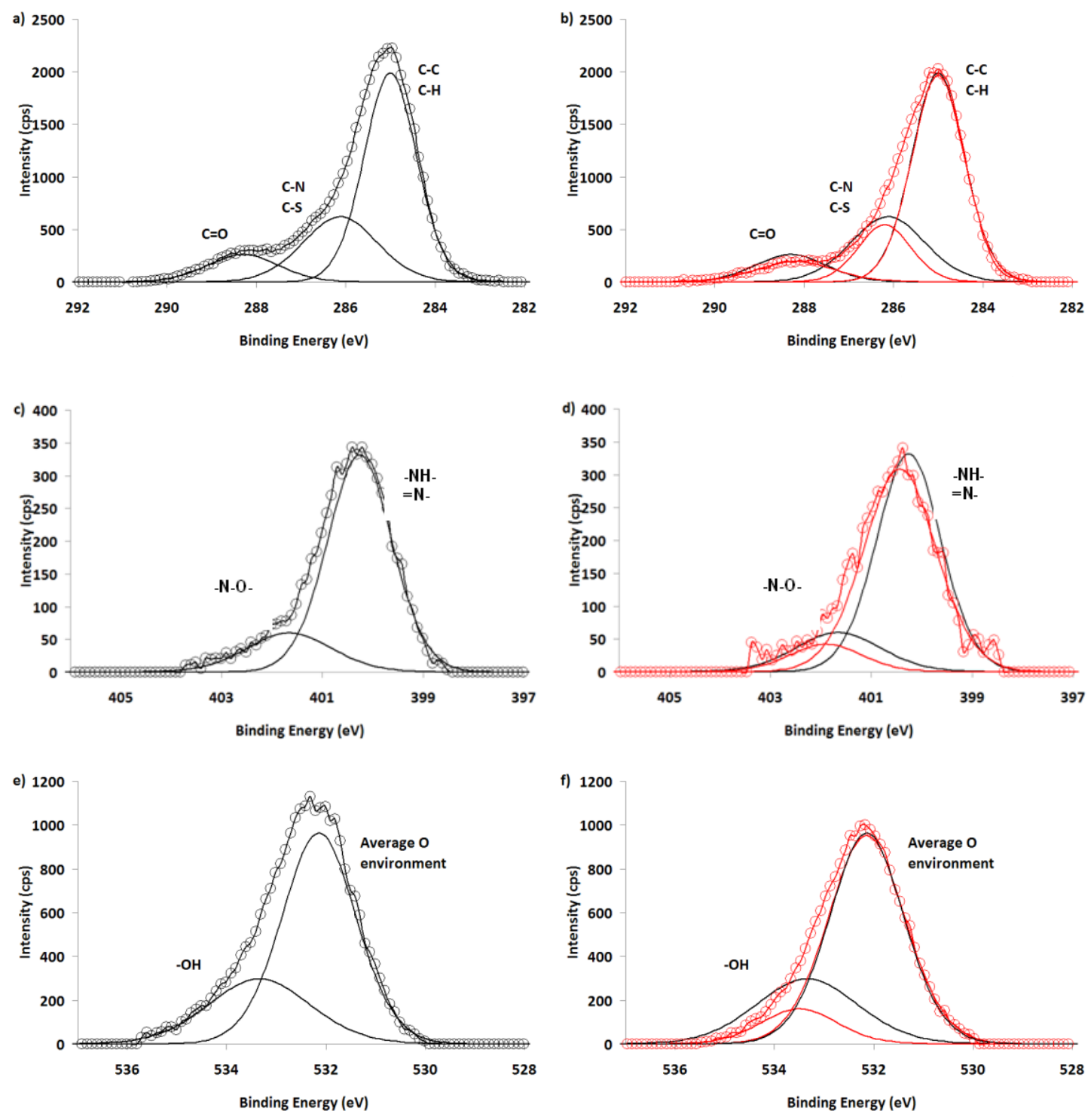

Figure 5.105: High resolution XPS spectra of $\mathrm{C} 1 \mathrm{~s}(\mathrm{a}), \mathrm{N}$ 1s (c) and $\mathrm{O}$ 1s (e) of a gold nanoparticle merino wool composite prepared by soaking untreated semi-worsted merino wool in a $160 \mathrm{ppm}\left(8.13 \times 10^{-4} \mathrm{M}\right)$ $\mathrm{Au}^{3+}$ solution for 24 hours at $\mathrm{RT}$, followed by ageing at $50{ }^{\circ} \mathrm{C}$ for 24 hours. b), d) and f) show an overlay or the corresponding $\mathrm{C} 1 \mathrm{~s}, \mathrm{~N}$ 1s and $\mathrm{O}$ 1s spectra of untreated semi-worsted merino wool (in red). 

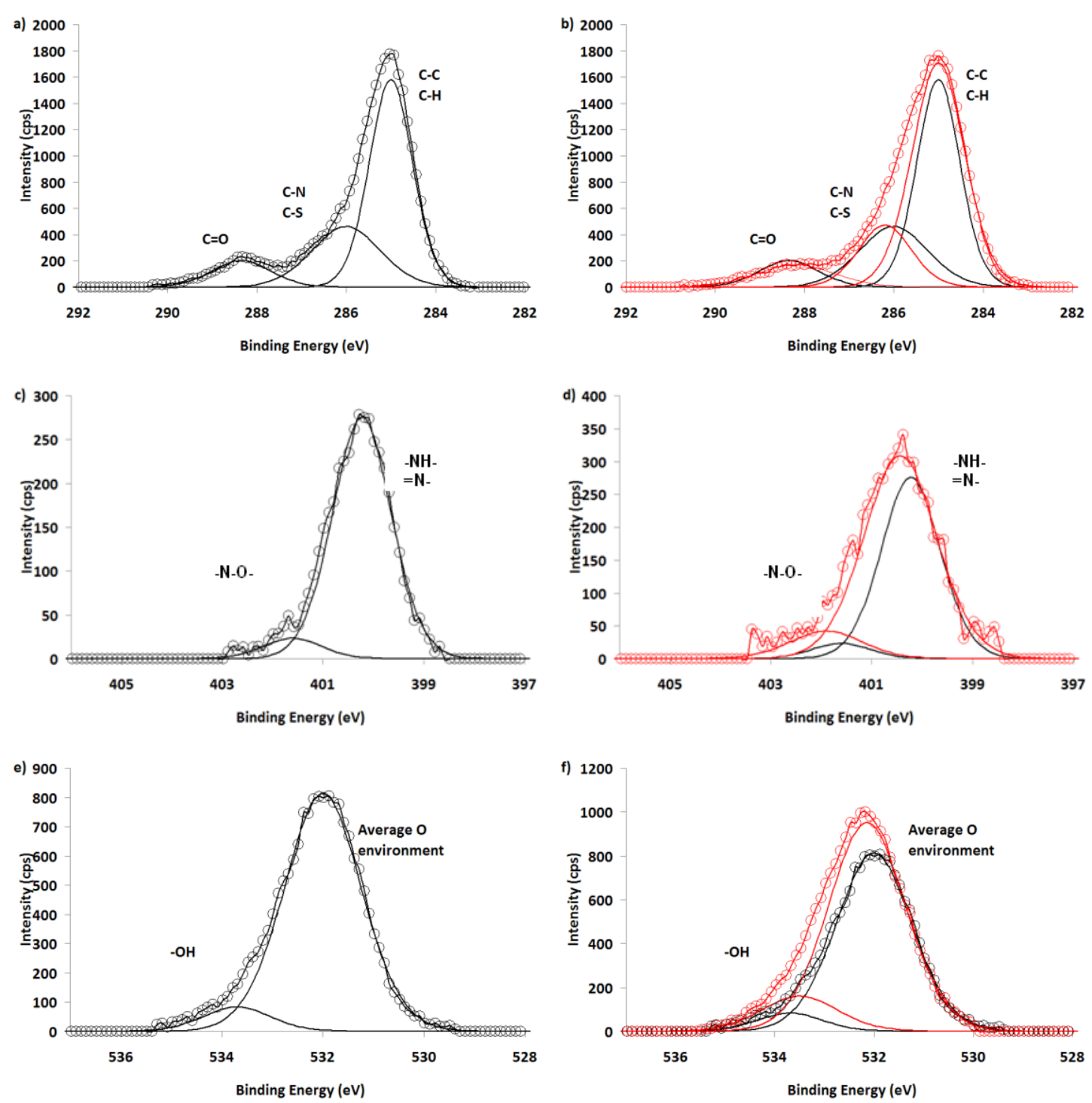

Figure 5.106: High resolution XPS spectra of $\mathrm{C} 1 \mathrm{~s}(\mathrm{a}), \mathrm{N}$ 1s (c) and $\mathrm{O}$ 1s (e) of a gold nanoparticle merino wool composite prepared by soaking untreated semi-worsted merino wool in a $160 \mathrm{ppm}\left(8.13 \times 10^{-4} \mathrm{M}\right)$ $\mathrm{Au}^{3+}$ solution for 24 hours at RT, followed by ageing at $50{ }^{\circ} \mathrm{C}$ for 168 hours. b), d) and f) show an overlay or the corresponding $\mathrm{C} 1 \mathrm{~s}, \mathrm{~N}$ 1s and $\mathrm{O}$ 1s spectra of untreated semi-worsted merino wool (in red). 
Table 5.12: XPS assignments for untreated semi-worsted merino wool and gold nanoparticle-merino wool composites (prepared by soaking untreated semi-worsted merino wool in a $160 \mathrm{ppm}\left(8.13 \times 10^{-4} \mathrm{M}\right) \mathrm{Au}^{3+}$ solution for 24 hours at RT, followed by ageing at $50{ }^{\circ} \mathrm{C}$ for 24 or 168 hours).

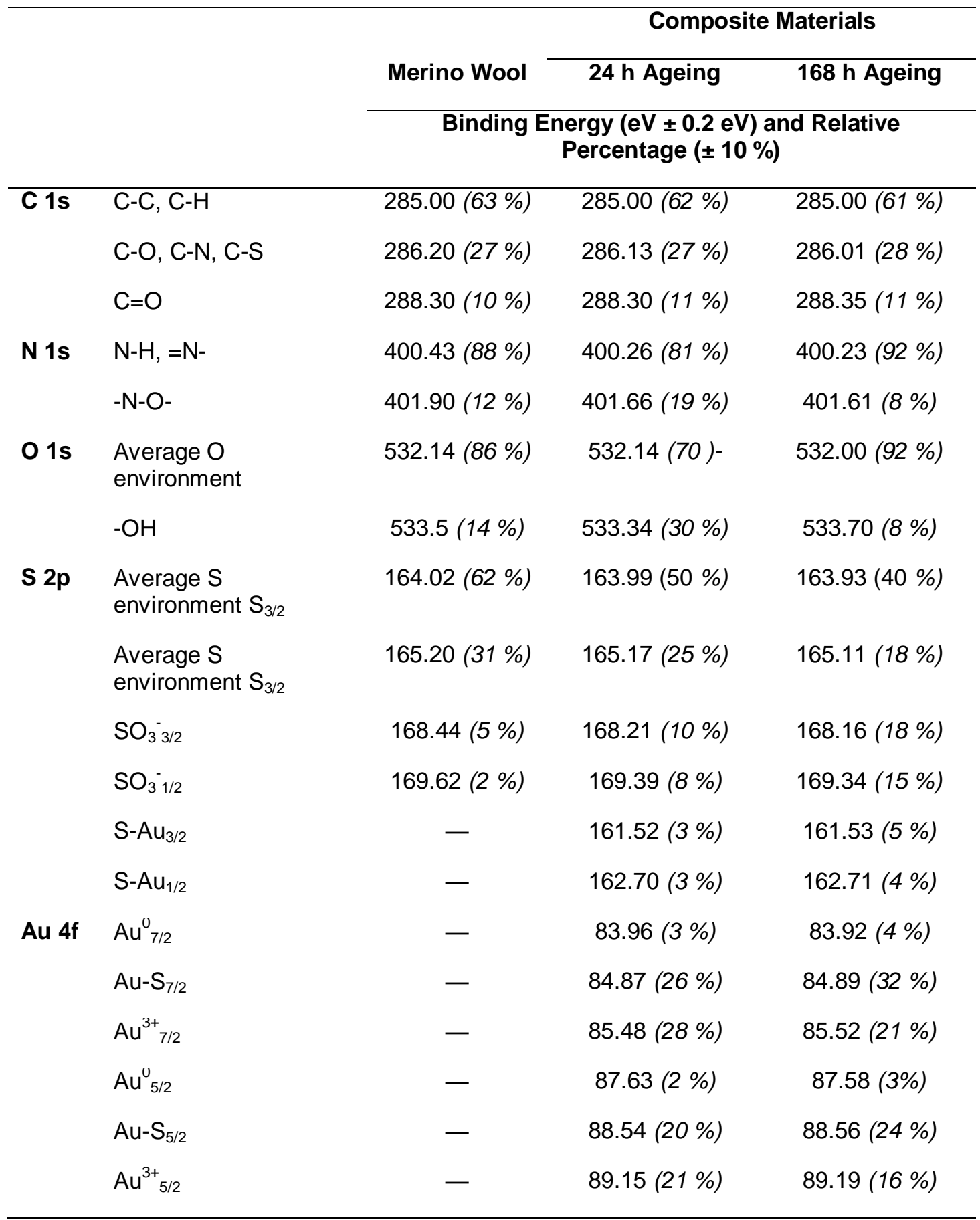

Changing the reaction conditions, such as the soaking and ageing solution composition and soaking time did not alter the way in which the gold nanoparticles bound to the merino wool fibres; the bonding was still predominantly via Au-S bonds. Figure 5.107 and Figure 5.108 offer the high resolution $\mathrm{S} 2 \mathrm{p}, \mathrm{Au} 4 \mathrm{f}, \mathrm{C} 1 \mathrm{~s}, \mathrm{~N}$ 1s and $\mathrm{O}$ 1s XPS spectra of gold nanoparticle- 
merino wool composites prepared with an ageing solution of altered $\mathrm{pH}(\mathrm{pH} 12)$ and no soaking time respectively. The peak assignments are summarised in Table 5.13. The Au-S bonding was evidenced by the appearance of the peak's centred at approximately 161.70 and $162.88 \mathrm{eV}$ in the $\mathrm{S} 2 \mathrm{p}$ spectra of the composite materials, and the peaks at approximately 85.0 and $88.6 \mathrm{eV}$ in the $\mathrm{Au} 4 \mathrm{f}$ spectra, all of which are indicative of a Au-S bond (Figure 5.107 and Figure $5.108 \mathrm{a}$ and $\mathrm{b}$ ). Additionally the peaks corresponding to amine and imine groups and oxidised nitrogen groups shifted relative to the base merino wool, which as was the case above, is likely a result of the nanoparticles bonding to the $S$ atoms in these amino acids. There was no concrete evidence of any other groups in merino wool bonding with the gold nanoparticles, as relative to the base fibre, there were no major changes in the $\mathrm{C} 1 \mathrm{~s}, \mathrm{~N}$ 1s and O 1s XPS spectra of the composites (Figure 5.107 and Figure 5.108 d).

Additionally, adjusting the $\mathrm{pH}$ of the ageing solution to 12 induced the formation of $\mathrm{Au}(\mathrm{OH})_{3}$ particles rather than $\mathrm{Au}^{0}$ nanoparticles. This was shown in the Au 4f and O 1s XPS spectra of such composite materials (Figure $5.107 \mathrm{~b}$ and e respectively). Peaks indicative of nanoparticulate $\mathrm{Au}^{0}$ (centred at approximately 84.0 and $87.6 \mathrm{eV}$ ) were much reduced in the $\mathrm{Au} 4 \mathrm{f}$ spectrum of the composites, and there was an increase in the proportion of $\mathrm{Au}^{3+}$, which combined with the peak centred at $529.8 \mathrm{eV}$ in the $\mathrm{O} 1 \mathrm{~s}$ spectrum, which is indicative of $\mathrm{Au}(\mathrm{OH})_{3}$, suggests the gold in these composites to be predominantly $\mathrm{Au}(\mathrm{OH})_{3}$. This still binds to the wool via $\mathrm{Au}-\mathrm{S}$ bonds (evidenced by the Au-S peaks in the Au $4 \mathrm{f}$ and $\mathrm{S} 2 \mathrm{p}$ spectra). 

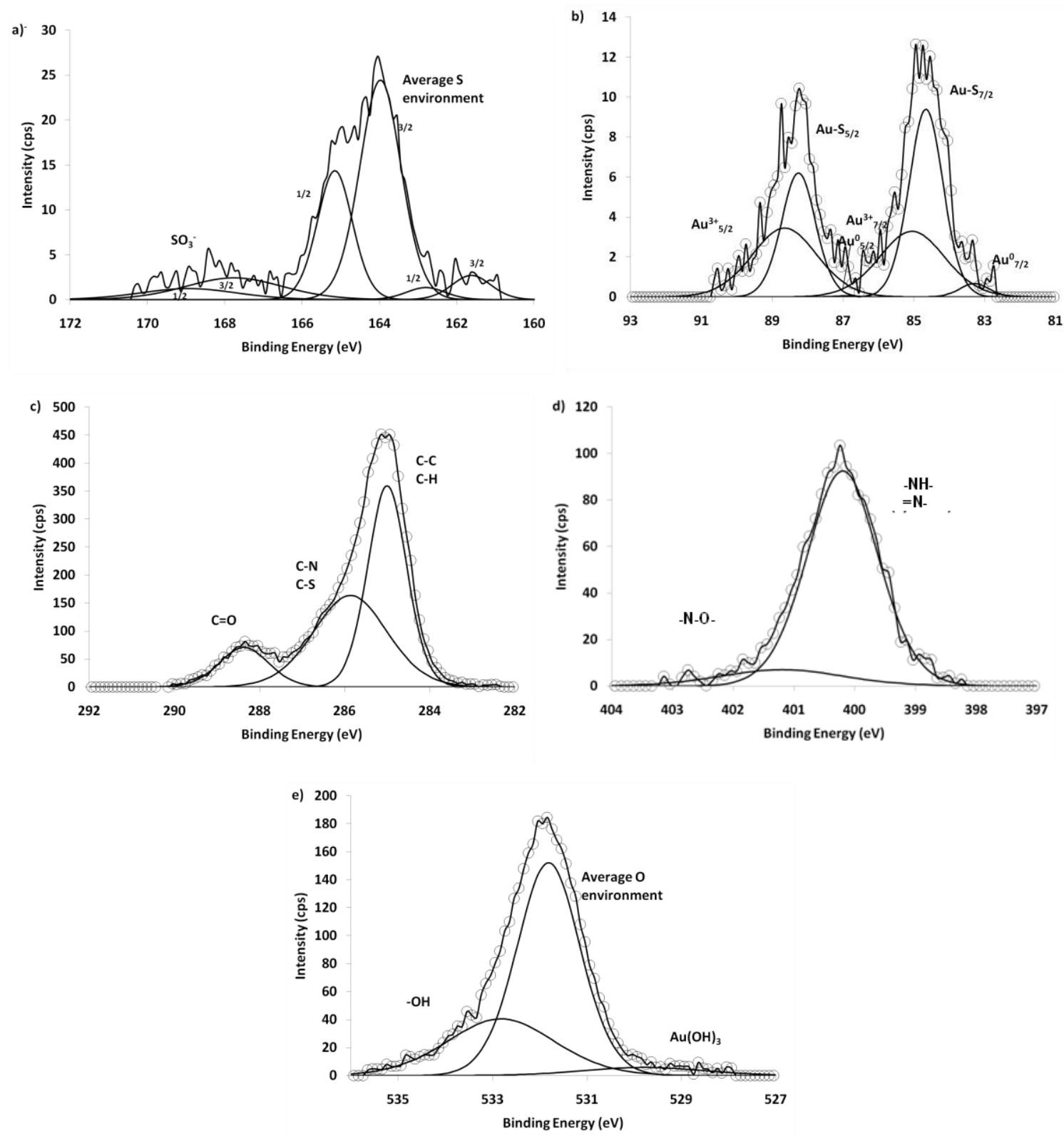

Figure 5.107: High resolution $S$ 2p (a), Au $4 \mathrm{f}(\mathrm{b}), \mathrm{C} 1 \mathrm{~s}$ (c), $\mathrm{N}$ 1s (d) and $\mathrm{O}$ 1s (e) XPS spectra of a gold nanoparticle-merino wool composite prepared by soaking untreated semi-worsted merino wool in a 160 ppm $\left(8.13 \times 10^{-4} \mathrm{M}\right) \mathrm{Au}^{3+}$ solution for 24 hours at RT, followed by adjusting the $\mathrm{pH}$ of the ageing solution to 12 and ageing at $50{ }^{\circ} \mathrm{C}$ for 168 hours. 

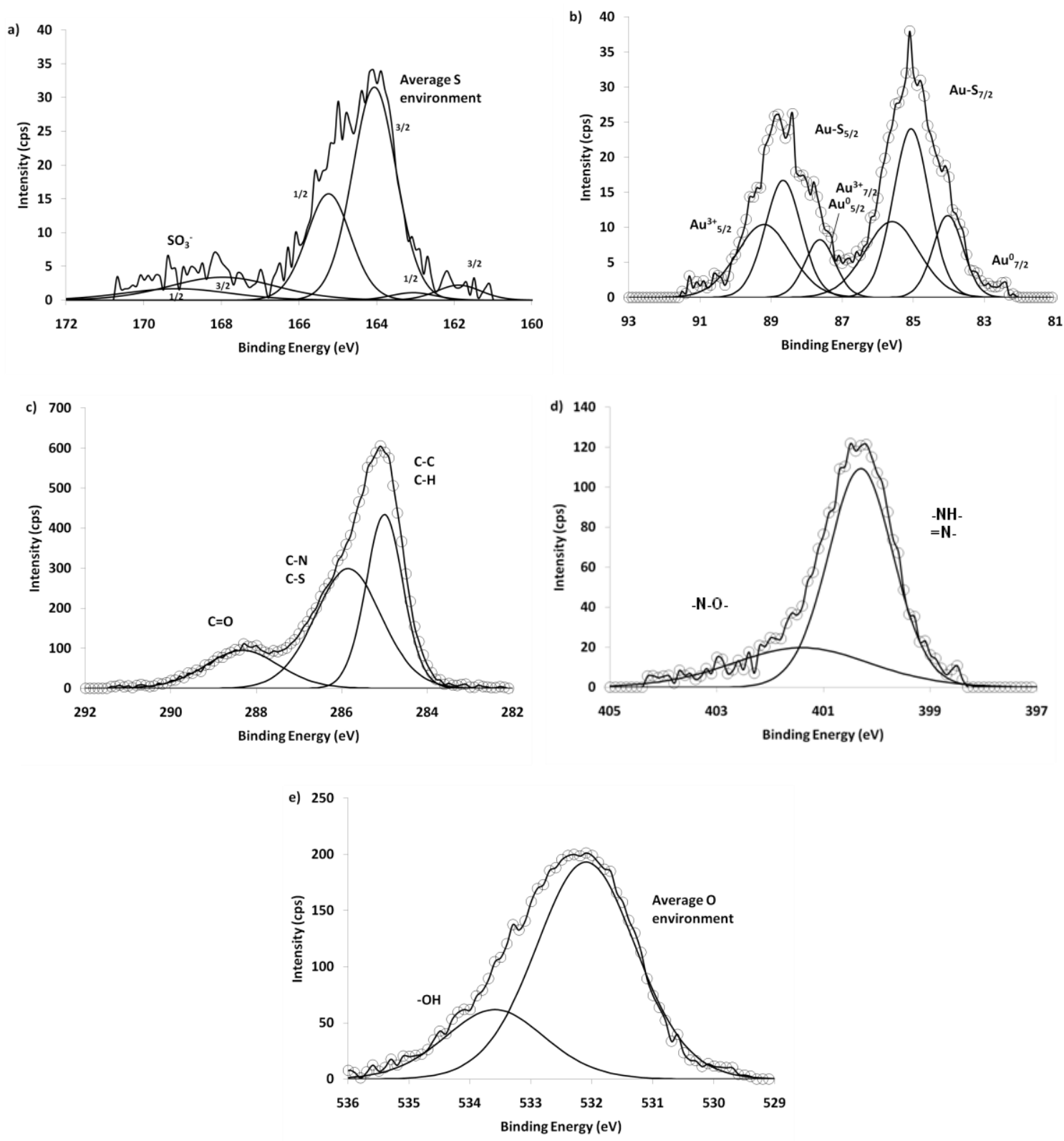

Figure 5.108: High resolution $\mathrm{S} 2 \mathrm{p}(\mathrm{a}), \mathrm{Au} 4 \mathrm{f}(\mathrm{b}), \mathrm{C} 1 \mathrm{~s}$ (c), $\mathrm{N}$ 1s (d) and $\mathrm{O}$ 1s (e) XPS spectra of a gold nanoparticle-merino wool composite prepared by ageing untreated semi-worsted merino wool in a 160 $\operatorname{ppm}\left(8.13 \times 10^{-4} \mathrm{M}\right) \mathrm{Au}^{3+}$ solution for 168 hours at $50{ }^{\circ} \mathrm{C}$. (Note, no soaking at RT prior to ageing). 
Table 5.13: XPS assignments of untreated semi-worsted merino wool and gold nanoparticle-merino wool composite materials, prepared with altered soaking and ageing solutions, soaking times and ageing temperatures.

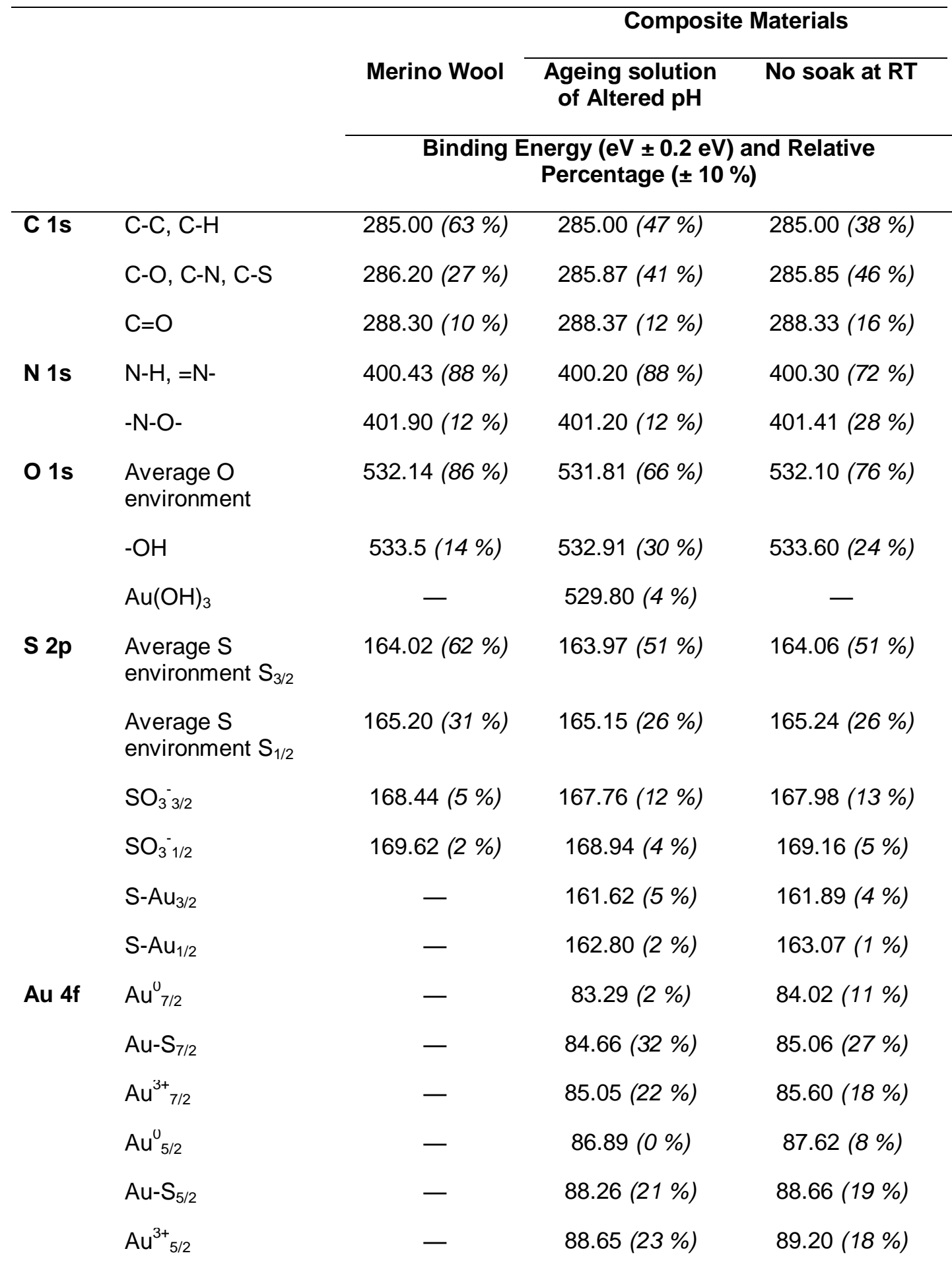




\subsubsection{KOH/MeOH Treated Semi-Worsted Gilled Sliver}

As discussed in section 5.1.4, employing $\mathrm{KOH} / \mathrm{MeOH}$ pre-treated merino wool as the fibre substrate was unsuccessful in the production of gold nanoparticle-merino wool composites, as the colour of the resultant materials was very under-developed. Comparisons drawn from SEM analysis of similarly coloured composites suggested this lack of colour to be due to the formation of an insufficient amount of nanoparticles. The high resolution $S 2 p$ and $\mathrm{Au} 4 \mathrm{f}$ spectra of these composites show gold to be present and to bond to the wool via $\mathrm{Au}-\mathrm{S}$ bonds, evidenced by the $3 / 2$ and $1 / 2$ peaks centred at 161.97 and $163.15 \mathrm{eV}$ in the $\mathrm{S} 2 \mathrm{p}$ spectrum (Figure 5.109 left), and the $\mathrm{Au}-\mathrm{S} 7 / 2$ and 5/2 peaks centred at 84.82 and $88.42 \mathrm{eV}$ respectively in the $\mathrm{Au}$ 4f spectrum (Figure 5.109 right). However the gold in these composites is present largely as unreduced $\mathrm{Au}^{3+}$ or $\mathrm{Au}^{+}$(in the form of $\mathrm{Au}-\mathrm{S}$ ). No nanoparticulate $\mathrm{Au}^{0}$, (illustrated by peaks centred at approximately 84 and $87.6 \mathrm{eV}$ ) is evident. As with gold nanoparticle-merino wool composites employing untreated semiworsted merino wool as the fibre substrate, there was insufficient evidence to suggest bonding to alternate groups, as there were no major changes in the $\mathrm{C} 1 \mathrm{~s}, \mathrm{~N} 1 \mathrm{~s}$ and $\mathrm{O} 1 \mathrm{~s}$ spectra upon incorporation of the gold nanoparticles. (These spectra are not shown).
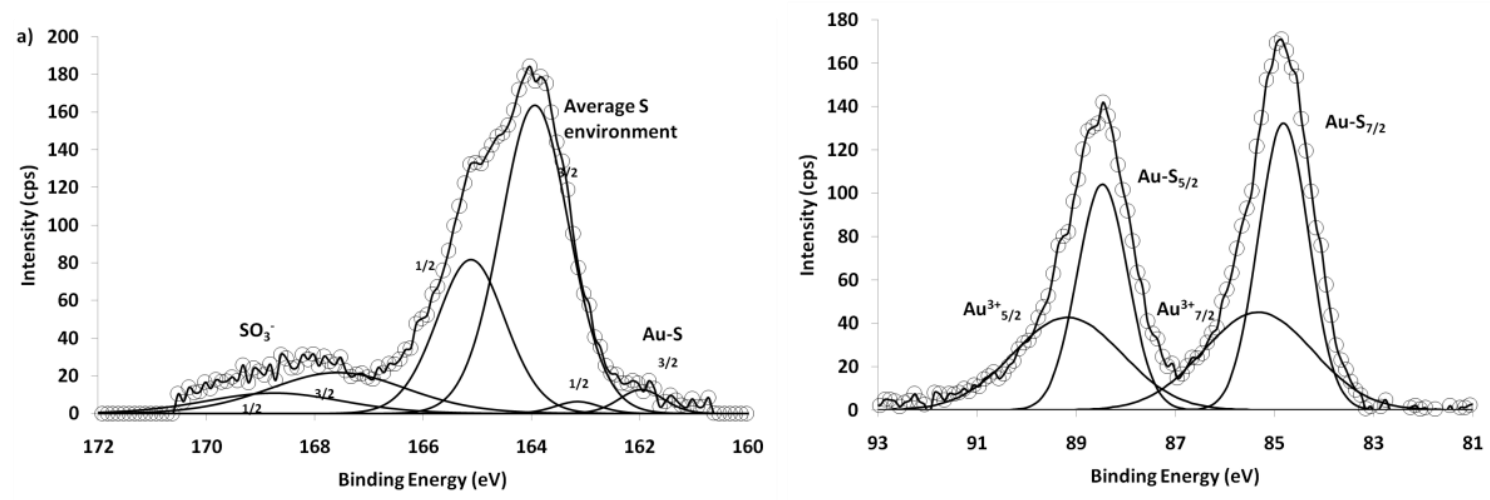

Figure 5.109: High resolution S 2p (left) and Au 4 f (right) XPS spectra of a gold nanoparticle-merino wool composite prepared by soaking $\mathrm{KOH} / \mathrm{MeOH}$ treated semi-worsted merino wool in a $160 \mathrm{ppm}(8.13$ $\left.\times 10^{-4} \mathrm{M}\right) \mathrm{Au}^{3+}$ solution for 24 hours at RT, followed by ageing at $50{ }^{\circ} \mathrm{C}$ for 168 hours. 
Table 5.14: XPS assignments for $\mathrm{KOH} / \mathrm{MeOH}$ treated semi-worsted merino wool and gold nanoparticlemerino wool composites (prepared by soaking $\mathrm{KOH} / \mathrm{MeOH}$ treated semi-worsted merino wool in a 160 $\operatorname{ppm}\left(8.13 \times 10^{-4} \mathrm{M}\right) \mathrm{Au}^{3+}$ solution for 24 hours at RT, followed by ageing at $50{ }^{\circ} \mathrm{C}$ for 24 or $\left.168 \mathrm{hours}\right)$. $\mathrm{KOH} / \mathrm{MeOH}$ Treated Composite

\begin{tabular}{|c|c|c|c|}
\hline & & Merino Woo & 168 h Ageing \\
\hline & & \multicolumn{2}{|c|}{$\begin{array}{c}\text { Binding Energy }(\mathrm{eV} \pm 0.2 \mathrm{eV}) \text { and Relative } \\
\text { Percentage }( \pm 10 \%)\end{array}$} \\
\hline \multirow[t]{3}{*}{ C 1s } & $\mathrm{C}-\mathrm{C}, \mathrm{C}-\mathrm{H}$ & 285.00 (33 \%) & 285.00 (55 \%) \\
\hline & C-O, C-N, C-S & 286.20 (25 \%) & 286.20 (25 \%) \\
\hline & $\mathrm{C}=\mathrm{O}$ & 288.20 (42 \%) & 288.09 (20\%) \\
\hline \multirow[t]{2}{*}{ N 1s } & $\mathrm{N}-\mathrm{H},=\mathrm{N}-$ & 400.46 (46\%) & 400.54 (64\%) \\
\hline & $-\mathrm{N}-\mathrm{O}-$ & 402.51 (54 \%) & 401.53 (36 \%) \\
\hline \multirow[t]{2}{*}{$01 \mathrm{~s}$} & $\begin{array}{l}\text { Average } \mathrm{O} \\
\text { environment }\end{array}$ & 531.8 (40 \%) & 531.92 (62 \%) \\
\hline & $-\mathrm{OH}$ & $533.53(60 \%)$ & 533.00 (38 \%) \\
\hline \multirow[t]{6}{*}{ S 2p } & $\begin{array}{l}\text { Average } \mathrm{S} \\
\text { environment } \mathrm{S}_{3 / 2}\end{array}$ & 163.98 (55 \%) & 163.94 (48 \%) \\
\hline & $\begin{array}{l}\text { Average } S \\
\text { environment } S_{1 / 2}\end{array}$ & $165.19(27 \%)$ & 165.12 (24\%) \\
\hline & $\mathrm{SO}_{3}^{-}{ }_{3 / 2}$ & $167.37(10 \%)$ & 167.58 (13\%) \\
\hline & $\mathrm{SO}_{31 / 2}^{-}$ & 168.55 (8 \%) & 168.76 (11\%) \\
\hline & $\mathrm{S}-\mathrm{Au}_{3 / 2}$ & - & 162.00 (2 \%) \\
\hline & $S-A u_{1 / 2}$ & - & 163.15 (2 \%) \\
\hline \multirow[t]{6}{*}{ Au $4 f$} & $A u_{7 / 2}^{0}$ & - & - \\
\hline & $\mathrm{Au}-\mathrm{S}_{7 / 2}$ & - & 84.82 (31\%) \\
\hline & $\mathrm{Au}^{3+}{ }_{7 / 2}$ & - & 85.51 (23 \%) \\
\hline & $A u_{5 / 2}^{0}$ & - & - \\
\hline & $A u-S_{5 / 2}$ & - & 88.42 (24 \%) \\
\hline & $\mathrm{Au}^{3+}{ }_{5 / 2}$ & - & 89.11 (22\%) \\
\hline
\end{tabular}

\subsubsection{Untreated Worsted Combed Top}

The bonding between the gold nanoparticles and untreated worsted combed top was the same as that between the nanoparticles and untreated semi-worsted merino wool; notably via $\mathrm{Au}-\mathrm{S}$ bonds. Again this was evidenced by the $3 / 2$ and $1 / 2$ peaks centred at 161.50 and $162.68 \mathrm{eV}$ 
in the S 2p spectra of a composite (prepared by soaking untreated worsted merino wool in a $160 \mathrm{ppm}\left(8.13 \times 10^{-4} \mathrm{M}\right) \mathrm{Au}^{3+}$ solution for 24 hours at RT, followed by ageing at $50{ }^{\circ} \mathrm{C}$ for 168 hours) (Figure 5.110, Table 5.15). Additionally, the predominant peaks in the Au $4 \mathrm{f}$ spectra of the composites were those indicative of a Au-S bond, present at 84.86 and 88.55 $\mathrm{eV}$ (Figure 5.111). There were also slight shifts and broadening of the amine, imine and oxidised nitrogen peaks N-C (Figure $5.113 \mathrm{c}$ and d). This was also the case in composites incorporating semi-worsted merino wool and is therefore likely reflective of the gold nanoparticles bonding to the sulfur atoms in the main $\mathrm{S}$ containing amino acids rather than indicating direct $\mathrm{Au}-\mathrm{N}$ bonds, as these are not seen in the $\mathrm{C} 1 \mathrm{~s}$ or $\mathrm{Au} 4 \mathrm{f}$ spectra of the composites.
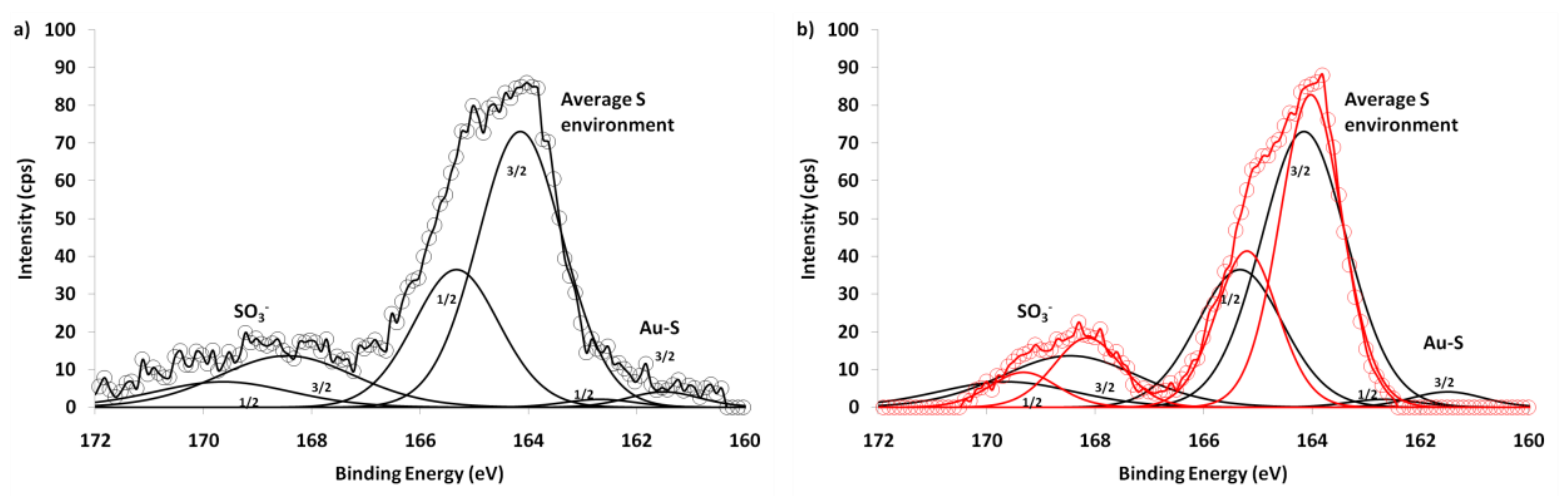

Figure 5.110: a) high resolution S 2p XPS spectra of gold nanoparticle-merino wool composites prepared by soaking untreated worsted merino wool in a $160 \mathrm{ppm}\left(8.13 \times 10^{-4} \mathrm{M}\right) \mathrm{Au}^{3+}$ solution for 24 hours at RT, followed by ageing at $50{ }^{\circ} \mathrm{C}$ for 168 hours. b) an overlay (in red) of untreated worsted merino wool.

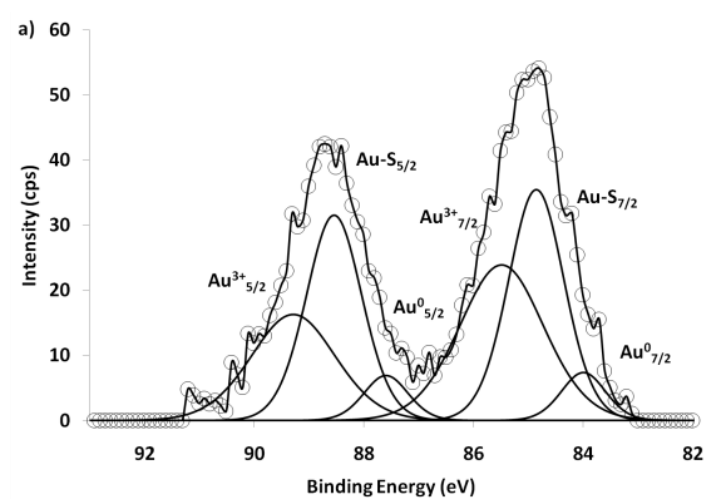

Figure 5.111: a) high resolution Au 4f XPS spectra of a gold nanoparticle-merino wool composite prepared by soaking untreated worsted merino wool in a $160 \mathrm{ppm}\left(8.13 \times 10^{-4} \mathrm{M}\right) \mathrm{Au}^{3+}$ solution for 24 hours at RT, followed by ageing at $50{ }^{\circ} \mathrm{C}$ for 168 hours. 
Comparing the $\mathrm{C} 1 \mathrm{~s}, \mathrm{~N}$ 1s and $\mathrm{O}$ 1s spectra of the composite materials to those of worsted merino wool, revealed very slight changes (Figure 5.112, Figure 5.113, Table 5.15). In the C 1s spectrum there is an increase in intensity and area of the peak centred at $286.2 \mathrm{eV}$, representative of $\mathrm{C}-\mathrm{N}, \mathrm{C}-\mathrm{S}$ and $\mathrm{C}-\mathrm{O}$ bonding. As there are no corresponding changes in other spectra to account for the increase in the amount of C-N, C-S and C-O species on the composite surface, it is likely that this change is due to impurities introduced to the samples (it is very easy to introduce carbon based impurities to materials during sample preparation, particularly in the form of oil etc).
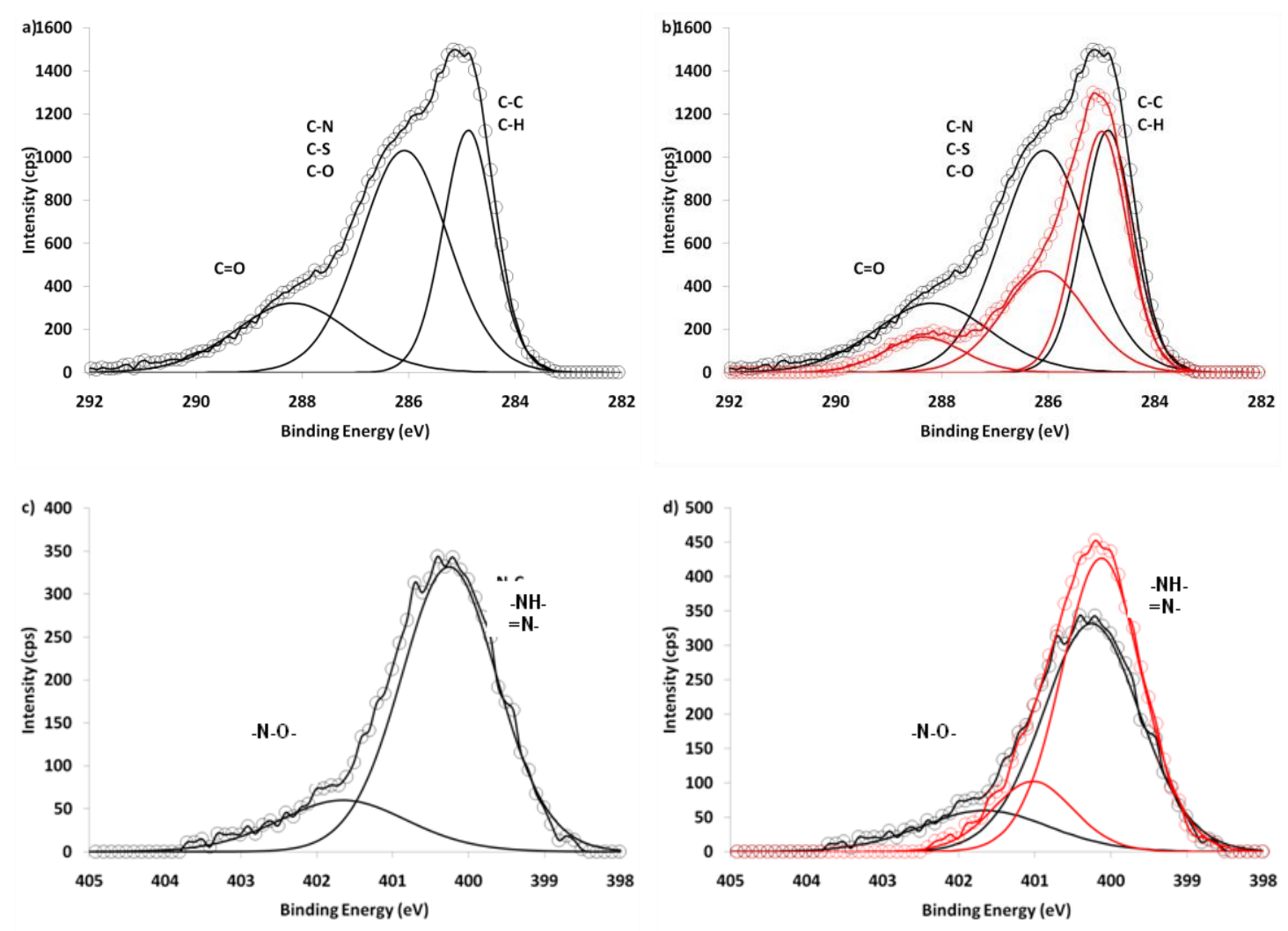

Figure 5.112: High resolution C 1s (a) and N 1s (c) XPS spectra of a gold nanoparticle merino wool composite prepared by soaking untreated worsted merino wool in a $160 \mathrm{ppm}\left(8.13 \times 10^{-4} \mathrm{M}\right) \mathrm{Au}^{3+}$ solution for 24 hours at RT, followed by ageing at $50{ }^{\circ} \mathrm{C}$ for 168 hours. b) and d) and f) show an overlay or the corresponding spectra of untreated worsted merino wool (in red). 

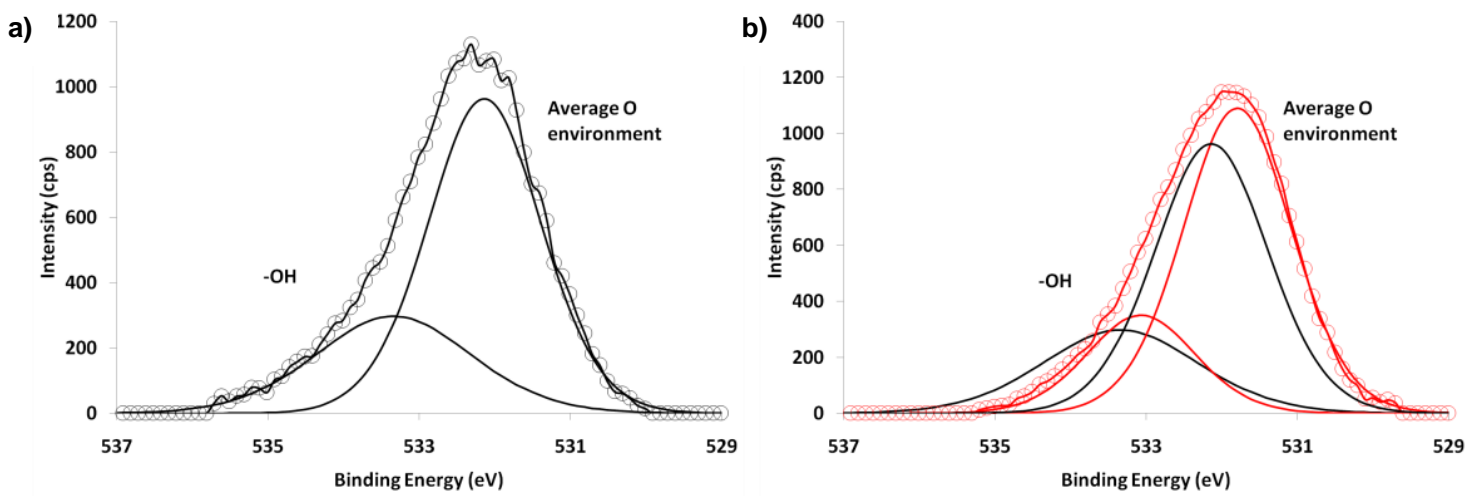

Figure 5.113: High resolution $O$ 1s (a) XPS spectra of a gold nanoparticle merino wool composite prepared by soaking untreated worsted merino wool in a $160 \mathrm{ppm}\left(8.13 \times 10^{-4} \mathrm{M}\right) \mathrm{Au}^{3+}$ solution for 24 hours at RT, followed by ageing at $50{ }^{\circ} \mathrm{C}$ for 168 hours. b) shows an overlay or the corresponding spectra of untreated worsted merino wool (in red).

Table 5.15: XPS assignments for a gold nanoparticle-merino wool composite material employing worsted merino wool as the fibre substrate, a $\mathrm{Au}^{3+}$ concentration of $160 \mathrm{ppm}\left(8.13 \times 10^{-4} \mathrm{M}\right)$, a soaking time, at RT, of 24 hours and an ageing time, at $50^{\circ} \mathrm{C}$ or 168 hours.

\begin{tabular}{|c|c|c|c|}
\hline & & & Composite \\
\hline & & Worsted Merino Wool & $168 \mathrm{~h}$ Ageing \\
\hline & & $\begin{array}{r}\text { Binding Energy (eV } \\
\text { Percenta }\end{array}$ & $\begin{array}{l}2 \mathrm{eV}) \text { and Relative } \\
( \pm 10 \%)\end{array}$ \\
\hline C 1s & $\mathrm{C}-\mathrm{C}, \mathrm{C}-\mathrm{H}$ & $285.00(52 \%)$ & 285.00 (31\%) \\
\hline & $\mathrm{C}-\mathrm{O}, \mathrm{C}-\mathrm{N}, \mathrm{C}-\mathrm{S}$ & 286.07 (36 \%) & 286.2 (49 \%) \\
\hline & $\mathrm{C}=\mathrm{O}$ & 288.34 (12\%) & 288.3 (20 \%) \\
\hline N 1 s & $\mathrm{N}-\mathrm{H},=\mathrm{N}-$ & $400.13(81 \%)$ & $400.28(63 \%)$ \\
\hline & $-\mathrm{N}-\mathrm{O}-$ & 401.03 (19 \%) & 401.59 (37 \%) \\
\hline $01 \mathrm{~s}$ & $\begin{array}{l}\text { Average } \mathrm{O} \\
\text { environment }\end{array}$ & $531.80(76 \%)$ & 532.11 (68 \%) \\
\hline & $-\mathrm{OH}$ & 533.07 (24 \%) & 533.92 (32 \%) \\
\hline S 2p & $\begin{array}{l}\text { Average } S \\
\text { environment } S_{3 / 2}\end{array}$ & $164.03(51 \%)$ & $164.15(50 \%)$ \\
\hline & $\begin{array}{l}\text { Average } S \\
\text { environment } S_{1 / 2}\end{array}$ & $165.21(26 \%)$ & $165.33(25 \%)$ \\
\hline & $\mathrm{SO}_{3}^{-}{ }_{3 / 2}$ & $168.15(13 \%)$ & $168.46(15 \%)$ \\
\hline & $\mathrm{SO}_{31 / 2}^{-}$ & $169.33(10 \%)$ & $169.64(7 \%)$ \\
\hline & $\mathrm{S}-\mathrm{Au}_{3 / 2}$ & - & 161.50 (2 \%) \\
\hline & $S-A u_{1 / 2}$ & & 162.68 (1\%) \\
\hline Au $4 f$ & $A u_{7 / 2}^{U}$ & - & 84.62 (13 \%) \\
\hline & $\mathrm{Au}-\mathrm{S}_{7 / 2}$ & - & $85.22(27 \%)$ \\
\hline & $\mathrm{Au}_{7 / 2}^{3+}$ & - & $85.92(30 \%)$ \\
\hline & $\mathrm{Au}_{5 / 2}^{0}$ & - & $88.22(5 \%)$ \\
\hline & $A u-S_{5 / 2}$ & - & $88.82(13 \%)$ \\
\hline & $\mathrm{Au}_{5 / 2}^{3+}$ & - & 89.52 (12\%) \\
\hline
\end{tabular}




\subsubsection{Chlorine Hercosett Treated Semi-Worsted Gilled Sliver}

Figure 5.114 offers the EDS spectrum of a gold nanoparticle-merino wool composite prepared from $\mathrm{Cl} / \mathrm{H}$ treated merino wool, whilst Figure 5.115 offers the cross sectional SEM and corresponding EDS micrographs. This composite material was prepared by soaking $\mathrm{Cl} / \mathrm{H}$ treated merino wool in a $160 \mathrm{ppm}\left(8.13 \times 10^{-4} \mathrm{M}\right) \mathrm{Au}^{3+}$ solution for 24 hours at RT, followed by ageing at $50{ }^{\circ} \mathrm{C}$ for 168 hours. As with the composites prepared from untreated merino wool, both the EDS spectrum (Figure 5.114) and maps (Figure 5.115) show the composites prepared from $\mathrm{Cl} / \mathrm{H}$ treated merino wool to consist of the main elements of merino wool, notably carbon, nitrogen, sulfur and oxygen. There are also low concentrations of chlorine present, again likely a residual of $\mathrm{AuCl}_{4}{ }^{-}$, and also remaining from the oxidation of the wool fibres during the $\mathrm{Cl} / \mathrm{H}$ treatment. As discussed previously in section $\mathbf{5 . 1 . 5}$, cross sectional EDS analysis showed that the gold in these composites was not confined to the surface of the fibres, rather it spread throughout the centre. However when viewed under the SEM, nanoparticles were not evident in the fibre centre. As with all other composite materials, there is the suggestion of $\mathrm{Au}-\mathrm{S}$ interactions between the gold nanoparticles and wool fibre, as where there are high concentrations of sulfur, there are also high concentrations of gold.

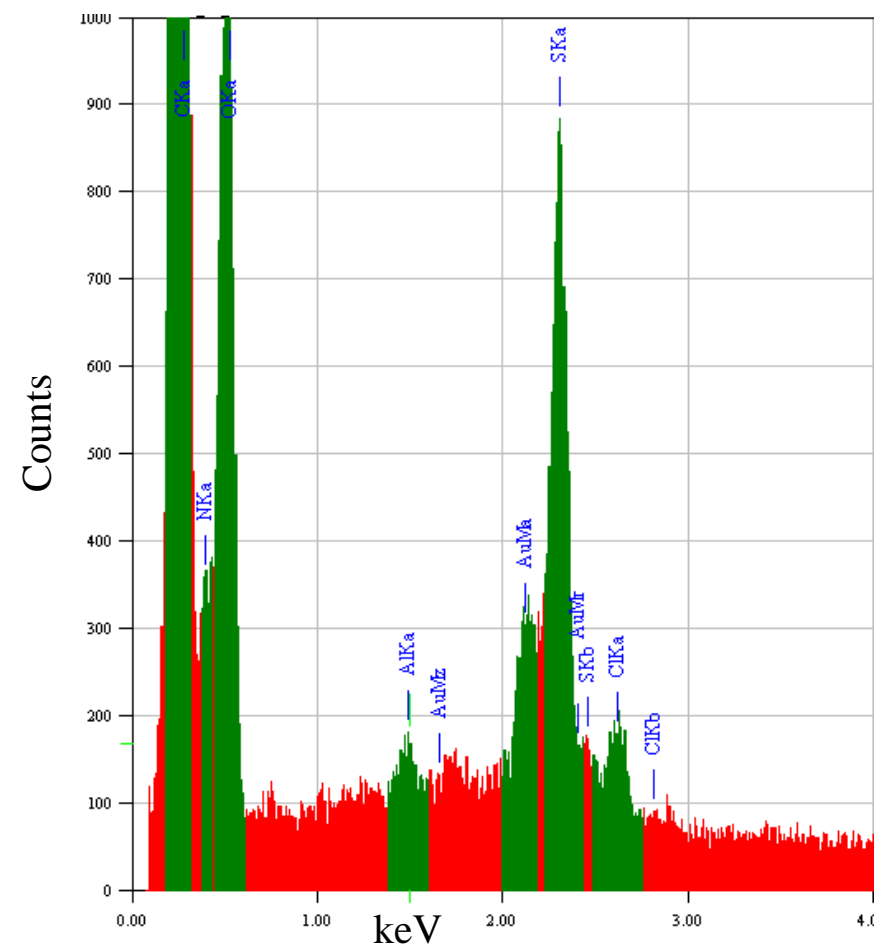

Figure 5.114: EDS spectrum of a gold nanoparticle-merino wool composite material prepared by soaking $\mathrm{Cl} / \mathrm{H}$ treated semi-worsted merino wool in a $160 \mathrm{ppm}\left(8.13 \times 10^{-4} \mathrm{M}\right) \mathrm{Au}^{3+}$ solution for 24 hours at RT, followed by ageing at $50{ }^{\circ} \mathrm{C}$ for 168 hours. 

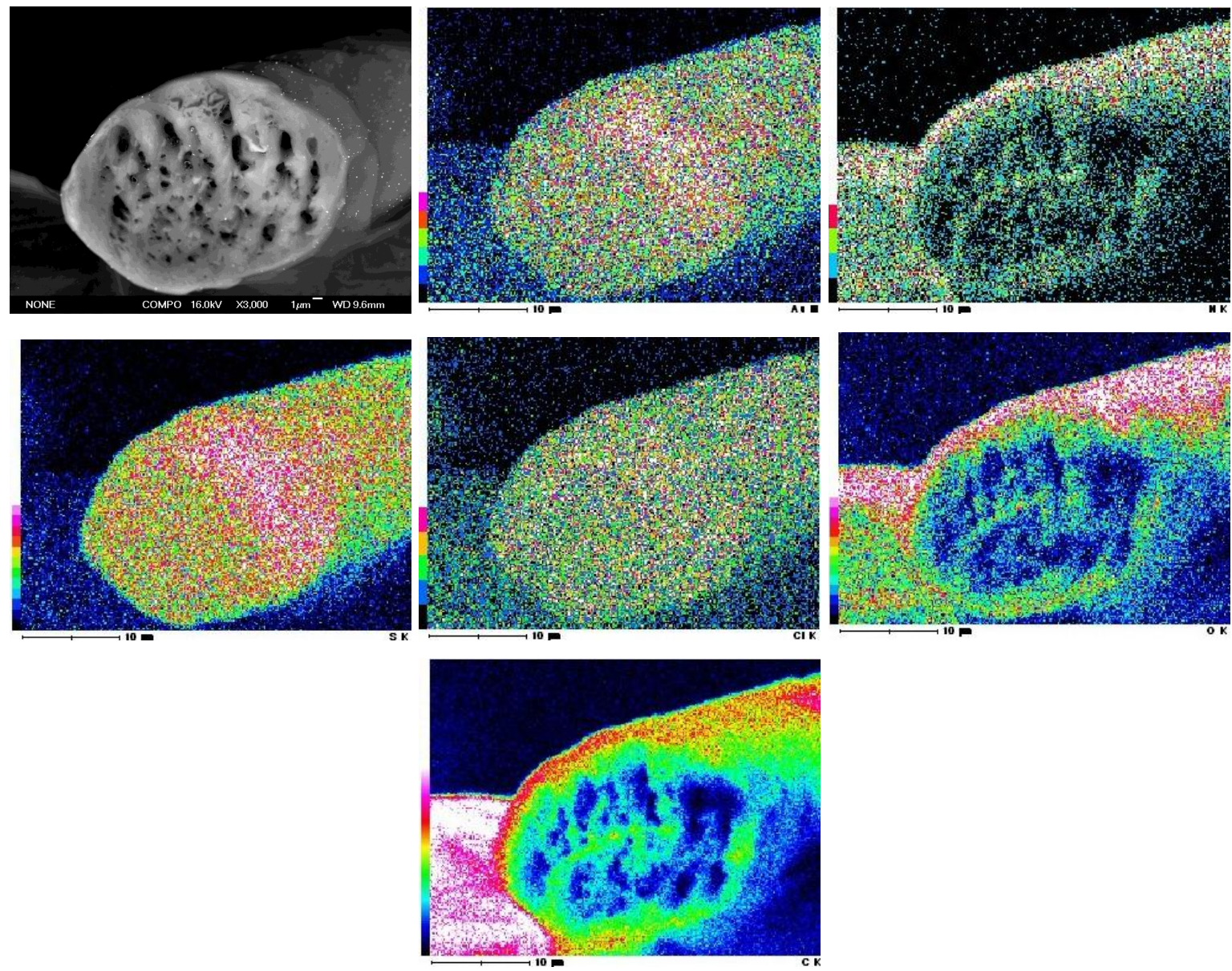

Figure 5.115: Cross sectional SEM micrograph and corresponding EDS micrographs of a gold nanoparticle-merino wool composite material, prepared by soaking $\mathrm{Cl} / \mathrm{H}$ treated semi-worsted merino wool in a $160 \mathrm{ppm}\left(8.13 \times 10^{-4} \mathrm{M}\right) \mathrm{Au}^{3+}$ solution for 24 hours at RT, followed by ageing at $50{ }^{\circ} \mathrm{C}$ for 168 hours.

XPS confirmed the bonding between the nanoparticles and wool fibre to be via Au-S bonding. It also suggested bonding of the gold nanoparticles to nitrogen groups. A comprehensive list of XPS peak assignments is provided in Table 5.16 below. The Au-S bonding was illustrated when comparing the high resolution, deconvoluted S 2p XPS spectra of the composites to that of the base fibre, $\mathrm{Cl} / \mathrm{H}$ treated merino wool (Figure $5.116 \mathrm{a}$ and $\mathrm{b}$ ). Both spectra show the $S 2 / 3$ and $1 / 2$ peaks representing the average sulfur environment of wool (S-H groups of cysteine and S-S groups of cystine), however the major peak's are the $3 / 2$ and $1 / 2$ peaks of cysteic acid $\left(-\mathrm{SO}_{3}{ }^{-}\right)$, the product of the oxidation of disulfide groups of cystine (occurring during the $\mathrm{Cl} / \mathrm{H}$ treatment (see section 1.2.2.1.5)), accounting for approximatley $88 \%$ of the sulfur species, compared to approximatley $7 \%$ in untreated merino wool. Additionally, the $S 2 p$ spectrum of the composite also displayed a small set of 
peaks centred at 161.94 and $163.12 \mathrm{eV}$, which are representative of Au-S bonding, confirming the bonding between the gold nanoparticles and $\mathrm{Cl} / \mathrm{H}$ treated merino wool fibres to occur through $\mathrm{S}$ atoms in the protein constituent of wool. This Au-S bonding was also shown in the $\mathrm{Au} 4 \mathrm{f}$ spectrum of the composite (Figure $5.116 \mathrm{c}$ ). As in the materials incorporating untreated merino wool as the fibre substrate, peaks indicating Au-S bonds, centred at 84.9 and $88.5 \mathrm{eV}$ are present.
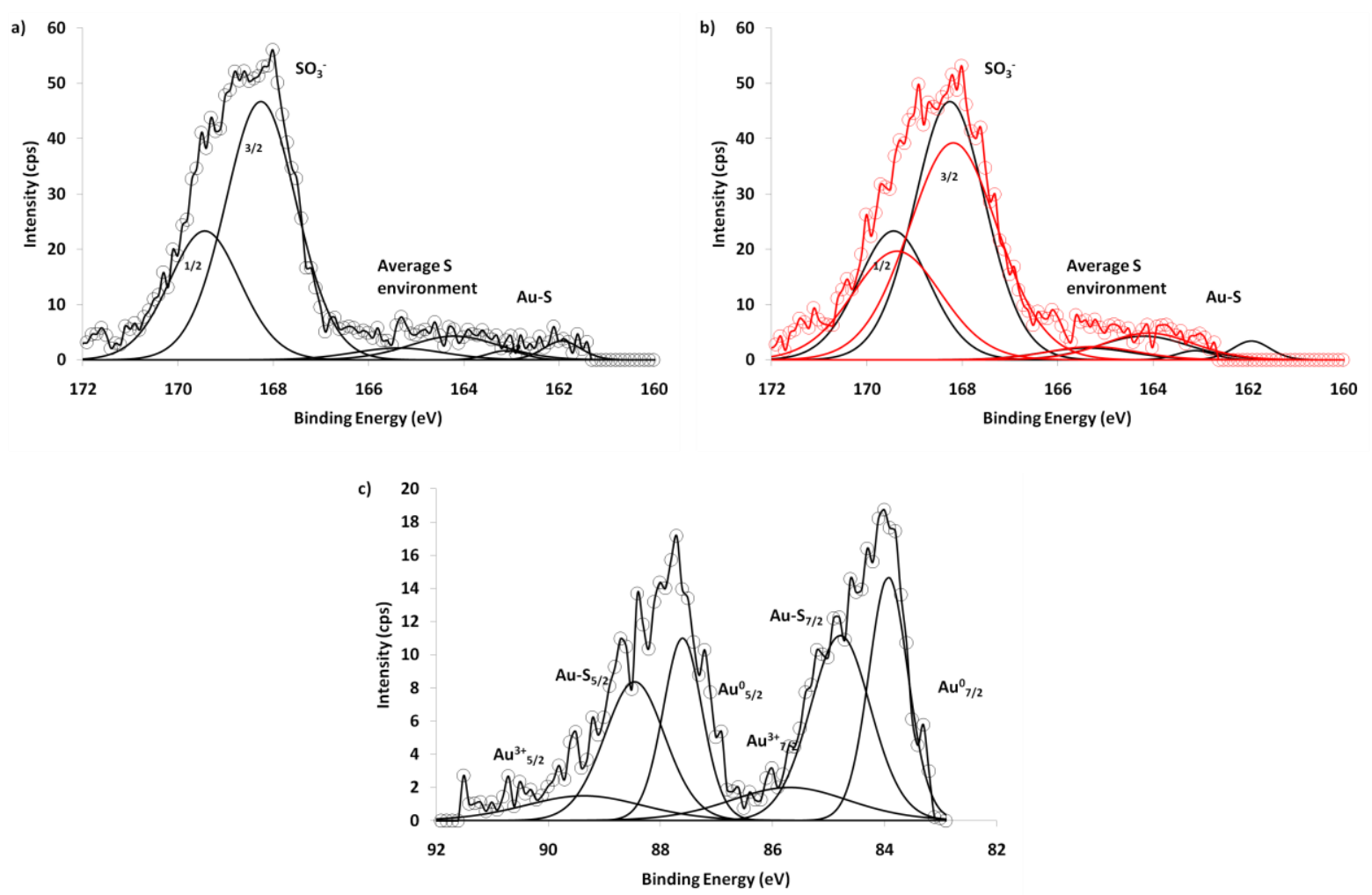

Figure 5.116: High resolution $S$ 2p (a) and Au 4f (c) XPS spectra of gold nanoparticle-merino wool composites prepared by soaking $\mathrm{Cl} / \mathrm{H}$ treated merino wool in a $160 \mathrm{ppm}\left(8.13 \times 10^{-4} \mathrm{M}\right) \mathrm{Au}^{3+}$ solution for 24 hours at RT, followed by ageing at $50{ }^{\circ} \mathrm{C}$ for 168 hours. b) An overlay (in red) of the S 2p XPS spectrum of $\mathrm{Cl} / \mathrm{H}$ treated merino wool.

In addition to bonding to sulfur groups, the gold nanoparticles also appeared to bond to the wool via Au-N bonds. This was evidenced by the appearance of the peak centred at 397.53 $\mathrm{eV}$ in the $\mathrm{N}$ 1s spectrum of the composites.[201] This peak was absent in the $\mathrm{N}$ 1s spectrum of $\mathrm{Cl} / \mathrm{H}$ treated merino wool (Figure 5.117). Additionally the $\mathrm{N}$ peaks of amine, imine and oxidised $\mathrm{N}$ groups shifted slightly, indicating the involvement of these groups (through either or both the $\mathrm{N}$ or $\mathrm{S}$ atoms) in bonding to the gold nanoparticles. 

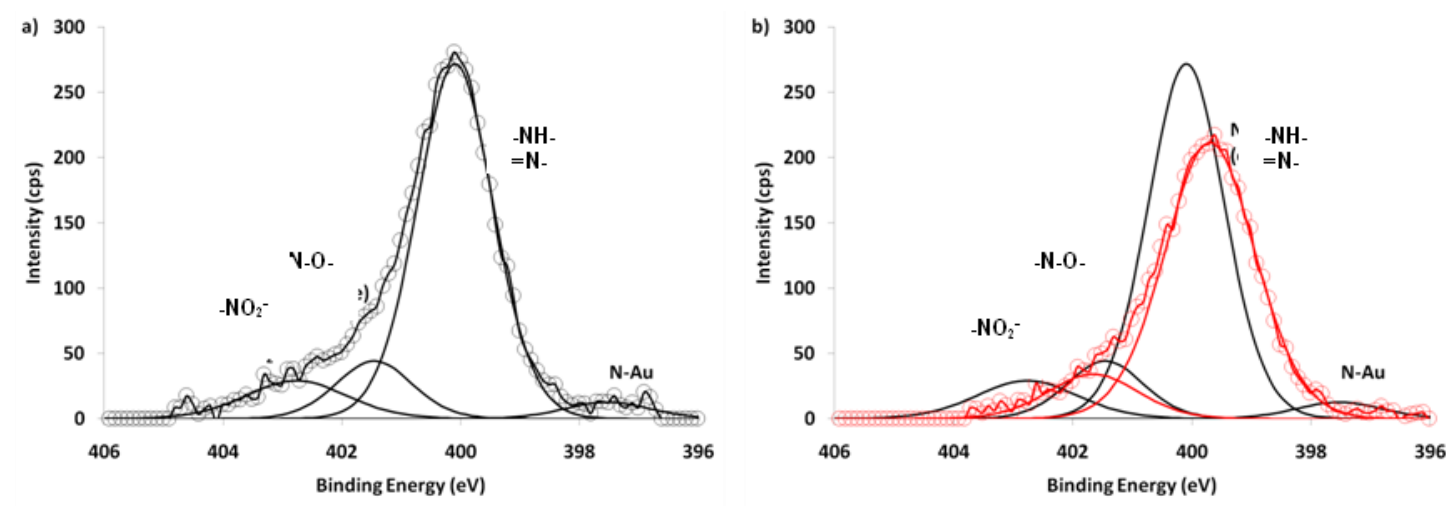

Figure 5.117: a) High resolution $N$ 1s spectra of a gold nanoparticle-merino wool composite prepared by soaking $\mathrm{Cl} / \mathrm{H}$ treated merino wool in a $160 \mathrm{ppm}\left(8.13 \times 10^{-4} \mathrm{M}\right) \mathrm{Au}^{3+}$ solution for 24 hours at RT, followed by ageing at $50{ }^{\circ} \mathrm{C}$ for 168 hours. b) An overlay (in red) of the $\mathrm{N} 1 \mathrm{~s}$ XPS spectrum of $\mathrm{Cl} / \mathrm{H}$ treated merino wool.

Comparing the high resolution $\mathrm{C} 1 \mathrm{~s}$ and $\mathrm{O} 1 \mathrm{~s}$ XPS spectra of the composites to that of the base fibre, $\mathrm{Cl} / \mathrm{H}$ treated merino wool does not yield any further information about the mode of bonding between the gold nanoparticles and wool fibres (Figure 5.118), as there are only very minimal changes in these spectra upon inclusion of the gold nanoparticles.
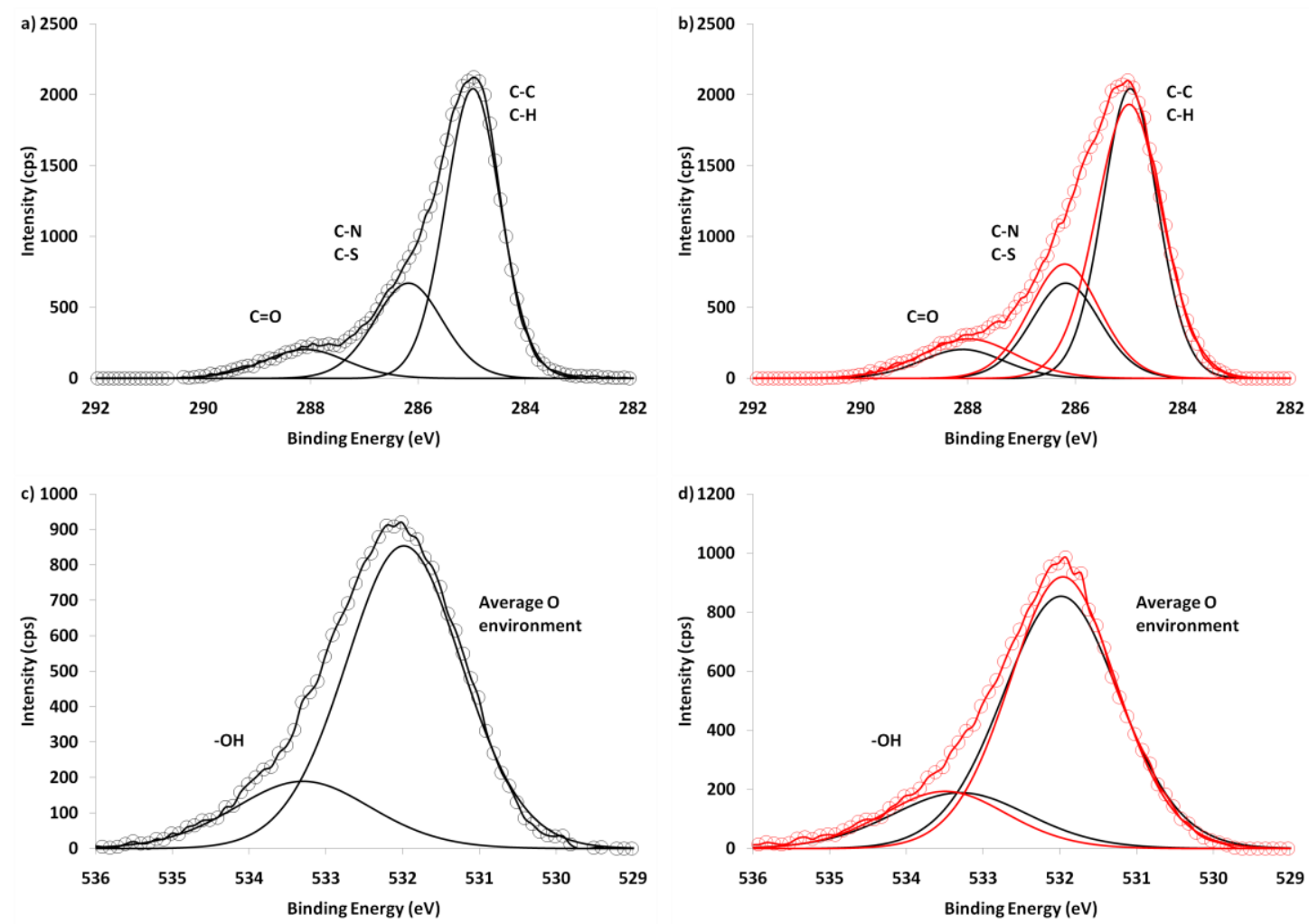

Figure 5.118: High resolution $C$ 1s (a) and $O$ 1s (c) XPS spectra of gold nanoparticle-merino wool composites prepared by soaking $\mathrm{Cl} / \mathrm{H}$ treated merino wool in a $160 \mathrm{ppm}\left(8.13 \times 10^{-4} \mathrm{M}\right) \mathrm{Au}^{3+}$ solution for 24 hours at RT, followed by ageing at $50{ }^{\circ} \mathrm{C}$ for 168 hours. b and d) offer an overlay (in red) of the $\mathrm{C} 1 \mathrm{~s}$ and $\mathrm{O} 1 \mathrm{~s}$ XPS spectrum of $\mathrm{Cl} / \mathrm{H}$ treated merino wool respectively. 
Table 5.16: XPS assignments for $\mathrm{Cl} / \mathrm{H}$ treated semi-worsted merino wool and gold nanoparticle-merino wool composites (prepared by soaking $\mathrm{Cl} / \mathrm{H}$ treated merino wool in a $160 \mathrm{ppm}\left(8.13 \times 10^{-4} \mathrm{M}\right) \mathrm{Au}^{3+}$ solution for 24 hours at RT, followed by ageing at $50{ }^{\circ} \mathrm{C}$ for 168 hours).

\begin{tabular}{|c|c|c|c|}
\hline & & $\begin{array}{c}\mathrm{Cl} / \mathrm{H} \text { Treated Merino } \\
\text { Wool }\end{array}$ & $\begin{array}{l}\text { Gold Nanoparticle-Merino } \\
\text { Wool Composite }\end{array}$ \\
\hline & & Binding Energy $(e V \pm c$ & $\begin{array}{l}\text { V) and Relative Percentage } \\
0 \%)\end{array}$ \\
\hline C 1s & $\mathrm{C}-\mathrm{C}, \mathrm{C}-\mathrm{H}$ & $285.00(61 \%)$ & 285.00 (64 \%) \\
\hline & C-O, C-N, C-S & 286.20 (27\%) & 268.18 (26 \%) \\
\hline & $\mathrm{C}=\mathrm{O}$ & 288.00 (12\%) & $288.10(10 \%)$ \\
\hline N 1s & $\mathrm{N}-\mathrm{H},=\mathrm{N}-$ & 399.70 (86 \%) & 400.09 (75\%) \\
\hline & $\mathrm{N}-\mathrm{O}$ & 401.66 (14\%) & 401.46 (12\%) \\
\hline & $\mathrm{NO}_{2}^{-}$ & - & 402.77 (11\%) \\
\hline & $\mathrm{N}-\mathrm{Au}$ & - & 397.53 (2 \%) \\
\hline $01 \mathrm{~s}$ & $\begin{array}{l}\text { Average } \mathrm{O} \\
\text { environment }\end{array}$ & 531.97 (94\%) & 531.99 (79\%) \\
\hline & $-\mathrm{OH}$ & 533.50 (6 \%) & 533.30 (21\%) \\
\hline S 2p & $\begin{array}{l}\text { Average S } \\
\text { environment } S_{3 / 2}\end{array}$ & $164.10(6 \%)$ & 164.20 (6 \%) \\
\hline & $\begin{array}{l}\text { Average } S \\
\text { environment } S_{1 / 2}\end{array}$ & 165.23 (3 \%) & 165.38 (3 \%) \\
\hline & $\mathrm{SO}_{3}^{-}{ }_{3 / 2}$ & $168.20(49 \%)$ & 168.27 (48 \%) \\
\hline & $\mathrm{SO}_{31 / 2}^{-}$ & 169.38 (42\%) & $169.45(40 \%)$ \\
\hline & $\mathrm{S}-\mathrm{Au}_{3 / 2}$ & - & 161.94 (2 \%) \\
\hline & $\mathrm{S}-\mathrm{Au}_{1 / 2}$ & - & $163.12(1 \%)$ \\
\hline Au $4 f$ & $A u_{7 / 2}^{0}$ & - & 83.94 (25\%) \\
\hline & $\mathrm{Au}-\mathrm{S}_{7 / 2}$ & - & 84.79 (29 \%) \\
\hline & $\mathrm{Au}^{3+}{ }_{7 / 2}$ & - & 85.70 (4 \%) \\
\hline & $A u_{5 / 2}^{0}$ & - & 87.61 (18\%) \\
\hline & $\mathrm{Au}-\mathrm{S}_{5 / 2}$ & - & $88.46(21 \%)$ \\
\hline & $\mathrm{Au}^{3+}{ }_{5 / 2}$ & - & 89.37 (3 \%) \\
\hline
\end{tabular}

\subsubsection{KOH Treated Chlorine Hercosett Treated Semi-Worsted Gilled Sliver}

Pre-treating the $\mathrm{Cl} / \mathrm{H}$ treated merino wool fibres with $0.1 \mathrm{M} \mathrm{KOH}$ prior to addition to the $\mathrm{Au}^{3+}$ solution did not alter the mode of bonding between the gold nanoparticles and wool 
fibres. The bonding between the nanoparticles and wool fibres still occurred through $S$ and to a lesser extent $\mathrm{N}$ atoms in the wool fibre. The former was evidenced by the set of peaks centred at 161.90 and $161.08 \mathrm{eV}$ in the $\mathrm{S} 2 \mathrm{p}$ spectrum of the composite (Figure $5.119 \mathrm{a}$ ) and also the peaks at 85.06 and 88.66 in the $\mathrm{Au} 4 \mathrm{f}$ spectrum (Figure $5.119 \mathrm{c}$ ). Bonding of the gold nanoparticles to $\mathrm{N}$ groups was illustrated by the peak centred at $389.36 \mathrm{eV}$ in the $\mathrm{N} 1 \mathrm{~s}$ spectrum (Figure 5.120). A complete list of peak assignments is provided in Table 5.17.
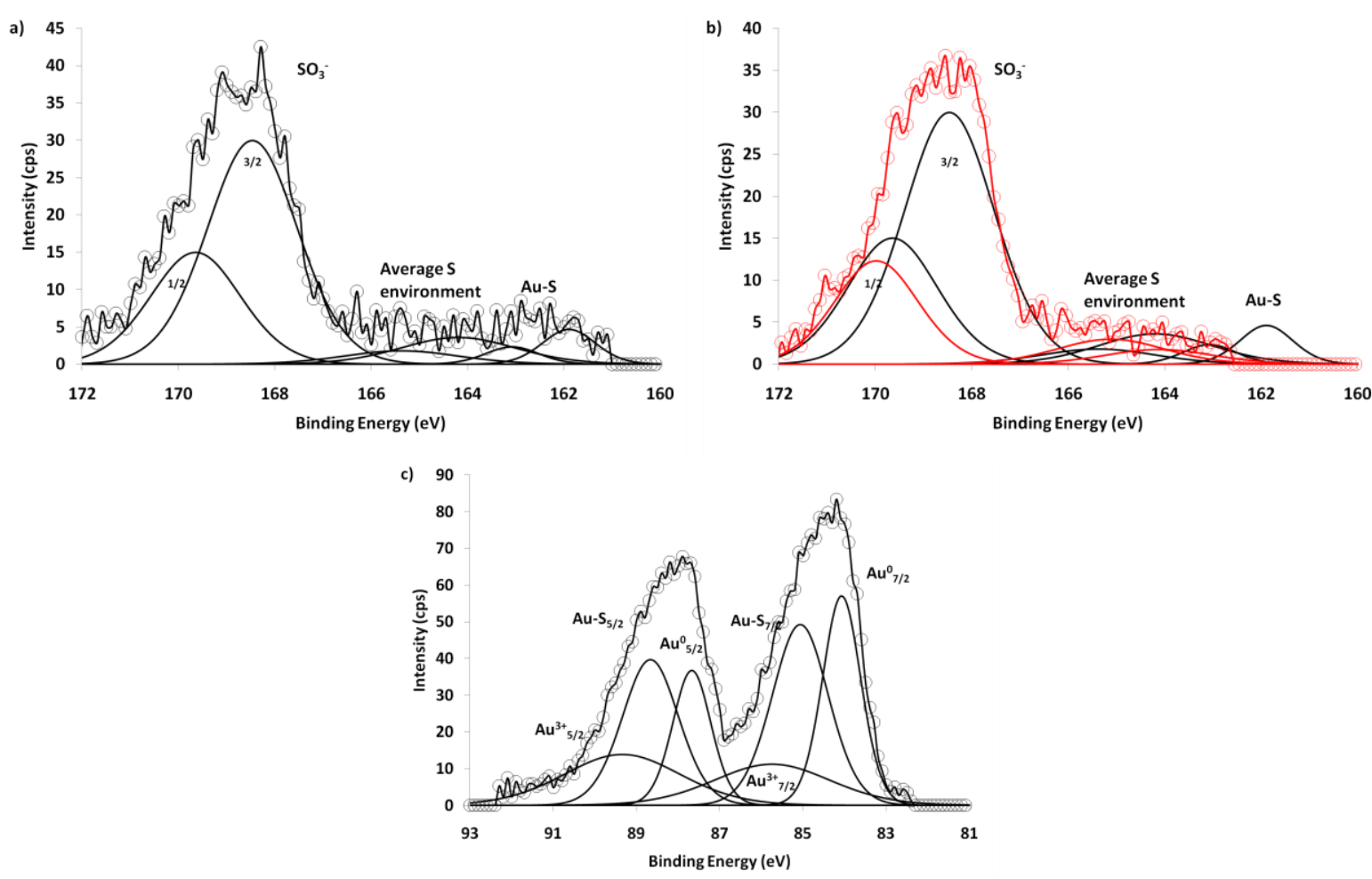

Figure 5.119: High resolution $S$ 2p (a) and Au $4 f$ (c) XPS spectra of gold nanoparticle-merino wool composites prepared by soaking KOH pre-treated $\mathrm{Cl} / \mathrm{H}$ treated merino wool in a $160 \mathrm{ppm}\left(8.13 \times 10^{-4} \mathrm{M}\right)$ $\mathrm{Au}^{3+}$ solution for 24 hours at $\mathrm{RT}$, followed by ageing at $50{ }^{\circ} \mathrm{C}$ for 168 hours. b) An overlay (in red) of the $\mathrm{S} 2 \mathrm{p}$ XPS spectrum of $\mathrm{KOH}$ pre-treated $\mathrm{Cl} / \mathrm{H}$ treated merino wool.
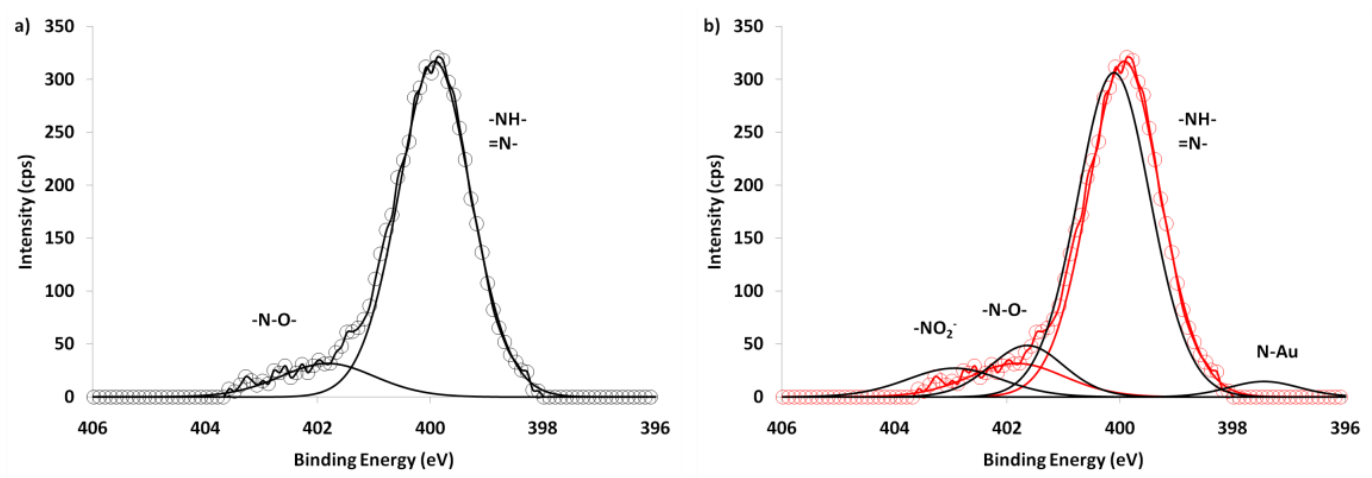

Figure 5.120: a) High resolution N 1s XPS spectra of gold nanoparticle-merino wool composites prepared by soaking $\mathrm{KOH}$ pre-treated $\mathrm{Cl} / \mathrm{H}$ treated merino wool in a $160 \mathrm{ppm}\left(8.13 \times 10^{-4} \mathrm{M}\right) \mathrm{Au}^{3+}$ solution for 24 hours at RT, followed by ageing at $50{ }^{\circ} \mathrm{C}$ for 168 hours. b) An overlay (in red) of the $\mathrm{N} 1 \mathrm{~s}$ XPS spectrum of $\mathrm{KOH}$ pre-treated $\mathrm{Cl} / \mathrm{H}$ treated merino wool. 
Table 5.17: XPS assignments for KOH pre-treated $\mathrm{Cl} / \mathrm{H}$ treated semi-worsted merino wool and gold nanoparticle-merino wool composites (prepared by soaking $\mathrm{KOH}$ pre-treated $\mathrm{Cl} / \mathrm{H}$ treated merino wool in a $160 \mathrm{ppm}\left(8.13 \times 10^{-4} \mathrm{M}\right) \mathrm{Au}^{3+}$ solution for 24 hours at $\mathrm{RT}$, followed by ageing at $50{ }^{\circ} \mathrm{C}$ for $\left.168 \mathrm{hours}\right)$.

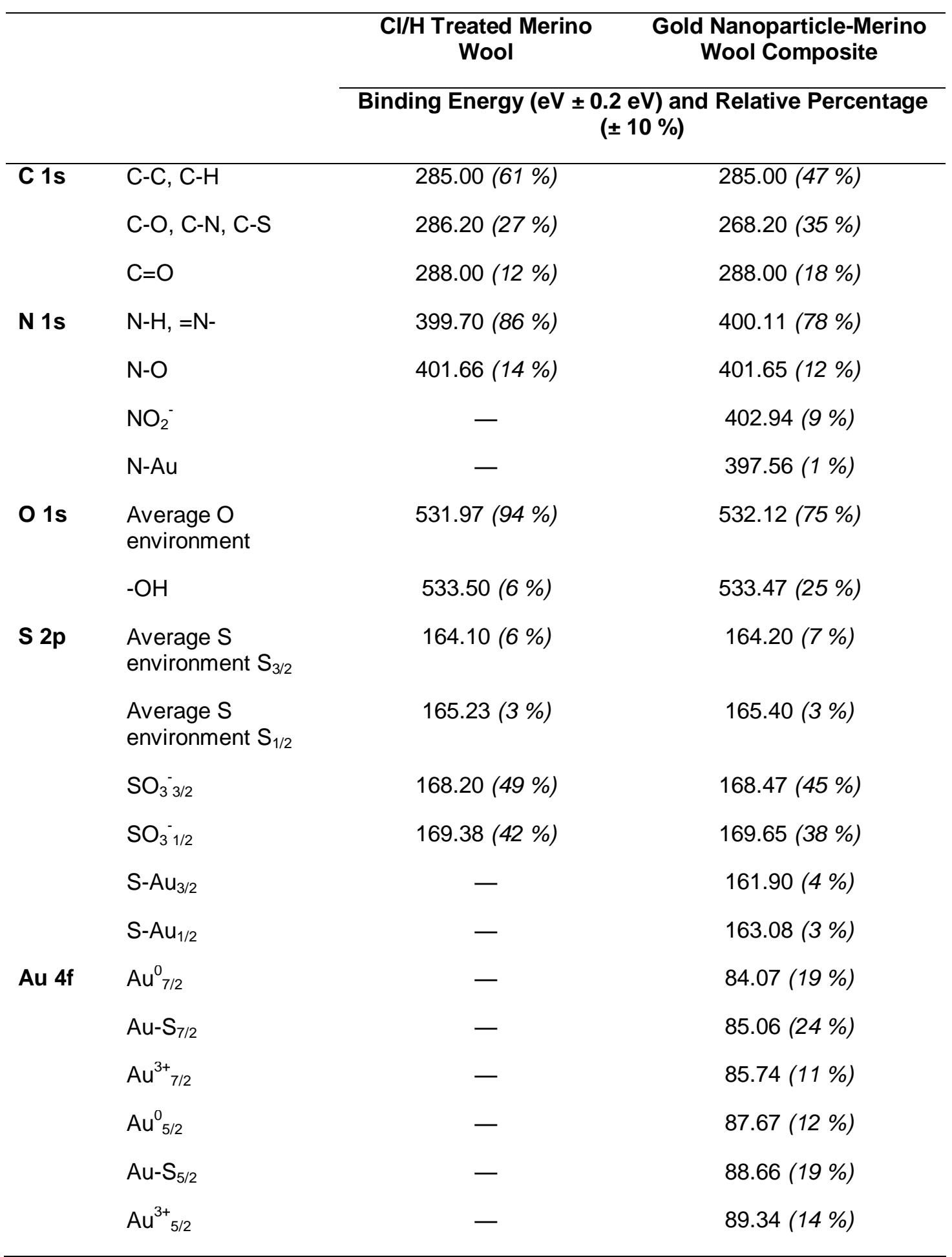




\subsection{Proposed Mechanism of Formation}

The preparation of the gold nanoparticle-merino wool composites involved the reduction of $\mathrm{Au}^{3+}$ to nanoparticulate $\mathrm{Au}^{0}$ on the surface and within the centre of merino wool fibres, with simultaneous stabilisation of the produced nanoparticles and bonding to the merino wool fibres. This reduction was facilitated by the keratin proteins present in merino wool, with the oxidation of functional groups in this protein forming a redox couple and providing the necessary electrons for the $\mathrm{Au}^{3+}$ to $\mathrm{Au}^{0}$ reduction. As mentioned, the production of the gold nanoparticle-merino wool composite materials involved soaking merino wool fibres in a $\mathrm{Au}^{3+}$ solution at RT, followed by ageing at $50{ }^{\circ} \mathrm{C}$ for $24-168$ hours.

Absorption studies suggested that gold was absorbed by the merino wool fibres as the $\mathrm{AuCl}_{4}{ }^{-}$ complex (see section 5.4). At room temperature, complete absorption from solution is usually achieved after approximately 1 hour, however a soaking time of at least 24 hours was required to achieve a uniform distribution of $\mathrm{AuCl}_{4}{ }^{-}$on the surface and throughout the centre of the fibres as a result of diffusion. Studies on the uptake of organic dyes by wool fibres have shown that dyes penetrate/absorb via junctions between wool cuticle cells.[232] Once absorbed, the dyestuffs were shown to diffuse throughout all of the non-keratinous regions of the wool fibre (those regions separating the four layers of the cuticle and the cuticle and cortex), and also the endocuticle (inner most cuticle cell) and intermacrofibrillar material regions of the cell membrane complex.[233, 234] The final stage of dyestuff diffusion inside wool fibres entails a progressive transfer of dye into the sulfur-rich matrix proteins surrounding microfibrils in the cortical cells.[39]

SEM and EDS analysis of the gold nanoparticle-merino wool complexes suggests that the absorption of $\mathrm{AuCl}_{4}{ }^{-}$by the wool fibres, and its subsequent diffusion through the fibres is not dissimilar to that of traditional dyestuffs. The gold nanoparticles in the composites were commonly found to reside along the edges of the cuticle cells, suggesting these areas to be points of entry for the $\mathrm{AuCl}_{4}{ }^{-}$complex. Additionally, cross sectional EDS analysis showed high concentrations of gold to be present at the fibre surface following 1 hour soaking at RT (Figure 5.121 a and b), with increasing soaking times seeing a spread of gold throughout the 
fibre centre, so that following 24 hours soaking, there were high concentrations of gold both on the surface and within the fibre centre, particularly in the sulfur rich paracortex (Figure $5.121 \mathrm{c}-\mathrm{e})$.
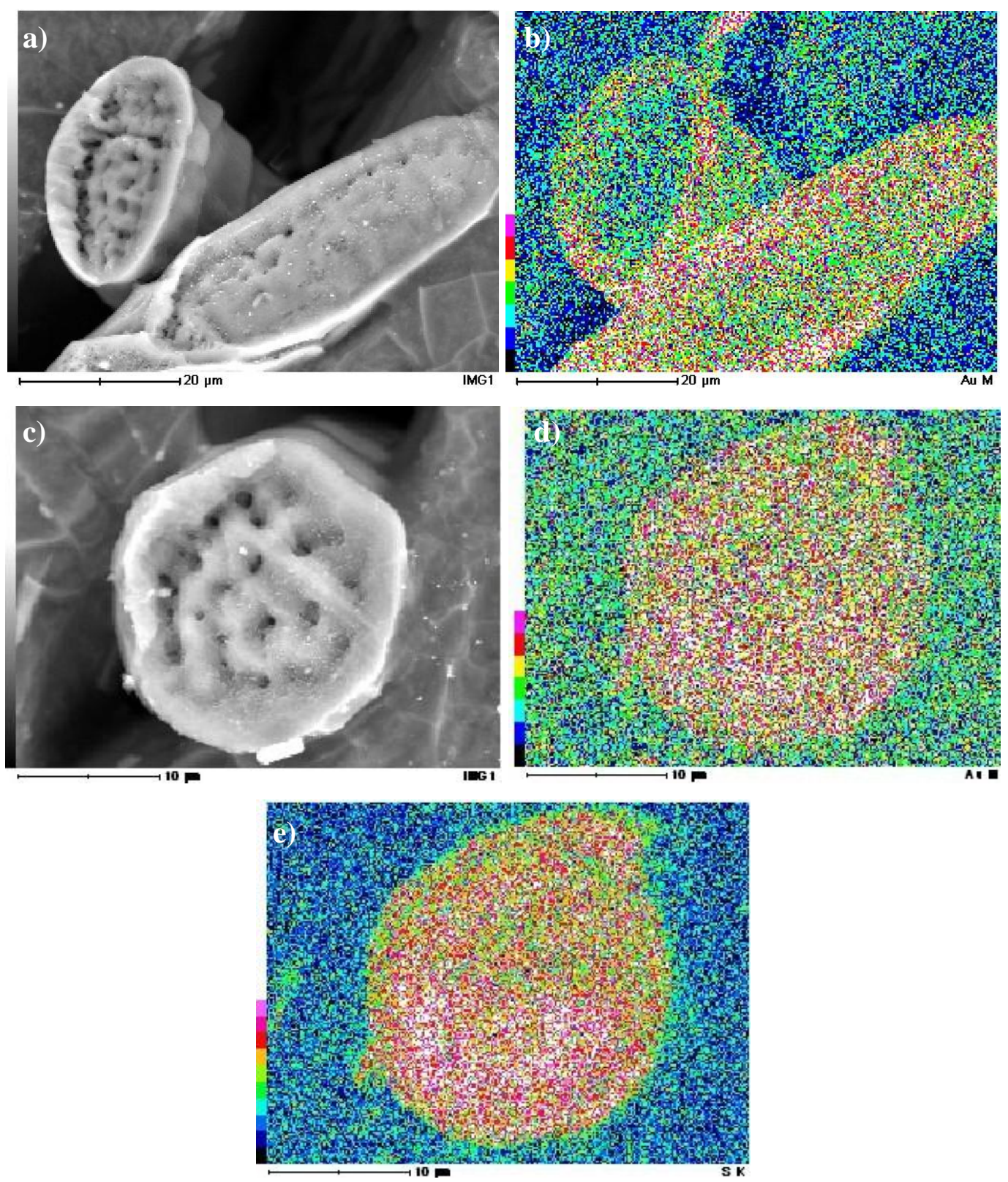

Figure 5.121: Cross sectional SEM micrograph (a and c) and corresponding Au (b and d) or S (e) EDS maps of merino wool fibres soaked in a $160 \mathrm{ppm}\left(8.13 \times 10^{-4} \mathrm{M}\right) \mathrm{Au}^{3+}$ solution for 1 (a and b) or 24 hours (c-d) at RT. 
During the soaking of merino wool fibres in $\mathrm{Au}^{3+}$ solutions a colour change of the solution from yellow to colourless was observed after approximately 1 hour, visually confirming the majority of $\mathrm{AuCl}_{4}{ }^{-}$to be absorbed. A simultaneous yellowing of the submerged wool fibres was also noted, however this yellow colour faded over the course of soaking so that after 24 hours, the merino wool fibres were similar in colour to untreated merino wool. XPS analysis of merino wool fibres that had been soaked at RT in $\mathrm{Au}^{3+}$ solutions for increasing amounts of time suggested that during soaking, a percentage of $\mathrm{Au}^{3+}$ was reduced to $\mathrm{Au}^{+}$, forming some kind of Au-S complex (Figure 5.122). This would account for the decreased yellow colour of the wool fibres occurring with prolonged soaking. Following 1 hour soaking, $67 \%$ of the gold absorbed into the merino wool fibres was present as $\mathrm{Au}^{3+}$, with the remaining $33 \%$ being $\mathrm{Au}^{+}$bound to $\mathrm{S}$. After 24 hours of soaking, the percentage of $\mathrm{Au}^{+}$increased to $42 \%$, and a very small percentage, $3 \%$, of nanoparticulate $\mathrm{Au}^{0}$ appeared (Table 5.18). As mentioned in section 5.1.2.7, SEM and TEM analysis of merino wool that had been soaked in a $160 \mathrm{ppm}\left(8.13 \times 10^{-4} \mathrm{M}\right) \mathrm{Au}^{3+}$ solution for 24 hours at RT, showed the presence of a very small amount of five-fold twinned gold nanoparticles, approximately 10-20 nm in diameter, however these nanoparticles did not impart any colour to the composite materials as they were present in such a low concentration.
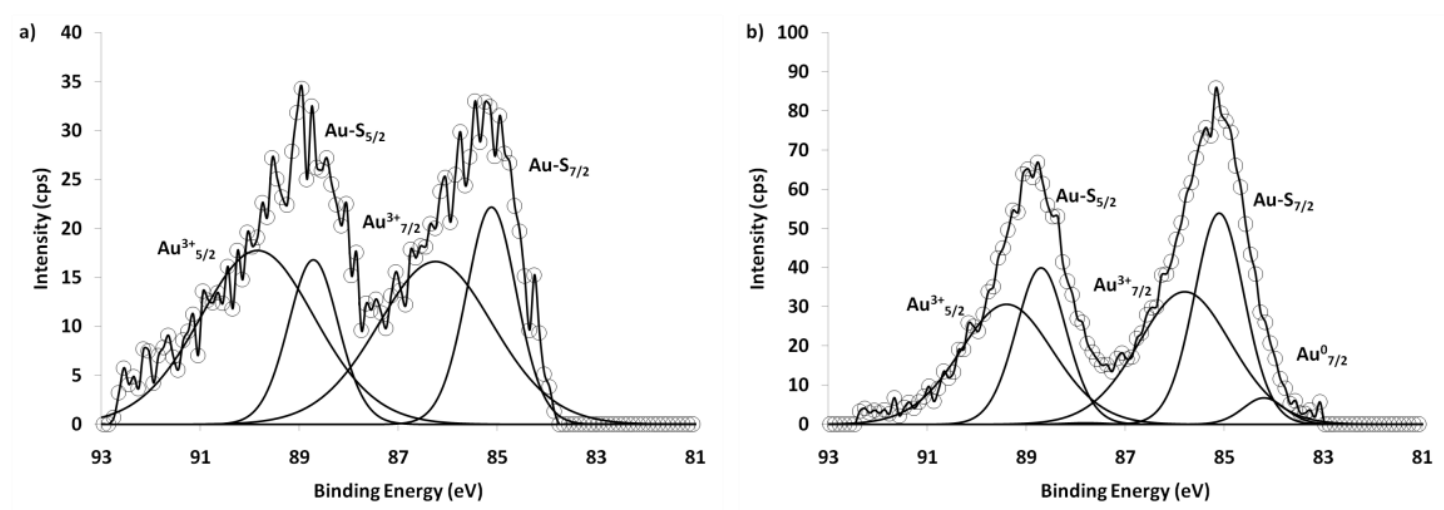

Figure 5.122: High resolution Au 4f XPS spectra of merino wool fibres that had been soaked in a 160 ppm $\left(8.13 \times 10^{-4} \mathrm{M}\right) \mathrm{Au}^{3+}$ solution, at RT, for a) 1 hour or b) 24 hours. 
Table 5.18: Au 4f XPS assignments for merino wool soaked in a $160 \mathrm{ppm}\left(8.13 \times 10^{-4} \mathrm{M}\right) \mathrm{Au}^{3+}$ solution, at RT, for 1 or 24 hours.

\begin{tabular}{cccc}
\hline $\begin{array}{c}\text { Soaking Time } \\
\text { (Hours, RT) }\end{array}$ & $\begin{array}{c}\% \mathrm{Au}^{3+} \\
( \pm \mathbf{1 0} \%)\end{array}$ & $\begin{array}{c}\% \mathrm{Au}^{+} \\
(\mathbf{\pm 1 0} \%) \\
(\mathrm{Au}-\mathrm{S})\end{array}$ & $\begin{array}{c}\% \mathrm{Au}^{0} \\
( \pm \mathbf{1 0} \%)\end{array}$ \\
\hline 1 & 67 & 33 & 0 \\
24 & 55 & 42 & 3 \\
\hline
\end{tabular}

The decrease in $\mathrm{Au}^{3+}$ and increase in both $\mathrm{Au}^{+}$and $\mathrm{Au}^{0}$ upon extended soaking times suggests that during soaking, a percentage of $\mathrm{Au}^{3+}$ was reduced to $\mathrm{Au}^{+}$, with continued soaking reducing either or both of $\mathrm{Au}^{3+}$ and $\mathrm{Au}^{+}$to nanoparticulate $\mathrm{Au}^{0}$. Comparing the relative percentages of $\mathrm{Au}^{3+}, \mathrm{Au}^{+}$and $\mathrm{Au}^{0}$ present in merino wool soaked in $\mathrm{Au}^{3+}$ for 1 hour or 24 hours at RT, and composite materials prepared by soaking merino wool in $\mathrm{Au}^{3+}$ for 24 hours at RT followed by ageing for 24 or 168 hours (therefore materials in which more $\mathrm{Au}^{0}$ nanoparticles had been formed) saw a trend in the relative amounts of the various forms of gold. Increasing the soaking time, at RT, and subsequently the ageing time saw an increase in the $\mathrm{Au}^{+}: \mathrm{Au}^{3+}$ ratio, from 0.49 in merino wool soaked in $\mathrm{Au}^{3+}$ for 1 hour to 1.51 in a composite material prepared with an ageing time of 168 hours (Table 5.19). This suggests that the continued formation of $\mathrm{Au}^{0}$ nanoparticles occurred through the reduction of additional $\mathrm{Au}^{3+}$ rather than $\mathrm{Au}^{+}$, with the $\mathrm{Au}-\mathrm{S}$ complexes likely to act as nucleation sites for this reduction and formation of nanoparticulate $\mathrm{Au}^{0}$.

Table 5.19: Au 4f XPS assignments for merino wool soaked in a $160 \mathrm{ppm}\left(8.13 \times 10^{-4} \mathrm{M}\right) \mathrm{Au}^{3+}$ solution, at RT, for 1 or 24 hours, and gold nanoparticle-merino wool composites (prepared by soaking untreated semi-worsted merino wool in a $160 \mathrm{ppm}\left(8.13 \times 10^{-4} \mathrm{M}\right) \mathrm{Au}^{3+}$ solution for 24 hours at RT, followed by ageing at $50{ }^{\circ} \mathrm{C}$ for 24 or 168 hours).

\begin{tabular}{cccccc}
\hline $\begin{array}{c}\text { Soaking Time } \\
\text { (Hours, RT) }\end{array}$ & $\begin{array}{c}\text { Ageing Time } \\
\left(\text { Hours, 50 }{ }^{\circ} \mathbf{C}\right)\end{array}$ & $\begin{array}{c}\% \mathrm{Au}^{3+} \\
(\mathbf{\pm 1 0} \%)\end{array}$ & $\begin{array}{c}\% \mathrm{Au}^{+} \\
(\mathbf{\pm 1 0} \%) \\
(\mathrm{Au}-\mathbf{S})\end{array}$ & $\mathrm{Au}^{+}: \mathrm{Au}^{3+}$ & $\begin{array}{c}\% \mathrm{Au}^{0} \\
( \pm \mathbf{1 0} \%)\end{array}$ \\
\hline 1 & - & 67 & 33 & 0.49 & 0 \\
24 & - & 55 & 42 & 0.76 & 3 \\
24 & 24 & 49 & 46 & 0.94 & 5 \\
24 & 168 & 37 & 56 & 1.51 & 7 \\
\hline
\end{tabular}


The reduction of $\mathrm{Au}^{3+}$ to nanoparticulate $\mathrm{Au}^{0}$, occurring to a slight extent during soaking and much more extensively during ageing, must be accompanied and facilitated by the oxidation of one or more functional group in the protein fibres of merino wool. This redox pair was ascertained when comparing the deconvoluted high resolution S $2 p$ spectra of various merino wool-gold materials and the base fibre, untreated semi-worsted merino wool. Firstly to investigate the reduction of $\mathrm{Au}^{3+}$ to $\mathrm{Au}^{+}$and then a small amount of $\mathrm{Au}^{3+}$ to nanoparticulate $\mathrm{Au}^{0}$ occurring during soaking at RT, the deconvoluted, high resolution S 2p XPS spectra of merino wool soaked in $\mathrm{Au}^{3+}$ at RT for 1 or 24 hours were compared to untreated semiworsted merino wool, with clear differences observed (Figure 5.123). The first was the presence of the set of peak's centred at approximately 161.5-162 and 162.7-163.2 eV in the wool-gold materials. These peaks were absent in merino alone, and as discussed in section 5.5.1 are indicative of Au-S bonding. The peak ratio of the various sulfur species also changed with increasing soaking times (Table 5.20). In the base fibre the average $S$ environment of wool (S-S, S-H) accounted for $\sim 97 \%$ of S species. Soaking the merino wool fibres in $\mathrm{Au}^{3+}$ solutions at RT saw a decrease in peak area relating to the average $\mathrm{S}$ environment of wool, to $80 \%$ after 1 hour soaking and $67 \%$ after 24 hours. This decrease was accompanied by an increase in the percentage of oxidised sulfur, cysteic acid $\left(\mathrm{SO}_{3}{ }^{-}\right.$, the product of the oxidation of cystine), from $7 \%$ in untreated merino wool, to $16 \%$ in merino wool soaked in $\mathrm{Au}^{3+}$ for 1 hour at RT and $30 \%$ for merino wool soaked in $\mathrm{Au}^{3+}$ for 24 hours. 

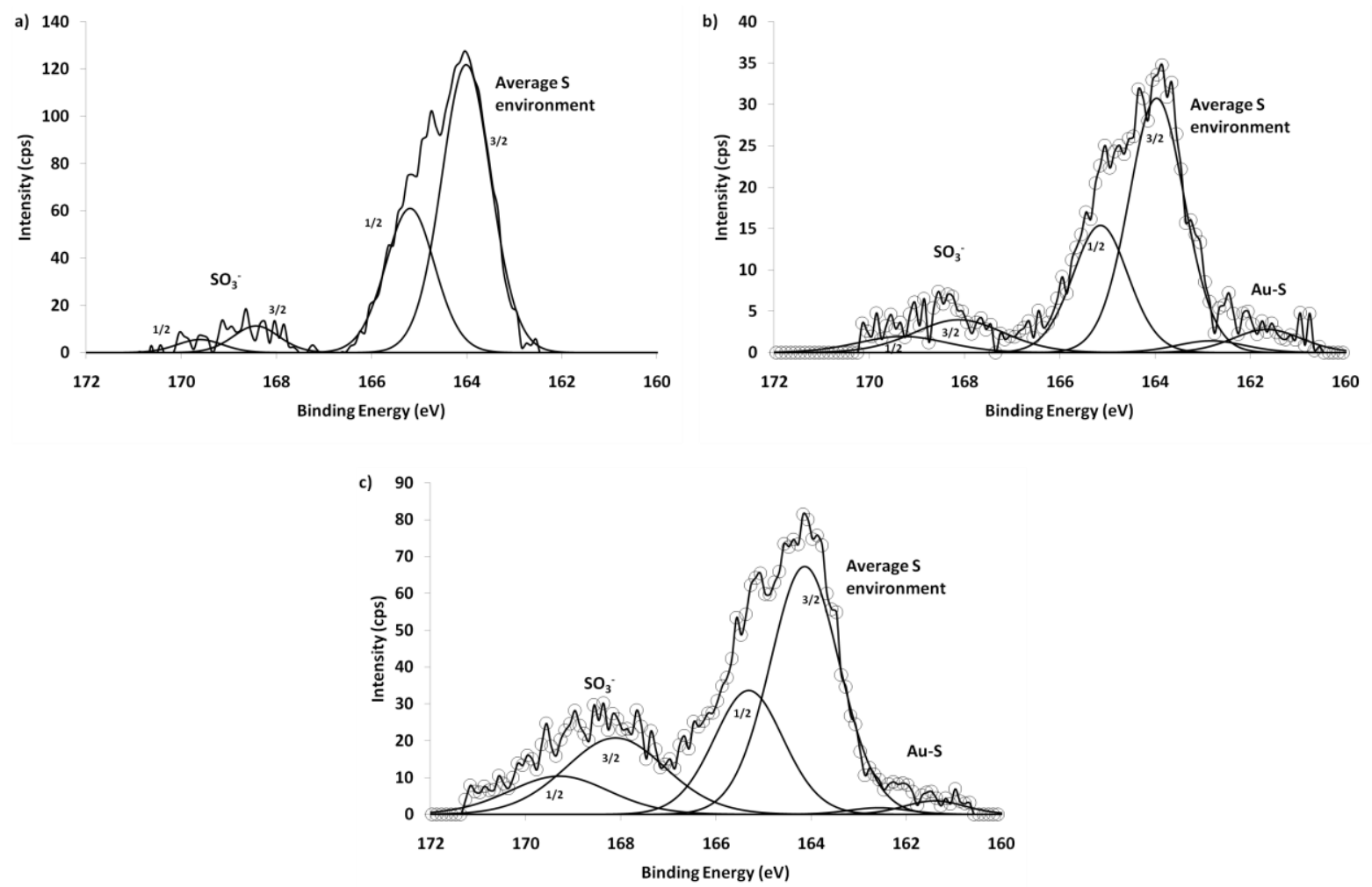

Figure 5.123: High resolution S 2p XPS spectra of a) untreated semi-worsted merino wool, b) untreated semi-worsted merino wool soaked in a $160 \mathrm{ppm}\left(8.13 \times 10^{-4} \mathrm{M}\right) \mathrm{Au}^{3+}$ solution for 1 hour at RT and c) soaked for 24 hours at RT.

Table 5.20: Relative percentage of sulfur species in untreated semi-worsted merino wool and merino wool soaked in a $160 \mathrm{pppm}\left(8.13 \times 10^{-4} \mathrm{M}\right) \mathrm{Au}^{3+}$ solution at RT for 1 or 24 hours.

\begin{tabular}{|c|c|c|c|}
\hline & \multicolumn{3}{|c|}{ Soaking Time, RT } \\
\hline & 0 hours & 1 hour & 24 hours \\
\hline S Species & \multicolumn{3}{|c|}{ Relative Percentage (\% $10 \%)$ ) } \\
\hline $\begin{array}{c}\text { Average S } \\
\text { environment } \\
\text { (S-S, S-H) }\end{array}$ & 93 & 80 & 67 \\
\hline $\mathrm{SO}_{3}^{-}$ & 7 & 16 & 30 \\
\hline S-Au & - & 4 & 3 \\
\hline
\end{tabular}

The decrease in the average $\mathrm{S}$ environment of wool (cystine $(\mathrm{S}-\mathrm{S}-)$ and cysteine $(\mathrm{S}-\mathrm{H})$ groups), and subsequent increase in cysteic acid (the oxidation product of cystine) suggests that the $\mathrm{Au}^{3+}$ to $\mathrm{Au}^{+}$and $\mathrm{Au}^{3+}$ to $\mathrm{Au}^{0}$ reductions were facilitated by the oxidation of the 
disulfide groups of cystine to cysteic acid. The continued reduction of $\mathrm{Au}^{3+}$ to nanoparticulate $\mathrm{Au}^{0}$, occurring during ageing was also thought to occur due to the oxidation of cystine to cysteic acid. Figure 5.124 offers a comparison of the deconvoluted, high resolution S 2p XPS spectra of gold nanoparticle-merino wool composites (prepared by soaking untreated semi-worsted merino wool in a $160 \mathrm{ppm}\left(8.13 \times 10^{-4} \mathrm{M}\right) \mathrm{Au}^{3+}$ solutions for 24 hours at RT, followed by ageing at $50{ }^{\circ} \mathrm{C}$ for 24 or 168 hours) and the base fibre, untreated semi-worsted merino wool. For ease of viewing only the $3 / 2$ deconvoluted peaks are shown. From a comparison of these spectra it can be seen that increasing the ageing time, and hence the amount of $\mathrm{Au}^{3+}$ reduced to $\mathrm{Au}^{0}$, saw a decrease in the amount of cystine (evidenced by a decrease in peak area for the peak indicating the average $\mathrm{S}$ environment), with a subsequent increase in the amount of the oxidised form of cystine, cysteic acid $\left(\mathrm{SO}_{3}{ }^{-}\right)$ (Table 5.21).

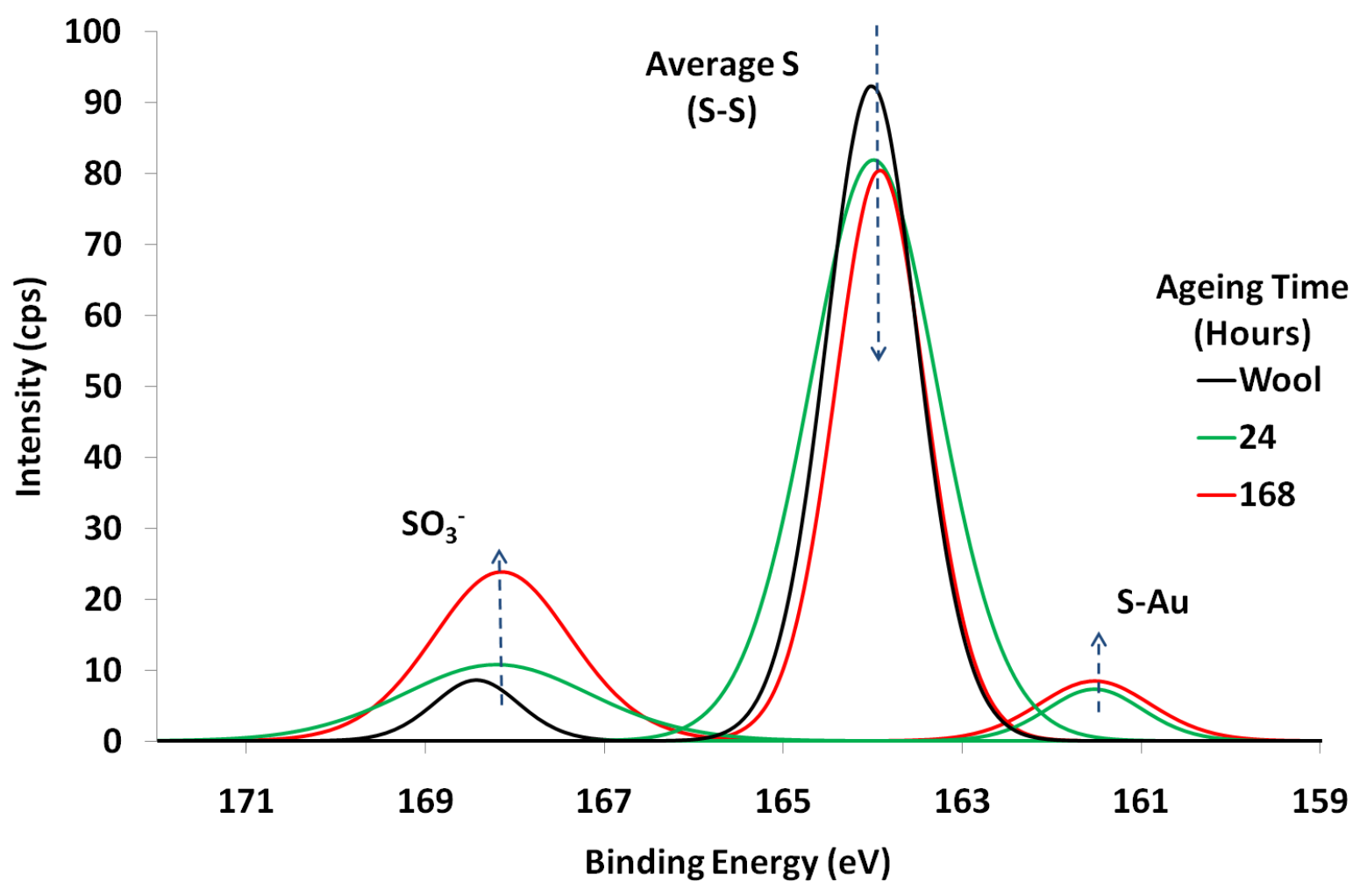

Figure 5.124: Comparisons of the deconvoluted high resolution S 2p XPS spectra of untreated semiworsted merino wool (black lines) and gold nanoparticle merino wool composites, prepared by soaking untreated merino-wool in a $160 \mathrm{ppm} \mathrm{Au}^{3+}\left(8.13 \times 10^{-4} \mathrm{M}\right)$ solution for 24 hours at $\mathrm{RT}$ followed by ageing at $50{ }^{\circ} \mathrm{C}$ for 24 (green lines) or 168 hours (red lines). 
Table 5.21: Relative percentage of sulfur species in untreated semi-worsted merino wool, wool soaked in $\mathrm{Au}^{3+}$ at RT, and gold nanoparticle-merino wool composites (prepared by soaking untreated semi-worsted merino wool in a $160 \mathrm{ppm}\left(8.13 \times 10^{-4} \mathrm{M}\right) \mathrm{Au}^{3+}$ solution for 24 hours at $\mathrm{RT}$, followed by ageing at $50{ }^{\circ} \mathrm{C}$ for 24 or 168 hours).

\begin{tabular}{|c|c|c|c|c|}
\hline & \multirow[b]{2}{*}{ Merino Wool } & \multirow[b]{2}{*}{$\begin{array}{l}\text { Merino Wool Soaked } \\
\text { in } \mathrm{Au}^{3+}(24 \text { hours) }\end{array}$} & \multicolumn{2}{|c|}{ Composite Material } \\
\hline & & & 24 h Ageing & $168 \mathrm{~h}$ Ageing \\
\hline S Species & \multicolumn{4}{|c|}{ Relative Percentage (\% $\pm 10 \%)$} \\
\hline $\begin{array}{c}\text { Average S } \\
\text { environment } \\
\text { (S-S, S-H) }\end{array}$ & 93 & 67 & 75 & 58 \\
\hline $\mathrm{SO}_{3}^{-}$ & 7 & 30 & 18 & 33 \\
\hline S-Au & - & 3 & 6 & 9 \\
\hline
\end{tabular}

As a control, the high resolution S 2p XPS spectrum of merino wool that has been soaked in a pH 3 solution for 24 hours at $\mathrm{RT}$, followed by heating at $50{ }^{\circ} \mathrm{C}$ for 168 hours is offered in Figure 5.125. This sample comprises $12 \%$ oxidised sulfur. This is slightly higher than that of untreated merino wool (which contained $7 \%$ oxidised sulfur) however it is still markedly less than that of the gold nanoparticle-merino wool composites which exhibited $~ 33 \%$ oxidised sulfur.

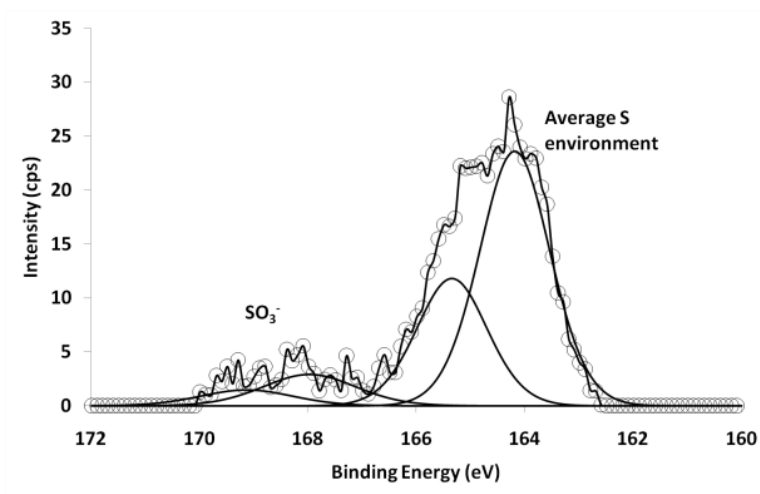

Figure 5.125: High resolution S 2p XPS spectrum of merino wool that had been soaked in a pH 3 solution for 24 hours at RT, followed by heating at $50{ }^{\circ} \mathrm{C}$ for 168 hours. 
Comparing the deconvoluted, high resolution $\mathrm{C} 1 \mathrm{~s}, \mathrm{~N}$ 1s and $\mathrm{O}$ 1s XPS spectra of the composite materials to those of untreated semi-worsted merino wool showed very little change, and as such did not provide substantial evidence for the oxidation of alternate functional groups, such as amines etc in merino wool during the production of the composite materials (see section 5.5.1, Figure 5.105, Figure 5.106 and Table 5.12). This confirms that, at least on and near the surface of the wool fibres, the reduction of $\mathrm{Au}^{3+}$ to nanoparticulate $\mathrm{Au}^{0}$ was induced by and coupled with the oxidation of cystine to cysteic acid.

The reduction mechanism for the formation of the nanoparticles in the centre of the fibres cannot be proposed with as much certainty due to the detection limits of XPS, which only provides information about the top $10 \mathrm{~nm}$ of a sample. However as high concentrations of gold in the fibre centre were seen to correlate to areas of high concentrations of sulfur, (notably in the paracortex) it is highly likely that nanoparticles were also formed in these areas, with the reduction facilitated by the sulfur containing amino acid cystine. The fact that these nanoparticles were only evident in materials that had been prepared with an extended ageing time, 168 hours, obviously shows that they took a long time to form. As gold was shown to reside in the fibre centres after 24 hours soaking at RT, the delayed formation of these nanoparticles was not due to lack of gold in these areas. Rather it may be related to steric hindrance as the paracortex is much denser than the orthocortex,[46] and as such the firmly packed paracortical cells may impair the nucleation of gold ions and hence the production of $\mathrm{Au}^{0}$ nanoparticles.

In light of these results, the following mechanism is proposed for the formation of the gold nanoparticle-merino wool composites prepared through the redox properties of the protein fibres in merino wool. During soaking at RT, $\mathrm{Au}^{3+}$ in the form of $\mathrm{AuCl}_{4}{ }^{-}$is absorbed by the wool fibres. The $\mathrm{Cl}^{-}$ions are likely electrostatically attracted to positively charged amine groups on the wool fibre destabilising the $\mathrm{AuCl}_{4}{ }^{-}$complex and facilitating the reduction of $\mathrm{Au}^{3+}$ to $\mathrm{Au}^{+}$by the disulfide containing amino acid cystine (scheme 5.2), (Figure 5.126 (1) and (2)). (It should be noted that due to the low concentration of $\mathrm{Au}^{3+}$ employed in the production of these materials (approximately $1.6 \mathrm{wt} \%$ ), following the reduction of $\mathrm{Au}^{3+}$ to $\mathrm{Au}^{+}$and later $\mathrm{Au}^{0}$, there would still remain a large concentration of un-oxidised disulfide 
groups, as cystine accounts for approximately 8-10 wt \% of the wool fibre).[39] The resultant $\mathrm{Au}^{+}$ions then bond to the wool fibre by mean of a coordinate covalent $\mathrm{Au}-\mathrm{S}$ bond (most likely through the main sulfur containing amino acids cystine and or cysteine (Figure $5.126(3))$, involving expansion of the valence shell of gold to $6 s$ orbitals. As this reduction proceeded, $\mathrm{Cl}^{-}$ions were seen to simultaneously diffuse back into solution (Figure 5.126 and Figure 5.127).

$\mathrm{Au}^{3+}+2 \mathrm{e}^{-} \rightarrow \mathrm{Au}^{+}$

$\mathrm{R}-\mathrm{S}-\mathrm{S}-\mathrm{R}+3 \mathrm{H}_{2} \mathrm{O} \rightarrow 2 \mathrm{R}-\mathrm{SO}_{3} \mathrm{H}+5 \mathrm{H}^{+}+5 \mathrm{e}^{-}$

$2 \mathrm{R}-\mathrm{S}-\mathrm{S}-\mathrm{R}+6 \mathrm{H}_{2} \mathrm{O}+5 \mathrm{Au}^{3+} \rightarrow 4 \mathrm{R}-\mathrm{SO}_{3} \mathrm{H}+10 \mathrm{H}^{+}+5 \mathrm{Au}^{+}$

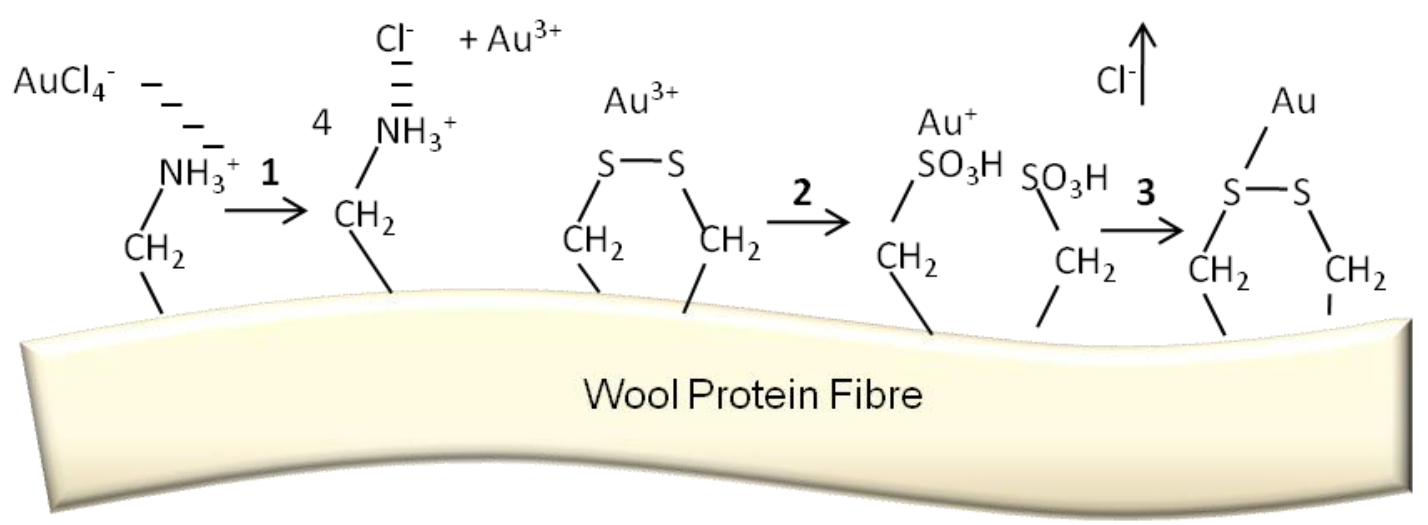

Figure 5.126: Schematic illustrating the electrostatic attraction between the $\mathrm{Cl}^{-}$ions of $\mathrm{AuCl}_{4}{ }^{-}$and positively charged amine groups (1), destabilising the $\mathrm{AuCl}_{4}{ }^{-}$complex and facilitating the $\mathrm{Au}^{3+}$ to $\mathrm{Au}^{+}$ reduction (2). The resultant $\mathrm{Au}^{+}$ions are thought to bond to the wool fibre via a Au-S bond (3).

Employing prolonged soaking and subsequently ageing times saw the reduction of additional $\mathrm{Au}^{3+}$ to nanoparticulate $\mathrm{Au}^{0}$. Again this reduction was facilitated by the oxidation of the disulfide groups of cystine to cysteic acid. Due to aurophilicity which sees $\mathrm{Au}^{+}$ions attracted to other $\mathrm{Au}^{+}$ions,[235, 236] it is likely that the $\mathrm{Au}^{+}$in the $\mathrm{Au}-\mathrm{S}$ complexes would be attracted to each other forming nanoclusters on which the additional $\mathrm{Au}^{3+}$ may accumulate (Figure 5.128 top). As the ratio of wool fibre protein (acting as a dual reductant and 
stabiliser) to $\mathrm{Au}^{3+}$ is high in these syntheses, it is likely that these clusters would grow into discrete nanoparticles through the reduction of $\mathrm{Au}^{3+}$ ions adsorbed onto the nanocluster surface, forming relatively small, monodisperse particles (as seen in SEM and TEM micrographs, see section 5.1.2, Figure 5.15). As mentioned, this reduction was accompanied by the oxidation of cystine to cysteic acid. The cystine groups do not need to be in direct contact with the gold nanoclusters, as the reaction is carried out in ionic solutions and electrons liberated from the cystine oxidation can be transferred to the nearest gold nanoclusters, providing the necessary electrons for the $\mathrm{Au}^{3+}$ to $\mathrm{Au}^{0}$ reduction (Figure 5.128). XPS showed these nanoparticles to bond to the wool fibre via Au-S bonds (section 5.5.1). This would lower the surface energy of the nanoparticles, and stabilise the nanoparticles towards aggregation as a consequence of Ostwald Ripening.

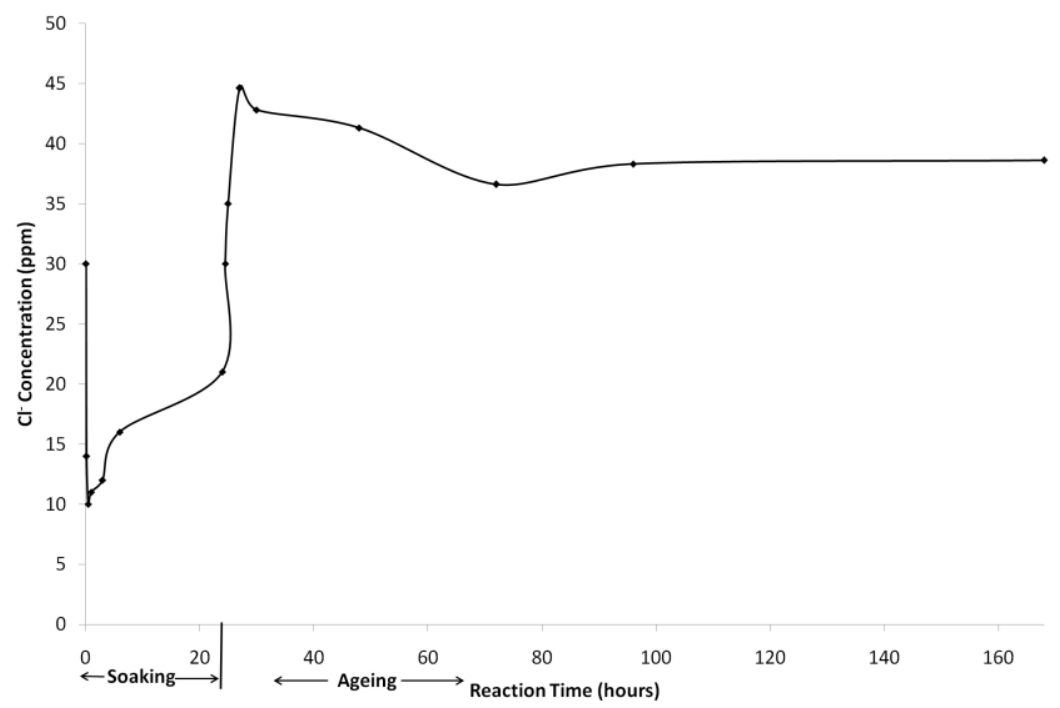

Figure 5.127: Concentration of chloride in the reaction mixture against time. 


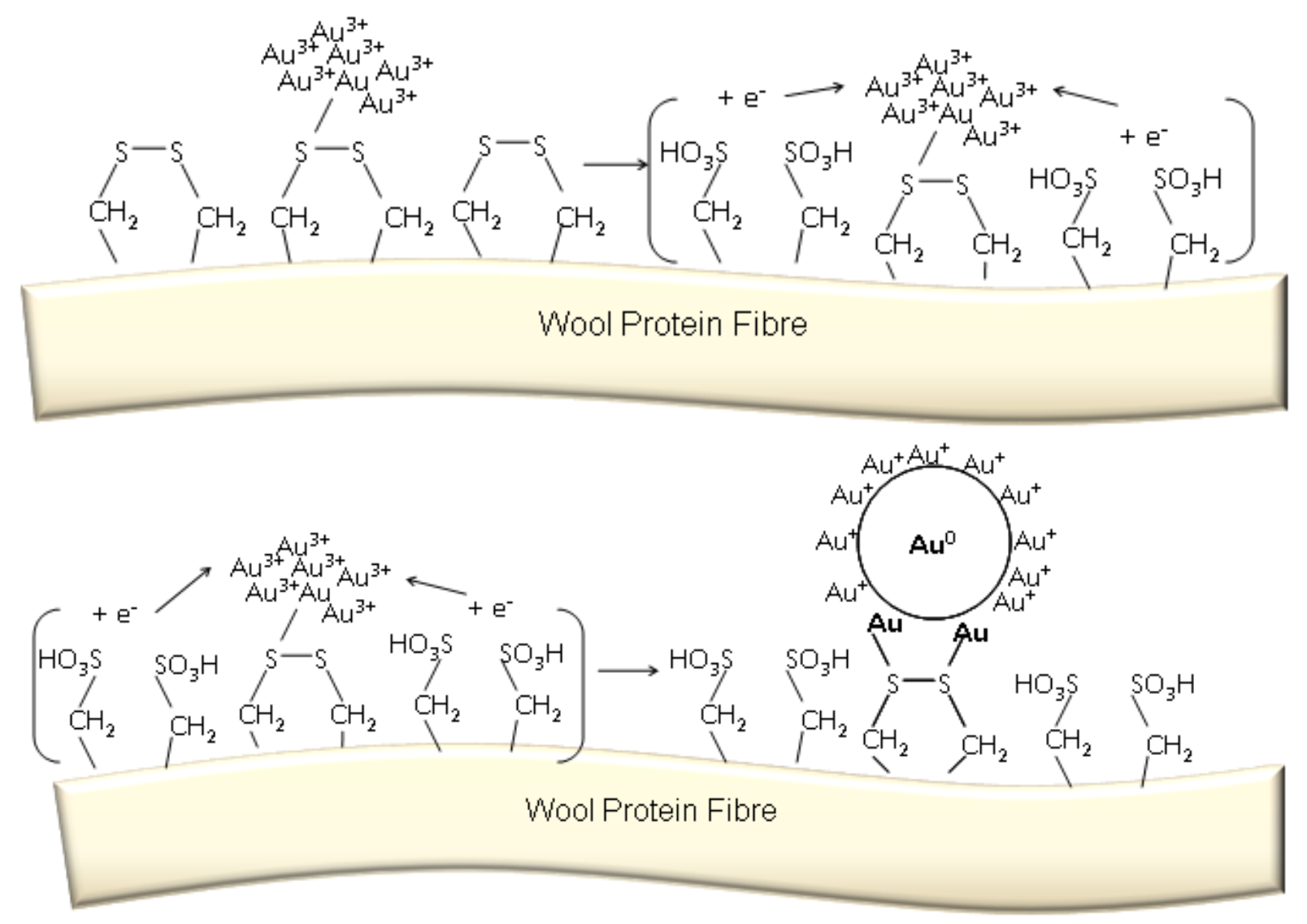

Figure 5.128: Schematic illustration showing the formation of gold nanoclusters and their subsequent reduction to nanoparticulate $\mathrm{Au}^{0}$.

Raman spectroscopy was employed with the aim of further clarifying the production mechanism of the gold nanoparticle-merino wool composites. It was hoped that comparisons of the spectra of the composites and base fibre would confirm the role of cystine in the reduction of $\mathrm{Au}^{3+}$ to $\mathrm{Au}^{0}$ and the formation of the composite materials. A gold nanoparticlemerino wool composite prepared by ageing untreated semi-worsted merino wool in an 800 ppm $\mathrm{Au}^{3+}$ solution for 24 hours at $50{ }^{\circ} \mathrm{C}$ was chosen as a representative of the composite materials as it possessed a very high concentration of nanoparticles at the wool fibre surface, increasing the likelihood of observing differences between the spectra of the base fibre and composite, as the formation of an increased amount of nanoparticles would require the oxidation of an increased percentage of functional groups in the wool fibre protein. 
Figure 5.129 offers the Raman spectra of the gold nanoparticle-merino wool composite, collected with a $633 \mathrm{~nm}$ laser. This is the only region in which signals were obtained, with any lines in the $3500-1800 \mathrm{~cm}^{-1}$ region being obscured by the natural fluorescence of the wool fibre,[237] which also impaired the collection of spectra for the base fibres under these conditions. The Raman spectroscopic signal is often enhanced by noble metal nanoparticles due to the surface sensitive process termed surface enhanced Raman spectroscopy (SERS), in which the Raman signal of molecules in close proximity to the nanoparticles have the potential to be enhanced by a factor of up to $10^{14}-10^{15}$ (section 2.3.11). Therefore the enhancement, appearance or loss of certain signals may provide information about the functional groups in the vicinity of the gold nanoparticles, and hence provide information about the reducing nature of merino wool.

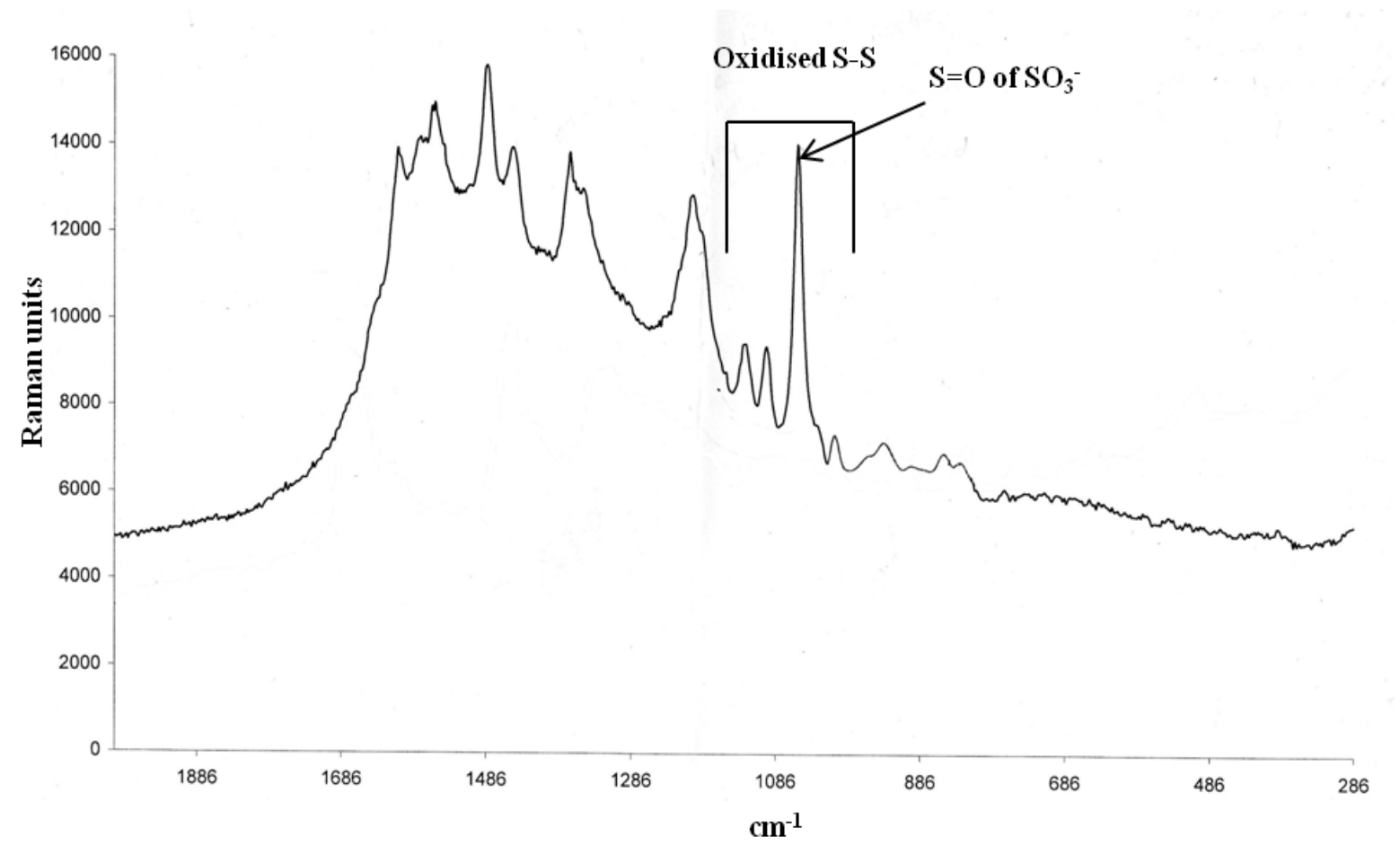

Figure 5.129: SERS spectrum of a gold nanoparticle-merino wool composite.

Characteristic signals associated with the protein fibre of merino wool are seen in the SERS spectra of the composite material, notably the lines in the region of approximately 1670$1650 \mathrm{~cm}^{-1}$ and $1270 \mathrm{~cm}^{-1}\left(\mathrm{CONH}_{2}\right)$ and $1450 \mathrm{~cm}^{-1}$ (C-H bending).[50, 237] Signals specific to the aromatic amino acids tryptophan are also seen at 1370 and $1350 \mathrm{~cm}^{-1}$ and tyrosine at 
1209, 844 and $819 \mathrm{~cm}^{-1}$.[50] These amino acids are particularly Raman active, which is likely to account for their appearance. However of particular interest are the peaks in the $1200-1000 \mathrm{~cm}^{-1}$ region. These have been assigned to partially oxidised disulfide species such as cystine monoxide and dioxide as well as cysteic acid, which exhibits a strong, characteristic peak at $1041 \mathrm{~cm}^{-1}$, assignable to the $\mathrm{S}=\mathrm{O}$ symmetric stretching vibration. Cystine itself exhibits a S-S stretch near $510 \mathrm{~cm}^{-1},[50]$ and this is absent or greatly diminished in the SERS spectra of the composite.

As mentioned above, due to the natural fluorescence of merino wool a Raman spectrum of the base fibres could not be collected under these conditions, instead near infra-red light was employed. Figure 5.130 offers the FT-IT Raman spectra of untreated semi-worsted merino wool. This spectra is not dissimilar to that of the SERS Raman spectra of the composite, with characteristic signals associated with the protein fibre of merino wool seen in the lines at $\sim 1670 \mathrm{~cm}^{-1}$ and $1270 \mathrm{~cm}^{-1}\left(\mathrm{CONH}_{2}\right)$ and $1456 \mathrm{~cm}^{-1}$ (C-H bending) (Table 5.22).[50] However of particular difference is the absence of the peaks associated with oxidised cystine, and the presence of the signal at approximately $520 \mathrm{~cm}^{-1}$, which is characteristic of the S-S stretch of cystine. The presence of the signals of the oxidation productions of cystine, and the loss or marked decrease of the S-S cystine signal in the SERS spectra of the composite materials suggest that the reduction of $\mathrm{Au}^{3+}$ to $\mathrm{Au}^{0}$ was facilitated by the oxidation of cystine to cysteic acid, substantiating the mechanism of formation of the gold nanoparticle-merino wool composites proposed above.

The role of cystine in the production of the gold nanoparticle-merino wool composites was investigated experimentally by reducing the cystine concentration in merino wool, and hence its reducing capability. This was achieved by reducing the disulfide groups of cystine to thiol groups with tris(2-carboxyethly)phosphine (TCEP), and then alkylating the resultant thiols (with maleic acid) to prevent their re-oxidation. This was carried out according to the Sweetman and Maclaren procedure outlined in section 2.2.2.3.1.[238] The reduction of the disulfide groups by TCEP is thought to occur via a nucleophilic attack at a sulfur atom by the phosphine, involving the expansion of the valence shell of sulfur to $3 d$ orbitals, followed by a nucleophilic displacement (scheme 5.3).[238-240] 


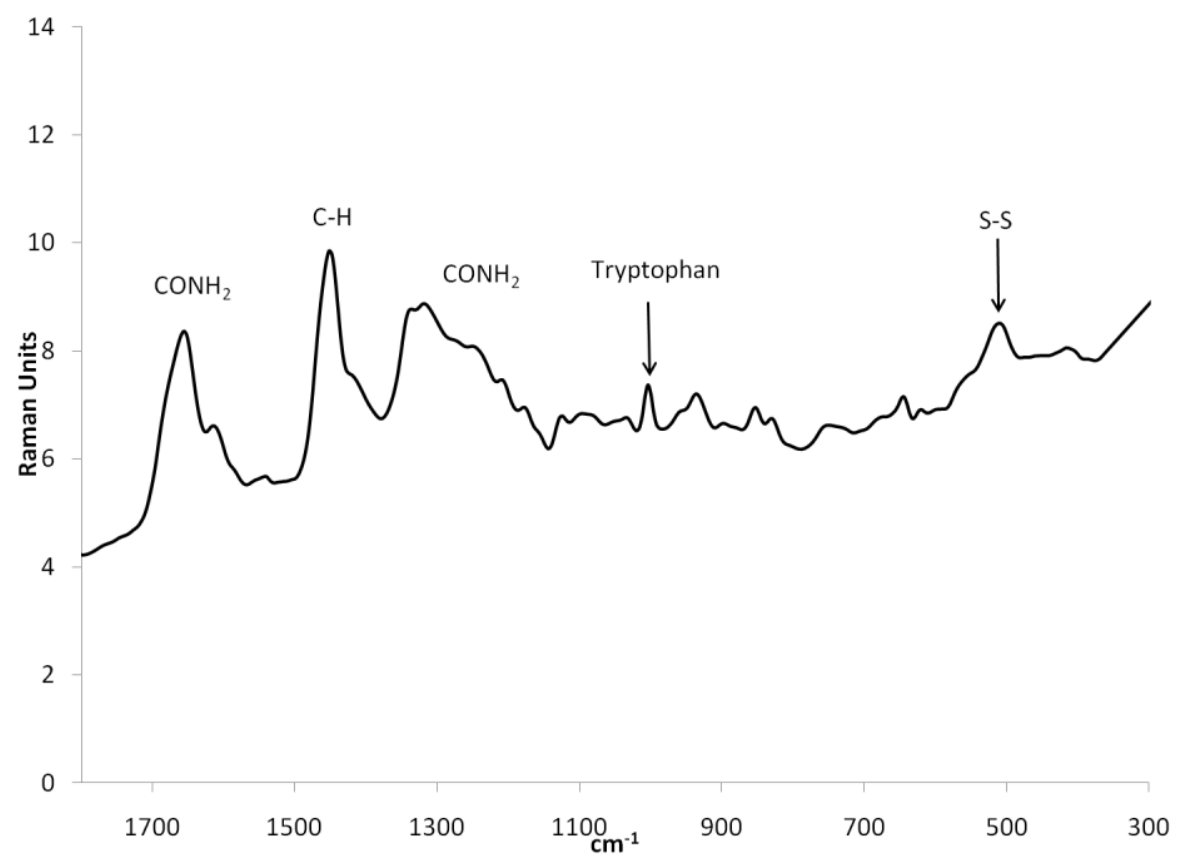

Figure 5.130: FT-IR Raman spectra of untreated semi-worsted merino wool.

Table 5.22: Vibrational assignments of untreated semi-worsted merino wool and a gold nanoparticlemerino wool composite.

\begin{tabular}{ll}
\hline Transition $\left(\mathbf{c m}^{-1}\right)$ & Proposed Assignment[50] \\
\hline 3320 & $\mathrm{~N}-\mathrm{H}$ stretching \\
3068 & $\mathrm{C}-\mathrm{N}-\mathrm{H}$ bending \\
2936 & $\mathrm{CH}_{3}$ stretching \\
1670,1270 & $\mathrm{CONH}_{2}$ stretching \\
1456 & $\mathrm{C}-\mathrm{H}$ bending \\
500 & S-S stretching \\
\hline
\end{tabular}

${ }_{\mathrm{R}}^{\mathrm{S}} \mathrm{S}_{\mathrm{S}}^{\mathrm{R}}+\mathrm{PR}_{3}^{-} \rightarrow\left[\mathrm{R}_{\mathrm{R}^{-}}\right.$

Figure 5.131 and Figure 5.132 offer pictures of gold nanoparticle-merino wool composites prepared with reduced (TCEP treated) and alkylated (TCEP + maleic acid treated) merino wool respectively. Pictures of composites incorporating merino wool soaked in a $\mathrm{pH} 4.5$ and 
$\mathrm{pH} 4.5+\mathrm{pH} 8$ buffer solution are also shown as controls, illustrating the effect the reduction and alkylation conditions had on the reducing capability of the fibres. From these pictures it can be seen that reducing and alkylating merino wool fibres prior to addition to the $\mathrm{Au}^{3+}$ solutions dramatically reduced their ability to reduce $\mathrm{Au}^{3+}$ to nanoparticulate $\mathrm{Au}^{0}$, resulting in the production of very under developed, spectrally impure coloured composite materials.

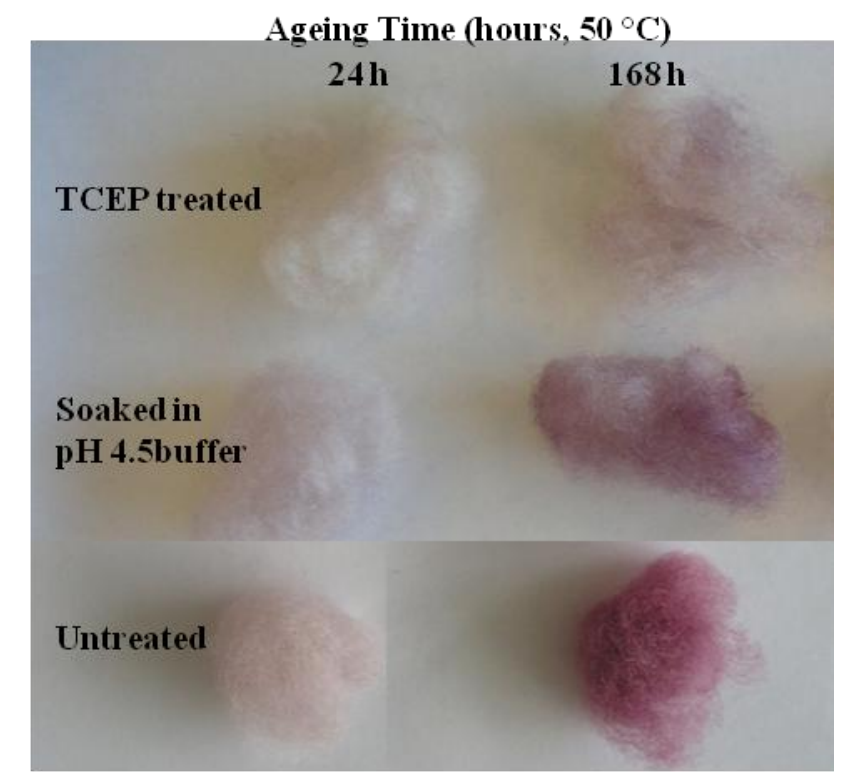

Figure 5.131: Gold nanoparticle-merino wool composites prepared by soaking TCEP pre-treated merino wool, merino wool that had been soaked in a $\mathrm{pH} 4.5$ buffer and untreated merino wool in a $160 \mathrm{ppm}(8.13$ x $\left.10^{-4} \mathrm{M}\right) \mathrm{Au}^{3+}$ solution for 24 hours at RT, followed by ageing at $50{ }^{\circ} \mathrm{C}$ for 24 or 168 hours.

XPS suggested the reduction of the disulfide groups of cystine by TCEP to be successful. In TCEP treated and alkylated merino wool there was a slight shift in the peak representing the average sulfur containing groups to lower binding energies (Figure 5.133), suggesting that there was a greater percentage of thiol functional groups relative to disulfide groups.[187] Examination of the deconvoluted, high resolution Au 4f XPS spectra of a gold nanoparticlemerino wool composite incorporating TCEP treated and alkylated merino wool (prepared with a soaking time, at RT of 24 hours and an ageing time, at $50{ }^{\circ} \mathrm{C}$ of 168 hours) showed the gold in these materials to be predominantly unreduced $\mathrm{Au}^{3+}(94 \%)$, with a small amount of $\mathrm{Au}^{+}$(in the form of $\left.\mathrm{Au}-\mathrm{S}\right)(5 \%)$ and a very small amount, $1 \%$, of nanoparticulate $\mathrm{Au}^{0}$ (Figure 5.134). These values may not be entirely correct as there may be slightly more $\mathrm{Au}^{+}$ and $\mathrm{Au}^{0}$, as these peaks may have been over shadowed by the very broad $\mathrm{Au}^{3+}$ peaks. The extremely small amount of $\mathrm{Au}^{0}$ nanoparticles on these fibres would account for the very under-developed colour of the materials. 


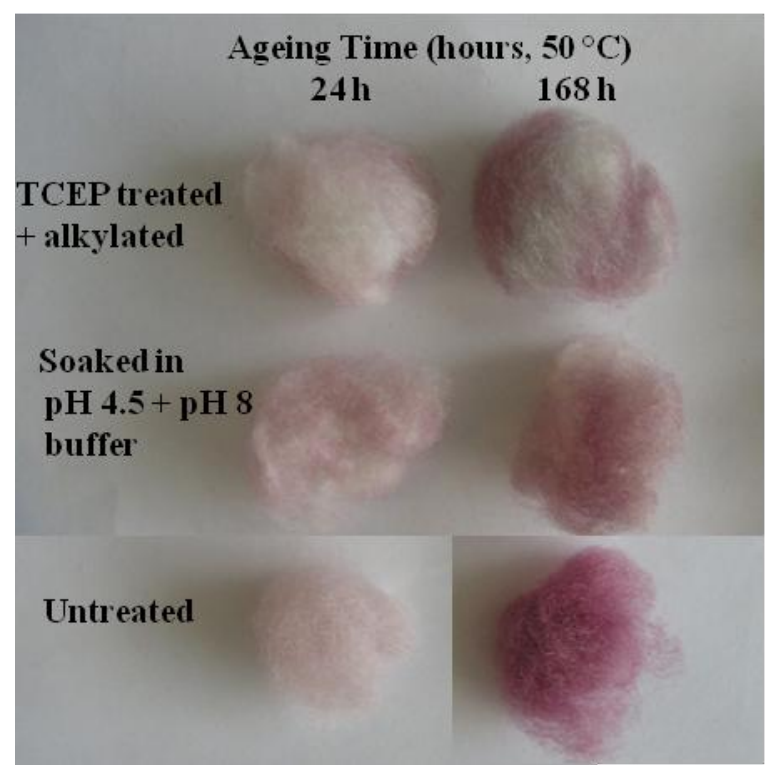

Figure 5.132: Gold nanoparticle-merino wool composites prepared by soaking TCEP + maleic acid pretreated merino wool, merino wool that had been soaked in a pH 4.5 and pH 8 buffer and untreated merino wool in a $160 \mathrm{ppm}\left(8.13 \times 10^{-4} \mathrm{M}\right) \mathrm{Au}^{3+}$ solution for 24 hours at $\mathrm{RT}$, followed by ageing at $50{ }^{\circ} \mathrm{C}$ for 24 or 168 hours.
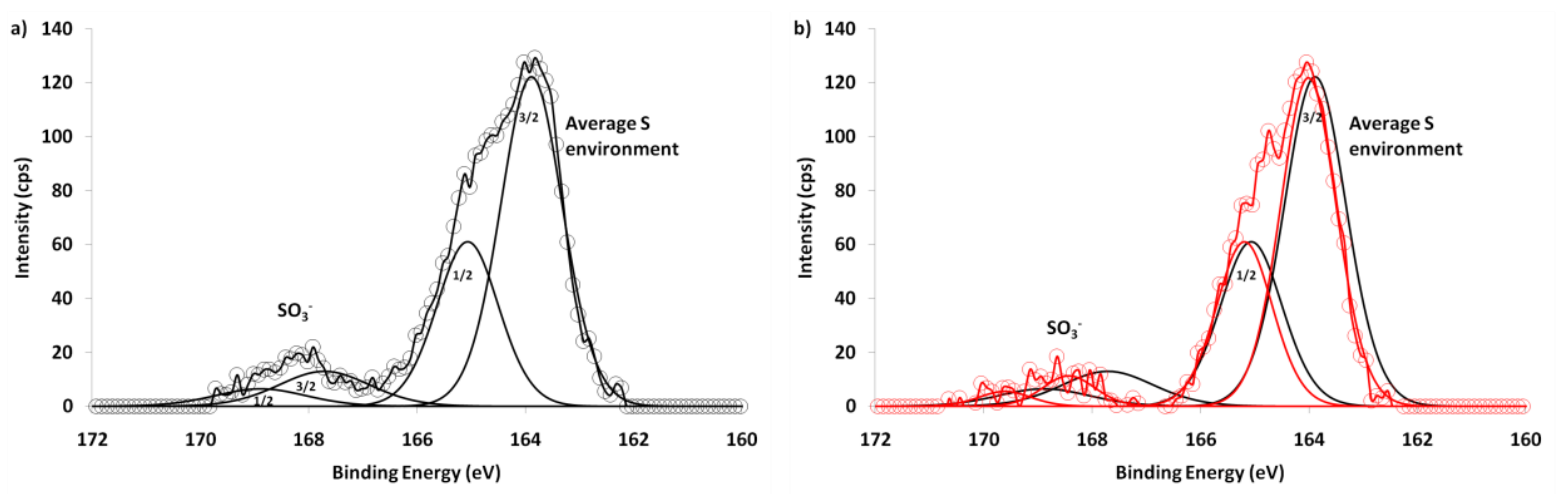

Figure 5.133: High resolution S 2p XPS spectra of a) TCEP treated merino wool and b) an overlay (in red) of untreated semi-worsted merino wool. 


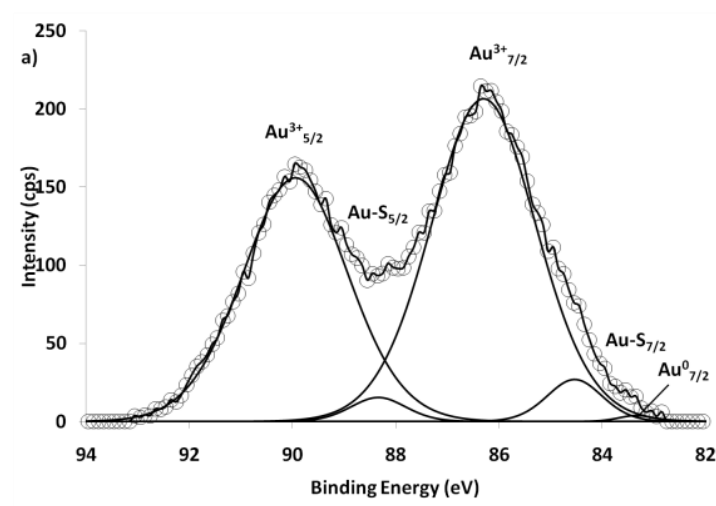

Figure 5.134: High resolution Au $4 \mathrm{f}$ XPS spectra of a gold nanoparticle-merino wool composites prepared by soaking TCEP treated and alkylated merino wool in a $160 \mathrm{ppm}\left(8.13 \times 10^{-4} \mathrm{M}\right) \mathrm{Au}^{3+}$ solution for 24 hours at RT, followed by ageing at $50{ }^{\circ} \mathrm{C}$ for 168 hours.

Examination of the $\mathrm{C} 1 \mathrm{~s}, \mathrm{~N}$ 1s and $\mathrm{S} 2 \mathrm{p}$ XPS spectra of the gold nanoparticle-merino wool composites incorporating TCEP treated and alkylated merino wool suggested that any gold nanoparticles formed in these materials bind to the wool fibres via both $\mathrm{Au}-\mathrm{S}$ and $\mathrm{Au}-\mathrm{N}$ bonds (Figure 5.135). The Au-S bonding was evidenced by the set of peaks centred at 161.25 and $162.43 \mathrm{eV}$ in the S $2 \mathrm{p}$ spectrum, and the $\mathrm{Au}-\mathrm{N}$ bonding by the peaks at $283.5 \mathrm{eV}$ and $398.8 \mathrm{eV}$ in the $\mathrm{C} 1 \mathrm{~s}$ and $\mathrm{N} 1 \mathrm{~s}$ spectra respectively. This suggests that due to reduction and alkylation, the number of $\mathrm{S}$ sites available for bonding was decreased relative to untreated merino wool, and as such bonding to $\mathrm{N}$ groups occurred.

Although bonding to nitrogen containing groups occurred, during the production of these composite materials there was no evidence of the oxidation of nitrogen containing functional groups such as amines, which would be illustrated by the presence of a peak centred at approximately $402 \mathrm{eV}$ in the $\mathrm{N} 1 \mathrm{~s}$ spectra. Rather the reduction of the very small amount of $\mathrm{Au}^{0}$ nanoparticles appeared to occur via the conventional route, notably via oxidation of a percentage of unreduced cystine disulfides to cysteic acid. This only occurred to a very small extent, and was evidenced by the slight increase in amount of cysteic acid relative to the general S environment of the wool (Figure 5.136, Table 5.23). As these changes were so minimal, and there were markedly less $\mathrm{Au}^{0}$ nanoparticles formed when employing TCEP treated and alkylated merino wool (as shown by XPS), it is highly likely that the reduction of $\mathrm{Au}^{3+}$ to $\mathrm{Au}^{0}$ during the production of the gold nanoparticle-merino wool composite materials is facilitated by the oxidation of cystine to cysteic acid. 

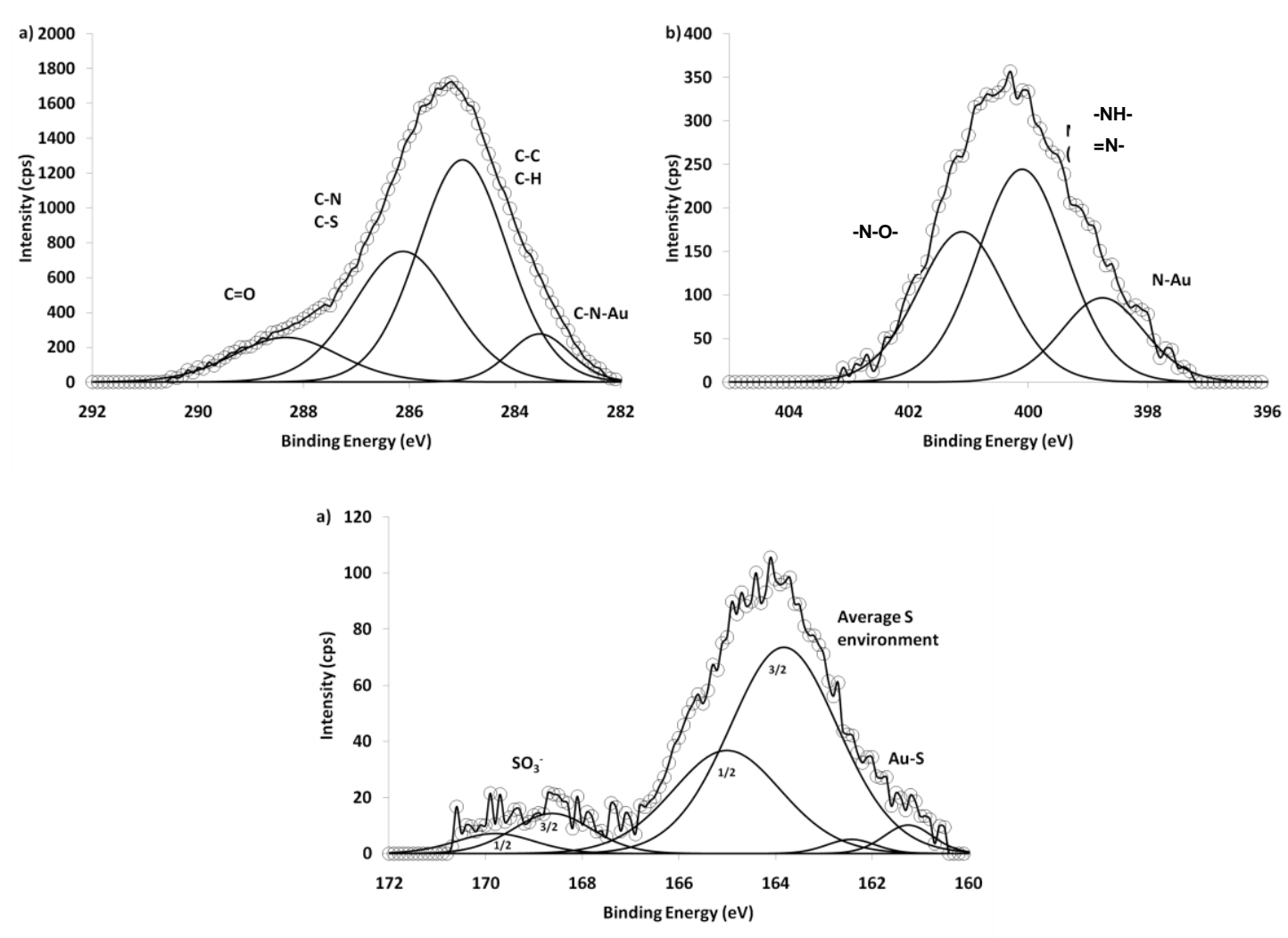

Figure 5.135: High resolution C 1s (a), N 1s (b) and S 2p (c) XPS spectra of a gold nanoparticle-merino wool composites prepared by soaking TCEP treated and alkylated merino wool in a $160 \mathrm{ppm}\left(8.13 \times 10^{-4}\right.$ M) $\mathrm{Au}^{3+}$ solution for 24 hours at RT, followed by ageing at $50{ }^{\circ} \mathrm{C}$ for 168 hours.

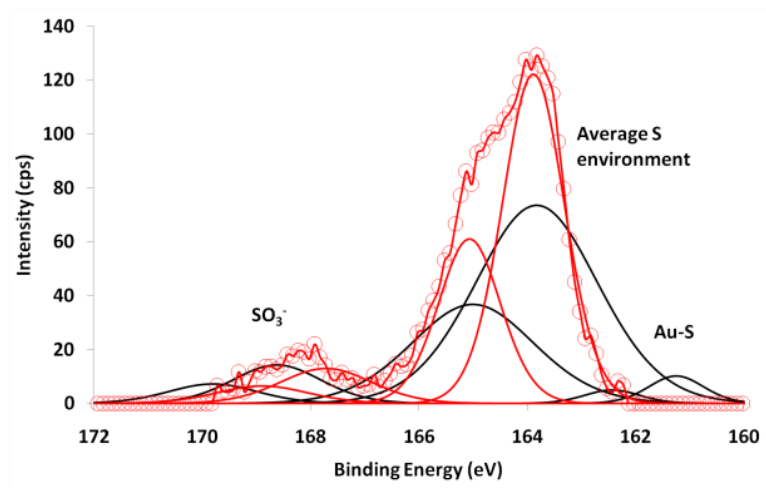

Figure 5.136: An overlay of the high resolution S 2p XPS spectra of a gold nanoparticle-merino wool composites prepared by soaking TCEP treated and alkylated merino wool in a $160 \mathrm{ppm}\left(8.13 \times 10^{-4} \mathrm{M}\right)$ $\mathrm{Au}^{3+}$ solution for 24 hours at RT, followed by ageing at $50{ }^{\circ} \mathrm{C}$ for 168 hours (black lines) and TCEP treated and alkylated merino wool (red lines). 
Table 5.23: S 2p XPS assignments of untreated TCEP treated and alkylated merino wool, and a gold nanoparticle-merino wool composite prepared from these fibres.

\begin{tabular}{|c|c|c|}
\hline & $\begin{array}{l}\text { TCEP treated } \\
\text { and alkylated } \\
\text { Merino Wool }\end{array}$ & Composite Material \\
\hline S Species & \multicolumn{2}{|c|}{ Relative Percentage (\% $\pm 10 \%)$} \\
\hline $\begin{array}{c}\text { Average S } \\
\text { environment } \\
\text { (S-S, S-H) }\end{array}$ & 84 & 80 \\
\hline $\mathrm{SO}_{3}^{-}$ & 16 & 14 \\
\hline S-Au & - & 6 \\
\hline $\mathrm{AvS}: \mathrm{SO}_{3}^{-}$ & 0.19 & 0.18 \\
\hline
\end{tabular}

It makes sense therefore that when employing $\mathrm{Cl} / \mathrm{H}$ treated merino wool as the fibre substrate in place of untreated merino wool during the production of the gold nanoparticle-merino wool composites the ability of the fibres to reduce $\mathrm{Au}^{3+}$ to nanoparticulate $\mathrm{Au}^{0}$ was drastically reduced. This was observed in the production of gold nanoparticle-merino wool composites prepared from $\mathrm{Cl} / \mathrm{H}$ treated merino wool, as employing ageing times of less than 168 hours (regardless of the $\mathrm{Au}^{3+}$ concentration) produced materials that were not dissimilar in colour to that of the base fibres, with SEM and XPS analysis of these materials revealing the presence of very little nanoparticulate $\mathrm{Au}^{0}$ (see sections 5.1.5 and 5.3). However when ageing times of 168 hours were employed nanoparticles were seen to form on the fibre surface. This imparted a rather spectrally impure, non-uniform purple colour to the materials.

During $\mathrm{Cl} / \mathrm{H}$ treatments the surface cystine groups of the wool fibres are oxidised to cysteic acid, thus dramatically reducing the ability of the fibres to reduce $\mathrm{Au}^{3+}$ to nanoparticulate $\mathrm{Au}^{0}$. This would account for the markedly underdeveloped colour of the composites prepared with an ageing time of less than 168 hours. However the fact that nanoparticles were formed when ageing times of 168 hours were employed, suggests that something other than the disulfide groups of cystine was facilitating the $\mathrm{Au}^{3+}$ to $\mathrm{Au}^{0}$ reduction. 
Examination of the deconvoluted high resolution XPS spectra of the composite materials prepared from $\mathrm{Cl} / \mathrm{H}$ treated merino, employing an ageing time of 168 hours suggested it was the Hercosett polymer on the surface of the fibres reducing $\mathrm{Au}^{3+}$ to $\mathrm{Au}^{0}$. Figure 5.137 offers a comparison of the deconvoluted, high resolution N 1s XPS spectra of a gold nanoparticlemerino wool composite (prepared by soaking $\mathrm{Cl} / \mathrm{H}$ treated merino wool in a $160 \mathrm{ppm}(8.13 \mathrm{x}$ $\left.10^{-4} \mathrm{M}\right) \mathrm{Au}^{3+}$ solution for 24 hours at RT, followed by ageing at $50{ }^{\circ} \mathrm{C}$ for 168 hours) and the base fibre $\mathrm{Cl} / \mathrm{H}$ treated merino wool. Several changes are observed in the spectra of the fibres upon inclusion of the gold nanoparticles; there is a shift in the amine and imine peaks and the formation of a new peak (centred at $\sim 397.53 \mathrm{eV}$ ) which as described in section 5.5.4, is likely reflective of the gold nanoparticles bonding to nitrogen atoms in either the fibre or the Hercosett polymer encapsulating the fibre.
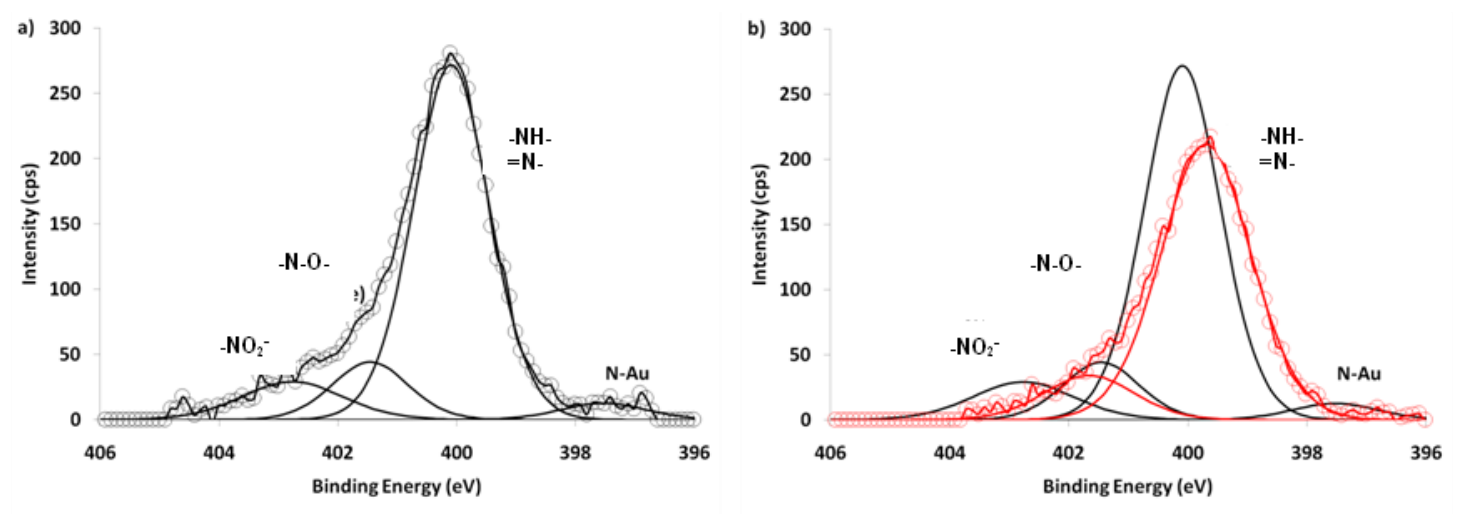

Figure 5.137: a) High resolution $N$ 1s spectra of a gold nanoparticle-merino wool composite prepared by soaking $\mathrm{Cl} / \mathrm{H}$ treated merino wool in a $160 \mathrm{ppm}\left(8.13 \times 10^{-4} \mathrm{M}\right) \mathrm{Au}^{3+}$ solution for 24 hours at RT, followed by ageing at $50{ }^{\circ} \mathrm{C}$ for 168 hours. b) An overlay (in red) of the $\mathrm{N} 1 \mathrm{~s}$ XPS spectrum of $\mathrm{Cl} / \mathrm{H}$ treated merino wool.

Additionally, a new peak centred at $402.77 \mathrm{eV}$ appeared in the composite. This peak has been reported to be representative of nitro groups $\left(\mathrm{NO}_{2}{ }^{-}\right),[241]$ which can be formed through the oxidation of primary amines. Both the protein fibres in the wool, and to a much lesser extent the Hercosett polymer possess primary amines (the latter found at the polymers terminating ends). It is unlikely that the amine groups in the wool fibres would undergo oxidation as this was not seen during the production of composites prepared from untreated merino wool. Oxidation of the primary amines at the terminating ends of the Hercosett 
polymer may occur; however as this polymer forms crosslinks via condensation reactions, these groups are present in very low concentrations. Prolonged heating in mildly acidic aqueous solutions (occurring during ageing) may hydrolyse a percentage of these crosslinks, leaving them available for oxidation, which if this is the case would account for the formation of nanoparticulate $\mathrm{Au}^{0}$ and subsequent development of colour occurring only after 168 hours ageing.

In addition to the oxidation of amine groups to nitro groups, the $\mathrm{Au}^{3+}$ to $\mathrm{Au}^{0}$ reduction may have been facilitated by the oxidation of the secondary alcohols of the Hercosett polymer to a ketone. However examination of the deconvoluted, high resolution O 1s XPS spectra of a gold nanoparticle-merino wool composite prepared from $\mathrm{Cl} / \mathrm{H}$ treated merino wool, and $\mathrm{Cl} / \mathrm{H}$ treated merino wool itself reveal little to no changes (Figure 5.138), therefore discrediting this reaction mechanism. Once formed, these nanoparticles appeared to bond to the $\mathrm{Cl} / \mathrm{H}$ treated merino wool through both $\mathrm{N}$ and $\mathrm{S}$ atoms (see section 5.5.4).
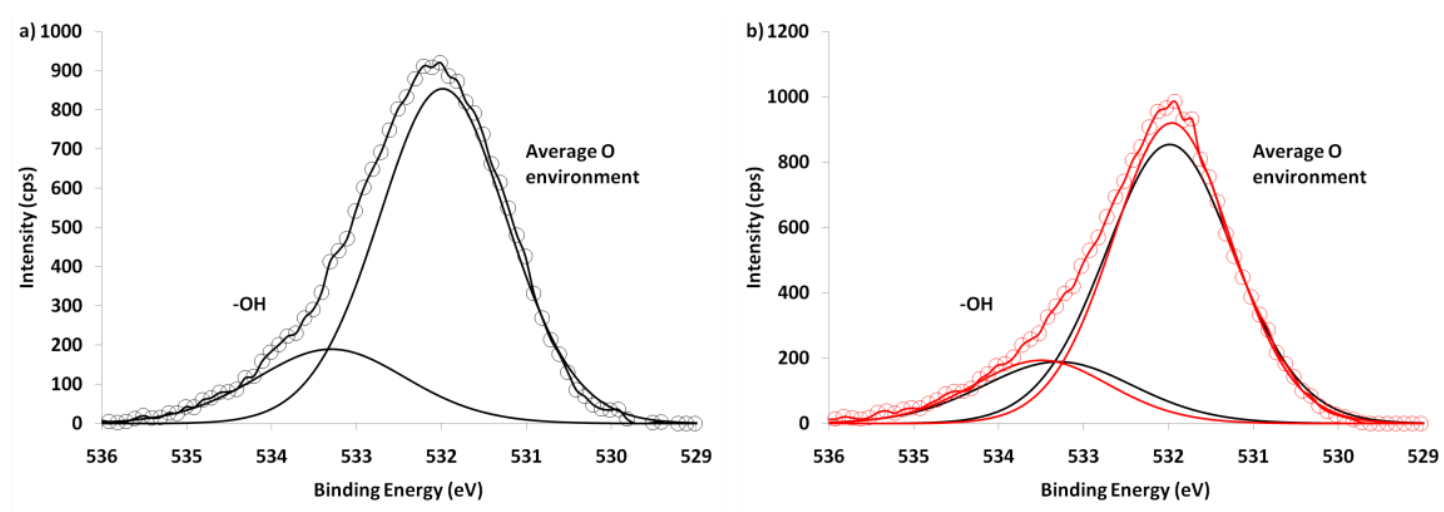

Figure 5.138: a) High resolution $O$ 1s spectra of a gold nanoparticle-merino wool composite prepared by soaking $\mathrm{Cl} / \mathrm{H}$ treated merino wool in a $160 \mathrm{ppm}\left(8.13 \times 10^{-4} \mathrm{M}\right) \mathrm{Au}^{3+}$ solution for 24 hours at RT, followed by ageing at $50^{\circ} \mathrm{C}$ for 168 hours. b) An overlay (in red) of the $\mathrm{O} 1 \mathrm{~s}$ XPS spectrum of $\mathrm{Cl} / \mathrm{H}$ treated merino wool.

Pre-treating the $\mathrm{Cl} / \mathrm{H}$ treated merino wool fibres with $0.1 \mathrm{M} \mathrm{KOH}$ solutions (as outlined in section 2.2.2.3.1) dramatically increased the colour of the resultant composites incorporating $\mathrm{Cl} / \mathrm{H}$ treated merino wool, due to the formation of a much larger concentration of 
nanoparticles (see section 5.1.5.1). These nanoparticles were located primarily on the surface of the wool fibres, and appeared to be lodged in the Hercosett polymer encapsulating the fibres. Additionally, during the ageing process, gold nanoparticles were formed in solution, something that did not occur in any other woollen system.

This suggests that base treating the $\mathrm{Cl} / \mathrm{H}$ treated merino wool prior to addition to the $\mathrm{Au}^{3+}$ solution dramatically enhanced the proteins' or the Hercosett polymer's ability to facilitate the $\mathrm{Au}^{3+}$ to $\mathrm{Au}^{0}$ reduction. As it was the Hercosett polymer that was thought to be facilitating this reduction in the composite materials incorporating untreated $\mathrm{Cl} / \mathrm{H}$ treated merino wool, it is likely that it was this polymer rather than the wool fibres facilitating the reduction in this case, with base treating making it more susceptible to oxidation.

The Hercosett polymer is a polyamide epichlorhydrin type polymer which is capable of crosslinking via condensation reactions through primary and secondary amino groups in the polyamide backbone. Thus it contains amide functional groups, which under mildly basic conditions can undergo hydrolysis to yield carboxylic acids and secondary amines (scheme 5.4). These reactions may occur within individual polymer moieties or between them, breaking crosslinks within the polymer

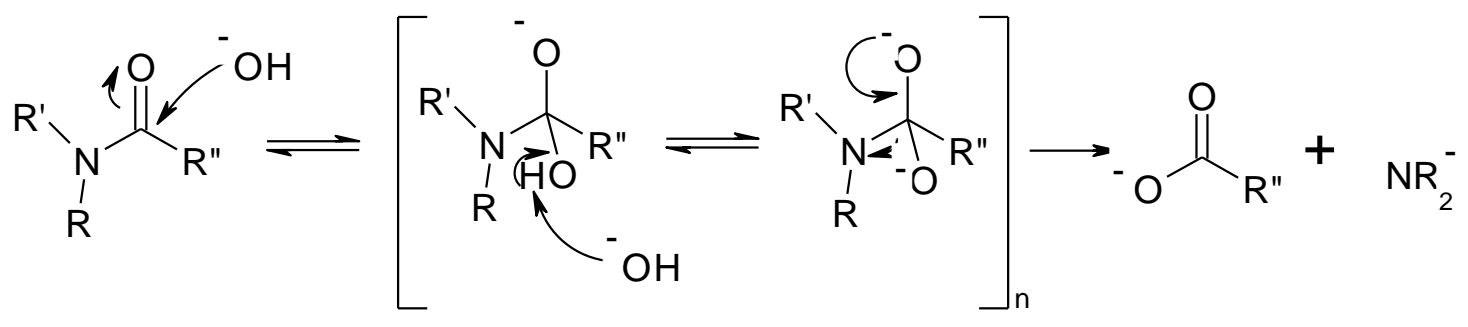

If amide hydrolysis was occurring during base treatment there would be more amine groups available to facilitate the $\mathrm{Au}^{3+}$ to $\mathrm{Au}^{0}$ reduction (in the form of terminal amine groups or amines formed through the hydrolysis of the amides in individual polymer molecules), thus increasing the reducing capability of the $\mathrm{Cl} / \mathrm{H}$ treated merino wool. The fact that nanoparticles were also formed in solution suggests that something was released from the $\mathrm{Cl} / \mathrm{H}$ treated wool fibre during the course of the reaction. This may be small amine 
containing molecules which could then reduce $\mathrm{Au}^{3+}$ to nanoparticulate $\mathrm{Au}^{0}$, (themselves being oxidized to some form of nitro compound) and simultaneously stabilise the resultant nanoparticles.

XPS was unable to substantiate or confirm these theories, as the deconvoluted, high resolution $\mathrm{C} 1 \mathrm{~s}, \mathrm{~N}$ 1s, $\mathrm{O} 1 \mathrm{~s}$ and $\mathrm{S} 2 \mathrm{p}$ XPS spectra of $\mathrm{Cl} / \mathrm{H}$ treated merino wool remained largely unchanged following base treatment (Figure 5.139 and Figure 5.140). There were slight changes in the position of both the amine/imine peak and nitrogen bound to oxygen peak in the base treated fibres however this did not provide substantial evidence of amide hydrolysis.
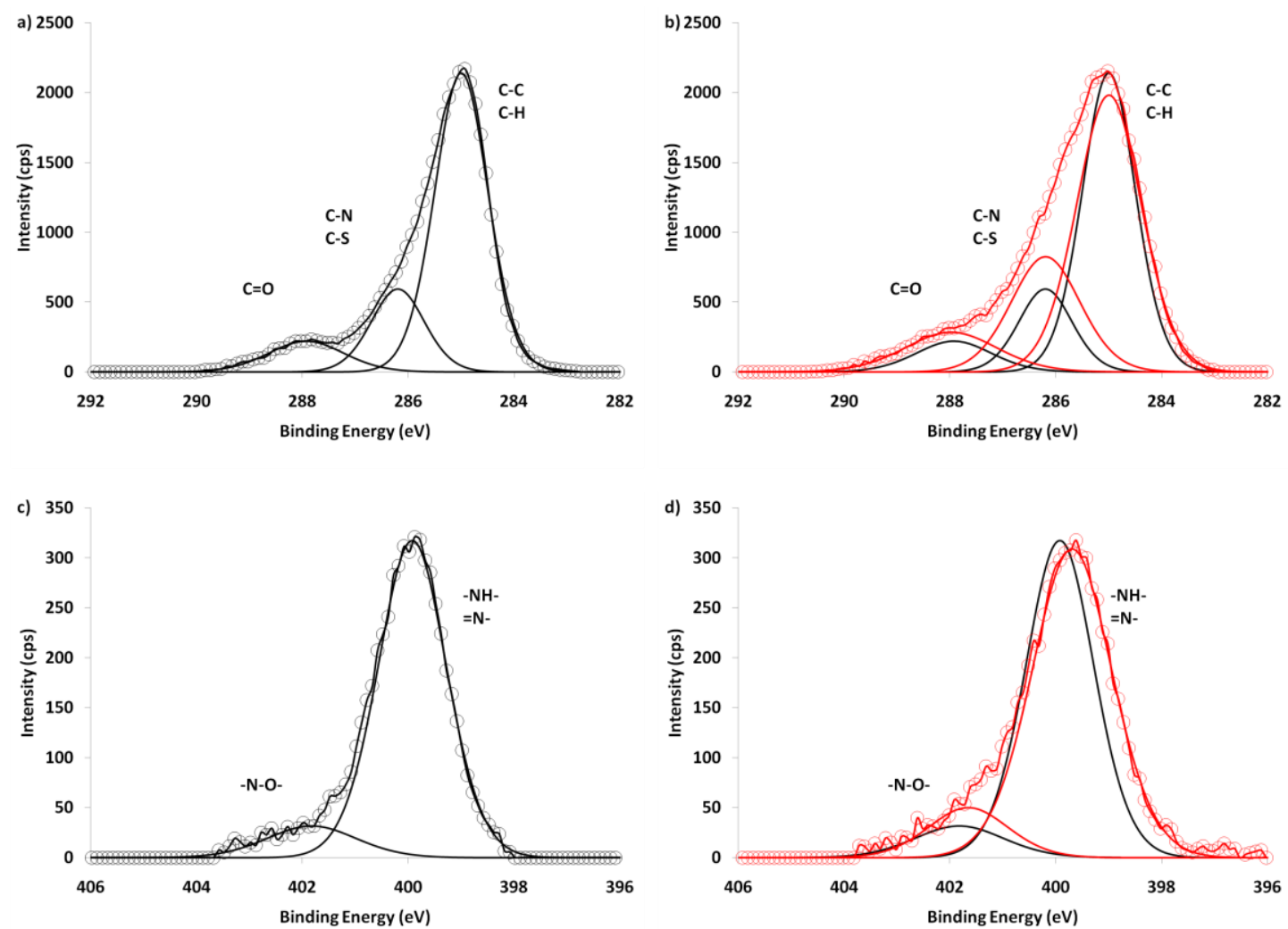

Figure 5.139: High resolution C 1s (a) and N 1s (c) XPS spectra of base treated Cl/H treated merino wool. b) and d) show an overlay or the corresponding $\mathrm{C} 1 \mathrm{~s}$ and $\mathrm{N} 1 \mathrm{~s}$ spectra of untreated $\mathrm{Cl} / \mathrm{H}$ treated merino wool (in red). 

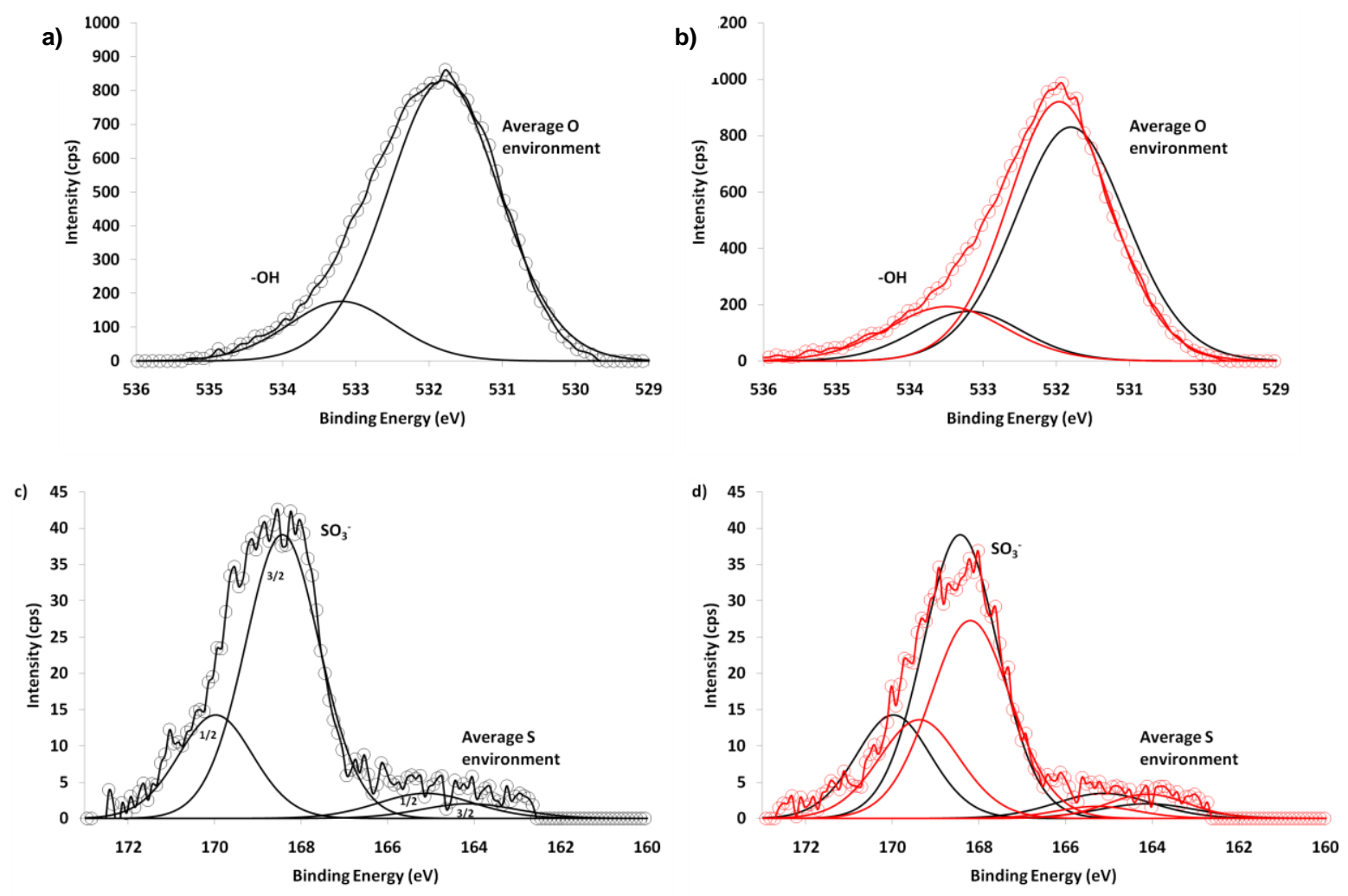

Figure 5.140: High resolution $\mathrm{O} 1 \mathrm{~s}(\mathrm{a})$ and $\mathrm{S} 2 \mathrm{p}$ (c) XPS spectra of base treated $\mathrm{Cl} / \mathrm{H}$ treated merino wool. b) and d) show an overlay or the corresponding $\mathrm{O}$ 1s and $\mathrm{S} 2 \mathrm{p}$ spectra of untreated $\mathrm{Cl} / \mathrm{H}$ treated merino wool (in red).

Comparisons of the XPS spectra of base treated $\mathrm{Cl} / \mathrm{H}$ treated merino wool and a gold nanoparticle-merino wool composite prepared from such fibres did however provide information about the reduction mechanism. There was a much greater percentage of nitro groups in the composite materials relative to base treated $\mathrm{Cl} / \mathrm{H}$ treated merino wool, suggesting that a proportion of amines had been oxidised (Figure 5.141). The oxidised amine groups accounted for $25 \%$ of the nitrogen species, $14 \%$ more than observed in composite materials prepared with untreated $\mathrm{Cl} / \mathrm{H}$ treated merino wool, suggesting that a greater percentage of amines had been oxidised, in turn reducing more $\mathrm{Au}^{3+}$ to nanoparticulate $\mathrm{Au}^{0}$. 

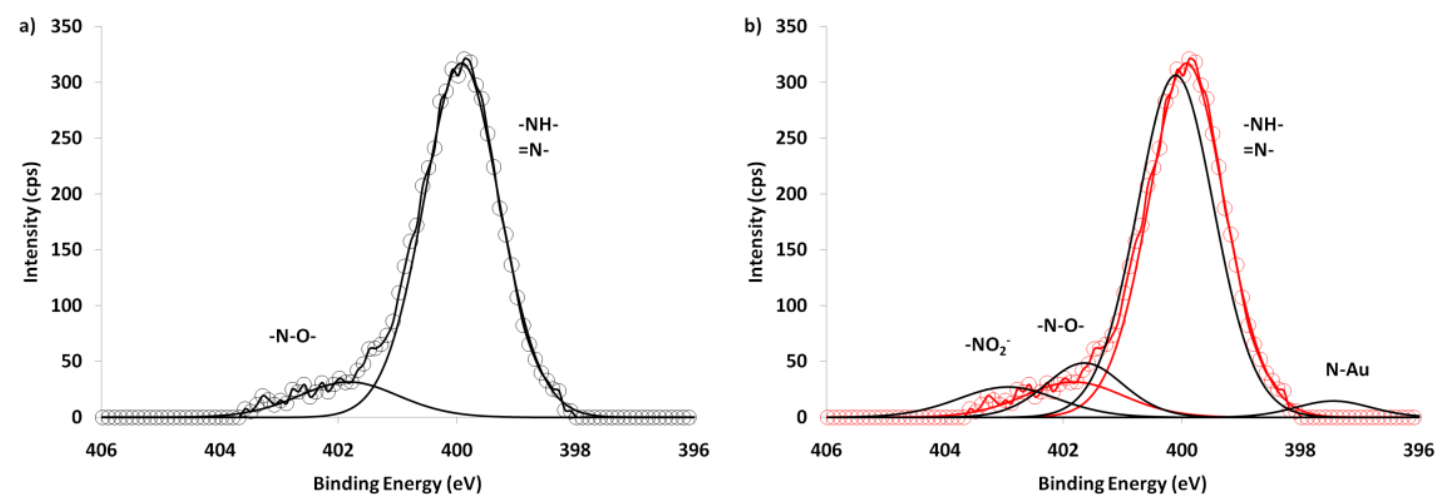

Figure 5.141: a) High resolution N 1s XPS spectra of gold nanoparticle-merino wool composites prepared by soaking KOH pre-treated $\mathrm{Cl} / \mathrm{H}$ treated merino wool in a $160 \mathrm{ppm}\left(8.13 \times 10^{-4} \mathrm{M}\right) \mathrm{Au}^{3+}$ solution for 24 hours at RT, followed by ageing at $50{ }^{\circ} \mathrm{C}$ for 168 hours. b) An overlay (in red) of the N 1s XPS spectrum of $\mathrm{KOH}$ pre-treated $\mathrm{Cl} / \mathrm{H}$ treated merino wool.

\subsection{Colour Fastness, Light Fastness, Washability and Wearability}

The applicability of the gold nanoparticle-merino wool composite materials (prepared through utilisation of the redox active nature of the proteins present in merino wool) for use in consumer products was investigated by testing their colour fastness to washing, rubbing, chlorinated water and light.

The colour stability of the materials is dependent upon the stability of the nanoparticle size, and also the robustness of the bond between the nanoparticles and wool fibres. As mentioned, nanoparticles possess high surface energies making them extremely reactive so that without surface passivation they tend to agglomerate together as a result of Ostwald Ripening. Immobilising the gold nanoparticles on the wool fibre imparts stability to the nanoparticles as the proteins present in merino wool, in particular the sulfur containing amino acids cystine and cysteine, bind to the nanoparticles acting as a capping agent. In theory this should stabilise the nanoparticles and hence the colour of the resultant gold nanoparticlemerino wool composites. 
The stability of the bond between the gold nanoparticles and merino wool fibres, and hence the colour stability of the composite materials was investigated via stimulated washability test (as outlined in section 2.3.14). This involved agitating the samples in a $0.1 \mathrm{wt} \%$ dishwashing liquid solution for half an hour to 24 hours at room temperature or $50{ }^{\circ} \mathrm{C}$. Composites prepared by soaking untreated semi-worsted merino wool in a $160 \mathrm{ppm}(8.13 \mathrm{x}$ $\left.10^{-4} \mathrm{M}\right) \mathrm{Au}^{3+}$ solution for 24 hours at RT, followed by ageing at $50{ }^{\circ} \mathrm{C}$ for 24 or 168 hours were chosen as representatives of the composites materials, as these were the most uniform, spectrally pure coloured textiles prepared through utilisation of the redox active nature of merino wool.

Figure 5.142 and Figure 5.143 offer photographs of samples that have been in the washing solution for 0.5 to 24 hours. Visually it appears that the colour of either set of samples had remained constant and not faded upon washing, even following extended washing (24 hours) at elevated temperatures $\left(50{ }^{\circ} \mathrm{C}\right)$.

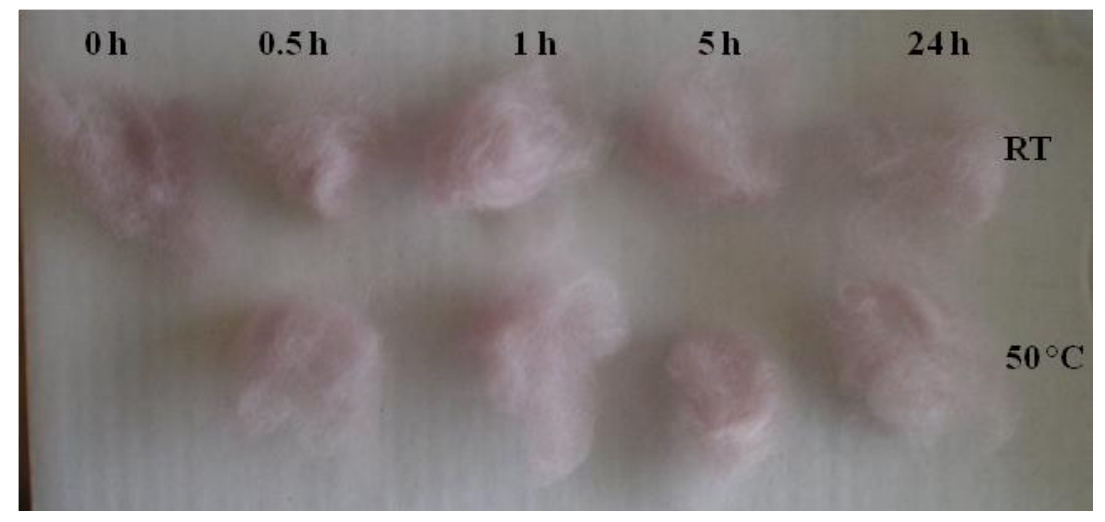

Figure 5.142: Gold nanoparticle-merino wool composites (prepared by soaking untreated semi-worsted merino wool in a $160 \mathrm{ppm}\left(8.13 \times 10^{-4} \mathrm{M}\right) \mathrm{Au}^{3+}$ solution for 24 hours at RT followed by heating at $50{ }^{\circ} \mathrm{C}$ for 24 hours) following simulated washability tests. 


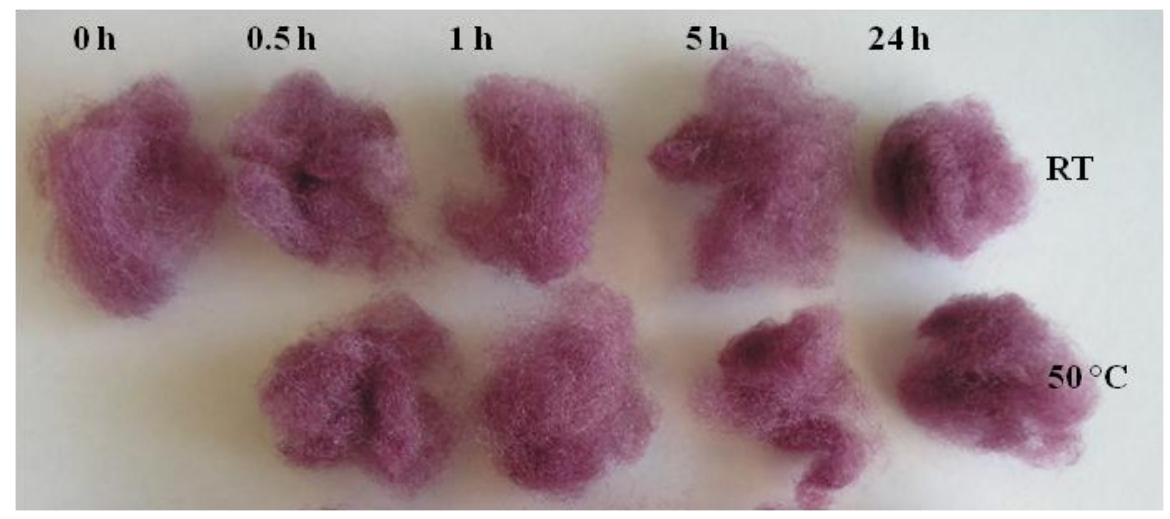

Figure 5.143: Gold nanoparticle-merino wool composites (prepared by soaking untreated semi-worsted merino wool in a $160 \mathrm{ppm}\left(8.13 \times 10^{-4} \mathrm{M}\right) \mathrm{Au}^{3+}$ solution for 24 hours at RT followed by heating at $50{ }^{\circ} \mathrm{C}$ for 168 hours) following simulated washability tests.

The CIE L*, a*, $\mathrm{b}^{*}, 457 \mathrm{~nm}$ brightness and $580 \mathrm{~nm}$ brightness values of the composite materials following washing are provided in Appendix IV. When washing either sample at RT, there were only very minimal decreases in the $457 \mathrm{~nm}$ brightness and $580 \mathrm{~nm}$ brightness values. These decreases occurred during the first half hour of washing, following which the values remained relatively constant (Figure 5.144 and Figure 5.145). These changes were more pronounced when washing at $50{ }^{\circ} \mathrm{C}$. This suggests that upon washing the composite materials became slightly lighter, most likely due to the dislodgement of nanoparticles loosely bound to the surface of the merino wool fibres. However as there was no apparent colour change upon washing observed by the eye, this lightening was minimal. 


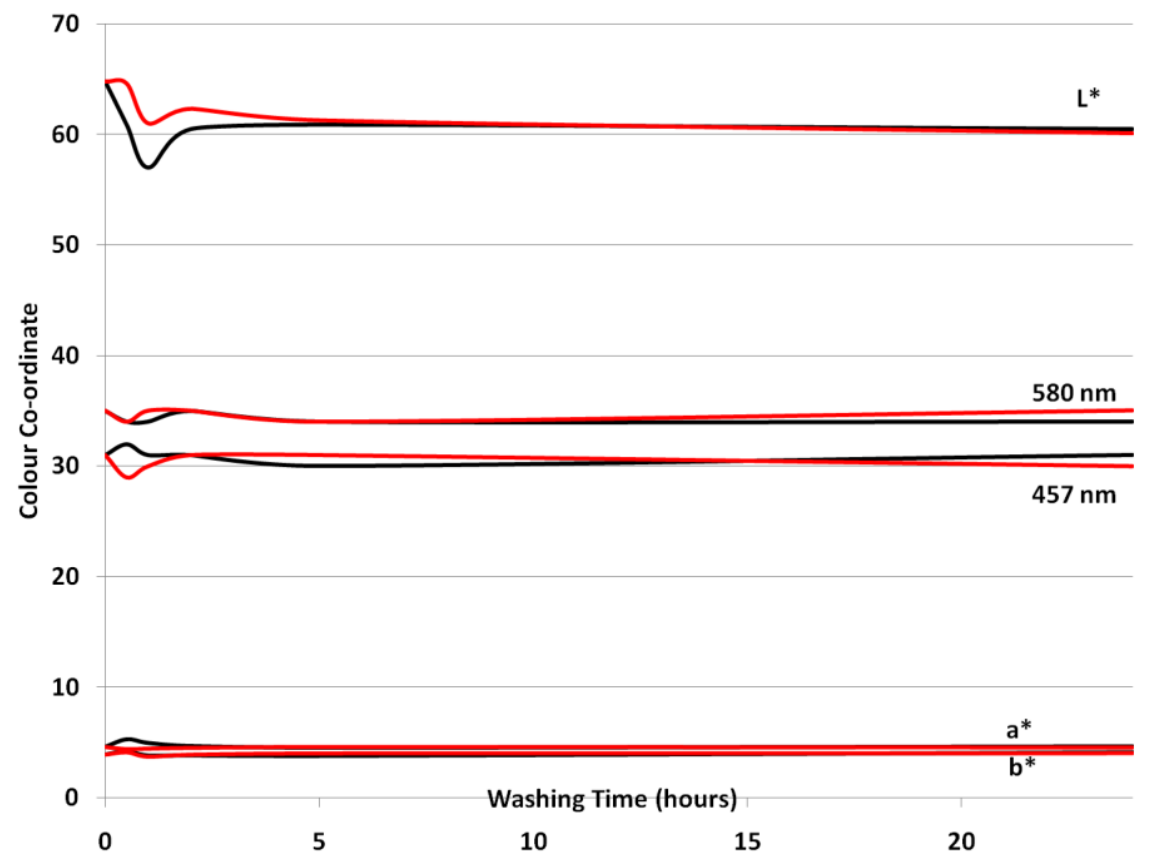

Figure 5.144: Changes in $L^{*}, a^{*}, b^{*}, 457 \mathrm{~nm}$ brightness and $580 \mathrm{~nm}$ brightness values for a gold nanoparticle-merino composite (prepared by soaking untreated semi-worsted merino wool in a $160 \mathrm{ppm}$ $\left(8.13 \times 10^{-4} \mathrm{M}\right) \mathrm{Au}^{3+}$ solution for 24 hours followed by heating at $50{ }^{\circ} \mathrm{C}$ for 24 hours) following simulated washability tests show the colour change due to washing. Washing at RT (black lines) or $50{ }^{\circ} \mathrm{C}$ (red lines).

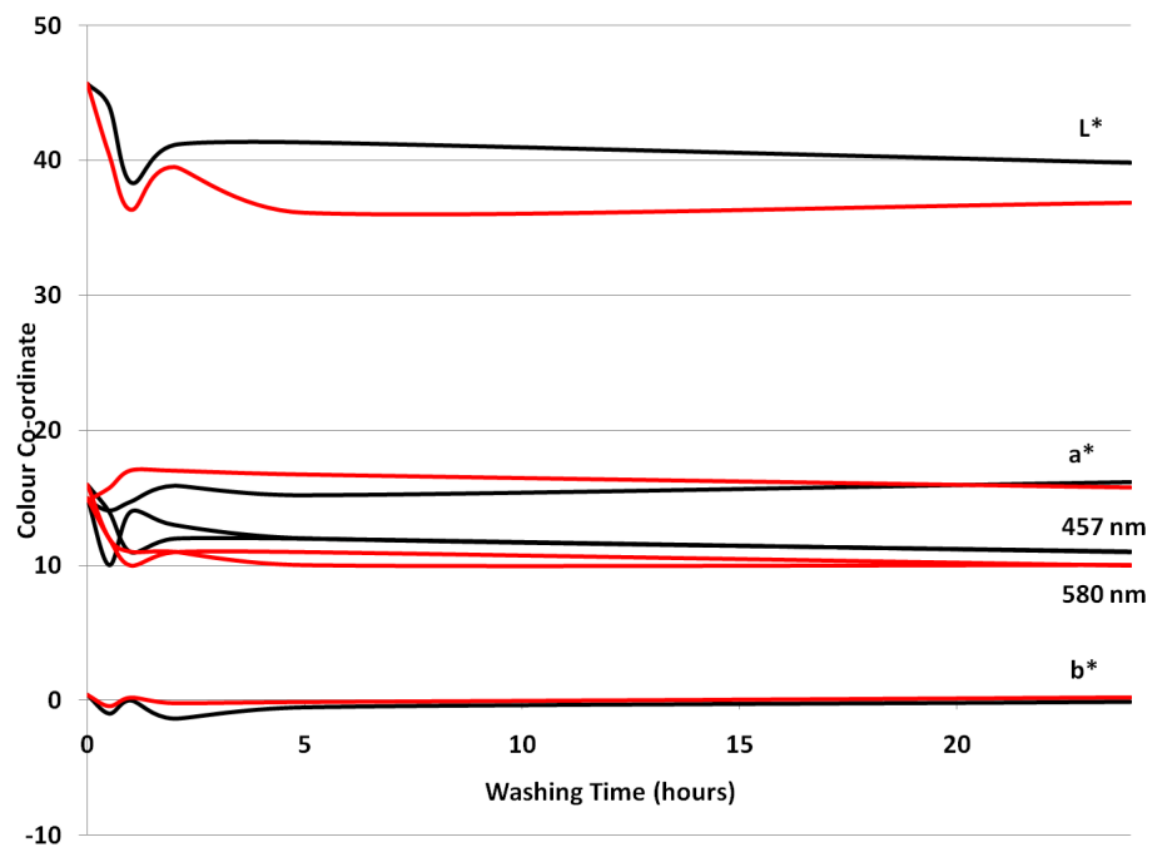

Figure 5.145: Changes in $L^{*}, a^{*}, b^{*}, 457 \mathrm{~nm}$ brightness and $580 \mathrm{~nm}$ brightness values for a gold nanoparticle-merino composite (prepared by soaking untreated semi-worsted merino wool in a $160 \mathrm{ppm}$ $\left(8.13 \times 10^{-4} \mathrm{M}\right) \mathrm{Au}^{3+}$ solution for 24 hours followed by heating at $50{ }^{\circ} \mathrm{C}$ for 168 hours) following simulated washability tests show the colour change due to washing. Washing at RT (black lines) or $50{ }^{\circ} \mathrm{C}$ (red lines). 
The colour fastness of these materials was tested further according to industry standard tests (see section 2.3.14). A summary of the results of these tests is provided in Table 5.24 below. Colour fastness to washing tests were carried out at AgResearch Ltd, Lincoln, according to the industry standard Woolmark Company Test Method 5 procedure. Possible results of these tests are grades ranging from 1 to 5, with 1 being poor and 5 excellent. Both samples (those that had been aged for 24 hours and those that had been aged for 168 hours) achieved excellent results, obtaining grades of 4-5, and are therefore colourfast with respect to washing, confirming the results obtained from the preliminary tests reported above.

In addition to testing the materials for colour fastness to washing, colour fastness to chlorinated swimming pool water and rubbing tests were also undertaken. The obtainable grades for these tests are 1 to 5 , with a grade of 1 denoting a severe change in colour and 5 no change in colour. In all, the gold nanoparticle-merino wool composites obtained on average a grade of 4-5, proving these materials to be extremely colour fast with respect to chlorinated swimming pool water and also rubbing in both wet and dry conditions.

It is likely that the materials were so colour fast with respect to washing in detergent and chlorinated swimming pool waters and also to rubbing in both wet and dry conditions as the nanoparticles are bound to the wool fibres via strong Au-S bonds. Additionally, these nanoparticles, which impart colour to the composites are not present solely on the surface of the fibre, rather they also reside under the cuticle cells and throughout the fibre centres. This makes these materials viable products for consumer applications, as their colour will not fade upon washing or rub off during wear.

In addition to colour fastness to washing and rubbing, the gold nanoparticle-merino wool materials were very light fast, obtaining a grade of 6 in industry standard tests, where a grade of 1 denotes poor light fastness and 8 excellent light fastness. A pass rate for apparel is a grade of 4-5. The slight change in colour of these materials during these tests was due to a yellowing of the merino wool itself, not the gold nanoparticles bound to it. The superior light fastness of these materials is an advantage considering the propensity of traditional organic dyes to fade or denature in light. 
Table 5.24: Results of industry standard colour fastness and light fastness tests. Note: the values in brackets are the obtainable grades, with the lowest being poor and highest excellent.

\begin{tabular}{cccccc}
\hline \multirow{2}{*}{ Sample } & Light Fastness & \multicolumn{4}{c}{ Colour Fastness To: } \\
\cline { 3 - 6 } & $(1-8)$ & $\begin{array}{c}\text { Washing } \\
(1-5)\end{array}$ & $\begin{array}{c}\text { Chlorinated } \\
\text { Water (1-5) }\end{array}$ & $\begin{array}{c}\text { Rubbing-Dry } \\
(1-5)\end{array}$ & $\begin{array}{c}\text { Rubbing-Wet } \\
(1-5)\end{array}$ \\
\hline Pink-24 h Age & 6 & $4-5$ & $4-5$ & $4-5$ & $4-5$ \\
Purple-168 h Age & 6 & $4-5$ & $4-5$ & $4-5$ & $4-5$ \\
\hline
\end{tabular}

\section{$5.8 \quad$ Leaching}

Little is known about the long term health and environmental impact of nanoparticles; hence it is important to limit their leaching from consumer products. As such, quantitative analysis of the washing solutions (obtained during the preliminary colour fastness to washing tests carried out in section 5.7 above) was undertaken to determine the amount of gold leached from the gold nanoparticle-merino wool composites during washing (see sections 2.2.2.5 and 2.3.4 for procedural details). Again composite materials prepared by soaking untreated semiworsted merino wool in a $160 \mathrm{ppm}\left(8.13 \times 10^{-4} \mathrm{M}\right) \mathrm{Au}^{3+}$ solution for 24 hours at RT, followed by ageing at $50{ }^{\circ} \mathrm{C}$ for 24 or 168 hours were chosen as representatives of the composites materials.

AA studies of the washing solutions revealed the leaching of very low amounts of gold, up to a maximum of $0.6 \mathrm{ppm} \pm 0.5 \mathrm{ppm}$, less than $1 \mathrm{wt} \%$ of the total gold loading for samples prepared with an ageing time of 24 hours, and $3.5 \mathrm{ppm}$, or approximately $2 \mathrm{wt} \%$ of the total gold loading for those prepared with 168 hours ageing (Table 5.25). These amounts are very low, and complement the results obtained in the colour fastness to washing tests, where the materials did not undergo any marked colour change even following extensive washing at elevated temperatures.

It is interesting to note that the purple coloured gold nanoparticle-merino wool composites, prepared with an ageing time of 168 hours leached more gold than those prepared with an 
ageing time of 24 hours. This is likely related to the increased amount of nanoparticles forming on the surface of the materials prepared with longer ageing times, with a similar percentage of gold leaching from nanoparticles bound to the surface of the fibres in each composite. Work will be undertaken in the future to determine the form of this leached gold.

Table 5.25: Gold leached from gold nanoparticle-merino wool composites (prepared by soaking untreated semi-worsted merino wool in a $160 \mathrm{ppm}\left(8.13 \times 10^{-4} \mathrm{M}\right) \mathrm{Au}^{3+}$ solution for 24 hours at RT,

followed by ageing at $50{ }^{\circ} \mathrm{C}$ for 24 or 168 hours) following simulated washability testing.

\begin{tabular}{|c|c|c|c|c|}
\hline Sample & $\begin{array}{c}\text { Washing } \\
\text { Temperature }\end{array}$ & $\begin{array}{c}\text { Washing } \\
\text { Time (hours) }\end{array}$ & $\begin{array}{l}\text { Gold Leached } \\
\text { (ppm) } \pm 0.5 \\
\text { ppm }\end{array}$ & $\begin{array}{l}\text { Gold Leached } \\
\text { (\% total gold } \\
\text { loading) }\end{array}$ \\
\hline \multirow{10}{*}{$\begin{array}{l}\text { Pink, Soak } 160 \\
\text { ppm } \mathrm{Au}^{3+} 24 \mathrm{~h} \text { RT, } \\
\text { heat } 50^{\circ} \mathrm{C} 24 \mathrm{~h}\end{array}$} & \multirow[t]{5}{*}{ RT } & 0.5 & 0.4 & $<1$ \\
\hline & & 1 & 0.3 & $<1$ \\
\hline & & 2 & 0.3 & $<1$ \\
\hline & & 5 & 0.4 & $<1$ \\
\hline & & 24 & 0.6 & $<1$ \\
\hline & \multirow[t]{5}{*}{$50 \stackrel{\circ}{C}$} & 0.5 & 0.4 & $<1$ \\
\hline & & 1 & 0.6 & $<1$ \\
\hline & & 2 & 0.5 & $<1$ \\
\hline & & 5 & 0.5 & $<1$ \\
\hline & & 24 & 0.6 & $<1$ \\
\hline \multirow{10}{*}{$\begin{array}{l}\text { Purple, Soak } 160 \\
\text { ppm } \mathrm{Au}^{3+} 24 \mathrm{~h} \mathrm{RT} \text {, } \\
\text { heat } 50^{\circ} \mathrm{C} 168 \mathrm{~h}\end{array}$} & \multirow[t]{5}{*}{ RT } & 0.5 & 2.3 & 2 \\
\hline & & 1 & 2.4 & 2 \\
\hline & & 2 & 3.0 & 2 \\
\hline & & 5 & 2.1 & 1 \\
\hline & & 24 & 2.3 & 1 \\
\hline & \multirow[t]{5}{*}{$50 \stackrel{\circ}{C}$} & 0.5 & 3.5 & 2 \\
\hline & & 1 & 2.9 & 2 \\
\hline & & 2 & 2.5 & 2 \\
\hline & & 5 & 2.5 & 2 \\
\hline & & 24 & 2.6 & 2 \\
\hline
\end{tabular}




\subsection{Anti-microbial and Insecticide Properties}

As with the Ag-PMA-clay composites, the gold nanoparticle-merino wool composites were tested for anti-microbial activity against the bacteria Staphylococcus aureus according to the procedure outlined in section 2.3.13. Composites prepared by soaking untreated semiworsted merino wool in a $160 \mathrm{ppm}\left(8.13 \times 10^{-4} \mathrm{M}\right) \mathrm{Au}^{3+}$ solution for 24 hours at RT, followed by heating at $50{ }^{\circ} \mathrm{C}$ for 24 or 168 hours were chosen and tested as representatives.

Figure 5.146 offers a picture of a range of gold nanoparticle-merino wool composite materials embedded on agar plates that have been incubated with Staphylococcus aureus for 24 hours and sterilized. Since the bacterium grows up to but not upon the samples they resist microbial attack, classing them as being bacteriostatic. Both the composite prepared with an ageing time of 24 hours and that prepared with 168 hours ageing exhibited comparable results.
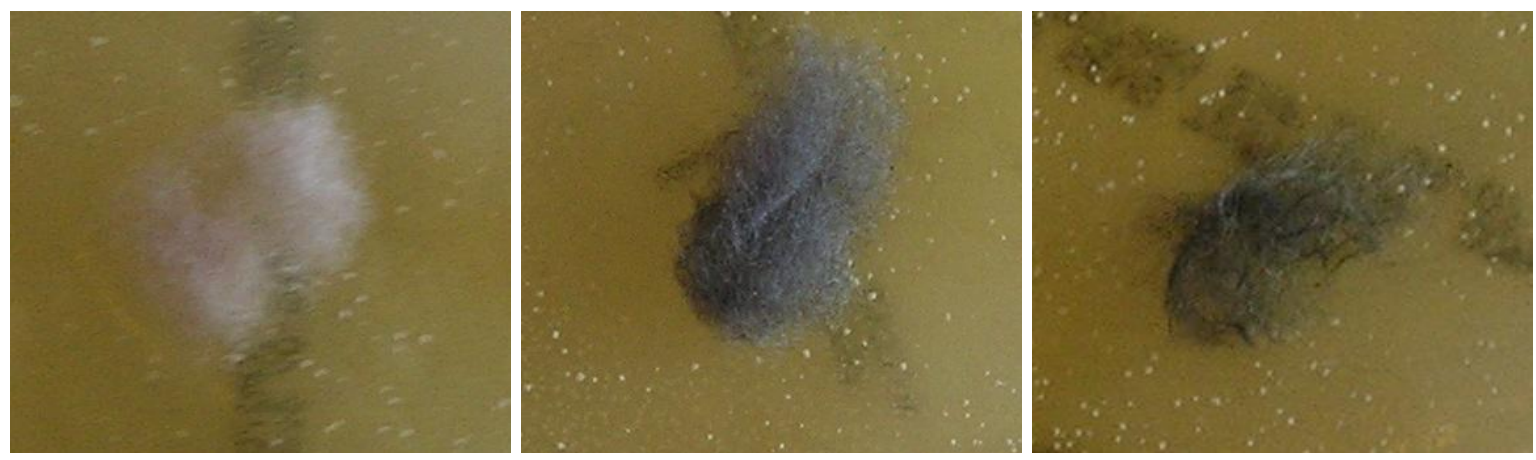

Figure 5.146: Gold nanoparticle-merino wool composites embedded on agar plates incubated with Staphylococcus aureus. Left: prepared by soaking untreated semi-worsted merino wool in a $160 \mathrm{ppm}$ $\left(8.13 \times 10^{-4} \mathrm{M}\right) \mathrm{Au}^{3+}$ solution for 24 hours at RT, followed by ageing at $50{ }^{\circ} \mathrm{C}$ for 24 hours. Middle and right: prepared by ageing untreated semi-worsted merino wool in a $960 \mathrm{ppm}\left(4.87 \times 10^{-3} \mathrm{M}\right)$ or $1040(5.28$ $\left.\mathrm{x} 10^{-3} \mathrm{M}\right) \mathrm{Au}^{3+}$ solution respectively for 24 hours at $50{ }^{\circ} \mathrm{C}$.

These gold nanoparticle-merino wool composites prepared by the redox active nature of the wool were also tested for their ability to resist the growth of moth larvae. Table 5.26 offers the results of Tineola bisselliella (moth larvae) bioassays carried out on three gold 
nanoparticle-merino wool composites. The materials were prepared by soaking untreated semi-worsted merino wool in varying amounts of $\mathrm{Au}^{3+}$, notably $3.2,32$ and $160 \mathrm{ppm}(1.62 \mathrm{x}$ $10^{-5}, 1.62 \times 10^{-4}$ and $8.13 \times 10^{-4} \mathrm{M}$ respectively) at RT for 24 hours, followed by ageing at 50 ${ }^{\circ} \mathrm{C}$ for 168 hours. To exert resistance to the growth of moth larvae a sample must exhibit a mass loss of $15 \mathrm{mg}$ or less, or a mortality rate of greater than $90 \%$. If this mortality rate was achieved the mass loss was irrelevant, and losses of over $15 \mathrm{mg}$ were acceptable. Table 5.26 shows the results of the moth larvae bioassays. It can be seen that increasing the concentration of $\mathrm{Au}^{3+}$ employed in the production of the composites increased the material's ability to inhibit the growth of moth larvae, however only the sample prepared with a 160 $\operatorname{ppm}\left(8.13 \times 10^{-4} \mathrm{M}\right) \mathrm{Au}^{3+}$ induced a mortality rate of more than $90 \%$, and therefore was defined as being capable of resisting the growth of moth larvae.

Table 5.26: Results of Tineola bisselliella (moth larvae) bioassays. Note, $\%$ pupation refers to the $\%$ of moth larvae reaching the pupa stage, the stage of metamorphosis that immediately precedes the adult stage.

\begin{tabular}{ccccc}
\hline $\begin{array}{c}\text { Sample Au } \\
\text { concentration } \\
\text { (ppm) }\end{array}$ & $\begin{array}{c}\text { Mortality } \\
(\%)\end{array}$ & $\begin{array}{c}\text { Pupation } \\
(\%)\end{array}$ & $\begin{array}{c}\text { Mass loss (mg) } \\
\pm \text { standard } \\
\text { error of mean }\end{array}$ & $\begin{array}{c}\text { Pass (P), } \\
\text { fail (F) or } \\
\text { borderline } \\
(\mathrm{B})\end{array}$ \\
\hline Control & 11.1 & 1.7 & $129.1 \pm 13.8$ & n.a. \\
Au 3.2 & 30.0 & 0.0 & $96.1 \pm 14.9$ & $\mathrm{~F}$ \\
Au 32 & 44.9 & 0.0 & $83.0 \pm 14.5$ & $\mathrm{~F}$ \\
Au 160 & 92.8 & 0.0 & $54.4 \pm 5.7$ & $\mathrm{P}$ \\
\hline
\end{tabular}

In addition to testing for resistance to the growth of moth larvae, the ability of the gold nanoparticle-merino wool composites to resist the growth of the furniture carpet beetle Anthrenocerus flavipes was also tested. The criterion which dictates whether or not a material is capable of inducing resistance to beetle larval growth is the same as that of the moth larvae tests, notably the material must exhibit a mass loss of $15 \mathrm{mg}$ or less or induce a beetle larvae mortality rate of at least $90 \%$ (at which point the mass loss is irrelevant). The gold nanoparticle-merino wool composite that exhibited resistance to the growth of moth larvae (prepared by soaking untreated semi-worsted merino wool in a $160 \mathrm{ppm}\left(8.13 \times 10^{-4}\right.$ M) $\mathrm{Au}^{3+}$ solution for 24 hours at RT, followed by heating at $50{ }^{\circ} \mathrm{C}$ for 168 hours) was tested 
for beetle larvae resistance, and the results of these bioassays are shown in Table 5.27 below. Unfortunately this material narrowly failed the bioassay, exhibiting a mass loss of $15.3 \mathrm{mg}$. This bioassay was carried out on a composite material in the top form. As such the fibres were very loose and significant fibre loss was observed during the process of the mortality assessment. AgResearch advised that if the same bioassays had been carried out on a woven fabric rather than a loose top the mass loss of the sample would have been lower, and it is highly probable that the gold nanoparticle-merino wool composites would have been effective in inhibiting the damage caused by beetle larvae.

Table 5.27: Results of Anthrenocerus flavipes (beetle larvae) bioassays. Note, \% pupation refers to the \% of moth larvae reaching the pupa stage, the stage of metamorphosis that immediately precedes the adult stage.

\begin{tabular}{lcccc}
\hline $\begin{array}{c}\text { Sample Au } \\
\text { concentratio } \\
\mathbf{n} \text { (ppm) }\end{array}$ & $\begin{array}{c}\text { Mortality } \\
(\%)\end{array}$ & $\begin{array}{c}\text { Mass } \\
\text { loss } \\
(\mathbf{m g})\end{array}$ & $\begin{array}{c}\text { Mass loss } \\
\text { (\% of the } \\
\text { voracity } \\
\text { control) }\end{array}$ & $\begin{array}{c}\text { Pass (P), } \\
\text { fail (F) or } \\
\text { borderline } \\
\mathbf{( B )}\end{array}$ \\
\hline Control & 0.0 & 76.0 & n.a & n.a. \\
Au 160 & 0.0 & 15.3 & 20.1 & $\mathrm{~F}$ \\
\hline
\end{tabular}

The resistance to the growth of moth larvae, and the potential resistance to the growth of beetle larvae exerted by the gold nanoparticle-merino wool composites is exciting, as it provides an alternative to the traditionally used permethrin, a broad-spectrum insecticide traditionally used by the wool industry to control insects that feed on wool (such as moths and beetles). This insecticide is finding disfavour, failing to meet a selection of international effluent discharge standards, as it has been shown to be toxic to aquatic invertebrates, affecting the growth of insects in rivers which are the first stage in a rivers ecological chain.[242] There have also been resistance issues with permethrin, causing increasing amounts to be used to ensure its effectiveness.

There have been a selection of scientific reports on the use of gold complexes and gold nanoparticles as anti-microbial agents, anti-tumour agents, and also in the treatment of rheumatoid arthritis (see section 1.3.4.2). It is generally proposed that the anti-microbial, 
anti-tumour etc activity of gold arises due to the instability of gold ions $\left(\mathrm{Au}^{3+}, \mathrm{Au}^{+}\right)$in biological environments, with many $\mathrm{Au}^{3+}$ or $\mathrm{Au}^{+}$complexes being capable of being reduced to $\mathrm{Au}^{+}$or $\mathrm{Au}^{0}$ by biologically occurring reductants such as thiols (-SH) or disulfides (-S-S-), which are themselves oxidised, inhibiting processes essential to cellular survival. To the best of our knowledge there have been no scientific reports on the use of gold complexes or gold nanoparticles as moth and or beetle insecticides, however it is likely that the gold nanoparticle-merino wool composites resist the growth of moth larvae (and potentially beetle larvae) in a similar way, notably through the oxidation of functional groups in these organisms. XPS analysis showed the gold nanoparticle-merino wool composites tested (prepared with an ageing time of 168 hours) to possess a percentage of unreduced $\mathrm{Au}^{3+}$, and also $\mathrm{Au}^{+}$in the form of $\mathrm{Au}-\mathrm{S}$ bonds between the nanoparticles and wool fibres (see section 5.3). It is possible that these $\mathrm{Au}^{3+}$ ions come in contact with the larvae when they eat the wool whereby $\mathrm{Au}^{3+}$ are reduced to $\mathrm{Au}^{+}$or $\mathrm{Au}^{0}$ by functional groups in the larval cellular makeup, resulting in the inhibition of processes essential to cellular survival. If this is the case composites prepared with a shorter ageing time should be expected to exhibit increased insecticidal properties, as these materials possess a greater amount of $\mathrm{Au}^{3+}$. Future work is planned to test this.

\subsection{Chlorine Hercosett Shrink Resistance Treatment}

The chlorine Hercosett shrink resistance treatment is the most common surface treatment applied to wool textiles as it allows woollen fabrics to be washed without significant felting and/or shrinkage. This treatment is particularly common in textiles destined for use in garments. As considerable difficulties were encountered when employing $\mathrm{Cl} / \mathrm{H}$ treated merino wool as the fibre substrate in the production of the gold nanoparticle-merino wool composites (see section 5.1.5) $\mathrm{Cl} / \mathrm{H}$ treatments were applied to the composite materials post inclusion of the gold nanoparticles.

Figure 5.147 shows gold nanoparticle-merino wool composites (prepared by soaking untreated semi-worsted merino wool in a $160 \mathrm{ppm}\left(8.13 \times 10^{-4} \mathrm{M}\right) \mathrm{Au}^{3+}$ solution for 24 hours at RT, followed by heating at $50{ }^{\circ} \mathrm{C}$ for 24 or 168 hours) both before and after $\mathrm{Cl} / \mathrm{H}$ 
treatment. The treatment clearly had a detrimental effect on the colour of the materials, causing both materials to turn a yellow/gold colour. This was much more pronounced in the pink composites prepared with an ageing time of 24 hours. During the $\mathrm{Cl} / \mathrm{H}$ process, oxidation of the fibres occurs through exposure to chlorine gas or hypochlorite. As such, the observed discolouration is likely due to oxidation of the $\mathrm{Au}^{0}$ nanoparticles to $\mathrm{Au}^{3+}$ (scheme 4.4), which subsequently combines with the generated $\mathrm{Cl}^{-}$ions to form yellow $\mathrm{AuCl}_{4}{ }^{-}$ (scheme 4.5). The $\mathrm{Cl} / \mathrm{H}$ treatment is surface specific, and as such it is probable that only the nanoparticles residing on the surface of the wool fibres are oxidized.

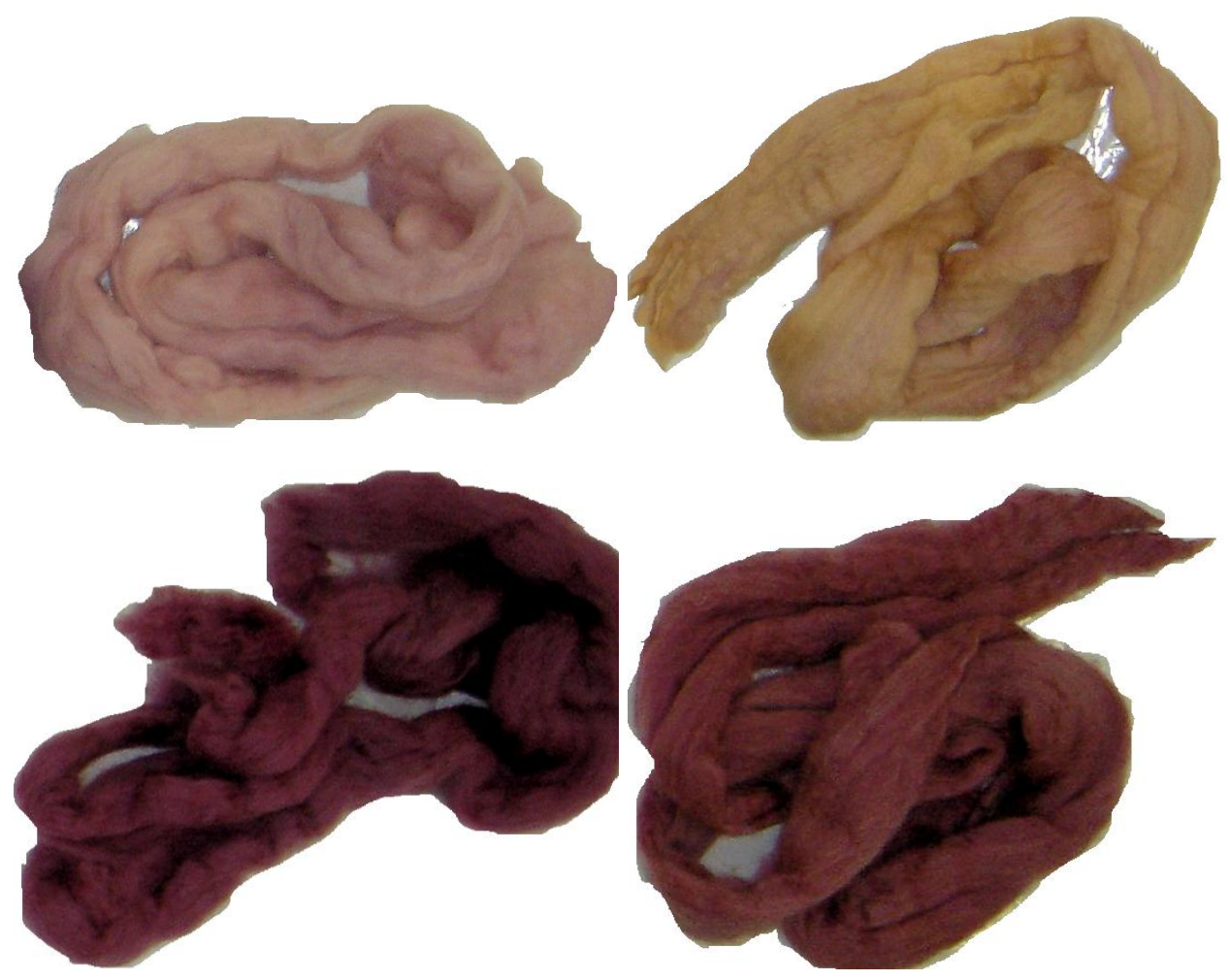

Figure 5.147: Left top and bottom: gold nanoparticle-merino wool composites (prepared by soaking untreated semi-worsted merino wool in a $160 \mathrm{ppm}\left(8.13 \times 10^{-4} \mathrm{M}\right) \mathrm{Au}^{3+}$ solution for 24 hours at RT, followed by heating at $50{ }^{\circ} \mathrm{C}$ for 24 (top) or 168 (bottom) hours). Right: the same composite materials following chlorine Hercosett treatment. 
It is likely that discolouration was more pronounced in the composites that had been aged for 24 hours rather than 168 hours as prior to exposure to the oxidizing conditions, the former materials possessed a greater percentage of $\mathrm{Au}^{3+}$ (as shown by XPS analysis, see section 5.3) which increases following $\mathrm{Cl} / \mathrm{H}$ treatment. This higher concentration of $\mathrm{Au}^{3+}$ would combine with the $\mathrm{Cl}^{-}$ions forming a greater concentration of yellow $\mathrm{AuCl}_{4}{ }^{-}$. Additionally, these pink coloured composites (prepared with an ageing time of 25 hours) possessed fewer nanoparticles on the surface of the fibres compared to those prepared with an ageing time of 168 hours. Therefore once surface oxidation had occurred there would be fewer nanoparticles present in the pink materials causing the yellow colour of $\mathrm{AuCl}_{4}{ }^{-}$to be more pronounced. SEM and TEM analysis showed the materials prepared with an ageing time of 168 hours contained small gold nanoparticles in the fibre centre. These were absent in materials prepared with an ageing time of 24 hours. As the $\mathrm{Cl} / \mathrm{H}$ treatment is surface specific, the nanoparticles in the centre of the fibres would not be affected, and as such would still exhibit surface plasmon resonances, which combined with the greater concentration of nanoparticles on the fibre surface, would account for the decreased discolouration of these materials.

As with the $\mathrm{Cl} / \mathrm{H}$ treated gold nanoparticle-merino wool composites prepared through incorporation of TSC reduced and stabilised gold nanoparticles, XPS of these $\mathrm{Cl} / \mathrm{H}$ treated composites is required to confirm that the discolouration arises due to the re-oxidation of $\mathrm{Au}^{0}$ to $\mathrm{Au}^{3+}$ and subsequent formation of $\mathrm{AuCl}_{4}^{-}$. This will be carried out in future work.

\subsection{Electrical Conductivity}

The electrical conductivities of the gold nanoparticle-merino wool composites were analysed through implementation of the linear four point probe method (see section 2.3.7 for details). Regardless of the synthesis conditions employed, the conductivity of these composite materials fell below the detection limits of the apparatus employed. The low conductivity of the composite materials is likely related to the distribution of the gold nanoparticles on the fibres. As shown in section 5.1, the nanoparticles commonly resided along the edges of the fibre cuticles, and did not form a continuous coating. This isolation of the nanoparticles 
would impair the flow of electrons through/along the fibres, resulting in their apparently low conductivity.

Although the linear four point probe method classed the gold nanoparticle-merino wool composite materials as being non-conductive, when spinning the materials into a yarn significantly less static electricity build up was noted.

\subsection{Scale up and Commercialisation}

The production of gold nanoparticle-merino wool composite materials prepared through the redox properties of the protein fibres has been successfully scaled up to a large laboratory scale. Sufficient deep and light purple coloured gold nanoparticle-merino wool material has been produced to enable it to be hand spun into a yarn (Figure 5.148 left), with the latter subsequently hand woven into the world's first 'golden wool' scarf (Figure 5.148 right) whose colour emanates solely from the gold nanoparticles it contains. Large samples (approximately $1 \mathrm{~kg}$ batches) of light pink and deep, regal purple coloured composite materials have also been produced.

Together with samples of gold nanoparticle-merino wool composites in a range of colours, these materials have been showcased at numerous national and international science and textiles conferences,[243-246] where they were very well received, sparking interest from several key plays in the textiles industry, including Wool Partners International Ltd, the World Gold Council, Cariaggi (an Italian spinning company supplying yarn to premier international fashion houses), John Smedley UK (a high quality fine knitwear manufacturer and retailer), NZ Merino Ltd and New Zealand Trade and Enterprise. Following discussions with several of these companies, we are currently in the process of commercialising this technology. 


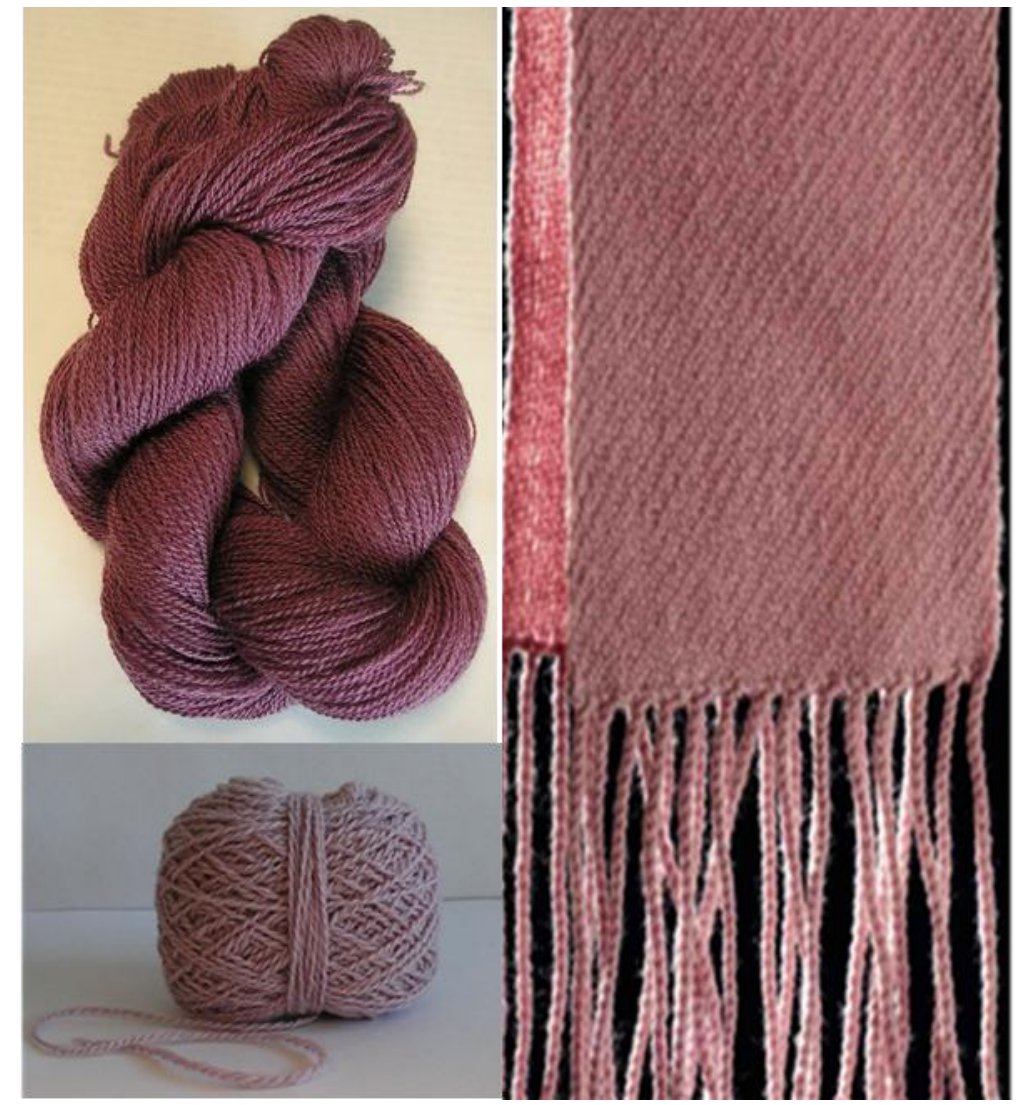

Figure 5.148: Examples of gold nanoparticle-merino wool sample that has been hand spun into a yarn (left) and subsequently hand woven into a scarf (right).

\subsection{Conclusions}

Gold nanoparticle-merino wool composites were successfully produced in the absence of an external reducing agent. The proteins present in merino wool acted as redox active biotemplates, facilitating the reduction of $\mathrm{Au}^{3+}$ to nanoparticulate $\mathrm{Au}^{0}$, with simultaneous binding of the produced nanoparticles both on the surface and within the centre of the fibres.

When synthesising gold nanoparticle-merino wool composites the base fibre used in production greatly influenced the resultant materials. There was very limited success when employing merino wool in a woven cloth or spun fibre form, as the resultant composite materials were very non-uniform in colour. The best results were obtained when employing 
untreated merino wool in sliver (top) form, as it was possible to produce uniform, and spectrally pure coloured composite materials. When merino wool processed via the worsted route was employed as the base fibre, it was necessary to firstly clean the fibres via a Soxhlet extraction, thus removing additional processing lubricants found on the fibre surface.

Pre-treating the merino wool fibres prior to addition to $\mathrm{Au}^{3+}$ solutions was unsuccessful, and in general produced materials that were not dissimilar in colour to untreated merino wool. However when $\mathrm{Cl} / \mathrm{H}$ treated merino wool was used as the base fibres, a colour development appeared with prolonged ageing. Base treating the $\mathrm{Cl} / \mathrm{H}$ treated merino wool dramatically increased this colour development, and hence the reduction of $\mathrm{Au}^{3+}$ to nanoparticulate $\mathrm{Au}^{0}$ in such materials. In contrast to untreated merino wool in which the $\mathrm{Au}^{3+}$ to $\mathrm{Au}^{0}$ reduction was facilitated by the proteins present in the fibres, in $\mathrm{Cl} / \mathrm{H}$ treated merino wool the reduction appeared to be facilitated by the Hercosett polymer, specifically its amine groups. It was proposed that base treating $\mathrm{Cl} / \mathrm{H}$ treated merino wool liberated more amine groups and hence increased the reducing capacity of the treated fibres.

In addition to the base fibre employed in the production of the gold nanoparticle-merino wool composites, the reaction parameters also influenced the colour of the resultant materials. Even though atomic absorption studies showed the majority of gold (in the form of $\mathrm{AuCl}_{4}{ }^{-}$) was absorbed by the wool fibres after 1-6 hours at RT, a soaking time of at least 24 hours was required to ensure an even distribution of $\mathrm{AuCl}_{4}{ }^{-} / \mathrm{Au}^{3+}$ throughout the fibre as a result of diffusion. This was assisted by gentle agitation so as not to cause matting of the fibres or shrinkage of the wool. If soaking times of less than 24 hours were employed the resultant materials possessed a high percentage of agglomerated gold nanoparticles on the fibre surface, likely due to insufficient diffusion of $\mathrm{Au}^{3+}$ into the wool fibre, forming an increased number of nanoparticles at the fibre surface and hence resulting in insufficient stabilisation of the initially produced nanoparticles due to the high ratio of gold to wool. Although in general the formation of such agglomerated nanoparticles was undesirable as it produced spectrally impure coloured composite materials, employing very high concentrations of $\mathrm{Au}^{3+}$ (greater than $840 \mathrm{ppm}$ ) and no soaking allowed for the production of grey coloured composites. Attractive bluey grey to steely grey coloured materials were produced in this way, however as so much gold went into their production, it was a very uneconomical 
approach and an alternative method for the production of grey coloured gold nanoparticlemerino wool composites is offered in chapter 8 below.

An ageing temperature of $50{ }^{\circ} \mathrm{C}$ was determined to be ideal, with temperatures of $80{ }^{\circ} \mathrm{C}$ increasing the $\mathrm{Au}^{3+}$ to $\mathrm{Au}^{0}$ reduction resulting in the formation of agglomerated particles. When employing a $\mathrm{Au}^{3+}$ concentration of $160 \mathrm{ppm}\left(8.13 \times 10^{-4} \mathrm{M}\right)$ increasing the ageing time, at $50{ }^{\circ} \mathrm{C}$ from $24-72$ hours saw the production of a greater concentration of spherical/five-fold twinned nanoparticles, approximately 20-25 $\mathrm{nm}$ in diameter. These nanoparticles resided preferentially along the cuticle edges. However when ageing for 168 hours these nanoparticles spread slightly across the fibre surface, and small spherical nanoparticles, approximately $5-10 \mathrm{~nm}$ in diameter were seen to form in the fibre centres. This increase in the concentration of similarly sized nanoparticles on the fibre surface corresponded to an increase in intensity of the pink colour of the composites, whilst the formation of smaller nanoparticles in the fibre centre induced a change in composite colour to a deep regal purple. Increasing the ageing time further did not alter the colour of the resultant materials.

The composition of both the soaking and ageing solutions influenced the uptake of $\mathrm{AuCl}_{4}{ }^{-}$ and the ability of the proteins in merino wool to facilitate the $\mathrm{Au}^{3+}$ to $\mathrm{Au}^{0}$ reduction and hence the colour of the resultant materials. $\mathrm{A} \mathrm{pH}$ of 2.7 was determined to be optimal for the soaking solution, with lower $\mathrm{pH}$ 's damaging the wool fibre and higher reducing the uptake of $\mathrm{AuCl}_{4}{ }^{-}$. However once $\mathrm{AuCl}_{4}{ }^{-}$was absorbed and had diffused through the fibre (therefore after soaking) increasing the $\mathrm{pH}$ of the ageing solution to a maximum of 9 (which following equilibrium with the fibre became 5.5) destabilised the $\mathrm{AuCl}_{4}{ }^{-}$system so that $\mathrm{Au}^{0}$ became the favoured species, increasing the $\mathrm{Au}^{3+}$ to $\mathrm{Au}^{0}$ reduction rate, and producing a deep regal purple coloured composite with shorter ageing times.

In addition to $\mathrm{pH}$, the presence of electrolytes in the soaking and ageing solutions also influenced the ability of merino wool to reduce $\mathrm{Au}^{3+}$. Increasing the electrolyte concentration of the soaking and or ageing solution increased the transfer of electrons between the wool fibre (the reductant) and the $\mathrm{Au}^{3+}$ ions, producing more nanoparticles in a 
shorter amount of time. (This occurred even when the electrolyte concentration of the soaking solution was increased independently to the ageing solution, as the electrolytes were seen to remain in the fibres once they were removed from the soaking solution). This resulted in the formation of a greater concentration of slightly smaller nanoparticles at the fibre surface, and hence more intense pink coloured composites when shorter (less than 168 hours) ageing times were employed. However the deep purple colour observed when soaking and ageing in the original $\mathrm{Au}^{3+}$ solutions was not obtained in these materials, which was proposed to be due to electrolytes in the fibre centres hindering $\mathrm{Au}^{3+}$ ions coming together to nucleate and hence forming nanoparticles.

When soaking and ageing solutions of decreased electrolyte concentrations were employed (for example distilled water) the colour of the composite materials decreased in intensity. Interestingly, when soaking and ageing solutions of nearly identical ionic strength to the original $160 \mathrm{ppm} \mathrm{Au}^{3+}$ soaking solution (for example a $10 \mathrm{ml}$ aqueous solution containing 40 $\mu \mathrm{L}$ of $0.1 \mathrm{M} \mathrm{HCl}$ ) the colour of the resultant materials was still lighter and underdeveloped relative to those prepared with the original soaking and ageing solutions, thus suggesting other ions (such as sodium or calcium) may be released from the wool fibres during soaking, increasing the ionic strength of the soaking solution from that originally calculated.

The concentration of the dissolved $\mathrm{Au}^{3+}$ or $\mathrm{AuCl}_{4}{ }^{-}$in relation to the amount and surface area of the wool fibre is important. When the concentration of the dissolved $\mathrm{Au}^{3+}$ or $\mathrm{AuCl}_{4}{ }^{-}$is increased but the same overall gold to wool fibre ratio is used, i.e. a lesser solution volume is used; the colour of the resultant material is more intense. This was found to be related to the surface density of absorbed $\mathrm{AuCl}_{4}{ }^{-}$, as higher $\mathrm{Au}^{3+}$ concentrations results in more $\mathrm{AuCl}_{4}{ }^{-}$at the wool fibre surface, inducing more collisions between $\mathrm{Au}^{3+}$ ions and hence nucleations, forming more nanoparticles and deeper, more intensely coloured composite materials. A desirable consequence of this is that the same colour can be achieved by using a higher concentration of $\mathrm{Au}^{3+}$ or $\mathrm{AuCl}_{4}{ }^{-}$in solution but a reduced solution volume in relation to the amount of wool fibre and hence a reduced amount of gold to weight of wool overall. 
EDS and XPS suggest the gold nanoparticles bind to the merino wool fibres primarily via coordinative covalent $\mathrm{Au}-\mathrm{S}$ bonds, most likely in the main sulfur containing amino acids cystine and cysteine. The one exception to this was when $\mathrm{Cl} / \mathrm{H}$ treated merino wool was employed as the fibre substrate, as in these composite materials the nanoparticles appeared to bond to the wool through both $\mathrm{Au}-\mathrm{S}$ and $\mathrm{Au}-\mathrm{N}$ bonds, the latter most likely through nitrogen atoms in the Hercosett polymer encapsulating such fibres.

The proposed mechanism of formation of the gold nanoparticle-merino wool composites involves the reduction of $\mathrm{Au}^{3+}$ to nanoparticulate $\mathrm{Au}^{0}$ by the disulfide groups of the amino acid cystine, which themselves are oxidised to cysteic acid. During soaking, a percentage of $\mathrm{Au}^{3+}$ was seen to be reduced to $\mathrm{Au}^{+}$by cystine, forming some kind of $\mathrm{Au}-\mathrm{S}$ complex. Upon ageing it is proposed that these Au-S complexes act as nucleation sites for the reduction of $\mathrm{Au}^{3+}$ to $\mathrm{Au}^{0}$, again facilitated by the oxidation of nearby disulfide groups of cystine, with the transfer of electrons from these oxidation reactions facilitated by the electrolytes present in the ageing solutions.

The applicability of these gold nanoparticle-merino wool composites in consumer products was investigated by testing their colourfastness to washing, rubbing in both wet and dry conditions, chlorinated water and light. They performed very well with respect to all of these industry standard tests, achieving values greater than a pass. It is likely that the materials performed to well with respect to colourfastness as the nanoparticles (which were inducing the colour) are bound to the fibres via strong Au-S bonds, and also because they were dispersed throughout the fibre centre rather than simply binding to the surface. The gold nanoparticle-merino wool composites also resisted microbial attach, inhibited the growth of moth larvae and reduced the build up of static electricity during spinning. However they did discolour following $\mathrm{Cl} / \mathrm{H}$ treatment, which as with the composites prepared through the incorporation of TSC or TA reduced and stabilised gold nanoparticles, was thought to be due to the re-oxidation of $\mathrm{Au}^{0}$ to $\mathrm{Au}^{3+}$, and the subsequent formation of $\mathrm{AuCl}_{4}^{-}$. As it is common to $\mathrm{Cl} / \mathrm{H}$ treat merino wool prior to its use in fashion garments (a target market for these materials) the discolouration of the composite materials during $\mathrm{Cl} / \mathrm{H}$ treatments needs to be addressed, or garments made from such materials will have to be dry-cleaned rather than washed. 
The production of the gold nanoparticle-merino wool composites has been scaled up to produce sufficient amounts of a light purple coloured material which was hand spun into a yarn and subsequently hand woven into a scarf. Large quantities of pink and deep regal purple coloured materials have also been produced. Together with a selection of all materials of all colours that can be produced, these have been showcased at national and international science and textiles conferences were they were very well received. 


\section{GOLD NANOPARTICLE-CROSSBRED WOOL COMPOSITES}

As a proof of concept, the production of gold nanoparticle-fibre composites, prepared through utilisation of the redox active nature of the fibre substrate was extended to crossbred wools. By definition crossbred wools comprise of a group of thicker diameter wools (greater than $35.4 \mu \mathrm{m}$ ). Aside from the fibre diameter, the only major difference between crossbred wool and merino wool is the relative proportions of paracortical and orthocortical cells. In merino wool the paracortex accounts for approximately $10-40 \%$ of the cortex, and is arranged bilaterally with the orthocortex (Figure 6.1).[46, 247] However in crossbred wool the paracortex makes up approximately $50-70 \%$ of the cortex, and the bilateral asymmetry observed in merino wool fibres is replaced by cylindrical asymmetry, with the paracortex found along the outer edge of the cortex (Figure 6.1).[44, 46]
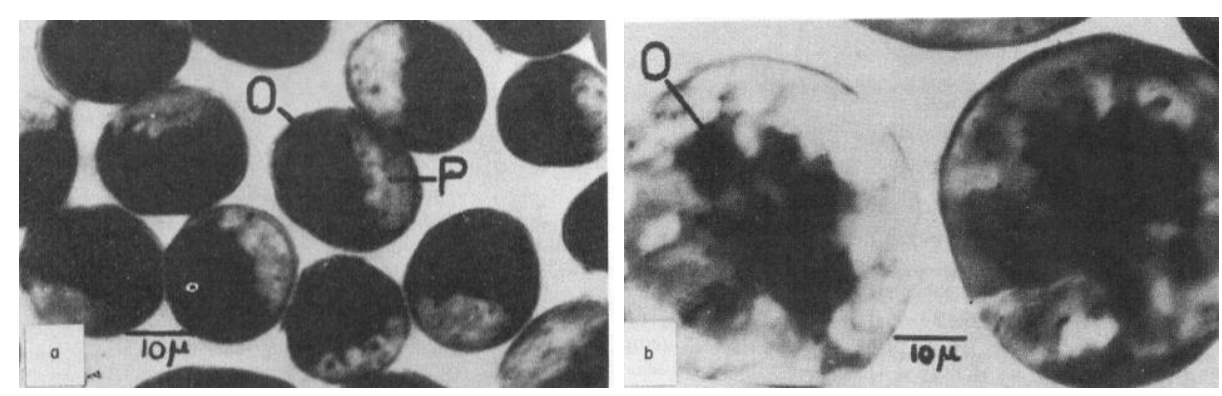

Figure 6.1: Cross sectional light micrographs of merino wool (left) and crossbred wool fibres (right) dyed with methylene blue to differentiate between the paracortex ( $\mathrm{P}$ - lightly stained) and orthocortex (Odarkly stained).[46]

The gold nanoparticle-crossbred wool composite materials were prepared via the same procedures used to produce the gold nanoparticle-merino wool materials. These procedures are outlined in section 2.2.2.3.

\subsection{Physical Characterisation and Morphology}

Figure 6.2 offers a picture of gold nanoparticle-crossbred wool composite materials prepared with various $\mathrm{Au}^{3+}$ solutions $\left(80-160 \mathrm{ppm},\left(4.06 \times 10^{-4}-8.13 \times 10^{-4} \mathrm{M}\right)\right.$ ), a soaking time of 24 
hours and ageing times of 24-168 hours. It is apparent from this image that increasing both the $\mathrm{Au}^{3+}$ concentration and also the ageing time only slightly intensified the colour of the resultant materials, with a deep regal purple coloured material produced with low $\mathrm{Au}^{3+}$ concentrations and short ageing times. This is in contrast to what was observed with the composites incorporating merino wool, as to achieve a similar deep regal purple colour with merino wool, a $\mathrm{Au}^{3+}$ concentration of at least $160 \mathrm{ppm}\left(8.13 \times 10^{-4} \mathrm{M}\right)$ and an ageing time of 168 hours was required.

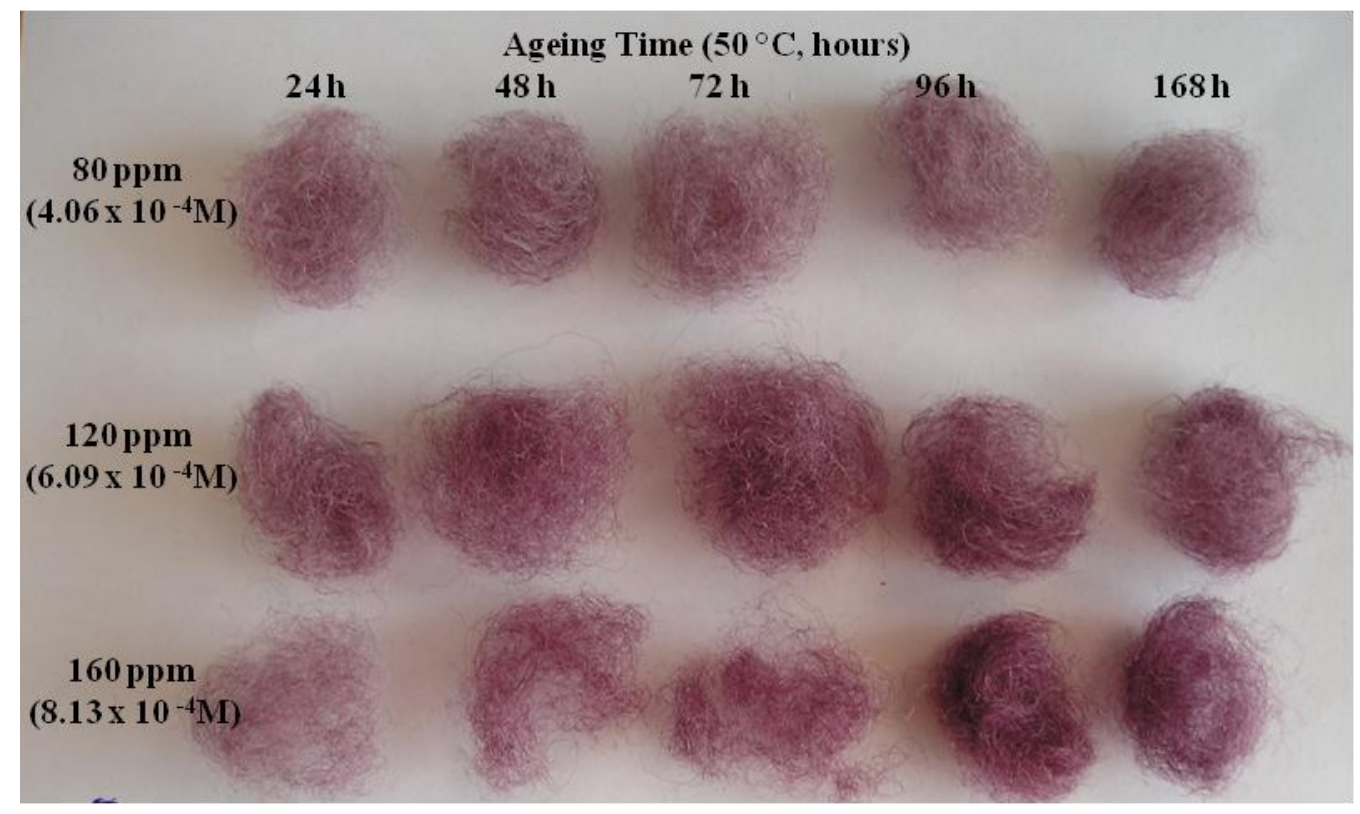

Figure 6.2: Gold nanoparticle-crossbred wool composite materials, prepared by soaking crossbred wool fibres in an 80, 120 or $160 \mathrm{ppm}\left(4.06 \times 10^{-4}, 6.09 \times 10^{-4}\right.$ and $\left.8.13 \times 10^{-4} \mathrm{M}\right) \mathrm{Au}^{3+}$ solutions for 24 hours at RT, followed by ageing at $50{ }^{\circ} \mathrm{C}$ for $24-168$ hours.

Figure 6.3 offers increasing magnification SEM micrographs of gold nanoparticle-crossbred wool composites prepared by soaking the fibres in an 80 or $160 \mathrm{ppm}\left(4.06 \times 10^{-4}\right.$ or $8.13 \mathrm{x}$ $\left.10^{-4} \mathrm{M}\right) \mathrm{Au}^{3+}$ solution for 24 hours at RT, followed by ageing at $50{ }^{\circ} \mathrm{C}$ for 24 or 168 hours. All of these materials possess spherical nanoparticles (approximately $20-30 \mathrm{~nm}$ in diameter), hexagonal platelets (approximately 100-300 nm in diameter), triangles (approximately 100 $\mathrm{nm}$ in diameter) and truncated triangles (approximately $100 \mathrm{~nm}$ in diameter) in similar concentrations. Increasing both the ageing time and $\mathrm{Au}^{3+}$ concentration appeared to increase the amount of spherical nanoparticles present, but only to a very small extent, and this is 
reflective of the relatively constant colour of the materials, with only a slight increase in intensity of the composites purple colour occurring with prolonged ageing and the use of increased $\mathrm{Au}^{3+}$ concentrations. Compared to the analogous composites incorporating merino wool, these materials possess a much larger concentration of gold nanoparticles with a broader spread in morphologies.
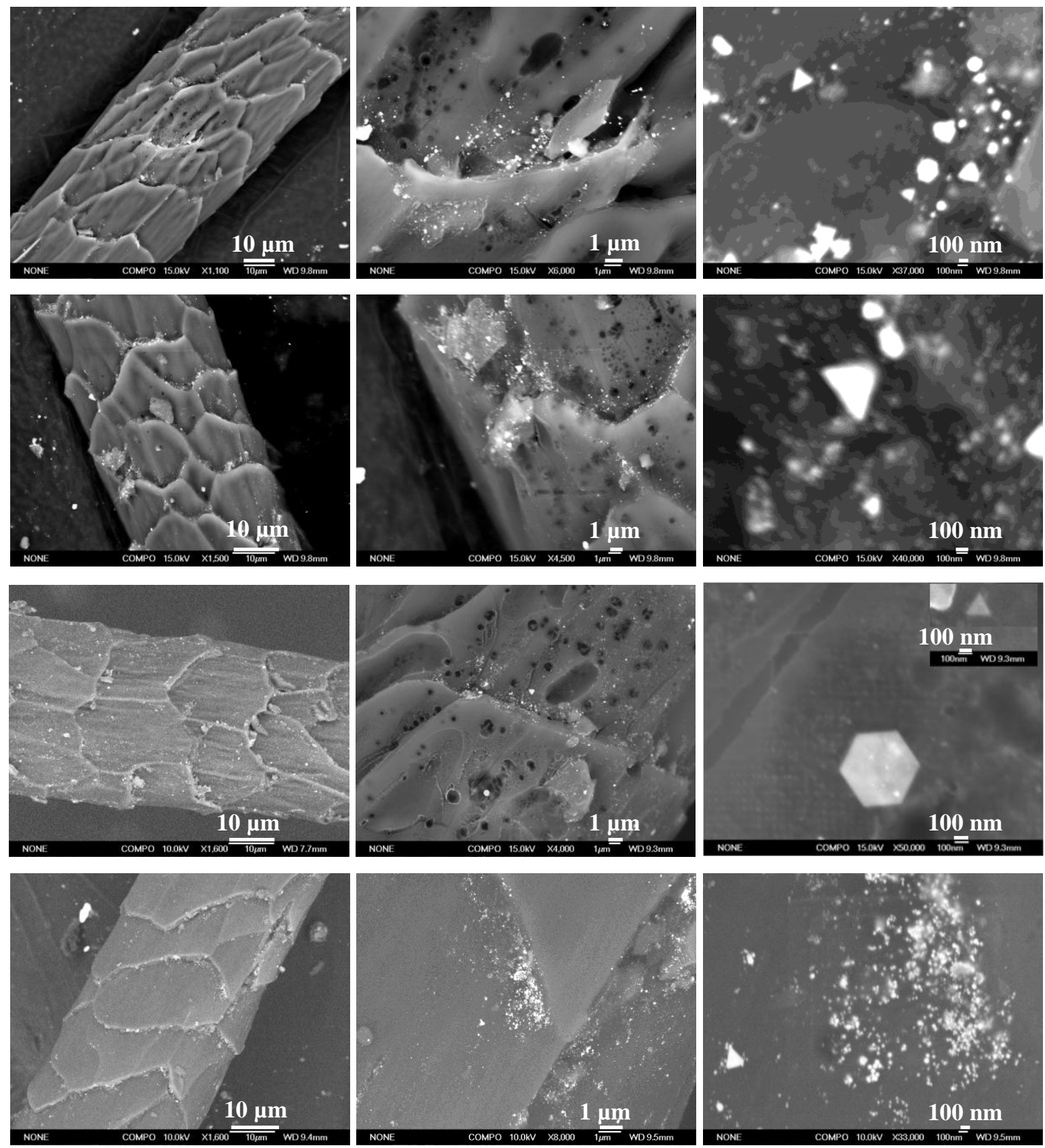

Figure 6.3: Gold nanoparticle-crossbred wool composite materials, prepared by soaking crossbred wool fibres in an $80 \mathrm{ppm}\left(4.06 \times 10^{-4} \mathrm{M}\right)\left(\mathrm{a}\right.$ and b) or $160 \mathrm{ppm}\left(8.13 \times 10^{-4} \mathrm{M}\right)\left(\mathrm{c}\right.$ and d) $\mathrm{Au}^{3+}$ solution for solutions for 24 hours at RT, followed by ageing at $50{ }^{\circ} \mathrm{C}$ for 24 (a and c) or 168 hours (b and d). 
It is likely that the higher percentage of anisotropic, hexagonal, triangular and truncated triangular gold nanoparticles observed in these materials relative to those prepared from merino wool are due to the specific surface area of the fibres. The fibre diameter of crossbred wool is much larger than that of merino, ( $\sim 35 \mu \mathrm{m}$ compared to $\sim 20 \mu \mathrm{m})$ therefore for the same weight of fibres, the specific surface area of the crossbred wool is lower. Hence for the same ratio of $\mathrm{Au}^{3+}$ : wool : solution volume, there is a higher density of absorbed $\mathrm{Au}^{3+}$ at the surface of the crossbred wools. As such when the initial nucleation events occur, a smaller percentage of $\mathrm{Au}^{3+}$ would initially be reduced (relative to the merino wool systems), leaving a relatively high concentration of unreduced $\mathrm{Au}^{3+}$ at the fibre surface.

As discussed in section 1.3.3 and 5.1.2.1 it is probable that a percentage of these initially formed nanoparticles would contain twin plane defects, creating favourable sites (grooves) for additional $\mathrm{Au}^{3+}$ ions to adsorb and become reduced, thus resulting in specific sides of the particles growing faster than others; promoting the formation of anisotropic nanoparticles. The unreduced $\mathrm{Au}^{3+}$ in solution may adsorb into these defects, and form hexagonal, triangular or truncated triangular nanoplates. The twin plane defect containing particles were also observed in the merino wool systems (see section 5.1.2.1), however due to the lower absorbed surface density of $\mathrm{Au}^{3+}$ in these systems (due to the larger specific surface area of merino wool) once these particles were formed there would be less $\mathrm{Au}^{3+}$ present to adsorb onto them and grow into anisotropic particles.

The fact that deep regal purple coloured composites were formed with lower $\mathrm{Au}^{3+}$ concentrations and shorter ageing times when employing crossbred wool as the base fibre in place of merino wool was also likely related to the different fibre diameters and hence the difference in surface areas of the fibre types. The smaller surface area per unit mass of the crossbred wool, and hence the larger density of $\mathrm{Au}^{3+}$ at the fibre surface, would induce a greater amount of collisions between the $\mathrm{Au}^{3+}$ ions, and hence more nucleations and nanoparticle formation in a shorter period of time, which would account for the development of the deep regal purple colour of the gold nanoparticle-crossbred wool materials after only 24 hours ageing. This would also explain why similar coloured gold nanoparticle-crossbred wool composites were formed with a much lower $\mathrm{Au}^{3+}$ concentration $(80 \mathrm{ppm})$ relative to the merino wool materials, as there would be a similar density of $\mathrm{Au}^{3+}$ absorbed at the surface of 
the crossbred fibres prepared with $80 \mathrm{ppm} \mathrm{Au}^{3+}$ solutions and the merino wool composites prepared with $160 \mathrm{ppm} \mathrm{Au}^{3+}$ solutions.

Cross sectional SEM and EDS analysis of the gold nanoparticle-crossbred wool composite materials suggested the gold nanoparticles reside preferentially at or near the surface of the wool fibres (Figure 6.4), even following prolonged soaking and ageing times (during which the diffusion of gold through the fibre could be accomplished). The fact that the gold nanoparticles, and also high concentrations of gold were found nearer to the fibre surface may be due to two reasons. Firstly the absorption of gold by the crossbred wool fibres was much slower than that observed for merino (see section 5.4), so that when ageing, and the reduction of $\mathrm{Au}^{3+}$ began, there would be a higher concentration of gold at or near the surface of the crossbred fibres, and as this reduction was seen to be faster in the crossbred systems (illustrated by the development of a deep purple colour after only 24 hours ageing) the $\mathrm{Au}^{3+}$ would be reduced to nanoparticulate $\mathrm{Au}^{0}$ before it had time to diffuse through the fibres to a large extent.
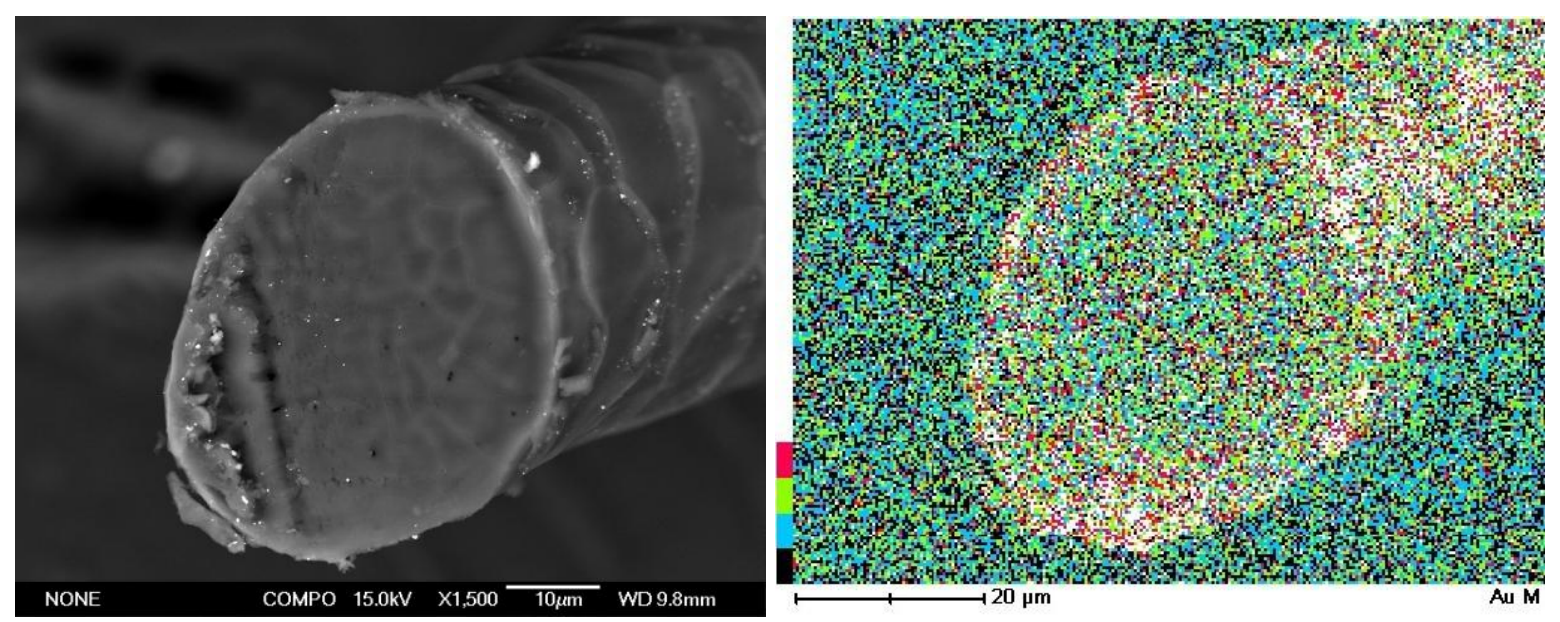

Figure 6.4: Left: cross sectional SEM micrograph and right: corresponding Au EDS map of a gold nanoparticle-crossbred composite prepared by soaking crossbred wool in a $160 \mathrm{ppm}\left(8.13 \times 10^{-4} \mathrm{M}\right) \mathrm{Au}^{3+}$ solution for 24 hours at RT, followed by ageing at $50{ }^{\circ} \mathrm{C}$ for 168 hours.

Alternatively, the high concentration of gold nanoparticles on or near the surface of the crossbred wool fibres may be due to the physical structure of these fibres. As mentioned 
above, the paracortex and orthocortex of crossbred wool is arranged with cylindrical asymmetry, and the paracortex (the sulfur rich region of the cortex) is located at the outer edge of the cortex. Therefore if cystine was facilitating the reduction of $\mathrm{Au}^{3+}$ to nanoparticulate $\mathrm{Au}^{0}$, it is in these regions that the reduction would be more likely to occur resulting in high concentrations of nanoparticles near the fibre surface.

\subsection{Colour}

The colour of the gold nanoparticle-crossbred wool composites were characterised through UV/Vis spectroscopy and via analysis of their CIE L*, a*, b*, $457 \mathrm{~nm}$ brightness and $580 \mathrm{~nm}$ brightness values. In general, an increase in concentration of nanoparticles of similar size and shape corresponded to a darkening and increase in intensity of the deep purple colour of the composite materials.

As with the analogous merino wool composites, the colour of the composites prepared with crossbred wool was influenced by the $\mathrm{Au}^{3+}$ concentration and ageing time, however these effects were quite minimal, with only a very slight increase in intensity of the colour of the composites occurring with increased $\mathrm{Au}^{3+}$ concentrations and ageing times. It is likely that other factors such as the soaking time, composition of the soaking and ageing solutions and the ageing temperature would also influence the colour of the composite materials, however as the synthesis of the gold nanoparticle-crossbred wool composites was simply a proof of concept, the effect of these parameters were not investigated.

As mentioned, the CIE L*, $\mathrm{a}^{*}, \mathrm{~b}^{*}, 457 \mathrm{~nm}$ brightness and $580 \mathrm{~nm}$ brightness values of the composites reflected these very slight changes. A comprehensive set of CIE values are offered in Appendix V. Increasing both the ageing time (Figure 6.5 and Figure 6.6) and also the $\mathrm{Au}^{3+}$ concentration (Figure 6.7) saw a general decrease in the $\mathrm{L}^{*}$ values (with $\mathrm{L}^{*}=100$ being white and $\mathrm{L}^{*}=0$ black), and $457 \mathrm{~nm}$ brightness and $580 \mathrm{~nm}$ brightness values,

confirming the visual darkening of the composites with increased ageing times and $\mathrm{Au}^{3+}$ concentrations. There was also a corresponding increase in $a^{*}$ values and decrease in $b^{*}$ 
values. As high $\mathrm{a}^{*}$ and $\mathrm{b}^{*}$ values denote a redder and yellow coloured material respectively, whilst lower denote greener and bluer, an increase in $a^{*}$ values with a corresponding decrease in $\mathrm{b}^{*}$ values with increased ageing times and $\mathrm{Au}^{3+}$ concentrations reflects the observed development of the deeper purple colour. The slopes of all of these lines are lower than those of the gold nanoparticle-merino wool composite materials (Figure 5.65) reflecting the faster rate of $\mathrm{Au}^{3+}$ to nanoparticulate $\mathrm{Au}^{0}$ in the gold nanoparticle-crossbred wool composites, with the colour of such materials being largely developed after 24 hours ageing.

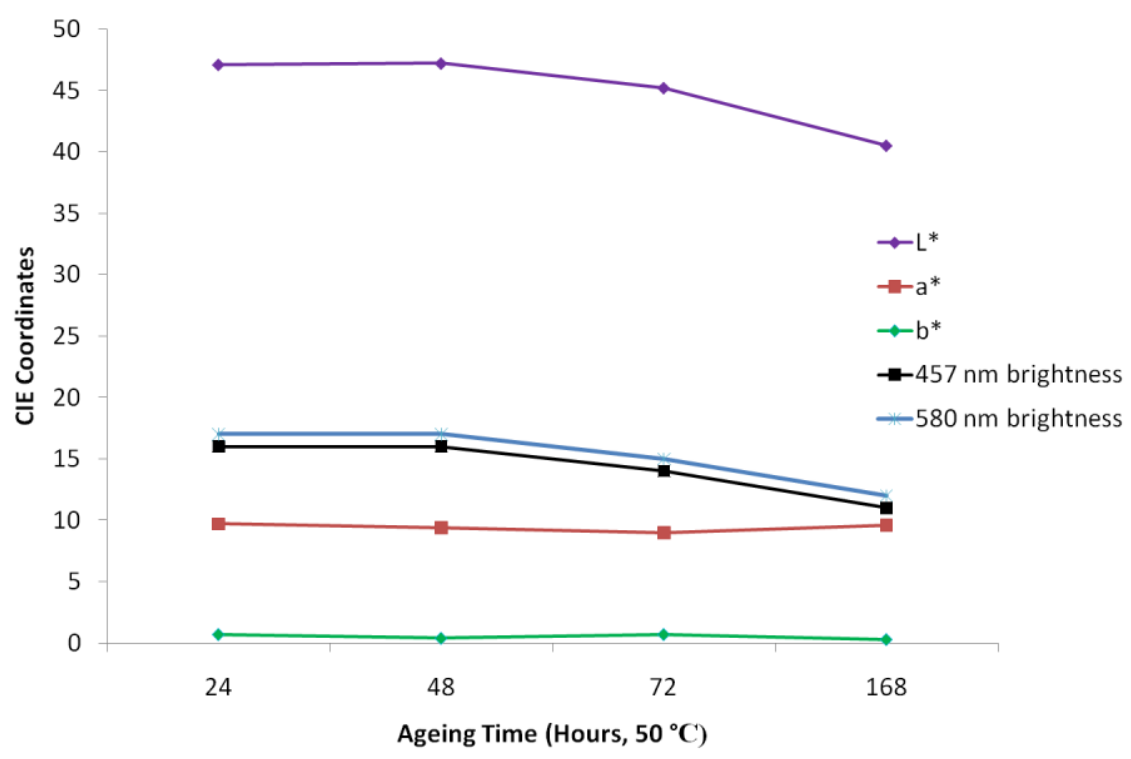

Figure 6.5: CIE $\mathrm{L}^{*}, \mathrm{a}^{*}, \mathrm{~b}^{*}, 457 \mathrm{~nm}$ brightness and $580 \mathrm{~nm}$ brightness values for gold nanoparticlecrossbred wool composites prepared by soaking the fibres in an $80 \mathrm{ppm}\left(4.06 \times 10^{-4} \mathrm{M}\right) \mathrm{Au}^{3+}$ solution for 24 hours at RT, followed by ageing, at $50{ }^{\circ} \mathrm{C}$ for $24-168$ hours. 


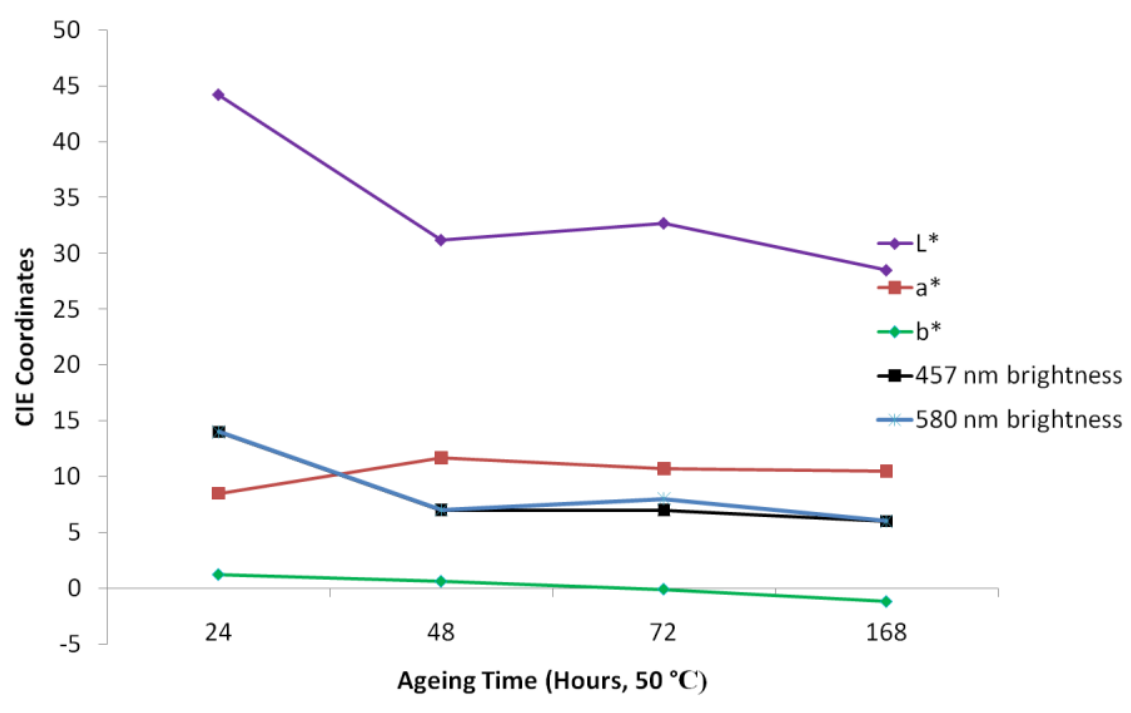

Figure 6.6: CIE $L^{*}, a^{*}, b^{*}, 457 \mathrm{~nm}$ brightness and $580 \mathrm{~nm}$ brightness values for gold nanoparticlecrossbred wool composites prepared by soaking the fibres in a $160 \mathrm{ppm}\left(8.13 \times 10^{-4} \mathrm{M}\right) \mathrm{Au}^{3+}$ solution for 24 hours at RT, followed by ageing, at $50{ }^{\circ} \mathrm{C}$ for $24-168$ hours.

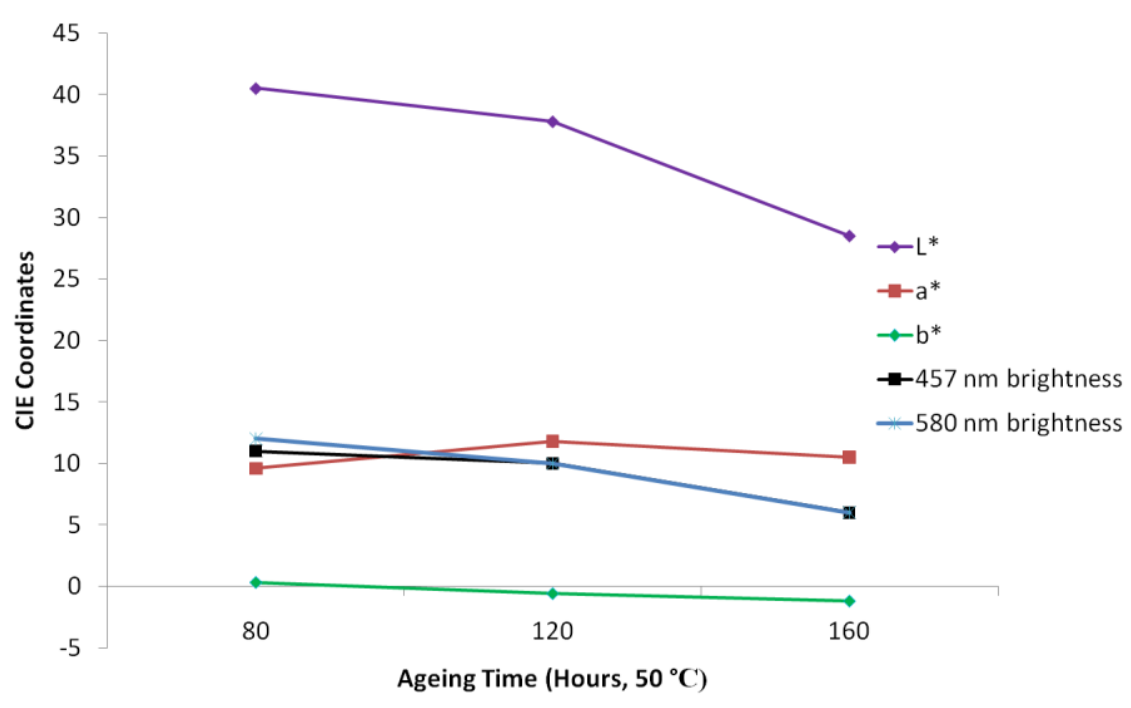

Figure 6.7: CIE $L^{*}, a^{*}, b^{*}, 457 \mathrm{~nm}$ brightness and $580 \mathrm{~nm}$ brightness values for gold nanoparticlecrossbred wool composites prepared by soaking the fibres in an 80,120 or $160 \mathrm{ppm}\left(4.06 \times 10^{-4}, 6.09 \times 10^{-}\right.$ ${ }^{4}$ or $8.13 \times 10^{-4} \mathrm{M}$ ) $\mathrm{Au}^{3+}$ solution for 24 hours at RT, followed by ageing, at $50{ }^{\circ} \mathrm{C}$ for 168 hours.

UV/Vis spectroscopy of the crossbred-Au materials also illustrated the colour development induced with increasing ageing times and $\mathrm{Au}^{3+}$ concentrations. The Kubelka Munk transformed UV/Vis spectra of gold nanoparticle-crossbred wool composites display four 
discernable peaks, centred at approximately 450, 515, 546 and $700 \mathrm{~nm}$ (Figure 6.8 and Figure 6.9). The peaks centred at 450, 515 and $700 \mathrm{~nm}$ related to the plasmon bands of anisotropic gold nanoparticles. The two former peaks correspond to the transverse plasmon bands of triangular gold nanoparticles and hexagonal/platelet gold nanoparticles respectively, whilst the latter corresponds to longitudinal plasmon bands of such particles.[210] The peak centred at approximately $546 \mathrm{~nm}$ is in the range expected for spherical or five-fold twinned gold nanoparticles approximately 20-30 $\mathrm{nm}$ in diameter. (This is slightly higher than that seen for the spherical nanoparticles in the merino wool composites, reflecting the slightly larger size of the nanoparticles in the crossbred wool composites). The presence of all of these peaks agree with the SEM observations made in section 5.1 above, reflecting the range of morphological forms found in these composite materials.

Figure 6.8 shows that increasing the ageing time from 24-168 hours, progressively increased the intensity of all plasmon bands, reflecting the SEM observations made above in which longer ageing times produced more nanoparticles of similar size and shape. Increasing the gold concentration from $120 \mathrm{ppm}\left(4.06 \times 10^{-4} \mathrm{M}\right)$ to $160 \mathrm{ppm}\left(8.13 \times 10^{-4} \mathrm{M}\right)$ also induced an increase in intensity of these peaks (Figure 6.9), again reflecting the increase in concentration of similarly sized and shaped nanoparticles, and hence a deepening in colour intensity of the resultant materials.

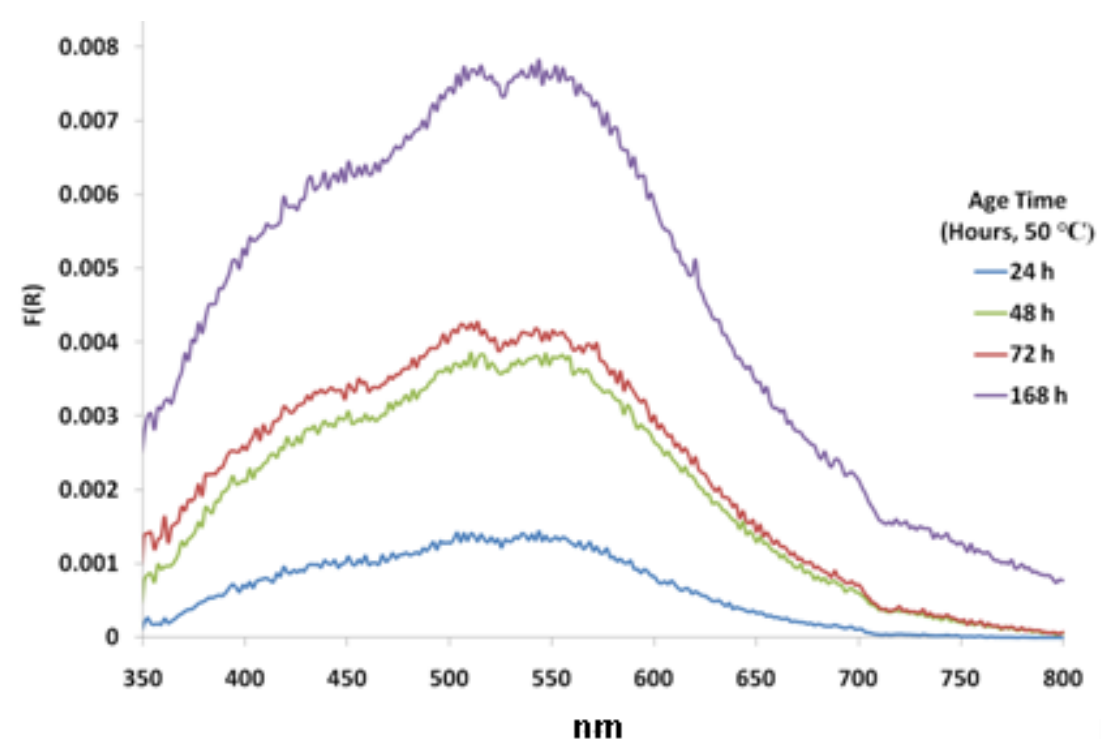

Figure 6.8: Kubelka Munk transformed UV/Vis reflection spectra of gold nanoparticle-crossbred wool composites prepared by soaking crossbred wool in a $160 \mathrm{ppm}\left(8.13 \times 10^{-4} \mathrm{M}\right) \mathrm{Au}^{3+}$ solution for 24 hours at $\mathrm{RT}$, followed by ageing at $50{ }^{\circ} \mathrm{C}$ for 24-168 hours. 


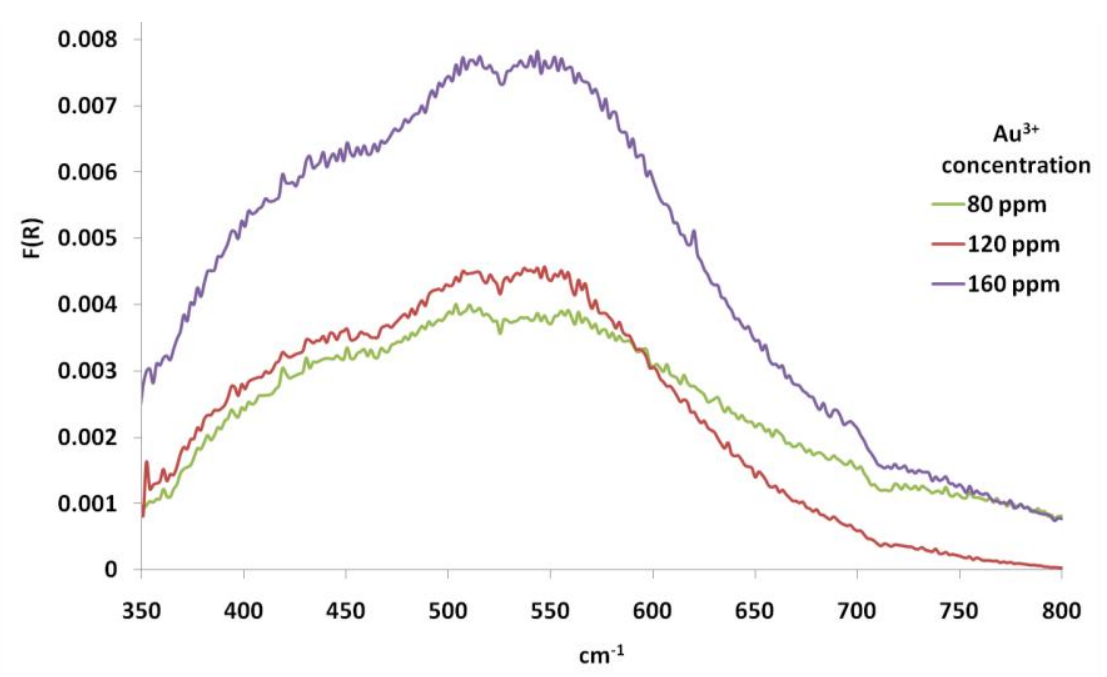

Figure 6.9: Kubelka Munk transformed UV/Vis reflection spectra of gold nanoparticle-crossbred wool composites prepared by soaking crossbred wool in an 80,120 or $160 \mathrm{ppm}\left(4.09 \times 10^{-4}, 6.09 \times 10^{-4}\right.$ or $8.13 \mathrm{x}$ $\left.10^{-4} \mathrm{M}\right) \mathrm{Au}^{3+}$ solution for 24 hours at RT, followed by ageing at $50{ }^{\circ} \mathrm{C}$ for $24-168$ hours.

\subsection{Confirmation of Gold}

As with the gold nanoparticle-merino wool composites, the presence of gold in the materials prepared from crossbred wool was first suggested by backscatter SEM, and confirmed by EDS and XPS analysis. As an example, Figure 6.10 offers SEM micrographs of composite materials prepared by soaking crossbred wool in a $160 \mathrm{ppm}\left(8.13 \times 10^{-4} \mathrm{M}\right) \mathrm{Au}^{3+}$ solution for 24 hours at RT, followed by ageing at $50{ }^{\circ} \mathrm{C}$ for 24 or 168 hours. The micrographs on the left were collected with a secondary electron detector whilst those on the right were collected with a backscatter electron detector. It is clear from these micrographs that when viewed under backscatter conditions, the gold nanoparticles residing on the fibres are much more apparent, appearing as bright white dots or triangles etc (depending on the morphology of the nanoparticles). As the intensity of the backscatter signal is directly related to atomic number, heavier elements reflect more signal than lighter elements, causing the gold nanoparticles to appear much brighter than the rest of the wool fibre, which is primarily comprises carbon, nitrogen, oxygen and sulfur. 

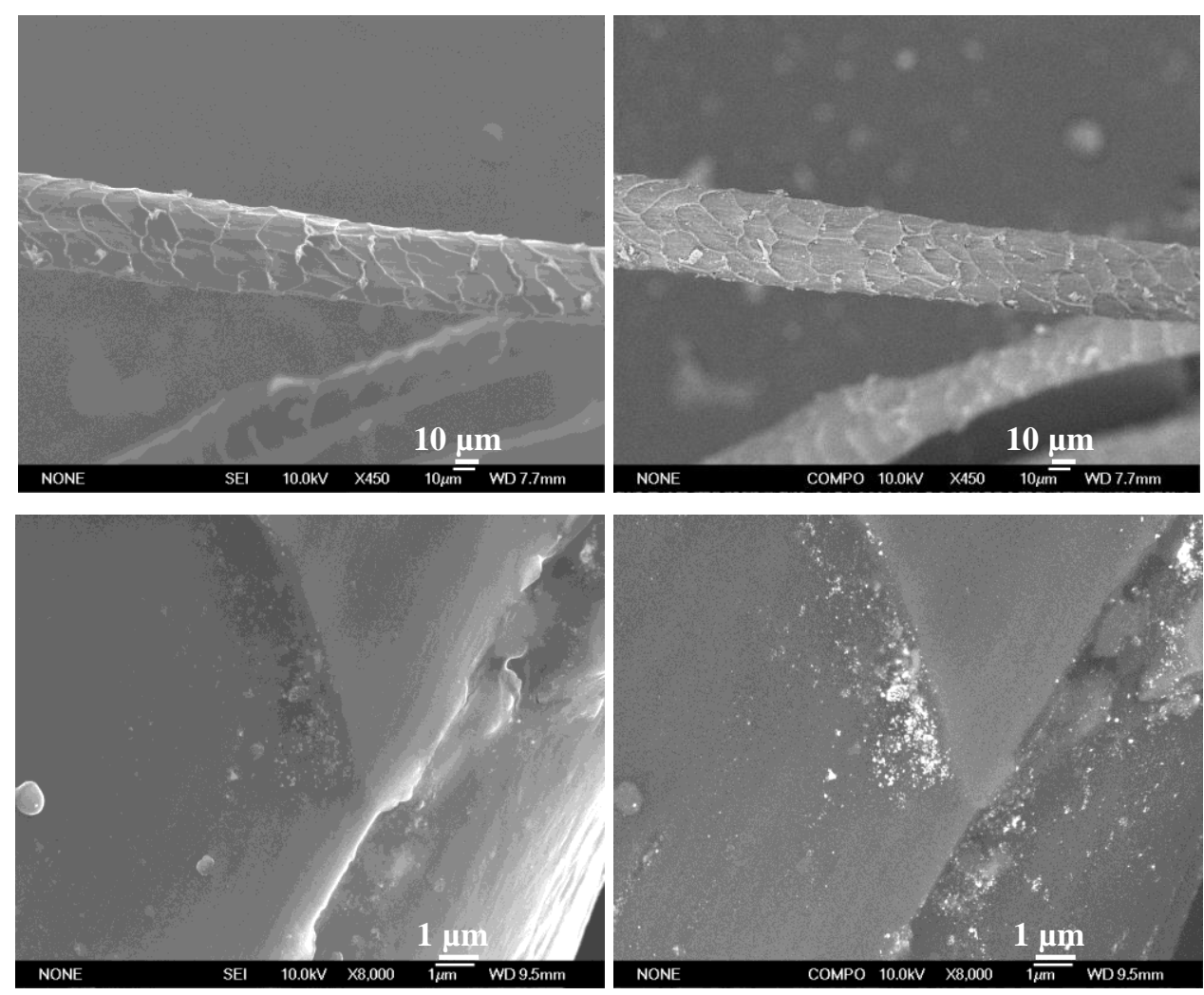

Figure 6.10: SEM micrographs of gold nanoparticle-crossbred wool composite materials (prepared by soaking the fibres in a $160 \mathrm{ppm}\left(8.13 \times 10^{-4} \mathrm{M}\right) \mathrm{Au}^{3+}$ solution for 24 hours at RT, followed by ageing at 50 ${ }^{\circ} \mathrm{C}$ for 24 hours (top) or 168 hours (bottom)). The micrographs on the left are collected with a secondary electron detector whilst those on the right are detected with a back scatter detector.

EDS analysis confirmed these bright white particles to be gold. Figure 6.11 offers SEM micrographs and the corresponding EDS Au maps of a selection of gold nanoparticlecrossbred wool composite materials. These maps show high concentrations of gold (depicted in bright white or red areas in the Au maps) to correlate to the position of the particles in the fibres. Additionally, Figure 6.12 and Figure 6.13 offer spectral snap shots of the areas under analysis, and substantiate the presence of gold due to the existence of the gold peaks. 

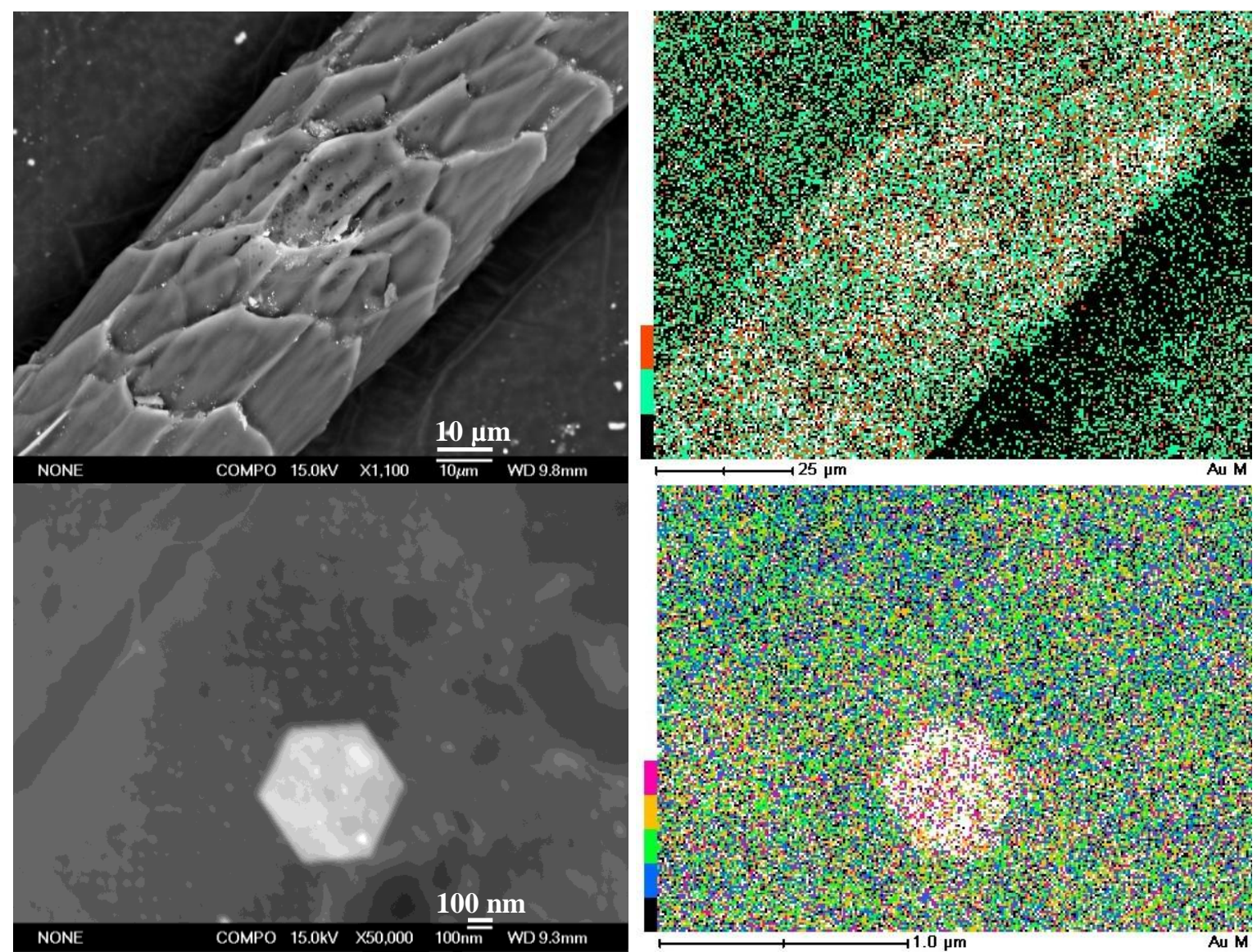

Figure 6.11: SEM micrographs and corresponding EDS Au maps of gold nanoparticle-crossbred wool composite materials.

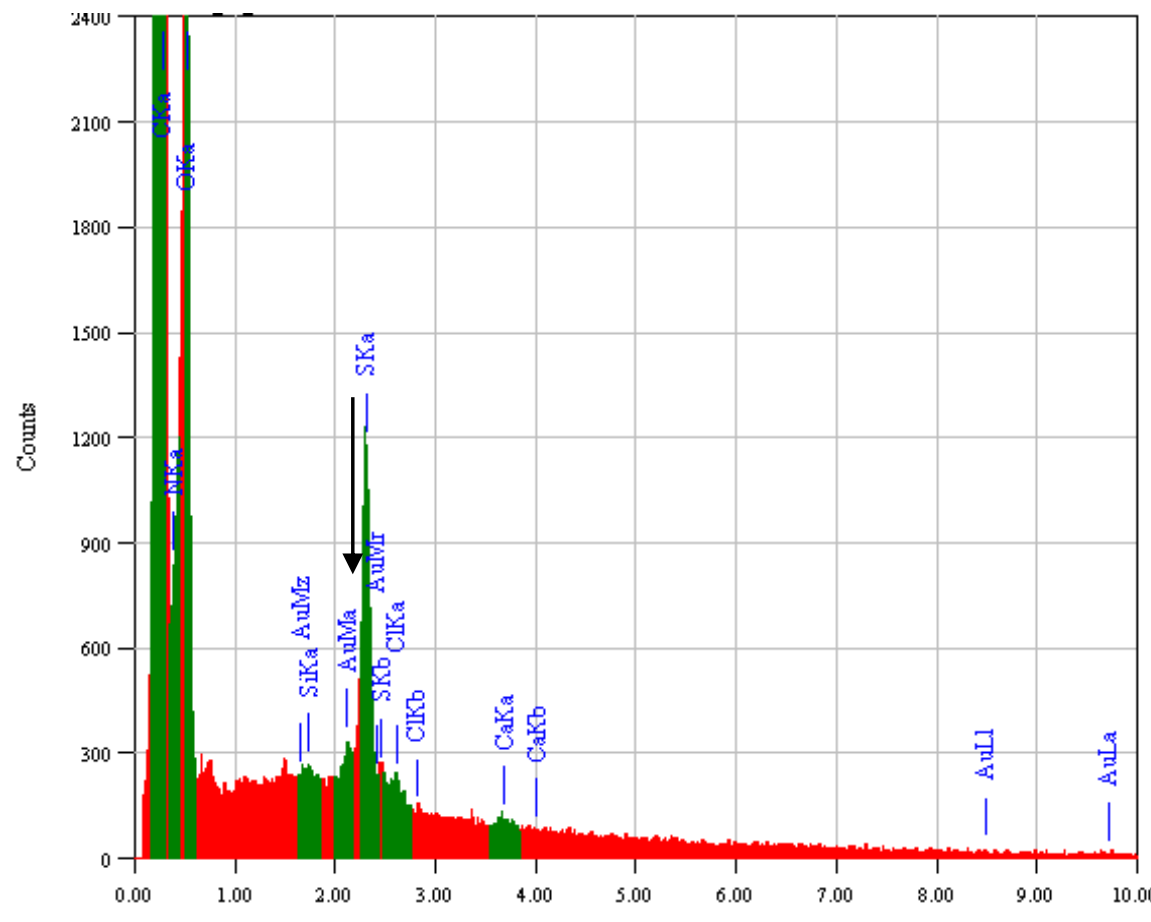

keV

Figure 6.12: EDS spectrum of the gold nanoparticle-crossbred wool composite shown in Figure 6.11 top. 


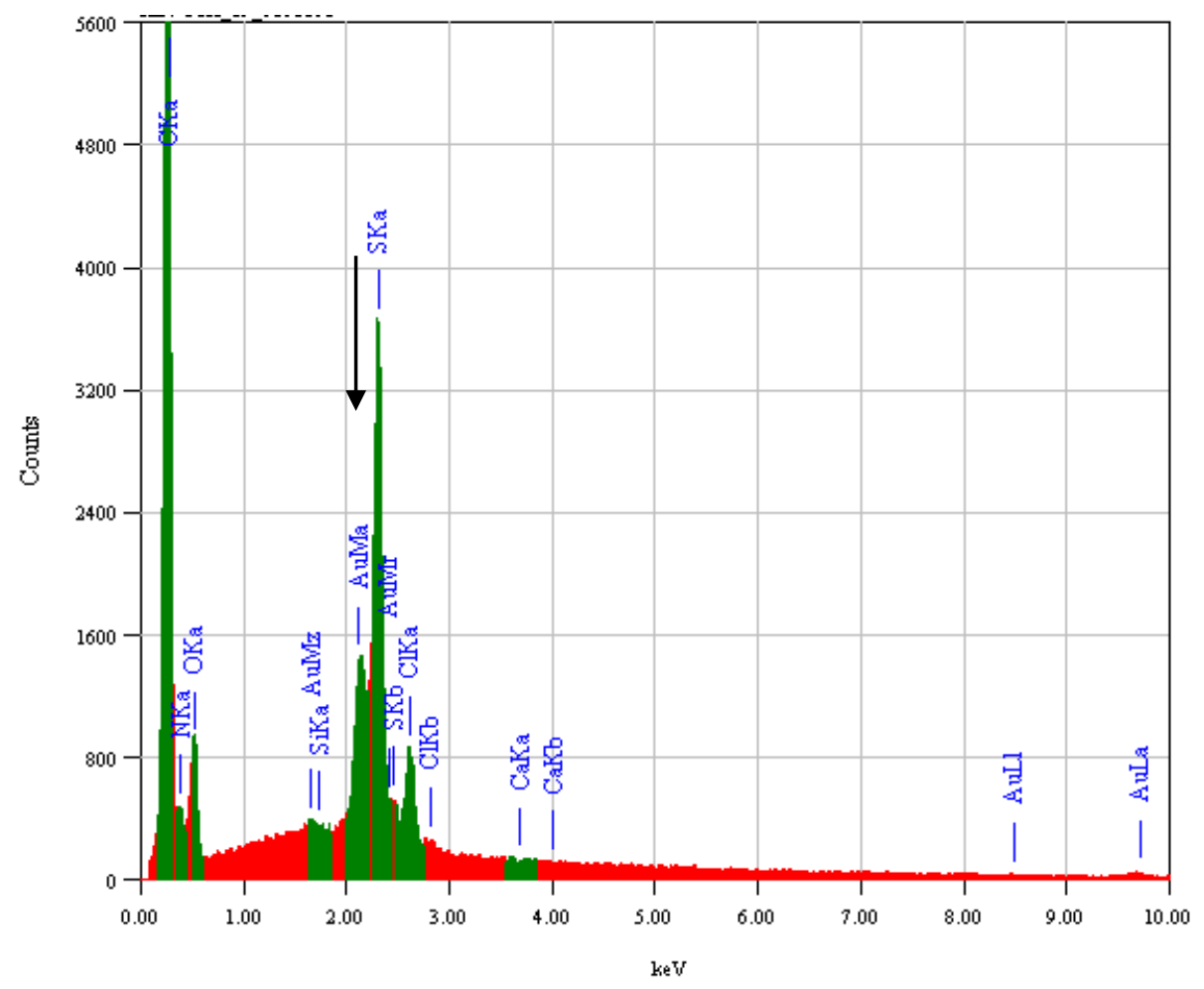

Figure 6.13: EDS spectrum of the gold nanoparticle-crossbred wool composite shown in Figure 6.11 bottom.

XPS further substantiated the presence of gold in the gold nanoparticle-crossbred wool composite materials, showing the composites prepared with a $\mathrm{Au}^{3+}$ concentration of $160 \mathrm{ppm}$ $\left(8.13 \times 10^{-4} \mathrm{M}\right) \mathrm{Au}^{3+}$ to consist of $0.18 \%$ gold (Figure 6.14, Table 6.1). Examination of the deconvoluted, high resolution $\mathrm{Au} 4 \mathrm{f}$ XPS spectra of the composite materials showed the relative percentages of $\mathrm{Au}^{3+}, \mathrm{Au}^{+}$(in the form of $\mathrm{Au}-\mathrm{S}$ ) and $\mathrm{Au}^{0}$ (Table 6.1). When employing a $\mathrm{Au}^{3+}$ concentration of $160 \mathrm{ppm}\left(8.13 \times 10^{-4} \mathrm{M}\right) \mathrm{Au}^{3+}$, with a soaking time of 24 hours, increasing the ageing time from 24 to 168 hours saw a decrease in the amount of $\mathrm{Au}^{3+}$ from $46 \%$ to $25 \%$. This decrease in $\mathrm{Au}^{3+}$ was accompanied by a simultaneous increase in both $\mathrm{Au}^{+}$(in the form of $\mathrm{Au}^{+}$bound to $\mathrm{S}$ ) and nanoparticulate $\mathrm{Au}^{0}$. This suggests that with increasing ageing times, more $\mathrm{Au}^{3+}$ was reduced to nanoparticulate $\mathrm{Au}^{0}$. 

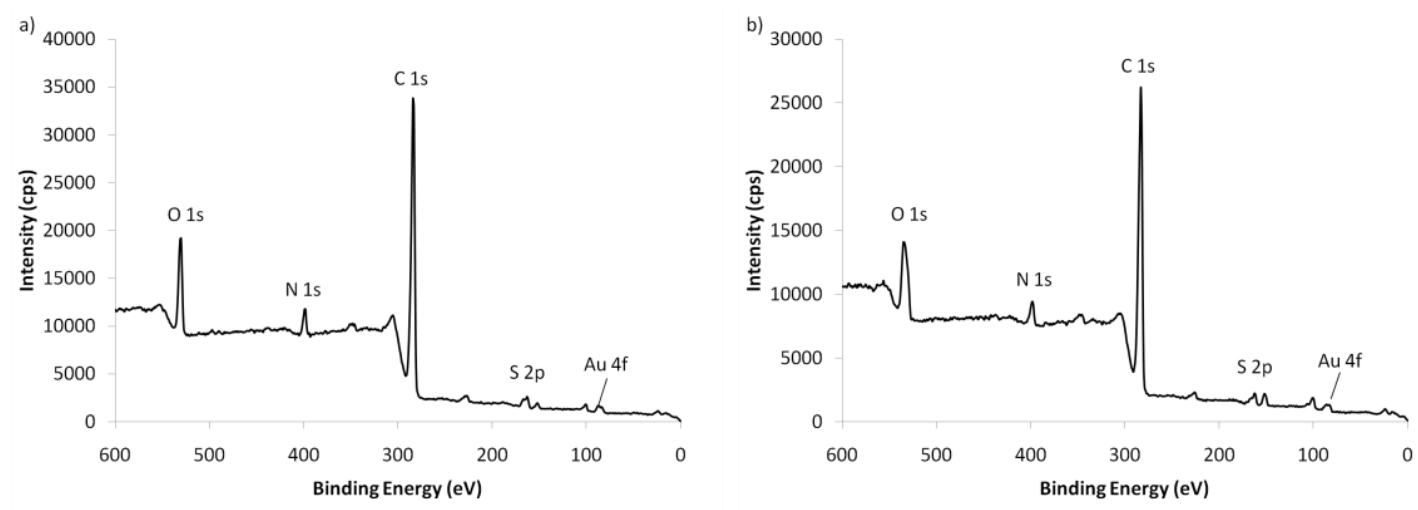

Figure 6.14: Wide XPS scans of gold nanoparticle-crossbred wool composites prepared by soaking the fibres in a $160 \mathrm{ppm}\left(8.13 \times 10^{-4} \mathrm{M}\right) \mathrm{Au}^{3+}$ solution for 24 hours at $\mathrm{RT}$, followed by ageing at $50{ }^{\circ} \mathrm{C}$ for a) 24 hours or b) 168 hours.

Table 6.1: Amount of gold present in gold nanoparticle-crossbred wool composites prepared by soaking the fibres in a $160 \mathrm{ppm}\left(8.13 \times 10^{-4} \mathrm{M}\right) \mathrm{Au}^{3+}$ solution for 24 hours at RT, followed by ageing at $50{ }^{\circ} \mathrm{C}$ for 24 or 168 hours.

\begin{tabular}{|c|c|c|c|c|c|}
\hline $\begin{array}{c}\mathrm{Au}^{3+} \\
\text { Concentration }\end{array}$ & $\begin{array}{l}\text { Ageing Time } \\
\text { (hours, } 50^{\circ} \mathrm{C} \text { ) }\end{array}$ & $\%$ Gold ( $\pm 10 \%$ ) & $\begin{array}{c}\% \mathrm{Au}^{3+} \\
( \pm 10 \%)\end{array}$ & $\begin{array}{c}\% \mathrm{Au}^{+} \\
( \pm 10 \%)\end{array}$ & $\begin{array}{c}\% \mathrm{Au}^{0} \\
( \pm 10 \%)\end{array}$ \\
\hline \multirow{2}{*}{$\begin{array}{c}160 \mathrm{ppm} \\
\left(8.13 \times 10^{-4} \mathrm{M}\right)\end{array}$} & 24 & 0.19 & 46 & 50 & 4 \\
\hline & 168 & 0.18 & 25 & 57 & 18 \\
\hline
\end{tabular}

\subsection{Extent of Gold Uptake by Crossbred Wool Fibres}

The uptake of gold by crossbred wool during the production of gold nanoparticle-crossbred wool composites was quantitatively analysed by atomic absorption (AA). The procedure is described in section 2.2.3.4, 2.3.4 and briefly in section 5.4. When employing a $\mathrm{Au}^{3+}$ concentration of $160 \mathrm{ppm}\left(8.13 \times 10^{-4} \mathrm{M}\right)$ the absorption of gold by crossbred wool at RT was complete after approximately 6 hours (Table 6.2). This is markedly slower than the absorption of gold by merino wool fibres (Figure 6.15 and Figure 6.16), with absorption of gold by these fibres being largely complete after only an hour. It is likely that the gold absorption rate was slower with crossbred wool relative to merino wool as the surface area of crossbred wool is much lower, thus presenting less sites for the gold ions to absorb onto and diffuse into the fibres. 


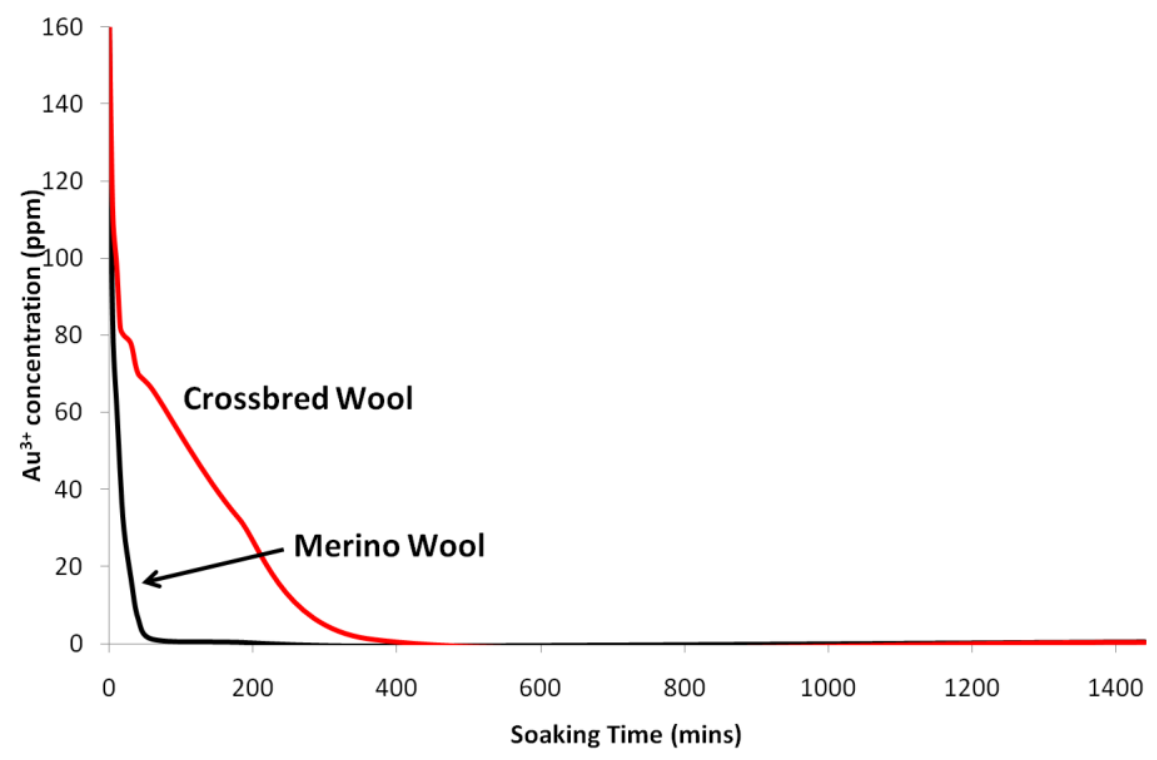

Figure 6.15: Gold uptake by crossbred or merino wool at RT. A $\mathrm{Au}^{3+}$ concentration of $160 \mathrm{ppm}(8.13 \mathrm{x}$ $10^{-4} \mathrm{M}$ ) was employed.

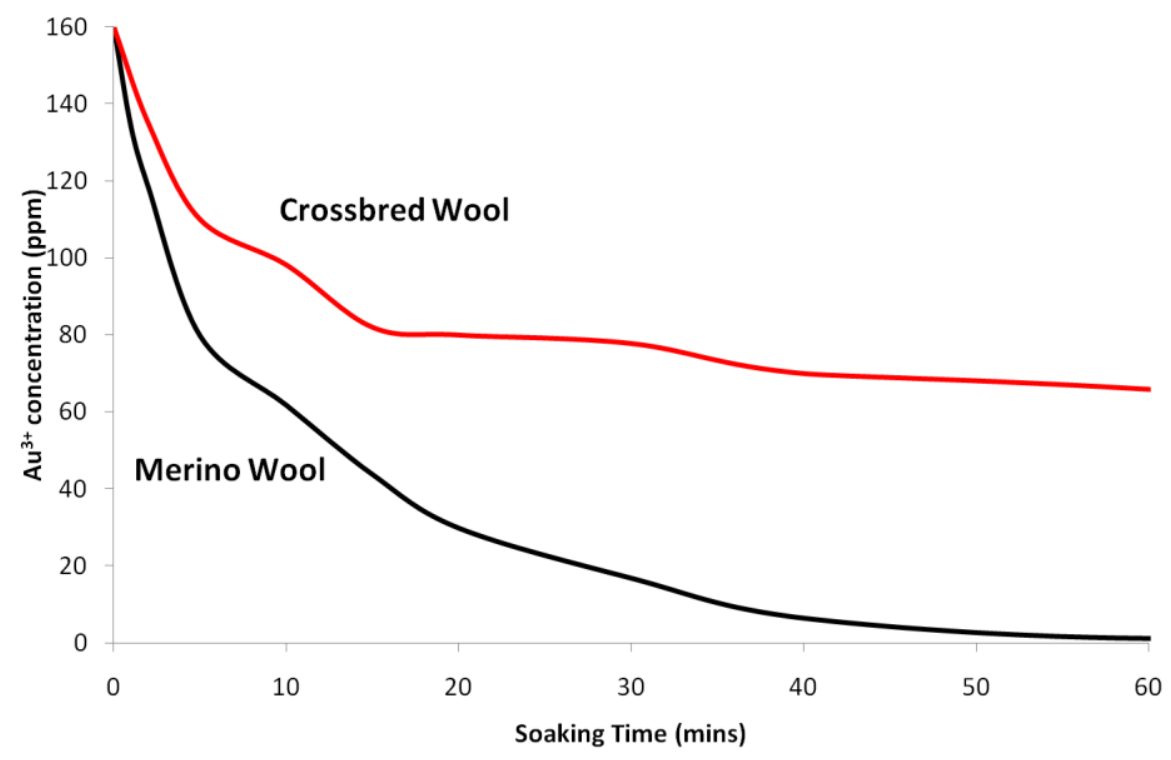

Figure 6.16: Gold uptake by crossbred or merino wool at RT. A $\mathrm{Au}^{3+}$ concentration of $160 \mathrm{ppm}(8.13 \mathrm{x}$ $10^{-4} \mathrm{M}$ ) was employed. 
Table 6.2: Absorption of gold by crossbred and merino wool at RT. A $\mathrm{Au}^{3+}$ concentration of $160 \mathrm{ppm}$ $\left(8.13 \times 10^{-4} \mathrm{M}\right)$ was employed.

\begin{tabular}{|c|c|c|}
\hline \multirow[b]{2}{*}{$\begin{array}{l}\text { Soaking/Absorption } \\
\text { Time (minutes) }\end{array}$} & \multicolumn{2}{|c|}{$\begin{array}{c}\text { Amount of } \mathrm{Au}^{3+} \text { remaining in the soaking } \\
\text { solution (ppm) }\end{array}$} \\
\hline & Crossbred Wool & Merino Wool \\
\hline 2 & 135 & 118 \\
\hline 5 & 110 & 80 \\
\hline 10 & 98 & 62 \\
\hline 15 & 82 & 43 \\
\hline 20 & 80 & 30 \\
\hline 30 & 78 & 17 \\
\hline 40 & 70 & 7 \\
\hline 60 & 66 & 1 \\
\hline 180 & 33 & 0 \\
\hline 360 & 1 & 0 \\
\hline 1440 & 0 & 0 \\
\hline
\end{tabular}

\subsection{Bonding of Gold Nanoparticles to Crossbred Wool Fibres}

As the chemical composition of crossbred wool is not dissimilar to that of merino wool, there are numerous sites in keratin (the major protein constituent of both fibres) to which the gold nanoparticles could bond, notably sulfur (thiols, disulfides), and or nitrogen (amine) containing amino acids. To investigate this bonding, EDS and XPS analysis of the produced composites was undertaken.

As with the composites prepared with merino wool, EDS analysis of the gold nanoparticlecrossbred composites showed that where there were high concentrations of gold, there were also high concentrations of sulfur (Figure 6.17), suggesting a chemical affinity of gold for sulfur in the protein fibres of the wool. 

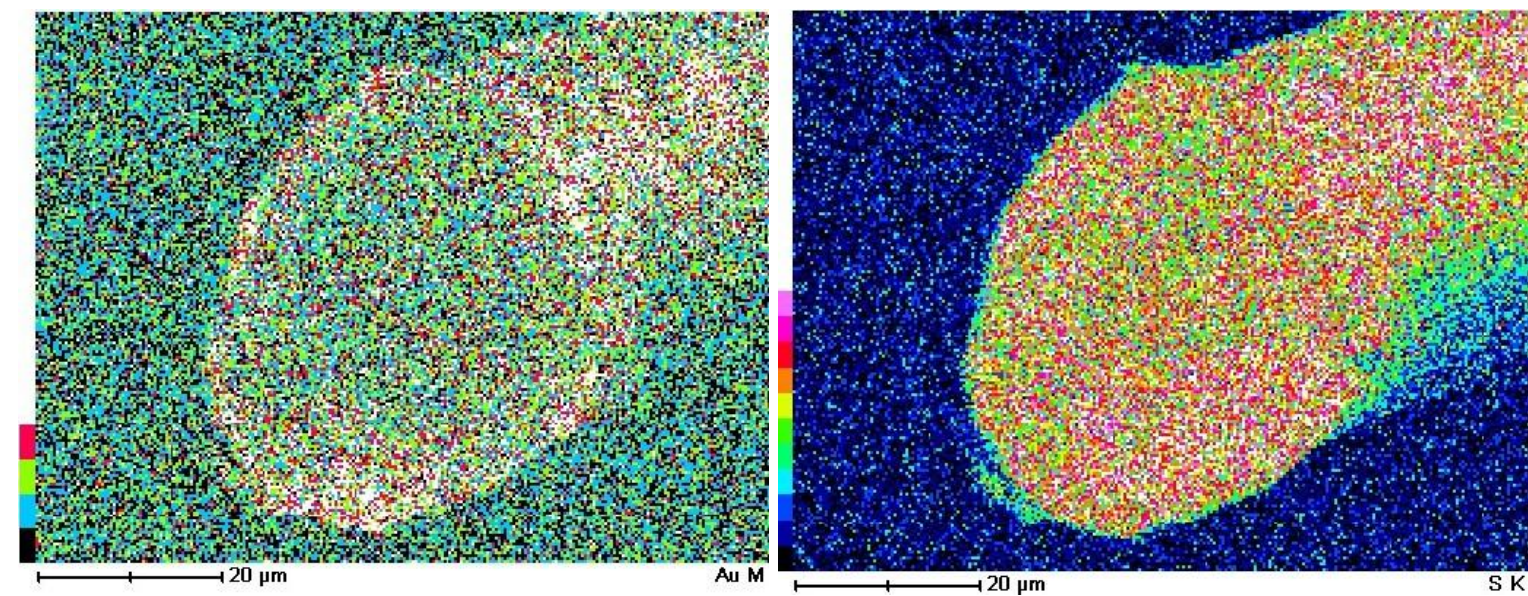

Figure 6.17: Cross sectional Au (left) and S (right) EDS maps of a gold nanoparticle-crossbred wool composite prepared by soaking crossbred wool in a $160 \mathrm{ppm}\left(8.13 \times 10^{-4} \mathrm{M}\right) \mathrm{Au}^{3+}$ solution for 24 hours at RT, followed by ageing at $50{ }^{\circ} \mathrm{C}$ for 168 hours.

This Au-S interaction was confirmed when comparing the deconvoluted high resolution $\mathrm{S} 2 \mathrm{p}$ XPS spectra of a gold nanoparticle-crossbred wool composite to that of crossbred wool (Figure 6.18). Upon inclusion of the gold nanoparticles, a new set of peaks centred at 162.35 and $163.53 \mathrm{eV}$, indicative of Au-S bonding arises. As with the merino wool composites, this Au-S bonding was further confirmed in the Au 4f XPS spectra of the composites (Figure 6.19), as the main peaks in this spectrum are those of the $7 / 2$ and $5 / 2$ peaks of Au-S, centred

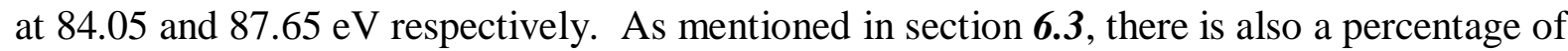
nanoparticulate $\mathrm{Au}^{0}$ and unreduced $\mathrm{Au}^{3+}$. The N 1s and O 1s XPS spectra of the composites is not dissimilar to those of the base fibres (as such they are not shown here), and as such there is no evidence of the gold nanoparticles bonding to other elements, such as oxygen or nitrogen. A comprehensive list of peak assignments is provided in Table 6.3 below.
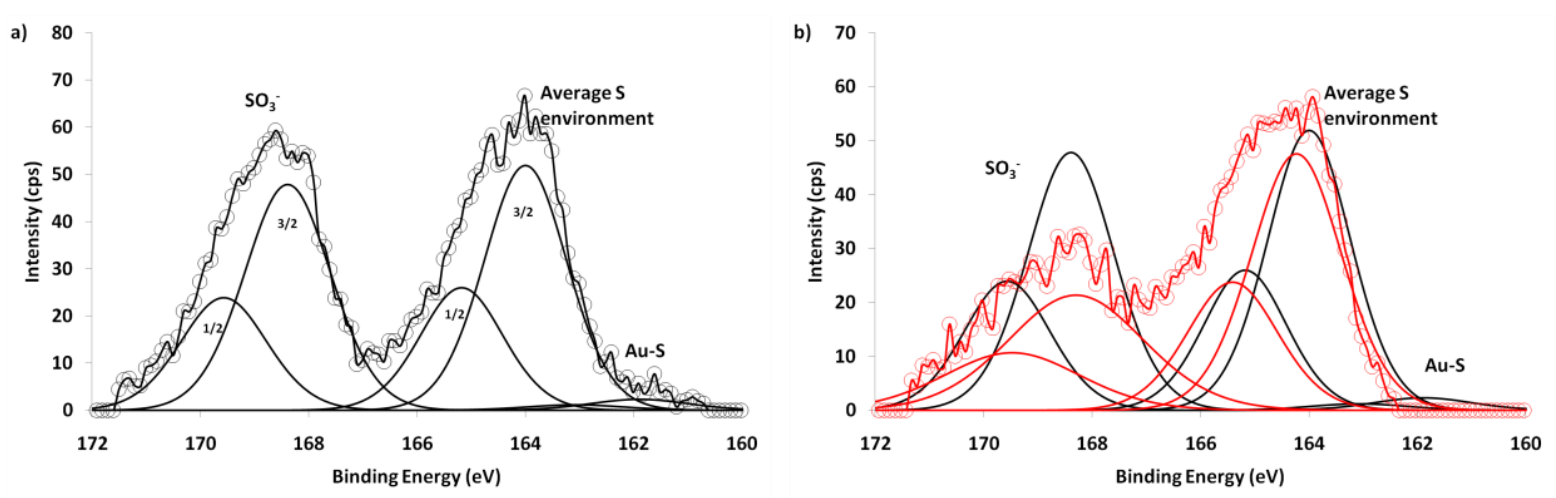

Figure 6.18: a) high resolution S 2p XPS spectra of gold nanoparticle-crossbred wool composites prepared by soaking crossbred wool in a $160 \mathrm{ppm}\left(8.13 \times 10^{-4} \mathrm{M}\right) \mathrm{Au}^{3+}$ solution for 24 hours at RT, followed by ageing at $50{ }^{\circ} \mathrm{C}$ for 168 hours. b) an overlay (in red) of crossbred wool. 


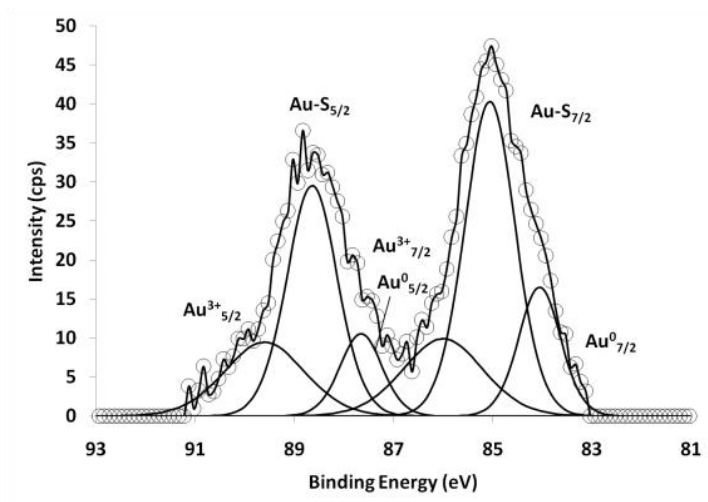

Figure 6.19: a) high resolution Au 4f XPS spectra of gold nanoparticle-crossbred wool composites prepared by soaking crossbred wool in a $160 \mathrm{ppm}\left(8.13 \times 10^{-4} \mathrm{M}\right) \mathrm{Au}^{3+}$ solution for 24 hours at RT, followed by ageing at $50{ }^{\circ} \mathrm{C}$ for 168 hours.

Table 6.3: XPS assignments of crossbred wool and gold nanoparticle-crossbred wool composite materials, prepared by soaking crossbred wool in a $160 \mathrm{ppm}\left(8.13 \times 10^{-4} \mathrm{M}\right) \mathrm{Au}^{3+}$ solution for 24 hours at RT, followed by ageing at $50{ }^{\circ} \mathrm{C}$ for 168 hours.

\begin{tabular}{|c|c|c|c|}
\hline & & Crossbred Wool & Composite \\
\hline & & $\begin{array}{r}\text { Binding Energy (e } \\
\text { Percen }\end{array}$ & $\begin{array}{l}.2 \mathrm{eV}) \text { and Relative } \\
( \pm 10 \%)\end{array}$ \\
\hline C 1s & $\mathrm{C}-\mathrm{C}, \mathrm{C}-\mathrm{H}$ & 285.00 (44 \%) & 285.00 (64 \%) \\
\hline & $\mathrm{C}-\mathrm{O}, \mathrm{C}-\mathrm{N}, \mathrm{C}-\mathrm{S}$ & 286.20 (29 \%) & 286.20 (23 \%) \\
\hline & $\mathrm{C}-\mathrm{O}-\mathrm{C}=\mathrm{O}$ & 287.27 (18 \%) & 287.41 (2 \%) \\
\hline & $\mathrm{C}=\mathrm{O}$ & 288.30 (9 \%) & 288.25 (10 \%) \\
\hline N 1s & $\mathrm{N}-\mathrm{H},=\mathrm{N}-$ & 400.21 (51\%) & 400.11 (58 \%) \\
\hline & $-\mathrm{N}-\mathrm{O}-$ & 401.38 (49 \%) & 401.06 (42 \%) \\
\hline $01 \mathrm{~s}$ & $\begin{array}{l}\text { Average } \mathrm{O} \\
\text { environment }\end{array}$ & 531.84 (22 \%) & 531.75 (58 \%) \\
\hline & $-\mathrm{OH}$ & 533.27 (36 \%) & 532.86 (31\%) \\
\hline & $\mathrm{C}-\mathrm{O}-\mathrm{C}=\mathrm{O}$ & 534.7 (42\%) & $534.32(11 \%)$ \\
\hline$S 2 p$ & $\begin{array}{l}\text { Average } S \\
\text { environment } S_{3 / 2}\end{array}$ & 164.18 (38 \%) & 164.09 (41\%) \\
\hline & $\begin{array}{l}\text { Average S } \\
\text { environment } S_{1 / 2}\end{array}$ & 165.36 (19 \%) & 165.27 (21\%) \\
\hline & $\mathrm{SO}_{3}^{-}{ }_{3 / 2}^{-}$ & 168.08 (29 \%) & 168.33 (18 \%) \\
\hline & $\mathrm{SO}_{31 / 2}^{-}$ & 169.26 (14 \%) & 169.51 (15\%) \\
\hline & $\mathrm{S}-\mathrm{Au}_{3 / 2}$ & - & 162.35 (3 \%) \\
\hline & $\mathrm{S}-\mathrm{Au}_{1 / 2}$ & & 163.53 (2 \%) \\
\hline
\end{tabular}




\begin{tabular}{llcc}
\hline & & Crossbred Wool & Composite \\
\cline { 3 - 4 } & & - & $\begin{array}{c}\text { Binding Energy (eV) and Relative } \\
\text { Percentage }\end{array}$ \\
\hline $\mathbf{A u} 4 f$ & $\mathrm{Au}^{0}{ }_{7 / 2}$ & - & $84.05(11 \%)$ \\
& $\mathrm{Au}^{-S_{7 / 2}}$ & - & $85.06(33 \%)$ \\
& $\mathrm{Au}^{3+}{ }_{7 / 2}$ & - & $86.00(13 \%)$ \\
$\mathrm{Au}_{5 / 2}^{0}$ & - & $87.65(7 \%)$ \\
$\mathrm{Au} \mathrm{S}_{5 / 2}$ & - & $88.64(24 \%)$ \\
$\mathrm{Au}^{3+}{ }_{5 / 2}$ & & $89.60(12 \%)$ \\
\hline
\end{tabular}

\subsection{Proposed Mechanism of Formation}

The formation mechanism of the gold nanoparticle-crossbred wool composites is not dissimilar to that of the merino wool materials, which considering the similar chemical composition of the two fibres, is not unexpected. Comparisons of the XPS spectra of the crossbred composites and crossbred wool itself suggest that the $\mathrm{Au}^{3+}$ to $\mathrm{Au}^{0}$ reduction was facilitated by, and coupled with the oxidation of the disulfide group of cystine to cysteic acid.

As with the merino wool systems, reduction of $\mathrm{Au}^{3+}$ to $\mathrm{Au}^{+}$, forming some kind of $\mathrm{Au}-\mathrm{S}$ complex with the protein fibres in the wool, appeared to occur during the 24 hour soaking period. This was evidenced in analysis of the high resolution Au $4 \mathrm{f}$ and S $2 p$ XPS spectra of crossbred wool that had been soaked in a $160 \mathrm{ppm}\left(8.13 \times 10^{-4} \mathrm{M}\right) \mathrm{Au}^{3+}$ solution for 24 hours at RT. Peaks centred at 85.00 and $88.60 \mathrm{eV}$ appeared in the $\mathrm{Au} 4 \mathrm{f}$ spectra, and a peak centred at $162.00 \mathrm{eV}$ appeared in the S $2 \mathrm{p}$ spectra (Figure 6.20). Upon ageing, a greater percentage of $\mathrm{Au}^{3+}$ was reduced to $\mathrm{Au}^{+}$and nanoparticulate $\mathrm{Au}^{0}$ (Table 6.4). The reduction of $\mathrm{Au}^{3+}$ to $\mathrm{Au}^{+}$and $\mathrm{Au}^{0}$, occurring during soaking, and to a much greater extent during ageing was accompanied by a decrease in peak area associated with cystine, and an increase in peak area of cysteic acid (Figure 6.21), confirming the role of cystine in the reduction of $\mathrm{Au}^{3+}$ to $\mathrm{Au}^{+}$and nanoparticulate $\mathrm{Au}^{0}$. 

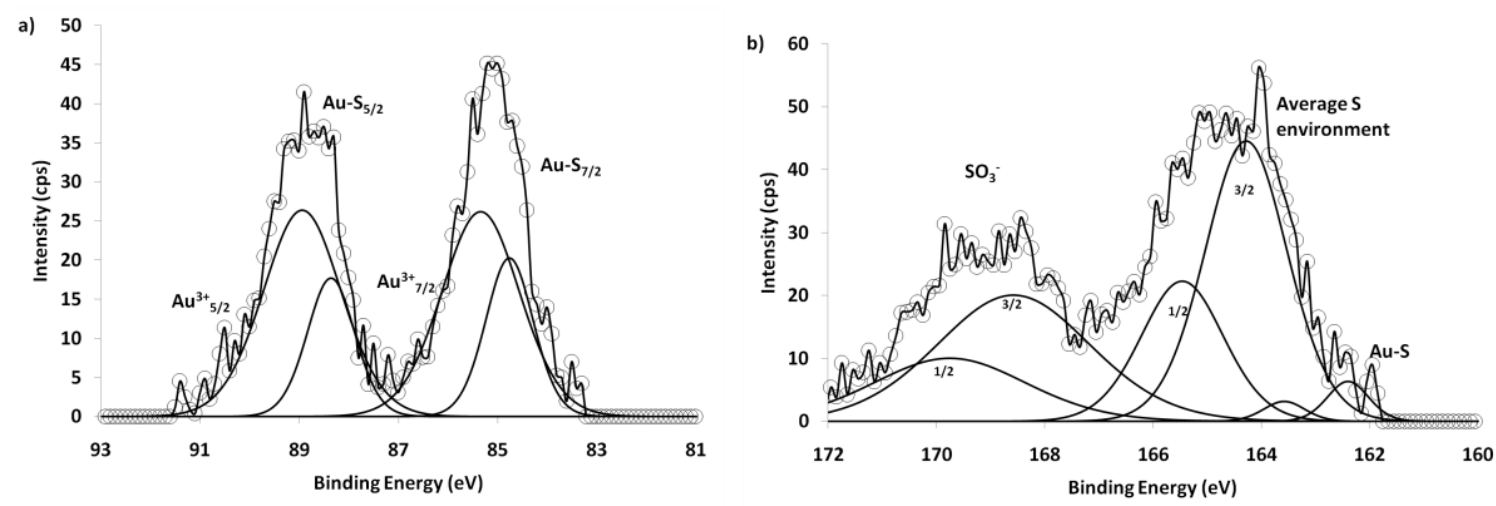

Figure 6.20: High resolution Au $4 f$ (a) and S 2p (b) XPS spectra of crossbred wool fibres that had been soaked in a $160 \mathrm{ppm}\left(8.13 \times 10^{-4} \mathrm{M}\right) \mathrm{Au}^{3+}$ solution, at RT for 24 hours.

Table 6.4: Amount of gold present in crossbred wool soaked in $\mathrm{Au}^{3+}$ and gold nanoparticle-crossbred wool composite materials.

\begin{tabular}{cccc}
\hline & $\begin{array}{c}\% \mathrm{Au}^{3+} \\
( \pm 10 \%)\end{array}$ & $\begin{array}{c}\% \mathrm{Au}^{+}( \pm 10 \%) \\
(\mathrm{Au}-\mathrm{S})\end{array}$ & $\begin{array}{c}\% \mathrm{Au}^{0}( \pm 10 \\
\%)\end{array}$ \\
\hline 24 h Soak & 70 & 30 & 0 \\
24 h Soak + 24 h Age & 46 & 50 & 4 \\
24 h Soak + 168 h Age & 25 & 57 & 18 \\
\hline
\end{tabular}

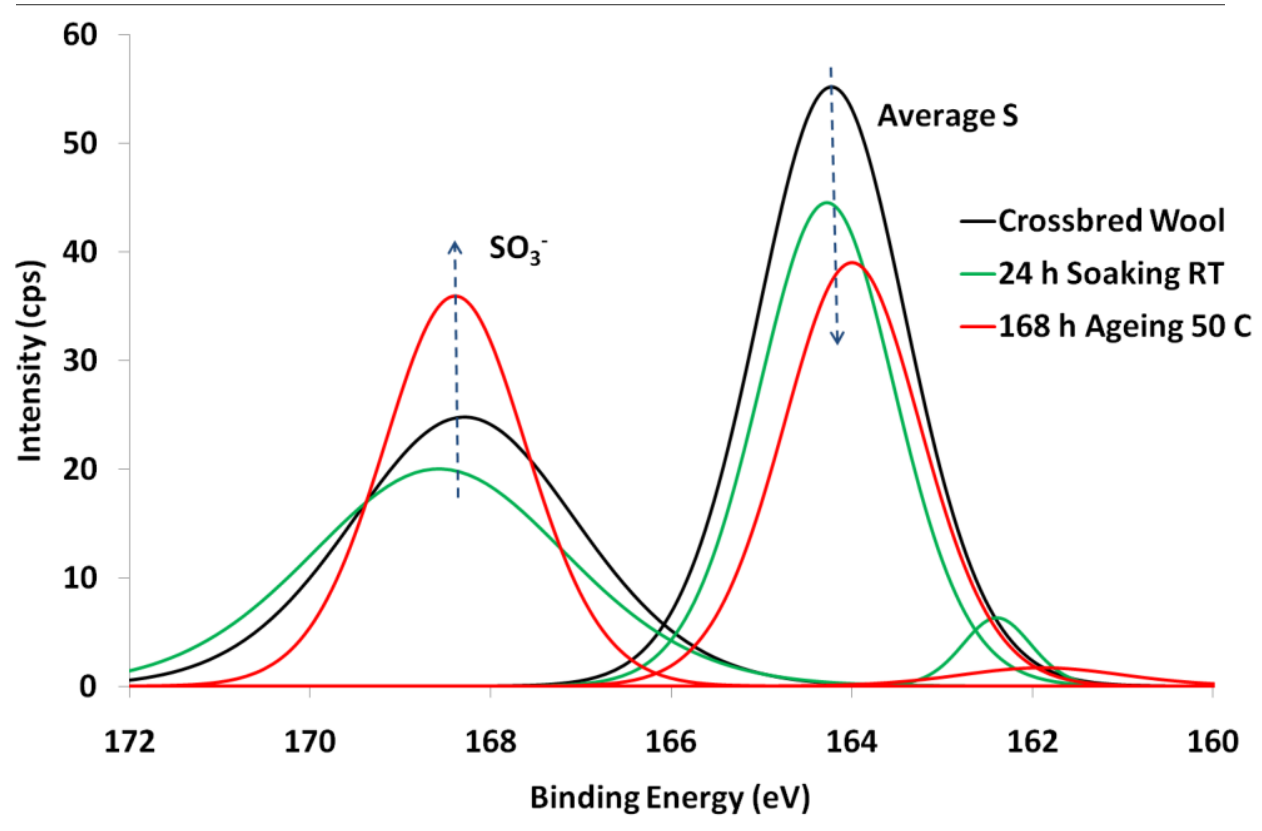

Figure 6.21 Comparisons of the deconvoluted high resolution S 2p XPS spectra of crossbred wool (black lines) and gold nanoparticle-crossbred wool composites, prepared by soaking fibres in a $160 \mathrm{ppm} \mathrm{Au}^{3+}$ $\left(8.13 \times 10^{-4} \mathrm{M}\right)$ solution for 24 hours at $\mathrm{RT}$ followed by ageing at $50{ }^{\circ} \mathrm{C}$ for 24 (green lines) or 168 hours (red lines). 


\subsection{Colourfastness to Washing}

As with the merino wool composites, the colourfastness to washing of the gold nanoparticlecrossbred wool composites were tested according to the synthesis outlines in section 2.3.13. A composite material prepared by soaking crossbred wool in a $160 \mathrm{ppm}\left(8.13 \times 10^{-4} \mathrm{M}\right) \mathrm{Au}^{3+}$ solution for 24 hours at RT and ageing, at $50{ }^{\circ} \mathrm{C}$ for 168 hours was chosen as a representative of the gold nanoparticle-crossbred wool materials.

Visually these materials appear to be very colourfast with respect to washing, as they do not seem to change colour even after prolonged washing at elevated temperatures (Figure 6.22). This is confirmed in the CIE L*, a*, b*, $457 \mathrm{~nm}$ brightness and $580 \mathrm{~nm}$ brightness values of the washed composites, as these values remained relatively constant (Appendix VI).

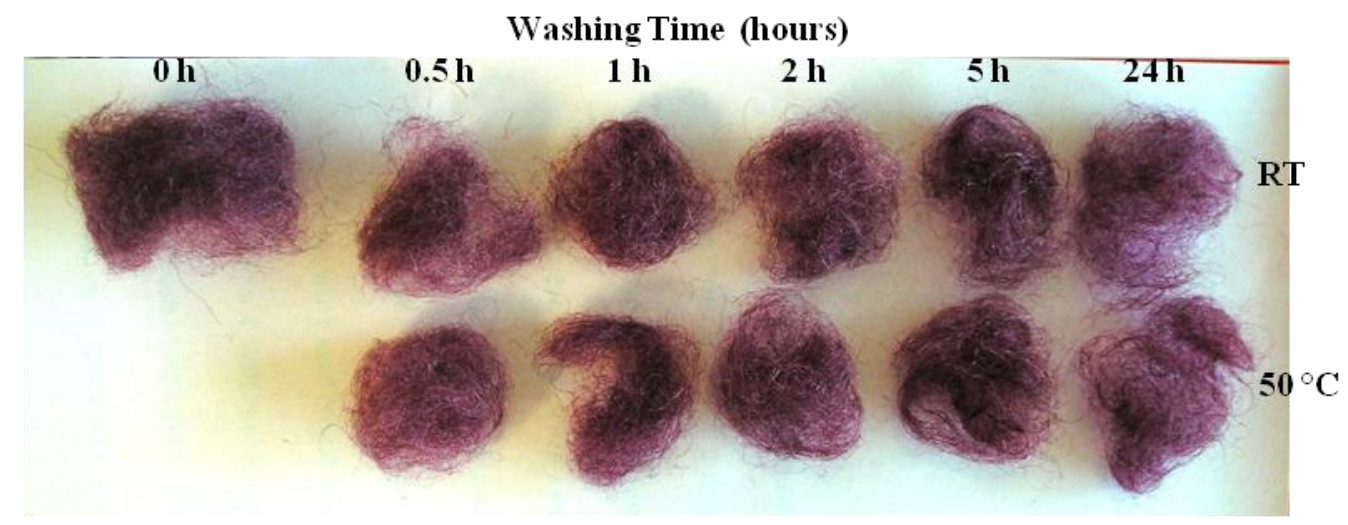

Figure 6.22: Gold nanoparticle-crossbred wool composites prepared by soaking crossbred wool in a 160 ppm $\left(8.13 \times 10^{-4} \mathrm{M}\right) \mathrm{Au}^{3+}$ solution for 24 hours at RT and ageing, at $50{ }^{\circ} \mathrm{C}$ for 168 hours, following simulated washability testing.

\subsection{Leaching}

Quantitative analysis of the washing solutions obtained during simulated washability testing (section 6.7) was undertaken to establish the amount of gold leached from the composites during washing (Table 6.5). The amount of gold leached from these materials was very low, 
leaching a maximum of $1.9 \%$ of the total gold loading, complementing the results obtained in the colour fastness to washing tests, where the materials did not undergo any marked colour change even following extensive washing at elevated temperatures. Similar results were obtained with the gold nanoparticle-merino wool composites (section 5.8).

Table 6.5: Gold leached from gold nanoparticle-crossbred wool composites (prepared by soaking crossbred wool in a $160 \mathrm{ppm}\left(8.13 \times 10^{-4} \mathrm{M}\right) \mathrm{Au}^{3+}$ solution for 24 hours at RT, followed by ageing at $50{ }^{\circ} \mathrm{C}$ for 24 or 168 hours) following simulated washability testing.

\begin{tabular}{|c|c|c|c|}
\hline $\begin{array}{l}\text { Washing Time } \\
\text { (Hours) }\end{array}$ & $\begin{array}{c}\text { Washing } \\
\text { Temperature }\end{array}$ & $\begin{array}{l}\text { Gold Leached } \\
(\mathrm{ppm}) \pm 0.5 \mathrm{ppm}\end{array}$ & $\begin{array}{c}\text { \% Total Gold } \\
\text { Loading }\end{array}$ \\
\hline 0.5 & RT & 1 & 0.6 \\
\hline 1 & & 2 & 1.3 \\
\hline 2 & & 2 & 1.3 \\
\hline 5 & $\mathrm{RT}$ & 1 & 0.6 \\
\hline 24 & & 2 & 1.3 \\
\hline 0.5 & $50{ }^{\circ} \mathrm{C}$ & 2 & 1.3 \\
\hline 1 & & 2 & 1.3 \\
\hline 2 & & 2 & 1.3 \\
\hline 5 & & 3 & 1.9 \\
\hline 24 & & 2 & 1.3 \\
\hline
\end{tabular}

\subsection{Scale Up}

As with the gold nanoparticle-merino wool composite materials, the production of crossbred composites has also been scaled up, producing large (approximately $10 \mathrm{~kg}$ ) quantities of a deep regal purple coloured material, which is destined to be spun into a yarn and subsequently woven into a carpet. 


\subsection{Conclusions}

As a proof of concept, the production of gold nanoparticle-merino wool composite materials was extended to include crossbred wool as a base fibre. This was successful, with the production of regal purple coloured gold nanoparticle-crossbred wool composites.

Increasing both the $\mathrm{Au}^{3+}$ concentration and also the ageing time only slightly intensified the purple colour of the resultant materials, with a deep, regal purple coloured material produced with low $\mathrm{Au}^{3+}$ concentrations and short ageing times. The increase in intensity of the purple colour upon increasing $\mathrm{Au}^{3+}$ concentrations and ageing times corresponded to a small increase in concentration of spherical gold nanoparticles, approximately 20-30 nm in diameter, located on the fibre surface. In addition to the spherical nanoparticles, all gold nanoparticle-crossbred wool composites possessed gold nanoparticles in a range of morphologies, notably hexagonal platelets (approximately 100-300 nm in diameter), triangles (approximately $100 \mathrm{~nm}$ in diameter) and truncated triangles (approximately $100 \mathrm{~nm}$ in diameter) in similar concentrations.

The much broader range of gold nanoparticle morphologies observed in the crossbred wool systems, and also the increased $\mathrm{Au}^{3+}$ to $\mathrm{Au}^{0}$ reduction rate relative to that seen in the merino wool composites is proposed to be due to the increased fibre diameter of crossbred wool, and hence its decreased specific surface area. With the same ratio of $\mathrm{Au}^{3+}$ : wool : solvent volume, there is a higher density of absorbed $\mathrm{Au}^{3+}$ at the surface of the crossbred wools, therefore when initial nucleation events occur, a smaller percentage of $\mathrm{Au}^{3+}$ would be reduced (compared to the merino wool systems), leaving a relatively high concentration of unreduced $\mathrm{Au}^{3+}$ at the fibre surface. This has the potential to adsorb into any twin plane defects present in the initially formed nanoparticles, increasing the probability of the production of anisotropic gold nanoparticles. Additionally, the higher $\mathrm{Au}^{3+}$ surface density would lead to more collisions between $\mathrm{Au}^{3+}$ ions, more nucleations and hence more nanoparticles formed at the surface of the fibres in a shorter amount of time, and the development of a rich regal purple colour in less time. 
As with the merino systems, the reduction of $\mathrm{Au}^{3+}$ to nanoparticulate $\mathrm{Au}^{0}$ by crossbred wool was proposed to be facilitated by the oxidation of cystine to cysteic acid, with bonding of the produced gold nanoparticles to the crossbred wool fibres occurring by means of $\mathrm{Au}-\mathrm{S}$ bonds. The gold nanoparticle-crossbred composite materials were very colourfast to washing. 
Since both merino wool and crossbred wool proved to be successful in facilitating the reduction of $\mathrm{Au}^{3+}$ to nanoparticulate $\mathrm{Au}^{0}$, producing textiles whose colour derived from the surface plasmons of the gold nanoparticles bound to the fibres, we were interested to see whether alternative natural protein fibres were also capable of facilitating this reduction, thus broadening the suite of natural fibre-gold nanoparticle composite materials. As such silk was employed as the base fibre in the production of gold nanoparticle-silk composite materials.

\subsection{Physical Characterisation and Morphology}

In a typical reaction, the production of gold nanoparticle-silk composites involved dispersing fibres in a $160 \mathrm{ppm}\left(8.13 \times 10^{-4} \mathrm{M}\right) \mathrm{Au}^{3+}$ solution at room temperature for 0-24 hours, following which some samples were aged by heating at $50{ }^{\circ} \mathrm{C}$ for $24-168$ hours. This was carried out at various pH's (notably $2.7,7,9-10$ or 12 ). As with the composites incorporating merino wool, the colour and colour intensity of the resultant gold nanoparticle-silk composites was changed by systematically altering the soaking time, ageing time and soaking and ageing solution $\mathrm{pH}$. Figure 7.1 shows a picture of a selection of gold nanoparticle-silk composites, illustrating the obtainable colour range. These composite materials still retain the shine, and iridescent lustre for which silk is renowned.

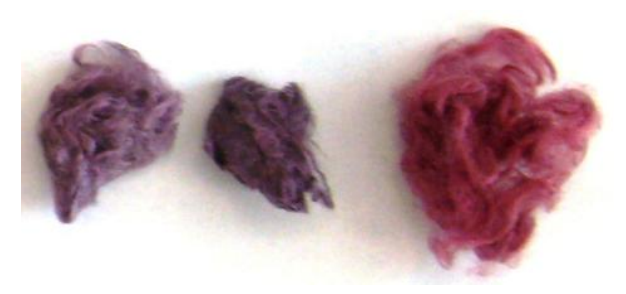

Figure 7.1: A selection of gold nanoparticle-silk composites.

When employing a soaking solution $\mathrm{pH}$ of 2.7 (the $\mathrm{pH}$ of the traditional $160 \mathrm{ppm}, 8.13 \times 10^{-4}$ $\mathrm{M} \mathrm{Au}^{3+}$ solution) a colour development was observed in the fibres during soaking at RT 
(Figure 7.2). Heating the materials post soaking produced deeper purple coloured materials, however these were a little spectrally impure, with prolonged heating slightly intensifying the colour (Figure 7.3). In addition to nanoparticles forming on the silk fibres whilst soaking at RT, nanoparticles also formed in the soaking solution after approximately half an hour's soaking, evidenced by a change in colour of the solution from yellow of $\mathrm{AuCl}_{4}{ }^{-}$to colourless and then a deep red wine colour. This colour intensified remained relatively constant during ageing, suggesting that the produced nanoparticles did not re-absorb onto the silk fibres. This is discussed in more detail in section 7.6.

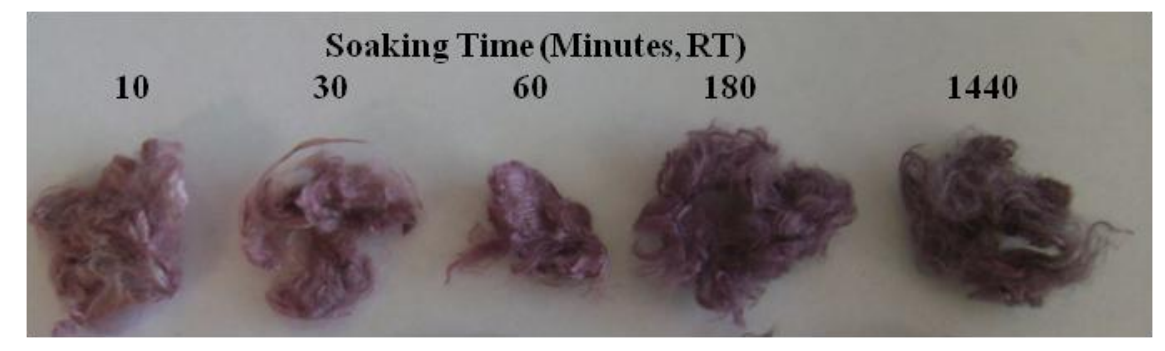

Figure 7.2: Gold nanoparticle-silk composite materials, prepared by soaking silk in a $160 \mathrm{ppm}\left(8.13 \times 10^{-4}\right.$ M) $\mathrm{Au}^{3+}$ solution for 10 minutes to 24 hours at RT.

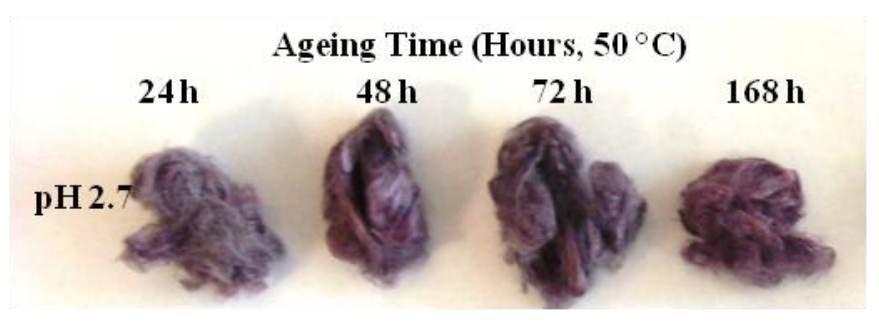

Figure 7.3: Gold nanoparticle-silk composite materials, prepared by soaking silk in a $160 \mathrm{ppm}\left(8.13 \times 10^{-4}\right.$ M) $\mathrm{Au}^{3+}$ solution for 24 hours at RT, followed by ageing at $50{ }^{\circ} \mathrm{C}$ for $24-168$ hours.

The increase in colour intensity of the gold nanoparticle-silk composites upon prolonged soaking and ageing times corresponded to an increase in the amount of similarly sized and shaped nanoparticles on the fibre surface. These nanoparticles were predominantly spherical or five-fold twinned in morphology, being smaller, approximately 5-10 $\mathrm{nm}$ in diameter, or larger approximately $20-40 \mathrm{~nm}$ in diameter, with agglomerations of a percentage of the larger nanoparticles seen (Figure 7.4). There were also a small amount of triangular nanoplates, approximately $80-100 \mathrm{~nm}$ in diameter. The presence of these agglomerated nanoparticles, 
and also the range in particle size and shape would account for the slightly spectrally impure colour of the composite materials prepared with a soaking and ageing solution $\mathrm{pH}$ of approximately 2.7 .
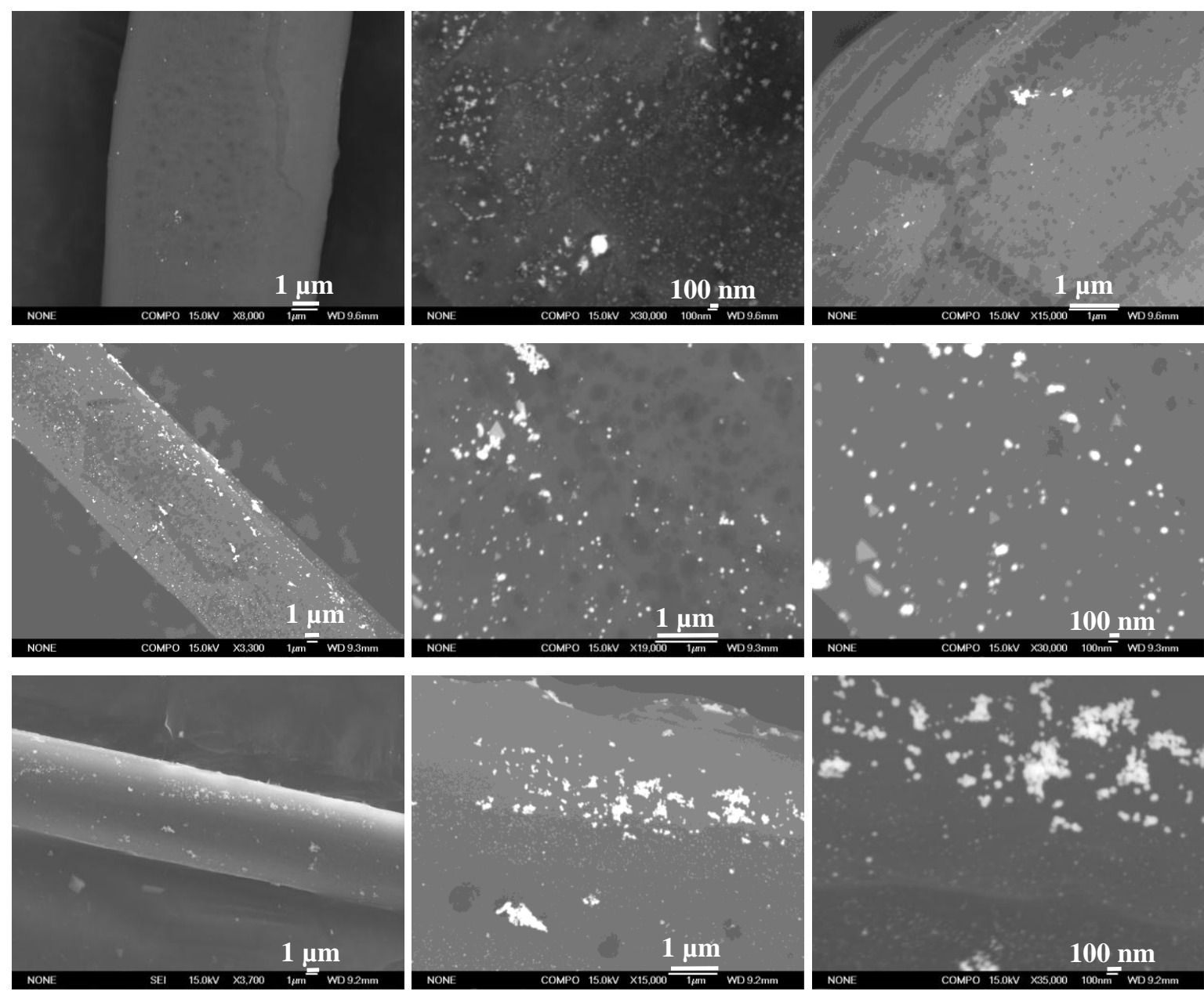

Figure 7.4: Gold nanoparticle-silk composite materials, prepared by soaking silk fibres in a $160 \mathrm{ppm}$ $\left(8.13 \times 10^{-4} \mathrm{M}\right.$ ) $\mathrm{Au}^{3+}$ solution for 10 minutes (top) or 24 hours at RT (middle), followed by ageing at $50{ }^{\circ} \mathrm{C}$ for 168 hours (bottom).

Cross sectional analysis of the gold nanoparticle-silk composites showed the nanoparticles to reside preferentially on the surface of the silk fibres (Figure 7.5). EDS analysis of the same cross section showed that in addition to gold nanoparticles forming predominantly on the fibre surface, very little gold diffused into the centre of the fibres, with high concentrations found solely on the fibre surface (Figure 7.6). 

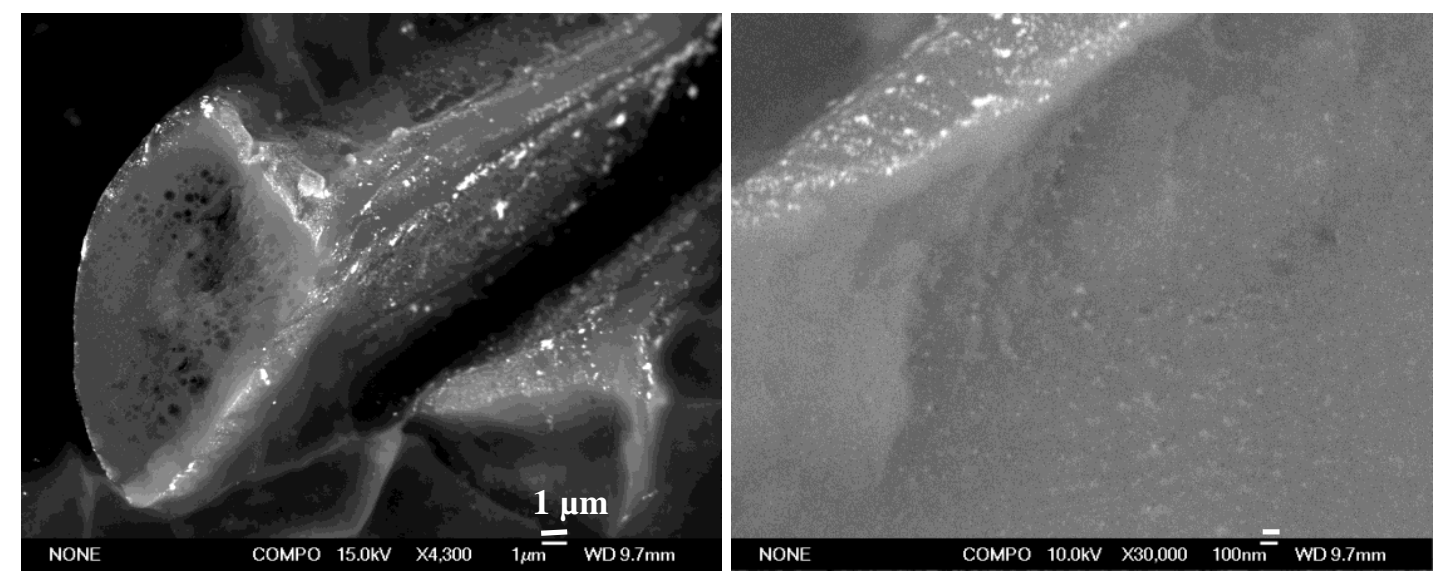

Figure 7.5: Cross sectional SEM micrographs of a gold nanoparticle-silk composite prepared by soaking silk fibres in a $160 \mathrm{ppm}\left(8.13 \times 10^{-4} \mathrm{M}\right) \mathrm{Au}^{3+}$ solution for 24 hours at RT, followed by ageing at $50{ }^{\circ} \mathrm{C}$ for 168 hours.
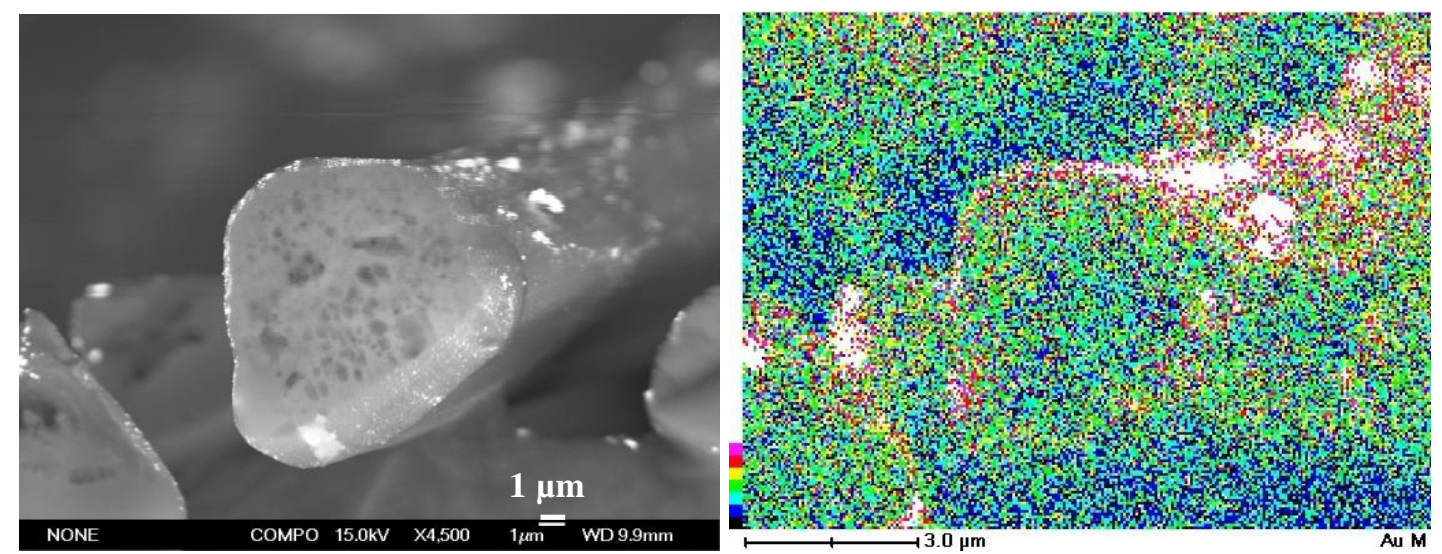

Figure 7.6: Cross sectional SEM micrograph (left) and corresponding Au EDS map of a gold nanoparticle-silk composite prepared by soaking silk fibres in a $160 \mathrm{ppm}\left(8.13 \times 10^{-4} \mathrm{M}\right) \mathrm{Au}^{3+}$ solution for 24 hours at RT, followed by ageing at $50{ }^{\circ} \mathrm{C}$ for 168 hours.

Increasing the $\mathrm{pH}$ of the soaking and hence ageing solution to approximately 7 and then 9-10 resulted in the formation of vibrant purple and pink/purple coloured composites respectively (Figure 7.7). Increasing the $\mathrm{pH}$ further to 12 produced materials that were not dissimilar in colour to that of the base silk fibres. (It should be noted that much like the merino wool systems, these pHs were only the initial pHs of the reaction solutions, as once added, the silk fibres titrated the additional base, resulting in an end $\mathrm{pH}$ of approximately 5.5, 7.8 and 9 for the $\mathrm{pH} \mathrm{7,9-10} \mathrm{and} 12$ systems respectively). These materials were prepared by soaking the silk fibres at $\mathrm{RT}$ in $\mathrm{Au}^{3+}$ solutions of altered $\mathrm{pH}$ for 10 minutes to 24 hours followed by ageing at $50{ }^{\circ} \mathrm{C}$ for 24 hours. Increasing the ageing time further did not change the colour of 
the resultant materials. It can be seen from Figure 7.7, that a soaking time of one hour was sufficient to allow for the production of a uniformly coloured composite material, as increasing the soaking time to 24 hours did not alter the colour of the resultant materials. Contrary to the materials prepared with a soaking solution $\mathrm{pH}$ of 2.7 , no colour development was observed in these materials or the reaction mixture during soaking. However upon ageing, nanoparticles were seen to form in the $\mathrm{pH} 7$ and 9-10 soaking solutions. This was evidenced by the development of a wine red or pink colour respectively. Figure 7.8 offers TEM micrographs of a sample of the $\mathrm{pH} 9-10$ ageing solution, and shows the nanoparticles to consist of a range of morphologies, from spheres and five-fold twinned particles (approximately $15-20 \mathrm{~nm}$ in diameter) to triangular nanoplates and rods (approximately 30 and $50 \mathrm{~nm}$ in diameter respectively).

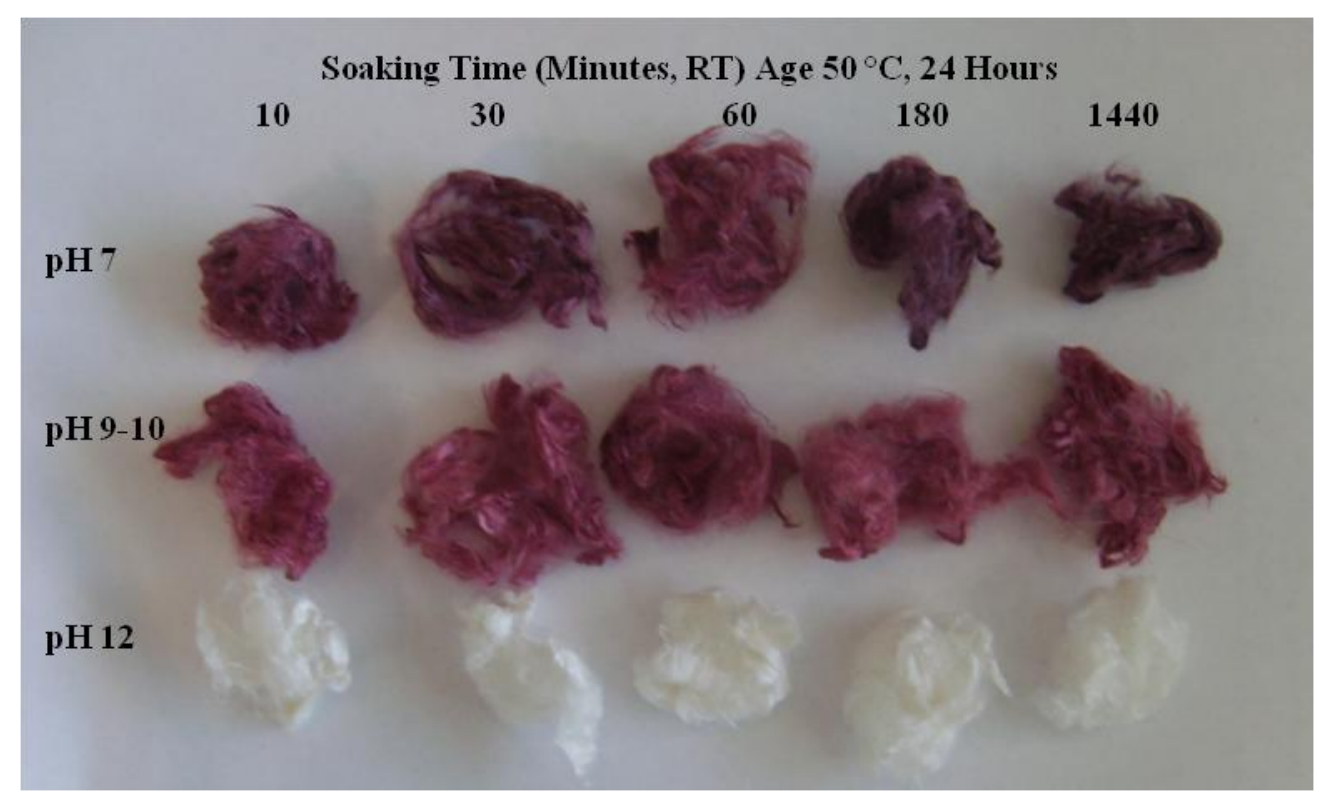

Figure 7.7: A selection of gold nanoparticle-silk composite materials prepared by soaking silk in a 160 ppm $\left(8.13 \times 10^{-4} \mathrm{M}\right) \mathrm{Au}^{3+}$, with a pH of 7, 9-10 or 12, for 10 minutes -24 hours at RT, followed by ageing at $50{ }^{\circ} \mathrm{C}$ for 24 hours. 

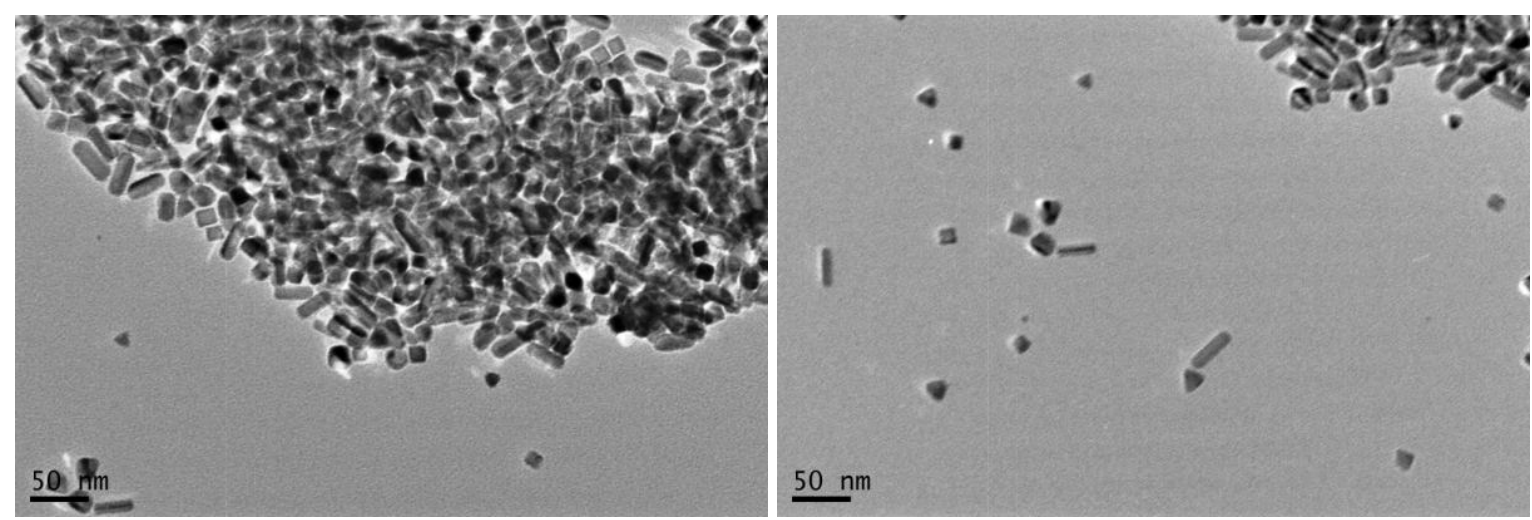

Figure 7.8: Increasing magnification TEM micrographs of an evaporated sample of the pH 9-10 ageing solution.

Figure 7.9 offers SEM micrographs of composite materials that have been prepared with soaking and ageing solutions of increasing pH. It can be seen from these micrographs that relative to those produced with a soaking and ageing solution $\mathrm{pH}$ of 2.7 , increasing the $\mathrm{pH}$ to 7 resulted in the formation of slightly smaller (approximately 10-15 $\mathrm{nm}$ in diameter), spherical nanoparticles. The percentage of agglomerated nanoparticles, and the presence of anisotropic triangular nanoplates also decreased in these materials. Increasing the $\mathrm{pH}$ of the soaking and ageing solution to 9-10 decreased the presence of agglomerated nanoparticles further still, with the nanoparticles present being spheres, approximately 10-15 nm in diameter (Figure 7.9 middle). The anisotropic triangular nanoplates and nanorods observed in the $\mathrm{pH}$ 9-10 ageing solutions were not seen in the composites. When employing a $\mathrm{pH} 12$ soaking and ageing solution, dramatically fewer nanoparticles were formed (Figure 7.9 bottom).

Cross sectional SEM analysis of the composite materials prepared with $\mathrm{pH}$ 9-10 soaking and ageing solutions showed gold nanoparticles to be formed both on the surface and also within centre of the fibres (Figure 7.10). TEM revealed the nanoparticles residing in the centre of the fibres to be a lot smaller, approximately 5-10 $\mathrm{nm}$ in diameter (Figure 7.11). 

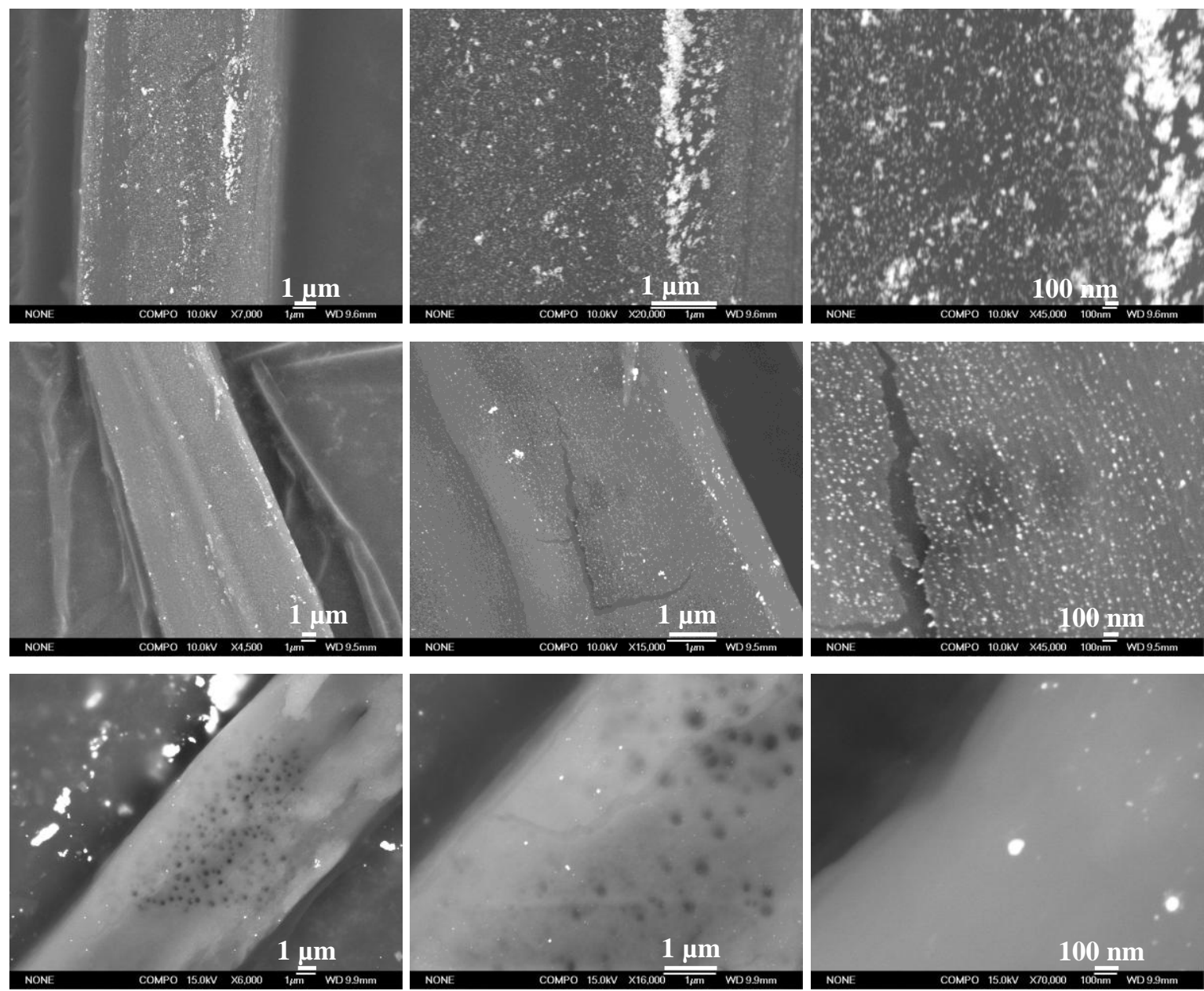

Figure 7.9: Increasing magnification SEM micrographs of gold nanoparticle-silk composites prepared by soaking silk fibres in a pH 7 (top), 9-10 (middle) or 12 (bottom) $160 \mathrm{ppm}\left(8.13 \mathrm{x10}^{4} \mathrm{M}\right) \mathrm{Au}^{3+}$ solution for 6 hours at RT, followed by ageing at $50{ }^{\circ} \mathrm{C}$ for 24 hours.
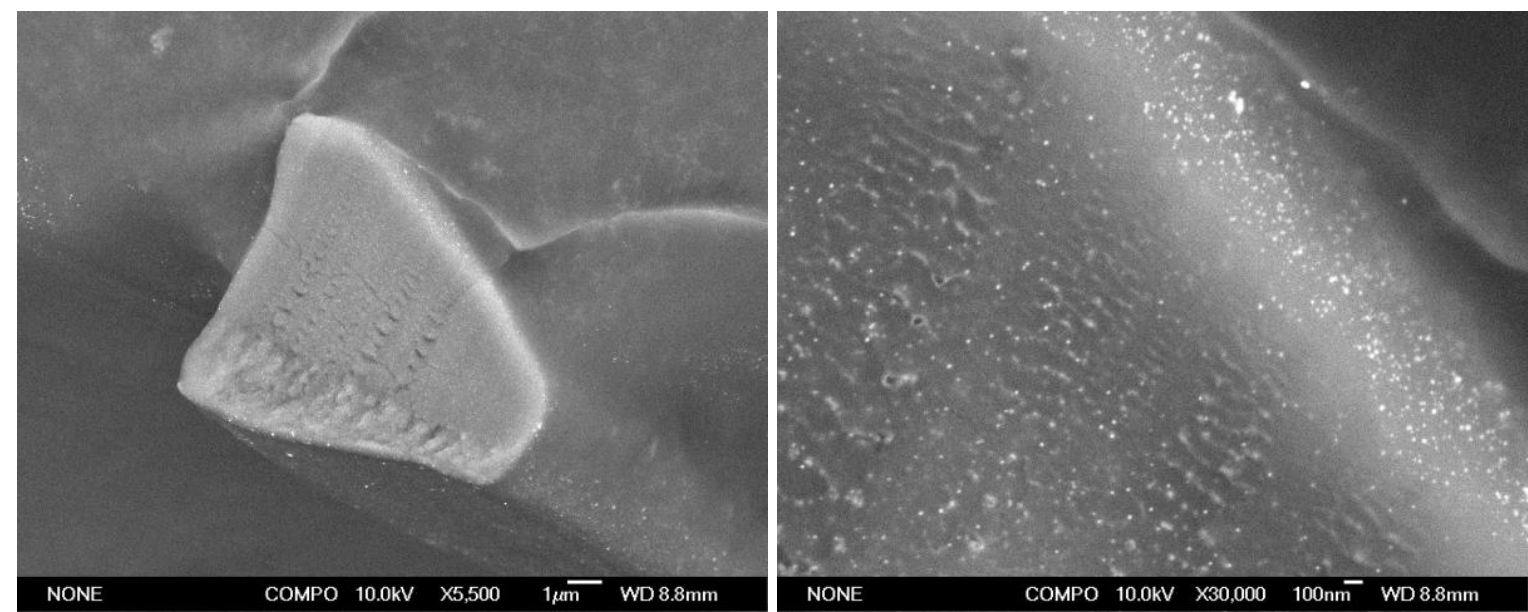

Figure 7.10: Cross sectional SEM micrographs of a gold nanoparticle-silk composite prepared by soaking silk fibres in a $160 \mathrm{ppm}\left(8.13 \times 10^{-4} \mathrm{M}\right) \mathrm{Au}^{3+}$ solution at pH 9-10 for 6 hours at RT, followed by ageing at $50{ }^{\circ} \mathrm{C}$ for 168 hours. 

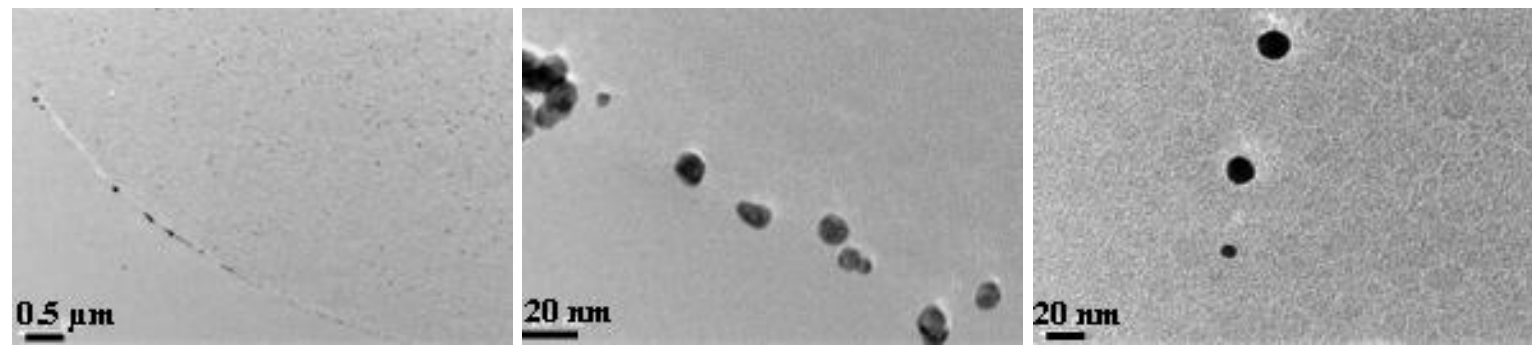

Figure 7.11: TEM micrographs of a silk seed prepared with a 6 hour soaking time in a pH 9-10 gold solution and 24 hours heating at $50{ }^{\circ} \mathrm{C}$. Left: Micrograph showing fibre surface and centre. Middle: Micrograph showing nanoparticles on the fibre surface and right: micrograph showing nanoparticles in the fibre centre.

\subsection{Colour}

The colours of the gold nanoparticle-silk composites were characterised through UV/Vis spectroscopy and via analysis of their CIE L*, a*, b*, $457 \mathrm{~nm}$ brightness and $580 \mathrm{~nm}$ brightness values. In general, an increase in the concentration of nanoparticles of similar size and shape corresponded to a darkening and increase in intensity of the deep purple colour of the composite materials prepared with a soaking and ageing solution $\mathrm{pH}$ of 2.7 , whilst increasing the $\mathrm{pH}$ of the soaking and ageing solutions to a maximum of approximately 10 corresponded to the production of smaller, increasingly isolated nanoparticles reflecting the more vibrant pink colour of such materials (Figure 7.12).
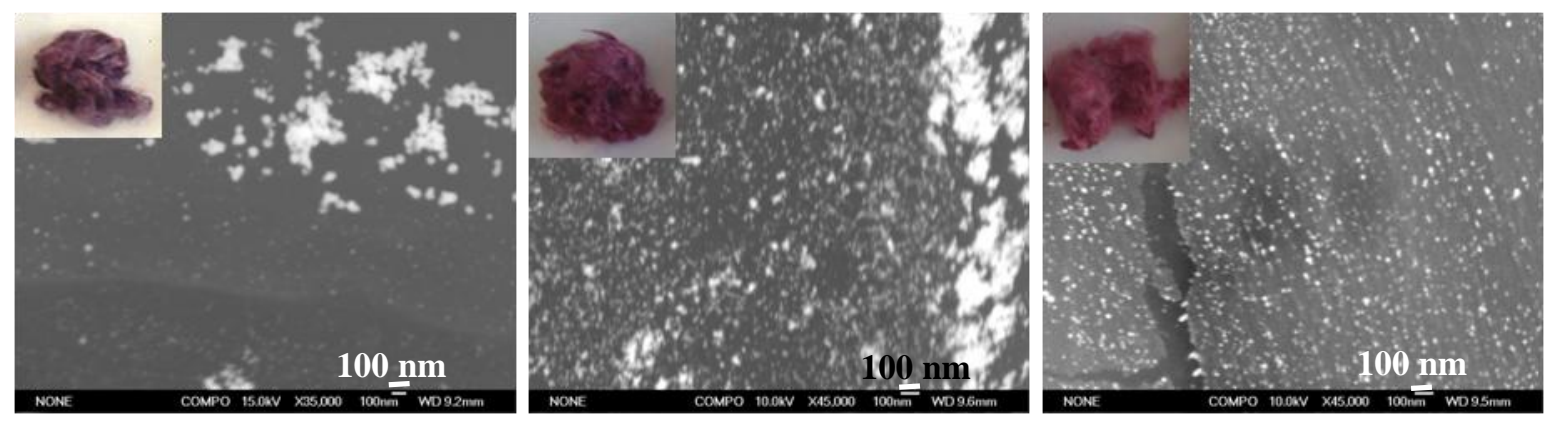

Figure 7.12: Relationship between size, shape and concentration of nanoparticles on the silk fibre and the colour of the resultant composite materials. 
As mentioned, the CIE L*, $\mathrm{a}^{*}, \mathrm{~b}^{*}, 457 \mathrm{~nm}$ brightness and $580 \mathrm{~nm}$ brightness values of the composite materials reflected the colour change induced by increasing soaking and ageing times (when employing a soaking and ageing solution with a $\mathrm{pH}$ of 2.7) and increasing solution pHs. A comprehensive set of CIE values are offered in Appendix VII. When employing a pH 2.7 soaking and ageing solution, nanoparticles were seen to form on the silk fibres during soaking at RT, producing light purple coloured materials. Employing increasing ageing times intensified this purple colour, however it still remained relatively spectrally impure. The development of the purple colour during soaking, and its subsequent intensification with ageing was accompanied by a general decrease in $\mathrm{L}^{*}, 457 \mathrm{~nm}$ brightness and $580 \mathrm{~nm}$ brightness values, confirming the observed darkening of the materials. Additionally, increasing the soaking and ageing times increased the $\mathrm{a}^{*}$ values and decreased the $b^{*}$ values of the resultant materials, reflecting their more purple colour (Figure 7.13 and Figure 7.14).

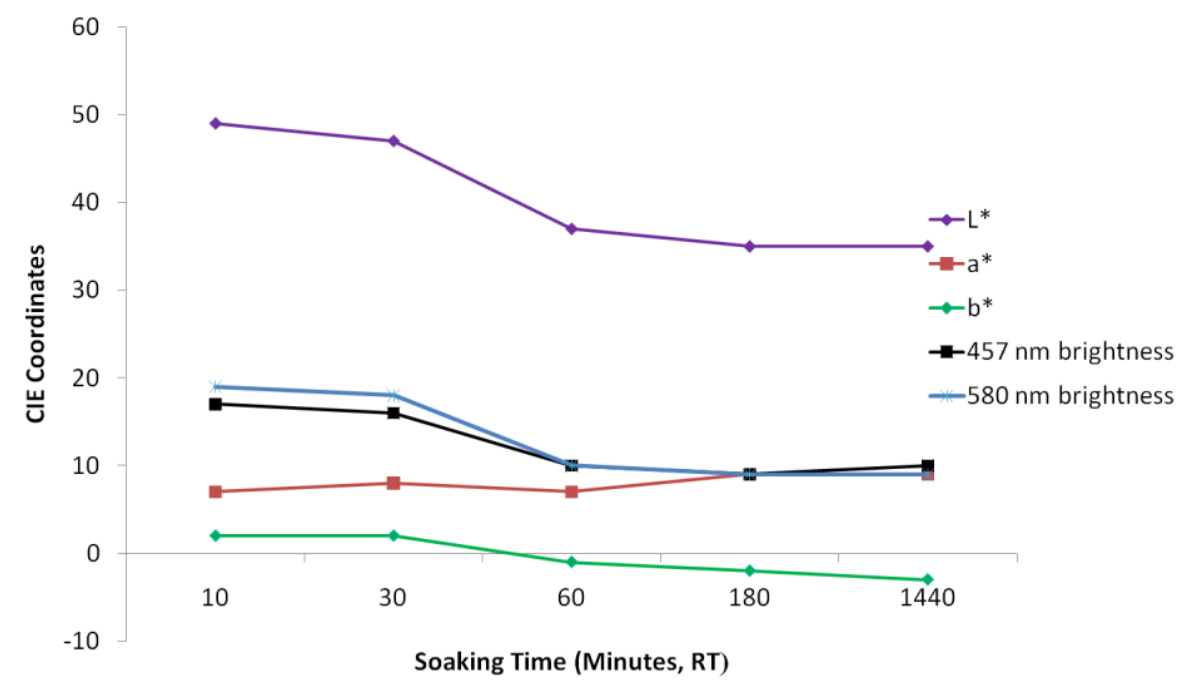

Figure 7.13: CIE $\mathrm{L}^{*}, \mathrm{a}^{*}, \mathrm{~b}^{*}, 457 \mathrm{~nm}$ brightness and $580 \mathrm{~nm}$ brightness values for silk fibres soaked in a $160 \mathrm{ppm}\left(8.13 \times 10^{-4} \mathrm{M}\right) \mathrm{Au}^{3+}$ solution, with a pH of 2.7 for 10 minutes to 24 hours at RT. 


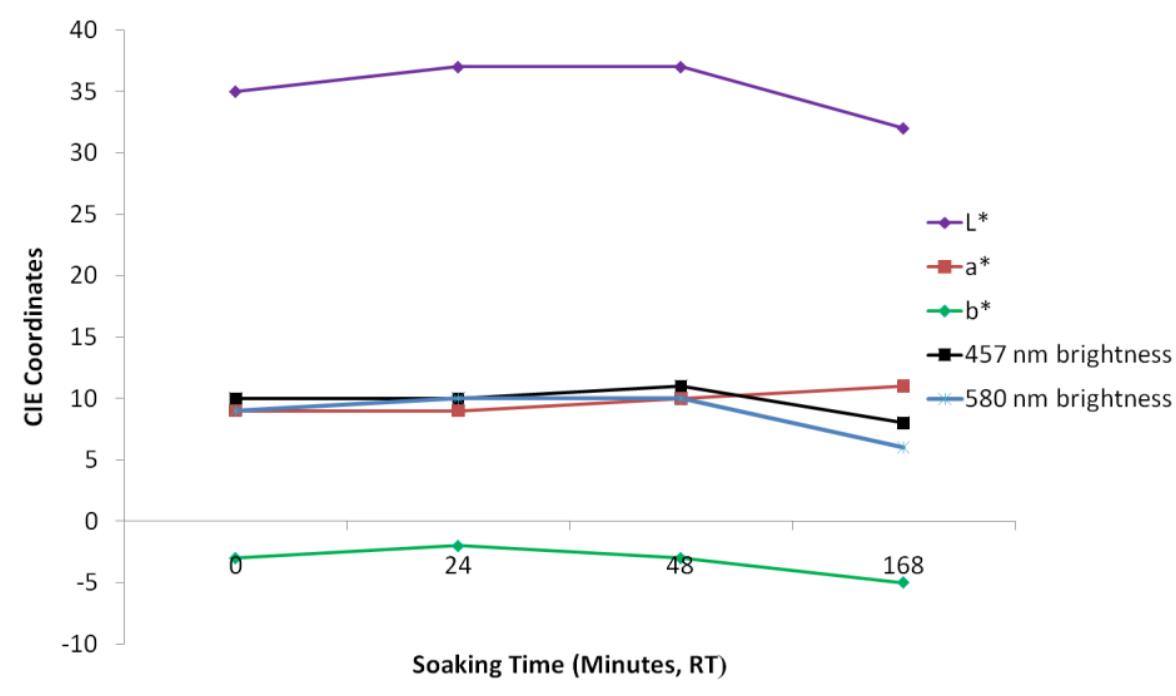

Figure 7.14: CIE $\mathrm{L}^{*}, a^{*}, b^{*}, 457 \mathrm{~nm}$ brightness and $580 \mathrm{~nm}$ brightness values for gold nanoparticle-silk composites, prepared by soaking silk in a $160 \mathrm{ppm}\left(8.13 \times 10^{-4} \mathrm{M}\right) \mathrm{Au}^{3+}$ solution, with a $\mathrm{pH}$ of 2.7 for 24 hours at RT followed by ageing at $50{ }^{\circ} \mathrm{C}$ for 0-168 hours.

Increasing the $\mathrm{pH}$ of the soaking and ageing solution to a maximum of 10 produced pinker coloured materials. This was reflected in the $a^{*}$ values of the composites, with those prepared with soaking and ageing solutions of higher $\mathrm{pH}$ exhibiting much larger $\mathrm{a}^{*}$ values (Table 7.1)

Table 7.1: CIE $\mathrm{a}^{*}$ values for gold nanoparticle-silk composites prepared by soaking silk in a $160 \mathrm{ppm}$ $\left(8.13 \times 10^{-4} \mathrm{M}\right) \mathrm{Au}^{3+}$ solution, with a pH of 2.7, 7 or 9-10 for 24 or 6 hours at RT, followed by ageing at 50 ${ }^{\circ} \mathrm{C}$ for 24 hours.

\begin{tabular}{cc}
\hline $\begin{array}{c}\text { Soaking and Ageing } \\
\text { Solution pH }\end{array}$ & $\mathbf{a}^{*}$ \\
\hline 2.7 & 9 \\
7 & 20 \\
$9-10$ & 24 \\
\hline
\end{tabular}

UV/Vis spectroscopy of the crossbred-Au materials also illustrated the colour development induced with increasing ageing times and the $\mathrm{pH}$ of the soaking and ageing solution. 
Similarly to the gold nanoparticle-crossbred wool composites, the Kubelka Munk transformed reflectance UV/Vis spectra of gold nanoparticle-silk composites display four discernable peaks, centred at approximately 450, 512, 552 and $700 \mathrm{~nm}$ (Figure 7.15 and Figure 7.16). The peaks centred at 450, 515 and $700 \mathrm{~nm}$ related to the plasmon bands of anisotropic gold nanoparticles. The two former peaks correspond to the transverse plasmon bands of triangular gold nanoparticles and hexagonal/platelet gold nanoparticles respectively, whilst the latter corresponds to longitudinal plasmon bands of such particles.[210] The peak centred at approximately $552 \mathrm{~nm}$ is in the range expected for spherical or five-fold twinned gold nanoparticles approximately $20-40 \mathrm{~nm}$ in diameter. When employing a soaking and ageing solution $\mathrm{pH}$ of 2.7 , increasing the ageing time from 24-168 hours progressively increased the intensity of the plasmon peaks, reflecting the observed increase in intensity of the colour of the resultant materials (Figure 7.15).

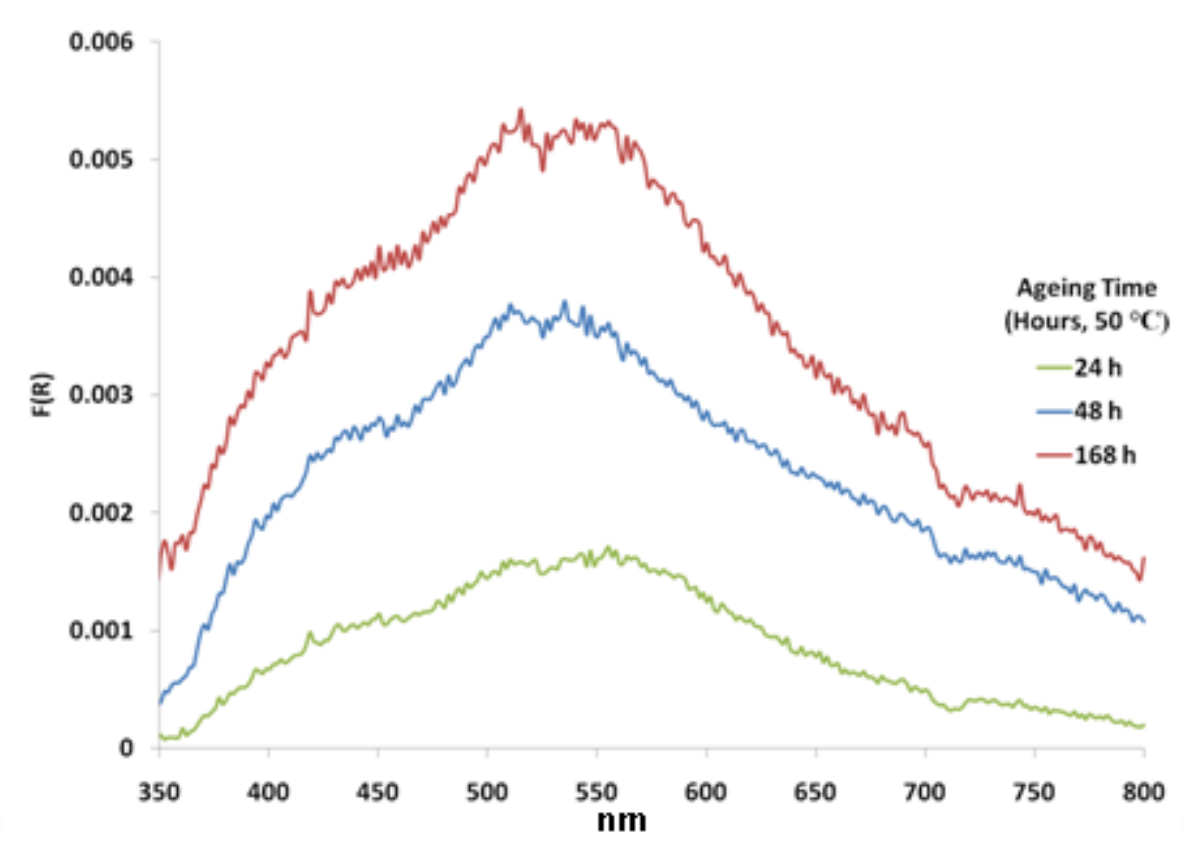

Figure 7.15: Kubelka Munk transformed UV/Vis reflection spectra of gold nanoparticle-silk composites prepared by soaking silk in a $160 \mathrm{ppm}\left(8.13 \times 10^{-4} \mathrm{M}\right) \mathrm{Au}^{3+}$ solution, with a $\mathrm{pH}$ of 2.7 for 24 hours at RT, followed by ageing at $50{ }^{\circ} \mathrm{C}$ for $24-168$ hours.

Increasing the $\mathrm{pH}$ of the soaking and ageing solutions also saw an increase in intensity of the plasmon bands of the gold nanoparticles bound to the silk fibres. Additionally, this increase in intensity was accompanied by a slight red shift in the peak characteristic of spherical or 
five-fold twinned particles (centred at approximately $550 \mathrm{~nm}$ ), and a decrease in full width at half maximum, reflecting the formation of smaller, increasingly isolated nanoparticles induced with higher $\mathrm{pHs}$. Increasing the $\mathrm{pH}$ further to $\mathrm{pH} 12$ produced materials that were not dissimilar in colour to the base silk fibres, and as such their UV/Vis spectra are comparable (Figure 7.16).

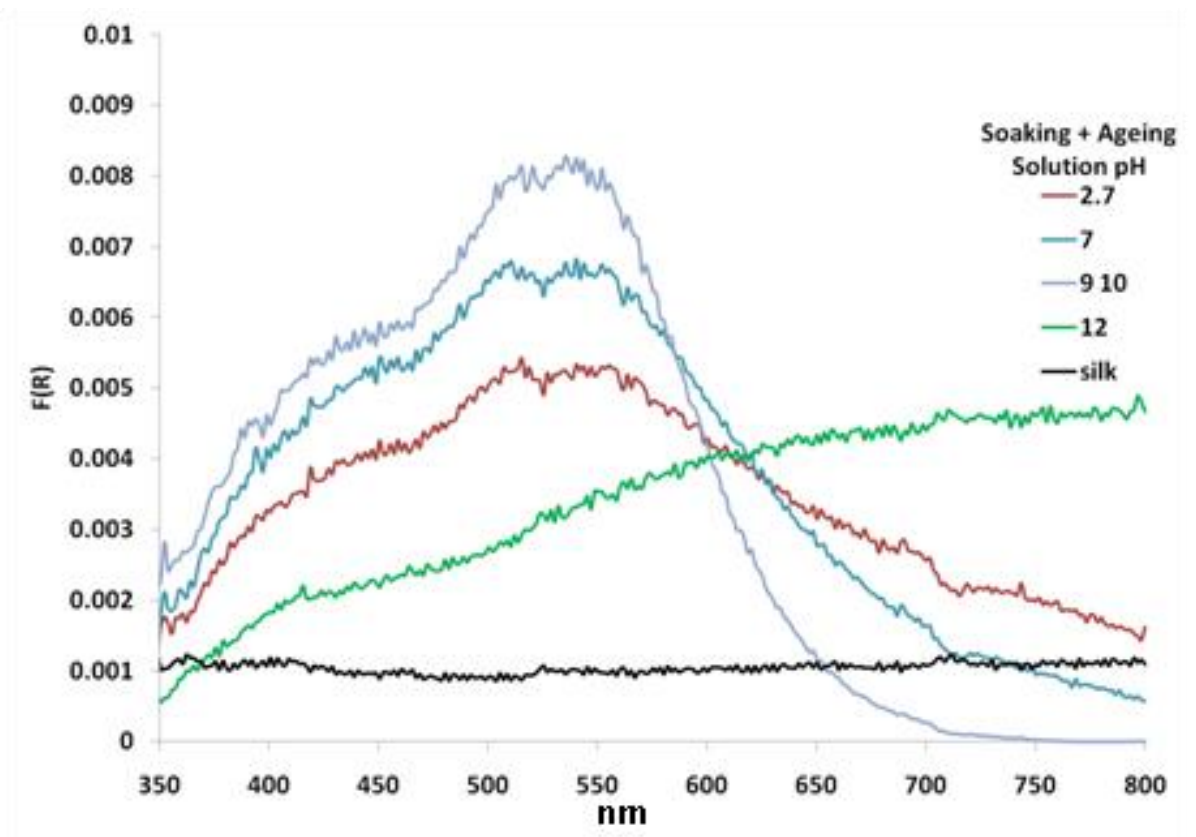

Figure 7.16: Kubelka Munk transformed UV/Vis reflection spectra of silk and gold nanoparticle-silk composites prepared by soaking silk in a $160 \mathrm{ppm}\left(8.13 \times 10^{-4} \mathrm{M}\right) \mathrm{Au}^{3+}$ solution, with a $\mathrm{pH}$ of 2.7, 7, 9-10 or 12 for 6 hours at RT, followed by ageing at $50{ }^{\circ} \mathrm{C}$ for 24 hours.

\subsection{Confirmation of Gold}

As with all other gold nanoparticle-natural fibre composites, the presence gold in the materials prepared from silk was first suggested by backscatter SEM microscopy, and confirmed by EDS and XPS analysis. As an example Figure 7.17 offers SEM micrographs, (collected with a secondary electron detector and a backscatter electron detector), of a gold nanoparticle-silk composite. It is clear from these micrographs that when viewed under backscatter conditions, the gold nanoparticles residing on the silk fibres are much more apparent, appearing bright white in colour. 

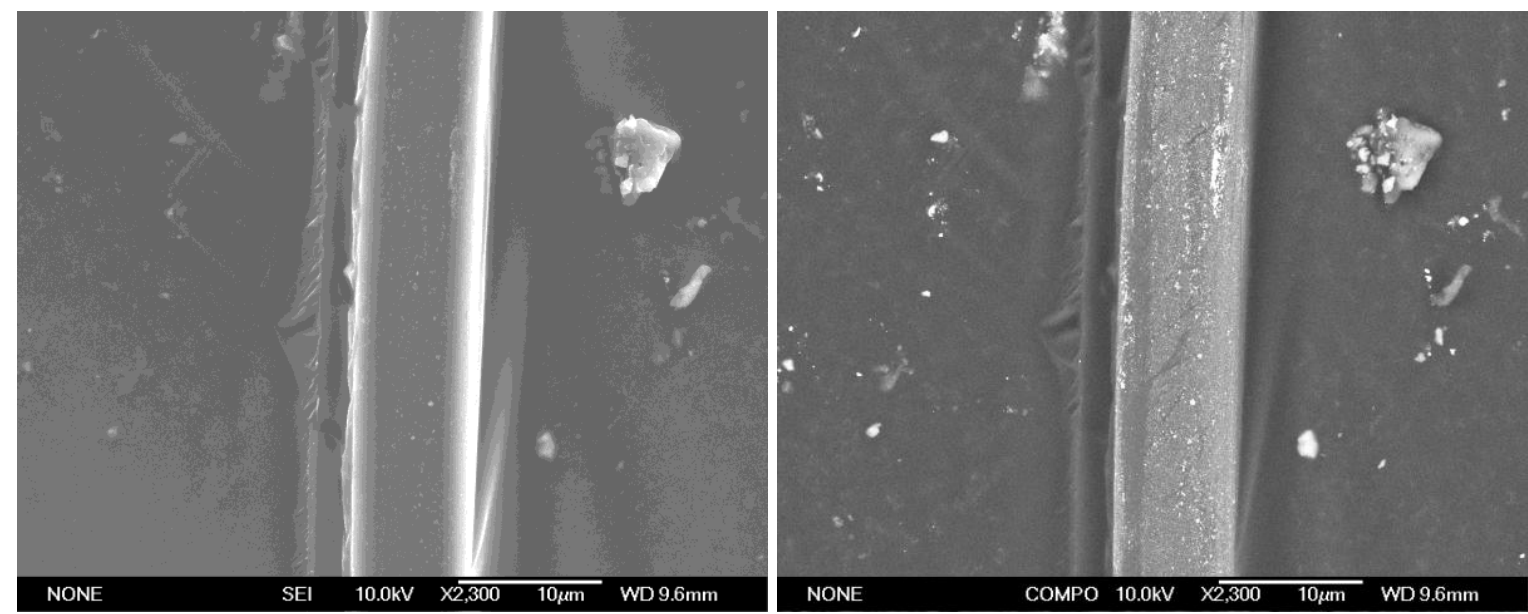

Figure 7.17: SEM micrographs of a gold nanoparticle-silk composite prepared by soaking silk fibres in a $160 \mathrm{ppm}\left(8.13 \times 10^{-4} \mathrm{M}\right) \mathrm{Au}^{3+}$ solution, at $\mathrm{pH} 7$ for 6 hours at RT, followed by ageing at $50{ }^{\circ} \mathrm{C}$ for 24 hours.

EDS analysis of the silk composites further substantiated the presence of gold on the silk fibres, confirming the bright white particles observed under backscatter SEM conditions to be gold. Figure 7.18 and Figure 7.20 offer SEM micrographs and the corresponding EDS Au maps of a selection of gold nanoparticle-silk composite materials. These maps show high concentrations of gold (depicted in bright white or red areas in the Au maps) to correlate to the position of the particles in the fibres. Additionally, Figure 7.19 and Figure 7.21 offer spectral snap shots of the areas under analysis, and substantiate the presence of gold due to the existence of the gold peaks.
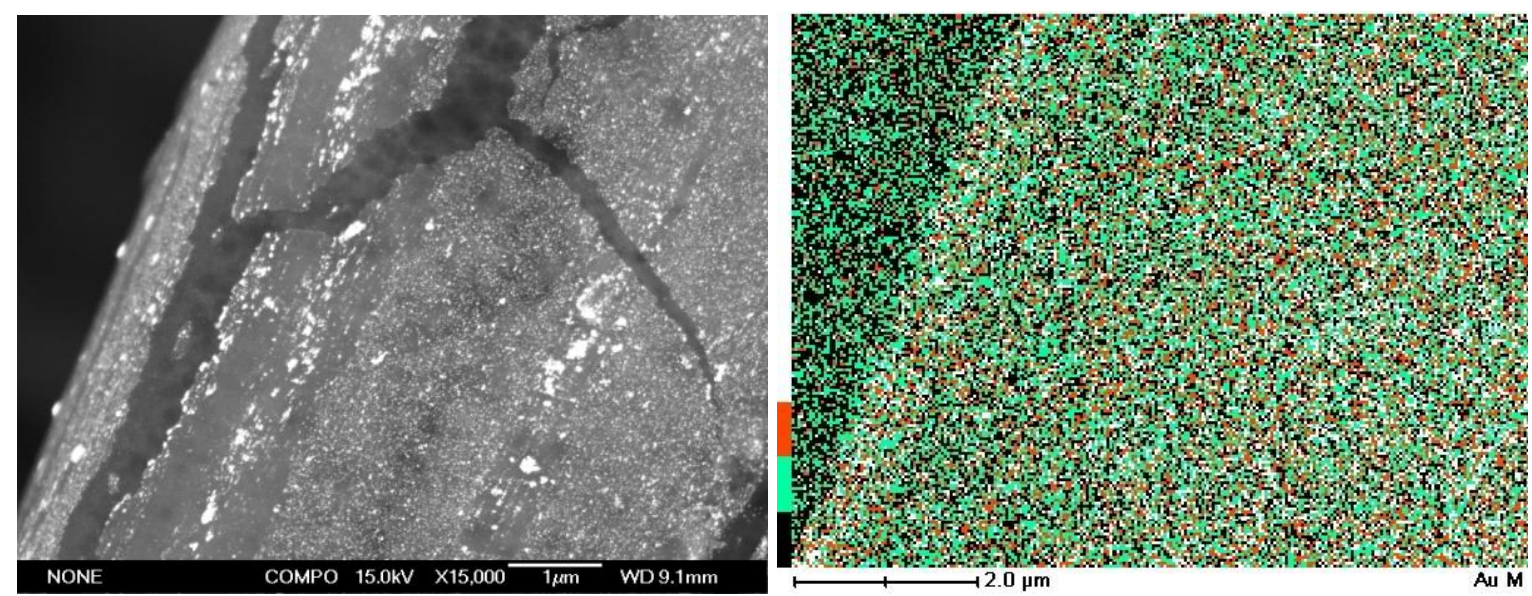

Figure 7.18: SEM micrograph and corresponding Au EDS map of a gold nanoparticle-silk composite prepared by soaking silk in a $160 \mathrm{ppm}\left(8.13 \times 10^{-4} \mathrm{M}\right) \mathrm{Au}^{3+}$ solution, at $\mathrm{pH}$ 7, for 6 hours at RT, followed by ageing at $50{ }^{\circ} \mathrm{C}$ for 24 hours. 


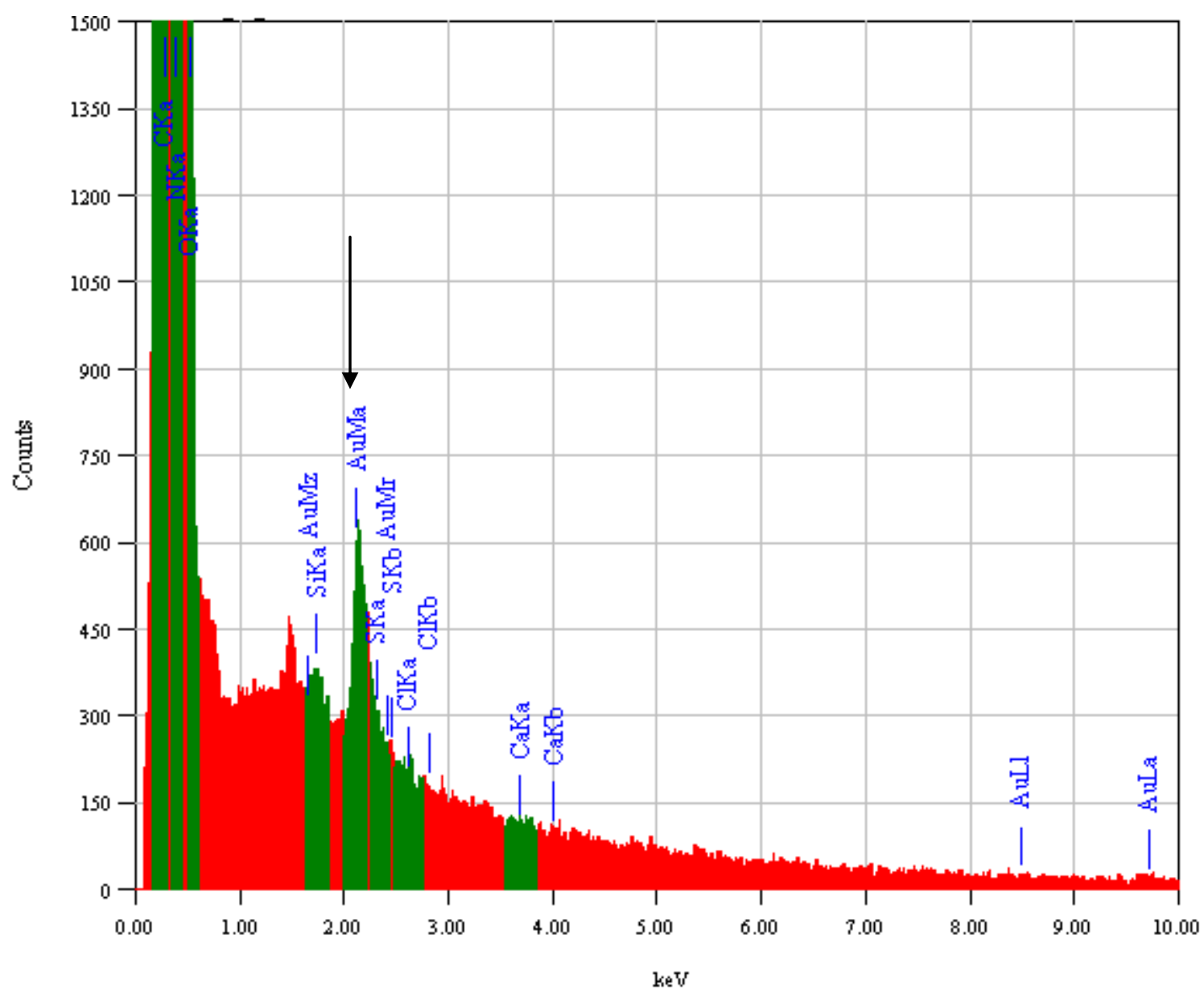

Figure 7.19: EDS spectra of the gold nanoparticle-silk composite shown in Figure 7.18.
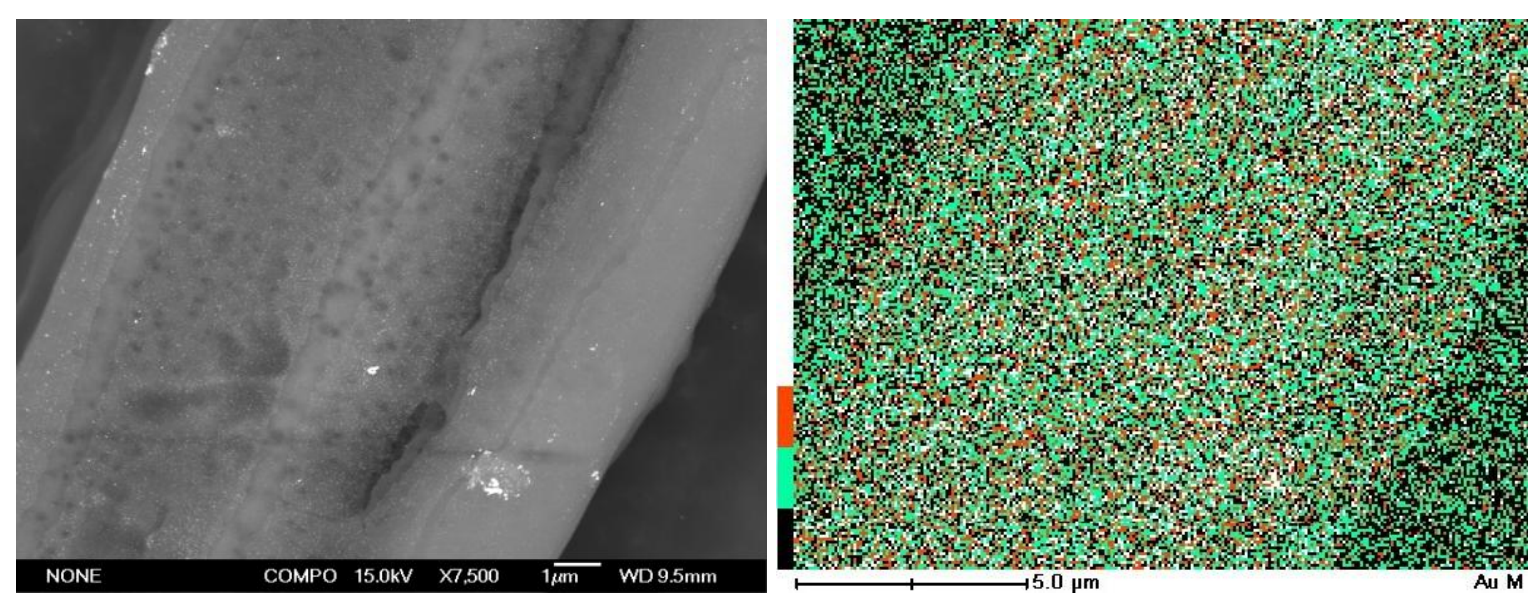

Figure 7.20: SEM micrograph and corresponding Au EDS map of a gold nanoparticle-silk composite prepared by soaking silk in a $160 \mathrm{ppm}\left(8.13 \times 10^{-4} \mathrm{M}\right) \mathrm{Au}^{3+}$ solution, at $\mathrm{pH} 9-10$, for 6 hours at RT, followed by ageing at $50{ }^{\circ} \mathrm{C}$ for 24 hours. 


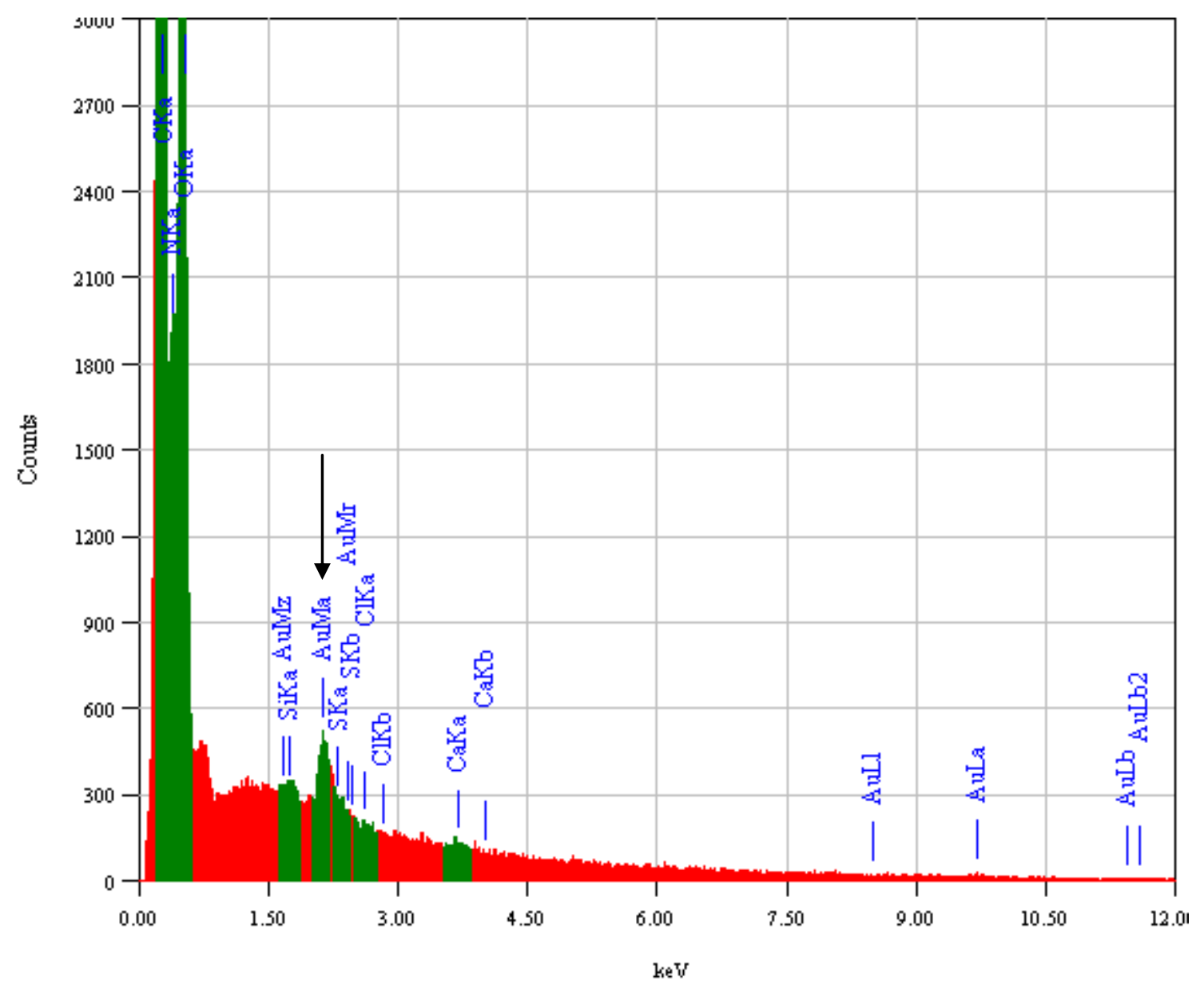

Figure 7.21: EDS spectra of the gold nanoparticle-silk composite shown in Figure 7.20.

XPS further substantiated the presence of gold in the gold nanoparticle-silk composite materials, showing those prepared with a soaking and ageing solution $\mathrm{pH}$ of 9-10 or 12 to consist of 1 and $0.09 \%$ gold respectively (Figure 7.22). Due to unavailability of the XPS spectrometer, analysis of composite materials prepared with a soaking and ageing $\mathrm{pH}$ of 2.7 or 7 could not be undertaken, however from SEM and EDS analysis it is suggested that these materials would possess a similar amount of gold as those prepared with a $\mathrm{pH} 9-10$ soaking and ageing solution. 

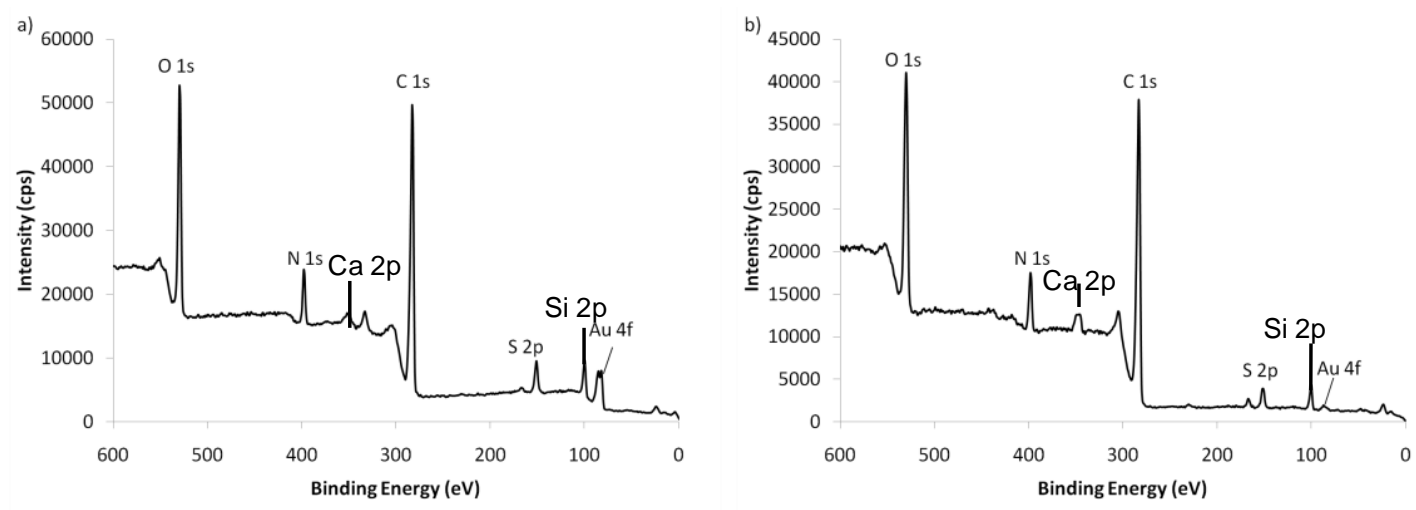

Figure 7.22: Wide XPS scans of gold nanoparticle-silk composites prepared by soaking the fibres in a 160 ppm $\left(8.13 \times 10^{-4} \mathrm{M}\right) \mathrm{Au}^{3+}$ solution for 6 hours at $\mathrm{RT}$, with a pH of a) 9-10 or b) 12, followed by ageing at $50{ }^{\circ} \mathrm{C}$ for 24 hours.

Examination of the deconvoluted, high resolution Au 4f XPS spectra of a composite material prepared with a $\mathrm{Au}^{3+}$ concentration of $160 \mathrm{ppm}\left(8.13 \times 10^{-4} \mathrm{M}\right)$ at $\mathrm{pH} 9-10$, a soaking time of 6 hours and an ageing time of 24 hours, showed the gold in this material to be predominantly $\mathrm{Au}^{3+}(60 \%)$, with the remaining $40 \%$ being nanoparticulate $\mathrm{Au}^{0}$. Therefore after 24 hours ageing at $50{ }^{\circ} \mathrm{C}$, only a percentage of $\mathrm{Au}^{3+}$ had been reduced to $\mathrm{Au}^{0}$. It is likely that continued ageing would reduce more $\mathrm{Au}^{3+}$ to $\mathrm{Au}^{0}$.

\subsection{Extent of Gold Uptake by Silk Fibres}

The uptake of gold by silk during the production of gold nanoparticle-silk composites was quantitatively analysed by atomic absorption (AA). The procedure is provided in section 2.2.2.3.4, 2.3.4 and briefly in section 5.4. When employing a $\mathrm{Au}^{3+}$ concentration of $160 \mathrm{ppm}$ $\left(8.13 \times 10^{-4} \mathrm{M}\right)$ with a $\mathrm{pH}$ of 2.7 , the absorption of gold at RT by silk fibres appeared to be complete after approximately 6 hours (Figure 7.23). Increasing the soaking temperature to $50{ }^{\circ} \mathrm{C}$ slightly increased the rate of absorption so that the majority of gold was absorbed after 3.5 hours. It is interesting to note that during soaking the first 10-15 minutes of soaking, the gold concentration rapidly decreased and then rose slightly, following which it again decreased (Figure 7.24). As this was observed in all pH 2.7 systems analysed, it is unlikely 
to be due to experimental uncertainties, rather it likely indicates that gold is initially absorbed by the silk fibres, following which a percentage is released and then perhaps re-absorbed.

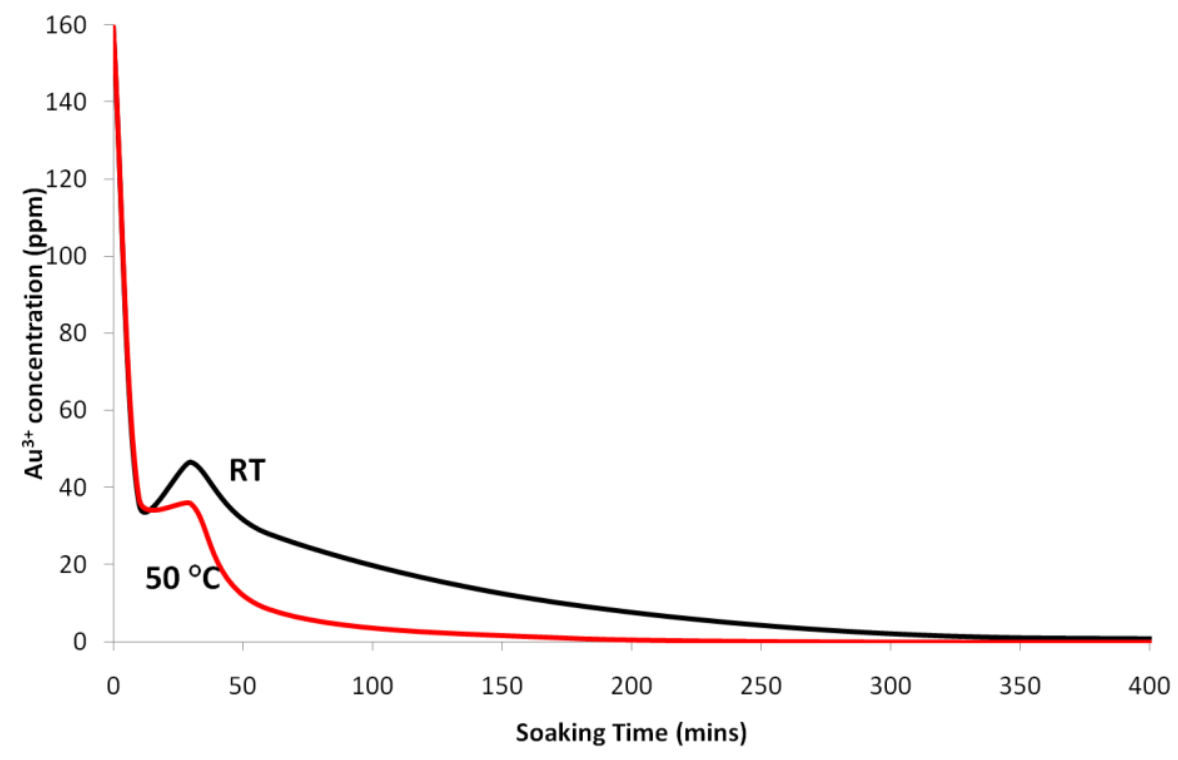

Figure 7.23: Gold uptake by silk at $\mathrm{RT}$ and $50{ }^{\circ} \mathrm{C}$. $\mathrm{A} \mathrm{Au}^{3+}$ concentration of $160 \mathrm{ppm}\left(8.13 \times 10^{-4} \mathrm{M}\right)$, with a pH of 2.7 was employed.

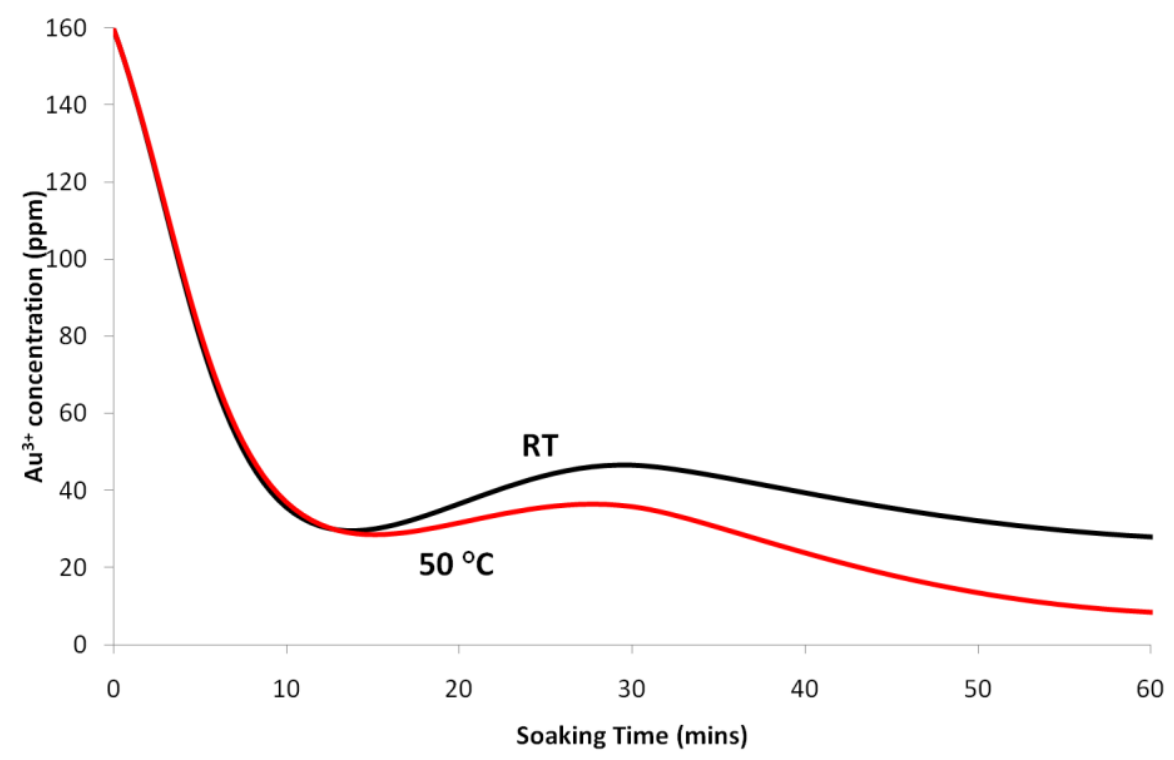

Figure 7.24: Gold uptake by silk at $\mathrm{RT}$ and $50{ }^{\circ} \mathrm{C}$. A $\mathrm{Au}^{3+}$ concentration of $160 \mathrm{ppm}\left(8.13 \times 10^{-4} \mathrm{M}\right)$, with a pH of 2.7 was employed. 
As mentioned in section 7.1, when employing a pH 2.7 soaking solution, nanoparticles were seen to form in solution after half an hour's soaking. Atomic absorption spectroscopy detects ground state ions when they are dissolved, and cannot detect colloidal $\mathrm{Au}^{0}$. Therefore it is likely that the formation of these nanoparticles accounts for the apparent decrease in the gold concentration for soaking times of greater than half an hour and as such the absorption data past this time point is inaccurate. It is therefore probable that gold is initially absorbed by the silk fibres, and then re-released, most likely due to the dislodgement of sericin.

Increasing the $\mathrm{pH}$ of the soaking solution to 9-10 decreases the gold absorption rate, such that following 24 hours soaking at RT, approximately 5 ppm gold remained in solution (Figure 7.25). No nanoparticles were observed to form during soaking in solutions of $\mathrm{pH} 9-10$ and hence this data can be considered relatively accurate. The isoelectric point of silk is approximately 4.5 , so with a soaking solution $\mathrm{pH}$ of 9-10, the silk fibre would possess a net negative charge. As such, the decreased absorption suggests that as with the merino, it is the negatively charged $\mathrm{AuCl}_{4}{ }^{-}$complex that is absorbed by the silk fibres rather than $\mathrm{Au}^{3+}$, with the higher $\mathrm{pH}$ causing the negatively charged fibre to electrostatically repel the $\mathrm{AuCl}_{4}{ }^{-}$ion.

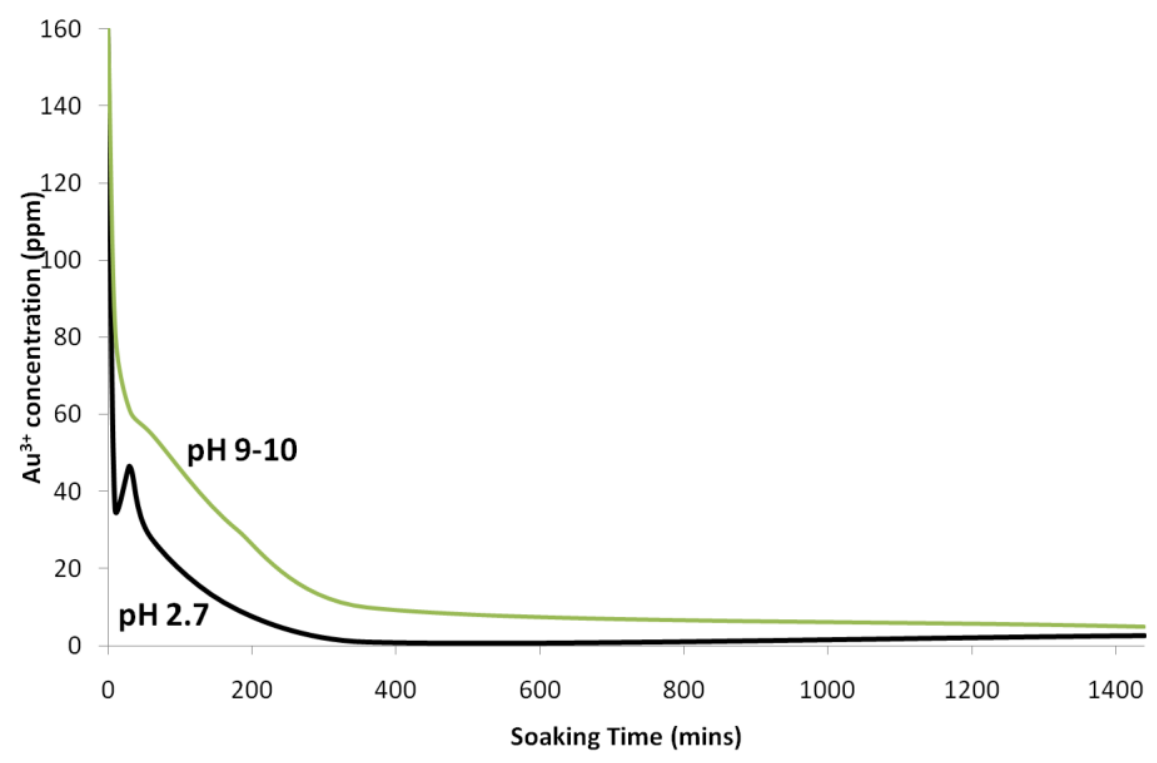

Figure 7.25: Gold uptake by silk at RT. A $\mathrm{Au}^{3+}$ concentration of $160 \mathrm{ppm}\left(8.13 \times 10^{-4} \mathrm{M}\right)$, with a pH of 2.7 or 9-10 was employed. 


\subsection{Bonding of Gold Nanoparticles to Silk Fibres}

Silk is a natural fibre, comprising two major protein constituents, fibroin and sericin, the former accounting for approximately $70-80 \%$ of the silk thread (section 1.2.2.2). As such, it offers numerous sites through which the gold nanoparticles could potentially bond, in particular nitrogen (amine, amide etc) or oxygen containing amino acid groups. Fibroin and sericin contain markedly less cystine than keratin, and as such there are less sulfur atoms available for bonding. To investigate the bonding between the gold nanoparticles and silk fibres EDS and XPS analysis of the produced composites was undertaken.

Figure 7.26 offers a cross sectional SEM micrograph, and corresponding EDS elemental maps of a gold nanoparticle-silk composite prepared by soaking silk fibres in a $160 \mathrm{ppm}$ $\left(8.13 \times 10^{-4} \mathrm{M}\right) \mathrm{Au}^{3+}$ solution, with a $\mathrm{pH}$ or 9-10 for 6 hours at RT, followed by ageing at 50 ${ }^{\circ} \mathrm{C}$ for 24 hours. Unlike the composite materials incorporating merino or crossbred wool, no apparent correlations between high concentrations of gold (shown in red areas in the gold map) and sulfur are seen, which is likely due to the low concentrations of sulfur in silk. Areas of high concentration carbon, nitrogen and oxygen correlate to areas of high concentrations of gold, however as there are high concentrations of these elements throughout the whole fibre, this does not provide an insight into the mode of bonding between the nanoparticles and silk fibres.

In an effort to elucidate this mode of bonding, XPS analysis was employed, and comparisons between the base fibre, silk and a composite (prepared by soaking silk fibres in a $160 \mathrm{ppm}$ $\left(8.13 \times 10^{-4} \mathrm{M}\right) \mathrm{Au}^{3+}$ solution, with a $\mathrm{pH}$ or 9-10 for 6 hours at RT, followed by ageing at 50 ${ }^{\circ} \mathrm{C}$ for 24 hours) was undertaken. A complete list of XPS assignments is provided in Table 7.2. Comparisons of the deconvoluted high resolution N 1s XPS spectra of a composite and silk provide insight into this bonding. The high resolution $\mathrm{N} 1 \mathrm{~s}$ spectra of silk can be resolved into two peaks, centred at 400.27 and $401.70 \mathrm{eV}$, the former representing amine and immine groups and the latter nitrogen bound to oxygen (Figure $7.27 \mathrm{~b}$ ). The $\mathrm{N} 1 \mathrm{~s}$ spectrum of the composite also exhibits these peaks, however two new peaks centred at 403.56 and $398.32 \mathrm{eV}$ also appear (Figure $7.27 \mathrm{a}$ ). The former peak is related to the mechanism of 
formation of the composites (see section 7.6) however the latter indicates a Au-N bond,[17, 201] suggesting the gold nanoparticles may bind to the silk fibres through nitrogen containing groups.
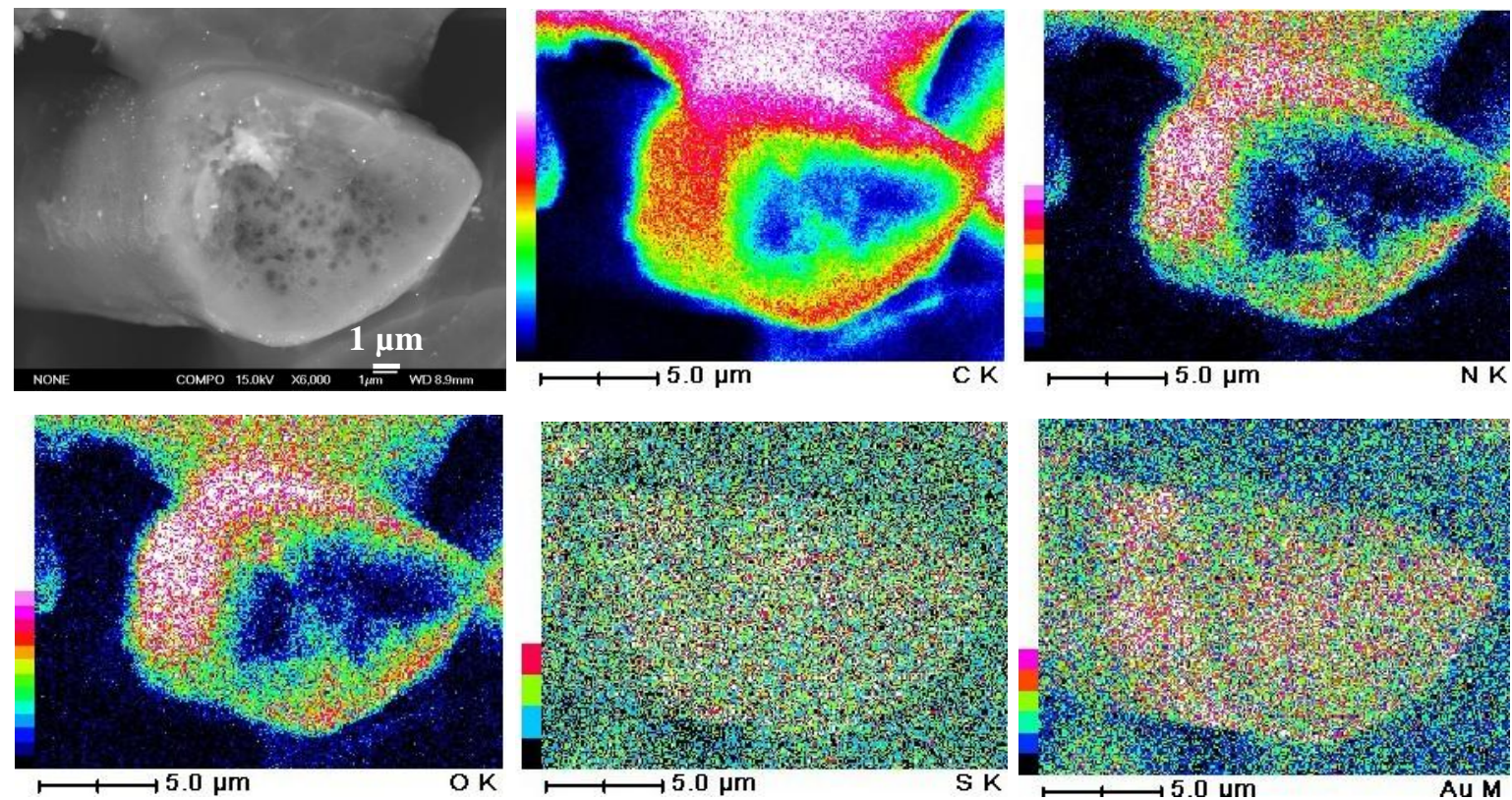

Figure 7.26: Cross sectional SEM micrograph and corresponding EDS micrographs of a gold nanoparticle-silk composite material, prepared by soaking silk fibres in a $160 \mathrm{ppm}\left(8.13 \times 10^{-4} \mathrm{M}^{-\mathrm{Au}^{3+}}\right.$ solution, with a pH of 9-10 for 6 hours at RT, followed by ageing at $50{ }^{\circ} \mathrm{C}$ for 24 hours.
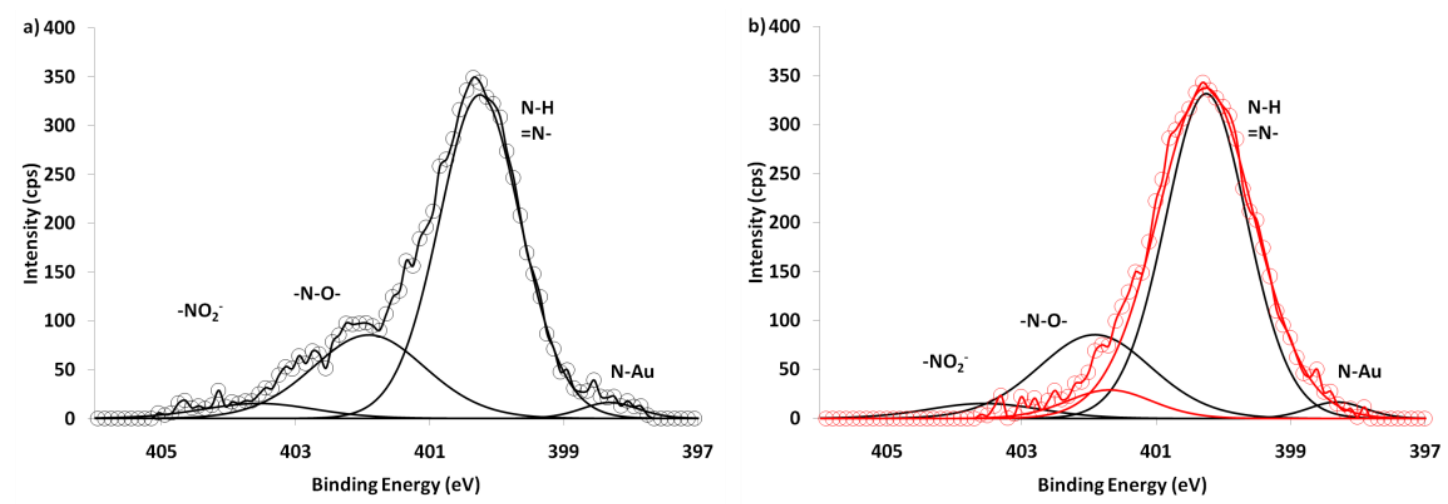

Figure 7.27: a) high resolution N 1s XPS spectrum of a gold nanoparticle-silk composite prepared by soaking silk in a $160 \mathrm{ppm}\left(8.13 \times 10^{-4} \mathrm{M}\right) \mathrm{Au}^{3+}$ solution, with a pH of 9-10 for 6 hours at RT, followed by ageing at $50{ }^{\circ} \mathrm{C}$ for 24 hours. b) an overlay (in red) of silk.

Examination of the deconvoluted, high resolution Au 4f XPS spectra of the gold nanoparticle-silk composite did not confirm the bonding between the nanoparticles and silk to be via $\mathrm{Au}-\mathrm{N}$ bonds. Figure 7.28 offers the $\mathrm{Au} 4 \mathrm{f}$ spectra, which exhibits four peaks, 
notably the $7 / 2$ and $5 / 2$ peaks of nanoparticulate $\mathrm{Au}^{0}$ (centred at 84.22 and $87.82 \mathrm{eV}$ respectively) and unreduced $\mathrm{Au}^{3+}$ peaks (centred at 85.33 and $88.93 \mathrm{eV}$ respectively). The nanoparticulate $\mathrm{Au}^{0}$ peaks have shifted to slightly higher binding energies relative to the $\mathrm{Au}^{0}$ peaks observed in the merino and crossbred wool composites. Generally this is thought to occur due to the presence of sulfur bound to the surface of the nanoparticles, with nitrogen bound to the surface causing a shift in the $\mathrm{Au}^{0}$ peaks to lower binding energy. However as no direct $\mathrm{Au}-\mathrm{S}$ bond was evident in these spectra, (and those seen in the S $2 \mathrm{p}$ spectra of the composites were not well resolved (see below)), this shift is likely not due to a Au-S interaction. Rather it may be related to the size of the nanoparticles. The gold nanoparticles residing on the surface of the silk fibres are smaller than those on the merino and crossbred wool fibres (approximately 15-20 nm in diameter compared to approximately 20-30 nm in diameter). It has been reported that decreasing the size of nanoparticles progressively increases their binding energies.[231] As such, although direct Au-N interactions (illustrated by a shift in the $\mathrm{Au}^{0}$ peaks to slightly lower binding energies relative to nanoparticulate $\mathrm{Au}^{0}$ ) cannot be ascertained from this spectrum, they may still be present, and simply be over ridden by the size induced shift.

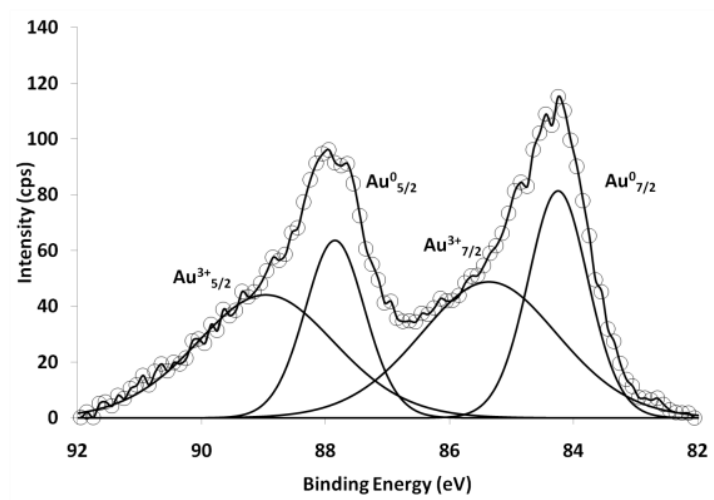

Figure 7.28: High resolution Au 4f XPS spectra of a gold nanoparticle-silk composite prepared by soaking silk in a $160 \mathrm{ppm}\left(8.13 \times 10^{-4} \mathrm{M}\right) \mathrm{Au}^{3+}$ solution, with a pH of 9-10 for 6 hours at RT, followed by ageing at $50{ }^{\circ} \mathrm{C}$ for 24 hours

In addition to the gold nanoparticles binding to the silk fibres through nitrogen groups, comparisons of the deconvoluted, high resolution S 2p XPS spectra of a composite and silk suggests that there may also be a small percentage of bonding of the nanoparticles to sulfur moieties in the silk, evidenced by the peak centred at $161.63 \mathrm{eV}$ in the $\mathrm{S} 2 \mathrm{p}$ spectra of the 
composite (Figure 7.29). (Due to the low concentration of sulfur in silk, the $S 2 p$ spectra of both the composite and silk itself exhibited a poor signal to noise ratio, so the assignment of this Au-S peak is not without caution. Note also that single peaks have been fitted rather than the $3 / 2$ and $1 / 2$ doublets due to the poor signal to noise ratio). If this bonding is genuine, it is likely to occur through sulfur atoms present in sericin, rather than in the fibroin filaments, as sericin contains approximately 5 times as much sulfur, (in the form of cystine groups), than fibroin.
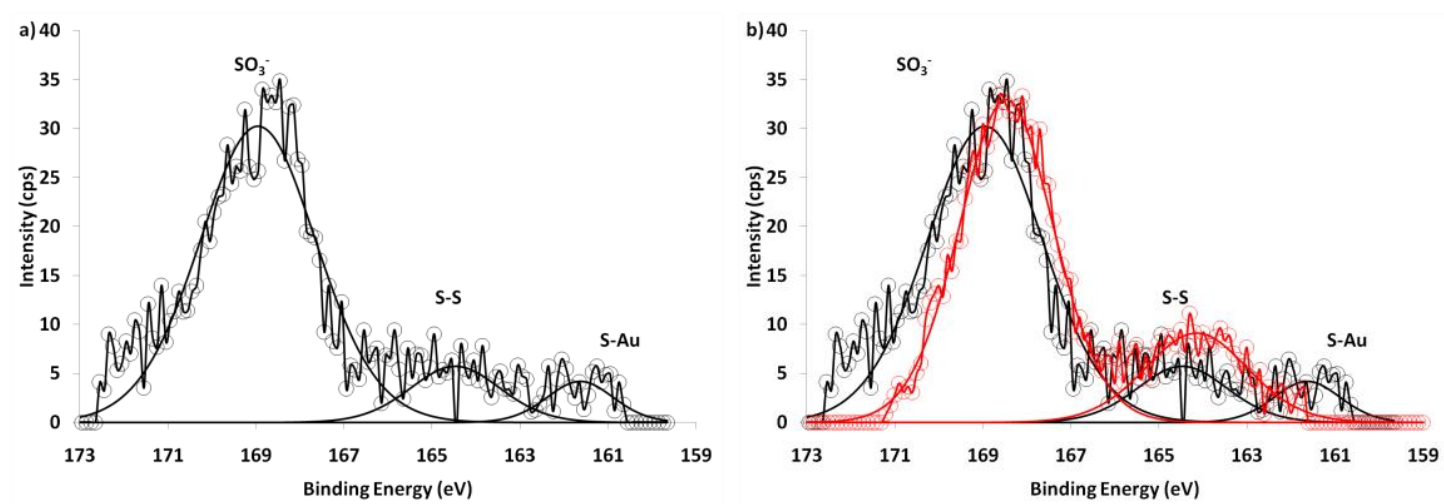

Figure 7.29: a) high resolution S 2p XPS spectra of a gold nanoparticle-silk composite prepared by soaking silk in a $160 \mathrm{ppm}\left(8.13 \times 10^{-4} \mathrm{M}\right) \mathrm{Au}^{3+}$ solution, with a pH of 9-10 for 6 hours at RT, followed by ageing at $50{ }^{\circ} \mathrm{C}$ for 24 hours. b) an overlay (in red) of silk.

Examination of the high resolution C 1s and O 1s XPS spectra of the composites only reveals slight changes from those of silk, with the observed changes reflective of the transformations occurring in silk during the reduction of $\mathrm{Au}^{3+}$ to nanoparticulate $\mathrm{Au}^{0}$ (section 7.6). As such, the bonding between the gold nanoparticles and silk fibres is likely to occur through nitrogen containing groups in the silk fibroin, and to a lesser extent sulfur groups in sericin. 
Table 7.2: XPS assignments for silk and a gold nanoparticle-silk composite (prepared by soaking silk in a $160 \mathrm{ppm}\left(8.13 \times 10^{-4} \mathrm{M}\right) \mathrm{Au}^{3+}$ solution, with a pH of 9-10 for 6 hours at RT, followed by ageing at $50{ }^{\circ} \mathrm{C}$ for 24 hours).[219]

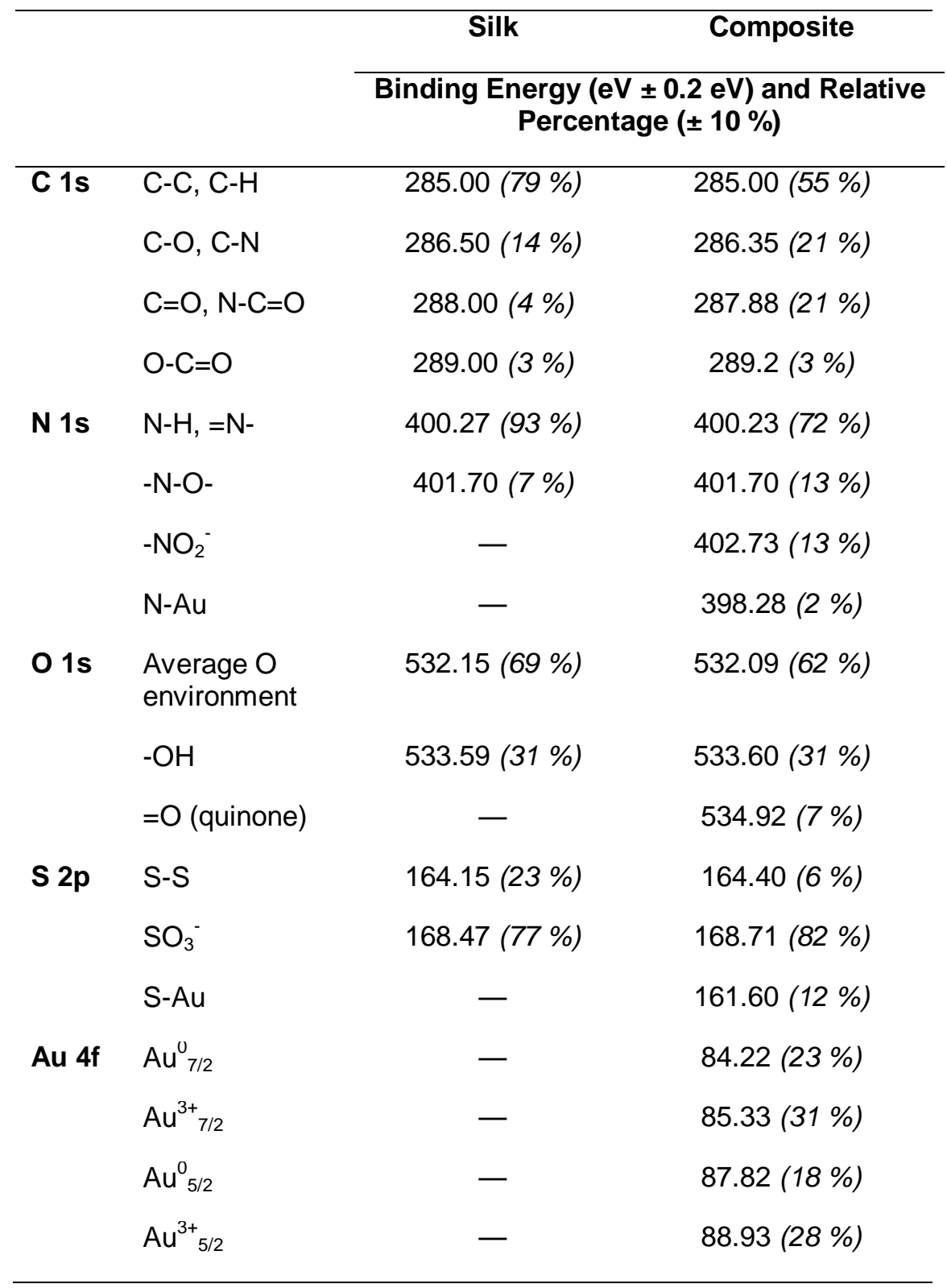

\subsection{Proposed Mechanism of Formation}

The preparation of the gold nanoparticle-silk composites involved the reduction of $\mathrm{Au}^{3+}$ to nanoparticulate $\mathrm{Au}^{0}$. Depending on the $\mathrm{pH}$ of the soaking and hence ageing solutions, this reduction occurred at the silk fibre surface, in the fibre centres or even in solution. The protein fibres in silk, fibroin, sericin or both, acted as a redox active bio-template, facilitating 
the reduction of $\mathrm{Au}^{3+}$ to nanoparticulate $\mathrm{Au}^{0}$. As mentioned, the production of the gold nanoparticle-silk composite materials involved soaking silk fibres in a $160 \mathrm{ppm}\left(8.13 \times 10^{-4}\right.$ M) $\mathrm{Au}^{3+}$ solution, with a $\mathrm{pH}$ of $2.7,9-10$ or 12 for 6 or 24 hours at RT, followed by ageing at $50{ }^{\circ} \mathrm{C}$ for $24-168$ hours.

XPS analysis was employed to elucidate this mechanism of formation, providing insight into which functional groups were involved in the $\mathrm{Au}^{3+}$ to $\mathrm{Au}^{0}$ reduction. Comparisons of the deconvoluted high resolution N 1s XPS spectra of a composite material (prepared by soaking silk fibres in a $160 \mathrm{ppm}\left(8.13 \times 10^{-4} \mathrm{M}\right) \mathrm{Au}^{3+}$ solution, with an initial $\mathrm{pH}$ of 9-10, for 6 hours followed by ageing at $50{ }^{\circ} \mathrm{C}$ for 24 hours) to that of silk revealed clear differences. Upon reduction of $\mathrm{Au}^{3+}$ to nanoparticulate $\mathrm{Au}^{0}$, a new peak centred at $402.73 \mathrm{eV}$ appears, and the percentage of $\mathrm{N}-\mathrm{O}$ groups increases from 7 to $13 \%$ (Figure 7.30, Table 7.2). This suggests that during the reduction of $\mathrm{Au}^{3+}$, various nitrogen containing groups, such as amines, were oxidised to nitrosyl or nitrite groups.
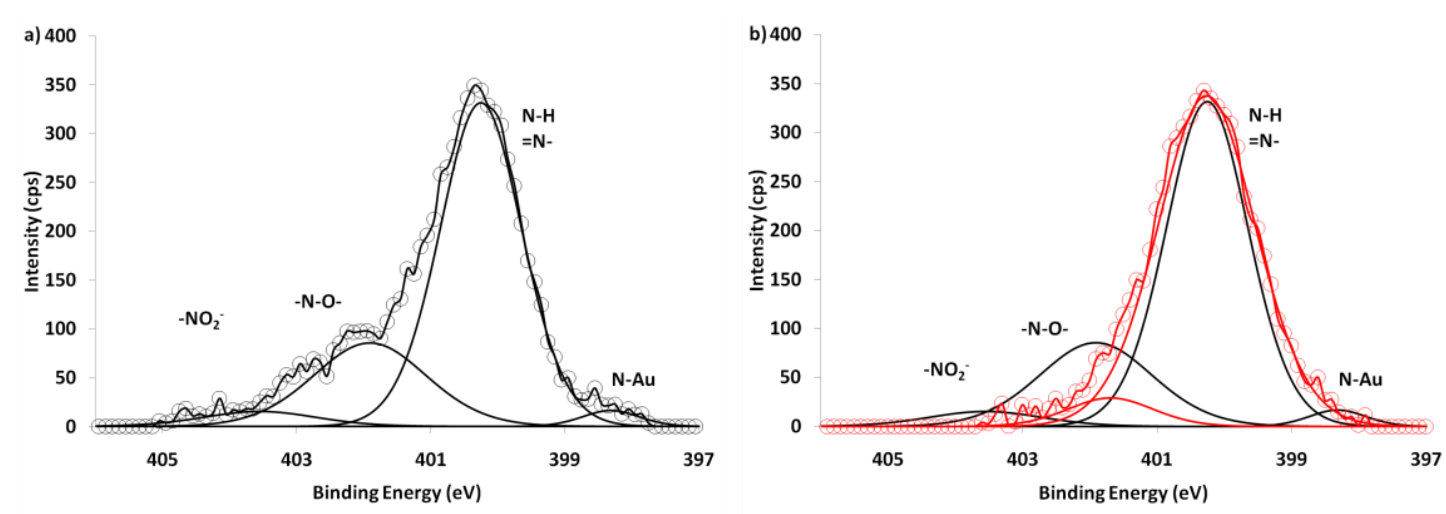

Figure 7.30: a) high resolution N 1s XPS spectra of a gold nanoparticle-silk composite prepared by soaking silk in a $160 \mathrm{ppm}\left(8.13 \times 10^{-4} \mathrm{M}\right) \mathrm{Au}^{3+}$ solution, with a pH of 9-10 for 6 hours at RT, followed by ageing at $50{ }^{\circ} \mathrm{C}$ for 24 hours. b) an overlay (in red) of silk.

Additionally, Zhou and co-workers [79] have reported the use of silk fibroin (dissolved silk proteins) as a redox active bio-template, facilitating the reduction of $\mathrm{Au}^{3+}$ (in the form of $\mathrm{AuCl}_{4}{ }^{-}$) to nanoparticulate $\mathrm{Au}^{0}$, forming a core-shell gold colloid-silk fibroin bioconjugate. Silk fibroin fibres (degummed silk fibres) have also been reported to be successful in the reduction of $\mathrm{Ag}^{+}$(in the form of $\mathrm{AgNO}_{3}$ ) to $\mathrm{Ag}^{0}$ nanoparticles.[248] In both systems the 
$\mathrm{Au}^{3+}$ to $\mathrm{Au}^{0}$ or $\mathrm{Ag}^{+}$to $\mathrm{Ag}^{0}$ reduction was said to be facilitated by the tyrosine amino acids present in the fibroin component of silk, in which the phenolic functionality of this amino acid was oxidised to a quinone (scheme 7.1).

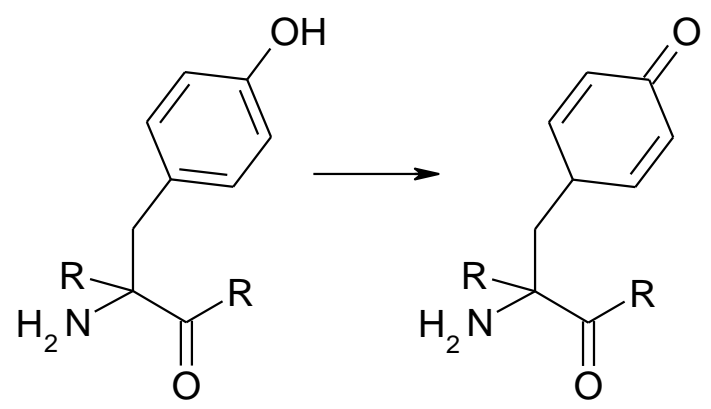

As such, in addition to nitrogen containing functional groups (such as amines), tyrosine residuals in silk may also be facilitating the reduction of $\mathrm{Au}^{3+}$ to nanoparticulate $\mathrm{Au}^{0}$. Examination of the deconvoluted high resolution C 1s and O 1s XPS spectra of a composite and silk provide evidence for the involvement of tyrosine in the $\mathrm{Au}^{3+}$ reduction. Comparisons of the C 1s XPS spectra of a composite and silk show a significant increase in area of the peak corresponding to carbonyl carbons (from 4 to $24 \%$, Figure $7.31 \mathrm{a}$ and $\mathrm{b}$ ). Additionally, a new peak centred at $531.92 \mathrm{eV}$ appeared in the $\mathrm{O} 1 \mathrm{~s}$ spectrum of the composite (Figure $7.31 \mathrm{c}$ and d). This peak has been reported to arise due to the presence of carbonyl quinones.[248] Combined, these observations suggest that tyrosine may be involved in the $\mathrm{Au}^{3+}$ reduction, with oxidation of its phenolic groups to a carbonyl quinone.

In addition to nanoparticles forming on the silk fibre, when employing a soaking/ageing solution $\mathrm{pH}$ of 2.7 or $9-10$, nanoparticles were seen to form in solution during soaking and ageing respectively. As such, something that was capable of facilitating the $\mathrm{Au}^{3+}$ to nanoparticulate $\mathrm{Au}^{0}$ reduction must have been liberated from the silk fibres during soaking in a $\mathrm{pH} 2.7$ solution, and ageing in a $\mathrm{pH} 9-10$ solution. This was likely to be sericin, a (relatively) sulfur rich glue like protein surrounding the fibroins. Generally sericin is removed from silk fibres prior to dyeing as it has a great influence on dyeing silk, with many defects found in dyed silk arising due to its incomplete removal. The removal of sericin is 

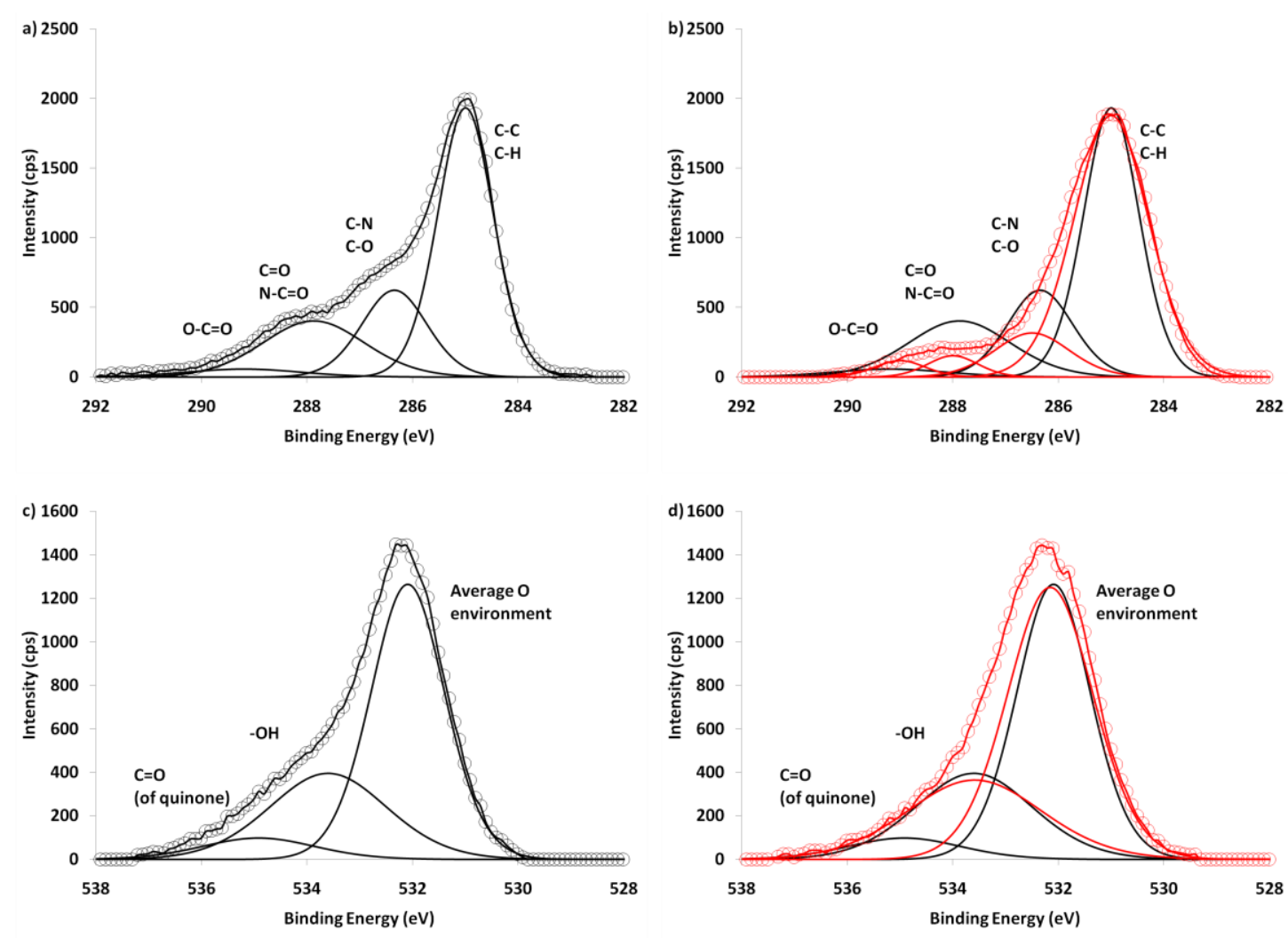

Figure 7.31: High resolution XPS spectra of $\mathrm{C} 1 \mathrm{~s}$ (a) and $\mathrm{O} 1 \mathrm{~s}$ (c) of a gold nanoparticle silk composite prepared by soaking silk in a $160 \mathrm{ppm}\left(8.13 \times 10^{-4} \mathrm{M}\right) \mathrm{Au}^{3+}$ solution, with a $\mathrm{pH}$ of 9-10 for 6 hours at RT, followed by ageing at $50{ }^{\circ} \mathrm{C}$ for 24 hours. b) and d) show an overlay or the corresponding $\mathrm{C} 1 \mathrm{~s}$ and $\mathrm{O}$ 1s spectra of silk (in red).

called degumming (see section 1.2.2.2.3), which usually employs hot dilute soap or alkaline solutions and occasionally dilute aqueous acids.[97] As such, if sericin was not completely removed from the silk fibres when employing a $\mathrm{Au}^{3+}$ solution with a $\mathrm{pH}$ of 2.7 , the acidic conditions may have dislodged sufficient sericin from the silk fibres during soaking to facilitate the reduction of $\mathrm{Au}^{3+}$ to nanoparticulate $\mathrm{Au}^{0}$. Alternatively when employing a $\mathrm{Au}^{3+}$ solution of $\mathrm{pH}$ 9-10, (which after equilibrium with the silk fibres results in a solution $\mathrm{pH}$ of approximately 7.8 ) it is likely that heat would be required to remove sericin from the silk fibres, due to the more mild conditions relative to the $\mathrm{pH} 2.7$ solutions.

In an effort to ascertain whether sericin was released from the silk fibres whilst soaking in a pH 2.7 soaking system, or ageing in a pH 9-10 solution, and then reducing $\mathrm{Au}^{3+}$, XPS analysis of a sample of a $\mathrm{pH} 2.7 \mathrm{Au}^{3+}$ soaking solution in which silk fibres had been 
immersed was undertaken. Figure 7.32 offers a wide XPS scan, and shows the sample to contain oxygen, nitrogen, carbon, sulfur and gold, suggesting that sericin may have been released from the silk fibres into solution, whereupon it reduced $\mathrm{Au}^{3+}$ to $\mathrm{Au}^{0}$. (Calcium and silicon were also present however they are likely to be impurities as calcium silicate is manufactured on a large scale in the lab in which this sample was prepared).

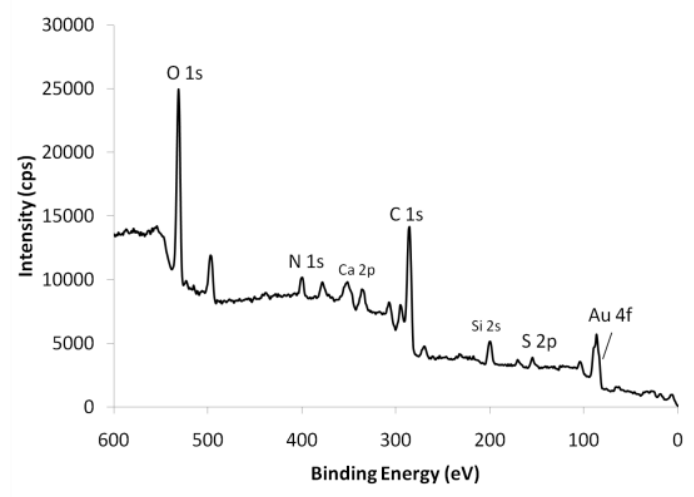

Figure 7.32: Wide XPS scan of the evaporated $\mathrm{pH} 2.7 \mathrm{Au}^{3+}$ soaking solution in which silk fibres had been soaked.

Examination of the deconvoluted, high resolution XPS spectra of this sample substantiated this proposal, as the $\mathrm{C} 1 \mathrm{~s}, \mathrm{~N} 1 \mathrm{~s}, \mathrm{O} 1 \mathrm{~s}$ and $\mathrm{S} 2 \mathrm{p}$ spectra exhibited peaks corresponding to a range of functional groups typical to the amino acid makeup of sericin (Figure 7.33 a-d, Table 7.3). Additionally, peaks denoting oxidised nitrogen and sulfur groups were observed in the $\mathrm{N}$ 1s and S 2p spectra, centred at 405.43 and $168.38 \mathrm{eV}$ respectively (Figure $7.33 \mathrm{~b}$ and d). This suggests that the formation of the gold nanoparticles in the soaking solution may have been facilitated by the oxidation of both nitrogen and sulfur groups in the amino acids of sericin. Additionally, peaks denoting N-Au bonds were seen in the $\mathrm{C} 1 \mathrm{~s}$ and $\mathrm{N}$ 1s spectra, centred at 28.5 and $398.4 \mathrm{eV}$ respectively, suggesting that once formed, the gold nanoparticles may have been stabilised by a layer of nitrogen containing groups. The $\mathrm{S} 2 \mathrm{p}$ spectrum exhibited a peak typical of Au-S bonds, centred at $161.30 \mathrm{eV}$, suggesting that sulfur atoms may also bond to the surface of the gold nanoparticles, thus also stabilising the produced particles. Examination of the deconvoluted Au 4f XPS spectra of this sample confirmed the role of nitrogen and sulfur atoms in the stabilisation of the gold nanoparticles, with peaks representative of nanoparticulate $\mathrm{Au}^{0}$ surrounded by both nitrogen and sulfur present (Figure 7.33 e,Table 7.3). 

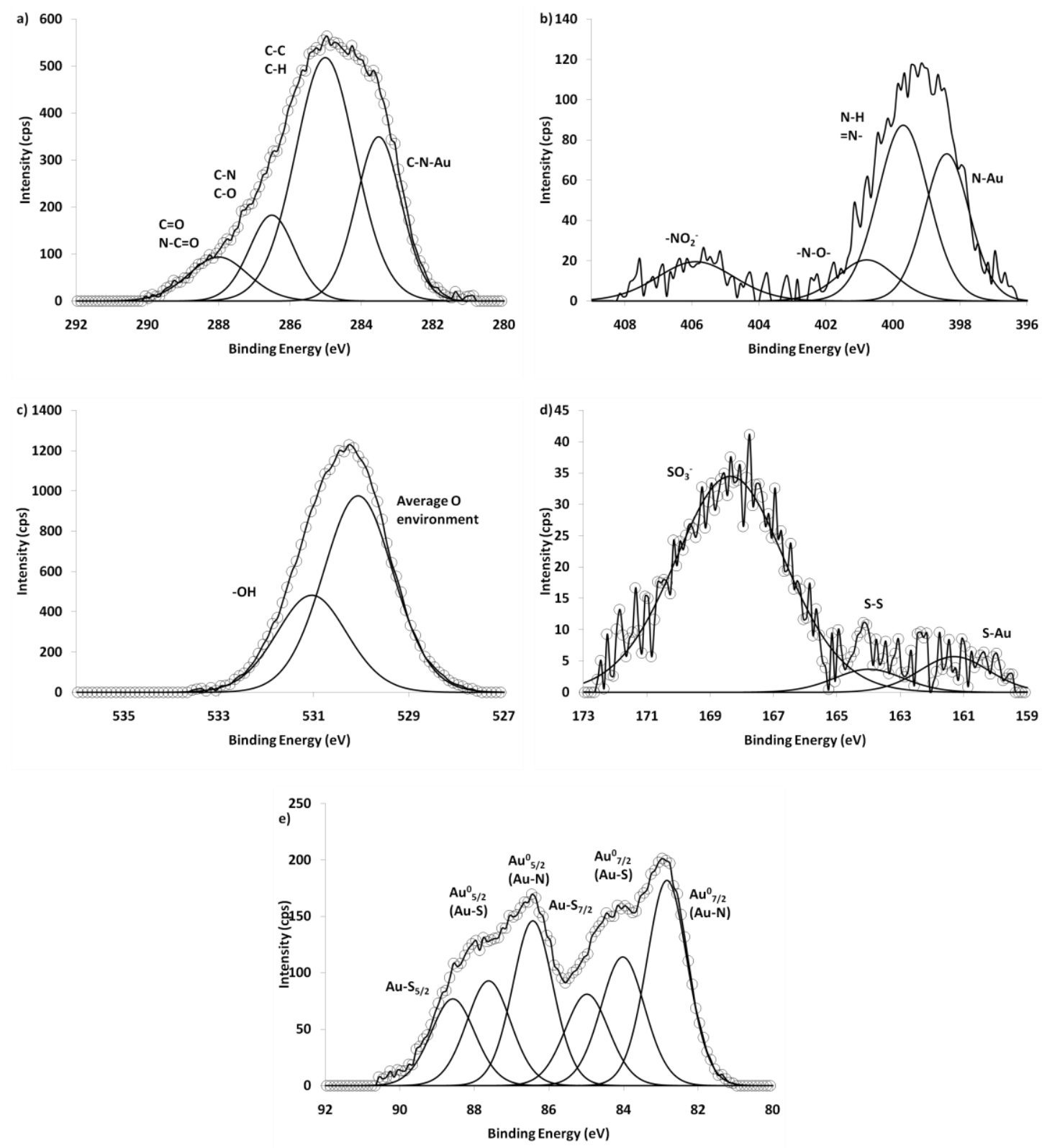

Figure 7.33: High resolution $\mathrm{C} 1 \mathrm{~s}(\mathrm{a}), \mathrm{N} 1 \mathrm{~s}(\mathrm{~b}), \mathrm{O} 1 \mathrm{~s}(\mathrm{c}), 2 \mathrm{Sp}$ (d) and Au $4 \mathrm{f}$ (e) XPS spectra of a pH 2.7 $\mathrm{Au}^{3+}$ soaking solution following the soaking of silk fibres at $\mathrm{RT}$. 
Table 7.3: XPS assignments of a $\mathrm{pH} 2.7 \mathrm{Au}^{3+}$ soaking solution following the soaking of silk fibres at RT.

\begin{tabular}{|c|c|c|}
\hline & & $\begin{array}{l}\text { Binding Energy }(\mathrm{eV} \pm 0.2 \mathrm{eV}) \text { and } \\
\text { Relative Percentage }( \pm 10 \%)\end{array}$ \\
\hline \multirow[t]{4}{*}{ C 1s } & $\mathrm{C}-\mathrm{C}, \mathrm{C}-\mathrm{H}$ & 285.00 (52 \%) \\
\hline & $\mathrm{C}-\mathrm{O}, \mathrm{C}-\mathrm{N}$ & 286.50 (13\%) \\
\hline & $\mathrm{C}=\mathrm{O}, \mathrm{N}-\mathrm{C}=\mathrm{O}$ & 288.00 (10\%) \\
\hline & $\mathrm{C}-\mathrm{N}-\mathrm{Au}$ & 283.50 (25 \%) \\
\hline \multirow[t]{4}{*}{ N 1s } & $\mathrm{N}-\mathrm{H},=\mathrm{N}-$ & 399.70 (43 \%) \\
\hline & $-\mathrm{N}-\mathrm{O}-$ & 400.79 (11\%) \\
\hline & $-\mathrm{NO}_{2}^{-}$ & $405.43(14 \%)$ \\
\hline & $\mathrm{N}-\mathrm{Au}$ & 398.4 (32 \%) \\
\hline \multirow[t]{2}{*}{$01 s$} & $\begin{array}{l}\text { Average } \mathrm{O} \\
\text { environment }\end{array}$ & 430.07 (67\%) \\
\hline & $-\mathrm{OH}$ & 531.04 (33 \%) \\
\hline \multirow[t]{3}{*}{$S 2 p$} & S-S & 164.0 (6\%) \\
\hline & $\mathrm{SO}_{3}^{-}$ & 168.38 (85 \%) \\
\hline & S-Au & 161.30 (9 \%) \\
\hline \multirow[t]{6}{*}{ Au $4 f$} & $A u_{7 / 2}^{0}\left(A u^{0}-S\right)$ & 82.84 (25\%) \\
\hline & $A u_{7 / 2}^{0}\left(A u^{0}-N\right)$ & 84.02 (17\%) \\
\hline & $\mathrm{Au}-\mathrm{S}_{7 / 2}$ & 84.99 (12\%) \\
\hline & $A u^{0}{ }_{5 / 2}\left(A u^{0}-S\right)$ & 86.44 (20\%) \\
\hline & $A u_{5 / 2}^{0}\left(A u^{0}-N\right)$ & 87.62 (14\%) \\
\hline & $\mathrm{Au}-\mathrm{S}_{5 / 2}$ & 88.59 (12\%) \\
\hline
\end{tabular}

In an attempt to ascertain whether sericin was liberated from the silk fibres during soaking or ageing in $\mathrm{pH} 2.7$ or 9-10 $\mathrm{Au}^{3+}$ solutions respectively, the silk fibres were degummed prior to addition to the $\mathrm{Au}^{3+}$ solutions. This involved heating the fibres ( $\left.1 \mathrm{~g}\right)$ (under reflux) in a $\mathrm{Na}_{2} \mathrm{CO}_{3}$ solution $(10 \mathrm{ml}, 0.1 \mathrm{M})$ for 1 hour, and then washing well with distilled water. Figure 7.34 offers a comparison of gold nanoparticle-silk composites prepared with untreated or degummed silk. It is apparent from this photograph that employing degummed silk produces composite materials that are uneven in colour, and slightly decreased in intensity relative to those prepared with untreated silk. Additionally, UV/Vis analysis of the gold colloid produced from either system whilst ageing shows the intensity of the plasmon band of 
the gold nanoparticles produced in the degummed systems to be less than that of the untreated systems, suggesting a lower concentration of nanoparticles were formed when employing degummed silk (Figure 7.35). This is likely due to the fact that when employing degummed silk, there was less sericin present to be liberated from the fibres, and hence less available to facilitate the $\mathrm{Au}^{3+}$ to $\mathrm{Au}^{0}$ reduction.

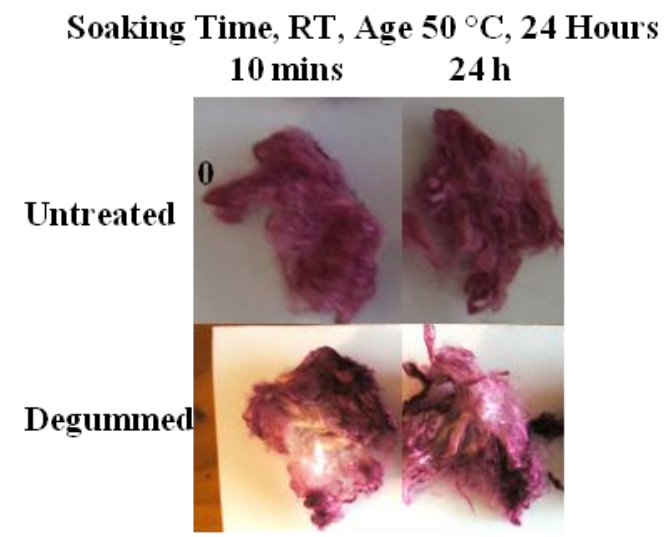

Figure 7.34: Gold nanoparticle-silk composites prepared by soaking untreated (top) or degummed silk (bottom) in a $160 \mathrm{ppm} \mathrm{Au}^{3+}$ solution, with a pH of 9-10, for 10 minutes or 24 hours, followed by ageing at $50{ }^{\circ} \mathrm{C}$ for 24 hours.

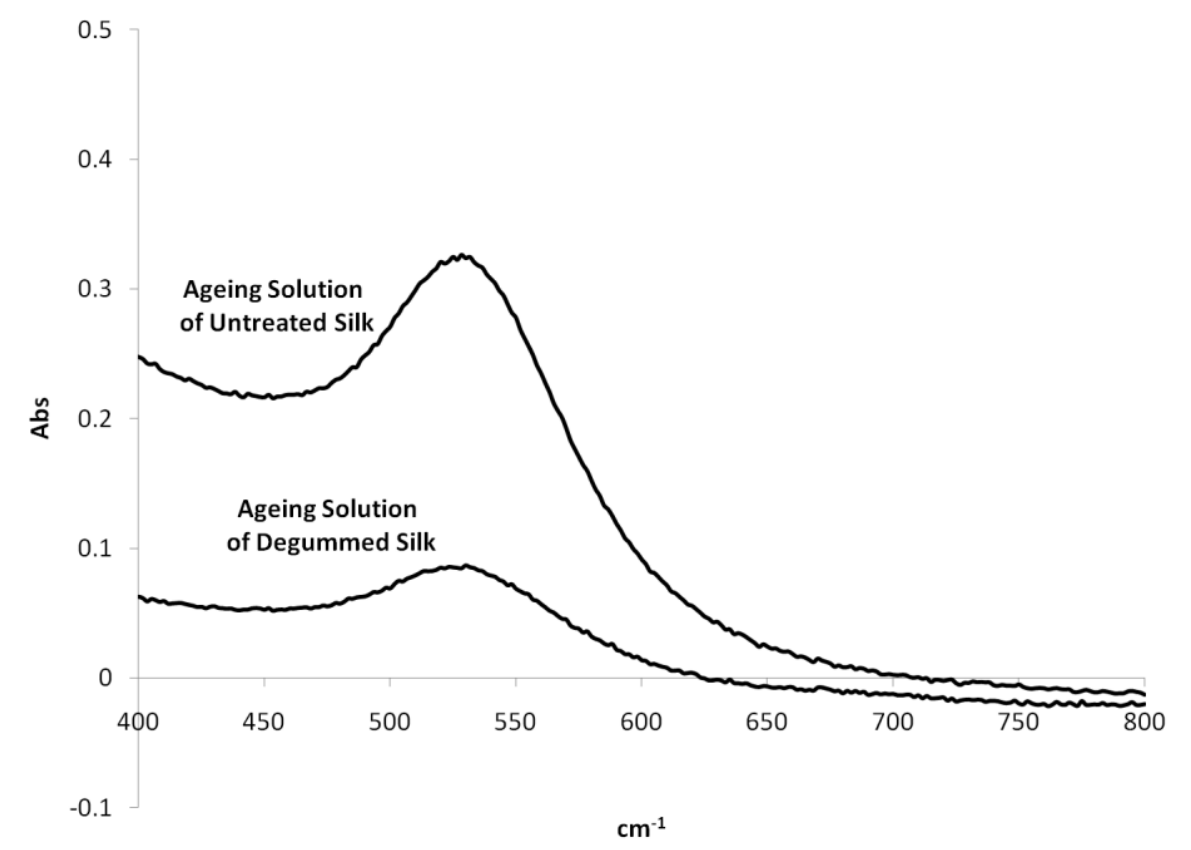

Figure 7.35: UV/Vis spectra of the gold colloids produced in the ageing solutions of untreated or degummed silk. 
Considering all obtained results, it is likely that the production of the gold nanoparticle-silk composites involved the absorption of $\mathrm{Au}^{3+}$ (in the form of $\mathrm{AuCl}_{4}{ }^{-}$), whereupon it was reduced to nanoparticulate $\mathrm{Au}^{0}$ by a combination of amine and tyrosine moieties. Additionally, nanoparticles were observed to form in solution due to the dislodgement of sericin, which reduced $\mathrm{Au}^{3+}$ to $\mathrm{Au}^{0}$, whilst the amine and disulfide groups of this protein were oxidised to nitrosyl and cysteic acid groups respectively. The nanoparticles formed in solution did not appear to re-absorb onto the silk fibres.

\subsection{Colourfastness to Washing}

As with all other gold nanoparticle-natural fibre composites, the colourfastness to washing of the gold nanoparticle-silk composites were tested according to the synthesis outlines in section 2.3.14. Composite materials prepared by soaking silk in a $160 \mathrm{ppm}\left(8.13 \times 10^{-4} \mathrm{M}\right)$ $\mathrm{Au}^{3+}$ solution, with a $\mathrm{pH}$ of 2.7 or $9-10$ for 6 or 24 hours at RT and ageing, at $50{ }^{\circ} \mathrm{C}$ for 168 hours or 24 hours respectively were chosen as representatives of the gold nanoparticle-silk materials.

Figure 7.36 and Figure 7.37 offer photographs of samples that have been in the washing solution for half an hour to 24 hours. Visually it appears that the colour of both sets of samples has faded upon washing, those prepared with a soaking and ageing solution $\mathrm{pH}$ of 2.7 slightly more so, suggesting they were not very colourfast to washing. (It should be noted that the colour of the samples prepared with a soaking and ageing solution $\mathrm{pH}$ of 9-10 was very non-uniform, even before washing. These materials were prepared on a larger scale, and when doing so difficulties in achieving a uniform colour was encountered). 


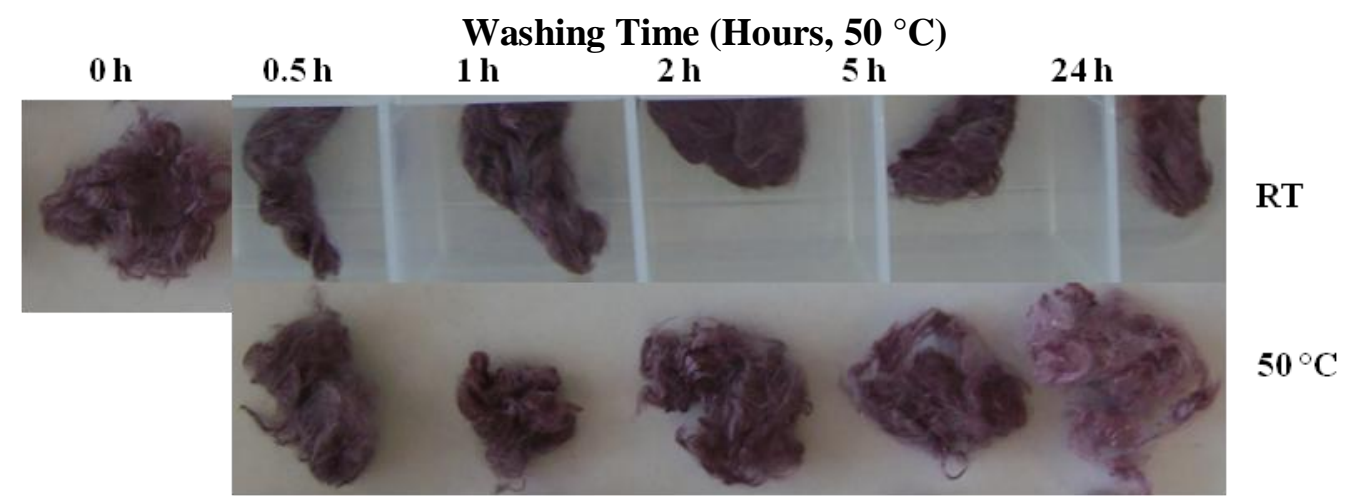

Figure 7.36: Gold nanoparticle-silk composites prepared by soaking crossbred wool in a $160 \mathrm{ppm}(8.13 \mathrm{x}$ $\left.10^{-4} \mathrm{M}\right) \mathrm{Au}^{3+}$ solution with a $\mathrm{pH}$ of 2.7 for 24 hours at $\mathrm{RT}$ and ageing, at $50{ }^{\circ} \mathrm{C}$ for 168 hours, following simulated washability testing at $\mathrm{RT}$ and $50{ }^{\circ} \mathrm{C}$.

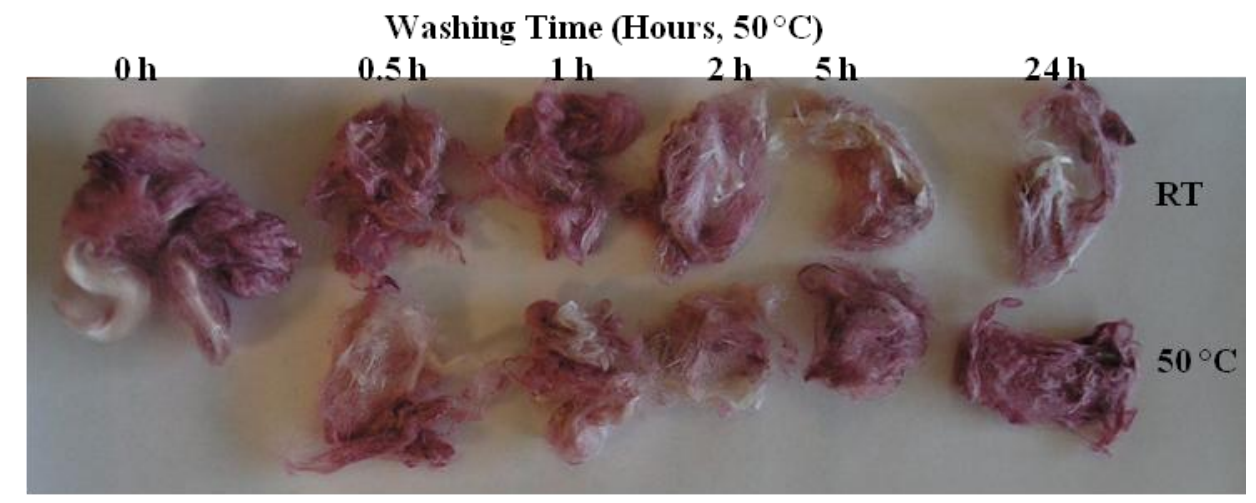

Figure 7.37: Gold nanoparticle-silk composites prepared by soaking crossbred wool in a $160 \mathrm{ppm}(8.13 \mathrm{x}$ $\left.10^{-4} \mathrm{M}\right) \mathrm{Au}^{3+}$ solution with a $\mathrm{pH}$ of 9-10 for 6 hours at $\mathrm{RT}$ and ageing, at $50{ }^{\circ} \mathrm{C}$ for 24 hours, following simulated washability testing at $\mathrm{RT}$ and $50{ }^{\circ} \mathrm{C}$.

The CIE L*, a*, $\mathrm{b}^{*}, 457 \mathrm{~nm}$ brightness and $580 \mathrm{~nm}$ brightness values of the composite materials following washing are provided in Appendix X. Following washing there was a general increase in $\mathrm{L}^{*}, 457 \mathrm{~nm}$ brightness and $580 \mathrm{~nm}$ brightness values of the materials prepared with a soaking and ageing solution $\mathrm{pH}$ of 2.7 , confirming the visual lightening, or colour fading upon increased washing times. This was more pronounced with washing temperatures of $50{ }^{\circ} \mathrm{C}$ (Figure 7.38). It is difficult to obtain any information from the CIE values of composites prepared with a $\mathrm{pH}$ 9-10 soaking and ageing solution following washing as the colour of the unwashed material was so uneven. However following washing there was a slight increase in both $\mathrm{L}^{*}, 457 \mathrm{~nm}$ brightness and $580 \mathrm{~nm}$ brightness values, reflecting the observed lightening of these materials following washing. 


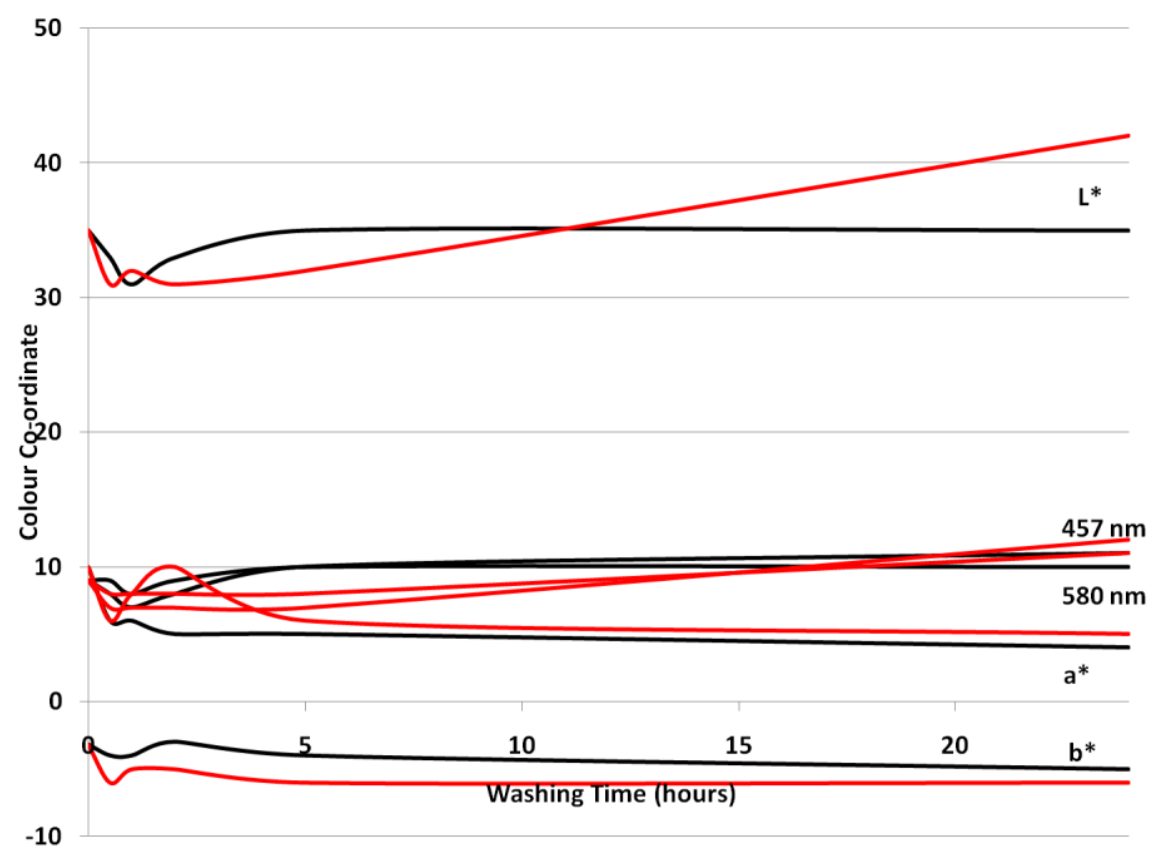

Figure 7.38: Changes in $\mathrm{L}^{*}, \mathrm{a}^{*}, \mathrm{~b}^{*}, 457 \mathrm{~nm}$ brightness and $580 \mathrm{~nm}$ brightness values for a gold nanoparticle-silk composite (prepared by soaking silk in a $160 \mathrm{ppm}\left(8.13 \times 10^{-4} \mathrm{M}\right) \mathrm{Au}^{3+}$ solution, with a pH of 2.7 for 24 hours at RT followed by heating at $50{ }^{\circ} \mathrm{C}$ for 24 hours) following simulated washability tests show the colour change due to washing. Washing at RT (black lines) or $50^{\circ} \mathrm{C}$ (red lines).

\subsection{Leaching}

Quantitative analysis of the washing solutions obtained during simulated washability testing (section 7.7) was undertaken to establish the amount of gold leached from the composites during washing (Table 7.4). The amount of gold leached from the materials prepared with a $\mathrm{pH} 2.7$ soaking and ageing solution was greater than that leached from materials prepared with a $\mathrm{pH}$ 9-10 soaking and ageing solution, leaching a maximum of $4 \mathrm{ppm} \pm 0.5 \mathrm{ppm}$, or $<1$ $\%$ of the total gold loading respectively. This complements the results obtained in the colour fastness to washing tests, where the materials prepared with a soaking and ageing solution of pH 2.7 appeared to exhibit a greater change in colour than those prepared with $\mathrm{pH} 9-10$ solutions.

As colourfastness to washing, and hence the amount of gold leached during washing is related to the robustness of the bond between the gold nanoparticles and silk fibres, the 
decreased colourfastness and greater amount of gold leached from the materials prepared with $\mathrm{pH} 2.7$ soaking and ageing solutions suggests that the bond between the nanoparticles and silk fibres was not as strong in these materials. This is likely due to the difference in physical morphology, and the position of the nanoparticles in the two composites. As shown above in section 7.1, employing a soaking and ageing solution $\mathrm{pH}$ of 2.7 saw the majority of nanoparticles form on the surface of the silk fibres, where they could be dislodged during washing. However when a soaking and ageing solution of $\mathrm{pH}$ 9-10 was used, nanoparticles formed both on the surface and within the centre of the silk fibres.

Table 7.4: Gold leached from gold nanoparticle-silk composites (prepared by soaking silk in a 160 ppm $\left(8.13 \times 10^{-4} \mathrm{M}\right) \mathrm{Au}^{3+}$ solution, with a $\mathrm{pH}$ of 2.7 or 9-10 for 6 or 24 hours at RT, followed by ageing at $50{ }^{\circ} \mathrm{C}$ for 168 or 24 hours respectively) following simulated washability testing.

\begin{tabular}{|c|c|c|c|c|c|}
\hline \multirow{3}{*}{$\begin{array}{c}\text { Washing } \\
\text { Temperature }\end{array}$} & \multirow{3}{*}{$\begin{array}{c}\text { Washing } \\
\text { Time (hours) }\end{array}$} & \multicolumn{4}{|c|}{$\mathrm{pH}$ of Soaking and Ageing Solution } \\
\hline & & \multicolumn{2}{|c|}{ pH 2.7} & \multicolumn{2}{|c|}{ pH 9-10 } \\
\hline & & $\begin{array}{c}\mathrm{ppm} \pm 0.5 \\
\mathrm{ppm}\end{array}$ & $\begin{array}{l}\% \text { Total Gold } \\
\text { Loading }\end{array}$ & $\begin{array}{l}\text { ppm } \pm 0.5 \\
\text { ppm }\end{array}$ & $\begin{array}{l}\% \text { Total Gold } \\
\text { Loading }\end{array}$ \\
\hline \multirow[t]{5}{*}{ RT } & 0.5 & 4.8 & 3 & 0.5 & $<1$ \\
\hline & 1 & 5.2 & 3 & 0.4 & $<1$ \\
\hline & 2 & 4.6 & 3 & 0.3 & $<1$ \\
\hline & 5 & 6.1 & 4 & 0.3 & $<1$ \\
\hline & 24 & 4.7 & 3 & 0.4 & $<1$ \\
\hline \multirow[t]{5}{*}{$50^{\circ} \mathrm{C}$} & 0.5 & 6.0 & 4 & 0.5 & $<1$ \\
\hline & 1 & 6.7 & 4. & 0.6 & $<1$ \\
\hline & 2 & 5.6 & 4 & 0.5 & $<1$ \\
\hline & 5 & 4.9 & 3 & 0.8 & $<1$ \\
\hline & 24 & 5.3 & 3 & 1.3 & $<1$ \\
\hline
\end{tabular}




\subsection{Conclusions}

The production of gold nanoparticle-silk composite material prepared through the redox active proteins in silk was successful, producing deep regal purple or pink/purple coloured composites respectively when a $\mathrm{pH} 2.7$ or 9-10 $\mathrm{Au}^{3+}$ solution was employed. These materials retained the original shine and lustre inherent to silk.

When employing a $\mathrm{Au}^{3+}$ solution with a $\mathrm{pH}$ of 2.7 nanoparticles were formed during soaking, indicated by the development of a purple colour in the silk fibres. Prolonged soaking and subsequently ageing intensified this colour, and corresponded to an increase in concentration of similarly sized and shaped nanoparticles located primarily at the silk fibre surface. These nanoparticles were spherical or five-fold twinned in morphology, being smaller, approximately 5-10 $\mathrm{nm}$ in diameter, or larger approximately $20-40 \mathrm{~nm}$ in diameter, with agglomerations of a percentage of the larger nanoparticles seen. There were also a small amount of triangular nanoplates, approximately $80-100 \mathrm{~nm}$ in diameter.

Increasing the $\mathrm{pH}$ of the soaking and hence ageing solution to approximately 7 and then 9-10 resulted in the formation of vibrant purple and pink/purple coloured composites respectively whilst increasing the $\mathrm{pH}$ further to 12 produced materials that were similar in colour to that of the base silk fibres. These colour developments and hence the reduction of $\mathrm{Au}^{3+}$ to nanoparticulate $\mathrm{Au}^{0}$ were complete after 24 hours ageing, and a soaking time of 6 hours was sufficient for the absorption and diffusion of $\mathrm{AuCl}_{4}{ }^{-}$onto and through the fibres. The change in colour from a deep regal purple to a pink/purple induced with increased $\mathrm{pH}$, corresponded to the production of slightly smaller, increasingly isolated gold nanoparticles, located both on the surface, and also within the centre of the silk fibres.

XPS suggested that the reduction of $\mathrm{Au}^{3+}$ to nanoparticulate $\mathrm{Au}^{0}$ was facilitated by the oxidation of amine and tyrosine residuals in the silks' fibroin fibres. Additionally, when a pH 2.7 or 9-10 soaking and ageing solution was employed nanoparticles were seen to form in solution during soaking and ageing respectively. This was proposed to occur through the 
dislodgement of sericin from the silk fibres, which reduced $\mathrm{Au}^{3+}$ in solution to $\mathrm{Au}^{0}$, whilst the amine and disulfide groups of this protein were oxidised to nitrosyl and cysteic acid groups respectively. The nanoparticles formed in solution did not appear to re-absorb onto the silk fibres. The nanoparticles reduced by the fibroin proteins of silk appeared to bond to the silk through nitrogen groups, and also through sulfur groups, most likely in any sericin remaining on the silk fibres.

In contrast to the gold nanoparticle-merino wool and crossbred wool composite materials, the gold nanoparticle-silk composites did not appear to be as colourfast with respect to washing, with both the materials prepared with a $\mathrm{pH} 2.7$ and 9-10 soaking and ageing solutions fading upon washing, the former more so. This decreased colourfastness is related to the relative strengths of the bonds between the nanoparticles and natural fibres, and suggests the Au-N bonding in the silk composites to be weaker than the Au-S bonding in the merino and crossbred wool composites. 


\section{SEED MEDIATED GROWTH OF GOLD NANOPARTICLES BY AN EXTERNAL REDUCTANT EMPLOYING GOLD NANOPARTICLE-FIBRE COMPOSITE MATERIALS AS SEED SOURCES}

\subsection{Gold Nanoparticle-Merino Wool Composites}

In an attempt to reduce the amount of gold used in the production of grey coloured gold nanoparticle-merino wool composites, a seed mediated growth approach was undertaken. The process is based on a synthesis reported by Brown and co-workers,[173] and is outlined in section 2.2.2.4. It involved the surface catalysed reduction of $\mathrm{Au}^{3+}$ to $\mathrm{Au}^{0}$ by $\mathrm{NH}_{2} \mathrm{OH}$ in the presence of gold nanoparticle-merino wool composites (termed seeds). Depending on the seed, gold concentration and ratio of $\left[\mathrm{Au}^{3+}\right]:\left[\mathrm{NH}_{2} \mathrm{OH}\right]$ the resultant materials ranged in colour from purple to light grey with a tinge of pink, steely grey and purple/grey.

\subsubsection{Seeds}

The seed sources employed were prepared by utilising the redox active nature of merino wool, which involved the absorption and subsequent reduction of $\mathrm{Au}^{3+}$ to nanoparticulate $\mathrm{Au}^{0}$ by merino wool. As outlined in Table 8.1, preparation of the seed sources (labelled 110) involved soaking untreated merino wool in gold solutions of various concentrations, under gentle agitation at RT, followed by heating at $50{ }^{\circ} \mathrm{C}$ for 24,72 or $168 \mathrm{~h}$.

The physical characterisation and morphology of these seeds is described in detail in sections 5.1, 6.1 and 7.1. However briefly, seed 1 is representative of a composite in which the nanoparticles are very small and present predominantly on the fibre surface. The nanoparticles in seeds 2, 5, 8-10 are also located predominantly on the surface, however they are slightly larger than those found in seed 1. In seeds 3, 4, 6 and 7 nanoparticles are found both on the surface, and within the centre of the fibres 
Table 8.1: Seed source preparation. Note, $0.1 \mathrm{~g}$ of merino wool was used in each system.

\begin{tabular}{ccccc}
\hline Seed & $\begin{array}{c}\text { Gold Solution } \\
\text { (Vol } \mathbf{4} \mathbf{~ w t} \% \mathbf{A u}^{3+} \text { added) }\end{array}$ & $\begin{array}{c}\text { Soak Time } \\
\text { (RT, hours) }\end{array}$ & $\begin{array}{c}\text { Heat Time } \\
\left(\mathbf{5 0}{ }^{\circ} \mathbf{C} \text { hours }\right)\end{array}$ & Colour \\
\hline $\mathbf{1}$ & $40 \mu \mathrm{L} \rightarrow 10 \mathrm{ml}$ & 6 & - & Very faint pink \\
$\mathbf{2}$ & $20 \mu \mathrm{L} \rightarrow 10 \mathrm{ml}$ & 24 & 24 & Pale pink \\
$\mathbf{3}$ & $20 \mu \mathrm{L} \rightarrow 10 \mathrm{ml}$ & 24 & 72 & Pink \\
$\mathbf{4}$ & $20 \mu \mathrm{L} \rightarrow 10 \mathrm{ml}$ & 24 & 168 & Pale purple \\
$\mathbf{5}$ & $40 \mu \mathrm{L} \rightarrow 10 \mathrm{ml}$ & 24 & 24 & Pink \\
$\mathbf{6}$ & $40 \mu \mathrm{L} \rightarrow 10 \mathrm{ml}$ & 24 & 72 & Pink/purple \\
$\mathbf{7}$ & $40 \mu \mathrm{L} \rightarrow 10 \mathrm{ml}$ & 24 & 168 & Deep purple \\
$\mathbf{8}$ & $40 \mu \mathrm{L} \rightarrow 6 \mathrm{ml}$ & 24 & 24 & Pink \\
$\mathbf{9}$ & $50 \mu \mathrm{L} \rightarrow 6 \mathrm{ml}$ & 24 & 24 & Pink \\
$\mathbf{1 0}$ & $60 \mu \mathrm{L} \rightarrow 6 \mathrm{ml}$ & 24 & 24 & Pink \\
\hline
\end{tabular}

During the preparation of the seeds, increasing the heating time from 24 to 168 hours resulted in an increased amount of $\mathrm{Au}^{3+}$ being reduced to $\mathrm{Au}^{0}$, forming as small (approximately $5 \mathrm{~nm}$ diameter) spherical nanoparticles in the centre of the fibres. The size and proportion of nanoparticles on the surface of the fibres remained relatively constant following prolonged heating, with these nanoparticles being predominantly five-fold twinned particles, approximately $20-25 \mathrm{~nm}$ in diameter (Figure 8.1 and Figure 8.2). Increasing the gold concentration saw a general increase in the amount of nanoparticles both on the surface, and in the centre of the fibres. With no heating, as was the case with seed $1, \mathrm{Au}^{3+}$ or $\mathrm{Au}^{+}$were the predominant forms of gold (determined by XPS analysis Table8.2). Little $\mathrm{Au}^{3+}$ had been reduced to nanoparticulate $\mathrm{Au}^{0}$, with any nanoparticles formed being relatively small (approximately 5-10 nm in diameter) and present predominantly on the surface of the wool fibres (Figure 8.1 a and Figure 8.4). 

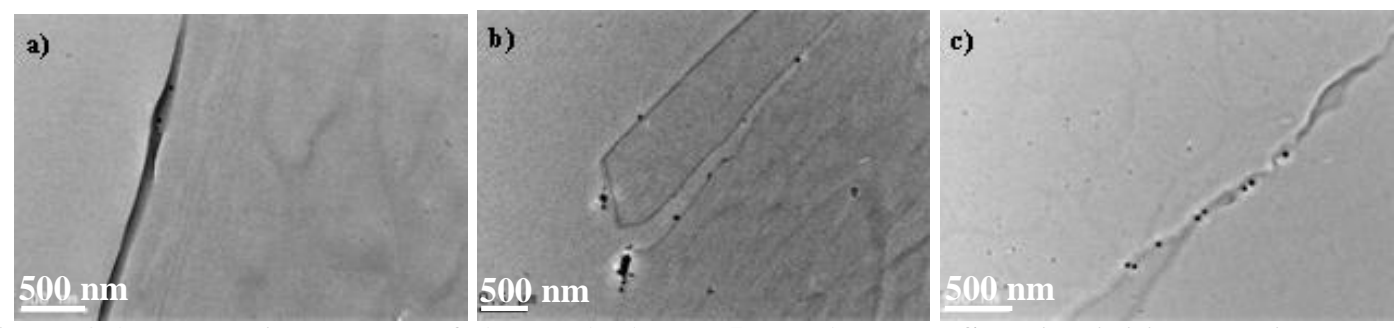

Figure 8.1: TEM micrographs of a) seed 1, b) seed 5 and c) seed 7. Showing initially the increase in amount of nanoparticles on the fibre surface and then in the centre with prolonged heating.
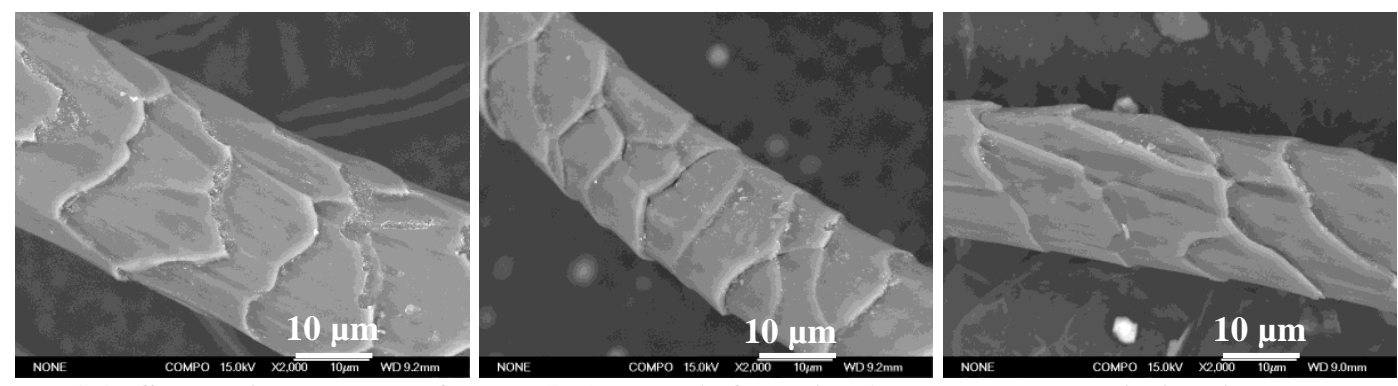

Figure 8.2: SEM micrographs of seeds 5, 6 and 7 (left to right). These appear similar in morphology.

Table 8.2: Relative percentage of $\mathrm{Au}^{0}$ and $\mathrm{Au}^{3+}$ present in the seeds 1 and 7 . Illustrating the effect of

\begin{tabular}{cccc}
\multicolumn{4}{c}{ prolonged heating. } \\
\hline Seed & $\begin{array}{l}\text { Heating Time } \\
\left(50{ }^{\circ} \mathbf{C} \text {, hours }\right)\end{array}$ & $\mathbf{A u}^{3+} / \mathbf{A u}^{+}$ & $\% \mathbf{A u}^{\mathbf{0}}$ \\
\hline $\mathbf{1}$ & 0 & 97.0 & 3 \\
\hline & 168 & 90 & 10 \\
\hline
\end{tabular}

As listed in Table 8.1, the seeds ranged in colour from light pink to purple (Figure 8.3), with increasing gold concentrations producing more intensely coloured seeds, and longer heating times darker colours.

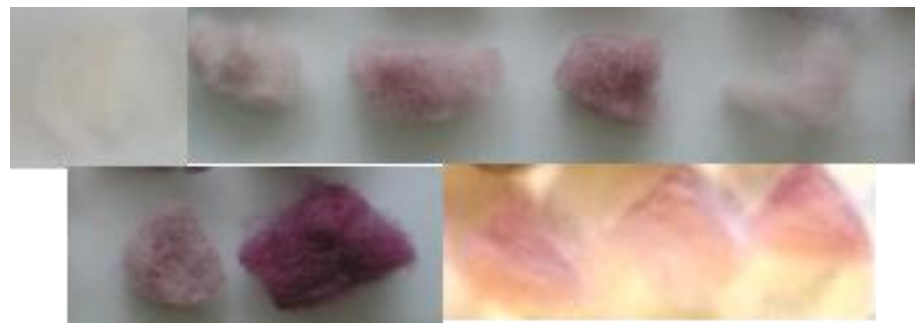

Figure 8.3: Seeds. Top, left to right, seed 1-5. Bottom, left to right, seed 6-10. 


\subsubsection{Preliminary Syntheses}

Initially, the reaction procedure was not altered greatly from that reported by Brown and coworkers.[173] The concentration of $\mathrm{NH}_{2} \mathrm{OH}$ was kept constant at $2.50 \times 10^{-4} \mathrm{M}$, and the amount of gold added was varied, so that in the end solutions the concentration ratio of $\left[\mathrm{NH}_{2} \mathrm{OH}\right]:\left[\mathrm{Au}^{3+}\right]$ varied from 1:1 to $1: 8$ (refer to section 2.2.2.4 for details). Two gold nanoparticle-merino wool materials were chosen as seed sources, notably seeds 1 and 7 (Table 8.1). As mentioned above, seed 1 was representative of a material in which the gold was present mainly as $\mathrm{Au}^{3+}$ or $\mathrm{Au}^{+}$, with a very low proportion of small $\mathrm{Au}^{0}$ nanoparticles (approximately 5-10 $\mathrm{nm}$ in diameter) present predominantly on the surface of the wool fibres (Figure 8.1 a). Alternatively, in seed 7, the wool had been soaked in gold for an extended period of time prior to heating at $50{ }^{\circ} \mathrm{C}$ for $168 \mathrm{~h}$. As such an increased amount of $\mathrm{Au}^{3+}$ had been reduced to $\mathrm{Au}^{0}$ nanoparticles (Table 8.2), which were located both on the fibre surface and throughout the centre (Figure $8.1 \mathrm{c}$ ). The nanoparticles on the surface of these materials were slightly larger than those in seed 1 (approximately $10-20 \mathrm{~nm}$ in diameter) (Figure $8.4 \mathrm{a}$ and $\mathrm{b}$ ), whilst those in the centre were of comparable size (approximately $5 \mathrm{~nm}$ in diameter) (Figure $8.4 \mathrm{c}$ ).
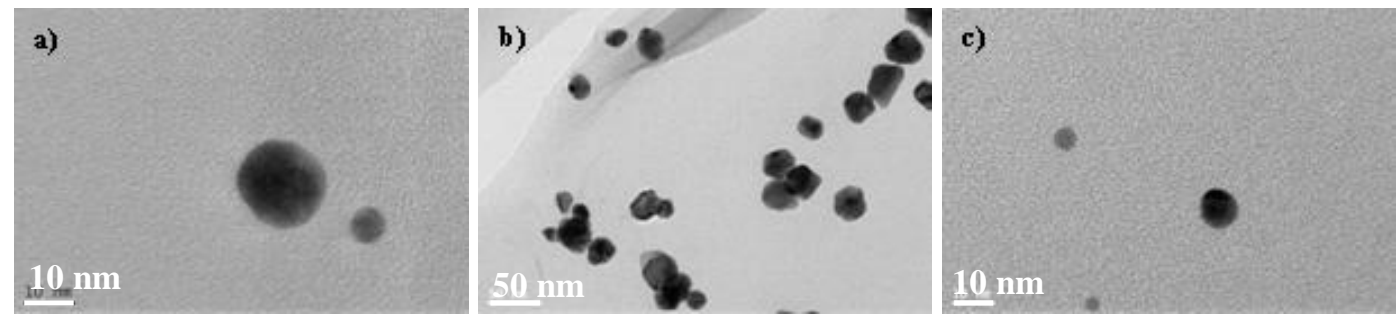

Figure 8.4: TEM micrographs of a) seed 1 and b-c) seed 7. Showing high magnification images of the nanoparticles on the fibre surface ( $a$ and $b)$ and in the fibre centre (c).

The gold nanoparticle-merino wool composites produced from seed 1 ranged in colour from a murky purple to dirty golden brown (Figure 8.5, top), whilst those produced from seed 7 appeared deep purple to dark purple/black (Figure 8.5, bottom). The colour change is reflected in the Kubelka Munk transformed UV/Vis reflection spectra of the materials. Higher ratios of $\left[\mathrm{NH}_{2} \mathrm{OH}\right]:\left[\mathrm{Au}^{3+}\right]$ (increasing to a ratio of $1: 8$ ) induced an increase in 
intensity and broadening of the gold plasmon band centred at approximately $538 \mathrm{~nm}$ (Figure 8.6 and Figure 8.7$)$. The CIE L*, $\mathrm{a}^{*}, \mathrm{~b}^{*}, 457 \mathrm{~nm}$ brightness and $580 \mathrm{~nm}$ brightness values of the resultant composites are offered in Appendix IX, and show a general decrease in the 457 $\mathrm{nm}$ brightness and $580 \mathrm{~nm}$ brightness values of the composites upon increasing ratios of $\left[\mathrm{NH}_{2} \mathrm{OH}\right]:\left[\mathrm{Au}^{3+}\right]$, confirming the visual darkening of the materials.

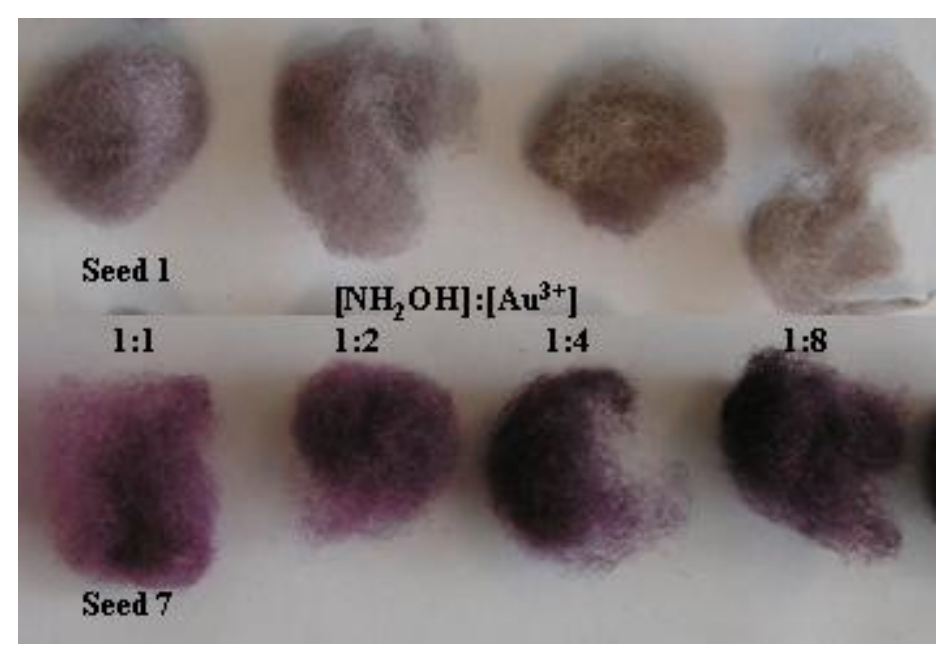

Figure 8.5: Composites prepared via the seed mediated approach. Top: produced from seed 1 and bottom: from seed 7 .

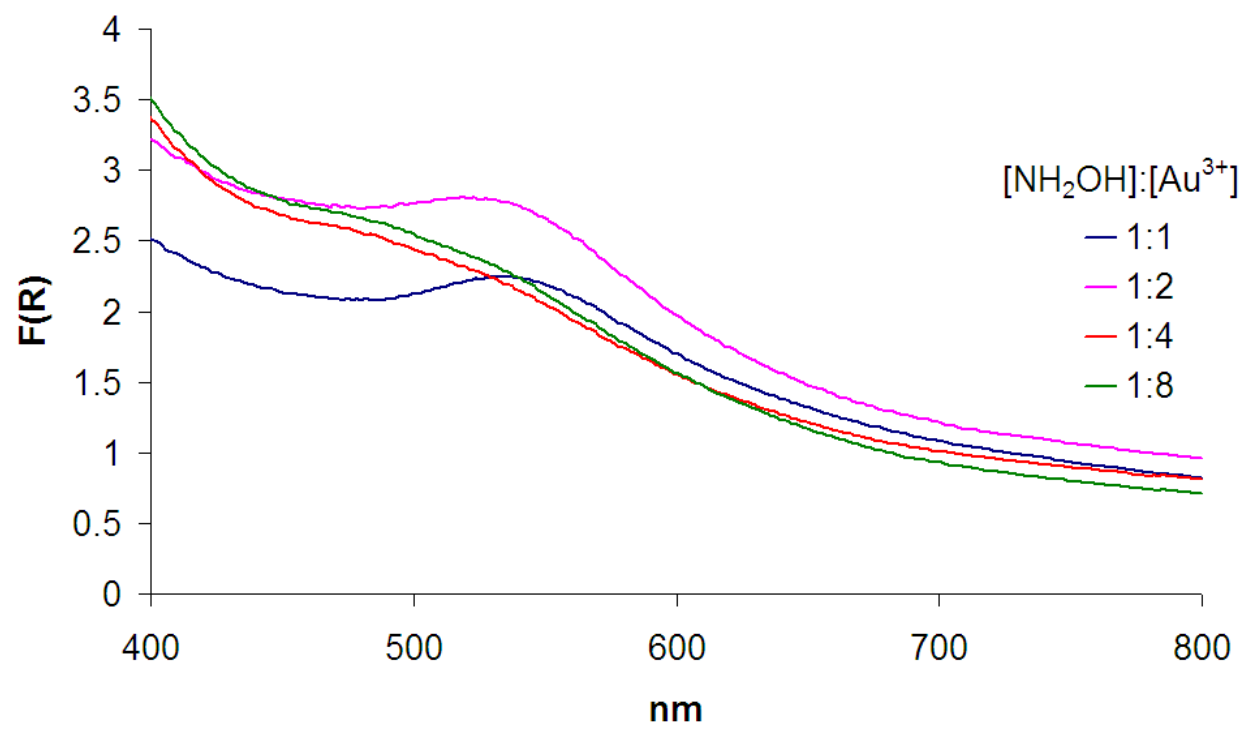

Figure 8.6: Kubelka Munk transformed UV/Vis reflection spectrum of gold nanoparticle-merino wool composites prepared via the seed mediated approach, utilising seed 1. 


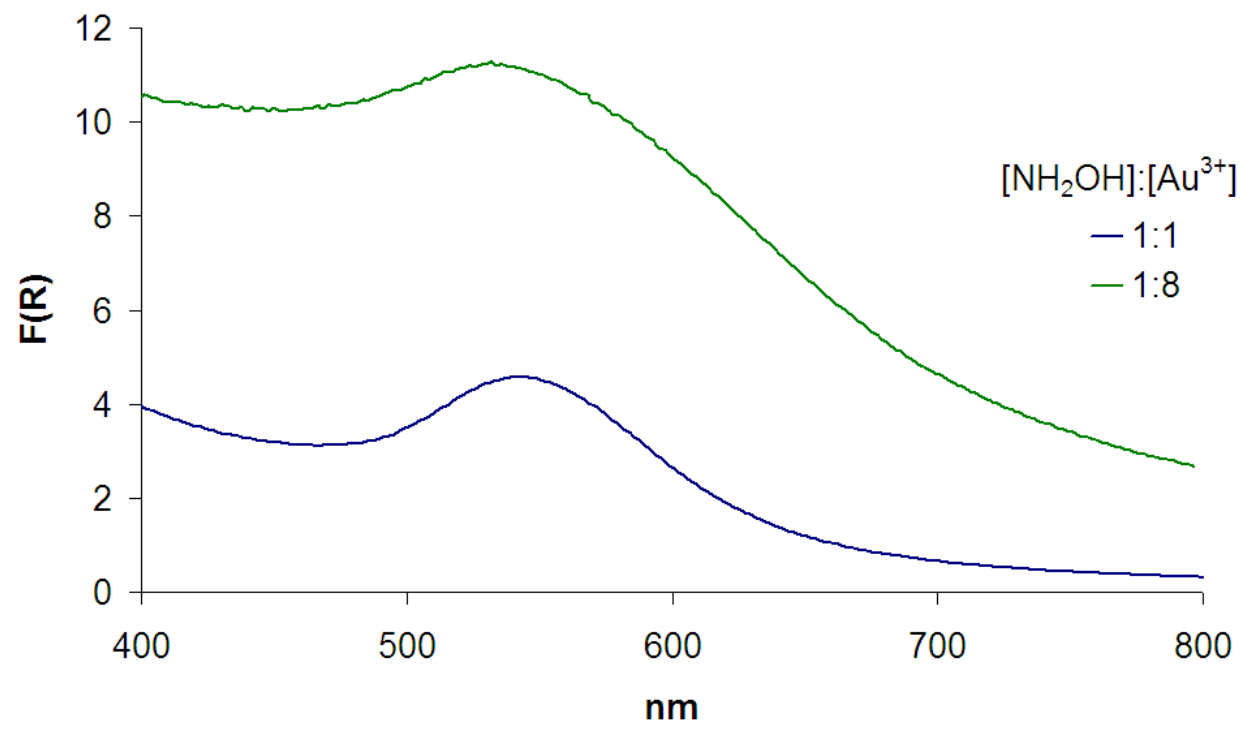

Figure 8.7: Kubelka Munk transformed UV/Vis reflection spectrum of gold nanoparticle-merino wool composites prepared via the seed mediated approach, utilising seed 7.

As a primary aim of this seed mediated approach was to produce grey coloured materials with the lowest amount of gold possible, the colours of the composites produced from this initial approach were unsatisfactory. Too much gold was employed in the synthesis, and the resultant materials were not grey. As such the synthesis method was altered, and the results of these altered syntheses are outlined below.

\subsubsection{Altered Syntheses}

In an attempt to lower the amount of gold used in the seed mediated approach, whilst producing a grey coloured composite, the synthesis method was modified so that the concentration of $\mathrm{Au}^{3+}$ remained constant, whilst the concentration of $\mathrm{NH}_{2} \mathrm{OH}$ varied. Gold concentrations ranging from $2.50 \times 10^{-4}$ to $1.35 \times 10^{-3} \mathrm{M}$ were employed, and the concentration ratio of $\left[\mathrm{Au}^{3+}\right]:\left[\mathrm{NH}_{2} \mathrm{OH}\right]$ was varied between $1: 1$ and 1:128. Additionally, numerous seeds were employed. 


\subsubsection{Physical Characterisation and Morphology}

Depending on the seed, gold concentration and ratio of $\left[\mathrm{Au}^{3+}\right]:\left[\mathrm{NH}_{2} \mathrm{OH}\right]$ the gold nanoparticle-merino wool composites prepared via this altered approach ranged in colour from purple to light grey with a tinge of pink, steely grey and purple/grey (Figure 8.8 to Figure 8.11). Seeds 2, 5, 8-10 were the most successful, producing grey coloured composites. The composites produced from seeds 3, 4, 6 and 7 appeared more purple in colour, regardless of the gold concentration or ratio of $\left[\mathrm{Au}^{3+}\right]:\left[\mathrm{NH}_{2} \mathrm{OH}\right]$ employed.

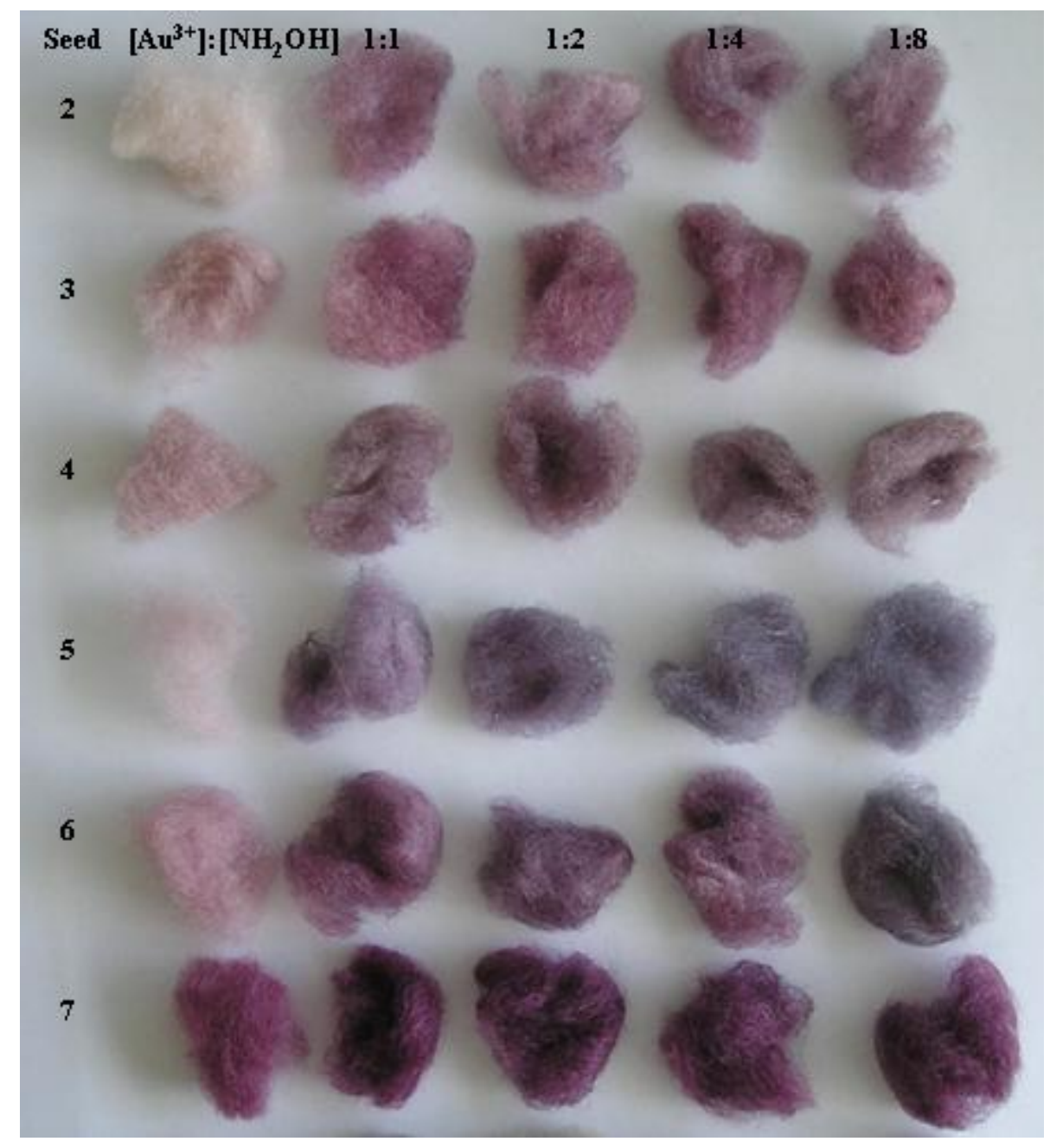

Figure 8.8: Gold nanoparticle-merino wool composites prepared with a $2.5 \times 10^{-4} \mathrm{M}$ gold solution (12.3 $\mu \mathrm{L} 4 \mathrm{wt} \% \mathrm{Au}^{3+}$ to $10 \mathrm{ml}$ ) and corresponding seeds. 


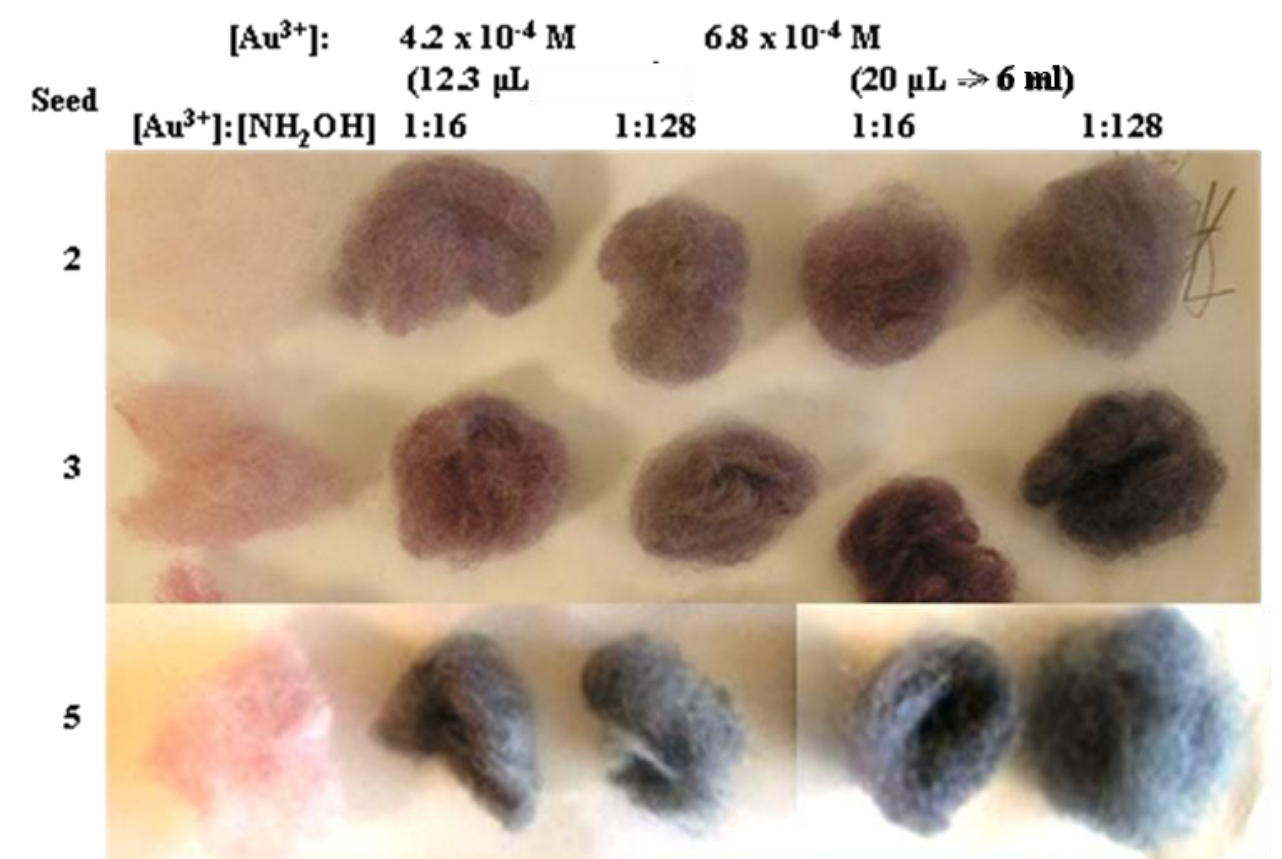

6

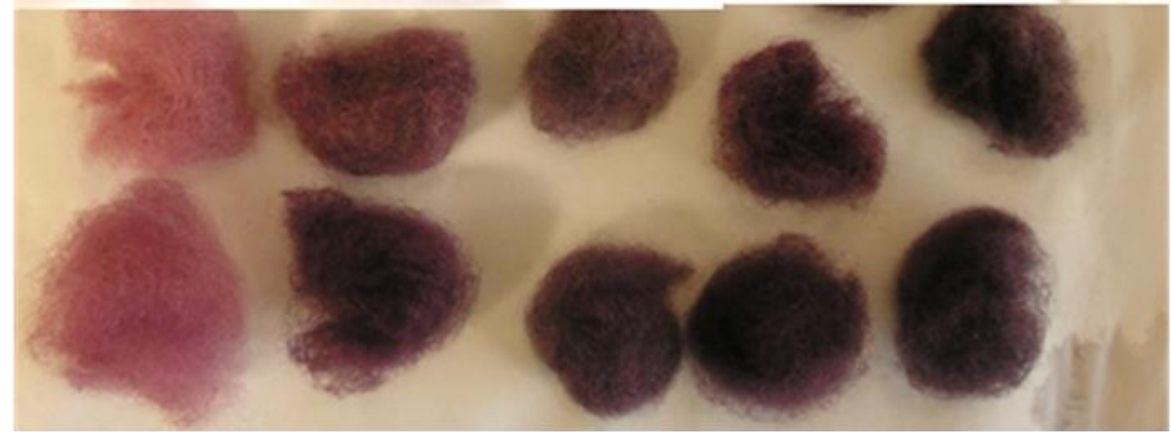

Figure 8.9: Gold nanoparticle-merino wool composites prepared with a $4.2 \times 10^{-4}$ or $6.8 \times 10^{-4} \mathrm{M}$ gold solution (12.3 or $20 \mu \mathrm{L} 4 \mathrm{wt} \% \mathrm{Au}^{3+}$ to $6 \mathrm{ml}$ ) and corresponding seeds.

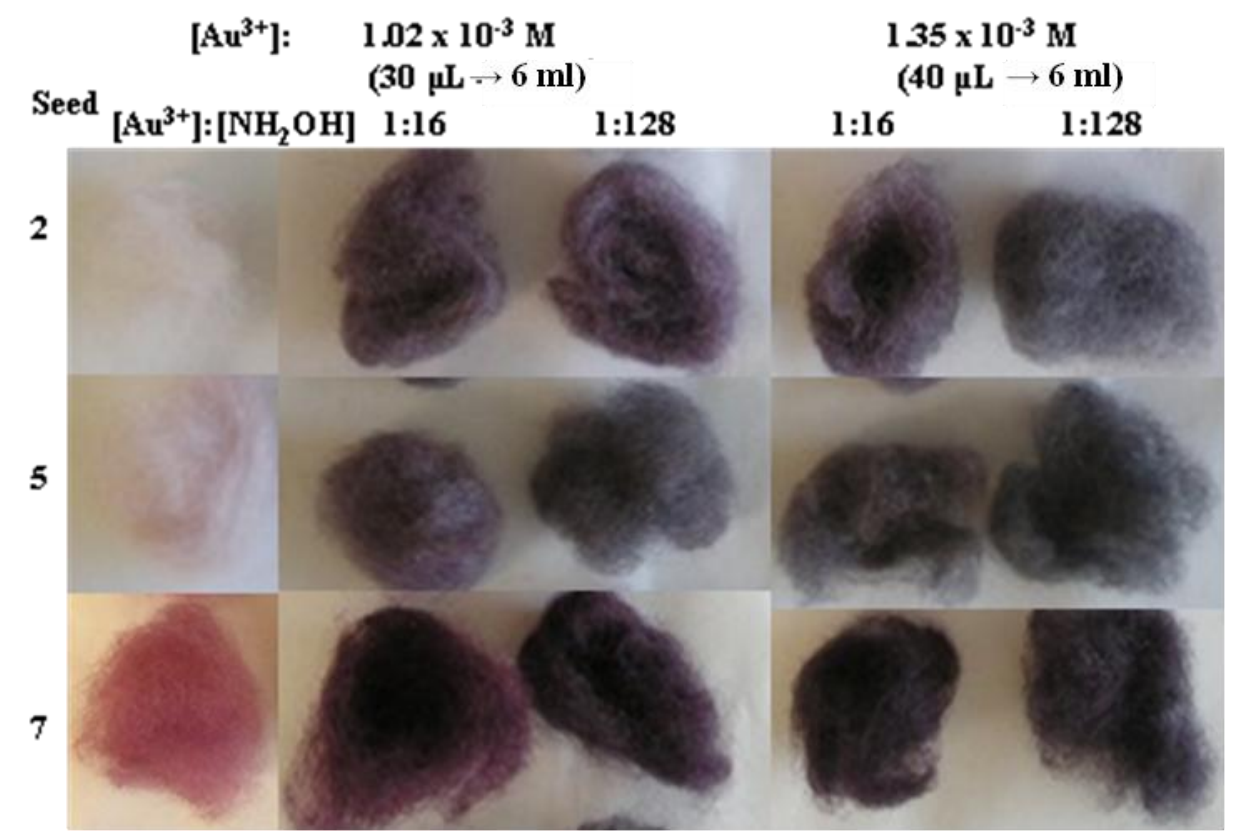

Figure 8.10: Gold nanoparticle-merino wool composites prepared with a $1.02 \times 10^{-3}$ or $1.35 \times 10^{-3} \mathrm{M}$ gold solution (30 or $40 \mu \mathrm{L} 4 \mathrm{wt} \% \mathrm{Au}^{3+}$ to $6 \mathrm{ml}$ ) and corresponding seeds. 


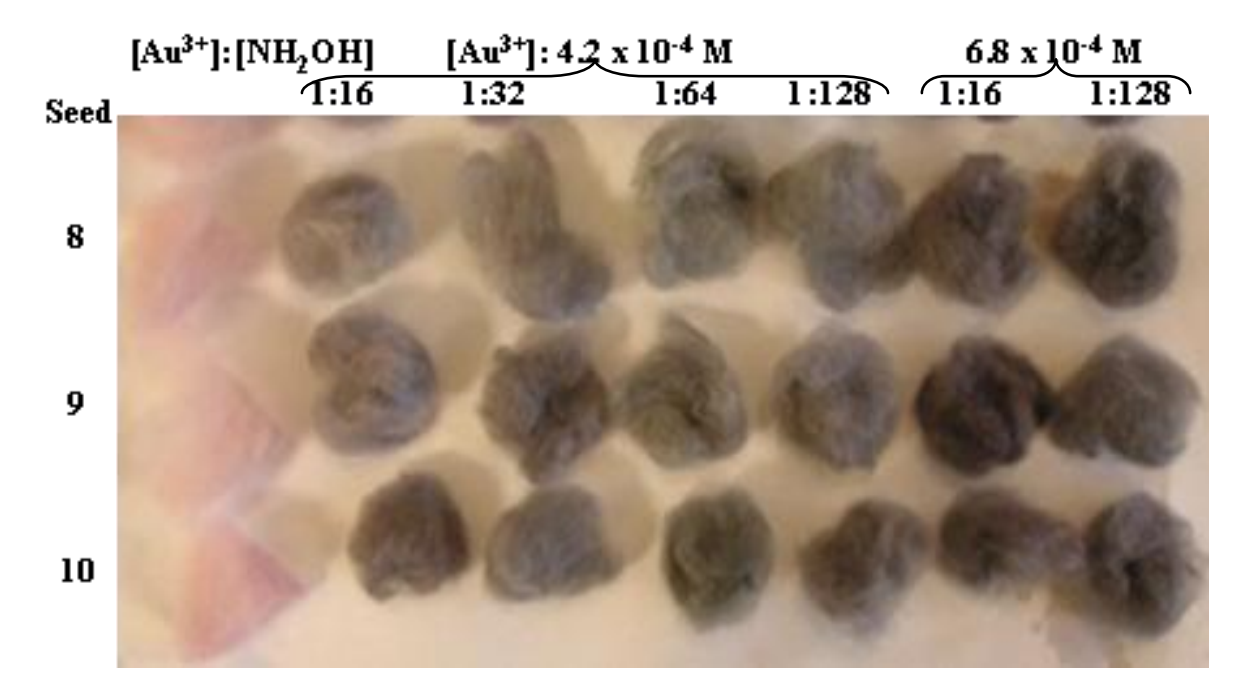

Figure 8.11: Gold nanoparticle-merino wool composites prepared with a $4.2 \times 10^{-4}$ or $6.8 \times 10^{-4} \mathrm{M}$ gold solution (12.3 or $20 \mu \mathrm{L} 4 \mathrm{wt} \% \mathrm{Au}^{3+}$ to $6 \mathrm{ml}$ ) and corresponding seeds.

SEM and TEM analysis (Figure 8.12 and Figure 8.13 respectively) suggested nanoparticle growth occurred in areas where nanoparticles resided in the seed materials, notably along the cuticle edges. Figure 8.12 offers increasing magnification SEM micrographs of a gold nanoparticle-merino wool composite prepared from seed 5, with an initial gold concentration of $2.50 \times 10^{-4} \mathrm{M}$ and a $\left[\mathrm{Au}^{3+}\right]:\left[\mathrm{NH}_{2} \mathrm{OH}\right]$ ratio of $1: 1$, and also the corresponding micrographs of seed 5. At low magnifications a discernable morphological difference is not apparent between the composite and seed, however increasing magnifications reveal the presence of a slightly greater proportion of nanoparticles located along the cuticle edges in the composite. TEM confirms these nanoparticles to be largely spherical in morphology, approximately 30 $\mathrm{nm}$ in diameter (Figure 8.13).

Increasing the ratio of $\left[\mathrm{Au}^{3+}\right]:\left[\mathrm{NH}_{2} \mathrm{OH}\right]$ to $1: 8$ saw an even greater amount agglomerates at the cuticle edges (Figure 8.14). However a more pronounced morphological difference was seen in the composites when the initial gold concentration was increased. Figure 8.15 offers increasing magnification SEM micrographs of composites prepared from seed 5, a $\left[\mathrm{Au}^{3+}\right]:\left[\mathrm{NH}_{2} \mathrm{OH}\right]$ ratio of $1: 16$, and gold concentrations ranging from $2.50 \times 10^{-4} \mathrm{M}$ to $6.80 \mathrm{x}$ $10^{-4} \mathrm{M}$. It is apparent that when higher gold concentrations are employed, the resultant materials posses a much greater proportion of agglomerated nanoparticles, located along the edges of the merino wool cuticles, with TEM showing these agglomerated particles to be 

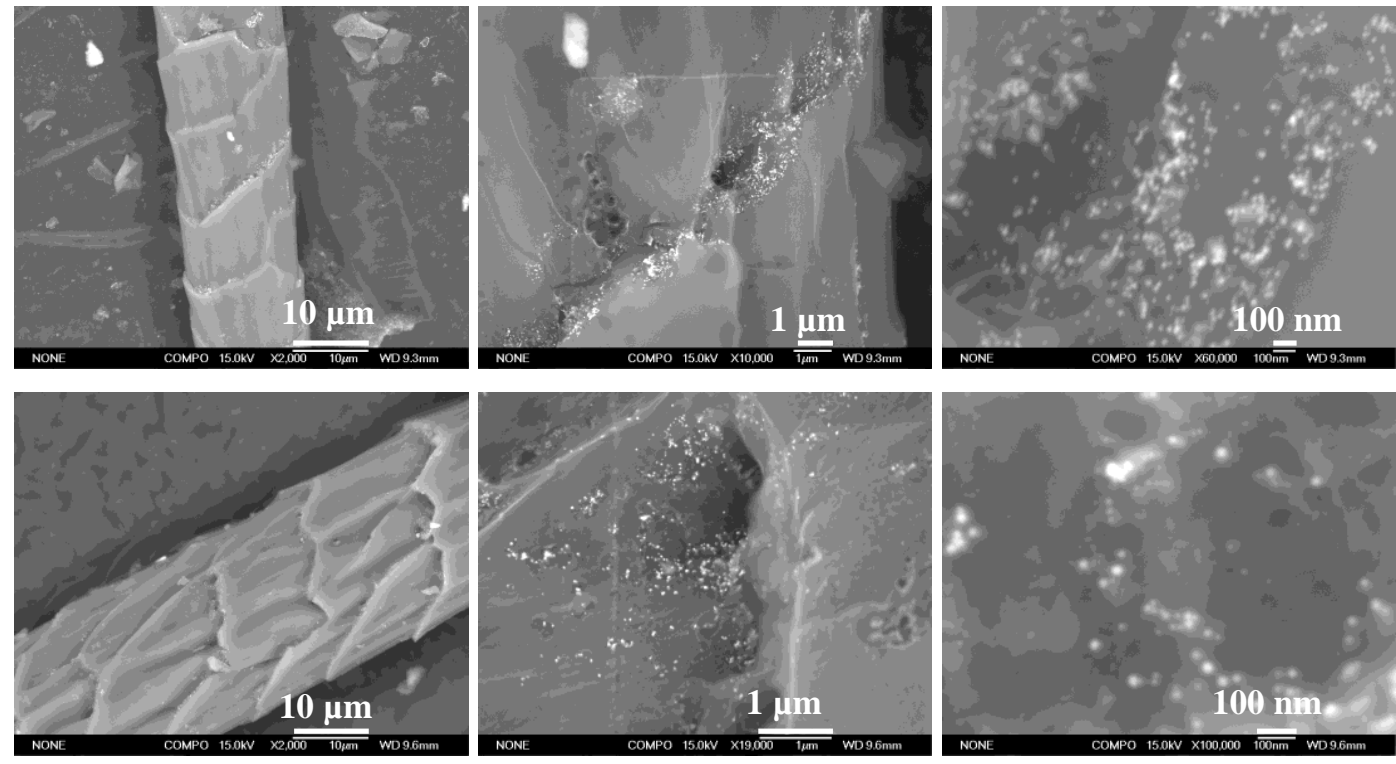

Figure 8.12:Top: increasing magnification SEM micrographs of a gold nanoparticle-merino wool composite prepared via the seed mediated approach, utilising seed 5 , a gold concentration of $2.5 \times 10^{-4} \mathrm{M}$ and a 1:1 ratio of $\left[\mathrm{Au}^{3+}\right]$ : $\left[\mathrm{NH}_{2} \mathrm{OH}\right]$. Bottom: Increasing magnification SEM micrographs of seed 5.

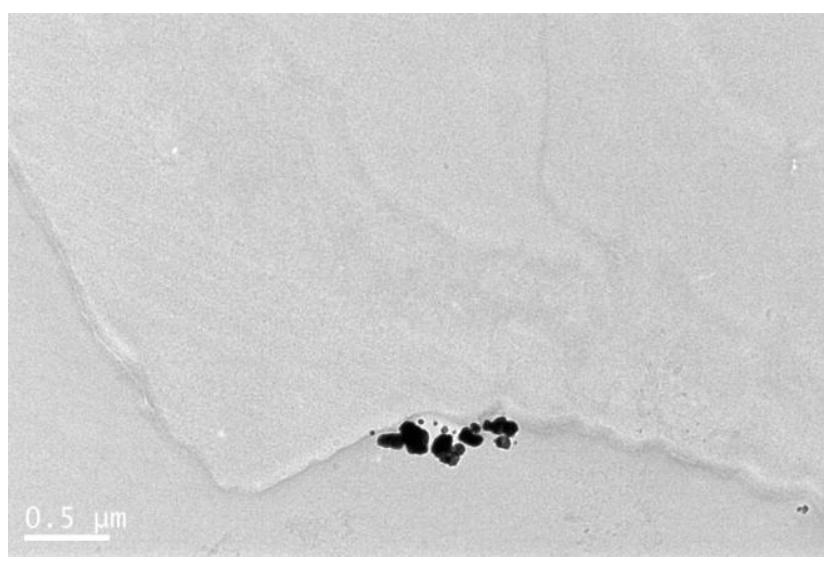

Figure 8.13: TEM micrograph of a gold nanoparticle-merino wool composite prepared via the seed mediated approach. Shows gold nanoparticles agglomerated at a cuticle edge.

irregularly shaped, ranging in size from approximately 50-100 nm in diameter (Figure 8.16 top). However when the gold concentration was increased further to $1.02 \times 10^{-3} \mathrm{M}$ and 1.35 x $10^{-3} \mathrm{M}$, the size of the agglomerated particles increased, with large, approximately $100 \mathrm{~nm}$ in diameter agglomerates present (Figure 8.16 middle and bottom). Additionally, new smaller gold nanoparticles (approximately 10-20 nm in diameter) appeared on the merino wool surfaces (Figure 8.16 middle and bottom and Figure 8.17). It is likely that this occurred as at these gold concentrations the ratio of gold seeds (nanoparticles) to $\mathrm{Au}^{3+}$ is very high, 
with both growth on the preformed seeds and new nucleation events more likely to occur compared to systems with low gold concentrations (discussed in further depth in section 8.1.3.4 below). Similar results have been reported by Jana and co-workers [249] during the seed mediated growth of gold nanoparticles.
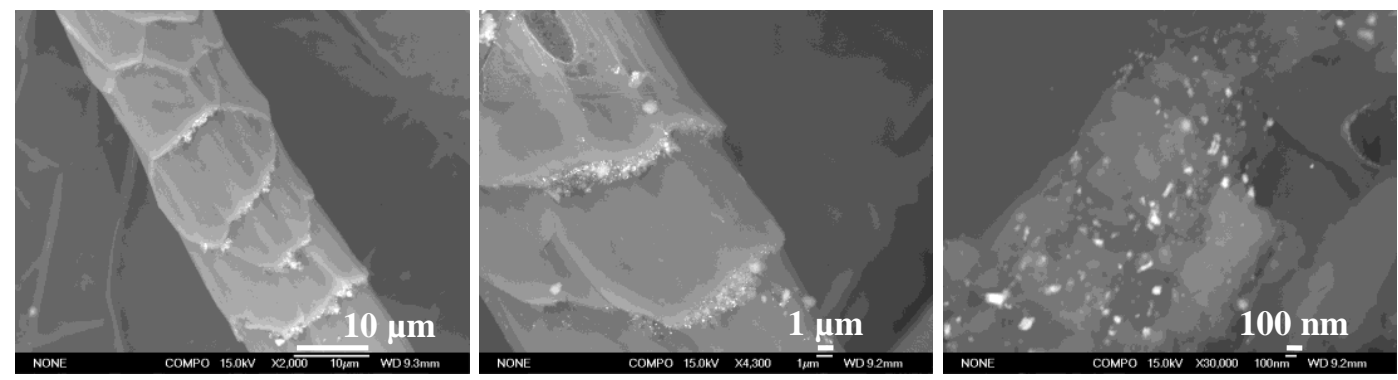

Figure 8.14: Increasing magnification SEM micrographs of a gold nanoparticle-merino wool composite prepared via the seed mediated approach, utilising seed 5 , a gold concentration of $2.5 \times 10^{-4} \mathrm{M}$ and a 1:8 ratio of $\left[\mathrm{Au}^{3+}\right]:\left[\mathrm{NH}_{2} \mathrm{OH}\right]$.
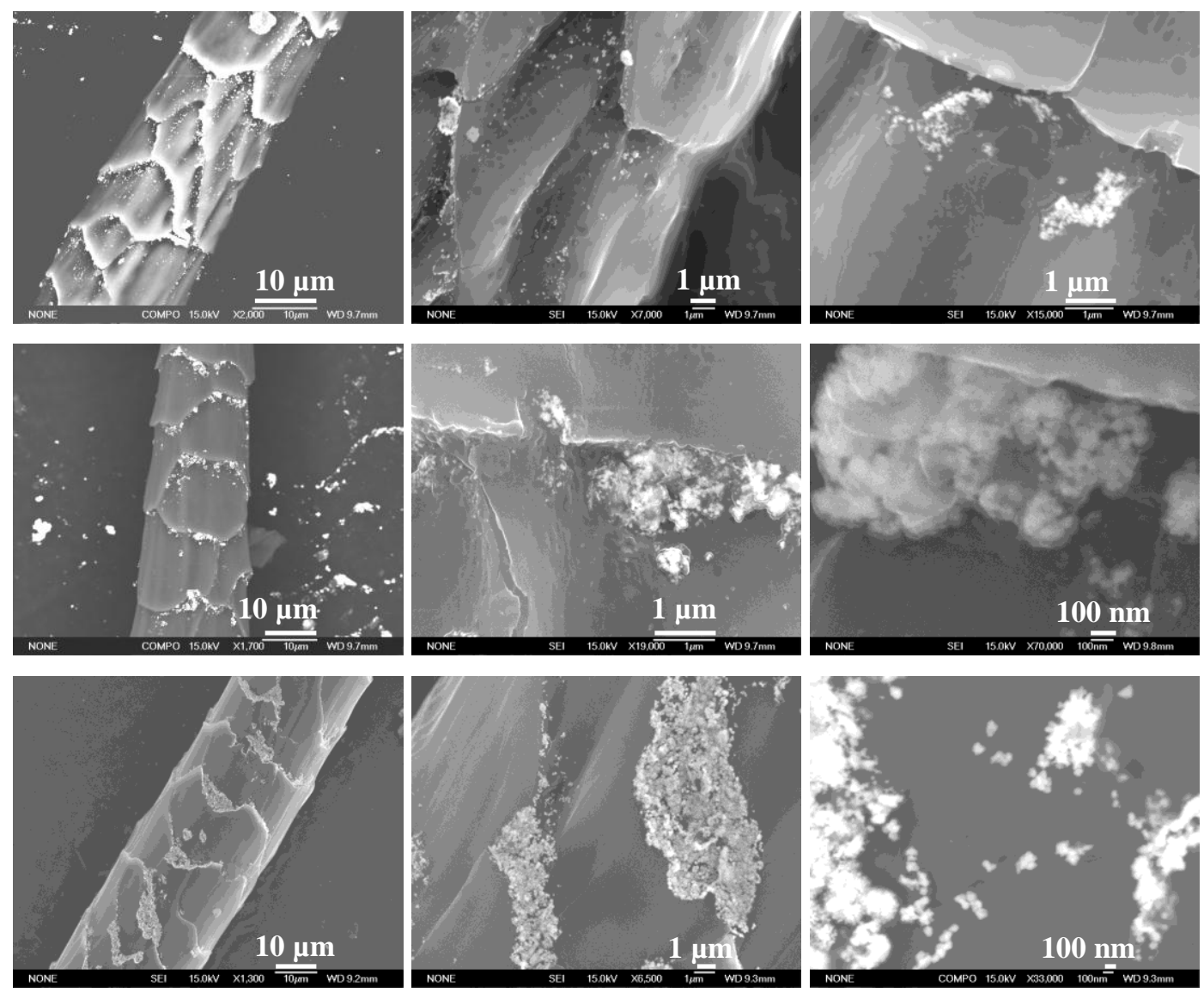

Figure 8.15: Increasing magnification SEM micrographs of gold nanoparticle-merino wool composites prepared via the seed mediated approach, utilising seed 5 , a $\left[\mathrm{Au}^{3+}\right]:\left[\mathrm{NH}_{2} \mathrm{OH}\right]$ concentration ratio of 1:16 and a gold concentration of, top: $2.5 \times 10^{-4} \mathrm{M}$, middle: $4.2 \times 10^{-4} \mathrm{M}$ and bottom: $6.8 \times 10^{-4} \mathrm{M}$. 

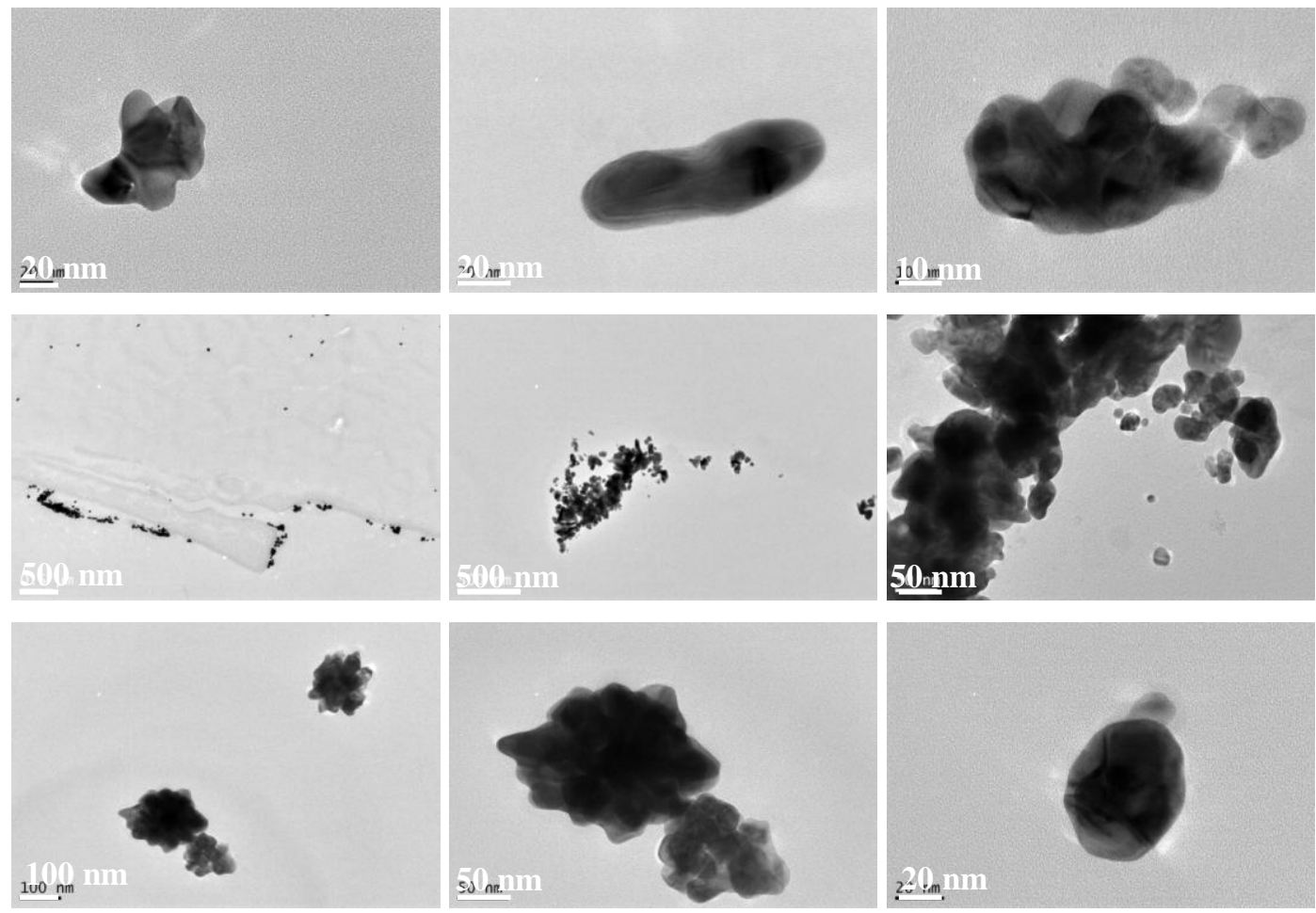

Figure 8.16: TEM micrographs of gold nanoparticle-merino wool composites prepared via the seed mediated approach, utilising seed 5 , a $\left[\mathrm{Au}^{3+}\right]:\left[\mathrm{NH}_{2} \mathrm{OH}\right]$ concentration ratio of $1: 16$ and a gold concentration of top: $4.2 \times 10^{-4} \mathrm{M}$ and middle and bottom: $1.35 \times 10^{-3} \mathrm{M}$.
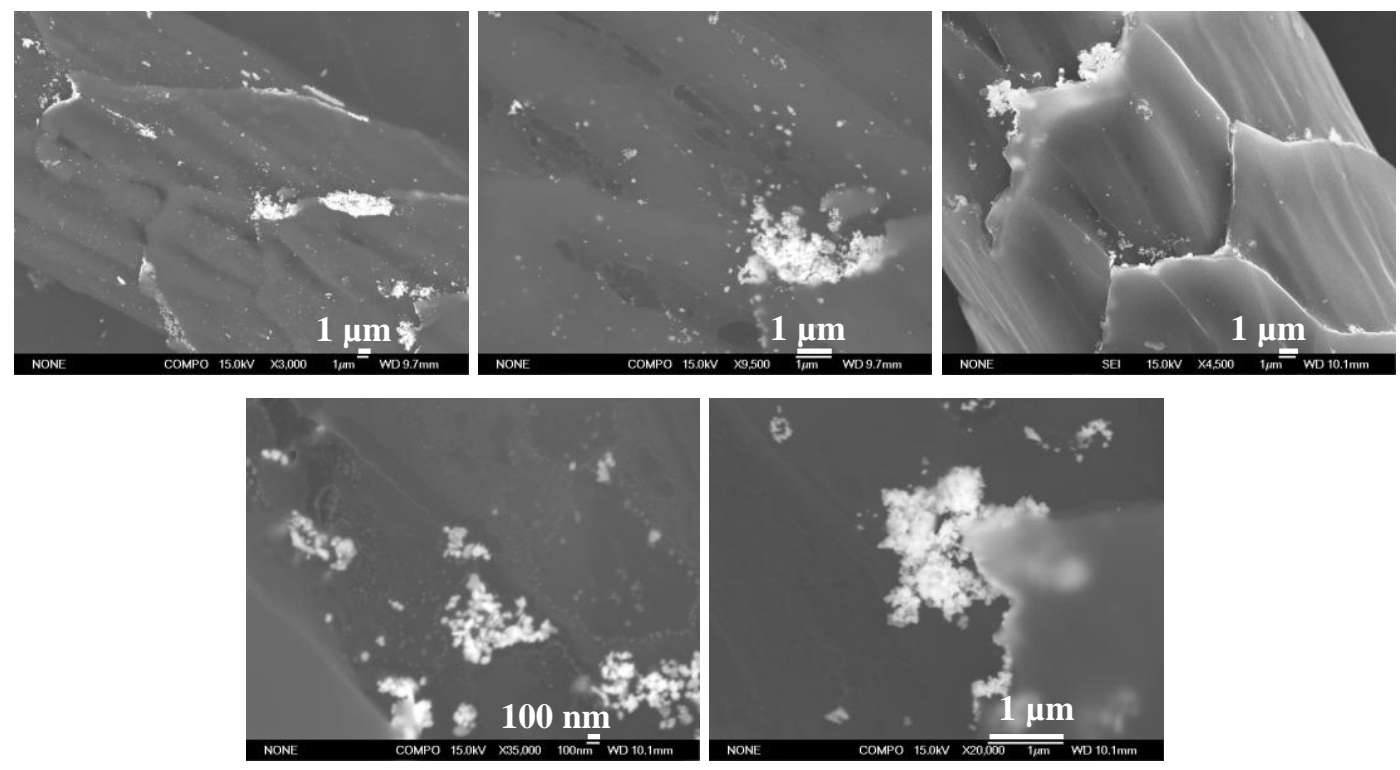

Figure 8.17: Increasing magnification SEM micrographs of gold nanoparticle-merino wool composites prepared via the seed mediated approach, utilising seed 5 , a $\left[\mathrm{Au}^{3+}\right]:\left[\mathrm{NH}_{2} \mathrm{OH}\right]$ concentration ratio of 1:16 and a gold concentration of, top: $1.02 \times 10^{-3} \mathrm{M}$ and bottom: $1.35 \times 10^{-3} \mathrm{M}$. 
As mentioned, employing different seed sources also influenced the colour of the resultant composite, with materials incorporating seeds containing both nanoparticulate $\mathrm{Au}^{0}$ and unreduced $\mathrm{Au}^{3+}$ (seeds 2, 5, 8-10) producing grey coloured composites whilst seeds in which a greater proportion of $\mathrm{Au}^{3+}$ had been reduced to $\mathrm{Au}^{0}$, (with the additional $\mathrm{Au}^{0}$ forming predominantly as nanoparticles in the fibre centres), generating materials that were more purple/black in colour. Comparing the SEM micrographs of the grey composites prepared from seed 5, to those of the purple/black materials prepared from seed 7, show those made from seed 5 to have slightly greater amounts of agglomerated nanoparticles on the fibre surface. This is likely due to the fact that there was more $\mathrm{Au}^{3+}$ present in seed 5 compared to seed 7, which could also be reduced by $\mathrm{NH}_{2} \mathrm{OH}$. Additionally, TEM analysis of materials prepared from seed 5 (Figure 8.16) revealed the small nanoparticles residing in the centre of the fibres to remain unchanged in the composites, they did not increase in size, suggesting the gold catalysed reduction of $\mathrm{Au}^{3+}$ took place predominantly on the nanoparticles bound to the fibre surfaces.
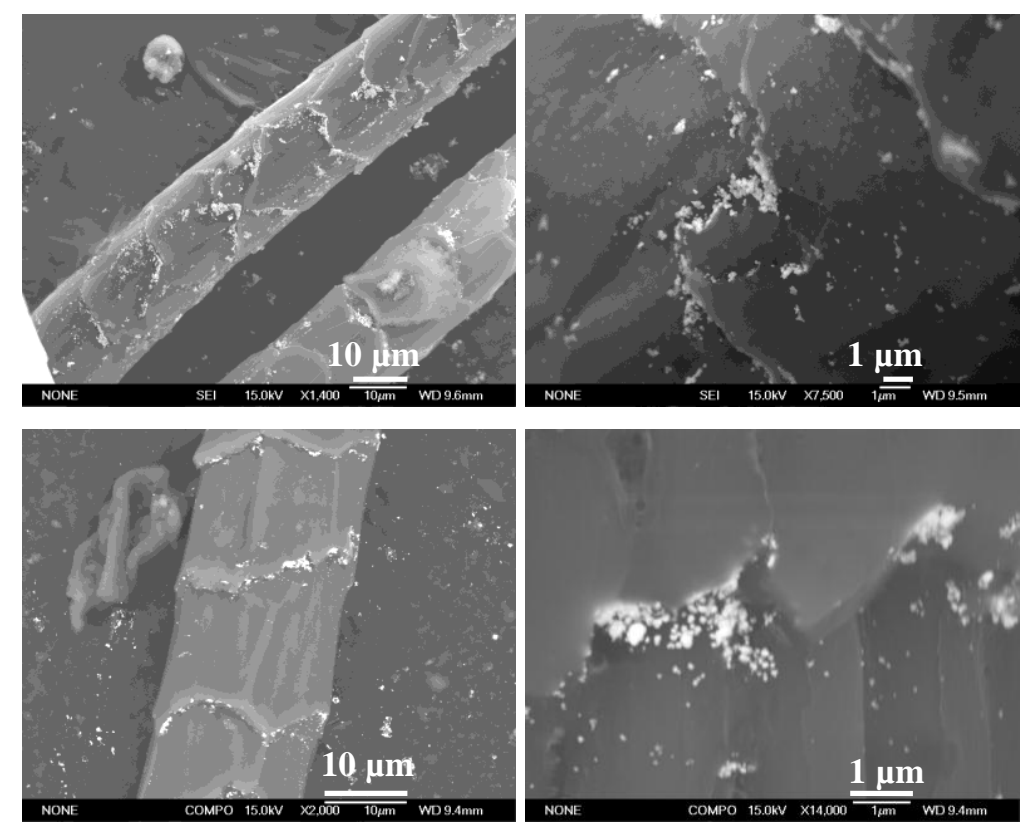

Figure 8.17: Increasing magnification SEM micrographs of gold nanoparticle-merino wool composites prepared from seed 5 (top) and seed 7 (bottom), employing a gold concentration of $2.50 \times 10^{-4} \mathrm{M}$, and a $\left[\mathrm{Au}^{3+}\right]:\left[\mathrm{NH}_{2} \mathrm{OH}\right]$ concentration ratio of $1: 16$. 


\subsubsection{Colour}

The colour of the composites produced via the seed mediated approach were characterised through UV/Vis spectroscopy and via analysis of their CIE L*, $\mathrm{a}^{*}, \mathrm{~b}^{*}, 457 \mathrm{~nm}$ brightness and $580 \mathrm{~nm}$ brightness values. A full set of CIE values are provided in Appendix V. In general, an increase in average size, and the subsequent formation and growth of gold nanoparticle agglomerates on the surface of merino wool fibres corresponded to a change in composite colour from pink to grey or purple to purple/black. This suggests that the change in reflected colour was due to a corresponding increase in particle size and also the extent of agglomeration.

As outlined above, when utilising seeds 2, 5, 8-10, where the nanoparticles are located predominantly on the fibre surfaces and there is unreduced $\mathrm{Au}^{3+}$ present in the seeds, increasing the ratio of $\left[\mathrm{Au}^{3+}\right]:\left[\mathrm{NH}_{2} \mathrm{OH}\right]$ from $1: 1$ to $1: 128$ resulted in a slight greying of the resultant composites. This grey was more apparent in composites incorporating seeds prepared with a greater concentration of gold $(10>9>8>5>2)$. The seeds prepared with greater concentrations of gold had more nanoparticles on the merino wool surface, and thus more sites at which the surface catalysed reduction of $\mathrm{Au}^{3+}$ to $\mathrm{Au}^{0}$ could occur. They also had an increased amount of unreduced $\mathrm{Au}^{3+}$, which could be reduced by $\mathrm{NH}_{2} \mathrm{OH}$, producing more $\mathrm{Au}^{0}$. Alternatively, the composites produced from seeds 3, 4, 6 and 7 appeared more purple than grey in colour. Increasing the ratio of $\left[\mathrm{Au}^{3+}\right]:\left[\mathrm{NH}_{2} \mathrm{OH}\right]$ deepened the purple colour, producing purple/black coloured materials. It is likely that the composites produced from these seeds appeared more purple/black than grey as the reduction of additional $\mathrm{Au}^{3+}$ by $\mathrm{NH}_{2} \mathrm{OH}$ occurred primarily on the gold nanoparticles bound to the surface of merino wool fibres, rather than those in the centre (as shown by SEM and TEM analysis). Therefore the small nanoparticles in the fibre centres in seeds 3, 4, 6 and 7 would not increase in size during the formation of the composites, and the materials produced from these seeds would possess both larger nanoparticles on the fibre surface and smaller nanoparticles (approximately $5 \mathrm{~nm}$ in diameter) in the centre, with both exhibiting different surface plasmon resonances. Hence the grey colour resulting from agglomerates formed on the fibre surface would be combined with the purple of those in the centre. Additionally, in these seeds $\left(3,4,6\right.$ and 7) a greater percentage of $\mathrm{Au}^{3+}$ had been reduced to $\mathrm{Au}^{0}$ during the seed 
production, as such there would be less $\mathrm{Au}^{3+}$ present that could be reduced by $\mathrm{NH}_{2} \mathrm{OH}$ and be incorporated in the growth of larger gold nanoparticles or agglomerates.

This change in colour to grey or purple/black upon increasing the ratio of $\left[\mathrm{Au}^{3+}\right]:\left[\mathrm{NH}_{2} \mathrm{OH}\right]$ was reflected in the CIE L*, a*, b*, $457 \mathrm{~nm}$ brightness and $580 \mathrm{~nm}$ brightness values of the resultant composites (Table 8.3). The values for $\mathrm{L}^{*}$, which measure a materials degree of whiteness (with $\mathrm{L}^{*}=100$ being white, and $\mathrm{L}^{*}=0$ being black), of a composite prepared from seed 2, with a $\left[\mathrm{Au}^{3+}\right]:\left[\mathrm{NH}_{2} \mathrm{OH}\right]$ ratio of 1:1 to $1: 128$ decreased slightly from 44 to 42 . The values of the composites prepared from seed 5 , which had a greater concentration of gold and hence a larger number of nanoparticles on the seed were lower still, notably 43 and 39 ([ $\left.\mathrm{Au}^{3+}\right]:\left[\mathrm{NH}_{2} \mathrm{OH}\right]$ ratio of $1: 1$ and $1: 128$ respectively), confirming the more pronounced greyness of these materials. The $\mathrm{L}^{*}$ values of all composites were substantially lower than those of their corresponding seeds.

There was a small amount of variation in the $a^{*}$ values of the composites upon increasing the ratio of $\left[\mathrm{Au}^{3+}\right]:\left[\mathrm{NH}_{2} \mathrm{OH}\right]$, however there was a general minor increase in these values, reflecting the slight red tinge observed in some samples. This was more apparent in composites produced from seed 2 rather than seed 5 or 7 , as there were not as many agglomerates in such composites, hence they did not appear as grey in colour. Increasing the ratio of $\left[\mathrm{Au}^{3+}\right]:\left[\mathrm{NH}_{2} \mathrm{OH}\right]$ used in the production of composites incorporating seeds $3,4,6$ and 7 also resulted in increased $\mathrm{a}^{*}$ values, and as mentioned, these materials were more purple/black than grey and as such their $\mathrm{a}^{*}$ values were higher than those from composites incorporating seeds 2,5 or 7 .

Increasing the ratio of $\left[\mathrm{Au}^{3+}\right]:\left[\mathrm{NH}_{2} \mathrm{OH}\right]$ decreased the value of $b^{*}$ (positive $b^{*}=$ yellow, negative blue) of composites produced from all seeds. The $b^{*}$ values were lower when seeds 2 or 5 were employed as these materials appeared more blue grey than those produced from seeds 3, 4, 6 or 7 . Finally the 457 and $580 \mathrm{~nm}$ brightness values of all composites decreased, mirroring their darkening upon increasing ratios of $\left[\mathrm{Au}^{3+}\right]:\left[\mathrm{NH}_{2} \mathrm{OH}\right]$. 
Table 8.3: CIE $L^{*}, a^{*}, b^{*}, 457 \mathrm{~nm}$ brightness and $580 \mathrm{~nm}$ brightness values for composites prepared using a gold solution concentration of $2.50 \times 10^{-4} \mathrm{moldm}^{-3}$. Shows the effect of increasing the ratio of $\left[\mathrm{Au}^{3+}\right]$ : $\left[\mathrm{NH}_{2} \mathrm{OH}\right]$ (refer toFigure 8.8-Figure 8.11 for pictures of these materials).

\begin{tabular}{|c|c|c|c|c|c|c|}
\hline Seed & {$\left[\mathrm{Au}^{3+}\right]:\left[\mathrm{NH}_{2} \mathrm{OH}\right]$} & $\mathbf{L}^{*}$ & $a^{*}$ & $\mathbf{b}^{\star}$ & $\begin{array}{c}457 \mathrm{~nm} \\
\text { brightness }\end{array}$ & $\begin{array}{c}580 \mathrm{~nm} \\
\text { brightness }\end{array}$ \\
\hline 2 & - & 56.2 & 3.7 & 3.9 & 22 & 25 \\
\hline \multirow[t]{2}{*}{2} & $1: 1$ & 43.8 & 9.2 & 0.5 & 14 & 14 \\
\hline & $1: 128$ & 41.6 & 7.7 & -1.8 & 12 & 13 \\
\hline \multirow[t]{3}{*}{3} & - & 53.6 & 7.2 & 3.0 & 20 & 22 \\
\hline & $1: 1$ & 46.6 & 13.9 & 0.9 & 15 & 17 \\
\hline & $1: 8$ & 40.4 & 11 & -0.6 & 12 & 12 \\
\hline \multirow[t]{3}{*}{4} & - & 43.7 & 7.4 & 1.9 & 13 & 14 \\
\hline & $1: 1$ & 44.0 & 6.9 & 0.8 & 9 & 9 \\
\hline & $1: 8$ & 43.1 & 5.9 & 1.5 & 13 & 14 \\
\hline \multirow[t]{3}{*}{5} & - & 58.2 & 6.2 & 4.5 & 24 & 27 \\
\hline & $1: 1$ & 42.8 & 5.6 & -1.8 & 14 & 13 \\
\hline & $1: 128$ & 38.9 & 1.4 & -1.3 & 13 & 13 \\
\hline \multirow[t]{3}{*}{6} & - & 47.3 & 6.2 & 2.9 & 15 & 17 \\
\hline & $1: 1$ & 40.2 & 10.4 & 0.8 & 12 & 12 \\
\hline & $1: 8$ & 35.8 & 3.9 & -0.2 & 9 & 9 \\
\hline \multirow[t]{3}{*}{7} & - & 31.3 & 13.7 & -0.7 & 7 & 7 \\
\hline & $1: 1$ & 30.5 & 15.3 & -1.7 & 7 & 6 \\
\hline & $1: 8$ & 26.1 & 12.9 & -1.6 & 5 & 5 \\
\hline
\end{tabular}

Increasing the gold concentration had a more substantial effect on the colour development of the composites than did altering the ratio of $\left[\mathrm{Au}^{3+}\right]:\left[\mathrm{NH}_{2} \mathrm{OH}\right]$. Figure 8.20 offers a picture of composites prepared from seeds 2, 5 and 7, whilst Figure 8.19 shows those prepared from 
seeds 8-10. It is evident from these images that with a $\left[\mathrm{Au}^{3+}\right]:\left[\mathrm{NH}_{2} \mathrm{OH}\right]$ ratio of $1: 128$, increasing the gold concentration from $2.50 \times 10^{-4}$ to $6.8 \times 10^{-4} \mathrm{M}$ caused composites produced from seed 2, 5, 8-10 to become a deeper grey, (the materials with a greater amount of nanoparticles on the fibre surfaces more so, $10>9>8>7>5$ ), whilst those produced from seed 7 (in which nanoparticles were present both on the surface and in the centre of the fibres) became a deeper purple/black. Increasing the concentration further to $1.35 \times 10^{-3} \mathrm{M}$ saw the appearance of a slight purple tinge in materials prepared from seed 2 and 5 . The purple/black colour of those produced from seed 7 simply deepened. It is likely that the colour change to grey and then purple/grey observed from composites incorporating seeds 2 , 5, 8-10 arose primarily from an increased amount of agglomerates, and then due to the formation of smaller nanoparticles, giving rise to the slight purple hues. Smaller nanoparticles may have formed due to the gold concentration being closer to that of the critical nucleation of gold, with higher concentrations promoting increased collisions between particles, resulting in the formation of nuclei which could potentially act as gold seeds to catalyse the reduction of $\mathrm{Au}^{3+}$ to $\mathrm{Au}^{0}$ by $\mathrm{NH}_{2} \mathrm{OH}$. Additionally, numerous groups have reported the formation of a greater amount of smaller nanoparticles during the surface catalysed reduction of $\mathrm{Au}^{3+}$ by $\mathrm{NH}_{2} \mathrm{OH}$ when the ratio of $\mathrm{Au}^{3+}$ to seeds is increased (more $\mathrm{Au}^{3+}$ relative to seeds).[104, 114, 249, 250]

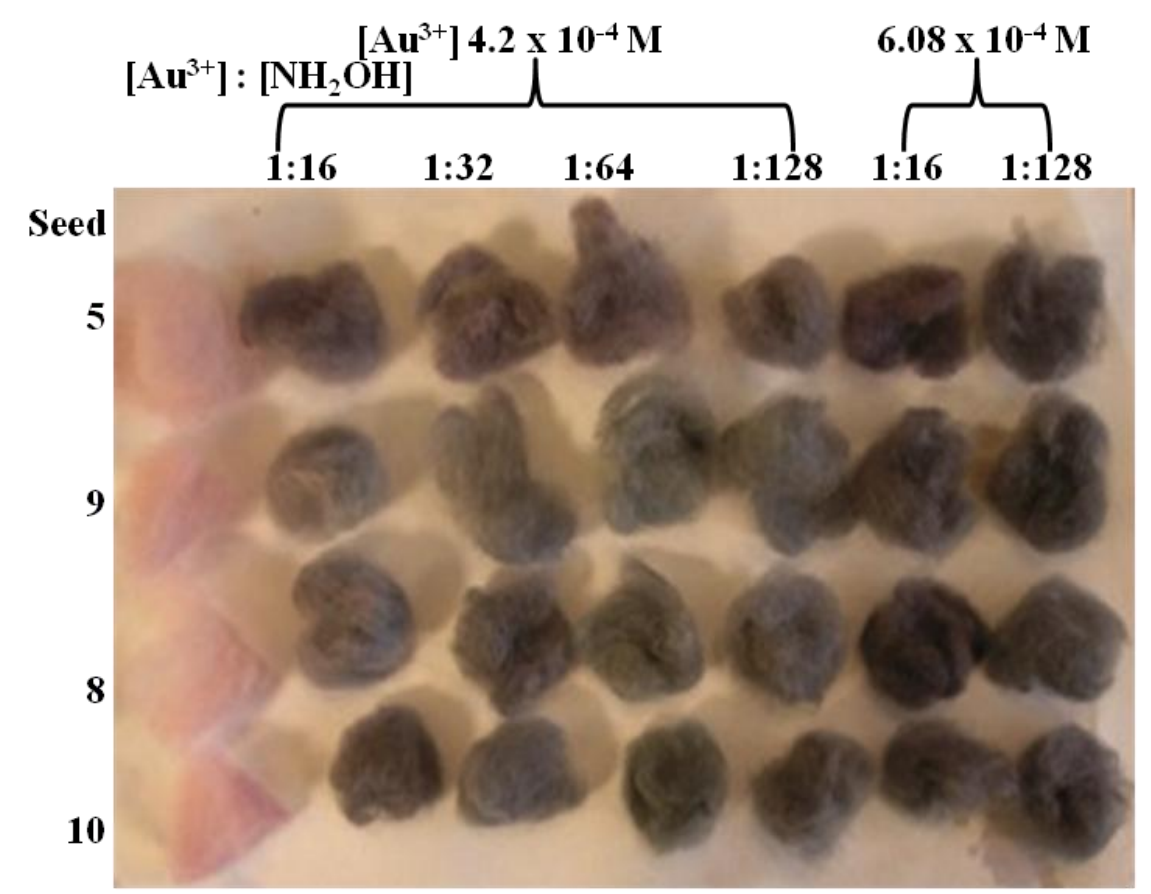

Figure 8.19: Gold nanoparticle-merino wool composites produced from seeds 8-10. A colour change upon increasing gold concentration is apparent. 


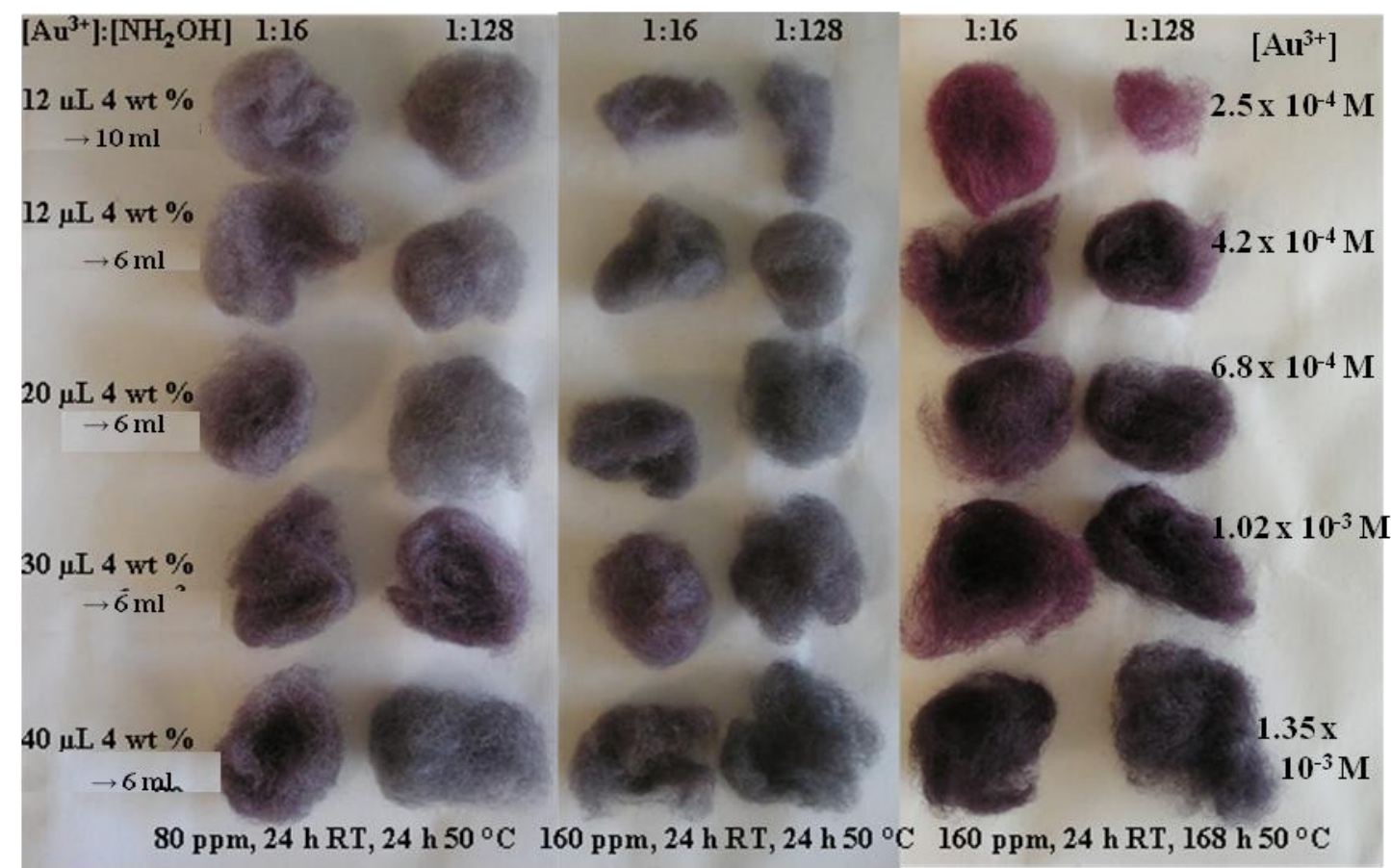

Seed 2

Seed 5

Seed 7

Figure 8.20: Gold nanoparticle-merino wool composites produced from seeds 2, 5 and 7. A colour change upon increasing gold concentration is apparent.

The colour change to a deeper grey observed in composites produced from seeds 2, 5, 8-10, and then grey with a tinge of purple in 2 and 5 upon increasing gold concentrations, and the deepening purple/black colour of those incorporating seed 7 was reflected in the CIE values of the materials (Table 8.4). In the production of all composites increasing the gold concentration resulted in a general decrease in $\mathrm{L}^{*}, 457 \mathrm{~nm}$ brightness and $580 \mathrm{~nm}$ brightness values confirming the visual darkening of the samples. The change to a deeper grey, and then grey/purple observed for seeds 2 and 5 was accompanied by a decrease, and subsequent increase in $\mathrm{a}^{*}$ values (with larger $\mathrm{a}^{*}$ values depicting a redder colour). The $\mathrm{a}^{*}$ values of the composites produced from seed 7 remained relatively constant. 
Table 8.4: CIE $L^{*}, a^{*}, b^{*} 457 \mathrm{~nm}$ brightness and $580 \mathrm{~nm}$ brightness values of composites prepared from seeds $2,5,7,8-10$, with a $\left[\mathrm{Au}^{3+}\right]:\left[\mathrm{NH}_{2} \mathrm{OH}\right]$ ratio of $1: 128$. Illustrates the effect of increasing gold concentrations. (Refer to Figure 8.19 and Figure 8.20 for pictures of these materials).

\begin{tabular}{|c|c|c|c|c|c|c|}
\hline Seed & $\begin{array}{c}\text { Gold } \\
\text { Concentration } \\
\left(\mathrm{mol} \mathrm{dm}^{-3}\right)\end{array}$ & $\mathbf{L}^{*}$ & $\mathbf{a}^{\star}$ & $\mathbf{b}^{*}$ & $\begin{array}{c}457 \mathrm{~nm} \\
\text { Brightness }\end{array}$ & $\begin{array}{c}580 \mathrm{~nm} \\
\text { Brightness }\end{array}$ \\
\hline \multirow[t]{5}{*}{2} & $2.5 \times 10^{-4}$ & 41.6 & 5.8 & -1.8 & 12 & 13 \\
\hline & $4.2 \times 10^{-4}$ & 45.4 & 3.5 & -1.3 & 15 & 15 \\
\hline & $6.8 \times 10^{-4}$ & 43.8 & 2.6 & -1.9 & 15 & 14 \\
\hline & $1.02 \times 10^{-3}$ & 34.9 & 6.2 & -1.8 & 9 & 8 \\
\hline & $1.35 \times 10^{-3}$ & 31.3 & 7.7 & -0.4 & 7 & 7 \\
\hline \multirow[t]{5}{*}{5} & $2.5 \times 10^{-4}$ & 38.9 & 1.4 & -1.3 & 13 & 13 \\
\hline & $4.2 \times 10^{-4}$ & 40.8 & 1.2 & -0.3 & 12 & 12 \\
\hline & $6.8 \times 10^{-4}$ & 31.7 & 4.8 & -1.1 & 7 & 7 \\
\hline & $1.02 \times 10^{-3}$ & 34.5 & 6.4 & 1.1 & 8 & 9 \\
\hline & $1.35 \times 10^{-3}$ & 32.5 & 5.5 & 0.3 & 7 & 8 \\
\hline \multirow[t]{5}{*}{7} & $2.5 \times 10^{-4}$ & 26.7 & 5.2 & -2.5 & 5 & 5 \\
\hline & $4.2 \times 10^{-4}$ & 24.4 & 5.9 & -2.6 & 5 & 4 \\
\hline & $6.8 \times 10^{-4}$ & 24.5 & 5.6 & -3.0 & 5 & 4 \\
\hline & $1.02 \times 10^{-3}$ & 24.1 & 7.6 & -3.0 . & 5 & 4 \\
\hline & $1.35 \times 10^{-3}$ & 22.0 & 6.6 & -2.0 & 4 & 4 \\
\hline \multirow[t]{2}{*}{8} & $4.2 \times 10^{-4}$ & 47.1 & 2.3 & -2.9 & 18 & 16 \\
\hline & $6.8 \times 10^{-4}$ & 39.7 & 2.5 & -0.4 & 11 & 11 \\
\hline \multirow[t]{2}{*}{9} & $4.2 \times 10^{-4}$ & 42.8 & 3.5 & -3.0 & 14 & 13 \\
\hline & $6.8 \times 10^{-4}$ & 41.1 & 1.4 & -1.9 & 13 & 12 \\
\hline \multirow[t]{2}{*}{10} & $4.2 \times 10^{-4}$ & 46.7 & 1.8 & -1.1 & 16 & 16 \\
\hline & $6.8 \times 10^{-4}$ & 36.8 & 2.6 & 0.4 & 13 & 13 \\
\hline
\end{tabular}


The colour change in the composites and the relationship between the size and shape of the nanoparticles bound to the fibres was also shown in SEM and TEM analysis and UV/Vis spectroscopy. With pale grey/pink coloured materials containing a small amount of largely isolated nanoparticales, approximately $30 \mathrm{~nm}$ in diameter, and greyer materials containing an increased amount of larger (approximately $50 \mathrm{~nm}$ in diameter) nanoparticles, agglomerated together. Materials produced with gold concentrations greater than $1.02 \times 10^{-3} \mathrm{M}$ possessed both agglomerated and isolated particles (Figure 8.21).
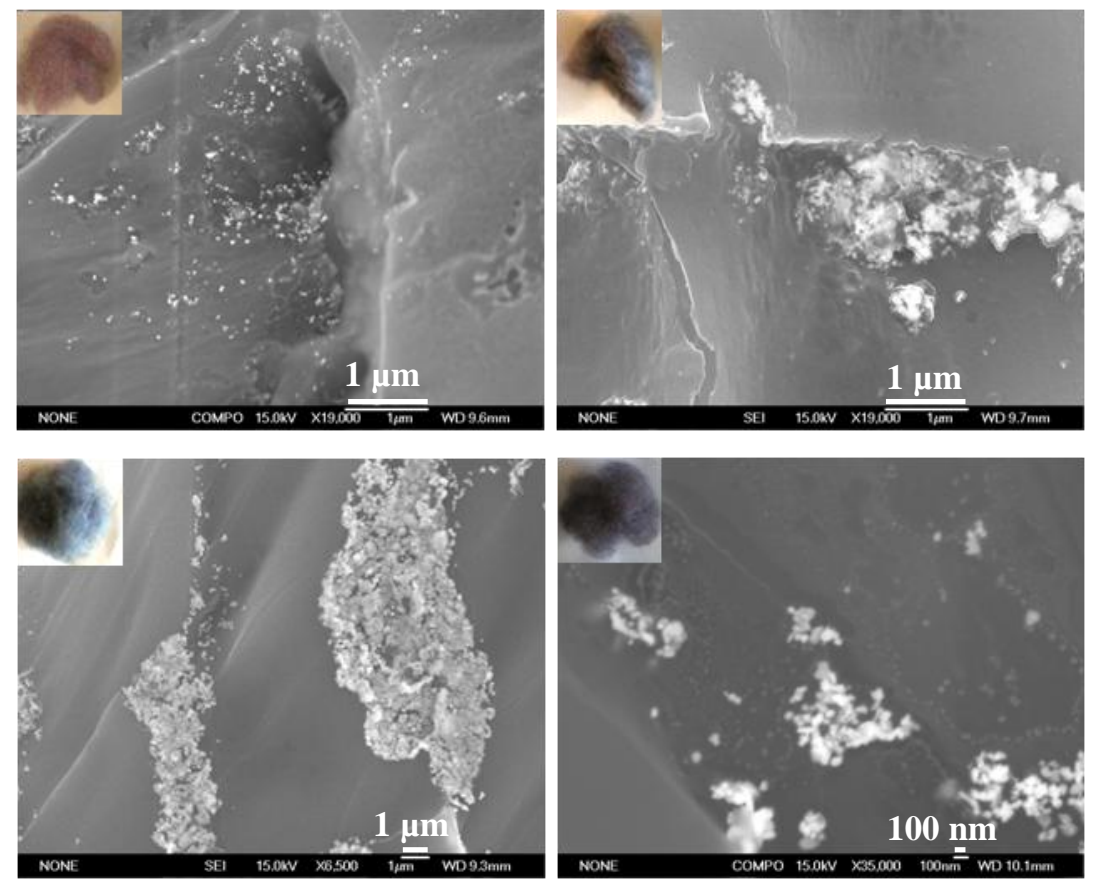

Figure 8.21: SEM micrographs of gold nanoparticle-merino wool composites prepared via the seed mediated approach. Shows the relationship between the colour of the composites and the size of the nanoparticles bound to the fibre surface.

As mentioned, increasing the number of gold nanoparticles bound to the surface of the seeds resulted in the production of greyer coloured composites. For example seed 10 produced greyer coloured materials than did seed 9,8,5 or 2. This colour development is reflected in the Kubelka Munk transformed UV/Vis reflection spectra of the composites, as progressing from materials prepared from seed 2, to 5, 8, 9 or 10 saw a broadening of the pseudo absorption peak (Figure 8.22). As the full width at half maximum of the plasmon peak is related to the extent of agglomeration, the broadening of this peak upon progressing through 
the seeds and producing greyer coloured composites confirms previous conclusions drawn from SEM and TEM analysis, that proposed the grey colour to arise due to nanoparticles agglomerated on the fibre surfaces.

Correspondingly, seeds with an increased amount of nanoparticles in the fibre centres (seed 7 $>6>4>3$ ) produced purple/black materials, with the composites produced from seed 7 being more purple/black than those produced from seed 5. Again this colour change is depicted in the Kubelka Munk transformed UV/Vis reflection spectra of the composites, with the plasmon band of the gold in these materials being narrower than the grey materials (Figure 8.22).

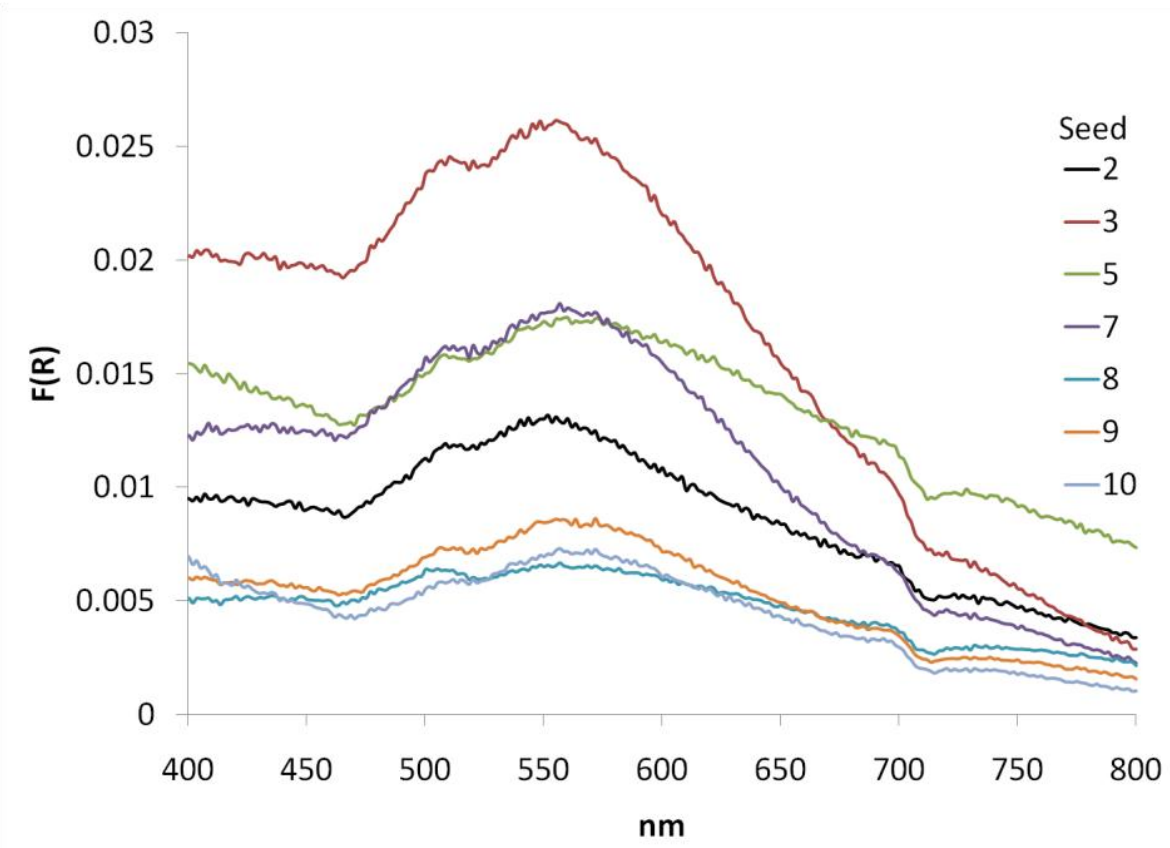

Figure 8.22: Kubelka Munk transformed UV/Vis reflection spectra of composites prepared from various seeds, with a gold concentration of $4.2 \times 10^{-4} \mathrm{M}$ and a $\left[\mathrm{Au}^{3+}\right]:\left[\mathrm{NH}_{2} \mathrm{OH}\right]$ ratio of 1:128.

Similar to the colour change induced by different seeds, the colour change resulting from increasing gold concentrations is also evident in UV/Vis spectroscopy. Figure 8.23 offers the Kubelka Munk transformed UV/Vis reflection spectra of composites produced from seed 5 with increasing gold concentrations. The ratio of $\left[\mathrm{Au}^{3+}\right]:\left[\mathrm{NH}_{2} \mathrm{OH}\right]$ remained constant at 
1:128. Again, an increased grey colour, induced with higher gold concentrations resulted in increased agglomeration on the fibre surfaces and a corresponding broadening of the gold plasmon band centred at approximately $558 \mathrm{~nm}$. The increased greying upon increasing the ratio of $\left[\mathrm{Au}^{3+}\right]:\left[\mathrm{NH}_{2} \mathrm{OH}\right]$ also resulted in a broadening, and slight blue shift of this plasmon peak (Figure 8.24).

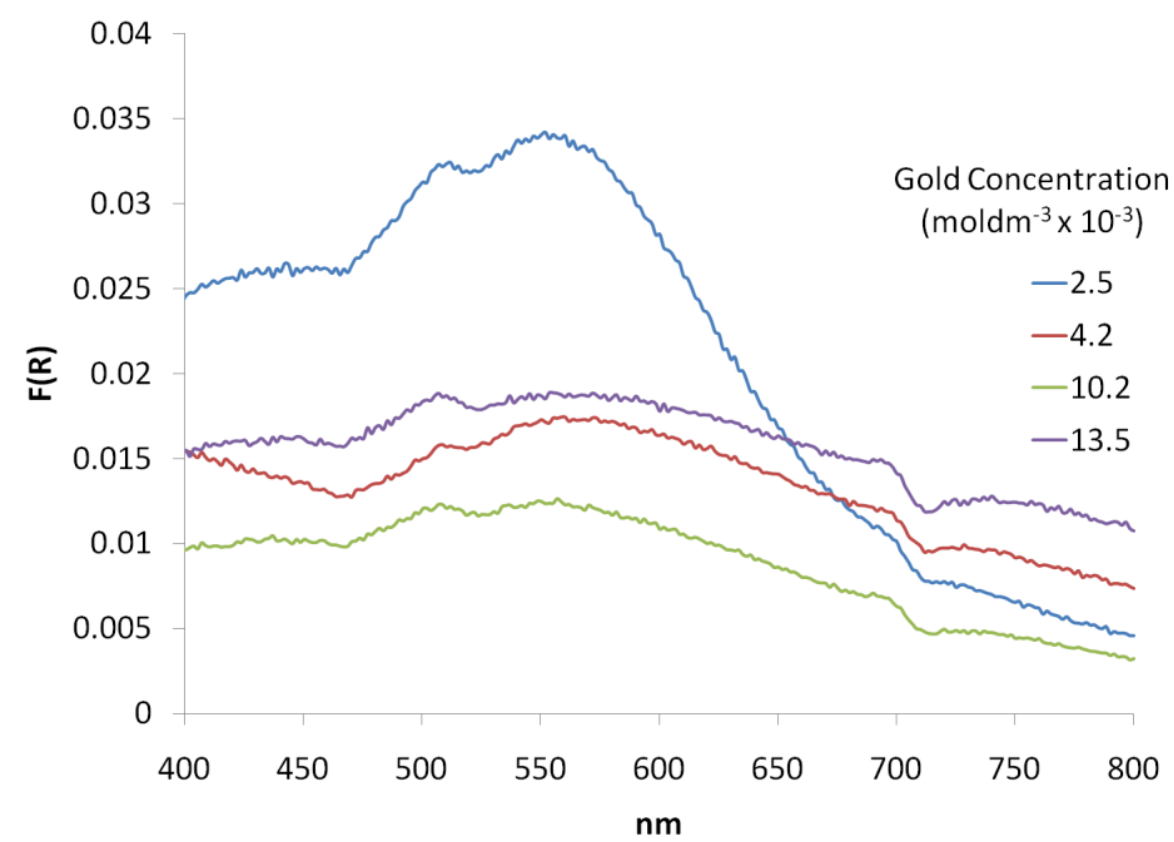

Figure 8.23: Kubelka Munk transformed UV/Vis reflection spectra of composites prepared seed 5 with various gold concentrations and a $\left[\mathrm{Au}^{3+}\right]:\left[\mathrm{NH}_{2} \mathrm{OH}\right]$ ratio of 1:128.

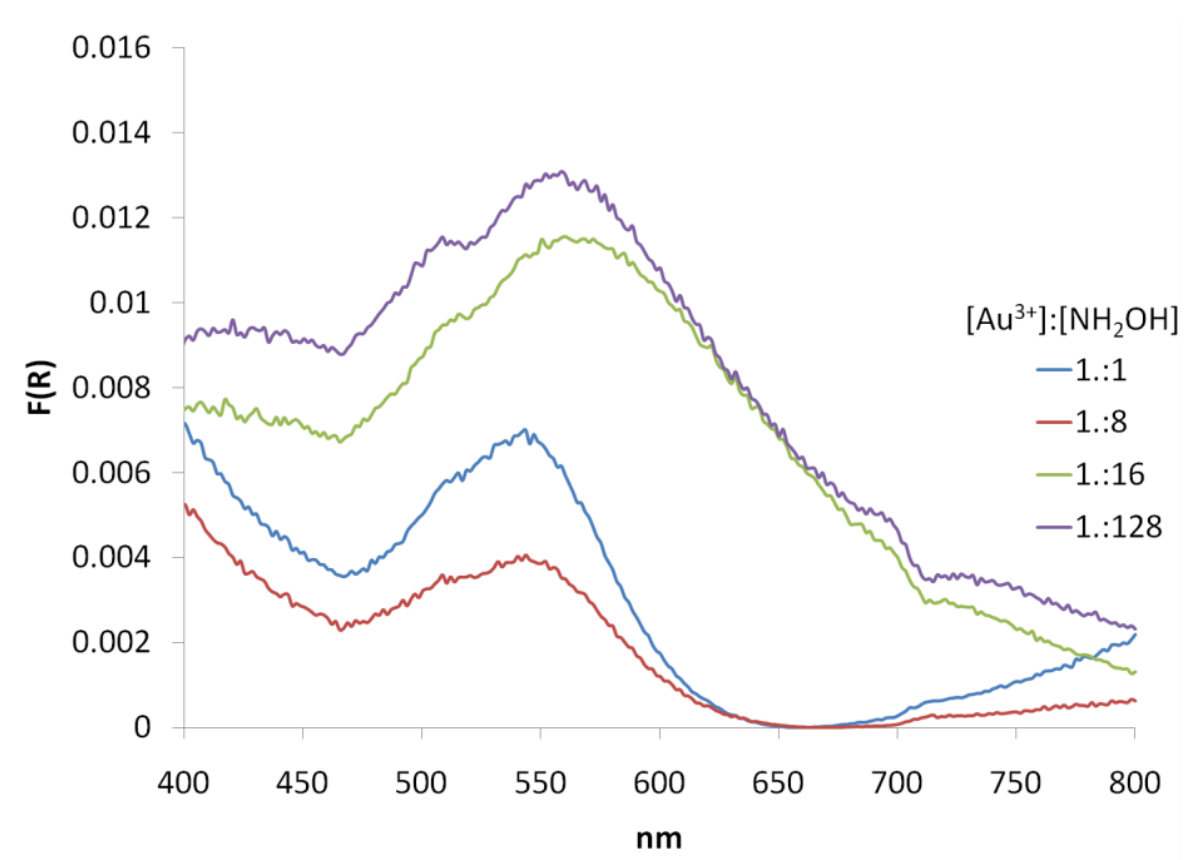

Figure 8.24: Kubelka Munk transformed UV/Vis reflection spectra of composites prepared seed 5 with a gold concentration of $4.2 \times 10^{-4} \mathrm{M}$ and various $\left[\mathrm{Au}^{3+}\right]:\left[\mathrm{NH}_{2} \mathrm{OH}\right]$ ratios. 


\subsubsection{Confirmation of Gold}

The presence of gold in the composites prepared via the seed mediated approach was established with EDS and XPS. EDS confirmed the bright white dots evident on the surface of the composites viewed under backscatter conditions to be gold. Figure 8.25 and Figure 8.27 offer the SEM and corresponding Au EDS maps of composites prepared from seed 5, a gold concentration of $4.2 \times 10^{-4} \mathrm{M}$, and $\mathrm{a}\left[\mathrm{Au}^{3+}\right]:\left[\mathrm{NH}_{2} \mathrm{OH}\right]$ concentration ratio of $1: 16$ and 1:128 respectively. High concentrations of gold are depicted in red and white areas. Additionally, Figure 8.26 and Figure 8.28 offer spectral snap shots of the areas under analysis, and substantiate the existence of gold due to the presence of the gold peaks.
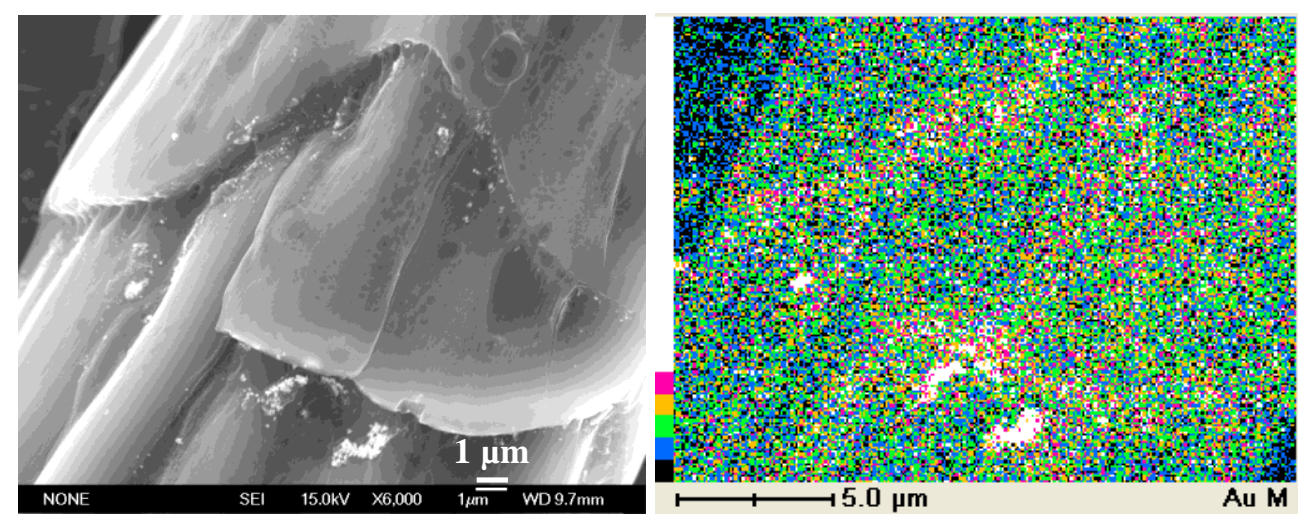

Figure 8.25: Left: Cross sectional SEM micrograph of a gold nanoparticle-merino wool composite prepared via the seed mediated approach, utilising seed 5 , a gold concentration of $4.2 \times 10^{-4} \mathrm{M}$ and a $\left[\mathrm{Au}^{3+}\right]:\left[\mathrm{NH}_{2} \mathrm{OH}\right]$ concentration ratio of 1:16, and right: the corresponding EDS map.

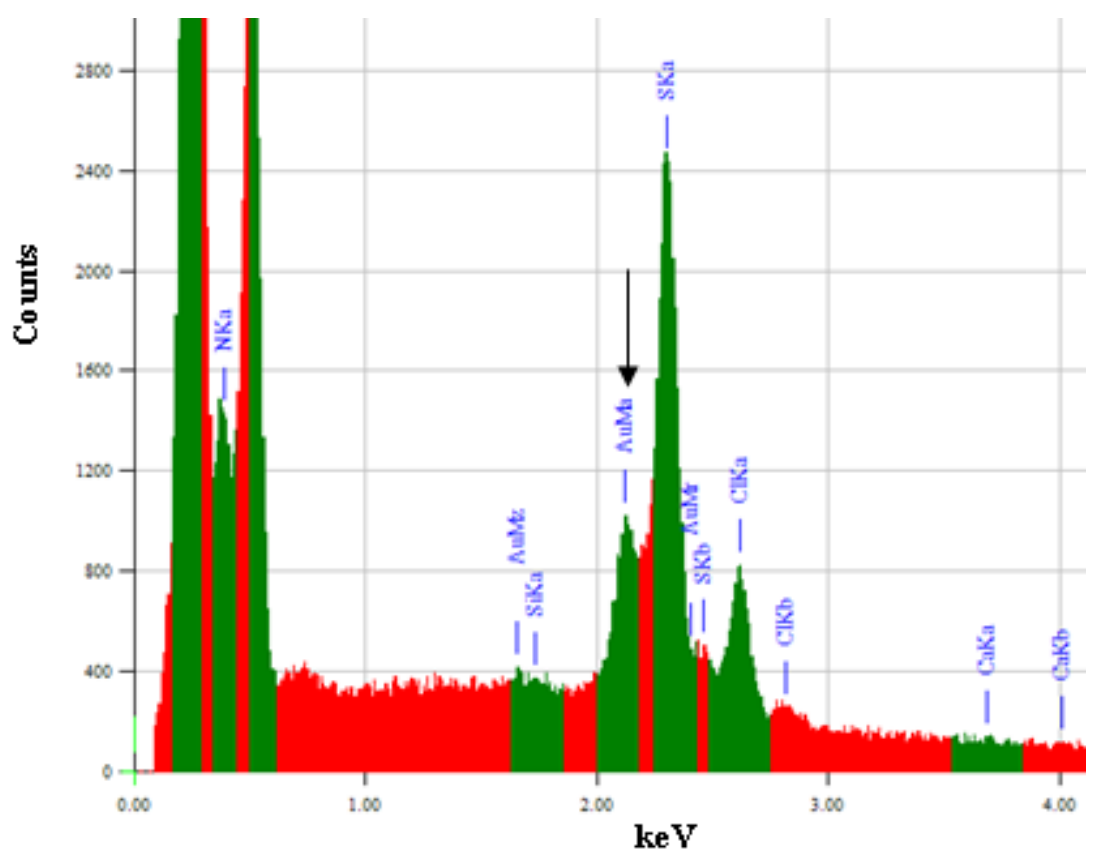

Figure 8.26: EDS spectrum of the gold nanoparticle-merino wool composite shown in Figure 8.25. 

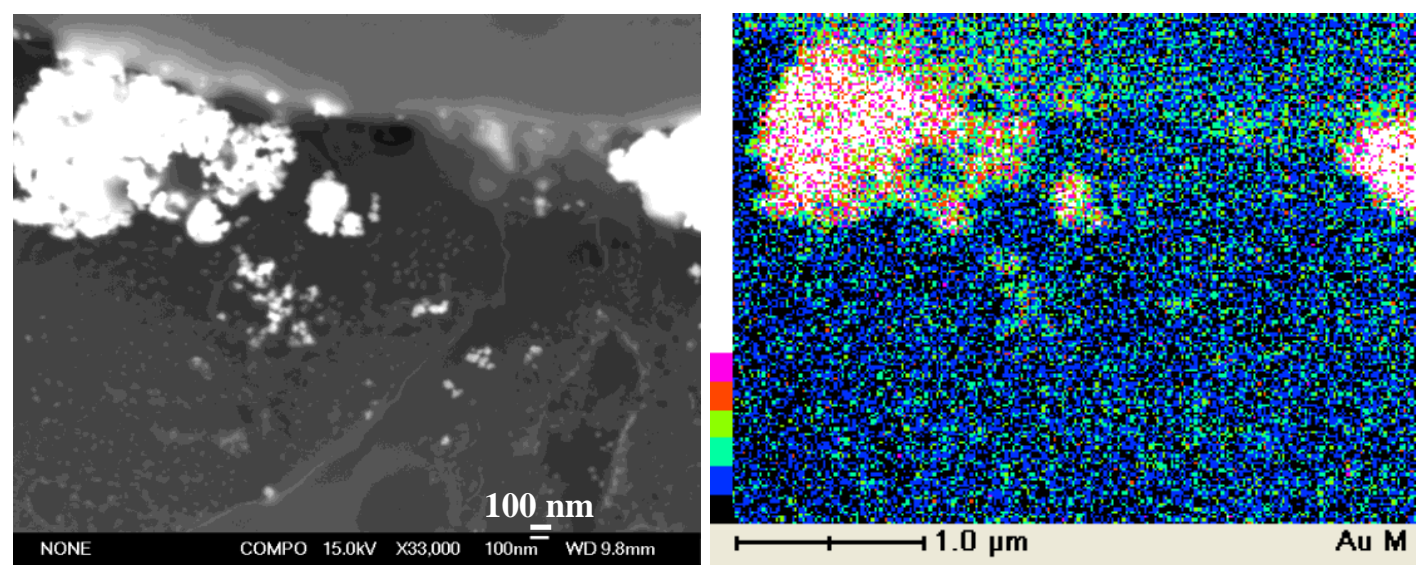

Figure 8.27: Left: Cross sectional SEM micrograph of a gold nanoparticle-merino wool composite prepared via the seed mediated approach, utilising seed 5 , a gold concentration of $4.2 \times 10^{-4} \mathrm{M}$ and a $\left[\mathrm{Au}^{3+}\right]:\left[\mathrm{NH}_{2} \mathrm{OH}\right]$ concentration ratio of $1: 128$, and right: the corresponding EDS map.

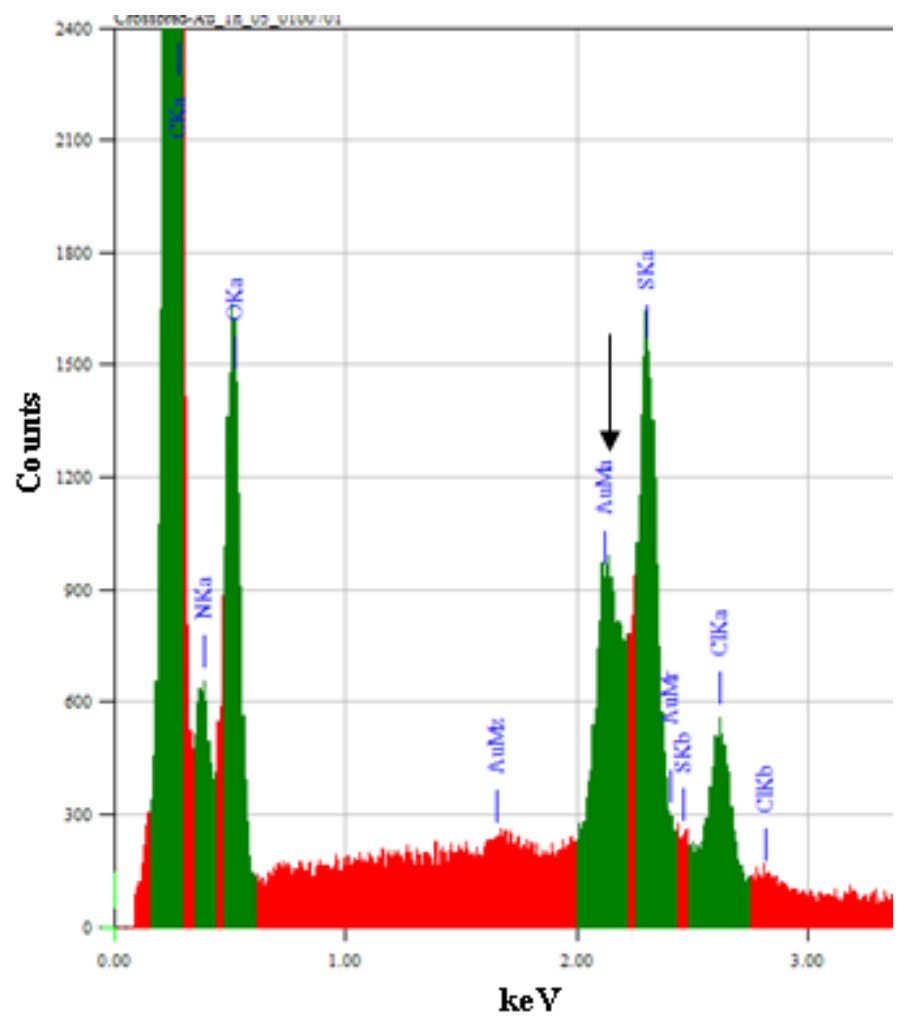

Figure 8.28 EDS spectrum of the gold nanoparticle-merino wool composite shown in Figure 8.27. 


\subsubsection{Proposed Mechanism for Seeded Growth and Bonding of Gold to Merino wool} Fibres

The reduction of $\mathrm{Au}^{3+}$ to $\mathrm{Au}^{0}$ by $\mathrm{NH}_{2} \mathrm{OH}$ occurs according the following scheme:

$$
\mathrm{HAuCl}_{4}+\mathrm{NH}_{2} \mathrm{OH} \cdot \mathrm{HCl} \rightarrow \mathrm{Au}+5 \mathrm{HCl}+\mathrm{NO}
$$

Under the reaction conditions employed, $\mathrm{NH}_{2} \mathrm{OH}$ is incapable of reducing $\mathrm{Au}^{3+}$ in solution. However the reduction is catalysed by $\mathrm{Au}^{0}$, so that in general when gold nanoparticles are present, no new nucleation occurs in solution and all additional $\mathrm{Au}^{3+}$ is reduced at the surface of the existing gold nanoparticles, causing them to increase in size.

The inability of $\mathrm{NH}_{2} \mathrm{OH}$ to reduce gold in solution was illustrated experimentally through the addition of $\mathrm{NH}_{2} \mathrm{OH}$ to a gold solution $\left(4.2 \times 10^{-4} \mathrm{M}\right.$, end $\left[\mathrm{Au}^{3+}\right]:\left[\mathrm{NH}_{2} \mathrm{OH}\right]$ concentration ratio of 1:16), and also to a gold solution containing untreated merino at RT. No colour change was observed in either the solution or the wool, suggesting little to no $\mathrm{Au}^{3+}$ had been reduced to nanoparticulate $\mathrm{Au}^{0}$ (Figure 8.29). This was confirmed by XPS analysis, as the gold in the merino wool soaked in the $\mathrm{Au}^{3+} / \mathrm{NH}_{2} \mathrm{OH}$ solution was predominantly $\mathrm{Au}^{3+}(82.7 \%)$ with the remainder being a Au-N complex (Figure 8.30).

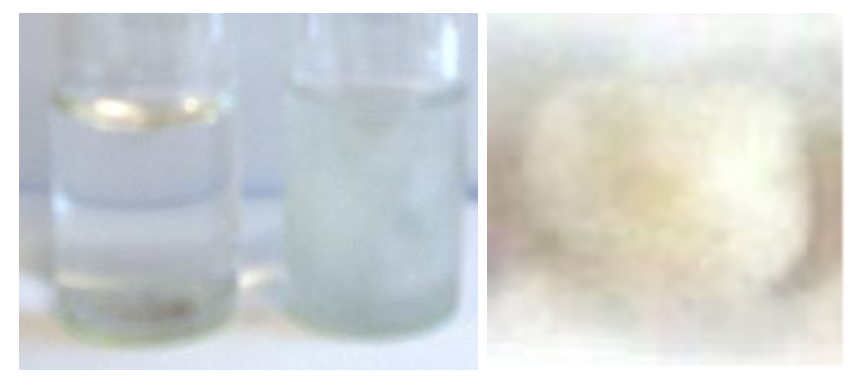

Figure 8.29:Left: a solution containing $\mathrm{Au}^{3+}$ and $\mathrm{NH}_{2} \mathrm{OH}$ that had been left to react over night. Middle: the same solution also containing untreated merino wool, and right: the same merino wool following 24 hours in the $\mathrm{Au}^{3+} / \mathrm{NH}_{2} \mathrm{OH}$. 


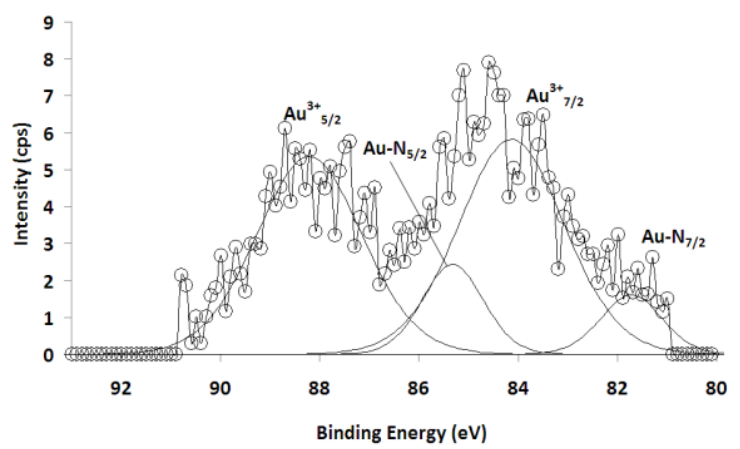

Figure 8.30: High resolution Au 4f XPS spectrum of merino wool soaked in $\mathrm{a} \mathrm{Au}^{3+} / \mathrm{NH}_{2} \mathrm{OH}$ solution for 24 hours at RT.

Furthermore, as shown previously the formation of larger gold nanoparticles, and nanoparticle agglomerations in the composites generally occurred in areas where gold nanoparticles were commonly found in the seeds, notably along cuticle edges, with new nucleation and the formation of isolated particles only occurring with relatively high concentrations of gold. These observations substantiate the suggestion that in general the reduction of additional $\mathrm{Au}^{3+}$ occurred predominantly on the surface of existing gold nanoparticles. This was demonstrated by XPS analysis, which showed the bonding between the gold in the composites to be similar to that of the gold in the seed particles, notably via a $\mathrm{Au}-\mathrm{S}$ bond. The bonding between the gold and wool in the seeds is discussed in detail in section 6.5, and is illustrated in the deconvoluted high resolution $\mathrm{S} 2 \mathrm{p}$ spectra, typical of most seeds, by the peak's centred between approximately 161.5-162 eV.[217, 251] Additionally, the predominant peaks in the $\mathrm{Au} 4 \mathrm{f}$ spectra of the seeds are the 7/2 and 5/2 peaks of $\mathrm{Au}-\mathrm{S}$ (Figure 8.30).[217]

Figure 8.31 and Figure 8.32 a and c show the high resolution $\mathrm{C}$ 1s, N 1s, O 1s and S 2p XPS spectra of a composite prepared from seed 5 , with a gold concentration of $4.2 \times 10^{-4} \mathrm{M}$, and a $\left[\mathrm{Au}^{3+}\right]:\left[\mathrm{NH}_{2} \mathrm{OH}\right]$ concentration ratio of $1: 16$, whilst Figure 8.31 , Figure $8.32 \mathrm{~b}$ and Figure $8.32 \mathrm{~d}$ offer an overlay of the corresponding seed used in the production of the composites. A complete list of peak assignments is provided in Table 8.5 below. It is evident from these spectra that the chemical environment of $\mathrm{C}, \mathrm{O}$ and $\mathrm{S}$ does not change to a great extent upon the reduction of additional $\mathrm{Au}^{3+}$. However two new peaks centred at 398.4 and $403.00 \mathrm{eV}$ appeared in the $\mathrm{N} 1 \mathrm{~s}$ spectrum of the composite. The former peak has been reported to be 
indicative of a direct $\mathrm{N}-\mathrm{Au}$ bond, and the latter oxidised nitrogen species.[201, 252] As a C$\mathrm{N}-\mathrm{Au}$ bond was not seen in the $\mathrm{C} 1 \mathrm{~s}$ spectrum of this composite, it is likely that the $\mathrm{N}-\mathrm{Au}$ interaction arose due to any unreduced $\mathrm{NH}_{2} \mathrm{OH}$ capping the produced nanoparticles, or absorbed onto the wool fibre. Additionally, the presence of the peak at $403.00 \mathrm{eV}$ suggests that during the reduction of $\mathrm{Au}^{3+}$ by $\mathrm{NH}_{2} \mathrm{OH}$, a small proportion of nitrogen containing groups such as amines were oxidised to nitrosyl (NO) or nitrite $\left(\mathrm{NO}^{2-}\right)$ groups.

Oxidation of the wool fibres during the production of the composites was also evidenced in the $S 2 p$ spectrum, with a decrease in area of the peak corresponding to the average sulfur environment in the seed, from75\% to $65 \%$ in the composite, and an increase in the peak indicative of cysteic acid $\left(-\mathrm{SO}_{3}{ }^{-}\right)$, the oxidised form of cystine, from $18 \%$ to $19 \%$ (Figure $8.32 \mathrm{~g}-\mathrm{h}$ ). There was also a slight broadening of the S-Au peaks in the composites, centred at $\sim 161.33$ and $162.44 \mathrm{eV}$. This suggests an increase in the variability of the S-Au binding environment, due to the broad size range of the gold nanoparticles and the presence of agglomerates.
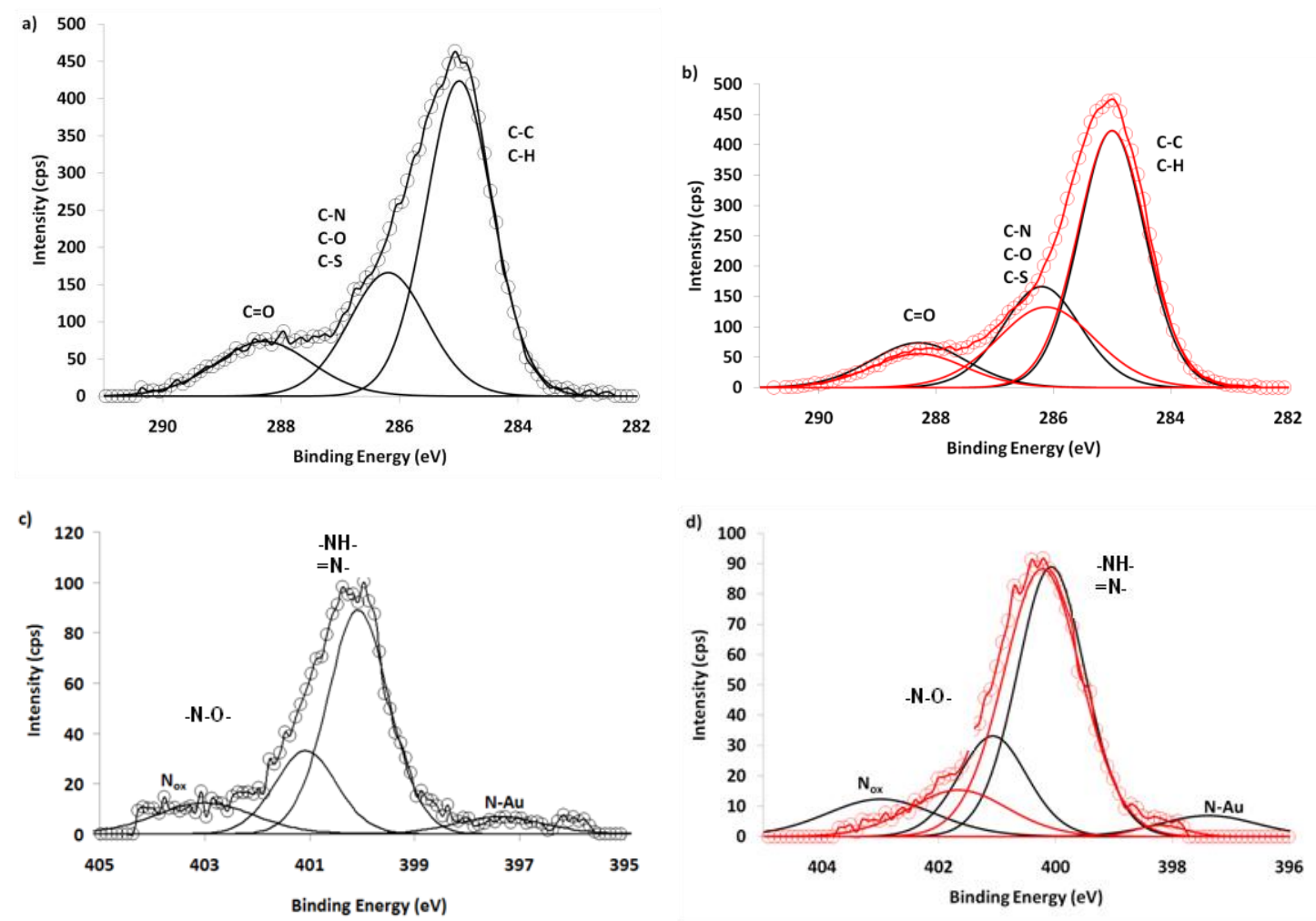

Figure 8.31: High resolution C 1s (a-b) and N 1s (c-d) XPS spectra of a gold nanoparticle-merino wool composite prepared via the seed mediated approach. Figures (b and d) show an overlay of the corresponding $\mathrm{C} 1 \mathrm{~s}$ and $\mathrm{N}$ 1s spectra of the seed material (in red). 
a)
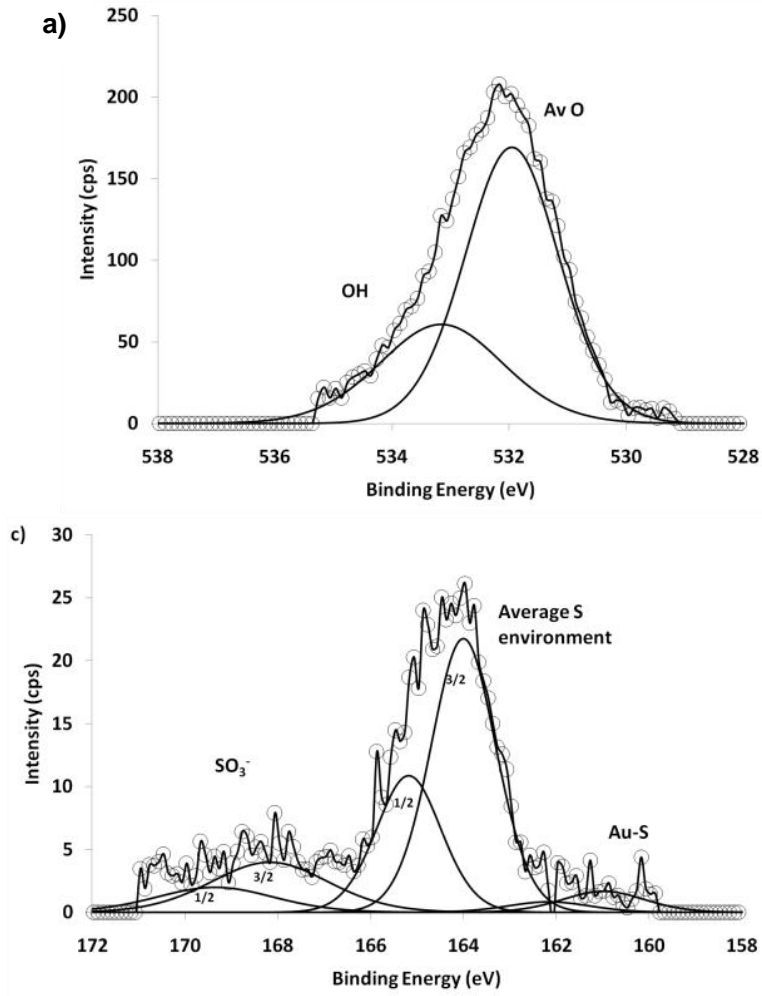

b)
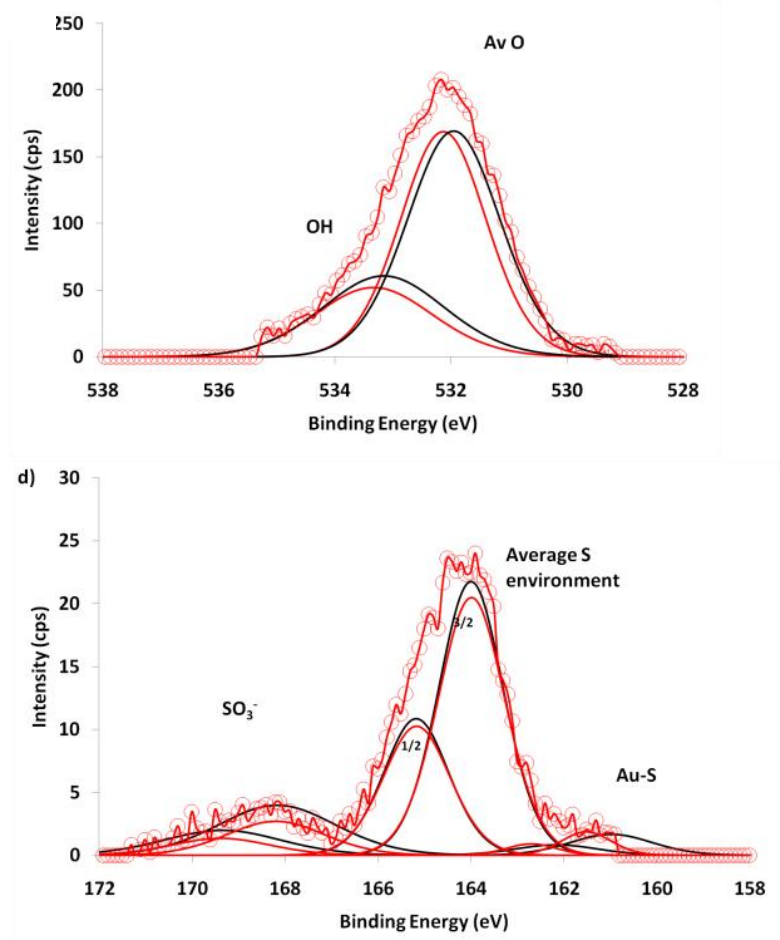

Figure 8.32: High resolution O 1s (a) and S 2p (c) XPS spectra of a gold nanoparticle-merino wool composite prepared via the seed mediated approach. Figures (b and d) show an overlay of the corresponding $\mathrm{O}$ 1s and $\mathrm{S} 2 \mathrm{p}$ spectra of the seed material (in red).

Comparing the high resolution $\mathrm{Au} 4 \mathrm{f}$ spectra of seed 5 to that of its composite showed slight changes (Figure 8.33). Notably a decrease in $\mathrm{Au}^{3+}$, from $44 \%$ in the seed to $28 \%$ in the composite, suggesting that not only was the additional $\mathrm{Au}^{3+}$ reduced by $\mathrm{NH}_{2} \mathrm{OH}$ during the seed mediated process, but also any $\mathrm{Au}^{3+}$ present in the seeds. There was also a substantial increase in $\mathrm{Au}^{0}$, from $8.1 \%$ in the seeds to $21.8 \%$ in the composite. In addition to being due to an increased amount of $\mathrm{Au}^{0}$, this increase is likely reflective of the larger average size of the gold nanoparticles in the composites, as bigger particles have smaller surface areas, thus exhibiting a greater proportion of $\mathrm{Au}^{0}$ than $\mathrm{Au}-\mathrm{S}$ (owing to gold atoms on the surface of the particles binding to $\mathrm{S}$ groups in wool). 

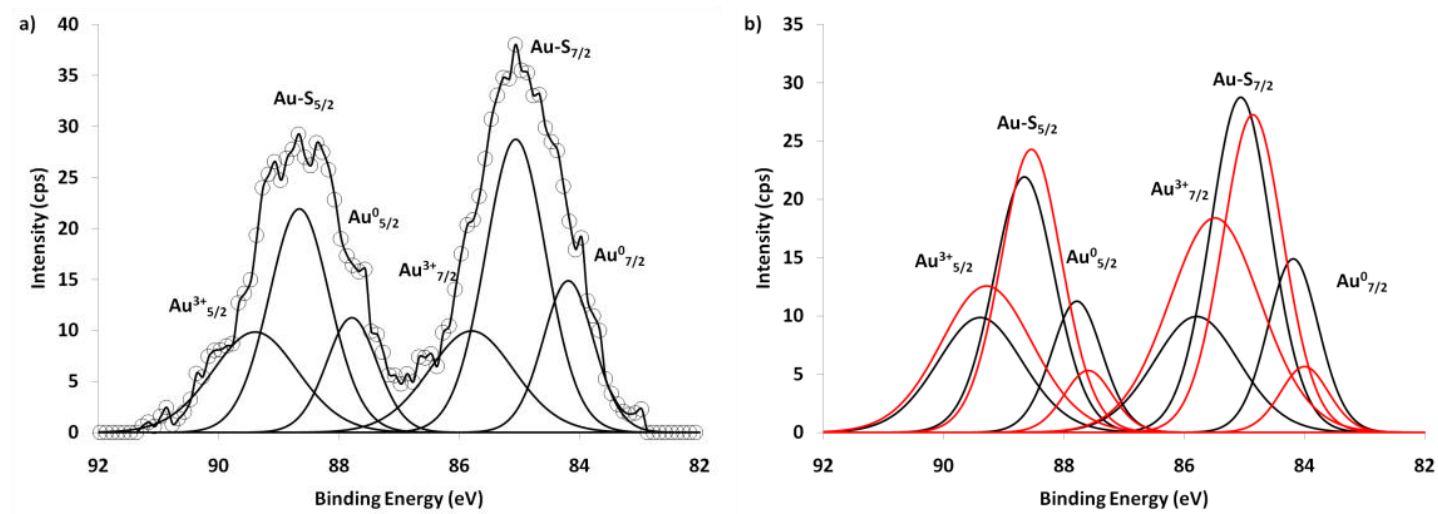

Figure 8.33:a) High resolution Au 4f XPS spectra of a gold nanoparticle-merino wool composite prepared via the seed mediated approach. b) overlay of the corresponding spectra of the seed material (red).

Table 8.5: XPS assignments for merino wool, seed 5, and a gold nanoparticle-merino wool composite (prepared from seed 5, a gold concentration of $4.2 \times 10^{-4} \mathrm{M}$ and a $\left[\mathrm{Au}^{3+}\right]:\left[\mathrm{NH}_{2} \mathrm{OH}\right]$ concentration ratio of 1:16).

\begin{tabular}{|c|c|c|c|c|}
\hline & & \multirow[b]{2}{*}{ Merino Wool } & \multicolumn{2}{|c|}{ Composite Materials } \\
\hline & & & Seed & Composite \\
\hline & & \multicolumn{3}{|c|}{ Binding Energy $(\mathrm{eV} \pm 0.2 \mathrm{eV})$} \\
\hline \multirow[t]{3}{*}{ C 1s } & $\mathrm{C}-\mathrm{C}, \mathrm{C}-\mathrm{H}$ & 285.00 & 285.00 & 285.00 \\
\hline & $\mathrm{C}-\mathrm{O}, \mathrm{C}-\mathrm{N}, \mathrm{C}-\mathrm{S}$ & 286.20 & 286.13 & 286.20 \\
\hline & $\mathrm{C}=\mathrm{O}$ & 288.30 & 288.30 & 288.30 \\
\hline \multirow[t]{4}{*}{ N 1s } & $\mathrm{N}-\mathrm{H},=\mathrm{N}-$ & 400.43 & 400.23 & 400.08 \\
\hline & $-\mathrm{N}-\mathrm{O}-$ & 401.90 & 401.67 & 401.08 \\
\hline & $\mathrm{N}_{\mathrm{ox}}\left(\mathrm{NO}^{2-}\right)$ & - & - & 403.00 \\
\hline & $\mathrm{N}-\mathrm{Au}$ & - & - & 398.4 \\
\hline \multirow[t]{2}{*}{$01 \mathrm{~s}$} & $\begin{array}{l}\text { Average } \mathrm{O} \\
\text { environment }\end{array}$ & 532.14 & 532.14 & 531.96 \\
\hline & $-\mathrm{OH}$ & 533.5 & 533.34 & 533.17 \\
\hline \multirow[t]{6}{*}{ S 2p } & $\begin{array}{l}\text { Average } S \\
\text { environment } S_{3 / 2}\end{array}$ & 164.02 & 163.99 & 164.00 \\
\hline & $\begin{array}{l}\text { Average } \mathrm{S} \\
\text { environment } \mathrm{S}_{3 / 2}\end{array}$ & 165.20 & 165.17 & 165.19 \\
\hline & $\mathrm{SO}_{3}^{-} 3 / 2$ & 168.44 & 168.21 & 168.18 \\
\hline & $\mathrm{SO}_{31 / 2}^{-}$ & 169.62 & 169.39 & 169.36 \\
\hline & $\mathrm{S}-\mathrm{Au}_{3 / 2}$ & - & 161.52 & 161.05 \\
\hline & $\mathrm{S}-\mathrm{Au}_{1 / 2}$ & - & 162.70 & 162.17 \\
\hline
\end{tabular}




\begin{tabular}{|c|c|c|c|c|}
\hline & & \multicolumn{3}{|c|}{ Composite Materials } \\
\hline & & Merino Wool & Seed & Composite \\
\hline & & \multicolumn{3}{|c|}{ Binding Energy $(\mathrm{eV} \pm 0.2 \mathrm{eV})$} \\
\hline \multirow[t]{6}{*}{ Au $4 f$} & $\mathrm{Au}_{7 / 2}^{0}$ & - & 84.00 & 84.19 \\
\hline & $\mathrm{Au}-\mathrm{S}_{7 / 2}$ & - & 84.86 & 85.07 \\
\hline & $\mathrm{Au}^{3+} 7 / 2$ & - & 85.49 & 85.8 \\
\hline & $\mathrm{Au}_{5 / 2}^{\mathrm{U}}$ & - & 87.60 & 87.79 \\
\hline & $\mathrm{Au}-\mathrm{S}_{5 / 2}$ & - & 88.55 & 88.67 \\
\hline & $\mathrm{Au}^{3+}{ }_{5 / 2}$ & - & 89.29 & 89.40 \\
\hline
\end{tabular}

Cross sectional SEM and EDS analysis suggested that the reduction of $\mathrm{Au}^{3+}$ to $\mathrm{Au}^{0}$ took place largely on the nanoparticles bound to the surface of merino wool fibres, rather than on those in the centre. Figure 8.34 (left) is typical of a cross sectional SEM micrograph of composites prepared via the seed mediated approach, whilst Figure 8.34 (right) offers the corresponding EDS map, where high concentrations of gold are shown in bright white. The nanoparticle agglomerates are clearly evident on the surface of the fibre, however they are absent in the centre. This is confirmed in the line profile of the EDS map (Figure 8.35), which provides information about elemental distribution within a specific area, as it shows a much greater concentration of gold on the outer edges of the fibre compared to the centre.
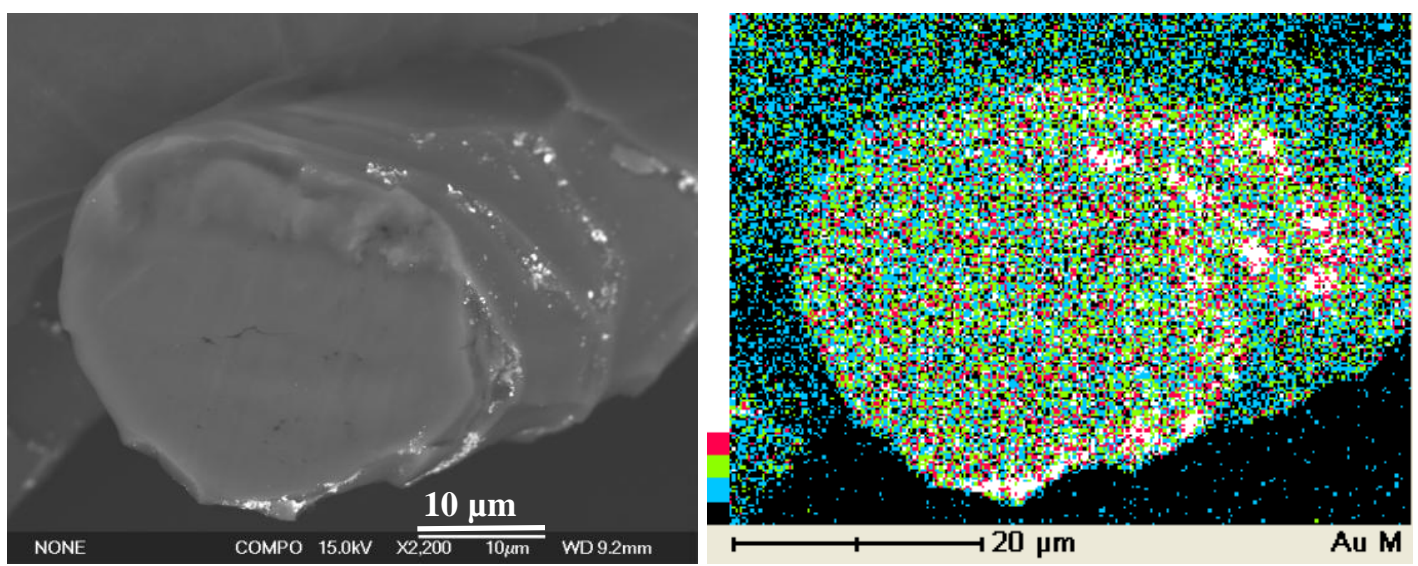

Figure 8.34: Left: Cross sectional SEM micrograph of a gold nanoparticle-merino wool composite prepared via the seed mediated approach, utilising seed 5, a gold concentration of $4.2 \times 10^{-4} \mathrm{M}$ and a 1:128 ratio of $\left[\mathrm{Au}^{3+}\right]:\left[\mathrm{NH}_{2} \mathrm{OH}\right]$ and right: the corresponding EDS map. 

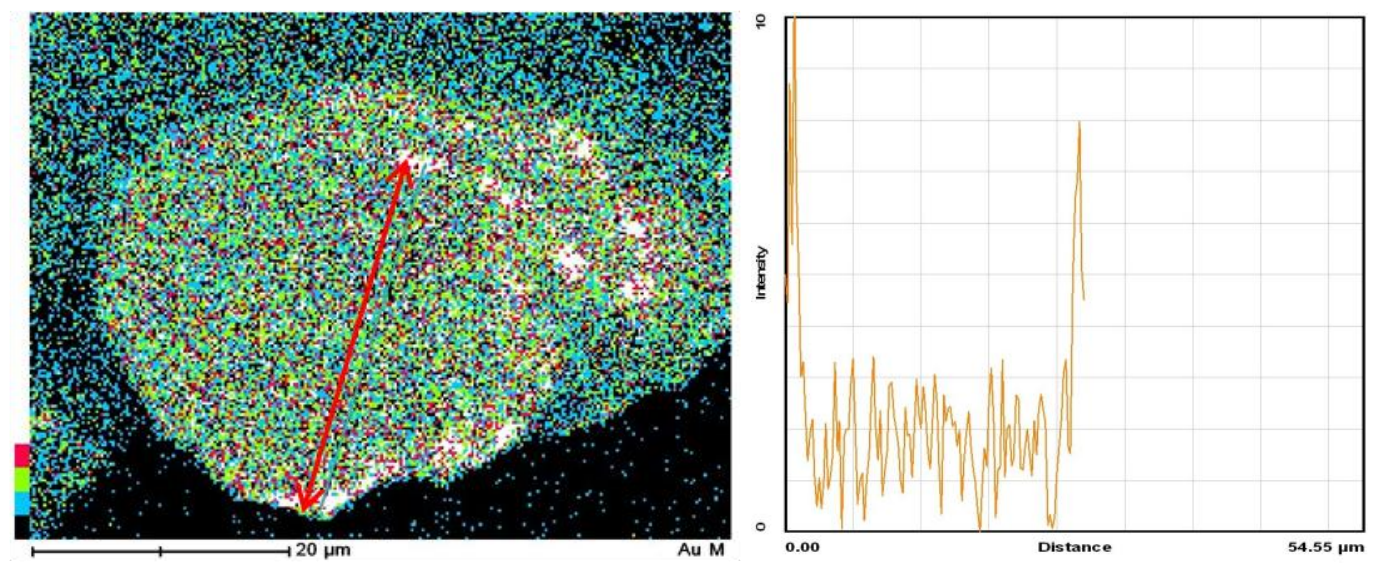

Figure 8.35: Left: Gold EDS map of a gold nanoparticle-merino wool composite prepared via the seed mediated approach, and right: the corresponding line profile showing higher concentrations of gold on the surface of the fibre than in the centre.

Additional nanoparticle formation solely on the particles residing on the fibre surface complements experimental data that examined the rate of the reaction. The growth of $\mathrm{Au}^{0}$ nanoparticles by $\mathrm{Au}^{3+} / \mathrm{NH}_{2} \mathrm{OH}$ mixtures was followed by UV/Vis spectroscopy, and also visually through colour development. In order to track the reduction rate, seed 5 was dispersed in a gold solution and various amounts of $\mathrm{NH}_{2} \mathrm{OH}$ were added dropwise with stirring (so that the final gold concentration was $2.50 \times 10^{-4} \mathrm{M}$ ) to give a $\left[\mathrm{Au}^{3+}\right]:\left[\mathrm{NH}_{2} \mathrm{OH}\right]$ ratio of $1: 1,1: 8$ or 1:16. The reaction was then left to proceed for 2 minutes to 5 hours, after which the reaction was stopped by removing and washing the wool. Figure 8.36 offers a picture of the resultant composites following reaction for 2 minutes to 5 hours. Visually it appears that with a $\left[\mathrm{Au}^{3+}\right]:\left[\mathrm{NH}_{2} \mathrm{OH}\right]$ ratio of $1: 1$ the reaction was largely complete after an hour, and this time was shorter when a ratio of 1:8 or 1:16 was employed, as in these systems the final grey colour appeared to have developed after approximately 30 or 15 minutes respectively. This colour development was accompanied by an increase in intensity of the gold plasmon band centred at approximately $550 \mathrm{~nm}$, which appeared to reach a maximum, and then vary slightly in intensity after 60,30 or 15 minutes in the systems employing a $\left[\mathrm{Au}^{3+}\right]:\left[\mathrm{NH}_{2} \mathrm{OH}\right]$ ratio of $1: 1,1: 8$ or $1: 16$ respectively (Figure 8.37 to Figure 8.39 ). The fast reaction time observed in these systems would account for additional nanoparticle growth occurring predominantly on the surface or outer edge of the merino wool fibres, as in this time it is likely that the gold would be absorbed onto the wool, but have insufficient time to diffuse through to the centre prior to being reduced. 


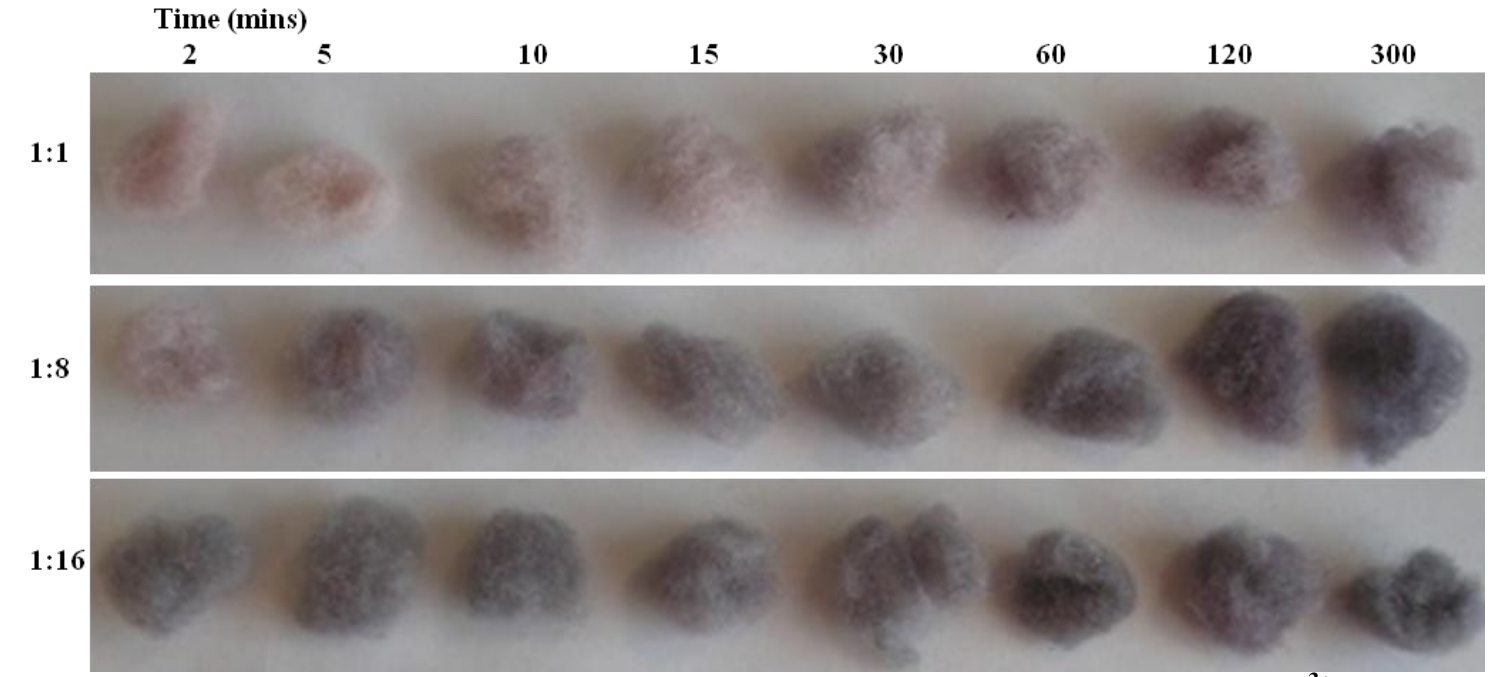

Figure 8.36: Gold nanoparticle-merino wool composites prepared from seed 5, and a $\left[\mathrm{Au}^{3+}\right]$ : $\left[\mathrm{NH}_{2} \mathrm{OH}\right]$ ratio of 1:1 (top), 1:8 (middle) or 1:16 (bottom), showing colour development with increased reaction time.

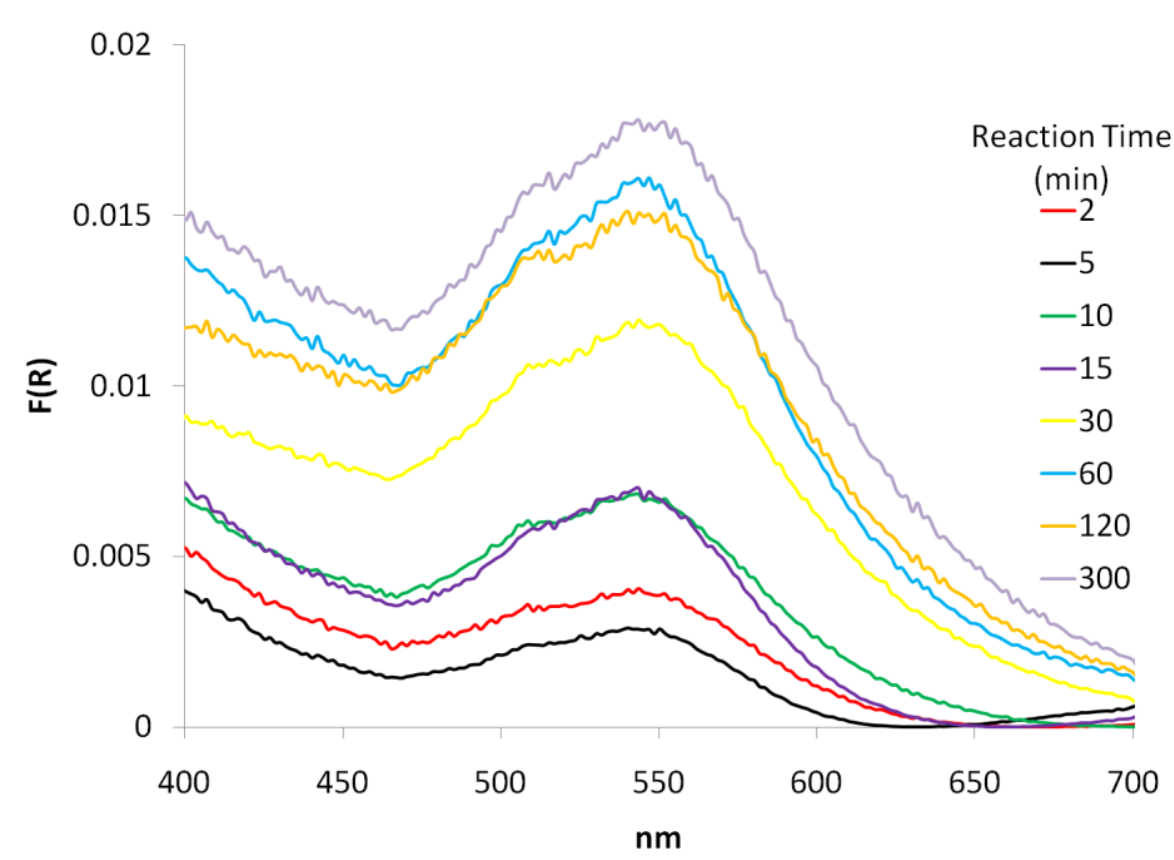

Figure 8.37: Kubelka Munk transformed UV/Vis reflection spectra of composites prepared from seed 5, with a gold concentration of $2.5010^{-4} \mathrm{M}$ and a $\left[\mathrm{Au}^{3+}\right]:\left[\mathrm{NH}_{2} \mathrm{OH}\right]$ ratio of 1:1. 


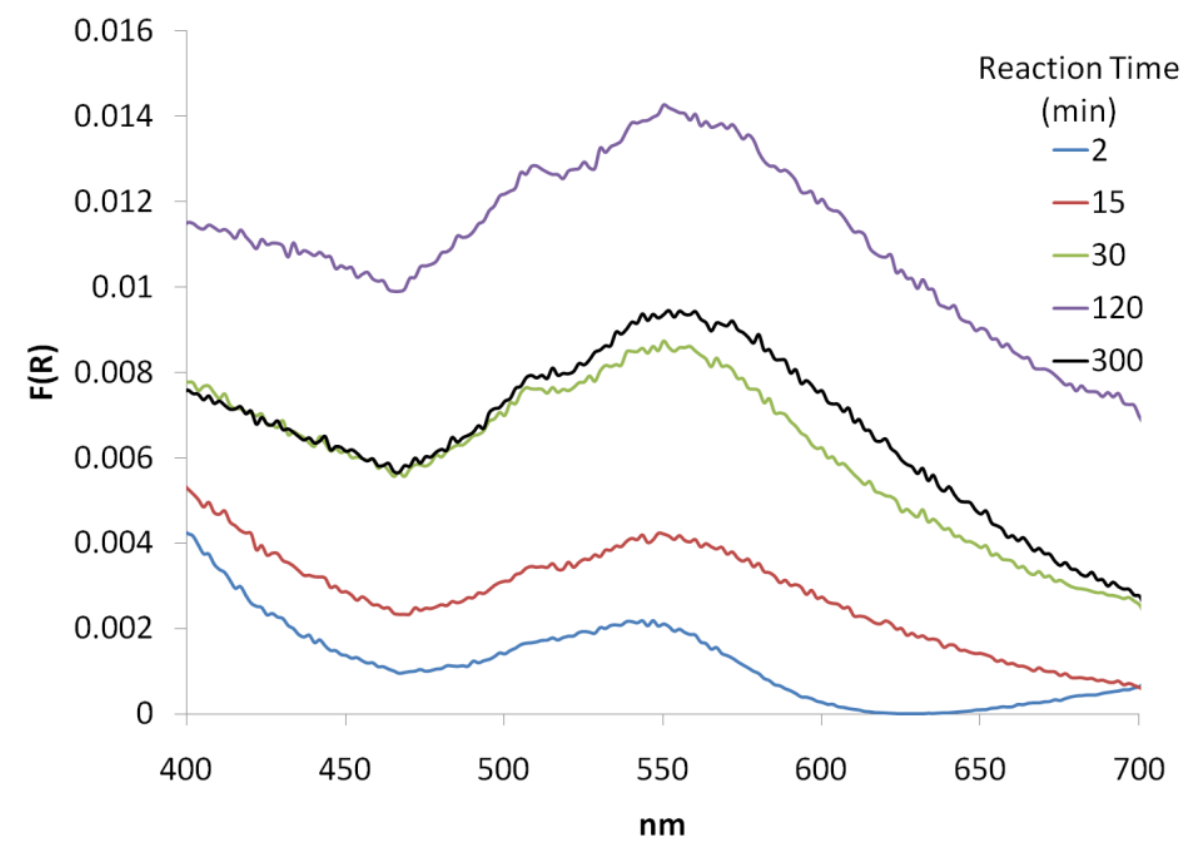

Figure 8.38: Kubelka Munk transformed UV/Vis reflection spectra of composites prepared from seed 5, with a gold concentration of $2.5010^{-4} \mathrm{M}$ and a $\left[\mathrm{Au}^{3+}\right]:\left[\mathrm{NH}_{2} \mathrm{OH}\right]$ ratio of 1:8.

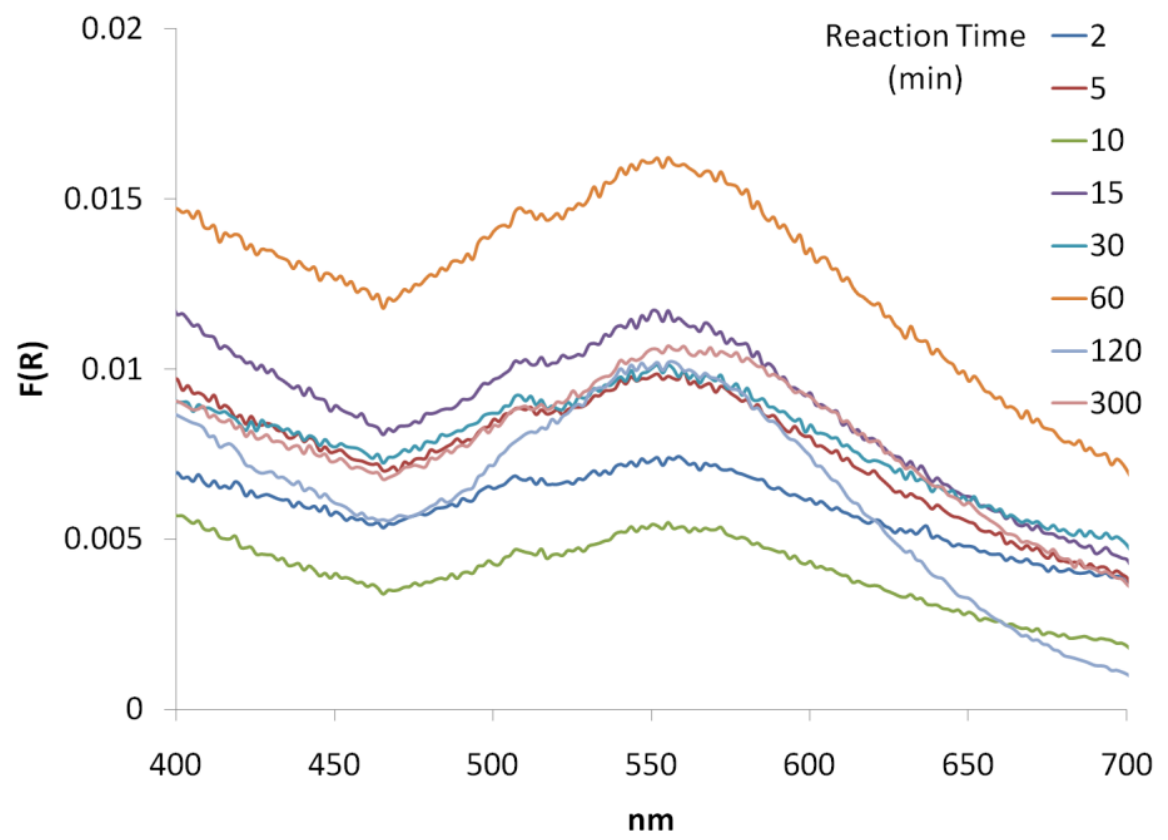

Figure 8.39: Kubelka Munk transformed UV/Vis reflection spectra of composites prepared from seed 5, with a gold concentration of $2.50 \times 10^{-4} \mathrm{M}$ and a $\left[\mathrm{Au}^{3+}\right]:\left[\mathrm{NH}_{2} \mathrm{OH}\right]$ ratio of 1:16. 


\subsubsection{Colourfastness to Washing}

The colourfastness of the gold nanoparticle-merino wool composites prepared via the seed mediated approach were analysed through simulated washability tests. The methodology is outlined in section 2.3.14. Figure 8.40 shows a picture of a composite material prepared from seed 5, a gold concentration of $4.2 \times 10^{-4} \mathrm{M}$ and $\mathrm{a}\left[\mathrm{Au}^{3+}\right]:\left[\mathrm{NH}_{2} \mathrm{OH}\right]$ ratio of 1:64. This material was chosen to be representative of all composites, as it was made from a seed with a medium amount of gold, employing an intermediate gold concentration and ratio of $\left[\mathrm{Au}^{3+}\right]:\left[\mathrm{NH}_{2} \mathrm{OH}\right]$.

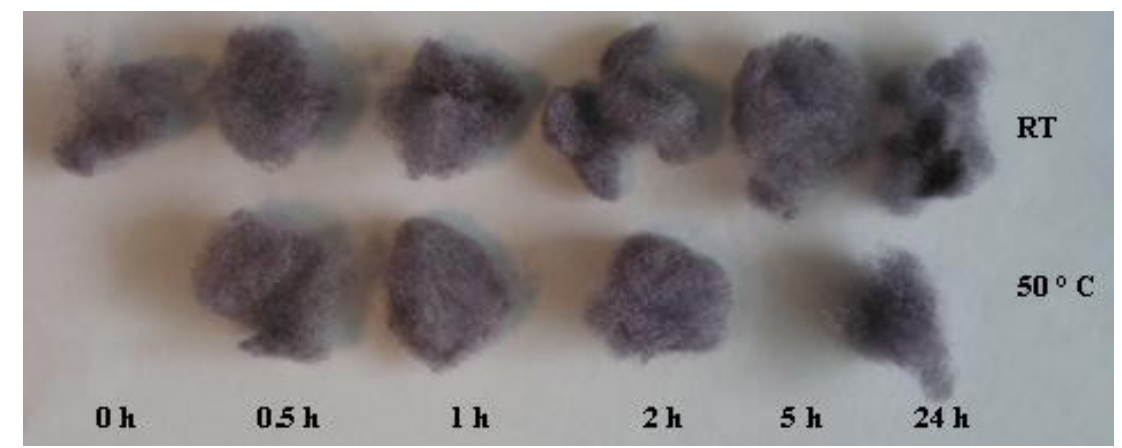

Figure 8.40: Gold nanoparticle-merino wool composites prepared from seed 5, a gold concentration of 4.2 $x 10^{-4} \mathrm{M}$ and $\mathrm{a}\left[\mathrm{Au}^{3+}\right]:\left[\mathrm{NH}_{2} \mathrm{OH}\right]$ ratio of 1:64 following simulated washability testing.

Visually, this composite appears to be colourfast to washing, exhibiting no apparent change in colour even after 24 hours simulated washing at $50^{\circ} \mathrm{C}$. This apparent colourfastness was reflected in the Kubelka Munk transformed UV/Vis reflection spectrum of the washed samples (Figure 3.41), as there was negligible change in position or full width at half maximum of the plasmon band of the gold bound to the composites. There was a slight variation in intensity of this peak, however this variation is minimal and is likely due to experimental uncertainties (amount of sample etc) rather than a change in colour. Additionally the CIE L*, a*, b*, $457 \mathrm{~nm}$ brightness and $580 \mathrm{~nm}$ brightness values of the composite did not change to a great extent following washing (Table 8.6). It is likely that these materials are so colourfast with respect to washing as the gold is bound to the merino wool fibres via a strong Au-S bond (suggested by XPS analysis (section 8.1.3.4)). 


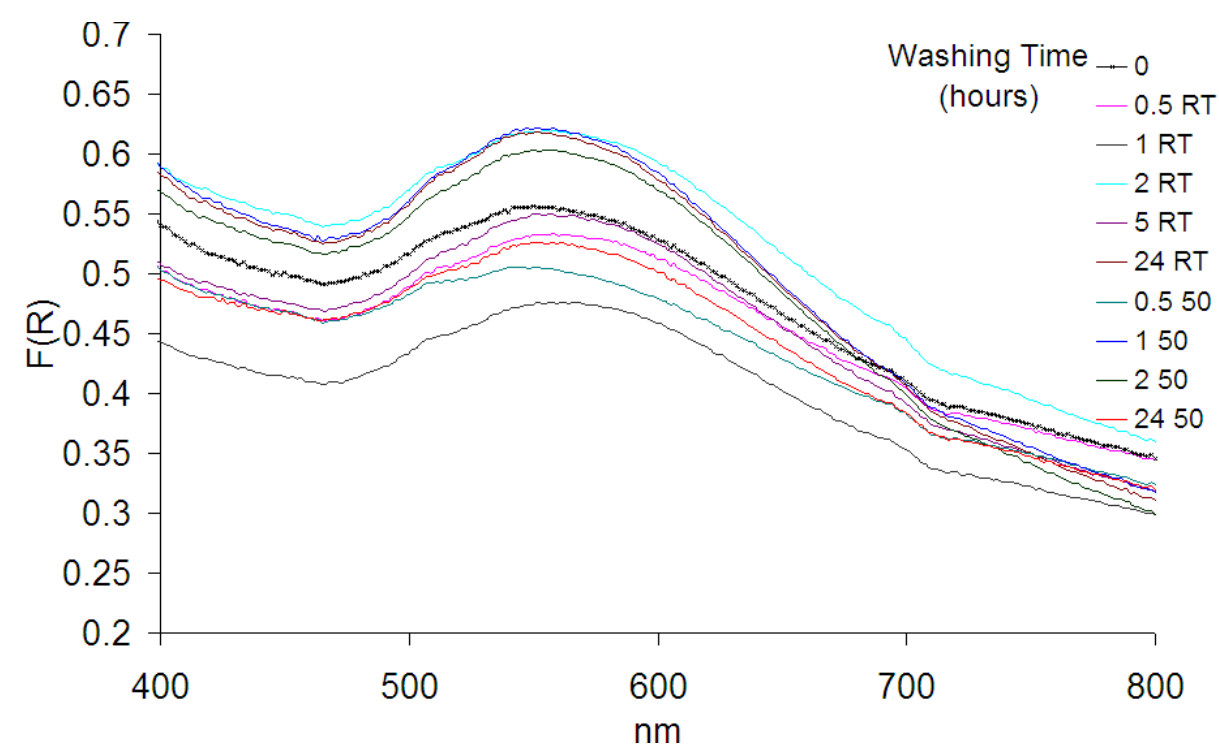

Figure 3.41: Kubelka Munk transformed UV/Vis reflection spectra of a gold nanoparticle-merino wool composite following simulated washability testing.

Table 8.6: CIE $\mathrm{L}^{*}, \mathrm{a}^{*}, \mathrm{~b}^{*}, 457 \mathrm{~nm}$ brightness and $580 \mathrm{~nm}$ brightness values of a gold nanoparticle-merino wool composite following simulated washability testing.

\begin{tabular}{ccccccc}
\hline $\begin{array}{c}\text { Washing } \\
\text { Temperature }\end{array}$ & $\begin{array}{c}\text { Washing time } \\
\text { (hours) }\end{array}$ & $\mathbf{L}^{*}$ & $\mathbf{a}^{*}$ & $\mathbf{b}^{*}$ & $\begin{array}{c}\mathbf{4 5 7} \mathbf{~ n m} \\
\text { brightness }\end{array}$ & $\begin{array}{c}\mathbf{5 8 0} \mathbf{~ n m} \\
\text { brightness }\end{array}$ \\
\hline $\mathbf{R T}$ & $\mathbf{0}$ & 37.2 & 2.4 & -2.0 & 10 & 9 \\
& $\mathbf{0 . 5}$ & 39.6 & 2.2 & -1.2 & 12 & 11 \\
& $\mathbf{1}$ & 42.2 & 3.0 & -1.7 & 13 & 13 \\
& $\mathbf{2}$ & 37.8 & 2.7 & 1.2 & 11 & 10 \\
$\mathbf{5 0}{ }^{\circ} \mathbf{C}$ & $\mathbf{5}$ & 41.2 & 3.0 & -1.8 & 13 & 12 \\
& $\mathbf{2 4}$ & 36.1 & 2.9 & -1.6 & 10 & 9 \\
& $\mathbf{0 . 5}$ & 40.6 & 2.3 & -0.6 & 12 & 11 \\
& $\mathbf{1}$ & 39.8 & 3.0 & -1.0 & 12 & 11 \\
& $\mathbf{2}$ & 39.1 & 3.5 & -1.3 & 11 & 11 \\
\hline
\end{tabular}

\subsubsection{Leaching}

Quantitative analysis of the washing solutions obtained during simulated washability testing (section 8.1.3.5) was undertaken to establish the amount of gold leached from the composites during washing. Table 8.7 lists the amount of gold leached from the composite material and 
its corresponding seed. In both cases this amount is very low, up to a maximum of $1.1 \%$ total gold loading from the composite and $0.36 \%$ from the seed. (The total gold loading was based on the amount of gold used in the seed preparation and in the preparation of the composite materials). In general slightly more gold is leached from the composite relative to the seed, which is likely due to the fact that in the composite materials the majority of gold is present on the fibre surface, whereas in the composites it is also present just under the surface of the fibre cuticles (see section 5.1 and 5.7), resulting in more difficult dislodgement. However the amount of gold leached from the composites is minimal, and does not adversely affect the colour of the materials, making them potentially viable products for consumer applications.

Table 8.7: Gold leached from a gold nanoparticle-merino wool composite (prepared via the seed mediated approach) and the corresponding seed source following simulated washability testing.

\begin{tabular}{|c|c|c|c|c|c|}
\hline \multirow{3}{*}{$\begin{array}{c}\text { Washing } \\
\text { Temperature }\end{array}$} & \multirow{3}{*}{$\begin{array}{c}\text { Washing } \\
\text { Time (hours) }\end{array}$} & \multicolumn{4}{|c|}{ Gold Leached (ppm) } \\
\hline & & \multicolumn{2}{|c|}{ Seed } & \multicolumn{2}{|c|}{ Composite } \\
\hline & & $\begin{array}{l}\mathrm{ppm} \pm 0.5 \\
\mathrm{ppm}\end{array}$ & $\begin{array}{c}\% \text { Total Gold } \\
\text { Loading }\end{array}$ & $\begin{array}{l}\text { pppm } \pm \\
0.5 \text { ppm }\end{array}$ & $\begin{array}{l}\text { \% Total } \\
\text { Gold } \\
\text { Loading }\end{array}$ \\
\hline \multirow[t]{5}{*}{ RT } & 0.5 & 0.4 & 0.2 & 0.8 & 0.3 \\
\hline & 1 & 0.3 & 0.2 & 0.9 & 0.4 \\
\hline & 2 & 0.3 & 0.2 & 0.8 & 0.3 \\
\hline & 5 & 0.4 & 0.3 & 0.6 & 0.3 \\
\hline & 24 & 0.6 & 0.3 & 1.0 & 0.4 \\
\hline \multirow[t]{4}{*}{$50^{\circ} \mathrm{C}$} & 0.5 & 0.4 & 0.3 & 1.7 & 0.7 \\
\hline & 1 & 0.6 & 0.4 & 2.5 & 1.1 \\
\hline & 2 & 0.5 & 0.3 & 2.7 & 1.1 \\
\hline & 24 & 0.5 & 0.3 & 1.7 & 0.7 \\
\hline
\end{tabular}




\subsubsection{Chlorine Hercosett Treatment}

In order to ascertain the applicability of the gold nanoparticle-merino wool composites prepared via the seed mediated approach in consumer applications, shrink resistant chlorine Hercosett treatments were applied. As with the colourfastness to washing and leaching tests, this treatment was undertaken on a composite prepared from seed 5, with a gold concentration of $4.2 \times 10^{-4} \mathrm{M}$ and $\mathrm{a}\left[\mathrm{Au}^{3+}\right]:\left[\mathrm{NH}_{2} \mathrm{OH}\right]$ ratio of 1:64. Figure 8.42 shows this composite material both before and after chlorine Hercosett treatment. The treatment clearly had a detrimental effect on the colour of the composite, causing areas to turn a dirty gold/brown colour. As with all other gold nanoparticle-merino wool composites (sections 4.1.2.7 and 5.10), this colour change is likely due to the oxidation of the $\mathrm{Au}^{0}$ nanoparticles bound to the fibres to $\mathrm{Au}^{3+}$ (scheme 4.4), which subsequently combine with $\mathrm{Cl}^{-}$ions generated in the process, forming yellow/brown $\mathrm{AuCl}_{4}{ }^{-}$(scheme 4.5).
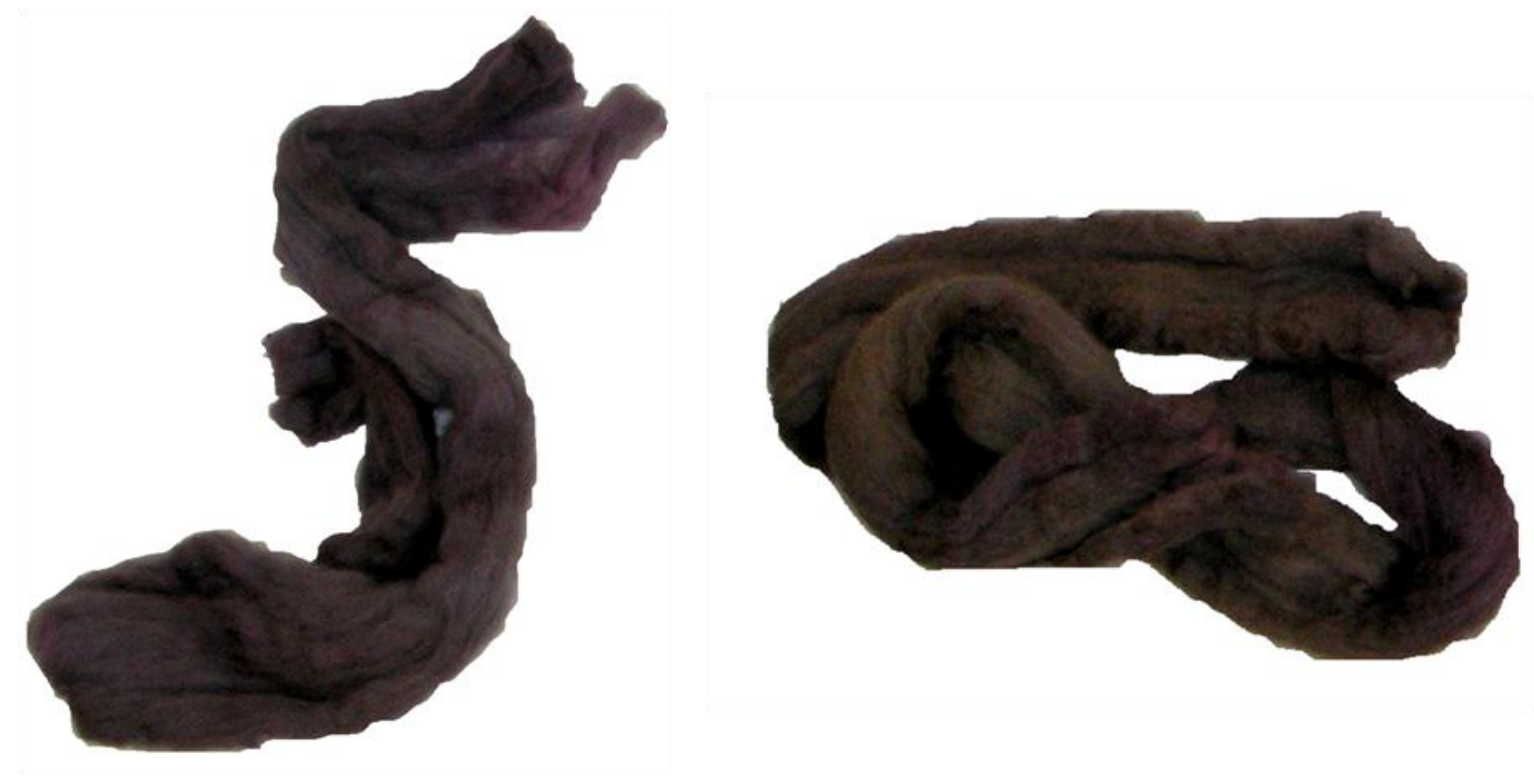

Figure 8.42: Right: a gold nanoparticle-merino wool composite prepared via the seed mediated approach. Left: the same composite material following chlorine Hercosett treatment. 


\subsection{Alternative Substrates}

This technology was extended to alternative substrates, notably crossbred wool and silk, with relatively successful results. As with the merino wool composites, the colour of the resultant materials was dependent upon the seed, gold concentration and ratio of $\left[\mathrm{Au}^{3+}\right]:\left[\mathrm{NH}_{2} \mathrm{OH}\right]$ employed, with those incorporating crossbred wool ranging in colour from light grey/pink to grey and dark purple/black, and silk from light grey to dark purple/black. The production of these composites was based on the most successful synthesis methods of the merino wool materials, notably gold concentrations of $4.2 \times 10^{-4} \mathrm{M}$ or $6.77 \times 10^{-4} \mathrm{M}$ were employed and the ratio of $\left[\mathrm{Au}^{3+}\right]:\left[\mathrm{NH}_{2} \mathrm{OH}\right]$ varied from $1: 16$ to $1: 128$.

\subsubsection{Crossbred Wool}

As with merino wool and silk, the seed mediated approach was successfully employed in the production of grey coloured gold nanoparticle-crossbred wool composites.

\subsubsection{Seeds}

Crossbred wool is not dissimilar to merino wool in its chemical composition, with the main differences being the average fibre diameter and typical processing routes. As a result, in much the same way as merino wool, the redox nature of crossbred wools was exploited in the reduction of $\mathrm{Au}^{3+}$ to nanoparticulate $\mathrm{Au}^{0}$ producing seeds. This involved soaking crossbred wool in gold solutions at room temperature, with gentle agitation, followed by ageing at $50^{\circ}$ C for various times (Table8.8). 
Table 8.8: Gold nanoparticle-crossbred wool seed source preparation.

\begin{tabular}{ccccc}
\hline Seed & $\begin{array}{c}\text { Gold Solution } \\
\left(\text { Vol } \mathbf{4} \mathbf{~ w t} \% \mathbf{A u}^{3+} \text { added }\right)\end{array}$ & $\begin{array}{c}\text { Soak Time } \\
(\mathbf{R T}, \text { hours })\end{array}$ & $\begin{array}{c}\text { Heat Time } \\
\left(\mathbf{5 0} \mathbf{~}^{\circ} \text { hours }\right)\end{array}$ & $\begin{array}{c}\text { Colour } \\
\text { (Figure 8.43) }\end{array}$ \\
\hline $\mathbf{1}$ & $10 \mu \mathrm{L} \rightarrow 10 \mathrm{ml}$ & 24 & 24 & Very faint pink \\
$\mathbf{2}$ & & & 168 & Faint pink \\
$\mathbf{3}$ & $20 \mu \mathrm{L} \rightarrow 10 \mathrm{ml}$ & 24 & Pink \\
$\mathbf{4}$ & & 268 & Deep pink \\
$\mathbf{5}$ & $40 \mu \mathrm{L} \rightarrow 10 \mathrm{ml}$ & 24 & Purple \\
$\mathbf{6}$ & & 268 & Deep purple \\
\hline
\end{tabular}

$\begin{array}{lllllll}1 & 2 & 3 & 4 & 5 & 6 \\ & & & & & \\ & & & & \end{array}$

Figure 8.43: Seeds used in the production of gold nanoparticle-crossbred wool composites.

The characterization of these seeds is provided in detail in section $\mathbf{5 . 2}$, as with merino wool, increasing the concentration of gold employed in the production of these materials resulted in a greater amount of gold nanoparticles incorporated into the fibres. These nanoparticles were predominantly spheres, (approximately $20 \mathrm{~nm}$ in diameter), however they also formed as hexagons (approximately $50 \mathrm{~nm}$ in diameter), triangles (approximately 70-100 $\mathrm{nm}$ in diameter) and truncated triangles (approximately $50-100 \mathrm{~nm}$ in diameter). Increasing the ageing time also saw a slight increase in amount of gold nanoparticles in the fibres (Figure 8.44), however unlike in merino wool, these nanoparticles were formed predominantly on the fibre surfaces rather than in the centre (Figure 8.45) (see section 5.2). 

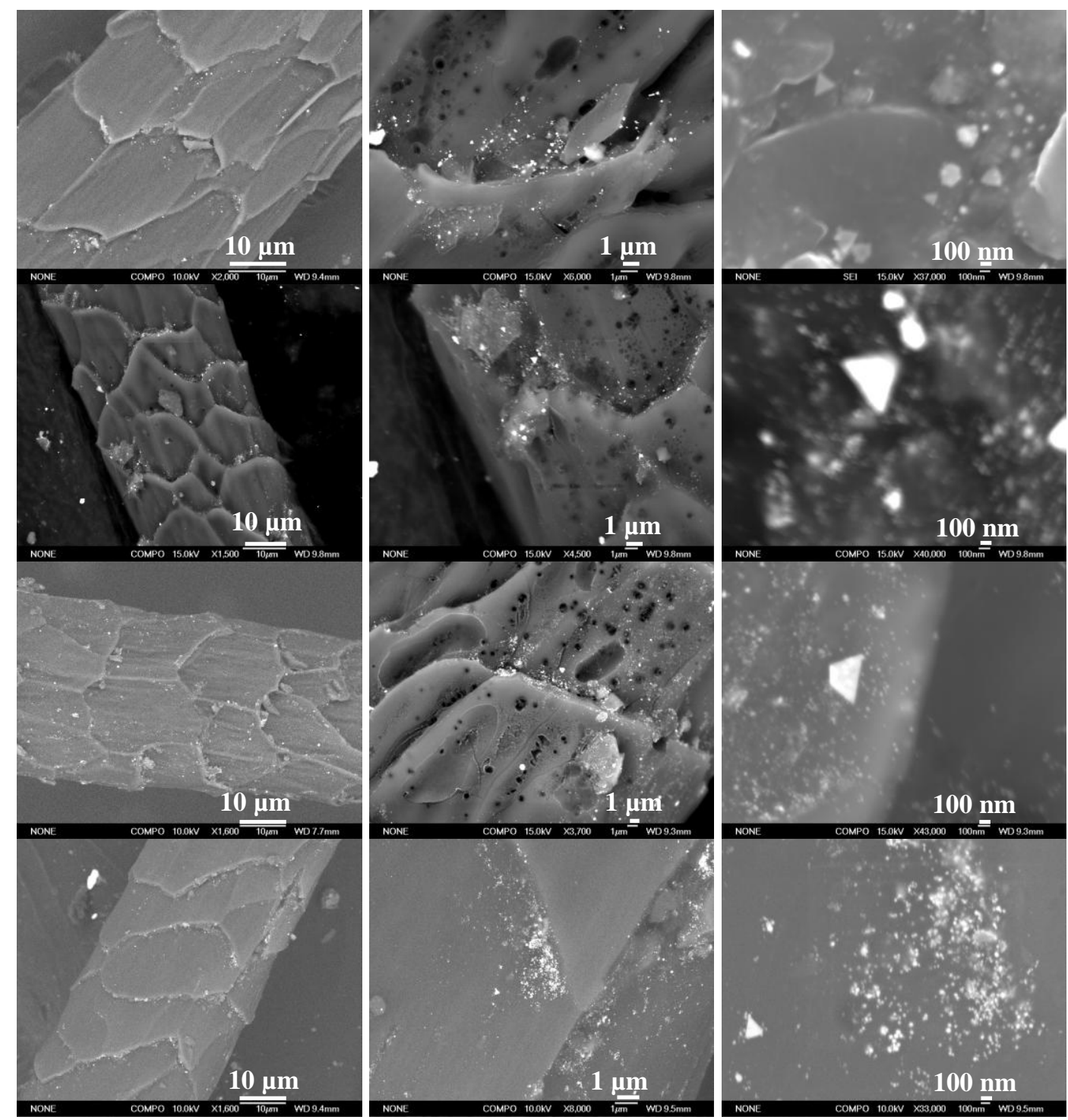

Figure 8.44: Increasing magnification SEM micrographs of seeds employed in the production of gold nanoparticle-crossbred wool composites. Top to bottom, seed 1, seed 3, seed 4 and seed 6.
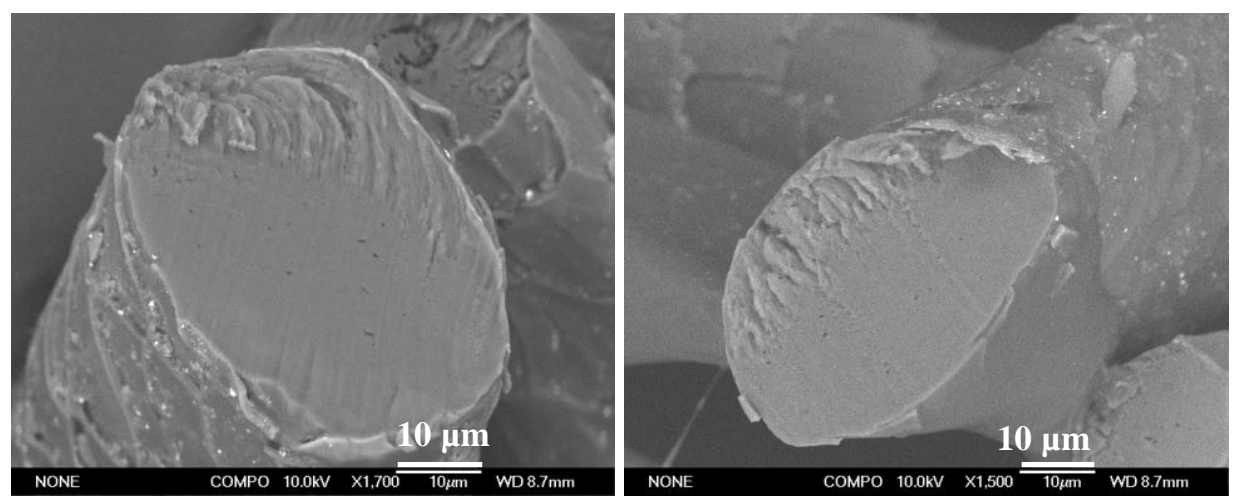

Figure 8.45: Cross sectional SEM micrographs of seed 4 (left) and seed 6 (right). 


\subsubsection{Physical Characterisation and Morphology}

The resultant gold nanoparticle-crossbred wool composites ranged in colour from light pink/grey to deep purple/grey (Figure 8.46). As with the systems incorporating merino wool and silk, these colours were dependent upon the seed, gold concentration and ratio of $\left[\mathrm{Au}^{3+}\right]:\left[\mathrm{NH}_{2} \mathrm{OH}\right]$ employed.

Due to the time constraints imparted on this research, a comprehensive morphological study of the produced composites could not be carried out. However SEM analysis of a composite prepared from seed 2, a gold concentration of $4.2 \times 10^{-4} \mathrm{M}$ and a $\left[\mathrm{Au}^{3+}\right]:\left[\mathrm{NH}_{2} \mathrm{OH}\right]$ concentration ratio of 1:128 was undertaken, and similar trends to those seen in the merino wool and silk systems were observed. The results are offered in Figure 8.47 below.

The presence of both large, micron scale gold nanoparticles and agglomerated nanoparticles are evident on the surface of the crossbred wool fibres (circled). There are also smaller, approximately $20 \mathrm{~nm}$ diameter nanoparticles present that do not appear to have increased in size during the reduction of additional $\mathrm{Au}^{3+}$ to $\mathrm{Au}^{0}$ by $\mathrm{NH}_{2} \mathrm{OH}$. These nanoparticles may have remained unchanged following the production of the composites as the nanoparticles in the seeds are located primarily on the surface of the wool fibres rather than also in the centre, as is the case with the merino wool seeds. Therefore during the production of the composites, there may have been excess sites at which the surface catalysed reduction of $\mathrm{Au}^{3+}$ could occur, resulting in some particles not increasing in size. 


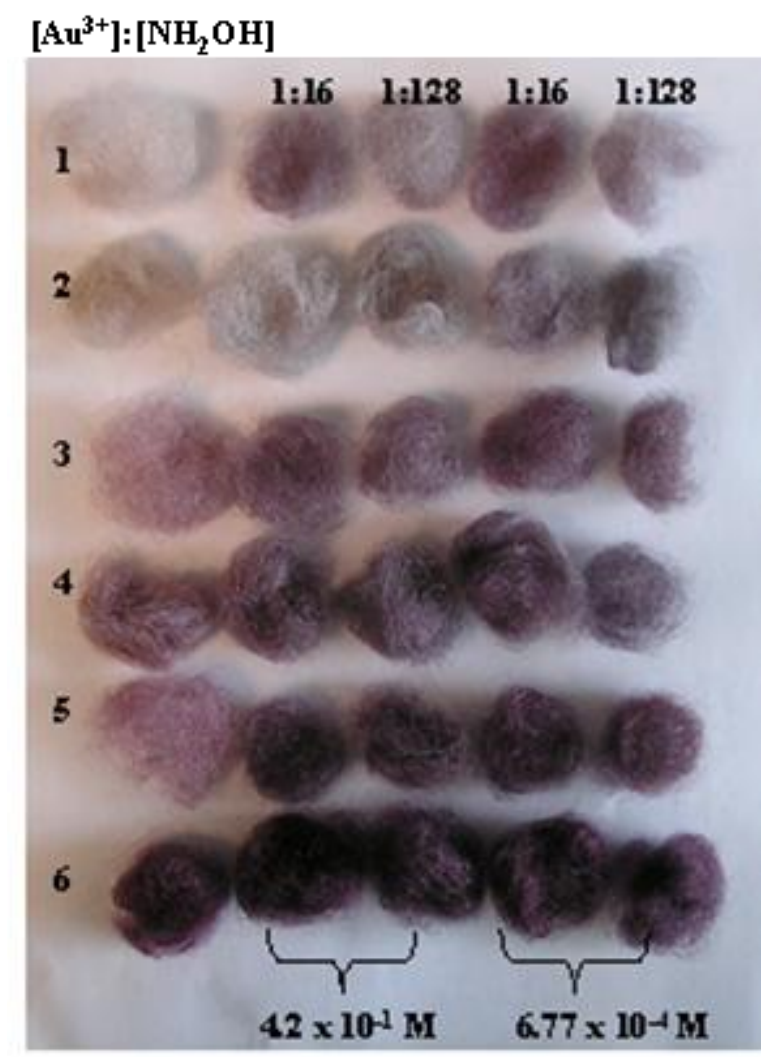

Figure 8.46: Gold nanoparticle-crossbred wool composites prepared via the seed mediated approach.
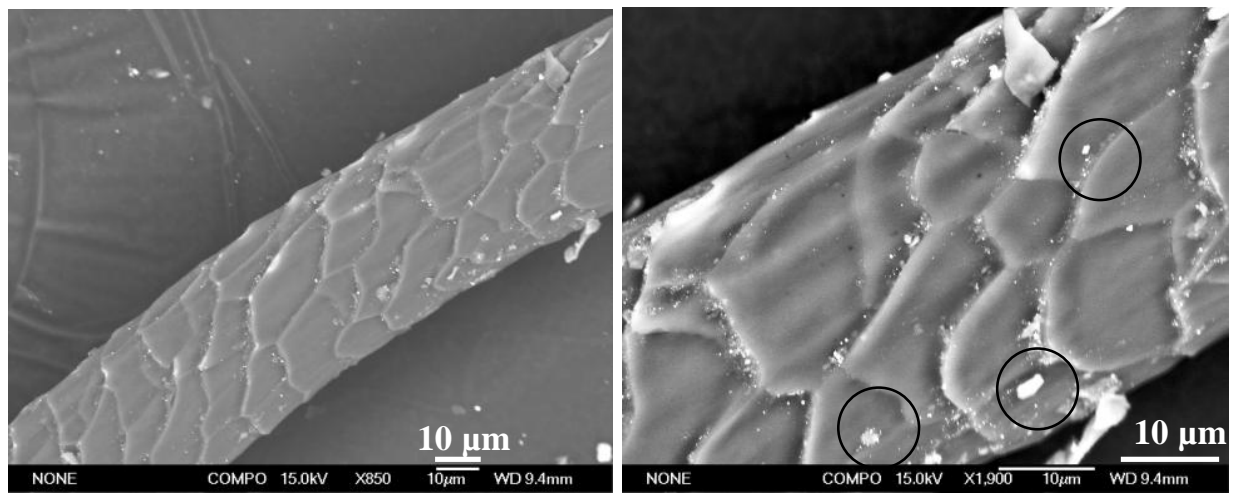

Figure 8.47: Increasing micrographs of a gold nanoparticle-crossbred wool composite prepared from seed 2, a gold concentration of $4.2 \times 10^{-4} \mathrm{M}$ and a $\left[\mathrm{Au}^{3+}\right]:\left[\mathrm{NH}_{2} \mathrm{OH}\right]$ concentration ratio of 1:128.

Additionally, it is likely that the composites prepared from seed 1 or 4 were slightly greyer in colour than those prepared from seed 3 or 6 , (which were more purple/black), was related to the ratio of $\mathrm{Au}^{3+}: \mathrm{Au}^{0}$ present in the seeds. As compared to seed 3 or 6 , less $\mathrm{Au}^{3+}$ had been reduced to $\mathrm{Au}^{0}$ in seeds 1 or 4 . Therefore there were fewer gold surfaces at which the reduction of additional $\mathrm{Au}^{3+}$ by $\mathrm{NH}_{2} \mathrm{OH}$ could occur, and relatively more $\mathrm{Au}^{3+}$ to reduce, 
resulting in materials with an increased amount of agglomerates present in the composite relative to isolated particles.

Similarly, the presence of these smaller nanoparticles would account for the fact that the majority of gold nanoparticle-crossbred composites exhibited a slight purple or pink tinge, rather than appearing purely grey in colour, as was the case with a selection of the merino wool composite materials (Figure 8.11).

\subsubsection{Colour}

As with the merino wool and silk materials prepared via the seed mediated approach, the factors that exerted the greatest influence on the colour of the crossbred composites were the seed and the gold concentration. In general, employing seeds containing greater concentrations of unreduced gold (seeds 1 or 4), saw the production of greyer coloured materials, whilst those prepared from seeds in which there was a higher ratio of $\mathrm{Au}^{0}: \mathrm{Au}^{3+}$ (seeds 2-3, 5-6) appeared more purple/black in colour. It was suggested above that the colour of the composites was related to the ratio of large, agglomerated gold nanoparticles and smaller isolated particles. With higher ratios (more agglomerated particles relative to isolated particles) producing greyer materials, and lower, purple/black materials. This was reflected in the Kubelka Munk transformed UV/Vis reflection spectrum of composites prepared from seed 1 and seed 3, under identical reaction conditions, as the plasmon peak of those prepared from seed 1 exhibited a broader full width at half maximum than those materials prepared from seed 3 (Figure 8.48), suggesting more agglomeration in materials prepared from seed 1 compared to seed 3.

Similar to the merino wool and silk materials, depending on the seed source employed, increasing the gold concentration, and also the ratio of $\left[\mathrm{Au}^{3+}\right]:\left[\mathrm{NH}_{2} \mathrm{OH}\right]$ resulted in the production of greyer or darker purple/black coloured materials. Again this is mirrored in the Kubelka Munk transformed UV/Vis reflection spectrum of the gold nanoparticle-crossbred wool composites, with higher gold concentrations inducing either an increase in the full 
width at half maximum, or an increase in intensity, of the plasmon peak centred at approximately $550 \mathrm{~nm}$ for systems incorporating seed 1 and 4 (Figure 8.49) or 2-3 and 5-6 respectively (Figure 8.50). The peaks centred at approximately 508 and $700 \mathrm{~nm}$, which are representative of the transverse and longitudinal plasmon bands of anisotropic gold nanoparticles did not change position or full width at half maximum, suggesting they did not increase in size to a great extent during the production of the composites.

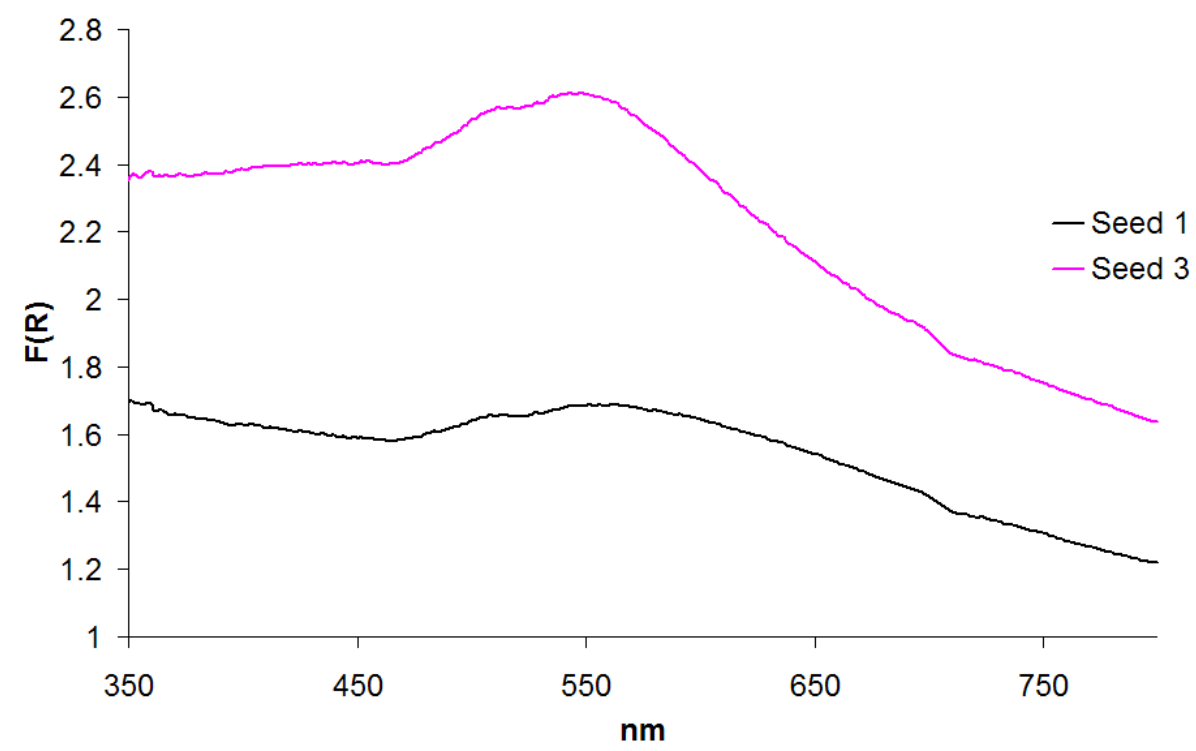

Figure 8.48: Kubelka Munk transformed UV/Vis reflection spectra of composites prepared from seed 1 and seed 3, with a gold concentration of $6.77 \times 10^{-4} \mathrm{M}$ and a $\left[\mathrm{Au}^{3+}\right]$ : $\left[\mathrm{NH}_{2} \mathrm{OH}\right]$ concentration ratio of 1:128.

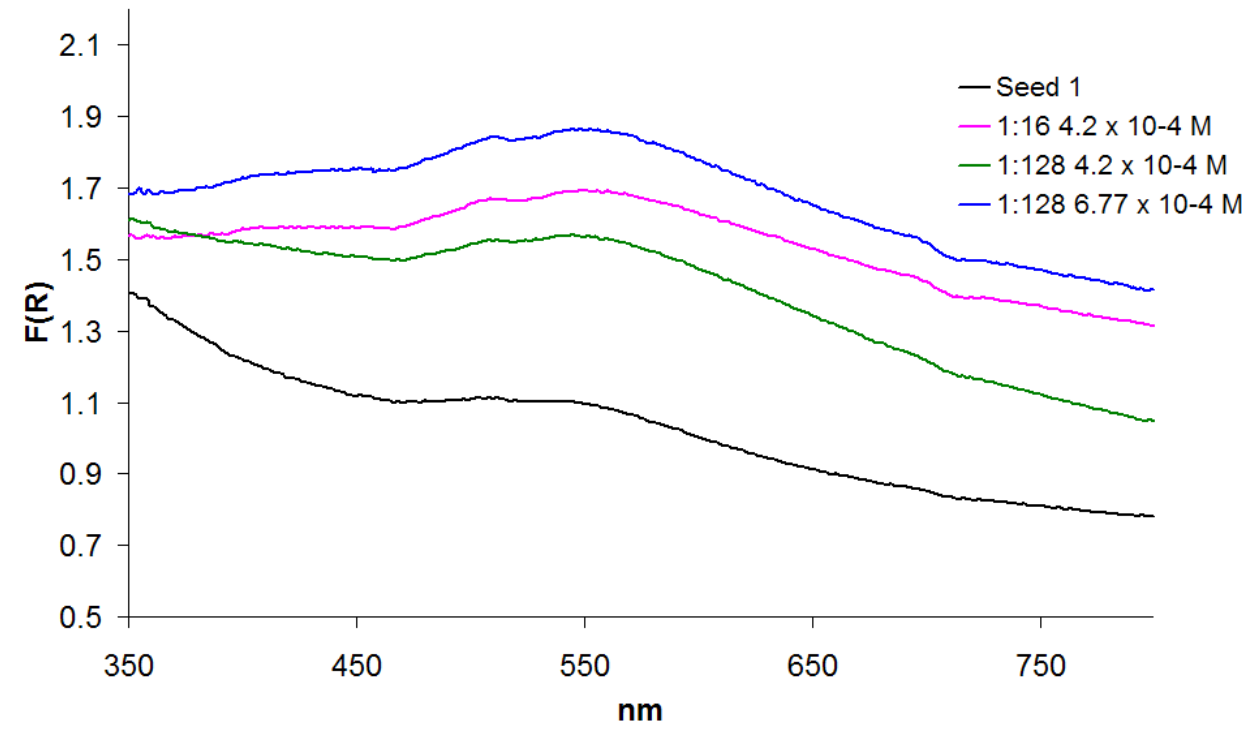

Figure 8.49: Kubelka Munk transformed UV/Vis reflection spectra of composites prepared from seed 1, various gold concentrations and ratios of $\left[\mathrm{Au}^{3+}\right]:\left[\mathrm{NH}_{2} \mathrm{OH}\right]$. 


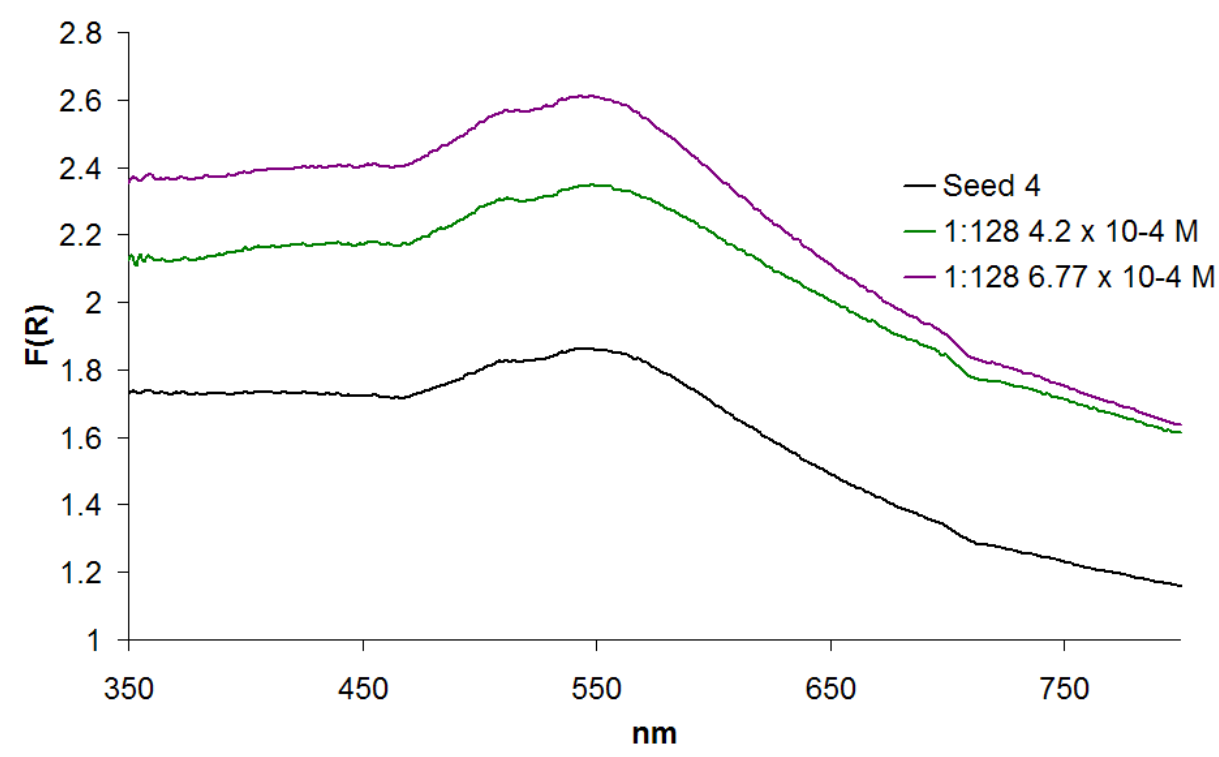

Figure 8.50: Kubelka Munk transformed UV/Vis reflection spectra of composites prepared from seed 4, various gold concentrations and ratios of $\left[\mathrm{Au}^{3+}\right]:\left[\mathrm{NH}_{2} \mathrm{OH}\right]$.

\subsubsection{Bonding of Gold Nanoparticles to Crossbred Wool Fibres}

As the gold nanoparticle-crossbred wool composites are not dissimilar to the corresponding merino wool materials, it is likely that bonding between the gold nanoparticles in the composites and the crossbred wool fibres occur in much the same way as the bonding between the gold and crossbred wool in the seeds, as was the case with the merino wool composites. SEM analysis suggested this, as the formation of larger gold particles and agglomerates occurred in areas where nanoparticles predominantly resided in the seeds, notably along cuticle edges. And as the reduction of $\mathrm{Au}^{3+}$ to $\mathrm{Au}^{0}$ by $\mathrm{NH}_{2} \mathrm{OH}$ is greatly accelerated by gold surfaces, it is likely that similar to the merino wool systems, the reduction of additional $\mathrm{Au}^{3+}$ occurred directly on the surface of the nanoparticles in the seeds, not altering the bonding between the crossbred wool fibres and gold nanoparticles. 


\subsubsection{Colourfastness to Washing}

As with the merino wool and silk composites, the colourfastness to washing of the gold nanoparticle-crossbred wool materials were tested according to the synthesis outlined in section 2.3.14. A composite prepared from seed 1, a gold concentration of $4.2 \times 10^{-4} \mathrm{M}$ and a $\left[\mathrm{Au}^{3+}\right]:\left[\mathrm{NH}_{2} \mathrm{OH}\right]$ ratio of 1:16 was chosen to be representative of gold nanoparticle-crossbred composites prepared via the seed mediated approach

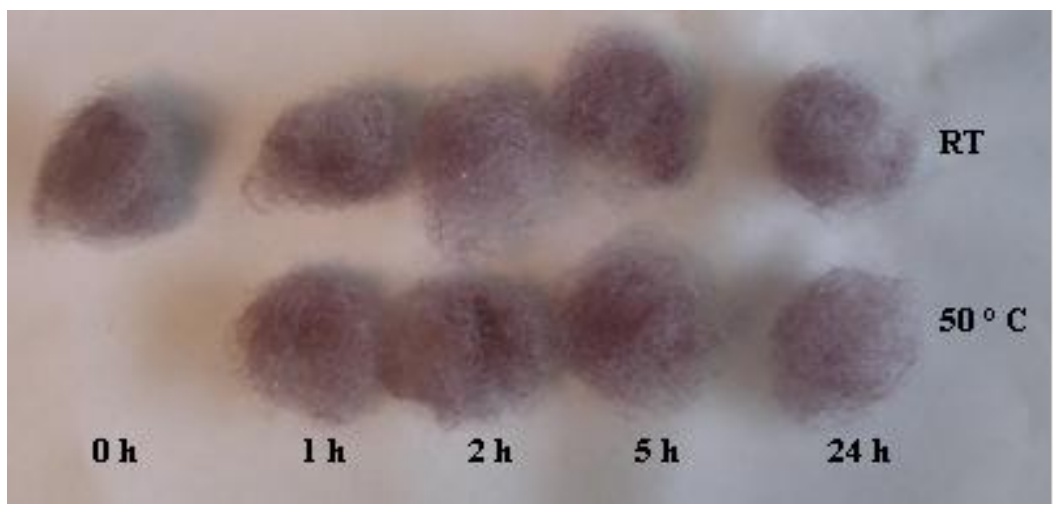

Figure 8.51: Gold nanoparticle-crossbred wool composites prepared from seed 1, a gold concentration of $4.2 \times 10^{-4} \mathrm{M}$ and a $\left[\mathrm{Au}^{3+}\right]:\left[\mathrm{NH}_{2} \mathrm{OH}\right]$ ratio of 1:16 following simulated washability testing.

Visually these materials appeared to be colourfast with respect to washing, exhibiting no apparent colour change even following 24 hours washing at $50{ }^{\circ} \mathrm{C}$ (Figure 8.51). This colour stability is illustrated in the Kubelka Munk transformed UV/Vis reflection spectrum of the composite following washing, as the plasmon band of the gold attached to the composites, centred at approximately $550 \mathrm{~nm}$, does not change position or intensity significantly (Figure 8.52). There is however a slight decrease in full width at half maximum of this peak following two hours washing at RT. This did not decrease any further following extended washing. This decrease in peak width was more apparent at $50{ }^{\circ} \mathrm{C}$, however as with washing at RT, prolonged washing did not accentuate this change. This suggests the dislodgment of weakly bound surface atoms during washing, and a slight change in colour from grey to grey with a slightly redder hue, although this is not discernable to the naked eye. 


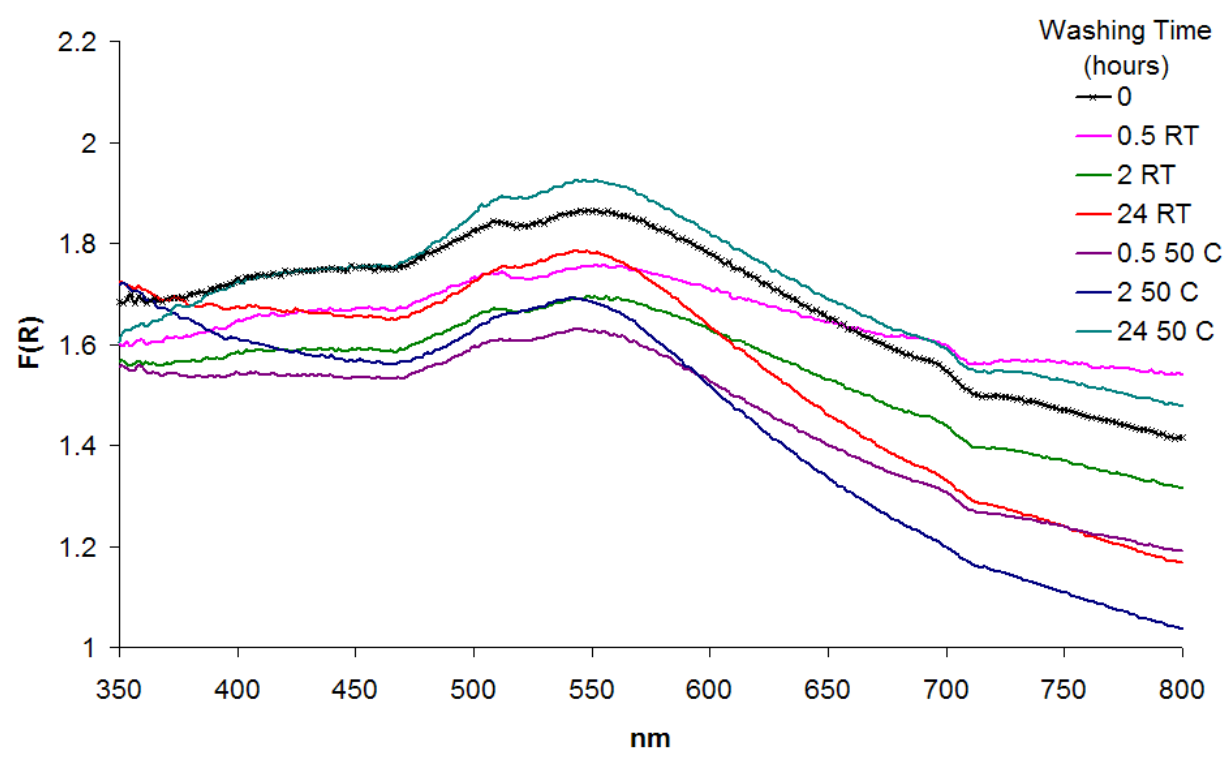

Figure 8.52: Kubelka Munk transformed UV/Vis reflection spectra of a gold nanoparticle-crossbred composite following washing at $\mathrm{RT}$ or $50^{\circ} \mathrm{C}$.

\subsubsection{Leaching}

Quantitative analysis of the washing solutions (section 8.2.1.5) suggested the leaching of very low amounts of gold, up to a maximum of $4.8 \mathrm{ppm} \pm 0.5 \mathrm{ppm}$, or $2 \%$ of the total gold loading (comparable to that of the seed source) (Table 8.9) confirming the very minor narrowing of the plasmon band of gold in the washed composites, and their visual colourfastness to washing. 
Table 8.9: Gold leached from a gold nanoparticle-crossbred composite (prepared via the seed mediated approach) and the corresponding seed source following simulated washability testing.

\begin{tabular}{|c|c|c|c|c|c|}
\hline \multirow{3}{*}{$\begin{array}{c}\text { Washing } \\
\text { Temperature }\end{array}$} & \multirow{3}{*}{$\begin{array}{c}\text { Washing } \\
\text { Time (hours) }\end{array}$} & \multicolumn{4}{|c|}{ Gold Leached $(\mathrm{ppm}) \pm 0.5 \mathrm{ppm}$} \\
\hline & & \multicolumn{2}{|c|}{ Seed } & \multicolumn{2}{|c|}{ Composite } \\
\hline & & $\begin{array}{c}\mathrm{ppm} \pm 0.5 \\
\mathrm{ppm}\end{array}$ & $\begin{array}{l}\% \text { Total Gold } \\
\text { Loading }\end{array}$ & $\begin{array}{c}\mathrm{ppm} \pm 0.5 \\
\mathrm{ppm}\end{array}$ & $\begin{array}{l}\text { \% Total } \\
\text { Gold } \\
\text { Loading }\end{array}$ \\
\hline \multirow[t]{5}{*}{ RT } & 0.5 & 1.3 & 0.8 & 1.2 & 0.5 \\
\hline & 1 & 1.8 & 1.1 & 1.1 & 0.5 \\
\hline & 2 & 1.7 & 1.0 & 1.4 & 0.6 \\
\hline & 5 & 1.4 & 0.9 & 1.9 & 0.8 \\
\hline & 24 & 2.1 & 1.3 & 1.9 & 0.4 \\
\hline \multirow[t]{5}{*}{$50^{\circ} \mathrm{C}$} & 0.5 & 2.5 & 1.6 & 2.2 & 0.9 \\
\hline & 1 & 2.2 & 1.4 & 4.8 & 2.0 \\
\hline & 2 & 2.2 & 1.4 & 3.7 & 2.0 \\
\hline & 5 & 2.6 & 1.6 & 3.0 & 1.2 \\
\hline & 24 & 2.2 & 1.4 & 3.5 & 1.4 \\
\hline
\end{tabular}

\subsubsection{Silk}

\subsubsection{Seeds}

As with merino wool, the redox nature of silk (described in detail in section 7.6) was exploited in the production of seed sources. This involved dispersing silk in a $160 \mathrm{ppm}$ $\left(8.125 \times 10^{-4} \mathrm{M}\right)$ gold solution, at various $\mathrm{pH}$ 's, followed by heating at $50{ }^{\circ} \mathrm{C}$ for extended periods of time. The seed production methods are outlined in Table 8.10 below. 
Table 8.10: Gold nanoparticle-silk seed source preparation. (Note a gold concentration of $160 \mathrm{ppm}(8.125$ $\mathrm{x} 10^{-4} \mathrm{M}$ ) was employed in the synthesis).

\begin{tabular}{ccccc}
\hline Seed & $\mathbf{p H}$ & $\begin{array}{c}\text { Soak Time } \\
\text { (RT, hours) }\end{array}$ & $\begin{array}{c}\text { Age Time } \\
\left(\mathbf{5 0}{ }^{\circ} \mathbf{C}, \text { hours }\right)\end{array}$ & Colour \\
\hline $\mathbf{1}$ & 3 & 1 & - & Very pale purple \\
$\mathbf{2}$ & 5 & - & Pale purple \\
$\mathbf{3}$ & 6 & 24 & Dark purple \\
$\mathbf{4}$ & & - & 1 & Pale purple \\
$\mathbf{5}$ & & - & 5 & Purple \\
$\mathbf{6}$ & $9-10$ & 1 & - & White \\
$\mathbf{7}$ & & 5 & - & White \\
$\mathbf{8}$ & & 6 & 24 & Bright purple \\
$\mathbf{9}$ & & - & 1 & Pale pink \\
\hline
\end{tabular}

When prepared at a $\mathrm{pH}$ of 3 , the gold nanoparticles formed predominantly on the surface of the silk fibres, rather than in the centre (Figure 8.53 top), with increasing soaking and ageing times producing materials with a greater proportion of gold nanoparticles (approximately 15$20 \mathrm{~nm}$ in diameter) on the silk surface (Figure 8.54). Increasing the $\mathrm{pH}$, from $\sim 3$ to $9-10$ (which falls to a $\mathrm{pH}$ of approximately 7.8 due to the buffer effect of the amino acids in the silk fibres) results in a slower reduction of $\mathrm{Au}^{3+}$ to $\mathrm{Au}^{0}$ by the silk, and thus $\mathrm{Au}^{3+}$ is capable of diffusing through to the centre of the fibre prior to being reduced to $\mathrm{Au}^{0}$, resulting in the formation of slightly smaller spherical nanoparticles both on the surface of the fibre (approximately 10-15 $\mathrm{nm}$ in diameter) (Figure 8.53 bottom and Figure 8.56 middle), and also in the centre (approximately 5-10 $\mathrm{nm}$ in diameter) (see section 7.1) (Figure 8.55 and Figure 8.56 right). 

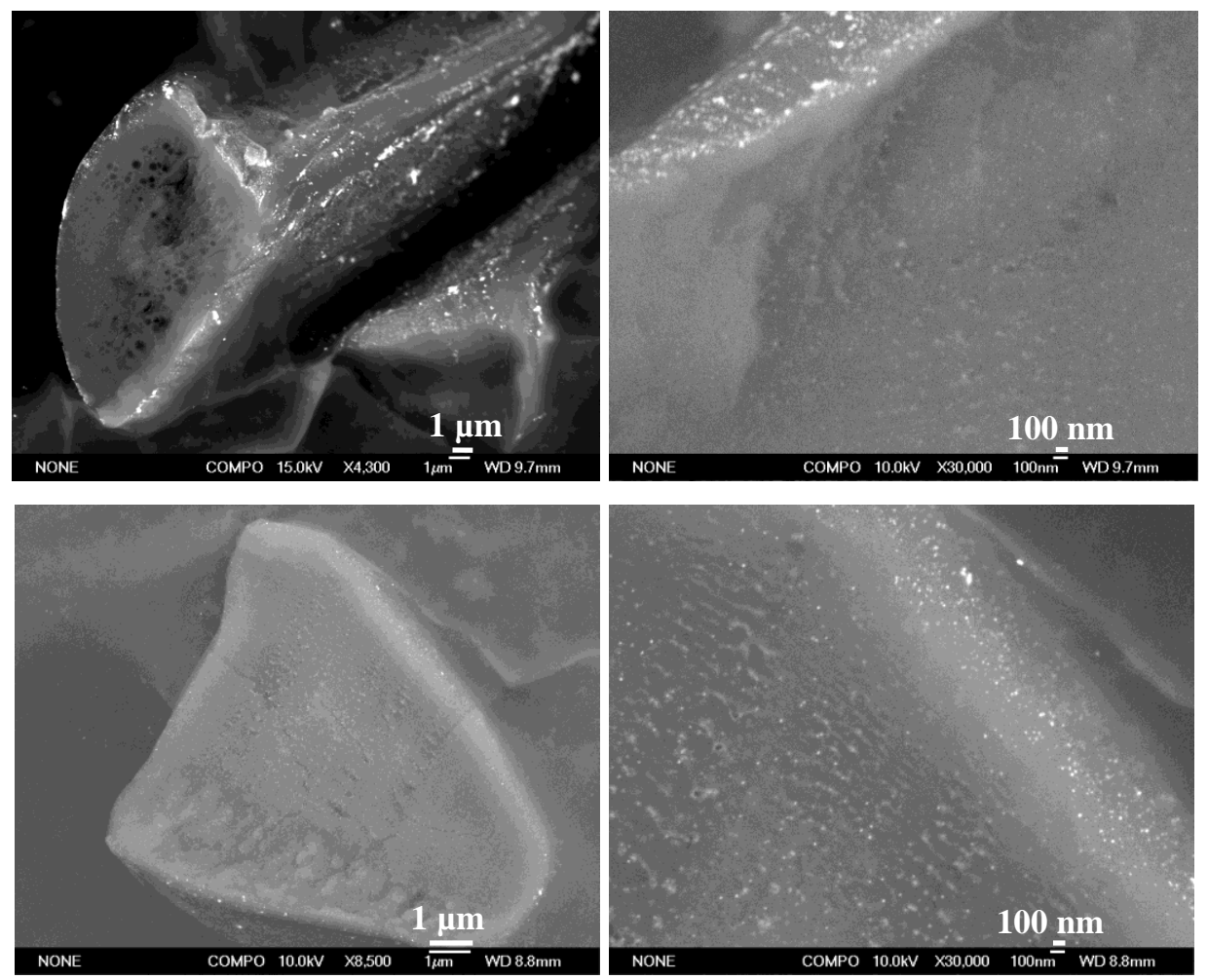

Figure 8.53: Increasing magnification (left to right) cross sectional SEM micrographs of silk seeds prepared with one hour soaking at RT followed by 24 hours at $50^{\circ} \mathrm{C}$. Top: the gold solution had a pH of $\sim 3$, whilst the bottom had a pH of 9-10.
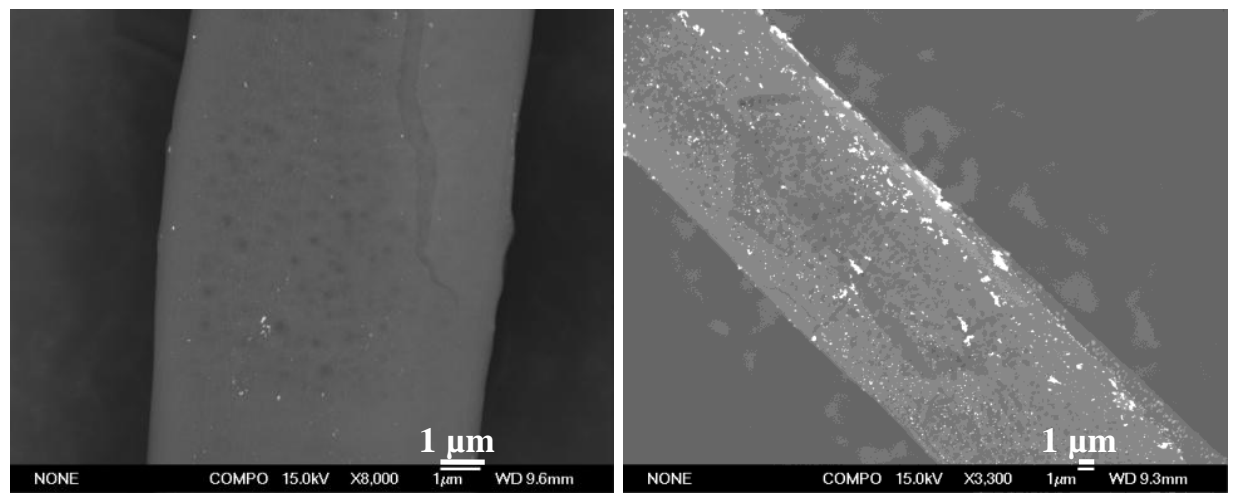

Figure 8.54: a) SEM micrographs of silk seeds prepared at RT, with a pH 3 gold solution, 10 minutes (left) and 1 hour reaction time (right ). Shows effect of increasing soaking time. 

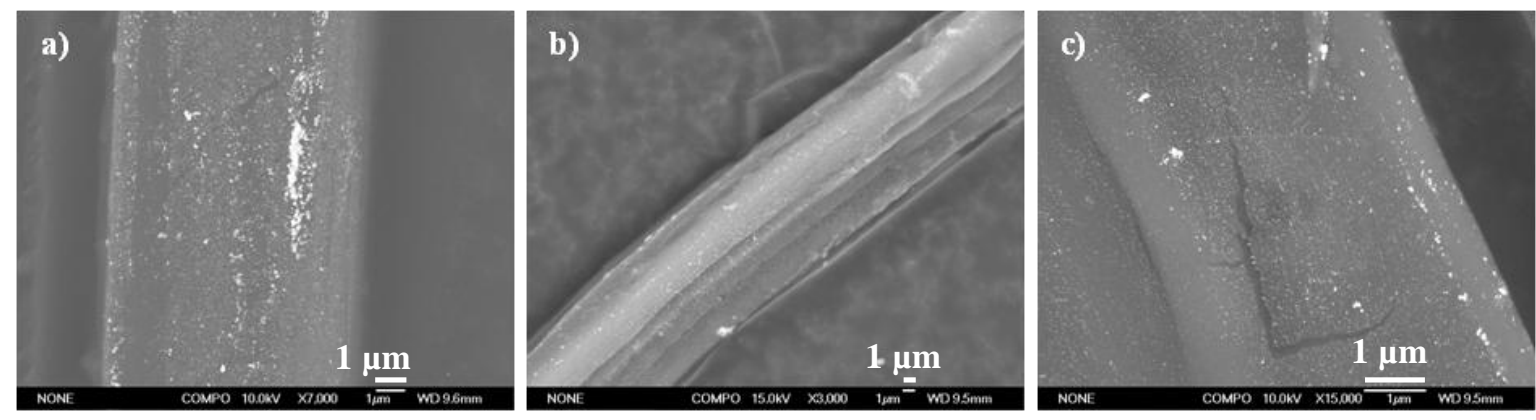

Figure 8.55: SEM micrographs of gold nanoparticle-silk composites prepared with a 6 hour soaking time and 24 hour heating time. a) Soaking in a gold solution of pH 3, b) and c) pH 9-10. Shows effect of increased $\mathbf{p H}$.
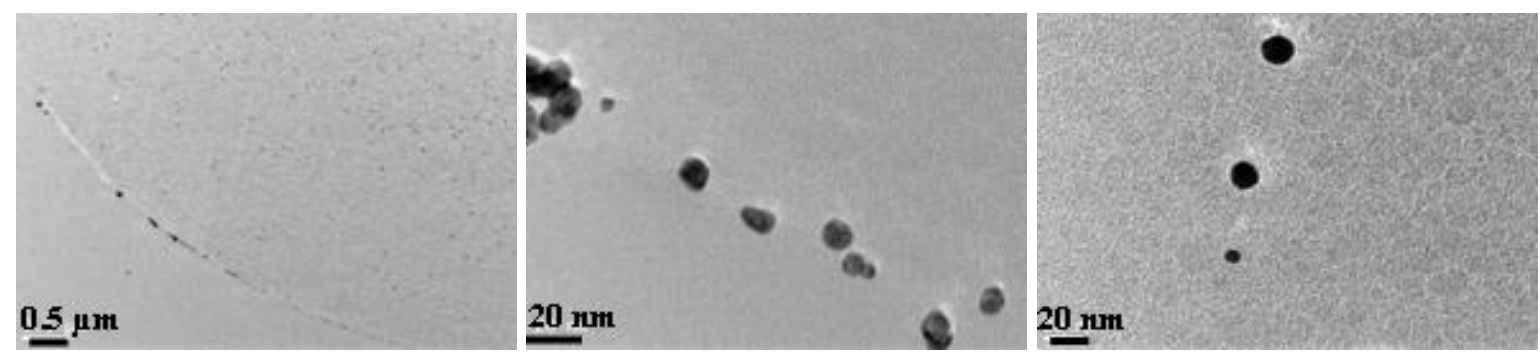

Figure 8.56: TEM micrographs of a silk seed prepared with a 6 hour soaking time in a pH 9-10 gold solution and 24 hours heating at $50{ }^{\circ} \mathrm{C}$. Left: Micrograph showing fibre surface and centre. Middle: Micrograph showing nanoparticles on the fibre surface and right: micrograph showing nanoparticles in the fibre centre.

\subsubsection{Physical Characterisation and Morphology}

The resultant gold nanoparticle-silk composites ranged in colour from very pale grey to purple/black (Figure 8.57 and Figure 8.58). As with the corresponding composites incorporating merino wool, seeds in which nanoparticles had formed and which also possessed a greater proportion of unreduced $\mathrm{Au}^{3+}$, notably seeds 9 and 1 , were the most successful in the production of grey coloured composites. (The reaction time employed in the preparation of seeds 6 and 7 was insufficient to produce a significant number of gold nanoparticles), whilst those prepared from seeds 2, 3, 8, 4 and 5 appeared more purple than grey, regardless of the gold concentration or $\left[\mathrm{Au}^{3+}\right]:\left[\mathrm{NH}_{2} \mathrm{OH}\right]$ ratio. 


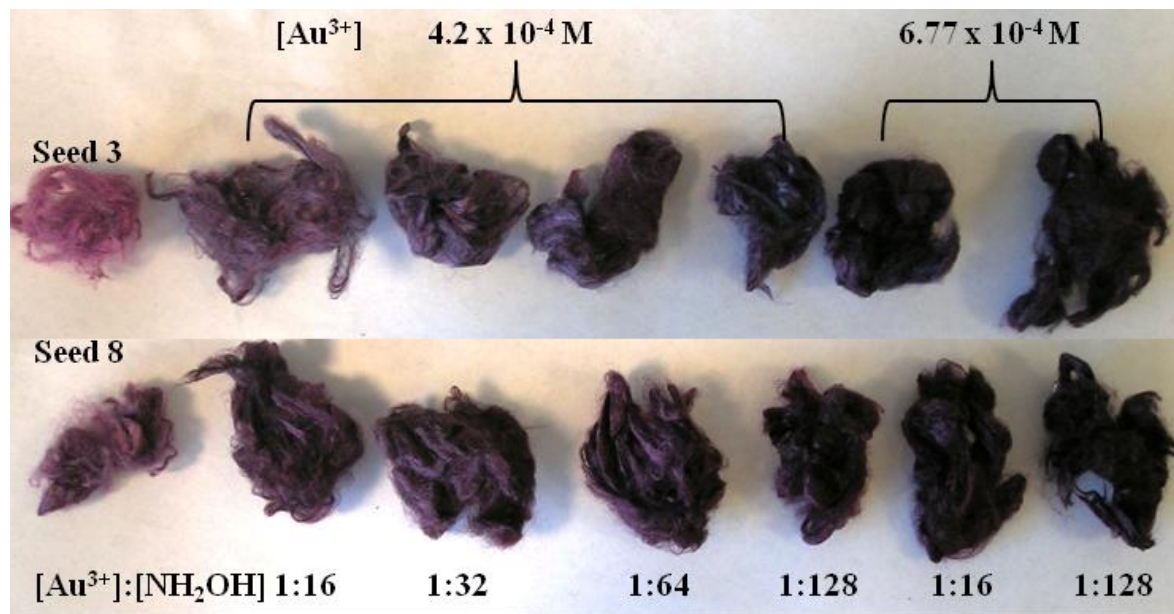

Figure 8.57: Gold nanoparticle-silk composites prepared from seed 3 (top) and seed 8 (bottom), employing a gold concentration of $4.2 \times 10^{-4} \mathrm{M}$ or $6.77 \times 10^{-4} \mathrm{M}$, and a $\left[\mathrm{Au}^{3+}\right]:\left[\mathrm{NH}_{2} \mathrm{OH}\right]$ ratio of 1:161:128.

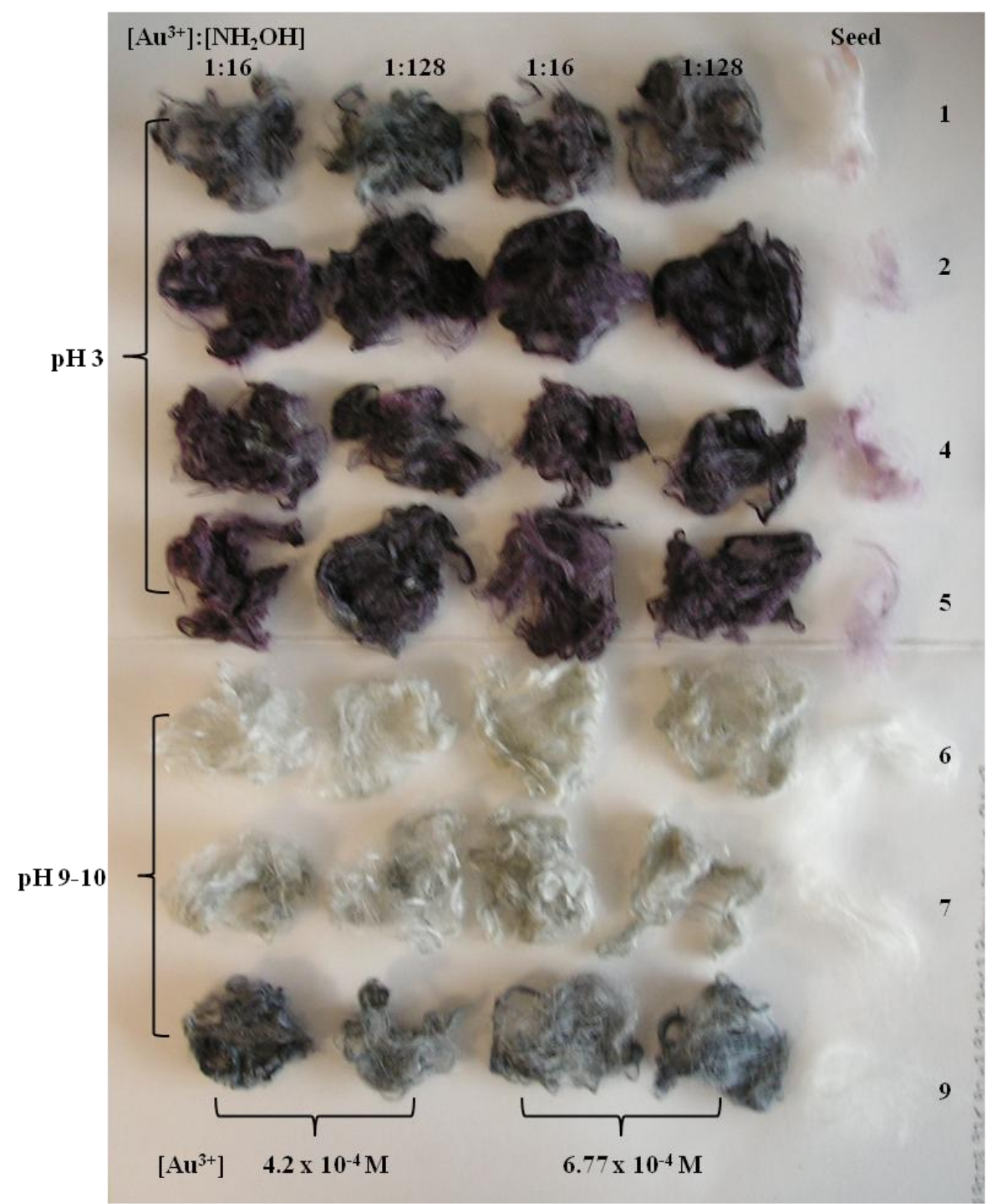

Figure 8.58: Gold nanoparticle-silk composites prepared from seeds 1, 2, 4, 5, 6, 7 and 9 (top to bottom), employing a gold concentration of $4.2 \times 10^{-4} \mathrm{M}$ or $6.77 \times 10^{-4} \mathrm{M}$, and a $\left[\mathrm{Au}^{3+}\right]:\left[\mathrm{NH}_{2} \mathrm{OH}\right]$ ratio of between $1: 16-1: 128$. 
SEM revealed the gold in the silk composites to be present largely as $50 \mathrm{~nm}$ nanoparticles, agglomerated together. Although they are not apparent in the obtained micrographs, it is likely that anisotropic gold nanoparticles, such as triangular nanoplates are also present on these materials, as they were present in the seed sources, and UV/Vis spectroscopy of the composites suggests their presence (section 8.3.2.3). It can be seen from Figure 8.59 that similarly to the corresponding gold nanoparticle-merino wool composites, increasing both the gold concentration and the ratio of $\left[\mathrm{Au}^{3+}\right]:\left[\mathrm{NH}_{2} \mathrm{OH}\right]$ resulted in the formation of a greater amount of similarly sized (approximately $50 \mathrm{~nm}$ in diameter) nanoparticles, agglomerated together. Also similarly to the merino wool composites, the reduction of additional $\mathrm{Au}^{3+}$ to $\mathrm{Au}^{0}$ appeared to occur predominantly on the surface of the silk fibres (Figure 8.60).
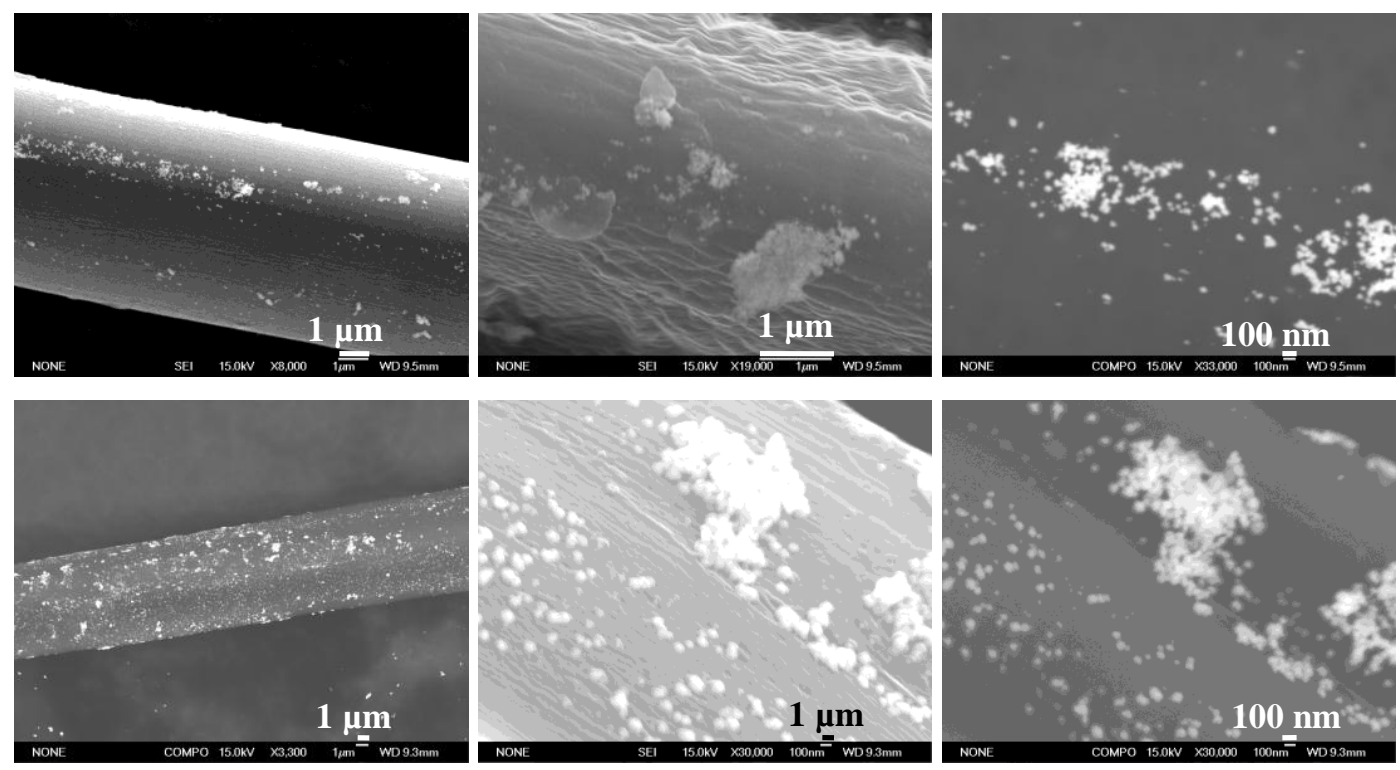

Figure 8.59: Increasing magnification SEM micrographs of gold nanoparticle-silk composites prepared via the seed mediated approach. Top: incorporating seed 1, a gold concentration of $4.2 \times 10^{-4} \mathrm{M}$ and a $\left[\mathrm{Au}^{3+}\right]:\left[\mathrm{NH}_{2} \mathrm{OH}\right]$ ratio of 1:16. Bottom: incorporating seed 1, a gold concentration of $6.8 \times 10^{-4} \mathrm{M}$ and a $\left[\mathrm{Au}^{3+}\right]:\left[\mathrm{NH}_{2} \mathrm{OH}\right]$ ratio of 1:128.

The morphology of composites prepared from alternative seeds could not be characterized due to time constraints. However it is likely that as with the merino wool materials, the more purple/black coloured composites (prepared from seeds 2-5) possessed both large agglomerates and smaller isolated nanoparticles upon which additional $\mathrm{Au}^{3+}$ had not been reduced further to $\mathrm{Au}^{0}$. 


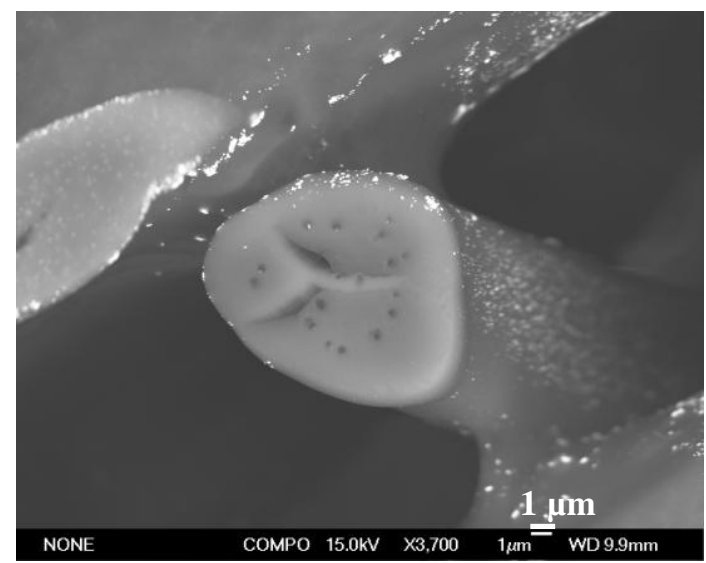

Figure 8.60: Cross sectional SEM micrograph of a gold nanoparticle-silk composite prepared via the seed mediated approach.

\subsubsection{Colour}

As with the composites incorporating merino wool, the variables that had the largest influence on colour development in the silk materials were the seed source and gold concentration. All seeds employed in the production of the silk composites were made with $160 \mathrm{ppm} \mathrm{Au}^{3+}$, with the only difference in the seed synthesis being the $\mathrm{pH}$ of the reaction mixture and the reaction time. As mentioned, during the production of the seeds, increasing the reaction time resulted in the production of a greater number of nanoparticles deposited on the silk surface (approximately 20-25 nm in diameter), whilst increasing the $\mathrm{pH}$ slowed the reduction rate and resulted in the formation of a decreased amount of much smaller nanoparticles both on the surface and within the fibres (approximately 5-10 and 10-15 nm in diameter respectively).

Composites prepared from seeds with a large amount of both unreduced $\mathrm{Au}^{3+}$ and nanoparticulate $\mathrm{Au}^{0}$, notably seeds 1 and 9 were the most successful in the production of grey coloured composites (Figure 8.58). Seeds 6 and 7 also possessed a large amount of $\mathrm{Au}^{3+}$, however $\mathrm{NH}_{2} \mathrm{OH}$ was unable to reduce a substantial amount of $\mathrm{Au}^{3+}$ in these seeds as they had insufficient nanoparticulate $\mathrm{Au}^{0}$ to catalyse the reduction. Utilising seeds in which more $\mathrm{Au}^{3+}$ had been reduced to $\mathrm{Au}^{0}$ (seeds 2, 3, 4, 5 and 8) resulted in the production of darker 
purple/black coloured composites. Considering this, there must exist a relationship between the colour of the resultant composites and the ratio of $\mathrm{Au}^{3+}: \mathrm{Au}^{0}$ present in the seeds.

The influence of the seeds on the colour of the resultant composites is mirrored in the Kubelka Munk transformed UV/Vis reflection spectra of the materials (Figure 8.61). When employing a $\mathrm{Au}^{3+}$ concentration of $6.77 \times 10^{-4} \mathrm{M}$, and a $\left[\mathrm{Au}^{3+}\right]:\left[\mathrm{NH}_{2} \mathrm{OH}\right]$ ratio of $1: 128$ the resultant composites prepared from seed 6 , in which there was a large proportion of $\mathrm{Au}^{3+}$, but no $\mathrm{Au}^{0}$, were white/colourless and as such did not exhibit any plasmon bands. Employing seed 9 , in which there was more $\mathrm{Au}^{3+}$ but still some $\mathrm{Au}^{0}$ saw the formation of grey coloured composites, and a very broad peak in the UV/Vis spectrum centred at approximately $565 \mathrm{~nm}$, and two smaller peaks at approximately 508 and $700 \mathrm{~nm}$. Utilising seed 4 in which the majority of $\mathrm{Au}^{3+}$ had been reduced to $\mathrm{Au}^{0}$ produced purple/black coloured composites, which exhibited a slightly narrower plasmon peak centred at approximately $550 \mathrm{~nm}$, with the same small peaks at approximately 508 and $700 \mathrm{~nm}$. The peaks centred at $550 \mathrm{~nm}$ are indicative of spherical or five-fold twinned gold nanoparticles, whilst those at 508 and $700 \mathrm{~nm}$ represent the transverse and longitudinal plasmon bands respectively of anisotropic gold nanoparticles. The decrease in full width at half maximum of the main peak at $550 \mathrm{~nm}$, and its slight increase in intensity seen when employing seed 4 reflects the increased spectral purity of these composites.

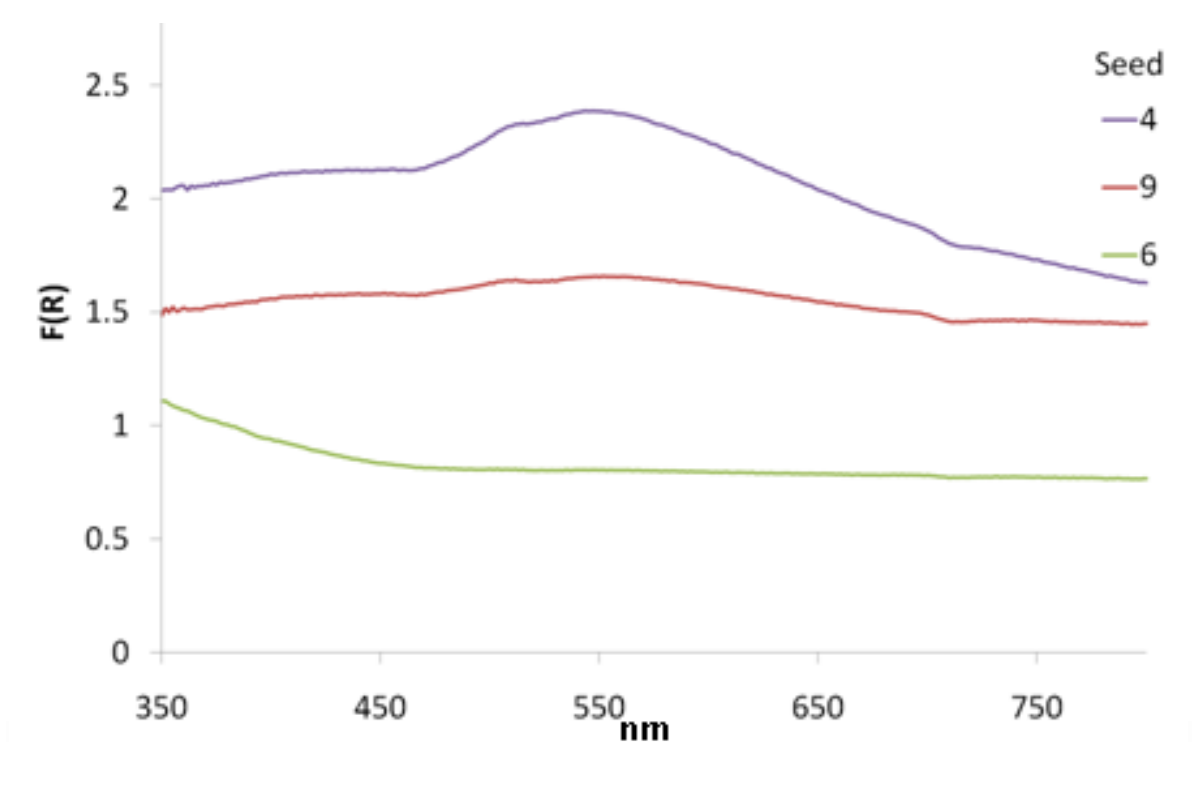

Figure 8.61: Kubelka Munk transformed UV/Vis reflection spectra of composites prepared from various seeds, with a gold concentration of $4.2 \times 10^{-4} \mathrm{M}$ and a a $\left[\mathrm{Au}^{3+}\right]:\left[\mathrm{NH}_{2} \mathrm{OH}\right]$ ratio of 1:128. 
In addition to the seed source, altering the amount of gold employed in the production of the composites also influenced the colour of the resultant materials, with increased gold concentrations producing deeper grey or purple/black coloured composites. SEM analysis suggested this colour change was due to a concentration effect, with more gold producing composites with an increased amount of nanoparticles. Again this colour change is illustrated in the Kubelka Munk transformed UV/Vis reflection spectra of the materials with increasing gold concentrations inducing an increase in intensity, blue shift and broadening of the plasmon bands centred at approximately 565 and $560 \mathrm{~nm}$ in the grey and purple/black coloured materials respectively (Figure 8.62 and Figure 8.63 respectively). The peaks representing anisotropic gold nanoparticles (centred at approximately 508 and $700 \mathrm{~nm}$ remained in relatively constant positions, suggesting they did not increase in size to any extent).

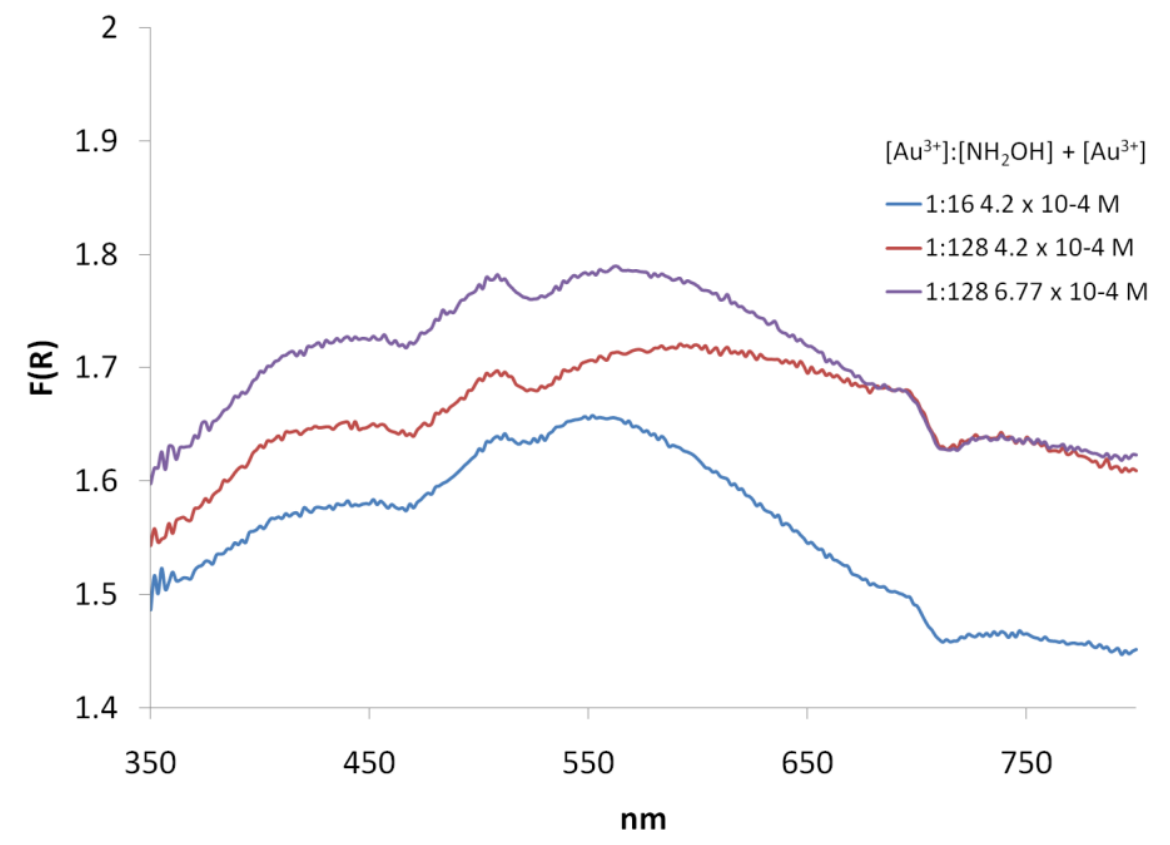

Figure 8.62: Kubelka Munk transformed UV/Vis reflection spectra of composites prepared from seed 9, with various gold concentrations and ratios of $\left[\mathrm{Au}^{3+}\right]:\left[\mathrm{NH}_{2} \mathrm{OH}\right]$. 


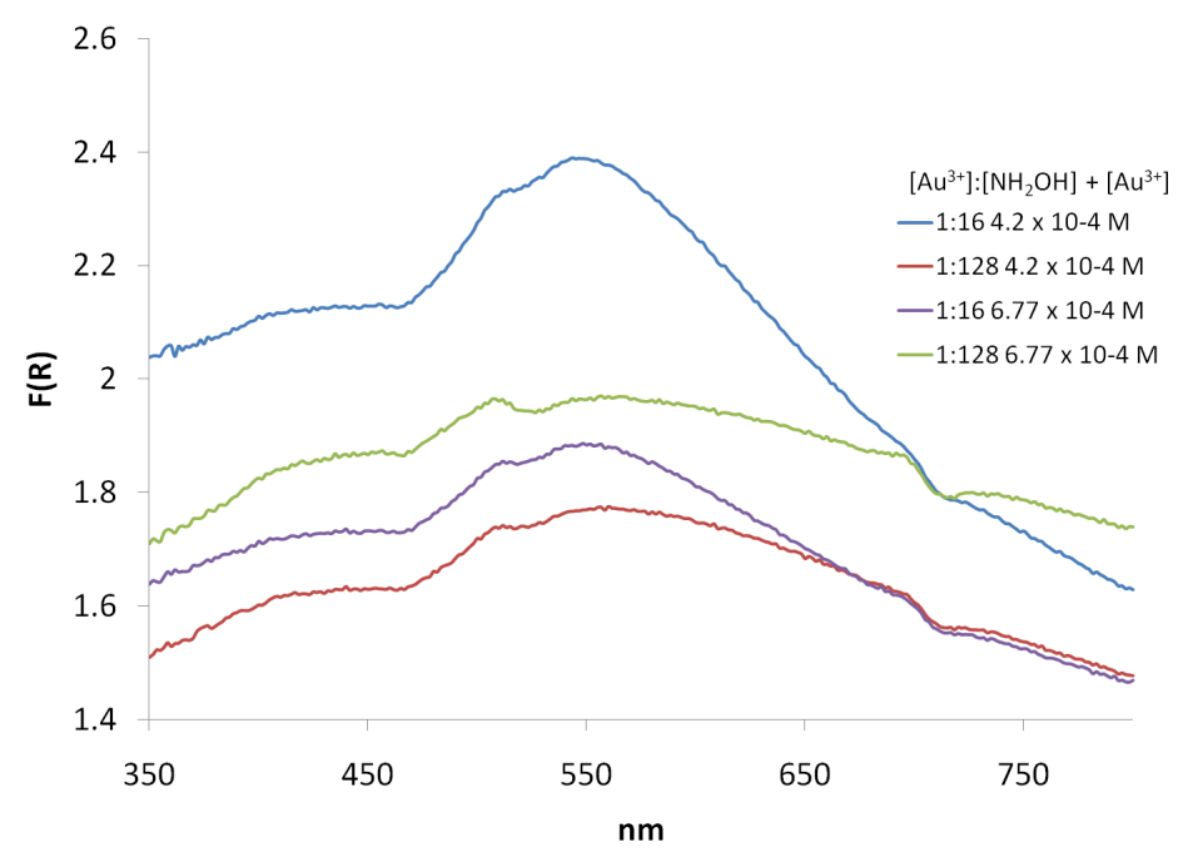

Figure 8.63: Kubelka Munk transformed UV/Vis reflection spectra of composites prepared from seed 5, with various gold concentrations and ratios of $\left[\mathrm{Au}^{3+}\right]:\left[\mathrm{NH}_{2} \mathrm{OH}\right]$.

The CIE L*, $\mathrm{a}^{*}, \mathrm{~b}^{*}, 457 \mathrm{~nm}$ brightness values and $580 \mathrm{~nm}$ brightness values of all gold nanoparticle-silk composites produced are provided in Appendix XI and reflect the materials colour change resulting from the utilisation of alternate seeds and gold concentrations.

\subsubsection{Confirmation of Gold}

As with the merino wool composites prepared via the seed mediated approach, the presence of gold in the silk materials was established with EDS. EDS confirmed the bright white dots evident on the surface of the composites evident when viewed under backscatter conditions, to be gold. Figure 8.64 offers the SEM and corresponding Au EDS map of a composite prepared from seed 1 , a gold concentration of $4.2 \times 10^{-4} \mathrm{M}$, and a $\left[\mathrm{Au}^{3+}\right]:\left[\mathrm{NH}_{2} \mathrm{OH}\right]$ concentration ratio of 1:16. High concentrations of gold are depicted in red and white areas. Additionally, Figure 8.65 offers a spectral snap shot of the area under analysis in Figure 8.64 and substantiates the existence of gold due to the presence of the gold peak. 

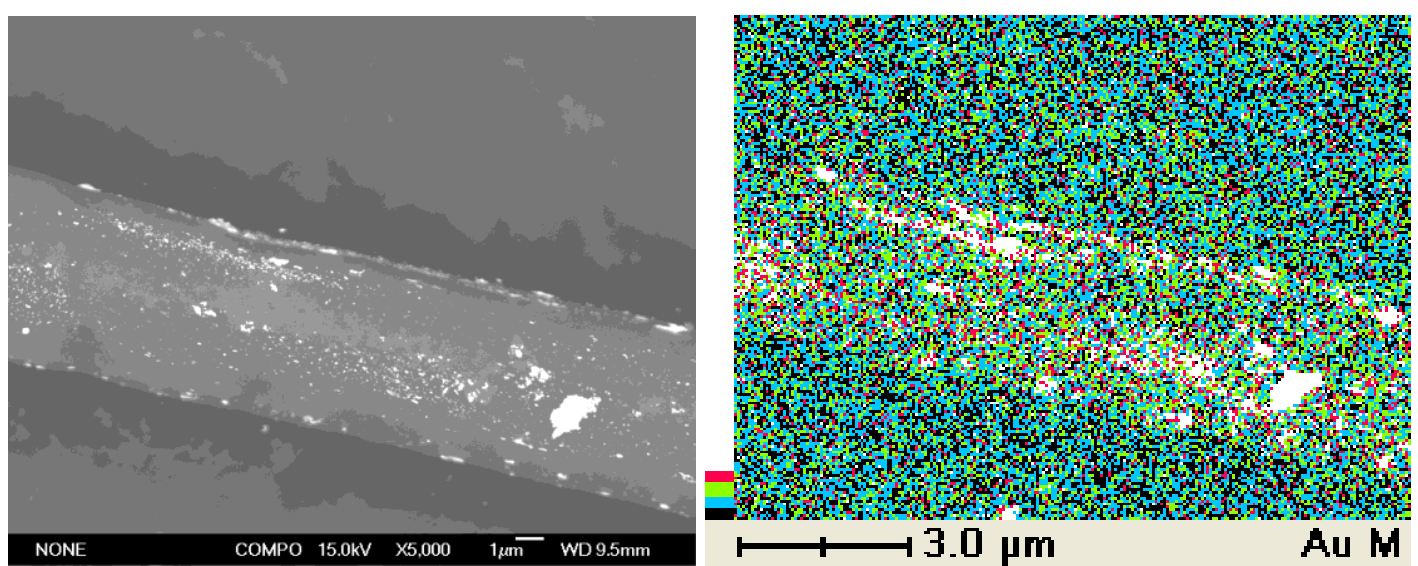

Figure 8.64: Left: Cross sectional SEM micrograph of a gold nanoparticle-silk composite prepared via the seed mediated approach and right: the corresponding EDS map.

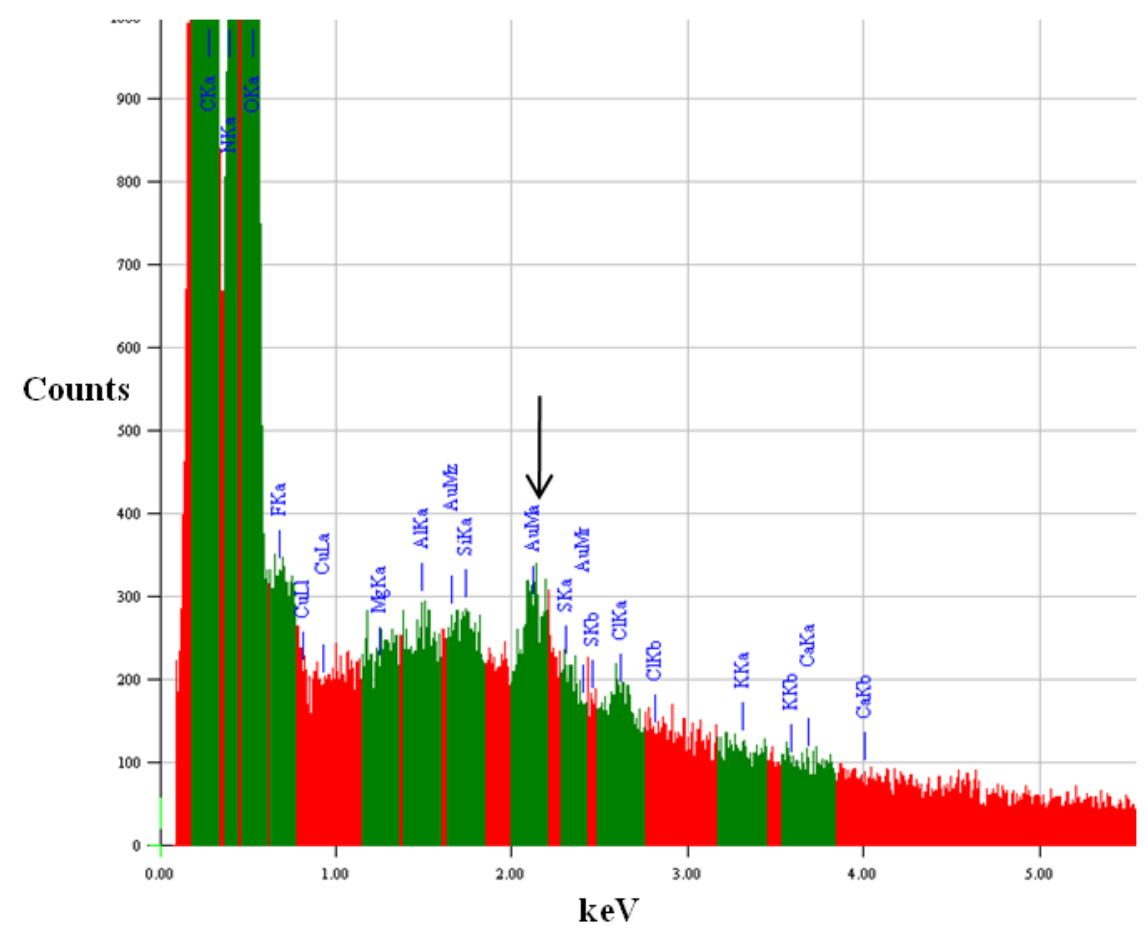

Figure 8.65: EDS spectrum of the gold nanoparticle-silk composite shown in Figure 8.64.

\subsubsection{Bonding of Gold Nanoparticles to Silk Fibres}

It is likely that the production of gold nanoparticle-silk composites occurred via a similar reaction mechanism to that of the corresponding merino wool materials, notably via the $\mathrm{NH}_{2} \mathrm{OH}$ gold surface catalysed reduction of $\mathrm{Au}^{3+}$ to $\mathrm{Au}^{0}$, resulting in the growth and agglomeration of gold nanoparticles present on the surface of the silk fibres (seeds). As such 
the bonding between the nanoparticles in the composites should be comparable to that of the bonding between the gold nanoparticles and silk in the seeds, notably through $\mathrm{N}$-Au and S$\mathrm{Au}$ bonds (see section 7.5). XPS studies will be undertaken in the future to verify/confirm this mode of bonding.

\subsubsection{Colourfastness to Washing}

As with the merino wool composites, the colourfastness to washing of the gold nanoparticlesilk composites were tested according to the synthesis outlined in section 2.3.14. A composite prepared from seed 1 , a gold concentration of $4.2 \times 10^{-4} \mathrm{M}$ and a $\left[\mathrm{Au}^{3+}\right]:\left[\mathrm{NH}_{2} \mathrm{OH}\right]$ ratio of 1:16 was chosen to be representative of gold nanoparticle-silk composites prepared via the seed mediated approach.

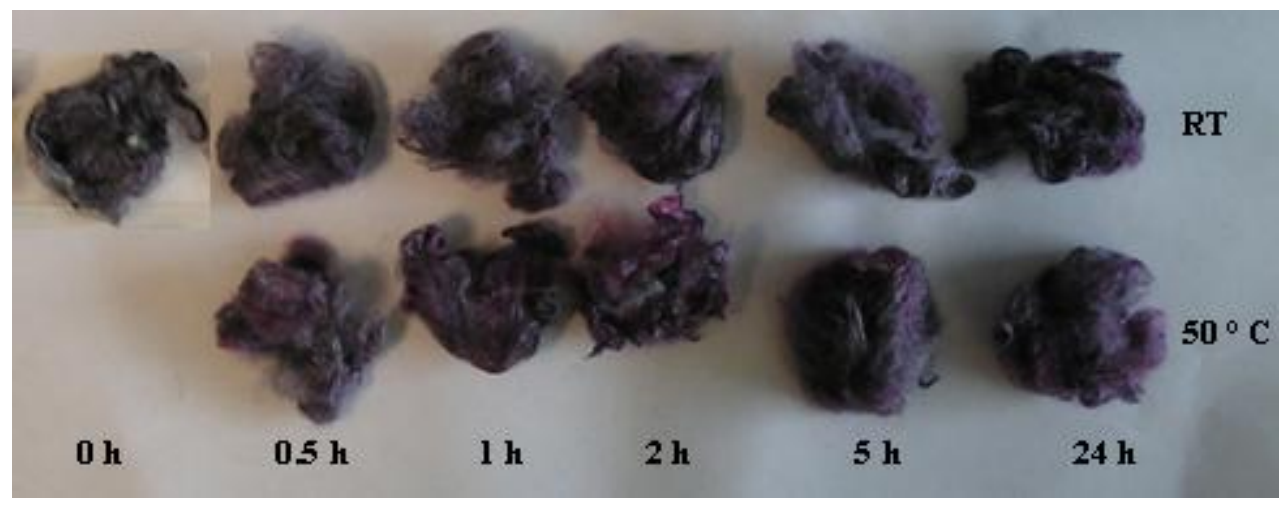

Figure 8.66: Gold nanoparticle-silk composites prepared from seed 1, a gold concentration of $4.2 \times 10^{-4} \mathrm{M}$ and $\left[\mathrm{Au}^{3+}\right]:\left[\mathrm{NH}_{2} \mathrm{OH}\right]$ ratio of 1:16 following simulated washability testing.

Visually these materials appear to be fairly colourfast with respect to washing, however there is a slight change from grey to purple with increased washing time and temperature (Figure 8.66). This is reflected in the Kubelka Munk transformed UV/Vis reflection spectrum of the washed samples, with continued washing resulting in a decrease in full width at half maximum of the gold plasmon peak (centred at approximately $545 \mathrm{~nm}$ ) of the composites following washing (Figure 8.67). This decrease is more apparent when washing at $50{ }^{\circ} \mathrm{C}$ compared to RT. As the full width at half maximum of the plasmon peak is related to the 
extent of agglomeration, and also the range of particle sizes and shapes present, this observed decrease is likely reflective of a dislodgement of loosely bound agglomerates.

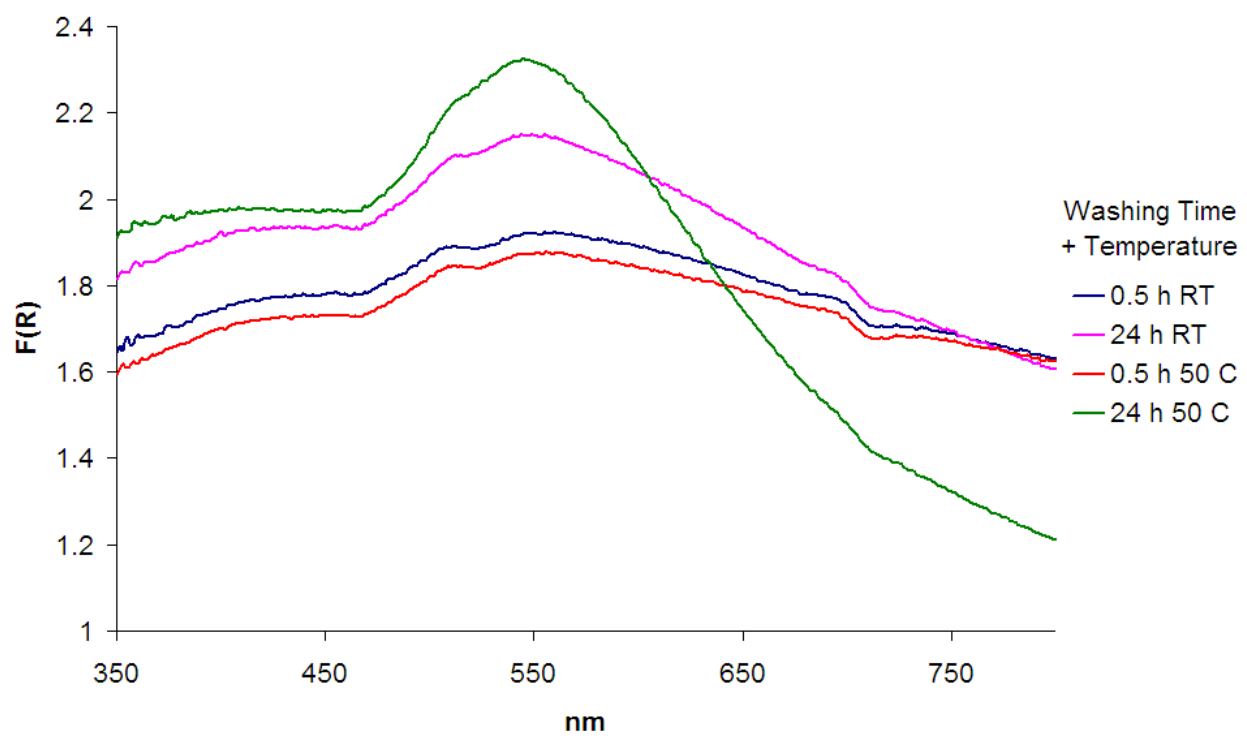

Figure 8.67: Kubelka Munk transformed UV/Vis reflection spectra of a gold nanoparticle-silk composite following simulated washability testing.

These gold nanoparticle-silk composites do not appear to be as colourfast with respect to washing compared to the corresponding merino or crossbred wool materials (sections 8.1.3.5 and 6.2.1.5 respectively). This may be attributable to the relative colour stability of the seed sources. The gold nanoparticles in the merino wool seeds are strongly bound to the fibres via a Au-S bond, and as such they, and the corresponding larger particles that grow around these are not easily dislodged. However in the silk seeds the gold is bound via a combination of Au-N bonds and through sericin, which can potentially be removed from silk fibres by washing at elevated temperatures.

\subsubsection{Leaching}

Quantitative analysis of the washing solutions obtained during simulated washability testing (section 8.3.2.6) was undertaken to establish the amount of gold leached from the composites 
during washing. Table 8.11 lists the amount of gold leached from the composite material and its corresponding seed. The maximum amount of gold leached from the composite materials was $5.0 \%$ of the total gold loading, and that of the corresponding seed $4.2 \%$, with the difference likely to be due to the dislodgement of weakly bound agglomerates in the composite materials. Compared to the merino and crossbred wool materials, the amount of gold leached from the silk materials is relatively large, approximately five times as much, and infers that the colour stability of the composites is directly related to the colour stability of the incorporated seeds, which is dependent upon the strength of the bond between the nanoparticles and fibres.

Table 8.11: Gold leached from a gold nanoparticle-silk composite (prepared via the seed mediated approach) and the corresponding seed source following simulated washability testing.

\begin{tabular}{|c|c|c|c|c|c|}
\hline \multirow{3}{*}{$\begin{array}{c}\text { Washing } \\
\text { Temperature }\end{array}$} & \multirow{3}{*}{$\begin{array}{c}\text { Washing } \\
\text { Time (hours) }\end{array}$} & \multicolumn{4}{|c|}{ Gold Leached $(\mathrm{ppm}) \pm 0.5 \mathrm{ppm}$} \\
\hline & & \multicolumn{2}{|c|}{ Seed } & \multicolumn{2}{|c|}{ Composite } \\
\hline & & $\begin{array}{c}\text { ppm } \pm 0.5 \\
\text { ppm }\end{array}$ & $\begin{array}{l}\text { \% Total Gold } \\
\text { Loading }\end{array}$ & $\begin{array}{c}\text { ppm } \pm \\
0.5 \text { ppm }\end{array}$ & $\begin{array}{c}\text { \% Total Gold } \\
\text { Loading }\end{array}$ \\
\hline \multirow[t]{5}{*}{ RT } & 0.5 & 4.8 & 3.0 & 9.3 & 3.9 \\
\hline & 1 & 5.2 & 3.3 & 12.1 & 5.0 \\
\hline & 2 & 4.6 & 2.9 & 5.3 & 2.2 \\
\hline & 5 & 6.1 & 3.8 & 8.6 & 3.6 \\
\hline & 24 & 4.7 & 2.9 & 7.4 & 3.1 \\
\hline \multirow[t]{5}{*}{$50^{\circ} \mathrm{C}$} & 0.5 & 6.0 & 3.7 & 9.8 & 4.1 \\
\hline & 1 & 6.7 & 4.2 & 11.1 & 4.6 \\
\hline & 2 & 5.6 & 3.5 & 6.2 & 2.6 \\
\hline & 5 & 4.9 & 3.1 & 8.1 & 3.4 \\
\hline & 24 & 5.3 & 3.3 & 10.3 & 4.5 \\
\hline
\end{tabular}


Although the amount of gold leached is not large, it does adversely affect the colour of the composites, and as such further research is required to limit this leaching and improve the colour stability to washing of these materials prior to their potential incorporation into consumer products.

\subsection{Conclusions}

The seed mediated approach was successful in producing dark coloured (dark purple, grey etc) gold nanoparticle-merino wool and silk composites with a minimal amount of gold. Gold nanoparticle-crossbred wool materials were also synthesized, however this approach was not as successful the majority of resultant materials exhibited a slight pink/purple tinge.

The reduction of additional $\mathrm{Au}^{3+}$ by $\mathrm{NH}_{2} \mathrm{OH}$ occurred predominantly on the gold nanoparticles located at the fibre surface of the seeds, rather than on those in the centre. Greater concentrations of gold, (up to $6.77 \times 10^{-4} \mathrm{M}$ ) and to a lesser extent higher ratios of $\left[\mathrm{Au}^{3+}\right]:\left[\mathrm{NH}_{2} \mathrm{OH}\right]$, resulted in the formation of larger nanoparticles and an increased amount of agglomerates at the fibre cuticles, which depending on the seed employed, produced darker grey or purple/black coloured composites. However with a gold concentration of 1.02 $\mathrm{x} 10^{-3} \mathrm{M}$ or higher, new nucleation events occurred, imparting a slight pink/purple tinge to the resultant composites.

The ratio of $\mathrm{Au}^{3+}: \mathrm{Au}^{0}$ present in the seeds exerted a major influence on the colour of the resultant materials, with composites prepared from seeds in which there was both $\mathrm{Au}^{0}$ and $\mathrm{Au}^{3+}$ present producing greyer coloured materials, whilst those in which there was predominantly only $\mathrm{Au}^{0}$ resulting in more purple/black coloured materials. The purple/black colour of the composites appeared to be due to the presence of smaller nanoparticles that did not increase in size during the reduction of additional $\mathrm{Au}^{3+}$ by $\mathrm{NH}_{2} \mathrm{OH}$. In the merino wool system these smaller nanoparticles resided in the fibre centre, whilst in the silk and crossbred materials they were located predominantly on the surface of the fibres. 
As the formation of larger gold nanoparticles and nanoparticle agglomerates appeared to occur solely on the surface of the gold nanoparticles bound to the seeds, the bonding between the gold nanoparticles and fibres in the composite materials was not dissimilar to that in the seeds. In the merino wool and crossbred materials this bonding was via strong $\mathrm{Au}-\mathrm{S}$ bonds, whilst in the silk materials the bonding occurred through Au-S and Au-N bonds and also through sericin, which can be dislodged with elevated temperature.

The colourfastness of these materials to washing appeared to be directly related to the colour stability of the incorporated seeds, which is dependent upon the strength of the bond between the nanoparticles and fibres. As such, the gold nanoparticle-merino and crossbred wool composites, in which the gold was bound via strong Au-S bonds, were very colour fast to washing, leaching up to a maximum of 1.1 and $2 \%$ of the total gold loading respectively. However the gold nanoparticle-silk composites were not as colourfast, since the bonding between the nanoparticles and silk fibres in the seed sources was not very strong (predominantly through Au-N bonds rather than Au-S bonds), resulting in up to $5 \%$ of the total gold loading being leached from the composites during washing, adversely affecting their colour.

A shrink resistant chlorine Hercosett treatment was applied to a gold nanoparticle-merino wool composite in an attempt to ascertain the applicability of incorporating materials prepared via the seed mediated approach into consumer applications. Unfortunately this treatment had a detrimental effect on the colour of this composite, due to the re oxidation of gold nanoparticles located at the fibre surface, and subsequent formation of $\mathrm{AuCl}_{4}{ }^{-}$. As such, if these materials are to find application in fine knitwear (one target market) further work is required to make these materials capable of withstanding chlorine Hercosett treatments, as such shrink resistance surface treatments are common practice for materials destined for these end uses. Such treatments are not applied to wool used in carpets, and such these materials have the potential be used without further treatment in carpet manufacture. 


\section{Summary}

Gold and silver nanoparticles have been successfully combined in a synergistic manner with particulate (kaolinite and halloysite clays) and fibrous (merino wool, crossbred wool and silk) substrates, producing novel multi-functional materials that have the potential to be incorporated into commercial products or act alone as high-value multi-functional entities.

Specifically, silver nanoparticle-kaolinite and halloysite composite materials were produced through a layer-by-layer deposition approach, involving the ex-situ preparation of PMA capped silver nanoparticles and their subsequent attachment to the clay particles by means of an electrostatic interaction with PDADMAC, a cationic polymeric linker bound to the clay surfaces. This resulted in the production of purple or yellow coloured composite materials, capable of actively hindering the growth of the bacterium Staphylococcus aureus.

The production of gold nanoparticle-natural fibre composite materials was achieved through three major approaches. Firstly gold nanoparticles were produced ex-situ by TSC or TA and subsequently attached to merino wool fibres. Depending on the amount of TSC or TA employed in the production of the nanoparticles incorporated in the composites, the resultant gold nanoparticle-merino wool materials ranged in colour from pale yellow to grey and murky light pink to purple. These nanoparticles were found to reside preferentially on the surface of the wool fibres, with bonding occurring through electrostatic interaction between the wool and TSC or TA bi-layer surrounding the nanoparticles, or directly via N-Au and S$\mathrm{Au}$ bonds following displacement of the capping agent by $\mathrm{N}$ and $\mathrm{S}$ atoms of wool. These materials displayed relatively poor colourfastness properties.

Alternatively, gold nanoparticle-natural fibre (notably merino wool, crossbred wool and silk) composite materials were produced in the absence of an external reducing agent. The reduction of $\mathrm{Au}^{3+}$ to nanoparticulate $\mathrm{Au}^{0}$ was facilitated by the proteins present in the fibres, notably cystine in merino and crossbred wools, and amine, tyrosine and to lesser extent cystine moieties in silk. The resultant nanoparticles bound to the natural fibres via strong 
covalent $\mathrm{Au}-\mathrm{S}$ bonds in merino and crossbred wool and $\mathrm{Au}-\mathrm{N}$ bonds, with a small amount of $\mathrm{Au}-\mathrm{S}$ bonds in silk. In general the nanoparticles were found to reside both on the surface and within the centre of the fibres, with an exception being the deep purple coloured silk composites, in which the nanoparticles resided predominantly on the fibre surface.

The robust bonding between the gold nanoparticles and merino wool and crossbred wool, and also their distribution in the fibres (both on the surface and throughout the fibre centre) resulted in these materials being very colourfast to washing and rubbing. The bonding between the gold nanoparticles and silk fibres was on average not as strong, and as such these materials displayed decreased colour stabilities. In addition to inducing optical/colourant properties to the natural fibres, similarly to the silver nanoparticle-clay composites, the gold nanoparticles also imparted resistance to microbial attack and provided insecticide properties

The final method by which gold nanoparticle-natural fibre composite materials were produced involved a seed mediated growth approach, in which additional $\mathrm{Au}^{3+}$ was reduced to $\mathrm{Au}^{0}$ by $\mathrm{NH}_{2} \mathrm{OH}$. The reduction of $\mathrm{Au}^{3+}$ by $\mathrm{NH}_{2} \mathrm{OH}$ is catalysed by $\mathrm{Au}^{0}$, and in the presence of gold nanoparticle-natural fibre composites, (prepared through the redox properties of the fibres) this occurred predominantly on the gold nanoparticles located at the surface of the fibres in the composite materials, rather than on those in the centre, resulting in the formation of larger gold nanoparticles and nanoparticle agglomerates. This method was successful in producing dark coloured (dark purple, grey etc) gold nanoparticle-merino wool and silk composites with a minimal amount of gold. Gold nanoparticle-crossbred wool materials were also synthesized, however this approach was not as successful as the majority of resultant materials exhibited a slight pink/purple tinge.

As the formation of larger gold nanoparticles and nanoparticle agglomerates appeared to occur solely on the surface of the gold nanoparticles bound to the seeds, the bonding between the gold nanoparticles and fibres in the composite materials was not dissimilar to that in the seeds. The colourfastness of these materials was directly related to the colour stability of the incorporated seeds, which is dependent upon the strength of the bond between the 
nanoparticles and fibres. As such, the gold nanoparticle-merino and crossbred wool composites were very colourfast, however the nanoparticle-silk composites prepared via the seed mediated growth approach were not as colourfast.

A selection of gold nanoparticle-natural fibre composite materials representing the range of colours obtainable when employing all three methods have been showcased at national and international science and textile conferences, where they, and this technology, were very well received, sparking interest from several key industrial players including Wool Partners International Ltd, the World Gold Council, Cariaggi (an Italian spinning company who provide fine yarn for premier fashion houses), John Smedley UK (a high quality fine knitwear manufacturer and retailer), NZ Merino Ltd and New Zealand Trade and Enterprise. Following discussions with several of these companies, we are currently in the process of commercialising the technology that utilises the redox active properties of the natural fibres to reduce $\mathrm{Au}^{3+}$. A preliminary business case has been prepared and discussions are underway with numerous key players in the New Zealand wool industry and international high-end textile manufacturers and suppliers. So as hoped, this technology has the potential to add significant value to New Zealand wool, and the New Zealand wool industry. The technological knowledge obtained during the course of this research programme will be beneficial during scale-up productions that will undoubtedly be required during commercialisation. The technology has been protected by a New Zealand and a PCT patent specification.[171]

Estimated costs for the production of the gold nanoparticle-natural fibre composites and silver nanoparticle-clay composites are offered in Table 9.1 below. These prices are based solely on the amount of silver or gold used in the production of the composites. 
Table 9.1: Estimated cost of silver nanoparticle-clay composite materials and gold nanoparticle-fibre composite materials. Based on the amount of silver and gold used in their production. $*^{1}$

\begin{tabular}{|c|c|c|c|c|c|}
\hline & \multicolumn{2}{|c|}{$\begin{array}{l}\text { Silver Nanoparticle-Clay } \\
\text { Composites }\end{array}$} & \multicolumn{3}{|c|}{ Gold Nanoparticle-Natural Fibre Composites } \\
\hline & $\begin{array}{l}\text { Photo Induced } \\
\text { Method } \\
\text { (section 3) }\end{array}$ & $\begin{array}{c}\mathrm{NaBH}_{4} \\
\text { Reduction } \\
\text { (section 3) }\end{array}$ & $\begin{array}{c}\text { ex-situ } \\
\text { Preparation (TSC } \\
\text { or TA) (section 4) }\end{array}$ & $\begin{array}{c}\text { in-situ } \\
\text { Preparation } \\
\text { (sections 5- } \\
7)^{\star 2}\end{array}$ & $\begin{array}{l}\text { Seeded } \\
\text { Growth } \\
\text { (section } \\
8)^{\star 3}\end{array}$ \\
\hline $\begin{array}{c}\text { Amount } \\
\text { Ag/Au (g) per } \\
1 \mathrm{~kg} \text { clay or } \\
\text { fibre }\end{array}$ & $43.15 \mathrm{~g} \mathrm{Ag}$ & $0.86 \mathrm{~g} \mathrm{Ag}$ & $16 \mathrm{~g} \mathrm{Au}$ & $16 \mathrm{~g} \mathrm{Au}$ & $\begin{array}{c}20.92- \\
32.00 \mathrm{~g} \mathrm{Au}\end{array}$ \\
\hline $\begin{array}{l}\text { Cost per kg } \\
\qquad(\$ N Z)\end{array}$ & $\$ 40.98$ & $\$ 0.82$ & $\$ 914.56$ & $\$ 914.56$ & $\begin{array}{l}\$ 1195.79- \\
\$ 1829.12\end{array}$ \\
\hline
\end{tabular}




\section{APPENDICES}

\section{Appendix I}

Table 10.1: CIE L*, a*, b*, 457 brightness and 580 brightness values following simulated washability tests for gold nanoparticle-merino wool composites incorporating TSC prepared nanoparticles.

\begin{tabular}{lllllcc}
\hline Temperature & $\begin{array}{l}\text { Washing } \\
\text { Time } \\
\text { (hours) }\end{array}$ & $\mathbf{L}^{*}$ & $\mathbf{a}^{*}$ & $\mathbf{b}^{*}$ & $\begin{array}{c}\mathbf{4 5 7} \mathbf{~ n m} \\
\text { Brightness }\end{array}$ & $\begin{array}{c}\mathbf{5 8 0} \mathbf{~ n m} \\
\text { Brightness }\end{array}$ \\
\hline $\mathbf{R T}$ & $\mathbf{0}$ & 48.5 & 0.5 & -2.9 & 19 & 17 \\
& $\mathbf{0 . 5}$ & 66.2 & 1.6 & -2.3 & 39 & 35 \\
& $\mathbf{1}$ & 62.3 & 0.9 & -2.3 & 33 & 30 \\
& $\mathbf{2}$ & 64.9 & 1.7 & -1.8 & 36 & 33 \\
& $\mathbf{5}$ & 63.7 & 1.6 & -2.1 & 34 & 32 \\
$\mathbf{5 0}$ ㅇ & $\mathbf{2 4}$ & 58.3 & 2.3 & -2.4 & 28 & 26 \\
& $\mathbf{0 . 5}$ & 67.3 & 0.9 & -1.4 & 38 & 36 \\
& $\mathbf{1}$ & 64.8 & 0.6 & -1.6 & 35 & 33 \\
& $\mathbf{2}$ & 62.0 & 1.4 & -1.8 & 32 & 30 \\
& $\mathbf{5}$ & 66.9 & 0.9 & -1.9 & 38 & 36 \\
& $\mathbf{2 4}$ & 61.3 & 1.6 & -2.0 & 31 & 29 \\
\hline
\end{tabular}

Table 10.2: CIE L*, $\mathrm{a}^{*}, \mathrm{~b}^{*}, 457$ brightness and 580 brightness values following simulated washability tests for gold nanoparticle-merino wool composites incorporating TA prepared nanoparticles.

\begin{tabular}{lllllcc}
\hline Temperature & $\begin{array}{l}\text { Washing } \\
\text { Time } \\
\text { (hours) }\end{array}$ & $\mathbf{L}^{*}$ & $\mathbf{a}^{*}$ & $\mathbf{b}^{*}$ & $\begin{array}{c}\mathbf{4 5 7} \mathbf{~ n m} \\
\text { Brightness }\end{array}$ & $\begin{array}{c}\mathbf{5 8 0} \mathbf{~ n m} \\
\text { Brightness }\end{array}$ \\
\hline RT & $\mathbf{0}$ & 50.8 & 3.9 & 3.8 & 17 & 20 \\
& $\mathbf{0 . 5}$ & 67.0 & 1.1 & 8.3 & 32 & 38 \\
& $\mathbf{1}$ & 63.9 & 0.9 & 8.2 & 28 & 34 \\
& $\mathbf{2}$ & 63.1 & 1.0 & 7.1 & 29 & 32 \\
\hline
\end{tabular}




\begin{tabular}{lllllcc}
\hline Temperature & $\begin{array}{l}\text { Washing } \\
\text { Time } \\
\text { (hours) }\end{array}$ & $\mathbf{L}^{*}$ & $\mathbf{a}^{*}$ & $\mathbf{b}^{*}$ & $\begin{array}{c}\mathbf{4 5 7} \mathbf{~ n m} \\
\text { Brightness }\end{array}$ & $\begin{array}{c}\mathbf{5 8 0} \mathbf{~ n m} \\
\text { Brightness }\end{array}$ \\
\hline $\mathbf{5 0}{ }^{\circ} \mathbf{C}$ & $\mathbf{5}$ & 63.1 & 1.0 & 5.8 & 30 & 32 \\
& $\mathbf{2 4}$ & 74.7 & 1.0 & 8.2 & 42 & 49 \\
& $\mathbf{0 . 5}$ & 69.3 & 0.3 & 7.6 & 35 & 41 \\
& $\mathbf{1}$ & 67.7 & 0.1 & 7.5 & 33 & 38 \\
& $\mathbf{2}$ & 70.1 & 0.4 & 7.0 & 36 & 42 \\
& $\mathbf{5}$ & 75.7 & 0.7 & 6.6 & 43 & 44 \\
& $\mathbf{2 4}$ & 74.7 & 0.8 & 6.4 & 44 & 51 \\
\hline
\end{tabular}

\section{Appendix II}

Table 10.3: CIE $L^{*}, a^{*}, b^{*}, 457 \mathrm{~nm}$ brightness and $580 \mathrm{~nm}$ brightness values of gold nanoparticle-merino wool composites prepared by soaking untreated merino wool in an 80, 120 or $160 \mathrm{ppm} \mathrm{Au}^{3+}(4.06,6.09$ or $8.13 \times 10^{-4} \mathrm{M}$ ) solution for 24 hours at RT followed by ageing at $50{ }^{\circ} \mathrm{C}$ for $24-168$ hours. Shows the effect of increased gold concentrations and ageing times on colour development.

\begin{tabular}{|c|c|c|c|c|c|c|c|}
\hline $\begin{array}{c}\text { Gold } \\
\text { Conc. (M) }\end{array}$ & $\begin{array}{l}\text { Soaking } \\
\text { Time } \\
\text { (Hours, RT) }\end{array}$ & $\begin{array}{l}\text { Ageing Time } \\
\text { (Hours, } 50^{\circ} \\
\text { C) }\end{array}$ & $\mathbf{L}^{*}$ & $\mathbf{a}^{\star}$ & $\mathbf{b}^{\star}$ & $\begin{array}{c}457 \mathrm{~nm} \\
\text { Brightness }\end{array}$ & $\begin{array}{c}580 \mathrm{~nm} \\
\text { Brightness }\end{array}$ \\
\hline \multirow{4}{*}{$\begin{array}{l}4.06 \times 10^{-4} \\
(80 \mathrm{ppm})\end{array}$} & \multirow[t]{4}{*}{24} & 24 & 63.8 & 3.8 & 5.7 & 29 & 34 \\
\hline & & 48 & 52.3 & 8.8 & 3.1 & 19 & 21 \\
\hline & & 72 & 52.5 & 3.3 & 4.6 & 20 & 21 \\
\hline & & 168 & 64.3 & 11.7 & 2.1 & 30 & 34 \\
\hline \multirow{4}{*}{$\begin{array}{l}6.09 \times 10^{-4} \\
(120 \mathrm{ppm})\end{array}$} & \multirow[t]{4}{*}{24} & 24 & 71.8 & 4.6 & 5.9 & 39 & 45 \\
\hline & & 48 & 52.7 & 6.0 & 3.0 & 20 & 21 \\
\hline & & 72 & 50.6 & 8.2 & 3.2 & 18 & 20 \\
\hline & & 168 & 42.8 & 12.3 & 1.4 & 13 & 14 \\
\hline \multirow{4}{*}{$\begin{array}{l}8.13 \times 10^{-4} \\
(160 \mathrm{ppm})\end{array}$} & \multirow[t]{4}{*}{24} & 24 & 64.8 & 3.9 & 4.6 & 31 & 35 \\
\hline & & 48 & 62.4 & 5.5 & 3.4 & 29 & 31 \\
\hline & & 72 & 60.4 & 7.6 & 3.2 & 29 & 29 \\
\hline & & 168 & 45.7 & 14.8 & 0.4 & 15 & 16 \\
\hline
\end{tabular}


Table 10.4: CIE $\mathrm{L}^{*} \mathrm{a}^{*}, \mathrm{~b}^{*}, 457 \mathrm{~nm}$ brightness and $580 \mathrm{~nm}$ brightness values for gold nanoparticle-merino wool composites prepared from alternate ageing solutions. Employing a $160 \mathrm{ppm}\left(8.13 \times 10^{-4} \mathrm{M}\right) \mathrm{Au}^{3+}$ solution, a soaking time, at RT of 24 hours and ageing times at $50{ }^{\circ} \mathrm{C}$ of 24-168 hours.

\begin{tabular}{|c|c|c|c|c|c|c|c|}
\hline $\begin{array}{c}\text { Gold } \\
\text { Conc. (M) }\end{array}$ & $\begin{array}{l}\text { Ageing } \\
\text { Solution }\end{array}$ & $\begin{array}{c}\text { Ageing Time } \\
\text { (Hours, } 50^{\circ} \\
\text { C) }\end{array}$ & $\mathbf{L}^{*}$ & $\mathbf{a}^{*}$ & $\mathbf{b}^{*}$ & $\begin{array}{c}457 \mathrm{~nm} \\
\text { Brightness }\end{array}$ & $\begin{array}{c}580 \mathrm{~nm} \\
\text { Brightness }\end{array}$ \\
\hline \multirow{10}{*}{$\begin{array}{l}8.13 \times 10^{-4} \\
(160 \mathrm{ppm})\end{array}$} & \multirow[t]{4}{*}{$0.1 \mathrm{M} \mathrm{NaCl}$} & 24 & 68.2 & 3.2 & 2.4 & 37 & 39 \\
\hline & & 48 & 65.7 & 6.6 & -0.5 & 36 & 35 \\
\hline & & 72 & 70.2 & 5.0 & 1.6 & 40 & 42 \\
\hline & & 168 & 62.0 & 6.1 & 1.1 & 31 & 30 \\
\hline & \multirow[t]{2}{*}{$\mathrm{H}_{2} \mathrm{O}$} & 24 & 72.0 & 3.3 & 4.6 & 41 & 44 \\
\hline & & 168 & 54.0 & 5.8 & 5.3 & 20 & 45 \\
\hline & \multirow{2}{*}{$\begin{array}{c}40 \mu \mathrm{L} 0.1 \mathrm{M} \\
\mathrm{HCl} \underset{\mathrm{H}}{\rightarrow} 10 \mathrm{ml} \\
\mathrm{H}_{2} \mathrm{O}\end{array}$} & 24 & 67.7 & 3.6 & 5.1 & 34 & 39 \\
\hline & & 168 & 58.3 & 5.7 & 4.6 & 24 & 27 \\
\hline & $\begin{array}{c}40 \mu \mathrm{LL} 0.1 \mathrm{M} \\
\mathrm{NaCl} \rightarrow\end{array}$ & 24 & 72.0 & 3.3 & 4.9 & 40 & 44 \\
\hline & $10 \mathrm{ml} \mathrm{H}_{2} \mathrm{O}$ & 168 & 65.5 & 5.8 & 4.9 & 32 & 35 \\
\hline
\end{tabular}

Table 10.5: CIE $L^{*}, a^{*}, b^{*}, 457 \mathrm{~nm}$ brightness and $580 \mathrm{~nm}$ brightness values of gold nanoparticle-merino wool composites prepared by soaking untreated merino wool in an 80, 120 or $160 \mathrm{ppm} \mathrm{Au}^{3+} \mathbf{( 4 . 0 6 , 6 . 0 9}$ or $8.13 \times 10^{-4} \mathrm{M}$ ) solution for 24 hours at RT followed by ageing at $80^{\circ} \mathrm{C}$ for $24-168$ hours. Shows the effect of ageing temperature on colour development.

\begin{tabular}{|c|c|c|c|c|c|c|c|}
\hline $\begin{array}{c}\text { Gold } \\
\text { Conc. (M) }\end{array}$ & $\begin{array}{l}\text { Soaking } \\
\text { Time } \\
\text { (Hours, RT) }\end{array}$ & $\begin{array}{c}\text { Ageing Time } \\
\text { (Hours, } 50^{\circ} \\
\text { C) }\end{array}$ & $L^{*}$ & $a^{*}$ & $\mathbf{b}^{\star}$ & $\begin{array}{c}457 \mathrm{~nm} \\
\text { Brightness }\end{array}$ & $\begin{array}{c}580 \mathrm{~nm} \\
\text { Brightness }\end{array}$ \\
\hline \multirow{2}{*}{$\begin{array}{c}4.06 \times 10^{-4} \\
(80 \mathrm{ppm})\end{array}$} & \multirow[t]{2}{*}{24} & 24 & 67.3 & 1.6 & 11.2 & 30 & 39 \\
\hline & & 168 & 69.8 & -0.2 & 14.5 & 31 & 42 \\
\hline \multirow{2}{*}{$\begin{array}{l}6.09 \times 10^{-4} \\
(120 \mathrm{ppm})\end{array}$} & \multirow[t]{2}{*}{24} & 24 & 60.6 & 7.8 & 6.4 & 25 & 30 \\
\hline & & 168 & 56.1 & 6.9 & 6.3 & 21 & 25 \\
\hline \multirow{4}{*}{$\begin{array}{l}8.13 \times 10^{-4} \\
(160 \mathrm{ppm})\end{array}$} & \multirow[t]{4}{*}{24} & 24 & 57.1 & 8.8 & 7.9 & 21 & 26 \\
\hline & & 48 & 48.1 & 9.5 & 7.4 & 14 & 18 \\
\hline & & 72 & 54.2 & 9.6 & 6.3 & 20 & 23 \\
\hline & & 168 & 51.1 & 6.5 & 9.4 & 16 & 20 \\
\hline
\end{tabular}


Table 10.6: CIE $\mathrm{L}^{*}, \mathrm{a}^{*}, \mathrm{~b}^{*}, 457 \mathrm{~nm}$ brightness and $580 \mathrm{~nm}$ brightness values of gold nanoparticle-merino wool composites prepared by soaking untreated merino wool in a $160 \mathrm{ppm} \mathrm{Au}^{3+}\left(8.13 \times 10^{-4} \mathrm{M}\right)$ solution with a pH of 7 or 10 for 24 hours at RT followed by ageing at $50{ }^{\circ} \mathrm{C}$ for 168 hours. Shows the effect of $\mathrm{pH}$ of the soaking solution on colour development.

\begin{tabular}{|c|c|c|c|c|c|c|c|}
\hline $\begin{array}{c}\text { Gold } \\
\text { Conc. (M) }\end{array}$ & $\begin{array}{c}\text { Soaking } \\
\text { Solution pH }\end{array}$ & $\begin{array}{l}\text { Ageing Time } \\
\text { (Hours, } 50^{\circ} \\
\text { C) }\end{array}$ & $\mathbf{L}^{\star}$ & $a^{*}$ & $\mathbf{b}^{\star}$ & $\begin{array}{c}457 \mathrm{~nm} \\
\text { Brightness }\end{array}$ & $\begin{array}{c}580 \mathrm{~nm} \\
\text { Brightness }\end{array}$ \\
\hline \multirow{2}{*}{$\begin{array}{l}8.13 \times 10^{-4} \\
(160 \mathrm{ppm})\end{array}$} & 7 & 168 & 68.4 & 3.7 & 7.6 & 33 & 40 \\
\hline & 10 & 168 & 64.5 & 4.8 & 5.9 & 30 & 35 \\
\hline
\end{tabular}

Table 10.7: CIE $\mathrm{L}^{*}, \mathrm{a}^{*}, \mathrm{~b}^{*}, 457 \mathrm{~nm}$ brightness and $580 \mathrm{~nm}$ brightness values of gold nanoparticle-merino wool composites prepared by soaking untreated merino wool in a $160 \mathrm{ppm} \mathrm{Au}^{3+}\left(8.13 \times 10^{-4} \mathrm{M}\right)$ solution with a pH of 3for 24 hours at RT followed by adjusting the pH to 4, 7, 9 or 12 and ageing at $50{ }^{\circ} \mathrm{C}$ for 24 168 hours. Shows the effect of $\mathrm{pH}$ of the ageing solution on colour development.

\begin{tabular}{|c|c|c|c|c|c|c|c|}
\hline $\begin{array}{c}\text { Gold } \\
\text { Conc. (M) }\end{array}$ & $\begin{array}{c}\text { Ageing } \\
\text { Solution pH }\end{array}$ & $\begin{array}{c}\text { Ageing Time } \\
\text { (Hours, } 50^{\circ} \\
\text { C) }\end{array}$ & $\mathbf{L}^{*}$ & $\mathbf{a}^{*}$ & $\mathbf{b}^{*}$ & $\begin{array}{c}457 \mathrm{~nm} \\
\text { Brightness }\end{array}$ & $\begin{array}{c}580 \mathrm{~nm} \\
\text { Brightness }\end{array}$ \\
\hline \multirow{16}{*}{$\begin{array}{l}8.13 \times 10^{-4} \\
(160 \mathrm{ppm})\end{array}$} & 4 & 24 & 63.6 & 5.2 & 5.1 & 29 & 33 \\
\hline & & 48 & 55.6 & 6.7 & 3.8 & 22 & 24 \\
\hline & & 72 & 51.2 & 9.4 & 3.4 & 18 & 20 \\
\hline & & 168 & 38.9 & 13.6 & 0.9 & 10 & 11 \\
\hline & 7 & 24 & 59.5 & 5.5 & 4.6 & 25 & 28 \\
\hline & & 48 & 56.0 & 7.6 & 3.5 & 22 & 25 \\
\hline & & 72 & 46.0 & 12.3 & 2.2 & 15 & 16 \\
\hline & & 168 & 33.7 & 14.8 & 0.9 & 8 & 8 \\
\hline & 9 & 24 & 60.4 & 6.5 & 6.9 & 25 & 30 \\
\hline & & 48 & 49.8 & 9.6 & 3.4 & 17 & 19 \\
\hline & & 72 & 40.5 & 11.9 & 2.3 & 11 & 12 \\
\hline & & 168 & 38.4 & 15.3 & 0.2 & 10 & 11 \\
\hline & 12 & 24 & 56.7 & 2.8 & 14.8 & 18 & 27 \\
\hline & & 48 & 56.2 & 2.3 & 15.8 & 17 & 26 \\
\hline & & 72 & 56.9 & 2.8 & 16.5 & 17 & 27 \\
\hline & & 168 & 54.7 & 2.4 & 21.7 & 13 & 25 \\
\hline
\end{tabular}


Table 10.8: CIE $\mathrm{L}^{*}, \mathrm{a}^{*}, \mathrm{~b}^{*}, 457 \mathrm{~nm}$ brightness and $580 \mathrm{~nm}$ brightness values of gold nanoparticle-merino wool composites prepared by soaking untreated merino wool processed via the worsted route in a 160 ppm $\mathrm{Au}^{3+}\left(8.13 \times 10^{-4} \mathrm{M}\right)$ solution for 24 hours at $\mathrm{RT}$ followed by ageing at $50{ }^{\circ} \mathrm{C}$ for $24-168$ hours.

\begin{tabular}{|c|c|c|c|c|c|c|c|}
\hline $\begin{array}{c}\text { Gold } \\
\text { Conc. (M) }\end{array}$ & $\begin{array}{l}\text { Soaking } \\
\text { Time } \\
\text { (Hours, RT) }\end{array}$ & $\begin{array}{c}\text { Ageing Time } \\
\text { (Hours, } 50^{\circ} \\
\text { C) }\end{array}$ & $L^{*}$ & $a^{*}$ & $\mathbf{b}^{\star}$ & $\begin{array}{c}457 \mathrm{~nm} \\
\text { Brightness }\end{array}$ & $\begin{array}{c}580 \mathrm{~nm} \\
\text { Brightness }\end{array}$ \\
\hline \multirow{4}{*}{$\begin{array}{l}8.13 \times 10^{-4} \\
(160 \mathrm{ppm})\end{array}$} & \multirow[t]{4}{*}{24} & 24 & 63.5 & 4.4 & 5.1 & 29 & 33 \\
\hline & & 48 & 62.9 & 4.6 & 4.6 & 29 & 32 \\
\hline & & 72 & 62.3 & 4.5 & 4.4 & 28 & 31 \\
\hline & & 168 & 57.4 & 5.6 & 2.4 & 24 & 25 \\
\hline
\end{tabular}

Table 10.9: CIE $L^{*}, a^{*}, b^{*}, 457 \mathrm{~nm}$ brightness and $580 \mathrm{~nm}$ brightness values of gold nanoparticle-merino wool composites prepared by soaking Soxhlet pre-treated merino wool processed via the worsted route in a $160 \mathrm{ppm} \mathrm{Au}^{3+}\left(8.13 \times 10^{-4} \mathrm{M}\right)$ solution for 24 hours at RT followed by ageing at $50{ }^{\circ} \mathrm{C}$ for 24 or 168 hours.

\begin{tabular}{|c|c|c|c|c|c|c|c|}
\hline $\begin{array}{c}\text { Gold } \\
\text { Conc. (M) }\end{array}$ & $\begin{array}{l}\text { Soaking } \\
\text { Time } \\
\text { (Hours, RT) }\end{array}$ & $\begin{array}{l}\text { Ageing Time } \\
\text { (Hours, } 50^{\circ} \\
\text { C) }\end{array}$ & $\mathbf{L}^{*}$ & $a^{*}$ & $\mathbf{b}^{\star}$ & $\begin{array}{c}457 \mathrm{~nm} \\
\text { Brightness }\end{array}$ & $\begin{array}{c}580 \mathrm{~nm} \\
\text { Brightness }\end{array}$ \\
\hline \multirow{2}{*}{$\begin{array}{l}8.13 \times 10^{-4} \\
(160 \mathrm{ppm})\end{array}$} & 24 & 24 & 62.7 & 5.3 & 6.8 & 27 & 32 \\
\hline & & 168 & 51.9 & 9.8 & 0.4 & 20 & 20 \\
\hline
\end{tabular}

Table 10.10: CIE $\mathrm{L}^{*}, \mathrm{a}^{*}, \mathrm{~b}^{*}, 457 \mathrm{~nm}$ brightness and $580 \mathrm{~nm}$ brightness values of gold nanoparticlemerino wool composites prepared by soaking merino wool in a $0.1 \mathrm{M} \mathrm{HCl}$ solution for 5 , 10 or $15 \mathrm{mins}$, followed by soaking in a $160 \mathrm{ppm} \mathrm{Au}^{3+}\left(8.13 \times 10^{-4} \mathrm{M}\right)$ solution for 24 hours at $\mathrm{RT}$ and ageing at $50{ }^{\circ} \mathrm{C}$ for 168 hours.

\begin{tabular}{cccccccc}
\hline $\begin{array}{c}\text { Gold } \\
\text { Conc. (M) }\end{array}$ & $\begin{array}{c}\text { Time in HCl } \\
\text { (mins, RT) }\end{array}$ & $\begin{array}{c}\text { Soaking } \\
\text { Time (Hours, } \\
\text { RT) }\end{array}$ & $\mathbf{L}^{*}$ & $\mathbf{a}^{*}$ & $\mathbf{b}^{*}$ & $\begin{array}{c}\mathbf{4 5 7} \mathbf{~ n m} \\
\text { Brightness }\end{array}$ & $\begin{array}{c}\mathbf{5 8 0} \mathbf{~ n m} \\
\text { Brightness }\end{array}$ \\
\hline $\mathbf{8 . 1 3 \times 1 0 ^ { - 4 }}$ & $\mathbf{5}$ & $\mathbf{2 4}$ & 62.1 & 3.1 & 8.1 & 31 & 36 \\
$(\mathbf{1 6 0} \mathbf{~ p p m )}$ & $\mathbf{1 0}$ & & 63.7 & 3.3 & 6.9 & 34 & 29 \\
& $\mathbf{3 0}$ & & 65.8 & 2.9 & 7.1 & 35 & 37 \\
\hline
\end{tabular}


Table 10.11: CIE $\mathrm{L}^{*}, \mathrm{a}^{*}, \mathrm{~b}^{*}, 457 \mathrm{~nm}$ brightness and $580 \mathrm{~nm}$ brightness values of gold nanoparticlemerino wool composites prepared by soaking merino wool in a $0.1 \mathrm{M} \mathrm{KOH/EtOH}$ solution for 5, 10 or 15 mins, followed by soaking in a $160 \mathrm{ppm} \mathrm{Au}^{3+}\left(8.13 \times 10^{-4} \mathrm{M}\right)$ solution for 24 hours at $\mathrm{RT}$ and ageing at 50

${ }^{\circ} \mathrm{C}$ for 168 hours.

\begin{tabular}{|c|c|c|c|c|c|c|c|}
\hline $\begin{array}{c}\text { Gold } \\
\text { Conc. (M) }\end{array}$ & $\begin{array}{c}\text { Time in } \\
\text { KOH (mins, } \\
\text { RT) }\end{array}$ & $\begin{array}{c}\text { Soaking } \\
\text { Time (Hours, } \\
\text { RT) }\end{array}$ & $\mathbf{L}^{*}$ & $a^{*}$ & $\mathbf{b}^{\star}$ & $\begin{array}{c}457 \mathrm{~nm} \\
\text { Brightness }\end{array}$ & $\begin{array}{c}580 \mathrm{~nm} \\
\text { Brightness }\end{array}$ \\
\hline \multirow{3}{*}{$\begin{array}{l}8.13 \times 10^{-4} \\
(160 \mathrm{ppm})\end{array}$} & 5 & 24 & 63.4 & 3.3 & 7.2 & 28 & 36 \\
\hline & 10 & & 65.9 & 2.2 & 7.8 & 30 & 36 \\
\hline & 30 & & 71.7 & 3.8 & 7.2 & 38 & 44 \\
\hline
\end{tabular}

Table 10.12: CIE $\mathrm{L}^{*}, \mathrm{a}^{*}, \mathrm{~b}^{*}, 457 \mathrm{~nm}$ brightness and $580 \mathrm{~nm}$ brightness values of gold nanoparticle-

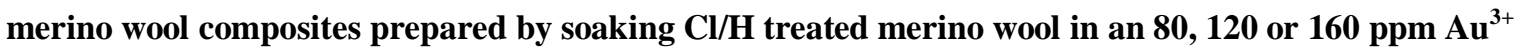
(4.06, 6.09 or $8.13 \times 10^{-4} \mathrm{M}$ ) solution for 24 hours at RT followed by ageing at $50{ }^{\circ} \mathrm{C}$ for $24-168$ hours.

\begin{tabular}{|c|c|c|c|c|c|c|c|}
\hline $\begin{array}{c}\text { Gold } \\
\text { Conc. (M) }\end{array}$ & $\begin{array}{c}\text { Soaking } \\
\text { Time } \\
\text { (Hours, RT) }\end{array}$ & $\begin{array}{l}\text { Ageing Time } \\
\text { (Hours, } 50^{\circ} \\
\text { C) }\end{array}$ & $\mathbf{L}^{*}$ & $\mathbf{a}^{\star}$ & $\mathbf{b}^{\star}$ & $\begin{array}{c}457 \mathrm{~nm} \\
\text { Brightness }\end{array}$ & $\begin{array}{c}580 \mathrm{~nm} \\
\text { Brightness }\end{array}$ \\
\hline \multirow{4}{*}{$\begin{array}{c}4.06 \times 10^{-4} \\
(80 \mathrm{ppm})\end{array}$} & \multirow[t]{4}{*}{24} & 24 & 76.1 & 0.3 & 7.7 & 44 & 51 \\
\hline & & 48 & 72.9 & 0.6 & 8.1 & 39 & 46 \\
\hline & & 72 & 75.0 & 1.9 & 9.3 & 41 & 50 \\
\hline & & 168 & 61.9 & 5.6 & 7.6 & 26 & 32 \\
\hline \multirow{4}{*}{$\begin{array}{l}6.09 \times 10^{-4} \\
(120 \mathrm{ppm})\end{array}$} & \multirow[t]{4}{*}{24} & 24 & 74.8 & -0.2 & 8.1 & 42 & 49 \\
\hline & & 48 & 70.3 & 1.3 & 10.1 & 34 & 43 \\
\hline & & 72 & 67.5 & 1.7 & 8.9 & 32 & 38 \\
\hline & & 168 & 56.1 & 7.3 & 6.5 & 21 & 25 \\
\hline \multirow{4}{*}{$\begin{array}{l}8.13 \times 10^{-4} \\
(160 \mathrm{ppm})\end{array}$} & \multirow[t]{4}{*}{24} & 24 & 76.6 & 0.4 & 8.5 & 44 & 52 \\
\hline & & 48 & 69.4 & 2.1 & 9.3 & 34 & 41 \\
\hline & & 72 & 70.0 & 2.4 & 8.7 & 35 & 44 \\
\hline & & 168 & 57.6 & 7.4 & 7.6 & 22 & 27 \\
\hline
\end{tabular}


Table 10.13: CIE $\mathrm{L}^{*}, \mathrm{a}^{*}, \mathrm{~b}^{*}, 457 \mathrm{~nm}$ brightness and $580 \mathrm{~nm}$ brightness values of gold nanoparticle-

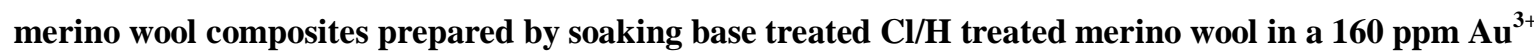
$\left(8.13 \times 10^{-4} \mathrm{M}\right)$ solution for 24 hours at RT followed by ageing at $50{ }^{\circ} \mathrm{C}$ for $24-168$ hours.

\begin{tabular}{|c|c|c|c|c|c|c|c|}
\hline $\begin{array}{c}\text { Gold } \\
\text { Conc. (M) }\end{array}$ & $\begin{array}{c}\text { Soak Time } \\
\text { (Hours, RT) }\end{array}$ & $\begin{array}{c}\text { Heat Time } \\
\text { (Hours, } 50 \stackrel{\circ}{ } \text { C) }\end{array}$ & $L^{*}$ & $a^{*}$ & $\mathbf{b}^{\star}$ & $\begin{array}{c}457 \mathrm{~nm} \\
\text { Brightness }\end{array}$ & $\begin{array}{c}580 \mathrm{~nm} \\
\text { Brightness }\end{array}$ \\
\hline \multirow{4}{*}{$\begin{array}{l}8.13 \times 10^{-4} \\
(160 \mathrm{ppm})\end{array}$} & 24 & 24 & 72 & 6 & 7 & 41 & 43 \\
\hline & & 48 & 74 & 7 & 7 & 41 & 47 \\
\hline & & 72 & 74 & 7 & 6 & 40 & 46 \\
\hline & & 168 & 76 & 8 & 4 & 42 & 46 \\
\hline
\end{tabular}

\section{Appendix III}

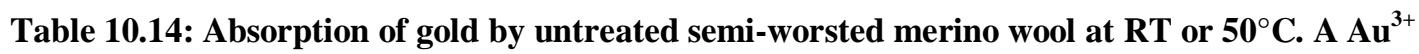
concentration of $160 \mathrm{ppm}\left(8.13 \times 10^{-4} \mathrm{M}\right)$ was eemployed.

\begin{tabular}{ccc}
\hline & \multicolumn{2}{c}{$\mathbf{A u}^{3+}$ Concentration (ppm) } \\
\cline { 2 - 3 } & Soaking/Absorption Temperature \\
\hline $\begin{array}{c}\text { Soaking/Absorption } \\
\text { Time (minutes) }\end{array}$ & $\mathbf{R T}$ & $\mathbf{5 0}{ }^{\circ} \mathbf{C}$ \\
\hline $\mathbf{2}$ & 118 & 85 \\
$\mathbf{5}$ & 80 & 37 \\
$\mathbf{1 0}$ & 62 & 13 \\
$\mathbf{2 0}$ & 43 & 6 \\
$\mathbf{3 0}$ & 30 & 2 \\
$\mathbf{4 0}$ & 17 & 1 \\
$\mathbf{6 0}$ & 7 & 1 \\
$\mathbf{1 8 0}$ & 1 & 0 \\
$\mathbf{3 6 0}$ & 0 & 0 \\
$\mathbf{1 4 4 0}$ & 0 & 0 \\
& 0 & 0 \\
\hline
\end{tabular}


Table 10.15: Absorption of gold by untreated semi-worsted merino wool at RT. Au ${ }^{3+}$ increased through the addition of more $\mathrm{Au}^{3+}$, constant wool:solution volume.

\begin{tabular}{|c|c|c|c|c|c|}
\hline \multirow[b]{2}{*}{$\begin{array}{l}\text { Soaking/Absorption } \\
\text { Time (mins) }\end{array}$} & \multicolumn{5}{|c|}{$\mathrm{Au}^{3+}$ Concentration (ppm, moldm ${ }^{-3}$ ) } \\
\hline & $\begin{array}{c}160,8.13 \\
\times 10^{-3}\end{array}$ & $\begin{array}{r}200,1.01 \\
\times 10^{-3-}\end{array}$ & $\begin{array}{c}240,1.22 \\
\times 10^{-3}\end{array}$ & $\begin{array}{c}280,1.42 \times \\
10^{-3}\end{array}$ & $\begin{array}{c}320,1.62 \\
\times 10^{-3}\end{array}$ \\
\hline 2 & 118 & 144 & 150 & 173 & 218 \\
\hline 5 & 80 & 91 & 120 & 144 & 154 \\
\hline 10 & 62 & 60 & 76 & 105 & 129 \\
\hline 15 & 43 & 42 & 49 & 68 & 40 \\
\hline 20 & 30 & 23 & 36 & 38 & 60 \\
\hline 30 & 17 & 7 & 8 & 20 & 24 \\
\hline 40 & 7 & 2 & 4 & 6 & 8 \\
\hline 60 & 1 & 1 & 1 & 2 & 4 \\
\hline 180 & 0 & 0 & 0 & 1 & 1 \\
\hline 360 & 0 & 0 & 0 & 0 & 0 \\
\hline 1440 & 0 & 0 & 0 & 0 & 0 \\
\hline
\end{tabular}

Table 10.16: Absorption of gold by untreated semi-worsted merino wool at RT. Au ${ }^{3+}$ increased by $^{2}$ lowering the solvent volume.

\begin{tabular}{|c|c|c|c|c|c|}
\hline \multirow[b]{3}{*}{$\begin{array}{l}\text { Soaking/Absorption } \\
\text { Time (mins) }\end{array}$} & \multicolumn{5}{|c|}{$\begin{array}{l}\mathrm{Au}^{3+} \text { Concentration (ppm, moldm } \\
\left.\text { Composition (Vol } 4 \text { wt } \% \mathrm{Au}^{3+}(\mu \mathrm{L}) \text { added to } \mathrm{Vol}^{-3} \mathrm{H}_{2} \mathrm{O}(\mathrm{ml})\right)\end{array}$} \\
\hline & $\begin{array}{c}160,8.13 \\
\times 10^{-3}\end{array}$ & $\begin{array}{l}213,1.08 \\
\times 10^{-3-}\end{array}$ & $\begin{array}{l}320,1.60 \\
\times 10^{-3}\end{array}$ & $\begin{array}{c}400,2.03 \\
\times 10^{-3}\end{array}$ & $\begin{array}{r}200,1.01 \\
\times 10^{-3}\end{array}$ \\
\hline & $40 \rightarrow 10$ & $40 \rightarrow 7.5$ & $40 \rightarrow 5$ & $40 \rightarrow 4$ & $40 \rightarrow 20$ \\
\hline 2 & 118 & 160 & 229 & 280 & 120 \\
\hline 5 & 80 & 141 & 156 & 171 & 71 \\
\hline 10 & 62 & 88 & 93 & 107 & 22 \\
\hline 15 & 43 & 58 & 34 & 38 & 7 \\
\hline 20 & 30 & 25 & 30 & 32 & 5 \\
\hline 30 & 17 & 11 & 5 & 5 & 3 \\
\hline 40 & 7 & 4 & 5 & 6 & 2 \\
\hline 60 & 1 & 1 & 1 & 1 & 0 \\
\hline
\end{tabular}




\begin{tabular}{|c|c|c|c|c|c|}
\hline \multirow[b]{3}{*}{$\begin{array}{l}\text { Soaking/Absorption } \\
\text { Time (mins) }\end{array}$} & \multicolumn{5}{|c|}{$\begin{array}{c}\mathrm{Au}^{3+} \text { Concentration (ppm, moldm } \\
\text { Composition }\left(\mathrm{Vol} 4 \mathrm{wt} \% \mathrm{Au}^{3+}(\mu \mathrm{L}) \text { added to } \mathrm{Vol} . \mathrm{H}_{2} \mathrm{O}(\mathrm{ml})\right)\end{array}$} \\
\hline & $\begin{array}{c}160,8.13 \\
\times 10^{-3}\end{array}$ & & $\begin{array}{c}160,8.13 \\
\times 10^{-3}\end{array}$ & & $\begin{array}{c}160,8.13 \\
\times 10^{-3}\end{array}$ \\
\hline & $40 \rightarrow 10$ & & $40 \rightarrow 10$ & & $40 \rightarrow 10$ \\
\hline 180 & 0 & 1 & 0 & 0 & 0 \\
\hline 360 & 0 & 0 & 0 & 0 & 0 \\
\hline 1440 & 0 & 0 & 0 & 0 & 0 \\
\hline
\end{tabular}

Table 10.17: Gold absorption by untreated semi-worsted merino wool at RT. A Au ${ }^{3+}$ concentration of 160 ppm $\left(8.13 \times 10^{-4} \mathrm{M}\right)$ was employed.

\begin{tabular}{|c|c|c|c|}
\hline \multirow[b]{3}{*}{$\begin{array}{l}\text { Soaking/Absorption } \\
\text { Time (mins) }\end{array}$} & \multicolumn{3}{|c|}{$\mathrm{Au}^{3+}$ Concentration (ppm) } \\
\hline & \multicolumn{3}{|c|}{ Soaking/Absorption Solution pH } \\
\hline & 2.7 & 5 & 7 \\
\hline 2 & 118 & 160 & 150 \\
\hline 5 & 80 & 159 & 137 \\
\hline 10 & 62 & 153 & 135 \\
\hline 15 & 43 & 147 & 132 \\
\hline 20 & 30 & 140 & 128 \\
\hline 30 & 17 & 130 & 120 \\
\hline 40 & 7 & 124 & 118 \\
\hline 60 & 1 & 123 & 114 \\
\hline 180 & 0 & 98 & 73 \\
\hline 360 & 0 & 40 & 63 \\
\hline 1440 & 0 & 10 & 55 \\
\hline
\end{tabular}


Table 10.18: Gold absorption by untreated or treated semi-worsted merino wool.

\begin{tabular}{cccccc}
\hline & \multicolumn{5}{c}{ Au $^{3+}$ Concentration (ppm) } \\
\cline { 2 - 6 } $\begin{array}{c}\text { Soaking/Absorption } \\
\text { Time (mins) }\end{array}$ & Mntreated & Acid Treated & $\begin{array}{c}\text { KOH/EtOH } \\
\text { Treated }\end{array}$ & $\begin{array}{c}\text { Cl/H } \\
\text { Treated }\end{array}$ & $\begin{array}{c}\text { KOH Treated } \\
\text { Cl/H Treated }\end{array}$ \\
\cline { 2 - 6 } $\mathbf{2}$ & 118 & 120 & 80 & 40 & 118 \\
$\mathbf{5}$ & 80 & 66 & 65 & 10 & 80 \\
$\mathbf{1 0}$ & 62 & 13 & 62 & 0 & 62 \\
$\mathbf{1 5}$ & 43 & 8 & 60 & 0 & 44 \\
$\mathbf{2 0}$ & 30 & 6 & 60 & 1 & 30 \\
$\mathbf{3 0}$ & 17 & 6 & 45 & 1 & 17 \\
$\mathbf{4 0}$ & 7 & 1 & 32 & 1 & 7 \\
$\mathbf{6 0}$ & 1 & 1 & 1 & 1 & 1 \\
$\mathbf{1 8 0}$ & 0 & 1 & 0 & 0 & 0 \\
$\mathbf{3 6 0}$ & 0 & 0 & 0 & 0 & 0 \\
$\mathbf{1 4 4 0}$ & 0 & 0 & 0 & 0 & 0 \\
\hline
\end{tabular}

Table 10.19: Gold absorption by untreated worsted and semi-worsted merino wool at RT.

\begin{tabular}{ccc}
\hline & \multicolumn{2}{c}{$\mathrm{Au}^{3+}$ Concentration (ppm) } \\
\cline { 2 - 3 } & \multicolumn{2}{c}{ Merino Wool Fibre } \\
\hline $\begin{array}{c}\text { Soaking/Absorption } \\
\text { Time (minutes) }\end{array}$ & Worsted & Semi-worsted \\
\hline $\mathbf{2}$ & 118 & 130 \\
$\mathbf{5}$ & 80 & 90 \\
$\mathbf{1 0}$ & 62 & 50 \\
$\mathbf{1 5}$ & 43 & 38 \\
$\mathbf{2 0}$ & 30 & 23 \\
$\mathbf{3 0}$ & 17 & 10 \\
$\mathbf{4 0}$ & 7 & 8 \\
$\mathbf{6 0}$ & 1 & 2 \\
$\mathbf{1 8 0}$ & 0 & 0 \\
$\mathbf{3 6 0}$ & 0 & 0 \\
$\mathbf{1 4 4 0}$ & 0 & 0 \\
\hline
\end{tabular}




\section{Appendix IV}

Table 10.20: CIE Co-ordinates of a gold nanoparticle-merino wool composite (prepared by soaking untreated semi-worsted merino wool in a $160 \mathrm{ppm}\left(8.13 \times 10^{-4} \mathrm{M}\right) \mathrm{Au}^{3+}$ solution for 24 hours at RT, followed by heating at $50{ }^{\circ} \mathrm{C}$ for 24 hours) following washing.

\begin{tabular}{lllllcc}
\hline Temperature & $\begin{array}{c}\text { Washing } \\
\text { Time } \\
\text { (hours) }\end{array}$ & $\mathbf{L}^{*}$ & $\mathbf{a}^{*}$ & $\mathbf{b}^{*}$ & $\begin{array}{c}\mathbf{4 5 7} \mathbf{~ n m} \\
\text { Brightness }\end{array}$ & $\begin{array}{c}\mathbf{5 8 0} \mathbf{~ n m} \\
\text { Brightness }\end{array}$ \\
\hline $\mathbf{R T}$ & $\mathbf{0}$ & 64.8 & 3.9 & 4.6 & 31 & 35 \\
& $\mathbf{0 . 5}$ & 60.88 & 4.20 & 5.32 & 32 & 34 \\
& $\mathbf{1}$ & 57.00 & 3.8 & 4.97 & 31 & 34 \\
& $\mathbf{2}$ & 60.49 & 3.81 & 4.67 & 31 & 35 \\
& $\mathbf{5}$ & 60.89 & 3.76 & 4.51 & 30 & 34 \\
$\mathbf{5 0}$ oC & $\mathbf{2 4}$ & 60.48 & 4.10 & 4.62 & 31 & 34 \\
& $\mathbf{0 . 5}$ & 64.62 & 4.10 & 4.40 & 29 & 34 \\
& $\mathbf{1}$ & 61.03 & 3.72 & 4.45 & 30 & 35 \\
& $\mathbf{2}$ & 62.34 & 3.89 & 4.52 & 31 & 35 \\
& $\mathbf{5}$ & 61.30 & 4.00 & 4.60 & 31 & 34 \\
& $\mathbf{2 4}$ & 60.13 & 4.02 & 4.55 & 30 & 35 \\
\hline
\end{tabular}

Table 10.21: CIE Co-ordinates of a gold nanoparticle-merino wool composite (prepared by soaking untreated semi-worsted merino wool in a $160 \mathrm{ppm}\left(8.13 \times 10^{-4} \mathrm{M}\right) \mathrm{Au}^{3+}$ solution for 24 hours at RT, followed by heating at $50{ }^{\circ} \mathrm{C}$ for 168 hours) following washing.

\begin{tabular}{|c|c|c|c|c|c|c|}
\hline Temperature & $\begin{array}{l}\text { Washing } \\
\text { Time } \\
\text { (hours) }\end{array}$ & $L^{*}$ & $a^{\star}$ & $\mathbf{b}^{*}$ & $\begin{array}{c}457 \mathrm{~nm} \\
\text { Brightness }\end{array}$ & $\begin{array}{c}580 \mathrm{~nm} \\
\text { Brightness }\end{array}$ \\
\hline \multirow[t]{6}{*}{ RT } & 0 & 45.7 & 14.8 & 0.4 & 15 & 16 \\
\hline & 0.5 & 44.0 & 14.06 & -0.98 & 10 & 14 \\
\hline & 1 & 38.4 & 14.72 & -0.01 & 14 & 11 \\
\hline & 2 & 41.2 & 15.91 & -1.36 & 13 & 12 \\
\hline & 5 & 41.6 & 15.20 & -0.52 & 12 & 12 \\
\hline & 24 & 39.8 & 16.17 & -0.13 & 11 & 11 \\
\hline $50 \stackrel{\circ}{\circ}$ & 0.5 & 40.4 & 15.72 & -0.43 & 12 & 12 \\
\hline
\end{tabular}




\begin{tabular}{lllcccc}
\hline Temperature & $\begin{array}{c}\text { Washing } \\
\text { Time } \\
\text { (hours) }\end{array}$ & $\mathbf{L}^{*}$ & $\mathbf{a}^{*}$ & $\mathbf{b}^{*}$ & $\begin{array}{c}\mathbf{4 5 7} \mathbf{~ n m} \\
\text { Brightness }\end{array}$ & $\begin{array}{c}\mathbf{5 8 0} \mathbf{~ n m} \\
\text { Brightness }\end{array}$ \\
\hline $\mathbf{1}$ & 36.3 & 17.03 & 0.20 & 10 & 11 \\
$\mathbf{2}$ & 39.5 & 17.00 & -0.21 & 11 & 11 \\
$\mathbf{5}$ & 36.1 & 16.72 & -0.13 & 11 & 10 \\
$\mathbf{2 4}$ & 36.8 & 15.76 & 0.20 & 10 & 10 \\
\hline
\end{tabular}

\section{Appendix V}

Table 10.22: CIE $L^{*}, a^{*}, b^{*}, 457 \mathrm{~nm}$ brightness and $580 \mathrm{~nm}$ brightness values for gold nanoparticlecrossbred wool composite materials.

\begin{tabular}{|c|c|c|c|c|c|c|c|}
\hline $\begin{array}{c}\text { Gold } \\
\text { Conc. (M) }\end{array}$ & $\begin{array}{c}\text { Soaking } \\
\text { Time } \\
\text { (Hours, RT) }\end{array}$ & $\begin{array}{l}\text { Ageing Time } \\
\text { (Hours, } 50^{\circ} \\
\text { C) }\end{array}$ & $L^{*}$ & $\mathbf{a}^{\star}$ & $\mathbf{b}^{*}$ & $\begin{array}{c}457 \mathrm{~nm} \\
\text { Brightness }\end{array}$ & $\begin{array}{c}580 \mathrm{~nm} \\
\text { Brightness }\end{array}$ \\
\hline \multirow{4}{*}{$\begin{array}{l}4.06 \times 10^{-4} \\
(80 \mathrm{ppm})\end{array}$} & \multirow[t]{4}{*}{24} & 24 & 47.1 & 9.7 & 0.7 & 16 & 17 \\
\hline & & 48 & 47.2 & 9.4 & 0.4 & 16 & 17 \\
\hline & & 72 & 45.2 & 9.0 & 0.7 & 14 & 15 \\
\hline & & 168 & 40.5 & 9.6 & 0.3 & 11 & 12 \\
\hline \multirow{4}{*}{$\begin{array}{l}6.09 \times 10^{-4} \\
(120 \mathrm{ppm})\end{array}$} & \multirow[t]{4}{*}{24} & 24 & 39.9 & 9.6 & 0.2 & 11 & 12 \\
\hline & & 48 & 35.2 & 11.9 & -0.7 & 9 & 9 \\
\hline & & 72 & 39.84 & 12.3 & -0.6 & 11 & 12 \\
\hline & & 168 & 37.8 & 11.8 & -0.6 & 10 & 10 \\
\hline \multirow{4}{*}{$\begin{array}{l}8.13 \times 10^{-4} \\
(160 \mathrm{ppm})\end{array}$} & \multirow[t]{4}{*}{24} & 24 & 44.2 & 8.5 & 1.2 & 14 & 14 \\
\hline & & 48 & 31.2 & 11.7 & 0.6 & 7 & 7 \\
\hline & & 72 & 32.7 & 10.7 & -0.1 & 7 & 8 \\
\hline & & 168 & 28.5 & 10.5 & -1.2 & 6 & 6 \\
\hline
\end{tabular}




\section{Appendix VI}

Table 10.23: CIE Co-ordinates of a gold nanoparticle-crossbred wool composite (prepared by soaking crossbred wool in a $160 \mathrm{ppm}\left(8.13 \times 10^{-4} \mathrm{M}\right) \mathrm{Au}^{3+}$ solution for 24 hours at RT, followed by heating at 50 ${ }^{\circ} \mathrm{C}$ for 168 hours) following washing.

\begin{tabular}{|c|c|c|c|c|c|c|}
\hline Temperature & $\begin{array}{l}\text { Washing } \\
\text { Time } \\
\text { (hours) }\end{array}$ & $L^{*}$ & $a^{*}$ & $\mathbf{b}^{*}$ & $\begin{array}{c}457 \mathrm{~nm} \\
\text { Brightness }\end{array}$ & $\begin{array}{c}580 \mathrm{~nm} \\
\text { Brightness }\end{array}$ \\
\hline \multirow[t]{6}{*}{ RT } & 0 & 30 & 16 & -1 & 10 & 6 \\
\hline & 0.5 & 37 & 16 & -1 & 10 & 10 \\
\hline & 1 & 35 & 14 & 0 & 8 & 9 \\
\hline & 2 & 37 & 15 & -1 & 10 & 10 \\
\hline & 5 & 34 & 15 & -1 & 8 & 8 \\
\hline & 24 & 33 & 15 & 0 & 8 & 8 \\
\hline \multirow[t]{5}{*}{$50 \stackrel{\circ}{C}$} & 0.5 & 36 & 16 & 0 & 9 & 10 \\
\hline & 1 & 30 & 14 & 0 & 6 & 6 \\
\hline & 2 & 36 & 16 & 0 & 9 & 10 \\
\hline & 5 & 38 & 16 & 0 & 10 & 11 \\
\hline & 24 & 31 & 15 & 0 & 7 & 7 \\
\hline
\end{tabular}

\section{Appendix VII}

Table 10.24: CIE Co-ordinates of a gold nanoparticle-silk composite prepared by soaking silk in a 160 ppm $\left(8.13 \times 10^{-4} \mathrm{M}\right) \mathrm{Au}^{3+}$ solution with a pH of 2.7 for 24 hours at RT, followed by heating at $50{ }^{\circ} \mathrm{C}$ for 24-168 hours.

\begin{tabular}{|c|c|c|c|c|c|c|c|}
\hline $\begin{array}{c}\text { Gold } \\
\text { Conc. (M) }\end{array}$ & $\begin{array}{c}\text { Soaking } \\
\text { Time (RT) }\end{array}$ & $\begin{array}{l}\text { Ageing Time } \\
\text { (Hours, } 50^{\circ} \mathrm{C} \text { ) }\end{array}$ & $L^{*}$ & $\mathbf{a}^{*}$ & $\mathbf{b}^{*}$ & $\begin{array}{c}457 \mathrm{~nm} \\
\text { Brightness }\end{array}$ & $\begin{array}{c}580 \mathrm{~nm} \\
\text { Brightness }\end{array}$ \\
\hline \multirow{3}{*}{$\begin{array}{c}8.13 \times 10^{-4} \\
(160 \\
\text { ppm), pH } \\
2.7\end{array}$} & $10 \mathrm{~min}$ & - & 49.0 & 7.2 & 2.9 & 17 & 19 \\
\hline & $0.5 \mathrm{~h}$ & & 47.1 & 8.1 & 2.7 & 16 & 18 \\
\hline & $1 \mathrm{~h}$ & & 37.3 & 7.9 & -1.0 & 10 & 10 \\
\hline
\end{tabular}




\begin{tabular}{|c|c|c|c|c|c|c|c|}
\hline $\begin{array}{c}\text { Gold } \\
\text { Conc. (M) }\end{array}$ & $\begin{array}{l}\text { Soaking } \\
\text { Time (RT) }\end{array}$ & $\begin{array}{l}\text { Ageing Time } \\
\left.\text { (Hours, } 50^{\circ} \mathrm{C}\right)\end{array}$ & $\mathbf{L}^{*}$ & $\mathbf{a}^{\star}$ & $\mathbf{b}^{*}$ & $\begin{array}{c}457 \mathrm{~nm} \\
\text { Brightness }\end{array}$ & $\begin{array}{c}580 \mathrm{~nm} \\
\text { Brightness }\end{array}$ \\
\hline & $3 \mathrm{~h}$ & & 35.8 & 9.1 & -2.3 & 9 & 9 \\
\hline & $24 \mathrm{~h}$ & & 35.1 & 9.2 & -3.3 & 10 & 9 \\
\hline & $24 \mathrm{~h}$ & 24 & 37.2 & 9.3 & -2.8 & 10 & 10 \\
\hline & & 48 & 37.6 & 10.5 & -3.9 & 11 & 10 \\
\hline & & 168 & 32.1 & 11.1 & -5.5 & 8 & 6 \\
\hline
\end{tabular}

Table 10.25: CIE Co-ordinates of a gold nanoparticle-silk composite prepared by soaking silk in a 160 ppm $\left(8.13 \times 10^{-4} \mathrm{M}\right) \mathrm{Au}^{3+}$ solution with a pH of 7, 9-10 or 12 for 10 minutes or 6 hours at RT, followed by heating at $50{ }^{\circ} \mathrm{C}$ for 24 hours.

\begin{tabular}{|c|c|c|c|c|c|c|c|}
\hline $\mathrm{pH}$ & $\begin{array}{l}\text { Soaking } \\
\text { Time (RT) }\end{array}$ & $\begin{array}{l}\text { Ageing Time } \\
\text { (Hours, } 50^{\circ} \\
\text { C) }\end{array}$ & $L^{*}$ & $\mathbf{a}^{*}$ & $\mathbf{b}^{*}$ & $\begin{array}{c}457 \mathrm{~nm} \\
\text { Brightness }\end{array}$ & $\begin{array}{c}580 \mathrm{~nm} \\
\text { Brightness }\end{array}$ \\
\hline \multirow[t]{2}{*}{7} & 10 mins & 24 & 37.1 & 20.5 & -1.1 & 7 & 7 \\
\hline & $6 \mathrm{~h}$ & & 37.4 & 16.1 & -2.5 & 7 & 6 \\
\hline \multirow[t]{2}{*}{$9-10$} & 10 mins & 24 & 39.8 & 24.8 & 0.1 & 7 & 8 \\
\hline & $6 \mathrm{~h}$ & & 39.3 & 24.5 & 0.4 & 8 & 10 \\
\hline 12 & $6 \mathrm{~h}$ & 24 & 84.7 & 1.1 & 6.1 & 57 & 66 \\
\hline
\end{tabular}

\section{Appendix VIII}

Table 10.26: CIE Co-ordinates of a gold nanoparticle-silk composite (prepared by soaking silk in a 160 $\operatorname{ppm}\left(8.13 \times 10^{-4} \mathrm{M}\right) \mathrm{Au}^{3+}$ solution with a pH of 2.7 for 24 hours at $\mathrm{RT}$, followed by heating at $50{ }^{\circ} \mathrm{C}$ for 168 hours) following washing.

\begin{tabular}{|c|c|c|c|c|c|c|}
\hline Temperature & $\begin{array}{c}\text { Washing } \\
\text { Time } \\
\text { (hours) }\end{array}$ & $L^{*}$ & $a^{*}$ & $\mathbf{b}^{*}$ & $\begin{array}{c}457 \mathrm{~nm} \\
\text { Brightness }\end{array}$ & $\begin{array}{c}580 \mathrm{~nm} \\
\text { Brightness }\end{array}$ \\
\hline \multirow[t]{5}{*}{ RT } & 0 & 35.1 & 10.4 & -3.2 & 9 & 9 \\
\hline & 0.5 & 33.3 & 6.3 & -4.1 & 9 & 8 \\
\hline & 1 & 31.1 & 6.0 & -4.4 & 8 & 7 \\
\hline & 2 & 33.7 & 5.0 & -3.2 & 9 & 8 \\
\hline & 5 & 35.5 & 5.8 & -4.5 & 10 & 10 \\
\hline
\end{tabular}




\begin{tabular}{llllccc}
\hline Temperature & $\begin{array}{l}\text { Washing } \\
\text { Time } \\
\text { (hours) }\end{array}$ & $\mathbf{L}^{*}$ & $\mathbf{a}^{*}$ & $\mathbf{b}^{*}$ & $\begin{array}{c}\mathbf{4 5 7} \mathbf{~ n m} \\
\text { Brightness }\end{array}$ & $\begin{array}{c}\mathbf{5 8 0} \mathbf{~ n m} \\
\text { Brightness }\end{array}$ \\
\hline $\mathbf{5 0}$ ․ & $\mathbf{2 4}$ & 35.2 & 4.4 & -5.8 & 10 & 11 \\
& $\mathbf{0 . 5}$ & 31.6 & 6.3 & -6.6 & 8 & 7 \\
& $\mathbf{1}$ & 32.9 & 8.1 & -5.2 & 8 & 7 \\
& $\mathbf{2}$ & 31.1 & 10.6 & -5.1 & 8 & 7 \\
& $\mathbf{5}$ & 32.0 & 6.4 & -6.2 & 8 & 7 \\
& $\mathbf{2 4}$ & 42.9 & 5.9 & -6.3 & 11 & 12 \\
\hline
\end{tabular}

Table 10.27: CIE Co-ordinates of a gold nanoparticle-silk composite (prepared by soaking silk in a 160 ppm $\left(8.13 \times 10^{-4} \mathrm{M}\right) \mathrm{Au}^{3+}$ solution with a pH of 9-10 for 6 hours at RT, followed by heating at $50{ }^{\circ} \mathrm{C}$ for 24 hours) following washing.

\begin{tabular}{lllllcc}
\hline Temperature & $\begin{array}{l}\text { Washing } \\
\text { Time } \\
\text { (hours) }\end{array}$ & $\mathbf{L}^{*}$ & $\mathbf{a}^{*}$ & $\mathbf{b}^{*}$ & $\begin{array}{c}\mathbf{4 5 7} \mathbf{~ n m} \\
\text { Brightness }\end{array}$ & $\begin{array}{c}\mathbf{5 8 0} \mathbf{~ n m} \\
\text { Brightness }\end{array}$ \\
\hline $\mathbf{R T}$ & $\mathbf{0}$ & 71.1 & 10.1 & 4.1 & 39 & 45 \\
& $\mathbf{0 . 5}$ & 48.6 & 16.1 & 3.0 & 16 & 19 \\
& $\mathbf{1}$ & 48.2 & 17.0 & 2.1 & 16 & 19 \\
& $\mathbf{2}$ & 60.8 & 12.0 & 4.0 & 27 & 31 \\
& $\mathbf{5}$ & 50.8 & 9.7 & 3.7 & 17 & 20 \\
$\mathbf{5 0}$ ㄷ & $\mathbf{2 4}$ & 54.6 & 12.9 & 3.35 & 21 & 24 \\
& $\mathbf{0 . 5}$ & 55.0 & 15.1 & 3.7 & 21 & 25 \\
& $\mathbf{1}$ & 57.1 & 15.1 & 4.8 & 22 & 27 \\
& $\mathbf{2}$ & 66.1 & 11.1 & 2.9 & 33 & 38 \\
& $\mathbf{5}$ & 44.6 & 14.4 & 3.4 & 13 & 16 \\
& $\mathbf{2 4}$ & 45.7 & 16.7 & 2.4 & 14 & 17 \\
\hline
\end{tabular}




\section{Appendix IX}

Table 10.28: CIE $L^{*}, a^{*}, b^{*}, 457 \mathrm{~nm}$ brightness and $580 \mathrm{~nm}$ brightness values for composites prepared via the preliminary synthesis route, using a $\mathrm{NH}_{2} \mathrm{OH}$ concentration of $2.50 \times 10^{-4} \mathrm{moldm}^{-3}$.

\begin{tabular}{|c|c|c|c|c|c|c|}
\hline Seed & {$\left[\mathrm{NH}_{2} \mathrm{OH}\right]:\left[\mathrm{Au}^{3+}\right]$} & $\mathbf{L}^{*}$ & $\mathbf{a}^{*}$ & $\mathbf{b}^{*}$ & $\begin{array}{c}457 \mathrm{~nm} \\
\text { brightness }\end{array}$ & $\begin{array}{c}580 \mathrm{~nm} \\
\text { brightness }\end{array}$ \\
\hline \multirow[t]{4}{*}{1} & 1:1 & 5.3 & 2.2 & 12.67 & 13 & 15 \\
\hline & 1:2 & 5.7 & 5.3 & 8.80 & 10 & 12 \\
\hline & 1:4 & 5.5 & 7.5 & 9.11 & 12 & 13 \\
\hline & $1: 8$ & 5.9 & 8.8 & 10.43 & 14 & 16 \\
\hline \multirow[t]{4}{*}{7} & 1:1 & 53.6 & 7.2 & 2.97 & 20 & 22 \\
\hline & $1: 2$ & 43.7 & 7.4 & 1.93 & 13 & 14 \\
\hline & $1: 4$ & 58.2 & 6.2 & 4.48 & 24 & 27 \\
\hline & 1:8 & 47.3 & 6.2 & 2.87 & 15 & 17 \\
\hline
\end{tabular}

\section{Appendix X}

Table 10.29: CIE $\mathrm{L}^{*}, \mathrm{a}^{*}, \mathrm{~b}^{*}, 457 \mathrm{~nm}$ brightness and $580 \mathrm{~nm}$ brightness values for composites prepared using a gold solution concentration of $2.50 \times 10^{-4} \mathrm{moldm}^{-3}$.

\begin{tabular}{ccccccc}
\hline Seed & {$\left[\mathrm{Au}^{3+}\right]:\left[\mathrm{NH}_{2} \mathrm{OH}\right]$} & $\mathbf{L}^{*}$ & $\mathbf{A}^{*}$ & $\mathbf{b}^{*}$ & $\begin{array}{c}\mathbf{4 5 7} \mathbf{n m} \\
\text { brightness }\end{array}$ & $\begin{array}{c}\mathbf{5 8 0} \mathbf{~ n m} \\
\text { brightness }\end{array}$ \\
\hline $\mathbf{2}$ & - & 56.2 & 3.7 & 3.9 & 22 & 25 \\
$\mathbf{2}$ & $\mathbf{1 : 1}$ & 43.8 & 9.2 & 0.5 & 14 & 14 \\
& $\mathbf{1 : 2}$ & 47.5 & 3.3 & 0.1 & 17 & 16 \\
& $\mathbf{1 : 4}$ & 49.7 & 8.5 & -1.0 & 19 & 19 \\
& $\mathbf{1 : 8}$ & 43.8 & 8.2 & -0.3 & 14 & 14 \\
\hline
\end{tabular}




\begin{tabular}{|c|c|c|c|c|c|c|}
\hline Seed & {$\left[\mathrm{Au}^{3+}\right]:\left[\mathrm{NH}_{2} \mathrm{OH}\right]$} & $\mathbf{L}^{*}$ & $A^{*}$ & $\mathbf{b}^{*}$ & $\begin{array}{c}457 \mathrm{~nm} \\
\text { brightness }\end{array}$ & $\begin{array}{c}580 \mathrm{~nm} \\
\text { brightness }\end{array}$ \\
\hline & 1:16 & 48.9 & 4.3 & -2.0 & 19 & 17 \\
\hline & $1: 32$ & 43.7 & 3.7 & -1.8 & 14 & 13 \\
\hline & $1: 64$ & 49.7 & 3.3 & -1.9 & 19 & 18 \\
\hline & $1: 128$ & 41.6 & 5.8 & -1.8 & 12 & 13 \\
\hline \multirow[t]{3}{*}{3} & - & 53.6 & 7.2 & 3.0 & 20 & 22 \\
\hline & $1: 1$ & 46.6 & 13.9 & 0.9 & 15 & 17 \\
\hline & $1: 8$ & 40.5 & 11 & -0.6 & 12 & 12 \\
\hline \multirow[t]{3}{*}{4} & - & 43.7 & 7.4 & 1.9 & 13 & 14 \\
\hline & $1: 1$ & 44.0 & 6.9 & 0.8 & 9 & 9 \\
\hline & $1: 8$ & 43.1 & 5.9 & 1.5 & 13 & 14 \\
\hline \multirow[t]{6}{*}{5} & - & 58.2 & 6.2 & 4.5 & 24 & 27 \\
\hline & $1: 1$ & 42.8 & 5.6 & -1.8 & 14 & 13 \\
\hline & $1: 8$ & 37.4 & 3.5 & -1.7 & 10 & 10 \\
\hline & 1:16 & 39.5 & 3.0 & -0.9 & 11 & 11 \\
\hline & $1: 64$ & 40.1 & 1.9 & -2.3 & 12 & 10 \\
\hline & $1: 128$ & 38.9 & 1.4 & -1.3 & 13 & 13 \\
\hline \multirow[t]{3}{*}{6} & - & 47.3 & 6.2 & 2.9 & 15 & 17 \\
\hline & $1: 1$ & 40.3 & 10.4 & 0.8 & 12 & 12 \\
\hline & $1: 8$ & 35.8 & 3.9 & -0.2 & 9 & 9 \\
\hline \multirow[t]{3}{*}{7} & - & 31.3 & 13.7 & -0.7 & 7 & 7 \\
\hline & 1:1 & 30.5 & 15.3 & -1.7 & 7 & 6 \\
\hline & $1: 8$ & 26.7 & 5.2 & -2.5 & 5 & 5 \\
\hline
\end{tabular}


Table 10.30: CIE $\mathrm{L}^{*}, \mathrm{a}^{*}, \mathrm{~b}^{*}, 457 \mathrm{~nm}$ brightness and $580 \mathrm{~nm}$ brightness values for composites prepared using a gold solution concentration of $4.2 \times 10^{-4} \mathrm{moldm}^{-3}$.

\begin{tabular}{|c|c|c|c|c|c|c|}
\hline Seed & {$\left[\mathrm{Au}^{3+}\right]:\left[\mathrm{NH}_{2} \mathrm{OH}\right]$} & $L^{*}$ & $\mathbf{a}^{*}$ & $\mathbf{b}^{*}$ & $\begin{array}{c}457 \mathrm{~nm} \\
\text { brightness }\end{array}$ & $\begin{array}{c}580 \mathrm{~nm} \\
\text { brightness }\end{array}$ \\
\hline \multirow[t]{3}{*}{2} & - & 56.2 & 3.7 & 3.9 & 22 & 25 \\
\hline & 1:16 & 40.8 & 4.5 & -2.2 & 13 & 12 \\
\hline & $1: 128$ & 45.4 & 3.5 & -1.3 & 15 & 15 \\
\hline \multirow[t]{3}{*}{3} & - & 53.6 & 7.2 & 3.0 & 20 & 22 \\
\hline & 1:16 & 43.3 & 7.9 & -1.6 & 14 & 14 \\
\hline & $1: 128$ & 45.0 & 4.0 & -2.0 & 15 & 14 \\
\hline \multirow[t]{3}{*}{5} & - & 58.2 & 6.2 & 4.5 & 24 & 27 \\
\hline & $1: 16$ & 48.4 & 1.6 & -0.9 & 18 & 12 \\
\hline & $1: 128$ & 40.8 & 1.2 & -0.3 & 12 & 12 \\
\hline \multirow[t]{3}{*}{6} & - & 47.3 & 6.2 & 2.9 & 15 & 17 \\
\hline & 1:16 & 33.8 & 7.8 & -1.2 & 8 & 5 \\
\hline & $1: 28$ & 26.9 & 10.2 & -1.0 & 5 & 5 \\
\hline \multirow[t]{3}{*}{7} & - & 31.3 & 13.7 & -0.7 & 7 & 7 \\
\hline & $1: 16$ & 22.6 & 8.5 & -2.8 & 4 & 4 \\
\hline & $1: 28$ & 24.4 & 5.9 & -2.6 & 5 & 4 \\
\hline \multirow[t]{3}{*}{8} & - & 39.6 & -0.2 & -1.0 & 11 & 11 \\
\hline & 1:16 & 51.2 & 0.7 & -0.9 & 20 & 19 \\
\hline & $1: 28$ & 47.1 & 2.3 & -2.9 & 18 & 16 \\
\hline \multirow[t]{3}{*}{9} & - & 41.8 & 0.0 & -0 . & 13 & 12 \\
\hline & $1: 16$ & 44.8 & 2.5 & -1.1 & 15 & 14 \\
\hline & $1: 28$ & 42.8 & 3.5 & -3.0 & 14 & 13 \\
\hline \multirow[t]{3}{*}{10} & - & 37.7 & 0.9 & -0.1 & 10 & 10 \\
\hline & 1:16 & 40.6 & 2.6 & 0.0 & 12 & 12 \\
\hline & $1: 28$ & 46.7 & 1.8 & -1.1 & 16 & 16 \\
\hline
\end{tabular}


Table 10.31: CIE $\mathrm{L}^{*}, \mathrm{a}^{*}, \mathrm{~b}^{*}, 457 \mathrm{~nm}$ brightness and $580 \mathrm{~nm}$ brightness values for composites prepared using a gold solution concentration of $6.8 \times 10^{-4} \mathrm{moldm}^{-3}$.

\begin{tabular}{|c|c|c|c|c|c|c|}
\hline Seed & {$\left[\mathrm{Au}^{3+}\right]:\left[\mathrm{NH}_{2} \mathrm{OH}\right]$} & $L^{*}$ & $\mathbf{a}^{*}$ & $\mathbf{b}^{*}$ & $\begin{array}{c}457 \mathrm{~nm} \\
\text { brightness }\end{array}$ & $\begin{array}{c}580 \mathrm{~nm} \\
\text { brightness }\end{array}$ \\
\hline \multirow[t]{3}{*}{2} & - & 56.2 & 3.7 & 3.9 & 22 & 25 \\
\hline & $1: 16$ & 44.1 & 4.8 & -2.6 & 15 & 14 \\
\hline & $1: 128$ & 43.8 & 2.6 & -1.9 & 15 & 14 \\
\hline \multirow[t]{3}{*}{3} & - & 53.6 & 7.2 & 3.0 & 20 & 22 \\
\hline & 1:16 & 31.5 & 8.3 & -1.9 & 7 & 7 \\
\hline & $1: 128$ & 34.4 & 2.9 & -3.4 & 9 & 8 \\
\hline \multirow[t]{3}{*}{5} & - & 58.2 & 6.2 & 4.5 & 24 & 27 \\
\hline & $1: 16$ & 34.4 & 5.7 & -0.9 & 9 & 8 \\
\hline & $1: 128$ & 31.7 & 4.8 & -1.1 & 7 & 7 \\
\hline \multirow[t]{3}{*}{6} & - & 47.3 & 6.2 & 2.9 & 15 & 17 \\
\hline & 1:16 & 31.6 & 6.9 & -1.0 & 7 & 7 \\
\hline & $1: 28$ & 28.4 & 6.2 & -3.2 & 6 & 6 \\
\hline \multirow[t]{3}{*}{7} & - & 31.3 & 13.7 & -0.7 & 7 & 7 \\
\hline & $1: 16$ & 30.5 & 9.0 & -3.8 & 7 & 6 \\
\hline & $1: 28$ & 24.5 & 5.6 & -3.0 & 5 & 4 \\
\hline \multirow[t]{3}{*}{8} & - & 39.6 & -0.2 & -1.0 & 11 & 11 \\
\hline & 1:16 & 43.4 & 2.9 & -0.2 & 14 & 13 \\
\hline & $1: 28$ & 39.7 & 2.5 & -0.4 & 11 & 11 \\
\hline \multirow[t]{3}{*}{9} & - & 41.8 & 0.0 & -0.7 & 13 & 12 \\
\hline & $1: 16$ & 34.1 & 4.4 & 0.2 & 8 & 8 \\
\hline & $1: 28$ & 41.1 & 1.4 & -1.9 & 13 & 12 \\
\hline \multirow[t]{3}{*}{10} & - & 37.7 & 0.9 & -0.1 & 10 & 10 \\
\hline & 1:16 & 43.1 & 2.4 & 0.4 & 13 & 13 \\
\hline & $1: 28$ & 36.8 & 2.6 & 0.4 & 13 & 13 \\
\hline
\end{tabular}


Table 10.32: CIE $\mathrm{L}^{*}, \mathrm{a}^{*}, \mathrm{~b}^{*}, 457 \mathrm{~nm}$ brightness and $580 \mathrm{~nm}$ brightness values for composites prepared using a gold solution concentration of $1.02 \times 10^{-3} \mathrm{moldm}^{-3}$.

\begin{tabular}{ccccccc}
\hline Seed & {$\left[\mathrm{Au}^{3+}\right]:\left[\mathrm{NH}_{2} \mathrm{OH}\right]$} & $\mathbf{L}^{*}$ & $\mathbf{a}^{*}$ & $\mathbf{b}^{*}$ & $\begin{array}{c}\mathbf{4 5 7} \mathbf{~ n m} \\
\text { brightness }\end{array}$ & $\begin{array}{c}\mathbf{5 8 0} \mathbf{~ n m} \\
\text { brightness }\end{array}$ \\
\hline $\mathbf{2}$ & - & 56.2 & 3.7 & 3.9 & 22 & 25 \\
& $\mathbf{1 : 1 6}$ & 32.1 & 5.9 & 0.5 & 7 & 7 \\
& $\mathbf{1 : 1 2 8}$ & 34.9 & 6.2 & -1.8 & 9 & 9 \\
$\mathbf{5}$ & $\mathbf{1}$ & 58.2 & 6.2 & 4.5 & 24 & 27 \\
& $\mathbf{1 : 1 6}$ & 37.6 & 5.0 & 1.9 & 7 & 8 \\
& $\mathbf{1 : 1 2 8}$ & 34.5 & 6.4 & 1.1 & 8 & 9 \\
$\mathbf{7}$ & $\mathbf{1}$ & 31.3 & 13.7 & -0.7 & 7 & 7 \\
& $\mathbf{1 : 1 6}$ & 19.8 & 10.0 & -1.4 & 3 & 3 \\
& $\mathbf{1 : 2 8}$ & 24.1 & 7.6 & -3.0 & 5 & 4 \\
& & & & & & \\
\end{tabular}

Table 10.33: CIE L*, $\mathrm{a}^{*}, \mathrm{~b}^{*}, 457 \mathrm{~nm}$ brightness and $580 \mathrm{~nm}$ brightness values for composites prepared using a gold solution concentration of $1.35 \times 10^{-3} \mathrm{moldm}^{-3}$.

\begin{tabular}{ccccccc}
\hline Seed & {$\left[\mathrm{Au}^{3+}\right]:\left[\mathrm{NH}_{2} \mathrm{OH}\right]$} & $\mathbf{L}^{*}$ & $\mathbf{A}^{*}$ & $\mathbf{b}^{*}$ & $\begin{array}{c}\mathbf{4 5 7} \mathbf{~ n m} \\
\text { brightness }\end{array}$ & $\begin{array}{c}\mathbf{5 8 0} \mathbf{~ n m} \\
\text { brightness }\end{array}$ \\
\hline $\mathbf{2}$ & - & 56.2 & 3.7 & 3.9 & 22 & 25 \\
& $\mathbf{1 : 1 6}$ & 36.4 & 5.3 & -0.8 & 10 & 9 \\
& $\mathbf{1 : 1 2 8}$ & 31.3 & 7.7 & -0.4 & 7 & 7 \\
$\mathbf{5}$ & $\mathbf{-}$ & 58.2 & 6.2 & 4.5 & 24 & 27 \\
& $\mathbf{1 : 1 6}$ & 33.1 & 5.0 & 1.9 & 7 & 8 \\
$\mathbf{7}$ & $\mathbf{1 : 1 2 8}$ & 32.5 & 5.5 & 0.3 & 7 & 8 \\
& $\mathbf{1}$ & 31.3 & 13.7 & -0.7 & 7 & 7 \\
& $\mathbf{1 : 1 6}$ & 20.4 & 6.9 & -2.2 & 3 & 3 \\
& $\mathbf{1 : 2 8}$ & 22.0 & 6.6 & -2 & 4 & 4 \\
& & & & & & \\
\end{tabular}




\section{Appendix XI}

Table 10.34: CIE $\mathrm{L}^{*}, \mathrm{a}^{*}, \mathrm{~b}^{*}, 457 \mathrm{~nm}$ brightness and $580 \mathrm{~nm}$ brightness values for gold nanoparticle-silk composites.

\begin{tabular}{|c|c|c|c|c|c|c|c|}
\hline Seed & $\begin{array}{l}\text { Gold conc. } \\
\left(\mathrm{moldm}^{-3}\right)\end{array}$ & {$\left[\mathrm{Au}^{3+}\right]:\left[\mathrm{NH}_{2} \mathrm{OH}\right]$} & $\mathbf{L}^{*}$ & $A^{*}$ & $\mathbf{b}^{*}$ & $\begin{array}{c}457 \mathrm{~nm} \\
\text { brightness }\end{array}$ & $\begin{array}{c}580 \mathrm{~nm} \\
\text { brightness }\end{array}$ \\
\hline \multirow[t]{4}{*}{1} & $4.2 \times 10^{-4}$ & $1: 16$ & 32.3 & 2.8 & 0.1 & 7 & 7 \\
\hline & & $1: 128$ & 34.0 & 0.6 & 0.8 & 8 & 9 \\
\hline & $6.77 \times 10^{-4}$ & $1: 16$ & 28.4 & 4.7 & 2.3 & 5 & 6 \\
\hline & & $1: 128$ & 30.2 & 2.9 & 1.5 & 6 & 6 \\
\hline \multirow[t]{4}{*}{2} & $4.2 \times 10^{-4}$ & $1: 16$ & 23.4 & 5.4 & -1.3 & 4 & 4 \\
\hline & & $1: 128$ & 20.4 & 3.9 & -1.0 & 3 & 3 \\
\hline & $6.77 \times 10^{-4}$ & 1:16 & 23. & 6.0 & -1.6 & 4 & 4 \\
\hline & & $1: 128$ & 19.1 & 4.0 & -0.2 & 3 & 3 \\
\hline \multirow[t]{4}{*}{3} & $4.2 \times 10^{-4}$ & $1: 16$ & 21.5 & 13.3 & -0.6 & 3 & 4 \\
\hline & & $1: 128$ & 17.2 & 11.2 & 0.5 & 2 & 3 \\
\hline & $6.77 \times 10^{-4}$ & $1: 16$ & 19.5 & 12.4 & 1.2 & 3 & 3 \\
\hline & & $1: 128$ & 17.8 & 10.6 & 0.9 & 2 & 3 \\
\hline \multirow[t]{4}{*}{4} & $4.2 \times 10^{-4}$ & $1: 16$ & 24.4 & 5.2 & -1.3 & 4 & 4 \\
\hline & & 1:128 & 23.8 & 3.4 & -0.3 & 4 & 4 \\
\hline & $6.77 \times 10^{-4}$ & $1: 16$ & 23.9 & 5.4 & -0.2 & 4 & 4 \\
\hline & & $1: 128$ & 23.9 & 3.8 & 0.1 & 4 & 4 \\
\hline \multirow[t]{4}{*}{5} & $4.2 \times 10^{-4}$ & $1: 16$ & 27.9 & 6.7 & -2.0 & 6 & 6 \\
\hline & & 1:128 & 27.1 & 2.9 & -1.5 & 6 & 5 \\
\hline & $6.77 \times 10^{-4}$ & 1:16 & 25.2 & 5.1 & -0.8 & 5 & 5 \\
\hline & & $1: 128$ & 21.9 & 4.2 & -0.4 & 4 & 4 \\
\hline
\end{tabular}




\begin{tabular}{|c|c|c|c|c|c|c|c|}
\hline Seed & $\begin{array}{l}\text { Gold conc. } \\
\left(\text { moldm }^{-3}\right)\end{array}$ & {$\left[\mathrm{Au}^{3+}\right]:\left[\mathrm{NH}_{2} \mathrm{OH}\right]$} & $\mathbf{L}^{*}$ & $A^{*}$ & $\mathbf{b}^{*}$ & $\begin{array}{c}457 \mathrm{~nm} \\
\text { brightness }\end{array}$ & $\begin{array}{c}580 \mathrm{~nm} \\
\text { brightness }\end{array}$ \\
\hline \multirow[t]{4}{*}{6} & $4.2 \times 10^{-4}$ & 1:16 & 60.8 & -0.7 & 3.2 & 27 & 30 \\
\hline & & 1:128 & 62.2 & -0.2 & 3.6 & 28 & 31 \\
\hline & $6.77 \times 10^{-4}$ & 1:16 & 56.0 & 0.0 & 3.6 & 22 & 24 \\
\hline & & $1: 128$ & 58.4 & -0.3 & 3.6 & 24 & 27 \\
\hline \multirow[t]{4}{*}{7} & $4.2 \times 10^{-4}$ & $1: 16$ & 54.0 & -0.7 & 1.7 & 21 & 22 \\
\hline & & $1: 128$ & 55.6 & -0.4 & 2.6 & 22 & 24 \\
\hline & $6.77 \times 10^{-4}$ & 1:16 & 53.1 & 0.2 & 3.0 & 20 & 22 \\
\hline & & $1: 128$ & 53.1 & -0.2 & 3.3 & 19 & 22 \\
\hline \multirow[t]{4}{*}{8} & $4.2 \times 10^{-4}$ & $1: 16$ & 26.4 & 10.2 & -3.0 & 6 & 5 \\
\hline & & $1: 128$ & 28.6 & 11.2 & -3.6 & 7 & 6 \\
\hline & $6.77 \times 10^{-4}$ & $1: 16$ & 21.8 & 10.9 & -2.6 & 4 & 4 \\
\hline & & $1: 128$ & 22.6 & 10.9 & -2.6 & 4 & 4 \\
\hline \multirow[t]{4}{*}{9} & $4.2 \times 10^{-4}$ & 1:16 & 36.6 & -0.3 & -2.2 & 10 & 9 \\
\hline & & $1: 128$ & 39.42 & -0.7 & -0.4 & 11 & 11 \\
\hline & $6.77 \times 10^{-4}$ & $1: 16$ & 34.16 & -0.4 & -0.7 & 8 & 8 \\
\hline & & $1: 128$ & 36.3 & -0.6 & 0.1 & 9 & 9 \\
\hline
\end{tabular}




\section{REFERENCES}

1. A. Bozzi, T. Yuranova, and J. Kiwi, Journal of Photochemistry and Photobiology: A Science, 2005, 172, 27-34

2. S. Dubas, P. Kumlangdudsana, and P. Potiyaraj, Colloids and Surfaces, 2006, 289, 105-109

3. H. Lee, S. Yeo, and S. Jeong, Journal of Materials Science, 2003, 38, 2199-2204

4. Z. Zhong, A. Subramanian, J. Highfield, K. Carpenter, and A. Gedanken, Chemistry, A European Journal of, 2005, 11, 1473-1478

5. $\quad$ Y. Luo, Materials Letters, 2007, 61, 1039-1041

6. K. Nakamura and Y. Mori, Journal of Chemical Engineering of Japan, 2001, 34, 1538-1544

7. S. Papp, A. Szücs, and I. Dékány, Applied Clay Science, 2001, 19, 155-172

8. R. Patakfalvi, A. Oszkó, and I. Dékány, Colloids and Surfaces, 2003, 220, 45-54

9. R. Jisr, H. Rmaile, and J. Schenoff, Angewandte Chemie. International Edition, 2004, 44, 782-785

10. W. Daoud, J. Xin, and X. Tao, Journal of the American Chemical Society, 2004, 87, $1782-1784$

11. E. Martines, K. Seunarine, H. Morgan, N. Gadegaard, C. Wilkinson, and M. Riehle, Nano Letters, 2005, 5, 2097-2103

12. K. Cho, J. Park, T. Osaka, and S. Park, Electrochimica Acta, 2005, 51, 956-960

13. T. Maneerung, S. Tokura, and R. Rujiravanit, Carbohydrate Polymers, 2008, 72, 4351

14. M. Khraisheh, M. Al-Ghouti, S. Allen, and M. Ahmad, Water and Environmental Research, 2004, 310, 2618-2623

15. B. Martel, M. Weltiowski, D. Ruffin, and M. Morcellet, Journal of Applied Polymer Science, 2002, 83, 1449-1456

16. C. Chen and P. Kuo, Journal of Colloid and Interface Science, 2006, 293, 101-107

17. M. Richardson, J. Johnston, and T. Borrmann, European Journal of Inorganic Chemistry, 2006, 2618-2623

18. G. Decher, Science, 1997, 277, 1232-1237

19. J. Hernández, F. Ruiz, D. Pena, F. Martínez-Gutiérrez, A. Martínez, A. Guillén, H. Tapia-Pérez, and G. Castaññón, Nanomedicine: Nanotechnology, Biology and Medicine, 2008, 4, 237-240

20. G. Price and D. Ansari, Physical Chemistry: Chemistry Physics, 2003, 5, 5552-5557

21. M. Otaitat and I. Al-Trawneh, Spectrochim. Acta. Part A., 2005, 61, 1519

22. E. Joussein, S. Petit, J. Churchman, B. Theng, D. Righi, and B. Delvaux, Clay Minerals, 2005, 40, 383-388

23. http://www.pubpages.unh.edu/ harter/crystal.htm. 2008.

24. L. Alexander, G. Faust, S. Hendricks, H. Insley, and H. McMurdie, American Mineralogist, 1943, 28, 1-18

25. T. Sudo, American Mineralogist, 1953, 1, 66-68

26. T. Bates, F. Hildebrand, and A. Swinefold, American Mineralogist, 1950, 35, 463484

27. H. Noro, Clay Minerals, 1986, 21, 401-415 
28. G. Honjo, N. Kitamura, and K. Mihama, Clay Minerals and Bulletin, 1954, 2, 133141

29. T. Bailey, Proceedings from the 9th International Clay Conference, 1990

30. L. Janik and J. Keeling, Clay Minerals, 1993, 28, 365-378

31. Y. Fu and L. Zhang, Journal of Solid State Chemistry, 2005, 178, 3595-3600

32. Y. Lvov, R. Price, B. Gaber, and I. Ichinose, Colloids and Surfaces A: Physiochemical Engineering Aspects, 2002, 198-200, 375-382

33. S. Puvvada, S. Baral, G. Chow, S. Qadri, and B. Ratna, Journal of the American Chemical Society, 1995, 116, (5) 2135-2136

34. B. Singh and R. Gilkes, Clays and Clay Minerals, 1992, 40, (2) 212-229

35. : Introduction to Wool and the Wool Industry, Canesis.

36. Meat and Wool New Zealand, Economics and Statistics, Wool Statistics,

37. Wool Production in New Zealand, The Ministry of Agriculture and Forestry.,

38. Treasuary, NZ Economic and Financial Overview, 2009,

39. H. Höcker, Wool: Science and Technology, W. Simpson and G. Crawshaw, Woodhead Publishing Limited, Cambridge, England, 2002,

40. H. Zahn, F. Wortmann, and H. Höcker, Chemie in Unserer Zeit, 1997, 31, 28-29

41. H. Lindley, Chemistry of Natural Fibres, Plenum Press, London, 1977,

42. H. Forward, The Chemical and Physical Structure of Merino Wool, CSIRO,

43. J. D'Arcy, Sheep Managment and Wool Technology, UNSW Press, 1990,

44. N. Ahman and W. Lang, Australian Journal of Biological Sciences, 1957, 10, 118

45. J. Davies, Textile Research Journal, 1963, 33, 1028-1029

46. J. Bradbury, The Structure and Chemistry of Keratin Fibres, in Andvances In Protein Chemistry, 1973, 111-210

47. G. Rogers, Annals of the New York Academy of Science, 1973, 83, 378-399

48. A. Haly, Textile Research Journal, 1957, 27, 82-84

49. J. Leeder, Wool Science Review, 1986, 63, 3-35

50. J. Church, G. Corino, and A. Woodhead, Biopolymers, 1996, 42, (1) 7-17

51. L. Jones, D. Rivett, and D. Tucker, Wool and Related Mammalian Fibres, in Handbook of Fibre Chemistry, M. Lewin and E. Pearce, Marcel Dekker INC, New York, 1998,

52. J. Bradbury and G. Rogers, Textile Research Journal, 1963, 33, 452-458

53. J. Lindberg, Textile Research Journal, 1949, 19, 43-45

54. J. Bradbury, Journal of the Textile Institute, 1960, 51, T1226

55. A. Negri, H. Cornell, and D. Rivett, Textile Research Journal, 1993, 63, (2) 109-115

56. C. Carr, I. Leever, and A. Hughes, Textile Research Journal, 1986, 56, 457-461

57. N. King and J. Bradbury, Australian Journal of Biological Sciences, 1968, 21, 375384

58. A. Negri, H. Cornell, and D. Rivett, Textile Research Journal, 1992, 62, 381-387

59. R. Kienle, G. Royer, and H. McCleary, American Association of Textile Chemists and Colorists, 1945, 42-53

60. J. Leeder and J. Rippon, Journal of the Society of Dyers and Colourists, 1985, 101, $11-16$

61. A. Negri, H. Cornell, and D. Rivett, Australian Journal of Agricultural Research, 1991, 42, 1285-1292

62. L. Jones and D. Rivett, Micron, 1997, 28, 469-485

63. J. Lindberg, B. Phillip, and N. Gralen, Nature, 1948, 162, 458-459

64. D. Orwin and R. Thompson, Journal of Cell Science, 1972, 11, 205-219

65. E. Wood, Overview of Wool Yarn Manufacture,

66. AgResearch, Fibre Processing Aids and Their Application, 
67. C. Anderson, H. Kratz, G. Wood, and M. Goldsmith, Textile Manufacturing, 1969, 95,84

68. K. Markison and J. Leed, Textile Research Journal, 1973, 43, 669

69. G. Mazingue, P. Ponchel, and J. Lubrez, Proceedings from the Applied Polymer Conference, 1971

70. Australian Wool Innovation Limited, Fibre Modification, 2007, 1-9

71. Y. Kamath, H.-D. Weigmann, and C. Dansizer, Textile Research Journal, 1979, 49, 343

72. K. Markison and J. Leed, Textile Research Journal, 1973, 44, 856

73. S. Anathanarayan, Silk Culture, Delhi, 2008,

74. R. Robson, Silk Composition, Structure and Properties, in Handbook of Fibre Chemistry, M. Lewin and E. Pearce, Marcel Dekker, 1998,

75. 2005, (Food and Agricultural Organisation of the United Nations: Economic and Social Development. The Statistical Division)

76. O. Hakimi, D. Knight, F. Vollrath, and P. Vadgama, Composites: Part B, 2007, 38, 324-337

77. M. Schoser, J. MacDonald, and B. Marcandalli, Silk, Yale University Press, Yale, 2007,

78. F. Sehnal and M. Zurovec, Biomacromolecules, 2004, 5, 666-674

79. Y. Zhou, W. Chen, H. Itoh, K. Naka, Q. Ni, H. Yamane, and Y. Chujo, Chemical Communications, 2001, 2518-2519

80. J. Roberston and M. Grieve, Forensic Examination of Fibres, CPC Press, 1999,

81. T. Gammo, T. Inokuchi, and H. Laufer, Insect Biochemistry, 1977, 7, 285

82. M. Lewin, S. Sello, and L. Lewin, Handbook of Fibre Science and Technology: Chemical Processing of Fibres and Fabrics-Functional Finishes Part B, CRC Press, New York, 1984,

83. G. Altman, F. Diaz, C. Jakuba, T. Calabro, R. Horan, J. Chen, H. Lu, J. Richmond, and D. Kaplan, Biomaterials, 2003, 24, 401-416

84. P. Poza, J. Perez-Riguerio, M. Elices, and J. Lorca, English Fractional Mechanisms, 2002, 69, 1035-1048

85. R. Fedic, M. Zurovec, and F. Sehnal, Journal of Biological Chemistry, 2003, 278, (35255-35264)

86. T. Sasaki and H. Noda, Biochimica Biophysics Acta, 1973, 310, 76

87. F. Takei, Y. Kikuchi, A. Kikuchi, A. Mizuno, and K. Shimura, Journal of Cell Biology, 1987, 105, 175

88. W. Schroeder and L. Kay, Journal of the American Chemical Society, 1955, 77, 3908

89. H. Zuber, K. Ziegler, and H. Zhan, Z, Naturforsh, 1957, 126, 734

90. M. Dunn, M. Camien, L. Rockland, S. Shaukman, and S. Goldberg, Journal of Biological Chemistry, 1944, 155, 591

91. K. Shimura, A. Kikuchi, Y. Katragta, and Y. Ohtomo, Journal of Sericulture Science Japan, 1982, 51, 20

92. D. Knight and F. Vollrath, Philosophical Transactions of the Royal Society, London B. Biological Science, 2002, 357,

93. J. Goslin, P. Guerette, C. Ortlepp, and K. Savage, Journal of Experimental Biology, 1999, 23, 3295-3303

94. C. Hayashi, N. Shipley, and R. Lewis, International Journal of Biological Macromolecules, 1999, 24, 271-275

95. J. vanBeek, S. Hess, F. Vollrath, and B. Meier, Proceedings from the National Academy of Science USA, 2002

96. Y. Zhang, Biotechnological Advances, 2002, 20, 91-100

97. M. Gulrajani, Review of Progressive Colouration, 1992, 22, 79 
98.

http://upload.wikimedia.org/wikipedia/commons/thumb/7/76/Stained glass w indow_depicting_Episcopal_baptism,

99. P. Thiessen, Kolloid Z, 1942, 101, 241

100. G. Savage, Glass and Glassware, Octopus Books, London, 1975,

101. M. Faraday, Philosophical Transactions of the Royal Society, 1857, 147, 145

102. G. Mie, Annalen der Physik, 1908, 25, 377-445

103. A. Alivisatos, Science, 1996, 271, 933-937

104. C. Daniel and D. Astruc, Chemical Reviews, 2004, 104, 293-346

105. P. Mulvaney, Langmuir, 1996, 12, 788

106. L. Liz-Marzán, Materials Today, 2004, 26-31

107. S. Link and M. El-Sayed, Journal of Physics and Chemistry, 1999, 103, 8410

108. J. Hafner, Plasmonics, 2006, 99-101

109. S. Guo and E. Wang, Analytica Chimica Acta, 2007, 598, 181-192

110. C. Petit, P. Lixon, and M. Pileni, Journal of Physics and Chemistry B, 1993, 91, 12974

111. K. Suslick, M. Fang, and T. Hveon, Journal of the American Chemical Society, 1996, 118,11960

112. G. Frens, Nature (Physical Science), 1973, 241, 20

113. A. Ullman, Chemical Reviews, 1996, 96, 1533

114. J. Turkevitch, P. Stevenson, and J. Hiller, Discussions of the Faraday Society, 1951, $11,55-75$

115. Y. Sun, B. Mayers, and Y. Xia, Nano Letters, 2003, 3, 675-679

116. M. Brust, J. Fink, D. Bethall, D. Schiffrin, and C. Kiely, Journal of the Chemical Society, Chemical Communications, 1995, 1655-1656

117. F. Chen, G. Xu, and T. Hor, Materials Letters, 2003, 57, 3282-3286

118. B. Sohn, J. Choi, S. Yoo, S. Yun, W. Zin, J. Jung, M. Kanehara, and T. Teranishi, Journal of the American Chemical Society, 2003, 125, 6368-6369

119. A. Manna, T. Imae, T. Yogo, K. Aoi, and M. Okazaki, Journal of Colloid and Interface Science, 2002, 256, 279-303

120. H. Jia, W. Xu, J. An, D. Li, and B. Zhao, SPectrochimica Acta Part A, 2006, 64, 956960

121. R. Jin, Y. Cho, C. Mirkin, K. Kelly, G. Schatz, and J. Zheng, Science, 2001, 294, 1901-1904

122. Y. Sun and Y. Xia, The Analyst, 2003, 128, 686-691

123. N. Jana, L. Gearheart, and C. Murphy, Chemical Communications, 2001, 7, 617-618

124. N. Jana, L. Gearheart, and C. Murphy, Journal of Physical Chemistry B, 2001, 105, 4065-4067

125. C. Murphy, T. Sau, A. Gole, C. Orendorff, J. Gao, L. Gou, S. Hunyadi, and T. Li, Journal of Physical Chemistry B, 2005, 109, 13857-13870

126. S. Link, M. Mohamed, and M. El-Sayed, Journal of Physical Chemistry B, 1999, 103, 3073-3077

127. Y. Yu, S. Chang, C. Lee, and C. Wang, Journal of Physical Chemistry B, 1997, 101, 6661-6664

128. C. Lofton, Advanced Functional Materials, 2005, 15, (1197-1208)

129. G. Bögles, J. Buijnsters, S. Verhaegen, H. Meekes, P. Bennema, and D. Bollen, Journal of Crystal Growth, 1999, 203, 554-563

130. G. Dieter, Mechanical Metallurgy, McGraw-Hill, New York, 1986,

131. Y. Xiong and Y. Xia, Advanced Materials, 2007, 19, 3385-3391

132. J. Clement and P. Jarrett, Metal Based Drugs, 1994, 1, 467-482 
133. N. Farrell, Transition Metal Complexes as Drugs and Chemotherapeutic Agents, Kluwer Academic Pulbishers, Dordrecht, 1989,

134. G. Zhao and S. Stevens, Biometals, 1998, 11, 27

135. J. Spadaro, T. Berger, S. Barranco, S. Chapin, and R. Becker, Microbial Agents Chemotheraphy, 1974, 6, 637

136. C. Lok, C. Ho, R. Chen, Q. He, W. Yu, H. Sun, P. Tam, J. Chiu, and C. Che, Journal of Proteome Research, 2006, 5, 916-924

137. K. Naoi, Y. Ohko, and T. Tatsuma, Journal of the American Chemical Society, 2004, 126, 3664-3668

138. K. Yoshida, M. tanagawa, S. Matsumoto, T. Yamada, and M. Stsuta, European Journal of Oral Science, 1999, 107, 141

139. T. Nonaka, W. Node, and S. Kurihara, Journal of Applied Polymer Science, 2000, 77, 1077

140. C. Chambers, C. Proctor, and P. Kabler, Journal of the American Water Works Association, 1962, 54, 208-216

141. A. Adams, E. Santschi, and M. Mellencamp, Vetenary Surgeons, 1999, 28, 219-225

142. M. Bosetti, A. Masse, E. Tobin, and M. cannas, Biomaterials, 2002, 23, 887

143. J. Schierholz, J. Beuth, and G. Pulverer, American Journal of Medicine, 1999, 107, 101

144. J. Schierholz, L. Lucas, A. Rump, and G. Pulverer, Journal of Hospital Infection, 1998, 40, 257

145. J. Hostynek, R. Hinz, C. Lorence, M. Price, and R. Guy, Critical Review, Toxicology, 1993, 23, 171-235

146. P. Kaur, M. Saxena, and D. Vadehra, Industry Journal of Medical Research, 1985, $82,122-126$

147. A. Russell and W. Hugo, Progressive Medicinal Chemistry, 1994, 31, 351-370

148. P. Snodgrass, B. Vallee, and F. Hoch, Journal of Biological Chemistry, 1960, 235, 504-508

149. W. Schreurs and H. Rosenberg, Journal of Bacteriology, 1982, 152, 7-13

150. S. Percival, P. Bowler, and D. Russell, Journal of Hospital Infection, 2005, 60, 1-7

151. H. Rosenkranz and H. Carr, Antimicrobial Chemotheraphy, 1972, 2, 367-372

152. P. Goddard and A. Bull, B5 Applied Microbiology and Biotechnology, 1989, 31, 314

153. P. Dibrov, Antimicrobial Chemotheraphy, 202, 46, 2668-2670

154. I. Sondi and B. Salopek-Sondi, Journal of Colloid and Interface Science, 2004, 275, 177-182

155. V. Alt, T. Bechert, S. Steinrucke, M. Wagener, P. Seidel, E. Dingeldein, E. Domann, and R. Schnettler, Biomaterials, 2004, 25, 4383-4391

156. B. Illingwoth, R. Bianco, and S. Weisberg, Journal of Heart Valve Disorders, 2000, 9, 135-141

157. K. Page, R. Palgrave, I. Parkin, M. Wilson, S. Savin, and A. Chadwick, Journal of Materials Chemistry, 2007, 17, 95-104

158. J. Wright, K. Lam, D. Hansen, and R. Burell, American Journal of Infection Control, 1999, 27, 344-350

159. G. Higby, Gold Bulletin, 1982, 15, 130-140

160. R. Parish, Interdisciplinary Science Reviews, 1992, 17, 221

161. S. Fricker, Gold Bulletin, 1996, 29, 53-60

162. O. Dhubhghaill and P. Sadler, Metal Complexes in Cancer Chemotheraphy, B, K. Keppler, VCH, Weinheim, 2008,

163. Y. Zhang, H. Peng, W. Huang, Y. Zhou, and D. Yan, Journal of Colloid and Interface Science, 2008, 325, 371-376 
164. Y. Hamada, N. Bayakly, A. Peipho, and B. Carison, Reactivity in Inorganic, MetalOrganic and Nano-Metal Chemistry, 2006, 36, (6) 469-476

165. M. Bolland, A. Posner, and J. Quirk, Clay Minerals, 1980, 28, 412-418

166. S. Smelt, Pharmaceutical Research, 2000, 17, 112-126

167. M. Zbik, Clays and Clay Minerals, 1998, 46, 153-160

168. B. Busbee, S. Obare, and C. Murphy, Advanced Materials, 2003, 15, 414-416

169. C. Huang, P. Chiu, Y. Wang, T. Meen, and C. Yang, Nanotechnology, 2007, (18) 295603-295609

170. R. Liu, H. Chen, and S. Hu, Transactions on Electrical and Electronic Engineering, 2007, 2, 468-472

171. J. Johnston, K. Burridge, F. Kelly, and A. Small, 2009, NZ Patent Application, NZ 581307

172. N. Brack, R. Lamb, D. Pham, and P. Turner, Surface and Interface Analysis, 1996, 24, 704-710

173. K. Brown and M. Natan, Langmuir, 1998, 14, 726-728

174. J. Moulder, W. Stickie, P. Sobol, and K. Bomben, Handbook of X-Ray Photoelectron Spectroscopy, J. Chastain, MN, Norwalk, 1992,

175.

http://www.casaxps.com/release/release2312/CasaXPS.HLP/Quantificati on/quantification of xps_spcetra.htm

176. K. Harrison and L. Hazell, Surface and Interface Analysis, 1992, 18, 368-376

177. J.C. M. Burrell, Surface and Interface Analysis, 1999, 27, 811-815

178. P. Swift, Surface and Interface Analysis, 1982, 4, 47-51

179. T. Barr and S. Seal, Journal of Vacuum Science \& Technology A: Vacuum, Surfaces and Films, 1995, 13, 1239-1246

180. A. Davydov, Molecular Spectroscopy of Oxide Catalyst Surfaces, N. Sheppard, John Wiley \& Sons Ltd, West Sussex, England, 2003, 668

181. J. Abid, A. Wark, P. Brevet, and H. Girault, Chemical Communications, 2002, 7, 792793

182. J. Belloni, M. Mostafavi, H. remita, J.-L. Marignier, and M. Delcourt, New Journal of Chemistry, 1998, 1239

183. C. Thomsen, D. Madsen, R. Keiding, J. Thorgersen, and O. Christiansen, Journal of Chemistry and Physics, 1999, 110, 3453

184. S. Chandran, J. Ghatak, P. Satyam, and M. Sastry, Journal of Colloid and Interface Science, 2007, 312, 498-505

185. J. Weaver and G. Hoflund, Journal of Physical Chemistry, 1998, 98, 8519-8524

186. X. Gao, S. Wang, J. Li, Y. Zheng, R. Zhang, P. Zhou, Y. Yang, and L. Chen, Thin Solid Films, 2004, 455-456, 438-442

187. J. Moulder, W. Stickle, P. Sobol, and K. Bomben, Handbook of X-ray Photoelectron Spectroscopy: A Reference Book of Standard Spectra for Identification and Interpretation of XPS Data, J. Chastain, Physical Electronics, 1995, 261

188. M. Chatenet, M. Molina-Concha, and J. Diard, Electrochim. Acta., 2009, 54, (6) 1687-1693

189. A. Callegari, D. Tonti, and M. Chergui, Nano Letters, 2003, 3, 1565

190. M. Maillard, R. Huang, and L. Brus, Nano Letters, 2003, 3, 1611

191. C. Sigmund, Advanced Functional Materials, 2005, 15, 1197-1208

192. H. Ortiz-Ibarra, N. Casillas, V. Soto, M. Barcena-Soto, R. Torres-Vitela, W.d.l. Cruz, and S. Gómez-Salazar, Journal of Colloid and Interface Science, 2007, 314, (2) 562-571

193. A. Henglein, The Journal of Physical Chemistry, 1993, 97, 5457-5471 
194. B. Wiley, Y. Sun, B. Mayers, and Y. Xia, Chemistry, A European Journal of, 2005, $11,454-463$

195. J. Mock, M. Barbic, D. Smith, D. Schultz, and S. Schultz, Journal of Chemistry and Physics, 116, 6755-6759

196. L. Simth, M. Nissamudeen, D. Philip, and G. Gopchandran, Spectrochimica Acta Part A: Molecular and Biomolecular Spectroscopy, 2008, 71, 186-190

197. A. Weber, S. Knecht, H. Brunner, and G. Trover, Engineering in Life Science, 2004, 4, 93-97

198. T. Barr, S. Seal, H. He, and J. Klinowski, Vacuum, 1995, 46, 1391-1395

199. R. Sa'nchez, E. Basaldella, and J. Marco, Journal of Colloid and Interface Science, 1999, 215, 339-344

200. I. Lopez-Salido, D. Lim, and Y. Kim, Surface Science, 2005, 588, 6-18

201. M. Richardson and J. Johnston, Journal of Colloid and Interface Science, 2007, 310, 425-430

202. C. Wagner, D. Zatko, and R. Raymond, Analytical Chemistry, 1980, 52, 1445-1451

203. J. Lambert, H. Shurvell, D. Lightner, and R. Cooks, Organic Structural Spectroscopy, Prentice Hill, Upper Saddle River, New Jersey, 1998,

204. G. Crosson, S. Choi, J. Chorover, M. Amistadi, P. O'Day, and K. Mueller, Journal of Physical Chemistry B, 2006, 110, 723-732

205. P. Barron, R. Frost, J. Skjemstad, and A. Koppi, Nature, 1983, 302, 49-50

206. G. Neal, M. Smith, M. Trigg, and J. Drennana, Journal of Materials Chemistry, 1994, 4, 245-251

207. K. MacKenzie, D. Brew, R. Fletcher, and R. Vagana, Journal of Materials Science, 2007, 42, 4667-4674

208. S. Eustis and M. El-Sayed, Chemical Society Reviews, 2006, 35, 209-217

209. P. Somasundaran, Encylopedia of Surface and Colloid Science, CRC Press, Florida, 2006,

210. S. Cha, J. Kin, and J. Lee, Materials Science and Engineering B, 2007, 140, 182-186

211. A. Pal, Materials Letters, 2004, 58, 529-534

212. T. Norman, C. Grant, D. Magana, J. Zhang, J. Daliang, C. Bridges, and A.V. Buuren, Journal of Physical Chemistry B, 2002, 106, 7005-7012

213. F. Mayer, Electron Microscopy in Microbiology, Academic Press Limited, London, 1988,

214. W. Cheng, S. Dong, and E. Wang, Angewandte Chemie. International Edition, 2003, 42, (4) 449-452

215. G. Li, M. Lauer, A. Schulz, C. Boettcher, F. Li, and J.-H. Fuhrhop, Langmuir, 2003, 19, 6483-6491

216. G. Schmid, R. Pfeil, R. Bose, F. Bandermann, S. Meyer, G. Calis, and J. Velden, Chem. Ber., 1981, 114, 3634-3642

217. G. Dodero, L.D. Michieli, O. Cavalleri, R. Rolandi, L. Oliveri, A. Dacca, and R. Parodi, Colloids and Surfaces A: Physiochemical Engineering Aspects, 2000, 175, 121-128

218. K. Juodkazis, J. Juodkazyte, V. Jasulaitiene, A. Lukinskas, and B. Šebeka, Electrochemical Communications, 2002, 2, 503-507

219. J. Shao, J. Liu, J. Zheng, and C. Carr, Polymer International, 2002, 51, 1479-1483

220. H. Chen, Y. Wang, S. Dong, and E. Wang, Polymer, 2006, 47, 763-766

221. L. Blacka, K. Garbeva, P. Stemmermanna, K. Hallamb, and G. Allenb, Cement and Concrete Research, 2003, 33, 899-911

222. T. Zhao and G. Sun, Journal of Applied Polymer Science, 2007, 103, (1) 482-486 
223. S. Dentel, J. Bottero, K. Khatib, H. Demougeot, J. Duguet, and C. Anselme, Water Research, 1995, 29, 1273-1280

224. M. Ngo, S. Smiley-Jewell, P. Aldous, and K. Pinkerton, Nanomaterials and the Environment, Wiley Interscience, 2008,

225. B. Sweetman, Textile Research Journal, 1967, 37, 834-844

226. C. Chang, Y.-J. Chen, and C. Yeh, Applied Catalysis A: General, 1998, 174, (1-2) 1323

227. J. Kah, N. Phonthammachai, R. Wan, J. Song, T. White, S. Mhaisalkar, I. Ahmad, C. Sheppard, and M. Olivo, Gold Bulletin, 2008, 41, (1) 23-36

228. R. Bradley, I. Clackson, and D. Syke, Surface and Interface Analysis, 1994, 22, 497501

229. M. Mason, Physical Reviews B, 1983, 27, 748

230. M. Mason, J. Gerenser, and S. Lee, Physical Reveiw Letters, 1977, 39, 288

231. S. Shukla and S. Seal, NanoStructured Materials, 1999, 11, (8) 1181-1193

232. O. Hall, Journal of the Society of Dyers and Colourists, 1937, 53, 341-344

233. J. Leeder, J. Rippon, and D. Rivett, Proceedings from the 7th International Wool Textiles Conference, 1985

234. J. Leeder, J. Rippon, F. Rothery, and I. Stapleton, Proceedings from the 7th International Wool Textiles Conference, 1985

235. H. Schmidbaur, Gold Bulletin, 1990, 23, (1) 11-21

236. H. Schmidbaur, S. Cronje, B. Djordjevic, and O. Schuster, Chemical Physics, 2005, 311, 151-161

237. E. Carter, P. Fredericks, J. Church, and R. Denning, Spectrochimica Acta, 1994, SOA, (11) 1927-1936

238. B. Sweetman and J. Maclaren, Australian Journal of Chemistry, 1966, 19, 2347-2354

239. A. Jenkins and L. Wolfram, Journal of the Society of Dyers and Colourists, 1963, 79, (2) $55-60$

240. C. Moore and B. Trego, Tetrahedron, 1962, 18, (2) 205-218

241. I. Lee, C. Yu, H. Shin, Y. Lee, T. Hur, and H. Kim, Thin Solid Films, 2007, 515, 4691-4695

242. P. Ingham, Textiles for a Sustainable Furture, AgResearch, 2007, 11, 18-19

243. K. Burridge and J. Johnston, Proceedings from the International Conference of the American Association of Textiles Chemists and Colorists, Myrtle Beach, USA, 2009

244. K. Burridge, F. Kelly, and J. Johnston, Proceedings from the AUTEX World Textile Conference, Biella, Italy, 2008

245. J. Johnston, K. Burridge, F. Kelly, and A. Small, Proceedings from the Institute of Nanotechnology Innovations in Textiles Conference, London, 2009

246. J. Johnston, K. Burridge, and M. Richardson, Proceedings from the NSTI Nanotech, Nanotechnology and Trade Show, Boston, USA, 2008

247. R. Bonès and J. Sikorski, Journal of the Textile Institute, 1967, 58, (11) 521-532

248. Q. Dong, H. Su, and D. Zhang, Journal of Physical Chemistry B, 2005, 107, 1742917434

249. N. Jana, L. Gearheart, and C. Murphy, Chemical Materials, 2001, 13, 2313-2322

250. A. Gole and C. Murphy, Chemical Materials, 2004, 16, 3633-3640

251. P. Liu and M. Zhao, Applied Surface Science, 2009, 255, (7) 3989-3993

252. E. Slavinskaya, Y. Chesalov, A. Boronin, I. Polukhina, and A. Noskov, Kinetics and Catalysis, 2005, 46, 555-564

253. www.goldprice.org 